Christian Neuhuber Stefanie Edler Elisabeth Zehetner

\title{
Bairisch-österreichische Dialektliteratur vor 1800
}

Eine andere Literaturgeschichte 
$\frac{3}{\frac{\pi}{2}}$ 
Christian Neuhuber / Stefanie Edler / Elisabeth Zehetner

\section{Bairisch-österreichische Dialektliteratur vor 1800}

Eine andere Literaturgeschichte 


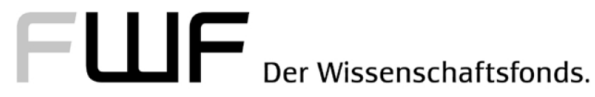 \\ Veröffentlicht mit Unterstützung des Austrian Science Fund ( FWF ): PUB 537-G30
}

\author{
Open Access: Wo nicht anders festgehalten, ist diese Publikation lizenziert unter der \\ Creative-Commons-Lizenz Namensnennung 4.0; siehe http://creativecommons.org/licenses/by/4.0/
}

Diese Publikation wurde einem anonymen, internationalen Peer-Review-Verfahren unterzogen.

Bibliografische Information der Deutschen Nationalbibliothek:

Die Deutsche Nationalbibliothek verzeichnet diese Publikation in der Deutschen Nationalbibliografie; detaillierte bibliografische Daten sind im Internet über http://dnb.de abrufbar.

(c) 2019 by Böhlau Verlag GmbH \& Co. KG.

Kölblgasse 8-10, 1030 Wien

Umschlagabbildung: Egbert van Heemskerk: Genreszene (Privatbesitz)

Korrektorat: Ute Wielandt, Baar-Ebenhausen

Satz und Layout: satz\&sonders, Dülmen

Druck und Bindung: Hubert \& Co., Göttingen

Printed in the EU

Vandenhoeck \& Ruprecht Verlage | www.vandenhoeck-ruprecht-verlage.com

ISBN 978-3-205-20630-9 


\section{INHALT}

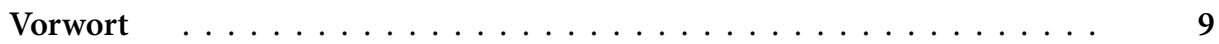

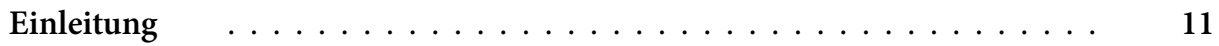

1 Glaube und Aberglaube $\ldots \ldots \ldots \ldots \ldots \ldots \ldots$

Lieder und Spiele des Weihnachtskreises _. . . . . . . . . . . . . . . . . . 22

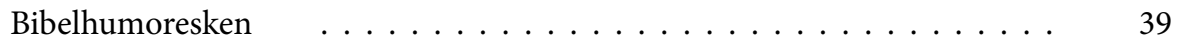

Heiligen- und Legendenspiele $\ldots \ldots \ldots \ldots$. . . . . . . . . . . . . . . . . . . . . . . . . . . .

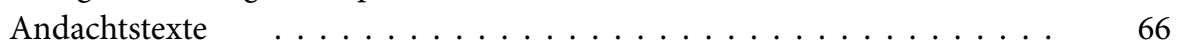

Kritisch-Komisches zu Glaubenslehren, -leuten und -dingen $\quad \ldots \ldots . . \quad 71$

2 Krieg und Frieden $\ldots \ldots \ldots \ldots \ldots \ldots \ldots \ldots$

Bedrohungsbilder des Reichs $\quad \ldots \ldots \ldots \ldots$. . . . . . . . . . . 97

Der Große Türkenkrieg (1683-1699) und seine Folgen . . . . . . . 97

Pfälzischer Erbfolgekrieg (1688-1697) _. . . . . . . . . . 112

Mediale Schlachten und die ,Wahrheit' der Propaganda:

Österreicher, Bayern, Preußen und Franzosen ～. . . . . . . . . . . 115

Spanischer Erbfolgekrieg $(1701-1714) \quad \ldots \ldots \ldots \ldots \ldots$

Österreichischer Erbfolgekrieg (1740-1748) _........ 130

Siebenjähriger Krieg $(1756-1763) \quad \ldots \ldots \ldots \ldots$

Bayerischer Erbfolgekrieg (1778/1779) _. . . . . . . . . . . . . . 142

Erster Koalitionskrieg (1792-1797) _. . . . . . . . . . . 144

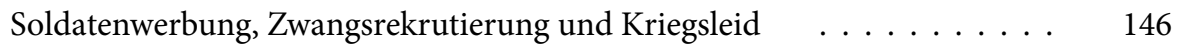

Polnischer Thronfolgekrieg $(1733-1738) \quad \ldots \ldots \ldots \ldots$

3 Herrschaft und Untertan $\ldots \ldots \ldots \ldots \ldots \ldots$

Repräsentationen dynastischer Schlüsselmomente:

Geburt - Hochzeit - Krönung - Tod . . . . . . . . . . . . . . . . 169

Inszenierter Patriotismus: Herrschaftsapologien und vaterländische

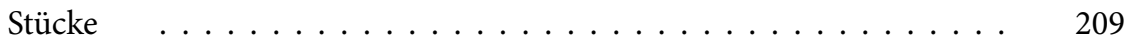

Brüchige Ordnung: Protest- und Revolutionsgesänge/Wildschützen-

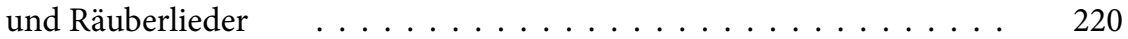

4 Land- und Stadtleben $\ldots \ldots \ldots \ldots$. . . . . . . . . . . . . 249

Inszenierungen des Bauernlebens: Klage und Lob _. . . . . . . . . . . . . . 251

Komisierung und Diskreditierung ländlicher Typen _ . . . . . . . . . . 267

Berufs- und Standeslieder ． . . . . . . . . . . . . . . . . . . 300

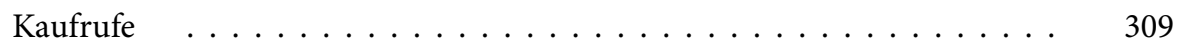

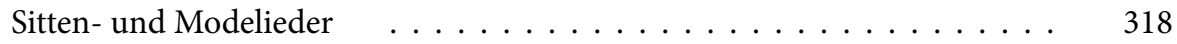

Lokal- und Gesellschaftssatiren $\ldots \ldots \ldots \ldots 26$ 
5 Fremdes und Eigenes $\ldots \ldots \ldots \ldots \ldots \ldots \ldots$

Nachhaltige und sporadische Volksstereotype $\quad \ldots \ldots \ldots$. . . . . . . . 341

Steirische Raufbolde und Kropfträger . . . . . . . . . . . 342

Tiroler Schützen, Händler und Unterhaltungskünstler ～. . . . . 350

Reiselieder, Reiseerzählungen, Länderklischees .. . . . . . 365

Grenzgänger der Sprachen ～. . . . . . . . . . . . . . . . . . . . 377

Romanische Wanderhändler und Lohnarbeiter . . . . . . . . 378

Kroaten und Ungarn - Krämer, Krieger, Heubauern . . . . . . . . 390

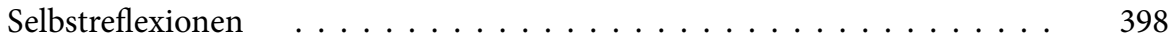

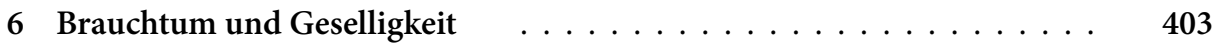

Allgemeine Brauchtumstexte ．.. . . . . . . . . . . . . 405

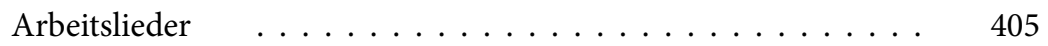

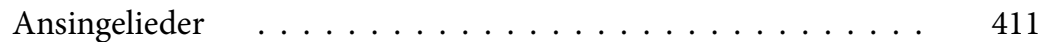

Hochzeitsbrauchlieder und -sprüche $\ldots \ldots \ldots . \ldots . \ldots 418$

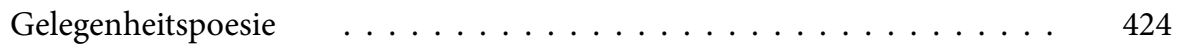

Taufmahl- und Hochzeitslieder ．.. . . . . . . . . . 424

Primiz-, Profess- und Prälatenwahllieder . . . . . . . . . . 430

Profane Anlasslieder: Defensio, Aderlass, Bärenbegräbnis . . . 441

Freizeitdichtung . . . . . . . . . . . . . . . . . . . . . 447

Trink- und Gesellschaftslieder . . . . . . . . . . . . . . 448

Gassllied und Tanz . . . . . . . . . . . . . . . 457

Inszeniertes Brauchtum $\ldots \ldots \ldots \ldots 4 \ldots \ldots$

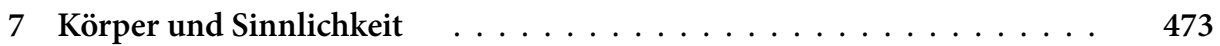

Kreatürliches, Krankhaftes und der Reiz des Ekelhaften . . . . . . . . . . . . . . 475

Der unzivilisierte Körper ～. . . . . . . . . . . . . 476

Verlachte Krankheit . . . . . . . . . . . . . . . . 482

Ekellieder . . . . . . . . . . . . . . . . . . 492

Liederliche Lieder und andere anstößige Texte $\ldots \ldots \ldots 501$

Camouflierte Wollust . . . . . . . . . . . . 501

Obszöne und pornographische Lieder _ . . . . . . . . . . 512

Fensterln, Gasslgehen, Werben in Lied und Schauspiel . . . . . . . . . . 519

Liebeslieder . . . . . . . . . . . . . . . . 520

Affären, Verführung, voreheliche Beziehungen _ . . . . . . 524

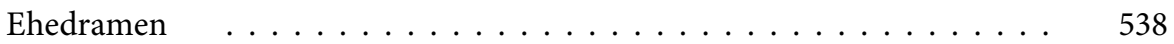

8 Fehden und Feindschaften $\ldots \ldots \ldots \ldots \ldots \ldots$. . . . . . . . 547

Konfessionelle Agitationstexte: Salzburger Emigration, theresianische

Transmigration, Toleranzpatent _. . . . . . . . . . . . . 548

Aus dem Kontext der Predigtkritik im Josephinismus . . . . . . . . . . 566

Hanswurststreit . . . . . . . . . . . . . . . . . . 582

Literatursatirische Dialektfunktionalisierung _. . . . . . . . . 595 
Editionskriterien $\ldots \ldots \ldots \ldots \ldots \ldots \ldots \ldots$................... 609

Abbildungsverzeichnis $\ldots \ldots \ldots \ldots \ldots \ldots \ldots \ldots 11$

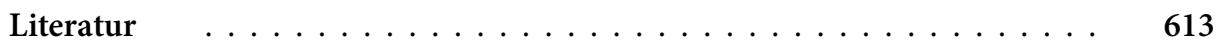

Wörterbücher und Idiotika $\ldots \ldots \ldots$. . . . . . . . . . 638

Autorenverzeichnis $\ldots \ldots \ldots \ldots \ldots \ldots \ldots \ldots \ldots \ldots$

Register $\ldots \ldots \ldots \ldots \ldots \ldots \ldots \ldots \ldots \ldots \ldots \ldots \ldots$

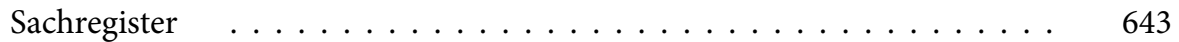

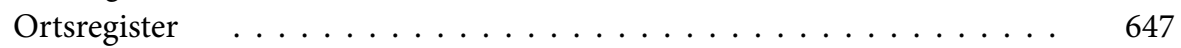

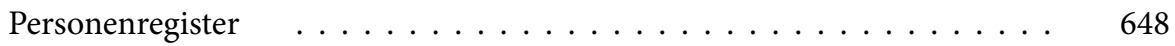




\section{VORWORT}

In den beiden aus Fördermitteln des FWF finanzierten Projekten Dialect cultures I (2010-2013) und Dialect cultures II (2013-2016) unternahm unser interdisziplinäres Team den Versuch, die erstaunliche Vielfalt an Erscheinungsformen und Funktionsweisen bairisch-österreichischer Dialektkunst vor 1800 wieder sichtbar zu machen. Gefunden wurden gut 4000 dialektale bzw. dialektnahe literarische Texte aus diesem Zeitraum, von denen die Hälfte nach diversen Auswahlverfahren (Authentizität, Datierung, Intentionalität und Extension des Dialektgebrauchs, Umfang etc.) in das Untersuchungskorpus aufgenommen wurde. Bekannt, doch noch nicht autopsiert sind weitere Tausende handschriftliche Seiten mit dialektalem Material in Bibliotheken und Archiven des Inund Auslands; dazu kommen noch Texte, die aufgrund von Datierungs- oder Zuordnungsproblemen zurückgestellt wurden oder vorerst nur in standardnäheren Fassungen vorliegen.

Da also die philologische Erfassung und Aufarbeitung des Materials letztlich nur als ,work in progress' möglich ist, wurden zwei Datenbanken erstellt: In einer lediglich teamintern zugänglichen Arbeitsdatenbank, die auch nach Projektabschluss weiterhin für laufende Forschungen, Lehrveranstaltungspraktika und als Projektarchiv in Betrieb bleibt, sind bislang beinahe 1500 Werke in 2200 Varianten eingetragen, kommentiert, ediert oder als Digitalisat einsehbar und im jeweiligen Wissenskontext verlinkt. Diese Datensätze werden - sobald die jeweiligen Lektorierungstätigkeiten abgeschlossen und die urheber-, medien- und bildrechtlichen Fragen geklärt sind - sukzessive in eine allgemein zugängliche Präsentationsdatenbank (http://gams.uni-graz.at/context:dic) eingespeist, um sie der Wissenschaft und einem interessierten Publikum zugänglich zu machen. Jeder Werkeintrag ist verlinkt mit der Autor/Komponist-Kategorie, mit den Quellenbeschreibungen sowie den Literaturangaben. Sind mehrere Varianten überliefert, werden die Differenzen in den jeweiligen Einträgen diskutiert. Auf die Rekonstruktion eines ,Originals' mittels Kollation und Lesartenanalyse wird im Sinne der New Philology verzichtet. Doch ist zur Orientierung eine Quelle als Primärvariante markiert, die (bis auf Widerruf) das Incipit bzw. den Titel des Werks bestimmt; in den meisten Fällen ist sie auch Basis der kritischen Edition, die als Datei ebenso beigefügt werden soll wie eine allfällige bereits veröffentlichte Transkription.

Die Vorteile dieser Präsentationsform liegen auf der Hand: Erstmals sind nun - im Idealfall und nach Maßgabe der (urheber-)rechtlichen Möglichkeiten - alle Materialien und Informationen von der Quelle bis zur Forschungsliteratur auf einer Plattform verfügbar. Die Transkription kann am Digitalisat überprüft, die Analyse mit dem Forschungsstand abgeglichen, das Werk biographisch und kontextuell verortet werden. Diese jetzt schon einzigartige Materialsammlung zur Dialektkunst umfasst Hunderte Ersteditionen. Dazu wurden bislang über 130 Autoren (darunter auch eine Dichterin) und Komponisten biographisch-bibliographisch erfasst, Pseudonyme soweit möglich aufgelöst, Werkzuschreibungen überprüft, getätigt oder auch revidiert. 
Als Ergänzung und Vertiefung dazu entstand - neben weiteren Editionen und Studien in gedruckter und digitaler Form - das vorliegende Buch, das die wichtigsten Arbeiten aus dem Korpus (und ihre Autoren) vielfach erstmals gedruckt präsentiert, kontextualisiert und in aktuelle kulturwissenschaftliche Forschungszusammenhänge stellt. Auf diese Weise wird nicht nur ein repräsentativer Überblick über die Vielfalt, Wirksamkeit und Aussagekraft älterer bairisch-österreichischer Mundartkunst gegeben, sondern implizit auch Material für eine transdisziplinäre Dialektästhetik aufbereitet, die die Grundlagen bis heute wirksamer Bewertungsmuster und Stereotype sichtbar werden lässt. Vollständigkeit wird dabei weder angestrebt noch vorgespielt. Denn Texte, die nur auszugsweise vorgestellt oder lediglich erwähnt werden, können in der Dialect cultures-Datenbank eingesehen und mit zahlreichen weiteren Gattungsbeispielen verglichen werden. Auf die sprachwissenschaftlichen Aspekte des Bairisch-Österreichischen wird nur dann eingegangen, wenn es für die Analyse der jeweiligen künstlerischen Ausdrucksformen von Bedeutung war. Auf die auch für unsere Arbeit grundlegenden Studien von Ingo Reiffenstein, Anthony Rowley, Hermann Scheuringer, Peter Wiesinger oder Ludwig Zehetner sei allerdings hier noch einmal nachdrücklich verwiesen. Die Texte wurden vom Autorenteam zu gleichen Teilen erarbeitet; für die Einleitung, systematisierenden Ausführungen an den Kapitelanfängen und Übergängen sowie für die Ausformulierung der Endfassung zeichnet der Projektleiter verantwortlich.

Ein wichtiger Hinweis zur Leseweise sei noch gestattet: Vor 1800 wurde das helle $a$ (im Gegensatz zu den verdumpften $a$-Lauten des Bairisch-Österreichischen) schriftlich zumeist mit $\langle\ddot{a}\rangle$ markiert. Diese in den edierten Texten übernommene graphische Konvention soll freilich nicht dazu verleiten, das helle $a$ als Umlaut zu realisieren. 


\section{EINLEITUNG}

Das Verschwinden des bairisch-österreichischen Dialekts wird seit dem 18. Jahrhundert mit unschöner Regelmäßigkeit und Eindringlichkeit beschworen. ${ }^{1}$ Noch vor wenigen Jahren hatte man ihm auf längere Sicht kaum eine Überlebenschance eingeräumt. Doch informelle, mündlichkeitsorientierte Kommunikationsweisen wie Mailen, Bloggen, Chatten oder Simsen bescherten regionalen Varietäten auch in verschriftlichter Form ein überraschendes Comeback, das sie wieder in den Fokus verschiedenster Forschungsdisziplinen rückte. Dialektliteratur dagegen bekommt nach wie vor nur selten wissenschaftliche Aufmerksamkeit. Denn der übliche Verdacht ist zunächst, dass man es bei Mundarttexten mit verschriftlichten Formen einer vor allem mündlichen Trivialkultur zu tun hat, vorzugsweise aus dem Feld der seichten Unterhaltungskomik, der sentimentalen Liebeslyrik oder des folkloristischen, rückwärtsgewandten Heile-WeltKitsches. Daran konnten auch die populären Mundartadaptionen der Konkreten Poesie, des kritischen Volkstheaters, der Kabarettszene oder der Neuen Volksmusik nicht viel ändern. Zu sehr assoziiert man Dialektkunst noch mit Ausprägungen, die seit dem 19. Jahrhundert forciert wurden: mit belangloser Almenromantik, mit süßlichen Gesangsvereinsliedern oder banalen Laientheaterschwänken.

Der bewusste Dialektgebrauch als ästhetisches Phänomen ist jedoch weitaus vielgestaltiger und weist seit seinen Anfängen eine beeindruckende funktionale Spannbreite auf. Einen ersten Höhepunkt erreichte Dichtung in und mit Mundart bereits im 18. Jahrhundert, als sie sich unter spezifischen sozialen und soziolinguistischen Rahmenbedingungen als künstlerische Ausdrucksform im bairisch-österreichischen Sprachraum etablieren konnte. Eine gerechte Beurteilung dieser Leistungen blieb ihr allerdings bislang verwehrt. Einzelaspekte wie das sprachliche Material, die literatursoziologische Einbettung oder die produktions- und rezeptionsästhetischen Bedingungen wurden und werden zwar zuweilen behandelt, doch mangelte es an einer übergreifenden Untersuchung des künstlerischen Dialektgebrauchs vor 1800. Gerade aber in dieser Frühzeit der Mundartkunst, in der sie noch nicht von der Volkssprache-Ideologie und ihren thematischen und formalen Normierungen geprägt war, konnte sie im bairisch-österreichischen Sprachraum erstmals eine vollwertige Eigenständigkeit entfalten: innerhalb der (hochsprachlichen, aber auch lateinischen, italienischen und französischen) ,Elitenkultur' ebenso wie als Trägerin einer Gegenkultur, in der das Inoffizielle, das Private, nicht Druckbare sein Recht bekam.

Tatsächlich war Dialektkunst im 17. und 18. Jahrhundert mehr als rustikale Trivialunterhaltung: Sie wurde gezielt in den politischen Diskurs eingebunden oder in

1 Stark gekürzte, überarbeitete und ergänzte Version der Ausführungen in Christian Neuhuber: Die vergessene Kunst. Prolegomena zu einer Ästhetik der österreichischen Dialektliteratur vor 1800. In: Franz M. Eybl (Hg.): Nebenschauplätze. Ränder und Übergänge in Geschichte und Kultur des Aufklärungsjahrhunderts. Bochum: Winkler 2014. (Das achtzehnte Jahrhundert und Österreich 28) S. 53-85. 
intellektuellen Fehden funktionalisiert, konnte Glaubwürdigkeit und Gruppenidentität vermitteln oder ausgrenzen und stigmatisieren, sie eignete sich bestens zur Satire oder zum Ausdruck des Unangepassten und Unangebrachten. Mit deklarierten Liebhabern und erbitterten Gegnern in den höchsten Bildungsschichten polarisierte diese Dialektkunst denn auch wie keine andere Gattung das zeitgenössische Werturteil. Sie wurde von Kaisern geliebt und von Kritikern verachtet, war im Alltag wie auf der Bühne in aller Munde, wurde von den großen Meistern ebenso verwendet wie vom ungebildeten Laien. Vor allem aber war sie eines: genuiner Ausdruck eines äußerst produktiven Kulturraums. Ihre spätere Marginalisierung zum heimatverklärenden, autochthonen ästhetischen Ausdruck des einfachen Menschen vom Lande, die erfolgreiche Desavouierung des Dialekts als defizitäre Sprachform der Ungebildeten und die bis heute andauernde Hegemonialstellung des protestantischen Aufklärungsparadigmas in der Kanonbildung machten jedoch diese frühe Blütezeit mundartlicher Kunst als wesentliches Charakteristikum des bairisch-österreichischen Kulturraums beinah völlig vergessen. Dementsprechend geringes Augenmerk wird der Zeit vor 1800 auch in den wenigen aktuellen Überblicksdarstellungen zur Dialektliteratur geschenkt, neigt man doch nach wie vor dazu, mit dem Beginn des 19. Jahrhunderts „den eigentlichen Beginn der Mundartliteratur anzusetzen“2. Quellenmaterial aus den Jahrhunderten davor wird nur selten berücksichtigt und wenn doch, dann stützt man sich großteils noch auf die zwar faktenreichen, zum Teil jedoch längst überholten Ergebnisse der älteren Forschung.

Mit den ersten Belegen aus dem frühen 17. Jahrhundert begegnet uns Mundart als bewusst eingesetztes, von standardsprachlichen Formen abgehobenes ästhetisches Mittel im bairisch-österreichischen Sprachraum ohnedies vergleichsweise spät. In etlichen anderen deutschen Dialekträumen werden die jeweiligen Varietäten vor allem im Drama bereits in der zweiten Hälfte des 16. Jahrhunderts literarisiert und poetisch funktionalisiert. ${ }^{3}$ Niederdeutsches findet sich schon 1578 in Franciscus Omichius' Newe Comoedia, Thüringisch in Martin Hayneccius' Schulkomödie Almansor (1582), schlesisch unterhalten sich die Hirten in Georg Goebels Die fart Jacobs (1586), neuberlinerisch im Berliner Weihnachtsspiel (1589). Brandenburgisch reden die Bauern in Johann Gulichs Spil von Wuterich dem Antiocho (1593), fränkisch, kölnisch und meißenisch in der Susanna (1593) des Herzogs Heinrich Julius von Braunschweig ${ }^{4}$ und im Speculum Puerorum

2 Klaus J. Mattheier: „Mit der Seele Atem schöpfen“. Über die Funktion von Dialektalität in der deutschsprachigen Literatur. In: Klaus J. Mattheier [u. a.] (Hg.): Vielfalt des Deutschen. Festschrift für Werner Besch. Frankfurt a. M. [u. a.]: Lang 1993, S. 633-652, hier S. 638. Ähnlich auch Polenz: „Von eigentlicher Mundartdichtung, als bewußter, kontinuierlicher Gegenbewegung zur antiregional gewordenen Hochliteratur, kann man erst im 19. Jh. sprechen“ (Peter von Polenz: Deutsche Sprachgeschichte vom Spätmittelalter bis zur Gegenwart. Bd. II: 17. und 18. Jahrhundert. Berlin/New York: de Gruyter 1994, S. 232).

3 Vgl. u. a. Alfred Lowack: Die Mundarten im hochdeutschen Drama bis gegen Ende des achtzehnten Jahrhunderts: Ein Beitrag zur Geschichte des deutschen Dramas und der deutschen Dialektdichtung. Leipzig: Hesse 1905. (Breslauer Beiträge zur Literaturgeschichte VII) - Friedrich Schön: Geschichte der deutschen Mundartdichtung. 3 Teilbde. Freiburg: Fehsenfeld 1920-1931. - Helmut Henne: Hochsprache und Mundart im schlesischen Barock. Studien zum literarischen Wortschatz in der ersten Hälfte des 17. Jahrhunderts. Köln/Graz: Böhlau 1966. (Mitteldeutsche Forschungen 44).

4 Mit dem Bauern Lendel findet sich in Herzog Heinrich Julius', Tragica Comoedia' Von einem Wirthe oder Gastgeber (1594) auch eine Nebenfigur, die bairische Sprachmerkmale aufweist. 
(1596) des Eislebener Domküsters Georg Pondo ist Brabantisch und Schwäbisch zu hören. Noch früher sind verschiedene alemannische Dialekte in der Schweizerdeutschen Dramatik zu finden, ohne dass allerdings Werke wie die Propagandaschrift Badenfahrt guter Gesellen 1521 zunächst zu einer eigenständigen Tradition mundartlicher Dichtung geführt hätten. ${ }^{5}$

Die Liste dramatischer Arbeiten mit Literarisierungen regiolektaler Varietäten ließe sich für die folgenden Jahre noch mühelos erweitern, ehe uns auch im bairisch-österreichischen Sprachraum mit dem 1618 in Regensburg inszenierten, wohl aus Wien stammenden Fastnachtspiel Von dem Hänsl Frischen knecht bairische Sprachfärbung zur kontrastierenden Charakterisierung der dramatis personae erstmals im größeren Umfang begegnet. In der Handlung von einem naiven Dörfler, der sich versehentlich zu Kriegsdiensten anwerben lässt, dominiert bereits der Bauernspott - die in der süddeutschen Literatur gebräuchlichste Funktionalisierung dialektaler Mündlichkeit im 17. Jahrhundert. In den oben angeführten Pendants nord- und mitteldeutscher Provenienz war die Komisierung autochthoner Sprachform keineswegs die Regel. Im Gegenteil: In diesen Anfängen literarischer Mundartverwendung ist die rusticus-Komik häufig ein lediglich sekundärer Wirkeffekt. Wird in Dramen Dialekt gesprochen, dient dies vorrangig dazu, durch den Abgleich von Ausdruck und Lebensraum bzw. sozialer Stellung eine realistische, zumeist ländliche Szenerie zu etablieren. Die mundartliche Rede signalisiert dabei die Authentizität des im Fiktionalen Vorgeführten und wurde schon früh zur Darstellung des gesellschaftlichen Nahbereichs und zur Individualisierung der Charaktere genützt. Dass der Bauernspott als literarisches Muster sich gerade im mehrheitlich katholisch regierten Süden im 17. Jahrhundert so stark ausprägte, ist vielleicht im Zusammenhang mit dem - von den Jesuiten getragenen - gegenreformatorischen Vorgehen gegen die zunächst überwiegend evangelische Landbevölkerung zu sehen.

Aber auch das ,Regensburger Fastnachtspiel' bleibt vorerst ein literaturgeschichtlicher Solitär. Denn auch wenn von weiteren Intermedien mit eindeutig mundartlicher Figurenrede im Ordenstheater ausgegangen werden kann, überliefert sind sie uns nicht. In anderen Teilen des deutschen Sprachraums dagegen entstanden in diesen Jahrzehnten so wichtige Dramen mit Dialektsequenzen wie Johann Rists und Ernst Stapels Irenaromachia (1630), der Friedens-Sieg (1642/48) des bedeutenden Sprachtheoretikers Justus Georg Schottelius und vor allem Andreas Gryphius' Die Geliebte Dornrose (1660). Erst ab Mitte der 1660er Jahre etabliert sich mundartliche Rede als wichtiges ästhetisches Mittel zumal in Verbindung mit Rollenspiel und Musik auch in Bayern und Österreich. ${ }^{6}$

In den Druck fanden die dialektalen Werke zunächst freilich selten. Als am Mündlichen orientierte Kunstsprache ist der literarisierte Dialekt vor 1800 über weite Strecken noch einer oralen Überlieferungs- und Aufführungstradition verpflichtet, einer Kultur

5 Vgl. Hans Trümpy: Schweizerdeutsche Sprache und Literatur im 17. und 18. Jahrhundert (auf Grund der gedruckten Quellen). Basel: Krebs 1955. (Schriften der Schweizerischen Gesellschaft für Volkskunde 36) S. $160 \mathrm{ff}$.

6 Vgl. Christian Neuhuber: y glab es trambt mie. Dialektale Rede in Wiener Stücken des Wander-, Ordensund Hoftheaters 1665/66. In: Christian Neuhuber/Elisabeth Zehetner (Hg.): Bairisch-österreichischer Dialekt in Literatur und Musik 1650-1900. Tagungsband. Graz: Leykam/Universitätsverl. 2015, S. 61-116. 
des gelegenheitsgebundenen Vortrags, in der die schriftliche Fixierung nur subsidiäre Bedeutung hatte. Wesentliche Werke sind uns oftmals nur mehr durch Titelnennung, Inhaltsangaben oder Szenare bekannt, sind in Jahrzehnte jüngeren und dementsprechend überformten Fassungen überliefert oder lassen sich lediglich per analogiam erschließen; der größte Teil dialektaler Kunst aus dieser Frühzeit muss ohnedies als verloren gelten. Was festgehalten wurde, liegt zumeist in handschriftlichen Varianten vor, die im lyrischen und (klein-)epischen Bereich von Folklorisierungs- und Umsingeprozessen, im dramatischen von Umarbeitungen und Leerstellen für Extempores geprägt sind. Mit dem rigiden Werkbegriff literaturwissenschaftlicher Prägung und seinen Implikationen wie Abgeschlossenheit, Eigenständigkeit, Autor-Instanz und Authentizität lässt sich diese ständigen Transformationen unterworfene Dialektkunst kaum fassen. Kein Wunder also, dass sich das Interesse der Editionsphilologie an diesen Werken (die nur selten auch einem konkreten Autor zugeordnet werden können) bislang in Grenzen hielt. Ein Großteil der grundlegenden Studien und Ausgaben hat sein Zentenarium bereits hinter sich, folgt - je nach Untersuchungsfokus - fragwürdigen editorischen Grundsätzen oder wissenschaftlichen Prämissen, deren Ergebnisse zuweilen nicht mehr an den inzwischen verlorenen Quellen zu überprüfen sind. ${ }^{7}$ Jüngere Arbeiten beschränken sich zumeist auf Einzeluntersuchungen aus verschiedenen kulturwissenschaftlichen Disziplinen ohne umfassenderen systematischen Anspruch. Unter diesen Bedingungen wurde Dialektkunst in den Epochendarstellungen marginalisiert, auch wenn sie zum Teil weitaus stärker in der Alltagskultur verankert war und im Gebrauch stand als heute kanonisierte Werke dieser Zeit.

Die Aufarbeitung der Materialbasis ist freilich kein einfaches Unterfangen. Schwierigkeiten bereitet bereits die Identifizierung dialektaler Kunst. ${ }^{8}$ Besonders heikel ist in diesem Zusammenhang die Frage des Verhältnisses von Buchstabe und Laut, da Schreiben eben „kein Transkribieren von Gesprochenem “ ${ }^{\text {" }}$ ist. Da normierte Graphien fehlen, präsentieren sich literarische Mundartverschriftlichungen in den verschiedensten Abstufungen, von der phonologisch möglichst präzise wiedergegebenen basisdialektalen Phrase bis hin zur lesefreundlicheren standardnahen Formulierung, deren morphosyn-

7 So nehmen Editoren und Forscher des 19. und auch noch frühen 20. Jahrhunderts bisweilen - gutmeinend und durchaus wohlbedacht - teils nicht unbeträchtliche Korrekturen am Text vor. Quellentreue ist zu dieser Zeit schlicht kein Teil forschungsrelevanter Paradigmen - vielmehr wird eine Verpflichtung den Textzeugnissen gegenüber erst gar nicht reflektiert, verschrieb man sich doch allem voran der dialektalen bzw. lautlichen Authentizität, die bei Vorliegen eines diesbezüglich als unzulänglich beurteilten Textzeugnisses in den Editionen völlig selbstverständlich sorgfältig nachbessernd ,wiederhergestellt' wurde. Editorische Eingriffe dieser Art finden sich etwa bei August Hartmann, einem der wichtigsten Vermittler dialektaler (heute zum Teil nicht mehr einsehbarer) Quellen, vgl. hierzu exemplarisch Marko Ikonić: Von dem Entsaz wien. Ein dialektales Propagandalied aus der Liedersammlung Ms. germ. oct. 230 der Staatsbibliothek zu Berlin. In: ebda., S. 118-132; hier 121ff.).

8 Zur „Krux des nur mittelbaren Zugriffs auf intendierte Dialektalität“ (S. 59) vgl. Stefanie Edler: Mündlich Verwurzeltes schriftlich konserviert. Überlegungen zur schriftlichen Repräsentation in der Überlieferung von Dialektliteratur des 17. und 18. Jahrhunderts. In: ebda., S. 39-59.

9 Utz Maas: Schrift - Schreiben - Rechtschreiben. In: Diskussion Deutsch 16 (1985), S. 4-25, hier 7. Buchstaben lassen sich - so Maas - nicht als Abbildung von Lautzeichen verstehen; sie sind „rein formale Distinktionselemente“, deren Organisation ,in Reflexion auf die Organisation der Sprechsprache entwickelt worden ist" (ebda., S. 8). 
taktische Struktur eine dialektale Umsetzung nahelegt. ${ }^{10}$ Aber nicht nur die graphische Markierung, auch die Differenzierung der Varietät von einer (sich erst herausbildenden) Schreibsprache oder die Abgrenzung von benachbarten Varietäten wie dem Schwäbischen oder Fränkischen erschweren die Korpusbildung. Weitere Herausforderungen sind etwa die Frage nach dem Anteil der literarisierten Mundart am Werkganzen, der vom sprachlichen Hintergrundphänomen über den punktuellen Einsatz bis hin zum durchgehend dialektalen Werk variieren kann, ${ }^{11}$ die Funktionsbestimmung bei sprachlicher bzw. graphischer Normabweichung bzw. die Artifizialität des literarisierten Dialekts als bewusste Kunstsprache, die Identifizierung produktions- und rezeptionsästhetischer Konstituenten zwischen den Polen ,Bildungselitenkunst' und ,Volkskunst' oder auch das Herausarbeiten thematischer und motivischer Traditionen.

Diese Vielseitigkeit und Komplexität dialektaler Kunst macht sie notwendigerweise zum Untersuchungsgegenstand mehrerer Disziplinen. Probleme der Auswahl, Verortung und Beurteilung dialektaler Texte sind ohne eine dialektologisch fundierte Differenzierung nicht zu lösen und die Identifizierung, Kategorisierung und systematische Beschreibung von schriftlich codierter, Nähesprachlichkeit' wird ohne eine linguistische Analyse kaum möglich sein. ${ }^{12}$ Noch offensichtlicher wird die Dringlichkeit eines interdisziplinären Austauschs an der für dialektale Kunst charakteristischen Tendenz zur Medienüberschreitung und Ausdrucksformenkombination. Wurden dem Zusammenspiel von Mundart, Musik und Mimus bereits einige erhellende Studien gewidmet (zumal, wenn Exponenten einer allgemein anerkannten Elitenkultur involviert sind) ${ }^{13}$, fanden dagegen die vielfältigen Arbeiten mit mehr oder weniger starker Dialektverwendung

10 Inwiefern solche an schreibsprachlichen Usancen angepasste Texte noch zur Dialektkunst gezählt werden können, ist noch lange nicht ausdiskutiert. Für einen sehr weit gefassten Begriff von Dialektliteratur vgl. den diasystemischen Ansatz von Martin Schröder: Ist eine strukturelle Theorie der Dialektliteratur möglich? In: Peter Wagener (Hg.): Sprachformen. Deutsch und Niederdeutsch in europäischen Bezügen. Festschrift für Dieter Stellmacher. Stuttgart: Steiner 1999, S. 281-288.

11 Zur Differenzierung und Terminologie vgl. Walter Schenker: Dialekt und Literatur. In: Zeitschrift für deutsche Philologie 96 (1977), Sonderheft Sprache, S. 34-48, hier S. 44.

$12 \mathrm{Zu}$ der hier grundgelegten Unterscheidung zwischen dem Medium (der entweder phonischen oder graphischen Codierung) und der (mehr oder weniger nähe- oder distanzsprachlichen) Konzeption einer sprachlichen Äußerung vgl. Peter Koch/Wulf Oesterreicher: Sprache der Nähe - Sprache der Distanz. Mündlichkeit und Schriftlichkeit im Spannungsfeld von Sprachtheorie und Sprachgeschichte. In: Romanistisches Jahrbuch 36 (1985), S. 15-33 bzw. Wulf Oesterreicher: Verschriftung und Verschriftlichung im Kontext medialer und konzeptioneller Schriftlichkeit. In: Ursula Schaefer (Hg.): Schriftlichkeit im frühen Mittelalter. Tübingen: Narr 1993, S. 267-292. - Für eine kritische Revision der dort entwickelten Perspektiven und Analysekategorien vgl. Mathilde Hennig: Grammatik der gesprochenen Sprache in Theorie und Praxis. Kassel: kassel university press 2006 sowie Mathilde Hennig: Thesen zur Erforschung historischer Nähesprachlichkeit. In: Maria Balaskó/Petra Szatmári (Hg.): Sprach- und literaturwissenschaftliche Brückenschläge. Vorträge der 13. Jahrestagung der GESUS in Szombathely, 12.-14. Mai 2004. München: Lincom 2007, S. 13-26.

13 Vgl. etwa die Ausführungen zu Mozarts dialektalen Liedarbeiten (Wolfgang Amadeus Mozart: Neue Ausgabe sämtlicher Werke. Serie III: Lieder, mehrstimmige Gesänge, Kanons. Werkgruppe 9: Mehrstimmige Gesänge. Vorgelegt von C.-G. Stellan Mörner. Kassel [u. a.]: Bärenreiter 1971) oder zu den Singspielen von Eberlin und Weiser (Ingo Reiffenstein: Sprachvariation auf dem Salzburger Hoftheater. Die Dialektstücke von Ignaz Anton Weiser (1749/1750). In: Hubert Bergmann [u. a.] (Hg.): Fokus Dialekt. Analysieren - Dokumentieren - Kommunizieren. Festschrift für Ingeborg Geyer zum 60. Geburtstag. Hildesheim/Zürich/ New York: Olms 2010, S. 329-352). 
etwa im Bereich der Volksnarration, des satirischen Zeitkommentars, der Agitationsliteratur oder der Kanzelrhetorik kaum Beachtung. Fächerübergreifend sind auch die Fragestellungen, die sich aus der thematischen Verankerung vorwiegend in den sozialen Niederungen, im Ländlichen oder auch im Familiär-Privaten ergeben. Zuweilen sind Dialekttexte die einzigen verbliebenen Zeugen für Alltagsdiskurse von hoher historischer, soziologischer und ethnologischer Aussagekraft. Um deren produktions-, inhaltsund rezeptionsästhetische Besonderheiten als Gegenbild zu den kanonisierten Leittexten zu erfassen, bedarf es der Zusammenarbeit verschiedener kulturwissenschaftlicher Disziplinen, die ihre spezifischen Ansätze, Methoden und Forschungsergebnisse in die Untersuchung einzubringen haben.

Vorbehalte gegen Mundartkunst sind allerdings nicht nur im Wissenschaftsbetrieb nach wie vor vorhanden. Die Argumentationsmuster haben sich durch die Jahrhunderte kaum verändert und zielen weniger auf das künstlerische Potenzial der Produzenten ab als auf den defizitären Charakter des Dialekts zumal in kommunikativer und ästhetischer Hinsicht: Durch seine beschränkte Reichweite büße das mundartliche Kunstwerk an Verständlichkeit ein, ${ }^{14}$ der dialogische, genuin mündliche Charakter des dialektalen Ausdrucks beschneide die künstlerischen Möglichkeiten und durch die schichtenspezifische Verwurzelung im bäuerlich-kleinbürgerlichen Lebensbereich enthalte Dialektkunst zu wenig Welthaltigkeit. Verschärft wird dieser Aspekt durch eine soziale Stigmatisierung des Dialekts, der als Ausdruck der Ungebildeten nicht geeignet sei, komplexere und abstrakte Inhalte zu gestalten. ${ }^{15}$ Dass viele Autoren überlieferter Mundartkunst vor 1800 aus der gebildeten Schicht stammten, ${ }^{16}$ wird dabei ebenso übersehen wie die Tatsache, dass damals eine überwiegende Mehrheit der geistigen und gesellschaftlichen Elite im oberdeutschen Sprachgebiet (auch) Dialekt sprach. Die Abwertung des Lokalidioms ist vor dem Hintergrund der vergleichsweise späten Verankerung einer überregionalen Einheitssprache zu sehen, die im zentrumslosen deutschsprachigen Raum nur zögerlich als schriftsprachliche Norm angenommen wurde. Umso schärfer fielen die Angriffe zahlreicher aufklärerischer Sprachpuristen aus, die regionale Varietäten als verderbte Abart und Hindernis für vernünftiges Denken abqualifizierten. ${ }^{17}$ Noch lange wirkte diese Geringschätzung in sprachgeschichtlichen Konzepten nach, die die Herausbil-

14 Schon Wieland wendet sich gegen das u. a. von Adelung postulierte Primat der Verständlichkeit von Sprache und führt dagegen literarästhetische Vorzüge dialektaler Ausdrücke ins Treffen. Vgl. Florian Gräfe: Dialektliteratur in Deutschland und Italien. Konstanz und Wandel von Bewertungsmustern. Marburg: Tectum 2004.

15 Vgl. Oskar Reichmann: Dialektale Verschiedenheit: zu ihrer Auffassung und Bewertung im 17. und 18. Jahrhundert. In: Klaus J. Mattheier [u. a.] (Hg.): Vielfalt des Deutschen. Festschrift für Werner Besch. Frankfurt a. M. [u. a.]: Lang 1993, S. 289-314.

16 Grob lassen sich dialektale Werke - natürlich mit den entsprechenden Überschneidungen und Doppelbesetzungen - vier Entstehungsbereichen zuordnen: dem kirchlichen (und hier zumal dem klösterlichen) Umfeld, den feudalen Herrschaftszentren und Adelssitzen, der stadtbürgerlichen Künstler- und Intellektuellenszene und der bäuerlichen Alltagskultur mit ihren zumeist unbekannten Verfassern.

17 Vgl. Ulrich Knoop: Zur Begrifflichkeit der Sprachgeschichtsschreibung. Der ,Dialekt' als Sprache des, gemeinen mannes' und die Kodifikation der Sprache im 18. Jahrhundert. In: Horst Haider Munske [u. a.] (Hg.): Deutscher Wortschatz. Lexikologische Studien. Ludwig Erich Schmitt zum 80. Geburtstag von seinen Marburger Schülern. Berlin/New York: de Gruyter 1988, S. 336-350. 
dung einer Einheitssprache als Notwendigkeit angesichts einer dialektalen Zersplitterung durch rückständige Provinzialismen sahen. Obwohl inzwischen die Defizit-Hypothese, nach der Dialekt im Vergleich zur hochsprachlichen Leitvarietät grammatisch mangelhaft ausgestattet wäre, wissenschaftlich längst obsolet ist, ${ }^{18}$ haftet mundartlicher Rede - und mit ihr historischer wie aktueller Dialektkunst - nach wie vor der Ruch des Trivialen und Mangelhaften an.

Doch gerade in diesen angeblichen ästhetischen ,Defiziten' liegen zugleich die genuinen Stärken dialektaler Kunst. Die bekrittelte räumliche und soziale Diversität mündlichkeitsbasierter Varietäten stellt nicht nur ein reiches Reservoir an zusätzlichem Sprachmaterial in Form von Heteronymen, Nischenvokabular oder Redewendungen bereit, das den Wortschatz und die Phraseologie der Literatursprache ergänzen kann. ${ }^{19}$ Sie ist auch Ursprung der dialektalen vis comica, die sich nicht immer in der Lächerlichkeit der sozial niedriger stehenden ,Sprache des Volks' entfaltet. Zum Lachen reizte auch schon in den Anfängen der bewusste Einsatz von Standardsprache als Zeichen des Phrasenhaften, Uneigentlichen, während Dialekt den Eindruck von ,Natürlichkeit oder ,Ursprünglichkeit‘ vermittelt. Die diatopischen, diastratischen und diaphasischen Eigenheiten von Mundart prädestinieren diese zudem zur Darstellung des gesellschaftlichen Nahbereichs, des Intimen und Privaten (ist sie doch bekanntlich nach Goethe das Element, „, in welchem die Seele ihren Atem schöpft ${ }^{\text {“20}}$ ). Dabei muss sich die mundartliche Formulierung freilich nicht auf das Nicht-Offiziöse beschränken, appellieren doch sprachinhärente Inklusionseffekte an ein Gemeinschaftsgefühl, das zu verschiedenen Zwecken genutzt werden kann. Dialekt hat also durchaus einen Mehrwert gegenüber normierter Schreibsprache: als Mündlichkeitsfiktion etwa oder zur regio-, soziooder emotiolektalen ${ }^{21}$ Figurencharakterisierung, als Zielgruppenansprache oder ironische Distanzierung, als Spiel mit der Dechiffrierlust der Lesenden oder aufmerksamkeitserregender Verfremdungs- und Deautomatisierungseffekt und vieles andere mehr. Werturteile zu den Anfängen der Dialektkunst basieren jedoch im Wesentlichen noch immer auf Argumenten, die sich auf Gattungsausformungen nach der ,Sattelzeit' um 1800 beziehen, die spezifischen Bedingungen für eine Kunst in bairisch-österreichischer Mundart vernachlässigen und nur einen geringen, unrepräsentativen Teil der Mundart-

18 Vgl. Heinrich Löffler: Dialektologie. Eine Einführung. Tübingen: Narr 2003, S. 4f.

19 Bereits ab der Mitte des 17. Jahrhunderts lässt sich dieser Bereicherungsgedanke in den Diskussionen um den Wert regionalsprachlicher Varietäten beobachten. Vgl. u. a. Reichmann, Dialektale Verschiedenheit, S. 304f. und Gräfe, Dialektliteratur in Deutschland und Italien, S. 25-33. Seinen konstruktivsten Ausdruck findet er schließlich in den verschiedenen Idiotika, in denen Provinzialismen gesammelt und sprachtheoretisch ,ursprüngliche‘ Ausdrücke aufgewertet wurden. Vgl. dazu Walter Haas: ,Die Jagd auf ProvinzialWörter'. Die Anfänge der wissenschaftlichen Beschäftigung mit den deutschen Mundarten im 17. und 18. Jahrhundert. In: Klaus Mattheier/Peter Wiesinger (Hg.): Dialektologie des Deutschen. Forschungsstand und Entwicklungstendenzen. Tübingen: Niemeyer 1994, S. 329-365 sowie Walter Haas: Provinzialwörter. Deutsche Idiotismensammlungen des 18. Jahrhunderts. Berlin/New York: de Gruyter 1994.

20 Johann Wolfgang Goethe: Aus meinem Leben. Dichtung und Wahrheit. Hg. von Peter Sprengel. München: dtv 1985, S. 274. (Sämtliche Werke nach Epochen seines Schaffens 16).

21 Angesprochen ist damit eine Nähesprachlichkeit, die in emotionalen Situationen deutlicher hervortritt im dramatischen Kontext etwa besonders gerne in Liebesszenen oder in Wutreden. 
kunst zu dieser Zeit vor Augen haben. ${ }^{22}$ Viele dieser Urteile sind rasch widerlegt, wenn man nicht die Ansichten einer (oftmals) ideologisch verbrämten älteren Forschung unreflektiert übernimmt, sondern den Blick auf das reiche Spektrum der Erscheinungsformen wagt, der erst eine differenzierte Betrachtungsweise des Phänomens Dialektkunst ermöglicht.

Schon der Vergleich mit den künstlerischen Produktionen anderer deutscher Dialekträume zeigt, dass die Literarisierung von mundartlicher Rede nicht isoliert von soziokulturellen Bedingungen und Veränderungen betrachtet werden kann. ${ }^{23}$ Viele Ausdrucksformen haben anderswo keine adäquate Entsprechung bzw. eine andere Häufigkeit, andere wiederum kommen im bairisch-österreichischen Raum nicht oder zu anderer Zeit vor. Unterschiede in der Verwendung und Bewertung von Dialekt, die Bedingungen seiner Entfaltung, der Wandel seiner gesellschaftlichen Aufgaben und die daraus resultierenden Stereotype und habituellen Normen beeinflussen massiv auch den künstlerischen Gebrauch. In diesem Buch werden deshalb auch die (sprach-)politischen, sozialen, konfessionellen und kulturellen Rahmenbedingungen rekonstruiert, in denen sich Dialektkunst entfalten konnte: die Ausbildung einer diglossischen Sprachsituation durch die schriftsprachliche Überdachung der Dialekte vor dem Hintergrund von Gegenreformation und wiedererstarktem Katholizismus; die Entwicklung der oberdeutschen Schreibsprache, ihr Verhältnis zum Basisdialekt und ihre Ablösung als Leitvarietät durch die ostmitteldeutsche Schriftsprache um 1750; die Verteilung der Dialektsprecher in den Gesellschaftsschichten; die sukzessive Pejorisierung des Dialekts und die soziale Stigmatisierung seiner Sprecher; der Einfluss medialer Entwicklungen auf Kommunikationsverhalten und Schreibgewohnheiten und anderes mehr. Aus einer sozialhistorischen Perspektive werden dabei jene kulturellen Felder rekonstruiert, in denen sich Dialektkunst zu einem wichtigen Ausdrucksmittel mit vielfältigen Aufgabenbereichen entwickelte. $\mathrm{Zu}$ den wichtigsten gehört die Konstruktion kollektiver Identitäten, wie sie in den gängigen Ausdeutungen einer kanongestützten Elitenkultur nur bedingt sichtbar werden, da alltagskulturelle Phänomene darin zumeist ausgespart bleiben. Dies dürfte auch eines der wichtigsten Argumente für eine Erschließung und Vermittlung der bairisch-österreichischen Dialektkultur vor 1800 sein: Das scheinbar Fremde als vergessenes bzw. ausgeblendetes Eigenes wieder sichtbar zu machen und so die Vielfältigkeit eines Kulturraums neu zu entdecken.

22 Dass allerdings auch eine Akzentuierung der Stärken des Dialekts ähnlich unheilvoll für eine wissenschaftliche Auseinandersetzung sein kann wie dessen Abwertung, zeigen die zahlreichen ideologieschwangeren Deutungsansätze zumal der ersten Hälfte des letzten Jahrhunderts, die Mundartkunst als, natürlichen Ausdruck einer heilen Gegenwelt zu den entfremdenden Zivilisationserscheinungen der Moderne hochstilisierten. Vgl. u. a. Monika Jaeger: Theorien der Mundartdichtung. Studien zu Anspruch und Funktion. Tübingen: Bissinger 1964, S. 69-80.

23 Vgl. Walter Haas: Dialekt als Sprache literarischer Werke. In: Werner Besch [u. a.] (Hg.): Dialektologie. Ein Handbuch zur deutschen und allgemeinen Dialektforschung. Zweiter Halbbd. Berlin/New York: de Gruyter 1983, S. 1637-1651. 
Der vorliegende Band erschließt die inhaltliche Breite dialektaler Literatur in acht Abschnitten: Religiöse Themen stehen im ersten Kapitel Glaube und Aberglaube im Zentrum: Neben den äußerst breit überlieferten Liedern und Spielen des Weihnachtskreises belegen Frömmigkeitstexte, aber auch humoristische und satirische Arbeiten zu Glaubensinhalten oder zu religiösen Institutionen den hohen Stellenwert dieses Themenfelds für die dialektale Kunst vor 1800. Weltlicher Macht und Herrschaft widmen sich die folgenden beiden Kapitel: In Krieg und Frieden werden literarische Arbeiten zu den vielfältigen militärischen Anlässen des 17. und 18. Jahrhunderts untersucht, die der Propaganda gegen den Feind, der Nachrichtenvermittlung, aber auch der Werbung von Soldaten dienen konnten; daneben finden sich auch kritische Texte zu Praktiken der Zwangsrekrutierung oder zum Leben der Soldaten. Dialektliteratur diente auch in Friedenszeiten der Bestätigung oder Ablehnung von Machtverhältnissen, wie im Kapitel Herrschaft und Untertan gezeigt wird: Geburt, Hochzeit und Tod von gekrönten Häuptern wie auch patriotische Bekundungen wurden auf diese Weise scheinbar in der Stimme des Volkes besungen; aber auch subversive Literatur bediente sich des Dialekts und damit der Möglichkeit, Nähe und Authentizität zu suggerieren. Im Fokus der Kapitel 4 und 5 steht Dialektliteratur in Zusammenhang mit sozialen und regionalen Differenzierungen. Beim Themenbereich Stadt und Land hat die Darstellung von Bauernfiguren - etwa als Leidende in Bauernklagen oder in lustigen Rollen - besonderes Gewicht; doch auch bei literarischen Bearbeitungen urbaner Typen und Gepflogenheiten markieren regio- und soziolektale Elemente Zugehörigkeit oder Abgrenzung. Ähnliches gilt für die Texte des Kapitels Fremdes und Eigenes, in dem der Blick zunächst auf die (Re-)Produktion von Stereotypen über Regionen und deren Einwohner gerichtet wird, um dann auf jene kulturellen Dokumente zu blenden, in denen Fremde in einer Mischung aus Fremdsprache und Mundart zu Wort kommen und damit als, eigene Fremde' Grenzen zwischen Eigenem und Fremdem überschreiten. Das sechste Kapitel Brauchtum und Geselligkeit untersucht Dialekttexte, die selbst dem Brauchtum dienten oder in denen verschiedene Bräuche und Verhaltensmuster in literarischer Form reflektiert werden. Im folgenden Kapitel Körper und Sinnlichkeit sind Texte versammelt, die damals nur bedingt literaturfähige Motive wie Krankheit, Ausscheidung, Ekelerregendes oder Sexualität, aber auch weniger Verfängliches rund um die Liebe aufgreifen. In Fehden und Feindschaften schließlich wird das polemische Potenzial dialektaler Literatur in den Mittelpunkt gerückt. Der Bogen reicht hier von agitatorischen Texten im Konfessionskampf über josephinische Streitschriften gegen die Predigtpraxis bis hin zu Debatten des Literatur- und Kulturbetriebs wie dem ,Hanswurststreit' oder den Diskussionen um Standardisierung und den Wert von Regionalsprachen. 


\section{GLAUBE UND ABERGLAUBE}

Die starke religiöse Überformung des gesellschaftlichen Lebens nicht nur im ländlichen Bereich macht Glaubensdinge zu einem der wichtigsten Themen für die Dialektkunst vor 1800. Als bewusstes Ausdrucksmittel steht die dialektale Formulierung jedoch nur in wenigen Bereichen tatsächlich im Dienste religiösen Handelns, noch seltener im liturgischen Kontext. Als Theolekt, also als geeignete Sprache, um über das Göttliche zu kommunizieren, diente der römisch-katholischen Kirche zu dieser Zeit (und letztendlich bis zum Zweiten Vatikanischen Konzil) vorrangig das Lateinische, das Ritus und Kultus bestimmte. ${ }^{1}$ Volkssprache konnte im liturgischen Gebrauch in der Homilie und in gesungenen Texten verwendet werden, allenfalls noch im Allgemeinen Gebet und in den Monitionen. Aufgrund des öffentlichen Charakters und der übergreifenden Ritualisierung dieser theolinguistischen Kommunikation bediente man sich dabei freilich fast ausschließlich der Leitvarietät (oberdeutscher, später dann mitteldeutscher Standard). Lokal gebundene und damit kommunikativ begrenzte Varietäten waren in der Liturgie nicht vorgesehen; wo Dialekt dennoch als rhetorisch-ästhetisches Mittel eingesetzt wurde, etwa bei der Predigt oder im Offertoriumsgesang, gab dies vielfach Anlass zu heftigen Diskussionen und wiederholten Verboten. ${ }^{2}$ Auch im paraliturgischen Bereich, ja selbst im religiösen Brauchtum und individuellen Gebet wirkte diese Orientierung am überregionalen Standard nach. Nur einige wenige Hochfeste des Kirchenjahrs und Andachtstermine für landschaftsspezifische Heilige boten Anknüpfungspunkte für Ausnahmen. Eng an die verschiedenen Traditionen des Volksbrauchs gebunden, übernahm mundartliche Poesie hier wesentliche Aufgaben in der Ausgestaltung von Frömmigkeitsformen. Den weitaus größten Teil bilden dabei die Lieder und Spiele zum Weihnachtsfestkreis, die als Beispiele gelebten Volksglaubens in vielfältigen Ausformungen überliefert und zum Teil bis heute im Volksbrauch lebendig sind. Daneben aber diente das christliche Sujet im mundartlichen Gewande zumeist ganz anderen Zwecken denn der individuellen oder gemeinschaftlichen Andacht: der entlastenden Komisierung, humorvollen Travestie oder affirmativen Kritik, aber auch der satirischen Verunglimpfung, aufrüttelnden Zeitklage oder dem systemunterminierenden Angriff auf die katholische Kirche.

1 Vgl. dazu die grundlegenden Ausführungen von Albrecht Greule: Dialekt als Theolekt? Überlegungen aus der Perspektive der Variationslinguistik. In: Elisabeth Frieben/Ulrich Kanz/Barbara Neuber/Ludwig Zehetner (Hg.): Dialekt und Religion. Beiträge zum 5. dialektologischen Symposium im Bayerischen Wald, Walderbach, Juni 2012. Regensburg: edition vulpes 2014, S. 29-36.

2 Vgl. dazu auch Kapitel 8 (Predigtkritiken). 


\section{Lieder und Spiele des Weihnachtskreises}

Kein anderer Bereich des Glaubenslebens ist so stark von Dialektkunst durchdrungen wie das Brauchtum zur Weihnachtszeit. In Advent- und Verkündigungsliedern wurde die nahende Ankunft des Herrn besungen, in den Herbergsuche-Liedern zumeist dialogisch seine Unbehaustheit in dieser Welt inszeniert, die Lieder zur Geburt Christi bejubelten die Menschwerdung des Heilands, der mit Kindelwiegeliedern symbolisch zur Ruhe gebracht wurde; auch die Neujahrslieder und Dreikönigslieder waren unverzichtbare Bestandteile des Repertoires der im Advent umherziehenden ,Ansinger ' und ,Kirchensänger', die sich auf diese Weise ein kleines Zusatzeinkommen ersangen. Die größte Gruppe des weihnachtlichen Liedguts aber stellen die sogenannten Hirtenlieder dar, die nachweislich seit dem 14. Jahrhundert im Heischegesang zum Einsatz kamen, in privaten Andachten vorgetragen wurden und in den Rorate-Messen oder auch in der Weihnachtsmette zu hören waren. ${ }^{3}$ Ein wesentlicher Grund für ihre Beliebtheit war wohl das hohe Identifikationsangebot für die bäuerliche Bevölkerung, das sich aus der Ausgestaltung der neutestamentarischen Überlieferung von den Hirten auf dem Feld ergibt, denen der Engel die Kunde von der Ankunft des Herrn überbrachte (vgl. Lukas 2, 8-20). Im Mittelpunkt steht hier der einfache, ungebildete Mensch, der dennoch das Unfassbare glaubt und beispielhaft die richtigen Schritte setzt. Die vielfältige Verbildlichung der bäuerlichen Lebenswelt, die unangestrengte Annäherung an ein zentrales Mysterium der christlichen Glaubenslehre, die auch Raum für komische Effekte lässt, und die besondere Nähe zur szenischen Umsetzung, all das macht das Hirtenlied zum fixen Bestandteil des weihnachtlichen Brauchtums.

Die ersten dialektal gehaltenen Weihnachtslieder begegnen uns im bairisch-österreichischen Raum ab der Mitte des 17. Jahrhunderts. Als frühester belegbarer Druck gilt eine (zurzeit nicht auffindbare) Flugschrift von 1656 aus der Innsbrucker Offizin des Hieronymus Paur, die als ersten von drei Weihnachtsgesängen In der stillen mittä Nacht bringt. ${ }^{4}$ Aus einem späteren, angeblich in Augsburg um 1700 entstandenen Druck stammt die folgende Fassung:

3 Vgl. u. a. Karl Weinhold: Weihnacht-Spiele und Lieder aus Süddeutschland und Schlesien. Mit Einleitungen und Erläuterungen. Mit einer Musikbeilage. Graz: Damian \& Sorge 1853, S. 396f. - Wilhelm Pailler: Weihnachtslieder und Krippenspiele aus Oberösterreich und Tirol. 2 Bde. Innsbruck: Wagner 1881 und 1883. - Sigrid Abel-Struth: Die Texte weihnachtlicher Hirtenlieder. In: Rolf Wilhelm Brednich/Lutz Röhrich/Wolfgang Suppan (Hg.): Handbuch des Volksliedes. Bd. 1: Die Gattungen des Volksliedes. München: Fink 1973, S. 419-444. - Walter Deutsch/Gerlinde Haid/Herbert Zeman (Hg.): Das Volkslied in Österreich. Ein gattungsgeschichtliches Handbuch. Wien: Holzhausen 1993, S. 336.

4 Vgl. u. a. Anton Dörrer: Hundert Innsbrucker Notendrucke aus dem Barock. Ein Beitrag zur Geschichte der Musik und des Theaters in Tirol. In: Gutenberg-Jahrbuch 14 (1939), S. 243-268, hier 268. - Karl M. Klier: Innsbrucker Lied-Flugblätter des 17. Jahrhunderts. In: Jahrbuch des österreichischen Volksliedwerkes 4 (1955), S. 56-77, hier 61. - Kurt Drexel/Monika Fink: Musikgeschichte Tirols: Von den Anfängen bis zur Frühen Neuzeit. Innsbruck: Wagner 2001, S. 689. 
1

IN der Still zu Mitternacht/ als ich bey mein Schäfflein gwacht/ da hört ich in Lufft ä Gschäll/ bin da gstandn / hab glost ä Weil/ gschwind / gschwind stehts auf/ gegn Bethlehem lauffts/ dort gehts fort in Stall hinein/ werds GOtt finden in Krippelein. 3 Nit / nit Buema platzt nit drein/ gmächlä gehts in Stall hinein/ schauts / schauts wie das Kind da ligt/ main es ist schon halb dästickt gehts gehts Buemä/ gebts / ä Fuetä/ Ochs und Esel machen warm/ armes Kindlein / daß GOtt ä barm. 5 Ist nit das än artle Sach/ liebe Nachbaurn denckts nä nach/ weil uns Adam Wundä weiß/ hat verschertzt das Paradeyß/ in das zu bringa/ muß GOtt springa/ von sein hohen Himmelreich/ und uns Menschen werden gleich. 7

Gehts nun zsamma / fallts auf d'Knye/ last uns anbettn GOtt allhie/ dencka gleichwohl auf das best/ das Kind uns hat all erlöst/ Adams-Kinda/ arme Sünder/ schau da hama bracht ä Lamm/ weilst uns hast erlöst allsamm. 9 So / so Nachbaurn singts hibsch mit/ GOtt sey Ehr und Menschen Frid/ schauts was wärs mit uns dann gwest/ wann uns GOtt nit hät dalöst/ last uns gfreun/ GOtt danckbar seyn/ vor uns hat er noch mehr wollen/ daß wir halt Ihn lieben sollen.
2

Liebe Nachbaurn mit mir geht/ last uns schauen / wies da steht/ was dann GOtt bey uns da macht/ was Er Neues vom Himmel bracht/ last uns seha/ wies dann gscheha/ daß vom Himmel kommen GOtt/ muß ja seyn ä grosse Noth.

4

Still / still Nachbaurn / loß / bleibt stehn/ wie die Engel singa schön/ wies nit all hübs musicirn/ singa / pfeiffa / und Geigna rirn/ last uns denckä/ was wir schenckä/ was wir haben bey der Herd/ das Kind ist ä alles werth.

6

Last uns singa lustig zsamm/ und da seyn in GOttes Nam/ alle froh zu diser Post/ wanns jeden schon etwas kost/ last uns noch mehr bringen daher/ daß man den Kind kochä kann/ möchte uns kemä hart davon. 8 Liebes Kind / du grosser GOTT/ was wirst noch nit habn für Noth/ wanns ä so schon jetzund anfangst/ was wirst nit no habn für Angst/ bist nit schuldig/ leyds gedultig/ das hat gmacht gegen uns auß Lieb/ was seyn wir nit schuldig dir.

10

Last uns Urlaub nehmen all/ s'Kind verehren z'tausendmahl/ dencka / daß Er zu uns kümmt/ wegen uns also annimmt/ armes Kindlein/ in den Windlein/ jetzund gehma wider rund/ b'hüt dich GOtt / und bleib fein gsund. ${ }^{5}$

1,3 Gschäll] Schall, Lärm 1,4 glost] (zu: losen) gelauscht, zugehört 3,1 Buema] Buben (Bub war Bezeichnung für die rangniedrigsten Knechte) 3,2 gmächlä] gemächlich 4,1 loß] horch 4,8 ä] auch 5,1 artle] seltsame 5,2 nä]

5 Das Erste: In der Still zu Mitternacht. In: Neun schöne Geistliche Lieder / Erstlich: Drey Weyhnacht=Lieder/ [o.O, o. J.] Auch wenn in der Forschung zumeist Augsburg als Druckort angegeben wird, spricht die sprachliche Gestalt des Texts doch eher für einen oberösterreichischen Verleger (Linz, Steyr). 
nur, bloß 6,8 kemä] kommen 7,7 hama] haben wir 7,8 weilst] weil du 10,1 Urlaub] Abschied 10,7 gehma] gehen wir

Das später weitverbreitete Lied $^{6}$ enthält bereits die drei motivischen Grundelemente des Genres, die im Lauf der Jahrhunderte zahllose qualitativ sehr unterschiedliche Abwandlungen gefunden haben: ${ }^{7}$ 1. die bei den Hirten Verwunderung erregende Verkündigung der Geburt Christi durch einen oder mehrere Engel, 2. die Beratschlagung, wie man mit der Neuigkeit umzugehen habe, und die Vorbereitungen für den Gang sowie 3. die Huldigung des Kinds an der Krippe mit abschließender Bitte um Segen. ${ }^{8}$ Hält sich die erste Motivgruppe oft noch relativ nah an die biblische Vorlage, indem sie den himmlischen Überbringer der Weihnachtsbotschaft und das Anbetungsgebot ins Bild setzt, gibt die zweite Motivgruppe vor allem Milieuschilderungen mit der Möglichkeit $\mathrm{zu}$ situationskomischen Brechungen Raum; die dritte Gruppe intensiviert über rührende, gemeinschaftsstiftende Liebesbeteuerungen und Frömmigkeitsbezeugungen den glaubenspraktischen Gehalt solcher Lieder. Innerhalb dieser motivischen Rahmenbedingungen, die uns in den Liedern verschieden akzentuiert begegnen, entfaltete sich ein beeindruckender Reichtum an inhaltlichen Ausschmückungen aus dem bäuerlichen Lebensumfeld.

Im Wechsel von Simultanbericht, Anrede und Rückblende strukturell ähnlich wie In der stillen mittä Nacht gestaltet ist das, Bayrische weynacht gsang' Huy liebe meine buebn, eines der ältesten handschriftlich überlieferten Hirtenlieder aus einer um 1690 im bayerisch-österreichischen Donauraum verfassten Liedersammlung, die aus dem Nachlass Karl Hartwig Gregor von Meusebachs in die heutige Staatsbibliothek zu Berlin gelangte. ${ }^{9}$ Im Folgenden ist diese älteste bislang erfasste Version einer etwa sieben Jahrzehnte später in Steyr gedruckten entstandenen Fassung gegenübergestellt, um die für dieses Genre durchaus üblichen Umsingeprozesse zu veranschaulichen, die u. a. dialektale Differenzen ausgleichen und innovative Elemente zugunsten veralteter integrieren:

1

Huy liebe meine buebn

was hebn wir an

huy last uns gschwind luegen

wohin wir wolln gahn

rueffts dlämpl beym Namma

treibts schaffl zusamma

die Rindä und gais

Huy buebmä auf drais.
1

IHr liebe meine Nachbaurn

was heben wir an,

uns stehts zu erwählen

wo wir heut hingan,

ruft d'Lämmlein zusammä, nennts alle beym Namä, daß d'Rinder und Gaiß, nicht hindern die Rays.

6 Vgl. Arnold Blöchl: Melodiarium zu Wilhelm Paillers Weihnachts- und Krippenliedersammlung herausgegeben in den Jahren 1881 und 1883. Unter Mitarbeit von Annemarie Gschwantler und Walter Deutsch. Hg. vom Oberösterreichischen Volksliedwerk. 2 Halbbde. Wien/Köln/Weimar: Böhlau 2000. (Corpus musicae popularis Austriacae 13) S. 904-908.

7 Vgl. die zahlreichen Hirtenlieder unterschiedlicher Fassung in der Datenbank Dialect Cultures, http:// gams.uni-graz.at/context:dic (letzter Zugriff am 10.05.2018).

8 Vgl. Abel-Struth, Die Texte weihnachtlicher Hirtenlieder, S. 421-424.

9 Staatsbibliothek zu Berlin, Ms.germ.oct. 230. 


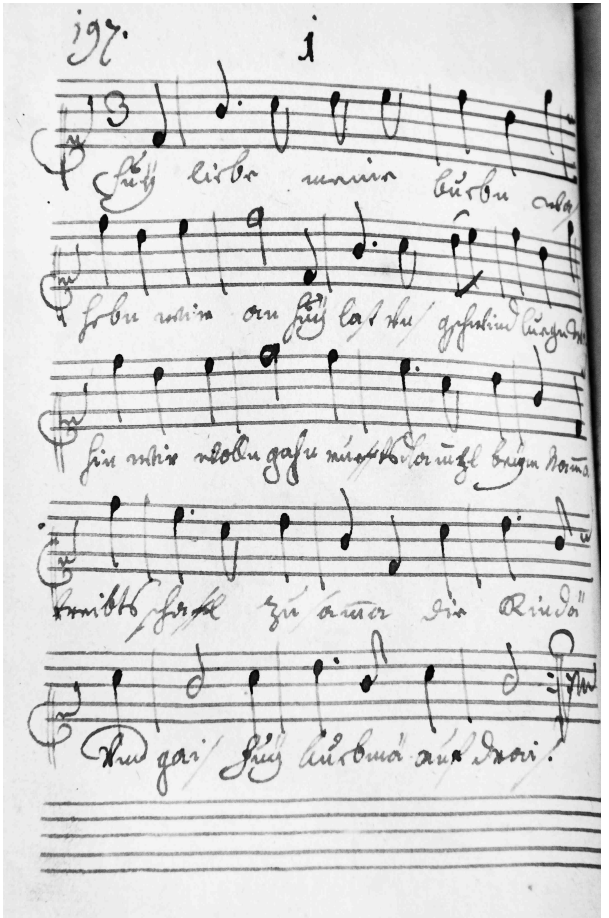

Abb. 1: Huy liebe meine buebn (Staatsbibliothek zu Berlin, Ms.germ.oct. 230, f. 197).

2

Hörts ainmahl auf zschnauffn vom schlaffn erwachts Nimbts dJoppn, thuets lauffn Nach Bethlehem trachts hört ihr nit schö singa den friden vns bringa Ist warlä kai traumb buem khaina si saumb. 3

Botz buemä thuets schaugn glob mei troi es brindt last schiessn die augn gleich Einwerths dorthint Was mues no bedeutn das liecht dort vo weitn koi foir ist es nit buem nachä i bitt.

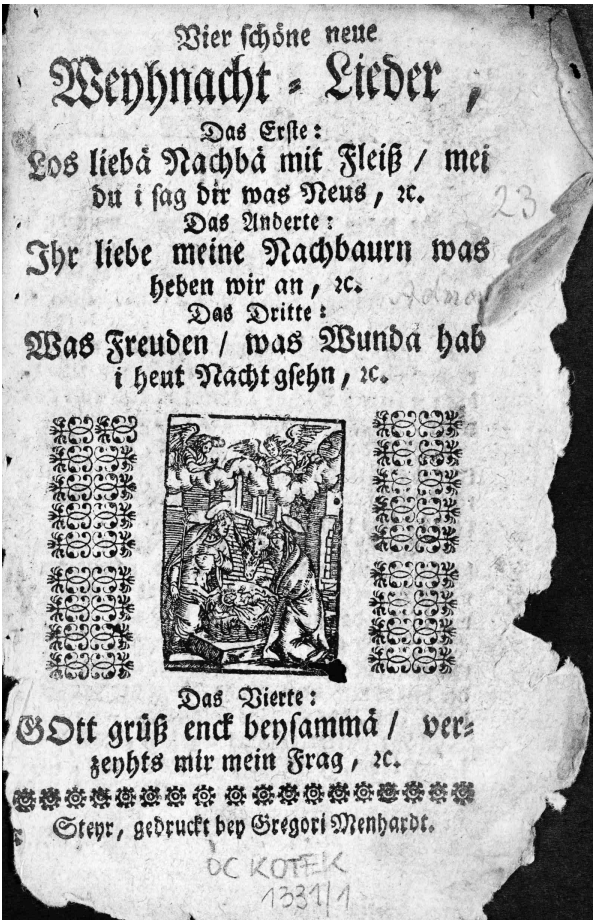

Abb. 2: Titelblatt der Flugschrift (Archiv des Österreichischen Volksliedwerkes/Österreichische Nationalbibliothek, ÖC Kotek 1331).

2

Hört einmal auf Schnauffen, vom Schlaff bald erwacht, ihr Hirten thut lauffen, nach Bethlehem tracht, hört ihr dann nicht singen, den Friden uns bringen, ist wärlä kai Traum, [nu]r kainä sich saum. 3

Gib Achtung mein Jodel, schau sey du kai Lapp, auf daß dir s'Unziefer kai Lämbl dädapt, [t]reibts alle zusammä, nennts alle beym Namä, [se]y Hännsel bem Vieh, und kains übersih. 
4

Wo wilst vns hiführn?

schau kradt nach dem stall

wür werden nit irren

den berg dort hinab

Eß thuet als erleichtn

dort vndtä dä Feüchtn

ä gälingä schein

was wunda mues sein.

5

Der hansel dort vndtä wolt nit mit vns gö

Vnd wir habn gfundä

ä Kündl so schö

Ey wirdts ihn nit reun

Ey wirdts ihn nit keien

Wan wir ihm wern sagä

was si hat zutragä.

6

los Märtl mei brueda

lass dNandl hier gö

zu secha der Muedä

ihr kündl so schö

Mei bue der mues weicha

thuet ihm gar nit gleicha

den mir meü wey bracht

die vorige Nacht.

7

Los wastl frischer bue

laff gschwind zu der herdt

ä Lampl bring herzue

so no nit ist gscherdt

Wir wolln es geben

das Mueda hab zlöbn

Vnd fürs kündt bring schnell

Milch pfandl vnd mehl.

8

Huy lusti mey Sandl

blas Morgn fey frueh

Es schlagt vns den Nandl

dMaul trumml darzue.

Die grädl Mues singä

der Riepl wird bringa

käs, brod, ayr, vnd schmalz

der Jodl das Salz.
4

Botz Buebmä thuts schauä, glaub mein Treu es brinnt, last schiessen die Augen, grad überwärts hin, was muß es bedeuten, das Liecht von der Weiten, kai Feur ists ja nicht, kommts nachä i bitt 5 Ich will euch hinführen, ja grad nach den Stall, wir werden nicht irren, den Weeg ab nach Thal, thut uns schon vorleuchten, wohl unter der Feuchten, ein gählinger Schein, was Wunder mag seyn.

6

Der Hiesl dort drunten hat ä wolln mitgehn, zu sehen der Mutter ihr Kindelein schön, es wird ihn wohl greuä, und darff ihn wohl freuä, wann wir ihms wern sagn, was wir gsehä habn.

7

Schau [Mö]rtel mei Bruder, laß d'Margareth her gehn, zu sehen der Mutter ihr Kindlein gar schön, mei Büberl der Mauß=Kopff tut ihm gar nicht gleichä, dens mir da habn bracht, die vorige Nacht.

8

Los liebä Bue Wästel, lauff flux zu der Heerd, bring her ä faists Lämbl, das noch nicht ist gscheert, das wollen wir geben, daß d'Muttä hat z'leben, fürs Kind bringet schnell, Milch, Pfann und ä Mehl. 
9

Wo ist dey sackhpfeiffa frey grandigä bue, vmb dleirä thue greiffä vnd stimm ä däzue du kholschwarzer Bärtl vom speckh schneid ä schwartl dem kündt gibß ins Maul frey rundi nit faul.

10

huy buemä seit Muntä dem kündlein zum preiß, hey, habä, legts vndä wents an alln fleis. Das Söxel hab zessen der Esel ä zfressn das Muedä unds kündt ä labung empfindt. 11

Was wir wolln göbä Nur euch nit lang bsindt so lang wir thuen löbä dem göttlichen Kündt thue i nit bedenkhn thue im mei herz schönkhn gib ihm auch als frey was immä mag sey.

12

Vor freuda thuet singä Mei hierz im leib springt den Fridn thuet bringä das göttliche Kündt Läffts buemä vnd Mannä läffts alle zuesammä Baur, Bayrn, Knecht Maid vergesst alles laidt.

13

Der hansel vndt Sarel seyndt tauglich zur Wacht Das Skündl vnd Marl die ganz lange Nacht Mögn schlaffn in rueh, wür singen darzue Wür seindt all gesindt zu bleibm beym kündt.

\section{9}

Sey lustig mein Bruder, blas morgen fein fruh, es schlagt uns das Nändel die Drommel darzu, die Resel kan singä, der Riepel muß bringä, Brod, Air und ä Schmalz, der Veitel das Saltz.

10

Wo ist der Sackpfeiffer, der rändige Bue, umd d'Leyren thuts lauffen, und stimmet darzu, die Geigen thut bringen, der Riepel muß springen, braucht euren Fleiß all, daß hellt in dem Stall.

11

Ihr Buemä seyts muntä, dem Kindlein zum Preys, Heu Habern gebts druntä, wends an allen Fleiß, das Ochslein hat z'fressen, der Esel zum besten, daß d'Mutter und s'Kind, ä Labung empfind.

12

Was wollen wir geben, euch ja nicht lang bsinnt, so lang wir werden leben, dem Göttlichen Kind, braucht nicht vil Bedenckä, will ihm mein Hertz schenkä, gib ihm nur als frey, was immer mag seyn.

13

Mein Hännsel und Sepperl seynd tauglich zur Wacht, aufs Kind thuts acht geben, und nehmets in acht, daß d'Muttä kan schlaffen, der Joseph thut schaffen, wir seyn ja all gsinnt, zu bleiben beym Kind. 
14

Wür singä dem Kündl vnd deckhn es zueg Wür küssn sein Mündl vnd bittn mit fueg Liebs Kündl thue schweiga i kaff dir ä geigä schlaff sichä mit rueh wir singä dir zue.

15

O Mei herzliebs Kündl dein aiglä gar schö dei lachendeß Mündl gibt vns zu versteh Wir solln dich Ehrn du wolst vns erhörn o Jungfreulichß Kündt was lieb ich empfindt. 16 Lob preis wür thuen singä dem Kündelein klein Vil tausendt grues bringä der Marl ganz rein den Joseph wir Ehrn vnd von ihm begehrn Das er bitt das Kündt für unsere Sündt. ${ }^{11}$
14

Wir singen dem Kindlein, und decken es zu, wir küssen sein Mündlein, und ruhen darzu, liebs Kindlein thu schweigen, ich kauff dir ä Geigen, schlaff sanft in der Ruh, wir schicken dirs zu.

15

O liebreiches Kindlein, uns Hirten erkenn, dein lachendes Mündlein gib uns zu verstehn, wir thuen dich ehren, du wolst uns erhören, $O$ goldenes Hertz, was leydest für Schmertz. ${ }^{10}$

1,2 hebn wir an] anheben: beginnen 1,3 luegen] schauen 1,6 schaffl] Schafe 2,7 warlä] wahrlich, fürwahr 3,1 Buemä] Jungen, Kameraden 3,2 mei troi] bei meiner Treu 3,8 nachä] weiter, kommt 4,6 Feüchtn] Fichte 4,7 gälingä] gähling: plötzlich 5,6 keien] bekümmern, plagen 6,1 Märtl] Kurzform für Martin 6,2 Nandl] Kurzform für Anna 7,1 los] hör wastl] Kurzform für Sebastian 7,3 Lampl] Lämmchen 7,8 pfandl] Pfanne 8,1 Sandl] Kurzform für Susanna 8,5 grädl] Kurzform für Margarethe 8,6 Riepel] Kurzform für Rupert/ Ruprecht 8,8 Jodl] Kurzform für Georg/Jodokus 9,1 sackhpfeiffa] Sackpfeife, Dudelsack 9,2 grandigä] mürrischer 9,3 dleirä] die Leier 9,5 Bärtl] Kurzform für Bartholomäus 9,8 rundi] schnell, flink 10,3 habä] Hafer 10,4 wents] wendet 10,5 das Söxel] das Öchslein 10,6 ä] auch 12,7 Bayrn] Bäurinnen 13,1 Sarel] Kurzform für Sarah 13,3 das Skündl] das Kind Marl] Kurzform für Maria 15,2 aiglä] Äuglein 3,2 Lapp] Dummkopf 3,4 dädapt] erwischt 6,1 Hiesl] Kurzform für Matthias 9,8 Veitel] Kurzform für Veit, Vitus 10,2 rändige] lustige

Auch in Huy liebe meine buebn ist ein Oberhirte der Wortführer, der seine Gefährten informiert und die Vorbereitungen für die Huldigung leitet. Weibliche Figuren, von denen die Bibelvorlage nichts berichtet, sind hier wie selbstverständlich in das Geschehen eingebunden; als Musikantinnen werden sie auch in realen Aufführungssituationen Aufgaben übernommen haben. Topoi des Genres wie die Sorge wegen einer Feuersbrunst, die unerklärliche himmlische Musik, die Verweigerung eines schlaftrunkenen Hirten, die Suche nach geeigneten Geschenken, die außergewöhnliche Schönheit des Kinds und

10 Vier schöne neue Weyhnacht-Lieder, Das Erste: Los lieber Nachbä mit Fleiß, mei du i sag dir was Neus, etc. Das Anderte: Ihr liebe meine Nachbaurn, was heben wir an, etc. Das Dritte: Was Freuden, was Wundä hab i heut Nacht gsehn, etc. Das Vierte: GOtt grüß enk beysammä, verzeyhts mir mein Frag, etc. Steyr, gedruckt bey Gregori Menhardt, f. 2r-3r.

11 Staatsbibliothek zu Berlin, Ms.germ.oct. 230, f. 197-206. 
Ähnliches finden sich schon hier, auch wenn ihr burleskes Potential noch nicht so konsequent ausgeschöpft wird wie in einzelnen Liedern des 18. Jahrhunderts. Ein weiteres typisches Merkmal, die topographische Spezifizierung der Szenerie über alpenländische Charakteristika in Naturdetails („feüchten“), Objekten („dJoppn“), Arbeitsalltag („hey, habä, legts vndä“) oder Bräuchen („Es schlagt vns den Nandl dMaul trumml darzue“), zeigt auffällige Parallelen zur volkskünstlerischen Tradition des Krippenbaus, die bis heute eben dort floriert, wo auch dialektale Hirtenlieder gesungen werden.

Das grundlegende Moment regionaler Verortung in diesen Liedern ist jedoch der mundartliche Ausdruck, dem auch als religionssoziologischer Hinweis wesentliche Bedeutung zukommt, signalisiert er doch in diesem Kontext eine sehr simple, unmittelbar vergegenwärtigende Auslegung der Heilslehre, die auch vor Missverständnissen nicht zurückscheut. Überlieferungsnähere, diskursivere oder auch formelhafte Auseinandersetzungen mit dem Glaubensgehalt des biblischen Weihnachtsstoffs sind dagegen fast ausschließlich standardsprachlich gestaltet. Auch in ansonsten dialektal gehaltenen Liedern finden sich dementsprechend bei den bibelnahen Verkündigungsszenen, bei den Anreden für Mutter und Kind und vor allem bei den abschließenden Huldigungs- und Bittformeln lexikalisch und morphologisch standardnähere Wendungen (vgl. „Wir solln dich Ehrn / du wolst vns erhörn / o Jungfreulichß Kündt / was lieb ich empfindt“). Deutlich wird dies bei expliziter Rollenverteilung. Die gängigste Variante ist das Zwiegespräch zwischen Engel und Hirt, wie etwa bei Auf auf ihr hierten aus einer Salzburger Handschrift aus der Mitte des 18. Jahrhunderts, wo die Differenz zwischen (oberdeutschem) Standard und mundartlicher Rede schon in den Anfangsstrophen des 10-strophigen Lieds deutlich sichtbar wird:

1

ENGL.

auf auf ihr hierten: hörth auf zu schlaffen, Stehts auf und lauft nach wethlehem, dort werdet ihr nach euren Verlangen, an heut ein grosßes wunder sehen, ein wunder der geheimnus voll, darob euch all erfreuen solt.
2

Hierth.

Boz hundert was höri heut schon, geh Riebl und lögti gschwind an, I her epbä singä es dueth so schen khling[ä] als ist entzünt, mecht ainer schier main der ganz himmel verbrint. ${ }^{12}$

2,1 höri] höre ich 2,2 lögti ... an] zieh dich an 2,3 epbä] irgendetwas

Bleibt in vielen Hirtenliedern die Perspektive des Sprechens so indifferent, dass ein Sprecherwechsel nicht unbedingt notwendig ist und das Lied somit auch von einem einzelnen Sänger vorgetragen werden kann, wird in Auf auf ihr hierten die dialogische Struktur im konsequenten Wechsel der Sprecher über alle zehn Strophen aufrechterhalten. Momente der zweiten und dritten Motivgruppe werden über die Verkündigungssituation hinaus durch vage Vorausdeutungen und Vergegenwärtigungen eingearbeitet. Dramaturgisch überzeugender sind freilich dialogische Lieder, die im raschen, zum Teil stichomythischen Wechsel der Repliken situative Anschaulichkeit und Lebendigkeit vermitteln, wie etwa das bis heute in Weihnachtsmessen zur Aufführung gebrachte Libl solst

12 Universitätsbibliothek Salzburg, MI 365, f. 12v-13r. 
gschwind aufsten eindrücklich belegt, das uns dieselbe Salzburger Liederhandschrift in einer siebenstrophigen Fassung erstmals textuell überliefert: ${ }^{13}$

1

Libl solst gschwind aufsten

was den day,

mich wunderts dast schlofa magst

ih schlaf schay,

Geh mit mir auf die weit

schau was fir Musi geit

ist so licht wie Bein Tag,

was wä das.

3

In ein stall ligt das khind

wer hats gsagt,

ich hab von ein Engel kert

hast dun gfragt,

Ein Jungfrau kheisch und rein

das soll die mueter sein,

dort wo der stern brint

ligt das khind
2

Die Musi gwert schon lang

ich her nichts,

Thrag dey Bfeif äh mit dir

Bin schon khricht,

dEngl dient singä obm

es sey äh khind geborn

wans dä Mesßiäs wä

das wä Rä.

4

Wölln ihm ein opfer dragn

ist schon Recht,

Wan är epä fleisch wilt habn

wan äs mecht,

sie seind so foller not

und ist der wahre got

hambt ga khay wiegel nit

Loig do nit. ${ }^{14}$

1,1 Libl] Kurzform für Philipp 1,2 day] tun 1,5 geit] gibt 2,1 gwert] dauert 2,3 äh] auch 2,5 dient] tun 2,8 Rä] rar, etwas Besonderes 3,3 kert] gehört 4,4 äs] er es 4,8 loig] lüge

Durch die Erweiterung des Figureninventars konnten dialogische Hirtenlieder den Charakter kleiner dramatischer Szenen gewinnen, die wohl auch dementsprechend mimisch-gestisch umgesetzt wurden. Dass so populäre Lieder wie Herr und Gott ist das ä Sach auch im dramatischen Kontext auftauchen, so etwa als Teil eines im steirischen Vordernberg 1740 belegten (von Weinhold sogar dem 15. oder 16. Jahrhundert zugeordneten) Weihnachtsspiels, kann also nicht verwundern. ${ }^{15}$ Gattungsgenetisch freilich ist schwer zu bestimmen, was denn nun am Anfang der Entwicklung stand: das Weihnachtsspiel, aus dem besonders beliebte gesungene Teile ausgekoppelt werden konnten, oder das Weihnachtslied, das über vermehrte Sprecherwechsel und gesprochene Anteile zur dramatischen Form erweitert wurde. Von Dilettanten zunächst in kirchlichen oder öffentlichen Räumen, dann auch in Privathäusern als ,Stubenspiele‘ zumeist ohne nennenswerte theatrale Mittel aufgeführt, weisen szenische Darstellungen um das Wunder der Inkarnation Gottes im deutschen Sprachraum eine beeindruckende Tradition auf. ${ }^{16}$

13 Das auffallend weitverbreitete Lied kursierte auch unter dem abgeänderten Incipit Stachal sollst g'schwind aufstöä, vgl. etwa einen undatierten Druck aus dem späten 18. Jahrhundert: Zwei schöne Krippel-Lieder [o. O., o. J.].

14 Universitätsbibliothek Salzburg, MI 365, f. 104v-105v.

15 Vgl. Weinhold, Weihnacht-Spiele und Lieder, S. 134, $162 \mathrm{f}$.

16 Vgl. u. a. Leopold Schmidt: Formprobleme der deutschen Weihnachtsspiele. Emsdetten: Lechte 1937. Dorette Krieger: Die mittelalterlichen deutschsprachigen Spiele und Spielszenen des Weihnachtsstoffkreises. Frankfurt/Main [u. a.]: Lang 1990. (Bochumer Schriften zur deutschen Literatur 15) - Karl Konrad Polheim: Studien zum Volksschauspiel und mittelalterlichen Drama. Mit einer Fotodokumentation. Paderborn [u. a.]: Schöningh 2002. (Volksschauspiele 5) - Ursula Schulze: Geistliche Spiele im Mittelalter und in der Frühen Neuzeit. Von der liturgischen Feier zum geistlichen Schauspiel. Eine Einführung. Berlin: Erich Schmidt 2012, S. 70-77. 
Wie schon die ältesten erhaltenen Textdokumente - das wohl noch aus dem 14. Jahrhundert stammende ,St. Galler Weihnachtsspiel', die ,Erlauer Weihnachtsspiele‘ oder das ,Hessische Weihnachtsspiel ${ }^{\star}$ - zeigen, tritt dabei die theologische Auseinandersetzung zugunsten einer genrehaften Ausgestaltung der Anbetung und der emotionalen Aneignung (die besonders im volkstümlichen Brauch des ,Kindelwiegens' zum Ausdruck kommt) zurück.

Die frühesten geistlichen Spiele mit bairisch-österreichischen Dialektanklängen finden sich in einem Codex, der um 1680 wohl in einem oberbayerischen oder salzburgischen Kloster niedergeschrieben wurde und heute in der Staatsbibliothek Berlin aufbewahrt wird. ${ }^{17}$ Das erste der darin enthaltenen vier Weihnachtsspiele (vermutlich ein und desselben Autors/Bearbeiters) ist der früheste bekannte Beleg für das Modell des von August Hartmann so benannten ,Halleiner Weihnachtsspiels', das in verschiedenen weiteren Fassungen aus dem 19. Jahrhundert überliefert ist, am umfangreichsten in der Handschrift des Joseph Häusl von $1840 .{ }^{18}$ Der Vergleich dieser Fassungen zeigt deutlich, wie einfach die standardnahe Formulierung der frühesten Niederschrift zu den mundartlichen Teilen der späteren Aufzeichnungen ausgestaltet werden konnte. ${ }^{19}$ Man wird deshalb mit der Vermutung nicht fehlgehen, dass das Spiel auch in den Anfängen schon merklich dialektaler realisiert wurde, als es das Schriftbild erwarten ließe. Mundartnahe Wendungen finden sich in allen vier Spielen als sozialer Marker natürlich vor allem bei den Hirten, deren Sprache sich von jener der Engel oder der Heiligen Familie abhebt und zumal in den Gesprächen untereinander ein eigenes Register erkennen lässt.

Am deutlichsten wird dies im vierten Spiel des Bands, dem kürzesten, da etliche bereits in den anderen Stücken verwendete Szenen und Lieder hier nicht ausgeschrieben sind. Es beginnt mit derselben Szene, die schon das dritte Spiel einleitete, in der der Wirt Maria und Joseph abweist, ihnen aber den Weg zum „hitlein“ weist. Dann folgt eine auf alte Schwanktraditionen zurückgreifende Unterhaltung zwischen den Hirten Haußer und Hännßl:

1 Hausser. Jezt hob ich fridt ein guete stundt

daß ist ä guets ding Nachbar

bleibt schon beim schoffen iezt mein hundt

der ist außbindig wachbar.

5 wan sich Gar z'hinderist in felt

gläb mir ä grillel rieret

Er gäb kain fridt, er schreyt, er pelt

alß wan man rain derschmiret.

er laufft scheib vmber nur vmb d'hert

10 im holz vnd auf der weidten

vndt wan halt nur ä Lämblein plert

so maint Er, er khundts nit leiden

17 Staatsbibliothek zu Berlin, Ms. germ. qu. 1327. Eine kommentierte Edition der vier Weihnachtsspiele erstellte Peter P. J. Rindler: Die Weihnachtsspiele der Handschrift Ms.germ.qu. 1327 der Staatsbibliothek zu Berlin. Textedition, Analyse und Kontextualisierung. Graz 2015 [Dipl.].

18 Vgl. Thomas Hochradner: Zur Überlieferung des ,Halleiner Weihnachtsspiels‘. In: Jahrbuch des Österreichischen Volksliedwerks 50 (2001), S. 41-62.

19 Vgl. die Gegenüberstellung der Fassungen in ebda., S. 46. 
Er ist mir nüzer alß ein Knecht

derf im kein laun nit geben.

15 HänNssL. Wan ich ein sötlen Zotl het

ich wolt In auch aufheben.

HaUsser. Mein Zotl ist mir wol nit faill

so lang Er nach mag lauffen

verkhauf In auch nit für mein thail

20 wolt eh mein gaiß verkhauffen.

HëNNSSL. Es ist halt wol ein munders ding ein hundt stet wol bein schaffen thuet ainer d'arbeith noch so ring khan ainer bißweillen gueting schlaffen.

25 vornächt het ich auch woll ain braucht ist es der wolf mer g'strichen, da bin ich recht vmb d'hert rumb g'staucht biß er ist nachi gwichen.

Hausser. Mein hänßl wie gehestes an

30 wie kanst ein wolf weckh Jagen wie treibst daß vnthier weckh daruon es ist sonst arg verschlagen

HänssL. Da nimb ich krat mein huet nimb ä bißweillen mein Joppen

35 ist d'ioppen ä diewet ä schon guet kans schan mit hey ein schoppen vnd pints fein an mein steckhen präf thues hinden nacher ziechen, vnd peel wie ein hundt vnd läf

40 biß der wolf thuet nachi fliehen.

Hausser. Mein hännßl wie der denkhst es no wie kanst ä so der dichten.

HännssL. Es lehrnt ein woll mein lieber g'spo wan ainer allain mueß wachten

45 Ja g’söll ä sötles gauggl spill mueß ain ä diebet anfangä ist allß guet, waß helffen will wie wärs mir nit sonst offt gangä.

Angelus. canit Gloria in Excellsis Deo

50 Hausser. Hännßl, i her ein Englisch gsang 20

1 Haußer] Kurzform für Waldhauser (Balthasar) 5 Gar z'hinderist] ganz hinten 6 ä grillel rieret] eine kleine Grille rühren würde 8 derschmiret] zu Tode prügeln würde 9 scheib vmber] ringsherum, rundherum 14 derf im kein laun] muss ihm keinen Lohn 15 sötlen] solchen Zotl] scherzhaft für langhaarigen Hund 21 munders] munteres, besonderes 25 vornächt] vorgestern 26 mer g'strichen] wieder herumgeschlichen 27 g'staucht] gelaufen, gehetzt 28 nachi] weg 29 gehestes] gehst du das 35 diewet] dennoch, doch 36 ein schoppen] hineinstopfen, ausstopfen 38 nacher ziechen] nachziehen 41 der denkhst] derdenken: ausdenken 42 der dichten] erdichten 43 g'spo] Gespann, Kamerad 46 diebet] doch, wirklich 49 canit] (lat.) singt Gloria in Excellsis Deo] (lat.) Ehre sei Gott in der Höhe

Nachdem den beiden Hirten die Frohbotschaft verkündet wurde, informieren sie ihre Kameraden Caspar und Lenzl, immerhin ließe sich schon am „herwagen“ (Sternbild des Großen Bären), der „,heunt deixel auchi kert | zu mitter Nacht“, ablesen, dass etwas

20 Staatsbibliothek zu Berlin, Ms.germ.qu. 1327, f. 96r-98r. 
Außergewöhnliches geschehen sein muss, und selbst der „hetlPokh“ (Leitbock) und die Schafe „seind halt g'sprungen freüden voll“, denn „sVich ist ä ä diebat gscheit “21. Dann berät man die Geschenke - Futter, Essen, ein Lamm; die Vorbereitungs- und Anmarschzeit überbrückt man mit dem Singen dreier Lieder in arkadischer Tradition. Auch die Huldigung des Kinds und seiner Eltern erfolgt - nun sehr standardsprachlich - gesungen.

Textüberschneidungen zwischen einzelnen Werken - hier durch Autor/BearbeiterIdentität und Überlieferungskontext wenig überraschend - sind generell nichts Ungewöhnliches in der Dichtung zum Weihnachtskreis. Dass populäre Einzelteile in andere Kontexte transferiert wurden, war gerade auch bei den Hirtenliedern Usus. Das eng abgesteckte thematische Feld, die Vorliebe für simple Strophenformen, die auch den Melodienaustausch einfach machte, die vorrangig mündliche Überlieferung und nicht zuletzt auch Geschäftsinteressen der Flugschriftdrucker förderten geradezu ein ,Bausteinsystem', das in der Kombination von Material unterschiedlicher Herkunft ,Neues entstehen ließ. Das im 18. Jahrhundert sehr populäre und dementsprechend breit überlieferte Hirtenlied GOtt grüß enck beysammä verzeyht $\beta$ mä mein Frag etwa begegnet uns erstmals 1744 in einem Liederdruck des Wiener Neustädter Verlegers Samuel Müller, als achtstrophige Fassung gesungen „Im Thon: In der stillen Mitternacht“ (dessen Strophen freilich deutlich länger und anders strukturiert sind!):

1

GOtt grüß enck beysammä verzeyhtß mä mein Frag/

i kenns nit vonnandä ist Tag oder Nacht/

wie daß mä denn heunt kein Hirten nit siecht/

und ist ja bey enck da so frölä und liecht.

2

Es nihmt mi groß Wundä / daß ös meine Leuth/

im Stall jetzundä beysammä da seyd/

mei sagts mä was fallt enck im Wintä jetzt ein/

daß mit den klein Kind in der Kält da mögt seyn.

3

Kanst dus käm däleyden du Stein altä Greiß/

hast Haar als wie Seiden hübsch wenig und Schneeweiß/

du Müttä bist ä ziemli zartlä und fein/

kanst ä von kein Hirten odä Baurn=Gschlecht seyn.

4

Thuts enck nie lang b’sinnä und eylts fein ä weng/ gehts mit in mein Hütten nehmts Kindl mit enck/ geh Muettä nihms Kindl nihms aufi aufm Armbn/ bey mir ist schön eing'heitzt schön Windstill und warm. 5

Hätt is recht vernommä und ehendä betracht/

hätt i für das Kindl ä Gütl mitbracht/

hätt ich für die Kält von ain Kitzl ä Fell/

zum essen fürs Kindl ä Ay und ä Mehl.

21 Ebda., f. 100r und 101v. 
6

Hab gnue soltlä Sachä lauf heim ä fein gschwind/

schau s'Biebel thut lachä O hertzigs liebs Kind/

O himmlischer Vattä i möcht schier vägehn/

ist das nit ä Schatzel so lieb und so schön.

7

Ich bleib dafür datä weils Kind so schön lacht/

O Vattä / O Vattä gib du fein recht acht,

wannst du'n recht däziegst wird werden zum Herrn/

ä Schriftg'lehrter Mann und ä Richter draus werden.

8

Wanns solt dazu kemä O herzigs liebs Kind/

zu dir thu mi nehmä und laß mi nit hint/

thu mi nit vädammä und denck fein daran/

daß i dich beym Krippel drum betten [ ] han. ${ }^{22}$

1,1 enck] euch 1,2 vonnandä] auseinander 2,1 ös] ihr 3,1 däleyden] erleiden 4,3 aufi] hinauf 5,1 ehendä] früher, eher 5,2 Gütl] Geschenk 6,1 soltlä] solche 6,2 Biebel] Bübchen, Junge 7,1 datä] da, hier (verstärkt) 7,3 däziegst] erziehst 8,1 kemä] kommen

Eine recht ähnliche Fassung findet sich noch in der wichtigsten Sammelhandschrift weihnachtlicher Lieder dieser Zeit im bairisch-österreichischen Raum, dem ab 1787 von Kajetan Wesenauer im Salzkammergut niedergeschriebenen Gesang buch. Ein Flugschriftdruck aus der Steyrer Offizin Gregori Menhardts (vermutlich aus den 1760er Jahren) kompiliert dagegen das Lied mit drei Strophen aus Schauts schauts liebä Buemä, das im Wiener Neustädterdruck noch separat als zweites dialektales Lied abgedruckt war. Diese Fassung findet sich auch im St. Oswalder Weihnachtsspiel wieder (dessen Anfänge allerdings ins 16. Jahrhundert weisen). ${ }^{23}$ Die Version des sogenannten ,Stubenberger Liederbuchs', einer durch den Lumpensammler Philipp Lenglachner ab 1796 angelegten zweibändigen Sammlung aus dem bayerisch-oberösterreichischen Grenzgebiet, ${ }^{24}$ kennt nur Anfang, Mitte und Ende des Lieds, fügt dafür aber zwei weitere Strophen voll rührender Kinderliebe hinzu, die aus anderen Hirtenliedern übernommen wurden. Bis zur Fassung in Wilhelm Paillers berühmter Weihnachts- und Krippenliedersammlung von 1881/83 sollten noch zahlreiche weitere Austausch- und Umstellungsprozesse ablaufen; auch an der hohen Anzahl an Vertonungen und Melodievarianten lassen sich die komplexen Traditionszusammenhänge dieses Lieds zumindest erahnen. ${ }^{25}$

Die erstaunliche Anzahl dialektaler Lieder des Weihnachtskreises (von denen wohl ohnedies nur ein Bruchteil auf uns gekommen ist) belegt deren feste Verankerung in der bayerischen und österreichischen Alltagskultur. Unzählige zumeist ungenannte Autoren

22 Vier schöne neue Geistl. Lieder. Das Erste. Gott grüß enk beysammä, verzeyhts etc. Das Anderte. Schauts / schauts liebä Buemä etc. Das Dritte. Frohlock, mein Seel / und fange an / etc. Das Vierdte. Vatter und Mutter, merckt auf mich etc. Neustadt, gedruckt bei Samuel Müller, 1744, f. 1r-1v.

23 Vgl. Pailler, Weihnachtslieder und Krippenspiele II, S. 249f.

24 Bayerische Staatsbibliothek, Cod. germ. 7340 (Ges[ä]ng[er] Bu[ch]) bzw. Cod. germ. 7341 (Geistliches Zeitten Buch). Für die zweibändige Sammlung finden sich in der Literatur die Bezeichnungen ,Stubenberger Liederbuch` oder auch ,Braunauer Liederbücher/Liederbuch`. Der erste Band, das ,Stubenberger Gesängerbuch', der sich für die Forschung zur Dialektliteratur als deutlich ergiebiger erweist, gliedert sich wiederum in zwei Teile mit einerseits geistlichen und andererseits weltlichen Liedern.

25 Vgl. Blöchl, Melodiarium, S. 752-762. 
setzten ihren Ehrgeiz daran, ihrem Wirkungsort eine eigene oder zumindest lokal angepasste Spielart zu bieten. Auch zahlreiche Meister der Tonkunst leisteten nachweislich ihren Beitrag zu dem Genre, etwa Georg Donberger (Gloria in excelsis), Johann Georg Zechner (Gehts, Buema, gehts frey gschwind), Franz Sparry (Solt i woanä, odä lachä), Franz Joseph Aumann (Liabe meine Hirten, laßt ey sag'n) oder die Kapellmeister am Hof der Esterházy Wenzel Zivilhofer, Gregor Joseph Werner (Wie gehts nä in dä Weld hiez zue) oder Joseph Haydn (Hörst, Nachbar, han, sag ma, was heunt für a Nacht). Beliebt war das Hirtenlied zumal als Offertoriumsgesang während der Weihnachtsmette. Johann Michael Binder, Sakristan aus Maria-Taferl, beschreibt in seinem Bericht für die Sonnleithner-Sammlung 1819 den typischen Ablauf mit Glockensignal, Nachtwächterlied, Bass-Sologesang und abschließendem Hirtenchor, wie er ihn in seiner Kindheit erlebt hatte:

Wenn in der Mette das nach dem Credo folgende Dominus vobiscum von dem Chore respondiert war, so präludierte der Organist, und wenn der Priester den Kelch abdeckte, so hörte er auf. Dann schlug ein dazu bestimmter Mann auf dem Chore hinter der Orgel auf eine Glocke, oder in deren Ermangelung auf einem Strohmesser mit einem hölzernen Hammer 12, und der Sänger fing gleich nach dem letzten Schlage an.

[hier folgt: Alli meini Herrn und laßts eng sagn]

Darauf wurde gleich mit der Musik, wenn eine vorhanden war, im anderen Falle aber mit der Orgel allein das Vorspiel des Krippelgesanges gespielet, und wenn dies geendigt war, das dazu gehörige Lied von dem Sänger mit möglichstem Kunst- und Kraftaufwand hervorgebrüllt. Solcher Krippel- oder Weihnachtgesänge gab es eine Menge. Hier ist eine Probe davon.

[hier folgt: He Bartl und Hansl]

Sowie nun dieses Lied gesungen und von der Instrumentalbegleitung oder von der Orgel allein das Nachspiel geendigt war, so wurde gleich der Hirten-Chor angestimmt. Diese Hirten-Chöre waren gleichsam der Schluss der Comödie, und meistens von solcher Art, wie hier eine Probe angeführt wird:

[hier folgt: Auf, singet, ihr Hirten ${ }^{26}$

Tatsächlich sind aus der zweiten Hälfte des 18. Jahrhunderts zahlreiche Beispiele für diese Singtradition überliefert, die sich sogar noch halten konnte, als mit dem von Kaiserin Maria Theresia verordneten offiziellen Liedgut des ,Katholischen Gesangbuchs (um 1774) ein Großteil der zuvor volkstümlichen Gesänge aus den Kirchen verschwand. Die „burlesken Gesänge“ waren nicht zuletzt deswegen „so sehr nach dem Geschmacke des Volkes“27, da sie ihr äußerst farbenreiches Bildprogramm unmittelbar der alpenländischen bäuerlichen Lebenswelt entnahmen und damit das religiöse Ereignis ,eingemeindeten'.

Besonders klar tritt das Umfeld der Zielgruppe in den Geschenken der Hirten zutage, in denen sich die Lebensumstände der ruralen Schicht spiegeln. Landwirtschaftliche Produkte sind die nächstliegenden Gaben der selbst beinah mittellosen Hirten: Nahrungsmittel wie Mehl und Milch, Butter und Käse, Eier, Schmalz, Brot, Salz, Gerste und

26 Zitiert nach Karl M. Klier (Hg.): Schatz österreichischer Weihnachtslieder. Aus den ältesten Quellen mit Weisen. Bd. 1: Weihnachtslieder und Hirtenspiele aus Niederösterreich. Klosterneuburg bei Wien: Augustinus-Druckerei [1936-40]. (Thesaurus Austriacus) S. 45-47.

27 Ebda, S. 47. 
Linsen, Suppe, ,Haidenbrein' (Buchweizenbrei), ,Müßerl' (Mus) und ,Kocherl' (Brei) ${ }^{28}$ (Losts auf Buemä, könnts den schlaffä), Kraut und Kohl, Speck, Honig, Nüsse, getrocknete Früchte und ,Kletzenbrot', sogar Geflügel oder ein ,Lämperl' bzw. auch nur dessen Fell oder Flaumfedern werden der Hl. Familie dargeboten, Viehfutter und Streu, Brennholz und Kienspäne, Küchenutensilien wie ,Häferl', ,Reindl' oder ,Pfandl', Stoffe wie Faschen oder ,Leinwath'. Speziell fürs Kind bringen sie Kleidungsstücke wie „ein Wutzel-Gwänderl, ä Hauberl, ä Netzerl, ä Pfaiderl ä feins, ä blabs päärl Strümpferl“, aber etwa auch ein „Sutzerl“ (Schnuller) mit frischgebackenem „Piperlpäpperl-Brot“29 (vgl. Auf auf he Buebn) oder eine ,Rodl' (Rassel); der häufig erwähnte ,Veiglstock‘ (Veilchenwurzel) soll das Zahnen erleichtern. Selbstgebranntes wie Zwetschgenschnaps, „ä Lägel voll Bier“"30 (Auf auf Kamerath / es ist nunmehr Tag) oder Selbstgestricktes wie Fäustlinge gibt es für den alten Joseph. Auf die (vor allem oberösterreichische) Tradition des Singvogelfangs verweisen Geschenke wie ein Vogelkäfig mit Zeisig oder Kohlmeise, deren Gesang den Kleinen erfreuen soll. Auch die Instrumente der an der Krippe zum Besten gegebenen Hirtenmusik mit Geige, ,Brumbaß', Dudelsack, Maultrommel, Schwegelpfeife oder Schalmei stehen in der alpenländischen Tradition.

Die konsequente Verankerung in der bäuerlichen Lebensrealität garantiert freilich nicht nur viel Lokalkolorit, sondern ist auch Quelle der publikumswirksamen humoristischen Aspekte des Hirtenlieds, die Topoi des barocken Bauernspotts aufgreifen. Oft muss ein verschlafener Hirte mit angedrohter oder vollzogener Gewalt zum Mitgehen erst motiviert werden, oft droht die Huldigung durch linkisches Verhalten konterkariert zu werden, dem Kleinkind will man mit Speck oder Schnaps aufwarten, Eier zerbrechen oder man vergreift sich im Tonfall der Hl. Familie gegenüber. Besonders gerne werden die metaphysischen Erscheinungen lachhaft naiv ausgedeutet, wie etwa im folgenden Liedanfang, wo die mitternächtliche Helle als himmlische Sonnwendfeier oder glühende Lockeneisen und der Gloria-Ruf als Schmerzensgeschrei missverstanden werden:

1

Hollä dä Pingel was giwts den me hoiä

drätzi den dwelt umb wirds Tag Beider nacht

Jausas du Stoffel ist das nit ä foiä

hambs den in himmel heit zumbent nacht,

ist als ä Retten das ganz firmä ment,

hamt je gwis dEngln das har aufi brent.

28 Vier schöne neue Weihnacht Lieder. Das Erste: Losts auf, Buema, könnts denn schlaffa, hörts denn nit das Jubel-Gscheil, Das Zweyte: Auf, auf, holla liebi Buema, i bin heut recht alls vazagt, Das Dritte: Ihr Hirten schlafet nicht, kommt thuts allhier sehen, Das Vierte: Schlaf Jesulein schlaf, das Bethlein ist hart, das Krippelein ist kalt. Gedruckt in diesem Jahr. [o. O., o. J.], f. 2r. [Exemplar des Archivs der Stadt Linz, Sammlung Klier 53/6-17].

29 Ein schönes neues Weihnachts-Lied. [Steyr]: Gregori Menhardt [o. J.], f. 2r-v.

30 Fünf schöne neue Geistliche Lieder. Das Erste: Ave Maria klare / Du lichter Morgen Stern, du bist ein Freud, etc. Das Anderte: Auf auf ihr Hirten / nicht schlafet so lang / eine neue Botschaft ist kommen jetzt an, etc. Das Dritte: Mein was hats denn mehr gebn bey dä Nacht, i mayn, ös haben etc. Das Vierte: Auf auf Kamerath / es ist nunmehr Tag. Das Fünfte: Mit süssen Schall / nun fröhlich singet all. Linz, gedruckt bey Ignatz Auinger [o. J.], f. 4r. 
2

Losts nä Puebm, Losts nä ih hasß schon dä ratten, schauts nä den Engl dort draust wie rä schreit, den hambs dö zottn und Sgnackh khlai ver bratten, und als so gsengtä auf dwelt ahä kheit, ofä dä dausend Er singt woltä schen, losts und seits stillä ich mechtn ver stehn. ${ }^{31}$

1,1 Pingel] Bündel, dicke Person, hier auch als Ausdruck der Überraschung bzw. für den Teufel gebraucht (,Hol mich der Teufel') me] bloß hoiä] heuer, dieses Jahr 1,2 drätzi] dreht sich 1,3 Jausas] verballhornende Interjektion für ,Jesus (hilf) ‘ und damit komischer Anachronismus Stoffel] Kurzform für Stefan 1,4 zumbent nacht] Sonnwendnacht 1,5 ä Retten] eine Röte 1,6 aufi brent] heraufgebrannt 2,1 Losts] horcht Puebm] Buben, Kameraden hasß] habe es dä ratten] erraten 2,2 wie rä] wie er 2,3 zottn] lange Haare Sgnackh] das Genick, Hals gsengtä] versengt ahä kheit] hinabgeworfen 2,5 woltä] mächtig, sehr

Kaum etwas oder jemand ist von den komischen Brechungen dieser dialektalen Lieder ausgenommen, Joseph wird als „hertzigä Dätl“32 (WAs muß nä bedeutä) präsentiert, sein Adoptivkind als „arms Häscherl“ ${ }^{33}$ (GOtt grüß dich mein Thomerl), ja sogar Gott selbst kann für eine Pointe dienen, wie dieser Ausschnitt aus dem beliebten Hola Lippl, was ist das zeigt:

10

Ei so lug, was buidsta ei

Wird gwiß Gott so narrisch sey

Er werd zu uns aba käme,

Er kinnt ins woi aufinema

I gang recht woi volla Freud

War ma woi der Wög nöt zweit. ${ }^{34}$

10,1 lug] lüge buidsta] bildest du dir 10,3 aba käme] herunterkommen 10,4 aufi nema] hinaufnehmen 10,6 War ma woi] wäre mir wohl

Nur Maria bleibt vom humoristischen Zugriff unberührt. Selbst den abschließenden Bittformeln lässt sich Komisches abgewinnen, wenn etwa einer der Hirten in He Bartl und Hansl trocken meint: „Und wannst den mueßt strafa, hör an meini Bitt: So straf halt in Mörtl und mich laß mit Fried! “35

Es waren vor allem diese mit brachialer Komik und lokalkoloristischen Effekten arbeitenden Abweichungen von der Heilslehre, die die Hirtenlieder ins Zentrum der Kritik rücken ließen. Versuche, sie zumindest aus dem liturgischen Kontext zu entfernen, finden sich schon früh. Mit dem Vormarsch der Aufklärung auch in katholischen Gebieten wurde denn der Ruf nach einem Verbot ständig lauter, so etwa im Pamphlet Ueber die Abschaffung der Weihnachtsmetten (1781), das sich im ersten Jahr der ,Erweiterten Preßfreiheit‘ unter der Regierung Josephs II. über die Zustände in Wiens Kirchen

31 Universitätsbibliothek Salzburg, MI 365 (Liederbuch der Salzburger Studienbibliothek), f. 101v-102r.

32 Neun schöne Geistliche Lieder. Erstlich: Drey Weyhnacht-Lieder. [o. O., o. J.], f. 2r; Dätl] Greis.

33 Vier schöne neue Geistl. Gesänger, Das erste: Erfreu dich jetzt mein Seel, etc. Das anderte: Komm her mein frommer Christ, etc. Das dritte: Schauts, schauts liebe Buema, etc. Das vierdte: GOtt grüß dich mein Thomerl, etc. Gedruckt in disem Jahr. [Wiener Neustadt: Joseph Fritsch, o. J.], f. 2 v.

34 Bayerische Staatsbibliothek, Mus. ms. 7098 (Liederbuch des Singknaben Markus Seitz), S. 66. Die Strophe findet sich auch in O Mein Lenzel was ist das.

35 Zitiert nach Klier, Weihnachtslieder und Hirtenspiele aus Niederösterreich, S. 47 (nach dem Exemplar aus der Sonnleithner-Sammlung). 
echauffierte. Das Bild, das der aufgebrachte Verfasser dabei zeichnet, ist kurioserweise den populären verklärenden Kindheitserinnerungen Peter Roseggers in Waldheimat gar nicht so unähnlich:

alldorten, um die Geburt des Erlösers recht natürlich vorzustellen, singen nicht nur allein die Vögelein in der Luft, es läßt auch sogar der Engel vom Himmel sein Gloria in excelsis erschallen, und um [!] damit man es ja weiß, daß die heilige Geschichte, die man producirt und profanirt, als heiliget und feyert, muß sich auch der arme Nachtwächter hören lassen: Alle meine Herren und Frauen laßt euch sagen, der Hammer hat zwölf geschlagen; eine Reihe Hirten fängt an, das nun neugebohrne Jesukind einzusingen; der Lipperl mit dem Dudel-Dudel-Dudelsack läßt sich sogar unter der Wandlung hören, um das Kindlein allerzärtlichst nach Hirtenart einzuwiegen. [...] Aber noch nicht genug, der Thomerl mit der Leyer, der Hiesel mit der Querpfeiffe, und noch alle übrige Hirten mit derley ländlichen Instrumenten, kurz was nur Ton von sich giebt, muß sich zu Ehren des anheut neugebohrnen Jesukindes hören lassen, damit die andächtigen Zuhörer weihnachtsmäßig unterhalten werden. Nichts fehlt noch zu dieser Feyerlichkeit, als daß sich auch der Esel producirte, und die papierne Mannschaft ein dreymaliges Salve abbrennte. ${ }^{36}$

Es ist eine liebenswerte Ironie der Geschichte, dass gerade solche entrüsteten Berichte, gerichtlichen Beschwerden und Verdikte in diversen aufgeklärten ,Intelligenzblättern` ihren Teil dazu beitrugen, dass Aufführungspraktiken und der genaue Wortlaut mancher Lieder auf uns gekommen sind. So wurde etwa das 1782 im oberpfälzischen Neunburg aufgeführte rhythmisch interessant gestaltete vierstrophige Matz blausn Sock af als Beispiel für solch „elendes Gewäsche“ ${ }^{37}$ zitiert:

1

Matz blausn Sock af, lausn wacka bruma,

dä Hiesl und Veith solln ä mit kuma,

solln pfeiffa, solln geiga, solln singa, solln springa,

solln all lusti seyn,

weil uns heut gebohren

ganz rein auserkohren

ein kindelein fein,

blaus Matz, Matz blaus,

Matz blausn Sack af, lausn wacka bruma,

dä Hansel und Veith, solln ä mit kumma.

Wir wollen ihn grüessen, und sünga darzue,

das Bieberl wird schloffa in süessester Rueh. ${ }^{38}$

1,1 Matz] Kurzform für Matthias oder Matthäus blausn] blas den Sock] Dudelsack lausn] lass ihn 1,2 Hiesl] Kurzform für Matthias ä] auch

Das als Beweis für die ästhetische Minderwertigkeit gedachte Zitat sicherte also die Verschriftung mündlich konzipierter und tradierter Aufführungskunst, die im gesamten süddeutschen Raum in verschiedensten Fassungen viele Jahrzehnte lang kursierte, ohne als Literatur im eigentlichen Sinn wahrgenommen zu werden.

36 Ueber die Abschaffung der Weihnachtsmetten und Veränderung in eine Tagandacht, wegen der dabey vorgehenden Unordnungen und bisweilen gelegenheitlichen Ausschweifungen. Wien: [o.V.] 1781, S. 8.

37 Münchner Intelligenzblatt 1783, Nr. IX (22. Februar), S. 90.

38 Ebda. 


\section{Bibelhumoresken}

Die starke figurative Verortung der Menschwerdungsmotivik im bäuerlichen Bereich und die lange Tradition der szenischen Ausgestaltung dieses zentralen christlichen Mysteriums im Alpenländischen prädestinieren mündlichkeitszentrierte regionale Sprachformen für die literarische Ausgestaltung der Weihnachtsliturgie. Im Bereich des geistlichen Lieds und Spiels allerdings ist die hier zu beobachtende intensive Verwendung von Mundart keineswegs repräsentativ, mehr noch: Betrachtet man das überlieferte Korpus, scheint außerhalb dieses besonderen Themenkreises die dialektale Gestaltung eine absolute Randerscheinung darzustellen. Darüber, wie stark hier die undurchsichtige Überlieferungslage das Bild der zeitgenössischen Produktions- und Rezeptionsgegebenheiten verzerrt, können zwar nur Spekulationen angestellt werden. Die Diskrepanz in der Zahl der Überlieferungsträger ist jedoch umso auffälliger, als aus äquivalenten paraliturgischen Feldern mit einer ähnlichen jahrhundertelangen Tradition des spielerischen Nachvollzugs von Szenen aus der Heiligen Schrift kaum eindeutig dialektale Fassungen auf uns gekommen sind.

Im weiteren Sinn noch dem Weihnachtskreis zuzuordnen sind die im süddeutschen Raum beliebten volkstümlichen ,Adam-und-Eva-Spiele‘, die sich aus dem seit dem 14. Jahrhundert bezeugten ,Paradeisspiel ${ }^{\star}$ entwickelten. ${ }^{39}$ Als Vorspiel zur Erlösungsgeschichte hatten solche szenischen Darstellungen des Sündenfalls traditionell ihren Platz im Advent, wo sie allerdings durch ihre häufig unseriöse Ausdeutung des biblischen Geschehens in späterer Zeit von der Obrigkeit nicht gern gesehen waren. So moniert eine kaiserliche Verordnung vom 19. Dezember 1719,

mit was ärgerlicher Aufführung verschieden Dienst-lose Bursch bey der heran-nahenden Heil. Weyhnachts-Zeit das so genannte Adam und Eva- wie auch das Bauern- oder Hochzeit-Spiel in denen Häusern vorstellen: benebst mit ungestümmen Blasen und Leyern, auch ungebührlichen Springen und Tantzen alle Plätz und Gässen biß in den spaten Abend abzugehen: und die allhiesige Inwohner andurch zu beunruhigen sich unterfangen haben. ${ }^{40}$

Fortan sollten diese Spiele nur mehr in den drei letzten Faschingstagen zu sehen sein. Dass solche Laienaufführungen, mit denen sich in den Wintermonaten ,dienstlose ' Arbeiter und Bauern Almosen zu verdienen hofften, durchaus im dialektalen oder zumindest dialektnahen Gewand präsentiert wurden, deutet eine ironische Zwischenszene an, die sich in Wolfgang Rinswergers (1658-1721) 1691 auf der Salzburger Universitätsbühne aufgeführtem lateinischem Weihnachtsspiel Christus Fabri Filius findet. ${ }^{41}$ Für die Darstellung des nur anzitierten Sündenfall-Motivs wird im Randkommentar nämlich

39 Vgl. u. a. Weinhold, Weihnacht-Spiele und Lieder, S. $293 \mathrm{ff}$.

40 Mathias Fuhrmann: Alt- und Neues WIEN, Oder Dieser Kayserlich- und Ertz-Lands-Fürstlichen Residentz-Stadt Chronologisch- und Historische Beschreibung Von den mittleren Biß auf gegenwärtige Zeiten. Anderter Theil. Wien: Prasser 1739, S. 1396f.

41 Vgl. Hans Pörnbacher/Benno Hubensteiner (Hg.): Bayerische Bibliothek. Texte aus zwölf Jahrhunderten. Bd. 2: Die Literatur des Barock. Ausgewählt und eingeleitet von Hans Pörnbacher. München: Süddeutscher Verlag 1986, S. $538 f$. 
ausdrücklich vermerkt „Locuti sunt hoc vernacula Salisburgensi“42 - die Rede der Darsteller des „mit Schallmey und Sackpfeifen“ begleiteten Adam- und Eva-Gspiel in Hemet mit einen Däxbaum etc. war also in Salzburger Mundart vorgesehen, auch wenn dies nur punktuell in der Verschriftung zum Ausdruck kommt:

Rhetorica. Was hast du für ein Persohn?

A. Ich / was ich bin? Ich bin der Engl / kenst mich dann nicht aus dem Schwert / und aus der Binden.

RHETORICA. Und was bist du?

5 B. Ich bin der Adam.

C. Und ich bin die Eva.

D. Und ich bin / und ich bin / mein: was bin ich halt?

C. Weiß der Esel sein Persohn nit mehr / wir werden mit dir ein schöne Ehr aufheben / ich mercks schon.

D. So sagts mirs / was bin ich dann?

C. Mein lebtag / bist ja du der Teufl.

D. Ist wohl wahr / gnädige Frau / jetzt weiß ichs schon. Ich bin der Teufl.

15 Rhetorica. Ite boni; abite. Nihil mihi negotii Vobiscum est.

A. Ich mein ihr stimmt uns nur?

D. Ja wohl stimmen / sie haben uns gar für Narren. Gehts / gehts haimb. Da gschicht uns doch kein Ehr nicht. ${ }^{43}$

15 Ite boni [... est] (lat.) Geht, ihr braven Leute, geht weg. Ich hab mit euch nichts zu schaffen. 16 stimmt] stimmen: sich lustig machen

Die Spitze gegen das kunstlose mündlichkeitsorientierte Laienspiel, mit dem die Allegorie der Rhetorik nichts zu schaffen haben will, galt wohl den Laufener Schiffleuten, ${ }^{44}$ die sich auch in Salzburg mit ihren Volksschauspielen einen Winterverdienst sichern durften und ein an Hans Sachs orientiertes ,Adam und Eva-Spiel' im Programm hatten, das die deutschen Passagen des Bibelstücks wohl dialektaler als auf den Ordensbühnen dieser Zeit gewohnt und schicklich präsentierte. ${ }^{45}$ Ein halbes Jahrhundert später jedoch griff mit Sebastian Sailers schwäbischem Singspiel Schöpfung der ersten Menschen, der Sündenfall und dessen Strafe (1743) auch das Ordenstheater auf den beliebten Stoff zurück, um ihn aus humoristischer Perspektive dialektal in Szene zu setzen. Dieses später als Schwäbische Schöpfung bekannt gewordene Glanzstück der deutschen Mundartkunst

42 Wolfgang Rinswerger: E funere Phoenix. Sive Operis posthumi Dramatum Pars Ima. Hg. von Johannes Heigl. Regensburg: Hanck 1729, S. 154.

43 Ebda., S. 154f.

44 Vgl. Heiner Boberski: Das Theater der Benediktiner an der alten Universität Salzburg (1617-1778). Wien: Verl. der Österr. Akademie d. Wissenschaften 1978. (Theatergeschichte Österreichs VI: Salzburg 1) S. $202 \mathrm{f}$. Zum Laufener Schiffertheater vgl. Hans Moser: Schifferbrauch und Volksschauspiel im alten Laufen. In: Leopold Schmidt (Hg.): Kultur und Volk. Beiträge zur Volkskunde aus Österreich, Bayern und der Schweiz. Festschrift für Gustav Gugitz zum achtzigsten Geburtstag. Wien: Museum für Volkskunde 1954, S. 285300.

45 Das scheint auch eine Version des,Laufener Adam-und-Eva-Spiels‘ zu bestätigen, die Hartmann aus den Angaben verschiedener Gewährsleute in den 1870er Jahren rekonstruierte. Zumal die Rolle des Teufels scheint dialektal angelegt gewesen zu sein. Das mundartliche Schlusslied, wohl in späterer Zeit hinzugefügt, gibt eine eigenständige Version des Stoffs und hat sich lange auch im Volksgesang erhalten. Vgl. August Hartmann (Hg.): Volksschauspiele. In Bayern und Österreich-Ungarn. Mit vielen Melodien, nach dem Volksmund aufgezeichnet von Hyacinth Abele. Leipzig: Breitkopf und Härtel 1880, S. 39-51. 
wurde 1784 von einem anonymen Bearbeiterduo erheblich gekürzt und mehr schlecht als recht „in die Oesterreicher Bauernsprache übersetzet“46 als Melodrama Adam und Eva im Paradeiß in den Druck gegeben. ,Österreicher' waren hier offenbar nicht am Werke, blieb doch in der inkonsequenten und ungeschickten bairischen Überformung eine deutlich schwäbische Markierung bestehen, zu der zuweilen noch mitteldeutsche Merkmale treten (z. B. ,Apl' für ,Apfel', ,Dummkop'). Eine kurze Synopse soll dies veranschaulichen:

Noits ischt Noits, und weat Noits weara, drum haun ih wölla an Wealt gebäara, grad um dui Zeit, wo's nimma viel schneit

5 und bessare Lüftla geit. [...]

So ischt's darbei blieba, und eaba im Meeza, $\mathrm{daß}$ is reacht sag, am fainfa zwanzgasta Tag haun ih anzunda Sonn, Maun, Planeita und älle himmlische Keeza.

Fainf Täg darnoah, aischt huir, haun ih verschaffa Holz, Stoin, Metal, Luft, Wasser, Erda und Fuir.

Beym Sappermeant!

15 Sieba wonderscheane Elameant! ällerloi Thier mit Flügel und Füessa

haund mar ussam stockfainschtera Noits raus müessa.

Und dös ällz, bei meiner Trui!

20 in oim Oadem, in oim Hui.

G'schwind

wia dar Wind,

hutig und schneall

ih vo mar seall. ${ }^{47}$
Niks is Niks, und wird au Niks wära, Drum hob i wolln a welt gebähra,

G'rod um die Zait

w'os kan Schnee mehr laid,

Und warme lüftla gait;

Dos is ebn in Merza,

Sunn und Mond und Planeta,

Und oll main himmlische Kerza,

In 6 Tagn erst haier

Hob i erschoffen Holtz, Stann, Metoll,

Luft, Wasser, Erdn, und Faier,

Baym Schlaprament!

Sibn wunder schöne Element.

Ollerlay Thir mit Fligl und Füssn,

Hobn mir aus stokfunstern Niks aussi müssn,

Und dos alles hat mir g'rotn in a hui, In an Othn, g'schwind, wie der Wind, Hurti und fain, i von mir allein. ${ }^{48}$

1 wära] fälschlich für: werden, wern 4 laid] liegt 19 hat mir g'rotn] habe ich geschafft 20 Othn] Atem

Mehr Talent sowohl im Theatralen als auch in der Literarisierung dialektaler Mündlichkeit verrät eine witzige einaktige Bibeltravestie, die der umtriebige Druckereifaktor Johann Karl Schuender (alias Scheudner) im Jahr zuvor vorgelegt hatte. Der Fall Adams und Evens im Paradiesgärtchen (1783) spielt im Wiener ,Paradeisgartel', das Sündenfall-Pärchen der ins Zeitgenössische verlegten Handlung sind wohlhabende Franzosen, die vom grantelnden Aufseher Hiesl beim Marillendiebstahl ertappt und im weitgehend unverfälschten Ostmittelbairisch zur Rede gestellt werden, wie der folgende Ausschnitt zeigen soll:

46 Melodrama Adam und Eva im Paradeiß. Ein musikalisches Bauernspiel vom Jahre 1250 in vier Aufzügen, verfasset von Sebastian Relies O. S. B. verbessert und vermehret von M.H. und A.M. zur privat Unterhaltung, musikalischer Dilettanten, aus dem Schwäbischen in die Oesterreicher Bauernsprache übersetzet. [o. O., o.V.] 1784, S. 1.

47 Sebastian Sailer: Schriften im schwäbischen Dialekte. Gesammelt und mit einer Vorrede versehen von Sixt Bachmann. Ulm: Stettin 1826, S. 5-7.

48 Melodrama Adam und Eva im Paradeiß, S. $7 f$. 
Hiesl. [... ] Holt Hiesl! Durt stenna a Poa! - Wei sie schaua! - Nu, nu! - eea toppt scho hin; Eitza hot a ana oogrissen; - Ha, nuch ana! - Laff, Hiesl, laff! - Den will i t'Leffiten lesa! (er läuft aus allen Kräften) Hei! Sie! Han sis gheat? - Sie! Woatens a weni! Adam, Eva, der Vorige

5 Adam. O Madame! Voila, das ist si schön Aprikose! (er steckt eine in den Mund) Et ma foi, recht delikat! Prenez en!

HiesL. (Zieht den Hut und brüstet sich) I bitt um Vazaijung, ihr Gnoden, weea Sie a sannt; Kotz Himmel-Kreuz-Stern- und Höllsaperment - i bitt um Vazaijung - Weea hat Ihna t’alaubt, Morilln oozreißn?

10 ADAm. Was sak sie die närrische Gerl?

Hiesl. I bitt um Vazaijung - zwo Morilln homs oogrissn.

Eva. Chansons (Narrenpossen) 'ab sie du sehn?

HiesL. Jo freyla! - i bitt um Vazaijung - Eea hots jo nu in Maul, Murd tausend teuflszeug! - i bitt um Vazaijung - die zwa schönste Morilln - i bitt um Vazajung.

15 Adam. De nefles (Ja Pfifferling) Pak sie fort, Grobian!

Hiess. Wos? Grobian? Potz Blitz und s Donnawetta - i bitt um Vazajung - Sie sannt a rechta Grobian, daß Sie Morilln ooreißn - i bitt um Vazajung - Han! is dos niat a rechta Schond va suo an Heean, wei Sie sannt? - um Vazajung - i hait Lust, i nehmat Sie ban Schopf, und dreschat Sie recht wokr oo, i bitt um Vezajung -

20 Adam. Vertu de ma vie (Potz tausend) Mak sie mir nit viel, Gerl; ik sak euk!

HiEsL. Sak euk hin, sak euk heea! - i bit- um Vazajung - Sie müeßen var ana Morilln an Zwanzka zohln; dos is a mol die Strof, - i bitt um Vazajung - (die Leute laufen zusammen und lachen.) ${ }^{49}$

1 stenna a Poa] stehen auch ein paar schaua] fälschlich für: schauen 2 Eitza] jetzt 3 Han sis gheat] Haben Sie es gehört? Woatens] Warten Sie 5 Et ma foi] und meine Güte! 6 Prenez] Nimm 8 t'alaubt] erlaubt 9 ooreißn] abreißen 11 homs] haben Sie 13 Eea hots jo nu] er hat sich ja noch 15 De nefles] eig.: nèfle: Mispel; etwas Geringes, Wertloses 17/18 va suo an Heean] für so einen Herrn 18/19 dreschat Sie recht wokr oo] würde sie ordentlich verdreschen 20 Vertu de ma vie] eig.: Kraft meines Lebens

Da sich das blasierte Pärchen zu zahlen weigert, sperrt Hiesl sie ein und lässt sich auch nicht von Adams Drohungen einschüchtern („Wenn Sie wolla ver an Schlog a poa tutzend Waatschn hobn, schlogns heea!“). Letztendlich müssen sie ihre Schulden begleichen und fliehen unter Applaus und Gelächter der Anwesenden aus dem öffentlichen Garten. Durch die launige Gestaltung des erzürnten und doch servilen Wärters, das gebrochene Deutsch der impertinenten Parkbesucher, die aus der Commedia dell'Arte entlehnte Figurenkomik von Jurist und Mediziner im hinteren Teil u. a. m. hebt sich das routiniert gebaute Dramolett aus der Zeit der Broschürenflut qualitativ vom Durchschnitt der damaligen Spaßliteratur deutlich ab.

Dies gilt uneingeschränkt auch für eine Sündenfall-Adaption des aus der Oberpfalz stammenden Augustinerpaters Marcellinus Sturm (1760-1812), von dem uns zahlreiche Lieder mit religionsbezogenen Motiven überliefert sind, die unterhaltsame Sujets mit durchaus auch kritischen und parodistischen Tönen verbinden. Sturm, der in seinem wohl großteils in den 1780er Jahren entstandenen Werk ganz bewusst Dialekt als selbstständiges Ausdrucksmittel einsetzt, ${ }^{50}$ enwickelt in Die Erbsünde eine originelle Zweistimmigkeit: Die humoristische Wirkung ergibt sich aus dem Zwiegespräch eines

49 Der Fall Adams und Evens im Paradiesgärtchen, mit der darauf erfolgten Strafe; oder: Dießmal ist Eva von dem Adam verführet worden. Von Scheudner. Wien: [o.V.] 1783, S. 4-7.

50 Vgl. Hans Pörnbacher: Bayerische Bibliothek. Texte aus zwölf Jahrhunderten. Bd. 3: Die Literatur des 18. Jahrhunderts. Das Zeitalter der Aufklärung. Vorarbeiten von Benno Hubensteiner. München: Süd- 
verbittert-pessimistischen und eines kalmierend-optimistischen Parts, die die Folgen des Sündenfalls ihrer Voreltern unterschiedlich interpretieren. Der Beschwerde über den gesellschaftlichen Verfall, die Verführbarkeit der Menschen sowie die Beliebigkeit des Glücks wird die Mahnung zu mehr Verständnis, Dankbarkeit und Demut entgegengehalten:

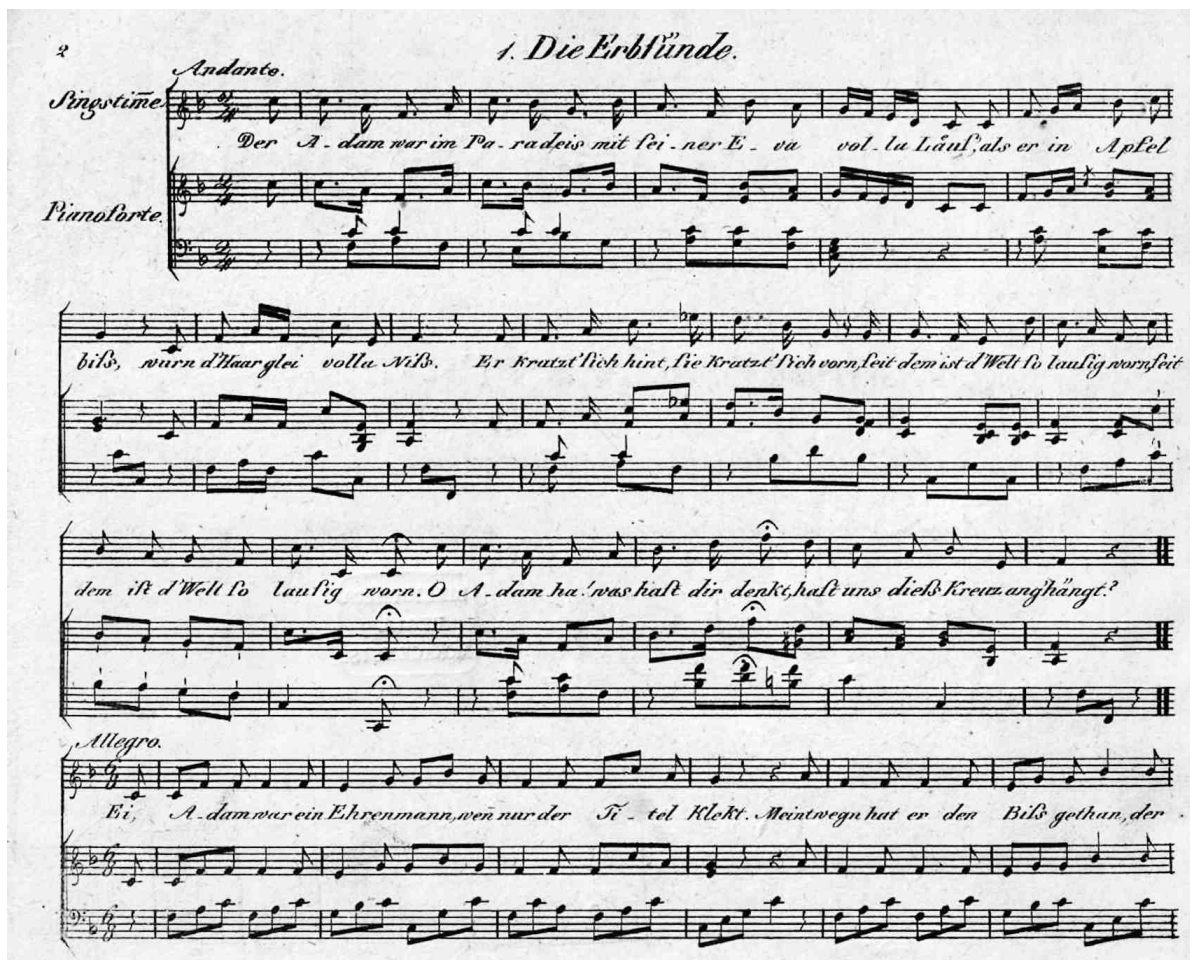

Abb. 3: Klavierliedfassung Joseph Giehrls zu Sturms Die Erbsünde (aus: Lieder zum Theil in baierischer Mundart, Bayerische Staatsbibliothek, 9351154 Mus.pr. 617-2, S. 2).

deutscher Verlag 1990, S. 1263. Sturms Lieder, die ein breites Themenspektrum umfassen und vielfach den Spagat zwischen Andacht und Unterhaltung, Ernst und Spaß versuchen, fanden rege Aufnahme im Volkgesang, der sie - mitunter in stark zersungenen und veränderten Versionen - weiter tradierte, vgl. u. a. Hyacinth Holland: Sturm, Nikolaus. In: Allgemeine Deutsche Biographie 37 (1894), S. 45-48. - Hans Pörnbacher: Literatur und Theater von 1550-1800. In: Max Spindler (Hg.): Handbuch der bayerischen Geschichte. Bd. 2: Das alte Bayern. Der Territorialstaat. Vom Ausgang des 12. Jahrhunderts bis zum Ausgang des 18. Jahrhunderts. München: Beck 1966, S. 848-883, hier 870. 
1Te Stimme.

Der Adam war im Paradeis,

Mit seiner Eva volla Läus',

Als er in Apfl biß,

Wurn d'Haar glei volla Niß.

Er kratzt sich hint, sie kratzt sich vorn,

Seitdem ist d'Welt so lausi worn, (rep.)

O Adam, han! was hast dir denkt,

Hast uns dieß Kreuz ang'hängt?

2

1Te Stimme.

Ich hätt' für d'Eva g'wiß Respekt,

Allein Sie hat mir als z'viel g'schleckt.

Man sieht ja D'Folg davo,

Ein jede schleckt halt no.

Dieß Schlecken liegt schon im Geblüt,

Und d'Männer machen d'Fotzenhüt (rep.)

Thun sich mitn Weibern selbst versteh'n,

Ich nähm gleich 'n Ochsenzehn.

3

1Te Stimme.

Wir könnten all wie Götter lebn, Jetzt müaßma tausend Geltsgott gebn,

Für unsern sauern Schwoaß,

Das ist mei Seel kein Spoaß,

Im Paradeis war alles gnueg,

Jetzt knüflma brav am Hungertuech (rep.)

Und kannst'n Dama nimma rührn,

So mußt vor Noth krepirn.

4

1Te Stimme.

Der Kopf war voll Verstand und Witz,

So hell und hurtig wie a Blitz,

War schlaucha als a Fuchs,

Sah weiter als a Luchs.

Jetzt is 's ganz Werk als wie a Traum,

Man kennt'n Pfiff beim Mondschein kaum. (rep.)

Studirt man auch nach längs und zwerch, Steht doch der Ochs am Berg.

\section{5}

1Te STImme.

Das Herz war g'wiß a guater Narr,

Es wußte nichts von Seelen-G'fahr,

Jetzt ist da Teufel los,

Bringt Sünden klein und groß.

Gott Vater hätt' noch unser Lieb,

Jetzt hats der schwarze Galgendieb. (rep.)

Der macht ja d'Leut zu solchen Narrn,

Daß ihm - hint eini fahrn. -
2Te Stimme.

Ei Adam war ein Ehrenmann,

Wenn nur der Titel kleckt,

Meintwegen hat er den Biß gethan,

Der ihm und uns nicht g'schmeckt.

Ihm hat halt vor sein'm Weib nicht graust, vielleicht hätt'st Du noch ärger g'haust.

2Te Stimme.

Ei Eva war ein Ehrenweib,

Dergleichen man nicht findt,

Des Adams liebster Zeitvertreib,

Zuvor, und nach der Sünd.

Hätts ihn Gott Vater nicht aufgeführt.

Er wär vor langer Weil krepiert.

\section{Te Stimme.}

Zum G'scheh'nen muß man s'beste redn,

Das macht das Leben froh,

Ist meiner Ohnfrau Sprichwort g'wen,

Und ich moan's auch a so.

Will Gott dem Spatzen Nahrung gebn, So laßt er d'Gimpel a no lebn.

2Te Stimme.

Halt Du nur brav die zehn Gebot,

Und was der Glaube lehrt,

So hilft der g'scheidste Mann vor Gott,

Mehr als ein Doktor werth,

Viel Wissen macht Dir nur Kopfweh, Und bläht Di wie an Brotz in d' Höh.

2Te STImme.

Gott hat uns Gnad und Mittel gebn,

Für unser Seelenheil,

Wir könnten doch viel g'scheidter lebn, Jetzt hättn wir schön daweil.

Er ist und bleibt der allerbest,

Wir selber stechn ins Wespennest. 
6

1Te Stimme.

Wollt ich erst d'Sach beim Licht anschaun, Mir gings gleich gelb und grün vor d'Augn, Wo ist denn mehr a Freud,

Giebts nicht verflixte Leut?

Der Spitzbub sitzt dem Glück im Schoos,

Der brave Kerl geht nackt und blos, (rep.)

Wie muß der g'meine Mann sich scherrn,

Vielleicht noch s'Teufels wern.

\section{7}

1Te Stimme.

Der Baum des Lebens, dies göttlich' G’schenk,

Der half für schwere Noth und Kränk,

Und machte Rutteng'sund,

Wohlauf wie a Pudelhund.

Jetzt ist die Kränk in Leib neig'fahrn,

Und s'schwere Noth darfst auch net sparn (rep.) Was gilts du stehst im Catalog.

Nacha kommt da Tod, da trauri Schwanz,

Und macht dem Arsch Vacanz. ${ }^{51}$
2Te Stimme.

Schau Esel wiest jetzt Gott anstimpfst,

Der Teufel mags anhören,

Wennst über alles d'Nasen rümpfst,

Nacha solls g'wiß besser wern,

Wie müssens schon geduldig leidn,

Gott könnt mei Seel noch ärger reitn.

2Te Stimme.

Gehts oan recht hoari nissig schlecht,

Wies doch den meisten geht,

O dann ist die Vacanz gewiß recht,

Es kommt ihm oft zu spät,

Drum bet, studier, und trag dein Joch,

2,2 g'schleckt] genascht 2,6 Fotzenhüt] Fotzenhut: derbes Schimpfwort für rückgratlose Männer, die die Laster ihrer Frauen akzeptieren 2,8 Ochsenzehn] Ochsenziemer: als Züchtigungsinstrument verwendete gedörrte Haut eines Bullenpenis bzw. dieser selbst 3,2 Geltsgott gebn] Danksagung für ein empfangenes Almosen 3,6 knüflma] (wohl fälschlich für: küflma) nagen wir 3,7 kannst'n Dama nimma rührn] du kannst den Daumen (zum Auszählen des Gelds) nicht mehr rühren, d. h. man ist mittellos 4,6 Brotz] Kröte 4,8 zwerch] quer 5,8 hint eini] hinten rein 7,1 hoari nissig] elend, armselig 7,2 Kränk] Krankheit 7,3 Vacanz] vorlesungsfreie Zeit, Ferien 7,5 neig'fahrn] hineingefahren

Westmittelbairische und oberfränkische Merkmale weist die textuelle Grundlage des Sündenfalllieds Da Gott die Welt erschaffa auf, das der oberfränkische Benediktinermönch Valentin Rathgeber (1682-1750) als Nummer 27 der ,Zweiten Tracht' in seiner musikgeschichtlich bedeutenden Liedersammlung Ohren-vergnügendes und Gemüth-ergötzendes Tafel-Confect (1733ff.) veröffentlichte.

Wie das Sündenfall-Motiv ließ sich auch das Gleichnis vom verlorenen Sohn als Beispiel der Hinwendung des liebenden Gottes zur erlösungsbedürftigen Seele gut in das szenische Angebot zur Adventzeit integrieren, wurde aber auch für Fasching, Fastenzeit und andere Gelegenheiten dramatisiert. ${ }^{52}$ Ein Wandertheaterstück englischer Komödianten hielt sich bis ins 18. Jahrhundert auf den süddeutschen Bühnen, die Jesuiten typisierten den Prodigus für ihre Tendenzdramen, während der Wessobrunner Benediktiner Leonhard Klotz (1685-1742) den Stoff humoristisch für das Salzburger Universitätstheater in seinem, Advent-Spil' Casimirl Der Ungerathne Sohn Im Neuen

51 Lieder zum Theil in baierischer Mundart von P. Marcelin Sturm, ehemaligem Augustiner. In Musik gesetzt nach den eigenen Melodien des Verfassers von dem kön. Advokaten Giehrl in Neunburg vorm Walde. [O. O.: o. V.] 1819, S. 1-4. Die Vertonungen zu ausgewählten Liedern finden sich in einem zweiten Band: Lieder Zum Theil in baierischer Mundart von P. Marzelin Sturm, ehemaligem Augustiner. In Musik gesetzt nach den eigenen Melodien des Verfaßers von J[oseph] Giehrl. [München: o. V. 1819], hier S. 2 f.

52 Vgl. Hans Schuhladen: Der verlorene Sohn. Vom Schul- und Ordensdrama zum bayerisch-tirolischen Volksschauspiel. In: Helge Gerndt/Klaus Roth/Georg R. Schroubek (Hg.): Dona Ethnologica Monacensia. Leopold Kretzenbacher zum 70. Geburtstag. München: AJZ 1983, S. 227-250. 
Testament (1620) verwertet, das zumindest zum Teil dialektal verfasst sein soll. ${ }^{53}$ Das Personenverzeichnis der Perioche zum verschollenen Stück mit seinen vielen bairischen Diminutivformen scheint dies zu bestätigen.

Auch im Osterzyklus finden wir ab dem Spätmittelalter eine Ausgestaltung biblischer Ereignisse mit folklorisierenden und zuweilen komischen Elementen in Anlehnung an das Fastnachtspiel: der Jüngerlauf zum Grab des Herrn, die Salbenkrämer-, Soldatenund Seelenfangszenen. ${ }^{54}$ Doch hier fehlen uns vergleichbare Umsetzungen mit dezidiert mundartlichen Anklängen (wie denn auch generell diese Szenen in der Frühneuzeit nicht annähernd dieselbe Volkstümlichkeit wie die Weihnachtsszenen erlangen). Auch in den beliebten Passionsspielen wurde Mündlichkeit - soweit die wenigen Textbelege aus dieser Zeit ein Urteil treffen lassen - zwar mit regionaler Färbung, doch nicht bewusst dialektal gestaltet. Dies zeigt sich etwa auch bei der Oberammergauer Passio nova (1750) des aus Wien gebürtigen Ettaler Piaristen Ferdinand Rosner (1709-1778), einer stilbildenden gereimten Fassung des seit 1634 inszenierten Spiels. Dass Rosner als Pater comicus seines Klosters und in Freising durchaus gewillt und imstande war, Mundart als künstlerischen Akzent wirken zu lassen, zeigen u. a. seine Faschingskomödie Der Teutsche Sultan (1760) oder die lateinisch-deutsche Schulendkomödie Praemia Bene, \& male meritis ante Solennem distributionem distributa (1773) mit den Dialekt sprechenden Faulpelzen Hircanus Soloecismus und Schach Nadir.

Nur ein kleiner Teilbereich aus der Leidensgeschichte fand tatsächlich auch seinen Weg in den mundartlichen Volksgesang: die Geschichte der Gefangennahme Jesu am Ölberg. Mittelpunkt ist jeweils die volkstümliche Gestalt des Apostels Petrus, der zunächst seinen Herrn mit dem Schwert verteidigen möchte, ihn dann aber aus Feigheit verleugnet. Das älteste bislang bekannte dialektale Ölberglied aus dem bairisch-österreichischen Sprachraum findet sich in einer Liedersammlung, die der Garstener Benediktinerpater Leander Kremser (1751-1829) während seiner Salzburger Studienzeit in den frühen 1770er Jahren anlegte. Es dürfte die Kontrafaktur einer älteren Liedpassion sein, die in der heiteren Inszenierung der menschlichen Schwäche des ,Kirchenfelsen' nicht den religiösen Ernst des Stoffs unterwandern, sondern den unvermeidbaren Sündenfall des Einzelnen entlasten will. Durchaus zeittypisch und im Einklang mit katholischen Moralvorstellungen wird dabei die Frau als eigentlicher Auslöser des sündhaften Tuns identifiziert:

53 Vgl. Nikolaus Huber: Die Literatur der Salzburger Mundart. Salzburg: Eigenverl. 1878, S. 6.

54 Vgl. Schulze, Geistliche Spiele im Mittelalter und in der Frühen Neuzeit. - Bernd Neumann: Geistliches Schauspiel im Zeugnis der Zeit. Zur Aufführung mittelalterlicher religiöser Dramen im deutschen Sprachgebiet. München: Artemis 1987. 
1

Als Unser Herr in Garten gieng

Stellt er ein gastmahl an Mit seinen Jungern allzumal war lustig iederman Aft wascht er Ihnen d haxen, Und truckerts ab gar schon, der Peter mit der Präxen wollt mit in garten gehn.

3

Dort bey des Caiphas Kollenfeur die Juden sassen dick da komt die schelmisch Dienstmagd her dem Peta zum Unglück,

Sie sprach, bist du nit ainer der mit in garten war der $\mathrm{P}[\mathrm{e}]$ ta laugnets wek vom Fleck du huer es ist nicht wahr. 5 Und wie der Peta durchs Haus hnaus kam da fing er zflena an ach wegen disen galgenhaus bin i a gschlagner Mann $\mathrm{O}$ du verfluchtes rabenvieh durch dich kom ich zum fall o die verdamte Katzenschwenz reit ia der Teufel all.
2

Die Praxen hat ein Scharten der Peter watzls gar sehr aft haut er ain aufen schwarten da giengs ga grausla her Der Jud der schrie gar mordion Und sach d(er) Heergott selbsten an Auwehe! auwehe mein Ohr ist hin Der Glatzkopf hats gethan.

4

Die Juden samt den Knechten

die brachten den Peta zweit

daß er aufn einen Blatzl

dreymal schwur einen Eid.

Aft wird der Peta zornig,

Und gieng flux aus dem Haus,

und denkt ihr Hundsfud allzusam

blasts mir den Hobel aus.

6

Ach wär das Weib die Hex nit gwest,

Mein aid, i häts nit than.

Drum last euchs zunna wahrnung seyn

und denkts an Petan dran.

D Apostel fallen selbsten

weils Mensch von weiten kimt

wie wird erst mit denselben gehen

ders gar beym kragn nihmt. ${ }^{55}$

1,6 truckerts] trocknet sie 1,7 Präxen] hier: Schwert 2,2 watzls] wetzt sie 2,3 aufen schwarten] auf den Kopf (Schwarte: behaarte Kopfhaut) 2,5 mordion] der mittelalterlichen Gerichtspraxis entstammender Ruf nach Hilfe (Zetermordio) 4,8 blasts mir den Hobel aus] habt mich gern 5,2 zflena] zu weinen 6,2 Mein aid] (Beteuerungsformel) Bei meinem Eid! 6,3 zunna] zu einer 6,6 weils] (hier:) wenn, sobald Mensch] Mädchen, Frau

Etwas später dürfte ein Lied entstanden sein, das lediglich die Malchus-Episode bei der Gefangennahme Christi thematisiert. Die witzige Ausdeutung der bei Johannes $(18,10-11)$ und Lukas $(22,50-51)$ unterschiedlich überlieferten Szene zeigt den störrischen ,Glatzkopf ' Petrus, der das Ohr des Gerichtsdieners abschlägt und in Wut gerät, als Jesus diesen umgehend wieder heilt. Varianten dieses, Passionslieds' scheinen im gesamten süddeutschen Raum verbreitet gewesen zu sein. In Des Knaben Wunderhorn etwa veröffentlichen Arnim und Brentano 1806 eine sehr zersungene, leidlich standardsprachliche Fassung ,mündlich aus Neckar; ${ }^{6}{ }^{56}$ und noch im 20. Jahrhundert war es im Volksgesang lebendig. ${ }^{57}$ Eine frühere, noch recht kunstlose Variante wurde wohl in den 1780er Jahren von Aloys Blumauer (1755-1798), einem der bedeutendsten österreichi-

55 Oberösterreichische Landesbibliothek, Hs 727 (Liederhandschrift Leander Kremsers), f. 13f.

56 Heinz Rölleke (Hg.): Achim von Arnim/Clemens Brentano: Des Knaben Wunderhorn. Kommentierte Gesamtausgabe. Bd. 1. Stuttgart: Reclam 1987, S. 342 f.

57 Vgl. Leopold Schmidt: Blumauer und das Volkslied. In: Germanisch-Romanische Monatsschrift XXVIII (1940), S. 87-100. 
schen Autoren der Aufklärung, betont dialektal überarbeitet und mit wirksamen Bildern erweitert. Diese beiden Fassungen sollen im Folgenden vorgestellt werden:

\section{Passionslied}

1

Als d'Juden den Herrn hamt gfanga ghabt

Da lieffen die Jünger davon

Den Petern hat aina beym Mantel datapt

Gelt Glatzkopf iezt hab ih dih schon.

2

Der Peter zog gleih seinen Säbel

Und wollt halt zum haua anhöbm

Er haut aber gar miserabl

Die meisten Streich gingen danöbn.

3

Da gab ihm der Herr einen Deuter

Stök ein mein Peter dein Schwerd

Du bist ja ein erz Bärenhäuter

Dein Schneid ist kein Teufel nicht werth.

4

Daß verdroß den Peter verzweifelt

Daß er der Niemand soll seyn

Er wöhrt sich auf einmal verteufelt

Und haut recht gar fürchterlich drein.

5

Der Malchus der stund just darnöben

Und hat sich gar nichts ertraut.

Den hat er a Duschn aufs Dach aufi göbm

Und s Ohrwaschl wurz wökä ghaut.

6

Der fangt gleih zum Heuln, und zan Rozn an

Und schreyt halt gleih überlaut

Herr heil mir doch wider mein Loser an

Dä Glazkopf der hat mirn wegghaut.

7

Da nahm der Herr des Malchus Ohr

Und that ihms gleich kuriren

Auf aimal springt aber der Petter hervor und fangt an zan räsonirn.

\section{8}

Was hat mih den iezt mein Haua genutzt da wär ih ja grad ä Schwanz

Wan ih ä so än Sakara zama putz

Machst du mir ihn gleih wieda ganz. ${ }^{58}$

\section{Petrus und Malchus}

Als d'Juda unsern Hearra bald gfanga habn ghabt,

Da liefen die Junga davon:

Den Peata hot oana beym Mantel de[r] tappt,

Rief: Glazkopf, ietzt hab i di schon.

Der Peata zieht hurtig sein Seitegwehr raus,

Und zoagt sein Curaschi als Mann,

Haut ummi, schreyt imma: Geh Flegel, laß aus,

Sonst kommst mir mein Oachel bös an.

Da gab ihm der Moasta an Deuta und sprach:

Geh Peata, steck eini dein Schweart:

Du Sprudelkopf, kommt dir glei 's Feuer ins Dach:

Dein Hitz ist kein Pfifferling wearth

Moanst, könnt mir nit selba glei schaffa 'n Ruah,

Wenn i mi lang wöhra do möcht:

Mein Vota göb selba Soldata dazu[e]

Vom Himmel, du warst mir der Recht,

Da nun das 'n' Peata gar gwaltig verdroß,

Daß er gar der Niemand soll seyn,

Pumps, geht er no oamol aufs Judagsind los,

Und haut jezt recht lästerli drein.

Schau! wie sie der Glazkopf so mausig do macht,

Schreyt Malchus, und lacht übalaut:

Patsch wird ihm von Peata bey finsterer Nacht

Der Ohrwaschel wurzaweg ghaut.

Der Malchus schreyt gräßli: Au weih Ach!

Auweih! Jezt bin i a gschlagena Mann,

Und bat glei den Hearra mit Zettageschrei,

Geh, hoal mein Loasa do an!

Der Moasta hoalt plötzlich des Malchus sein Ohr,

Als wär ihm kaa bißle dran gschea;

Und Peat[a] streckt gräuli den Kraga empor,

Und loßt sie fuchsteufls wild sea.

Schau, schau nur, was hot mi mein Hauen denn gnutzt,

Do war oana wohl recht a Schwanz,

Wenn man so 'm Sakra den Schedel hot gstutzt,

So machst ihm den Kopf wieda ganz.

Der Moasta sprach: Peata schweig, red nit so dumm,

Und steck iezt dein Saberl in d' Scheid;

Denn wer damit drein schlagt, der kommt damit um.

Das merk dir, und werd einmol gscheid! ${ }^{59}$

1,3 datapt] erwischt 3,3 Bärenhäuter] (Schimpfwort) Dummkopf 5,3 Duschn] starker Schlag aufi] hinauf 5,4 wurz wökä] ganz weg 6,1 Rozn] (übertriebenes) Weinen 6,3 Loser] Ohr 7,4 räsonirn] streiten 8,3 Sa-

58 Österreichische Nationalbibliothek, Musiksammlung, Mus.Hs. 3093, f. 2v [Schlussstrophe fehlt durch Blattverlust. Der dritte und vierte Vers jeder Strophe wurde wiederholt].

59 Aloys Blumauer: Sämmtliche Gedichte. Zweites Bändchen. Wien, Prag: Haas 1800, S. 473-476. 
kara] (Schimpfwort) verfluchter Kerl zama putz] zusammenschlage 5 Seitegwehr] Waffe, Schwert 6 Curaschi] (franz. courage) Mut 8 mein Oachel] (Beteuerungsformel) bei meinem Eid!

Blumauer macht die in der Vorlage nur vereinzelt verwendete volkstümliche ChevyChase-Strophe zur verbindlichen Grundform, glättet das Metrum, ergänzt situationsgerechte direkte Reden, die mit redeeinleitenden Verben zugeordnet werden, und findet neue, wirksam pointierte Bilder. Ein Autograph hat sich nicht erhalten, um die irritierenden Fehler der Erstedition zu hinterfragen; auf den aus Oberösterreich stammenden Ex-Jesuiten gehen Formen wie ,Juda', ,Hearra' oder ,kaa bißle‘ wohl kaum zurück - im Gegensatz zu den mündlichkeitsfernen Präteritumformen, die der metrischen Gestaltung geschuldet sind und uns auch bei anderen Literarisierungen des Dialekts dieser Zeit begegnen. Im Volksgesang blieb das Lied in Vertonungen u. a. von Johann Baptist Henneberg und Franz Xaver Gruber lange lebendig.

Dass sich auf den Ordensbühnen auch in alttestamentarische Stoffe Dialektfiguren integrieren lassen, bezeugen etwa zwei lateinische Schuldramen aus Admont. In Sacrificium divinae providentiae seu filia Jephtes (1755), vermutlich aus der Feder des Konventualen Sigismund von Springenfels (1723-1803), ist der Schmiedgeselle Brontilles noch Teil der mythologischen Parallelhandlung. Im musikalischen Huldigungsstück Isaac in agro meditans Rebecca desponsatus aber, das 1767 in den Faschingstagen zu Ehren Abt Matthäus Offners zur Aufführung kam, sind der ,Camelarius' (Kameltreiber) und der ,Nuntius ad Abraham praemissus' in die biblische Handlung eingebunden. Letzterer möchte dem Patriarchen die Ankunft Rebeccas, reimweis' ankündigen und gibt dabei einen witzigen selbstreflexiven Einblick in die Nöte eines Elogen-Dichters. Das Ergebnis erinnert nicht zufällig an die sinnentleerten bittersüßen Operettenliebesarien späterer Zeiten:

Nuncius. Au wehe! Hab ich mi nit erhizt: hais, hais, hais! Das haisst ehrlich gschwizt, daß es mir beym Hirn aussä sprizt. D’Sonn thut ä schon toif abi weichä: wie ein blaß balg muß ich keichä. Potz tausend wie reispen-dürr ist mein zung? Doch es braucht nur ein Kazen-Sprung, so bin ich behendt, an Orth und Endt; da wird sich mein Gurgel schon laben: maisterlich will ich mich zu der Pippen haben: s'Wasser hat von mir heunt gutten Frid: Wasser, (da wär ich nit gscheid) Wasser trink ich nit: bring ich leicht viel z'gutte zeitung mit. Jezt aber, wann ich tritt ins Haus, wie richt ich mein Bottschaft auß? Der Alte Dätl muß mir bald flennä, bald lachä: fein zierlich, manierlich, revierlich will ich's machä: Reimweis muß man ein so gutte Bost vortragn: ich werd halt singen, und sagn:

Auß Mesopotamien komm ich daher.
Liebä Tädtl, altä Greiß!
Schickä thuens mi bottenweis.
Dir zu machen einen Trost
Richt ich außä gutte Bost:
Ein junge, Blut-schöne, verständige Braut,
der Freundlich- und Fromkeit beym Augen außschaut,
So Rebecca wird genannt
Her auß deinem Vatterlandt,
Auß den Hauß des Bathael
Bringen heunt noch die Cameel.


Aber was reimt sich auf Rebecca wohl: auch Ihr ein Liedlein machen soll. La schaun, la schaun: es dörf nit seyn so gnaun. Bey ünserm Haus will ichs ansingä, wann's wird von Cameel ahäspringä:

Rebecca! bist da?

Wie bin ich so froh:

Du brenn-gutte Seel

Steig a von Cameel

Cameel Cameel - - so hel so hel - - -

So schnell so schnell - - Cameel Cameel

Scheint nit der Mond so hel

Reitt nit der Todt so schnel.

Lyrum lärum löffel-Stihl: das wär um ein ganzen Häxen z’viel.

Gott grüß dich mein Rebecca!

Ich wais nit, was ich auf Rebecca auffi schrauf: mein söchs! es reimt sich nit viel drauf. (Wann ich mich kunt ein wenig bey den Taig-Hänsl consultiren, oder die Sach beym Mahler-Simmerl incaminieren: Sie würden mich gar bald von Labyrinth aussä führen; doch scheint der leztere mehr mit Wiz und Hirn in der ungebundenen Redens-Art zu excellirn.

Fahl ein, fahl ein! - - - Kan’s dann gar nit seyn? aber warum will ich mir den Kopf so graußlä brechä: kan ich leicht anstatt Rebecca: Beccerl außsprechä: Beccerl - - - Zweckerl - - Zeckerl - Schneggerl. Das reimt sich alles fürn Isaac, und Rebecca zusam: Doch muß ich auch einhi bringen den Abraham: Alter Tädtl - - - Delicatl - - - Räbbätl - - - Ponädtl. Es geht schon. Es muß ein wenig närrisch seyn: sunst legt man kain Ehr ein. Dieses Lied ist für die Braut bestimmt: La schaun, wie’s öppä aussä kömt.

$\mathrm{Du}, \mathrm{du}, \mathrm{du}$ ! ja du wirst seyn

Des Isaac Freud allein.

Seins Herzen Zeckerl

O du Purpur Schneggerl

$\mathrm{Du}, \mathrm{du}, \mathrm{du}$ ! ja du wirst seyn

Unsers Alten Tädtl

Zuckersüß Ponädtl

Ganzes Delicatl

O Du Blum-Räbbäthl

60

$\mathrm{Du}, \mathrm{du}, \mathrm{du}$ ! ja du wirst seyn

All unser Freud allein. ${ }^{60}$

2 aussä] heraus toif abi weichä] tief runterbiegen 3 reispen-dürr] dürr wie etwas Abgebrochenes 5 Pippen] Zapfhahn 7 Dätl] Greis 20 Bathael] Vater Rebeccas 22 La] lass 24 ahäspringä] herabspringen 28 a] ab 33 Lyrum lärum löffel-Stihl] bekannter Faschingsspruch Häxen] Fuß (Metrum) 36 auffi schrauf] raufschrauben, reimen mein söchs] meiner Sechs (Ausruf der Bekräftigung, vermutlich zu Sech: Schwert) 37 Taig-Hänsel] Hans Taig, wohl historische Admonter Persönlichkeit Mahler-Simmerl] Simon Mahler, s.v. 38 incaminieren] einfädeln, in die Wege leiten aussä] heraus 39 excelliren] hervorstechen 44 einhi] hinein 45 Räbbatl] Blumenbeet, bepflanzte Grünfläche Ponädtl] Panatel: Semmelsuppe, Brei aus Semmel, Fett und Ei 47 öppa] etwa

60 Stiftsbibliothek Admont, Cod. 35/43, S. 12-14. 
Der Autor dieses lateinisch-bairischen Singspiels, das den zumal bei Hochzeiten beliebten Stoff ins Alpenländische translozierte, war wohl der damalige Rhetorikprofessor und spätere Abt Kolumban Wieland (1735-1787).

Wie beliebt auch die biblische Überlieferung der Opferung Isaaks durch Abraham im Volksschauspiel war, belegt indirekt ein Kuriosum: das ,Tyroler Spihl' des aus Luzern gebürtigen Jesuiten und Pfarrers Franz Alois Schumacher (1703-1784). Für die Fastnachtszeit in Rothenburg bei Luzern 1743 verfasst, verhinderte die Stadtregierung letztendlich eine Aufführung von Isaac der Alt Testamentische. Denn die gestrengen Luzerner Zensoren attestierten dem Skandalstück blasphemischen Gehalt und eine Verballhornung der Bibelgeschichte (zugleich freilich sicherten sie mit ihrem Gutachten auch die Überlieferung). Schumacher selbst hatte schon im Prolog klargestellt, dass es ihm nicht um eine Infragestellung der alttestamentarischen Erzählung oder der christlichen Lehre ginge, sondern um eine Satire gegen deren Vereinnahmung im naiven Volksschauspiel. Immerhin hätten die Rothenburger ihr Spiel „nit aus der bibel gnommä, / sonder sie haben den innhalt von den tirolerä bekommä“ ${ }^{61}$, deren einfältiges Theaterwesen sie nachäffen würden. Seine Komik erhält das Stück neben der inszenierten Inkompetenz der Schauspieler vor allem durch die Präsentation des biblischen Geschehens im ,genus humile‘. Wesentliches Stilmittel ist dabei die Verwendung von Dialekt, der hier überraschenderweise ein künstliches (mit alemannischen Elementen der Luzerner Mundart vermengtes) Bairisch ist, das sich Schumacher offenbar während seines Noviziats in Landsberg in den Grundzügen angeeignet hatte und das in seinem Werk für das ,Tirolerische' stehen sollte. Dieser Kunstdialekt war also als Verfremdungssignal für das Schweizer Aufführungsumfeld gedacht, produziert mit einigen wenigen Nachahmeregeln und somit weit entfernt von dialektgeographischer Korrektheit, doch deutlich genug, um seine parodistische Wirkung zu erreichen. Dass das Spiel bei den Zuschauern wohl durchaus für Lacher gesorgt hätte, soll der folgende, „,öllig nach der tyroler rubric“ gestaltete Auszug zeigen, in dem Abraham seinen Sohn erschießen soll und sich bewusst tollpatschig gibt. Brachialkomisches trägt auch der pflichtvergessene Engel Cherubindel bei, der Gottvater in Rage bringt:

Aвraham. So seys, ih will mih entschließä, recht rabiatisch drej z'schießä. Da schaut er z'ruk zu gottv.

Nur um das bitt ih dih, wans los gangen ist, so mahn mih.

Gott vod ̈̈ DER Neu. Ä so mueß ja der schuß fähl geh, wart ih will där bok steh.

Aвraham. Stand, ä gotts namä standt, sonst pfupfi in die läär wand. Jetz ists gar artli.

GotT vodä DER NEU. Sä schieß zue bartlj!

Авванам. Ih will nur z'erst d'nase schneuzä, und ä bizelä in d'händ speüzä.

Halt du davor

61 Walter Haas: Franz Alois Schumachers ,Isaac'. Eine Volksschauspielparodie aus dem 18. Jahrhundert. Luzern: Rex 1975, S. 194. Zur Analyse der Sprachgestaltung siehe S. 79-143. 
undterdeßä s'rohr.

Jetz mueß gschoßä sey

undt kosts ä zentner bley.

GOTT VODÄ DER NEU. Schütt maulaff, schütt da drobä! er schüttet gott vattä.

Dä bist wohl ä grobä!

G’hörst du flägel:

schütt auffä zündtägel!

Cherubindle. Jä, jä, jä... Iterum affundit.

GoTT VODÄ DER NEU. Jetz hör nur fej gschwind, oder ih ghei där die gantz welt j grind. Da laßt gottv. d'büchs gheiä, undt / ergreifft d'welt kuglä mit beden händen.

Cherubindle. Jä, jä, jä ... Iterum affundit.

GOTT VODÄ DER NEU. Warth du tennrisel,

Michel bring ä munifisel!

Ih wills dem komerhansle recht machä,

klopfä wil ih ä, bis äm d'rüppj im kopf obe krachä.

GotT VODÄ DER ALT (= SANT Michel). Vodä warum so hön, warum so bös?

GotT VODÄ DER NEU. Das findelkind verdient ja 100 stös.

Schau, wie er mär mei barth hat gnezt,

und die gantz baroggä verpflezt. Da ziecht gottv. dä barth / undt d'baroggä ab.

GOTT VODÄ DER ALT. Gibs nur mihr, es ist grad wider troch, ih henkes nur ä wenig vor s'höllä loch. ${ }^{62}$

6 bok steh] Bock stehen, gebückt eine Schießauflage bieten 8 pfupfi] schieße ich fehl 10 bartlj] Bartl, Kurzform für Bartholomäus 12 speuzä] speien, spucken 20 zündtägel] Zündpfanne der Muskete, auf die Schwarzpulver geschüttet wurde 21 Iterum affundit] (lat.) er schüttet wiederum 23 ghei] keien: werfen grind] (im Alemannischen derb für) Kopf 26 tennrisel] Tennenreisel: was beim Abladen des Getreides auf die Tenne fällt und besonders ausgedroschen wird 27 munifisel] Ochsenziemer 28 komerhansle] Kummerhansl (?) 29 d'rüppj] die Rippen (?) obe] hinunter 30 hön] zornig 33 verpfletzt] verfilzt 34 troch] trocken

Besonders pikant wird die Szene, weiß man um den im süddeutschen Raum mehrfach belegten Spruch (zu einer bildlichen Darstellung): „O Abraham - 's alles umsunst, | Weil dir der Engel auf d'Zündpfannen brunst. “63

Lapidarer als Schumacher bringt Marcellinus Sturm die Geschichte in seinem 53-strophigen Quodlibet auf den Punkt, das zentrale Motive der christlichen Mythologie nach Pointen abklopft, die heute noch beim (leidlich bibelfesten) Leser ihre Wirkung nicht verfehlen:

9

Schlacht' deinen Isak, dies Gebot

War freili ziemli streng,

Doch rief an Engl, g'schickt von Gott,

Bst! Alter! halt a weng,

Die spanisch Inquisition

Ist nöt nach unserm Fuß,

Viel g'scheider ists! du nimmst dein Sohn,

Und kochst ihm z'Haus a Mues. ${ }^{64}$

9,4 a weng] ein wenig

62 Ebda., S. 286-288.

63 Zitiert nach ebda., S. 303 (vgl. Werner Busch: Nachahmung als bürgerliches Kunstprinzip. Ikonographische Zitate bei Hogarth und in seiner Nachfolge. Hildesheim/New York: Olms 1977, S. 137).

64 Sturm, Lieder zum Theil in baierischer Mundart, S. 99. 
Einige weitere Proben aus diesem respektlosen Bibelextrakt, der abwechselnd alt- und neutestamentarische Szenen persifliert, machen verständlich, dass dieser vermutlich in den 1780er Jahren entstandene, für den mündlichen Vortrag konzipierte Text erst 1819 gedruckt wurde. Zugleich zeigen sie, wie geschickt Sturm die ungefilterte, aktualisierende Direktheit der dialektalen Rede mit dem schreibsprachlichen Duktus der Überlieferung zu einer amüsanten Inkongruenz zusammenführt, die den Tabubruch zelebriert:

5

Der Abel schwamm in seinem Blut,

Und hot sich doch nicht g'rührt,

Der Kain ruckt nöt a mol sein Hut,

Wie Gott mit ihm diskrirt,

Soll ich meins Bruders Hüter sein,

Sprach der infame Knopf,

Schnaps schlagtn an Engl in d'Freßn hinein,

Und beutelt ihn beim Schopf.

[...]

21

Zachäus steig noh g'schwind vom Ast,

Und schmeiß auf alle Feign,

Denn Christus will bei dir als Gast

In d'Schüßl eini steign!

Glei war er wie der Blitz herunt,

Und lief der Kuchel zue,

Weib, sprach er, heut seynd Küchl g'sund,

Schmarozer kommen gnue.

[...]
7

Der Noe hat wohl hundert Jahr

An seinem Kasten baut,

Doch lachte alles der Gefahr,

Habn grad aus Spaß zug'schaut,

Kotz Blitz, jetzt lacht ma koana mehr,

Es heulen Groß und Klein,

Denn plötzlich kummt a G’wäsch daher,

Und wässert d'Stockfisch ein.

[...]

38

Ihr Herrn! darf ich mich unterstehn,

Wo geht der Marsch hinaus;

Sprach Christus, heut ists Wetter schön,

Spazierns g’wiß nach Emaus?

Drauf führten sie vom Gottessohn

Ein auferbaulichs G'spräch,

Doch in der Schenk schleicht er davon,

Und läßts brav in der Zech. ${ }^{65}$

5,3 nöt a mol] nicht einmal 5,4 diskriert] redet, diskutiert 5,7 Schnaps] lautmalerisch für ein kurzes Ereignis 21,4 eini] hinein 21,7 Küchl] Kuchen

Ähnlich wie Sturm verpackt auch der bayerische Aufklärungssatiriker Anton von Bucher (1746-1817) seine Kritik gern in humoristisch angelegte Schriften, doch richten sich seine Texte weniger auf allgemeinmenschliche Verfehlungen, sondern arbeiten sich an konkreten gesellschaftlichen, von der Kirche (mit)verantworteten Missständen ab. Nicht umsonst gibt sich der Theologe Bucher gewöhnlich nicht namentlich als Autor zu erkennen, sondern verschanzt sich hinter komplexen Verfasserkonstrukten; anzunehmen ist jedoch, dass seine Verfasserschaft für die betreffenden Schriften weithin bekannt war. 1782 erschien sein Geistliches Vorspiel, eine Travestie auf jene in der Vorrede vordergründig angepriesenen Komödien, „wie man sie hin und wieder auf dem Lande in der Fasten spielt, daß die Bretzen und das dinne Bier besser weggehen ${ }^{\text {“ }}{ }^{66}$ Das Thema der großen ,Sündflut' war im Schultheater der Jesuiten, denen auch Bucher seine -

65 Ebda., S. 97f., 102, 107.

66 [Anton von Bucher]: Geistliches Vorspiel zur Passionaction, betitelt: In DILVVIo CoMeta sIngVLIs orIens; oder Fürwahr ein Schreckstern jedem ist, der Sündflutgrund zu aller Frist, das ist die erschrecklichste Tragödia aller Tragödien, welche die erste Person in der Gottheit, als nämlichen GOtt Vater ein Schöpfer der sündigen Welt, in dem ersten Buch Genesis Cap. 6to mit den Sündern des Erdbodens, quia omnis caro corruperat viam suam I Gen. cap 6.v.z. auf dem großen Theater der Welt selbeigen produciret und agiret hat. Von einem unsers Ordens-Pater inventiret, Nun aber zu grösserer Ehre GOttes von mir corrigirt, mit unzahlbaren Exhibitionen decorirt ad peruersum Saeculi Genium applicirt, mit schönen neuen Versen und Zusätzen amplificirt, und zur Auferbauung der Glaubigen in ein hellers Taglicht producirt. 
sehr skeptisch beurteilte - Bildung verdankte, ein gern gewähltes, konnten doch mit dem Gottvertrauen Noahs und der Bestrafung menschlicher Autonomiebestrebungen grundlegende Punkte der Ordenslehre exemplifiziert werden. Was Bucher aus dem Stoff machte, war „bei aller grobianischen Ausgelassenheit ein galliger und grimmiger Abgesang auf eine pervertierte und säkularisierte Religiosität, der die heiligsten Dinge nur Mittel für höchst irdische Zwecke sind“67. Dass er in der Dekonstruktion Szenen schuf, die dem Lesepublikum mit burlesken Einlagen, Anachronismen, Sprachwitz, Figurenkomik und den vertrottelten Exkursen und Anmerkungen der Autorfiktion ,P. Umgang hochgradiges Lachpotential boten, wusste schon Goethe anzuerkennen. ${ }^{68}$ Im Zentrum der Handlung des Vorspiels steht der ewig aktuelle Streit des Bauherrn Noah mit seinen Handwerksleuten, die beim Bau der Arche keine Eile zeigen:

Noe. Pfui Teufel! Habt ihr auch ein G'wissen,

Maister? das haißt d'Leuth recht b'schissen.

Machts mir auf hundert Thaler ein' Ueberschlag

und sagts, ös brauchts vier Wochen grad,

Und itzt bauts wirklich hundert Jahr,

und zahlt hab ich über tausend Thaler schon gar.

Ehender ließ ich mich ertränken,

Oder thät mich früher henken,

Eh ich nochmal bauen thät.

Baumeister. Das ist wohl recht närrisch g'redt.

Hab ich öngs g'schaft, daß s'bauen sollt,

Als wenns die ganze Welt logieren wollt.

Ihr seid ein Narr mit euren Haus,

Es macht öng jedermann ein' Plaus.

Wer wirds denn auf ein Nägerl wissen,

Wie viel man Täg wird brauchen müssen?

Noe. Ha! Nägerl, und hundert Jahr,

Soll einer mayn'n, wärts b’sessen gar!

Baumeister. Der Winter frißt wohl auch ein' Zeit,

Wo man am längsten müssig leyt.

Kurzum, ich laß mit mir nicht zanken,

Zahlts, oders sagts mir eure Gedanken,

Ich brich das Haus gleich wider ab,

Und nehme dann an Holz, was ich verdienet hab'

Könnts öng daweil ein wenig b’sinnen,

Ich will dafür eins trinken da drinnen.

Noe. Potz Himmel, Stern, und noch kein End,

Die Leuth seynd gar Impertinent.

Die ZimmerLeuthe trinken Gesundheiten.

Viuat Bauherr Noemus.

Anno reparatae Salutis 1782. In: Entwurf einer ländlichen Charfreytagsprocession sammt einem gar lustigen und geistlichen Vorspiel zur Passionsaction. Hg. von einem Ordenspater. [o. O.] 1782, S. [103]-[212], hier [105].

67 Reinhard Wittmann: Nachwort. In: Anton von Bucher: Bairische Sinnenlust bestehend in welt- und geistlichen Comödien, Exempeln und Satiren. Mit einem Nachwort hg. von Reinhard Wittmann. München: Idion 1980, S. 1-26, hier 18.

68 Vgl. Goethes Ausruf: „Wie ist es möglich, daß solch ein Mann mir so lange verborgen bleiben konnte!“, als Brentano ihm das Sintflutspiel vorlas; zitiert nach Wittmann, ebda., S. 1. 
Frisch und g'sund, wie Haselnus!

Ju he! Ju he! Ju he! Werfen das Glas weg, und schenken ein anders ein.

Noe. Das Plunderg'sindl, wies mich plagt,

Thut Noth, daß s'Gläser auch erschlagt.

Die Zimmerleuthe trinken wieder.

Viuat unser Maister desgleichen,

So stark und vest, als wie ein' Eichen.

Ju he! etc. Werfen wieder das Glas weg.

Noe. Wirft mir noch einer ein Glas davon,

So zieh ihms ab an seinem Lohn.

Veitu. Lippl! In welchem Kloster hat man jeder frißt

Ein Mehlspeiß?

LipPL. Narr, wo der Prälat ein Schmarn ist.

Hiesl. Beim Noe giengs bald auch so her.

Die Zimmerleuthe trinken wieder.

Es lebe jeder Zimmergesell,

Flink, wie der Teufel in der Höll.

Ju he etc. Und da werfen alle ihre Gläser weg.

NoE. Nein! Gott Vater, das ist nimmer ausz'stehen,

Müßt' selbst um die Sündflut mit dem Kreutz noch gehen,

Oder etlich wächserne Mändl verlobn,

$\mathrm{Daß}$ es einmal losbrechen thät oben.

GotT VATER schaut zum Fenster heraus.

$\mathrm{Ha}$, ha, Noe! Ist dir sbändl endlich brochn;

NoE. Ja, wie mich plagn die grobn Zochn: ${ }^{69}$

4 ös] ihr 11 öngs g'schaft] ihnen es angeschafft, befohlen 14 Plaus] Gerede, üble Nachrede 51 wächserne Mändl] Wachsfiguren als Bittopfer in Wallfahrtsorten 54 sbändl ... brochn] Geduldfaden gerissen 55 Zochn] verächtliche Bezeichnung für Männer

\section{Heiligen- und Legendenspiele}

Neben den kirchlichen Hochfesten und den hierarchieverkehrenden Tagen vor der Fastenzeit konnten auch liturgische Gedenktage und Kirchweihfeste Gelegenheit und Thema geben, Legendarisches szenisch umzusetzen. Beliebt waren seit dem 14. Jahrhundert etwa am Dorotheentag im dramatischen Kontext dargebotene Heischelieder über das Martyrium der Heiligen, mit denen sich ein Almosen verdienen ließ. ${ }^{70}$ Häufig im Volksschauspiel des bairisch-österreichischen Raums anzutreffen sind auch Dramatisierungen zur Genoveva-Legende und Nikolausspiele. ${ }^{71}$ Sollten diese bereits vor 1800

69 Bucher, Geistliches Vorspiel, S. 171-174.

70 Vgl. Christian Neuhuber: Ein Gottesgeschenk für die Bühne. Dramatisierungen der Dorothea-Legende im deutschen Sprachraum. In: Margita Havličková / Christian Neuhuber (Hg.): Johann Georg Gettner und das barocke Theater zwischen Nikolsburg und Krumau. Brno: Masarykova Univerzita 2014, S. 131-182.

71 Vgl. u. a. Anton Schlossar: Deutsche Volksschauspiele. In Steiermark gesammelt. Mit Anmerkungen und Erläuterungen. Halle: Niemeyer 1891. - Hartmann, Volksschauspiele. 
dialektale Passagen enthalten haben, so haben sie sich nicht in zeitgenössischen Niederschriften erhalten. Das früheste Heiligenspiel, das stark am Mündlichen orientierte, dialektnahe Dialogsequenzen bei Nebenfiguren aufweist, ist das Oberinntaler Legendenspiel Comedia Barbara des Fließer Pfarrers Michael Raggl (1609-1649). Das 1644 in Fließ (unweit der Barbara-Kapelle) aufgeführte Spiel integriert in den eingelegten komischen Szenen zahlreiche Fastnachtspielmotive, wie sie sich im dialektalen Liedbereich des 18. Jahrhunderts wiederfinden, so etwa den publikumswirksamen Streit eines Zimmermanns mit einem Maurer, der handgreiflich zu enden droht:

Zewer. [...] Zuedem Wos du thust gwinnen ols, dos ist Vorhin schon durch den hols, gwinst nit Ein guetes hosentuech,

Altwerth. Du schütst den wein auch nit in d schuch Mogst da wol Von dir selber sogen.

ZEwer. Ich dörfft dir bold ains ins Moul schlogen.

Altwerth. Beuth dir den truz, thus won du wilt,

Zewer. Es dorf Kein truz, Se hin es gilt, ${ }^{72}$

7 Beuth] beiten: warten, (hier:) verzichten 8 Se hin] nimm das, da hast du

Dialektale Zwischen- und Nachspiele als unterhaltendes Element in Heiligen- und Märtyrerstücke einzufügen, war gängiger Usus; diese haben aber selbst zumeist keinen religiösen Inhalt und sind oft nur lose mit der Legendenhandlung verknüpft. Bekannt sind hier u. a. die von einer Dachauer Dilettantentruppe unter Leitung des ,Ludi Magister Franz de Paula Kiennast (1728/29-1783) aufgeführten und zum Teil wohl auch von ihm verfassten Stücke, die Oskar Brenner 1893 aus den heute verschollenen Handschriften edierte. ${ }^{73} 1759$ wurde Die von Neydt und Eyfersucht verfolgte Unschuldt, das ist Hyrlanda Herzogin auß Burgundt mehrfach aufgeführt, ein Stoff, der im 18. Jahrhundert wohl zum Standardrepertoire des alpenländischen geistlichen Spiels gehörte, obwohl die als Volksheilige verehrte Hirlanda von der katholischen Kirche niemals kanonisiert wurde. Nur die komischen Einlagen sind im bairischen Dialekt gehalten; hier der Beginn des dritten Intermediums, in dem Hansdampf ganz im Stile seines Vorbilds Hanswurst die Auswirkungen der Festbankette beschreibt, mit denen die Rückkehr der unschuldig verstoßenen Hirlanda gefeiert wird:

Hansdampf. Ju hei, beym hundert Flikherment, iezt is alleweill Kirdä bey hof, mei first, der hr. artli, der ist so froh, das er sei Hyrländerl wider bekemmä hat, i ho iems weidä nit verübl, den $7 \mathrm{Jahr}$ ohne wei sei, is mei sechs ä lange zeit. dös weiberl hat do guraschi, das sie so lang in der frembdt blibn, auf ä weibsbilt is ä kekhs stuckh, dös guraschi hät i nit ghofft vo ihr, no, no, mirs is recht; aber iezt mechti halt gern sechä, das dös fresßn, sauffä, und tumuliern ä mahl ä Endt nämb, den in d'leng ko is nimmä thai, alle tag sternvoll sei will was sagn, braucht än Mo,

72 Zitiert nach: Ellen Hastaba: Komische Szenen in geistlichen Tiroler Spielen des 17. Jahrhunderts, aufgezeigt am Beispiel der ,Comedia Barbara', Fließ 1644. In: Max Siller (Hg.): Fastnachtspiel - Commedia dell'Arte. Gemeinsamkeiten - Gegensätze. Akten des 1. Symposiums der Sterzinger Osterspiele. Innsbruck: Wagner 1992, S. 75-101, hier 93. Vgl. auch die (im Detail abweichende) Gesamtedition in Ellen Hastaba: Das Volksschauspiel im Oberinntal. Innsbruck, Phil.-Diss. 1986, S. 285f.

73 Vgl. Oskar Brenner (Hg.): Altbairische Possenspiele für die Dachauer Bühne bearbeitet. München: Kaiser 1893. 
iezt soll ainä ä stainige Natur habn und än Magn, als wie ä zechetstadl. i sags rund raus, wön dös frösn, und sauffä bey hof no lenger wiert, mues i schai wider ä Purgier von A b c trekhler einemmä, oder i mus zum schäffler gieh, das er mir etli raif an d'wampen olegn lasst. ${ }^{74}$

1 Kirdä] Kirchtag(fest) hr. artli] Herr Artus, Gatte Hirlandas 2 i ho] ich habe 3 wei] Weib, Frau mei sechs meiner Sechs (Ausruf der Bekräftigung) guraschi] (franz. courage) Mut 4 kekhs] mutiges 5 tumuliern] Tumult machen, Mutwill treiben ä mahl] einmal 6 thai] tun än Mo] einen Mann 7 zechetstadl] Zehentstadl: Scheune zur Aufbewahrung der Zehentabgaben 8 Purgier] Purgiermittel: Abführmittel A b c trekhler] Verballhornung von Apotheker 9 schäffler] Fassbinder wampen] Bauch

Dass diese Anreicherung der Legendendramatisierung mit dialektalen Nebenrollen schon im frühen 18. Jahrhundert nichts Ungewöhnliches war, belegt der Prolog einer Tragœedia Hirlandioe, die 1713 in Lambach aufgeführt worden war. Dort begegnet uns mit dem ,Nachtwachter“ („Allö herrn vnd frauä laß euch sagn / der hammer der hat treu gschlagen “75) eine mundartliche Figur, die schon in Heinrich Ignaz Franz Bibers (16041704) berühmter Serenada à 5 (1683) ihren Auftritt hat („Lost Ihr Herrn undt last eüch sagen, der hammer der hat Neyne [Zehne] gschlagen, hüets feyer, hüets wohl“ ${ }^{\text {76}}$ ) und sich im weihnachtlichen Offertoriumsgesang (vgl. S. 35) ebenso finden lässt wie in den Hanswurstburlesken des Kärntnertortheaters. ${ }^{77}$ Auch die 1791 mehrfach aufgeführte Hirlanda in der Fassung des Laaser Theatermanns Johannes Ulrich Federspiel (17391794) weist Hanswurstszenen im Tiroler Dialekt auf (die offenbar dem traditionellen Spielrepertoire der semiprofessionellen Vintschgauer Schauspieltruppen entnommen sind, wie Parallelen zum Laaser Spiel vom Eigenen Gericht vermuten lassen). ${ }^{78}$

In der Dachauer Joanna von Arc (1770) sind zwei Szenen mit Mundartspäßen nur lose mit der Handlung verknüpft, während die Getruckht aber nit Undertruckhte Unschuld oder die heilige Itta (um 1765) ein wohl von Kiennast selbst stammendes dialektales ,Nachgspill‘ aufweist, das sich als aberwitzige ,Katechismusstunde' des Bauern Hans an die Grenzen des damals noch Zeigbaren herantastete und selbst vor der Verballhornung des zentralen christlichen Gebets nicht zurückschreckte:

Hans. seydts still ös zway arabische bürgEsel! wie lang gehts schon in d'schuell.

RUBeLLE. 7 viertl Jahr.

Hans. Und kindts ös Vatter unser no nit? nur gedult, i will euch flögl s'Vatter unser mit meinen hölzernen Paternoster halt lehrnä. zeigt ihnen den stekhen.

CASPERLE. Vodä in der Schuell sagt mäs uns freyli, aber mä vägißts glei wider weil mä dahaimb nimmer widerholln mueß.

HANs. iezt mörkhts no gschwindt auf, und betts ma nach Vatter unsä.

Амво. Vatter unsa

74 Ebda., S. 9f.

75 Vgl. Stiftsarchiv Lambach, Cod. chart. 202, f. 1 sowie Konrad Schiffmann: Drama und Theater in Österreich ob der Enns bis zum Jahre 1803. Linz: Verlag des Museums Francisco-Carolinum 1905, S. 68ff.

76 Zitiert nach Charles E. Brewer: The Instrumental Music of Schmeltzer, Biber, Muffat and Their Contempories. Farnham: Ashgate 2011, S. 246.

77 Vgl. u. a. Alli meini Herrn und laßts eng sagn (s. o.) bzw. Colombine Leben und Todt. Oder Hanns-Wurst, Höllischer Nacht-Wachter sowie Bernardon als Nachtwachter, siehe Österreichische Nationalbibliothek, Cod. 12708 (Teutsche Arien, Welche auf dem Kayserlich=privilegirten Wienerischen Theatro in unterschiedlich producirten Comoedien, deren Titul hier jedesmahl beygerucket, gesungen worden).

78 Vgl. Toni Bernhart (Hg.): Johannes Ulrich von Federspiel. Hirlanda. Durch falschheit zu feir verdamte unschuld: Edition des Legendenspiels nach der Laaser Handschrift von 1791. Wien/Bozen: Folio 1999. 
Hans. der du bist

Амво. der du bist.

HaNs. im himmel, und auf erden.

Амво. in himmel und auf Erden.

Hans. Der fir uns begraben

Амво. der fir uns begraben

HANs. gecreuziget und gestorben worden.

Амво. gecreuziget und gestorben worden. iezä miesßmä lachä.

Rubelle. schau, dä Vodä ist selbst ä lauterer Esel.

CASPERlE. schau, schau, den Vadä an, was ä fir ä bifflox ist. ${ }^{79}$

1 ös] ihr bürgEsel] Gebirgsesel 3 kindts] könnt 4 Paternoster] Vaterunser, Rosenkranz, (hier:) Knüppel 7 betts ma] betet mir 16 mießmä] müssen wir 18 bifflox] büffelochs

Schon von 1694 ist uns handschriftlich ein gereimtes Singspiel über diese Heilige aus Toggenburg erhalten, die wegen vermeintlichen Ehebruchs von ihrem Mann Heinrich vom Turm gestoßen wurde und wundersam überlebte. In Innocentia Pressa, sed non Oppressa, das ist Wunderlich endtöckhte Vnschuldt der Hl. Itta sind die teils Dialekt sprechenden Narrenfiguren direkt im Spiel integriert und interagieren zwanglos mit den (stark oberdeutsch sprechenden) herrschaftlichen Protagonisten in typischen Klamaukszenen, wie sie in Wandertheaterstücken beliebt waren:

Scena 4

Pomponius bekhlagt sich yber sein Ehe: Lobt Henrici standt. Pomponius mit .2. khnäbl.

Pomponius. exit mit einer khräxen auf den Buckhl worin die .2.

Habs offt ghört, daß selten ein Ehe, wo nit bißweillen einschleicht das wehe.

Das hab ich auch in wönig Jahrn

Schon mehr als tausendmall erfahrn.

Hab ein weib ist gwiß nit die böst;

wolt ich wurd noch heünt darvon erlöst. sözt die khraxen nider. höbt .2. büebl auß der khräxen.

Hab da zway buebn, derhaimb noch mehr,

die lign mir täglich auf der ster.

Minor. Dätn ä päxn.

Maior. Vadä gib mir ä brod.

Pomponius. Sechts, Liebe Leid, so gehts alleweill, däbarmns Gott.

Maior. Gib mier brod.

Minor. mier ä.

Uterque. odä ich zreiß pfaid.

Pomponius. Wo nimm iezta brod, habts nit ä gsaid.

Maior. Mei Vada, khonst ja än Laib onschneidn.

Pomponius. Limmeln, wo ist er. So mues ich leiden.

Nimm ichs darnach, gleich wo ich woll.

Wünsch offt, das alls der gugu holl. fangen bede an zu rozen.

Rozen dölpeln scho mehr ä weill ains daher. liebkhoset ihnen auf all weiß.

Schweigts still meine Holzseellige,

annemliche, außbündige,

79 Brenner, Altbairische Possenspiele, S. 18. 
Schöne, und woll gstalte Khindterlein,

Du mein trüffterl, und du mein bindterlein,

Du bist mein Liebs paradeyß Engele,

Vnd du mein Zuckhersüesß khraut strugele.

Schweigts, khlopfft an. da wölln wür unsre glider Labn.

Scena 5

Pomponius macht mit seinen Söhnen Henrico, und Itae einige Khurzweill.

Garten negst am Saall.

Henricus. Itta. Pomponius. Famulus. Infanti.

Famulus exit. truzig ad Pomponium.diser noch truziger

Famulus. Scherr dich zum toifel, du khnopf, was wilst habn?

Pomponius. Respect! du tropff, oder ich will dir zeigen,

wer, und was ich bin, truz thue mir nit schweign.

Las mich nur gschwintd zu der herrschafft hinein.

Famulus. Gehe umb ein Haus weiter, da khans nit sein. aperitur. Henricus \& Itta süzen zu tisch.

Henricus. Was gibts? ad Famulum. Las ihn herein. glaub er sey nit gscheid.

Pomponius. Recht: so mues man respectiren uns Edlleith.

No buebn, geths gravitätisch, das hüetl zuckht,

Machts reverenz, das füesßl fein sauer buckht.

Henricus. ad intrantem Pomponium. Woher khombtsn, auß was für einem Landt?

Pomponius. Aus Frißlandia, so woll bekhandt,

vnd brüembt ist wegen des streitbaren gschlecht,

Henricus. Glaubs, wo man mit khrieg, und glöser fecht.

wie heist, und woher fiehrest dein Stammen.

Pomponius. Pomponius ist mein nammen,

Mein V-Vhraltes Stammenhauß

khombt auß Na-Narbonien herauß. Zieht herauß ein närrischen wapen brief.

Das bezeigt mit ein wort brief, und wappen.

Henricus. Wohl schön, stat des helms füehrts ein Narnkappen.

Pomponius. Das habn schon für die höchste Zierdt

Meine vhralte öndl, und andl gfiehrt.

ITtA. ad Pomponium Die Zwey sein gwiß deine Söhnlein.

Pomponius. Ja freylich: Zway widl sind noch dahaim.

Sie wurllen umb, wie d'Fäkhl in Khott, und Laim.

Dö schönsten zwö nam ich mit mier, scilicet den Triffterl und Binderle

weils mein Stammen göbn ein grosße Ziehr.

Henricus. Sicht ihm gleich. Nun Last iezt sehn eur khunst.

Pomponius. Der wagn geht nit, es ist umbsunst,

wen man ihn nit zuvor schmirbet woll. greifft nach ein Glaß angleichen auch die buebn.

Trinckhts fein gmach, so würd kheiner voll.

wer vill fragt, geht weit yrr: gilt scho.

TriffterL. Saullus Vadä.

Binderle. Ju hey! dön dro.

Henricus. Da heist es, Vader, gehe du voran.

ITTA. Ist aber woll ein schlechter hofmann.

TRIFFTERLE. nachdem sie außgsoffen. Wär dös gläsl no so voll gwöst,

So wär i do nit worn dä löst.

BINDERLE. Brüderl, i hät dier gwiß nichts nachgöbn.

Popmponius. Gelts Buebn, dös zoigl hat enk gschmökht.

Jezt bumpt, und gumpt wies khündt, und mögt

hier khünen sie ein gfecht, danz, oder dergleichen halten. 
HenRICUs. Ist schon gnueg: da khündts weiter reisen. gibt ihm eine schänckung.

Pomponius. No buebn, thuets ench dankbar weisen. ${ }^{80}$

3 exit] tritt heraus, tritt auf khräxen] Kraxe: hölzernes Tragegestell mit Armgurten Buckhl] Rücken 9 büebl] Jungen 10 derhaimb] daheim 11 lign ... auf der ster] machen Mühe 12 minor] (lat.) der Kleinere Dätn] Vater, Papa ä päxn] ein Gebäck (?) 13 maior] (lat.) der Größere 14 Sechts] seht däbarmns Gott] Gott erbarme sich unser 16 mier ä] mir auch 17 uterque] (lat.) beide pfaid] Hemd 18 habts nit ä gsaid] was redet ihr daher 22 gugu] Kuckuck rozen] weinen 23 scho mehr ä weill] schon eine ganze Weile 29 strugele] Strudel 33 Famulus] (lat.) Bedienter Infanti] (lat.) Kinder 34 ad] (lat.) zu 39 aperitur] (lat.) es wird geöffnet (der Vorhang zur Hinterbühne wird aufgezogen) 42 das hüetl zuckht] den Hut gezogen, gelüftet 43 Machts reverenz] verbeugt euch 44 ad intrantem] zum eintretenden 47 khrieg] Krüge fecht] fechtet 51 Narbonien] das heutige Arrondissement Narbonne (Namenskomik) 55 öndl] (Diminutiv zu En, An: Ahne): Großvater, ,Ahnherr andl] Großmutter 57 widl] Bund (als Gruppenangabe beim Tierverkauf, etwa 4 Stück umfassend) 48 wurllen umb] drängen, herumwälzen Fäkhl] Ferkeln Laim] Lehm 49 scilicet] (lat.) das heißt, nämlich 53 schmirbet] schmiert 56 Saullus] (fälschlich für lat.) Salus: Heil, Zum Wohl! 57 dön dro] den dran (?) 61 wär i do nit worn dä löst] wäre ich doch nicht erlöst worden 62 nachgöbn] nachgegeben, zurückgestanden 63 zoigl] Zeug enk] euch 64 bumpt, und gumpt] hüpft lustig und geräuschvoll herum 66 khündts] könnt ihr 67 ench] euch

Auffällig häufig scheint die Legende der Hl. Notburga von Rattenberg für das Laienspiel dramatisiert worden zu sein. Selbst Magd und Wirtschafterin, wurde die aus Tirol stammende Hutmacherstochter als Patronin der Dienstboten und der Landwirtschaft vor allem von der bäuerlichen Unterschicht im Alpenraum verehrt, immerhin galt sie als Erfinderin des Feierabends, der Begrenzung der Arbeitszeit. Zumindest zwei volkstümliche Stubenspiele zu ihrer Legende sind aus dem 18. Jahrhundert überliefert; beide kommen ohne Bühne aus, sind ungegliedert und in stark mundartlich gefärbter Sprache gehalten. Die Reimb von der Hl. Nothburg (1774) aus einer Kiefersfeldener Handschrift vergegenwärtigen einen zentralen Moment aus dem Leben mit der Weigerung Notburgas, auf ihre Gebetszeit zu verzichten, und dem anschließenden Sichelwunder (bei dem das gen Himmel geworfene Arbeitsgerät an einem Sonnenstrahl hängenblieb). ${ }^{81}$ Das andere Spiel aus den Unterlagen der 1773 aufgelassenen Jesuitenresidenz Traunkirchen ist ein Zwiegespräch zwischen Bäurin und Knecht, der durch das gottesfürchtige, doch selbstbewusste Vorbild auf den Weg der Läuterung gebracht wurde:

KNeCht. Es war a schöns Dirndl, is stark ah dabei.

Weil s' aber so frumm is, so merkan 's d' Buam gleih:

$\mathrm{Da}$ is nix zan macha

Mitn Kitzln und Lacha.

Sie hat Augn wiar a Biber so wunderschön braun

Und tuat nix anders als Gott damit anschaun.

BäUerin. Daß d' Notburg, net schandlih und frumm ah dabei,

Dir's Luadern verwiesen hat, gmacht hat die Reu.

Du hast kriagt a Nasen,

Sie hat dir's abblasen

Das Umaroln und Roasen, drum laß es ah sein,

Dann wird 's amal hoaßen, ja der Hiasel is fein!

KNECHT und BäUERIN. sprechen zusammen

80 Bayerische Staatsbibliothek, Cod. germ. 4063, S. 10-13.

81 Vgl. Hans Moser: Zwei Notburga-Spiele aus dem bayerischen Inntal. In: Beiträge zur Heimatkunde des nordöstlichen Tirol. Festschrift zum 70. Geburtstag Matthias Mayer's. Innsbruck: Wagner 1954. (SchlernSchriften 138) S. 151-162. 
Den Feierabend hat uns die Notburg aufbracht.

Hiaz kann ih faullenzen in Feierabend auf d' Nacht.

Bauer, Bäuerin und 's Gsindl,

Sie kriagen an Schwindel,

Koan Arbat nach'n Feierabend mir nimmer anschaun,

Und wann 's uns wurdt angschafft, mir taten uns net traun. ${ }^{82}$

8 Luadern] liederliches Leben 9 hast kriagt a Nasen] bist beschämt worden 11 Umaroln] unsteter Lebenswandel Roasen] Sich-Herumtreiben

Im Fall der Notburga-Legende scheint es also so etwas wie eine Tradition dialektaler Verarbeitung zu geben, wobei natürlich die Fallzahlen für derartige Schlüsse denkbar klein sind. Es liegt die Vermutung nahe, dass diese Heiligenfigur stärkere Identifikationsmöglichkeiten für die ländliche Bevölkerung bot und damit auch stärker in deren Sprache verehrt wurde. Notburga selbst allerdings spricht, wenn sie im Spiel auftritt, Standardsprache. Auch hier also markiert die Abstufung zwischen den Varietäten eine implizite Hierarchie, die allerdings nicht durch den sozialen Status, sondern in der moralischen Überlegenheit der Heiligen begründet ist.

Es ist in der Dialektliteratur des 18. Jahrhunderts vergleichsweise selten, dass diese sprachliche Differenzierung nach Rang bzw. Status aufgehoben wird und Höherstehende in der fiktionalen Gestaltung dasselbe Register verwenden wie die Niedereren. Zwei dieser raren Beispiele sind uns bereits in Schumachers Volksspielparodie Isaac und Buchers Sintflut-Burleske begegnet. Ein weiteres scheint ein scherzhaftes Heiligenspiel zu sein, das aus dem ehemaligen Augustinerchorherrenstift Beuerberg stammt. Bedauerlicherweise ist das eigentliche Stück, eine Klosteroperette um den Tod des Hl. Antonius, der sich ein letztes Mal gegen die Versuchungen der Dämonen wehren muss, nur als handschriftliches Szenar erhalten. Aber die Anlage mit seinen burlesken Szenen (so etwa der traditionelle Gesichtschwärz-Lazzo auf Kosten St. Michaels), vor allem aber der im Wortlaut erhaltene Prolog des, Spielgrafen' lassen vermuten, dass die gesamte Figurenrede in Dialekt verfasst war. Das ist insofern bemerkenswert, als sich auch Gottvater im liturgischen Gewand unter den Agierenden, die sich vorweg singend vorstellen, findet:

ista proponuntur per modum ariettce

Gоттуёттё. in rauhmantel vnd in dä stoll bin i gott vättä wol fein vnd doll

Michael. Vnd i schwör Enh auf ein aid däs i bi ä Engl in dä weisn Pfaid

Antoni. Vnd i deafs nit sagn, ös könts mi wol der hl. antoni i seyn soll däs i sein soll ös kennts mi woll

DeIfl. Vnd wir 2 tuifl aus der höll kemä ä her an die stöll

82 Zitiert nach Hans Commenda: Ein oberösterreichisches Notburga-Spiel. In: Oberösterreichische Heimatblätter 23 (1969) H. 1/2, S. 36-40, hier 39. Auch Commenda gibt lediglich eine Abschrift der verschollenen Originalhandschrift wieder. 
SPILGRAfF. iezt gehts nur ä bisl her i wil eng göbn ä guete lehr.

Aria.

wants aussi kembt auf bin

hälts zsämä Enhern sin

vnd seits mä no fei gschikt

bey leib mir nit dä schrikt

2

Du gott vättä halt dei gravität

bey leib drauhmantl nit verzöt

Du lucifer beyn solament

halt ybern tuefel guet regement

geregent, schnedere gent, gent, gent.

\section{Recitativ.}

aber däs uns spil recht wol duet glinge,

wölmä vor ä gsängl singe.

\section{Aria.}

o heiliger antoni du Englischer Mo

Ri di widi wä gäleison.

wir rueffä dä all adächig o

Ridiwidi wä gäleison. Hanc aria repetunt coeteri ${ }^{83}$

1 ista ... ariettæ] (lat.) dies wird im Stil einer Arietta vorgetragen 2 rauhmantel] Pluviale: liturgischer mantelähnlicher Umhang stoll] Stola: liturgisches Gewandstück, Stoffstreifen unter dem Pluviale 4 Enh] euch 5 Pfaid] Hemd 6 ös kents mi] ihr kennt mich 11 kemä] kommen 14 wants] wenn ihr aussi kembt] hinaus kommt bin] Bühne 15 hälts zsämä] haltet zusammen 16 seits mä] seid mir fei] Füllwort: bloß, wohl 17 dä schrikt] erschreckt 18 gravität] Erhabenheit, Würde 19 verzöt] verzetten: anpatzen, bekleckern 20 beyn solament] Nachdrücklichkeitsfloskel 24 wölmä] wollen wir

Die abschließende Arie zitiert sicher nicht zufällig eines der bekanntesten Salzburger Scherzlieder, das in vielen unterschiedlichen Versionen im gesamten süddeutschen Raum kursierte und - entgegen gängiger Forschungsmeinung ${ }^{84}$ - spätestens in der ersten Hälfte des 18. Jahrhunderts entstanden war: die Pinzgauer Wallfahrt. Hier der Beginn einer 13-strophigen Einzelabschrift aus der Sammlung des Garstener Kapitularen Leander Kremser:

1

Die Pinzgrä die wollten Kirfarstn gehen

widi wadi weh eleison

Wo St. Salvada in dum thut stehen

widi [wadi weh eleison]

Pinzgra Leut sama das waist ja von ehe

83 Bayerische Staatsbibliothek, Cod. germ. 5719, f. 1v-2r.

84 Rainer, der zu einem anderen Ergebnis kommt, kennt weder den Innsbrucker Codex 980, aus dem bereits Blümml zwei Fassungen edierte (vgl. Emil Karl Blümml: Volkslied-Miszellen. In: Archiv für das Studium der neueren Sprachen und Literaturen 59, Bd. 115 (1905), S. 30-66), noch das Beuerberger Spiel, die 20-strophige Version aus einer frühen Liedersammlung von Ernest Frauenberger (Stiftsbibliothek Kremsmünster, Ccn 1073) oder die hier anzitierte Fassung Leander Kremsers (Oberösterreichische Landesbibliothek, Mappe 779). Vgl. Werner Rainer: „Dö Pinzgara wolt’n kirfiart'n gehen“, in: Salzburg Archiv 29 (2004), S. 165-186. 
Juhahe, widi wadi wehe gelobt sei d'Khristl [und Salome].

2

St. Salvada, du goldener Man, widi wadi [weh eleison]

Hör ins arme Pinzgera an, widi wadi [weh eleison] grobi Leut sama das waist ja von ehe Juhahe [widi wadi wehe gelobt sei d'Khristl und Salome]. 3

Schick ins Streu und schick ins Heu. widi wadi [weh eleison] Und dazu ein randigs Wei widi wadi [weh eleison] a dalgati mogn ma nit das waist ja von ehe Juhahe [widi wadi wehe gelobt sei d'Khristl und Salome]. 4

Schick ins Kuh und schick ins Rinda, widi wadi [weh eleison] Und dazu nicht gar zviel Kinda, widi wadi [weh eleison] A Stumvoll ist gnue, das waist ja vo[n ]ehe Juhahe [widi wadi wehe gelobt sei d'Khristl und Salome]. $[\ldots]^{85}$

1,1 Pinzgrä] Pinzgauer Kirfarstn] wallfahrten, wallfahren 1,3 Salvada] Salvator: in der Giebelmitte der Salzburger Domfassade steht eine Christus-Statue als Salvator mundi 3,3 randigs Wei] tolles Weib 3,5 dalgati] dumme, ungeschickte 4,5 A Stumvoll] eine Stube voll

Wie dieses Spottlied die unfreiwillig komischen Prozessionsgesänge der Zeller Pilger in Salzburg aufs Korn nahm, so komisierten Stücke wie das Beuerberger Antonius-Spiel die ebenso beliebten wie unzeitgemäßen laienhaften Produktionen im Volksschauspiel. Offenbar waren diese in der konkreten Realisierung weitaus dialektaler gehalten, als es die wenigen originalen Textbelege vor 1800 vermuten ließen.

Eine theatersatirische Absicht steht wohl auch hinter einer Innsbrucker Bearbeitung der Engelsturzlegende, die - wie Schumachers Isaac - eine gelungene Parodie der literarischen Gattung des Volksschauspiels ist und deren regional gebundene, vom Standard deutlich abweichende Sprachgebung in der Aufführungssituation wohl nicht nur imitiert, sondern stark überzeichnet. Die Legende vom tiefen Fall Lucifers ist seit frühchristlichen Zeiten belegt und dichtet marginale alt- und neutestamentarische Hinweise auf den gestürzten Lichtbringer weiter. Das ,Fastnachtspiel in Tyroler Bauern Reimen Der Engelsturz ist eine derb-komische Dramatisierung dieser Geschichte, in der, wie zu erwarten, der aufsässige Lucifer hinters Licht geführt und letztendlich vom Erzengel Michael - dem eigentlichen Fokus des Stücks - in einem an burlesken Szenen nicht

85 Oberösterreichische Landesbibliothek, Mappe 779 [o. Sign.]. 
armen Endkampf besiegt und in die Hölle gestoßen wird. Aber auch den übrigen Figuren wie Gott Vater, Gott Sohn und dem Heiligen Geist kommen nicht die erwartete numinose Souveränität und Dignität zu. Laut Moriz Enzinger, Ersteditor des dem vorbarocken Fastnachtspiel nahestehenden Stücks, sei dabei keine Verspottung des Heiligen intendiert, sondern eher eine profanierende Angleichung an das Menschliche und seine Schwächen. ${ }^{86}$ Die Gefolgschaften Lucifers etwa werden durch einen Schweizer Korporal mit der Aussicht auf Wurst, Schinken und ähnlich Erquickliches auf den Kampf eingeschworen, während Gottes Heerscharen mit Wein gestärkt antreten. Am deutlichsten aber wird die Vulgarisierung im Sprachlichen, da sämtliche Rollen im Unterinntaler Dialekt ohne statusabhängige Nuancierung gesprochen werden, wie der folgende Ausschnitt belegen soll. Hier schwärzt Gott Vater dem naiv-ambitiösen Lucifer mit Ruß das Gesicht, um ihn zu demütigen:

LUZIFER. Hier bin i Gott Voter noch dein Begehren, Än göttlichen Vergleich jez anzuhören. Und vorgstöllt z'wearn der englischen Macht, wie sichs gebihrt mit Ehr und Pracht.

Es soll sich in allwög gebühren,

Der schönste Engel soll än Zepter führen,

Du waist ja selber, alls Fleisch ist heu,

Obschon naß oder trucken sei,

So ists do der Würmer Speis,

Die taugen nicht ins Paradeis,

Den mei, wie wurds schicken si,

Wenn ä die Würm ungrifen di,

Darum hast du wohl gethun,

$\mathrm{Da}$ du anstatt eines Menschensuhn

Willst sötzen mi an deine Seit,

Wie in vernuommen allbereit.

Gotт Voter. Ja, du hasts zwar nit verdient um mi,

$\mathrm{Da} ß$ unter meine Augen ließ kemmen di,

Denn du mueßt wissen, wer i bin,

Daß du aufgwahrt nur obenhin,

Zum Frössn und Saufen brauch i kaine Leut,

Du wärst kain Nahr, i wär ä so gscheid,

I will aber nit viel machen drauß,

Das Spiel, das werd schon kemmen heraus.

Weil ober dir no viel ogeht,

wenn du an Gott willst gleichen nett,

So muest än Purpur trogen un,

Dein Gsicht muß glanzen, wie die Sunn,

Än Zepter mueßt führn in der Hand,

Mit dem regierst Leut und Land;

kimm also, i will dir ä Färbl unstreichen,

So mueßt du mir bald netto gleichen.

Michel. Schaugts, Luzifer ist ä Gott nu woarn,

Wer ist no zu solchem Glück geboarn?

Gotт Voter. Also, jez sicht er uns völlig gleich,

86 Vgl. ebda., S. 346f. 
izt taugt er Erst recht ins Himmelreich,

Hidriel. Au weah, mier müeßen jezt alle derblinden,

Luzifer, loß dir da die Augen verbinden.

Dein Glanz, o grosser Luzifer,

kun unser Blödheit nit ausstean mehr.

LUZIFER. A solche Röd ist alls werth,

thiets nu, was ös von mier begeart,

wahrhaftig die Gottheit empfind ich schon,

Von der klain Zea, fängt si än.

Gotт Voter. Nun Luzifer, leg auch den Purpur an,

Und söz auf die goldne Kron,

Hier host $n$ Zepter ä in die Hand,

Gib acht, daß d'n Himmel nit bist ä Schand.

LuzIFER. Seits une Sorg Gott Voter mein!

Enk alle will $i$ än Ehre seyn.

Ja, ich will enk versichern ganz,

Mein Gottheit gibt erst enk den Glanz.

Gabriel. Au weah, au weah der Augen mei,

I kunt nit ausstean diesen Schei[n]

HeIL. GeIst. Ihr Engel seyd wohl recht nicht gscheid,

Den Glanz macht alle sein Gottheit,

Den Glanz kunt man nit so verbinden,

Däß er nit kunt än Ausgang finden;

LUZiFER. Bin i wohl so gar schön.

Michel. Du glaubst nit, Luzifer, bleib nur stean;

Deine Engel thoan di nimmer kennen,

Dein Glanz macht si gwiß alle wökrennen.

Gотт Soнn. Geaths Engel, bringts ä Wasser und ä Saifen-Bäzen,

Daß Gott Voter ku waschen seine rußigen Tazen. ${ }^{87}$

2 än] den 12 ä] auch 33 woarn] geworden 41 Röd] Rede 44 Zea] Zehe 50 Enk] euch 61 thoan] tun 63 SaifenBäzen] Seifenstück 64 ku] kann

Autor dieser Himmelsposse aus der ersten Hälfte des 18. Jahrhunderts, die uns nur in einer einzigen späteren Abschrift überliefert ist, soll der biographisch nicht eindeutig festzumachende Jesuit und Innsbrucker Rhetorikprofessor Joseph Sieberer gewesen sein. ${ }^{88}$ Wie beim Beuerberger Antonius-Spiel fehlen auch hier entsprechende Aufführungshinweise. Doch kann es kaum Zweifel daran geben, dass derartige theatrale Gratwanderungen wohl nur in der normaufhebenden Zeit des Faschings auf die Klosterbühnen kamen.

87 Österreichische Nationalbibliothek, Hs 12742, f. 13r-14r, zitiert nach Moriz Enzinger: Der Engelsturz. Fastnachtspiel in Tiroler Bauernreimen von Joseph Sieberer S. J. In: Maske und Kothurn 10 (1964), S. 324375, hier 364-366.

88 Im Katalog der Österreichischen Nationalbibliothek wird die Handschrift 12742 auf „18. Jhdt. (zw. 1727 u. 1738)“ datiert und die Autorschaft ebenjenem Joseph Sieberer zugewiesen. Enzinger jedoch, der den Text bereits 1964 edierte, relativiert diese Angaben: so soll es sich nicht um eine eigenhändige Niederschrift des Verfassers des Stücks handeln, sondern um eine spätere Abschrift; zudem ist auch unklar, ob Sieberer als ursprünglicher Autor zu gelten habe oder vielmehr nur die Abschrift anfertigte. Explizit zweifelt Enzinger an der im ÖNB-Katalog vorgenommenen Datierung und vermutet - aufgrund einer abweichenden Deutung des numerischen Schlussschnörkels und inhaltlicher Hinweise -, dass die Handschrift in der vorliegenden Form erst 1817 entstanden sei; das Spiel selbst stuft Enzinger allerdings als älter ein - vielleicht noch über das 18. Jahrhundert zurückreichend (vgl. ebda., S. 326ff. und 345). 


\section{Andachtstexte}

So häufig sich Mundartliches im Fest- und Feierkontext des christlichen Brauchtums findet, so selten begegnet es uns abseits dieser ,Ausnahmezeiten' im rituellen Alltag. Das mag - wie so oft - der Tatsache geschuldet sein, dass das Besondere leichter den Weg in die Schrift findet, als Erinnerung oder Dedikation, als Arbeitshilfe in der Aufführungssituation oder zur Sicherung des Weiterbestands, als Verständniserleichterung oder auch abschreckendes Beispiel. Generell aber scheint der Dialektgebrauch in gewisser Weise nicht der Würde des Gegenstands angemessen zu sein, wenn die sakralen die säkularen Komponenten überwiegen, die unterhaltende hinter die spirituelle Funktion zurücktritt. Als wesentlich an Texten orientierte Buchreligion hat das schriftlich Fixierte im Christentum Offenbarungscharakter; in ihm konkretisiert sich das göttliche Handeln. Die mündlichkeitsbedingte Abweichung von der Schrift kann dementsprechend als Unterwanderung und Verfälschung des kollektiv Verbindlichen verstanden werden, das sich eben nicht regional, sondern entgrenzend versteht. Ritualisierte Andachtsformen wie das Gebet oder das gemeinsame Singen basieren trotz ihrer persönlichen und kommunikativen Komponente auf der Verbindlichkeit der Reproduktion durch Formelhaftigkeit und entziehen sich somit der Spontaneität und Variabilität des Mündlichen. Das bedeutet freilich nicht, dass im persönlichen Austausch mit dem Numinosen nicht auch regional markierte Nähesprachlichkeit zum Tragen kommen kann - ganz im Gegenteil. Verschriftlicht findet man diese ,intimen' Dokumente der Glaubenspraxis allerdings nur höchst selten; und auch da ist zumeist davon auszugehen, dass es sich nicht um konzeptionelle Dialektalität handelt, sondern um eine allmähliche Anpassung der Sprechgewohnheiten aufgrund einer mündlichkeitsnahen morphologischen, syntaktischen und semantischen Struktur der Ausgangstexte.

Ein Beispiel für diese an sich transitorische orale Literatur ist den Wiener Predigtkritikern Leopold Alois Hoffmann und Cajetan Tschink zu verdanken, ${ }^{89}$ die 1787 in den Kritischen Bemerkungen über den religiösen Zustand der $k$. $k$. Staaten ein Morgengebet mit dialektalen Formen als abschreckend gedachtes Beispiel einer untragbaren Volksfrömmigkeit präsentierten:

Heut aufsteh i,

Gegen Gott geh i,

Gegen Gott tritt i,

Meinen lieben himmlischen Vater bitt i,

Daß er mir verleih'

Der höchsten Engel drei,

Der erste, der mi weißt,
Der andre, der mi speißt,

Der dritte, der mi behüt und bewahrt,

Daß mir kein Leid widerfahrt.

Das helf mir Gott der Vater,

Und der Sohn,

Und der heilige Geist. Amen. ${ }^{90}$

Der Text, der - so monieren die entrüsteten Aufklärer - „noch häufig gebethet wird“, war ursprünglich wohl nicht mundartlich verfasst, sollte aber in dieser Form die Un-

89 Zum zeitgenössischen Diskurs zu klerikaler Praxis und Glaubensvermittlung siehe auch Kapitel 8.

90 Kritische Bemerkungen über den religiösen Zustand der k. k. Staaten. Herausgegeben von einer Gesellschaft. Zweyter Band. Wien 1787. Gedruckt auf Kosten der Gesellschaft. In Kommission bei Sebastian Hartl, S. $391 f$. 
sinnigkeit volksreligiöser Gebetsformen hinlänglich demonstrieren. Dass die schlichten Zeilen wohl schon damals - wie noch im 20. Jahrhundert nicht nur in Österreich, sondern auch in Mähren (Mackovice/Moskowitz) und Ungarn (Nagyesztergár / Großestergai) belegt - vor allem als Kindergebet fungierten, wird freilich nicht erwähnt. ${ }^{91}$ Auch das ,Stubenberger Liederbuch 'überliefert zwei anonyme Lieder, die Andacht und Frömmigkeit im Fokus haben. Bezeichnend ist dabei, dass auch hier dialektale Merkmale zumindest in der gegebenen Verschriftung - nur sehr zurückhaltend einfließen. Beim ersten dieser Texte - Melodien sind in beiden Fällen nicht überliefert - handelt es sich um das Marienlied Jetz mues ich mich aufmachen, in dem die menschliche Sterblichkeit angesprochen und abschließend Marias Beistand erbeten wird. Die dialektale Anlage des Lieds, im Vortrag sicher stärker markiert, konkretisiert sich in der Niederschrift erst in den Schlusszeilen, die an die Gottesmutter als Fürsprecherin gerichtet sind:

5

Wan es kombt zum sterben: ja sterben:

dis wird sein mein letztes wordt:

hilff maria von guetten rath:

thue uns im himmel aufnehmä:

wan mir kemmä: ${ }^{22}$

Das zweite Lied ist ein Anrufungslied, in dem mit repetitiven Formeln ein frommes Leben auf Erden bis zum Eintritt in das Himmelreich gelobt wird, nachdem jeweils stropheneinleitend verschiedene himmlische Instanzen angerufen werden. Dass auch dieses Lied dialektnah realisiert wurde, verrät schon der Anfangsvers:

1

O Himlischer Vatter: steig abä zu mir,

so wil from leben, wil bleiben bey dir,

from wil ich sein: from wil ich sein:

bis ich zu euch kom im himmel hinein, ${ }^{93}$

$1,1 \mathrm{abä]}$ herab

Welche Textsorte sich für die dialektale Gestaltung eignet, hängt auch deutlich mit den spezifischen Bedingungen des betreffenden Varietätenraums zusammen. Ein vollkommen anderes Bild zeigt sich etwa im Zimbrischen. ${ }^{94}$ Überblickt man die erhaltenen Texte aus dem 17. und 18. Jahrhundert, so zeigt sich im Vergleich $\mathrm{zu}$ jenen des bairischen Kerngebiets ein deutlicher Unterschied im thematischen und inhaltlichen Gewicht. Denn hier spielt eben gerade auch der geistliche Bereich in der Überlieferung eine große Rolle. Als älteste bairisch-österreichische Sprachinselmundart und als Idiom, das wohl den ältesten Sprachzustand unter den lebenden deutschen Mundarten vorstellt, schließt

91 Zur Überlieferung vgl. u. a. Anton Hofer: Sprüche, Spiele und Lieder der Kinder. Wien: Böhlau 2004. (Corpus Musicae Popularis Austriacae 16) S. 103.

92 Bayerische Staatsbibliothek, Cod. germ. 7340 (Stubenberger Gesängerbuch), Teil 1, S. 15.

93 Ebda., S. 79-80.

94 Die Zimbern siedelten sich im 11. und 12. Jahrhundert in Gebieten Oberitaliens an. Zu den zimbrischen Sprachinseln zählen die Sieben Gemeinden und Dreizehn Gemeinden in der Region Venetien sowie mehrere Ortschaften in der Region Trentino-Südtirol (darunter etwa Lusern). 
das Zimbrische an einen älteren Sprachstand an als die bairischen Dialekte des Stammgebiets zur gleichen Zeit. ${ }^{95}$ Charakteristisch ist zudem die mediale Fokussierung des Dialekts, der - nach Karin Heller - „als fast ausschließlich mündlich gebrauchtes Kommunikationsmittel durch Jahrhunderte hin überlebt ${ }^{\text {“96 }}$ habe. Dementsprechend dürftig ist auch die Überlieferungslage. ${ }^{97}$

Im uns bekannten zimbrischen Liedgut sind die geistlichen Lieder dominant vertreten. Zwar waren Latein und Italienisch die offiziellen Kirchensprachen, doch gab es offenbar Bestrebungen, religiöse Inhalte in der Volkssprache zu transportieren. ${ }^{98}$ Ein kurzer Auszug aus einem Lobgesang soll einen exemplarischen Eindruck dieser Art von geistlicher Dichtung geben (anbei die Übertragung von Heller):

Benne gherüstet

Dar Gott mit tuncheln

Bolchen, un veure,

Preghtet me Tondere, un volghet dear

Un vun me podeme

Auf bûûlt, un trûbet dez tiife mear;

Un béar di groozen

Urrane túmmele;

Un bear n'almaghtighen

Pallen arm z'inthalten ber guut un stargh?

Bear di hefteghen

Schitten ba fisarnt

Kent zu dem armuste

Baighen bear môegte inkeen, bizzan z'margh.

Net vun den Reghorsten

Houga vortraghe,

Net vun den starghen

Gighenten zouightigh koffertiga maght

Di aiseran rucken,

Di eckelne petten

Bia bôera iname binte

Bia bachs imme véure zorloent un zermaght.
Wenn gerüstet

der Gott mit dunklen

Wolken und Feuer

spricht mit Donner, gefolgt

von seinem Poltern erschüttert die Erde

und vom Boden aufgewühlt und trübt das tiefe Meer.

Und wer die großen

schrecklichen Getöse

und wer den allmächtigen

starken Arm einhalten kann, wer ist gut und stark?

Wer die heftigen

Blitze, die da zucken

und zur Armbrust werden,

wer kann weichen und ihre Grenzen wissen?

Nicht von den Rechten

hohes Erdulden,

nicht von den starken

Giganten zeigt sich die hoffärtige Macht,

die eisernen Rücken,

die stählernen Brüste?

Wie ein Nebel im Wind,

wie Wachs im Feuer vergehen und vernichtet werden. $^{99}$

Jenseits der zimbrischen Gebiete fand Dialekt auch im Dienste der unterhaltsamen Lehre, Erbauung und Ermahnung der christlichen Unterschichten ein breites Anwen-

95 Heller bemerkt zur Sprachform, sie könne „weder dem Alt- noch dem Mittelhochdeutschen zugeordnet werden, [sei] aber auch lange nicht in jeder Hinsicht neuhochdeutsch“ (Karin Heller: Barocke Dichtung aus den 7 Gemeinden: Zimbrische Texte aus dem 17. und 18. Jahrhundert. Wien: VWGÖ 1988, S. 1).

96 Ebda., S. 6.

97 Hinsichtlich des soziokulturellen Status der Sprache ist hier freilich mitzubedenken, dass das Zimbrische neben das Italienische zu stellen ist, während sich das Bairische im Kerngebiet von einem Standard (bzw. einer Schriftsprachennorm) abhebt, der nur skalare Unterschiede aufweist.

98 Heller, Barocke Dichtung, S. 6 f.

99 Edition und Übertragung zitiert aus: Heller, Barocke Dichtung, S. 62ff.; es handelt sich um die dort als Version B geführte Variante. Der Lobgesang ist, wie es einleitend heißt, 1796 in Asiago entstanden und dem dortigen Pfarrer Josef Strazzabosco gewidmet. 
dungsgebiet, vor allem im lyrischen Bereich. Beliebt war bei den Erbauungs- und Bekehrungsliedern eine duologische Anlage, die dem Rede-Antwort-Schema des Katechismus nachempfunden war, aber zwischen den beiden - zumeist bäuerlichen - Gesprächspartnern kein starkes Kompetenzgefälle konstruierte. So bleibt der theologisch-moralische Diskurs zwar selbstredend auf einer sehr simplen Ebene, erleichtert aber kontextuelle Orientierung, Identifikation und Nachvollzug. Mehrfach überliefert in handschriftlicher und gedruckter Form ist das folgende, wohl aus Oberösterreich stammende Lied, hier in der Variante einer Flugschrift aus der Sammlung Klier:

1

Willkomm mein liebä Leopold, Gott dank dä mein Hanns, hab di schon lang nicht g'sehä, jetz gehn mä miteinand, du mußt mä was sagn, ich bitt dich gar schön, wo dä rechte Weg in Himmel thut gehn, ich wär so gern droben, du kannst mäs nit glaub’n, dann weils mä auf dieser Welt nicht mehr thut taug'n. 2

Was fragst mi um den Himmel, wie soll i das verstehn, meinst leicht es ist ein Wirthshaus, daß mä grad kan eini gehn, wer den Himmelweg will suchä, allhier in dä Welt, der muß die Sünd verflucha, und thun was Gott gefällt, und Gott von Herzen lieben, und halten sein Geboth ein christlichs Leben führen, ja bis in den Tod. 3

Potz tausend liebä Leopold, ich merks schon an dir, du bist ä gewiß aina, der Gott von Herzen liebt, so thu mas noch sagen, und hilf mä aus der Noth, wie ich Gott soll dienä, und halten sein Geboth, und was die besten Werke seyn zum Himmel alsdann, vielleicht haben wir das Glück, das mä dorten kömmän z'samm. 4

Das will ich dir wohl sagen, merk auf nur mit Fleiß, und was die besten Werk seyn zur Seligkeit, das Bethen, das Fasten, das Allmosengeben, dabey must du führen ein recht reines Leben, dein Nächsten auch lieben, wies in der Schrift thut stehn, das ist der rechte Weg der in Himmel thut gehn. 5

Wil ich dir noch was vertraun, o liebä Brudä mein, es gibt viel Seelenraubä, das ist der böse Feind, die Tag und Nacht thun lauren, auf deine arme Seel, da must du wohl aufschauen, daß den Weg nit verfehlst, viel tausend seynd schon g'wesen auf dem rechten Himmelweg, seynd wieder irr gegangen, und kommen in die Höll.

6

Will dir abä was rathen, als ein gutä Freund, daß dir nit kann schaden der höllische Feind, nach Gott thu du lieben und ehren mit Freud, die lieb Mutter Gottes dein ganze Lebenszeit, die kann den Feind verjagen, mit ihrer starken Hand, daß er dir nit kann schaden, und kommst ins Himmelsland. 
7

Ich thu dir danksagen, mein Brudä Leopold,

die Lehr ist mir lieber als Silber u. Gold,

das will ich uns wünschen all zween miteinand,

daß mä in den Himmel dort kommen zusamm,

da wolln mä Gott loben und preisen allzeit,

die lieb Mutter Gottes in alle Ewigkeit. ${ }^{100}$

2,2 leicht] vielleicht, etwa 3,3 mas] mir es

Flugschriften mit dieser Strategie konnten sowohl im Sinne der weltlichen als auch der geistlichen Obrigkeit verbreitet werden. Im vorangegangenen Beispiel und weiteren stark moralisierenden Liedern wie Willikomm mein lieber Veit oder Gott griesti Bruedä veitl bleibt es beim Aufruf zu einem frommen Leben; wer sich vertrauensvoll in die Hand Gottes begebe und den nicht näher bestimmten ,Seelenräubern' ausweiche, werde von den himmlischen Mächten beschützt und belohnt.

Dass die Hinwendung zu einem allzu frommen Leben aber auch hinterfragt werden kann, zeigt ein anderes Beispiel aus dem Bereich mundartlicher Erbauungslieder. Wiewohl ebenso mit frommen Hintergedanken verfasst, zeigt das Pfarer Lieth aus dem 1742 verfassten ,Gesang Büechl' der steirischen Gewerkensgattin Maria Hasenhütl sowohl in seiner formalen wie auch in seiner inhaltlichen Struktur eine weniger von oben herab belehrende Ausrichtung. Inhaltlich schließt es gewissermaßen an das obige Lied an, wenn der Sänger berichtet, dass ihm die Mahnungen des Pfarrers einen solchen Schrecken eingejagt hätten, dass er nun schleunigst mit einem ,heiligen Leben` anfangen wolle:

1

Unßer H[err] Pfarer der hat mich derschröckht,

hat mier In ganzen Leib grimben Erwöckht,

wie Iich ihmb hab gebeicht

da hat Er mih geleicht

der doifel het mich schon

gott Behieth vnß daruon.

2

Er hat vnß den himmel Recht schen auß geffälierth,

daß Iich mit Lust wer Balt Einy gespazirth,

Er hat mier die höll hergenenth

wieß ä So grob Nicht Prend

wan mier Nä gueth wöllen Thän,

vnd Leben Rain.

3

Hiezt fangt ich daß Heillige Leben schon an

Strickh Kätten gaißel daß hab Iich auch schon

Puben döß armen Tropf

ich du Enkh auf dem Kopf,

100 Vier schöne Neue Lieder. Das Erste: Was willst du dich erheben, o Mensch du fremder Gast, etc. Das Zweyte: Willkomm mein liebä Leopold, Gott dank dö mein Hanns, etc. Das Dritte: Potz tausend das ist halt a Leb’n, daß so viel schlimmi Weiba thut geb’n, etc. Das Vierte: Ach, ach entweichet verliebte Gedanken, etc. Gedruckt in diesem Jahr. [Linz (?), ca. 1790], f. 2r-3r. 
weils ös mich offt auß gelacht

Ins Ellent Bracht. ${ }^{101}$

1,3 Iich] hier konsequent Schreibung mit Doppel-i für ,ich` 1,4 geleicht] erleuchtet, erläutert 2,1 ausß geffälierth] hier wohl: ,gefällig gemacht', ev. als Vermischung mit , ausgemalt 2,3 hergenenth] hier: her(bei) geredet, beschrieben 2,4 Prend] brennt 3,1 Hiezt] jetzt 3,3 döß] ihr 3,4 ich ... Kopf] ich scheiß auf euch, leckt mich am Arsch 3,5 ös] ihr

Dann allerdings wendet sich das Lied kritisch gegen die asoziale Überheblichkeit solcher Frömmler, die glauben, nunmehr andere nicht mehr nötig zu haben (Str. 4) und sich als Eremiten nicht mehr um den Lebensunterhalt kümmern zu müssen, sondern sich erhalten lassen zu können: „schenckhs Nur glath alles Mier / Iich Bett dorfier“ (5,5f.). Eine tatsächlich asketische Lebensweise aber („wurzel Esßen“, 6,2), auch das wird kritisiert, scheint dann doch zu beschwerlich. Die Moral am Schluss vertritt stattdessen einen pragmatischen Zugang: Man müsse nicht von der Welt Abschied nehmen, um ein gottgefälliges Leben zu führen. Wer gute Werke vollbringe und sie von Herzen meine, komme auch so in den Himmel:

8 Guete werckh Kan Man der haimb auch wohl Tain, won Mer Nur alles von herzen Recht Mainth dor ja Nicht Heillig Sein,

Kumb doch In himmel Ein, won Iich Nur Ckhristlich Tue ist ä schon genueg. ${ }^{102}$

8,3 dor] hier: darf, muss 8,6 ä] auch

Die durchaus genretypische Empfehlung der aurea mediocritas, die tätiges Leben und religiöse Hingabe nicht als Gegenteil begreift, kann freilich auch bereits als Reflex einer aufklärerischen Kritik am monastischen Wesen im Allgemeinen und an kontemplativen Orden im Besonderen verstanden werden, die im ,Klostersturm' kulminierte.

\section{Kritisch-Komisches zu Glaubenslehren, -leuten und -dingen}

Nicht nur christliche Motive werden gerne humoristisch verarbeitet, auch kirchliche Würdenträger, das Kirchvolk, liturgische Bräuche oder Glaubensinhalte finden mehr oder weniger konkret Eingang in Spottlieder, Humoresken und Satiren. Dabei reicht die Bandbreite von harmlos-heiterer Unterhaltung über kritische Auseinandersetzung bis hin zu beißendem Spott - wobei nicht vergessen werden darf, dass diese Texte zu einem Gutteil im und für das kirchliche Umfeld entstanden. Oft sind allerdings die jeweiligen

101 Steiermärkisches Landesarchiv, HS 1483 (Gesang Büechl Gehörrig Maria Vrsula Cordula Judith Haßenhietlin, ein geborne von Sulzberg Anno 1742), S. 47f.; leicht normalisierte Edition bei Wolfgang Suppan: Lieder einer steirischen Gewerkensgattin aus dem 18. Jahrhundert. Handschrift 1483 des Steiermärkischen Landesarchivs Graz. Graz: Selbstverlag des Historischen Vereins für Steiermark 1970, S. 23 f.

102 Steiermärkisches Landesarchiv, HS 1483, S. $49 f$. 
Gründe und Intentionen, weshalb die Ernsthaftigkeit unterminiert oder in Frage gestellt wird, nicht mehr festzumachen oder schwer nachvollziehbar; zuweilen aber sind es Anliegen, die mutatis mutandis auch heutzutage noch Thema sind.

In der Halberzwölffö Meeß etwa ist es das unangebrachte Verhalten der Kirchgänger, das ins Zentrum einer Sitten- und Zeitklage rückt. Die älteste bislang eruierte Handschrift von 1799 weist einen Johann Sichler als Schreiber aus; ob er auch Autor des Texts ist bzw. irgendeinen Bezug zur Problematik hatte, muss dahingestellt bleiben. Das Lied thematisiert auf heitere Weise, doch mit mahnendem Unterton den eingetretenen Sittenverfall der städtischen Kirchbesucher in „da jezing Zeit“. Im Wechselgespräch zweier Dorfbewohner, die sich gerade auf dem Weg in die Messe befinden, werden die Fauxpas bei Messgang und Messe lebhaft vor Augen geführt: mangelndes Interesse am Gottesdienst, regelmäßiges Zuspätkommen, Unruhe und Getuschel während der Messe oder auch unmanierliche Haltung. Zudem würde die Jugend die Messe vielfach vor allem dafür nutzen, nach Ledigen des jeweils anderen Geschlechts Ausschau zu halten. Dass der Gang zur Messe für manche offenbar tatsächlich vor allem im Zeichen der Unterhaltung und Geselligkeit stand, bestätigt sich auch durch einen Kommentar Franz Sartoris zu den Linzern und deren Gewohnheiten: In seiner Reisebeschreibung Neueste Reise durch Österreich ob und unter der Ens, Salzburg, Berchtesgaden, Kärnthen und Steyermark bemerkt er zu den ortsüblichen Vergnügungen, dass diese „Zwar noch etwas kleinstädtisch und gewöhnlich“ "seien, entschuldigt dies aber damit, dass es den Ortsansässigen schließlich an geeigneteren Optionen fehle. So bestünden die Unterhaltungen der Linzer erstens in Kulinarischem;

[e]ine zweyte Unterhaltung aber von ganz anderer Art ist die Messe Sonntags um halb zwölf Uhr in der Domkirche. Das schöne Geschlecht, oder was sich dazu rechnet, versammelt sich da, wird von den jungen Herren gesehen; da entwickeln sich Bekanntschaften, da werden Rendez-vous gegeben. ${ }^{103}$

Die Ausführungen Sartoris bestätigen spätere Überlieferungsträger, die das Lied in Linz situieren. Eine Vertonung für Streichtrio und Singstimme ist dem Bad Ischler Amtsschreiber Johann Michael Schmalnauer (1771-1845) zugewiesen. ${ }^{104}$ Die Textwiedergabe hier folgt der 1799 entstandenen Handschrift der Wienbibliothek:

1

Will kum mey Bruda Hannß!

wird nöt bald zeit int küra,

Grüß godt wie gehts dein Wey,

Ja Söbl heünt gehts führa!

was macht den aft das klain,

O! Mann dös macht ins zschaffa,

Dö ganze Nacht a gschrai!

Mir kinan kains nöt schlaffa.
2

Du Söpp mir müssn gehn!

Sunst möcht ma dMöß vasamma

Heünt hats a weng an Reif!

Und dord, und da a Rama

Du Narr so laß da zeit,

was dat ma so bözeiten,

Hat no not halbö gschlang!

Laß erst das Erstö leüten.

103 Franz Sartori: Neueste Reise durch Österreich ob und unter der Ens, Salzburg, Berchtesgaden, Kärnthen und Steyermark in statistischer, geographischer, naturhistorischer, ökonomischer, geschichtlicher und pittoresker Hinsicht unternommen. Wien: Doll 1811, S. 424.

104 7-strophige Fassung, Privatbesitz Christian Neuhuber. 
3

Aft ja wölln ma nu!

a Virtlstünd was kauschn! und von da jezing Zeit, waist wohl a wenig blauschn mörck aba auf aufs schlagn Das mir uns nöt vawaschen und öba von da Möß, Das löztö Trum da haschn. 5

Ja Bruda in da Stadt! da sagst da deini Wunda, wie viell kai Möß nöt herrn! oft klewa in an Sunda, Ja scha waies ichs selbn! wies oft a is scha gscheha, Erst kürzli wari trin! Ha meini Wunda gseha, 7

Es war ja no nöt auß, wanns fleisö datn betn, So haltns goschn zue, ma solt eins grad valetn, Da kimt öba daher, a-so a schopfats Miedl, Sie reist in schädl um, als gang a in an Schirrl. 9

Was ma da alles sicht, ma durt si grad valosn, Dort laint aina in ök, Hat Brazn in da hosn, Balt waglns mitn Fues, Balt dans indt taschn graiffa, Aft zerstens d=ofizier, Dant stadtn betn pfeiffa. 11

So geht do Möß zu End, mit lauda kumplimendn Wann i dat Tausent seng kam 20, a buech in händen, Da Rosn=Kkranz is e Zum bitn nima Modi, Das Hand werk wird auf tlözt, no ganz und gar marodi.
4

Halts den das für a Sünd, wann ma ra aizigs mall! zu spatt int Küra kamm, I sötz da mal den Vall! Da geistli war scha da, Eh das ma rai keman! Denn bey da jezing Zeit, Derf mas so hart nöt nöma. 6

Ja Bruda in da Stadt, is eh a Kumots Wösn, Um halwö zwölffo wird! Dä lözto Möß gelösen, Da kemans halt daher! Und dern sand gar viellö, A Hundert menigs mall, Erst nachn Evangöli.

\section{8}

Mit Menschan is recht aus! wies auf dö löding Kundn, Da weil i Jung bi gwöst! hab is a so nie gfundn, Kam sechans ain in Stull, Wies aba weng duet gschehn, ös bleim gley bey da Thür, Das alles kinnant sehn.

10

Wans zu da Wandlung kimt, Da duets mi recht vatroißen, Da hotzn dlimmeln da, wans datn Hasn schoissn, Als wans gott nöt wär werd, Das datn thaxen boia, Weil so gradt sari hamt, Ös dannt eins knie dazoia 12

Aft auf dö löding Bursch, und auf das lödi gsündl Sand menscha wie da Fux! wan aina macht an Schwindl, wann er si gschafti Tradt, $\mathrm{da}$ Schedl is ei budert, und eirm a weng a Spitz, Um dFozn uma pludent. 


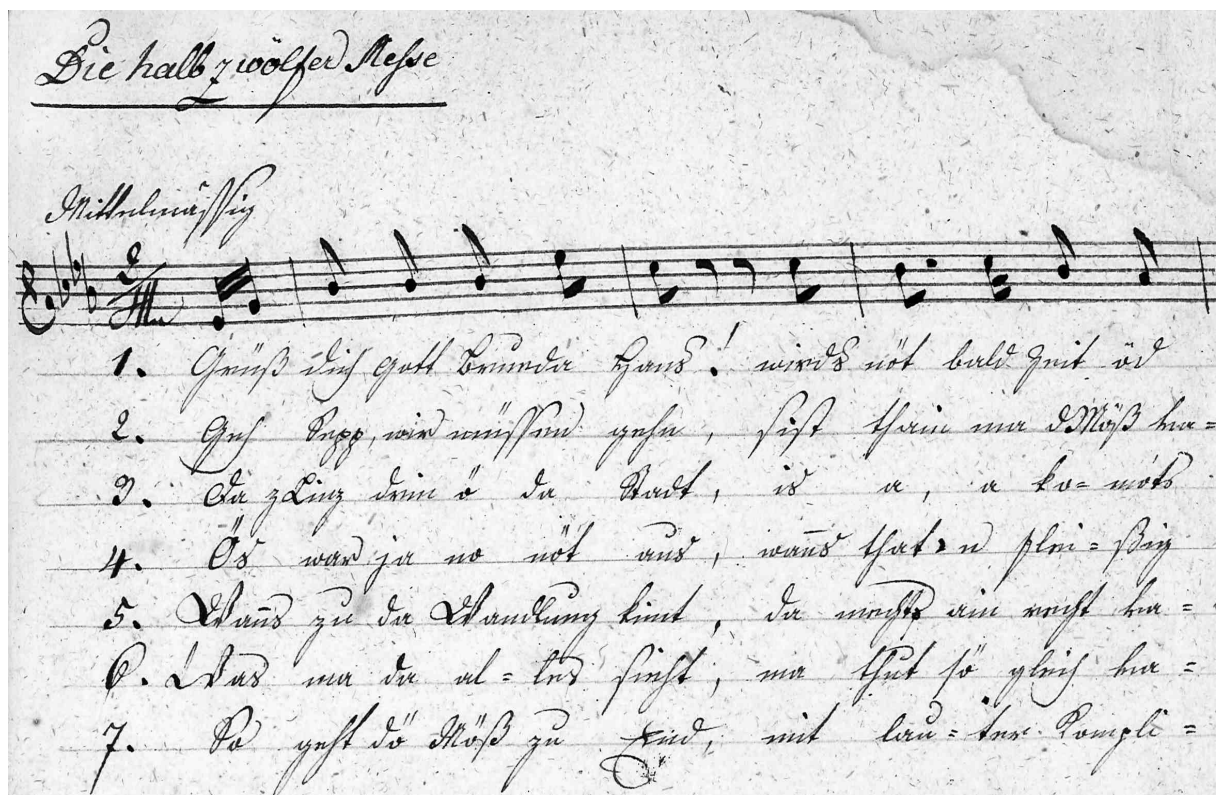

Abb. 4: Singstimme zu Schmalnauers Die halbzwölfer Messe (Privatbesitz).

13

Es is schan recht mey Bue,

Kain Bettbrudern zu macha,

Da zimt im zwischen den,

Stehtn ö a Mitl socha,

Den zwischn 1 und 2.

Steht alli mal a Punktn,

Das hani auf ar Uhr,

No allimall schier gfundtn.

15

Du loß ös hat in Dorf,

den aungblik halbi gschlaha,

Es wird nöt lang ansteh,

Da schoist da Pfahra aha,

Du laß mi zimt ös dannt,

in dorf drin zama leudtn,

Wann mir an stull wölln ham,

So gehn ma fey bözeiten. ${ }^{105}$
14

Wir selba is a Gall,

$J$ kas nöt zwöng bringa,

Das iso winsln soll,

und mitn händen ringa,

Ma ka ja in da still,

Recht auferbeuli betten,

den $s$ rauzn mai ni selm,

Hats wieda nöd vonetn.

1,2 küra] Kirche 2,4 Rama] Kruste, gefrorene Schmutzschicht 3,2 kauschn] kauschen: bellen, hier wohl: sich unterhalten 3,7 öba] etwa 4,2 ra] ein (a mit Sprosslaut r) aizigs] einziges 5,4 klewa] knapp, kaum Sunda] Sonntag 6,2 Kumots] angenehm, bequem 6,5 kemans] kommen sie 6,7 menigs mall] manchmal 7,3 goschn] Mund 7,4 valetn] verlöten, zulöten 7,6 schopfats] mit auffälligem Haarschopf, extravaganter Frisur Miedl] Kurzform für Maria 7,8 gang a in an Schirrl] als ginge er in einem Geschirr, als wäre er in ein Zuggeschirr eingespannt 8,1 Menschan] Mädchen, jungen Frauen 8,2 dö löding Kundn] die ledigen Kerle, Burschen 8,5 sechans] sehen sie 8,7 ös] sie (hier: Personalpronomen der 3. Pers. Pl.) 9,2 valosn] verhören 9,3 laint] lehnt 9,4 Brazn]

105 Wienbibliothek im Rathaus, H. I. N. 115053. 
Bratzen, hier: Hände 10,2 vatroißen] verdrießen 10,4 schoissn] schießen 10,6 thaxen boia] die Beine beugen 11,3 seng] sehen 11,4 kam] kaum 11,8 marodi] krank schwach 12,2 gsündl] Gesindel 12,3 menscha] Mädchen, jungen Frauen 12,5 gschafti Tradt] eifrig dreht 12,6 ei budert] eingepudert 12,8 dFozn] den Mund uma pludent] muss eig. „uma pludert“ heißen: herumflattert 13,2 Kain Bettbrudern zu macha] nicht den Frömmler zu spielen 14,2 zwöng] zu wenig 14,6 auferbeuli] auferbaulich 15,1 loß] hör, horch 15,2 gschlaha] geschlagen 15,4 schoist [... ] aha] schießt herab: eilt herbei 15,5 ös dannt] sie tun

Öfter noch als die Kirchgänger begegnet uns die Geistlichkeit in humoristischen Texten und aus unterschiedlichen Perspektiven. Schon der Entschluss zu einem klerikalen Leben gab hinreichend Material zur komischen Reflexion, standen den Vorteilen (sozialer Aufstieg, Sicherheit, geregelter Alltag) doch auch genügend Einschränkungen gegenüber. Weitverbreitet seit den 1770er Jahren ist etwa das Kandidatenlied Vetterl was willst geistlich werden, in dem ein Verwandter den jungen Probanden auf die Nachteile des Klosterlebens hinweist. In den letzten Strophen des Lieds, das uns im Liederbuch des Weingartener Konventualen Meingosus Gaelle auch mit Noten überliefert ist, werden diese ,Warnungen' wieder etwas zurückgenommen; dem ernsteren Zugeständnis, dass der Angesprochene seinen Weg gehen und , mit seinem Stand vergnügt' bleiben solle, steht allerdings auch am Ende die Trauer um den Verlust des Kameraden gegenüber.

1

Vetterl was willst geistlich werden denke doch es ist noch Zeit denke nach was für beschwerden dir das Klostr zubereit Must fast allweil singen bethen, schreyn, Studieren, fruh aufstehn, darfst nit brandeln und nit Labetten Must dafür in dMetten gehn.

\section{2}

Därfst kein grüenes gwandel tragen,

Schneiden dir dein Härl ab;

Därfst kein tänzel nimer wagen

Schaust grad aus als wir an Rab.

Wärst sonst recht ein Schönes büeberl und last dich a so verführn Hast in Wang zwey runde grüberl und Ein schönes hohes hirn.

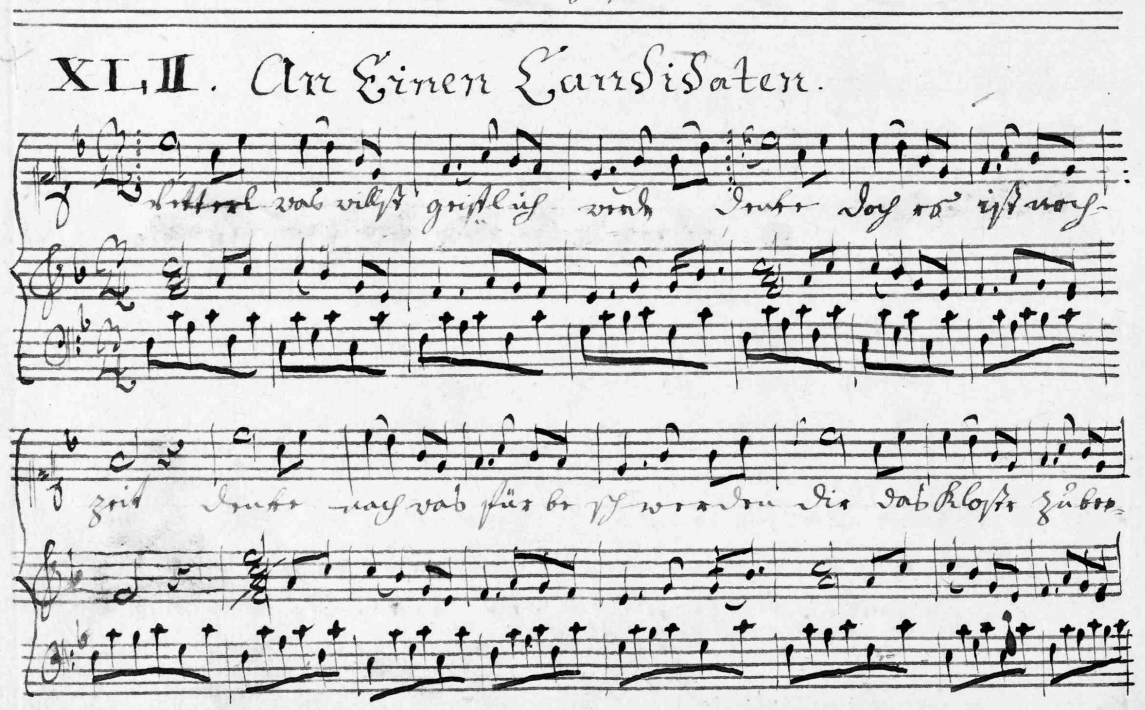

Abb. 5: Beginn von Vetterl was wilst geistlich werden (Österreichische Nationalbibliothek, Musiksammlung, Mus.Hs. 19029, f. 61v). 
3

Chor auskehrn und leichter butzen,

Scheiter tragn, und sindsla schaun,

Kutten, Kragen, und Kaputzen

Wird dir schmeken wie Alaun

Nähn dich ein als wie ein todten

darfst gar nicht mehr ausa gehn,

Mußt offt Essen auf dem Boden,

und als wie ein Narr da stehn.

5

Vetterl bhüt dich Gott, und bleibe

Stets mit diesem Stand vergnügt,

Halts Brevier vors rechte Weibe

Bis dein Seel in Himmel flügt,

Bhüt di Gott jez komt mir SRozen

Es verspringt mir schier das herz

Vor lieb macht i di jetz fotzen;

Geh doch es wachst nur mein Schmerz. ${ }^{106}$
4

Aber na bleib drinn beyn pfaffen, denn ich moas nu grad im Spoas, desswegn kannst uns doch angaffen Vetterl wünsch dir glück auf d'Roas. Thu gott recht von herzen lieben, Seine Mutter sey dein Brauth, Wans dich doch bis weiln betrüben, Friss von der Gedult das Kraut.

1,1 Vetterl] Diminutiv zu Vetter: männlicher Verwandter 1,7 brandeln] Brändeln: Kartenspiel 1,7 Labetten] Kartenspiel (von franz. la bête für den Einsatz beim Kartenspiel) 3,1 leichter] Leuchter 3,2 sindsla] schuldbewusst, klagend 3,4 Alaun] Kaliumaluminiumsulfat: Gerbe- und Beizmittel 3,7 offt] dann 4,2 moas] meine es 4,4 Roas] Reise 5,5 SRotzen] das Weinen 5,7 fotzen] schlagen, eine Ohrfeige geben

Weitaus deftiger formuliert der Lambacher Benediktiner Maurus Lindemayr (17231783) die Bedenken gegen einen Klostereintritt. Zur Zeit der Entstehung des Lieds (um 1755) war er als Prior seines Klosters zugleich auch Novizenmeister, der die Eignung der Kandidaten zu überprüfen und sie auf die anspruchsvollen Aufgaben vorzubereiten hatte. Mit seiner witzigen Weltabsage präsentierte er dem Konvent zur Faschingszeit eine Antithese der erwarteten und eingeforderten Ernsthaftigkeit. Denn nicht verschmähte Liebe, sondern bewusster Verzicht sollte der Entscheidung zum Zölibat zugrundeliegen, nicht die gescheiterte Suche nach einer Frau, sondern die aufrichtige Suche nach Gott. Umso komischer ist es denn auch, wenn sich die drastische Absichtserklärung des lächerlichen Kandidaten zunehmend als leere, jederzeit revidierbare Drohung erweist, sollte das weibliche Geschlecht doch noch Entgegenkommen signalisieren.

1

Leckts mön Arsch Menschä! iezt geh i davon,

Ös nächst böstö Klastä, das i nä trief an;

I will eintrettn, ös braucht gar nöt viel,

Weil mi kain ainzigi Sauhaut nöt will.

106 Österreichische Nationalbibliothek, Musiksammlung, Mus.Hs. 19029 (Das Unschuldige Vergnügen, Bestehend in LX Ausserlesten, Ernst und Schertz Haften, doch Jedesmal Sehr Eingerzogennen Lieder, gesammelt undt zwahr auff die Harpfen Eingericht undt Mäistens mit Neuen arien versehen, auch zu größerem Nach-truck mit zwey Violinen versterckhet von F. M. Gölle, der H. Gottes Gelehrtheit undt geistlichen Rechten Beflißenen, in saltzburg. Ihm Jahre MDCCLXXVII), f. 61v-62v [An einen Candidaten]. Abgedruckt in Emil Karl Blümml (Hg.): Die Liederhandschrift des Weingartner Benediktiners P. Meingosus Gaelle aus dem Jahre 1777. Als Beitrag zur Geschichte des geistigen und studentischen Lebens an der Benediktiner Universität Salzburg. Wien: Ludwig 1912. (Quellen und Forschungen zur deutschen Volkskunde VIII) S. 64f. 
2

O meini Menschä, wie mögts mi so plagn?

Hät eng vä Herzn gern, derfs gar nöt sagn,

Wann i ös Klastä geh, und wür vädamt,

Seids ös fein saubä dran schuldi insgsamt.

3

Menschä! gehts thuets mäs recht aufrichti sagn,

Obs mö denn recht für än Lappen wölts habn?

Wölts mi nöt liebm, und nue allweil fexirn,

Wird mi dä Toifel ins Klastä bald führn.

4

Menschä! gehts her da, stehts zam in ain Krais

Sinst is mit eng grad ä Tröck und ä Schais,

Wann i eng zwiedä bin, sagts mäs ins Gsicht

Das mi fein hintärucks kainö ausricht.

5

Menschä jezt thue i eng 's löztömal fragn:

Wölts mi no lieb habn? thuets aufrichti sagn;

Wanns mi no lieb habts, i bin no nöt hin,

Geht mä dä Klostägeist grads ausm Sinn. ${ }^{107}$

1,1 Menschä] Mädchen 3,2 Lappen] Lapp: Tölpel, einfältiger, aber aufrichtiger Mensch 3,3 fexirn] vexieren: necken, zum Besten halten 4,2 Schais] Furz 4,3 zwiedä] zuwider, widerwärtig 4,4 ausricht] ausrichten: (einen Abwesenden) schlecht machen 5,1 eng] euch

Auch Anton von Bucher - wie Lindemayr Geistlicher, doch weitaus systemkritischer und reformbewusster als dieser - war die Anwerbung Untauglicher für das klerikale Leben ein Dorn im Auge. Als Rektor der Deutschen Schulen in München war er mit der Neustrukturierung des Unterrichts nach der Aufhebung des Jesuitenordens betraut gewesen und hatte in der unheilvollen Vermengung von seelsorgerlichen und pädagogischen Aufgaben eines der zentralen Probleme sowohl des Mönchtums als auch des Bildungswesens erkannt, gegen das er in seinen antiklösterlichen Satiren anschrieb. Wie kaum ein anderer verstand es dieser Meister der parodistischen Funktionalisierung katholischer Gebrauchs- und Erbauungsliteratur, mit fingierter Nähesprachlichkeit falsches Bewusstsein aufzudecken, wie der folgende Ausschnitt aus einem Brief der Jungfer Katherl an ihren hochgeehrten Herrn Göthen belegt:

Neues weiß ich nichts zu schreiben, als daß wir Soldaten auf Execution hier haben, welche immer an mir zupfen und rupfen, mir seynd aber die Schreiber vom Pflegg'richt lieber, und unser Badergesell der Martl. Und daß ich ins Kloster gehe, weiß der H. Gödt schon. Der P. Maurus sagt, ich könne sonst nicht selig werden, weil ich dazu berufen bin. Er hat mir auch schon ein Jeserl geschenkt. Der Badermartl, hat mir aber nächst den Kopf abgebrochen aus Dalkerei, und ich muß es erst wider leimen lassen. Den Ring habe ich auch schon, und die Klosterfraun habn mich gern. Hat der Vatter nächst gsagt, gehe Diendl, gehn wir hinauf ins Kloster. Und da hab ich g'sagt, ja Vatter. Und hab das reich Mieder anglegt, und die reich Haubn aufgsetzt, und s silberne Gschnür gnommen mit den silbernen Ablaßpfening, und der coralinen Feigen, und hab mich schön aufputzt. und neben dem Halstüchl habe ich die rosenfarben Skapulierbändl herausschauen lassen, daß sie gesehen haben, daß ich eine Christinn bin, und dann hat der Vatter ein Faßl Wein und ein

107 Maurus Lindemayr: Dialektlieder. Kritische Ausgabe. Hg. und kommentiert von Christian Neuhuber. Bd. 1: Text. Wien: Praesens 2008. (Schriften zur Literatur und Sprache in Oberösterreich 13/1) S. 116f. 
wilds Fakl durch den G’selln hinaufgschickt, und etwas in einem Papierl für die würdige Mutter mitg'nommen, und hernach seynd wir hin aufs Kloster, und wies die Klosterfraun gsehn habn, wie viel unser seynd, ich, und der Vatter, und ein Fakl, und Wein, und fürn P. Beichtvatter Messen, nahher haben wir gessen, und truncken, grad gnug, und da habn wir gschnittne Nudl und eine Henn, eine Pastetten, Fleisch, Kraut, Karminadl drauf, Hühner, Hasen, Antn, Kopn, und hernach allerhand Gschnattlwerk, und da hat der Vatter gsagt, hörts auf, ich waiß ja nimmer wohin damit, müßt einem ia d'Wampen verspringen, und da habens g'lacht, und habn gsagt, ich brauch ohne dem einen Blasbalg, den ich soll s Orglschlagn lernen, und damits der H. Gödt waiß, jetzt lern ich das Orgelschlagn. ${ }^{108}$

Martl] Koseform für Martin Gödt] Taufpate Jeserl] Jesuspuppe als Kinderersatz für Nonnen Dalkerei] Dummheit nächst] vor kurzem Diendl] Mädchen Gschnür] Miederkettchen Ablaßpfening] vom Papst geweihter Schaupfennig (silbern für Höhergestellte) coralinen Feigen] aus Korallen geschnitzte Faust mit durch Zeige- und Mittelfinger gestecktem Daumen, am Geschnür befestigt zur Abwehr von Dämonen rosenfarbenen Skapulierbändl] (kleines) Skapulier: zwei mit Schnüren verbundene kleine Stoffvierecke, die als Symbol der Hingabe an Christus auf Rücken und Brust getragen werden; rot sind Passionsskapuliere Fakl] Ferkel Karminadl] Rostbraten Antn] Enten Kopn] Kapaun: Masthahn Gschnattlwerk] Geschnätzeltes, unbedeutendes, aus vielen Teilen bestehendes Zeug d'Wampen] der Bauch

Natürlich spielt Bucher hier mit den Klischeebildern von feisten Ordensleuten, die es sich auf Kosten ihrer Untertanen gut gehen ließen, ist die Überzeichnung doch wichtiges Stilelement seiner Polemik im Sinne der katholischen Aufklärung. Ins andere Extrem wird das Klosterleben in der sehr simplen Scherzklage Capucini verzerrt, die ein Vierteljahrhundert zuvor ein Klostergeistlicher vermutlich in der Gegend von Ingolstadt handschriftlich festhielt. Hier lamentiert ein Kapuziner über sein hartes Dasein, zumal über das schlechte Essen, das wohl auch für die im Refrain beklagte Flatulenz verantwortlich ist:

1

unser leben war schon recht, wans no nit war gar so schlecht. auwe, wie blats $\mathrm{mi}$, auwe, wie blats $\mathrm{mi}$. [...]

7

öpfl, birn, gersten, reis

ist fast unser täglich speis. auwe etc.

9

und dabey kein dropfn wein,

kint den a was schlechters sein.

auwehe etc.

[...]

15

an brokha brod, den gibt ma her

freß aina offt 3 mahl mehr.

auwe etc.
6

die bitschen bier, die war schon recht, die kost ist halt zimla schlecht. auwehe etc.

8

alleweil collation,

der magen will halt a nit dran. auwehe etc.

14

wassa trinckha no dazue, war uns boden sitzen gnue. auwe etc.

16

drauff soll ma schlaffen gehen,

kan ainer kaum aufn bainern stehen, auwe etc.

108 [Anton von Bucher]: Auserlesenes Delieberierbüchlein oder geistliches Suchverlohren. Von einem alten Klosterbeichtvater. Noch unverdorbenen Mädchen und Jünglingen ans Herzen gelegt. Mit Erlaubniß der Obern an kaiserlich. Grenzen. [o. O., o.V.] 1784, S. 92 f. 
17

es garzt da bauch a no damit,

er gibt die ganze nacht kain fried.

auwe etc. ${ }^{109}$

1,3 blats mi] bläht es mich 6,1 bitschen] Gefäß aus Kupfer, Zinn oder Blech mit Deckel und Henkel für den Transport von Flüssigkeiten 8,1 collation] wenig nahrhafte Zwischen- bzw. Abendmahlzeit während der Fastenzeit (vorwiegend Obst, Salat und Brot) 16,2 bainern] Beinen, Füßen 17,1 garzt] knarrt, knurrt

Wie nachhaltig oft die falschen Erwartungshaltungen der jungen Leute enttäuscht wurden, thematisiert Will mir selbst von herzen gönnen aus einer im Umfeld der Salzburger Universität entstandenen Handschrift aus Admont, wo ein entsprungener Novize die Vor- und Nachteile der verschiedenen Orden rekapituliert, um letztendlich zum Schluss zu kommen, nur mehr zum Trinken ein Kloster zu betreten:

11

Nun so seys, es ist schon gschechen,

bleibt darbey jezt für und für,

Klöster werdn mich wohl nicht sehen,

habm ein guetten frid uon mir;

soll ich ohne dem für müessen,

nichts uerredt, kehr donnoch zue,

und will die bekante grüessen,

bis ich mir hab gsoffen gnue. ${ }^{110}$

Aber auch bewährte Kirchenleute entkommen nicht der Häme dialektaler Spottlieder. Besonders lustvoll arbeiteten sich etliche an den rangniederen kirchlichen Autoritäten $a b$, mit denen der Gläubige vom Dorf im direkten Kontakt stand. So kannte man denn auch deren berufsbedingte Eigenheiten und menschliche Schwächen nur zu gut, manche liebenswert, manche unverständlich, manche ärgerlich. Freilich sind die Charakterisierungen zumeist allgemein und entkontextualisiert genug gehalten, um sie auf jeden beliebigen Gottesmann anzuwenden. Gern aufs Korn genommen wurden vor allem die Kapläne, dem Pfarrer unterstellte und oft auch ausgenutzte Hilfspriester.

109 Zitiert nach Emil Karl Blümml: Volkslied-Miszellen. In: Archiv für das Studium der neueren Sprachen und Literaturen Jg. 59 / Bd. 115 (1905), S. 30-66, hier 35f. (Universitäts- und Landesbibliothek Tirol, Cod. 980, f. 4r-5r).

110 Stiftsbibliothek Admont, Cod. 820, f. 7v. 
1

Buba, was schenkts mir wohl, wenn ich euch sagen soll, was vor ein brafer Mann unser Capalon, wärla ich schwör ein Eyd, darumma weit und breit, trefts mir kein solchen an, der so viel kan, glaubt nur er ist kein Narr taugt wohl in unser Pfarr, hat ein verschlagens Hirn, kan braf studiren, unser Capolo ist halt ein Monn wer mirs nicht glauben will, seh ihn drum an. 3 Wenn er uns predigen thut, macht er sein Sach so gut, als zu Zeit jedermann, fangt z'pflana an, er redt als so sehr, daß kaum a Wunder wär, wann er als selbsten hätt gestift $\mathrm{da}$ er trift,

sagt die nicht gut thun wollen, die wird der Teufel holen, weil sie aufs Fenstern gehn gar nichts verstehn, unser Capolon ist halt a Mann, der uns zum Guten recht predigen kan. 5

Bringt man a kleines Kind, ist der Capolon so geschwind, daß er des Adams Fleck gleich wasch hinweg, setzt sich hier noch gleich hin, zu der Frau Gevatterin, sagt wie mans Kind so wohl aufziehen soll, stellt man ein Creutzgang an, trottelt der Capolon voran, singt und schreyt grimmt das Maul stellt sich nicht faul unser Capalon ist halt a Monn der Pfarrer zu als brauchen kan. ${ }^{111}$
2

Wenn man in Kirchen tritt, gibt der Capalon kein Fried, fangt gleich an Hochs Amt an, kräht wie ein Hahn, so balds kommts zum Agnes Deh, kräht er in alle Höh, und biet uns täglich Brod, das uns ist Noth, wanns Amt vorbey ist, lauft er in aller Frist, geschwind in den Wald hinaus, um ein Ballen-Strauß, unser Capolon ist halt a Monn, er nimmt den Wedel in d'Händ und spritzt uns an.

4 Kommt einer zu der Beicht, da ist er als durchleucht, daß er uns Buben gibt so viel Lehr, muß einer Steiner seyn, wanns nicht ins Herz hinein gieng wie ein Donnerkeil sein Ohr hinein, wann wir von Menschern sagn, will er uns gar naus jagen, wann wir nur rauschig seyn thut er gleich grein, unser Capolon ist halt a Mann, der uns in Beichtstuhl recht herkampeln kan. 6 Hält man a Karten-Spiel ist Capolon nit zu viel, wann er so straffen thut, er spielt gar gut, wann er ein Rehbock macht, das Herz im Leib ihm lacht, zieht hortig Geld hinein, sagt das ist sein, wann er was gwunnen hat, behält ers nicht über Nacht, fängt gleich ein anders Spiel an in der Still, unser Capolon ist halt a Mann, der zu Zeit Karten Spiel recht mischen kan.

111 In der handschriftlich überlieferten Fassung des Stubenberger Gesängerbuchs heißt es hier, dem Vers- 
7

$\mathrm{Na}$, na, mein Herr Capolon

ihr seyd a solcher Monn,

den ich letzten muß

fallen zu Fuß,

und bitten um Pardon,

daß ich im Himmel komm

wär mir der größte Spaß,

wann ich schon drinnensaß,

hab ich euch unrecht gethan

verzeyht mirs Herr Capolon,

seyd sonst ein grosser Herr

in eurer Lehr,

unser Capolon

ist halt a Mann,

den ich bey meiner Treu

nicht feind seyn kan. ${ }^{112}$

1,4 Capalon] Kaplan 1,5 wärla] wahrlich 2,5 Agnes Deh] (lat.) Agnus Dei (Lamm Gottes) 2,8 das uns ist Noth] hier wohl in ironischer Weise verwendet: das wir notwendig haben 2,12 Ballen-Strauß] hier als bildliche Bezeichnung für den Weihwasserwedel 3,4 z'pflana] zu flennen, zu weinen 3,7 als] hier: alles 4,16 herkampeln] kampeln: kämmen, d. h. hier etwa: ,den Kopf waschen` 5,3 Adams Fleck] bildlich für die Erbsünde; die Taufe ist das ,Hinwegwaschen' des Adamsflecks

Ob in diesem Lied mit seiner gstanzlähnlichen Metrik die Tätigkeit des Kaplans bei aller Hänselei anerkennend hervorgehoben werden soll oder ob auch die scheinbar lobenden Passagen nur ironisch gemeint sind, ist schwer zu sagen. Eindeutig desavouierend ist zumindest der Bericht über die Spielfreudigkeit des Kaplans; auch im Zusammenhang mit seinen Predigten wird impliziert, dass dieser die Untaten, die er so bewegend schildert, wohl selbst begangen haben muss. Bezeichnenderweise sind in einer Variante aus der Ebermannstädter Liederhandschrift genau diese Passagen ausgespart und andere spöttische Wendungen deutlich entschärft. ${ }^{113}$ Die Überlieferungssituation des Lieds legt nahe, dass es bereits im zeitgenössischen Kontext für unterschiedliche Aussagen funktionalisiert wurde, sowohl als liebevolle Neckerei als auch als boshafter Spott.

Explizite Personalsatiren auf Geistliche haben sich - nicht nur in der Dialektkunst selten schriftlich erhalten oder wurden durch Tilgung der betreffenden Namen entschärft. Wäre nicht einer der späteren Kopisten indiskret gewesen, wüssten wir auch nicht, dass Was habts halt von än gwissen Herrn aus der Feder des Stadlschreibers Peter

schema besser entsprechend: „den der Herr Pfarrer, zu als brauchä ka“ (Bayerische Staatsbibliothek, Cod. germ. 7340, Teil 2, S. 123).

112 Sechs schöne gantz neue Weltliche-Lieder, Das Erste. Adjeu mein Engels Kind, ich muß etc. Das Andere. Ach, ach! meine liebe Mutter wann etc. Das Dritte. Brich Felsen entzwey, entzwey, spreng etc. Das Vierdte. Buba, was schenkts mir wohl, wann etc. Das Fünffte. Nur lustig, nur lustig, ist allweil etc. Das Sechste. Nun mein Herz ist mir erlaubet, dir etc. Gedruckt in diesem Jahr [o. O., um 1770].

113 Vgl. Rolf Wilhelm Brednich/Wolfgang Suppan (Hg.): Die Ebermannstädter Liederhandschrift geschrieben um 1750 von Frantz Melchior Freytag Schulrektor zu Ebermannstadt (Staatsbibliothek Bamberg Msc.misc. 580a). Deutsches Volksliedarchiv Freiburg. Kulmbach: Freunde der Plasseburg E.V. 1972. (Schriften für Heimatforschung und Kulturpflege in Ostfranken 31) S. 99f., hier 99. Die Vermutung von Brednich/Suppan, dass das Lied ein in Ebermannstadt verfasstes Gelegenheitsgedicht sei und tatsächlich auf einen beliebten Kaplan Bezug nehmen könnte (vgl. S. 22f.), muss zumindest angezweifelt werden. 
Gottlieb Lindemayr (1741-1799) auf den streitbaren Traunkirchener Pfarrer Mathias Stiebinger (1724-1802) gemünzt war, der sich im Kammergut großer Beliebtheit erfreute, doch bei den Obrigkeiten wegen seiner Grobheiten und Leidenschaft für das illegale Fischen im schlechten Licht stand:

1

Was habts halt von än gwissen Herrn

Nöt für ä Gschrai und Löbm?

Als wanns seins gleichä nah und fern

Nöt thät auf Erden göbm?

Ös iß schon wahr, er ist ä Mann,

Der ain oft untähalten kann;

Allain, was I nöt lob,

Iß das: - dä Mann iß z'grob.

3

Mä mag hah odä niedä sein,

Mär iß von iehm nöt frei.

Ös dunkt mi schier, ä bildt iehm ein,

$\mathrm{Daß}$ ain ä Gnad no sei,

Wann er bo seinä Leiern bleibt,

Und schimpft, und trinkt und endli speibt.

Wo iß denn da ä Lob?

Nä ä, das iß mä z’grob.

5

In Kammäguet (I sag nä grad)

Da bethens iehn fast an;

Wer immä was väbrochä hat,

Dem is ä sein Patran:

Sagts Oberamt nöt freundlä ja,

So iß ä mit sein Schimpfen da;

In ain vädient ä s'Lob,

In andern is ä z'grob.
2

Zum bösten gehts iehm dort von Mäl,

Wanns Köpfel waräm wird;

Da daurt äs zwar ä gueti wäl,

Ä jödä wird schimpfirt;

Da schont ä ga kain Menschen nöt,

Was iehm is Mäll kimmt, iß ä grödt:

Vädient denn das ä Lob?

Nä ä, der Mensch iß z'grob.

4

Was afä z'lobm is, sag I ä;

Zum Fischstehln kann ä guet.

I glaub nöt, daß ainr z'finden wä,

Der iehms da nachhi thuet.

Ä Fischä iß er, das iß wahr,

I sags, er iß mit Haut und Haar;

In dem göbührt iehms Lob,

Zum gspaisseln iß ä z’grob.

6

Da habts mei Mainung ohni Scheu,

Wie I von Pfarrä denk;

Er macht in seinä Narräthei

Schon iebel gueti Schwenk;

Zum öftern abä grathens nöt,

Drum röd ihs no, und hans schon grödt,

Vo mir hat Er kain Lob;

Warum? ä kimmt mä z'grob. ${ }^{114}$

1,2 Löbm] Leben, (hier:) Lärm, Aufheben 2,1 Mäl] Maul 2,2 waräm] warm 2,3 wäl] Weile 2,4 schimpfirt] schimpfieren (latinisierend zu schimpfen) 3,1 hah] hoch 3,6 speibt] speien: hier wohl nur bildlich gemeint für den Wutredeschwall 4,8 gspaisseln] Spaß treiben, einen Streich spielen 5,1 Kammäguet] Kammergut: Gebiet, das sich vom Koppental bis zum Nordende des Traunsees bei Gmunden erstreckt und als große, mehrfach unterteilte Grundherrschaft der landesfürstlichen (habsburgischen) Finanzverwaltung (Kammer) unterstand 5,4 Patran] Patron, Fürsprecher, Schutzherr 5,5 Oberamt] Salzoberamt, Verwaltungszentrale des Salinenwesens in Oberösterreich 6,4 iebel] manchmal, ab und zu Schwenk] Pl. zu Schwank: lustiger, oft auch boshafter Streich

Doch nicht nur in direkten Charakterisierungen bot die Geistlichkeit Unterhaltungswert; ein weites Betätigungsfeld war die indirekte Komisierung in der Interaktion mit den Schäfchen der Kirchengemeinde. Maurus Lindemayrs Scherzlied Hätt nöt glaubt daß's Kinätäfä schildert uns etwa eine Taufe von den Vorbereitungen der Zeremonie bis zur Bezahlung der Stolgebühr aus der Sicht eines bäuerlich-naiven Ich. Dass Teile der zeremoniellen Handlung für die Anwesenden damals unverständlich blieben, kann nicht verwundern, war diese doch vorwiegend in Latein gehalten. Nach altem Ritus empfängt

114 Peter Gottlieb Lindemayr: Lieder in oberösterreichischer Mundart. Kritische Erstausgabe. Hg. und kommentiert von Christian Neuhuber. Wien: Praesens 2010, S. 84-86 bzw. 299-302. 
der Priester den Täufling an der Kirchentür, lässt sich den Namen nennen und beginnt die exorzistischen Handlungen, durch die der Täufling aus der Macht des Bösen befreit werden soll, mit Exsufflatio (Aushauchen des unsauberen Geistes) und Insufflatio (Einhauchen des Hl. Geistes). Nach dem Bekreuzigen des Kinds auf Stirn und Brust legt der Pfarrer ihm die Hand auf, segnet das bereitgestellte Salz und gibt etwas davon in den Mund des Täuflings als Symbol der Weisheit. Dann legt er das Ende der Stola auf das Kind, berührt dessen Ohren und Nase mit Speichel und spricht,effata' (,öffne dich'), um deutlich zu machen, dass es offen sein soll für das Wort Gottes. Die Paten schwören nun stellvertretend dem Satan ab, dann salbt der Priester mit Katechumenenöl Brust und Nacken des Täuflings. Nach den Glaubensfragen, die die Paten beantworten, gießt der Priester gesegnetes Wasser dreimal in Kreuzform auf das Haupt des Kinds und spricht die Taufformel. Dann salbt er betend dessen Scheitel mit Chrisam, legt ihm ein weißes Leinen als Zeichen der wiederhergestellten Unschuld um und reicht dem Täufling eine Kerze mit dem Auftrag, das Licht des Glaubens stets leuchten zu lassen. Etliche dieser zeremoniellen Punkte werden in Lindemayrs Lied recht genau dargestellt, doch im Blick des Bauern komisierend umgedeutet. Nicht den Symbolwert, sondern allein den praktischen Nutzen des Lichtspendens sieht er in der Taufkerze, noch weniger kann er sich die apotropäischen Handlungen der Teufelsabwehr erklären. Das Salz wird mit Schnupftabak verwechselt und die Salbung als ebenso sinnlos eingeschätzt wie die vielen Gebete und Segenssprüche. Kein Wunder, dass den bäuerlichen Sprecher die 15 Groschen für das unverständliche Procedere schmerzen.

1

Hätt nöt glaubt daß's Kinätäfä

Brauchät so viel Narredey,

Z’ersten mueß dä Mößnä läfä

Umä Liecht, was thuet's dabey?

Kunten 's Kind ä so wohl kennä,

Ob s' ä Mädl odär Bue,

Mein! was hilft dös Körzen brennä

Bän hellichten Tag dazue.

3

Aften thuet ä's Kind āblasen,

Maint vielleicht ös hat sih brennt,

Übän Kopf und übä d' Nasen

fahrt ä Kreuzweis mit dä Hend.

Mein, was braucht's denn soviel Sachä

Mögts eng so lang schern dämit

Dörft's nöt soviel Kreuzl machä,

's Kind iß ja kain Tiofl nit.

5

Thät als wie viel außä lösen

Aus än Buech, aft blättlt är um,

Mein! was brauchts den soviel Wösen?

's Kind dös waiß ä so nichs d'rum.

Kunten ja gar viel auslassen,

Wohl den halben Thail ungfähr,

's Kind kanns ja ä so nöt fassen,

Wanns schan zöchä Jahr alt wär.
2

Mä thät sih nöt gar lang b'sinnä,

Dä Herr Pfarrä lögt was an,

Iß kain Pfaid, sänd Falten d'rinnä,

Daß ih's halt nöt nennä kann.

Und däzue ä langi Guerten

Wirft är umä Hals ganz g'schwind

Sagt bald d'rauf mit kurzen Wurten:

Gfadä! wie soll haißen 's Kind.

4

Er thuet sich ä nöt lang b'sinnä,

Giebt 'n Kind än schnopftabäck,

Hat was in än Büchsel drinnä,

Und greift's hinten an bän Gnäck

's Kind angschmiert, soviel ih g'sehä,

Äf dä Brust, und hintän Hals,

Und das wär ä ganz gschwind gschehä,

Thäts abwischen wider alls.

6

Und dort stund schan äf än Tischl,

Nichs als d' Wahrhait sagen thue

Gar ä schöni liechti Schüßl,

Dö wär ä schan g'richt dazue.

Und da habns halt Wassä gossen

Übän Schedl grads 'n Kind;

Iß dakemmä, hats vädrossen

Hat anghöbt zän wainä gschwind. 
7

's Greßl, 's Pfaidl gschwind hernemmä

's Kind umdräht, und s Liecht öd d Hend

Hat's dä Gfadä käm bekemmä,

Hat dö Kindstäf schan än End.

Han mäs aufschreibn lassen müessen,

funfzöhn Groschen wär dä Lohn,

Zöhn dä Pfarrä hat zu gniessen,

Fünf dä Meßnä trait dävon. ${ }^{115}$

2,3 Pfaid] Hemd sänd Falten d'rinnä] gemeint ist das Chorhemd (Rochett), ein hüft- bzw. knielanges weißes, gefälteltes Obergewand 2,5 lange Guerten] Stola, schalartiges, knielanges Kleidungsstück als Zeichen des priesterlichen Amts; der Priester trägt Talar, Chorhemd und Stola bei der Sakramentspendung 2,8 Gfadä] Taufpate wie soll haißen 's Kind] die Frage nach dem Namen des Kindes beim Empfang an der Kirchentüre ist erster Teil des Taufritus 3,1 āblasen] ab dem 4. Jh. für Kindertaufen belegtes Ritual 4,2 schnopftabäck] gemeint ist das geweihte Salz 4,5 's Kind angschmiert] Salbung mit dem Katechumenenöl 5,8 zöchä] zehn 6,7 dakemmä] erschrecken, Angst bekommen 6,8 anghöbt] anheben: anfangen, machen 7,1 Greßl] zwei Deutungen möglich: 1) Chrisam (Salböl), 2) Krösenhemd (Taufhemdchen) 's Pfaidl gschwind hernemmä] nach der Chrisamsalbung wird über den Täufling ein weißes Taufhemd gelegt als Zeichen der wiederhergestellten Unschuld 7,2 s Liecht öd d Hend] zum Abschluss der Feier wurde dem Täufling eine Kerze übergeben mit dem Auftrag, das Licht des Glaubens stets leuchten zu lassen 7,8 trait] trägt

Eine sehr dankbare Konstellation für humoristische Effekte ist auch das prekäre Vertrauensverhältnis in der Beichtsituation. Denn bei diesem formalisierten Vieraugengespräch mit dem Ziel der Absolution können aufgrund der verbindlichen Geheimhaltung Verfehlungen ausgesprochen werden, die im Alltagsdiskurs nicht ohne weiteres thematisiert würden. So wird der Zuhörer in diesen Liedern zum Ohrenzeugen von Peinlichkeiten, mangelnder Reue und verweigerter Wiedergutmachung, ja von bewusster Provokation des Priesters, dem lustvoll jene Dinge unterbreitet werden, denen er entsagen soll. In Der beichtente Baurens Knecht, erstmals in einer klösterlichen Sammelhandschrift überliefert, ist es tatsächlich ein Zwiegespräch, in dem der Knecht testet, wie weit er in seinen Geständnissen gehen kann, und der Kaplan mit Zureden, Drohungen und schließlich Zusagen dem Beichtkind den vorgeschriebenen guten Vorsatz abzunötigen versucht:

1 Der Knecht.

Herst dus Kaplan,

will dir mein beicht vertrauen, mörck auf thue fleissig schaun; was ich hab than, es ist mä laid das ich fast alli Tag, so viel I kinna hab, geschwört auf mein Aid I wolt ä gern mehr sagn, fürcht, mögst mi schlagn drum I dich Bitt, erzürn dich nä nit.
2 Der Kaplan.

Hertzliebstes Kind, wann du zur Beicht willst gehn, muest alles fein redlich bstehn und zeigen an, was du hast gethan, sonst wird es gelten nit, auch nur ein falscher Tritt vor gottes Thron. Mein sag wie lang ists her, das du hast Beicht nicht mehr Bsinn dich nur wohl, Beicht wie es sein soll.

115 Lindemayr, Dialektlieder I, S. 83-87. 
3 KNeChT.

Ja Lieber Herr

fertn in Habän Bau,

seither halt hanni schau,

Beicht halt nöt mehr,

das waiß I wohl,

das I fast alli tag

wie i nur kinä hab,

gwösn sternvoll,

bin oft aufs gäsßl grennt,

die Boßheit hat mi brent

gib mir ä lehr,

kans lassn nöt mehr.

5 KNeCht.

Hab mirs wohl denkt,

du frätschelst gwis so lang,

bist mä magst Angst und Bang,

das hat mi kränckt,

was fang I an,

Das I mit schenä Ehr,

vor iehm weit drausn wär,

heut käm davon.

wen i thät mehrä sagn,

kunst ain wohl gar dä schlagn,

weilst bist so köck,

und schaft ain wöck.

7 KNECHT.

Ja Liebä herr,

mein Diendl is so schön,

wans mä dät wockä gehn,

füels mä halt schwer

göstern auf $\mathrm{d}=\mathrm{Nach}$,

sag dir's gley ohnö scheu

hat mä dö Höppin

3 Küechl haim bracht,

mey sag, wie wä halt dir,

wans ä so käm zu dir,

gelt, halt fein gschlecht,

es wär dir ä recht. ${ }^{116}$
4 Kaplan.

Last du es nöt,

so zieg nur aus die Schue

und lauf der Höllen zue,

Bist schon gericht

solst sein so köck,

solst sagn, kans lassen nit;

hast noch so schlime Sit,

scher dich Hinweck.

Verspricht kein Besserung mir,

es ist schon aus mit dir,

Bist schon verwirt,

wirst nicht absolvirt.

6 Kaplan.

Hertzliebstes Kind, wie bist so gar verblendt

von guetn abgewendt,

wie bist so blind,

Dich nur Bekehr

must dann gleich lauffen forth

ich will kein Wort,

dir geben mehr.

hast gsindigt noch so groß,

will ich dich machen los,

wanst nur nit mehr,

sündigst wie vorher.

1,7 i kinnä] ich können 1,8 auf mein Aid] äußerst beliebter bäuerlicher Beteuerungsausspruch 1,9 ä] auch 1,12 nä] nur 3,2 Fertn] letztes Jahr in Habän bau] beim Haferanbau (um April) 3,3 hanni] habe ich 5,2 frätschelst] redest 5,3 mä] mir 5,10 dä schlagn] erschagen 7,3 mä dät] mir täte 7,7 Höppin] Kröte (derbes Kosewort)

Derber gibt sich Marcellinus Sturms Reumüthige Beicht des sterbenden Falotten Jackl, der - angesichts des Todes von Gewissensbissen geplagt - in einer confessio vitae dem rasch herbeigeholten Kapuziner sein gottloses Leben Revue passieren lässt. Dass erst die unmittelbare Angst vor der Hölle in der Fiktion diese Besinnung auf die erlösende Kraft der Lebensbeichte bewirkte, zeigt sich nicht zuletzt im nur schlecht unterdrückten Stolz, 
mit dem die Schandtaten vorgetragen werden. Letztendlich war es ja ein erfülltes Leben in vollen Zügen, ohne Rücksichten und Verbindlichkeiten. Ob Jackels Vertrauen auf die Absolution und Gottes Gnade berechtigt ist, sollte wohl jeder Rezipient für sich selbst entscheiden:

7

I war durchaus koan Teuxel nutz

Schon in mein jüngsten Tag'n!

Wie oft hab I mein Vodan z'trutz

Mein Mueda in d'Fressen g'schlagn!

Es traut mir a koa Bue nöt z'viel,

Koa Diendl nöt von weiten;

Denn wenn d'Brennessel brenna will,

Brennts g'moaniglich bei Zeitn.

10

Ja Herr! I bin a Pürschel g'we'n,

A Mändl, Rutteng'sund.

Dies mueß die ganze Gegend redn,

So voll, so stark, so rund!

Ich machte Kreuzspring wie a Hecht,

Sah aus wies ewig Leben,

Hab wie a Bürstenbinda zecht,

Wos guets brauns Bier hat gebn.

12

An Kräften war I wie a Bär,

Und wie der Teufel keck;

Namm Alls gleich bei der Bürsten her,

Drosch neunmal auf ein Fleck.

Der Schergenschwanz hat früh und spat

Mein Lebenslauf beluchst;

Drum hat da Pflega ohne Gnad

Mein Beutl oft gottlos g'fuchst.

14

Es ist mein Seel a Schand und Spott

Wie mich dieß Fleisch hat g'juckt,

Drum bin I üba s'sechst Gebot

Oft wie a Sau eingruckt.

I hätt mein Landsherrn vor mei End,

(Herr Pater! ich läugn' es nicht:)

Mit tausend Lust, a Regiment

Selbst g'macht und selbst aufg'richt.
8

Das Schulgehn hat mich, wie den Hund

Das Hachellecka g'freut;

Denn da war mir a halbe Stund

A ganze Ewigkeit.

Dieß bracht mein Lehrer g'walti in d'Höh;

Er hätt' mi bald dawürgt,

Drum hat vom ganzen A. B. C.

Mein A - das meist sich g'mürkt. [...]

11

Hab I's Wirthshaus amal daschmeckt,

Da blieb I fest wies Pech;

A halbe Sud hat oft kaum kleckt,

Mein Oad, das gab a Zech!

Denn alles hatte z'saufa gnueg;

Niemd hats ein Haller kost;

Jetzt zittert mir beim Wasserkrug

Das Herz im Leib vor Frost.

13

Ich hab aus Lieb zum Müßiggang

Um koan Vodienst mich b'strebt;

Und, wie da Letzenbeda, lang

Selbst vo mein Mitteln g'lebt.

Habs ganz Jahr a koan eigna Herd,

Ja wohl, an Ehestand denkt!

Doch s'Nächsten Hausfrau oft begehrt,

Und viel an d'Huren g'henkt.

15

A Lump, der seines Gleichen sucht,

War ich bei Tanz und Spiel:

Hab gleich Kreuz Tausend Sacker g'flucht,

Gings nöt recht auf mein Mühl.

Hätt mancher s'Geld das ich verlor,

Selbst bei dem besten Trumpf!

Er krieget g'wiß, trotz Eselohrn,

An g'scheidtn Docktastrumpf ${ }^{117}$

7,1 Teuxel] Teufel 7,5 koa] kein 7,8 g'moaniglich] gemeinhin, im Allgemeinen 8,2 Hachellecka] das schmerzhafte Lecken an der Hechel, einem brettförmigen Arbeitsgerät mit scharfen Metallspitzen zum Durchziehen und Reinigen des Flachses 8,6 dawürgt] erwürgt 10,2 Rutteng'sund] gesund wie eine Aalraupe, Quappe (Süßwasserfisch) 10,5 Kreuzspring] Kreuzsprünge: akrobatische Sprünge 11,1 daschmeckt] scherzhaft für: gefunden 11,3 Sud] Pfütze, Lache kleckt] gereicht, gelangt 11,4 Mein Oad] bei meinem Eid (Beteuerungsformel) 13,3 Letzenbeda] Spottname für Müßiggänger (?) 15,8 Docktastrumph] verbrämte Ehrenbekleidung, Rektormantel

117 Sturm, Lieder zum Theil in baierischer Mundart, S. 48-50. 
Noch deutlich schamloser ist das Aloys Blumauer zugeschriebene Beichtlied Herr Pater! recht an's Gader an, dessen blasphemische, vor allem aber erotische Provokationen im Kapitel 7 vorgestellt werden.

Einen Blick auf den Alltag hinter Klostermauern ermöglicht der gelehrte Innsbrucker Ex-Servit Karl von Güntherode (Günderrode, 1740-1796) in seiner von der französischen Aufklärung inspirierten Polemik gegen die legislative Tätigkeit des Papsttums in Das römische Gesetzbuch. ${ }^{118}$ Um die Lächerlichkeit obrigkeitlich verordneter Sühneprozeduren offenzulegen, führt der abgesetzte Universitätsprofessor für Kirchengeschichte ein Beispiel für die Beichtroutine in einem Tiroler Konvent an, die sich in der Auflistung von Banalitäten ad absurdum führt. Seine besondere Perfidität erhält dieser anekdotische Bruch des Beichtgeheimnisses durch die ausgiebige Verwendung des geschickt eingesetzten Dialekts:

Alle Wochen ein- oder zweimal (es ist festum ad libitum) ruft der Prior mit dem Conventglöck-
lein das ganze Kloster zusammen, hält ihnen im Kapitel, oder im Refectorio, eine kernhafte Rede,
in welcher fürchterliche Apostrophen an den leidigen Satan vorkommen, und sodann muß ein
Mönch nach dem andern seine Schuld bekennen, die vielgeliebten Layenbrüder machen den An-
fang, z. B. Erewerdn P. Prior, i bekenn demüthig mein Schuld. I bin unwillig und zornig g'wesen,
schleißig in meiner Arbet, die Lockathür stark zuegschlagen, mit die Augen hin und her g'schaut,
neulich a Gabl übern Tisch abigschmissen, epes gloapetz verschitet, und mit die Reverender Pater
grob g'wesen. Von diesen und dergleichen Schulden klag i mi an, versprich mit der Gnad Gottes
zu bessern, und bitt Erewerdn P. Prior um a heilsame Bueß. Der Prior gibt ihm zur Antwort, wie
folgt: Vielgeliebter Bruder! seitz do in Gottsnamen nit gar so entsetzlich grob, es klagen alle Pater
über enk, es miet wissen, daß zwischen enk, und zwischen an Pater an Unterschied ist. Zu enkerer
Bueß demnach bettetz zu Ehren der Muetter gottes, auf daß sie dieses ehrwürdige Convent von
der Feuersbrunst bewahren wolle, 3 Vater unser und 3 Ave Maria ausgespannter im Refectorio. ${ }^{119}$

Kapitel] Kapitelsaal: Versammlungsstätte einer klösterlichen Gemeinschaft Refectorio] Refektorium: Speisesaal eines Klosters Erewerdn] Ehrwürden schleißig] nachlässig Lockathür] (Verballhornung zu lat. locus: Toilette, Abtritt) Toilettentür abigschmissen] hinuntergeschmissen epes] etwas gloapetz] Schmieriges, Klebriges Reverender Pater] (Verballhornung zu lat. reverendi patres bzw. reverendus pater) ehrwürdigen Patres seitz do] seid doch enk] euch miet] müsst ausgespannter] mit ausgespannten Armen (als zusätzliche Buße)

Dem Sakrament der Beichte kommt im Christentum insofern eine besondere Bedeutung zu, als sich dem Menschen erst durch die Vergebung der Sünden in der Gnade Gottes ein Weg ins Himmelreich eröffne. Doch trotz der starken Jenseitsorientierung der barocken Theologie gab es keine klare Richtlinie, in welcher Form das Leben nach dem Tod gedacht werden konnte. Die dogmatische Vorstellung der beseligenden Gottesschau (die auserwählten Menschen auch schon zu Lebzeiten möglich ist) ließ großen Raum für Spekulationen und Volksvorstellungen, die wiederum eine reizvolle Folie für humoristische Ausdeutungen abgaben. Beliebt waren u. a. Lieder über Bauernfiguren, die von ihren Erfahrungen im Himmel berichten, wo ihnen all die kleinen trivialen Freuden ermöglicht werden, die sie auf Erden entbehrten. Wohl noch im letzten Jahrzehnt des

118 Zu Güntherode vgl. Karl Wehrl, Der ,neue Geist'. Eine Untersuchung der Geistesrichtungen des Klerus in Wien von 1750-1790. In: Mitteilungen des Österreichischen Staatsarchivs 20 (1967), S. 36-114, hier 87f.

119 [Karl von Güntherode:] Das römische Gesetzbuch. Mit Anmerkungen. Frankfurt, und Leipzig. 1787, S. 301f. 
17. Jahrhunderts wurde Der bairische Bauer im Himmel aufgezeichnet, das ein sehr irdisches Bild der himmlischen Freuden bietet:

1

Ju hai sä sä es ist scho khradn

i namm mey aidt kain schön dugadn

das i nit eim himmel wier

da göths freyla andärst hier

da i lebte ai der Welt

hat mä dis bald Jens gefält

wan i scho zum bier wolt geh

sing da beydl nä lass stöh.

3

Ju hay sä sä das Gott sey danckh

da siz i im sössl zhaus auf der baunckh

da iss $i$ ä henna haut

zaus friss i nix alß saurs kraut

zhauß drinckh i aus am hilzänä napfn

da trinckh i aus am güldänä schapfn

bhiet mir gott mein guldenen himml

gab in nit vmbs pflägars schimml,

5

Ju hay sä sä mir ist recht wol

recht wies im himml aim sey soll

ist mir warla dweil nit lang

nach der welt kain bissn bang

da bin i ä gmachtä herr

hör der kündär gschray nit mehr

dattä bäppä schau i bitt

hät no tag no nocht kain fridt.
2

Ju hay sä sä wans glickh recht will brauchst nit das aim der Mensch hilfft vill schickht si alles wies sey soll sey air niechtär oder voll

Räd von baurna oder pfaffen

dem hat Gott dan himmel pschaffen

der mues halt in himmel ney

soll er ä ä schindä sey.

4

Ju hay sä sä mi froid äi ding

drum warla recht vo herzn sing

das i vo mein bösn wey

do ä mol erledigt sey

Ob i si fircht zwar kain bissn

do wan si dos ding thät wissn

wie äs mir ergeht so fey

wais si wolt ä im himml sey.

6

Ju hay sä sä brisill tobackh

da geth als auf die altö hackh

do redt mir koi mensch nit ey

khert der ganze himml mey

zhaus wolt mei verfluchtes weyb

disä guthät meinem leib

nit zu lassn biss i ihr

schier zu fuessn gfallen schier. ${ }^{120}$

1,1 khradn] geglückt 1,3 wier] wäre 1,8 beydl] Geldbeutel 2,4 air] einer niechtär] nüchtern 2,6 pschaffen] geschaffen 2,7 ney] hinein 2,8 ä ä schindä] auch ein Schinder, Abdecker 3,3 henna haut] Hühnerhaut 3,5 hilzänä napfn] hölzerner Napf 3,6 güldänä schapfn] goldenes Schöpfgefäß 3,7 bhiet] behüt 4,5 Ob] auch wenn bissn] bisschen 5,7 dattä] Vater 5,8 no tag no nacht] weder Tag noch Nacht 6,1 brisill tobackh] Brasiltabak, Tabak aus Brasilien 6,2 auf die altö hackh] wie früher 6,4 khert] gehört mey] mir

Mit noch mehr Anleihen an traditionelles Material des Bauernspotts und der Schwankdichtung malt Maurus Lindemayr seinen Bauernhimmel in den beiden Liedern So bhiet dich Gott du eitli Welt und Nu schauts ih bin halt doirtä gwöst. Im ersten Lied projiziert das Ich bloß die zeitlichen Freuden eines Herrenlebens, deren Nichtigkeit es selbst im Stil einer Vanitas-Klage anprangert, in höhere Sphären, wo sie als Ausgleich für das schlechte Erdendasein zu erwarten seien. Diese lächerliche Trivialisierung von Transzendenz - die ja u. a. auch den Tod als empirische Voraussetzung ausblendet - findet im zweiten Lied ihre Fortsetzung, das in anschaulich-komischen Bildern die Erlebnisse des Bauerntölpels schildert. Vor der Himmelspforte angekommen, erregt die Jubilatio der Engel - zeitgemäß nach den barocken ikonographischen Vorstellungen als Putti mit

120 Staatsbibliothek zu Berlin, Ms.germ.oct. 230, S. 159-162. Vgl. auch Johannes Bolte: Der Bauer im deutschen Liede. 32 Lieder des 15.-19. Jahrhunderts nebst einem Anhange. In: Acta Germanica I,3 (1890), S. 175-303, S. 266f. (Erstedition, Melodie im Anhang, S. IV). 
Geigen, Flöten und Orgel dargestellt - seine Aufmerksamkeit. Nicht vertraut mit den Gepflogenheiten der höheren Künste, missdeutet er die Bewegungen des Dirigenten anerkennend als Züchtigungen zur Disziplinierung der kindlichen Musiker:

1

$\mathrm{Nu}$ schauts ih bin halt doirtä gwöst,

Gar rain in Himmel drinä,

Han, mein Ayd, gsegn ä ganzes Nöst

Groß Buebm und klainö Kinä.

Häufti hamt geigt und dö mehrän hambt pfüffen

Ainä hat gar äf ä Truchä umgriffen.

I kann engs nöt däzölln

Wie schön sä sö thaint stölln

Als ainä, han ih mir gedacht,

All Augnblick dö klain Buebm schlacht,

Hamt ä so gschrien,

Thaint sih nöt rirhen

Ey woltö än söltän Gsölln. ${ }^{121}$

1,2 rain] beinah, fast 1,3 mein Ayd] (Redewendung zur Betonung der Nachdrücklichkeit) wirklich, wahrhaftig 1,5 Häufti] ein Haufen voll, viele, haufenweise dö mehrän] (die mehreren) die meisten 1,6 Truchä] Truhe, (hier scherzhaft für:) Orgel, Orgelpositiv 1,7 engs] euch däzölln] erzählen 1,8 thaint] tun 1,13 söltän] solchen

Auch Marcellinus Sturm ließ sich von dieser Tradition zu einem Doppelgesang Die Hölle/Der Himmel inspirieren. Die antagonistisch aufeinander bezogenen (nach gleichem Schema konstruierten und zur gleichen Melodie zu singenden) Texte beschreiben, was der in das jeweilige Reich Eintretende zu erwarten habe, wobei es weder hier noch dort tatsächlich ernst zugeht. So drastisch in den 24 Strophen von Die Hölle die höllischen Strafen im Stil der Exempel einer Bußpredigt geschildert werden, nimmt nicht zuletzt die pointierte dialektale Formulierung dem burlesken Treiben der Teufel das Bedrohliche:

4

Kaum donnert das Urtheil des Fürsten,

So packens di glei bei der Bürsten,

Und taucha dich wie an Pudl

Im feuerigen Strudl,

Daß der Rauch und der Dampf davon geht, Und der Kopf sich im Wirbl h'rum dreht.

6

Nacha wird ma g'räuchert wie d'Schunka, wird Schwefel und Pech drauf getrunka,

Bue, das ist a Saufa

A Lärm und a Raufa,

Da geht oft ein Teufl a Horn,

Bald a Schwanz, bald a Gaisfuß verlohrn.
5

Dort siedns in an endrischen Hafen

Viel' Könige, Fürsten und Grafen,

Und Bettler beisammen,

Und kaum sagt man Amen,

So werden aus Prälaten-Schädel'n,

Für'n Luzifer Lebaknedln.

7

Jetzt stranzen sich d'Teufel all nieder,

Und schmeißen und speien dich wieder,

Du wirst di kaum b'sinna,

So liegst wieda drinna

In an kohlschwarzen eiskalten See,

Blitz! zieht ma da d'Nasn in d'Höh. ${ }^{122}$

5,1 endrischen Hafen] ungeheuren Topf 6,1 Schunka] Schinken 7,1 stranzen ... nieder] niederstanzen: sich niederlegen $7,6 \mathrm{da}$ ] dir

121 Lindemayr, Dialektlieder I, S. 141.

122 Sturm, Lieder zum Theil in baierischer Mundart, S. 77. 
Selbst Teile der Liturgie waren vor dem - zumeist aus dem geistlichen Umfeld erfolgenden - parodistischen Zugriff nicht sicher, sei es als unverbindlich-entlastendes Spiel mit den Zeremonien und Riten oder als Infragestellen von deren Offenbarungscharakter und Relevanz im Gottesdienst. Zur ersteren Gruppe gehören die beliebten Messparodien, die nicht auf die Verunglimpfung der verwendeten liturgischen Texte abzielten, sondern auf textunsensible Vertonungsmoden, auf musikalische Inkompetenz oder die spirituelle Entwertung im Probenkontext. Berühmt zu ihrer Zeit war die sogenannte Schulmeistermesse des Augustiner Chorherren aus St. Florian, Franz Joseph Aumann (1728-1797), in der ein Dorfschulmeister mit seiner Frau und dem Präceptor eine musikalisch reizvolle Messe einstudiert, die den liturgischen Text jedoch gnadenlos verkürzt, verfälscht und verstümmelt. Das Lateinische wird derart durch falsche Aussprache („Tominus“, „padris“) und Zergliederung der Silben zum unverständlich gestotterten („pa pa pax“, „mu mu mu mu mundi“ etc.) oder unfreiwillig komisch arrangierten Kauderwelsch (z. B. ,eleison' zu „so so leis leis“). Ihren besonderen Reiz gewinnt die Spottmesse jedoch durch die teils ausnotierten derbkomischen Zwischenkommentare des Schulmeisters - z. B. „schneits di amahl Sändl“"123 (Schneuz dich mal, Susanne) -, die die Probensituation simulieren und den fragwürdigen Gesang (auch im eigentlichen Sinn) kontrapunktieren.

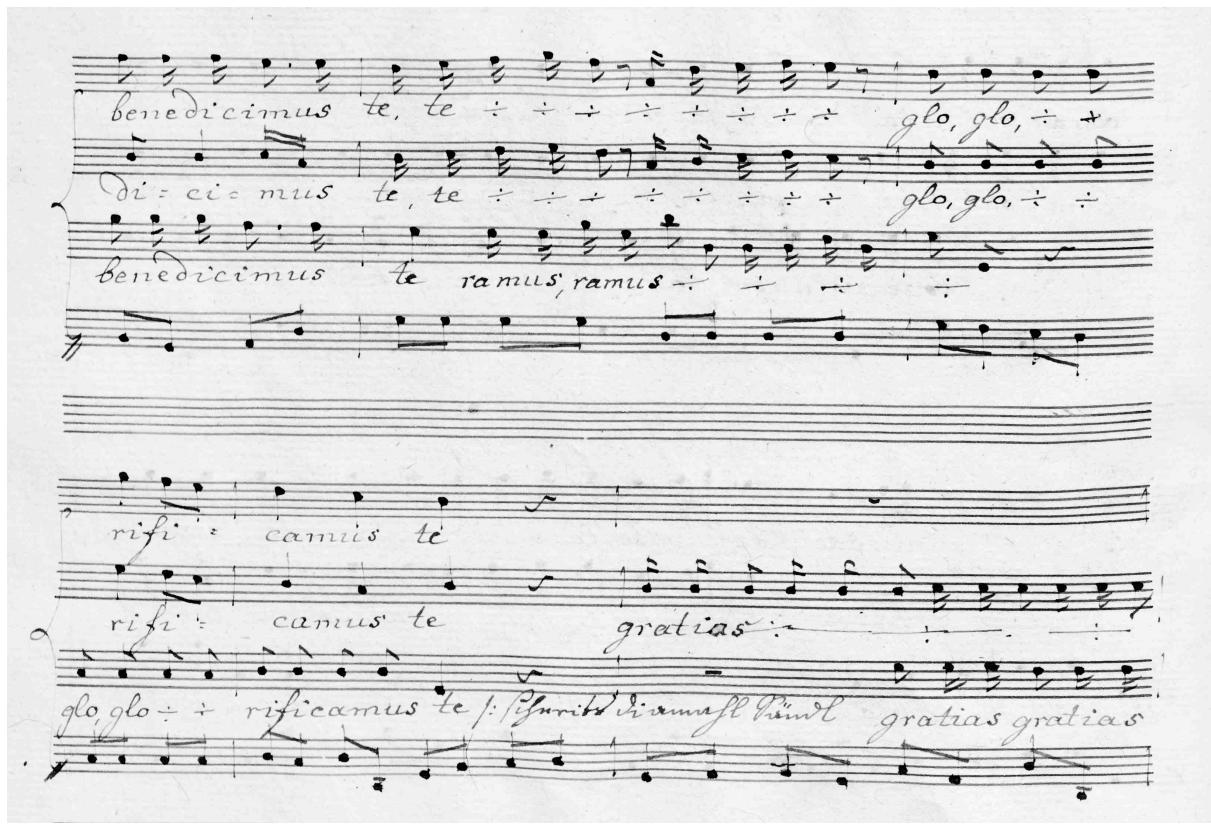

Abb. 6: Partiturausschnitt zu Aumanns ,Schulmeister-Messe‘ (Österreichische Nationalbibliothek, Musiksammlung, Mus.Hs. 15905, f. 7v). 
Das ,Dona nobis pacem ' wird schließlich in einem sechstaktigen dialektalen Adagio nachgeäfft, das von allen drei Stimmen gesungen wird: „Trets ihm das Pätz aus“ (Tretet ihm die Innereien, den weichen Körperinhalt raus). Musikalische Scherze wie diese wurden - so berichtet Giuseppe Carpani - gerne zum Fest der Musikpatronin Cäcilia öffentlich gegeben. ${ }^{124}$ Das außerordentlich populäre musiksatirische Werk, das u. a. auch Mozart, den Haydns und Franz Xaver Brixi zugeschrieben wurde und kaum einmal zu Ende gesungen werden konnte, weil Publikum und Sänger unfehlbar ins Lachen kamen, ${ }^{125}$ fand freilich oft auch Kritik. Noch Hans Joachim Moser kommentiert etwas pikiert: „Die Harmlosigkeit, mit der hier ein Kirchenkapellmeister das oberste Mysterium seines Bekenntnisses einschließlich Incarnatus und Crucifixus persifliert, hat etwas schier Geschmackloses, um nicht zu sagen Zynisches, und ist wohl nur der Zeit des Rationalismus erträglich gewesen. " ${ }^{126}$ Die meisten Abschriften finden sich allerdings gerade in Klosterarchiven oder stammen aus diesen; hier hatte man offenbar weniger Bedenken, ein Sakrileg zu begehen.

Auch für das reizende Trio Der Schulmeister kann man ein klösterliches Entstehungsumfeld im ostmittelbairischen Raum vermuten. Der nicht eben zimperliche Pädagoge (Basso) instruiert, korrigiert und beschimpft in der Generalprobe des Messgesangs seine Schüler Natzerl und Micherl, die musikalische und textuelle Unsicherheiten offenbaren und dazu noch über die auch brachialen Übergriffe des Vorgesetzten wehklagen. Es ergibt sich so eine kunstvoll gesetzte Mischung aus dialektaler Meckerei und sakralen Schlüsselwörtern, die das Mittel der komischen Fallhöhe ausreichend zu nutzen weiß, wie der Basso-Part zeigt:

Was! was! du Talk du! kannst den net lesen? Du Esel du! Kyrie, was treibst denn du; weist denn nit wost bist, eleison gebts fein acht so iß recht; machts mä heut nur glei kan Schand Christe e eleison i sag dirs Michael schau fein auf den Tackt, und du machs Maul fein auf du Esel du Et in Terra, o du Ochs du, siehst denn nöt, daß et in terra heißen muß, nur fort, sonst machst an jeden irr, pro hominibus da hast a Tätschen, weilst nit obacht obacht giebst hominibus Bubn gebts auf'd Kreitzln acht gratias agamus tibi Natzerl du i kum dir übern Schopf, und du schau dahin, sonst kriegst a Fotzen, hominibus, hominibus Kreitzsakra! jetzt bin i selber irr worn, singt nur fort Bubn Agnus Dei iezt singt der Esel Sanctus wieder, i reib dir d'Ohren auf du Hackstock hörst denn nit, daß mä beym Agnus Dei sand du Flögl du, bist nit glei still i hab mit Fleiß nur glei gfellt gebts fein acht, iezt hamas dona dona nobis pa pa pa pacem, kirr nit ä so du schreist ja drein als wie ä gaisbock, dona nobis pacem, Bubn i man ös treibt eng d'Ängsten aus, und ös habt's all zwen in die Hosen Than, iezt raißt na abä glei. ${ }^{127}$

Talk] Dummkopf net] nicht wost] wo du mä] mir kan] keine Tätschen] Ohrfeige Kreitzln] Kreuze (Vorzeichen) gratias agamus] fälschlich für: gratias agimus (lat. ,wir danken') Natzerl] Kurzform für Ignaz Fotzen] Ohrfeige mä] wir gfellt] gefehlt, einen Fehler gemacht hamas] haben wir es kirr] schreien, quietschen eng] euch ös] ihr all zwen] beide raißt na abä] verschwindet nur

124 Vgl. Giuseppe Carpani: Le Haydine ovvero Lettere su la vita e le opere del celebre maestro Giuseppe Haydn. Milano: Buccinelli 1812, S. 112.

125 Vgl. ebda.

126 Hans Joachim Moser: Corydon, das ist: Geschichte des mehrstimmigen Liedes und des Quodlibets im Barock. Bd. 1. Braunschweig: Litolff 1933, S. 91.

127 Österreichische Nationalbibliothek, Musiksammlung, Mus.Hs. 5143, f. 1v-2v. 
Richtet sich die satirische Spitze dieser musikalischen Scherze gegen den inadäquaten Umgang mit liturgischen Texten, ohne freilich diese selbst in Frage zu stellen, so zielt die Kritik in Buchers wohl bekanntestem Werk dezidiert gegen den Ritus selbst. In seinem Entwurf einer ländlichen Charfreytagsprocession (1782) bemüht sich der bereits erwähnte einfältige ,Pater Umgang' trotz eines entsprechenden landesherrlichen Verbots um die Abhaltung des Karfreitagsumzugs in der althergebrachten Form, da ihn das Volk ungern missen wollte:

Alle Herrgott, und Gaisler, und Kreutzzieher seynd abg'schaft in der Charfreytag-Proceßion. Der laidige hölzerne Hergott in der Rast allein dörf noch herumgetragen werden; die Lebendige sind alle - Suma Sumarum alle abg'schaft, völlig abg'schaft. ${ }^{128}$

Verbote dieser Art hatten tatsächlich für erhebliche Kontroversen gesorgt, da sie nicht nur einen harschen Eingriff in das glaubensmotivierte Brauchtum bedeuteten, sondern auch in viele mit kirchlichen Feierlichkeiten verknüpfte säkulare Traditionen. Dass an christliche Anlässe anknüpfende Zusammenkünfte, Festlichkeiten und Aufzüge ein gewisses Potential zur Einbindung profaner Lustbarkeiten bergen, ist heute noch ebenso nachvollziehbar wie das Missfallen aufklärerischer Köpfe an der Verzerrung geistlichen Gehalts durch Volksfeststimmung, gewerbliche Vorteilnahme und scheinheilige Selbstgefälligkeiten. Völlig uneinsichtig zeigt sich der ,Pater Umgang', der eine in seinen Augen idealtypische, realiter durch und durch lächerliche Melange aus den Höhepunkten aller Prozessionen der umliegenden Orte beschreibt, um dadurch die Obrigkeit wieder umzustimmen. Bei aller possenhaften Überzeichnung gibt der katholische Aufklärer Bucher dabei ein ebenso aufschlussreiches wie detailliertes Bild der vielfältigen Umzugsbräuche: penibel geregelte Schaustellungen mit absurd überzeichneter Emblematik, demonstrative Berufsstandsrepräsentationen, gespielte Trivialszenen aus der Heilsgeschichte, Passionslieder und vieles mehr, das vielfach seine Komik durch eine deplatzierte konzeptionelle Mündlichkeit erhält.

In seiner Seraphischen Jagdlust (1784) agitiert Bucher gegen das Ablassunwesen - allerdings arglistigerweise unter dem Namen des Kapuzinerpriesters Martin von Cochem (1634-1712), der als Autor zahlreicher weitverbreiteter religiöser Erbauungsschriften bekannt, später aber wegen seiner simplen Darstellungen Ziel vielfältiger Kritik geworden war. Sein Name ist Symbol einer scheinheiligen Volksfrömmigkeit, die am Beispiel des sogenannten Portiunkula-Ablasses aufs Korn genommen wird. Dieser konnte am 2. August oder am darauf folgenden Sonntag als vollkommener Ablass für einen selbst wie auch für andere erlangt werden und gab gelegenen Anlass für volksfestartige Zusammenkünfte, deren Besucher und geschäftstüchtige Nutznießer im zweiten, Traktätlein zu Wort kommen und eine bizarre Vorstellungswelt vom Sinn oder Unsinn des Gnadenakts offenbaren:

128 Bucher, Charfreytagsprocession, S. [5]f. 
Daß dich poz tausend! Gehst gleich weg. - D’ Händ von der Butte, sag' ich. - Nun, schau nur her da. - Jezt hast mir den Schnürriem z'rissen - kannst mir einen andern kauffen, Hans! sagt Gred zu Hansen unter Lichtzeiten beim Kammerfenster. - So, ist er z'rissen! So nuzt kein Schonen nichts mehr. Sei nicht so unhabig. D' Wochen ist Porziunkula. Da geht 's Beichten und Schnürriemkaufen grad in einem hin, sagt Hans.

$[\ldots]$

STöFL. [...] Als ich den heiligen Ablaß ein Stück ein dreimal gewonnen hatte, dachte ich mir: Ist schon gnug für heuer und mit dem wollte ich zum Wirth gehen. - Aufn Weg begegnet mir des Görgels sein Mensch. Bist allein? frage ich - Ja sagts. - Ist dein Görgel nicht da? Nein sagts. Magst mit mir gehen? Ja, sagts. Geh'n wir miteinander heim auch? - Ja, sagts. Durchs Waldl? sage ich und lache. - Versteh dich schon, sagts und lacht auch. Wenn aber der Görgl kommt? Wir hab'n uns zerkeit, sagts. Wir pochen. So, sag ich drauf. Thust recht. Einen solchen Görgel kannst allemal habn. - Aber, verstehst mich, vor Nacht geh ich nicht heim. - Ich auch nicht, sagts. - Und durchs Waldl? sag ich wieder. Wenn ichs einmal sag, sagts. - D’ Hand drauf, sagt ich. - Da hast sie, sagts, und druckt mich. Wir verstunden einander.

Geh'n wir hinein auf einen, sagt ich. - Meintwegen, sagts. Wir geh'n hinein, trinken und machen ein paar Ringl aufm Dudlsack herum. Da kommt der Görgl. Er mich mit seinem Menschen tanzen sehen, und mir eine Ohrfeigen stecken, daß mir das Aug hätte bis auf die Schuhbandl heraushangen mögen, war eins. Wo komst du her, Görgl? sagt ich drauf. Schnurgrad vom Ablaß, sagt er. - So, sag ich drauf, bringt man den Ablaß so ein? Ich wollte ihm nämlich eine gute Lehr gebn, und nicht so grob drein plumpsen, wie er, sondern die heilige Zeit ehren. So sagt er wieder, bringt man den Ablaß bei Görgels seinem Menschen ein? Da bin ich aufgangen, weil er den heil. Ablaß und sein Mensch unter ein Hütl gebracht hat, und weil ich indessen meinen [V]otzring gerichtet habe, habe ich ihm, den heiligen Ablaß zu defendiren, eine hinaufgegeben, daß er wie ein Mehlsack vor mir hing'fahlen ist. Ich lache, aber seine Kammeraden nicht faul, ziehen über mich ein, und schlagen mich, daß der Bader und der Pfarrer 6 Wochen zu mir gegangen seynd, und noch empfinde ichs, wenn unstilles Wetter ist. - Wenns mich die Schwengeln nur grad gar erschlagen hätten. Ich wäre als ein Martirer von Mund auf in Himmel g'fahren; denn habe ich den Ablaß nicht gewonnen, so hat ihn Niemand gewonnen. Aber g'segne es ihm Gott dem Görgl. Er hat nicht dran gedacht, daß heuer wieder Porziunkula wird. Ihm zu Liebe gehe ich hin, und da soll er den Ablaß gewinnen. Ich und meine Kameraden verstehen aneinander. Wir treffen ihn schon an in der Kreppen. Da soll er Porziunkula kriegen, daß er's so lange merkt, als ich seine. Ich würde ihm ja an seinem Mensch nichts herabgetanzt haben, dem Esel. ${ }^{129}$

unhabig] ungehalten, beleidigt Porziunkula] volkstümliche Bezeichnung der Wallfahrtskapelle Santa Maria degli Angeli, für deren gläubige Besucher Papst Honorius III. einen vollkommenen Ablass gewährte; später auf alle Franziskanerkirchen ausgeweitet ein Stück ein dreimal] ungefähr dreimal Mensch] Mädchen zerkeit] überworfen, zerstritten pochen] zanken, streiten Ringl] Tanz zur Musik aufgangen] wütend geworden Votzring] Schlagring Kreppen] Hohlweg

Buchers satirischer Blick auf die Trivialität volksfrömmiger Vorstellungen sollte illustrieren, wie obsolet viele Aspekte des religiösen Brauchtums bereits waren, da die spirituelle Dimension völlig verwässert war, die ökonomisch-unterhaltende dagegen Überhand genommen hatte. Was von der katholischen Orthodoxie noch immer als Ausdruck eines gefühlsbetonten, kindlich-vertrauensvollen Glaubens verteidigt wurde, dekuvrierte der katholische Aufklärer als sinnentleerte Gesten einer Pseudofrömmigkeit mit fatalem Hang zu Aberglauben und Missbrauch. In protestantischen intellektuellen Kreisen

129 [Anton von Bucher]: Seraphische Jagdlust, das ist, vollständiges Porziunkulabüchlein von P. Martin Cochem, Kapuzinerordens. Mit Erlaubnis der Obern. München, bei Joh. Bapt. Strobl. 1784, S. 63, 68-70. 
wurde diese pointierte Verzerrung des energischen Weltpriesters und Illuminaten freilich nur zu gern als allgemeine Zustandsbeschreibung missverstanden und als Beleg für die intellektuelle Rückständigkeit der katholischen Gebiete im Allgemeinen genommen. ${ }^{130}$

130 Vgl. Wilhelm Haefs: „Charfreytagsprocession“, „Sündfluthspiel“ und „Monachologie“. Zur Literatur und Theologie der Katholischen Aufklärung. In: Hans-Edwin Friedrich/Wilhelm Haefs/Christian Soboth (Hg.): Literatur und Theologie im 18. Jahrhundert. Konfrontationen - Kontroversen - Konkurrenzen. Berlin/New York: de Gruyter 2011, S. 32-63. 


\section{KRIEG UND FRIEDEN}

Die Vielzahl der kriegerischen Auseinandersetzungen, die im 17. und 18. Jahrhundert an verschiedenen Orten und in wechselnden Allianzen ausgefochten wurden, war von einer Fülle höchst manipulativer Texte mit zumeist recht begrenzter Aktualität medial begleitet. Unter all diesen Kriegsliedern und Bauerngesprächen, Propagandatexten und Agitationsschriften finden sich nicht zufällig auch viele dialektale Texte, die sich das breite Spektrum der ästhetischen und funktionalen Möglichkeiten mündlichkeitsnaher Sprache zunutze machen. Die frühesten Belege für bewusst literarisierte bairisch-österreichische Mundart in Texten zu historischen Ereignissen und Kriegen lassen sich in oberösterreichischen Bauernkriegsliedern der 1620er Jahre ausmachen. Unmissverständlich dialektal markiert sind darin allerdings nur die Kampfrufe zu Beginn und nicht der Liedtext selbst, auch wenn davon auszugehen ist, dass die tatsächliche Umsetzung wesentlich näher an den regionalen Sprechgewohnheiten orientiert war:

DRäff / dräff / ihr Nachbauren all zu muth/

vnser Sach die wird noch werden gut/

wagt nur dazu ewer Blut/

die Statt Linz wöllen wir gewinnen fein/

aigenthumblich soll sie vnser seyn/

so bald wir kommen drein. ${ }^{1}$

Vereinzelt nützt auch schon der österreichische Jurist und Erfolgsautor Matthias Abele von und zu Lilienberg (1616/18-1677) Dialekt zur Charakterisierung bäuerlicher Sprecher. Im 36. Casus seiner Metamorphosis Telae Iudiciariae, Das ist: Seltzame GerichtsHändel (1655) kommt er auf die Kriegsgräuel im Dreißigjährigen Krieg zu sprechen, unter denen besonders die Bauernschaft zu leiden hatte. Doch auch die Bauern kannten zuweilen keine Gnade, wenn sich Gelegenheit bot, und verschonten selbst Soldatenfrauen und -kinder nicht:

Haben nicht die Soldaten vor ihrem Untergang hören müssen / hei patzete Krott / hei Höppin! hab ich dich einmal erdappt. Was gilts / ich will dir jetzt lausen / daß du deß Sacraments und Teuffel holens vergessen must. [... ] Hat nicht mancher Laur geschrien? recht auf enck / ihr Krotten! seyd nichts nutz / ös seyt in Mutterleib verderbt / nur fort mit enck Rabenaaß / die kleine Krotten seynd schier rändiger / als die grossen Brotzen. [...] O Teuffelsgespenster / O geschwollne Höppin! also muß man enck das Gifft außdröschen. ${ }^{2}$

patzete Krott] fette Kröte Höppin] Kröte Laur] Spitzbube enck] euch ös] ihr rändiger] toller Brotzen] Kröte

1 Drey schön newe Weltliche Lieder. Das 1. Weiß mir ein prafen Rittersman / der sich vor seim Feind wehren kan / etc. Das 2. Dräff / dräff / ihr Nachbauren all zu muth / unser Sach die wird noch werden gut / etc. Von den Ländischen Bauren. Das 3. Ihr lieben Herrn vernemmet wie / ein seltzame History hie / etc. Wie ein Baur seinen Soldaten Wiegen muß. Im Thon: Wie man das Schlauraffenland singt. Gedruckt in disem Jahr, f. $2 \mathrm{v}$.

2 Matthias Abele: Metamorphosis Telae Iudiciariae, Das ist: Seltzame Gerichts-Händel / Samt denen / hierauf gleichfalls seltzam erfolgten Gerichts Aussprüchen: Zusammen getragen / mit lustigen Anmerckungen erläutert / auch unterschiedlichen Geschichten vermehret / und an vielen Orten verbessert. Nürnberg / In Verlegung Michael Endters / Im Jahr 1655, S. 183 f. 
Durchgehend dialektal gestaltete Texte zu konkreten Kriegsereignissen begegnen dagegen erst ab der zweiten Türkenbelagerung von 1683, dafür zu diesem Zeitpunkt bereits in unterschiedlichen literarischen Kontexten. Ab dem 18. Jahrhundert sind dann für alle größeren kriegerischen Auseinandersetzungen im süddeutschen Raum auch dialektale Texte überliefert, die in unterschiedlicher Weise Stimmung machten und Partei ergriffen, an Zusammengehörigkeitsgefühle und Vernunfthaltungen appellierten, die Feinde diffamierten und die Eigenen stilisierten, die Informationen ebenso parteiisch vermittelten wie filterten und in den meisten Fällen als gezielt gesteuerte Propaganda für und wider eine bestimmte Sache entstanden waren. ${ }^{3}$

Die Hauptaufgabe des Dialekts liegt dabei sicherlich darin, die Überzeugungskraft der Texte durch die Einnahme einer fingierten, Perspektive von unten' zu unterstreichen: Nicht die Stimme der Obrigkeit sollte durch die Texte sprechen; vielmehr sollte die einfache Bevölkerung in den dialektalen Texten das Vertrauen in die eigene Streitkraft, die Loyalität zu den Herrschern, die Freude über den Sieg durch, einen von ihnen vermittelt bekommen. Immer wieder lässt sich auch das Bemühen beobachten, an angenommene Befürchtungen und Zweifel in der Bevölkerung anzuschließen und diese durch die Figur eines ,ebenbürtigen' Sprechers aus dem Weg zu räumen. Aber nicht nur im Versuch, Zuversicht und Siegesfreude zu verbreiten, wurde Dialekt als Anschluss an lebensweltliches, allägliches Sprechen eingesetzt. Zentral in einer Vielzahl an Kriegsliedern ist auch der Spott über die Gegner und die Verhöhnung der Feinde. Auch in diesem Zusammenhang war es Dialekt - als Sprache der Nähe und der Mündlichkeit eine vergleichsweise weniger regulierte, an Konventionen gebundene Sprachform -, durch den man besonders erbarmungslos auch sprachlich gegen den Feind ins Feld ziehen konnte. Quer zu diesen unmittelbaren Aufgaben, die Dialekt in Kriegs- und Propagandaliteratur des 17. und 18. Jahrhunderts erfüllte, liegen weitere, mittelbarere Funktionen, denen die Texte dienen konnten: der sukzessive Auf- und Abbau von Feindbildern, die Stereotypisierung gegnerischer Völker, die Ausbildung eines kampfbereiten Patriotismus, aber auch die Diskussion über Kommunikationswege, über wahre und falsche Informationen zum Kriegsgeschehen oder die Entlarvung gegnerischer Propaganda. All diese Aspekte bilden auch die Analysegrundlage für jene, systemaffirmativen' Texte, die sich thematisch von der Türkenbelagerung 1683 bis zu den Koalitionskriegen Ende des 18. Jahrhun-

3 Zahlreiche dialektale Arbeiten finden sich bereits in den goßen Sammlungen von Ditfurth und Hartmann und sind zum Teil auch nur mehr dort greifbar, vgl. Franz Wilhelm von Ditfurth (Hg.): Die historischen Volkslieder des Bayerischen Heeres von 1620-1870. Aus fliegenden Blättern, handschriftlichen Quellen und dem Volksmunde gesammelt und herausgegeben. Nördlingen: Beck 1871. - Franz Wilhelm von Ditfurth: Die historischen Volkslieder der Zeit von 1648 bis 1871. Bd. 1: Die historischen Volkslieder der Zeit von 1648 bis 1756: Die historischen Volkslieder vom Ende des dreißigjährigen Krieges, 1648, bis zum Beginn des siebenjährigen Krieges, 1756. Heilbronn: Henninger 1877. Bd. 2: Historische Volkslieder der Zeit von 1756 bis 1815: I. Die historischen Volkslieder des siebenjährigen Krieges, 1756-1763. II. Die historischen Volkslieder vom Ende des siebenjährigen Krieges, 1763, bis zum Brande von Moskau, 1812. Berlin: Lipperheide 1871/72. - August Hartmann (Hg.): Historische Volkslieder und Zeitgedichte vom sechzehnten bis neunzehnten Jahrhundert. Bd.2: Von Mitte des siebzehnten bis zu der des achtzehnten Jahrhunderts. München: Beck 1910. 
derts spannen. Nicht zuletzt aber gibt es auch noch einen völlig anderen Modus, in dem Krieg und Frieden dialektalästhetisch verhandelt werden konnten. Nicht alle der überlieferten Texte sind tatsächlich Propagandaschriften im Sinne der Obrigkeit - vielmehr haben sich, wenn auch vereinzelt und in der Regel ungedruckt, auch Belege einer anderen Sichtweise erhalten, in denen mit den Versprechungen und Verlockungen, mit denen die einfache Bevölkerung angeworben werden sollte, hart ins Gericht gegangen wurde. Das Leid und die Entbehrungen des Kampfes, die Trauer um in den Krieg gezogene Familienangehörige, die Anklage der unmenschlichen Behandlung innerhalb des eigenen Heeres: Auch darüber wurde gesungen und geschrieben, und es ist sicherlich anzunehmen, dass diese Texte, anders als es die Überlieferungslage heute darstellt, im zeitgenössischen Diskurs nicht nur eine Randstellung einnahmen.

\section{Bedrohungsbilder des Reichs}

Das Bejubeln der eigenen Siege und der agitatorische Zuspruch für spätere Auseinandersetzungen wirken dort am überzeugendsten, wo das Bedrohliche und Abscheuliche, aber auch das Groteske und Verlachbare der Gegner herausgestrichen werden konnte. Vor einer solchen Folie des Andersartigen vermochte die Tapferkeit und Glorie der eigenen Streitkräfte noch beeindruckender hervorzutreten. Bevorzugte Objekte einer derartigen Feindbildkonstruktion waren im ausgehenden 17. Jahrhundert vor allem die ,Erbfeinde des Reichs: die Türken im Südosten und die Franzosen im Westen, deren militärische Expansionsgelüste Kaiser Leopold I. vielfach in die Bredouille brachten. Die Erfolge in diesen Auseinandersetzungen ermöglichten letztendlich den Aufstieg des Habsburgerreichs zur europäischen Großmacht.

\section{Der Große Türkenkrieg (1683-1699) und seine Folgen}

Als im Frühjahr des Jahres 1683 das osmanische Heer unter der Führung Kara Mustafas mit Unterstützung der Ungarn gegen Westen hin aufbrach, war man im Habsburgerreich nicht unvorbereitet. ${ }^{4}$ Kaiser Leopold I. hatte Bündnisse mit Bayern, Polen und Sachsen geschlossen; von Papst Innozenz XI. kam Unterstützung in Form von Subsidien. Die kaiserliche Armee unter Oberbefehl Herzog Karls V. von Lothringen trat den

4 Zum historischen Hintergrund vgl. u. a. Gertrud Gerhartl: Belagerung und Entsatz von Wien. Wien: Österr. Bundesverlag 1983. - Klaus-Peter Matschke: Das Kreuz und der Halbmond. Die Geschichte der Türkenkriege. Darmstadt: Wiss. Buchgesellschaft 2004. - Martin Scheutz: 1683 - Zweite Türkenbelagerung Wiens. Internationale Konflikte, beginnende Zentralisierung der zusammengesetzten Habsburgermonarchie und Konfessionalisierung. In: Martin Scheutz/Arno Strohmeyer (Hg.): Von Lier nach Brüssel. Schlüsseljahre österreichischer Geschichte (1496-1995). Innsbruck/Wien/Bozen: StudienVerlag 2010, S. 111134. 
Gegnern am 6. Mai in Kittsee gegenüber, musste sich im Verlauf der folgenden zwei Monate aber immer weiter nach Westen zurückziehen. Während der kaiserliche Hof aus Wien floh, erwartete die Armee gemeinsam mit einem Heer aus Männern der Bürgerwehr und Freiwilligen die Osmanen, die am 13. Juli Schwechat erreichten und in den nächsten Tagen Wien vollkommen einschlossen. Da auf Befehl des Stadtkommandanten Ernst Rüdiger von Starhemberg die Vorstädte in Brand gesetzt worden waren, bot sich den Osmanen zu wenig Schutz für einen offenen Angriff; darum begannen sie mit der Untergrabung der Stadtbefestigung für einen von Sturmangriffen begleiteten Minenkrieg. Zu Septemberbeginn war die Wiener Bevölkerung nach langen Wochen des Widerstands durch Hunger, Sorgen um Nachschub, ständige Beschießung, soziale Probleme und eine Ruhrepidemie zermürbt und sehnte das versprochene Entsatzheer herbei. Tatsächlich hatten sich inzwischen die unterstützenden Truppen der Verbündeten angenähert. Am 12. September fand die entscheidende Schlacht am Kahlenberg statt, in der in zähen Kämpfen die Höhen vor der Stadt eingenommen werden konnten. Nach erbitterten Gefechten bei Weinhaus konnten die osmanischen Truppen letztlich in die Flucht geschlagen werden. Diese Ereignisse, die nicht nur politisch relevant, sondern vor allem auch für die Bevölkerung nicht nur Wiens von großer Tragweite waren, wurden vielfach und in verschiedener Form auch literarisch - und für die gesangliche Verbreitung - verarbeitet. ${ }^{5}$ Naheliegend, dass aus diesem Kontext dialektale künstlerischer Erzeugnisse im Zeichen von Propaganda, Agitation und Herrscherlob bzw. Hetze gegen den Gegner entstanden, in denen auch die Nöte und Ängste der Bevölkerung anklingen konnten.

Ganz im Zeichen der Siegesfreude steht das - deutlich dialektal gestaltete - Lied Vom Entsatz wien, das undatiert und anonym überliefert ist, aber vermutlich in unmittelbarer zeitlicher Nähe zum Ausgang des Geschehens entstanden sein dürfte und triumphierend den Sieg über die Türken feiert. ${ }^{6}$ Die dramatischen und nachhaltigen Konsequenzen für die Bevölkerung werden hier völlig ausgeblendet - die Jubelstimmung sollte augenscheinlich ungetrübt bleiben, geht es doch darum, den glorreichen Potentaten zu huldigen, den Sieg des Christentums zu feiern und den ketzerischen Feind noch einmal rhetorisch in Grund und Boden zu stampfen. Dem heiteren Auftakt mit „Huy huy lustö

5 Einen Überblick geben Şenol Özyurt: Die Türkenlieder und das Türkenbild in der deutschen Volksüberlieferung vom 16. bis zum 20. Jh. München: Fink 1972. - Bertrand Michael Buchmann: Türkenlieder zu den Türkenkriegen und besonders zur zweiten Wiener Türkenbelagerung. Wien/Köln/Graz: Böhlau 1983. Sandra Bittmann: Der mediale Diskurs um die zweite Türkenbelagerung Wiens zwischen 1683 und heute. Wien 2008 [Dipl.].

6 Eine erste, normalisierende Edition des Lieds erschien bei Hartmann, Historische Volkslieder und Zeitgedichte 2, S. 70ff. Diese Edition wurde weitgehend übernommen in Buchmann, Türkenlieder, S. 98ff. Die Normierungen, phonetischen Adaptionen und unmarkierten Emendierungen dieser Editionen werden aber nicht nur dem originalen Wortlaut nicht mehr gerecht, sondern wirken teils sinnentstellend. Eine wortgetreue Edition des Lieds findet sich im Aufsatz von Marko Ikonić: Von dem Entsaz wien. Ein dialektales Propagandalied aus der Liedersammlung Ms. germ. oct. 230 der Staatsbibliothek zu Berlin. In: Christian Neuhuber/Elisabeth Zehetner (Hg.): Bairisch-österreichischer Dialekt in Literatur und Musik 1650-1900. Graz: Leykam/Universitätsverl. 2015, S. 118-132, hier $126 \mathrm{ff}$. 
seids wol auf" folgen massive Spitzen gegen die Osmanen und ihren Sultan Mehmed IV., gegen den Oberbefehlshaber Kara Mustafa und selbst gegen den Propheten Mohammed.

1

Huy huy lustö seids wol auf denlä vndt ihr buemä östs no wäckha rundö drauff knödl fleiß vnd ruema kudlfleckh vnd brodwürst gnue kiechäl ä dänobn i will enkh mei böste khue heud zum böstn göbn. [...] 6

So Mai Sultl ziech no hi mit da langn Nosn gspaltnä kopf hast iez zum gwy vnd an giagtn hasn bleib än andärs mal fey zhauß thue di bössä bsinä las di nimmä foppn nauß lass di nit so stimmä. [...]
5

Gsundheit allä redling leuth do habn hölffn fechtn Miesma no ais winckhn heith gsundheit frischä knechtn gelt si habn än dirkhn zaust habns lehrna danzn habns ausn löchern gmaust ausn doiffn schanzn.

\section{9}

Du haist gmaid dei Mochomet wer da haltn dstangä wies schmalz bey dä sonnä bsteht so dä bist ä bstannä gelt mei grauss stolzä Vezier Sherzl thuet da krachä bist deim kaisä ä graisa zier läs dä kiechl bachä. ${ }^{7}$

1,2 Denlä] Mädchen buemä] Buben, Jungen 1,3 östs] esst wäckha] wacker: ordentlich rundö] tüchtig, reichlich 1,4 ruema] Rüben 1,5 kudlfleckh] Kuttelfleck: in Streifen geschnittener Rindermagen brodwürst] Bratwürste 1,6 gnue] genug kiechäl] Diminutiv zu Kuchen 1,7 enkh] euch dänobn] daneben, darüber hinaus, außerdem 5,4 knechtn] emendiert aus, kneckhtn' 5,5 än dirkhn zaust] den Türken zerzaust, dem Türken übel mitgespielt 5,6 habns lehrna danzn] haben sie tanzen gelehrt 5,8 doiffn] tiefen 6,1 Sultl] Diminutiv zu Sultan ziech] zieh 6,3 gwy] Gewinn 6,4 giagtn] gejagten, erlegten 6,5 fey] (Füllwort) nur, ruhig 6,6 bsinä] besinnen 6,7 foppn] täuschen 9,1 gmaid] gemeint 9,4 bstannä] beständig, standhaft 9,6 Sherzl] das Herz (Dimin.) 9,7 graisa] große 9,8 bacha] backen

Das Bild eines feierlichen üppigen Festmahls, das einleitend inszeniert wird, prägt auch den Motivkontext der weiteren Strophen. Das Thema ,Essen' wird dabei nicht nur zur Illustration der Siegesfeierlichkeiten genutzt, sondern findet auch als Spott und Verhöhnung der Türken in fast jeder Strophe bildhafte Verwendung: ${ }^{8}$ Nicht nur werden die osmanischen Gegner dafür verlacht, dass sie sich letztlich als so beständig wie ,Schmalz in der Sonne‘ erwiesen hätten und ihnen ihr ,Brei versalzen` worden sei; auch koprolalischer Spott, bei dem mehrfach von Darmentleerung und Diarrhö die Rede ist, wird ausgiebig genutzt.

7 Staatsbibliothek zu Berlin, Ms.germ.oct. 230, f. 75v, 76v-77v.

8 Vgl. dazu auch Ikonić, Von dem Entsaz wien, S. 122. 
11

Was für billäl nimbst du ey

dö ä so burgiern

ä gueckhsilbä mueß drei sey

weils gley durch Matschiern

go gschwindt kimbt di slaffn oh

host dos läffät gädärl

gwis dö teusch burgatio

hat da zrissn än adärl. ${ }^{9}$

11,1 billäl] Pillen 11,2 burgiern] purgieren: abführen 11,5 slaffn] das Laufen: gemeint ist Diarrhö 11,6 läffät gädärl] laufendes Katherl: „laufende Katharina“: gemeint ist Diarrhö 11,7 burgatio] (lat. purgatio) Abführen, Abführmittel

$\mathrm{Zu}$ dieser Verunglimpfung - zu der auch diminuierende Benennungen wie ,Sultl' oder ,dirkhl' gehören - kommen andere abwertende Stereotypisierungen der Türken. So wird von der langen Nase und dem krausen Haar gesprochen sowie auch von einer "graussn [großen] käppn“, und während eigene Kämpfer als Löwen, Tiger und Greifen repräsentiert sind, fallen für die Gegnerseite Bezeichnungen wie Eber (aufgrund des Verbots des Schweinfleischverzehrs eine besonders starke Herabwürdigung) und Teufel. ${ }^{10}$

Natürlich hatte die Desavouierung des gefürchteten Feinds eine nicht unbedeutende Entlastungsfunktion und diente in der kontrastiven Gestaltung vorrangig dazu, ein patriotisch-christliches Gemeinschaftsgefühl zu etablieren, mit den siegreichen Kämpfern als vorbildliche Projektionsfiguren. Auf die nicht unumstrittene Haltung des Kaisers, der aus sicherer Entfernung seines Fluchtorts Linz die Entwicklung abwartete, reagiert das Propagandalied HA Jodel was sagt man doch dort in der Statt. Die deutlich mundartlichere originale Fassung, die Schmeller noch vorlag, ${ }^{11}$ ist zwar verschollen. Doch noch in einer sprachlich geglätteten, wohl für einen Absatzmarkt jenseits des bairisch-österreichischen Raums konzipierten Fassung tragen Jodel und sein Gesprächspartner Hänsel ihre entschuldigenden Elogen auf Leopold I. in merklich ,bäurischer ' Idiomatik vor:

16 JODEL.

Was brauchts vil der Handel der gieng so wacker an/

daß die Türcken nicht wusten wo aus oder wo an/

ja mehr als viertzig tausend der Türcken sind gfallen/

ein grausames metzlen muß sagen vor allen.

17 HäNSEL.

Es wäre noch lang nicht bey demselben verbliben/

man hät noch so vil der Bluthund auffgriben/

sie haben sich offt auff die Pferdte verlassen/

was gibst und hast gritten vnd alls zuruck glassen.

9 Staatsbibliothek zu Berlin, Ms.germ.oct. 230, f. 78r.

$10 \mathrm{Zu}$ den Stereotypen und Zuweisungen vgl. v. a. Özyurt, Die Türkenlieder und das Türkenbild.

11 Vgl. Johann Andreas Schmeller: Bayerisches Wörterbuch. Sammlung von Wörtern und Ausdrücken die in den lebenden Mundarten sowohl, als in der älteren und ältesten Provincial-Litteratur des Königreichs Bayern, besonders seiner Ältern Lande, vorkommen, und in der heutigen allgemein-deutschen Schriftsprache entweder gar nicht, oder nicht in denselben Bedeutungen üblich sind, mit urkundlichen Belegen, nach den Stammsylben etymologisch-alphabetisch geordnet. Dritter Theil, enthaltend die Buchstaben R und S. Stuttgart, Tübingen: Verlag der J. G. Cotta'schen Buchhandlung 1836, S. 430 und 618. 
Abb. 7: Flugschrifttitelseite (Staatsbibliothek zu Berlin, Ye 7971).

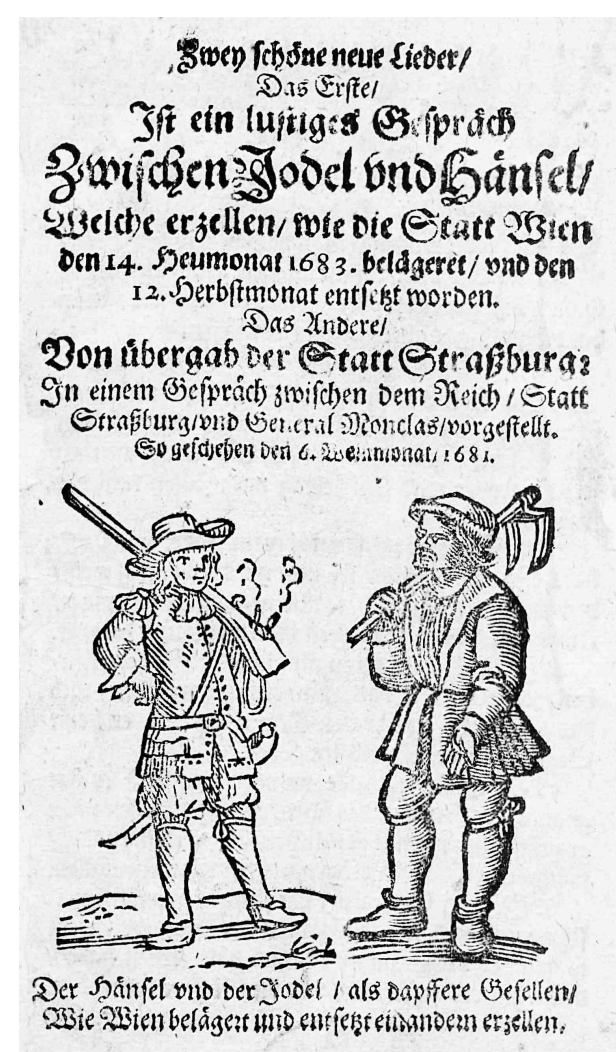

18 JODEL.

Wann man das Ding vor einem Monat hät gsäyt/

es häts wol kein Mensch glaubt ich sags bey meim Eid/

ein jeder hat unseren Käyser veracht/

und gmeint es hab Wien schon die Türckische Macht.

20 HäNSEL.

Fürwahr so gehts wo man redlich zusamen hält/

rechtschaffene Männer thut schicken ins Feld/

vnd hät der Käyser das Ding eh wargenommen/

der Türck wer gewißlich so weit noch nicht kommen. ${ }^{12}$

17,3 offt] dann, daraufhin 17,4 was gibst und hast] so schnell wie möglich 18,1 gsäyt] gesagt 19] Strophe fehlt im Original

Dieser Hinweis auf die Unzufriedenheit der Bevölkerung mit ihrer politischen Führung ist bezeichnenderweise in einer erweiterten, stark dialektalen Fassung des Lieds, das

12 Zwey schöne neue Lieder / Das Erste / Ist ein lustiges Gespräch Zwischen Jodel und Hänsel / Welche erzellen / wie die Statt Wien den 14. Heumonat 1683. belägeret / und den 12. Herbstmonat entsetzt worden. Das Andere / Von übergab der Statt Straßburg: In einem Gespräch zwischen dem Reich / Statt Straßburg / und General Monclas / vorgestellt. So geschehen den 6. Weinmonat/ 1681, f. 2v. 
Hartmann mit Melodie aus einer Mainzer Handschrift überliefert, nicht mehr zu finden. ${ }^{13}$

Die erfolgreiche Entsetzung von Wien war Beginn einer Reihe weiterer Erfolge der Alliierten unter Herzog Karl, die die Osmanen und ihre Verbündeten immer weiter zurückdrängen und in der Folge Gran (1683), Neuhäusel (1685) und Ofen (1686) zurückerobern konnten. Die Siegesmeldungen zogen weitere Propagandalieder nach sich wie etwa das 15-strophige Ho, Jäckl, wie lustig! was gilt das Schaff Trayd, das die Einnahme Ofens in ebenderselben Melodie („Im Thon: Amena erlaub mir in Garten zu gehen“) besingt wie das oben genannte Lied, ähnliche Bildfelder verwendet und auch stilistisch so auffällige Parallelen aufweist, dass sich eine Autoridentität zumindest vermuten lässt. Auch hier wird die Kriegsberichterstattung in einem Bauerngespräch inszeniert, das mit einem für das Genre typischen Prosit auf die siegreichen Truppen endet:

14

Dä Türckische Kaysä wird krimpen die Nasn,

Weil er jetzt mueß Ofä die Vestung entlaßn.

Gott thue ins beschützen no fernä im Streit,

Daß wir ihm weck nemmä Stätt, Länder und Leuth!

15

Das freut mi, mei Jäckl! jetzt geh no mit mir!

I zahl dir geh krechätz glat Wein und gnue Bier.

Bring dirs gsegn Gott, Nickel! laß dir's wol bekemmä!

Gsund denä, die Ofä habn helffä ei nemmä! ${ }^{14}$

14,1 krimpen] krümmen, rümpfen 15,2 geh] jetzt, nun krechätz] geradewegs, ohne Umschweife gnue] genug 15,3 Bring dirs] Trinkspruch (und Aufforderung zum Trinken) gsegn] segne dich bekemmä] bekommen 15,4 Gsund denä] Gesundheit denen

Nach dem wichtigen Sieg der kaiserlichen Truppen bei Mohács 1687, der das Osmanische Reich in eine innenpolitische Krise stürzte, ist ein Oesterreichisches Freuden-Lied, über Die glücklich wider den Erb-Feind gesegnete Waffen unterschiedlicher Hoher Potentaten entstanden. Das durch einen Druck aus dem Jahr 1688 überlieferte Lied schlägt bei der Diffarmierung des Feinds in die gleiche Kerbe wie Vom Entsatz wien, geht darüber hinaus aber stärker auf das Leben der Landbevölkerung in Kriegszeiten ein.

Der (wohl nicht extra angefertigte) Holzschnitt am Titelblatt weist das Lied auch bildlich als Bauerngespräch aus. Dementsprechend setzt der dialektal markierte Text ${ }^{15}$ auch mit der prototypischen Floskel der Aufmerksamkeitseinforderung, „Lost ihr Brüder, ich

13 Vgl. Hartmann, Historische Volkslieder, S. 60-67.

14 August Hartmann: Zum 2. September 1886. In: Allgemeine Zeitung (München), 2. September 1886, Nr. 243, Beilage; Fassung der Erstedition, die das verschollene Original wohl getreu wiedergibt. In den Historischen Volksliedern (S. 108-110) passt Hartmann die Schreibung seinen eigenwilligen Normierungsregeln an.

15 Die dialektale Gestalt des Textes ist allerdings nicht wirklich authentisch: Es brechen immer wieder schriftsprachliche Formen durch, zudem finden sich auch vereinzelt schwäbische Anklänge (was wohl auf Schreiber, Drucker oder Setzer zurückzuführen ist). Intendiert ist aber eindeutig eine bairisch-österreichische Prägung. 
Abb. 8: Titelvignette aus Oesterreichisches Freuden-Lied (Staatsbibliothek zu Berlin, Ye 8101).

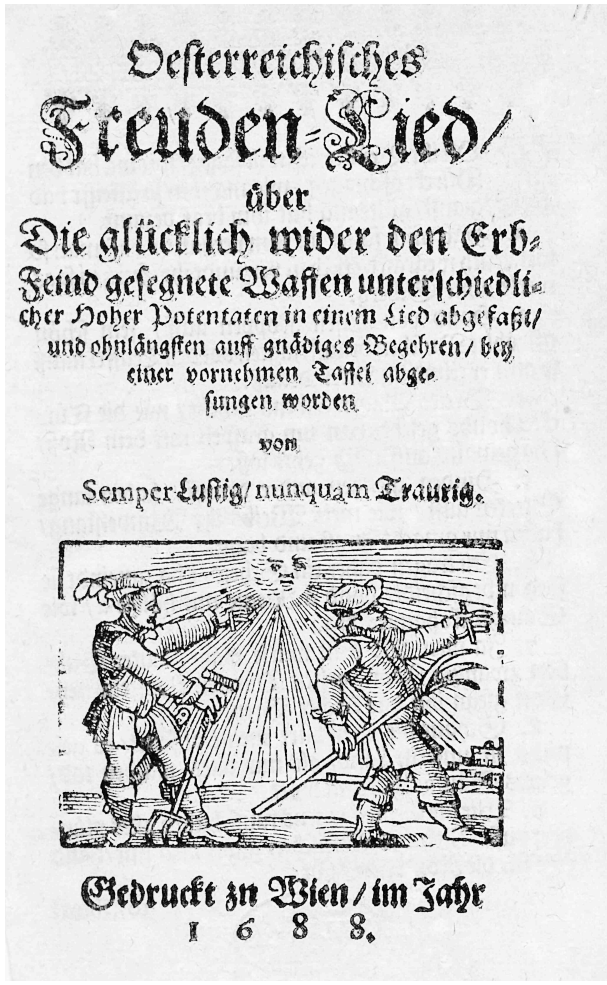

will sagen“, ein. Zum Autor selbst, der sich pseudonymisch „Semper Lustig, numquam Traurig“ nennt, ist nichts bekannt. ${ }^{16}$

Thema ist wieder der Sieg über die Türken, wobei zur Betonung der feindlichen Niederlage üppig aus dem gesamten semantischen Feld geschöpft und das Niederstrecken des Gegners vielfach metaphorisch verbildlicht wird: So werden die Türken geschlagen, gelaust, zerzaust, hinausgejagt, auf sie wird eingeklopft, sie müssen die selbst gekochte Suppe nun auch essen, müssen Zoll und Fersengeld geben, werden geschert usw. Im Gegensatz zu den oben zitierten Liedern geht es hier jedoch nicht nur um die Rekonstruktion des Kampfverlaufs und die Verhöhnung der Türken, sondern auch um die Klage darüber, was das osmanische Heer (das teilweise auch direkt angesprochen wird) und das Kriegsgeschehen über die habsburgischen Untertanen gebracht haben. Die eigene Seite wird nicht nur im glorreichen Triumph, sondern auch in der Erfahrung von Leid und Verlust gezeichnet, der Gegner nicht nur verlacht, sondern in seiner Grausamkeit und Gier auch angeklagt. Eine stereotypisierte, abwertende Zeichnung der Türken steht auch hier im Zentrum, worauf etwa die scheinbar tautologische Zeile „wie die Türcken honds gelebt“ hinweist, die auf die lange Tradition der Türkenfeindlichkeit und

16 Hartmann vermutet, dass die Phrase möglicherweise die Initialen des Verfassers enthalten könnte, vgl. Hartmann, Historische Volkslieder, S. 121. 
die tief verwurzelte, von verschiedenen obrigkeitlichen Instanzen geschürte Angst vor den Osmanen verweist. ${ }^{17}$ Dazu kommt eine ganze Reihe an Schimpfwörtern: „Säusäck“, „Stincker“, „Praler“, „Spreitzer“; beliebt waren kollektivsymbolische Entlehnungen aus der Tierwelt: „Croten“, „Brotz“ (Kröte), „stoltzer Fabia“ (Pavian), „tauffte Fledermauß“, „gstutzter Hund“, „Lamp“ oder „nasser Hund“. Nicht zuletzt gehört die Beschreibung des typischen Erscheinungsbilds der türkischen Soldaten dazu, mit ihren auffälligen Helmen mit (Feder-)Buschen, ihren Säbeln („Breite Plätzer“) und ihren Bärten („Geißbärt“, „Dürgen Bärtel“). Das Lied mündet im herablassend-moralisierenden Urteil, dass die Türken ihr nunmehriges Unglück aus Hochmut und Selbstüberschätzung selbst heraufbeschworen hätten und nun die Konsequenzen tragen müssten.

1

LOst ihr Brüder, ich will sagen/ wie ma hat den Dürcke gschlagen/ wie ma ihm so gsteifft had glaust/ gälts mä hät ihm braf dezaust. 3 Hond von Eisen Koppen auff/ sein schön gströblet Buschen drauff/ jagten vol den Teuffel nauß wann er stund im Acker drauß. $[\ldots]$

9

Wie die Croten zagens rauß/ haben alles plündert auß/ Vie und Menschen gnommen mit/ hand jetzt für die Roß kein Gsidt. 11

Schau Vezier du letzer Tropff/ wie du dir zerreist den Kopff/ zu deim Käyser darffst du nidt/ geld du miechest jetz gern Fried. 13

Hast gwiß gmant es geld nichs mehr/ Keiser gimmer alles her/ ha du Brotz wie bisch so gscheidt/ satttel umb und weiter reit. [...]

\section{2}

Hab mich schier an ihm vergafft/ daß man so viel Leuth wegrafft/ etlich ist verzündt ihr Hertz/ i sags werle ohne Schertz. 4 Breite Plätzer habens gehebt/ wie die Türcken honds gelebt/ han um graspelt mit dem Roß/ i ha gemaint auff mich gehts loß.

10

Uberal hands gsengt und brennt/ ihnen selbst das Loch verrennt/ hättes dNarre lassen stehn/ dürfftens hungrig nidt heim gehn. 12

$\mathrm{Nu}$ mei Buo nimm jetz nur ein/ die Stöß ghören allsandt dein/ dann du hättsts uns au nidt gspart/ wenn wir hätten auff dich gwart. 14

Schau du stoltzer Fabia/ was hebst nu für Händel a/ rennst herauß mit gantzem Gwalt/ gelt die Christen händ di zahlt.

17 Der Türke als Schreckgespenst - besonders auch im Konnex mit der Belagerung - verankert sich gleichsam als phraseologisches Angstbild und wird immer wieder in unterschiedlichsten Kontexten zitiert, wenn es um den Ausdruck großen Schreckens geht (vgl. Kap. 5) - mitunter selbst dann, wenn die Türken inhaltlich nicht die geringste Rolle spielen. Eines von vielen Beispielen hierfür findet sich etwa im Bäurischen OsterMärl, das zur Feier der Geburt Erzherzog Leopold Johanns verfasst wurde (vgl. Kap. 3, S. 170): hier führen im Rahmen der Feierlichkeiten abgefeuerte Ehrensalven dazu, dass sich ein Bauer derart erschreckt, dass er gar die Türken vor den Stadttoren vermutet (Str. 5). 
20

Gelt mein Spreitzer du schweigst still/ merckst den Bossen wos nauß wil/ habens di nit brav dezaust/ sDürgen Bärtel schön auffgraust. [...]

27

Nimm nu dStös an mit Gedult/ hasts begehrt gib keim kein Schuld/

hast mich a rebellisch gemacht/ und mein Kopff in Harnisch bracht. ${ }^{18}$
21

Schau du liederlicher Lamp/ wie ma dir jetz stutzt dein Kamp/ wie man dir erschlagt dein Geist/ daß du nach deim Mahomet schreist.

1,1 LOst] Hört 1,3 gsteifft] kräftig glaust] verprügelt, niedergestreckt 1,4 dezaust] fertiggemacht 2,1 vergafft] verschaut 2,4 werle] (fälschlich für wärlä) wirklich 3,2 gströblet] großmächtig, opulent gekraust 4,1 Plätzer] Säbel 4,3 um graspelt] Wirbel verursacht, Unruhe erzeugt, Lärm gemacht 9,1 Croten] Kröten 9,1 zagens raus] zogen sie hinaus 9,4 Gsidt] Gesött: nährstoffarmes Abfallmaterial vom Futterschneiden und Dreschen, das gesotten im Winter als Viehfutter verwendet wird 10,1 hands] haben sie 11,1 letzer] übler, schlimmer 12,3 gspart] verschont 13,2 gimmer] gib mir 13,3 Broz] Kröte 14,1 Fabia] Pavian 20,1 Spreitzer] Prahler 20,2 Bossen] Possen 20,3 dezaust] s. o. 20,4 auffgraust] aufgekraust: nach oben gerichtet 21,1 Lamp] Lampel: einfältiger Tropf, Trottel 21, 2 Kamp] Kamm

Als sich 1689 mit dem Einmarsch französischer Truppen im Rheinland eine zweite Front eröffnete, musste der Fokus der Alliierten vorerst auf die Stabilisierung der bestehenden Lage im Südosten gelegt werden. Der überraschende und vernichtende Sieg bei Zenta 1697, der den Oberbefehlshaber Prinz Eugen schlagartig berühmt machte, und neue Machtverhältnisse nach dem Frieden von Rijswijk, mit dem der Pfälzische Erbfolgekrieg sein Ende fand, führten schließlich zu den Friedensverhandlungen von Karlowitz (1699), die einen Schlusspunkt unter den Großen Türkenkrieg setzten.

In der Erinnerungskultur nahmen die Geschehnisse, die den Aufstieg der Habsburgermonarchie zu einer europäischen Großmacht ermöglichten, in den folgenden Jahrzehnten einen herausragenden Platz ein. Ein wesentlicher Beitrag auf dem Theater war das um 1715 entstandene Hanswurst-Spiel Türckisch-bestraffter Hochmuth oder das ANNO 1683. von denen Türcken belagerte und von denen Christen entsetzte WIENN, in dem Hanswurst als „kurzweilige Salve-Guarde des Frauen-Zimmers, lächerlicher Spion, und zum Tode verdamter Mißethäter " ${ }^{19}$ zu sehen war. Das in der älteren Forschung Josef Anton Stranitzky (1676-1726), dem Erfinder der Wiener Spielart des Hanswursts, zugeschriebene Stück ${ }^{20}$ aus dem Umfeld der ,Teutschen Comoedianten' am Kärntnertortheater ist in doppelter Hinsicht bemerkenswert: Von den später durch Gottsched

18 Oesterreichisches Freuden-Lied, über Die glücklich wider den Erb-Feind gesegnete Waffen unterschiedlicher Hoher Potentaten in einem Lied abgefaßt, und ohnlängsten auff gnädiges Begehren, bey einer voernehmen Taffel abgesungen worden von Semper Lustig, numquam Traurig. Gedruckt zu Wien, im Jahr 1688.

19 Wienbliothek im Rathaus, H. I. N. 160870 (Türckisch-bestraffter Hochmuth), S. 1. Erstmals ediert wurde das Stück von Fritz Brukner (Hg.): Joseph Anton Stranitzky: Türckisch-bestraffter Hochmuth, oder Das ano 1683. von denen Türcken belagerte und von denen Christen entsetzte Wienn, und Hans Wurst, die kurzweilige Salve-Guarde des Frauen-Zimmers, lächerlicher Spion, und zum Tode verdamter Mißethäter. Innsbruck [u. a.]: Tyrolia 1933.

20 Die Autorschaft des Stücks ist nach wie vor ungeklärt. Rommel sah es aufgrund qualitativer Mängel nicht im Kontext des Kärntnertortheaters (Otto Rommel: Die Alt-Wiener Volkskomödie. Ihre Geschichte vom 
diffamierten typischen ,Haupt- und Staatsaktionen' des professionellen Theaters der Zeit (und somit auch von den bekannten, von Rudolph Payer erstmals edierten 15 Wiener Haupt- und Staatsaktionen) unterschied es sich durch den spezifischen Zeit- und Ortsbezug, der den Bearbeitungen italienischer Opernlibretti mit ihrem exotischen, zeitentrückten Setting fehlt. Vielmehr hat man es hier mit einem vaterländischen Drama zu tun, das im Zeichen von Herrscherlob und Christenpreis steht. Dabei werden - wenn auch nicht immer akkurat - die historischen Ereignisse von der Besetzung bis zum entscheidenden Gegenschlag und der Befreiung mit allen relevanten historischen Personen detailreich ausgeführt. Die Szenen wechseln zwischen der Seite der Türken und jener der Österreicher mit diversen Lagebesprechungen und Sitzungen, Botenentsendungen und dem allmählichen Zusammenschluss der nahenden Unterstützungstruppen; aber auch Lebensmittelknappheit, Versorgungsprobleme oder Ängste der Bevölkerung werden in diesem „Kaleidoskop des großen Augenblicks der jüngeren Nationalgeschichte ${ }^{\text {“21 }}$ beinahe dokumentarisch ins Bild gesetzt. Das Bild der Türken entspricht dabei jenem, das auch die lyrischen Bearbeitungen liefern: Sie werden als tyrannisch, unerbittlich, furchteinflößend grob und roh dargestellt, auch wenn der Text nie Zweifel an der Überlegenheit der christlichen Verteidiger lässt. Inszeniert wird vor allem eine religiöse Opposition zwischen Christentum und Islam: Die Stärke, Macht und Beständigkeit der Christen, durch die der Feind letztlich niedergerungen und in die Flucht geschlagen worden sei, speise sich selbstverständlich aus dem rechten Glauben, so der Tenor des Stücks. Gesiegt worden sei auch und vor allem im Namen und zu Ehren Gottes.

Dialekt kommt über die Figur des Hanswurst ins Spiel, dessen Rede - anders als in jenen frühen ,Staatsaktionen' aus Stranitzkys Umfeld - auch schriftlich immer wieder deutlich regional markiert wird. Dies mag mit der zweiten Eigentümlichkeit des Stücks in Verbindung stehen: Hanswurst tritt - auch wenn er im Verlauf des Stücks die ihm typische Dienerposition einnimmt und seine Typenstilisierung beibehält („ich bin ein

barocken Welttheater bis zum Tode Nestroys. Wien: Schroll 1952, S. 997); darin folgt ihm auch Janke, die auf Diskrepanzen zwischen diesem und anderen Stücken aus dem Umfeld Stranitzkys in Hinblick auf Stoff, Figurenanzahl, Dekorationen und Art der Einbindung des Hanswurst hinweist (vgl. Pia Janke: Die Wiener Haupt- und Staatsaktionen des frühen 18. Jahrhunderts. In: Jahrbuch der österreichischen Goethe-Gesellschaft 108/109/110 (2004/2005/2006), S. 259-271, hier 264). Nachdem in der jüngeren Forschung etliche Stücke des Wiener ,Haupt- und Staatsaktionen'-Konvoluts genetisch verortet werden konnten (vgl. Bärbel Rudin: Heinrich Rademin, Hanswursts Schattenmann. Jurist, Bühnenchef, Stückeschreiber - Versuch über eine Gründerfigur des Wiener Theaters. In: Maske und Kothurn 48 (2002), H. 1-4: Theater am Hof und für das Volk. Beiträge zur vergleichenden Theater- und Kulturgeschichte. Festschrift für Otto G. Schindler zum 60. Geburtstag, S. 271-301), schließt diese Diskrepanz freilich nicht die Autorschaft Stranitzkys aus. Gegen den Hamburger Heinrich Rademin (1674-1731), den Schindler als möglichen Autor ins Spiel bringt, spicht möglicherweise die dialektale Anlage der Hanswurstfigur (vgl. dazu Otto G. Schindler: Rademin, Heinrich. In: Rudolf Flotzinger (Hg.): Österreichisches Musiklexikon. Bd. 4: Ober - Schwaz. Wien: Verl. der Österr. Akad. der Wissenschaften 2005, S. 641). Vgl. weiter auch Walter Lehr: Die szenischen Bemerkungen in den Dramen des Altwiener Volkstheaters bis 1752. Wien 1965 [Diss.]. - Helmut G. Asper: Hanswurst. Studien zum Lustigmacher auf dem deutschen Theater im 17. und 18. Jahrhundert. Emsdetten: Lechte 1980, S. 165, 382f. - Beatrix Müller-Kampel: Hanswurst-Stranitzky. Zur Revision seiner Biographie. In: LiTheS. Literatur- und Theatersoziologie. Forschung, Dokumentation, Lehre. Webportal: http://lithes. uni-graz.at/forschung.html (letzter Zugriff am 11.05.2018), S. $6 f$.

21 Hugo Aust/Peter Haida/Jürgen Hein: Volksstück. Vom Hanswurstspiel zum sozialen Drama der Gegenwart. München: Beck 1989. (Arbeitsbücher zur Literaturgeschichte) S. 54. 
Saltzburger meiner profehsion und von Geburt ein Wurst Schütz“22) - in seinem ersten Auftritt als einer jener Vorstädter auf, die hinter die Stadtmauern flüchten mussten. Diese lokale Verortung der Hanswurst-Figur als Wiener bleibt jedoch noch relativ oberflächlich und wird auch nicht systematisch aufrechterhalten. Im weiteren Verlauf der Handlung als Kundschafter im Nachrichtendienst eingesetzt, kann auch er mit mehr Glück als Verstand seinen kleinen Teil zum Entsatz der Stadt beitragen:

K. Mustapha. He du, von wannen bistu, und was ist dein Gewerbe, indem ich wohl sehe daß du kein Soldat bist,

Hanswurst. ich bin ein Araber

K. Mustapha. Aus welchem, aus dem glückseeligen, steinigten, oder wüsten Arabien

Hanswurst. das weiß ich selber nicht

K. Mustapha. Aber wie nennet sich die Stadt, darinnen du gebohren und welches ist dein Geschäfte und handthierung,

Hanswurst. ich bin ein Saltzburger meiner profehsion und von Geburt ein Wurst Schütz

K. Mustapha. Aber du Kerl scheinest mir verdächtig, indem du nicht Arabisch, sonden gar gut Teütsch redest,

Hanswurst. ich bin halt ä Teütscher Türck, und wer weiß wanns auf die Prob kommt, werden wir wohl alle beyde weder Arabisch noch Türckisch können,

K. Mustapha. du hund rede die Warheit und gib Antwort, oder ich will dich Augenblicklich in Stücke zerhauen laßen: Sage bist du ein Musulmann und beschnitten,

Hanswurst. ja ja ich bin verschnitten

K. Mustapha. So bist du gar verschnitten, wohl, ich werde dich nach Constantinopel schicken im Serrail zu dienen,

HANswurst. was soll ich da machen was ist das Seragl oder Schmarackl,

K. Mustapha. denen Weibern des Groß-Sultans im Serrail solt du aufwarten, weil man dazu deines gleichen Leüth braucht,

Hanswurst. Ah ha, das ist die hoffstuterey, wann mans auf Arabisch ausspricht,

K. Mustapha. hast du Lust dahin,

Hanswurst. Nä Herr Türck, ich mag nicht nach Constantinopel, ich muß heim zu meinem Weib gehen,

Selim. du dieses ist der Vizier gib ihm seinen gebührenden respect

Hanswurst. der Visir, gewiß der Visir-Schneider der den Weibern im Serrail das Maaß nimt, deßwegen hat er mich auch gefragt, ob ich beschnitten bin,

K. Mustapha. Aber was machstu dann mit einem Weib, da du deiner Außage nach verschnitten bist,

Hanswurst. ich hab ä hübsch junges Weib, ich weiß nicht daß Sie über mich klagt, vielmehr hat sie mich allezeit heimlich gelobt,

K. Mustapha. holla, dieses ist ohne Zweiffel ein Schelm und Spion, Alsobald lasse man ihn besuchen, ob er keine Brieffe bey sich hat, die Türcken visitiren ihn

Hanswurst. Greiffts nur selber eine ins felleisen, zeigt ihnen den hintern

IвRAнiм. Was bistu aber zu verrichten Vorhabens gewesen,

HanswUrst. ich bin von meinem herrn Wein zu kauffen ausgeschickt worden,

K. Mustapha. Ah Vogel anjetzo sehe ich daß du ein Christ bist; Alsobald gebe man Befehl daß der hund gespiest werde

Hanswurst. No ä Spieß der ist schon recht, wann nur eine gute Spänn Sau dransteckt, ich friß Sie gar gern,

Selim. Siehe du Bößwicht, ob du nicht so gar auch Schweinenfleisch ißest, welches allen Musulmännern ein Greüel ist,

22 Türckisch-bestraffter Hochmuth, S. 35. 
K. Mustapha. Ihr Soldaten führt ihn weg; daß er allen Verräthern zum Exempel seinen verdienten Lohn empfange, Selim, Hans Wurst mit der Wacht ab Anjetzo mache sich alles fertig zum Sturm, dann ich noch heüte die Stadt haben, und denen Christen den Garaus machen will, ${ }^{23}$

Schmarackl] Smaragd; auch: Wunderwerk eine] hinein felleisen] lederner Rucksack

Wann das patriotische Stück entstand, lässt sich nicht mit Sicherheit sagen. Doch ist anzunehmen, dass es am Kärntnertortheater gerade in einer Zeit reüssierte, als das Osmanische Reich mit dem Angriff auf die venezianische Peloponnes (1714/1715) eine neue militärische Offensive startete. Aufgrund der Bündnispflicht, die Unterstützung gebot, entsandte Kaiser Karl VI. 1716 Truppen unter der Führung Prinz Eugens. Trotz schlechter Voraussetzungen (das türkische Heer war nicht nur größer, sondern auch besser positioniert) ging die kaiserliche Armee aus der Schlacht von Peterwardein siegreich hervor. Auch die Belagerung von Temesvár konnte noch 1716 erfolgreich abgeschlossen werden und wurde rasch im Reich kommuniziert. Ein dialektaler Holtz-seeliger BaurnDiscurs Zwischen Gori und Hyazinth wurde wohl nicht zufällig in Regensburg gedruckt, wo der Reichstag dem Kaiser eben erst zusätzliche Türkensteuern bewilligt hatte und nun Erfolge sehen wollte:

6

Grad nächten kam ä Ofä-Zierdt

Hat mächti Scharas g'schnitten

„Juhe!" sagt er „wohlauf, Herr Wirt!“

Wir haben trefflä g'stritten.

Es ist schon unser Temeswar

Mit Putz und Stingel, Habernarr! ${ }^{24}$

6,1 nächten] gestern, gestern abends Ofä-Zierdt] Offizier 6,2 mächti] sehr, ausgiebig Scharas g'schnitten] (gestische) Komplimente gemacht, einen Kratzfuß gemacht 6,6 Putz] Kerngehäuse des Apfels Habernarr] (mildes) Schimpfwort, jemand, den der ,Hafer gestochen hat', der übermütig ist.

Nach der Eroberung des Banats (das als letztes ungarisches Gebiet noch in osmanischer Hand geblieben war) zielte man auf eine Befreiung des von den Türken besetzten Belgrad, das aufgrund seiner geographischen Lage eine strategisch wichtige Stellung hatte. Nach wechselhaftem Kriegsverlauf mussten die Türken letztlich kapitulieren und abziehen. Die Auseinandersetzungen dieser Jahre und ihr Ausgang hatten zur Folge, dass die seit Jahrhunderten stets präsente Türkengefahr an Schrecken verlor. Der Friede von Passarowitz besiegelte 1718 die territorialen Gewinne der Auseinandersetzungen dieser Jahre und sicherte die politische Großmachtstellung des Hauses Österreich. Wie bei den großen Erfolgen der 1680er Jahre zogen auch diese Ereignisse eine Fülle literarischer Bearbeitungen nach sich, mit denen der Triumph der eigenen Truppen gefeiert wurde. In diesem Fall ließ sich vor allem Prinz Eugen - mit seinem stets offensiven Vorgehen und vor dem Hintergrund des glücklichen Ausgangs - trefflich als Held stilisieren. In der

23 Türckisch-bestraffter Hochmuth, S. 34-35.

24 Vgl. Hartmann, Historische Volkslieder, S. 225. Hartmann gibt den in der Mundart der Oberpfalz bzw. des westlichen Bayrischen Waldes gehaltenen Bauerndiskurs Potz Taubennest! was gibt es Neu's? (S. 224-229) bearbeitet wieder. Das bei Johann Baptist Lang 1716 gedruckte Original konnte bislang nicht aufgefunden werden; die vorliegende Schreibung ist aus Hartmanns Edition und Kommentar rekonstruiert. 
breiten Überlieferung der noch über lange Zeit volkstümlichen Prinz-Eugen-Lieder ${ }^{25}$ haben sich auch etliche dialektale Beispiele erhalten. Ein Flugblattdruck mit drei Beispielen stammt wohl - die Huldigung zweier Wittelsbacher Prinzen spricht dafür - aus Bayern. ${ }^{26}$ Vor allem das erste, Jägerl bist drina, wie so oft ein Bauerndialog, nimmt den österreichischen Oberbefehlshaber in den Fokus, dessen Großtaten freilich als bekannt vorausgesetzt werden:

1

Jägerl bist drina / mein komb a kleine Weil heraus/

thue dich nit lang bsinna gengma ins Wirtshauss/

trinck ma beym Adler / sauffen dort / ist nur glei a Freud/

trinck ma a Mässl / vergeht uns Zeit.

2

Meinthalbn kombst glei recht / hab zu dir hinunter wölln gehn/

han dich wol gseha beym Thomerl stehn:

Bue du kanst lösn / es hat unser Peta Steffel / Müllna Bue/

aus Ungarn gschriba / was sagst du darzue.

3

Was werd ich sagn / schreibt halt dass unser Printz der Held/

und Alexander vorm Jahr im Feld/

so tapffer gfochten: das wissma ohn alles schreibn schon

das Printz Eugeni ein tapffrer Mann.

4

Was mainst mein Brueda / ich denckma offt haimbla bey der Nacht/

dass halt so graussla muss seyn bey der Schlacht,

ich waiss wies zugeht / wann die Baurnbuebn raffa mit einand/

ich kam vor Schröcka glei von Verstand.

5

Namla ists graussla / schlagn da wie der Donner alle drein/

fertn habs gseha zu Peterwardein/

hoier wirds erst stincken / wann die Rossschwaiff her hencken/

bitt umb Gnad, bleib da Strick, Türck dir, und uns Belgrad.

6

Jägerl geh bring mass / gsunds Printzen, alle Herren Officier/

es leben die Reuta, und Musgatier/

es sieg Eugeni / stärck seine Waffen / es grüne seine Treu,

Belgrad lebt nun von Türcken frey. ${ }^{27}$

1,2 gengma] gehen wir 1,4 Mässl] Maß (im Habsburgerreich 4 Seidel = 1,4 1) 2,3 Bue] Junge, Bursche lösn] lesen 4,1 haimbla] heimlich 4,2 graussla] grausig, grausam 4,3 raffa] raufen 5,1 Namla] denn, nämlich 5,2 fertn] letztes Jahr 5,3 hoier] heuer Rossschwaiff] wurden im osmanischen Reich als Rangabzeichen verwendet: je hö-

25 Vgl. Özyurt, Die Türkenlieder, S. 343-375.

26 Die Flugschrift (Vier schöne neue Weltliche Lieder), die drei dialektale und ein standardsprachliches Lied enthält, ist uns nur über Zingerle überliefert. Der verschollene Druck ist nicht datiert, lässt sich aber aufgrund der enthaltenen Angaben relativ genau auf Herbst/Winter 1717 datieren (vgl. Oswald Zingerle: Lieder aus der Zeit der Türkenkriege. In: Anzeiger für Kunde der Deutschen Vorzeit. N.F. 27 (1880), Sp. 180-183, hier 181).

27 Vier schöne neue Weltliche Lieder / das Erste: Jägerl bist drina / komb a kleine Weil heraus / etc. Das Ander: Still, still hörts mir a wenck zue / ich bin a Bayrischer Bue / etc. Das Dritte: Grüss dich Thomerl / Veilt [sic], Hiessl seyts mir alle Gott etc. Das Vierdte: Wer da / wer da / wer kombt vor die Zeiten zur Nacht / etc. Jedes in seiner eignen Melodey zu singen. Gedruckt in diesem Jahr [1717]. Wiedergabe nach Zingerle, Lieder aus der Zeit der Türkenkriege, Sp. 181-182. 
her die Anzahl, desto höher stand der Würdenträger in der Hierarchie; unter den christlichen Soldaten beliebte Trophäen 6,1 bring mass] Aufforderung zum Trinken gsunds] auf die Gesundheit

Origineller und wesentlich detaillierter in der Medialisierung der Kriegserfolge ist ein in Wien gedruckter vierteiliger Lustiger Bauren-Discurs zur Schlacht von Belgrad, das von den Truppen unter Prinz Eugen am 16. August 1717 durch einen nächtlichen Überraschungsangriff eingenommen werden konnte. Im ersten Teil GRieß dich GOtt Gredl berichtet Hänsel seiner Verlobten von den Vorkommnissen, die ein Eilbote in der Residenzstadt verkündet hatte. Die komisierende Rekapitulation der Kampfhandungen fokussiert auf die Schlagkraft der Kaiserlichen, auf die (überzeichneten) Verluste der Türken und die Kriegsbeute, darunter auch das gewonnene Gebiet, das für loyale Siedler wie den redeführenden Hänsel als neue Zukunftsperspektive interessant ist:

15

Also seynds außzogn / und gangä dävon/

Es seynd ihrer gwesen bey 20000. Mann/

Die Deserter werden bekemä gwiß/

Vom Printzen EUGENI im Hindern ein Spiß.

$[\ldots]$

17

Ich geh jetzt auff Belgrad/ und halt mich nit auff/

Will warten dem Printzen EUGENI schön auff/

Sie sagn / er schenckt schier ein jeden ein Hauß/

O Gredl / liebs Hertzerl / das wär uns ä Schmauß.

18

Ich ließ mich mit dir gleich beym Pfarrer zamgeben/

zu Belgrad wolten wir in Ruehe afft lebn/

Den Pfleger und Schreiber / den lachet ich auß/

Wann ich zu Belgrad noch heur krieget ein Hauß. ${ }^{28}$

15,3 bekemä] bekommen 18,1 zamgeben] verheiraten 18,2 afft] dann 18,4 heur] dieses Jahr

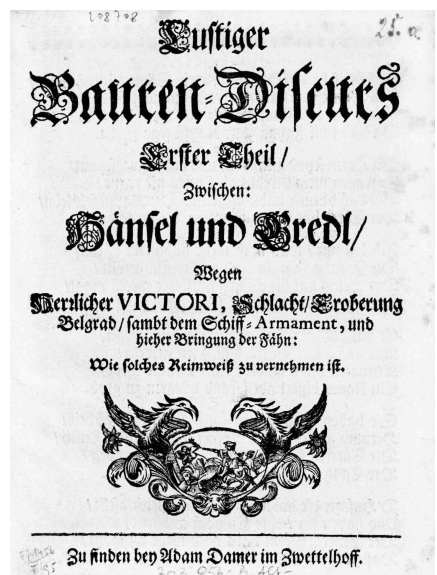

Abb. 9: Titelblatt zu Lustiger Bauern Diskurs (Österreichische Nationalbibliothek/Kooperationspartner Google, Sammlung von Handschriften und alten Drucken, 303956-B).

3u finben bey 2roam Damer im 3wettellboff.

28 Lustiger Bauren-Discurs Erster Theil / Zwischen: Hänsel und Gredl / Wegen Herrlicher Victori, Schlacht / Eroberung Belgrad / sambt dem Schiff-Armament, und hieher Bringung der Fähn: Wie solches Reimweiß zu vernehmen ist. [Wien]: Adam Damer im Zwettelhof [1717], f. 2v. 
Im zweiten Teil ist es nun ein kroatischer Soldat, der aus der (fingierten) eigenen Erfahrung die Kampfhandlungen unter besonderer Würdigung der kroatischen Armeeteile beschreibt. Ihren besonderen Reiz erhält diese Propagandalyrik durch den ,gebrochenen' Dialekt des kroatischen Soldaten, dessen mundartliche Rede sich durch grammatische (nicht lexikalische) Fehler als nicht-autochthon verrät; zugleich aber zeigt er sich in seinem standardfernen Sprechen als ,heimischer Fremder' (vgl. Kap. 5):

1

LIebi Jurco muß dir sagä / wies der ist halt gangä zue/

Habn mir schlagä / auf die Kragä / Türckä schon in aller frue/

Habn mä nehmä / was bekemmä / schöni Rossel / schöni Zelt/

Schöni Haubä / dät auffklaubä / noch däzu viel Türckisch Geld.

2

Seyn wir gstigä / habn weck tribä / Türckä von ihr grosses Schantz/

Habn uns trauet als zam ghauet / wärlä war ein schöni Tantz/

Wie die Teuffel gantz verzweiffel / hat geschlagä die teutsch Soldat/

Türcken alli schir zam falli / ist ä großi Hauffä dat.

3

Biß 40. tausä thut mir grausä / wan der nur thue denckä dran/

All der Schoissen / hat verdroissen / wärlä häbn mir kein Perdon/

Müsten springä über Klingä / Janischären alli samb/

Habn ders lehrnä / dapffer singä / schier blieb ihnä gar kä Mann.

4

Spähi habn mä wäckä gschlaga / drey Meyl in ihr Land hinein/

Hat gar vilen ihren Kragä golten / kund nit bessä seyn/

Habns bey Zeiti schwind macht reuti / Halla Halla schryrens Jaur

Wir sänd nachi / habns dertappi / wärla das war ihn zu saur.

5

Habn wäck nehmä / und bekemmä / schöni Säbl / schöni Zäm/

Schöni Büchsä / dät schön glitzä / allessam Crabatl nämb/

Schöni Zeug und schöni Deckä / wärlä nämb der Teutsch zu sich/

Weil die Türckä / all verreckä / blieb das Lager alls in Stich.

$[\ldots]$

20

Darumb gehn wir gern zum Teutschen / weil sie all seyn redlä Leut/

Wann sie thain den Türckä peitschen / machmä ä mit ihna Beuth/

Thain wir ä als z'gleich verkauffen / kern beyn Marckätanter ein/

Mit den Teutschen alls versauffen / in lauter Bier und guten Wein. ${ }^{29}$

1,1 Jurco] Koseform von Juraj (Georg) gangä zue] zugegangen 1,3 mä] wir bekemmä] bekommen Rossel] Rösser dät auffklaubä] hoben wir auf 2,2 zam] zusammen 2,4 zam falli] fallen zusammen 3,2 wärlä] wahrlich, wirklich 3,3 Janischären] Janitscharen: (aus zwangsrekrutierten christlichen Kindern herantrainierte) Elitetruppe und Leibwache des Sultans 4,1 Spähi] Späher 4,3 reuti] reiten Halla] wohl zu yalla' (arab. für ,auf!', ,los!', von ya allah: oh Gott) schryrens] (sic) 4,4 dertappi] ertappt, erwischt 5,1 Zäm] Zaumzeug 5,2 Crabatl] Kroate 20,2 thain] tun machmä ä] machen wir auch

Dass es neben Unterhaltung, Information, Identitätsbildung auch eine vorrangige Intention der Serie war, die Besiedlungspolitik mit katholischen Untertanen aus der Bau-

29 Curioser Crabatischer Discurs / Anderter Theil. In welchen dem Jurco Die herrliche Victori, sambt der Belagerung Belgrad / Schiff-Armament / Sprengung deß Pulver-Thurns / und Außmarsch der Quarnison / erzehlet wird. Alles in Crabatischen Reimen verfasset. In diesem 1717. Jahr. [Wien]: Adam Damer / im Zwettel-Hof, f. 1v und 2v. 
ernschicht zu propagieren, wird aus dem dritten Teil TAusendmahl sey mir gar schen willikumb ersichtlich. ${ }^{30}$ Hier ist Hänsel inzwischen nach Belgrad gereist, wo er tatsächlich von Prinz Eugen ein Haus und Grund zur Rodung zugesprochen bekam. Voller Freude berichtet er seiner Gredl von der Großzügigkeit des Prinzen („Das ist mir mein Aichel ä gnädiger Mann“"31), den er auch zur Hochzeit in Belgrad einladen möchte. Auch der vierte Teil $J U$ he mein Greterl es ist umb und dran, der humoristisch dörfliche Hochzeitsbräuche skizziert und die jüngsten Kriegserfolge einbringt, arbeitet an der Legendarisierung des siegreichen Feldherrn, der Serbien wieder zum sicheren Land für christliche Siedler gemacht habe.

21

Wir seynd so guet sicher als in Oesterreich/

i bleib so gern da als drobn / gilt mir alls gleich/

der Türck kriegt sein Lebtag die Vöstung nit mehr/

darumb ich mich nix mehr umbs Oesterreich scher. ${ }^{32}$

\section{Pfälzischer Erbfolgekrieg (1688-1697)}

Die Verteufelung des Gegners, die in den Türkenliedern auf vielfältige Weise gestaltet wurde, konnte freilich auch für propagandistische Texte gegen Feindbilder des eigenen Kulturkreises genutzt werden. Wie das folgende, 1690 gedruckte Bauerngespräch zeigt, wurden auch Gegenspieler aus dem christlichen Europa der - wie es im Titel des Drucks heißt - „Aller-Unchristlichste[n] Schand-Brand-Greul- und Mord-Thaten“ 33 bezichtigt. Der Vorwurf galt Ludwig XIV. von Frankreich bzw. den von ihm provozierten Kampfhandlungen um die Pfalz, die heute u. a. als ,Pfälzischer Erbfolgekrieg` oder ,Neunjähriger Krieg` bekannt sind. Im Hintergrund standen französische Annexionsbestrebungen, die in den Jahren zwischen 1688 und 1697 zu kriegerischen Auseinandersetzungen führten. In der aggressiv-agitativen Schrift wird Ludwig XIV. als, frantzösischer Attila' adressiert - ein im zeitgenössischen Kontext geläufiger Vergleich. ${ }^{34}$ Der Text behandelt die ersten Jahre der Kriegsgeschehnisse, ist aber vor allem als Anklage gegen den französischen König und sein rücksichtsloses Vorgehen zu verstehen.

30 Vgl. Lustiger Discurs, Dritter Theil. Continuatio Deß Hänsel und Gredl / Wie solcher zu der Kayserl. Armee abgereiset / und den Printzen Eugenium gebetten umb ein Hauß zu Belgrad / welches er ihme auch geschencket / und wie er will allda sein Hochzeit anstellen / und den Printzen auch darzu einladen: Wie solches alles in disem Lied zu vernehmen ist. In disem Jahr 1717. [Wien]: Adam Damer / im Zwettl-Hof.

31 Ebda., f. 2v.

32 Vierdter Discurs, Von deß Hänßl und Gredl Hochzeit / Wie solche lustig zu vernehmen ist. Im Jahr 1717. [Wien]: Adam Damer / im Zwettelhoff, f. 2v.

33 Der frantzösische Attila, Ludovicus XIV Und dessen Aller-Unchristlichste Schand-Brand-Greul- und Mord-Thaten / Durch seine ungerechte Waffen ausgeübet / An denen Ur-alt berühmtesten herrlichen Rhein-Necker-Saar- und Mosel-Städten Gegen alle gegebene Treu / Glauben / Promessen und Accord / vorgestellet In ihren erbärmlichen Ruinen und jämmerlichen Verwüstungen / und der Teutschen Christenheit / zu einem Abscheu dieses verführischen Hanen-Geschreys / samt einer accuraten Land-Charte und denck-würdigen Anhang / aller ruinirten Oerter / herausgegeben / Durch Christian Teutschmuth. 1690.

34 Er findet sich bereits in einem von Gottfried Wilhelm Leibniz entworfenen Manifest Leopolds I., das auf einen von französischer Seite 1688 veröffentlichten Text reagiert. 
Der Bauerndialog in - allerdings nicht konsequent umgesetzter - dialektaler Gestalt $^{35}$ folgt einer standardsprachlichen Beschreibung der Kämpfe um die Stadt Mainz, die seit Oktober 1688 in französischer Hand gewesen war und Anfang September 1689 durch die kaiserlichen Truppen zurückerobert werden konnte. Die scheinbar authentische Stimmungsillustration, die Hans und Enres geben, entpuppt sich rasch als Stimmungsmache gegen die Franzosen. Dabei werden neben den politischen Hintergründen vor allem Aspekte angesprochen, die die Auswirkungen des Krieges auf die einfache Bevölkerung betreffen: Mehrfach wird betont, dass die Franzosen grausam, unmenschlich und mit gewaltiger Zerstörungswut vorgegangen seien, verwüstete Landstriche zurückgelassen sowie mit systematischen Brandlegungen gearbeitet hätten. Schuld an dieser unbarmherzigen Kriegsführung seien Ludwigs Generäle Mélac und vor allem Feuquières, der trotz seines mickrigen Erscheinungsbilds Angst und Schrecken verbreitete. Denn einer offenen Feldschlacht wurde in der ersten Phase des Kriegs ausgewichen; vielmehr versuchte man den Gegner durch gezielte Verheerung und erzwungene Zahlungen so weit zu zermürben, dass die Bedingungen des französischen Königs akzeptiert wurden.

ENRES.

Ey leiba Gfatter Hanso! Was sagt mer aufs neu?

Sen es unra Bauern denn noch nit all frey?

Dei jüngst die Franzosn, die schölmischen Rob’n

In unneren Gräntzn gefanga dou hob’n?

HaNs.

Jo wul, Gfatter Enres, wos sagt Ihr von frey?

Ich glab daß der Teuff'l ihr Brouder goa sey,

Sie weit'n und tob'n noch immer so seier,

Eas hout mit den Schelmen noch lang gwieß kah Höier.

Sie priegeln und ploug'n und martern die Leut,

Und stehln wei Sperber, und mach'n viel Beuth,

Jo, zünd'n die Häuser und S[t]äd'l gor oh,

Den Greul ich Euch Werla! derzehl'n kahn koh.

Nau kuppels uns Bauern zusamma weis Veich,

Und schlepn es halt immer, mit obi im Kröig,

Dou möisn wir schantz'n und schöißn offt gor,

Und stenna zu förderst, in schröcklier Gfohr.

ENRES.

Ey gödi, was sagt Ihr? Ich höiers nicht gern,

Und wolt, daß sie all wou der Pfeffer wächst wärn!

Wos mouß sie für ah Vogl denn feihern su ohn?

Der alla dei Find'n so masterli kon?

Dort hob Ih ah moula von Melac gihört,

Und aner haßt Vekier, is ag nit viel werth,

35 Der Text erweist sich als sprachlich nicht homogen: Einerseits ist die Lautrepräsentation teils nicht konsistent gleich stark markiert, andererseits ist keine eindeutige Zuordnung zu einem Dialektgebiet möglich, sodass die sprachliche Gestaltung insgesamt nicht sehr authentisch wirkt. Wagner, der für die wissenschaftliche Erstedition verantwortlich zeichnet, ordnet den Text weitgehend dem Nürnberger Dialekt zu, weist zugleich aber auch auf oberpfälzische Züge hin (vgl. Joseph Maria Wagner: Ein historisches Volkslied vom Jahre 1689. In: Die deutschen Mundarten 7 (1877), S. 243-252), zumal Nürnberg ohnehin - insbesondere im zeitgenössischen Kontext - als nordbairisch-ostfränkisches Interferenzgebiet zu begreifen ist. 
Sey gor ah klaner, dörrer, und schmachtiger Kerls, Und mach doch der Teuffl su schröckli viel Quärls. In Summa, es sen es dear Gsell'n su viel, Ih wolt, daß sie alla mit Stumpff und mit Stiel, Mit Hus'n, mit Wammes, mit Bixen und Deg'n, Fein wacker im Rhein und im Mahn dort unt leg'n. Nur dauerts mi greuli, daß unnera Leut, Su grausamli sen von den Lüfft'n geheut, Dei gleichwol nichts anners nit wiß’n noch kenna; Als Stel'n und Rab'n, und senga, und brenna. Sie tenna uns Teutsch'n jo schröcklia Quol, Und kost es beym Weber! su manchen Genrol, Und tapffern Offizöir, der meihrer versteht, Als derer Scher-Schleiffer ah gantza Armee. Dou hattns neuli wider an Anschlog vor Hand, Und wärn gern g'wes'n in Würtenbergs-Land, Den Schwartz Wold hinüber, in Schwob'n und Franck'n, Nou hausns, daß ihnens der Teuffl möcht danck'n. Verwöistn, verheern, verderb’n dos Lond, Uns zeiha dou Kreutzweis herum aufn Brond, Jo, schreibn goa Breiff aus, und mach'n Umständ, Ih mahn, daß mers halti Contrition nennt. ${ }^{36}$

Enres] Andreas $1 \mathrm{mer}$ ] man 2 Sen es unra] sind uns unsere 3 Rob’n] Raben 7 weit'n] wüten 8 Höier] Stillstand, Ruhe 11 Städ'l] (im Druck: Seädl) Scheune 12 Werla] wahrlich kahn koh] kaum kann 13 Nau] danach, dann weis Veich] wie das Vieh $14 \mathrm{obi}$ ] hinab 16 stenna] stehen 17 gödi] Taufpate 19 feihern su ohn] anfeuern 20 Find'n] Finten, Listen 21 ah moula] einmal Melac] Ezéchiel du Mas, comte de Mélac: französischer General 22 Vekier] Antoine de Pas de Feuquières, französischer General 24 Quärls] Wirbel, Streit (von franz. querelles) 28 Mahn] Main 30 Lüfft'n] leichtsinnige, oberflächliche Menschen (Franzosenspottwort) geheut] geplagt, geschlagen 33 tenna] tun 35 meihrer] mehr 36 Scher-Schleiffer] Scherenschleifer (Franzosenspottwort) 44 mers] man es Contrition] Kontributionszahlung

Etwa auf halber Länge des Dialogs schwenken Ton und Stimmung jäh um; die Anklage und das Beklagen werden abgelöst durch den Lobpreis auf die eigenen Truppen und die Verhöhnung der Gegner. Die Schilderung der Erfolge in Mainz durch die Befehlshaber Maximilian von Bayern, Johann Georg von Sachsen und Karl von Lothringen steht hierbei - nicht nur inhaltlich, sondern auch in Ton und Duktus - in deutlichem Gegensatz zu dem Voranstehenden, sodass angenommen werden kann, dass hier einem früheren Text (von 1688) ein aktuellerer Nachtrag aufgepfropft wurde. Bezug genommen wird am Ende - hier in vergleichsweise nüchternem Ton - auch noch auf den verhandlungspolitischen Hintergrund, wobei dafür plädiert wird, dass entsprechend dem skrupellosen, vertragswidrigen Verfahren der Gegenseite der bestehende Vertrag auch von der eigenen Regierung ohne Rücksicht und Diplomatie über Bord geworfen werden sollte. Mit einer höhnischen Schimpftirade gegen die Franzosen klingt das Gespräch aus:

Indessen su leb es die Helden-Armee,

Dei also den Hanen macht grausams Leib-Wöih,

Der Bayer-Ferst, der Sachs'n-Gerg und Lothringer leb!

Daß ihnen der Himmel noch weiter Glück geb!

36 Der frantzösische Attila, S. 176-179. 
Doch daß sie den Frantzen nit halten Accord,

Weil jo der Prolhans es ag alles dermord,

Und über Tyrannisch, ja, hadnisch, sich weiste,

Ah sog mer ans worum er der Christlichst den heist?

Pfuy Frantzmoh! Pfuy Teuffl! Pfuy Spott und Pfuy Hohn!

Das trägt eitz dein schnarch'n Moch'n darvon,

Gott stroufft es den Freffel und Mahn-Ad durchaus,

Zöich immer mei Sultan dein Brouder, nouch Haus. ${ }^{37}$

1 Hanen] Franzosen (gallischer Hahn) 3 Der Bayer-Ferst] Maximilian II. Emanuel, Kurfürst von Bayern Sachs'n-Gerg] Johann Georg III., Kurfürst von Sachsen Lothringer] Karl V. Leopold, Herzog von Lothringen, kaiserlicher Oberbefehlshaber 5 Accord] (franz.) Abkommen 6 es ag] uns auch dermord] ermordet 7 hadnisch] heidnisch 10 schnarch’n Moch'n] Angeberei (Schnarcher = miles gloriosus) 11 Mahn-Ad] Meineid

Der Franzose soll sich mit seinem Bruder im Geiste, dem Türken, davonmachen, so die unmissverständliche Aufforderung. Unmissverständlich zumindest für die Rezipienten, denn dem direkten Adressaten dieser Zeilen, dem gescholtenen „Frantzmoh“, muss das Lied, das schon in den nördlicheren Teilen des Reichs Verständnisprobleme bereitet hätte, selbstverständlich unverständlich bleiben. Wenn Türken und Franzosen als Erbfeinde des Reichs beschimpft und verhöhnt werden, dann hat dies vor allem gemeinschaftsbildende, nicht abschreckende oder provozierende Funktion. Die Sprachbarriere verhindert eine derartige Rezeption.

\section{Mediale Schlachten und die ,Wahrheit' der Propaganda: Österreicher, Bayern, Preußen und Franzosen}

Was aber ist, wenn der Gegner die eigene Sprache spricht, und nicht nur eine standardisierte überregionale Sprache, sondern denselben verbindenden Dialekt? Dieser Fall ergab sich wenige Jahre später. Im Mittelpunkt stand einer der gefeiertsten Helden sowohl der Türkenkriege als auch des Pfälzischen Erbfolgekriegs: der Kurfürst von Bayern. ${ }^{38}$ 1683 war Maximilian II. Emanuel mit 11.000 Mann nach Wien geeilt und hatte sich als Unterfeldherr gegen die Osmanen derart verdient gemacht, dass Leopold I. der Heirat mit seiner Tochter Maria Antonia, einer möglichen Erbin des spanischen Throns, zustimmte. 1688 war er als Oberfeldherr - selbst in den vordersten Reihen kämpfend für die Befreiung Belgrads verantwortlich, dann wandte sich der ,Türkenbezwinger im Neunjährigen Krieg gegen die Franzosen, wurde 1691 zum Generalstatthalter der spanischen Niederlande ernannt und sah sich schließlich 1698 vor der Erfüllung seines Traums von einer wittelsbachischen Großmacht, als der kinderlose Karl II. von

37 Ebda., S. 184f.

38 Vgl. Reginald de Schryver (Hg.): Max II. Emanuel von Bayern und das spanische Erbe. Die europäischen Ambitionen des Hauses Wittelsbach 1665-1715. Mainz: von Zabern 1996. (Veröffentlichungen des Instituts für Europäische Geschichte 156) - Elisabeth Weinberger (Hg.): Kurprinz Joseph Ferdinand, Prinz von Asturien (1692-1699). Kinderleben im Konzert der Mächte. München: Staatliche Archive Bayerns 2012. (Veröffentlichungen der Staatlichen Archive Bayerns 37). 
Spanien Maximilians Sohn, den 1692 in Wien geborenen bayerischen Kurprinzen Joseph Ferdinand Leopold, zum Erben bestimmte. Der unerwartete Tod des sechsjährigen Kaiserenkels, der zur Vorbereitung auf künftige Aufgaben nach Brüssel geholt worden war, machte im darauffolgenden Jahr mühsam ausverhandelte Verträge zwischen den Bourbonen und den Habsburgern hinfällig und führte letztendlich zum Krieg um die spanische Krone.

Die Todesumstände des Kurprinzen, die nie restlos geklärt werden konnten, gaben dabei einigen Anlass zu Gerüchten. ${ }^{39}$ Ein - leider nur in einer sehr fehlerhaften späteren Edition, ohne Hinweise auf die Quelle erhaltenes - ,Klagliedl zwayer Bayrischen Baure[n]' bespricht die brisanten Komplikationen, die sich aus den Ambitionen des Kurfürsten und dem Tod des Kurprinzen ergaben recht offenmütig. Deutlich wird im Verlauf des Lieds auch, dass der Autor ein Kaisertreuer war, der das Liebäugeln des schwer verschuldeten, ambitiösen bayerischen Kurfürsten mit den Franzosen als massive Gefahr für das Reich sah, die ehestens unterbunden gehörte. Ein gangbarer Weg war offenbar, den Erbfeind mit diesem Lied anzuschwärzen, indem man ihn des Giftmords am Universalerben bezichtigte - eine Strategie, die übrigens auch die Gegenseite nicht ohne Erfolg verfolgte:

21 STÖFFEL.

Wirdt nit izt der Franzos lachä, das verlohren des churfürsts sachä, hi sämt sambt der Pauren schwais, hett mä no den Fürst hirobä, wolt mär entli no gaut lebä, leith vergösn do Spanischa gais. 23 STÖFFEL.

Wais es ist schon öfftä gschechä, wo mä ain nit gern thuet sechä, richt mä si auf solche weis, Dö Spanisch vnd dö Französisch tropfä, Dö wölschä khinnä ä västopfa, Den leuthn smaul mit gifftä speis. 25 STÖFFEL.

Söll dän in den Bayrisch landän Khai treia teuschä sein vörhandän, rehn dan wälsch d'Franzosen vor. Bayrisch gelt dä Fürst do libet, vnsärs peitl wacker klibet, wenä Bayrn missnä höbn empor.
22 JODL.

Dössl ist ä grobä Possän, fürcht do gais do hab ä gstossän vnsä Prinzl in die grueb.

Dä mä seith do Spanisch Suppn pflägn Dieb mit gifft zustuppen, Schau so gehts min libä bue. 24 JodL.

Schau was sämä do für lappen, trachtn umb ä Königs kappen mit dem Prinzl auf den Thron. Dän Aussländrn danno trauet, Als auf wälsch Franzosen bauet, Ihnä gibt mä dopplät lohn.

26 JODL.

Hoss offt Khert mei leiba nachbä, Khai landtskindt dem Fürsten achtbär, Dreff ä nit vill vor sey gsicht. Wennä vo im will was habn, mues mä nur än wälsche labn, das är aim das wort vorspricht.

39 Vgl. Peter Boruth: Die Krankengeschichte des Kurprinzen Joseph Ferdinand von Bayern (1692-1699). Textedition mit Übersetzung. München, Diss., 1985. 
27 STÖFFEL.

Auf mein aidt aba vnsa Adl

Ist dahin gä vollä tadl

leidet alläs mit gedult

Beim Taback, weispier sö sizn,

nit vill in den bichern schwizn,

lassn lign aufm bult.
28 JoDL.

Schau mir Pauren missn mörcka, das d'Herrn izt nichts guets mer würcka, löbn in alten Khaisä ney, huren vnd buebn, frössn, trinnkhä, stäts muess maul vom Weinfass stinnkhä, thuen kain etwas aufm schein. ${ }^{40}$

21,3 sämt] fälschlich für sänt: sind 21,4 hirobä] heroben (in Bayern; der Kurfürst residierte in Brüssel) 22,1 Dössl] dies, das 22,2 ä] auch 22,4 mä seith] man sagt 22,5 zustuppen] zu bestreuen, Pulver hinzumengen 23,1 gschechä] geschehen 23,5 wölschä khinnä ä] die Welschen (Italiener und Franzosen) können auch 24,1 sämä do] sind wir doch lappen] Narren 24,2 Königs kappen] Königskrone 25,2 Khai treia teuschä] kein treuer Deutscher 25,3 rehn] reden 25,5 peitl] Beutel klibet] spaltet, (hier: ) leert 25,6 wenä] wenn er missnä höbn] er muss heben 26,1 Hoss offt Khert] habe es oft gehört 26,3 Dreff] wohl fälschlich für Derff: darf 26,4 Wennä] wenn einer 26,5 än wälsche labn] einen Franzosen bezahlen 27,1 Auf mein aidt] Beteuerungsfloskel 28,3 löbn in alten Khaisä ney] nehmen den alten Kaiser (Leopold I.) aus

So bizarr verstümmelt der Text überlieferungsbedingt auch ist, scheint doch eines unübersehbar: Hier hat man es mit einem Lied zu tun, das gezielt die Regierungspolitik untergrub und die erfolgreiche Allianz zwischen Habsburg und Wittelsbach prolongiert wissen wollte. Dass der Auftraggeber aus Österreich kam, ist zumindest nicht unwahrscheinlich. Die gewählte Präsentationsform insinuierte, dass auch das ,gemeine Volk dieser Meinung war: Stöffel und Jodl präsentieren sich als bayerische Patrioten, denen das Wohl des Landes am Herzen liegt. Ihre Mundart signalisiert, wo die eigentlichen Verbindlichkeiten liegen und wem man sich verbunden fühlen sollte. Auf den verkommenen und korrupten bayerischen Adel sei ebenso wenig Verlass wie auf „dö Aussländä“41.

\section{Spanischer Erbfolgekrieg (1701-1714)}

Weder solche Propaganda noch der diplomatische Druck aus Wien konnten den Kurfürsten allerdings davon abhalten, die Fronten zu wechseln, als in der letzten testamentarischen Verfügung des spanischen Königs ein Enkel Ludwigs XIV. und Neffe Maximilians, Philipp von Anjou, als Alleinerbe Spaniens genannt wurde. ${ }^{42}$ Seine Hoffnung, über dieses Verwandtschaftsverhältnis doch noch seinen Aufstieg in den Kreis der europäischen Großmächte zu verwirklichen, ließ ihn ein Bündnis mit dem französischen König eingehen. Im folgenden Krieg um die spanische Krone, den die Haager Große Allianz

40 Klagliedl Zwayer Bayrischen Baurey [sic], yber den laidig Todtfahl des Chur-Prinzens. Zitiert nach: Anton Birlinger: Zur Kunde der süddeutschen Mundarten des 17. und 18. Jahrhunderts. In: Archiv für das Studium der neueren Sprachen und Literaturen 23 (1868), H. 43, S. 221-236, hier 229f. Wie es zu den vielfach sinnentstellenden und zuweilen absurden Fehlern kommen konnte, ist unklar. Bierlinger veröffentlichte das Lied ohne Erläuterungen und Quellenangabe. Hartmann versuchte - allerdings in seiner eigenwilligen Transkriptionstechnik - den originalen Text (wohl eine Handschrift) zu rekonstruieren und verweist auf Schmeller, der zwei Zeilen des Texts (offenbar aus einer anderen Quelle) zitiert, vgl. Hartmann, Historische Volkslieder, S. 126-134.

41 Birlinger, Zur Kunde der süddeutschen Mundarten, S. 231.

42 Zum historischen Kontext vgl. u. a. Matthias Schnettger: Der Spanische Erbfolgekrieg 1701-1713/14. München: Beck 2014. - Michael Hochedlinger: Oberösterreich im Spanischen Erbfolgekrieg 1702-1706. Wien: ÖBV 1993. (Militärhistorische Schriftenreihe 66). 
um Leopold I. (Reich, Großbritannien und Niederlande) gegen Frankreich und seine Verbündeten führte, sicherte Maximilian zunächst durch die Besetzung der wichtigen Donauübergänge von Ulm, Neuburg und Regensburg die Verbindung zu den französischen Truppen, bevor er versuchte, über Tirol nach Italien vorzustoßen, um sich mit den Franzosen unter Kommando des Herzogs von Vendôme zu vereinigen. In Tirol jedoch stieß er nach der Einnahme von Kufstein, Wörgl, Rattenberg, Hall und Innsbruck Anfang Juli auf erbitterten Widerstand der Bevölkerung, die erzürnt über die dilettantische Kriegsführung des kaiserlichen Generals Johann Martin Freiherr Gschwindt und die überzogenen Kontributionsforderungen des Kurfürsten die Verteidigung der Grafschaft selbst in die Hand nahm. ${ }^{43}$ Die autonome Mobilisierung der Tiroler Wehrverfassung ließ Tausende Waffenfähige im Oberland zusammenfinden, die die bayerischen und französischen Soldaten rasch zurückdrängten und mit Scharfschützen stark dezimierten. Unter der Führung des Landecker Postwirts Johann Linser und des Laudegger Pflegeverwalters Martin Andreas Sterzinger wurde ein feindliches Expeditionskorps in den Schluchten von Prutz durch Steinlawinen und Beschuss vollständig aufgerieben. Auch in den folgenden Wochen gelang es den Angreifern nicht, den Widerstand am Brenner zu brechen, im Gegenteil: Die Schießkünste der Tiroler Scharf- und Scheibenschützen, die vornehmlich auf die französischen Eindringlinge zielten, fügten Maximilians Armee hohe Verluste zu und waren Signal für einen allgemeinen Aufstand von Bürgern und Bauern. Bis Anfang August war Tirol weitgehend wieder von den Bayern befreit, mehr noch: Nach Zusammenschluss mit den kaiserlichen regulären Truppen stießen die Landesschützen plündernd bis ins Oberbayerische zwischen Isar und Lech vor.

Diese kriegerischen Vorgänge, die mit dem verharmlosenden Etikett ,Bayrischer Rummel' in die Geschichtsbücher eingehen sollten, bilden ein wesentliches Ideologem für Tiroler Geschichtsbewusstsein und Identitätsbildung. Die Grundlage dafür wurde bereits unmittelbar nach den europaweit vielbeachteten Erfolgen der Landesschützen durch eine geschickte mediale Kampagne (wohl aus dem Umfeld des Kaiserhofs) gelegt. Wesentlichen Anteil hatte dabei auch das illustrierte Flugblatt Lustiger Muster-Platz der Tyrolischen Bauern, unter dem Commando deß tapffern Martin Läningers. Es zeigt den legendären Bauernführer Martin Laninger, der acht Kampfgefährten auf die Schlacht einschwört. Ein etwas abseits stehender jugendlicher Verwandter fungiert als Tambourmajor, die übrigen martialischen Gesellen, die ihre todbringenden rustikalen Waffen bereits im Namen tragen, versuchen sich in der Ausschilderung wilder Kampfeslust gegenseitig zu übertrumpfen:

43 Vgl. u. a. P. Albert Jäger: Tirol und der baierisch-französische Einfall 1703. Aus archivalischen und andern gedruckten und ungedruckten Quellen bearbeitet. Innsbruck: Wagner 1844. - Michael Forcher: BayernTirol. Die Geschichte einer freud-leidvollen Nachbarschaft. Wien: Herder 1981. - Fritz Kirchmair: Die Gefechte an der Pontlatzer Brücke 1703 und 1809. Wien: Österreichischer Bundesverlag 1983. (Militärhistorische Schriftenreihe 48). 
1 Martin Läninger.

STölts ench Buemä, gleich ö d' Glidä, Machts dös Bayrfürsts Renn-Säu nidä, Helffts änandä ohni Sämä,

$\mathrm{Daß}$ mäs Gsindl aussy rämä!

Abär Achtung müsts halt göben,

Daß nicht geh' ä Straich dänöben!

Thüets dö Schwein zäsammä jagen, Wagger auff dö Rüessel schlagen,

Thüet sö untä d' Stainä graben, Daß mä Frid im Land mögn haben! Lasts dö Kriegs-Schaar bräff anläffä, Künnts mit jen afft dapffä räffä, Greiffts nä flux nach enchän Waffen, Leuchts den Gösten ewig schlaffen, Män wird ench, wäl d' Welt steht loben, Drunt zu Wien, und da heroben, Daß ihrn Kaysä troy thüt bleiben, Helfft jem seine Feind auffreiben, Werd von jem nit falsch abwendig, Lebt und sterbt für jem beständig.

2 RÜEPl LÄNINGER, TRUmmelschlageR Z' rauffen müests nit ehe anhöben, $\mathrm{Biß}$ i ench thues Zaichen göben, Bald i Trummel werde rüehren, Jeder soll sein Gwöhr recht führen.

3 Chrischtl Trischling.

An mie solt ös nit äbwinden, Kan än Stil dä Hackä finden, Will dö Trischel tapffä schwingä, Meinen Batzen wohl anbringä, Wenn i ain an Kopff han troschen? Gäb i umb sein Löbn kain Groschen.

4 BÄrschtl Kolbinger.

WIll mit Kolben den Bayren lausen, Daß jen soll dä Buggel grausen, Will so offt auff ain Orth schlagen, $\mathrm{Biß}$ mäns todt von mier mueß tragen, Wird nach jen kain Hund mehr fragen, Wenn sie schon die Rabn abnagen.

5 Grögä GABlmaYr. Bhüt äm GOtt vor Gabel-Spissen, Bayrn, wenn ös nit thüet wissen? Will enchs lehrnä mit mein Stöchä, Daß von drey stich werdn neun Löchä,
Seyds auffs nächst nit mehr so hitzig, Werds fein nit mit Schaden witzig.

6 Blasel Pengling.

Ich gib denen Schweinfurts-Engeln, Einen Willkumb mit den Pengeln, Wölln auff mi dö Kriegä schiessen, Müessen sö miers doppelt büessen, I will jens so stattlä mössen,

$\mathrm{Daß}$ sö solln das Löbn fägössen.

7 Michl Bixler.

Wögen meinen zächen Knütteln, Bayern jeni Grind werdn schütteln, Es soll manchen mein Zaun-Steckä, Lassen an seim Leib ä Leckä,

Daß es afft mit jem wird heissen: In das Graß, Sol[d] at must beissen.

8 Hannss Tremler.

I Will d' Säu beyn Berscht änropffen, D’ Rüessel mit den Tremeln klopffen, Denen Bayrischen Frantzosen, Solls mehr tragen Dorn, als Rosen, Werden dös zum Besten haben, Daß sö künnen fülln ein Graben.

9 Wolff Morgensterner.

In dä nahet (nit von feren)

Leucht i gern mit Morgen-Steren, Obs schon Bayern nit begehren,

Werd i sö wohl dennoch scheren, I will sö an Schedel tröschen, $\mathrm{Daß}$ sö wie ä Liecht außlöschen.

10 Veit Stainberger.

Will mit Stain dö Bayern schwären, Als wenn sö Kraut-Fässä wären, Mueß ja sö ä so bedöckä, Jen groß Unrecht zu västöckä Jetzt Tyrolä (braucht nix weitä) Als dö Bayrn vil gescheidä.

\section{MARTin LÄNINGER}

Buemä, habts zäsammä geschworen, Daß nit geh das Land verlohren? Helffts nur ä däzue öß Schützen, Bleibts nit hintärn Offen sitzen, Denn, wies Sprichwort haist, vil Händ, Machen bald dä Sach än END. ${ }^{44}$

1,1 ö d'] in die 1,2 Renn-Säu] vor allem auf Bayern gemünztes Schimpfwort (ursprünglich Preis bei Wettbewerben) 1,3 ohni Sämä] ohne Säumen, unverzüglich 1,4 aussy rämä] hinausräumen 1,12 jen afft dapffä räffä]

44 Lustiger Muster-Platz der Tyrolischen Bauern / unter dem Commando deß tapffern Martin Läningers. [o. O., 1703], f. 1r. 


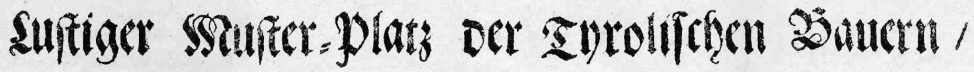

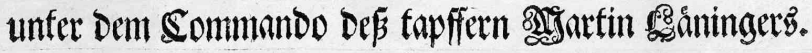

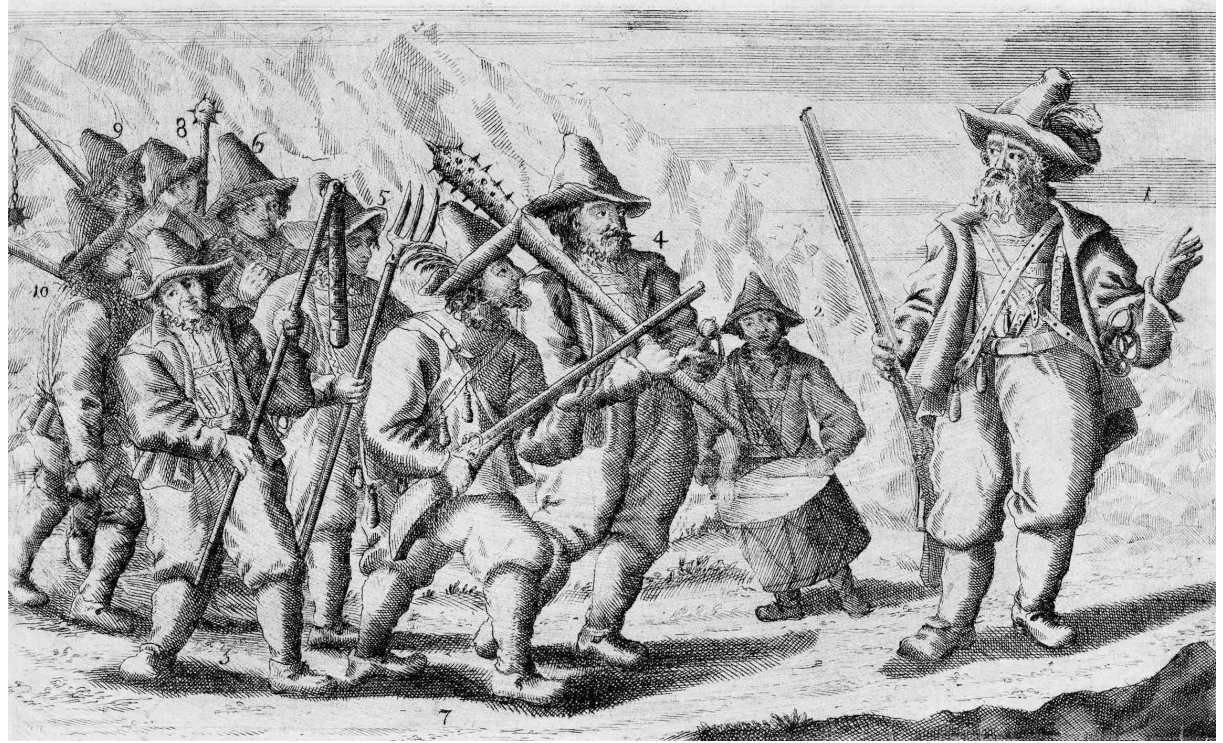

Abb. 10: Kupferstich zu Muster-Platz der Tyrolischen Bauern (Staats- und Universitätsbibliothek Dresden, Digitale Sammlungen, Hist.Austr. 198,1.p).

ihnen dann tapfer raufen 1,13 enchän] euren 1,15 wäl] solange 2 Rüepl] Kurzform von Rupert 3,1 äbwinden] scheitern 3,2 än Stil dä Hackä finden] ein Mittel zum Zweck finden, eine passende Waffe finden 3,3 Trischel] Dreschflegel 3,4 Batzen] Stockschlag auf die Hand 4 Bärschtl] Kurzform für Sebastian 4,1 Kolben] Knüppel, Keule 4,2 dä Buggel grausen] vom Entsetzen gepackt werden 5 Grögä] Gregor 5,1 äm] einen 5,5 auffs nächst] in Zukunft 6 Blasel] Kurzform von Blasius 6,1 Schweinfurts-Engeln] Schweinfurt: Reichssstadt in Bayern 6,2 Willkumb] Empfang 6,2 Pengeln] Zillertaler Dreschflegel, Ahornzylinder mit durchgestecktem krummem Stab an einem Ende 7,1 Knütteln] Keulen 7,2 Grind] Schorf, Krätze, Hautausschlag; hier: die krätzigen Schädel 7, 4 Leckä] Sprung in einem Geschirr, (allgemein:) Schaden, Beschädigung 8,1 Berscht] Borst (Kollektivum für Borsten) 8,2 Tremeln] Streitkolben 10,4 jen] ihr 10,6 vil gescheidä] auseinandertreiben und so kampfunfähig machen

Die sprechenden Namen, die humoristisch überzeichnete Kraftmeierei der Amateurkrieger, ihre dürftige Ausrüstung und die topischen Elemente der Brandreden lassen keinen Zweifel, dass es sich bei diesem Propagandatext nicht um eine wirklichkeitsgetreue Situationsschilderung handelt. Entstanden offensichtlich nach dem spektakulären Erfolg an der Pontlatzer Brücke, zielte die Agitation nicht auf die Legendarisierung historischer Persönlichkeiten (auch wenn Laninger unmissverständlich nach dem Vorbild des Gerichtspflegers Sterzinger gebildet ist). Die Stilisierung realer bäuerlicher Abwehrkämpfer zu Kriegshelden hätte nicht zuletzt die nicht allzu ruhmreiche Rolle der kaiserlichen Militärprofessionisten und regulierten ständischen Truppen in ein bedenkliches Licht gerückt. Mit der ,unsterblichen', garantiert kaisertreuen Kunstfigur Laninger und typisierten Tiroler Bauernberserkern ließ sich die patriotische Landesverteidigung auf einer allgemeineren - und unterhaltsameren - Ebene als vorbildlich inszenieren. Der 
eigentlichen Botschaft, auch in ausweglosen Situationen auf Gott und das Vaterland $\mathrm{zu}$ vertrauen und für dieses zu kämpfen, tat dies keinen Abbruch. Es ist zu vermuten, dass der unbekannte Autor des Propagandablatts nicht aus Tirol stammte und von den Vorgängen wohl auch nur über diverse ,Kriegsrelationen' informiert war. Ein Hinweis dafür ist zumindest die verwendete Mundart: ein einigermaßen neutrales Mittelbairisch, das nur mit einigen Frikativa vorwiegend in den Personennamen („Chrischtl“, „Barschtl“) Tirolerisch simuliert. Auch die Gegenseite war überzeugt, dass hinter dem höchst erfolgreichen Pasquill der Wiener Hof stand. In seinen Verträulichen politischund Historischen Discursen erbittert sich etwa der Bayer P. Mannhart Kriegensdorffer (wohl ein Pseudonym) über derartige Schmähschriften und fordert entsprechende Konsequenzen:

Bey welcher Beschaffenheit ich nit begreiffen kan / was man zu Wienn für Ursach habe, von der Chur-Bayrischen Entreprise in Tyrol - und von der gantzen unserer Nation - vorderist aber von unserm in Wahrheit- und der Sach selber Königlichen Helde / so schimpfliche Pasquill ins Kupfer- und im Truck kommen zulassen / als man diser Tagen, in 3.erley Stucken zusehen und zulesen gehabt: deren zwey dem Tyrolerbaurn Marthin Lainniger- und das 3.te dem so genannten Christl Troyling zuehren der Chur-Bayrischen Armée aber zum Hohn verfertigt und concipirt worden; Darfür denen Authorn gewiß niemand anderer als der Hencker den Lohn geben sollte: Wiewohl / vor etwan 24. Stunden ein fürnehmer Patriot hierüber also gescherget [sic]/ daß man die aberwitzigen Wienner nur immer mit papierenen Pralereyen fechten lassen - unsers theils aber mit Land und- Vestung einnemmen wacker fortfahren - und auff die letzt acht geben sollte / wer / auß disen beeden Kämpfern, das Gewinnet darvon tragen werde[.] ${ }^{45}$

Die angesprochenen und noch weitere Flugblätter ${ }^{46}$ belegen, wie wirkungsmächtig die agitative Mythenbildung war. Allein schon der Muster-Platz hat zumindest zwei Auflagen ( 1500 Exemplare) erlebt, wobei man sich die Mühe machte, den originalen Kupferstich nachzustechen. ${ }^{47}$ Mit dem 40-jährigen, kaisertreuen Christl Troyling schuf man dem älteren Laninger ein gleichfalls fiktives Bauernführer-Pendant, das sogar eine Audienz in Wien erhalten haben soll; beide Figuren hatten - als historische Persönlichkeiten verkannt - ein reiches literarisches Nachleben. ${ }^{48}$

45 Nutz- und Lust-erweckende Gsellschafft Der Vertrauten Nachbarn am Isarstrom: Das ist: Etlicher - in selbiger Chur-Bayrischen Refier wohnender guten Freund. Verträuliche- politisch- und Historische Discursen über allerhand Zeit-läuffige Begebenheiten, und dardurch veranlassende Materien. Vierter Theil. Außgefertiget Vom Herrn P. Mannhart Kriegensdorffer. [München:] Und Getruckt im Jahr deß Heyls 1703, S. $227 \mathrm{f}$.

$46 \mathrm{Zu}$ nennen sind u. a. zwei illustrierte Blätter zur Befreiung der Festung Rattenberg, eines davon mit deutschem und niederländischen Bericht sowie eine satirische „Grab-Schrifft / Welche der Helden-müthigTyrolerische / seinem Aller-Genädigesten Keyser / und Herrn / Herrn / etc. etc. träu-bleibende / Bauer MARTIN LANINGER/ Als ein Anführer seiner Mit-Gesellen / denen / mit Frantzosen behafften / Bäyren (ihren andern Nach-folgern zu einem NB.) so / gleichsam nach Art deß alten Testaments / meistens von sothanenen zwischen denen Tyrolerischen Bergen aller-jüngest versteiniget worden / verabfasset haben solle“, in der die gefallenen „Bäyrische[n] Soldaten,/ Voll mit Frantzosen-Gifft beladen“ [f. 1r] verspottet werden. Vgl.auch Bayerisch-Tirolische G’schichten ... eine Nachbarschaft. Bd. 1: Katalog. Innsbruck: Landesmuseum Ferdinandeum 1993, S. 168-170.

47 Für diesen Hinweis sei Marko Ikonić herzlich gedankt. Der vermutlich ältere Druck zeigt die Kämpfergruppe mit grimmigeren Gesichtern; das auch online einsehbare Exemplar der Sächsischen Landesbibliothek - Staats- und Universitätsbibliothek Dresden gibt sich etwas weniger martialisch.

48 So etwa in Joseph Anton Destouches' Arco-Drama (1806), in Johann Kalchbergs Erzählung Die tapferen Tiroler (nach 1810) oder in einem Dialektgedicht Karl von Lutterottis (1854). 
Auch im östlich angrenzenden Oberösterreich war man angesichts der bayerischen Militäroperationen nicht untätig geblieben, Schützenlisten wurden erstellt, Magazine angelegt, administrative Verteidigungsstrukturen geschaffen, zusätzliche Truppen angefordert. ${ }^{49}$ Am kaiserlichen Hof in Wien war man sich der Wichtigkeit dieses künftigen Kriegsschausplatzes bewusst und organisierte trotz fehlenden Kapitals Anfang 1703 ein Heer für einen Präventivschlag, der im März mit einem bayerischen Gegenangriff erwidert wurde. Während des Tiroler Feldzugs kam es immer wieder zu Plänkeleien, Plünderungen und Drangsalierungen der Bevölkerung auf beiden Seiten. Mit einigem Glück konnten sich die Bayern im Herbst wieder aus dem Würgegriff der kaiserlichen Truppen befreien und starteten im Jänner 1704 eine neue Offensive Richtung Osten. Passau wurde recht einfach eingenommen, da die kaiserliche Besatzung schwach und die Unterstützung der Bauern kaum vorhanden war; auch Peuerbach und Eferding wurden besetzt und zu Kontributionszahlungen genötigt, bevor man sich ins Winterquartier zurückzog. Bei kleineren Überfällen in den folgenden Wochen wurde versucht, die oberösterreichische Bevölkerung mit Gewaltexzessen einzuschüchtern. Nun erkannte der Wiener Hof, dass die in Auflösung geratene Landesverteidigung neu organisiert werden musste. Da der chronische Geldmangel den Einsatz regulierter Truppen beschränkte, setzte man auf eine Generalmobilmachung. Am 12. Februar wurden alle waffenfähigen Bewohner des Hausruck- und Traunviertels - mehr als 10.000 Mann - zu den Sammelstätten beordert und je nach Bewaffnung zugeteilt.

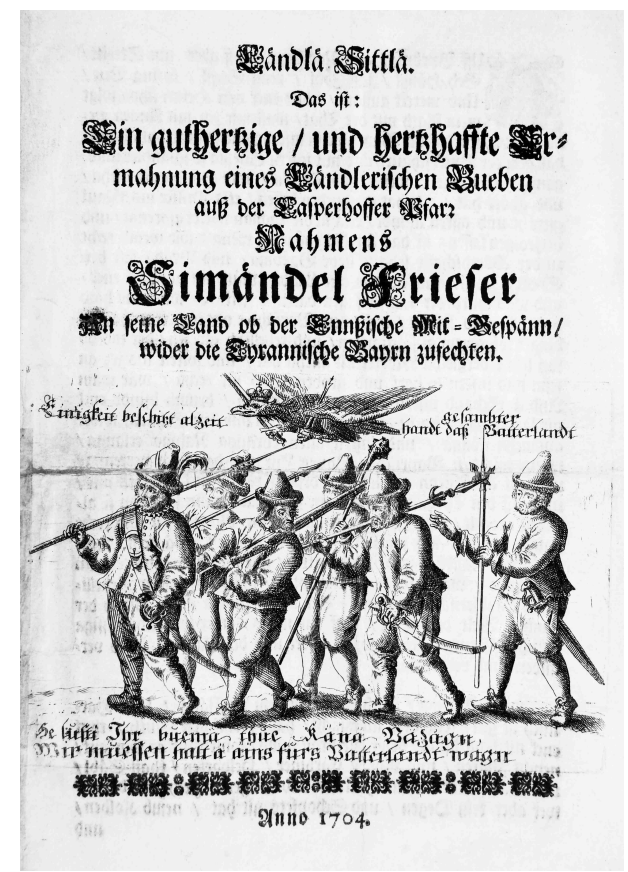

Abb. 11: Titelblatt von Ländlä Sittlä (Oberösterreichisches Landesarchiv, Flugschriftensammlung, Schachtel C2).

49 Vgl. hier und im Folgenden Hochedlinger, Oberösterreich im Spanischen Erbfolgekrieg. 
Begleitet wurde die Rekrutierung mit massiver medialer Agitation, um die Bauern, die aufgrund der unzähligen Steuerlasten, Dienste, Zwänge und Auflagen (v. a. etwa die Wildhegebestimmungen) nicht ohne weiteres gewillt waren, für ihre Herrschaft das Leben zu riskieren, auf Linie zu bringen und gegen den Feind einzuschwören. Auch hier war es eine wirksame Strategie, mit berichteten Greueltaten die unmittelbare Bedrohung von Leib und Leben vor Augen zu führen, zugleich aber auch mit jüngsten Erfolgen gegen die bayerischen Aggressoren Kampfbereitschaft zu schüren. Ländlä Sittlä, der erste Teil einer inhaltlich und formal miteinander verknüpften dialektalen Propagandaschriftserie, wird bereits Ende Februar 1704 unter die Leute gebracht worden sein. Der Autor des mit einem martialischen Kupferstich versehenen doppelseitigen Drucks bleibt anonym; seine ,Ermahnung، zur Einigkeit im Kampf für das Vaterland, die Elemente des Propagandalieds mit Kriegsberichterstattung im oberösterreichischen Basisdialekt verbindet, legt er dem (natürlich fiktiven) Gaspoltshofer Bauernburschen Simändel (Simon) Frieser in den Mund:

AUff Buebma / auff Nachbarn / auff alles zum Streitt / Geh Hänßl / läff Jodl / renn Steffl / spring Veit / Und merckt auff mi / i bitt enck von Hertzn scho / folgt mein Rath mit der That / wail mir jetz mit Augen gseha hambd / wie daß der Bayrfürst in insern Land so grob hat ghaust / daß aim der Buckl schaurt / und mit insern Buema so schändler umbganga / daß mas ä weder von Türckn / und Haydn nit gsehä und ghört hat / etla hat er schinden lassen / etla Pulfer ins Maul gsträht und afften azündt / etla in die Donau nacket gsprengt / und derfroissen lassen; ist das ä redlä? warst ä weng; wir wemb recht zu der Würthschafft seha / liebe Buebma / und Brüda last den Spott / Noth / und Todt inserer Lands-Leuth nit ligen äff enck / und was wurd der Kayser sagen darzu? gelts Er wurd ins bald vorupffa und straffa / daß insere Vorfahrer mit dem Stepha Fädinger wieder iem auffgestanden / und rebellisch gwesen / der ins dö soy lebta dergleiha Marter nit antha hat / und solten ins iez an seim und insern so hart und groben Feind nit recha / wär main Ayd ä Schand insern gantzen Nachkömblä / drumb bsints enck nit lang / dann jetzt ist die beste Zeit / daß mir dise Schartn wider außwetzen könna / und insern alten ehrlinga Nahma erlanga / wann mir den Bayrischen Baurn Tyran / das Loch verrenna / und nit äff Wienn ahi lassen; drumb richts enck / folgts mir / und last den Tyrolarn die Ehr nit gar allai/ [... $]^{50}$

Buebma] Burschen, junge Männer Jodl] Kurzform für Georg enck] euch gseha hambd] gesehen haben aim der Buckl schaurt] ihm das Entsetzen kommt schändler] schändlich etla] etliche, einige gsträht] gestreut afften] dann azündt] angezündet derfroissen] erfrieren ä redlä] auch redlich warst] (wohl fälschlich für ,warts‘:) wartet wemb] werden äff enck] auf euch vorupffa] etwas vorhalten Stepha Fädinger] charismatischer Oberhauptmann der aufständischen Bauern im oberösterreichischen Bauernkrieg gegen die bayerische Besatzung 1626 dö] fälschlich für ,do‘: doch soy lebta] sein Lebtag, zeit seines Lebens antha] angetan main Ayd] Beteuerungsformel Nachkömblä] Nachkommen äff Wienn ahi] nach Wien hinab

Ob der Verweis auf die ,Schande‘, im Bauernkrieg gegen den Kaiser (eigentlich aber gegen die tyrannische bayerische Besatzung unter Graf Herberstorff) aufbegehrt zu haben, tatsächlich motivierend war, darf angesichts der Popularität des Bauernführers Fadinger, der noch immer inakzeptablen Lebensbedingungen für den bäuerlichen Stand und nicht zuletzt aufgrund des hohen Anteils an Kryptoprotestanten in Oberösterreich durchaus angezweifelt werden. Wirksamer war sicherlich die plastische, quasi-simultane Schilderung, was man von den grausamen Feinden zu erwarten hatte und wie sie zu bekämpfen

50 Ländlä Sittlä. Das ist: Ein guthertzige / und hertzhaffte Ermahnung eines Ländlerischen Bueben auß der Casperhoffer Pfarr Nahmens Simändel Frieser An seine Land ob der Ennßische Mit-Gespänn / wider die tyrannische Bayrn zu fechten. Anno 1704, f. 1v. 
wären. Dass man hier wie so oft auch mit falschen bzw. manipulierten Angaben operierte, gehört zum Wesen des Genres:

Losts Nachbahrn eben da mir davo reden / kombts Brad Micherl Bue gantz schnauffet / und schwitzt wie ä Bayrische Sau / was no mehr bey aitler Nacht / vor lauter Forcht und Schröcka hat er d'Hosen und s'Jauck-Gschier vagessn / und vo lauta Zitarn kan er käm reden / so vil mä västeht / sagt ä / daß deß Bayrfürsten Lands-Knecht Jomä und Noth zu Franckamarkt mehr angfanga habn / mä hat ihnen z'fressn und z'sauffn und ä Gelt zur Cotiburzio (wies d'Narren jezt nenna) geben.

Aber dano seynd d'Schelma so GOtts jammerli mit insern Buma und Burgern umbganga / und wies d'Häusa anzind / seynd d'Leuth zugloffa / habens Feuer dempffa und röttn wölln / aber die Türckischen Wäschel seynd vor etlich zwaintzig Jahr nit so Tyrannisch mit den Christn umbganga; Dann Bayrn haben etli Leuth ins Feuer gworffa; deß Wöba Lentzel / der so bräff lesen und schreibn hat könna / ist ä von Bayrn z'haut / und in Feuer verbruna.

Ja so gar d'Weiba / und d'Menscha beym spina haben kain Frid g'habt / und werdn vil inserne Dirn Bayrische Gauß-Raben tragen müssn / und das haben d'Narren mit Fleiß tha / nur daß mir Ländla von insern lieben Kaysa ins a'wenden / und rebellisch werdn soll / jö gäß schauts Lindmayr Simändl ist ä scho nacha kemma / und sagt / daß unsre Buma also erbittert wärn / und 3000. auf Beyrbach in voll Zorn und Grima gloffa / dorten über 400. Bayrische Land-Knecht tedt / welche eben von insern Nachbarn Cotribuzo-Gelter pressen wollen. ${ }^{51}$

Losts] hört mir] wir kombts Brad Micherl Bue] kommt der Sohn des Michael Brad/Breit schnauffet] schnaufend was no mehr] darüber hinaus aitler] hier: tiefer s'Jauck-Gschier] Zuggeschirr, hier scherzhaft für: Brustfleck, Hosenträger ä] er Jomä] Jammer Cotiburzio] Kontribution dano] danach Buma] Buben, jungen Männern anzind] agezündet zugloffa] hingelaufen Wäschel] Schimpfwort deß Wöba Lentzel] der WeberSohn Lenz ä] auch Menscha] Mädchen Dirn] Mädchen Gauß-Raben] Vergewaltigungskinder tha] getan Ländla] Bauern aus dem Landl (volkstümliche Bezeichnung v. a. für das oberösterreichische Kernland, etwa zwischen Wels, Vöcklabruck und Gmunden) jö gäß] Ausruf (wohl Verballhornung von Jesus) Simändl] Koseform von Simon nacha kemma] nachgekommen Beyrbach] Peuerbach tedt] getötet

Bizarr scheint es freilich, zunächst wider die Entmenschlichung des Gegners zu wettern, der mordbrennend und vergewaltigend durch die Lande zog, um dann nach dem alttestamentarischen Vergeltungsprinzip eben diese Kriegsverbrechen selbst von den eigenen Leuten einzufordern:

Aber frisch auff Nachbarn ä Kayserischer General hat grosse Lieb an insern Buema / und haben sich scho 3000 von lauter bräffn insern Lands-Leuthen zu ihn mit Leib und Blut zamb geschworen / ins Bayrfürsten Land einz'fahln / und senga und brenna / was nur antreffa / wöllens zu Butza und Stingl hauen. Drum sämbts enck nit lang / mir wölln halt nachi alls zamb schlagn helffa. ${ }^{52}$

von lauter bräffn] von den besten zamb] zusammen zu Butza und Stingl] (eig. Apfelgehäuse und Stengel) kurz und klein sämbts enck] säumt euch

Von selber Hand stammen drei weitere Propagandaschriften, die das Thema erweitern und nun durchgehend in Versen gehalten sind. Zeitnahe zu Ländlä Sittlä dürfte auch Denck- und Lobwürdiger Land-Tag Oder Neu-gehaltener Kriegs-Rath Der Ländlerischen Bauren verfasst worden sein. Es übernimmt das Aktionsmodell des MusterPlatzes, indem auch hier nun typisierte, auf dem Titelkupfer zugeordnete Kunstfiguren mit sprechenden Namen die Kampfstärke ihrer Pfarren und Strategien der Feindabwehr präsentieren.

51 Ebda., f. 2r.

52 Ebda., f. $2 v$. 


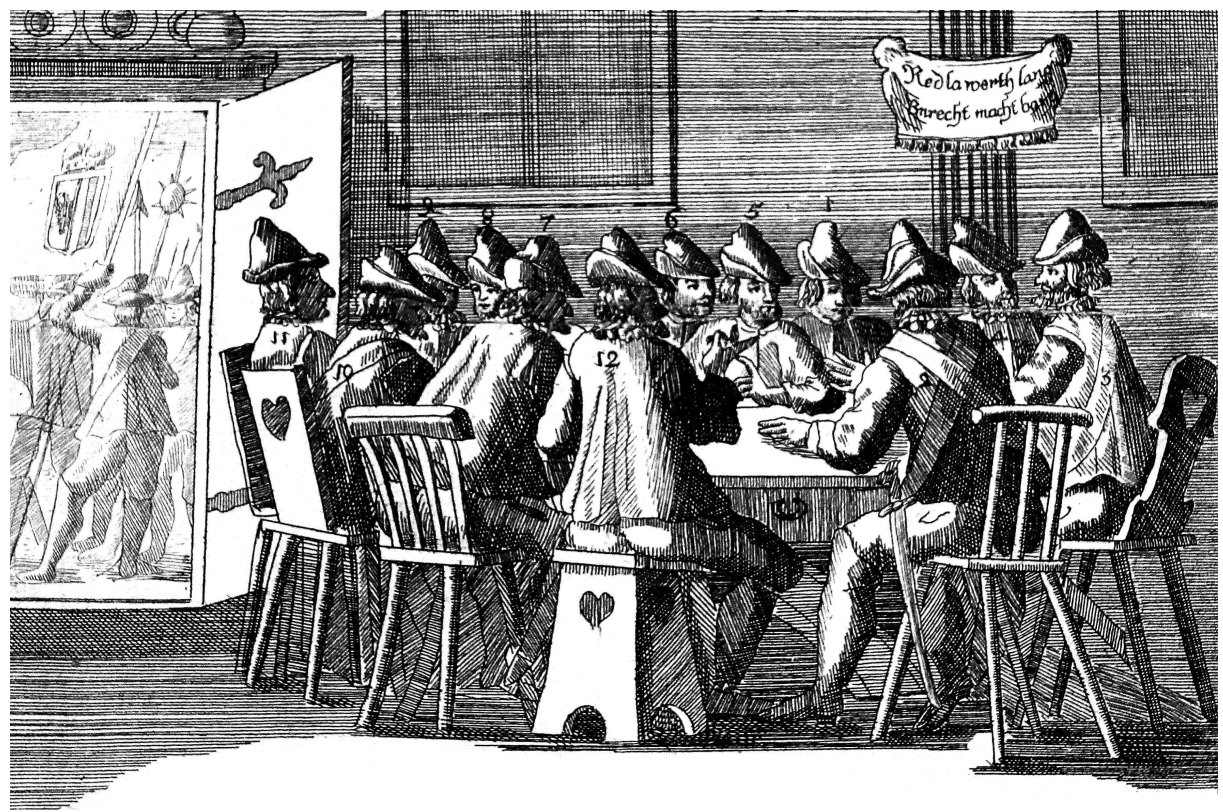

Abb. 12: Titelkupfer zu Denck- und Lobwürdiger Land-Tag (Oberösterreichisches Landesarchiv, Flugschriftensammlung, Schachtel C2).

Argumente und Schreckbilder der ersten Schrift werden wieder aufgenommen und künstlerisch überformt, neue kommen dazu. Bemerkenswert sind dabei vor allem die Hinweise zur Zwangsrekrutierung („Und der si will spreitzn / den nimbt man mit Gwalt / Außgnomma was z'jung ist / und öppa gar alt") und zur Exekution Fahnenflüchtiger:

11

Lienhard Trutzbärtl / Richter in Dratenegger-Pfarr

UNd eh mir marschieren / fein alles vortragt/

Wann oiner davon will / daß man ihn todt schlagt/

Sinst möcht ins der Hauffa doch werdn zu gring/

Bey Henckn verbieten / daß koiner wegg spring. ${ }^{53}$

11 Dratenegger-Pfarr] Trattenegg: Ortschaft in der oberösterreichischen Gemeinde Schlüßlberg mit abgegangener Burg (damals im Besitz der Hohenecker) 11,1 mir] wir

Verse wie diese verdeutlichen das herrschaftliche Interesse hinter der Schrift und sind wohl auch als Hinweis darauf zu lesen, dass die Mobilmachung keineswegs nur auf Zustimmung bei der bäuerlichen Bevölkerung getroffen war. Auch das grundsätzliche Verhältnis zu den Bayern wird nun reflektiert; immerhin gehören auch sie zum potentiellen Rezipientenkreis:

53 Denck- und Lobwürdiger Land-Tag / Oder Neu-gehaltener Kriegs-Rath Der Ländlerischen Bauren. Welcher Im Februario / Anno 1704. auff Anfrischung und hertzhafften Ermahnung deß fix- und gewixten Buebm Simändl Friesen / von zwölff Richtern im Marckt Efferting ober Lintz / wider alle Feinde deß Hauß Oesterreich zu kriegen / gehalten worden. Und Was in diesem Rath geredt / und abgehandelt ist / hat der Gerichts-Schreiber allda J: C: M: solches in deren Mutter-Sprach in folgenden Reimen gestellt / und einem guten Freund nach Lintz überschickt. [o. O., 1704], f. 3v. 
4

Wolff Trapp/Richter von Wildberg am Haselgrabn

ES sänd ja die Bayrn sinst gute Land-Leuth/

Wan i nur oin gseha / so hats mi glad gfreut/

I glaub sie sänd gschloffa in andere Hosen/

Der Tuiffl hats bschissn mit lauter Frantzosen:

Si hieten sein Lebta ä söltes nit gwagt/

Nur oiner ist schuldi / so hat man mir gsagt.

Do gleiwohl ists gscheha / und wer sie ä seynd/

So sänd sie deß Kaysers / und insere Feind;

Sie thun ja fast alles da dortn außstrieln/

Kain Pfifferling lassens / den sie nit durchwieln/

Drumb maini wer soll ins für übl außdeutn?

Wan mir so schlimm Nachbarn mit Kolben außleuthn.

Wo aber ain ehrlinger Bayr möchte seyn/

Der misch sich in inseren Handl nit ein/

Den redlingä Bayrn mir gebn die Ehr/

Der falsch ist der komb nur ins Ländl nit mehr. ${ }^{54}$

4 Wildberg am Haselgrabn] Ort mit ältester Burganlage des Mühlviertels und Schloss der Starhemberger (heute: Gemeinde Kirchschlag bei Linz) 4,3 gschloffa in andere Hosen] sind verändert, haben sich ein anderes Verhalten angeeignet 4,5 hieten] hätten sein Lebta] zeit seines Lebens ä söltes] so etwas 4,7 ä] auch 4,9 außstrieln] ausrauben 4,10 durchwieln] durchwühlen 4,11 maini] meine ich 4,15 redlingä] redlich 4,16 Ländl] volkstümliche Bezeichnung für das oberösterreichische Kernland, insbesondere das Hausruckviertel mit Teilen des Traunviertels, etwa zwischen Wels, Vöcklabruck und Gmunden

Deutlich humoristischer inszeniert ist der dritte Teil der Propagandaserie Unlängst beschehene wunderlich und lächerliche General-Musterung der Ländlerischen Bauren, der nun die 12 im Denck- und Lobwürdigen Land-Tag vorgestellten Bauernführer an der Spitze ihrer je 2500 Mann starken Kontingente zeigt (nun allerdings ohne illustrierenden Kupferstich). Mit aufmunternden Worten geben sie ihren kampfunerfahrenen Leuten, die mit archaischen Gerätschaften und zweckentfremdetem Werkzeug angetreten sind, die letzten Instruktionen vor der Schlacht. So etwa der bereits bekannte Wildberger Gemeindevorsteher:

4

WOLfF TRAPp / Richter VON WiLdBerg/ führt auf und exerciert auch 2500. Buebm mit Schwingl und Trischl.

WAn öppa der Feind soll mit Gwalt auf uns brecha/

Tröschts klein ab / daß man sie möcht zam recha/

Hebts alle zugleich auf / probiret enck a mahl/

Schlagst nida / last seha / was geits für ain Holl.

Du Rippl must wärla / der Tenn-Meister seyn/

Gibts öppes zu tröschen / so schlagts nu braff dreyn/

Vom Bayrischen Waytzen / d'Französisch Unkraut/

Nit leichtla werd bringa / schlagts tapffer auf d'Haut. ${ }^{55}$

4 Schwingl] Schlagteil des Dreschflegels Trischl] Dreschflegel 4,1 öppa] etwa, gar 4,2 zam recha] auf einen Haufen rechen 4,3 enck a mahl] euch einmal 4,4 geits] gibt es Holl] Hall, Ton 4,5 Rippl] Kurzform für Rupert oder Ruprecht Tenn-Meister] verantwortlicher Aufseher beim Dreschen 4,6 öppes] etwas

54 Ebda., f. 2v.

55 Unlängst beschehene wunderlich und lächerliche General-Musterung Der Ländlerischen Bauren / Welche Gleich nach gemeltem Land-Tag und Kriegs-Rath / in Februarii/ 1704. durch eben die zwölff Richter selbi- 
Die schon im Titel angekündigte Lächerlichkeit des Unterfangens korrespondiert mit der realen Unzulänglichkeit des Landsturm-Aufgebots, das den bayrischen Söldnertruppen an Mannstärke zwar überlegen, militärisch aber unterlegen war. Warum aber wurde dieses beunruhigende Faktum zu Zwecken des Amüsements ausgestaltet? Wären die Bauern die eigentlichen Adressaten, hätten Schriften wie diese deren Moral nicht gefährlich unterwandert? Es ließe sich vermuten, dass die Schrift - die zumindest drei Auflagen erreichte ${ }^{56}$ - erst entstand, als der Sieg über die Bayern bereits feststand und man die Lage aus der Distanz bereits humorvoll betrachten konnte. Allerdings bespricht sie Der neu-bestellte Agent von Haus aus bereits Anfang April und scheint die Informationen durchaus ernst zu nehmen. ${ }^{57}$ Die eigentliche Intention der Diffamierung könnte dementsprechend gewesen sein, dem Wiener Hof zu signalisieren, dass man auf mehr reguläre kaiserliche Truppen angewiesen war, da mit einem Haufen untrainierter Rekruten mit unzulänglicher Bewaffnung das Land ob der Enns überrannt werden würde. Ein Indiz dafür ist die fiktive Adressierung auf den Titelblättern: Gibt der Verfasser im Denck- und Lobwürdigen Land-Tag noch vor, er habe seine Dichtung „einem guten Freund nach Lintz überschickt" ${ }^{58}$, soll seine Lächerliche General-Musterung "gar nacher Wien überschickt worden sein “ ${ }^{59}$. In beiden Fällen stellt er sich mit dem Kürzel J. C. M. als Eferdinger Gerichtsschreiber vor - auch das wohl eine Mystifikation, da bislang in den Pfarrmatrikeln kein Eintrag gefunden werden konnte, der den Initialen entspräche.

Die letzte Schrift der Serie, ein Kurtzweiliges Gespräch / Oder: Bauern-Disputation / Eines Bayrisch-Tyrolerisch-Schwäbisch- und Schwartz-Wälderischen Bauren, ist ein eher lauer Abgesang nach der Zweiten Schlacht von Hochstädt, bei der am 13. August 1704 ein alliiertes Heer der Kaiserlichen und Reichsarmeeteile unter Prinz Eugen sowie englische Truppen unter dem Duke of Marlborough die französisch-bayerische Armee vernichtend schlagen konnten. Kurfürst Maximilian II. Emanuel musste mit Reichsacht belegt ins Exil, sein Land wurde von alliierten Truppen des Heiligen Römischen Reichs besetzt. In diesem Bauerngespräch sieht sich nun ein zwangsrekrutierter bayerischer Bauer mit Vorwürfen seiner Standeskollegen aus Tirol, Schwaben und dem Schwarzwald konfrontiert, die ihm ein Schuldeingeständnis abnötigen wollen:

gen Raths / in die 30000. Mann starck auff der Welser Heyd in zwölff Theil allerhand Gewöhrs abgetheilt, auff Steffa Fadingers Manier / folgender gestalt exercirt und angeführt worden./ Diese seltzame Musterung hat mehr gedachter Curiose Gerichts-Schreiber von Efferting / J. C. M. in folgenden Reimen gar nacher Wien überschickt. Gedruckt, im Jahr Christi 1704, f. 2v-3r.

56 Vgl. die in der Setzung und in der Dialektverschriftlichung leicht differierenden, ansonsten weitgehend identischen Drucke, die als Online-Digitalisate der British Library bzw. der Bayerischen Staatsbibliothek einsehbar sind. Der (verschollene) Erstdruck wies noch ein Titelkupfer mit zum Kampf gerüsteten Bauern auf, vgl. [Andreas Stübel]: Der neu-bestellte Agent von Haus aus / mit allerhand curieusen Missiven, Brieffen / Memorialien, Staffeten, Correspondencen und Commissionen, nach Erforderung der heutigen Staats- und gelehrten Welt. Der Ersten Fonction Erste Dêpêche. Freyburg / Bey Johann Georg Wahrmund / Anno 1704, S. 190.

57 Vgl. ebda: „Vor dem Jahr mußten wir der Tyrolischen Bauern Tapfrigkeit admiriren und rühmen/ [...] wer weiß / was noch ferner durch armselige Bauern / da die Noth am Mann gehet / gutes entstehen kan."

58 Denck- und Lobwürdiger Land-Tag, f. $1 \mathrm{r}$.

59 Lächerliche General-Musterung, f. 1 r. 
BAYR.

ICh bin mein Ayd nit schuldig daran / die Roll hat mich so troffen/

Meldts euch bey meinem Churfürst an / wann er nicht schon entloffen/

Im Schwaben-Land ein Kuh / drey Gänß / hab ich redla bekömmä/

Die Krägen habi mit der Senß / abghaut / afft thät ichs nemma.

TYROLER.

GElt mir hast nit getraut so wohl / du förchst di steini Bixen/

Bist nit weit kömmä ins Tyrol / nit gar hinein auf Brixen/

Den Weeg hast wider bald zuruck / in aller Eil / gefunden/

Was geist was hast schnell für Inspruck bist gloffen voller Wunden. ${ }^{60}$

13,1 mein Ayd] Beteuerungsformel 13,4 afft] dann 14,1 steini Bixen] Steinbüchse: Geschütze mit Steinkugeln Was geist was hast] was gibst, was hast: Redewendung für eine sehr eilige Aktion

Die Rede der vier Bauern, die auf der Titelillustration in ihren Trachten vorgestellt werden, ist nun schwächer dialektal markiert; nur der Schwabe darf deutlich mehr in seiner Mundart ,schwätza', von der allerdings nur der nach ,a' tendierende Schwa-Laut authentisch wirkt.

SO will ich auch verschona nix / kombt her ihr Cameratha/

Mit Spieß und Stanga / mit der Bix / im Land wend dir auffwartha/

Gänß, Enta / Hüner / Säu und Schaff / nemmen was wir verdapa/

Und der sich wörth / dem wend wir praff ains geba uff sein Schlappa. ${ }^{61}$

Bix] Büchse, Gewehr wend] werden verdapa] erwischen

Auch wenn in der letzten Strophe eine Versöhnung der vier Sprecher anklingt, deutet die Propagandaschrift an, was das unterlegene Bayern von seinen Feinden zu erwarten hatte. Tatsächlich wurde Bayern unter der österreichischen Besatzung rücksichtslos ausgebeutet. Leopolds Nachfolger Joseph I. ließ die Steuern drastisch erhöhen und ordnete Zwangsaushebungen an. ${ }^{62} \mathrm{Da}$ die kaiserlichen Soldaten beim Rekrutieren und Eintreiben der Versorgungsleistungen mit aller Brutalität vorgingen, kam es bald zu Aufständen in der bäuerlichen Bevölkerung, die wenig später auch durch Offiziere, Aristokraten und Beamte unterstützt wurden. Erste Rentämter (Regierungsbezirke) konnten übernommen werden, darunter Braunau, wo sich die kurbayerische Landesdefension organisierte und mit dem ,Braunauer Parlament' eine frühe demokratische Regierungsform mit Vertretern der vier Stände im Gasthof Breuninger tagte. Mit der Befreiung Münchens, das in der Christnacht 1705 von den im Sternmarsch vorrückenden Revolutionären mit Unterstützung einer Stadtbürgerwehr eingenommen werden sollte, erhoffte man sich ein Ende der Fremdherrschaft. Die kaiserlichen Besatzer allerdings waren vorgewarnt und besiegten in der ,Sendlinger Mordweihnacht' die Aufständischen; auch Gegner, die sich bereits ergeben hatten, wurden gnadenlos niedergemetzelt. ${ }^{63}$

60 Kurtzweiliges Gespräch / Oder: Bauern-Disputation / Eines Bayrisch-Tyrolerisch-Schwäbisch- und Schwartz-Wälderischen Bauren / Welche unlängst in einem Wirthshauß zusammen getroffen / sich / wegen zugefügten Schaden auf dem Lechfeld / verglichen / dapffer gesoffen / und durch J. C. M. in folgende Reimen geloffen. [o. O., o.V., o. J.], f. 3v.

61 Ebda., f. $4 \mathrm{r}$.

62 Vgl. Hochedlinger, Oberösterreich im Spanischen Erbfolgekrieg, S. 78-85.

63 Vgl. Christian Probst: Lieber bayrisch sterben. Der bayrische Volksaufstand der Jahre 1705 und 1706. München: Süddeutscher Verl. 1978. - Henric L. Wuermling: Die Sendlinger Mordweihnacht. 1705 - die erste 
Nach dem endgültigen Zusammenbruch des bayerischen Volksaufstands im Jänner 1706 versuchte der Wiener Hof dessen politische Bedeutung herunterzuspielen; man hatte erkannt, wie sehr dieses demokratische Gegenmodell an den Fundamenten des absolutistischen Staats rüttelte, und begann mit gezielter Propaganda, die Bayernerhebung als bloße Bauernrevolte ins Lächerliche zu ziehen. Ein instruktives Beispiel für diese Strategie ist ein Spottbild auf den Braunauer Landesdefensionskongress: ${ }^{64}$

Der Kupferstich Das Rebelische bayrn Parlament zu Brauna diffamiert die Abgeordneten, die wie beim Neu-gehaltenen Kriegs-Rath namentlich zugeordnet sind, als skrupellose Maulhelden, die sich von den Franzosen aufwiegeln ließen:

1. Der Franzos[ische] Hann so die Rebelische bayrn aufgeweckt.

2. Stadt Richter Martin Schalckh. Burger, Bauren und alle Lansleith, Get Schlagts Kaisa LandsKnecht Todt alzgleich.

3. Hofbaur Georg Hamershlag. i gei däzu mein hab und guet, Wans a glei gilt mai aigens bluet.

4. Millner und Stadschreiber zu filshoffen. Sagts engre meinug nur gsteift oh, denn unserm Churfürst ligt Mächtig vil dro.

5. Richter von Pläting Adam Zweiffelhafft. Ich sags engs grod und schweig nit still, der schluß hart käma wird zu end und zil. dan sKaisa leith seind starck und frisch, werden uns klopfa wie dstockfisch.

6. Schneider zu Brauna. Ich allein schlag 6 mann Todt.

7. Schulmaister Peter Limel. Sagts mirs na, wans get zum Räffä, dschuler bueben miessen al mit läffä.

8. Matthaeus Craus burger und Metzger zu Kelheimb. sols halt geltn mein balck und krogn, so will ich des Kaisa Soltaten Helfa daschlogn.

9. Pfarer $\mathrm{u}[\mathrm{nd}]$ bauren Commentant, so Camb eingenohmen. Die Heillig schrifft sagt klar und frey, daß nit zwey Herrn zu Dienen sey.

10. der Keyserl[ich] Allierte Soltat zeigt den Rebelischen bayrn Parlament die feigen.

11. Christoph Haltnvöst Stadtschörg. alle abdöckha und schörgenknecht, stehn eng a zu diensten recht.

12. ein Schwartzer Hund so dem Bayrischen Parlament auf das Concept Sch ... ${ }^{65}$

gei] gebe Wans a] wenn es auch filshoffen] Vilshofen, Stadt im Landkreis Passau, ab 27.11.1705 in Händen der Aufständischen engre] eure gsteift] wacker, mutig dro] daran Pläting] wohl Plattling, Stadt im Landkreis Deggendorf käma] kommen sKaisa leith] die Leute des Kaisers na] nur dschuler bueben] die Schulbuben läffä] laufen Matthaeus Craus] Matthias Kraus (1671-1706) besetzte im Dezember 1705 seine Heimatstadt Kelheim (Kreisstadt in Niederbayern) daschlogn] erschlagen Pfarer und bauren Commentant] gemeint ist Florian Sigmund Maximilian von Miller, Pfarrer von Oberviechtach, unter dessen Führung die oberpfälzische Kreisstadt Cham am Silvestertag 1705 eingenommen wurde zeigt ... die feigen] obszöne Geste, bei der der Daumen zwischen Zeige- und Mittelfinger gesteckt wurde abdöckha] Schinder eng a] euch auch

europäische Revolution. München, Wien: Langen Müller 1985. - Johannes Erichsen/Katharina Heinemann (Hg.): Brennpunkt Europas 1704. Die Schlacht von Höchstädt/The Battle of Blenheim. Begleitbuch zur Ausstellung in Schloss Höchstädt an der Donau, 1. Juli bis 7. November 2004. Stuttgart: Thorbecke 2004.

64 Zum historischen Hintergrund vgl. Herbert G. Brandstetter: Der bayerische Volksaufstand im oberen Innviertel. In: G'wunna hat z'letzt nur unseroans. Der bairische Volksaufstand 1705/1706 im Spanischen Erbfolgekrieg. Vom Innviertel nach Tölz, zur Sendlinger Mordweihnacht und zur Schlacht bei Aidenbach. Marktgemeinde Kopfing, Marktgemeinde Aidenbach, Bund der Bayerischen Gebirgsschützen-Kompanien (Hg.). Ried im Innkreis: Moserbauer 2005, S. 71-81. - Karl Härter: Early Modern Revolts as Political Crimes in the Popular Media of Illustrated Broadsheets. In: Malte Griesse (Hg.): From Mutual Observation to Propaganda War. Premodern Revolts in Their Transnational Representations. Bielefeld: transcript 2014, S. 309-350.

65 Bezirksmuseum Braunau am Inn, Kupferstich 11859 (zitiert nach der Abbildung auf Wikimedia). 
Neben historischen Persönlichkeiten des Aufstands werden in diesem bösartigen Spottbild auch fingierte Gegner mit sprechenden Namen verhöhnt. Die meisten von ihnen disqualifizieren sich schon selbst als ungebildete Rabauken durch ihr breites Bairisch. Nur Pfarrer Miller, aus einer oberpfälzischen Beamtenfamilie stammend, begründet standardsprachlich seine Vorstellung vom christlichen Widerstandsrecht mit einem Zitat aus der Bergpredigt, das aus katholischer Sicht freilich mit dem Paulussatz ,Jedermann sei untertan der Obrigkeit' (Römer 13,1) in Frage gezogen wurde. Im Vordergrund des Kupferstichs grunzend abgebildet ist die sprichwörtliche ,bayrische Sau' mit ihren nicht minder bösartig blickenden Ferkeln. Sie versinnbildlicht das gespannte Verhältnis zum ,Stammesbruder', dessen Schreckensherrschaft in Oberösterreich nach der Verpfändung im Dreißigjährigen Krieg (1620/21-1628) tief in der kollektiven Erinnerung verankert war. Auch in den folgenden Jahrzehnten konnten die Spannungen zwischen den Wittelsbachern und Habsburgern trotz einer mit dynastischen Verbindungen verfolgten Appeasement-Politik nicht gänzlich beseitigt werden und bekamen eine neue Qualität, als sich wieder eine günstige Möglichkeit bot, das Haus Wittelsbach als europäische Großmacht zu etablieren. Tatsächlich aber gelang dies in den folgenden Jahrzehnten einem anderen Rivalen: Brandenburg-Preußen, dem Antipoden Habsburgs im Heiligen Römischen Reich.

\section{Österreichischer Erbfolgekrieg (1740-1748)}

Als Kaiser Karl VI. 1740 starb, hinterließ er keinen männlichen Nachfolger, hatte aber schon lange zuvor in einem diplomatischen Kraftakt die Linealprimogenitur und subsidiäre weibliche Erbfolge durchgesetzt. Nach der 1713 erlassenen Pragmatischen Sanktion sollte die Thronfolge demnach an seine älteste Tochter Maria Theresia übergehen was aber von Seite verschiedener anderer europäischer Mächte in Frage gestellt wurde, die ihrerseits die Chance für Macht- und Gebietsgewinne nutzen wollten. Ansprüche auf das Habsburger-Erbe bzw. das römisch-deutsche Kaisertum stellten aufgrund verschiedener genealogischer Konstellationen Bayern, Sachsen, Frankreich und Spanien; Preußen wiederum verlangte für seine Anerkennung der Pragmatischen Sanktion die Provinz Schlesien. Deren Annexion führte zum Österreichischen Erbfolgekrieg, ein letztlich weltumspannender Krieg mit wechselnden Allianzen, der erst 1748 mit dem Frieden von Aachen endete. Einige Gebiete, insbesondere Schlesien, mussten abgetreten werden, insgesamt aber konnte Maria Theresia ihren Thronanspruch behaupten. ${ }^{66} \mathrm{Zu}$ Beginn des Krieges allerdings hatte kaum noch jemand an den Erfolg geglaubt: Dem modernen stehenden Heer Preußens hatte man zunächst wenig entgegenzusetzen, während zugleich der bayrische Kurfürst Karl Albrecht mit seinen von sächsischen und franzö-

66 Vgl. Reed Browning: The War of the Austrian Succession. Stroud: Alan Sutton 1994. - Michael Hochedlinger: Austria's Wars of Emergence. War, State and Society in the Habsburg Monarchy 1683-1797. London [u. a.]: Pearson Education 2003, S. $246 f f$. 
sischen Verbänden unterstützten Truppen nach Oberösterreich vorstieß, dann weiter nach Prag, wo er sich von den böhmischen Ständen zum König krönen ließ. Anfang 1742 wurde er in Frankfurt zum Kaiser Karl VII. gewählt und von seinem Bruder, dem Erzbischof von Köln, als erster nicht-habsburgischer Kaiser seit fast 300 Jahren gekrönt. Inzwischen aber hatten die Österreicher mit Hilfe der Ungarn zum Gegenschlag angesetzt und München eingenommen; Prag konnte wieder entsetzt, in Italien die Spanier mit Unterstützung Großbritanniens besiegt werden. Angriffe der Preußen ermöglichten es bayrischen und französischen Truppen allerdings, Bayern zurückzuerobern. Als Karl VII. 1745 starb, schloss sein Sohn Maximilian III. mit Maria Theresia den Frieden von Füssen, in dem er zusicherte, ihren Ehemann Franz Stephan von Lothringen bei der Kaiserwahl zu unterstützen.

In diesen ersten Jahren des Kriegs um die Habsburgische Erbfolge zwischen Bayern und Österreich begegnen uns dialektale Lieder in Flugschriften beider Seiten, in denen die jeweils eigene Position - oft gegen den eigentlichen Kriegsverlauf - als günstig dargestellt, Solidarität beschworen und die Feinde mit Hohn überschüttet werden. Deutlich wird dabei stets, wie Dialekt dazu dienen soll, eine manipulative Perspektive ,von unten ' zu fingieren, um an die Befürchtungen der Bevölkerung direkt anzuschließen und Zuversicht zu verbreiten. In dem österreichischen Lied GOtt grüß di mein Fräntzel entstanden offensichtlich im Sommer 1741 - berichtet etwa ein Bauer einem anderen besorgt, dass ein großes bayerisches Heer ins „Ober-Land“ einrücke; der andere versichert aber, dass die eigenen Truppen dem Feind „den Böltz präf außstauben“ werden, und weiter:

6

Die Ungarn mein Fräntzl die richten sich schon,

wolln ihm entgegen schicken bey zwölf tausend Mann, sie wurden dem Bayrfürst schickä so haim,

daß er nichts thät als flenä und wain.

7

Unser gnädigste Königin wird ä nit schweigen,

es wird dir den Bayrfürsten stattlä aufreiben,

so bald der Bayr ins Land herein ruckt,

so treibn ihm Tyroler ins Bayrn zuruck. ${ }^{67}$

7,1 ä nit] auch nicht 7,2 es] sie (hier: Personalpronomen der 3. Pers. Sing. Fem.) stattlä] gründlich

Lieder wie dieses sollten dem ,kleinen Mann' in seinem eigenen Idiom Vertrauen in die Regierung geben, berechtigte oder unberechtigte Ängste nehmen, Gerüchte dementieren und vorweg verhindern, dass man sich mit den Besatzern arrangierte. Identifi-

67 Vier schöne Neue Lieder, Das Erste: GOtt grüß die mein Fräntzel, etc. Das Anderte: Jackerl den Winter ists traurig gewesen, etc. Das Dritte: Ach hört wer vor der Thür, etc. Das Vierdte: O Heiliger Johann, Weltkündig ist dein Nahm, etc. Gedruckt in diesem Jahr. [o. O., o. J.]. Nach einer anderen Quelle erstmals abgedruckt in Anton Schlossar: Deutsche Volkslieder aus Steiermark. Zugleich Beiträge zur Kenntniß der Mundart und der Volkspoesie auf bairisch-österreichischem Sprachgebiete mit Einleitung, Anmerkungen und ausgewählten Melodien herausgegeben. Innsbruck: Wagner 1881, S. $286 f$. 
kationsfiguren aus dem Bauernstand repräsentieren dabei die patriotische Einstellung, die nicht von oben herab diktiert, sondern im quasi-authentischen Sprachausdruck als aus dem Volk kommend erscheint. Was hier - und bei vielen ähnlichen Bauerndialogen - auffällt: Untersucht man die Strophen darauf, wie die Rede auf die beiden Figuren verteilt ist, wer also im Lied was berichtet, wird deutlich, dass die Fiktion der Berichterstattung nicht durchgehalten wird; die Verteilung der Rede scheint vielmehr weitgehend willkürlich. Die Fiktion im Lied zielt also weniger darauf, eine authentische Szene abzubilden und so dem Publikum vorzuspielen, wie die Sorgen des einen besänftigt werden. Vielmehr ist das Lied als dialogisch in einem anderen Sinne zu begreifen, indem nämlich das Publikum selbst als eingebunden vorgestellt werden muss. Die zwei Namen bzw. Figuren im Lied fungieren insofern nur als Platzhalter, denen keine konsistente Rolle zugeschrieben werden muss, sondern an denen nur verschiedene Aspekte festgemacht werden, die dem Publikum angeboten werden und die Identifikationsmöglichkeiten eröffnen. Wenn dem Dialekt hier also die literarische Funktion der realistischen Abbildung alltäglicher Sprech- und Kommunikationsgewohnheiten zukommt, dann nicht im Sinne eines literarischen Realismus oder Naturalismus, dessen Ziel es wäre, die Figuren bzw. Situationen in charakteristischer Weise abzubilden. Vielmehr scheint die realistische Nachbildung dialektaler Kommunikation als identifikatorischer ,Türöffner zu dienen, auch im Kontext einer - fiktiven und im konkreten Fall wohl auch tatsächlichen - mündlichen Vermittlung.

Nicht nur feindliche Mächte stellten freilich die Rechtmäßigkeit der Thronfolge durch eine Frau in Frage. Auch das österreichische Volk selbst scheint ursprünglich seine Zweifel gehabt zu haben, die allerdings mit den ersten militärischen Erfolgen im Erbfolgekrieg und der erfolgreichen Bewältigung der Regierungsaufgaben schwanden. Diesen Eindruck versucht zumindest das folgende Lied zu erwecken, das die Herrschaft Maria Theresias über zugeschriebene, männliche' Attribute rechtfertigt (auch wenn freilich herausgestellt wird, dass sie gleichwohl immer noch auf die Kampfkraft der Männer zurückgreifen müsse):

1

$\mathrm{HAb}$ mein Lebtag nie vil ghalten, auf das Weiber-Regiment, habn kaum so vil Kittl-Falten, als daß sich ihr Sinn umwendt, mayn sie seynd all die bräffn, schreyn und rennä um in Haus, habn ein Hauffen läre Gschäften, richten nebenbey wenig aus. 3

Erstens hats der Preuß angriffä drin in Schlesien unvertraut, der Sachs der hat ihr ä zupfiffä, und hat auf sein Fortl gschaut, Bayrn, Frantzosen seynd ä kemmä in Böhmen und Oesterreich, grad, als wolt mä ihr als nemmä, gsäh ihm schier der Handel gleich.
2

Aber jetzt muß ich bekennä, $\mathrm{da}$ oft manche gscheyd regiert weill aus alln nur eine nennä: so die Cron in Hungarn führt, man thuts Maria Threßl tauffä, daß muß wohl ein strall-Weib seyn, thut mit König umä rauffä, und schlagt wie der Toiffel drein. 4

Man thut zwar im Sprichwort sagen, vil Hund seynd des Haasen Todt, hat sich doch bräf außi gschlagen, ist ihren Feinden schier ä Spott, Oesterreich hats widä gwunnä, und das halbe Bayrn dazu, Preussen, Sachsen seynd ä zwungä, daß sie haim gehn in die Ruhe. 
5

Jetzt seynd ä d'Frantzosen gloffen all weg aus der Prager-Stadt, gelt, es zittern ihnen d'Hosen, wissen nicht wo auf noch ab, die Kön'gin thut ä Bayrn noch bsetzen, mit ä grosser Kriegs-Armee, last sich nicht gleich außi hötzen, muß Frid oder gräfft seyn ehe. 7

Dann der Graf von Khevenhüller ist mein Ayd ä bräffer Held, und ein guter Kögl-Spiller, wo die Kugeln fliegn im Feld, ich möcht wohl das Spill nicht treibn, wann ich als ein Kögl stund, möcht mich ainer nider scheibn, daß ich nicht mehr aufstehä kunt.
6

Drum wird jeder sagn müssen, daß die Frau recht wohll regiert, hät kein Mann zsagen auf den Füssen, wie mans z'erst hat attaquiert, zu Hülf seynd die Hungarn kemmä, Weiber, loßt, was mä jetzt sagt, thuts enck nit zu viel übernemmä, d'Männa habnt die Feind verjagt. 8 Will vil lieber G'sundheit sauffä, vivat das Haus Oesterreich, daß den Frantzosen zam thut rauffä, und wird mit dem Bayren gleich, juhe thuts rund einschenckä, gsund der Königin fein doll, wann ich nur auf sie thue denckä, schmeckt mirs trinckä noch so wohl. ${ }^{68}$

1,3 Kittl] Rock 2,7 umä rauffä] herumraufen, kämpfen 3,4 Fortl] hier: Vorteil 3,5 seynd ä kemmä] sind auch gekommen 3,7 als] alles 3,8 Handel] Verrichtung, Angelegenheit 4,3 außi] hinaus 5,8 gräfft] gerauft, d.h: es muß zuvor Frieden werden, oder gerauft (gekämpft) werden 6,6 loßt] hört, horcht 6,7 enck] euch 7,2 mein Ayd] bei meinem Eid! (Redewendung zur Betonung der Nachdrücklichkeit) 7,3 Kögl-Spiller] Kegel-Spieler 7,7 nider scheibn] von ,Kegel scheiben', d. h. niederschießen 8,5 rund] passend, schön, ordentlich.

Dialekt kann aber auch, und das kommt in vielen Liedern zum Österreichischen Erbfolgekrieg zum Ausdruck, den Jubel über Siege und den Spott über die Gegner in besonders handfester Weise ausdrücken. Hilfreich dabei sind das reiche Spektrum an Schimpfwörtern und die vielfältigen Möglichkeiten des Tabubruchs, die den Dialekt als nichtnormalisierte Sprachform im mehrfachen Sinn für die Agitation prädestinieren. So sind die Lieder durchwegs geprägt von derbem Spott über die fremden Herrschenden und von unbarmherziger Schadenfreude über die Misserfolge und Schwierigkeiten der anderen Heere. In dem Ende 1744 entstandenen Lied von der „Pandurenth'resel“ etwa, das von bayerischer Seite die Österreicher und ihre Truppen aus den Kronländern angreift, wird nicht mit deftigen Bildern und unflätigen Begriffen gespart:

1

D’ Pandurenth'resel stolzmüthig floriert

Mit ihren Soldaten, so Schelmer und Dieb.

Husaren, Panduren, Razen, Krabat'n,

Seynd lauter Gesindel, wie's Herodes Soldat'n.

2

Der Th'resel Soldaten, die schau man nur an!

Wie viel gehen nackend, kein Montur haben's an;

68 Siben schöne Neue Gesänger. Das Erste: Lusti bin ich immerzu, ich sag dirs Urberl etc. Das Anderte: Bayrfürst und du ä Frantzos, könnts enck wohl etc. Das Dritte: Te Deum Laudamus ihr Völcker heut'singt, etc. Das Vierdte: Hab mein Lebtag nie viel ghalten, auf das etc. Das Fünfte: GOtt grüß enck mein Vattä und Muttä all zwey. Das Sechste: Menschä was soll das mehr seyn, die Sach etc. Das Sibende: Hösä mei liebe Frau mein Jahr das ist nun aus, etc. [o. O., 1743]. Abgedruckt in: Karl M. Klier: Historische Lieder des 18. Jahrhunderts aus Österreich. Zugleich ein Beitrag zur Metrik des Volksliedes. In: Jahrbuch des österreichischen Volksliedwerkes 8 (1959), S. 22-51, hier 31. 
Gar viel ihrer Soldaten die haben vor Schand

Den bloßen A... verdeckt mit der Hand.

3

Betracht man nur der Th'resel Pandurenregiment!

Es seynd ja viel Schön're in Galgen gehenkt;

Sie seynd so viel Niß und seynd so viel Läus -

Katzen finden in der ganzen Montur nit drei Mäus.

4

Schau einer nur d'Rothmänntler an,

Wie d'Läus herumkriechen, du kanst es schaun;

Es seynd lauter Räuber und Schelmer darbei -

Gelt? schöne Soldaten hat d'Königin, wie d'Säu! ${ }^{69}$

1,1 Pandurenth'resel], Panduren-Theresia': die Panduren waren ursprünglich meist kroatische, rumänische, ungarische oder serbische Soldaten, die die Grenze des habsburgischen Reichs gegen die Osmanen verteidigten; in der Zeit des Österreichischen Erbfolgekriegs bzw. der Schlesischen Kriege waren die Panduren eine besonders berüchtigte Einheit des österreichischen Heeres 1,3 Razen] Serben, auch griechisch-katholische Slawen 1,3 Krabat'n] Kroaten 4,1 d'Rothmänntler] der rote Mantel war Kennzeichen der Panduren

Die Verhöhnung der gefürchteten Panduren als rechtloses Lumpengesindel war freilich nicht allzu weit hergeholt, hatte deren Anführer, der Obrist Franz von Trenck, seine Männer doch aus allen Völkern des Balkans mit der Zusage angeworben, dass sie die beim Feind gemachte Beute behalten dürften. Weitaus empörender waren dagegen die Invektiven gegen das Oberhaupt der Truppen, die wohl auch deshalb sexuell konnotiert waren, weil das Ziel des Spotts weiblich war:

9

Jetzt, gelt, du mein Th'resel, bist g'fall'n in Dreck?

Lauf du nur g'schwind heim thu'n Sabel hinweck!

Du siehst ja, daß schon daher kommt der Preuß,

Sonst sicher er dir in dein Scheid hineinsch...

10

Ha, Th'resel, i mein, es dir ziemlich schon graust,

Weil du so gehest mit Drecknas'n in Schmaus

Den ungrischen Belz, sorgst, klopfen's dir aus -

In Böhmen hast a nit mehr ein Sch... haus. ${ }^{70}$

Freilich war auch die Gegenseite wenig zimperlich, wie etwa die Verspottung Karls VII. in Franzl, ich hab dirs gesagt belegt, das den frischgekrönten Kaiser als Herrscher ohne Reich und Macht bloßstellt, ${ }^{71}$ oder in Geh, Bartl, nihm ein Degen, das ihn als rücksichtslosen Feigling denunziert. ${ }^{72}$ Auch das folgende Lied, das sich gleichfalls von österreichi-

69 Hier abgedruckt nach der (sicherlich normierten) Fassung bei Ditfurth, Historische Volkslieder 1, S. 58f., der als Quelle nur angibt: „Liederbuch jener Zeit“. Zur Eroberung der Stadt 1741 und der Krönung Karl Albrechts hat sich mit D'Stadt Prag ist eing'nommen ein zeitnahes dialektales Lied von bayerischer Seite erhalten, vgl. Ditfurth, Historische Volkslieder 2, S. 336-39. Die Eroberung von Passau 1741 thematisiert Schau, Gori, wie geht's zue.

70 Ditfurth, Historische Volkslieder 1, S. 59.

71 Vgl. Karl Weinhold: Ueber das deutsche Volkslied in Steiermark. In: Mitteilungen des historischen Vereins der Steiermark 9 (1859), S. 61-84. Mit Franzl, ich will dir sagen findet sich ein weiteres Dialektlied aus dieser Zeit ediert.

72 Vgl. Leopold Schmidt: Historische Volkslieder aus Österreich vom 15. bis zum 19. Jahrhundert. Ausgewählt und kommentiert von L.S. Wien: Österr. Bundesverlag 1971. (Wiener Neudrucke 1) S. 95-98. 
scher Seite gegen Bayern und Franzosen wendet, macht deutlich, dass die „volkstümlich eingekleidete Staatspropaganda " 73 im Medium des Dialekts besonders erbarmungslos mit den Feinden umging. Hintergrund ist hier der sehr verlustreiche Rückzug der Franzosen aus Prag über Eger (heute Cheb im Westen Tschechiens) im Dezember 1742. ${ }^{74}$ Bei diesem Lied fällt auf, dass der Text zwar dialektal ist, aber vergleichsweise stark in Richtung Standard überformt scheint - insbesondere dort, wo standardnähere Formen den metrischen und syntaktischen Anforderungen der Versform eher entsprechen. Dialekt bildet also nirgends einfach authentische Rede ab; aber umgekehrt wird noch einmal deutlich, dass er in diesem Kontext durchaus bewusst eingesetzt wurde:

1

BAyrfürst und du ä Frantzoß, könts enck wohl kratzen in Kopf, habts gmaint habts Böhmer-Land, aber es müsts fort mit Schand, zu Prag werds lenger gern blibn, so hat enck der Hunger vertribn. 3

z'Prag ists ihm auch ä so gschen, z'Eger wirds wieder so wern, dann der Fürst Lokowitz, ja Bruder glaub mirs gwiß, hat schon umrungä die Stadt, d'Frantzosen leyden gröste Noth. 5 Vil tausend Frantzosen in Prag, seynd dir erhungert i sag, afft seynds auf Eger fort, habnt gmaint an selben Orth werns dä bekömmä Brod und Fleisch, aber es ist ä weit gfehlt. 7

Unsre Generaln und Oficier können d'Frantzoßen curiern, d'Medicin ist nit gut, man laßt ihnä nichts z'Essen zu, Stuck Kugel, Bommen glaub mir, das ist deß Frantzosen Cur. 9

Fiat es bleibt schon dabey, ich wünsch all unsern Generaln Gsundheit und langs Lebn, darzu bräff Beut darnebn, und allen Soldaten zugleich, daß sie kein Hunger thaint leydn. ${ }^{75}$

\section{2}

Der Frantzos der ist dir ä Mo, Hungä leyden ist er schon gwohnt, wann er kommt an ein Orth, so geht er ehe nicht fort, biß ihn der Hungä vertreibt, er ist ja warlä nicht gscheid. 4 Es wird nicht gar lang anstehn, d'Frantzosen die werden dir bald gehn mit dem hungringä Bauch, wern Eger beurlaubn, wern dä quittirn das Böhm, weil mä von ihna nichts will hörn. 6

Der General Fürst Lokowitz zaigt ihnen den lären Spiß, laßt ihnä kain Vogl zu, d'Frantzosen liebä Bue, schreyen dir von Hunger so sehr, daß mäs auf zwo Stund weit hört. 8 Von Bayrfürsten habnts dä nechst gredt, er solt sich gfangä habn gebn, ists wahr oder dälogn, das kan i dir nicht sagn, man thut jetzt wohl öffta was redn, von Loign darff mä kai Mauth niemahls gebn.

73 Karl M. Klier: Linz im Liede. In: Jahrbuch der Stadt Linz (1954), S. 553-580, hier 556.

74 Vgl. Klier, Historische Lieder des 18. Jh., S. 30.

75 Siben schöne Neue Gesänger (s. Anm. 67), f. 1v-2r. Ediert bei Klier, Historische Lieder des 18. Jh., S. 30; vgl. auch Klier, Linz im Liede, S. 556. 
1,1 Bayrfürst] gemeint ist der Wittelsbacher Karl Albrecht von Bayern (1697-1745) 3,3 Fürst Lokowitz] Georg Christian Fürst von Lobkowitz, 1686-1755, im Erbfolgekrieg Feldmarschall in Böhmen 6,2 lären] leeren 7,5 Stuck] Stück, Gestück: Kanone (als Kollektiv- oder Einzelbezeichnung) Bommen] Bomben 8,1 nechst] kürzlich 8,3 dälogn] erlogen 8,6 Loign] Lügen 9,1 Fiat] Sprachspiel mit ,fiat' (lat: es werde, so soll es sein) und ,Pfiat' (di Gott): ,Behüte' (dich Gott) 9,6 thaint] tun

Im Gegensatz zum Lied von der ,Pandurenth'resel' wird hier das lexikalische Potenzial für Hohn und Spott nur bedingt ausgeschöpft. Dennoch spielt Dialekt hier ebenfalls eine Rolle dabei, Grenzen des (sprachlichen) Umgangs mit Gegnern und Opfern des Krieges $\mathrm{zu}$ überschreiten, wenn etwa in fünf der neun Strophen mitleidlos die verhungernden Franzosen erwähnt werden. Noch drastischer schildert ein weiteres Lied derselben (wohl Linzer) Flugschrift (TE Deum Laudamus ihr Völcker heut singt) die Greuel des Kriegs an den Auswirkungen der Belagerung und des erzwungenen Ausfalls der Franzosen bei eisiger Kälte:

4

Nicht weit von der Moldau, i bitt dich betracht, da habns dir großmächtige Gruebnä aufg'macht, jetzt bild dir nur ein was dises mus seyn, da schmissens lauter todte Frantzosen hinein. 5

Man macht nicht vil b'sonders, man läut ihnen nicht aus, sie führns aufn Wägnä wie d'Scheitter hinaus, ja sehr viele Wägen wie die Zeitung hat g'meldt, daß bald mit Frantzosen hätten d'Moldau ang'schwellt. $[\ldots]$

10

Vil hundert Frantzosen an all Orth und End, lagen erfrorner auf alln Strassen behend, ja sehr vil Marode so kunten nit fort, müsten elend crepiren an manichen Orth. ${ }^{76}$

5,2 Scheitter] Holzscheite 10,3 Marode] erschöpft Liegengebliebene

Dialekt als schwächer regulierte, dominant mündliche Sprachform scheint geeigneter, solche Aspekte - insbesondere für Propagandazwecke - im Text zu transportieren. Die mundartliche Wendung in derart zeitnah kolportierten Liedern suggeriert aber auch, Nachricht aus erster Hand zu sein, vom Augenzeugen direkt und mündlich weitergegeben, ohne dass eine übergeordnete Instanz aus taktischen oder anderen Gründen steuernd in die Informationsweitergabe eingegriffen hätte. Die ästhetische Überformung, die mediale Verbreitung, die inszenierte Naivität: das alles spricht zwar gegen eine höhere Glaubwürdigkeit dieser Werke mit ihrer forcierten Mündlichkeit. Und doch lässt sich der Adressat zumeist gerne auf diese Fiktion ein, selbst wenn ihm die manipulative Intentionalität durchaus bewusst ist.

Zuweilen wird dieser Aspekt, die Zuverlässigkeit von Nachrichten bzw. die Authentizität der verbreiteten Berichte, in den politisch-historischen Liedern auch selbst zum Thema. Texte, die der feindlichen Seite gezielte Falschinformationen und lügnerische

76 Siben schöne Neue Gesänger (s. Anm. 67), f. 2r-v. 
Berichte unterstellen, gehören genauso hierher wie Texte, in denen der Mangel an verlässlichen Nachrichten oder das Abwägen verschiedener Informationen selbst dargestellt werden.

\section{Siebenjähriger Krieg (1756-1763)}

Gut können diese Zusammenhänge an Dialektkunst zum Siebenjährigen Krieg nachvollzogen werden. Dieser Konflikt, der in britisch-französischen Auseinandersetzungen in Nordamerika seinen Ausgang genommen hatte, weitete sich im Mai 1756 zum offenen Krieg aus, wobei letztlich alle europäischen Großmächte der Zeit beteiligt waren: Auf der einen Seite standen Großbritannien und Preußen (unter Friedrich II.), auf der anderen Seite Österreich bzw. das Heilige Römische Reich sowie Frankreich und Russland. ${ }^{77}$ Nicht umsonst wird in Zusammenhang mit dem Siebenjährigen Krieg häufig von einem ersten Weltkrieg gesprochen, ging es doch um Auseinandersetzungen von globaler Ausdehnung - nicht nur in Mitteleuropa, sondern auch in Amerika und Indien. Aus österreichischer Sicht stand freilich der Konflikt mit Preußen im Vordergrund, der seit dem Ende des Österreichischen Erbfolgekriegs weiterbestanden hatte, wobei es Österreich vor allem (und letztlich ohne Erfolg) um eine Rückeroberung des verlorenen Schlesien ging. Die kriegerischen Auseinandersetzungen zwischen Preußen und Österreich konzentrierten sich vor allem auf Teile Mitteldeutschlands, Böhmen und Mähren, wobei über die Jahre beide Seiten - und häufig unter extremen Verlusten - mehrmals vorrücken konnten und wieder zurückgedrängt wurden, ohne dass von einer der Parteien entscheidende Erfolge erzielt werden konnten. 1758 war die Lage für Preußen zunehmend schwieriger geworden, und nach der Schlacht von Kunersdorf 1759 schien die völlige Niederlage bevorzustehen; doch auch die Gegenseite konnte nicht zum entscheidenden Schlag ausholen. Erst Anfang 1762 wendete sich die Lage Preußens durch den Tod der Zarin Elisabeth: Ihr Nachfolger Peter III. schloss einen Friedens- und Bündnisvertrag mit den Preußen und ermöglichte ihnen so, mit den frei werdenden Kräften die Österreicher und Franzosen zurückzudrängen. 1763 kam es schließlich zum Friedensschluss, bei dem der Status quo ante bellum wiederhergestellt wurde. Auch wenn der Siebenjährige Krieg als vergleichsweise ,gezähmte‘, kontrollierte Auseinandersetzung gilt, ${ }^{78}$ zählt er dennoch zu den blutigsten Konflikten des 18. Jahrhunderts: Es wird von insgesamt über 500.000 gefallenen Soldaten und weiteren 400.000 Todesopfern bei der Zivilbevölkerung ausgegangen. ${ }^{79}$ Dabei war vor allem die bäuerliche Bevölkerung

77 Vgl. dazu allgemein Sven Externbrink: Einleitung: Der Siebenjährige Krieg - ein europäischer Weltkrieg im Zeitalter der Aufklärung. In: Sven Externbrink (Hg.): Der Siebenjährige Krieg (1756-1763). Ein europäischer Weltkrieg im Zeitalter der Aufklärung. Berlin: Akad.-Verl. 2011, S.9-26. - Marian Füssel: Der Siebenjährige Krieg. Ein Weltkrieg im 18. Jahrhundert. München: Beck 2010. - Hochedlinger, Austria's Wars of Emergence, S. $330 \mathrm{ff}$.

78 Vgl. Füssel, Der Siebenjährige Krieg, S. 9 und Externbrink, Der Siebenjährige Krieg, S. 14.

79 Vgl. František Stellner: Zu den Ergebnissen des Siebenjährigen Kriegs in Europa. In: Prague Papers on History of International Relations 4 (2000), S. 85-98, hier 86. 
aufgrund der erhöhten Abgaben, der Subsidialleistungen und Zwangsrekrutierungen besonderem Druck ausgesetzt. ${ }^{80}$

Nicht zuletzt war der Siebenjährige Krieg aber auch ein Medienereignis von besonderen Dimensionen: Der Krieg hat eine erstaunlich große Anzahl an Flugschriften hervorgebracht, ${ }^{81}$ darunter auch eine Fülle literarischer Bearbeitungen, häufig in Liedform. Von österreichischer Seite haben sich - meist als Flugschriften, zuweilen auch handschriftlich - allein über ein Dutzend in Dialekt verfasste historische Lieder über die Kriegsereignisse erhalten, die in der Regel anonym erschienen. Angesichts der zahlreichen Einfachüberlieferungen ist zudem davon auszugehen, dass nur ein Bruchteil derartiger Texte überliefert wurde. Allen diesen Flugschriften ist gemein, dass sie - neben ästhetisch-unterhaltenden Aufgaben - öffentliche und private Sichtweisen prägen wollen, um durch selektive und manipulative Informationsvergabe bestimmte Reaktionen beim Zielpublikum zu erreichen.

Die Frage der Authentizität und Glaubwürdigkeit von Informationen wird vor allem im gegen Ende des Kriegs entstandenen Dialog Der großmüthige Husar, und der besiegte Preußische Dragoner (1763) aufgegriffen. Während die meisten der dialektalen Kriegslieder sich in der fiktionalen Rahmung an die ungebildete und häufig illiterate Landbevölkerung wenden, ist dieser Text eher an ein gebildetes, bürgerliches Publikum adressiert, wie schon die formale Umsetzung in klassischen Alexandrinern nahelegt, die in der österreichischen Lyrik zum Siebenjährigen Krieg grundsätzlich vorherrschte. ${ }^{82}$ Aber auch hier wird die Diskrepanz zwischen regional markierten Sprachvarianten ästhetisch verwertet, spricht doch der ungarische Husar in - zumindest abschnittsweise deutlich dialektal geprägter Sprache mit ungarischem Akzent. Die sprachliche Gestaltung dient in diesem Zusammenhang weniger dazu, die Authentitzität des Berichts zu

80 Auch die widrigen Lebensumstände, denen die Bevölkerung ausgeliefert war, wurden in manchen Liedern erwähnt, etwa in dem deutlich kritischen Lied Ist einer weil dort wohl in der Stadt drinn (Vier schöne Neue Lieder, das Erste: König aus Preussen, was bildest dir ein etc. Das Anderte: O Preuß, du grausamer Tyrann etc. Das Dritte: Nächt hat mi mein Muttern in d'Stadt eini gscheckt etc. Das Vierte: Ist einer weil dort wohl in der Stadt darinn etc. Gedruckt in diesem Jahr. [Linz?, 1758], zitiert nach Klier, Historische Lieder des 18. Jh., S. 34f.), in dem es um die Behandlung von Rekruten und Fahnenflüchtigen geht, oder im Lied Auweh, das ist halt ein Leben (Fünf neue weltliche Lieder, Das Erste: von der Toback-Übergabe [o. O., o. J.]), in dem die Leiden der ländlichen Bevölkerung durch durchziehende Truppen geschildert werden (vgl. dazu auch ebda., S. 35 und 41f.). Nicht zuletzt spiegelt auch Maurus Lindemayrs Lied Gotts Sagrä! wen Siech $i$ var meinä die ernüchterte Sicht auf durch den Krieg bedingte Nöte der ländlichen Bevölkerung (vgl. Lindemayr, Dialektlieder II, S. 86).

81 Vgl. Manfred Schort: Politik und Propaganda. Der Siebenjährige Krieg in den zeitgenössischen Flugschriften. Frankfurt am Main, Wien [u. a.]: Lang 2006, S. 11. Schort weist darauf hin, dass aus keiner anderen Epoche der Frühen Neuzeit - abgesehen von der Reformationszeit und dem Dreißigjährigen Krieg - eine solche Fülle an Flugschriften bekannt ist (bezieht sich dabei jedoch weniger auf Liedflugschriften denn auf Berichte, Aufrufe und propagandistische Schriften während des Kriegs). Vgl. zu dem Zusammenhang allgemein auch Holger Dainat: Der Siebenjährige Krieg in den Medien. In: Wolfgang Adam/Holger Dainat (Hg.): „Krieg ist mein Lied“. Der Siebenjährige Krieg in den zeitgenössischen Medien. Hg. in Verbindung mit Ute Pott. Göttingen: Wallstein 2007. (Schriften des Gleimhauses Halberstadt 5) S. 9-26.

82 Vgl. Ingrid Eyer: Das lyrische und dramatische Werk Philipp Hafners. Seine weltanschauliche und stilistische Position in der österreichischen Literatur der Maria-Theresianischen Ära. Wien 1986 [Diss.], S. 20. 
unterstreichen, als die Figur des ungarischen Husaren als, österreichischen' Soldaten zu markieren - im Gegensatz zu dem Preußen, der Hochdeutsch bzw. auch norddeutschen Dialekt verwendet. Im Zentrum steht der Vorwurf an die Preußen, Niederlagen nicht einzugestehen, sondern sie wie Siege verbreiten zu lassen oder Zeitungsmeldungen zu fälschen: Gerade im Siebenjährigen Krieg war nicht nur die Frage relevant geworden, über welche Vorkommnisse berichtet wird und über welche nicht, sondern auch das Problem, wie der Ausgang einer Schlacht überhaupt zu deuten sei. Feldschlachten wie etwa die bei Lobositz 1756 ließen durchaus Deutungsspielraum zu, ob die ,Niederlage (der Österreicher) nicht eher als taktischer Rückzug zu interpretieren wäre und der ,Sieg ‘ aufgrund der hohen Verluste nicht ebenfalls als Niederlage. ${ }^{83}$ Vor diesem Hintergrund gesteht der gefangene preußische Soldat im Dialog selbst ein, dass die preußischen Zeitungen vor allem „Lügen stiften“, woraufhin er vom Husaren begnadigt wird:

\section{Preuss.}

$[\ldots]$

Doch weiß schon alle Welt, daß unsre Zeitungschriften

Die wahre Quellen sind, die solche Lügen stiften:

Sie schildern Sieg und Glück in ihrem Zeitungblat

Nach eignem Willen ab; [...]

Husar.

Du bist no redli Mensch! steh auf! du hab Pardon;

Weil du so Wahrheit red, drum di Husar verschon:

Nur möcht i wünsch, daß i statt dir das Zeitungschreiber,

Das selbst sein Landsleut fopp, das lüg wie alti Weiber,

In meini Händ thät krieg; i wollt mach Wahrheit red,

Wo nit, gleich Seel aus Leib mit meini Zischma trett!

Jetzt steck i Sabel ein! jetzt schenk Husar dir Leben! ${ }^{84}$

10 Zischma] (ungar. csizma) Halbstiefel

Das gängigste dialektalästhetische Schema, mit dem das natürliche Informationsbedürfnis der Staatsbürger bedient wird, ist die inszenierte Form des mündlichen Berichts: etwa durch einen offiziellen Boten, häufiger noch durch einen, einfachen Mann', der aus einem urbanen Zentrum als Nachrichtenumschlagsplatz die Neuigkeiten mitbringt, die er dort , aus direkter Quelle` erhalten habe. Die verschiedenen Möglichkeiten der Übermittlung werden dabei explizit angesprochen, insbesondere gedruckte „Relationen“ und „Zeitungen“. Rezeptionsform ist dabei in der Regel das ,Lesen Hören', wie etwa die einleitende Strophe in diesem Lied deutlich macht:

83 Vgl. Schort, Politik und Propaganda, S. 412ff. - Bernhard Jahn: Die Medialität des Krieges. Zum Problem der Darstellbarkeit von Schlachten am Beispiel der Schlacht von Lobositz (1.10.1756) im Siebenjährigen Krieg. In: Wolfgang Adam/Holger Dainat (Hg.): „Krieg ist mein Lied“. Der Siebenjährige Krieg in den zeitgenössischen Medien. Hg. in Verbindung mit Ute Pott. Göttingen: Wallstein 2007. (Schriften des Gleimhauses Halberstadt 5) S. 88-110.

84 Der großmüthige Husar, und der besiegte Preußische Dragoner, eine poetische Unterredung. WIENN, Gedruckt und zu finden bey Joseph Kurtzböck, Univ. Buchdr. in der Bognergasse im Hofglaserischen Hause. 1760 , f. $4 \mathrm{r}-4 \mathrm{v}$. 
Hiessl um was muß ich dich fragen,

Aber thu mir d'Wahrheit sagn,

Bist z’Wienn drinn ä gwesn,

Hast Zeitung hörn lesn,

Ob der Preuß noch im Feld steht,

Oder wies sonsten zugeht. ${ }^{85}$

Wie sich die Nachrichten in der Stadt ausbreiten, wo sie in verschiedenen Gaststätten weitergegeben und kommentiert werden, ist auch im 13-strophigen Lied Sey du mir auch will kom mein lieber Greger aus einer wohl in Salzburger Studentenkreisen um 1780 entstandenen Handschrift ein zentraler Aspekt:

1

Sey du mir auch will kom mein lieber Greger!

hab kein wort gwusst daruon, das du bist wegger.

dein Regerl hat mirs gsagt, das z Wienn bist gwesen

mit Körb und zöger waar und langen bösen.

2

Ja bruder Ferdinand so ist es gschechen,

z Wienn bin ich freylich gwesst, hab auch was gsechen,

draus in der Cärnthner strass bey den 3 haasen,

ritten 3 Post knecht für, habn mächtig blasen.

3

Da bin ich eini grent zum stockh am eysen,

da habn d:Leuth gredt daruon sagen weegen Preussen,

zwey herrn habn gar erzehlt, glaub, sie habns gsechen,

das halt den Preussen ein grosser schad gschehen. ${ }^{86}$

1,2 wegger] weg, fort 1,4 zöger] Zöger, Zeger: Handkorb, geflochtene Tasche

Dass der mündliche Vortrag der neuesten Nachrichten aufgrund der Illiteralität großer Teile des Publikums notwendig war, wird in einem anderen Lied explizit thematisiert, dessen Eingangsstrophe formal wieder ganz ähnlich wie die der oben genannten Lieder aufgebaut ist.

SEy mä GOtt wilich kom Bruder Simmändel,

kommst jetzt von Preussen Krieg, wie gen die Händel,

du kanst mä d'Wahrheit sagen, bist däbey gewesen,

d'Zeitung laut wolla gut, kans obä nit lesen. ${ }^{87}$

1 wilich kom] willkommen Simmändel] Kurzform für Simon 2 Händel] Streitigkeiten

85 Zwey schöne neue Weltliche Lieder, Das Erste: Hießl, um was muß ich dich fragen, aber thu mir d'Warheit sagn, etc. Das Anderte: König aus Preußen, was bildest dir ein, wilst dann ein Herrscher etc. Gedruckt im Jahr 1760. Hier nach Rudolf Wolkan: Wiener Volkslieder aus fünf Jahrhunderten. 1. Band: Einleitung/ 1500-1799. Wien: Wiener Bibliophilen-Gesellschaft 1924-26, Nr. XXXVII, S. 143-145. Abgedruckt bereits in Heinrich M. Richter: Österreichische Volksschriften und Volkslieder im siebenjährigen Kriege. Beiträge zur Geschichte der politischen Literatur im achtzehnten Jahrhundert. Wien: Gerold 1869, S. 158-160.

86 Admonter Liederhandschrift Cod. 820, Nr. 47, f. 30r-31r. - Teilweise normalisierte Edition bei J[osef] von Zahn: Historische Lieder des 16. und 18. Jahrh. In: Steiermärkische Geschichtsblätter 5 (1884), S. 245-255, hier 253-255, mit dem (ergänzten) Titel „Auf den Entsatz von Olmütz von den Preussen“.

87 Ein schönes neues Lied. [o. O., um 1759] - Auch in einer zweiten, abweichenden Variante überliefert: Ein neues Kriegs-Lied. [o. O., o. J., um 1759], ediert bei Klier, Historische Lieder des 18. Jh., S. 37 f. 
Auch hier wird deutlich, dass aufgrund der verwirrenden Informationsfülle, die die Geschehnisse des Siebenjährigen Krieges gerade wegen der starken Medienpräsenz begleitete, die Wahrheit des Erzählten besonders wichtig ist. Die Authentizität des Berichts, die durch jene gewährleistet werden soll, die - wie im Lied suggeriert wird - „däbey gewesen“ sind, bekommt besonderes Gewicht. Dem Dialekt kommt in diesen Fällen auch die Rolle zu, diese Unmittelbarkeit zu unterstreichen. Gerne wurde dafür die Figur des Heimkehrers bzw. Fronturlaubers gewählt, der in seiner Montur kaum noch von seinen eigenen Eltern erkannt wird. ${ }^{88}$ Eine interessante Form des vermittelten Augenzeugenberichts bietet Maurus Lindemayrs Losts auf alli Herrn, eine Kombination aus Hochzeitslied und historisch-politischem Lied, wo in der Aufführungsfiktion der bäuerliche Sprecher den Hochzeitsgästen aus einem Brief seines Sohnes vorliest, der im Jahr zuvor eingezogen worden war und nun aus dem Winterquartier vor Dresden gleichsam als Kriegsberichterstatter seine Eindrücke wiedergibt:

1

Losts auf alli Herrn, wanns innä wöllt wern

Ä Zeiting, mit der I dö Brautleut will ehrn.

Mein Suhnbue, der ferten än Reitä hat gebm,

Und no ist (sei Gottlob!) glücksällig beim Lebm,

Der hat an mi dacht, sän Aufwarting gmacht

Nächt hambs mä vo Dresden dös Schreibm von iehm bracht.

2

Er schreibt äf än Bogn, kain Wort is dälogn,

daß insä Armee jizt auf Dresden ist zogn.

Dort und in däselbingä ganzen Revier

Liegn etlä 50 Tausend in Wintäquartier.

Rain bis in Aprill bleibms baiderseits still,

Weil, glaub I, dä Preuß selbm hoir ausrasten will.

3

Dös Jahr, schreibt mä Bue, giengs gräuslä oft zue,

I han mä 's Soldatenlebm währlä schon gnue.

d'Armee hat si fünfmal in d' Schlacht müessen stölln,

d' Scharmüzl, dö kann I gar selbm niemä zöhln.

Kain Tag schier väläft, wo nit rundi werd gräft,

Doh hat mä kain Preuß nie 's Goraschi akäft. ${ }^{89}$

1,1 Losts auf] passt auf, hört zu 1,2 Zeiting] Nachricht, Neuigkeit 1,3 Suhnbue] Sohn ferten] im vergangenen Jahr 1,5 Aufwarting] Besuch, Gruß 1,6 Nächt] gestern (Abend) 2,3 däselbingä] demselben 2,6 hoir] heuer, dieses Jahr ausrasten] ausruhen väläft] verläuft rundi] ordentlich, richtig Goraschi] (franz. courage) Mut, Beherztheit, Schneid

Hatte Lindemayr 1760 in seiner Treuherzigen Unterredung noch an Durchhaltevermögen und Vaterlandsliebe appelliert, sieht er in diesem 18-strophigen Lied von 1761 die allgemeine Lage bereits deutlich ernüchtert. Kurz vor Ende des Siebenjährigen Kriegs ist in seinem ebenso umfangreichen Heimkehrerlied Gotts Sagrä! wen Siech $i$ var meinä (1763), das wieder eine Wiedersehensszene zum Ausgangspunkt des Berichts nimmt,

88 Vgl. etwa GOtt grüß enck mein Vattä und Muttä all zwey in: Siben schöne Neue Gesänger (s. Anm. 67), f. $3 \mathrm{v}$.

89 Oberösterreichische Landesmuseen MS 284, f. 5 r. 
der patriotische Appell an die Staatsbürgerpflicht bereits der Sorge um die ländliche Bevölkerung gewichen, deren wirtschaftliche Nöte in Kriegszeiten wahrheitsgetreu geschildert werden. ${ }^{90}$

\section{Bayerischer Erbfolgekrieg (1778/1779)}

Nicht immer aber ist es eine eindeutige Botschaft, die in den Texten propagiert werden soll. Zum Bayerischen Erbfolgekrieg ist eine mehrteilige Propagandaschrift ${ }^{91}$ erhalten, die sich als Gespräch zwischen einem Böhmen, einem Schlesier, einem Sachsen und einem Bayern (nur dieser spricht - verhältnismäßig authentisch - Dialekt) gibt und in dem die Positionen der verschiedenen am Konflikt beteiligten Parteien gegeneinander abgewogen werden: Als zu Jahresende 1777 durch den Tod des Kurfürsten Maximilian III. Joseph die bayerische Linie der Wittelsbacher ausstirbt, erhoben die Österreicher Anspruch auf Niederbayern und die Oberpfalz und marschierten im Land ein, woraufhin Preußen Österreich den Krieg erklärte.

Politisch bezieht der Autor der Schrift in dieser Lage keine klare Position, was auch durch die Form des Gesprächs zwischen verschiedenen Figuren ermöglicht wird: Er spricht dem neuen Landesherrn Karl Theodor von Pfalz-Sulzbach Engagement und guten Willen nicht ab, findet jedoch auch für Kaiser Joseph, der durch seinen Einmarsch in Bayern den Krieg heraufbeschwor, verständnisvolle Worte. Man hoffte offensichtlich noch auf eine gütliche Einigung, bei der Bayern ungeteilt blieb, ob unter pfälzischer, preußischer oder österreichischer Herrschaft. Die bedauerlichen Zeitumstände werden deswegen weniger durch aktuelle Geschehnisse begründet als mit Topoi der Gesellschaftskritik und abergläubischen Vorstellungen. Zentrales Thema, auf das mehrfach Bezug genommen wird, ist die unsichere Informationslage. Zum einen wird von den Figuren betont, selbst nur Wahres kundzutun - so verspricht der Sachse, „die wichtigsten Neuigkeiten mit Wahrheitsgrunde “92 erzählen zu können, und ist bestrebt, im Gegenzug auch von den anderen „was Neues und Gründliches zu vernehmen“93. Zum anderen kommt immer wieder zur Sprache, dass die Glaubwürdigkeit der Auskünfte und Quellen nicht gesichert sei. Hinsichtlich des erhofften baldigen Friedens scheint die Lage schwer einschätzbar, da vielfach Auskünfte nur mittelbar - über Berichte Dritter - zu erlangen sind und fragwürdig ist, welche Schlüsse sich aus dem, was sich in Erfahrung bringen lässt, ziehen lassen und welchen Hinweisen und Berichten man trauen darf.

90 Vgl. Lindemayr, Dialektlieder I, S. 46-51.

91 In der fiktiven Vorrede sind drei Fortsetzungen angekündigt, uns liegen allerdings nur zwei Folgen vor. Ob ein dritter Teil nur nicht aufgefunden wurde bzw. nicht überliefert ist oder möglicherweise auch gar nicht mehr gedruckt wurde, ist nicht bekannt.

92 Fortsetzung des kriegerischen Bauerngesprächs zwischen einem Baier, Böhm, Schlesier, und Sachsen, den dermaligen Kriegslauf betreffend, mit dem Portrait Sr. Majestät des Königs in Preussen. Zweytes Stück a 4 kr. Gedruckt bey Christian Lebrecht 1779. Zu finden bey uns 4 Bauern um baare Bezahlung. f. 2r.

93 Ebda. 
Der Baier. Oes rödt's b’ständi von den geistlichen Sachen daher, erzählt lieber vom Krieg was! Neulich hab' ich von meinem Hrn. Pfarrer g'hört, das im Fruhjahr recht über einander gehen soll; i hob ä in einer gewissen Zeitung etwas gelesn, und so viel i mir einbilden ko, so is der Erlanger Zeitungsschreiber g'wesn; er bringt sonst die g'scheidesten Sachen, ich weis aber nöt, wer sein Korrespondent ist.

Der SaCHs. Ich habe zwar selbst auch gehört, und in einer bekannten Zeitung N. 227 im 1778 Jahr gelesen, daß Troppau und Jägerndorf von Ihro Majestät dem König in Preussen solln eingenommen worden sey[n], und täglich 3000 Mann von Bauern und andern Unterthanen zur Schanzarbeit und Anlegung der Wälle und Laufgräben sollen angehalten worden seyn, welche sie so gut sollen bevestiget haben, daß kein Feind im Stande selbe einzunehmen.

Der BöHм. Der Erlanger Zeitungsschreiber, ja dieser hat es angeführt, aber dieser hat schon öfters gelogen; ich weis noch gar zu wohl, daß er in einem gewißen Krieg den König in Preussen so sehr durchgelassen, und eine unverschämte Lüge in seine Zeitung gedruckt, daß er sich durch selbe den Schlagfluß auf seinen Podex gezogen, und von einem preussischen Offizier seines Wohlverhaltens halber 50 Arschkrapfen zu einem Rekompens überkommen.

Der Schlesier. Diesem feinen Knaben ist schon recht geschehen, es ist schon erlaubt den wahren Kriegeslauf unpartheyisch zu beschreiben, keinem aber ist erlaubt über ein hohes Haupt zu schmähen; man wird auch nicht hören, daß bey der Nobleße und hohen Herrschaften so niederträchtig, wie in den offentlichen Schenken oder Bierhäusern wider so hohe Häupter gesprochen wird.

Der BöHм. Wahr ist es, das gemeine Volk verfehlt sich in vielen Stücken gröblich, und besonders wenn dergleichen Dumköpfe besoffen sind, und dieß macht's, weil eine Parthey gut preußisch, die andere derselben gut kaiserlich ist.

Der BAier. Dös is 'm gmain Mann nit allemal glei also für übl z'habn, wenn er davo rödt, denn mä wais scho, daß mer allemal viel hab’n leidn müssn, wenn ä Krieg g'wesn is: oft ainer muß von Haus und Hof, und ko sei Weib und Kinder nimmer ernöhrn, weil ihm d'Soldaten alles weg gnomma habn, dös Ding thut aim halt gar weah, wenn mä ä so dro denkt, und nachä weards uns, globi niemand vor übl habn. ${ }^{94}$

Oes rödt's] ihr redet $\mathrm{i}$ hob ä] ich habe auch Erlanger Zeitungsschreiber] die zwischen 1741 und 1829 in Erlangen (damals Erlang) erschienene ,Real-Zeitung', gegründet von Johann Gottfried Groß, war das bedeutendste deutschsprachige politische Nachrichtenblatt der Zeit Arschkrapfen] Stockhiebe auf das Gesäß Rekompens] Belohnung 'm gmain] dem gemeinen globi] glaub ich

Die Referenz auf den ,Erlanger Zeitungsschreiber' und die Replik des Sachsen, seine Informationen auch nicht irgendwoher, sondern aus, einer bekannten Zeitung zu beziehen, positionieren die Bauern in einem zeitgenössischen Diskursfeld, zu dem eben solche populären ,Bauern-Gespräche einen nicht unwichtigen Beitrag leisten. Dass politische Information und Kriegsberichterstattung zumal über die Grenzen der konfliktführenden Parteien hinweg freilich niemals frei bleiben von Einflussnahme und Tendenziösität, ist auch den vier erstaunlich vernünftigen, wahrheitssuchenden Bauersleuten klar.

94 Fortsetzung des kriegerischen Bauerngesprächs, f. 2v-3r. 


\section{Erster Koalitionskrieg (1792-1797)}

Nicht um eine differenzierte Analyse der Situation, sondern um die Mobilisierung zum Abwehrkampf bemühen sich die mundartlichen Kriegslieder während des Ersten Koalitionskriegs, der mit den Franzosen einen ,Erbfeind' des Reichs wieder auf österreichisches Gebiet brachte. Die radikale Abschaffung des feudalabsolutistischen Ständestaats während der Französischen Revolution hatte die europäischen Monarchien zutiefst verunsichert und eine große Koalition aus Österreich und Preußen ermöglicht, die mit anderen deutschen Staaten und ab 1793 mit weiteren Großmächten wie Großbritannien und Spanien gegen das revolutionäre Frankreich vorging. Nach anfänglichen Erfolgen der Alliierten konnte sich die französische Armee immer besser behaupten, zumal nach dem Ausscheiden wichtiger Gegner im Frieden von Basel (1795). Im Italienfeldzug 1796/97 gelangen Napoleon Bonaparte erhebliche Gebietsgewinne, ehe er sich gegen die alpenländischen Kerngebiete Österreichs wandte. Auf Tiroler Boden allerdings konnte der Vormarsch (vorerst) gestoppt werden; trotz Napoleons Manifest vom 14. Juni 1796, in dem er die Tiroler zur Niederlegung der Waffen aufforderte, nahmen die Landsturmtruppen und Schützen den Kampf auf und nutzten das Gelände gegen den schier übermächtigen Gegner. ${ }^{95}$

Begleitet wurde der Abwehrkampf von bellizistischer Propaganda, bei der sich vor allem der Innsbrucker Archivar Johann Friedrich Primisser (1757-1812) und der Schwazer Chorregent Peter Paul Staudacher (1757-1806) hervortaten. ${ }^{96}$ Beide Autoren bemühen sich in ihren Liedern nicht um Ursachenvermittlung, sondern zeichnen ein agitatives Bild des Tiroler Landstürmers als kriegserfahrenen, kaisertreuen Meisterschützen. Primissers Lied im Franzosen Rummel 1796 erinnert explizit an militärische Erfolge der jüngeren Zeit, um Kampfbereitschaft und Siegeszuversicht zu vermitteln:

1

N'Stutzen hear bam Sokara

Was wölln denn d' Franzosen

He! moanen si mit ihrem Gschroa

Mier haben 's Hearz in d'Hosen:

a schwantziger Tiroler Bue

laßt si aft nit lang trotzen

und wird er wirsch, schau ainer zue

er schlagt ihm in die Fotzen.

[...]
4

Mei Voda hat mär oft erzählt, Wie er hat Boarn gschossen sie purzelten vom Bley geföllt von machtig hoachen Rossen. Und was das hoase Bley verschont, dermaggeten die Stoaner, i selber sach in Oberlond ein Haufen Leichenboaner $[\ldots]$

95 Vgl. u. a. Ute Planert: Der Mythos vom Befreiungskrieg. Frankreichs Kriege und der deutsche Süden. Alltag - Wahrnehmung - Deutung 1792-1841. Paderborn: Schöningh 2007. - Martin P. Schennach: Revolte in der Region. Zur Tiroler Erhebung von 1809. Innsbruck: Wagner 2009. (Veröffentlichungen des Tiroler Landesarchivs 16).

96 Vgl. Sandra Hupfauf/Silvia Maria Erber: Liedgeschichten. Musik und Lied in Tiroler Politik und Gesellschaft 1796-1848. Hg. von Thomas Nußbaumer und Brigitte Mazohl. Innsbruck: Wagner 2013, S. 87-89. 
5

Und znagst erst in dem Türkenkrieg da wars a Jubel gwesen.

Auf jeden Schuß sachst du die Bieg in d' Heach: - im Sand die Fresen. Tiroler! hieß es, putz mir dort den Türken Laggl weeka aft schlog i on, a Mann a Wort da lag er schon im Drecka. [...]

\section{7}

Wenn eppar oanar afs Fensta geat Vom Mensch Pfietgott zu nehman Da rotzts und rearts nit lang und theat mar halt fein wiedar kemman. aft hoaßts marschiert was geist was hast obaus ins blueti Schwaben da lassmar uns koa Rueh koa Rast, bis mir d' Victory haben. ${ }^{97}$

1,1 bam Sokara] Interjektion zum Ausdruck der Nachdrücklichkeit 1,5 schwantziger] flotter, stattlicher 1,8 Fotzen] Maul, Mund 4,2 Boarn] Bayern 4,6 dermaggeten] zerquetschten 5,1 znagst] vor Kurzem 5,3 Bieg] Steigbügel 5,4 Heach] Höhe 7,1 eppar] etwa 7,2 Pfietgott] Abschied 7,3 rotzts] schluchzt rearts] weint 7,5 was geist was hast] was gibst du, was hast du: Redewendung für ,so schnell wie möglich

In Anlehnung an Primissers Lied, aber formal wie inhaltlich wesentlich aggressiver, appelliert Staudachers Duxer Lied an die Tyrolischen Landesvertheidiger (Wax auf, beym Schlaggarar, 1797) an Heimatliebe und Franzosenhass des Tirolers, „welcher sich“ - so eine zeitgenössische Erläuterung - „,in seiner Eigenständigkeit von allem fremden Amalgama, eben so frey von Englischen Stolze als von Französischer Höflichkeitsgrimasse erhalten hat" ${ }^{98}$ :

2

Fürchts dö Franzosen nit,

Dö dürr'n Sprissal!

Nemmts ös hear bey da Grid,

Maggst ös a Bissal.

Aft wearn Si Blearar thain,

Aft wearn Si rotzen;

Schaints söllan Zipfel kain,

Schlagts ien auf d'Fotzen.

[...]

5

Wann der Tyrolar wöll

(Oes därfts mars glam)

Falln Französlar viel,

Füll'n dö Grabn.

Sia wissans lange schain,

Wie mar öhns machen:

Büchsn und Häuf'n Stain

Laß mar drauf krachn.

$[\ldots]$
4

Nieth wahr, Tyrolar Bueb'n

Fürchten wohl kainen?

Miar haun na zamm, wie d'Rueb'n

Er mag schain draihnen.

Sechsö ums Hüatal rum

Steckt gar an jadar,

I steah mei Wuart nieth um,

Lebt frischö Brüadar!

7

Greifts frisch mit Kräften un,

Warö Tyrolar!

Und gebats kain Pardun,

$S$ ' ist desto dollar.

Vatilgst dö ganzö Bruat,

Aft habn mar Rua;

Varschaints kain Franklar Bluat,

Hammarts kaif zua.

[...]

97 Othmar Schissel von Fleschenberg: Die erste handschriftliche Fassung von J. F. Primissers Kriegslied „N’ Stutzen hear bam Sokara“ 1796. In: Zeitschrift des Ferdinandeums für Tirol und Vorarlberg 3/49 (1905), S. 447-451, hier 449f. Eine Fassung aus Johann Baptist Gänsbachers Autobiographie von 1796 (Tiroler Landesmuseum Ferdinandeum, Innsbruck, FB 15546) ist ediert bei Hupfauf/Erber, Liedgeschichten, S. $29 \mathrm{f}$. 98 Salzburger Intelligenzblatt 1797, H. XI (18. März), S. 160. 
8

Schützet das Vadarland

Vor diesem G'schmaisö,

Oes seyts as leicht an Stand,

Tradts ös, wie d' Laisö.

Das wird den Franzal frai'n

Unsarn liebn Kaisar!

Wann mar aft Jubal schrayn,

Bis mar san haisar.
9

Miar haltn allö z’am,

Saind trai und biadar,

Und schoiss'n an Gottas Nam

Varreathar niadar.

Miar hab an Glaubn noch,

Sand guate Laithe;

Haißts glai: Tyrolar Zoch! -

Uns is a Fraidte. $[. . .]^{99}$

2,2 Sprissal] Holzsplitter 2,3 Grid] Grind, hier: Kopf, Schädel 2,4 Maggst ös] walkt, quetscht sie 2,5 Aft] dann Blearar thain] plärren 2,6 rotzen] (übertrieben) weinen 2,7 Schaints] verschont 2,8 auf d'Fotzen] aufs Maul 4,4 draihnen] drohen 4,5-6 Sechsö ... jadar] mit sechs nimmt es ein jeder auf 5,2 Oes] ihr glam] glauben 5,6 öhns] es ihnen 9,7 Tyrolar Zoch] Tiroler Zeug (abwertend für Waren der fahrenden Händler aus dem Tirolerischen) 8,3 Oes seyts as] ihr seid es 8,4 Tradts ös] zerquetscht, tötet sie

Tatsächlich soll das martialische Lied als Kampfgesang im Tuxertal zum Einsatz gekommen sein. Die Vehemenz dieses rhetorischen Feldzugs gegen die Franzosen, der auch nicht vor biologistischen Ungeziefer-Vergleichen und Vernichtungsphantasien zurückschreckt, ist im Zusammenhang mit einem sich herausbildenden nationalen Selbstbewusstsein zu sehen, das in der ethnischen Abgrenzung politisch funktionalisiert wurde und den Befreiungskampf-Mythos von 1809 erst möglich machte.

\section{Soldatenwerbung, Zwangsrekrutierung und Kriegsleid}

Dass immer wieder junge Männer aus der Landbevölkerung - ob standardsprachlich oder dialektal - als Identifikations-, Projektions- oder Verlachfiguren in der Kriegsliteratur vor 1800 fungieren, kann nicht verwundern. Sie mussten den Hauptanteil der damit verbundenen Belastung über Steuer- und Naturalienabgaben, Dienste, Zwangseinquartierungen, Requirierungen, Flurschäden etc. tragen. Vor allem aber stellte die bäuerliche Bevölkerung traditionell bei Weitem das größte Soldatenkontingent.

Seit der Mitte des 17. Jahrhunderts bis zur Mitte des 18. Jahrhunderts hatten sich in nahezu allen europäischen Staaten stehende Heere etabliert, die auch in Friedenszeiten bestanden und durch den Staat bezahlt, versorgt und ausgestattet wurden, ${ }^{100}$ was die Staatsausgaben stark steigen ließ - in Preußen etwa betrug der Anteil der Militäraufwendungen zur Zeit Friedrichs des Großen sogar in Friedenszeiten regelmäßig 80\% der Staatsausgaben. ${ }^{101}$ Auch die Truppenstärke nahm zuvor unbekannte Dimensionen an und tendierte im Verlauf des Jahrhunderts zu etwa 2\% der Gesamtbevölkerung. ${ }^{102}$

99 Ebda., S. 160f.

100 Vgl. Michael Busch: Der Bauer als Soldat. Ein gescheitertes Konzept der Heeresaufbringung? In: Ralf Pröve (Hg.): Klio in Uniform? Probleme und Perspektiven einer modernen Militärgeschichte der frühen Neuzeit. Köln/Weimar/Wien: Böhlau 1997, S. 143-166, hier 151f.

101 Vgl. Rolf-Dieter Müller: Militärgeschichte. Köln/Weimar/Wien: Böhlau 2009, S. 152.

102 Vgl. Wolfgang von Hippel: Armut, Unterschichten, Randgruppen in der frühen Neuzeit. 2., aktual. u. um einen Nachtrag erw. Aufl. München: Oldenbourg 2013. (Enzyklopädie deutscher Geschichte 34) S. 28. 
Die Werbung geschah in Friedenszeiten zumeist auf freiwilliger Basis, in Kriegs- oder Krisenzeiten dagegen war dieses Prinzip - aufgrund höherer Sollzahlen, aber auch aufgrund von Abgängen durch Verwundung, Tod und Desertion - meist nicht aufrecht zu erhalten. Die sozialen und ökonomischen Lebensbedingungen der Soldaten waren dabei keineswegs ansprechend: Das Landsknechtdasein des 16. Jahrhunderts mochte für junge, kräftige Männer in finanzieller Hinsicht mit vergleichsweise hohem Einkommen und zusätzlicher Aussicht auf Beute noch einigermaßen verlockend sein. Die stehenden Heere in der Zeit des Absolutismus dagegen waren eine "geschlossene Welt mit eigenem Rechtsstatus bei äußerst harten Dienstbedingungen und schlechter Besoldung “ 103 . Prügel gehörten zum soldatischen Alltag, der gesellschaftliche Status der unteren Chargen war gering, Aufstiegschancen gab es nur bedingt - was auch Heirat und Familiengründung erschwerte. Desertion wiederum wurde mit drakonischen Strafen belegt, kam aber dennoch sehr oft vor. ${ }^{104}$ Nach der Entlassung bildete der Übergang in das zivile Leben einen besonders kritischen Punkt; nur wenige gelangten in gehobenere oder abgesichertere Stellungen, Alters- und Invalidenfürsorge gab es praktisch keine, und nicht wenige abgedankte oder fahnenflüchtige Soldaten drifteten ins Milieu der Armen, Bettler, Vaganten oder auch Räuber ab. ${ }^{105}$ Insgesamt also hatten die Söldner oder zwangsrekrutierten Untertanen des 18. Jahrhunderts eine prekäre soziale Position - eine „Randstellung in der zivilen Gesellschaft, die durch gesonderten Rechtsstatus zusätzlich unterstrichen wurde, ungünstige wirtschaftliche Verhältnisse und entsprechend geringes soziales Ansehen." 106 Angesprochen fühlten sich von diesen Anforderungen und Bedingungen daher meist bloß Ungelernte oder, gescheiterte Existenzen' sowie jene, die aus Leichtsinn oder aufgrund von Notlagen den Werbern zufielen; dazu sorgten auch „Betrug und Zwang bis hin zu Menschenraub für Nachschub“ ${ }^{107}$ - vor allem eben in der bäuerlichen Bevölkerung.

103 Ebda., S. 30.

104 Regional und zeitlich scheinen unterschiedliche Dienstzeiten - von 3 bis 6 Jahren bis zu 15 bis 20 Jahren üblich gewesen zu sein; in Österreich waren laut Müller die Dienstzeiten sogar prinzipiell unbeschränkt. Vgl. Jutta Nowosadtko: Ordnungselement oder Störfaktor? Zur Rolle der stehenden Heere innerhalb der frühneuzeitlichen Gesellschaft. In: Ralf Pröve (Hg.): Klio in Uniform? Probleme und Perspektiven einer modernen Militärgeschichte der frühen Neuzeit. Köln/Weimar/Wien: Böhlau 1997, S. 5-34, hier 25. Hippel, Armut, S. 30. - Müller, Militärgeschichte, S. 153.

105 Historischen Untersuchungen zufolge betrug der Anteil abgedankter oder desertierter Soldaten im 17. und 18. Jahrhundert bis zu einem Viertel der auf den Landstraßen aufgegriffenen Vaganten. Einige Historiker gehen daher davon aus, dass das Militär nicht nur Auffangbecken für Kriminelle oder frühzeitig zum Militärdienst begnadigte Zuchthausinsassen war, sondern dass der Militärdienst eine solche spätere Laufbahn beförderte, da beim Militär der Umgang mit physischer Gewalt erlernt wurde. Zudem hatten Soldaten bereits jahrelang ohne festen Wohnsitz gelebt, ihre Bindungen zu Heimat und Familie oft verloren und auch neue moralische Vorstellungen übernommen. Vgl. Carsten Küther: Menschen auf der Straße. Vagierende Unterschichten in Bayern, Franken und Schwaben in der zweiten Hälfte des 18. Jahrhunderts. Göttingen: Vandenhoek \& Ruprecht 1983. (Kritische Studien zur Geschichtswissenschaft 56) S. 36. - Jürgen Kocka: Weder Stand noch Klasse. Unterschichten um 1800. Bonn: Dietz 1990. - Nowosadtko, Ordnungselement oder Störfaktor, S. 9.

106 Hippel, Armut, S. 29.

107 Ebda. 
Das Motiv des Soldaten-wider-Willen zählt dementsprechend zu den beliebtesten und am frühesten nachweisbaren Handlungselementen von Spielen mit Dorfsetting und Dialektgebrauch, auch wenn sich die existenzielle Bedrohlichkeit in der dramatischen Adaption zumeist ins Komische wendet. Schon im Fastnachtspiel Von dem Hänsl Frischen knecht, dem frühesten im bairisch-österreichischen Sprachraum bislang erfassten Beispiel für bewusst literarisierte regionale Sprachfärbung, ist es das handlungsmotivierende Thema. Das 1618 in Regensburg aufgeführte, durch den Tischler und Autor Steffan Egl handschriftlich festgehaltene Stück dürfte wohl - wie die erwähnten Ortsnamen Grinzing und Döbling sowie ostmittelbairische Endungen nahelegen - ursprünglich aus dem Wiener Raum stammen. Ein intermedientypischer vierteiliger Aufbau und eine lateinische Regiebemerkung weisen zudem auf einen jesuitischen Hintergrund hin. In der Handlung, die sich um einen naiv-dümmlichen Dörfler dreht, der sich versehentlich zu Kriegsdiensten anwerben lässt, dominiert bereits der Bauernspott - die im süddeutschen Gebiet gebräuchlichste Funktionalisierung dialektaler Mündlichkeit im 17. Jahrhundert. Der schwachköpfige Hänsel, unglücklich mit seinem Leben am heimischen Hof, glaubt sich um eine Knechtstelle zu bewerben, als er bei einem Feldschreiber vorspricht. Dieser bemüht sich zwar redlich, ihm die Konsequenzen seines Handelns zu erklären, schreibt ihn aber letztlich ein. Erschreckt führen ihm sein Vater und sein Schwiegervater in spe die Tragweite seiner Entscheidung vor Augen, doch der Schreiber lässt sich nicht mehr umstimmen. Entsetzt ist auch Hänsels Verlobte Rosl, die sich um das Heiratsversprechen betrogen glaubt. Doch Hänsel schafft es, seinen Kriegseinsatz

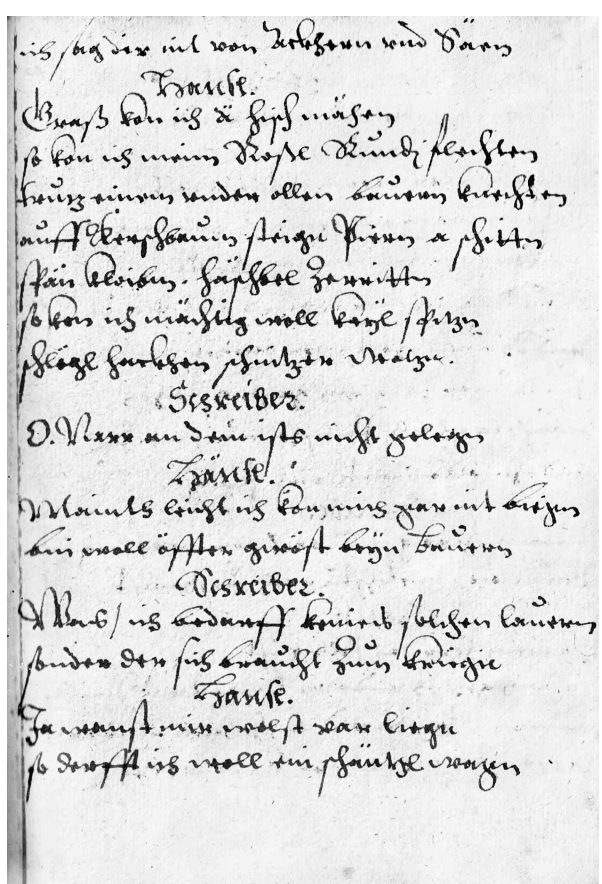

Abb. 13: Ausschnitt aus Ein kurtzweilig Faßnachtspill (Archiv des Historischen Vereins für Oberpfalz und Regensburg, MS.R 161, f. 46r). 
zu überleben, von dem er nach seiner Rückkehr nichts Gescheiteres zu erzählen weiß als Folgendes:

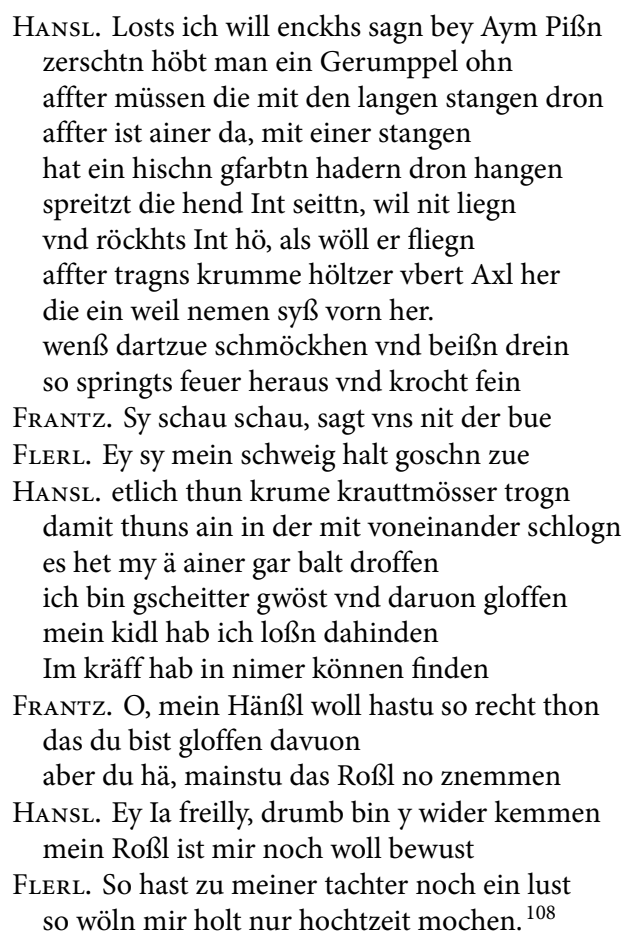

1 Losts] hört, horcht enckhs] euch es 2 zerschtn] zuerst höbt man ... ohn] fängt man an 3 affter] danach 5 hischn gfarbtn hadern] hübschen gefärbten Stoff 6 Int] in die 13 goschn] Mund 16 my ä] mich auch 17 gwöst] gewesen 18 kidl] Kittel, hier: Uniformrock 18 kräff] Geraufe hab in] habe ich ihn

Da auch die zunächst widerstrebende Rosl schließlich zustimmt, steht einem glücklichen Ende samt Hochzeit nichts im Wege. Die militärrechtlichen Konsequenzen der Desertion bleiben im Rahmen des Fastnachtspiels jedoch ausgeblendet. In einem Intermedium zur Kaiser Leopold gewidmeten Staatsszene Widerwertig- und glückselige Liebe Cambises (1666) wird zumindest zum Thema, welche Strafen die Militärjustiz bei Eigentumsvergehen vorsieht. Hauptfigur des gleichfalls vierteiligen Zwischenspiels des Wiener Pfalzgrafen Johann Friedrich Scholtz von Scholtzenberg (1637-?) ist der tumbe Knecht Florian, in seiner elementaren Triebhaftigkeit und Körperfixierung eine ,lächerliche Figur', die vorausweist auf Stranitzkys Wiener Hanswurst. Verbittert, weil sein Arbeitgeber ihm die Hand seiner Tochter Gredl verwehrt, lässt er sich von den Werbern zum Trinken verleiten und schließlich auch dazu, das Handgeld zu nehmen, nicht ohne zuvor noch Gredl geschwängert zu haben. Das raue Soldatenleben allerdings mit

108 Archiv des Historischen Vereins für Oberpfalz und Regensburg, MS.R 161, f. 54r-55v. Vgl. dazu auch die Erstedition bei August Hartmann: Regensburger Fastnachtspiele. In: Oskar Brenner/August Hartmann (Hg.): Bayerns Mundarten. Beiträge zur Deutschen Sprach- und Volkskunde. Bd. 2. München: Kaiser 1895, S. 1-59, hier 20-27. 
seiner mickrigen Bezahlung, den harten Diensten und nicht weniger harten Bestrafungen bei Fehlverhalten behagt ihm nicht; als er sich mit Diebstählen ein Zubrot verdienen will, wird er gefasst und in den Kerker geworfen. Wäre da nicht der Bauer Mopsus, der unbedingt die Ehre seiner Tochter retten möchte, hätte Florian wohl den Strang zu erwarten:

Florian. Es vergeht ain der lust zum Soldaten leben? wan einer ein gspert ist, vndt hat nichts zfressen? Ich hab zwar draust auch wenig ghabt, aber da gar nichts, vnd Mues mir noch förchten, ob man mich nit henckht? doch wäres schier besser gschwindt auf knipfft, alß daß einer so lang mues eingsperter Hunger leiden. An den ding allen ist Kein andrer Mensch schuldig, alß der Mops mein gwester herr, Ich wär mein lebtag Kein Soldat worden, wan Er mir sein Grethl glassen hett, ö der bernheitter? aber Ich habn schon präff zalt, sein Tochter wirdt baldt grosser werden, alß gwest ist, Ja Kombt der alte MaußKopff.

Mopsus. Mueß man dich da finden du Erbarer Gsell? das ist wohlgar ä rechts hauß fir solche Vögel.

FLORIAN. Waß habt Ihr darnach zu fragen?

Mopsus. Du solst wohl so baldt nit rauß Khommen, warth nur.

Florian. Vnndt warumb dan?

Mopsus. Du Schelm waß hast du mir dörffen mein Tochter schenden?

FLorian. Daß ist erlogen, vnndt wär ich draust, Ich wolt dir waß anderst sagen.

Mopsus. Waß will duß Laugnen? hats nit schon bekhent auf dich?

Florian. Auf mich? Ö die hure, ist dan schwanger?

Mopsus. Ey so frag du galgen Vogel? du wirst es ehe wol wisßen, vnd sag nur gschwindt ob dus nemmen wilst, oder Ich gehe gleich zu deinen Haubtman, der wird dich gwiß Zwiffeln?

FLORIAN. Sag waß du wilt Ich glaubs nit daß schwanger sey, biß daß Ichs sieh.

Mopsus. Worth Ich will dirs gleich vnders gsicht stellen, sie wird dirs sagen, wanß gschehen ist, vnndt mein Nachbahren will Ich mit nemmen, daß Er Kan Zeignuß geben.

Florian. Daß ist frössen fir mich, ach wan ich halt mit dem handl Kunt Ledig werden auß den Kerckher vnndt von Soldaten leben: Es mueß gehen, oder es mues brechen, der Nar wirt iezt hingehen zum Haubtman, wird mich verklagen, der haubtman wird mir auflegen ich solls nemmen, so will Ich ihm aber gleich sagen, nein ich nimbs nit, wan Er mich nit lossmacht von Soldaten leben: vnd solt man mich auch driber henckhen, wan ichs nit ehe verschuldt hab: vnndt recht: solt ich erst noch darzue weib, vnndt Kindt mit ein ander nemben, vnndt solt ein Soldat bleiben, wo miest ich ihnen zfressen schaffen, Hab ich doch allein nit gnueg, Ich mues Ja dreymahl mehr stellen alß vor? vnndt wär mir der galgen gwiß, wan Ichs dan gwiß weiß, waß will ih mich mit den weib erst schleppen, henckht man mich, so bin ich Todt, ich mues doch einmahl sterben. Wan er mich aber außkhaufft, so wil ichs nemmen: vnndt es Kan gar leicht sein, dan vnßer Haubtman ist gar Geldt Hungerig. ${ }^{109}$

bernheitter] Bärenhäuter: Schimpfwort mit unsicherer etymologischer Deutung Zwiffeln] quälen, bestrafen

Florians Kalkül ist erfolgreich; tatsächlich lässt ihn der korrupte Hauptmann für 15 Gulden laufen - ein wohl nicht allzu unrealistischer Einblick in die damaligen Gepflogenheiten. Bildmächtig ist die amüsante Klag der soldaten für vier Singstimmen und Cembalo des Doppeltalents Johann Beer (1655-1700), die der gebürtige Oberösterreicher und protestantische Exulant zwar nicht dezidiert dialektal schrieb, die aber in der

109 Österreichische Nationalbibliothek, Cod. 10160 Han., f. 101v-102v. Erstediert ist das Intermedium (dessen dialektale Teile unterschiedlich stark markiert sind) in Christian Neuhuber: y glab es trambt mie. Dialektale Rede in Wiener Stücken des Wander-, Ordens- und Hoftheaters 1665/66. In: Christian Neuhuber/ Elisabeth Zehetner (Hg.): Bairisch-österreichischer Dialekt in Literatur und Musik 1650-1900. Tagungsband. Graz: Leykam/Universitätsverl. 2015, S. 61-116. 
Reimbildung (so etwa „Wer da“ auf „miserio“) und Schreibung eine dialektnahe Realisierung nahelegt, wie der folgende Ausschnitt zeigen soll:

So bald wür schwören zu der Fahn, so fiehrt man vnß hinauf den Plan, dort wirdt man linkhs nun exerciert, Vnd vnß der Pugel abgeschmiert. Vill bösser ists, $\mathrm{i}[\mathrm{ch}]$ bleib zu hauß, als daß ich züeh ins feld hinauß wo man sich in vill lastern wölzt, vnd lauter miserere schmöltzt [...] wo bleibt dan unser Monath soldt Commiss brodt kriegen wür vor goldt. das ist zerfrösßen von der mauß, man beist sich fast die Zähn dran auß. nach vnß verlasßne Musquetier, dan dieß ist ihre alte weiß, sie nehmens geldt und wür die leiß. [...] im feldt muß vnser labsall sein ein süesßer saft haißt gänßewein, das Kleidt ist auch so fein vnd nett, wie [we]nß ein wolff zerrisßen hett. anstatt des schnubtuechs wischen wür die Naße an das partelier, vnd wer kein partelier nicht hat, der braucht darzue ein Kartenblath. ${ }^{110}$

2 Plan] ebene Fläche, Exerzierplatz 4 Pugel] Rücken 8 miserere] (lat. erbarme dich) Elend 10 Commiss brodt] haltbares Soldatenbrot 16 leiß] Läuse 18 gänßewein] spöttisch für Wasser 21 partelier] Bortenbesatz der Uniform (?)

Das Thema der unfreiwilligen Werbung zählt auch in den folgenden Jahrzehnten zu den beliebtesten Handlungsentwürfen in Bühnenwerken mit dialektalen Figuren, vor allem im Ordenstheater. Schon der spätere Abt von Michelfeld in der Oberpfalz, Wolfgang Rinswerger (1658-1721), verwertet das Motiv in Potinus (um 1697), einer seiner häufig mit dialektalen Sequenzen versehenen lateinischen Schulkomödien, die er als Rhetorikprofessor und Pater comicus für das Salzburger Universitätstheater verfasste. Dem versoffenen Titelhelden wird im ersten Akt von seiner Familie und Studenten vorgegaukelt, er habe sich im Rausch anwerben lassen und müsse nun ein Leben als Soldat fristen. Eine ganz ähnliche Intrige finden wir auch in Matthias Preggs (1730-1775) zweiaktigem Zwischenspiel Trinkgern (1760), das durch den Salzburger Hofkapellmeister Johann Ernst Eberlin (1702-1762) vertont wurde. ${ }^{111}$ Mit viel Humor lässt der Kremsmünsterer Kapitular, in diesen Jahren auch Pater comicus der Klosterbühne, seinen Protagonisten Todesängste ausstehen, als er verkatert erwacht und der Student Gscheid einen brutalen Werbeoffizier mimt:

Trinkgern. Was saust ä so? wo bin i do? dä Kopf ist zimmlich schwär, was saust ä so? wo bin i do? wie ist mä nöt so rär?

Gscheid. Steht auf Canaille! steh auf, was zauderst du! vnd leiste den gehorsamb

Trinkgern. Das geht mä gar nöt zamb.

GscheID. wie? hast du nicht zum Fahn geschworn? vnd noch dazu das Handgeld von mir selbst bekommen?

Trinkgern. Kain Kreuzä nöt.

GscheID. Gehts, suchts die Säcke auß.

TRINKGERN. und sollts än hällä find'n (i hab ja göstern alls vätrunkä) so laß ich mi lebendi schind'n. ${ }^{112}$

110 Stiftsarchiv Lambach (Abschrift von 1706, zurzeit nur in Kopie vorliegend, Original verschollen). Für den Hinweis sei Peter Deinhammer herzlich gedankt.

111 Vgl. Johann Ernst Eberlin: Der Trinkgern, ein Zwischenspiel in zwei Aufzügen. Hg. von Werner Rainer. Wien: Doblinger 2002.

112 Musikarchiv Kremsmünster A-KR/ G 14/38, Stimmauszug Trinkgern, f. 1r., Stimmauszug Gscheid, f. 1r. 
ä so] (verstärktes) so mä] mir rär] seltsam zamb] zusammen än hällä] einen Heller

Natürlich wird der zuvor zugesteckte Taler gefunden und der Scherz auf Kosten des Trunkenbolds vorangetrieben, bis dieser gelobt, Wirtshäuser fortan zu meiden. Auch in seinem Zwischenspiel Die gestrafte Kinds-Närrin (1762), vertont vom Kremsmünsterer Stiftsmusiker Friedrich Kramel (1727-1782), setzt Pregg auf die Zwangsrekrutierung als Schreckgespenst zu Bekehrungszwecken. ${ }^{113}$ Hier ist es der faule, von seiner Mutter verzärtelte Student Vallerl, der von seinem Stiefbruder und dessen Vormund an bestochene Werbesoldaten verkauft und als unnützes Mitglied der Gesellschaft eingezogen wird, sodass Hans der Hof bleibt.

Auch im interludialen Dialektsingspiel (Musik: Georg Vogl, 1725-1761) zur Faschingskomödie Der Teutsche Sultan des aus Wien gebürtigen Freisinger Pater comicus Ferdinand Rosner ist Angst vor dem Eingezogenwerden ein - zur Zeit des Siebenjährigen Kriegs durchaus nachvollziehbares - Handlungsstimulans des einfältigen Bauern Veitl:

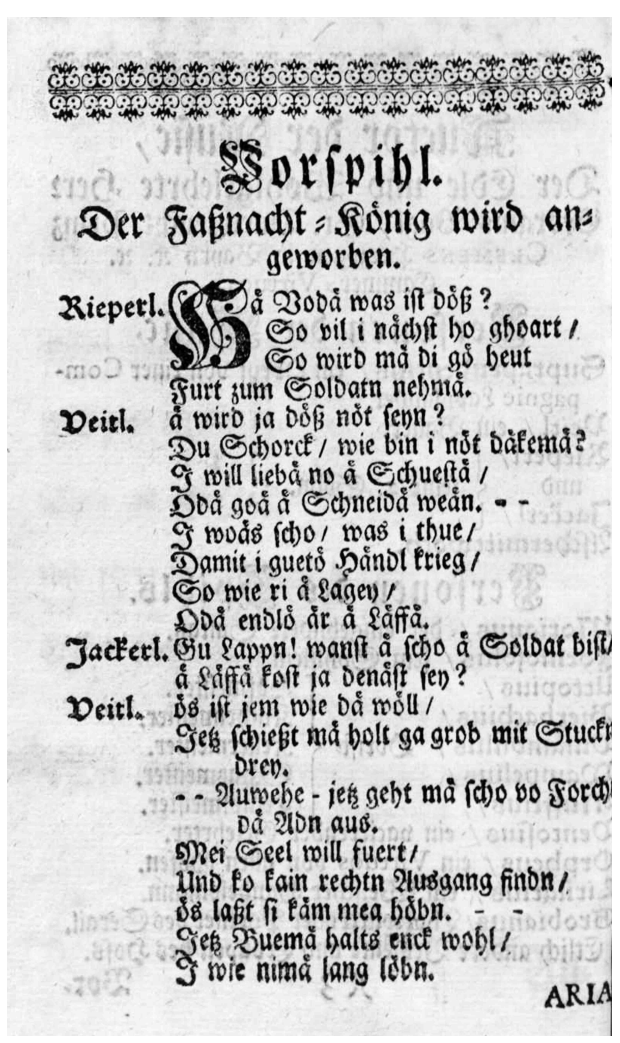

Abb. 14: Beginn des Zwischenspiels aus Der

Teutsche Sultan (1760, Bayerische Staatsbibliothek, Slg. Her 2198).

\section{ssoripibl.} genoorben.

西

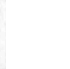


Rieperl. Hä Vodä was ist döß?

So vil i nächst ho ghoart/

So wird mä di gö heut

Furt zum Soldatn nehmä.

VeItL. ä wird ja döß nöt seyn?

Du Schorck / wie bin i nöt däkemä?

I will liebä no ä Schuestä/

Odä goä ä Schneidä weän. - -

I woäs scho / was i thue/

Damit i guetö Händl krieg/

So wie ri ä Lagey/

Odä endlö är ä Läffä.

JACKERL. Gu Lappn! wanst ä scho ä Soldat bist/

ä Läffä kost ja denäst sey?

Veitl. ös ist iem wie dä wöll/

Jetz schießt mä holt ga grob mit Stuckn drey.

- Auwehe - jetz geht mä scho vor Forcht

dä Adn aus.

Mei Seel will fuert/

und ko kain rechtn Ausgang findn/

ös laßt si käm mea höbn. - -

Jetz Buemä halts enck wohl/

I wie nimä lang löbn.

ARIA.

Mei Heartz macht Dickä Däck/

ös zittert wie ä Lämpel-Schwaiff/

Gehts holts mä gschwind än Bindä-Raiff/

Däß no beynondä höbt.

Do halts / ös iß ä guetä Rad

Jetz fie mei Heartzl scho zu spad;

I gläb / däß nimä löbt. ${ }^{114}$

2 nächst] vor kurzem, unlängst 3 gö] gleich 6 däkemä] erschrocken 12 är ä Läffä] auch ein Läufer, Bote 13 Gu Lappn] He, du Schwachkopf wanst ä] wenn du auch kost ja denäst] kannst du ja dennoch 15 wie dä wöll] wie auch immer 16 Stuckn] Kanonen 19 Adn] Atem 22 höbn] hier: ertragen 23 Buemä] Burschen, junge Männer enck] euch 27 Bindä-Raiff] metallene Fassreifen 28 höbt] hält

Maurus Lindemayr bringt das Thema der Zwangsrekrutierung in Der ernsthafte Spaß mit derbkomischen Charakteren auf die Bühne: Neben dem Säufer Hanns auch sein keifendes Eheweib Margareth, die zunächst nicht unfroh ist, ihren Mann an das Heer zu verlieren, bis sie erfährt, dass sie als Soldatenfrau in die Fremde mitziehen müsste. Als sich letztlich die Werbung als grober Scherz des Feldwebels entpuppt, atmet Hanns auf, denn:

Ih hätt mä, glaubt's mä's gwiß, ga bald än Wolfen g'ritten.

Denn 's Reiten taubt mä nöt, dös wär mein grösti Bueß;

Und gieng ih, thät mä schreyn: schaut's, schaut's! ä Reitä z'Fueß.

Das Ding vädroissät mih, ih litt kain lötzi Goschen

Und wurd ih zän än Pätz mit haslern Stöckern droschen.

114 [Ferdinand Rosner:] Der Teutsche Sultan. Ein Lust-Spihl Zur Faßnachts-Zeit Vorgestellet Von denen Benedictinerischen Musen In Freysing Den und Hornung. Gedruckt zu Closter Tegernsee, 1760, f. 3v. 
Ämal dästäch ih ain, denn hitzi bin ih gleih

Aft hätt ih's teufels Neath, und ös bräf Keyerey. ${ }^{115}$

1 mä] mir än Wolfen] einen Wolf, Intertrigo 2 taubt mä nöt] tut mit nicht gut 4 kain lötzi Goschen] kein Gespött 5 zän än Pätz] zu Brei (Batz: dicke Flüssigkeit, die aus einem zerquetschten Körper austritt) haslern] aus Haselnussholz 6 dästäch] erstäche 7 Neath] Not ös] ihr bräf Keyerey] ordentliche Streiterei, Schererei, richtiges Problem

So erfolgreich war das Singspiel, dass es im 18. Jahrhundert gleich dreimal vertont wurde, u. a. auch von Franz Xaver Süßmayr (1766-1803). Realistischer behandelt Lindemayrs wohl letztes Theaterstück, die Stiftsoperette Der befreyte Land Rekrut (um 1782), das Thema Zwangsrekrutierung. Nun ist es kein arbeitsscheuer Alkoholiker, sondern der brave Bauernsohn Anere, der „nicht zur Straf seiner bisherigen schlechten Aufführung, aber doch ex officio ad militiam abgegeben worden “116. Mit einem gefälschten Attest des Dorfbaders gelingt es den verzweifelten Eltern, den aufgrund der bestehenden Gesetzeslage rechtmäßig eingezogenen Hoferben doch noch beim korrekten Oberst auszulösen. Dass die entstandene Lücke mit einem anderen Rekruten aus dem Dorf gefüllt werden muss, um dem Landesfürsten ein schlagfertiges Heer zu sichern, wird hier allerdings nicht verschwiegen.

Nicht immer freilich verband sich mit der Werbung für das Heer schiere Angst, zu „väderäbm und steräbm “117; für sozial schlechter Gestellte konnte der Eintritt in militärische Dienste einen Aufstieg bedeuten, wie auch der Oberst ins Treffen führt, wenn er auf den literarisch vielfach ausgeschlachteten Fall ,Hanns von der Werth 'verweist, der es vom Bauernjungen zum „Generalissimus über die ganze Armee“118 gebracht hatte. Ein Stück über den berühmten Reitergeneral im Dreißigjährigen Krieg Johann von Werth kursierte noch mehr als ein Jahrhundert nach seinem Tod im bairisch-österreichischen Laienspiel, etwa der Laufener Schiffer. Lindemayr selbst verarbeitete den Stoff für eine Spiel-im-Spiel-Situation in seiner von Joseph Langthaller (1725-1790) vertonten Klosteroperette Die Komödieprob, die 1776 beim 30-jährigen Abtjubiläum mit großem Erfolg aufgeführt wurde. ${ }^{119}$ Sie zeigt die Zwangsverpflichtung des jungen „Hännsel von dä Wert“, den der Pfleger wegen seines losen Lebenswandels gemäß Hofbefehl ausgewählt hat. Seine anfängliche Verzweiflung weicht nach dem Zuspruch seines Umfelds, das an seine erfolgreichen Raufhändel erinnert und die Karrieremöglichkeiten skizziert, der Abenteuerlust:

115 Stiftsarchiv Lambach, Ccl 718/I, f. 74. Erstmals ediert in Maurus Lindermayr's Dichtungen in ob der ennsischer Volksmundart. Von Verehrern seiner Muse gesammelt. Linz: k. k. priv. akademische Kunst-, Musik- und Buchhandlung 1822, S. 55-108, hier 106.

116 Stiftsarchiv Lambach, Ccl 718/II, f. 72. Erstmals ediert ist Der befreyte Land Rekrut in Maurus Lindemayr's Sämmtliche Dichtungen in obderennsischer Mundart. Mit einer biographisch-literarischen Einleitung und einem kurzgefaßten Idiotikon. Hg. von Pius Schmieder. Linz: Korb 1875, S. 237-253.

117 Stiftsarchiv Lambach, Ccl 718/II, f. 72.

118 Ebda., f.73.

119 Vgl. Christian Neuhuber: „Ehrbar will man ergetzt werden ...“ Die hochdeutschen Lustspiele von P. Maurus Lindemayr. In: Maurus Lindemayr: Die hochdeutschen Komödien. Kritische Ausgabe. Hg. von Christian Neuhuber. Bd. 2: Kommentar. Wien: Praesens 2006, S. 13-150, hier S. 57. 
Hanns. Schan recht: nä frisch und köck.

LIPPERL. An wem, denst äuigfadert,

Habnt oft bäwärti Leut nit doktäriert, und badert?

GrescherL. Wer hat dä intadanzt, denst nit hast gueting zweillt?

Wer hat dä hui zuegschrüen, denst nöt schier d'Augn auskreillt?

Hast da n'Buemän oft schier d'Därm, und s'Bätz auströden;

So machs iezt ä ä so, wennst inhi kimmst fürn Schwöden.

Gib Foyr, und säbel drein, stes, hau, und sey ä Mann,

Sag: Schwöden, gschiecht enk recht; zwö greifts n'Kaisär an.

HäNNSEL. Mir is nur um mein Lebn, um d'Früesäur, und um d'Jausen.

LIPPERL. Was hast halt nit für Sätz, für wunäligi Fausen.

GrescherL. Hän! bleibt denn Niemd beym Lebn? kimmst Gsundähait dävan;

So hast ä Kumpäni, ä heai Stöll zum Lahn.

Du denkst auf d'Simisäur: denk liebä auf d'Dugätl,

Auf d'Thallä, und auf d'Beut, aufs Rindfleisch, und aufs Brätl,

Dös oft dö ganz Armee mit Semeln statt n’Bread,

Beym Bier, und bösten Wein in Lagä zössen hat.

HänNSEL. Mein Aid, i krieg än Lust.

GrescherL. Kimmst als ä Haupmann haimä,

Wie wird si Atensäm, und d'Friondschaft deinä braihmä!

Schauts schauts wirds schreün angehn, wie hat si halt väkehrt

Da rotzi Hannsen Bue, dä Hännsel von dä Wert!

HäNNSEL. Ist wahr, ä so wernds rödn.

Grescherl. Da wird di als än Helden

Dä Richtä, und dä Rath än gnadign Herrn schelten.

Mä wird där überall än Sitz göbn miträ Lain,

Dä Schreibä wird n' Huet, dä Pfarrä d'Haubn athäin.

HäNNSEL. Für mi?

LIPPERL. Wie denn! für di.

HäNNSEL. Und muist, äs wird mä glückä?

Grescherl. Wennst Annäs dapfä streitst, und d'Schwöden bräf wirst schrickä.

HäNNSEl. Streng Herr! I bin Soldat. Juhe! potz fikräment!

I geh gen Ainsgangs fort, und wier ä Regiment. ${ }^{120}$

1 nä] nur 2 denst äuigfadert] den du herausgefordert 3 bäwärti] bewährte badert] durch den Bader behandelt 4 hat dä intadanzt] ist dir in die Quere gekommen denst nit hast gueting zweillt] den du nicht ordentlich verprügelt hast 5 hui zuegschrüen] mit einem Ruf herausgefordert auskreillt] ausgekratzt 6 n'Buemän] den Buben, den jungen Männern 6 s'Bätz auströden] die Eingeweide, Weichteile herausgetreten 7 ä ä so] auch so inhi] hinein 7 stes] stoße 8 zwö] weswegen 9 Früesäur] Sauersuppe (aus saurer Milch, Mehl und Essig), von der bäuerlichen Bevölkerung als Frühstück gegessen 10 Sätz] Launen wunäligi Fausen] wunderliche Anwandlungen, Flausen 11 Hän] he, was Niemd] niemand 12 ä Kumpäni] einen Kompanie heai] hohe 13 Simisäur] Sauersuppe, die um sieben Uhr gegessen wird Dugätl] die Dukaten 19 Atensäm] Ottensheim (basiert auf der fälschlichen Annahme, Johann von Werth wäre aus Goldwörth bei Ottensheim gebürtig) Friondschaft] Verwandtschaft, Familie braihmä] rühmen, prahlen 25 miträ Lain] mit einer Lehne 26 athäin] abnehmen, ziehen 29 muist] meinst du 30 Wennst Annäs dapfä] wenn du besonders tapfer schrickä] peitschen, schlagen 32 gen Ainsgangs] sofort wier ä] werde ein

120 Die Komödieprob auf die allenfällige allerhöchste Ankunft Sr. Maiest. des Kaisers. Ein Lustspiel von dreyen Aufzügen in der gebundenen Oberennserischen bauerischen Mundart. Aufgeführt zu Kloster Lambach An dem Wahltage Sr. Hochwürden und Gnaden des nunmehr durch 30. Jahre seinem Löblichen Stifte höchst rühmlichst vorstehenden Herrn Herrn Abtens Amandi etc. etc. den 25. Weinmonats 1776. Steyr, mit Wimmerischen Schriften gedruckt [1776], f. 18f. 
Was Lindemayr hier ins Dramatische überträgt, sind Argumentationsstrategien, wie wir sie auch in zahlreichen Werbeliedern dieser Zeit finden, die gegen den chronischen Soldatenmangel künstlerisch ankämpften. Dazu wurden üblicherweise zwei Aspekte angesprochen: Zum einen ging es um die Frage, warum es sich lohne, in diesem Krieg zu kämpfen. Die Wiederholung und Überhöhung von Feindbildern spielte dabei eine wichtige Rolle, wobei auch eine religiöse Aufladung der Konflikte offenbar als wirksames Mittel galt (vgl. die Türkenlieder). Zum anderen wurden in der Bevölkerung die (angeblichen) sozialen und ökonomischen Vorzüge des Lebens als Soldat propagiert. Prototypisch für diese Art ist das Lied Lusti Guraschi, das uns in vier verschiedenen Quellen in jeweils unterschiedlichen Fassungen vorliegt, da es für stets neue Kontexte neue Konflikte und andere Feindbilder - angepasst wurde. Die wohl bereits zu Beginn des Spanischen Erbfolgekriegs entstandene Grundform bleibt jedoch immer gleich: Ein Knecht kündigt einem Bauern seinen Dienst auf, um als Soldat selbst Herr zu werden. Ausschlaggebend ist also die Befreiung aus sozialer Abhängigkeit; mit der Aussicht „praf Beut“ zu machen, lässt sich idealerweise der Wunsch nach einem freien und selbstständigen Leben verwirklichen. Schließlich wird auch an die Abenteuer- und Streitlust der jungen Männer appelliert:

1

Lusti Guraschi, jetzt ist mein Jahrl aus, Bauer richt Laschi, und zahle mich aus, ich dien mein Aichl kein Baurn nicht mehr, will ein Soldaten gebn, ist ja ein bessers Lebn, und bin a Herr.

3

Dann den Franzosen

scheu ich kein Teufel nicht, zittern ihm d'Hosen, wann er mich ansieht, wer mit Guraschi wie Teufel drein haut, man weiß vor Hochstätt schon, was sie alldort gethan, wer häts enttraut. 5 Man kennt die Deutschen, was sie vor Brüder seyn, wie sie zupeitschen, und schlagen drein, solts auch nichts regnen, als Feuer und Bley, stehen sie doch mauerfest, wöhrn sich aufs allerbest, seynd frisch darbey.
2

Allo nur lustig,

Baur richt mir s'Geld auf'n Tisch, ich bin schon giftig,

wills wagen frisch, und mit den Franzosen eins rauffen herum, gwiß ich Schläg oder Geld draussen im weiten Feld zur Beuth bekomm.

4

Den Spaniolen, ich schwör bei meiner Treu, es sollt ihm holen der Teufel gleich, er muß mir tanzen, als wie ich ihm pfeif, ich schlag ihm, daß ihm graust, wann ich ihm mit meiner Faust einmal ergreif.

6

Bhüt dich Gott Gredl, jetzt zieh ich schon davon, gilts dann mein Schädl, was ligts daran, will mir das Glück, daß ich bekomm praf Beut, solst du mein Weiberl seyn, und ich der Rieppel dein, bis der Todt uns scheidt. 
7

Johannes-Seegen, alle Wirth Wein herauf,

bin schon verwegen,

es gilt eins drauf,

Kaisers Soldaten

zu Fuß und zu Pferd,

solten schlagen drein,

und allzeit siegreich seyn,.

Vivat es werd. ${ }^{121}$

1,1 Guraschi] (franz. courage): Mut 1,3 Laschi] (franz. l'argent) Geld 1,5 mein Aichl] mein Aich(e)l: Interjektion zum Ausdruck der Bestätigung (vermutlich aus der Beteuerungsformel ,mein Aid!') 2,3 giftig] zornig, böse 3,7 vor Hochstätt] Höchstädt an der Donau, Schwaben; im 18. Jahrhundert mehrmals Schauplatz kriegerischer Handlungen, etwa im Spanischen Erbfolgekrieg oder in den Koalitionskriegen 3,9 wer häts enttraut] wer hätte es vermutet 6,6 praf] tüchtig, anständig 6,8 Rieppel] Kurzform von Rupert 7,1 Johannes-Seegen] im Namen des Hl. Johannes gesegneter Wein, der u. a. zum Abschied vor Reisen getrunken wurde 7,2 alle Wirth] vermutlich Druckfehler für, allo/allon Wirt', von franz. allons, ,gehen wir', ,los‘

Auch im folgenden Lied sollte die Soldatenwerbung unterstützt werden, indem der jungen ländlichen Bevölkerung eine soziale wie auch materielle Besserstellung als Soldat versprochen wird. Es ist hier allerdings nicht die Aussicht eines Knechts auf ein besseres Leben, sondern die retrospektive Erzählung des bereits wieder aus dem Krieg zurückgekehrten Sohnes, der nun - die Wortwahl ist ähnlich wie im obigen Lied - Bewunderung erregt und wie ein ,Herr' auftritt. Die Heimkehrer-Situation, in ähnlichen Liedern zur Kommentierung des Kriegsgeschehens genützt, dient hier vor allem dazu, die Vorzüge des Soldatenstands herauszustreichen: standesgemäße Einkleidung, Armierung, Bereitstellung eines Reitpferdes und höherer Statut. Der Kommentar des Vaters in der letzten Zeile - „er möcht uns main aichl glei wieder fort gehn“ - bringt noch einmal die Botschaft des Lieds zum Ausdruck: Angesichts des aufregenden und Ehrfurcht erweckenden Soldatendaseins würde (bzw. sollte) der Sohn - und damit sind wohl auch die jungen Männer unter den Hörern des Lieds angesprochen - am liebsten gleich wieder Soldat werden.

1

GOtt grüß enck mein Vattä und Muttä all zwey,

kennt ös no den Jackerl der in Krieg ist grayst,

ein Jahr und 3. Wochä wird scho seyn auf d'Läng,

gelt Vattä du hätts mi bald nimmä kennt.

2

Botz schlaprament Jackerl bist dann du mein Sohn,

wie bist du so stattlä, jetzt kenn i di schon,

i hon warlä gmait wies bist gangä daher,

du bist unsä Schreibä, oder gar der streng Herr.

121 Drey neue Weltliche Lieder. Das Erste. Hört was ich will verkün-kün-künden, wann ich etc. Das Zweyte: Lusti Guraschi, jetzt ist mein Jahrl aus, Bauer richt etc. Das Dritte: Armes Herz hör auf zu etc. Gedruckt in diesem Jahr. [o. O., o. J.], f. 3r-4r. 
3

O lieber mein Jackerl wärs obä dä Brauch, daß i mi soll buckä, abnehmen mei Haubn, weilst bist im Feld gweßn, und hast ä was gsehn, so sollt mä di Jackerl halt haissen ein Herrn. 4

Schau loß nur mei Vattä, wie i wurd Soldat, da thains mi schön klayden, daß ein Nomä hat, schö Stifel, noi Hosen, Camisoll und Rock, ein einbrämten Hut setzns mir aufn Kopf. 5 Afft gebns mä ein Säbel bey meiner basttreu, der ist ä lang mächti, und hat ä zwo Schneid, O mei liebä Vatter i will dir nit loign, glaub unser schwartz Räpel das hät a dran d'zoign. 6

Afft thains mä vorweisen ein grosmächtigs Roß, daß ist dir da g’standen als wie halt ä Stock, Pistollnä, Carbinä, das ist dir dran ghenckt, ja Vattä mein aichl dort hettst mi nit kennt. 7

Afft seyn mä halt gritten in das Böhmer-Land, da verstund i kein Menschen, da wär mir recht bang, da gehts dori däck, jä ne mäm Klebo, das haist halt auf Teusch, mir habn selber kein Brod. 8

O mei lieber Jackerl weilst nur dähaimt bist, thu dich nit lang spreitzn, und setz dich zum Tisch, geh Muttä bach Krapffen, gibn Jackerl ä zwen, er möcht uns main aichl glei wieder fort gehn. ${ }^{122}$

1,2 ös no] ihr noch 2,1 Botz schlaprament] Ausruf des Unwillens (als verkapptes ,Sakrament') 2,3 i hon warlä gmait] ich habe wahrlich gemeint 3,4 streng Herr] Pfleger, Anredeform für höhere Beamte ohne Adelstitel 4,1 loß] hör, horch zu 4,4 einbrämten] verbrämten, verzierten 5,3 loign] vorlügen 5,4 Räpel] Rappe, schwarzes Pferd 6,1 Afft thains mä] dann tun sie mir 6,4 mein aichl] Beteuerungsformel 7,3 dori däck] (tschech. dobrý tak) gut so jä ne mäm Klebo] (tschech. já ne mám chlébo) ich habe kein Brot 8,3 ä zwen] auch zwei

Soldatenwerbelieder ohne konkrete Bedrohungsbilder ließen sich schnell für unterschiedliche Anlässe adaptieren. Wie sie in konkreten Konflikten eingesetzt werden konnten, soll ein Lied aus einer Flugschrift zum Polnischen Thronfolgekrieg veranschaulichen.

\section{Polnischer Thronfolgekrieg (1733-1738)}

Die europäische Machtpolitik und schwelende Rivalitäten zwischen Frankreich und Österreich bzw. dem deutschen Reich hatten in den Jahren 1733-1735 erneut zum Krieg geführt, wobei Streitigkeiten um die Nachfolge des verstorbenen polnischen Königs August des Starken den Ausgangspunkt zu den Auseinandersetzungen bildeten. ${ }^{123}$ Frank-

122 Siben schöne Neue Gesänger (siehe Anm.67), f. 3v. Auch abgedruckt in Klier, Historische Lieder des 18. Jh., S. 32f.

123 Vgl. Hochedlinger, Austria's Wars of Emergence, S. 208-212. 
reich favorisierte den früheren polnischen König Stanislaus Leszczyński, Schwiegervater Ludwigs XV., als Nachfolger. Um diesen als Thronfolger zu verhindern, unterstützte Österreich gemeinsam mit Russland den Sohn des verstorbenen Königs, Friedrich August von Sachsen. Nach der Absetzung Leszczyńskis erklärte Frankreich dem deutschen Reich den Krieg, in dem die schwach aufgestellte österreichische Armee vor allem in Italien empfindliche Verluste erlitt. Mit dem Präliminarfrieden von 1735 wurde August als polnischer König bestätigt, Frankreich konnte sich aber Einfluss über einige Gebiete, insbesondere Lothringen, sichern.

Angesichts der Tatsache, dass es sich um einen - auch im historischen Rückblick vergleichsweise unbedeutenden Krieg handelt, in dem die Interessenlage auch für die zeitgenössische Bevölkerung nur schwer zu durchschauen war, sind jene Lieder aufschlussreich, die vornehmlich der Frage dienten, wofür es sich überhaupt zu kämpfen lohne. Um Werbemaßnahmen zur rechtfertigen, musste die Obrigkeit die bäuerliche Bevölkerung so ansprechen, dass sie sich möglichst unmittelbar betroffen fühlte. In WAs Wundä, was muß I dir sagn werden zunächst die Kriegsgeschehnisse kritisch gesehen. Der junge Mann, dem von den Ereignissen berichtet wird, ist anfangs wenig motiviert, sich selbst in Gefahr zu begeben. Doch dient diese ablehnende Haltung als Gelegenheit, die verschiedenen Register der Soldatenwerbung zu ziehen: Die Auseinandersetzung, so heißt es etwa, sei harmlos und ,koste nicht gleich den Kopf ${ }^{\circ}$, dafür warteten Siege und nicht zu vergessen - Beute. Schließlich aber verlange es die Ehre, Österreich - so wie es schon die Tiroler auf beeindruckende Weise getan hätten - gegen die feindlichen Franzosen zu verteidigen:

1

WAs Wundä, was muß I dir sagn, was sie nä für Händl zu tragen, zWienn bin I jetzt gwösen, hand Zeitung hörn, lösn, gantz kürtzlä in wenigen Tagn, solt an gehn das Räffä und Schlagn. 3

Daß thut ihm vodroissen so sehr, daß [er] nöt ist worden ä Herr, ${ }^{124}$ daß er si aus Pohln $\mathrm{h}[\mathrm{at}]$ müssen fort trollen, jetzt daß er nöt auswa[...] zu letzt, hat er den Frantzosen anghötzt. 5

O Hießl wie wär I ä Narr, das I [mi] solt göbn in d'Gfahr, solts Haimät volassen matschiren ä Strassen, wo I meinä löbtä n[ie] gwöst, bleib liebä dä haimbten in Nöst.
2

Wer hat dir nä döß mehr däzöhlt, wer hat nä dö Händl angstölt, Stanislaus in Pohln, hat König wehren wolln, das Glück hat ihm abä nöt gwölt, statt seinä än andärn erwölt.

4

Was wöhln nä dFrantzosen anhöbn, w[ir] thain iehn kain Härl nachgöbn, ihr Silba und Läschi, macht ins nä Guraschi, wann wirs werdn bekemmä zur Beuth, wie wöllmä ins machä ä Freud.

6

Du Lapp, du zaghäfftigä Tropf, ös thut nöt gleich gelten den Kopf, ders Unhayl will dämpfä, muß wälä bräf kämpfä, gring wagn Müthl und Blut, und denckä daß afften wird gut.

124 Hier und in der Folge Textverlust am ersten Blatt aufgrund des ausgerissenen Blattrands. 
7

Hast dus den dein löbtä nit ghört, das offt ain ä Glück ist beschert, ders köck thut anfangä kan öffters wohl glangä zum Sig und Victori mit Freud, bißweiln ä machä praf Beuth.

[...]

11

So seys den so will ichs probirn, wils Bauren Löbn gäntzlä quitirn, wils andern voschenckä

ä Praxen anhenckä, will hauä und fetzen drein, villeicht kan I Obristä seyn.
10

Ja wohl nä mein Hießlätä Bueb,

der Tantz kost noh mehr äs paar Schueh,

bey jetzigen Zeiten,

haists ritterlich Streitten,

än Esel der immä ist faul,

dem fliegen kaini Vögel ins Maul.

12

Und wen I än Obristä wir, so trinck I kain Most und kai Bier, Sterz, Knödl und Nockä, ä Stabn volli Brockä, den will I sValedi bald göbn, flangirn so lang I werd löbn. ${ }^{125}$

1,4 hand] habe 4,3 Läschi] (franz. l’argent) Geld 4,4 Guraschi] (franz. courage) Mut 4,6 wöllmä ins] wollen wir uns 6,4 wälä] wahrlich 6,6 afften] dann, danach 10,1 Hießlätä] Spiel mit dem Namen Hiesl (Matthias) und der Bedeutung ,dümmlich` 11,4 Praxen] säbelähnliches Messer, verächtlich für Schwert; auch Spottname für ein schlechtes Gewehr 12,4 Stabn] Hohlmaß volli Brockä] voller Brocken 12,5 Valedi] (lat. valete: ,lebt wohl') Abschiedsgruß 12,6 flangirn] müßig herumziehen

Zumindest in diesem Lied greifen die Argumente und der Angesprochene will sein Glück als Soldat versuchen. Seine anfänglichen Bedenken freilich waren nicht unbegründet. Anders als es die Jubel- und Siegesmeldungen, vor allem aber die Soldatenwerbelieder glauben machen wollen, waren Krieg und Soldatenleben weder lustig und unbeschwert, noch konnten sie tatsächlich für das oft versprochene gute Leben abseits von sozialer und ökonomischer Abhängigkeit garantieren. Dass die Bevölkerung in dieser Hinsicht keineswegs so ahnungslos und blauäugig war, wie es viele obrigkeitliche Lieder suggerieren, machen Texte deutlich, die nicht ohne Grund in der Regel handschriftlich überliefert sind und dieser Propaganda ein ganz anderes Bild gegenüberstellen. Realistische Schilderungen des Krieges, die nicht hurrapatriotische Stimmung wecken wollten oder heroisch-idyllisch verbrämt waren, kamen kaum durch die Zensur bzw. fanden nur selten einen Verleger. In den meisten Fällen ist die Kriegsliteratur im Sinne der Herrschenden manipuliert; negative Schilderungen werden nur als Propagandamittel gegen den Feind zugelassen. ${ }^{126}$

In einem Ende des 18. Jahrhunderts im Stubenberger Gesängerbuch überlieferten Lied wird die Thematik falscher Versprechungen und Erwartungen in Form eines (scheinbar neutralen) Bauerngesprächslieds aufgerollt. Dialogisch aufgebaut, liefert der gesang zwischen den hänsl und hiesl ${ }^{127}$ eine scheinbare Pro-und-Kontra-Konfrontation,

125 Vier gantz neue Kriegs-Lieder / Das Erste: Was Wundä / was muß i dir sagn / etc. Das Anderte: Frantzos was bildst dir ein / daß du mit so verwegnen Muth, etc. Das Dritte: He lusti Kurasche es geht schon drauf loß / wo ist dann mein Bixen, etc. Das Vierdte: Leicht ich dann fort muß in Krieg / etc. Steyr / gedruckt bei Johann Jacob Jahn/ 1734. Eine leicht bereinigte Edition findet sich auch schon bei Klier, Historische Lieder des 18. Jh., S. 26.

126 Vgl. dazu u. a. Rudolf Schenda: Volk ohne Buch. Studien zur Sozialgeschichte der populären Lesestoffe 1770-1910. Frankfurt a. M.: Klostermann 1970, S. 374-379.

127 Der Titel ist dem Text im Stubenberger Gesängerbuch nicht vorangestellt, findet sich aber im Register. 
die in den vorgebrachten widerläufigen Meinungen die zeitgenössischen Vorstellungen spiegelt. Dabei wird Hänsel - der sich ein angenehmes Leben bei guter Bezahlung und damit eine vielversprechende Besserung zum gegenwärtigen Auskommen erwartet - als letztlich leichtgläubige und unwissende Bauernfigur gezeichnet, die ihr Leben mit ihrer Naivität leichtfertig aufs Spiel setzt. Ohne explizit belehrend zu sein - und ohne dass eine der vorgebrachten Positionen letztlich offen , siegt ${ }^{\star}$ - wird damit im Text doch deutlich Kritik an den Werbestrategien geübt, die die Unbedarftheit der Landbevölkerung ausnutzen und aus deren Wunsch nach einem besseren Leben Profit schlagen.

1

HäNSL.

Potz Blundä Liebä Bue, hast du kaein lust darzue, jetz kanst du wern ä her, kanst habm än guetn Mueth, es wär Mein aeichl dol, schau hänsl Mürkh nä wohl, Mir kinän jetz Soldaten göbn, so sangt Mir habm das Böste löbm, göbmt uns bräff geld in $\mathrm{d}$ hand, ä fungl Neus gewand 3 HÄNSL.

Es wär aber recht dol, es gfiel mir selbä wohl, wan mir hetn guete täg, wie wurds uns daey so wohl, wan Mä hättn Bier und fleisch, das war ä guettö speiss, wär Bössä als das häbärä Brodt, geh Bruedä mir bleibm nimmä da, richt du dir dein Sächl zam, geh gehn Mir Mitternand: [...]

12

Hiesl i wil däs sagn, du würst wern bräff däschlagn, kaperaln dö seind nöth faul mit aeinän höslän stabm, wanst du lernst s Exerziern, und wilst Nöth Recht bariern, so wernstä än Pukhl waeigä guet, glaub du Mein hansl lieber Bue, bleib du dafür nur da und wür nur kaey Saldat:
2

HiesL. ${ }^{128}$

Hiesl vexier Mi Nit, i geh dir wohl Nit Mit, und wan da wär vil guets darbey, die hern dätns Nöth, sö seind ja sunst gley da, und ziegnt das böst däva, sö wurdn dirs Nöth lassn zue, es seind ja sonst gar gschwindi buebm, Nä Nä i drau dir Nöth: i geh dir wohl Nöth Mit: 4 HiesL.

Ich las Mi wohl Nöth Brön, i ha Nä kradt aey löbm, und wan i halt däschossen würd, so het än Pfifferling, was heilff Mi Nachä s geld, wan i kaey löbm mehr het, i wil dafür dahaeimbten bleibm, beim bauern gsott und fuetter schnein, und össen härbäs Brodt, eh i Mein leben wag,

13

Es ligt mir wohl nix dra, jezund raeis i dävon, wer waeis was würth aus mir, kan wern ein leitenambt, oft schau i auf Mein treu, das i krieg ä schens weib, d Saldatten weibä gfalnt mir wohl, dö kinänt Mein aeichl kochä dol, Mues schau das i aeinö thu kriegn, jezund wil i Mäschiern: ${ }^{129}$

1,1 Potz Blundä] Ausruf des Erstaunens 1,5 Mein aeichl] Interjektion zum Ausdruck der Nachdrücklichkeit 1,6 Mürkh nä wohl] merke nur auf, pass auf, hör zu 1,8 so] wohl Schreibfehler für ,sö‘, sie 1,9 bräff] tüch-

128 Die Sprecherrollenzuweisungen widersprechen teils der Verwendung der Namen im Liedtext. Die jeweiligen - strukturell nicht schlüssigen - Nennungen entsprechen dem Original.

129 Bayerische Staatsbibliothek, Cod. germ. 7340 (Stubenberger Gesängerbuch), Teil 2, S. 172-173. 
tig, anständig, ansehnlich 2,1 vexier] (lat. vexare: schütteln, plagen) necke, verarsche 2,4 dätns Nöth] ,täten es nicht' (modal: die Herren woll(t)en es nicht tun) 2,6 ziegnt das böst däva] suchen sich das Beste heraus 3,4 daey] eigenwillige Schreibweise für ,thai': tun 3,7 häbära] aus Hafer 4,1 Brön] prellen 4,2 i ha Nä kradt aey löbm] ich habe nur gerade ein Leben 4,8 gsott] nährstoffarmes Abfallmaterial vom Futterschneiden und Dreschen, das gesotten im Winter als (zusätzliches) Viehfutter verwendet wurde 4,9 härbäs] s. o. 3,7 12,2 däschlagn] erschlagen, hier eher im Sinn von: durchgeprügelt 12,3 kaperaln] Korporäle 12,4 höslän stabm] Haselstab 12,7 wernstä] werden sie dir än Pukhl] den Buckel: Rücken waeigä] walken: schlagen, verprügeln 13,4 leitenambt] Leutnant

Während es hier noch um ein eher allgemeines Abwägen verschiedener Gründe geht, greifen andere Texte zu wesentlich drastischeren Darstellungen. Besonders aufschlussreich sind in dem Zusammenhang drei Texte der Bayerischen Staatsbibliothek, die sprachlich zwar eher ins Fränkische weisen, hier aber aus inhaltlichen Gründen dennoch erwähnt seien. Interessanterweise findet sich dabei die Heimkehrerkonstellation des bereits besprochenen GOtt grüß enck mein Vattä und Muttä all zwey (siehe S. 157) praktisch wörtlich wieder. Auch der Topos vom ehrfurchtgebietenden Auftreten des Soldaten kommt in beiden Fällen inhalts- und teilweise auch wortgleich vor. ${ }^{130}$ Jenseits dieser Übereinstimmungen aber entsteht in diesen handschriftlichen Belegen ein völlig anderer Eindruck. So wird in zwei Strophen des Lieds Gott grüß di mein Voter, Gott helff der mei Mutter die oft betrügerische und zwangsweise Werbungspraxis folgendermaßen geschildert:

5

Wei i bin ferten ins Östereich ganga,

dau hobmi man achel die Werber aufgfanga,

sie hobmi reinzogen an Wein gschwind rei drogen,

gsund des Kaisers zu zecht,

daß i nimmer ho gmöcht.

6

Oftn führtens mi halt ins Ungerland ohi,

dau hobmer gschwind denkt wos thu i wos machi,

hob wöllen entrinna hob ober nit könna,

a jeder schwört drauf

ma häng mi glat auf. ${ }^{131}$

5,1 ferten] im vergangenen Jahr 5,2 hobmi] haben mich man achel] Beteuerungsformel 5,4 gsund des Kaisers zu zecht] auf des Kaisers Gesundheit getrunken 6,1 Oftn] dann

Im zweiten (in zwei Varianten überlieferten) Lied Ey grüß di gott Voter und Muter wird anschaulich das Leid sowohl der Soldaten als auch der Daheimgebliebenen thematisiert:

130 Die metrische Gestaltung allerdings weicht relativ stark ab, wobei die gedruckte Version die üblichen auftaktigen Vierheber im Paarreim verwendet, während die Verse der handschriftlichen Texte deutlich komplexer gestaltet sind. Dies ist wohl ein Hinweis auf unterschiedliche Rezeptionsverläufe: Die heute handschriftlich vorliegenden Lieder wurden sicher mündlich überliefert und waren damit stets mit einer Melodie verbunden, die auch eine komplexere Metrik ermöglichte. Dagegen erreichte die gedruckte Version potenziell auch ein Publikum, das das Lied ohne Melodie rezipierte. Eine komplexe Metrik wie in der ersten Version hätte hier durchaus Verstehensprobleme bewirken können, zumal in den Drucken ja die Verse nicht an der Textoberfläche gekennzeichnet wurden.

131 Bayerische Staatsbibliothek, Cod. germ. 5290, Faszikel C, Bl. 4 (Sammlung verschiedener handschriftlicher Lieder, nicht gebunden; 12 Strophen). 
2

Ha Jodel wei haut ders denn ganga, ho gmant du seyst scho gfanga, dei Muttern war schier narrisch worn, hob gmant sie wahnt vor lauter Zorn, oda wurd sie gar aufhanga, des Veitl sei dirn haut gjammert haut gschrihn, war schier ins frasch nei gfalln, i hob ers wol öffter als neunmal gsagt, sie soll ja seyn nit so verzagt, haut danni nit helfen wolln. [...]

5

Wey i mir hob laußen probirn, dos hast mers l'exercirn,

dann kumma viel mitn hästlen stab, sie klopfen an den buckel prav a oft muß ma a bald marschirn, ma muß sie umkehrn, das schüßen erst lern, i ko dir nit Wunder sogn, sie schreyha daß aner verzogn möcht, wend umma dei bixn halb links halb recht, oft wöllns an halma derschlogn.
4

A Vota so lauß der halt sogn, wi i mi hob meiß wogn, as war ka wunner i war schon todt hon ausgestanden à sotni Noth, daß aner schier möcht verzogn, und wann iß thu mana so muß i bald wahna, vor lauter lad $u$. schmerzn, und wann is wogn muß no a halbs Jahr so bring i davo ka haut ka hauer, es liegt mer a stan aufn herzn.

6

Aftn san ma mit Spießn und Stanga wohl nei ins Ungarland ganga, da han i gschriha als wie a Koder, hob ausgeseha as wie a doder ho gmant der Türk wurd mi fanga, so hon i oftn an ganzen Tog, ka Nudel ka sterzl nit gsea, a manche Tog a halbs labl brod, die läuß die sitzn wol in der Pfod, so übel ist mirs no nit ganga. [...] ${ }^{132}$

2,1 wei haut ders denn ganga] wie ist es dir denn ergangen 2,6 des Veitl sei dirn] die Tocher des Veit 2,7 frasch] Frais: Krampf, hysterischer Anfall; , in die Frais fallen' auch spöttisch 2,10 danni] dennoch 4,2 meiß] müssen 4,4 sotni] solche 4,9 hauer] hier für: Haar 5,2 hast] heißt: nennt 5,3 hästlen stab] Haselstab 5,4 prav] ordentlich, tüchtig (bekräftigendes Adverb) 5,10 halma] halb 6,1 Aftn san ma] dann sind wir 6,9 Pfod] Hemd

Auch ein noch aus der Zeit des Siebenjährigen Krieges stammendes Lied behandelt die Praxis der Anwerbung durch Zwang oder Überrumpelung und das beschwerliche Leben, vor allem aber die drastischen Schikanen und Strafmaßnahmen, die das Soldatendasein prägen. Betont wird dabei wieder vor allem die Diskrepanz zwischen den Versprechungen und Gaben, die die Werbung begleiten, und der tatsächlichen Behandlung: Die Ausstattung mit Kleidung („ä Joppen und ä G’säß“), Geld und Waffen (vgl. Str. 2) war wohl ein wirksames Mittel, um junge Männer aus der Unterschicht anzulocken. Das tägliche Leben allerdings sah, so wird im Lied deutlich gemacht, anders aus und war durch Geldnot, Hunger und brutale Strafen gekennzeichnet:

1

ISt einer weil dort wohl in der Stadt drinn,

hat einer etwas zu g'winna, so lassens eim kein Fried,

da trommelns auf und ab,

wann sie einen Bauern Buebm sehn, so greiffens gleich darnach.

2

Hand-Geld gebens ein fünf Gulden, ä Joppen und ä G’säß,

ä Gürtel auch von Leder und dran ein eisernes G'fräß,

ä Schiessen gebns eim ä,

das heist man eini Muscöten, da sät man's Pulver drauf.

132 Ebda., f. 5r-6r (8 Strophen). Auf f. 13r-v findet sich eine zweite Variante (Incipit: Greiß die Gott vota und Muta), die die ersten vier Strophen in nur leicht abgewandelter Form enthält. 
3

Aft gebns ein Tag fünf Kreutzer, da soll man sich ernähren,

da kan man sich beym Preussen vor Hunger nicht erwehren,

s'Stehln thut man ä nit leiden,

wär Noth, wir fanget d'Hüner beym Bauern aus der Steign.

4

Geht einer heimli durchi, da wollns sie ein schon zwagn,

da kommen sie gleich nacher, und nehmen ein beym Kragn,

und wolln ein hangen gschwind,

oder gar derschiessen, daß Ding geht mir um in Grind.

5

Aft thains aufn Platz hersetzen, hat vier Füß und ein Kopf,

ist das ein artliche Fröttn, hat hint und vorn ein Schopf,

hat lange, lange Ohren,

aft wann man nur drauf reit, so thuts eim bitter zorn.

6

Muß einer a Weil drauf jucka, ä Stund ä zwey ä drey,

da wird eim s'Maul so truckä, das G’säß so heiß darbey,

daß mans nicht glauben kan,

der Teixel hohl den Esel, reit ohne Zaum darvon. ${ }^{133}$

2,1 G’säß] Hose 2,2 G’fräß] hier offenbar Seitenwaffe 2,3 Schiessen] hier als Subst. für Schießgewehr 4,1 zwagn] waschen; (hier:) zurechtweisen 4,4 Grind] Kopf, Schädel (verächtlich) 5,1-6,4 Aft ... darvon] bezieht sich, so Klier, „auf die Strafe des Eselreitens, auf einem hölzernen Gestell mit dachartigen Seitenflächen sitzen“ 5,2 Fröttn] unzureichende Einrichtung, Vorrichtung 5,4 zorn] abzehren 6,4 Teixel] Teufel

Sozialkritische Sprengkraft gewinnt das Lied durch die schonungslose Offenlegung der Schikanen, denen die zwangsrekrutierten Soldaten ausgesetzt waren, und die drastischen militärrechtlichen Konsequenzen für Fehlverhalten, die in den Werbeliedern natürlich ausgeblendet bleiben. Eine Schilderung des Kriegsleides allein ließe sich wieder dazu funktionalisieren, Stimmung gegen den Feind zu machen und die ,patriotische Gesinnung' wachzuhalten. Hier aber richtet sich die Kritik direkt gegen die Obrigkeit und die eigenen Befehlshaber. Das kennzeichnet dieses Lied tatsächlich als ,Lyrik von unten ' - die wohl nicht zufällig nur handschriftlich überliefert ist.

Die Existenzängste der Zwangsrekrutierten, jedoch aus herrschaftsaffirmativer Perspektive, behandelt auch ein Text aus bekannter Feder: Michael Denis (1729-1800), der bedeutende Ossian-Übersetzer und Kirchenlieddichter, veröffentlichte im zweiten Band seiner Lesefrüchte (1797) unter dem Stichwort ,Mundart' den „Abschied eines Recruten“ im - wenn auch im Detail fehlerhaften - „obersteyerischen Bauerndialecte“. ${ }^{134}$ Obwohl das Gedicht auf den ersten Blick eine wehmütige Stimmung zu vermitteln scheint und

133 Vier schöne Neue Lieder, das Erste: König aus Preussen, was bildest dir ein, daß du in Sachsen etc. Das Anderte: O Preuß, du grausamer Tyrann hör auf, du hast schon etc. Das Dritte: Nächt hat mi mein Muttern in d'Stadt eini gschickt, da hab etc. Das Vierte: Ist einer weil dort wohl in der Stadt darinn, hat einer etc. Gedruckt in diesem Jahr. [Linz (?), 1758]. Zitiert nach Klier, Historische Lieder des 18. Jh., S. 35.

134 [Michael Denis]: Lesefrüchte. Zweyter Theil. M bis Z. Wien: Rötzel 1797, S. 68. Zur Entstehungszeit finden sich bei Denis selbst keine Angaben, auch lässt sich dies nicht aus anderen Quellen exakt eruieren. Klier/Seemann konstatieren: „Da Denis Steiermark 1756 verließ, kann die Entstehung dieser wohl ältesten Mundartdichtung des Landes in die Mitte des 18. Jhdts. verlegt werden“ (Karl Klier/Erich Seemann: Kunstlieder im Volksmunde. Nachweise. In: Jahrbuch für Volksliedforschung 2 (1930), S. 156-160, hier 160). Dies scheint zwar naheliegend, doch ist keineswegs auszuschließen, dass Denis nicht auch in 
durchaus brisante Themen rund um die Rekrutierung wie die Denunzierung Wehrfähiger, die Selbstverstümmelung als Mittel zur Untauglichkeit oder den Entfall einer Arbeitskraft für den heimatlichen Hof anspricht, will es nicht Missstände des Systems decouvrieren. Es ist vielmehr die Feigheit und Dienstunwilligkeit des sich verabschiedenden Rekruten, die dieser literarische „Scherz“ (wie Denis selbst seine Dichtung bezeichnet) anprangert:

No, Vadä! bhiet di Gott! I siechs, i mueß frey gien.

Blib i no lengä da, so käm i grauslä z'hien.

Hiett i das Ding mä groät, i soll d'Muschkötn tragn,

I hiett mär ohni Scheu än Fingä bissn a,

Aft derfät i nöt furst, aft möcht i bleibn da.

Hiezt afä hoaßts ins Feld, hiezt muß i widän Preußn,

Oes hilft koän Zahneinschlagn, ös hilft koän Fingäbeißn.

Ach Gott! wie wirsts mä gien, wanns kimmt zun Foyägöbn!

I bin ä jungä Bue, wie schad is um mein Löbn.

Wie bössä wärs fie mi, wann i dähoäm kinnt bleibn,

An Werstä hüsch bon Pflue, an Feyrstä Köglscheibn,

Ä Vierstl Wein däzue, oäns Tanzn odä Karstn.

Alloän ös is umsist. Koän Schmölzä han i z'gwarstn,

Dö Nudl saind väbai, koän Dunkäts krieg i meh. -

Schau, Vadä! dä Kabral wie finstä schaut ä he.

I moän, dä gränti Kunt will mi schon hiezet schmirn.

I bitt oi, bas Giduld! hinz kimmt zun Exäzirn.

$\mathrm{Du}$, Simerl! hilf halt du in Vadä rödlä hausn.

$\mathrm{Du}$, Fränzl! sey nix sperr, und laß dä fleißi lausn.

Wanns ibän Dienä kemmpts, der mi verradn hat,

So bröchts den znichtn Schurk dö Häxn ohni Gnad.

Wer woäß, dälöbts an mir no wohl än groäßn Herrn,

Aft mögts ös olli zwien no meini Reidknet wern,

Und unsä Schwöstä d’Maiz kriegt söi däwal koän Mann,

Aft nimm i söi halt ä zu meinä Köchinn an.

Löbts wohl, oll meini Gspän! Löbts wohl, dös Roß und Ochsn,

Und laßts enk koän grabs Haar von wögn meinä wochsn.

Für olli Lieb und Troi dank i enk fleißi schoän.

In Fuedän mag i enk halt ä koän Giet meh thoän.

Vor olln afä du, mein Muedä! löb frey wohl!

Wie loädi bin i niet, daß i mi schoädnä scholl!

I derf niet denkn auf, sist kimm i grauslä z'hien.

Löbts olli wohl bonand! I siechs, i mueß frey gien. ${ }^{135}$

1 frey] nur, nun gien] gehen 2 hien] (laut) weinen 3 Hiett i] hätte ich mä groät] mir gedacht, vermutet 4 bissn a] abgebissen 5 Aft derfät i nöt furst] dann müsste ich nicht fort 11 Werstä] Werktag Feyrstä] Feiertag 12 Karstn] Karten (spielen) 13 Schmölzä] Schmelzer: Mehlspeise gwarstn] erwarten 14 Dunkäts] Getunktes:

Wien ein Gedicht in steirischer Mundart verfasst haben könnte; zumindest aber lassen seine Angaben zum Entstehungskontext vermuten, dass der Text einige Zeit vor Abdruck entstanden sein wird.

135 Denis, Lesefrüchte II, S. 68-70. Interessant sind die Anmerkungen, die Denis dem Text zur sprachlichen Gestalt beigibt. Für die schriftliche Wiedergabe bedauert er, dass „das gewöhnliche Alphabet [...] kümmerlich hinreichet“ (S. 68), und konstatiert abschließend: „Das Ganze würde verständlicher seyn, wenn man es vortragen hörte, als da man es liest, weil man einige Töne, wie ich schon erinnert habe, mit unseren Buchstaben nicht ganz genau bezeichnen kann" (S. 70). 
Mehlspeise 15 Kabral] Korporal 16 dä gränti Kunt] der missmutige Kerl 17 bas] mehr 18 rödlä hausn] redlich, ordentlich wirtschaften 19 sperr] hier: widerspenstig lausen] schinden, prügeln 20 ibän Dienä kemmpts] dem Gerichtsdiener, Schergen begegnet 21 znichtn] bösartig, nichtswürdig Häxn] Beine 23 ös olli zwien] ihr alle beide 24 Maiz] Maria 26 Gspän] Freunde, Kameraden dös] ihr 27 enk koän grabs] euch kein graues 29 In Fuedän] beim Füttern 31 loädi] leidig, verdrossen schoädnä scholl] scheiden soll (Druckfehler) 32 sist] sonst 33 bonand] beieinander

Als Verfasser der bekanntesten österreichischen Sammlung an patriotischen Kriegsliedern zum Siebenjährigen Krieg (Poetische Bilder der meisten kriegerischen Ereignisse in Europa seit 1756), lag es dem Kustos der Hofbibliothek und k. k. Hofrat selbstredend fern, zur Zeit des für Österreich unglücklich verlaufenden Ersten Koalitionskriegs subversive, die militärische Moral unterwandernde Texte zu publizieren - auch wenn sie in eine andere Zeit („widän Preußn“) verweisen. Dem zeitgenössischen Leser konnten die starken Ironiesignale ohnehin nicht entgehen: die überzeichnete Mündlichkeit, der unangebrachte Hedonismus, das triefende Selbstmitleid des Rekruten, die fehlgeleitete Aggression in den Rachephantasien gegen den Vernaderer, die Großmannssucht im Fall eines Karrieresprungs, die lächerlichen Abschiedsworte an die Nutztiere etc. Und doch vermag die Komisierung den Nachvollzug einer emotionalen Ausnahmesituation nicht gänzlich zu überdecken, die durch das staatlich verordnete Herausreißen aus dem engen sozialen Gefüge und die unsichere Zukunft hervorgerufen wird. Denn die Angst vor dem Kommenden in einer kriegerischen Zeit ist nur allzu menschlich. 


\section{HERRSCHAFT UND UNTERTAN}

Jeder kriegerische Angriff von außen birgt neben der unmittelbaren Gefahr für Land und Leute stets auch eine immanente Bedrohung bestehender Herrschaftsordnungen. Denn mit dem Versuch einer möglichst effektiven Mobilisierung gegen den Feind wird der auf verschiedene Weise gerechtfertigte Führungsanspruch der Elite im Herrschaftsgebiet selbst auf eine ernste Probe gestellt. Gerade in Zeiten des Kriegs ist deshalb das Bedürfnis nach Herrschaftsaffirmation und -legitimation besonders ausgeprägt, um die Loyalität der Untertanen zu ihrem Land und seiner Führung zu sichern. Nach der bereits im Mittelalter entwickelten Korporationslehre konstituiert sich ein Volk über seine Vertretung durch eine Herrscherpersönlichkeit. Als Haupt eines organologisch gedachten Staats kommt ihr eine Sonderstellung zu - nicht nur durch ihre autoritative Führung, sondern auch durch die Aufgabe, den vielteiligen Staatskörper zu repräsentieren. ${ }^{1}$ Dies setzt freilich den politischen Rückhalt durch Untertanen voraus, die den Führungsanspruch des Herrschers und seines Herrschaftsapparats akzeptieren. In der Zeit des sich herausbildenden Absolutismus entwickelte Thomas Hobbes diese Vorstellung einer Identitäts-Repräsentation, die den Konsens zwischen Untertanen und Repräsentanten voraussetzte, zur Auffassung einer Repräsentationsbeziehung weiter, in der der Souverän das Volk inkorporiert. ${ }^{2}$ Von der Notwendigkeit, seine Herrschaft zu legitimieren, entband freilich auch diese staatsrechtliche Vorstellung den absolutistischen Herrscher nicht. Ein zentrales Mittel, um das gesellschaftliche Gefüge sinnfällig zu machen, ist ritualisierte Repräsentation, die die strukturerhaltende Kontinuität der sozialen Hierarchie herausstellt und die in der Person des Herrschers transportierten Wert- und Ordnungszusammenhänge öffentlich wahrnehmbar macht. In den signifikanten Ausprägungen des höfischen Lebens, in der zeremoniellen Vergegenwärtigung des gesellschaftlichen Status, in Machtdemonstrationen, Verhaltenscodes und Handlungsmodellen wird das Verhältnis zwischen Herrschenden und Beherrschten je neu vergegenwärtigt und stabilisiert.

Konstitutives Moment erbmonarchischer Systeme ist die dynastische Geschlechterabfolge, die die kontinuierliche Besetzung der politischen Spitzenpositionen garantiert

1 Vgl. Hasso Hofmann: Repräsentation. Studien zur Wort- und Begriffsgeschichte von der Antike bis ins 19. Jahrhundert. Berlin: Duncker \& Humblot 1998, S. 116ff.

2 Vgl. Adalbert Podlech: Repräsentation. In: Otto Brunner/Werner Conze/Reinhart Koselleck (Hg.): Geschichtliche Grundbegriffe. Historisches Lexikon zur politisch-sozialen Sprache in Deutschland. Bd. 5. Stuttgart: Klett-Cotta 1984, S. 509-547. - Hedda Ragotzky/Horst Wenzel (Hg.): Höfische Repräsentation. Das Zeremoniell und das Zeichen. Tübingen: Niemeyer 1990. - Horst Wenzel: Repräsentation. In: Reallexikon der deutschen Literaturwissenschaft. Neubearbeitung. Hg. von Jan-Dirk Müller. Bd. III: P - Z. Berlin/New York: de Gruyter 2003, S. 268-271. - Horst Wenzel: Höfische Repräsentation. Symbolische Kommunikation und Literatur im Mittelalter. Darmstadt: Wiss. Buchgesellschaft 2005. - Jan Andres / Alexa Geisthövel/Matthias Schwengelbeck (Hg.): Die Sinnlichkeit der Macht. Herrschaft und Repräsentation seit der Frühen Neuzeit. Frankfurt a. M. /New York: Campus 2005. - Albrecht Koschorke: Paradoxien der Souveränität. In: Albrecht Koschorke [u. a.] (Hg.): Der fiktive Staat. Konstruktionen des politischen Körpers in der Geschichte Europas. Frankfurt a. M.: Fischer 2007, S. 113-119. 
und die Teilhabe an universellen Ordnungsprinzipien symbolisiert. Umso wichtiger war es, dynastische Schlüsselmomente wie Geburt, Hochzeit, Krönung, aber auch Tod den Untertanen in rechter Weise zu vermitteln, sie in der Öffentlichkeit sichtbar zu machen: durch Festlichkeiten verschiedenster Form, durch Inszenierungen, Bilder, Denkmäler, Bauten, Illuminationen und andere erinnerungskulturelle Unternehmungen. Diese Veröffentlichung des eigentlich Privaten, die das Volk teilhaben lässt am Herrschaftsleben als einer - suggerierten - stabilen gesellschaftlichen Konfiguration, wäre aber semiotisch auf eine vergleichsweise geringe Adressatenzahl beschränkt, würde Repräsentation nicht auch diskursive und kommunikative Konzepte der Weitergabe beinhalten. ${ }^{3}$ Literatur bildet in dieser Hinsicht - wie auch bildende Kunst und Musik - einen essentiellen ästhetischen Beitrag zur medialen Vermittlung und Ausdeutung des Repräsentationsakts; sie ist, mit Horst Wenzel zu sprechen, „Repräsentation der Repräsentation“ 4 auf einer Metaebene, die ganz gezielt bestimmte Aspekte für bestimmte Zielgruppen aufbereitet und dadurch selbst wieder soziale Verhältnisse sinnlich erfahrbar macht. Früh fand dabei auch Dialekt als ästhetisches Mittel Verwendung, nicht zuletzt um über Nähesprachlichkeit und simulierte Mündlichkeit die besondere Relevanz des Vorgeführten auch für die Unterschichten zu vermitteln. Neben dieser von oben gesteuerten oder zumindest geförderten Literatur etablierte sich im Verlauf des 18. Jahrhunderts mit ,vaterländischen` Texten eine andere Form herrschaftsaffirmativer Literatur. Sie repräsentiert die Identifikation des Volks mit der gesellschaftlichen Ordnung als Ausdruck einer Internalisierung seiner Herrschaft, wenn in ihr das gelingende Leben der Bevölkerung fernab der Herrschaftszentren ursächlich mit der Bestätigung der bestehenden politischen Strukturen in Zusammenhang gebracht wird. Um die demonstrierte Vaterlandsliebe des einfachen Volks authentischer wirken zu lassen, ließ man die in ihrem genuinen Umfeld agierenden Protagonisten dabei gerne auch in ,ihrer', freilich geglätteten Mundart sprechen. Konnte Literatur auf diese Weise in der fiktionalen Festschreibung für die Stabilisierung der labilen gesellschaftlichen Rangordung funktionalisiert werden, vermochte sie freilich ebenso die Instabilität des gesellschaftlichen Gefüges, seine Widersprüchlichkeiten und Problemfelder offenzulegen und Gegenmodelle zu lancieren. Dass sich derlei Dichtungen im 18. Jahrhundert seltener erhalten haben, bedarf angesichts der immer rigideren Zugriffsmöglichkeiten des Staates keiner Erklärung. Zufall allerdings ist es keiner, wenn für die Gestaltung und Verbreitung auch hier gezielt mündlichkeitsnahe Sprachformen literarisiert wurden, die an ein Gemeinschaftsgefühl der Unterdrückten und Minderprivilegierten appellierten und sich die kommunikativen Vorzüge volkskultureller Traditionen zunutze machten.

3 Vgl. Ragotzky/Wenzel, Höfische Repräsentation, S. 183ff.

4 Wenzel, Höfische Repräsentation, S. 19. 


\section{Repräsentationen dynastischer Schlüsselmomente: Geburt - Hochzeit - Krönung - Tod}

Es war keine alltägliche Geburt, die am 13. April des Jahres 1716 in Wien Anlass zu Jubel und vielfältigen Festlichkeiten gab: Es war die Geburt des lange ersehnten Thronfolgers, der Kaiser Karl VI. beerben und somit die männliche Sukzession im Habsburgerreich sichern sollte. Schon bei der Wahl einer passenden Ehefrau hatte der Aspekt der Thronfolge eine wesentliche Rolle gespielt; nicht nur die Herkunft musste bedacht werden, sondern auch der Gesundheitszustand, um die Eignung zur Mutterschaft abschätzen zu können. Die Wahl fiel letztlich auf Elisabeth Christine von Braunschweig-Wolfenbüttel, die dem Sohn Leopolds I., damals als Karl III. noch spanischer (Gegen-)König, 1708 angetraut wurde. Als drei Jahre später sein Bruder Joseph I. unerwartet starb, trat Karl die Nachfolge in der Habsburgermonarchie an und wurde im Dezember 1711 zum Kaiser gekrönt.

Aus den Erfahrungen im Spanischen Erbfolgekrieg heraus setzte Karl 1713 mit der Pragmatischen Sanktion auch rechtliche Schritte zu einer den Bestand sichernden Regelung der Thronfolge. Die wichtigsten Punkte der Urkunde legten eine Folge fest, die seine männliche Nachkommenslinie (beginnend mit dem ältesten Sohn) vorreihte, der alle anderen männlichen Linien folgen würden, ließ aber darüber hinaus bei fehlenden männlichen Erben auch weibliche Thronfolger zu. Zudem wurde die Unteilbarkeit und Untrennbarkeit aller habsburgischen Territorien festgelegt. All diese Bemühungen unterstreichen die Bedeutung der Nachkommenschaft für das Kaiserpaar, das dem Druck ausgesetzt war, für den Fortbestand der Dynastie Sorge zu tragen. Umso schwerer wog die jahrelange Kinderlosigkeit. Erst nach achtjähriger Ehe konnte Elisabeth Christine am Ostermontag endlich einen Sohn, Leopold Johann, zur Welt bringen. Die mit viel Pomp begangenen offiziellen Feierlichkeiten fanden ihren Widerhall in mehreren Jubelschriften, die die Geburt feierten, dem jungen Erzherzog huldigten und auch den Eltern Ehrerbietung entgegenbrachten, wobei häufig auch die lange Zeit des Wartens und die nunmehrige Erlösung thematisiert wurden. Im unmittelbaren zeitlichen Produktions- und Rezeptionskontext war selbstverständlich nicht denkbar, dass dem Glück kein langer Bestand gewährt sein sollte; bereits wenige Monate später, am 4. November desselben Jahres, starb der Prinz. In weiterer Folge erwies sich die vorsorglich getroffene und mit vielen diplomatischen Zugeständnissen leidlich abgesicherte gesetzliche Verankerung der Thronfolge als reichserhaltende Maßnahme. Denn da dem Paar kein weiterer Sohn beschieden war, trat 1740 die erstgeborene Tochter Maria Theresia die Nachfolge in den habsburgischen Ländern an.

Ein besonders interessantes Zeugnis aus dem Kontext der höfischen Repräsentation rund um Geburt und Taufe ihres frühverstorbenen Bruders ist eine dreiteilige dialektale Liedfolge, die zeitnahe zum Ereignis als poetisches Äquivalent zu den offiziösen Relationen im nächsten Umfeld des Hofs entstanden und schon als Serie geplant worden sein dürfte. Im ersten Teil mit dem Titel Bäurisches Oster-Märl und gesungen nach der Melodie des (verschollenen) Lieds Grüß di GOtt Vötter / danck dir GOtt Mäm berichtet der eben aus der Stadt zurückgekehrte Bauer Veitl seinem Standesgenossen Stöffl von den 


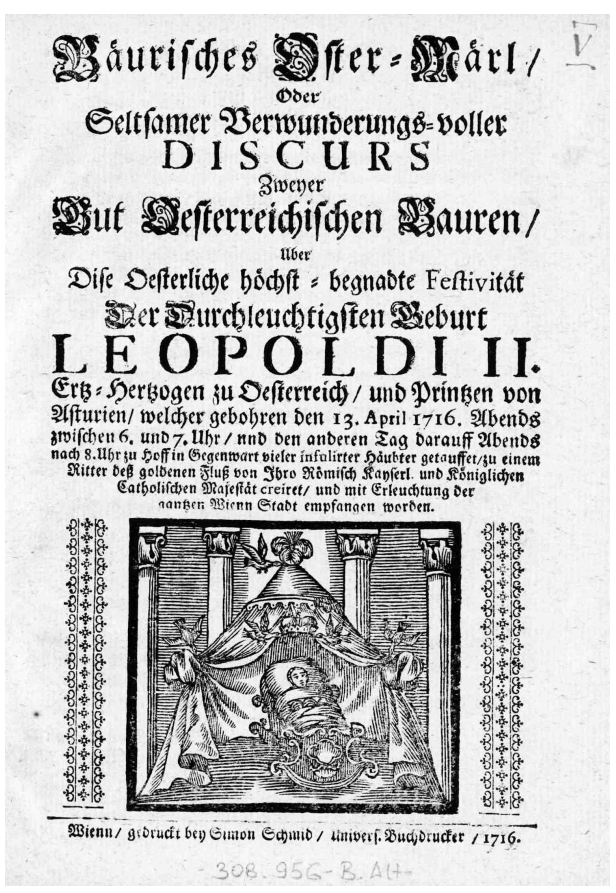

Abb. 15: Titelblatt zu Bäurisches Oster-Märl (Österr. Nationalbibliothek/Kooperationspartner Google, Sammlung von Handschriften und alten Drucken, 308956-B).

epochalen Ereignissen und der Jubelstimmung in der Residenzstadt. Genretypisch für den ,Bauerndiskurs' werden im Erfahrungsaustausch die Eckpunkte der Feierlichkeiten aus betont naiv-beschränkter Perspektive, die aber keinen Zweifel an der Vaterlandsliebe, Loyalität und Bewunderung der beiden Sprecher lässt, präsentiert. Die dialektale Umsetzung der panegyrischen Dichtung im dörflichen Setting soll die Unmittelbarkeit der Erfahrung und die Authentizität des Gefühlsausdrucks noch unterstreichen. Die Glaubwürdigkeit der guten Nachrichten wird dabei eben über den prinzipiellen Zweifel an den verfügbaren Informationen und die abwägende Ausdeutung des Selbsterlebten verbürgt:

\author{
1 STÖFFL. \\ GRüß di GOtt Veitl! woher heut so spatt? \\ Bist leicht gewösn zu Wienn in dä Stadt? \\ Sag mä / wie lang noch die Leut wern liegn? \\ Daß d'Kayserin jetzo ain Bumb solte kriegn. \\ 2 Veitl. \\ Danck dä GOtt Stöffl / kimbst just grecht zu mie/ \\ Hör! was für Wundä i sagn mueß die/ \\ Geh halt mit mie doch / mie kehrn noch ein/ \\ G’sund dä guetn Zeitung gesoffä mueß seyn. \\ 3 Stöfrl. \\ Wanst mi nit foppetst / i hät ein Lust schie/ \\ Zahlet auff mein Aiß ä guete Zöch Bie/
}


Trau die nit recht do / denn wie i erfahr/

Was mä jetzt loign thuet / ist halbet kämb wahr. ${ }^{5}$

1,2 leicht] vielleicht, denn, etwa (Modalpartikel) 1,3 liegn] lügen 2,4 G’sund ... gesoffä] auf etwas angestossen 3,2 auff mein Aiß] Beteuerungsformel (wie: , auf meinen Eid') 3,4 loign] lügen halbet] zur Hälfte kämb] kaum

Wie für ,Bauerngespräche üblich wird auch im Oster-Märl die humoristische Komponente bedient, großteils durch Missdeutungen und Missverständnisse der bäuerlichen Sprecher, die der Rezipient unschwer auflösen kann. So bekommt er einen eingängigen Überblick über die offiziellen und privaten Freudenbekundungen in Wien: Salutschüsse mit den Geschützen werden als Türkenangriff fehlinterpretiert, Jubelrufe als Feuerwarnung, das Gedrängel der Boten als bedrohlicher Tumult, die festliche Illumination der Stadt als Feuersbrunst oder die Farbpapierverzierungen der Fenster als Geschossschutz. Das Herausstreichen der Unglaublichkeit des Gesehenen und Gehörten verpufft hier freilich nicht nur im bloßen Bauernspott, sondern versinnbildlicht vor allem, dass etwas Außergewöhnliches geschehen ist, mit dem sich das Volk durch und durch identifiziert. Wirte lassen sich die Zeche nicht bezahlen, Stadthäuser werden verziert, die Nacht wird zum Tag gemacht - um und um wird versucht, der Einzigartigkeit des Moments gerecht zu werden:

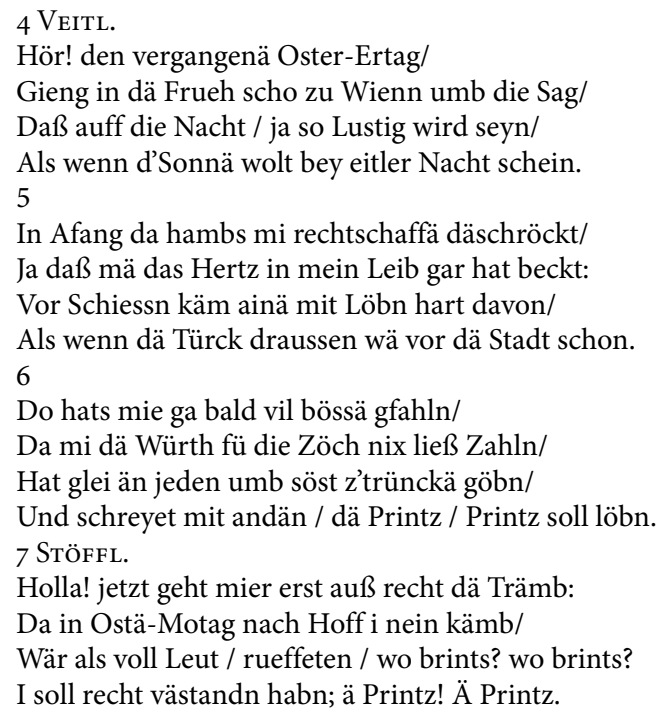

5 Bäurisches Oster-Märl / Oder Seltsamer Verwunderungs-voller DISCURS Zweyer Gut Oesterreichischen Bauren / Uber Dise Oesterliche höchst-begnadete Festivität Der Durchleuchtigsten Geburt LEOPOLDI II. Ertz-Hertzogen zu Oesterreich / und Printzen von Asturien / welcher gebohren den 13. April 1716. Abends zwischen 6. und 7. Uhr und den anderen Tag darauff Abends nach 8 Uhr zu Hoff in Gegenwart vieler infulirter Häubter getauffet zu einem Ritter deß goldenen Fluß von Ihro Römisch Kayserl. und Königlichen Catholischen Majestät creiret / und mit Erleuchtung der gantzen Wienn Stadt empfangen worden. Wienn / gedruckt bey Simon Schmid / Univers. Buchdrucker/ 1716, f. 1v. 
8

Ey! hät i dem Pflögä g'schwind s'Böten-Brod bracht/

Die Stoja hät döß Jahr nit halb so vil gmacht;

I förchtet mä aber / nix guets das bedeüt/

$\mathrm{Daß}$ als vo dä Burig wöck läffet / und reüt.

9

I mainät halt / wenns lötztlä umb und umb kämb/

Daß man nit leicht unserain ä drumb hernämb/

Bi außg'loffä / was i nur brächt auß dä Haut/

I hät mä nit haimb und haimb umbz'ehä traut.

10 Veitl.

Du zaghafftä Nar! Sih! dort sänd ja all Leut/

Vowögn des noin Printzen gewösen voll Freud;

Es wolt halt än jedä dem andern füekömä/

Damit ä vor ihm mecht das Trinck-Gelt einnemmä.

11

O hör nu / wies nach dem no widär ist gangä/

Was man mit dem aintzingä Buimb als angfangä;

Sö habn dö Trommöten und Trommel als g'rührt/

Und auff alli Schantzn dö Stück gar auffgführt.

12

Vämacht mit Papie wärn d'Fenstä so schön/

Damit kain Stuck-Kugl sollt eppä eingehn/

I sag däs / es sey mie nöt anders füekemmä/

Als wenns Biebl gantz allain d'Stadt wolt einnemmä.

13

Auff d'Nacht / wie i gmaint han / es wär als vergangä/

Da hätte das Toiffls-Kötz erst recht angfangä:

Es hambt Thür und Fenstä recht Foiär außg'spibn/

Und do alli Häussä gantz uverlötzt blibn.

14

Afft thätns mit fleiß ga dö gantz Stadt anzündtn/

Es Foirät vorn grausamb / und krachät schieh hintn:

I müest dö Leut schie für Zigeinär erkennä/

Dö alles azündtn / und do nix väbrennä. ${ }^{6}$

4,1 Oster-Ertag] Oster-Dienstag 5,2 beckt] gepocht 6,3 umb söst] umsonst 7,1 geht mier erst auß] verstehe ich erst 7,3 brints] brennt es 8,1 Böten-Brod] Botenbrot als rituelle Gabe für Überbringer guter Nachrichten 8,2 Stoja] Steuer 8,4 Burig] Burg wöck läffet] wegläuft 9,1 umb und umb kämb] dazu käme 9,2 ä drumb hernämb] auch dafür (als Soldat) hernähme, einzöge 9,3 außg'loffä] fortgelaufen was i nur brächt auß dä Haut] so schnell ich konnte 9,4 umbz'ehä] nach hinten sehen 10,2 Vowögn] wegen 10,3 füekömä] zuvorkommen 10,4 Trinck-Gelt] Belohnung für die Nachricht 11,3 Trommöten] Trompetten 11,4 Stück] Kanonen, Geschütze 12,1 Vämacht] verdeckt 12,2 Stuck-Kugl] Kanonenkugel eppä] gar, etwa 13,2 Toiffls-Kötz] Teufelsgehetz, Teufelswerk 14,2 Foirät] feuert, brennt, lodert schieh] hässlich, furchtbar

Sogar in die dem Volk an sich verwehrten Bereiche der kaiserlichen Repräsentation wie die Taufe im Kreis des Hofstaats und der kirchlichen Oberhäupter gewährt der affirmative Bauernbericht Einblick und macht sie öffentlich. Denn in der Fiktion stolpert Veitl versehentlich in die Feierlichkeiten, die er sich nur schwer erklären kann. In komi-

6 Ebda., f. 1v-2r. 
scher Brechung wird die symbolische Ernennung des kleinen Erbprinzen zum Ritter des Ordens vom Goldenen Vlies zunächst als Mordanschlag oder Abhärtungstraining gedeutet, ehe die Geste mit dem Schwert als (schon am Titelblatt erwähnter) Ritterschlag durch den eigenen Vater erläutert wird.

15

Als i nit mehr wissät / wo auß oder an/

Da wär i än als g’ähr zu Hoff drinnä schon/

I wolt in dö lange Stumb still hinei läffä/

Da thätns den Printzn grad justäment täffä.

16

Wolt wünschn / mein Nachbar! du wäst bey mie gwösn/

Damit du hättst g'sehä dös wunderlä Wösn:

Dei Löbtag bist gwösn nie bey solchä Täff/

Es hät bald än jedä ä Bischoff-Kappn auff.

17

Dä Kaysä nämb afften ä Schwerdt in dö Händ/

Und machät dem Printzn ä Creutz übä d'Lend/

I mainät ä wolt schie damit fangä an/

Als wiedä Herodes den Kindern hat than.

18

I gläb / daß man döß thuet no Klainähait gern/

Damit ja das Kind nit soll Säbel schieh wern:

Dö Leut abä homb dö Sach anderst ausdacht/

Dä Kaysä den Printzn zum Reutä hät g’macht. ${ }^{7}$

15,2 än als g'fähr] plötzlich 15,3 Stumb] Stube, Saal 15,4 täffä] taufen 17,1 afften] dann 18,1 no Klainähait] solange es klein ist 18,2 Säbel schieh] ängstlich vor Säbeln 18,4 Reutä] (eig. Reiter) Ritter

In den letzten Strophen schließlich wird noch einmal die Frage der Glaubwürdigkeit solch erstaunlicher Dinge aufgeworfen, die den simplen Verstand der Dörfler übersteigen. Zumal die Erläuterung der „Gmähl [...] und Schrifftn“" , also der öffentlich ausgestellten Bilder und Sprüche, mit denen dem neugeborenen Thronfolger in der Stadt gehuldigt wurde, bedürfe höherer Bildung. So wird für die Fortsetzung angekündigt, den Rat des Schulmeisters einzuholen.

Tatsächlich ist die kurz darauf erschienene Continuation über vorgegangenes Bäurisches Oster-Märl ein Gespräch zwischen Veichtl und dem Schulmeister, nun allerdings „Im Thon: GOtt grüß euer Vestlichkeit / habt mir nix für übel“9 gesungen. Mit dem Dorfpädagogen wird eine weitere beliebte Figur solch mundartlicher Systempropaganda

7 Ebda., f. 2 r-v.

8 Ebda., S. f. $2 \mathrm{v}$.

9 Continuation über vorgegangenes Bäurisches Oster-Märl / Vorstellend einen Irrdischen Himmel / Dann betreffend Die auff das prächtigst in der Ritter-Stuben deß Kayserl. Hoffs celebrirte Tauff-Ceremonien, Deß Durchl. Printzens LEOPOLDI II. Ertz-Hertzogen zu Österreich / und Printzen von Asturien / welcher gebohren den 13. April 1716. Abends zwischen 6. und 7. Uhr / und den andern Tag darauff Abends nach 8. Uhr zu Hoff / in Gegenwart vieler infulirter Häubter / getauffet / zu einnem Ritter deß goldenen Fluß von Ihro Röm. Kayserl. und Königlich-Catholischen Majestät creiret / und mit Erleuchtung der gantzen Wienn Stadt empfangen worden. Wienn / gedruckt bey Simon Schmid [1716], f. 1r. 
eingeführt, die sich als Intellektueller im Kreise der Ungebildeten schon sprachlich abhebt und von den Bauern dementsprechend auch eine Beachtung der sozialen Distanz einfordert:

1 VeIChTL.

Herr Schul-Maister / möcht dich gern bitten umb was/

Versprich dirs / diß ich dichs umb sunst thain nit laß/

Ich schick ein Jahr länger mein Buebm dir in d'Schul/

Und gib auch ihm noch mit sein aignen Laihn-Stuhl.

2 Schul-Maister.

Kein Wunder ists / daß schlecht mit euern Buemb geht/

Weil eben sein Vatter nit mehrer versteht/

Wann ihr ihn zu lehrnen nur so vil verstund/

$\mathrm{Da}$ er seinen Schul-Maister irrizen kund.

1,4 Laihn-Stuhl] Lehnstuhl 2,4 irrizen] mit ,ihr' (2. Pers. Pl.) ansprechen

In Anknüpfung und Erweiterung des ersten Teils erfolgt nun die unverständige Schilderung der Taufzeremonien en détail, die zwei beliebte Muster der alpenländischen Volksliteratur aufgreift: das Bauer-im-Himmel-Motiv und die Anbetung des göttlichen Kinds. Literarisch durchaus geschickt wird hier also der - absolutistischer Repräsentation immer innewohnende - Transzendenz-Immanenz-Abgleich bzw. die Verankerung der weltlichen Ordnung im Numinosen ins Komische aufgelöst. Die strukturelle Parallelität repräsentativen Handelns im säkularen und profanen Bereich wird zur komplexen Pointe, wenn Veichtl die Pracht des höfischen Zeremoniells im Rittersaal der Hofburg und die zufällig beobachteten Taufrituale als Jenseitserfahrung deutet: Er hält Soldaten für die himmlische Heerschar, sieht im päpstlichen Nuntius, der das Sakrament spendet, den Hl. Nikolaus, identifiziert Ordensritter als die vierzehn Nothelfer, den Chor als singende Engel und die Fanfaren als Ankündigung des Jüngsten Gerichts. Auch das Taufritual („Der Nicola nämb Ihn / und waschet ihms Kapl / Mir hat recht erbarmet / das arme gut Läpl“) und der Ritterschlag („Er wär auch nit faul / und hauet bräff zu / Ich dencket mir haimblä: Jetzt helfft dä GOtt! Bue ${ }^{10}$ ) werden in lächerlicher Verzerrung geschildert, ehe in der Huldigung des Erbprinzen mit den bekannten alpenländischen Weihnachtstopoi die Engführung von weltlicher und geistlicher Heilsbotschaft auf die Spitze getrieben wird:

20

Sie thäten nacheinander zum Kind darnach tretten,

Mit bogenen Knyen / dort gleichsamb anbetten;

Wann ich nit wüst / daß nur ist ain GOtt allein,

Ich glaubet der Printz müst ä neuer GOtt seyn.

21

Krad gähling hats ang'fangt zu rumpeln / und knalln/ Als wär schon dem Himmel der Boden eing'fahln;

Ich hielt mich so vest daroben an das Thür G'schwöll/

Damit ich nit pflumpfet in Abgrund der Höll.

10 Ebda., f. 2r. 
22

Ich hört ober meiner zwar d'Engl schön singen/

Kund aber kain aintzign ins Angesicht bringen;

Ich hab offt g'hört sagen / der Himmeln seynd neun/

So muß ich im rechten noch g'wesen nit seyn. ${ }^{11}$

21,1 Krad gähling] plötzlich 21,3 G’schwöll] Schwelle

In der naiven Wiedergabe der prunkvollen Festakt-Inszenierung, die dem größeren Publikum notwendigerweise verborgen bleiben musste, wird höfische Repräsentation als überhöhtes, gleichsam überirdisches Geschehen in ihrer Diskrepanz zum alltäglichen Leben sinnfällig. Macht und Umfeld, Kleidung und Haltung, Ausdruck und Habitus der Anwesenden manifestieren das Gottesgnadentum der Majestät; Literatur aber schafft dem einfachen Volk die Möglichkeit, an diesem symbolischen Verweisungszusammenhang teilzuhaben.

Im dritten Teil schließlich, der Letztlichen Continuation, wird der Blick zunächst auf die künstlerischen Tribute bei der ,Beleuchtung' gelenkt, mit der die Bevölkerung das Neugeborene ehrte. Veitl beschreibt in diesem Teil die in den Fenstern ausgestellten Bilder und Sinnsprüche, die ihm der Schulmeister ausdeutet. Es waren keine Erfindungen des unbekannten Autors, die hier vorgestellt werden; etliche Beispiele finden sich in ähnlicher Form auch in Wienerische Beleuchtigungen (1716), einer Sammlung der Embleme und Sentenzen, die der Begründer des ,Wienerischen Diariums' Johann Baptist Schön-

Abb. 16: Titelblatt zu Letztliche Continuation (Wienbibliothek im Rathaus, Druckschriftensammlung A-11527).

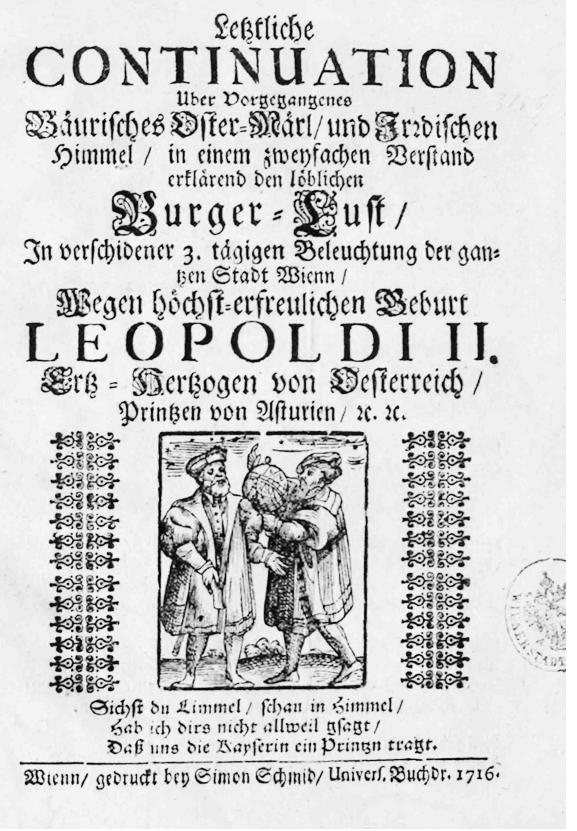

11 Ebda., f. 2v. 
wetter in einer Anthologie zusammenstellte, so etwa auch der für das Titelblatt (mit einem nur leidlich passenden Holzschnitt) adaptierte Spruch:

11 Schulmeister

Zum Stern-Gugger sagte der Baur: Du Limmel!

So schau jetzund / wie du wilst / auffy in Himmel;

Mein! wie offt hab ich dirs nicht vorhin schon g'sagt?

$\mathrm{Daß}$ die Kayser Lißl ein Buebn uns noch tragt. ${ }^{12}$

Im Original, wie es in den Wienerischen Beleuchtungen überliefert ist, lautete der Vierzeiler, deutlich standardsprachlicher:

Je du Limmel!

Schau in Himmel/

Hab ich dirs nicht zuvor gesagt

$\mathrm{Daß}$ die Kaiserin ein Prinzen tragt. ${ }^{13}$

Dann wird der Sinn der Ehrenpforten und Lichter erläutert, bevor Veitl abschließend in einem burlesken Erlebnisbericht die Wohltaten und Almosen des Hofs drastisch ins Bild setzt:

16 VeITL

Am Hoff meinet ich / wär in Schnaraffen-Land/

Wo Krapffen / und Brättl vom Bäum fallen in d'Hand/

Ich hab auff der Erden so lang herum g'schnabt/

$\mathrm{Biß}$ ich hab ein Maul voll weiches erdabt.

$[\ldots]$

18 VeITL

Als ich mir im Essen ein Grausen schier g'nommen/

Zu allem Glück auff den Neumarckt bin kommen/

Da kam ein Platz-Regen über mich ohn als gfähr/

$\mathrm{Da}$ ich vor Wein trincken ersoffen bald wär.

$[\ldots]$

20 VeITL

Ein silberner Schauer afft über thät gehen/

Ein jeder im dickisten Rüsel wolt stehn/

Säh ich daheim solche Wolcken von weiten/

Ich ließ gögn dem Wetter den Meßner nicht leiten. ${ }^{14}$

16,2 Brättl] (Schweins-)Braten 18,2 Neumarckt] Neuer Markt in der Wiener Innenstadt 18,3 ohn als gfähr] plötzlich 20,2 Rüsel] Niederschlag 20,4 leiten] läuten (mit Glockengeläute wurde versucht, heranziehende Unwetter abzuhalten)

12 Letztliche Continuation Uber Vorgegangenes Bäurisches Oster-Märl / und Irrdischen Himmel / in einem zweyfachen Verstand erklärend den löblichen Burger-Lust / In verschidener 3.tägigen Beleuchtung der gantzen Stadt Wienn / Wegen höchst-erfreulichen Geburt LEOPOLDI II. Ertz-Hertzogen von Oesterreich, Printzen von Asturien / etc.etc. Wienn / gedruckt bey Simon Schmid / Univ. Buchdr. 1716, f. 2r.

13 Wienerische Beleuchtigungen / Oder Beschreibung Derjenigen Sinn-Bildern / Welche bey denen / Zu Ehren der Geburt Des Durchleuchtigsten Erz-Herzogs Zu Oesterreich / Und Prinzen von Asturien / Den 14. 15. und 16. April/ 1716 angestellten Freudens-Bezeugungen an denen sowohl offentlichen, als andern Häusern zusehen gewesen; Zusammen getragen und verlegt Von Johann Baptist Schönwetter / Kaiserlichen Hof-Buchhandler / Wien / gedruckt in der Kaiserlichen Reichs-Hof-Buchtruckerey, S. 82. Weitere Parallelen auf dieser Seite und S. 89.

14 Letztliche Continuation, f. $2 \mathrm{v}$. 
Mit Freiessen, Weinbrunnen und Münzenauswerfen ließ die Regierung bei besonderen Anlässen das Volk an der Freude teilhaben und zeigte sich zugleich als volksnah und mildtätig. Dass dabei nur ein sehr geringer Teil der Bevölkerung in den Genuss der Geschenke kam, tat dem gewonnenen Renommee keinen Abbruch. Denn mit geschickter Propaganda wie der vorliegenden wurde der Wirkeffekt potenziert und das Publikum für die Repräsentation massiv erweitert. So endet das Bauerngespräch auch mit einem allgemeinen Hoch auf Österreich, indem der Schulmeister die Geburt des Prinzen als Garantie für den sicheren und unendlichen Fortbestand des Reiches auslegt und programmatisch triumphiert: „S'Hauß Oesterreich in der Welt seyn wird das letzt“. ${ }^{15}$

Mit besonders prächtigen Illuminationen wurde auch in den folgenden Jahrzehnten die Sicherung der Erbfolge gefeiert. Bei Anlässen dieses Ranges war es üblich, das nicht zuletzt auch verordnete - Zelebrieren als allgemeine Volksbelustigung zu inszenieren und die Stadt hell erstrahlen zu lassen. Geschmückt wurden Paläste, aber auch Kirchen und Bürgerhäuser. Die Dekoration war vielfältig und reichte von Gemälden mit Figuralszenen über Scheinfassaden, allegorische Figurenensembles, Ehrentempel und Säulengänge bis zu kleineren dekorativen Elementen wie Girlanden, Vasen, Blumenstöcken, Füllhörnern und dergleichen. Zur Beleuchtung wurden Fackeln, bunte Lampen und Kerzen hinter Farbpapier verwendet, in aristokratischen Residenzen auch Luster, die in die Fenster gehängt wurden. Gebäude wurden mit Beleuchtungen versehen, indem die Umrisslinien ihrer Fassaden mit Lichtern besetzt wurden, sodass die beleuchteten Konturen im Dunkeln eine Lichtarchitektur ergaben. Wo sich keine geeigneten Gebäude anboten, wurden teils Scheinarchitekturen bzw. Illuminationsgerüste errichtet und mit Leuchtern, Lampen oder Fackeln versehen. Gestelle mit transparentem Papier oder Gewebe wie Leinen oder Seide bzw. mit Wachs getränkten Leinwänden überzogen trugen Malereien und bildeten von hinten beleuchtet allegorische, biblische oder mythologische Inhalte ab. In dieser Form wurden auch lobpreisende Inschriften angebracht und das emblematische Kunstwerk zum Erstrahlen gebracht. Der glanzvolle Anblick dieser zu dieser Zeit schlicht spektakulären Beleuchtung wurde zudem von Musikanten klangvoll untermalt. ${ }^{16}$

Zwar wurden Teile oder auch ganze Apparate solcher Inszenierungen (mit Veränderungen im Detail) für weitere Anlässe wiederverwendet, dennoch ergab sich daraus immer ein erheblicher - vor allem auch finanzieller - Aufwand, zumal die Feierlichkeiten auch durch Festakte und Bankette komplettiert wurden. Einen hervorragenden Eindruck über den Umfang des Festprogramms vermitteln zwei vom Hofbuchdrucker Johann Peter von Ghelen herausgegebene, mehrere hundert Seiten starke Drucke mit

15 Ebda.

16 Vgl. u. a. Christine Salge: Studien zur Wiener Festkultur im Spätbarock. Feuerwerk und Illumination. In: Martin Engel [u. a.] (Hg.): Barock in Mitteleuropa. Werke - Phänomene - Analysen. Hellmut Lorenz zum 65. Geburtstag. Wien/Köln/Weimar: Böhlau 2006/2007. (Wiener Jahrbuch für Kunstgeschichte LV/LVI) S. 401-418, hier 411f. - Martin Krummholz: „Zu unaussprechlicher Freude allerhöchsten Herrschaften wie auch zum höchsten Troste allhiesiger Inwohner." Zwei Illuminationen vor dem Wiener Stadtpalais Schwarzenberg anlässlich der Geburt der ältesten Söhne Maria Theresias. In: Jiř́i Kroupa/Michaela Šeferisová Loudová/Lubomír Konečný (Hg.): Orbis artium. K jubileu Lubomíra Slavíčka. Brno: Masarykova univerzita 2009, S. 539-553, hier 539ff. 
umfassenden Beschreibungen der Illuminationsinszenierungen zur Geburt Josephs II. (1741) und zur Geburt seines jüngeren Bruders Karl Joseph (1745). Formal an Schönwetters Kompendium orientiert, veranschaulichen sie auf eindrucksvolle Weise die Bandbreite der kombinierten Elemente, die neben Huldigung und allgemeiner Hochstimmung auch humoristische Akzente, Kampfansagen oder Eigenwerbung nicht aussparen. Die dazu gehörigen Bilder sind bedauerlicherweise nur beschrieben. ${ }^{17}$ Zahlreiche der unterhaltenden Sprüche, Szenen und Beitexte sind dezidiert dialektal. Sie bemühen zum Teil wieder die Anbetungstopoi der Weihnachtsdichtungen wie im folgenden Beispiel, das in der pictura „Bauers-Leut beederley Geschlechts“ zeigt, die dem neugeborenen Kind und seiner Mutter knieend Geschenke darbieten:

Mä kömmä gstreng Frau Kinnigin / und falla Eng zu Fiessa/

Da Richta / und die gantzi Gma Eng lassen gar schön griessa/

Sie bitta halt gar feindla hübsch / ös möchts do nix verschmeha/

Was mä da engern kloana Kind / zbringa uns untersteha.

Globt sey der lieb Herr JEsu Christ / er schenk Eng al langs Leben/

Möcht aber a dem lieben Schatz viel Glück / und Segen geben. ${ }^{18}$

1 Mä] wir Eng] euch $2 \mathrm{Gma}$ ] Gemeinde 3 ös] ihr 4 engern] eurem 6 a] auch

Beliebt sind auch Text-Bild-Relationen mit populären Lustspielfiguren, die bei aller patriotischen Gesinnung durchaus auch zweitdeutig und deftig ausfallen können. So weist etwa eine Tiroler Bauchladen-Krämerin auf ihre (offenbar ausladende) Brust und meint:

Schauts nur an mein Krämmel/

Und recommendirts mich nach Hof zu einer Ammel. ${ }^{19}$

Krämmel] Kramladen, Bauchladen recommendirts] empfehlt Ammel] Amme

Auch Bauernspott mit den üblichen Vorurteilen, wie sie in zahllosen Genrebildern bildnerisch wiedergegeben wurden, durfte natürlich nicht fehlen:

$17 \mathrm{Zu}$ unterschiedlichen Festakten finden sich zwar etliche Kupferstiche, doch sind hier ganze Fassaden oder Festsaalbeleuchtungen abgebildet, ohne die einzelnen Szenen im Detail wiederzugeben. Dennoch vermitteln Ghelens Beschreibungen einen guten Eindruck des Anblicks, der sich als atmosphärische Grundierung auch in den entsprechenden Festliedern findet.

18 Wiennerische Beleuchtungen / Oder Beschreibung Aller deren Triumph- und Ehren-Gerüsten, Sinn-Bildern / Und anderen sowol herrlich- als kostbar / und annoch nie so prächtig gesehenen Auszierungen / Welche bey denen Zu Ehren der höchst-gewünschten Geburt JOSEPHI Den 13. Martii das erstemal / Und sodann Bey Allerhöchst-Ihro Majestät der Königin von Hungarn / und Böheim / Ertz-Hertzogin zu Oesterreich / und vermählten Hertzogin zu Lothringen und Bar / Groß-Hertzogin von Toscana / etc. etc. MARIAE THERESIÆ Unserer Allergnädigsten Frauen / Frauen Geseegneten Hervorgang / Den 23. und 24. April zum andert- und drittenmal / allstäts Abends / und die Nächte hindurch / nicht nur in alhiesig frohlockender Stadt Wienn / sondern auch mancher Orten in denen herum ligenden Vor-Städten angestellten allgemeinen Freudens-Bezeugungen / sowol an Geistlichen Collegien / Klöstern / und Stiften / als auch weltlichen Pallästen / und Privat-Häusern zu bewunderen / und zu sehen gewesen. Zusammen getragen / und verlegt von Johann Peter v. Ghelen / Königl. Hof-Buchdruckern / und Verlegern des alhiesigen Wienerischen Diarii. Wien, gedrukt und zu finden in der Königl. Hof-Buchdruckerey im Neuen Michaeler-Haus. 1741, S. 46.

19 Ebda., S. 224. 
Drey Bauern an einen Tisch sitzend / und einer dem andern zutrinkend / auf der Seite ein TudelSack-Pfeifer.

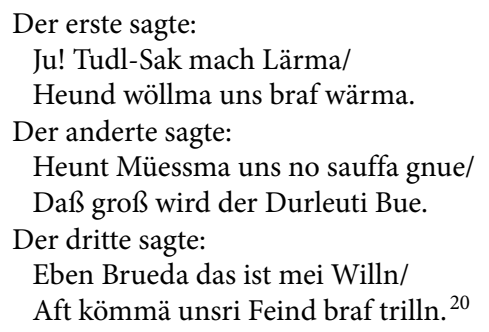

wöllma] wollen wir Durleuti Bue] durchlauchtige Bub kömmä] können wir trilln] plagen, hart zusetzen

Martialische Töne waren zur Zeit des Österreichischen Erbfolgekriegs natürlich keine Seltenheit. Dem ,gallischen Hahn' an den Kragen wollte man in der folgenden Illumination eines Bierhauses, das in einem Fenster „[e]ine Schaar Weiber mit Hahnen und Messern in denen Händen. Neben ihnen etwelche Männer mit Säbeln“ abgebildet zeigt; dazu der Spruch:

Wann die Hahnä zuviel thun krähen,

So mueß man so mit ihnen umgehen,

Seyds fleissi, Weibä, helfts halt zamb,

Rupfts ihna d'Federn, stutzts den Kamb,

Wir Männä helfn enk a mit Freuden,

Sie wern wol müssn das Krähen meiden. ${ }^{21}$

3 zamb] zusammen 5 enk a] euch auch

Gegen die preußische Aggressionspolitik richtete sich die folgende aufwändige Installation, die die Kampfbereitschaft des gesamten österreichischen Volks recht drastisch ins Bild setzte, denn dort

[hi] enge vom fünften Stok ein goßer Kuchel-Hafen herunter, welcher mit 80. Lampen inwendig beleuchtet, anbey eine Elen weit, und zwey Elen hoch ware. Darauf waren einer Seits etwelche Preussische Deserteurs mit Stäben in denen Händen, dann einige Hafnerinnen mit ihnen rauffend, und sie mit Häfen, und Krügen bombardirend, gemahlen, mit diesen beygesetzten Reimen: Ich raht enks ös Lumpen, gebts a mal a Ruh,

Jetzt hab mä zwä Printzen, ich glaub, es ist gnue;

20 Ebda., S. 108.

21 Wiennerische Beleuchtungen, Oder Beschreibung Aller deren Triumph- und Ehren-Gerüsten, Sinn-Bildern / Gemählden / Und anderen sowol überaus schön- als prächtig- besonders aber an Kostbarkeit unvergleichlichen Auszierungen / welche bey denen wegen der höchst-erfreulichen Geburt des zweyten Ertz-Hertzogs von Oesterreich CAROLI Am Sonntag Reminiscere, nemlich den 14den Martii 1745. Als am Tag Ihrer zu Hungarn und Böheim Königl. Majestät / Ertz-Hertzogin zu Oesterreich / vermählten Hertzogin zu Lothringen / und Barr / Groß-Hertzogin von Toscana etc. etc. MARIAE THERESIÆ Unserer Allergnädigsten Frauen / Frauen Geseegneten Hervorgang Abends, und selbige Nacht hindurch nicht nur in alhiesig frolockender Stadt Wien, sondern auch mancher Orten in denen herum ligenden VorStädten angestellten allgemeinen Freudens-Bezeugungen, sowol an denen Herrschaftlich- und allgemeinen Pallästen, als Geistlichen Collegien, Klöstern, und Stiftern, wie auch Privat-Häusern, Wohnungen, und Gewölbern zu bewunderen / und zu sehen gewesen. Zusammen getragen, und verlegt von Johann Peter v. Ghelen / Königl. Hof-Buchdruckern, und Verlegern des Wienerischen Diarii. Wien, gedrukt und zu finden in der Königl. Hof-Buchdruckerey im neuen Michaeler-Haus 1745, S. 160. 
Wolts enk nit Rue göben, so warts nur ä wenk,

Mir Menscher helfen zsamä, kumen all über enk.

Auf der anderen Seite sassen einige Neu-geworbene an einem Tisch, wo auf dem Tisch eine Schüssel voll Knödel, und ein Brättel ware, und die neue Soldaten braf sauften, worunter folgende Reime stunden:

He lusti, ös Buemä heunt gehts bey uns zue,

S'gibt Brätl, und Knödl, und z'sauffen ä gnue,

Wann Knödl überbleiben, so schöiß mäs hinaus,

Und wann mäs väschossen, mit'n Säbel heraus. ${ }^{22}$

Kuchel-Hafen] Küchentopf Elen] Elle: Längenmaß (in Österreich 77,6cm) enks] es euch ös] ihr a mal a] einmal eine gnue] genug warts] wartet ä wenk] ein wenig Menscher] Mädchen, Frauen Brättel] (Schweins-)Braten Buemä] Burschen, junge Männer schöiß mäs] schießen wir sie

Vertreter bestimmter Berufsstände nutzten die Beleuchtung aber auch zu recht unverfrorener Eigenwerbung, um das Geschäft anzukurbeln, so etwa der Hutmacher Grailberger, der einer Kundschaft in den Mund legte:

Stulpts auf ein feines Hütel/

Mit Schnürel und Knöpfel/

Kosts auch mein halbes Gütel

Fürs Printzen sein Köpfel. ${ }^{23}$

Etwas subtiler ist ein Sinnbild, das drei Bauern zeigt, von denen einer Äpfel von einem Baum pflückt. Unter dem Baum liegen zwei mit dem Erzherzogshut verzierte Äpfel, mit der subscriptio:

Schau Jägl: der Stöffl

Im Winter brokt Aepfl,

Zwey hat er ab'gschütt,

Aufs Jahr fallt der dritt. ${ }^{24}$

Aussagen soll dies offensichtlich, dass Maria Theresia und Franz I. Stephan nach dem nunmehr zweiten Sohn auch noch ein dritter gewünscht wird (wobei zugleich auch die Reichsapfelsymbolik miteinfließt). An einer anderen Fassade zeigt eines der Bilder „[v]iele Bauren, welche ihre Hertzen anzündend, in vollkommener Freud sich jauchzend darstelleten“. Die zugehörige Inschrift lautet:

Himl! ob ma in da Stadt

Glei da mengi Kerzn hat,

Zintma an a unsre Herzn,

Brinna bessa, als die Kerzn. ${ }^{25}$

$1 \mathrm{ob}$ ] auch wenn 3 da mengi] jede Menge 3 Zintma] zünden wir a] auch

Die wenigen Beispiele können freilich nur einen vagen Eindruck der Fülle und Vielfalt dieser Öffentlichkeitskunst geben, zu der breite Teile der Stadtbevölkerung beigetragen haben.

22 Ebda., S. 493.

23 Ebda., S. 208.

24 Ebda., S. 167.

25 Ebda., S. 344. 
Abb. 17: Titelkupfer zu Curioses Gespräch zwischen Hänsel und Lippel (Wienbibliothek im Rathaus, Druckschriftensammlung E-11689).

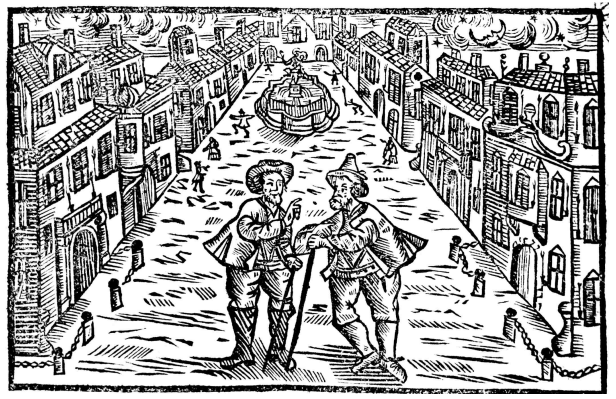

So wie Ghelens Wiennerische Beleuchtungen an den Kompendien seines Vorgängers Schönwetter anknüpfen, weist auch eine Flugschrift dieser Zeit nicht zufällig formale und literarästhetische Ähnlichkeiten mit der Oster-Märl-Reihe auf. Das Curiose Gespräch zwischen Hänsel und Lippel entstand zur Geburt des zweiten Sohns Maria Theresias, Prinz Karl, der am 1. Februar 1745 zur Welt kam. Die Feierlichkeiten zu seinen Ehren wurden jedoch erst am 13. März begangen, da das Ende des Wochenbetts Maria Theresias abgewartet werden sollte. So kam es zur Überschneidung mit den Feierlichkeiten zum vierten Geburtstag des älteren Bruders Joseph.

Auch in diesem Dialoglied diskutieren zwei Bauern die prunkvolle Festinszenierung, auch hier klingt angesichts des endlos scheinenden Lichtermeeres das Paradiesmotiv an. Der eigene Reiz aber ergibt sich daraus, dass der Leser die beiden beim Flanieren und Staunen gleichsam simultan begleitet und derart ein sehr atmosphärisches Bild des illuminierten Wien geboten bekommt. Ganz in diesem Sinne ist das Lied auch durch eine Titelblattgraphik ergänzt, die die beiden Bauern augenscheinlich rege im Gespräch begriffen zeigt; hinter ihnen, in einiger Entfernung, tanzen, torkeln und promenieren Menschen auf dem erleuchteten Platz, obwohl Mond und Sterne tiefe Nacht anzeigen. Und auch das Lied selbst nimmt Bezug auf die prachtvollen Dekorationen, auf prunkvolle Feierlichkeiten mit Gratis-Verköstigung, Almosen und herrschaftlicher Musik, die die visuellen Eindrücke untermalt. Die ekphrastischen Partien sind nun zu einer lächerlichen Ausdeutung durch Lippel modifiziert:

6 HäNSEL.

Geh, Lippel tritt ä bissel für/

Da ist kein Narradey;

O wolt es wär der Meßnä hier,

Der kennt die Mahlerey.

8 HäNSEL.

Möcht wissen / wer der auf dem Bild?

Dort grad in selben Haus/

Er führt in Händen Spieß / und Schild/

Geh / leg mirs rundi aus.

10 HäNSEL.

Und der dort mit dem Säbel droht

In stahlnem Kappen-Gschirr/

Schaut aus der Wolcken / wie ä Gott/

Er kumt mir graußli für.

\section{LipPEL.}

Du redst / als wann ichs nit verstund

So gut / als dieser Mann/

Und auf ä Haar auslegen kunt

Trutz / wie der Herr Caplan.

9 LIPPEL.

Er ist / halt ja / ich weiß es schon/

Fallt mir so glei nit ein;

Hab in der Predi ghört darvon/

Daß wird der Pallas seyn.

11 Lippel.

Das ist Herr Marsch / und der bedeut:

Der Printz wird seyn ä Held/

Und Ritterli zu seiner Zeit

Sich halten ä im Feld. 
12 HäNSEL.

Ju he! wie trifst du Lippel das/

So hurti / und so fein!

Dort sieh i was / als wärs ä Vaß/

Schau rundi was solls seyn.
13 LIPPEL.

ä Wein rinnt oben beym Pallast/

Und würft mä aus ä Müntz/

Da ist ä Ghötz / daß man es fast

Mecht hören biß auf Lintz. ${ }^{26}$

6,1 ä bissel für] ein bisschen nach vor 9,4 Pallas] Beiname der Göttin Athene 11,1 Marsch] Verballhornung für den röm. Kriegsgott Mars 13,3 Ghötz] Spaß, Trubel

Besonders eingängig sind die Wohltaten für das Volk in Szene gesetzt; zugleich aber wird in der Unmäßigkeit der Beschenkten und ihrer Unverständigkeit die soziale Differenz zu den kultivierten Gönnern betont, denen die obligate Huldigung am Schluss des Lieds gilt.

14 HänSEL.

Potz tausend! geh mä aus der Gaß/

Da räffens mit dem Krug.

Dort fliegt ä Kandel / da ä Glaß/

Seyn uns nit sicher gnug.

16 HäNSEL.

Dort essens Stockfisch / und ä Hecht/

O HErr! daß ist ä Kost!

Da tarckelns hin und her bezecht/

Als suffens lauter Most.

18 HäNSEL.

Gelt! wann vier Halter blasen than/

Das gfahlt dir Lippel ja/

Da hört man ein tra ra / tra ran/

Als wär der Toiffel da.

20 HäNSEL.

Mein ayd! habs nie so lieblä ghört/

Es saust mä hint' und vorn/

Daß sich das Hertz im Leib verkehrt/

Paß-Geigen / Jägerhorn.

22 HÄNSEL.

Sing / Bruder! was du wilst daher/

Wann sich nur solches schickt/

Gib gleichwol acht / daß dich nit wer

Auf d'Goschen aufi flickt.

24 HäNSEL.

Geh trinck mä lieber ains dafür/

Mi hungert schier / und dürst/

Läf nur zum gulden Pflueg mit mir/

Da leb mä wie ä Fürst.
15 LIPPEL.

O Hänsel! daß ist nur ä Späß/

Geht halt das Vivat an/

Aus Bier und Wein / und solchen Gfräß/

Daß ich nit nennä kan.

17 LIPPEL.

Wir kummen d'Nacht nit aus dem G'hetz/

Es juckt mi was im Ohr;

Geh / Bruder! sag wo seyn mä jetz/

I hör ä Spilleuth-Chor.

19 LIPPEL.

So stattli solche Musi wär/

So wär sie do grad nix/

Hier machens no weit örga her/

Schau nur wie rund und fix.

21 LIPPEL.

Ja Hänsel! s'ist mir schier ä so/

Es lust mi was ich sich/

ä Liedel möcht i singa no/

So volla Freud bin ich.

23 LIPPEL.

O ho! da wär i wie der Wind/

Und thet nit viel Proceß/

I thät ihn nider-rennä gschwind/

Und gäb ihm wider Steß.

25 LipPEL.

Mein ayd! der Wein ist hextra gut/

Steigt schon in obern Stock/

Sauf nur wann s'Geld nit glöckä thut/

Versauff mä no den Rock.

26 Curioses Gespräch Zwischen Hänsel und Lippel, Zweyen Oberländischen Bauren, Bey der Den 14. Märtzen 1745. in der Königl. Haupt- und Residentz-Stadt Wienn Solenniter gehaltenen Illumination, Uber die so glücklich- als höchst-erfreuliche Geburt eines Zweyten Königl. Printzen und Ertz-Hertzogen CAROLI JOSEPHI etc. Wienn, gedruckt bey Johann Jacob Jahn, Universitäts-Buchdruckern, im Pfeifferischen Haus untern Tuchläden, f. $1 \mathrm{v}-2$ r. 
26 HäNSEL.

Die Königin ist alles werth/

Und ä der Hertzog mit/

Kein solche Herrschaft ist auf Erd/

Möchst glauben / oder nit.

28 HäNSEL.

Allo! vivat das gstaifte Paar/

Und aller König Zier!

Vivat! wills GOtt! so ist aufs Jahr

Ein frischer Kirchtag hier.

30

Printz Sepperl kam zu erst herbey/

Carl ist der ander Bue/

Weil aller guten Ding seyn Drey/

Komt gwiß der Dritt' darzue.
27 Lippel.

Allo! vivat all zway zugleich/

Weil sie so wacker seyn.

Vivat Printz Carl von Oesterreich!

Schenck Hänsel no ains ein.

29 LIPPEL.

Noch ains. I sag dir was ins Ohr/

Mir ist wie dir ums Hertz;

Der Baum kriegt noch ein grössern Flor/

Dencks köck / es ist kein Schertz:

\section{Aller Ehren Ist Oesterreich Voll. ${ }^{27}$}

14,1 mä] wir 14,3 ä Kandel] eine Kanne 17,1 G'hetz] Getümmel 18,1 Halter] Viehhirten 20,1 Mein ayd] meiner Treu, fürwahr 21,2 lust] gefällt sich] sehe 22,4 Goschen] Mund, Maul 25,3 glöckä] ausreichen, genügen 28,1 gstaifte] tüchtige, hervorragende

Der herausragendste dialektliterarische Beitrag zur Geburt Karl Josephs aber ist eine witzige, während der Feierlichkeiten am Burgplatz uraufgeführte Kantate, die im Wiener Ordensschulenkontext entstanden sein dürfte. Bedauerlicherweise ist die Musik der Bueben zu Wienn (1745) verschollen, aber schon das Libretto gibt einen ausgezeichneten Eindruck über den performativen Reiz des Dramoletts mit seinen Rezitativen, Arien und Chorteilen für Knabenstimmen und (vermutlich) einem Bass. Es lässt uns in eine Lateinstunde blicken, in der sich der gutmütige Schulmeister äußerst irritiert über den allgemeinen Jubel zeigt, in den auch seine Zöglinge einstimmen. Als er schließlich den Grund erfährt, ist er allerdings schnell bereit, seine Kunst in den Dienst der großen Sache zu stellen:

Schulmeister. Verpäntes, verzweiffeltes Bueben=Geschmäß! Ist das nit ä Leben, i män, es habts d'Fräß!

Chorus. Ey wohl nit, den gantzen Tag lernen mir nimmer!

Schulmeister. Es werds mir ja alli Tag ärger und schlimmer.

Chorus. än Printzen, än Ertz-Hertzog Hesa sa sa!

Hat unsä Frau Königin Theresia!

Nätzel. Herr Schulmäster jetzt wäß i, was der Herr g'fragt.

Schulmeister. Gelt, daß dirs die Bueben in d'Ohren ham g'sagt?

Was habts dann es Bueben, was laufts hin und wieder?

Die Königin kommt erst in 4. Wochen nieder.

Сноrus. Ja sauber! die Königin ligt schon im Beth,

Darneben ä Wiegen cum Principe steht.

Jetzt mag der Herr greinen, und rasen, und hausen,

Und wegen uns sich die Parocken verzausen.

Wir geben halt dannoch kä Ruh und kä Fried.

Mach uns der Herr lieber ä Kindel-Beth-Lied!

Schulmeister. Es seyts mir ja schlimme, verteixelte Kinder!

27 Curioses Gespräch zwischen Hänsel und Lippel, f. 2r-v. 
Je mehr i die Ruthen erspahre, je minder

Seyts es mir gehorsam. Doch ligt mir daran,

$\mathrm{Da}$ i diese Zeitung gewiß wissen kan.

Friedel. So frag der Herr dorten die Herren beysamen,

Sie wissen vielleicht schon des Printzen sein Nahmen.

ANDREDL. I läff gschwind zum Vatter, leicht wäß ers no nit,

I krieg epper Kipfel, die bring i Enck mit.

Wie wärs nacher, wann mir in d'Stadt eini rennen,

Da wur $[\mathrm{t}]$ en mir besser umjugetzen können?

Schulmeister. Nu Bueben jetzt hab ich die Zeitung gehört,

Mit der ihr mir meine Konzepter verstört:

Wahrhaftig ein Zeitung in Superlativo!

Jetzt gehet es besser im Indicativo.

Jam flectite pueri, dancken wir GOtt:

Das bringt bona tempora, Seegen, und Brod.

Nätzel. der Herr gibt uns aber jetzt Recreazionen?

Schulmeister. Auf etliche Täge will ich euch verschonen.

JAKERL. Und sag der Herr nacher, was fangen mir an?

Mir jugetzen, daß uns der Printz hören kan?

Mir läffen gar auffi bis zu ihm ins Zimmer,

Mir kriegen än jeder ä Hand-voller Simmer. ${ }^{28}$

1 Verpäntes] verfluchtes 2 i män, es habts d'Fräß] ich meine, ihr habt einen Anfall 7 Nätzel] Kurzform für Ignaz wäß i] weiß ich 12 cum Principe] (lat.) mit dem Prinzen 13 hausen] schimpfen 17 verteixelte] verteufelte 23 I läff] ich laufe 24 epper] vielleicht Enck] euch 26 umjugetzen] herumjuchzen 31 Jam flectite pueri] (lat.) kniet schon nieder, Buben 32 bona tempora] (lat.) gute Zeiten 38 Simmer] Siebenkreuzer-Münzen

Gemeinsam wird dann eine simple lateinische Eloge einstudiert. Da aber das Singen

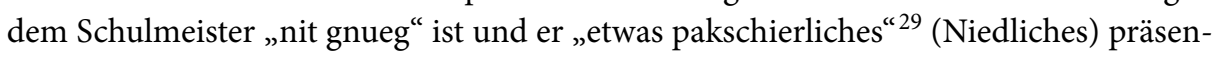
tieren möchte, dichtet er einen steifen Lobpreis für die Illumination. Den Schülern aber ist es eher nach einem zünftigen ,Liedel', mit dem sie bis in die Privatgemächer der Königin vorzudringen gedenken:

Aria.

O hertzige Wiegen,

O Englisches Beth!

O kunt $\mathrm{i}$ jetzt fliegen!

O was i nit thet!

SChulmeister. Du bist halt ä Hiemperl; was thetest hernach?

JAKERL. Wär das für mi nit ä glückseelige Sach?

Von Fenster zu Fenster da flug i halt ummer;

Als wie die Weinfaltern und Vögel im Summer,

Da käm i leicht eini zum Printzen ans Beth,

Das in der Frau Kinigin Schlaf-Kammer steht.

28 Die Bueben zu Wienn, Oder Dieser tugendsamen Schaar In einer CANTATA Abgejugetztes, Und wegen des den 1. Febr. 1745. Andert-gebohrnen Ertz-Hertzogens CAROLI JOSEPHI In dem Königl. Burg-Platz, Nahmens des gantzen Frohlockenden Volcks Aufgeführtes VIVAT. Wienn, gedruckt, und zu finden bey Frantz Andre Kirchberger, Universit. Buchdruckern, und auf dem alten Fleischmarckt im Kullmayrischen Haus, f. 2r-v.

29 Ebda., f. 3v. 
Aria.

Wie wolt i nit hupfen

Am Tuchetel zupfen!

Das Printzel zerbussen,

Die Bueben zamm hussen.

Daß alle mit mir

Mit schönster Manier

Um d'Wiegen

Umfliegen

Umspringen

Umsingen,

Mit Händen und Füssen

Umpocken, umtantzen, umjugetzen müssen!

SCHUlmeister. Man wurd Enck bald zammen zum Zimmer naus butzen,

Und dir deine Flügel mit Haselnuß stutzen!

Was gilts der Printz Pepperl der brächts Argument,

Zum Wehren, zum Wiegen, zum Heideln gerennt?

Er hat schon än Säbel von Ungrischen Stahl;

Er rämet Enck alli zamm aussi zum Saal? ${ }^{30}$

5 Hiemperl] einfältiger Mensch, Dummerle 8 Weinfaltern] Schmetterlinge 9 eini] hinein 12 Tuchetel] (kleines) Federbett, Bettdecke 13 zerbussen] abbusserln, küssen 14 zamm hussen] antreiben, anstacheln 22 Umpocken] umspringen 25 Printz Pepperl] Thronfolger Joseph 26 Heideln] streicheln, liebkosen 28 rämet Enck alli zamm aussi] er würde euch alle zusammen hinausräumen, hinausschmeißen

Mit einem liebevollen Seufzer („Es seyts mir halt Bueben/Abdräht wie die Rueben“" ${ }^{31}$ ) quittiert der Schulmeister die dreisten Pläne seiner Eleven; ein gemeinsames lateinisches Gebet für die Regenten beschließt das Werklein.

Ein Schullehrer begegnet uns auch in der Prosaszene Der Freuden- und Ehrentag (1792), die die dörflichen Geburtstagsfeierlichkeiten für den Landesfürsten Karl Theodor (seit 1777 Kurfürst von Bayern) zu einer recht aufdringlichen Unterweisung in Herrscherliebe und Vaterlandstreue nutzt. Er soll den begeisterten Dörflern, die sich nach der Messe beim Wirt zusammengefunden haben, die Festpredigt ausdeuten:

Peter. Solt's leben, Augustin! geh kommt's da auf unsern Tisch her. Heute seyd ihr Zechfrey: habt auch viele Mühe g'habt, viel Arbeit, bis 's alles so herg'stellt habt. Aber 's soll euch nicht reuen: 'sfiel alles gut aus.

Schulmeister, Messmer zugleich. Nu! wenn alles Beyfall fand, so freut mich's herzlich. $[\ldots]^{32}$

Der kurze Propagandatext diente ganz offensichtlich zur ideologischen Gleichschaltung des bayerischen Volks, dem - angesichts der Vorfälle in Frankreich - das Gottesgnadentum seines Landesfürsten Selbstverständlichkeit sein und die Vorzüge des monarchischen Prinzips vor Augen geführt werden sollte. Aus dialektästhetischer Sicht birgt

30 Ebda., f. 4 r.

31 Ebda., f. $4 \mathrm{v}$.

32 Der Freuden- und Ehrentag. Ein Gespräch auf dem Lande, bey Gelegenheit des höchsten Geburtsfestes unsers durchlauchtigsten Landesvaters Karl Theodors, im Jahre 1791. München, gedruckt bei Joseph Zangl, bürgerl. Stadtbuchdrucker 1792, S. $5 f$. 
das Gespräch wenig Interessantes; mundartliche Panegyrik findet sich in Bayern des 18. Jahrhunderts generell wenig, und wenn doch, ist der Dialekt recht schwach markiert.

Schuf die Geburt die personellen Vorausetzungen für die dynastische Kontinuität, so sollte die planmäßige Verheiratung der Herrschersprosse den Fortbestand der regierenden Häuser sichern. Es galt, durch gezielte Verbindungen mit anderen Herrscherfamilien strategische Allianzen zu schaffen, sich über Erbschaftsverhältnisse möglichen territorialen Zugewinn oder politischen Einfluss zu sichern oder Kriegsparteien zu befrieden. Die effektive Heiratspolitik der Habsburger fand im vielzitierten barocken Distichon ,Bella gerant alii, tu felix Austria nube | Nam quae Mars aliis, dat tibi diva Venus' ihre (zuweilen auch spöttisch interpretierte) Würdigung. ${ }^{33}$ Doch auch diese Politik gehörte entsprechend vermittelt, zumal in einer Zeit, in der man mit politischen Schwierigkeiten zu kämpfen hatte.

Es ist vielleicht der begabte unbekannte Autor der Bueben zu Wienn, der schon im Jahr zuvor für eine dreiteilige Huldigungsschrift zur Feder griff, die im Zusammenhang mit der Hochzeit Erzherzogin Maria Annas (der jüngeren Schwester Maria Theresias) mit Karl Alexander von Lothringen (dem Bruder Franz Stephans) 1744 und deren darauffolgender Abreise in die österreichischen Niederlande, wo das Paar die Statthalterschaft antreten sollte, entstand. Die Texte sind als Brieffiktion gestaltet; kein Zufall, sondern ein europaweiter Trend, bei dem - in der Nachfolge von Montesquieus Lettres persanes - der kritische Blick des reisenden Fremden auf gesellschaftlich Bemerkenswertes oder Problematisches im Mittelpunkt stand. Auch in der komischen Literatur kam diese ,distanzlose Erzählhaltung verstärkt zum Einsatz, da sie stärker noch als der ,Bauerndiskurs' die narrative Unmittelbarkeit des Gesehenen und Geschehenen vermitteln und aus der metrifizierten Verschriftlichung des Authentizität suggerierenden Mündlichen noch zusätzlich Lacheffekte erzeugen konnte. Ganz in diese Richtung zielt auch der Vorbericht des Verlegers, der - neben interessanten Hinweisen zur richtigen Aussprache des verwendeten Dialekts und der adäquaten schriftlichen Umsetzung - explizit den Stellenwert der Bauernfigur in Texten dieser Art anspricht: Neben die belustigende Funktion treten Werthaltungen wie Ehrlichkeit, Aufrichtigkeit und Loyalität, wie sie dem prototypischen guten Untertan zukommen:

GEneigter Leser. Gegenwärtige Beschreibung ist ihrer Wahrheit, und Einfältigkeit wegen zum Druck befördert worden. Gefallt dir die andere nicht, so ist gewiß, daß die erste bey dir allen Beyfall haben werde. Es ist überflüssig, den Hergang, durch welchen solche mir zu Handen gekommen, zu erzehlen; viel weniger nöthig, ein und andere Fehler, oder Bäurische Arten zu entschuldigen; du wirst Vernunft-mäßig nicht die Ausdruckungen, sondern das aufrichtige Gemüt dieses einfältigen Baurens, dem sich alle getreue Oesterreicher gern zugesellen, in Betrachtung ziehen, anbey aber geneigt in Acht nehmen, daß wegen der Oesterreichischen Mund-Art der

33 Vgl. u. a. Andrea Sommer-Mathis: Tu felix Austria nube. Hochzeitsfeste der Habsburger im 18. Jahrhundert. Wien: Musikwissenschaftlicher Verlag 1994. - Alfred Kohler: „Tu felix Austria nube ...“. Vom Klischee zur Neubewertung dynastischer Politik in der neueren Geschichte Europas. In: Zeitschrift für historische Forschung 21 (1994), S. 461-482. 
Buchstaben a wohl zu entscheiden, dahero das blosse a ohne darauf gesetzten Strichel wie ein geschlossenes a, oder fast wie o; hingegen jenes ä, welches mit e oder Stricheln gezeichnet, wie ein Lateinisches a auszusprechen seye. ${ }^{34}$

Im ersten Teil der Trilogie, der Beschräibing Des Uhfägleichlichä Küritags, berichtet der Schreiber mit dem bezeichnenden Namen Leopold Österreicher seinem Vater Ulrich im heimatlichen Bergwiesenfeld (das die Ländlichkeit und den Stadtgegensatz gleich in dreifach tautologischer Form betont) von den Hochzeits- und Abschiedsfeierlichkeiten aus Wien, die mit großem Pomp gehalten wurden, um in Zeiten des Erbfolgekriegs dem gegnerischen Ausland den ungebrochenen Führungssanspruch der Habsburger (und wohl auch die finanziellen Ressourcen) zu demonstrieren. Es sollte eines der letzten großen Wiener Hoffeste zur absolutistischen Selbstdarstellung sein, wirkungsvoll arrangiert durch den italienischen Szenographen Giuseppe Bibiena, der die Winterreitschule in der Hofburg zu einem prächtigen Ballsaal ausstaffierte, und über diverse Publikationen in Ghelens Wienerischem Diarium für die breite Leserschaft kommuniziert.

Die sicherlich sinnlichste Beschreibung dieses herrschaftlichen ,Kirchtags' bietet der fingierte Dialektbrief, der sich zwar der typischen Motive, Formulierungen und lexematischen Wortfelder des Genres bedient, ${ }^{35}$ sich aber von weniger kunstvollen Beispielen durch die meisterhafte Sprechweise in erstaunlich authentisch wirkenden heroischen Alexandrinern deutlich abhebt. Zunächst beschreibt der begeistert staunende Sohn dem Daheimgebliebenen den opulent geschmückten Festsaal mit seinen Säulen, Galerien, Lustern und der aufwändigen Dekoration, wie sie auf einem zeitgenössischen Stich zumindest ansatzweise für die Nachwelt festgehalten ist:

Z'Wienn in äm grossen Saal gehts fäindli ergä her.

Da findt ma s'Himmelreich, und alle Fraid beysammä,

I glaub, der d'Stern hat gmacht, hat da a mustä gnommä.

Hipsch iß wohl s'Firmament, doch abä nit so schön,

Ma kan viel tausend Stern grad nach dä Zailen seh’n.

In äm mahl um und um seyn vier und vierzi Saulen.

I glaub, in tausend Jahr ka käni nit fäfaulen,

Si seyn fu blauem Stän, mit lautä Stern väziert,

Daß mä fu lautä Schäun fast übäsichti wird.

Däzwischen überall, si hässens Kirlandonen

Die hencken vollä Stern wie helli Sonnä-Kronen.

Gar in dä höh' da ist just ä ä solche Ray

34 Mein Lepolt Oestäreichers S’Hof-Baurens zu Bergwiesenfeld eltesten Suhns an sein'n Vatten[!] durch än ägnä Bothen übäsendti Beschräibing Des Uhfägleichlichä Küritags, Der zu Wienn In äm unkäyr grossen, und Funckel-neuen Saal, dens d'Rait-Schul hässen, Nach der Hochzeit Unserä Frau Kinigin ihrä Frau Schwestä MARIANNA, Und ihres Herrn, Herrn Brudäs Prinz Karls Zu erst fämeldtä Frau Mäesteht unserä Frau Kinigin MARIA THERESIA G'stäifft und wackä angstellt worden. Im 12. Janari 1744. Wien gedruckt und zu finden, bey Frantz Andre Kirchberger, Universitäts-Buchdruckern, auf dem alten Fleischmarkt im Kullmeyrischen Haus. [Abdruck als Anhang (neben anderen thematisch entsprechenden Schriften) im Wienerischen Diarium, No. 10, 1. Februar 1744].

35 An drei Stellen zeigen sich sogar sehr enge, fast wortgleiche Parallelen zum Curiosen Gespräch zwischen Hänsel und Lippel, wobei letzteres am vorliegenden Text Anleihen genommen haben dürfte. Denkbar aber durch die starke Ähnlichkeit weniger wahrscheinlich - wäre auch, dass spezifische Phrasen in diesem Kontext kursierten und in Werken dieses Themenkreises immer wieder aufgegriffen wurden. 


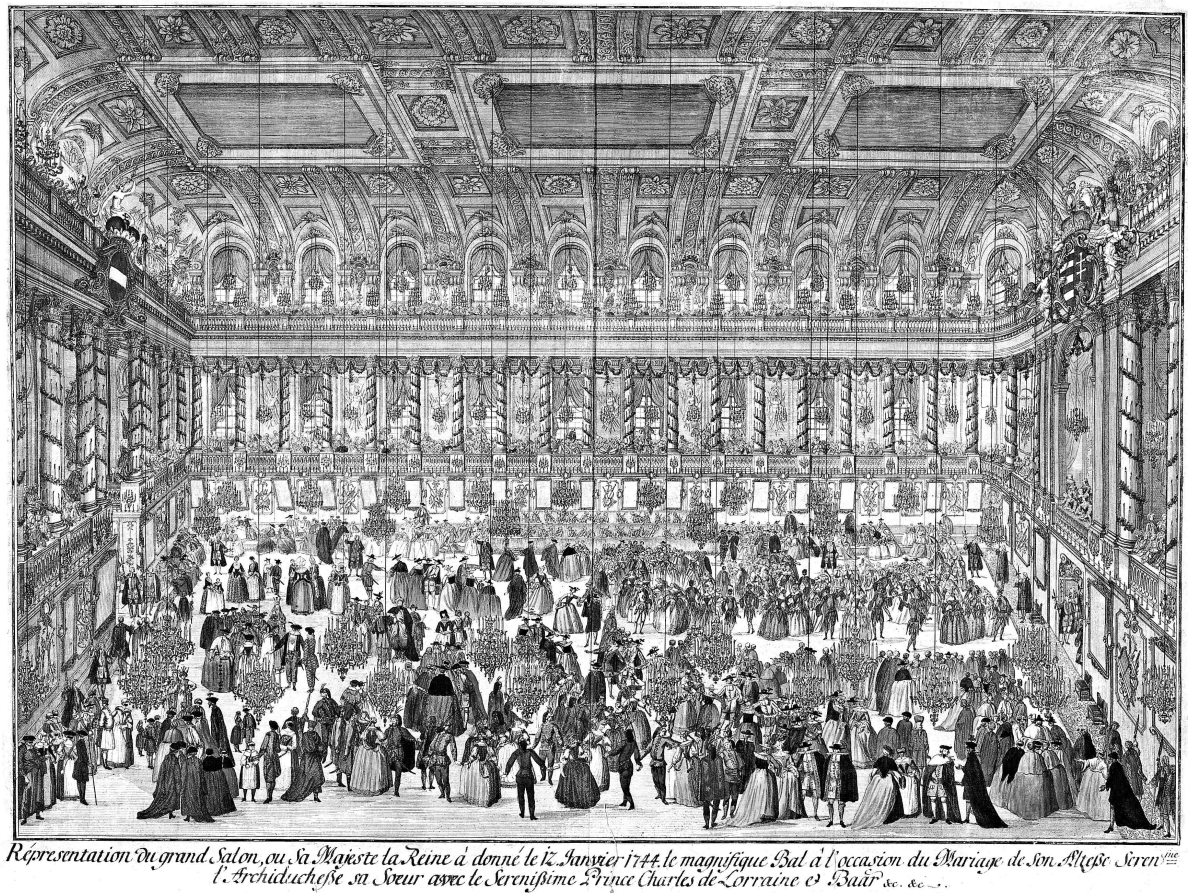

Abb. 18: Kupferstich zum kaiserlichen Maskenball vom 12.1.1744 (Johannes Andreas Pfeffel nach Giuseppe Galli Bibiena, Wien Museum, Inv.Nr. 31.600).

Als wär bey jedem Liecht ä b'sondre Gasteräy.

In Mitten in da Luft, doch unten her nicht oben

Da seyn viel tausend Stern au[s] lautä Glaß erhoben.

Vier Klaftä von der Erd bis an den ersten Stock

Da henckt, doch nur gemahlt, all zehä Spann a Schock

Von tausend Sachen rum: Trompeten, Stuck und Geigen,

Schildt, Eisen-Kläd, und Schwert, mit andern Krieges-Zeugen,

Passeteln, Pfeil, und Horn, Spieß, stahlnes Kapen-G’schier,

Pistolen, Trummeln, Röhr, und ä Spil-Leüt Papier,

Hackbrettä, Harpfen, Hüt, Schallmayen, Mersä, Paucken,

Und tausend solches G'schmäß, mit dems d'Frantzosen jaucken.

A Million fu Leüt entsetzli schärmäriert,

Steht zwä mahl oben rum, und nichts als spintisiert

Wie lustig d'Welt ka seyn, wers recht wäß aussä z'grüblen,

Ders angstellt, sagt mir wer, kan mehr als 100. Biblen,

I hab sein Nachmä g'hört, er kumt fur Bibel her:

Pi... Pibiena? Ja: ä Welschä? So häßt er.

$[\ldots]$

AUf bäden Saiten seyn zwä hohe Fenstä-Rayen,

Dazwischen wiederum viel solche Mahlereyen.

Bay jedem henckt ä Tuch fu rother Saiden g'macht,

Das hässens fu Damaschg, und dort seys hergebracht.

I bin die Läng und Zwerch' da Platz herummä g'schlichä, 
I hab fast alle Eck, und Winckel zamä g'strichä,

So find i nach da Läng recht grosse hundert Schritt, Und dreyßi übä Zwerch, sunst ist kän untäschied.

Der Platz ist halt so groß, daß fünf Bartalion

Fu lautä Kirisier mit Roß und Muschgezon

A Schlacht, wie groß sie will, da kunten pretendiren, Und glaub, es wurd no Mann, no Roß ä Har fulieren.

Ja, Vattä, unsä Dorf, das ist wohl feindli groß,

Do setzt'is Mitten drein mit samt des Graffens Schloß;

Und wann dä Jahr-Marck ist, so gibts kä solche Völlen,

An manchen Ort hams druckt, daß änä möcht däschnellen.

DIe Wand am Platz herum seyn fuftzig Spiegel her,

Die Fincketzen so hell, als wanns im Summer wer.

Daruntä überall stehn Stäffel Bänck herum,

Und schaut halt alles aus, wies Gulden-Sekulum. ${ }^{36}$

1 fäindli ergä] hier: noch viel besser 7 ka käni] kann keine 8 blauem Stän] blauem Stein (die Säulen aus weißem Eggenburger Stein wurden drapiert) 9 übäsichti] durch das Gesehene überfordert (?) 10 hässens Kirlandonen] heißen es Girlanden; in einer Fußnote beigefügt: „Mann zehlte etlich und 90. gläserne Cronen=Leichter, nebst so viel holtz=vergoldten Pyramidal=Arm=Leichter“ " 12 ä ä] auch eine 13 Gasteräy] Fest 16 Klaftä] Klafter (Längenmaß; Wiener Klafter etwa 1,9m) 17 zehä Spann] zehn Spannen (Längenmaß; Wiener Spanne etwa 21 cm) Schock] Haufen, Anzahl 18 Stuck] Kanonen 20 Passeteln] Bassgeigen Kapen-G'schier] Rüstung (?) 23 G’schmäß] Plunder jaucken] jagen 24 schärmäriert] ,charmant' seiend, bezaubernd (?) 25 spintisiert] eingebildet, erfunden 26 wäß] weiß, versteht 28 Nachmä] Nachname 29 ä Welschä] ein Italiener 33 Damaschg] Damast (von Damaskus) 34 Zwerch] Quere 35 zamä g'strichä] zusammengestrichen: ausgeschritten, abgemessen (tatsächlich misst die Winterreitschule 58 x 18m) 39 Kirisier] Kürassier: Soldat der schweren Kavallerie Muschgezon] Muskete (?) 40 pretendiren] nachahmen, vortäuschen 41 fulieren] verlieren 45 däschnellen] zerplatzen 47 Fincketzen] glitzern

Im weiteren Verlauf des Briefs widmet sich Leopold der Schilderung des Maskenballs und dem Einzug der Königin, die mit Vollkommenheitsattributen nur so überhäuft wird („die Allerschönst“, „so g'schaid, und ä so volla Gnad““37), ehe der eigentliche Grund des Auflaufs verraten wird: die Hochzeit „von zwä fäliebten Seelen“, „a grosse Frau Mariandl“ mit „Carl Lothringä“ 38 , deren Vorzüge herausgestrichen werden. Dem folgt ein Hoch auf Österreich, dessen Bestand nun gesichert sei, da die vier Potentaten gleich den tragenden Eckpfosten des heimatlichen Stadels Österreich tragen. Dem Abschiedsgruß folgt im „Boschcritum“ ein heiteres Freudenlied.

Fortsetzung findet die Schrift in der Antwort Des Ulri Oestäreichäs S’Hof-Baurens $z u$ Bergwiesenfeld an sein Suhn Lepold, der zunächst mit viel Laune und szenischer Gestaltungskraft berichtet, wie die Neuigkeiten in der bäuerlichen Dorfgemeinschaft aufgenommen worden waren:

Just Mitichä ists g’west, um fieri na Mitta,

So war scho mit doim Brief dä Bott recht schlainä da,

Und sagt mär: Euä Suhn fu Wienn, der last eu grüssen;

36 Beschräibing Des Uhfägleichlichä Küritags, f. 2r-v.

37 Ebda., f. 3v.

38 Interessant ist diese Nebenbemerkung, da es sich tatsächlich um eine Liebesehe handelte, die aufgrund des als zu gering erachteten politischen Stellenwerts des Bräutigams nicht ohne Hürden eingegangen werden konnte; erst nach dem Tod Kaiser Karls VI. und einigen Verhandlungen mit Maria Theresia konnte die Erlaubnis erwirkt werden. 
Was! schry i gläi, main Suhn! und sprung mit z'glaichä Füssen,

Riß ihm da Brief fur Hand. Mäin Poltel bildäs äin,

Gläi war ä d'Muetä da, und steckt ihr Nasen dräin.

Däin Schwestä, Brudä, s’Mentsch, alls läft fu Fraiden zamä,

Und ham, was du mir schräibst, mit ofnäm Maul fänomä.

Im gantzen Dorf ist glai de Zäiting ummä g'rent,

As wann ä Hahn het Krät, wie d'Sunnä fürä brennt, ${ }^{39}$

1 Mitichä] Mittwoch 2 fieri na Mitta] vier Uhr nachmittags 5 bildäs äin] stell dir vor 7 s'Mentsch] Dienstmagd zamä] zusammen 9 Zäiting] Nachricht ummäg'rent] herumgelaufen 10 fürä] hervor

Das ganze Dorf strömt zusammen, um Leopolds Bericht zu diskutieren, Treuebekenntnisse abzugeben und diese gleich anschließend bei einem Trinkgelage zu begießen. Mit dem Auftritt des Dorfrichters kommt ein weniger erfreulicher Aspekt des höfischen Zeremoniells ans Licht, der die Dörfler als Leibeigene direkt betrifft: In den nächsten Winterwochen waren als Handdienst für die Grundherrschaft Wegrobotarbeiten zu leisten, um die Reise des Prinzenpaars und seines Gefolges in die Niederlande zu erleichtern:

WIes Nacht stät ani wurd; dä Mond ä fürä brochä;

So ham si maini Gest stät na und na väkrochä.

No bäi dä Nacht müst alls auf d'Strassen aussi furt;

Der nu fum Wain grien gwest, hat wohl ä weni g'murrt.

Viel Wochä hieß äs nu: fahr, robat; mach Anstalten;

Raib zu; lad auf; fahr her; grab aus; väschütt, laß halten.

Alls, was mä g'schaft, das g'schäch, und endli führt mä zui,

Daß d'Herrschaft, Leuth, und Roß, und alls fain z'essen gnui. ${ }^{40}$

1 stät ani] schön langsam fürä] hervor 3 aussi] hinaus 5 robat] leiste Frondienst, arbeite 6 Raib zu] einen Spalt füllen, schließen 7 mä g'schaft] man befohlen hatte 8 gnui] genug

Als Lohn für ihre Mühe wurde den Untertanen aber - so zumindest in der Logik des affirmativen Texts - die Gnade zuteil, die Ankunft des Herrscher- und des Prinzenpaars, die sich hier auf der ersten Reisestation trennten, aus nächster Nähe zu beobachten. ${ }^{41}$ Erneut wartet der Bericht mit breiten enkomiastischen Passagen auf, die wieder die Vorbildlichkeit Maria Theresias herausstreichen. Der Brief schließt mit der Empfehlung an den Sohn, beim Militär sein Glück zu versuchen.

Dieser aber arbeitet mittlerweile als Kammerdiener bei einem Studenten, wie der Leser im dritten Teil, der Gegen-Antwort Des Lepolt Oestareichäs An seinen Vatter Ulri, erfährt. Die Brieffiktion wird beibehalten, doch weicht der Text formalstilistisch und thematisch von den vorausgehenden insofern ab, als er nicht in Alexandrinern, sondern

39 Antwort Des Ulri Oestäreichäs S’Hof-Baurens zu Bergwiesenfeld an sein Suhn Lepold auf die B'schräibing Des Uhfägleichlichä Küritags / Der In am Saal / dens d'Rait-Schul hoässen / am 12. Janari. Ani curentis g'halten worden. Just bey der Abreiß Unserä Frau Ertz-Hertzogin MARIA ANNA Und ihres Herrn / Herrn Eh-Gmahl Printz Carls Den 23. Febr. 1744. [...] Wien gedruckt und zu finden, bey Franz Andre Kirchberger, Universitäts-Buchdruckern, auf dem alten Fleischmarckt im Kullmeyrischen Haus, f. 2r.

40 Ebda., f. 3v.

41 Da das erste Nachtlager laut Wiener Zeitung in Stockerau war, könnte der Dichter aus dem Umfeld des dortigen Franziskanerklosters stammen, in dem vermutlich umfangreiche Abendunterhaltung geboten wurde. 
in zu Langzeilen gefügten kreuzgereimten Vierhebern verfasst ${ }^{42}$ und stärker agitatorisch ausgerichtet ist. Leopold berichtet von seinen aktuellen Lebensumständen und den Begebenheiten und Beobachtungen seines Arbeitsalltags. Im Zentrum stehen die Gespräche im Freundeskreis seines Herrn, die die aktuellsten Entwicklungen des Erbfolgekriegs rund um die Schlacht von Toulon (22. Februar 1744) behandeln, freilich stark patriotisch gefärbt und entsprechend verzerrt. Auch der frischgebackene Kammerdiener bringt sich in den sehr lebhaft wiedergegebenen Gesprächsverlauf regelmäßig ein, zumeist in der Rolle des Zweiflers, der von den jungen Herren belehrt wird und dadurch die propagierten Erfolge und militärtechnischen Errungenschaften noch weitaus wirkungsvoller aussehen lässt. Auch wenn in seiner brieflichen Nacherzählung noch immer die Skepsis mitschwingt, gibt er doch einen informativen Auszug dessen, was in den Wiener Zeitungen an schöngefärbten Kriegsnachrichten zirkulierte:

Wie es halt nu immä seyn mög, i schreib, was ä mir dazehlt;

Kanst äß glauben, und nit glauben, koäns kost di koän Kräiza Gelt.

I bidiens halt, schau auf d'Glesä, bring bald z'drinckä und bald z'essen,

Den was wolt i wegen Sachä, de mer z’rund sayn, mi zästessen?

Kurtz däna kimt erst dä Dritti, macht an Serfuß, setzt si hin.

Jetz, denck i, jetzt wirts no ergä Zaiting geben, in maim Sin.

Denckt, und g'schehen war schier oän Ding. Herren schauts wie sie d'Frantzosen

Wiedä saubä aussäbutzen, sagt ä, i fieng glai an z'losen:

d’Spanningä de sayn bitrogen; ihri alläbesti Fraind

Hams in grösten Unglück lassen stecken, weil si gloffen seynd;

D’Engälendä giengä hitzi auf de Spänningische Flotten,

Wie d'Franzosen das ham gsehen, fangt der erst glai an zum Pfnotten,

Gibt saim Schif ä tutzet Sporen, läft, daß er nit rafä muß,

Saini Kamaraten denckten: Wait dafu ist gut für'n Schuß.

Just bigehrt mein Herr zum trincken, und dätapt mi just im Lachä,

Was, sagt er, was machst für Gsichtä? wer soll denn bei solchen Sachä

Ernstli sayn, gib i zur Antwort, woäs denn nit di gantzi Welt,

Was für Stroäch d'Franzosen machen, was si nit scho an ham gstellt? ${ }^{43}$

1 dazehlt] erzählt (hat) 4 zästessen] zerstoßen: in Streit geraten 5 macht an Serfuß] macht seine Reverenz, grüßt 6 Zaiting] Neuigkeit, Nachricht 8 aussäbutzen] herausputzen, sich neu formieren z'losen] zuzuhören 9 d'Spanningä] die Spanier 12 Pfnotten] schnauben (um seinen Unwillen auszudrücken) 13 ä tutzet Sporen] scherzhafte Katachrese für: die Segeln setzen, sich schnell davonmachen (die spanische Flotte machte dem französischen Begleitschutz den Vorwurf, sich bei der Seeschlacht von Toulon aus dem Gefecht gehalten zu haben) rafä] raufen, kämpfen 15 dätapt] ertappt 18 Stroäch] Streiche

42 Auf unterschiedliche Autorschaft muss daraus nicht geschlossen werden. Eine Bemerkung im Vorwort, in dem der geneigten Leserschaft „ein Muster von so genannten Trochaischen Versen“ anempfohlen wird, deutet den Versuch an, dem Publikumsgeschmack besser zu entsprechen. Interessanterweise weicht in dialektaler Hinsicht auch das erste Stück der Folge ab, da Leopold hier eher das wienerische lange, helle „ä“ (für den mittelhochdeutschen Diphthong ei vor Nasalen und bestimmen Konsonanten) als das allgemein mittelbairische „oä“ verwendet - allerdings auch dies nicht konsequent.

43 Gegen-Antwort Des Lepolt Oestareichäs An seinen Vatter Ulri, Oder Des Bäurischen Brief-Wexels Drittes Stuck. über Verschiedene von einer See-Schlacht, von einem Meer-Sturm zu Dunkerk, und von der Spanischen Flucht in der Romany eingeloffenen Zeitungen. Wienn gedruckt und zu finden, bey Frantz Andre Kirchberger, Universitäts-Buchdruckern, auf dem alten Fleischmarckt im Kullmayrischen Haus, 1744, f. 3v. 
Mit der obligaten Huldigung der Herrscherin und dem Verweis auf die erneuerte habsburgische Kampfeskraft, die der patriotischen Kriegsbegeisterung ihrer Untertanen zu verdanken sei, endet die Brieffiktion:

OAs muß d'Kinigin ja gfrayä, wann ma ihri Faind so zwifelt,

Sag i; i wollt ä wohl räffä; was gilts, i wer ä glai gstifelt?

Laß nu gehn, sagt wiedä oanä, d'Kinigin schraibt wie lang auf;

Drum hoässts entli zamä räten: Vogel friß, stirb, odä lauf;

Zwoä mahl hundät tausend Säbel sinkezen scho hin und wiedä

Lassmä de nu zammä kummä; s'Hauen s'halbet Frankrai nidä?

Jetz woäst, Vottä? was de Zaiting z'negst so viel hat z'reden gmacht.

Bhüt di GOtt, und grüssmä d'Muttä. Mein Herr rieft mi. Guti Nacht. ${ }^{44}$

Die Perfektion der metrischen Formgebung, die leichthändige Integration idiomatischer Phraseologie, das dramatische und humoristische Geschick bei der Gesprächswiedergabe, die Bildhaftigkeit des Ausdrucks und die beeindruckende Breite des Wortschatzes - das alles zeigt einen Meister am Werk, der wohl ganz gezielt für diese stimmungsmachenden Arbeiten herangezogen wurde. Wer es war, werden zukünftige Forschungen hoffentlich enthüllen.

Sprachlich wesentlich anspruchsloser präsentieren sich die holprigen paargereimten Vierheber des Huldigungslieds SO grieß enk GOtt Wiener, mei kents mich den nödt, das anlässlich der Hochzeit des Thronfolgers mit der spanischen Infantin Isabella von Bourbon-Parma 1760 entstand. Hier ist es ein oberösterreichischer Bauer, der zum MostVerkauf in die Residenzstadt reist und sich seine simplen Gedanken zum bevorstehenden Ereignis macht, indem er es mit seiner Lebenswelt in Einklang setzt:

6

Weil ihn GOtt erhalten vor aller Gefahr, und ist jetzt schon alt über neunzehn Jahr; so ist ja ganz billich, daß er kriegt a Weib, gebts ihm fein a hübsche, so hat er a Freud. 7

Mein miterer Bue hat jetzt schon a Glück gemacht, den han i halt gschwind zum Häußl zuebracht; aina ist im Feld, er wird sein General, wannich doch nicht fehl, oder gar Corporal. 8

Nächst han i mein Pfarrer sein Winter-Waiz baut, da hams a so gred von des Prinzen sein Braut; bey uns ist die schöne, des Mesner Lena, sie ists aber nit, es toins anderst nenna. 9

Sö sagn, das Mensch wär für an Prinzen als zgmain, wanns a reich und schön wär, wurd gleichwol nichts tain; die Braut muß h[e]rstamma von Königl. Blut, fürs Mesner Me[n]sch ist da Präcepter schon gut.

44 Ebda., f. 4r. 
10

Um Braut hab aber gleich noch a mal ge[fra]gt,

so hat mirs doch endlich da Caplan [ges] agt;

Prinzeßin von Parma, Infantin [wi]rds gnent,

der Nahm Isabella, vortreflich und schön. ${ }^{45}$

8,1 Nächst] vor kurzem han i] habe ich 8,4 toins] tun sie 9,1 zgmain] zu gewöhnlich, nieder 9,4 Mesner Mensch] Mesner-Mädchen Präcepter] Schullehrer

Unterhaltsame Auftragsdichtungen zu Festveranstaltungen anlässlich dynastischer Vermählungen lieferte mit Maurus Lindemayr ein weiterer Meister seines Fachs. Die Anlässe waren allerdings komplizierter, sodass in beiden Fällen jeweils nur die allein reisende Braut gefeiert wurde. 1765 war es die bayerische Prinzessin Maria Josepha, die auf der Fahrt nach Wien zu ihrer Hochzeit mit Joseph II. im Kloster Lambach nächtigte. Hier, beim ersten Aufenthalt auf österreichischem Boden, fand auch die sogenannte ,Auswechslung' statt, die Verabschiedung des vertrauten bayerischen Personals und die Übernahme des österreichischen. Zur Feier dieses symbolischen Akts dichtete Lindemayr seinen Brautgesang Losts Nachbärn stehts zamä, der die bevorstehenden königlichen Vermählungsfeierlichkeiten in den traditionellen Fixpunkten einer bäuerlichen Hochzeit spiegelt. Zunächst müssen die Heiratserlaubnis bei der Grundherrschaft und das Plazet der Kirche eingeholt werden, nach den Verhandlungen mit dem Wirt werden die Gäste geladen, die am Hochzeitsmahl mit Musik teilnehmen, am folgenden Tag findet ein Preisschießen als Belustigung statt und schließlich lässt man noch eine Dankesmesse lesen. Geschickt eingeflochten in diese Beschreibung sind Hinweise auf das königliche Brautpaar und den zu erwartenden Nachwuchs:

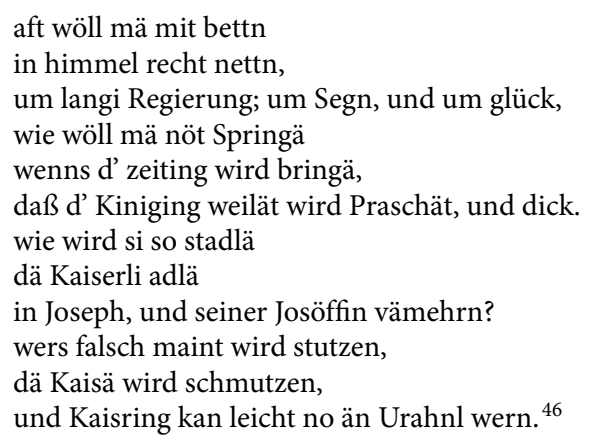

1 aft] dann 2 nettn] nötigen, zwingen, erzwingen 5 zeiting] Nachricht 6 weilät] schön langsam, nach einer Weile Praschät] aufgedunsen, dick, (hier:) schwanger 11 schmutzen] lächeln 12 Urahnl] Urgroßmutter

Die Wünsche sollten allerdings nicht in Erfüllung gehen, war doch die Ehe von vornherein zum Scheitern verurteilt. Nach dem Tod seiner geliebten ersten Frau Isabella wollte der österreichische Thronfolger nicht mehr heiraten. Doch für Maria Theresias Netzwerk an Allianzen war eine weitere Vermählung ihres ältesten Sohns unabdingbar. Letztlich entschied sich die Kaiserin für die bayerische Option, da Maria Josephas

45 Gutmeynender Ländler-Baur / Uber das Vermählungs-Fest / Des Erz-Herzogen und Cron-Prinzen von Oesterreich, f. 1v-2r.

46 Lindemayr, Dialektlieder I, S. 127. 
Bruder, Maximilian III., noch keinen Erben hatte und sich eine Ausweitung des Reichs erhoffen ließ. Nur widerwillig fügte sich der frisch ernannte König in diese Hochzeit aus Staatsraison und vermied nach der Vermählung möglichst jeden persönlichen Kontakt. Als Josepha schließlich 1767 wie ihre Vorgängerin an den Pocken verstarb, blieb ihr Ehemann dem Begräbnis fern. Dass die kinderlose Ehe vermutlich nie vollzogen worden war, hielt Joseph allerdings nicht davon ab, nach dem Tod Maximilians und dem Aussterben der bayerischen Linie der Wittelsbacher Ansprüche auf Niederbayern und die Oberpfalz zu erheben und damit den Bayerischen Erbfolgekrieg auszulösen.

Berühmter noch war der Besuch, den das Stift 1770 beherbergte: Erzherzogin Maria Antonia (1755-1793), besser bekannt als Marie Antoinette. Die Dauphine verbrachte in Lambach ihre letzte Nacht auf österreichischem Boden, bevor es Richtung Frankreich weiterging, wo es zum ersten Zusammentreffen mit ihrem per procurationem angetrauten Ehemann, dem späteren König Ludwig XVI., kommen sollte. Drei Monate lang hatten sich Stift und Ort auf dieses Ereignis vorbereitet und ein ausgefeiltes Programm mit Theater, Tänzen und Feuerwerk zusammengestellt, um den illustren Gast standesgemäß zu empfangen. ${ }^{47} \mathrm{Da}$ der Ablauf des Festempfangs minutiös geplant war, konnte Lindemayr sein Lied Bi vor acht Tagen in Wochämark gwösen, das die Vorbereitungen und Feierlichkeiten aus Sicht der bäuerlichen Bevölkerung humorvoll beleuchtet, schon Wochen zuvor fertigstellen. Es ist der lebensnahe und humorvolle Quasi-Simultanbericht eines Spalier stehenden Bauern, der den Blick auf den prominenten Gast zum Höhepunkt eines Untertanenlebens stilisiert:

Däß di Gotts Sagrä! es thuet mä schon glückä;

Meinä Treu, Nachbä! i hans schon däguckt.

Schau, wie s' so freundli auf inns her thuet blickä!

Wie sä si nämli nit schnippert, und buckt.

Hats nit ä Gstältl, ma kanns nit so mahlen,

Bluetrathi Wängel, ä schneeweißi Haut.

Wirds n Französischen Bräuckä nit gfallen,

$\mathrm{Daß}$ er iehm so ä schöns Danerl ausgschaut! ${ }^{48}$

2 i hans] ich habe sie däguckt] erspäht 4 schnippert] schnippern: schnippisch sein 7 Bräuckä] Bräutigam 8 Danerl] Diminutiv zu Antonia

Seine Glückwünsche am Ende des Lieds sollen für die Stimme des österreichischen Volks stehen, das für einen Tag die Unbilden des Alltags vergessen konnte - zumindest in der literarischen Fiktion. In der Realität blieb das regnerische Wetter des Festtags auch in den folgenden Wochen erhalten und führte in der Folge zu großflächigen Überschwemmungen und Missernten, die Ausschlag gaben für die letzte große Hungersnot

47 Zum Kontext vgl. Lindemayr, Dialektlieder II, S. 50ff.

48 Ebda., S. 12. 
des 18. Jahrhunderts. Das nächste Mal, dass es im Frühjahr so andauernd regnete, war 1793, jenes Jahr, in dem die französische Königin ihr gekröntes Haupt unter der Guillotine verlor.

Der Krönung eines Herrschers kam im dynastischen Repräsentationsgefüge als symbolischer Akt der Legitimation und des Konsenses eine besondere Bedeutung zu, die der politischen Öffentlichkeit entsprechend vermittelt werden musste - zumal, wenn der Konsens keineswegs gesichert war. Als etwa 1742 Karl Albrecht von Bayern als erster Nicht-Habsburger seit beinahe drei Jahrhunderten zum Kaiser gekrönt wurde, besetzten österreichische Truppen gerade Bayern, sodass der ehrgeizige Wittelsbacher, der die Pragmatische Sanktion nicht anerkennen wollte und sich selbst zum Erzherzog von Österreich ernannt hatte, ohne Land und Macht im Frankfurter Exil festsaß. Umso wichtiger war es, seinen Untertanen den Rechtsanspruch und die Gültigkeit seiner Herrschaft $\mathrm{zu}$ vermitteln. In diesem Sinn ist auch ein leider nur unvollständig erhaltenes, schwach dialektal markiertes Flugschriftlied zu sehen, in dem nach erprobtem Schema ein ,einfacher' Mann die neuesten Vorkommnisse aus Frankfurt berichtet, wo die Kurfürsten zur Wahl zusammengekommen sind. Der Favorit für den Sprecher ist klar: Es muss der Sohn des Türkenbezwingers Maximilian sein, der wie kein anderer für die militärische Stärke Bayerns stand:

1

SO geh nur mein Jodel, ich muß dir was sagen, was sich hin und wider für Sachen zutragen, wie man muß vernemmen, daß Churfursten all, zusammen wärn kommen, und halten die Wahl. 2 Man thut mir erzehlen, in Franckfurth am Mayn, dort werdens erwöhlen, wer Kayser soll seyn, von Churfürsten einen, wird näch darzu kämmen, glaub nit, daß ein Gmeiner, ja Kayser werd werden. 3

Es ist ja kein stärckrer an Glauben und Schwerdt, so vil man kan mercken, als Carl Albert, wünsch daß all zusagen das Römische Looß, thut leicht ein Cron tragen, ist schon so viel groß. 4

Wie hat nit auf d'Goschen der Maximilian, die Türcken gedroschen, das weiß jeder schon. Es seynd ja zum Rauffen die Beyer wacker Leuth, schlagen einen übern Hauffen, wann sie seyn im Streitt. ${ }^{49}$

4,1 d'Goschen] das Maul

49 Vier schöne weltliche Neue Lieder, Das erste: So geh nur mein Jodel, ich muß dir was sagen, etc. Das andere: Lustig frölich guter Dingen, thu ich meine Zeit zubringen, etc. Das dritte: Schönste thu bekennen, wann ich dich darff nennen, etc. Das vierte: Lustig wohl auf, jetzt bin ich content, bin nit mehr der etc. Gedruckt in diesem Jahr. [o. O., o. J., 1742], f. 1v. (im Deutschen Volksliedarchiv Freiburg ist nur ein Blatt erhalten mit Titel und den ersten 4 Strophen des ersten Lieds). 
Doch auch die Gegenseite rechtfertigte mit der edlen Abstammung das angestammte Thronrecht. Als die Truppen der Kaisertochter Maria Theresia 1742 Prag wiedereroberten, wo sich ein Jahr zuvor Karl Albrecht zum König ausrufen und huldigen hatte lassen, war es wichtig, die Wiederherstellung der Ordnung entsprechend zu kommunizieren. Gekrönt konnte der Wittelsbacher nicht werden, da die böhmischen Krönungsinsignien rechtzeitig nach Wien geschafft worden waren. Mit einer prächtigen Krönungszeremonie wollte nun die verärgerte Habsburgerin den untreuen Böhmen ihren Herrschaftsanspruch unmissverständlich klarmachen. Dass sie die Wenzelskrone in einem Billett an den Hofkanzler Philipp Joseph Graf Kinsky despektierlich als „Narrenhäubel“ ${ }^{50}$ tituliert, ist unmissverständliches Zeichen ihres Unmuts. Nach außen hin aber sollte das Bild der fürsorglichen Landesmutter transportiert werden, zumal bei den bäuerlichen Unterschichten, die Karl Albrecht mit Zusagen wie der Aufhebung der Leibeigenschaft gegen die österreichische Herrschaft aufwiegeln wollte. ${ }^{51}$ Um ihnen die alte neue Herrschaft wieder schmackhaft zu machen, setzte die Propaganda auch hier auf die bereits bekannten Bilder von Gratisverköstigung und Geld für die notleidende Bevölkerung:

1

LUsti bin ich immerzu, ich sag dirs Urberl mei Bue, was Neus will i dir sagen, was sich hat zugetragen, zu Prag merck nur auf behend, dort habens die Königin crönt. 3

Ja Bue Gnad ist mir gschehen, daß i di Crönung hab gsehen, hat mir das Hertz gelacht, wies habn ä Musi gmacht, hättens mir d'Königin geben, i hätt mit ihr tantzt für mein Leben. 5 Ein Wein liessens ä abrinnä, und ich hab kein fangä könnä, weil ich kein Krueg hab ghabt, hab i umb mein Hüttl dapt, und hab mir gfangen ä drein, möcht bey ein Mäßl gwest seyn.
2

Weil sie kommt von Kaysers-Stamm, so gebührt ihr auch die Cron, sie heißt Theresiä, GOtt wird sie seegnen ä, daß sie ihre Länder b'schutzt, und all ihren Feinden biet trutz.

4

Das hat mi ä noch so gfreut, Geld habens gantz Händ voll auskeyt, habn ja recht gräfft und gschlagen, i hab wöllens mehrer haben, hon denckt es thät mir schon noth, hab schon ä drey Tag kein Brod. 6 Jetzt schrey ich he ju he sa sä, ä Geld han i und ein Wein ä, bin lusti guter Ding, soll leben die Königin, wünsch ihr den Göttlichen Seegen, den ihr GOtt selber wird geben.

50 Alfred von Arneth: Maria Theresia's erste Regierungsjahre. Bd. 2: 1742-1744. Wien: Braunmüller 1864, S. 246.

51 Vgl. Bertold Bretholz: Geschichte Böhmens und Mährens. Bd. 3: Dreißigjähriger Krieg und Wiederaufbau bis 1792. Reichenberg: Sollor 1924, S. 135. 
8

Urberl jetzt gehn mir in d'Stadt,

zum Würth der den besten Wein hat,

trincken ä Mäßl aus,

wann mir glei kriegn ein Rausch,

legn uns all zwen unter d'Banck,

d'Leuth meynt gleiwohl mir seynd kranck. ${ }^{52}$

4,2 auskeyt] ausgeworfen 4,3 gräfft] gerauft 4,5 hon denckt] habe gedacht 5,4 dapt] gegriffen 5,6 Mäßl] Maß (etwa 1,4 l)

Nach dem frühen Tod des weitgehend isolierten und machtlosen Karls VII. wurde 1745 Maria Theresias Gemahl und Mitregent Franz Stephan von Lothringen zum römisch-deutschen Kaiser erwählt. Bei der Rückkehr von den Krönungsfeierlichkeiten in Frankfurt wurde das Kaiserpaar mit prächtigen Illuminationen empfangen. Auch hier publizierte eine Sammelschrift Ghelens die zahlreichen künstlerischen und poetischen „Freuden-Bezeigungen “ ${ }^{53}$, mit der die Residenzstadt in der Nacht vom 28. auf den 29. Oktober geschmückt war. Wie wenige Monate zuvor bei den Beleuchtungen zur Geburt Karl Josephs kamen vereinzelt emblematische Huldigungen in mehr oder weniger deutlich markiertem Dialekt zum Einsatz, zumal bei den Gastwirtschaften. Originelles ist weniges darunter; vor allem sind es trinkfreudige Bauern („Ey Gredl sey nur lustig / und wolauf / Heut muß noch gehen unser Gütl drauf“) und rauflustige Jugendliche, die gegen den Erbfeind Frankreich wettern:

Von dem Wirts-Haus über ware im Ek des Fensters eine Hütten zu sehen / in welcher der Hahn aus einem Fenster heraus krähete / auf der Gassen stunde eine Menge Buben mit Steken / und Steinen versehen / und warfen dem Hahn die Fenster ein. Unten ware zu lesen:

Buemä schlagts die Fenster ein/

Wo der Hahn will Meister sein. ${ }^{54}$

Etliche dialektale Krönungslieder begegnen uns wieder in den 1790er Jahren. Als lancierter Ausdruck einer patriotischen Grundstimmung waren sie vor allem als Identifikationsangebot zu lesen: Die Mundart suggerierte die Perspektive des Volks, das durch

52 Siben schöne Neue Gesänger, f. 1r-v, vgl. Kap. II, Anm. 67. Strophe 7 des Lieds fehlt im Flugblattdruck. Ediert bei Klier, Historische Lieder des 18. Jh., S. 30f.

53 Wiennerische Beleuchtungen, Oder Beschreibung Aller deren Triumph- und Ehren-Gerüsten, Sinn-Bildern / Gemählden / Und andern sowol prächtig- als kostbar- und unvergleichlichen Auszierungen / welche bey denen wegen der zu Frankfort glorreichest beschehenen Kaisers-Wahl und Crönung Seiner RömischKaiserlichen Majestät FRANCISCI zu Germanien / und Jerusalem Königs / Hertzogs zu Lothringen / und Barr / Groß-Hertzogs von Toscana etc. etc. Dann allerhöchst Deroselben nebst Ihrer gleichfalls Kaiserlichauch zu Hungarn / und Böheim Königl. Majestät MARIAE THERESIÆ Dero Allerdurchleuchtigsten Gemahlin, unser allergnädigsten Landes-Fürstin / und Frauen / Frauen Den 27. Octobris lauffenden Jahrs 1745. von gedachten Frankfort in die alhiesig Freud- und Jubel-volle Kaiserl. Residentz-Stadt Wienn erfolgten glüklichen Zurukkunft Donnerstags den 28. Oktob. als am Fest deren HH. Aposteln Simonis und Judä darauf Abends, und selbige Nacht hindurch nicht nur in hiesig frohlokender Stadt, sondern auch mancher Orten in denen herumligenden Vor-Städten angestellten allgemeinen Freuden-Bezeigungen, sowol an denen Herrschaftlich Pallästen, als geistlichen Collegiis, Klöstern, und Stiftern, wie auch PrivatHäusern, Wohnungen, und Gewölbern zu sehen gewesen. Zusammen getragen, und verlegt von Johann Peter v. Ghelen, Kaiserl-Königl. Hof-Buchdruckern. Wienn, gedrukt und zu finden in der Kaiserlich-Königlichen Hof-Buchdruckerey im neuen Michaeler-Haus nächst der Burg, S. 1.

54 Ebda., S. 71 und 165. 
den quasi-authentischen Gefühlsausdruck des gewöhnlichen Manns repräsentiert wird. Im Zentrum steht dabei die Beschreibung der Festlichkeiten: die aufwändigen Feiern, das Abfeuern von Kanonen und Gewehrsalven, das Beleuchten der Fenster und die Menschenmengen. Umrahmt werden diese Schilderungen von den obligatorischen Lobesformeln für die Herrscher, die Teil der Beschreibung der Geschehnisse sind, aber gleichzeitig auch im Lied wiederholt und bestätigt werden. Drei Dialektlieder haben sich zum Regierungsantritt Kaiser Leopolds erhalten, in den man 1790 nach dem überraschenden Tod Josephs II. große Hoffungen setzte, hatte er doch in den 25 Jahren seiner Herrschaft in der Toskana ein Reformprogramm verwirklicht, das das Großherzogtum zu einem Vorzeigeland europäischer Aufklärungspolitik machte. Die Modernisierungen in Verwaltung, Justiz und Wirtschaft - mit Bedacht durchgeführt und zuvor im Kleinen auf ihre Tauglichkeit geprüft - fanden nicht nur den Beifall der Intellektuellen, sondern kamen auch den sozial schlechter Gestellten zugute. Die Lage des Habsburgerreichs war bei Leopolds Amtsantritt alles andere als stabil. Finanziell am Rande des Abgrunds, durch Separationsbestrebungen und Kriege in seinem Bestand bedroht, bedurfte es einer raschen Kurskorrektur, für die man sich - gerade auch in Zeiten der Französischen Revolution - die Unterstützung des Volks sichern wollte, auf dessen Eigenverantwortlichkeit Leopold schon in der Toskana gesetzt hatte. Eine Flugschrift aus dieser Zeit diente in der Vergegenwärtigung der Wahl- und Krönungszeremonie offensichtlich der Stimmungsmache für den noch weitgehend unbekannten Herrscher. Ein erstes Lied Von der Abreis in Wien skizziert - retrospektiv, doch Simultanität simulierend - den Reiseverlauf, die prächtige Ankunft in Frankfurt und die Wahl am 30. September:

1

He Stephl, und Riepel, Hansl, Woferl kommt her, ich muß euch erzehlen neu Zeutung schon mehr, was sich jetzt wird zutragn zu Frankfurt am Mayn, seyts fröhlä, saufts umä, und thuts lusti seyn.

2

Das allerhöchst Oberhaupt vom ganzen Reich, ist von Wien nächst abgraist, mit zwey Prinzen zgleich, sie habns Prinz Karl, und Leopold g'nennt, weil mans gar schön voneinander hat kennt.

$[\ldots]$

6

In Frankfurt wirds Leut gebn, daß wimmelt als dick, mit Chur- und Reichsfürsten, das ist halt ä Glück, für den König Leopold Erzherzogen zgleich, seynd d'Stimmä ausgfallen, vom römischen Reich.

$[\ldots]$

10

Der Einzug ist gangä der Kirchen grad zue, wie schön das Ding z'sehn, derfst glauben mein Bue, es war all's voll Jubl und Freuden da gwest, den 9. Oktober bey dem Krönungsfest.

1,1 Riepel] Kurzform für Rupert/Ruprecht 1,2 Zeutung] Nachricht 2,2 nächst] neulich, unlängst 
Mit der Perspektive auf die Krönungszeremonie endet das Lied. Hier setzt der zweite Bauerngesang Von der Krönung ein, der die Vorgänge und Feiern im fingierten Augenzeugenbericht mit den genreüblichen Akzenten wiedergibt:

1

Vikori! jetzt ist nun die Krönung vorbey,

es hat all's z'samm g'schrien, leb Kaiser voley.

Leopold der Zweyt ist regierender Herr,

der Himmel bescher ihm sehr viele Jahr mehr.

2

$\mathrm{Zu}$ Frankfurt da haben sie alles vollbracht, habn g'jubelt und g'schossen, daß alles hat kracht, jetzt haben wir ein Leopold, der ist unser Herr:

Er ist doppelt König, und Kaiser nunmehr.

3

Mein Hiesl du glaubst nit, was g'schehen noch ist, ich willt dirs erzehlen, weilst gar so brav bist, da ist all's z'samm g'loffen den ganz gschlagnen Tag, da hat man nur z'schaun g'habt, auf was man nur mag. 4

In d'Kirchen seynds gfahren, habn glassen niemd ein, nur Fürsten und Grafen zu Frankfurt am Mayn, alldort habns krönt mit der goldenen Kron, der Scepter, Reichsapfel habn gscheint wie die Sonn. 5

Das Schwert zu verfechten die ganz Christenheit, wider Türken und Haiden, barbarische Leut, habns herbracht, ich wais nit, soll gscheint habn von fern, als wann wär aufgangen der schön Morgenstern. 6

Die Mahlzeit ist gwesen bis in die spat Nacht, än Ochsen habns braten, daß aim s'Herz hat glacht, auf d'Tafel ä Stückl habns aufgsetzt dävon, d'Leut habn dävon g'essen, s'Wein Rinne geht an. 7 Verschiedne Geldsorten von Silber und Gold, ausg'worf'n seynds worden, hat wundä schön g'rollt. Seynd preis gebn alln Leuten so herrliche Ding, Fleisch, Brod, Wein, und Früchten, wem es nur geling. 8 Die Gsundheit habens trunken dem Kaiser zur Ehr, leb Leopold der II. je länger, je mehr, dem ganzen Haus Oesterreich, und römischen Reich, all Chur- und Reichsfürsten, den allen zugleich. 9

Viel Stuck habens abgschossen, daß donnert und kracht, ein Feuerwerk ist gwesen fast die ganze Nacht, all Fenster seynd b'leucht worn, aufs allerschönst ziert, wer immer nur gschaut hat, hat sich nicht verirrt. 
10

Weil d'Liechter habn brunnen die ganz liebe Nacht,

da ist oft was g'schehn, haben alle z'samm g'lacht,

mein Hiesl ich sag dirs, das ist schön gewest,

mit Freuden habens g'halten dies kaiserlich Fest. ${ }^{55}$

1,1 Vikori] eigentlich Viktori (lat. victoria): Sieg 1,2 voley] völlig, ganz (?) 9,4 Stuck] Kanonen 10,1 brunnen] gebrannt

Mit seinen ersten Amtshandlungen schien Kaiser Leopold II. der hohen Erwartungshaltung durchaus gerecht zu werden. Mit viel Geschick in außen- wie innenpolitischen Fragen suchte er eine Annäherung an Preußen, nahm Verhandlungen mit der Hohen Pforte zur Beendigung des Kriegs auf und leitete durch die Rücknahme allzu überhasteter Reformen seines Vorgängers eine vorsichtige Liberalisierung im Reich ein. Viel Spielraum ließ ihm die budgetäre Situation freilich nicht, sodass nicht wenige seiner Änderungen in den ersten Monaten seiner Herrschaft eher symbolischen Charakter hatten. Obwohl wie sein Bruder Joseph ein Anhänger eines aufgeklärten Reformkatholizismus, agierte Leopold auch in kirchenpolitischen Belangen weitaus behutsamer - ein Aspekt, den auch Peter Gottlieb Lindemayr, der als Lambacher Stadlschreiber sowohl auf staatlicher als auch klösterlicher Lohnliste stand, in seinem Fürstenpreis Es leb dä Kaisä Leopold ansprach. Mit der Inszenierung privater Religiosität signalisierte er dem Volk den Fortbestand der im Aufklärungsdiskurs unterminierten christlichen Werthaltungen und Traditionen:

5

Ä schützt, und ehrt d'Religian,

Das graicht $\mathrm{n}$ Land zum Bösten:

Und derf än jeden Untäthan,

Vä Herzen freun, und trösten:

Z'Linz vor - und nach n Mittämahl

Hat $\mathrm{Er}$ - Sie - und die Kinder all

So fleißi beth.... Das kimmt ia da

Bei uns itzt wällät völli a.

\section{6}

Allain i wettet um wais was:

Und gieb enks auf än Stempel

Äs geht bald aus än annern Faß,

Nach 's Kaisä sein Exempel.

Dö si bisher so mausi gmacht,

Und alls, was heilli ist, väracht,

Dö ziehngt n Schwaif ganz sicher ein,

Und wernd aufs nächst ganz dästi seyn. ${ }^{56}$

5,8 wällät] wahrlich völli] beinahe, fast 6,2 enks] euch es, es euch 6,5 si $\ldots$. mausi gmacht] widerspenstig waren 6,7 ziehngt] ziehen 6,8 aufs nächst] demnächst dästi] kleinlaut, unterwürfig still

Die Datierung des Lieds auf den 15. November 1790 ist nicht zufällig gewählt: Es war der Tag der ungarischen Inthronisation Leopolds, der im ganzen Reich mit Feierlichkeiten und Treuekundgebungen begangen wurde, bei denen panegyrische Lieder und Gedichte vorgetragen wurden. In diesen zumeist recht schwülstigen Gelegenheitsdichtungen spiegelt sich die Hoffnung, die die Bevölkerung, Konservative ebenso wie Aufklärer, in ihr neues, tatkräftiges Oberhaupt setzten.

55 Zwey neue Lieder, von der zu Frankfurt am Mayn den 30. September 1790. Freudenvoll geschehenen Römischen Königswahl, und den 9. Oktober darauf folgenden Kaiserkrönung Leopolds II. dieß Namens. [o. O., ev. Linz oder Steyr]. Gedruckt im Jahre 1790. Auch abgedruckt in Wolkan, Wiener Volkslieder 1, S. 222-224.

56 Lindemayr, Lieder in oberösterreichischer Mundart, S. 41f. 
Der Schock war groß, als Leopold nach nur zwei Jahren starb und sein Sohn Franz ihm viel früher als erwartet auf den Thron folgte. Dass er aufgrund der politischen Umstände als Franz II. der letzte Kaiser des Heiligen Römischen Reichs werden sollte, war zu dieser Zeit noch nicht abzusehen. Doch blieb seine Krönung im Frankfurter Dom am 14. Juli 1792 (provokanterweise am dritten Jahrestag des Pariser Bastillesturms) die letzte deutsche Kaiserkrönung. Obwohl noch nicht einmal die Schulden des letzten Krönungsfests abgezahlt waren, wurde auch diese Zeremonie mit großem Pomp begangen, wohl nicht zuletzt als Signal an in- und ausländische antimonarchistische Kräfte. Wie ein Triumphzug gestaltete sich auch die Rückkehr, mit zahlreichen Festakten an den verschiedenen Reisestationen und Nächtigungsorten. In Linz wurde dem Aufenthalt des aus Frankfurt kommenden Kaiserpaars sogar eine kleine ,ländliche Oper ' gewidmet, wie schon deren umständlich-devoter Titel verrät: Der gest'rige Tag! oder Margareth, das ist ein herzallerliebster Mann Unser neuer Kaiser Franz (1793). Verfasser war der landständische Kanzlist Wenzel Blima (?-1823), der für die Vertonung des Singspiels den Rohrbacher Tabakverleger Kaspar Lachner gewinnen konnte und sich merklich an Maurus Lindemayrs Werk orientierte. Die zweiteilige Handlung ist simpel und dient allein der Demonstration der patriotischen Gesinnung des oberösterreichischen Volks. Im Mittelpunkt steht der Bauer Hanns Liebhold, der mit seinen Kindern Augenzeuge der Linzer Feierlichkeiten war. Euphorisiert gibt er nach der Rückkunft ein spontanes kleines Fest, bei dem den Zuhausegebliebenen die großen und auch kleinen Erlebnisse lebensnah geschildert werden:

Hans. Still! He! noch eins - Schauts, daß aber sehts, daß ich mich nicht umsonst g'freu - so muß ich euch noch was erzähln - Schauts! in Landhaus in Saal ist neben meiner ein gmainer Burgersmann, aber schon ein ziemlich alter Dadel g'standen. In Um- und Umschaun erblick ich auf einmal in sein G'sicht, daß ein Zähe den andern schlagt - Mei? frag ich - warum weint dann der Herr? Was meinst, was er mir g'antwort hat? - Vor lauter Freuden hat er g'sagt. Denn sagt er - die Ankunft erinnert mich natürlich auf die Zeiten, da die grosse Maria Theresia mit den geliebtesten Kaiser Franz in der Flor, und Schönheit ihrer Jugend in Linz g'wesen ist - und der Jubel hat die nachfolgende gute Regierung vordeut - und er wollt sein Hab und Gut verwetten, daß bey den gegenwärtigen jungen Kaiserleuten das nämliche erfolgen wird, besonders weil's die nämlichen Näm hab’n. ${ }^{57}$

Dadel] alter Mann Zähe] Träne in Linz g'wesen ist] 1743 kam Maria Theresia nach Linz, um die Erbhuldigung der Stände entgegenzunehmen

Auch hier unterstreicht die dynastische Vorstellung der Herrschaftskontinuität über Generationen hinweg die gottgegebene Repräsentationsbeziehung. Hans spricht die Korporationssymbolik sogar explizit an, wenn er im zweiten Akt seinen Freundeskreis für Privatfeierlichkeiten im aristokratischen Bereich anwirbt:

Hans. Aft! was ist's ohne Oberhaupt? Gar nichts, ein purer Tauderlau! Nemt's nur selest ein Wirtschaft, wo Knecht, Dirn'n, und alles untereinander handirt, und regirt - Entweder es g'scheht nichts - oder es g'schieht alles in Raffen, Zancken und schlag'n oder es g'schieht alles später, und schlechter als g'schehn wär, wann ein Herr regirt hötte - Schauts! es ist halt grads so, wie

57 [Wenzel Blima:] Der gest'rige Tag! oder Margareth, das ist ein herzallerliebster Mann Unser neuer Kaiser Franz. Linz, [o. V.] 1793, S. 54. 
ma' ein' ganzen Menschen in seiner Bauart anschaut - Er ist's Haupt - und wir seynd der Leib. $^{58}$

Aft] dann, also Tauderlau] Nichts, unnütze Sache

Mit Illuminationen und einem bäuerlichen Hochzeitstanz endet das Stück, dem - da aus pragmatischen Gründen die Figurenrede nur andeutungsweise „nach der oberösterreicher Bauernart “59 abgedruckt wurde - eine kurze Anweisung zur ,Oberösterreichischen Bauernsprache' beigegeben wurde. Einen etwas bescheideneren Reflex fanden die Feierlichkeiten in Steyr, wo mit Freuden- und Lobrufen, mit Gewehrsalven und Illumination dem neuen Kaiser gehuldigt wurde, wie uns ein ,Kassazionslied ${ }^{60}$ auf bäuerische Art ${ }^{\star}$ sehr dialektal und in teils eigenwilliger Schreibung schildert:

1

Wie lustö öß heut nöt da zSteyr bey dä Nacht

Döß Glizln, döß Glanzen, hat d’ Kaysäwahl gmacht;

In Himml kas wärlä viel schönä nit sei.

Soll löbm Kaysä Franz: hörrt mä überall schrei.

$[\ldots]$

4

Aen jeden scheunt d'Freud heut bän Augnä scho aus,

Oeß brint än jeds Fenstä, ös glizt ä jeds Haus,

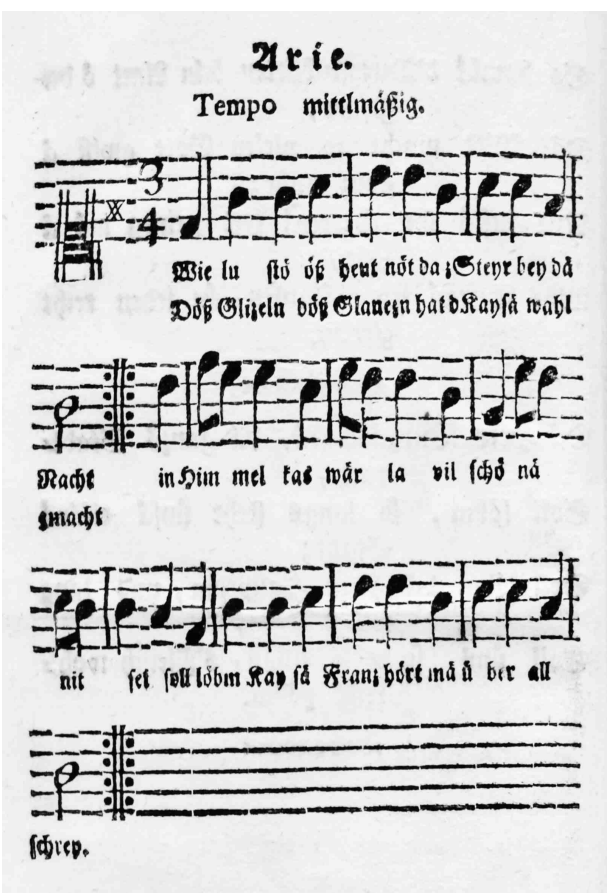

Tempo mittlmápigig.

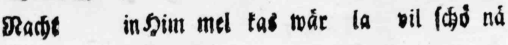

smadst

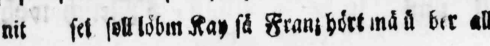

(దுiep.
Abb. 19: Zweytes Kassazionslied (Oberösterr. Landesbibliothek, I 4966).

58 Ebda., S. $114 \mathrm{f}$.

59 Ebda., S. [IX].

60 Darunter verstand man ein meist unter freiem Himmel aufgeführtes heiteres Anlasslied. 
D’Reim sänd nät zän mörkä, öß sänd gar als z’viel,

Dä Kaysä selbm stund än Eicht überall still.

5

Schad daß ä nöt selbm mit dä Kayserin da,

Was schrie die Stadt Steyr nöt für Vivat laut na;

Es löb Kaysä Franz, und d'Frau Reßl dänöbm,

Gott schenk üns bald Prinzen, den Zwayen langs Löbm. ${ }^{61}$

1,1 öß] ist es 4,3 d'Reim] die in den beleuchteten Fenstern und an Hausfassaden ausgestellten Sinnsprüche und Verse 4,4 än Eicht] eine Weile 5,3 d'Frau Reßl] Maria Theresia von Neapel-Sizilien

Die Art der Darstellung, die den Fokus auf die Loyalität der Untertanen legt, muss im historischen Kontext gesehen werden, war doch die Kaiserkrönung bereits überschattet vom Ausbruch des Ersten Koalitionskriegs gegen das revolutionäre Frankreich. Das Lied bzw. die gedruckte Sammlung, in der es enthalten ist, sollte wohl jegliche Bedenken - in der Bevölkerung wie bei der Obrigkeit - zerstreuen, dass das Volk nicht geschlossen hinter dem Herrscher stünde; ganz im Gegensatz zu Frankreich, wo die Revolution bald auch die Köpfe des Herrscherpaars fordern sollte. Ein zweites dialektales Lied derselben Sammlung (Heut hat üns mei Pflögä was nois publizirt), das stolz ein kaiserliches Dankesdekret für die erwiesenen Huldigungen zum Anlass nimmt, einen noch detaillierteren Überblick über den Festtag zu geben, deutete in der Abschlussstrophe dieses Schicksal bereits an:

Soll löbm ünsä Kaysä, d’Frau Reßl soll löbm,

Fünf Prinz, söchs Prinzösina soll ie Gott göbm;

Do soll kai Prinzösön si nöt untästehn,

Als Braut ö döß mördärösch Frankrei mehr z’gehn. ${ }^{62}$

Jeder Tod eines Herrschers stellt eine Bedrohung für das monarchische System an sich dar, denn sein ,politischer' Körper, jenes überindividuelle Konstrukt, das die Einheit der Korporation und damit die Fortdauer des Staats garantierte, durfte nicht sterben. ${ }^{63}$ Die Vergänglichkeit des biologischen, individuellen Körpers des Souveräns allerdings war unleugbar. So war es nötig, dass nach dem Verlust des Haupts die Kontinuität der Herrschaftsfolge entsprechend rasch sichergestellt wurde und der politische Körper wieder als unversehrt präsentiert werden konnte im Sinne des rituellen ,Der König ist tot! Lang lebe der König!‘. Auch in den dialektalen Propagandatexten ist diese Idee der sukzessiven Körperschaft als Signal an das Volk häufig mit simplen Mitteln umgesetzt, wie etwa

61 Sammlung von Liedern, welche bei den Feierlichkeiten zu Steyr über die Krönung zu Frankfurt Sr k. k. apostol. Majestät Franz des Zweiten gesungen wurden im Jahr 1792. Steyr, gedruckt und zu finden bei Josef Medter. f. 3r-v. - Wohl 1793 erschienene Flugschrift mit insgesamt vier Liedern, die vermutlich älteres Material von 1792 mit neuem Material verbindet, das die Reaktion auf die Feierlichkeiten bereits eingearbeitet hat. Bei Hartmann, Historische Volkslieder und Zeitgedichte II, S. 51ff. (Nr. 207-210) sind die Lieder (in normalisierter Form) mit Noten ediert.

62 Ebda., f. 10v.

$63 \mathrm{Vgl}$. - mit entsprechender Adaption für das 18. Jahrhundert - Ernst H. Kantorowics: Die zwei Körper des Königs. Eine Studie zur politischen Theologie des Mittelalters. Aus dem Amerikanischen übersetzt von Walter Theimer. Stuttgart: Klett-Cotta 1992, S. $322 \mathrm{ff}$. 
ein 10-strophiges Flugschriftlied (Gott grüß eng meine Herren allsamt wohl) kurz nach Leopolds Tod zeigt, ein seltsames Amalgam aus Tirolerlied, Scherzlied, Trauerlied und Eloge auf den neuen Herrscher Franz. Nach einführenden Strophen zur Charakterisierung des Schützen Peter Füx berichtet dieser von den Trauerfeierlichkeiten im fernen Innsbruck und drückt seine Sorge um die Nachfolge aus, wird aber rasch eines Besseren belehrt:

4

In Insprug hat der Stadt Pfarherr selbst gar, aufgmacht ein großmächtige Todtenbahr, vier Kronner habns oft aufi gstehlt, und Liechta es häts keiner zählt, oft schwarze Leut hats gebn a grosse Schaar. 6 Verzeih ma was ich sagn will meine Herrn, wann alle Rieth bei eng die Kaiser sterbn, es seynd noch kaum worden zwey Jahr, liegt Kaiser Leopold auf der Bahr, wer wird auf Lezt bey eng noch Kaiser wern. 8

O Bruder wannst ihm siehst es ist a Freud, er sieht ja unsern Kaiser Joseph gleich, und dieser neu junge Held, war mit Joseph in dem Feld, und hat den Türken sein Guraschy zeigt. ${ }^{64}$
5

Ich stund da wie a Stock hon zu gschaut wohl, und han nit gwist was das bedeuten soll, da hab ich ein Soldaten gfragt, der hat mir gleich die Wahrheit gsagt, daß gstorben ist der Kaiser Leopold. 7

Ha Narr hat meiniger Landsman zu mir gsagt, weist nit daß Treßel hat viel Kinder ghabt, und dö han [sö] so viel vermehrt, sant Prinzen unserer Liebe werth, jetzt habn wir wieder ein guten Vater griegt.

4,3 oft] dann aufi] hinauf 4,5 schwarze Leut] wohl Anspielung auf die ,Schwarzmander ' (Bronzefiguren am Prunkgrabmal Maximilians I.) 5,1 hon] habe 6,2 alle Rieth] alle Augenblicke, in kurzen Abständen 7,2 Treßel] Maria Theresia von Österreich 8,5 Guraschy] (franz. courage) Mut

Was der zweite Sprecher des Lieds als Begründung für die Herrschaftskontinuität ins Treffen führt, hat durchaus seine Berechtigung. Maria Theresias Kinderreichtum ist wohl nicht zuletzt auch eine Reaktion auf die letztendlich nur bedingt erfolgreichen Anstrengungen ihres Vaters, mit der Pragmatischen Sanktion die Thronanwärterschaft auch über subsidiäre weibliche Erbfolge zu regeln. Nach dem Tod Kaiser Karls VI. war man dementsprechend bemüht, die Rechtmäßigkeit auch bei den Untertanen zu verankern. Ein instruktives Beispiel dafür ist das folgende Lied, in dem ein ,Mann aus dem Volk' im Wirtshaus die Generationenfolge kommentiert. Die Perspektive der einfachen Leute wird schon durch den Verweis auf das bäuerliche Umfeld suggeriert, das um einen aufschlussreichen Hinweis auf die Kommunikationsbedingungen der Zeit erweitert ist: Es war offenbar nicht selbstverständlich, dass sich die Nachricht vom Tod des Kaisers über den Winter überall hin verbreitete:

64 Drey schöne neue Weltliche Lieder, Das Erste: Das Fiackerlied. Das Zweyte: Ein rechtes Theater ist die Welt. Das Dritte. Gott grüß eng meine Herrn allsammt. Gedruckt in diesem Jahr. [o. O., 1792] Erhalten hat sich der Text in einem Sammelband der Wienbibliothek mit Flugschriften, die 1804 von der kaiserlichen Zensurkommission für eine Weiterveröffentlichung überprüft wurden. An diesem Lied hatte der Beamte im Gegensatz zum vorhergehenden - verständlicherweise nichts auszusetzen. 
1

JAckerl den Winter ist traurig g'wesen, daß man sogar kein Spillmann hat g'hört, ich hab fort g'maint, es ist von wegn s'Lösen, das hat den Hauern den Weingarten gfrört, aber jetzt han is recht erfahrn, daß uns ist unser Kayser gstorbn, der ist in der Ewigkeit, hat braucht hertzhafte Leuth, im Feld zum Streit.

3

Der Kayser hat schon alls verordnet, weil er no g'west ist ä Herr in der Welt, wann er solt in den Tod erbleichen, hat er uns seine Tochter gestellt, Jackerl die thue i haubt gut kennä, beym Nahm thut mans Theresl nennä, die hat statt Traurigkeit uns bracht ä grosse Freud, zu diser Zeit.

5

Wann d'Nöstl brennt, so brennts bey Zeiten, das ist ein g'meines Sprich-Wort im Land, ja mit dem Printzen wirds ä noch gwiß gsehä, dann ich glaub schon er hat jetzt ein Verstand, er thut schon mit dem Händl deuten, man soll wieder dem Feind recht streiten, daß man den Sig erhalt, weils den klein Kind schon g'falt, ist doch nit alt.

7

Last unsern Pfarrer Laudamus singä, all Doppelhacken und Bixen schoist los, und wir wollen betten, das d'Fötz thain springä,

für unsern Printzen, biß daß er wird groß, er wird uns unser Land regieren, dann er thut Cron und Scepter führen, so singt Victoria,

unsern Rex Gloria, dancken wir ä. ${ }^{65}$
2

I wünsch ihm nix als die ewige Glori, alleweil traurig seyn thut ja kein gut, wann i stäts will in der Traurigkeit leben, krieg i mein aichl ja gar ein todts Blut, liebä wölln wir auf ihn gedenckä, und ihm ein Vatter unser schenckä, dann der Armen Gebett, wanns recht von Hertzen geht, bey GOtt gut steht.

4

D'Freud die wär schlecht ausser kemmä, wanns es GOtt nit hät anderst gemacht, man kans ja wohl bey dem leicht nemä, wann uns die Theresl kein Printzen hät bracht, in unsern Land giengs über, und über, wir hätten kriegt das zitteret Fieber, aber das ist was werth, daß uns hat GOtt erhört, ein Printzen b'schert. 6 Jackerl jetzt her i bald auf von singä, hör aber, was i von dir noch begehr, wär viel lieber, du thäst mir eins bringä, ist mir der Hals und mein Maul ja so sperr, doch heists nit alleweil trinckä und essen, sBetten das müssen wir ä nit vergessen, für die Theresia, für den klein Printzen ä, daß gsund bleim ä

1,3 fort] vorher, zunächst 1,3 s'Lösen] das Lesen, d.h. die Weinlese 1,4 Hauern] Winzern (1740 war im Wiener Raum ein sehr kalter Sommer, gefolgt von einem früh einsetzenden harten Winter, sodass es kaum Wein gab) 1,6 Kayser gstorbn] gemeint ist Kaiser Karl VI. von Österreich, der am 20. Oktober 1740 starb 2,4 mein aichl] Interjektion zum Ausdruck der Bestätigung 3,2 weil er no g'west ist] als er noch gewesen ist 3,5 haubt] überhaupt 3,6 Theresl nennä] gemeint ist Maria Theresia von Österreich 4,1 ausser] heraus 4,4 Printzen] der Thronfolger Joseph (II.), Sohn von Maria Theresia und Franz Stephan von Lothringen, kam am 13. März 1741 zur Welt 4,6 zitteret] zittrig 5,1 Wann d'Nöstl brennt, so brennts bey Zeiten], Wenn die Nessel brennt, brennt sie gleich von Beginn weg': Sprichwort, um Prädisponiertheit auszudrücken 5,3 gsehä] wohl

65 Vier schöne Neue Lieder, Das Erste: gott grüß die mein Fräntzel, etc. Das Anderte: Jackerl den Winter ists traurig gewesen, etc. Das Dritte: Ach hört wer vor der Thür, etc. Das Vierdte: O Heiliger Johann, Weltkündig ist dein Nahm, etc. Gedruckt in diesem Jahr. [o. O., 1741/42]. 
fälschlich für gschehä: geschehen 6,4 sperr] trocken, dürr, herb 7,1 Laudamus] (lat. ,wir loben') vom kirchlichen Lob- und Bittgesang Te Deum laudamus (,Dich, Gott, loben wir') 7,2 Doppelhacken] Doppelhaken: auf Rädern ruhendes kleines Geschütz Bixen] Büchse: Gewehr schoist] schießt 7,3 Fötz] Mäuler, Münder

Der Fokus des offenbar recht populären Lieds ${ }^{66}$ liegt unmissverständlich darauf, Kontinuität und Legitimität der Herrschaft als gesichert darzustellen: Der Kaiser habe noch zu Lebzeiten alles geregelt, seine Tochter habe die Herrschaft übernommen, und mit der Geburt des Thronfolgers sei auch die Nachfolge sichergestellt. ${ }^{67}$ Besonderes Gewicht wird gerade auf diese Sicherstellung der männlichen Nachfolge gelegt: Denn dass die Herrschaft auf eine Frau überging, war sowohl im Volk rechtfertigungsbedürftig als auch im internationalen Kontext - siehe Erbfolgekrieg - eine Gefahr. So konzentriert sich das Lied auf die Versicherung, dass es im Land nicht zu chaotischen Zuständen kommen werde. Eine mögliche Infragestellung der Legitimität der weiblichen Thronfolge wird bezeichnenderweise nicht erwähnt; auch die Auseinandersetzungen mit anderen europäischen Mächten klingen im Lied nur im allgemeinen Aufruf an, stets, gegen den Feind zu streiten'.

Auch die Begräbnisfeier selbst bot als zeremonieller Abschluss einer Ära die Möglichkeit, Herrschermacht demonstrativ zu inszenieren, wobei sich liturgisches und höfisches Zeremoniell bei der pompösen Prachtentfaltung gegenseitig ergänzten. Kaiserin Maria Theresia wollte ein schlichtes Begräbnis, doch Joseph hielt sich nach ihrem Tod am 29. November 1780 nicht daran, da ihm der identitätsstiftende Wert des minutiös geplanten traditionellen Staatsakts durchaus bewusst war. Drei Tage war die Verstorbene in der Hofkapelle auf einem Trauergerüst im - wie von ihr gewünscht - einfachen Kleid ausgestellt; am Abend des 3. Dezembers aber bekam das schon damals für seinen Totenkult bekannte Wien seine, schöne Leich', ein aufwändiges Bestattungszeremoniell laut Protokoll mit der faszinierten Bevölkerung als Publikum. ${ }^{68}$ Wer nicht anwesend war,

66 So wird in einer anderen Flugschrift der Zeit beim Weihnachtslied Auf auf ihr Hirten nicht verweilet (nicht dialektal) angegeben: „Im Thon: Jackerl den Winter ist traurig g’wesen“, vgl. Vier schöne neue Weihnacht Lieder. Das Erste: Geh bruder steh Fruh auf, legs etc. Das Zweyte: Schau schau was ist dann das schon mehr, etc. Das Dritte: Auf auf ihr Hirten nicht verweilet, Das Vierte: Mein was hats denn mehr gebn bey dä Nacht, etc. Gedruckt in diesem Jahr.

67 Die quasi-familiäre Beschreibung des Herrscherhauses operiert in einer nur bei Ditfurth überlieferten fünfstrophigen Variante auch wieder mit Topoi des Hirtenlieds: 3

Loßma dem Kindel a Mueßelein kocha,

Laß ihm bei Leib kai Mongel nit seyn,

Thut ihm fein wacker Semel drein brocken,

Daß es fein hübsch stille thut schweig'n.

Es thut schon mit den Handel deuta,

$\mathrm{Daß}$ man brav wider den Feind soll streita;

Hast du kai Liecht'l nit,

Daß es halt spielt domit,

Und weinet nit.

Abgedruckt in Ditfurth, Historische Volkslieder 1, S. 314f.; Quellenangabe dort: „Fl. Blatt mit ausgerißnem Titel. “ Diese Variante weicht in Strophe 3-5 von der obigen Version ab.

68 Vgl. Walter Koschatzky (Hg.): Maria Theresia und ihre Zeit. Zur 200. Wiederkehr des Todestages. Katalog zur Ausstellung 13. Mai bis 26. Oktober 1980 Wien, Schloss Schönbrunn. Salzburg/Wien: Residenz 1979, S. $201 \mathrm{ff}$. 
konnte sich über Druckschriften informieren; darunter - kaum verwunderlich - auch ein dialektaler Bauerndialog, von dem Leichgepränge', der auffälligerweise in Prosa gehalten ist. Der aus der Stadt Zurückgekehrte berichtet von seiner zufälligen Beobachtung eines Trauerzugs auf dem Weg zur Kapuzinergruft. Erst zum Ende der detaillierten Beschreibung verrät er seinem Gesprächspartner, dass es das Begräbnis der Monarchin war, über deren Tod sich beide äußerst betroffen zeigen:

Steffel. D'Leut seynd Hauffenweis eini marschirt, sogar Kinder habns aufm Arm eini tragn, aber Wagn habens nit viel eini lassen, wie i in d'Stadt bin kumma auf den großen Platz, wo sies Mehl feil haben, hab i nu vielmehr Soldaten g'seha, als vor zwey Jahren bey uns sand im Quartir glegen, ja Nachbar unser Mark war für sie glat zeng, Reuter und andere sand in allen Gassen gstanden, und haben d'Leut, wie sie sich haben wolln zubi tränga, mit der Schoißen aufi gstessen. Nacher sand a ganzi Menga geschekata Männer und Weiber, i man, sand Kinder a dabey g'west, alle bey ainer Kirchen sands aussa kumma, die neben der Pastey steht, ja Bruder, wie unsre Herrn im Palmsonntag, alle paar und paar, aber Nachbar, wie die gar sand gwest, habi so viel Pater gsehn, sie habn just so ausg'schaut, wies ofter aussa kuma, sand a zwa und zwa miteinanda ganga, habn alle schneeweiße Lichter in Händen g'habt und voraus überall an schön Herrgott, nacher sand wieder andere daher köma, die habn ausschaut, wie unser Vikari beym Predinga, Chorhemada habns anhabt und schwarze vierekete Hauben auf, just wie unser Pfarrer, mein Nachbar.

JAKEL. Das hätt i a sehn mögen.

Steffel. Is nu nit gar. Jetzt kumts erst; lauter vornehme Herrn, alle sand schwarz daher ganga, sand a viel dabey gwest mit so Barocka, wie unser Verwalter hat, endlich hab i Leut gscheha, die habn a nit schlecht auschaut, aber alli traurig sands gwest, nacher war ma bald die Zeit lang warn, vor lauter warten, endli sänd wieder Soldaten köma, und noch ima zwa kohl Rabenscharze Reitter, den ist a Wagn mit 4 Rossen nachgfahren, sand a vornehme Herrn drina g'sessen, abermal sand zwa Wagn kumma, in den sand 8 schwarze Herrn drina gwest, mehr aber Nachbar habi an langmächtinga Wagn g'sehn, 6 schwarze Rappen habna zogn, i hab g'sehen Herrn aussteigen, sand alln goldene Schlüsseln beym Taschen agnat gwest, schwarze Manner sand nacher so viel daher kumma, aber kaner hat kan Hut aufghabt.

JAKEL. Aber alle schwarz?

Stefel. Nur Zeit g'lassen Nachbar, wird als kumma, a Wagn ist still daher g'fahren, durchaus schwarz ausg'macht, daneben sand 12 saubri Knaben mit dickmächtinga Waxkerzen ganga, zwa aber a kohlschwarzi sand ohne Huit sachti beym Schlag fortg'schritt, um die hab i allerhand vornehme Herrn gsehn, sand kam recht Soldate[n] g'west, und habn do a so ausgschaut, neb'n meiner, sagt anar, es sand Hatschiern und Leibguardi, die aber auf d'Pferd sand gritten, haben Tromeln und messinge Pfeiffen voraus ghabt. Wagn sand wieder drey auf d'lezt köma, mit 6 Rossen, sand mani lauter schwarzi Grafina drina g'sessen, und Soldaten sand nachi maschirt a ganza Plunda, habn Musick g'macht, aber ganz trauri.

JAKEL. Das Ding kümt ma für, als war wer g'storben.

STEFFEL. Schon darathn, laß am voneh gar dazehln; i hab mi zubidruckt, denki i, muß da seha, was dann weita giebt, so habn's den schwarz'n Wag'n aufg'macht, und hab'n a recht schöni Trucha aussa g'höbt, mitlauta guldana Handhab'n, auf die Trucha hab'ns a Tuch aufbratt, ist glaubi a völli Silba oda Gold g'west, und an Herrgott hab'ns aufi g'stellt, ja Nachba, an recht an hibsch'n, nebst ihm aba hab'ns allahand gliezende Sacha hing'stellt, ganz guldane Hauben, mit an verguldten Zaga, Bilda hab'ns a umadum ang'hängt, hab'n just ausg'seha, wie ma sagt, es hats da Kaser im Schield, nacha ist a ganzi Mengi Präcepta köma, die hab’n alli Musi g'macht, und Nachbar, Vikari hat's geb'n, all schwarz und weis anzog'n, a ganza Hauff'n Bischof sand hinden drein kuma, gut a sechzehn, und nach ihna gar a Vornehma, s'habn g'sagt, seys der Kardinal, a mit Bischofhaub'n, und a ganzi Schaar mit ihm, hab'n alli g'stickte Klada bis auf die Knie ang'habt, von der schön Trucha sand vier guldene Schnür abi g'hengt, die hab’n recht pravi Herrn in Händen g'habt, d'Leut hab’n g'sagt, es war'n Fürst'n, neben ihna sand lauta Sau- 
bri ganga, mit Stanga, und wieder zwölf schöni Knab’l mit dicken Kerzen, nacha sand nu fünf Herrn köma von der Nuniversität mit gar schön Kladern, aba Nachha; alli von Soldat'n umrunga, wie das ist gar g'west, habi an gehn g'seha, hat ausg'schaut ganz betrübt, i ma gar der Kaser Joseph ists g'west, mit sein Bruda und Schwaga; wie ma nacha d'Leut g'sagt habn, und die lange Mant'l hab'n ihna lauta junge Herrn nachtrag'n. Den Zug aba hab'n allahand vornehme Leut b'schlossen, da i kan z'nenna waß.

JAKEL. Aba was ist dann das g'west, und wo sands hinganga?

Steffel. Aber wana muß i, wann ichs sag die Kaserin habns begrab’n zu die Kapuziner, Sie ist gar nit lang krank g’west, ja Nachba, das geht ma zu Herz'n, die g[u]iti Frau - ewig schad um Sie.

JAKEL. Ewig schad, mir ist so lad, daß ima fast d'augn aus dem Kopf wanna möcht. Aber ka Mensch hat nichts g'sagt, und lest doch unser Pfarrer und Richter alle Tag d'Zeitung, Ey, ey! ist halt die guti Frau warla tod?

STEFFEL. Ja richti, mein Schwiegasuhn hat g'sagt, er hats g'seha liegen auf a schwarzen Stiegn und um und um sand Lichter g'standen, a schöns Kreuz mit an silbern Weihkessel drey Tag lang in der Hofkapellen, ihr Herz sagta habns schon in Samstag in an silbern Böcher zum Augustinern begraben, und das Ingwad zu St. Stephan, ist alles recht vornehm g'west.

JAKEL. Hätt i das Ding g'wust, i war glei mit dir eini ganga.

StefFel. Was nutzt itzt dei Reden, z'spatt ists g'sagt, itzt wolln ma für Sie ans bethen - Aber Gott giebt Ihr g'wis den Himmel, s'hat a gern beth.

Jakel. Tröst Sie Gott! unse Kaser Joseph ist statt Ihrer, mir ist recht load um Sie, aber Sie hat gut regiert, wird schon der Suhn a so regiern, leb wohl Nachba. ${ }^{69}$

zubi tränga] hinzudrängen mit der Schoißen aufi gstessen] mit dem Gewehr zurückgestoßen geschekata] bunt, bunt gemischt i man] ich meine aussa kumma] herausgekommen Pastey] Bastei: Befestigungswerk köma] gekommen Vikari] Vikar: (Hilfs-)Pfarrer Barocka] Perücken agnat] angenäht saubri] schöne, vornehme Hatschiern] Hartschier (ital. arciere = Bogenschütze): zeremonielle Haustruppe, Hofgarde Grafina] Gräfinnen a ganza Plunda] ein großer Haufen, viele darathn] erraten voneh] vorher aussa g'höbt] herausgehoben mitlauta] mit lauter, mit ausschließlich Handhab'n] Griffen aufbratt] ausgebreitet Zaga] Zeiger Präcepta] Präceptoren: Lehrer, hier Musiker abi g'hengt] heruntergehangen wana] weinen ima] ich mir Stiegn] gemeint ist das vierstufige Trauergerüst in der Hofkapelle Augustinern] das Herz wurde am 2. Dezember in der Loretokapelle der Augustinerkirche beigesetzt Ingwad] Eingeweide (kamen in die Herzogsgruft zu St. Stephan)

Beim obligaten Verweis auf die Herrschaftskontinuität durch „Kaser Joseph“, der seine Sache gleichfalls gut machen werde, schwingt leise Skepsis mit: Auch wenn Maria Theresia wichtige Modernisierungen in die Wege geleitet hatte, blieb sie dennoch barocken Traditionen und dem konservativen Katholizismus verpflichtet. Das aufklärerische Reformprogramm ihres Sohnes aber zielte auf einen weitreichenden gesellschaftlichen Wandel. ${ }^{70}$

69 Gespräch zweyer Bauern, die sich von dem Leichengepränge Ihro k. k. Majestät Mariae Theresiae unterreden. Wien, gedruckt mit Schulzisch-Gastheimischen Schriften [1780], f. 2r-4v.

70 Vgl. Ernst Wangermann: Die Waffen der Publizität. Zum Funktionswandel der politischen Literatur unter Joseph II. Wien: Verlag für Geschichte und Politik. München: Oldenburg 2004. (Österreich Archiv) S. $30 f$. 


\section{Inszenierter Patriotismus: Herrschaftsapologien und vaterländische Stücke}

Geburten, Hochzeiten, Todesfälle und ähnliche Ereignisse aus dem Umfeld des Herrscherhauses sind regelrecht disponiert, als Impuls für Huldigungsschriften zu dienen. Der Fokus ist dabei auf die Repräsentanten des Staats gerichtet; das Volk selbst übernimmt die Rolle des berichtenden Statisten. Als Identifikationsangebote für die Abwesenden kommen typisierte Betrachtende, Mitfeiernde, Trauernde zur Sprache, die am Ende zumeist in einer Licenza ihre Treue und Liebe zum regierenden Geschlecht und/ oder zum Vaterland ausdrücken. Doch bedarf es nicht immer derart singulärer Anlässe für literarisiertes Herrscherlob. Gerade in Zeiten drohender oder auch eben erst überwundener Gefährdung für das Reich häufen sich Dichtungen, die den Blick nun auf das ,einfache Volk' wenden, das in seiner patriotischen Begeisterung und Herrschaftsloyalität ins Bild gesetzt wird. Die Identifikation des Volks mit der gesellschaftlichen Ordnung ist hier keine von oben repräsentierte Staatsidee, sondern wird als Konstituens eines gelingenden Lebens vorgeführt, in dem sich das Gottgewollte der Herrschaft spiegelt. Im Mittelpunkt dieser ,vaterländischen Dichtung', die natürlich gleichfalls als systemaffirmative Agitation zumeist gezielt von der Obrigkeit gefördert oder von Systemträgern verfasst wurde, stehen idealtypische Volksfiguren, deren moralische Integrität, Fleiß und äußere Vorzüge für die Gesundheit des ,Volkskörpers'stehen. Dialekt ist nun nur mehr sekundär ein Mittel der Komisierung, als Stigma der intellektuell Unbedarften. Nun dient er - neben sozialer und regionaler Verortung der Sprecher - vorrangig als Signal für Authentizität, Unverfälschheit, Bodenständigkeit und natürlichen Gerechtigkeitssinn.

Ein Beispiel dafür stellt das Lied Den Keisser den sein mir, recht alle verpflicht dar, ein Lobpreis auf Joseph II., der - leider ohne Noten - handschriftlich im Stubenberger ,Gesänger Buch' überliefert ist. Die betonte Aufrichtigkeit der Sprecherfigur aus dem Bauernstand sollte der Herrscherapologie mehr Glaubwürdigkeit geben, als es die Rechtfertigung eines möglicherweise mit Kalkül handelnden Gebildeten geschafft hätte - zumal der Text sich an diese ländliche Zielgruppe richtet, aus der sich wohl kritische Stimmen vernehmen ließen (siehe 4,1f.). Ihr wird der Kaiser, der das „Bauernvolkh ehrt“ (11,2), als Wohltäter vor Augen geführt, dessen Wirken „zum bösten vürs Bauern Volkh gmaeidt“ $(4,4)$ sei. Zusammen mit dem in der Handschrift vorangehenden Lied Loss, Liebä vödä, und las dä was sagn werden speziell steuerpolitische Novellierungen angesprochen, die von vielen Seiten Kritik und Widerstand erfuhren. Bereits Maria Theresia hatte 1748 ein Patent erlassen, das die Verstaatlichung der ständischen Steuerverwaltung vorsah und die allgemeine Steuerpflicht festsetzte, sodass auch Adel und Geistlichkeit für ihren Bodenbesitz abgabenpflichtig waren. Dennoch aber blieb ein deutliches Ungleichgewicht bestehen, indem die Sätze unterschiedlich geregelt waren, da zwischen höher besteuertem Rustikalbesitz, also Land, über das die Bauern verfügten, und geringer besteuertem Dominikalbesitz in den Händen der Grundherren unterschieden wurde. Zudem dienten als Grundlage selbst bekundete Fassionen bzw. Kapitalschätzungen, die freilich vielfach zu eigenen Gunsten geschönt wurden; da- 
rüber hinaus gab es regionale Unterschiede. Im Zuge der josephinischen Reformen sollte durch eine Katastralvermessung für alle ertragsfähigen Grundstücke Einheitlichkeit geschaffen werden, wobei die Ausmessung durch ortsansässige Richter und Geschworene unter Mitwirkung der Besitzer erfolgen sollte. Die neue Regulierung sah eine allgemeine, gleiche Besteuerung nach einheitlichem Satz unabhängig von Stand und Rang vor. Als Basis dienten Fläche und Güte des Grundes, woraus ein Bruttoertrag ermittelt wurde. Die Regelung, die durch das kaiserliche Patent von 20. April 1785 angeordnet wurde und mit 1. November 1789 in Kraft trat, stieß vor allem bei Adel und Geistlichkeit auf harte Kritik. ${ }^{71}$ Für die Bauern sahen die Reformen nicht nur eine Einschränkung der Steuern und Robotleistungen vor, sondern auch rechtliche Besserstellungen sowie die Aufhebung der Leibeigenschaft (wenngleich diese auch in der Geschichtsschreibung teils als Pro-forma-Bestimmung abgetan wird). Dennoch aber zeigte sich auch unter den Bauern Widerstand, denn der Bruttoertrag als Berechnungsgrundlage wurde als ungerecht empfunden, da die teils stark schwankenden Erträge naturgemäß zu Ungleichmäßigkeiten führen mussten. Aufgrund der starken Widerstände hob Leopold II. 1790 die Regulierung wieder auf. ${ }^{72}$

Die zwei Lieder zu dieser Thematik aus dem Jahr $1790^{73}$ sind einem Bauern aus dem Innviertel (das erst seit 1779 zu Oberösterreich gehörte) in den Mund gelegt, unterscheiden sich allerdings vom Tenor her. Loss, Liebä vödä, und las dä was sagn zeigt einen Bauern, der dem enormen Aufwand von Messung und Datenaufnahme skeptisch gegenübersteht und verärgert ist, zur Mithilfe als Geschworener genötigt zu sein. Erst die letzten beiden Strophen stellen den Maßnahmen letztlich ein positives Urteil aus. ${ }^{74}$ Sehr viel propagandistischer als - teils expliziter, teils suggestiver - Appell zur Würdi-

71 Zumal diese von weiteren anderen Reformpunkten betroffen waren wie Klosteraufhebungen, staatlichen Eingriffen in kirchliche Institutionen, der Verstaatlichung der Priesterausbildung, neuen Auflagen für Gottesdienste und Begräbnisse und anderen Maßnahmen, die den Klerus anbelangten sowie einer Beschneidung der Privilegien des Adels wie etwa die Abschaffung von Sondergerichten oder anderer rechtlicher Vorteile.

72 Vgl. etwa u. a. Werner Drobesch: Bodenerfassung und Bodenbewertung als Teil einer Staatsmodernisierung. Theresianische Steuerrektifikation, Josephinischer Kataster und Franziszeischer Kataster. In: Reto Furter/Anne-Lise Head-König/Luigi Lorenzetti (Hg.): Les migrations de retour. Rückwanderungen. Zürich: Chronos 2009. (Geschichte der Alpen/Histoire des Alpes/Storia delle Alpi 14) S. 165-183, hier 165169. - Gerda Lettner: Das Spannungsfeld zwischen Aufklärung und Absolutismus. Die Ära Kaunitz (17491794). Göttingen: Vandenhoeck \& Ruprecht 2016. (Forschungen zur Kirchen- und Dogmengeschichte 105) S. $128 \mathrm{ff}$.

73 Dies ergibt sich aus dem knappen Rahmen, in dem die Regelung gültig war: von 1. November 1789 bis zur Revision am 1. Mai 1790. Verknüpft man dies mit Referenzen aus den Texten, lässt sich ein relativ genauer Entstehungszeitpunkt eruieren. Zum einen berichtet der Bauer im zweiten Vers des ersten Lieds, dass die Vorgänge „seyd fert“ (also seit vergangenem Jahr) im Gang seien, vgl. Willibald Ernst: Innviertler Spuren im sogenannten Stubenberger Gesängerbuch. In: Der Bundschuh 11 (2008), S. 27-43, hier 33. Zum anderen sind die Werbung für die Maßnahmen und der Aufruf zur fallweise gefragten Kooperation nur während der Zeit, in der die Regulierung noch gültig war, denkbar und sinnvoll. Ernst macht darüber hinaus auf Strophe 20 aufmerksam. Hier sinniert der Bauer darüber, ob er im Zuge der Ausmessungsarbeiten vielleicht noch „von Paeyerland bis Pelgräd und weidä hinab“ (Bayerische Staatsbibliothek, Cod. germ. 7340, Teil 2, S. 71) komme, was ebenfalls Hinweise auf die zeitliche Einordnung gibt, da Belgrad am 8. Oktober 1789 von der habsburgischen Armee erobert wurde.

74 Vgl. Loss, Liebä vödä, und las dä was sagn, Str. 23 u. 24 (Bayerische Staatsbibliothek, Cod. germ. 7340 (Stubenberger Gesängerbuch), Teil 2, S. 70. 
gung der Reformmaßnahmen fällt das zweite Lied aus. Dass „d herschaft und d klester“ $(5,2)$ und „dö grossen Besizä“ $(5,4)$ murren, sei nachvollziehbar. Den über die Maßnahmen klagenden Bauern jedoch wird vorgeworfen, sich in ihrem Urteil gravierend zu verschätzen. Ihnen sollen die Augen für das zu ihren Gunsten ausfallende Wirken des Kaisers geöffnet werden, der ihnen endlich eine gerechte Verteilung der Steuerlast beschert und dementsprechend apotheotisch inszeniert wird:

7

Drumb käm kaeissä Josseph von himmel daher:

und sprach machts ös anders das ding geht nicht mehr, ein jeder sol stoyern ein jeder sol löbm, und nach sein vermögen, in d stadts kässä lögn, 8 glaubts nöth das i döswögn mehr ausgabm Begehr, so i bin kaeissä es bleibt wie vorher, wer wenkh hat gibt wenkhä und freud si darzue, wer mehr hat gibt mehrä, hat denät no gnue, 9

Drumb gehts meine kinder und möst fein recht aus, nembts stangen und zürkhel und kötten hinaus, ein jeder solt sich fein beim gwissen fädtiern, dä stoyä fuess lasts si nicht anders einfüehrn, 10

Was dä Kaeyssä aussprücht, wer hat ebs endtgögn, mir Baurn woln nimmä, uns is selbä dran glögn, mir wern gar zur richtern und gschwornö däwölt, wo hat sonst ä kaeissä, gley d bauern angstölt, 11

Der Titl als Richtä ist denät ebs wert, schau wie nöth der kaeisser, sein Bauernvolkh ehrt, und um dö gschwornä ist wohl kaey schlechts ding, ä $\mathrm{n}$ jedä än schwür daey ist wällä nöth gring, 12

Dös ganz ding ist mit der fätierung gethan, das jedä dö ausgab und einkünft sagt an, es trifft gmaeyne bössä ein jedä mues sagn, mit aein seiner vntroy wernd nachtbarn al gschlagn, 13

Darumb blaibt fein ä $n$ jedä in gwissen verpflicht: das er i fatieren nach der redlichkeit sprücht, sonst wär er ä schlenkhl i sag engs gley ganz, in Inviertl dromät, hies i aein än schwanz, 14

I drau auf mein kaeissä, und trau auf sein wordt, was mein ist von den nimbt mir Josseph nix fordt, und was i ka Beytragn fürn kaeissä und d stadt, das bin i ja schuldi, und dues Liebä kradt, 15

I Pste meinö Sämmä, dö wissen und Land, und möst ä Beim nachtbarn so guet als ichs fand, der kaeyssä der hat auf uns Bauernleuth Baut, drumb müessen mir zaeign das er billig uns traut, 
16

Mi freuds das dä kaeyssä auf Bauernleuth denkht,

mey Josseph du hast uns ja wärlä vil gschenkht,

dö rowolt dö straffen und schiergn Regement,

got Lob al der Teyxl hat würkhlä ein end, ${ }^{75}$

7,4 stadts kässä] Staatskasse 8,4 denät] dennoch 9,3 fädtieren] bekennen, angeben (im Sinne von ,korrekte Angaben machen') 10,1 ebs] etwas 10,3 däwölt] erwählt 11,3 kaey] kein 11,4 daey] tun 12,3 gmaeyne] Gemeine: einfache Leute, Bauern 13,3 schlenkhl] liederlicher, nachlässiger Mensch engs] es euch 13,4 dromät] oben schwanz] Schimpfwort für einen unredlichen Menschen 15,1 Pste] bestelle 15,4 billig] rechtmäßig, zu Recht 16,3 rowolt] Robot (regelmäßige an den Grundherren zu entrichtende Leistung) straffen] Strafen schiergn] Schergen, Gerichtsdiener 16,4 Teyxl] Teufel

Mit guten Wünschen für den Herrscher und Treuebezeugungen klingt das Lied aus.

Ist es hier ein vorbildlicher Einzelner, der seinen Standesgenossen ins Gewissen redet und dabei an Anständigkeit, Pflichtbewusstsein und Dankbarkeit für die obrigkeitlichen Maßnahmen appelliert, so begegnet uns in den ,vaterländischen Stücken ' der folgenden Jahre gleich eine Vielzahl solcher Vorzeigeuntertanen aus den bäuerlichen Schichten. Die Figur des moralisch integren Bauern ist freilich keine Erfindung der 1790er Jahre. Sie findet sich bereits in Joseph von Pauersbachs (1737-1802) Schauspiel Der redliche Bauer und großmüthige Jud (1774). Bemerkenswert ist hier bereits das Vorwort in dreierlei Hinsicht: erstens in der Verteidigung des ,Niedrigkomischen' als Spielmaterial der privilegierten Wiener Theater in Zeiten des (weitgehend ausgefochtenen) Hanswurststreits, ${ }^{76}$ zweitens die freimaurerisch-liberale Verteidigung des Jüdischen (die dezent an Lessings Die Juden und den - später entstandenen - Nathan erinnert) ${ }^{77}$ und drittens die vehemente Parteinahme für eine dialektale Bühnensprache, denn die Figurenrede - so Pauersbachs Forderung - müsse

dem Orte gemäß, wo die Handlung vorgeht [sein]. Sollten unsere österreichische Landleute nicht ihre Sprache dürfen hören lassen, da die Obersächsischen in Obersachsen, niedersächsische in Niedersachsen, und französische Bauern in Frankreich es dürfen? ${ }^{78}$

Pauersbachs Stück zeigt nach dem Modell des rührenden Lustspiels den redlichen Bauern Hannsmichel, der mit gefundenem Geld sein Glück gemacht hat und so viele wie möglich daran teilhaben lässt. Als er den alten Juden Moses bei einem Kutschenunglück vor dem sicheren Tod rettet, kommt es zur genretypischen Tugendprobe: Denn eben dieser hatte damals das Vermögen verloren. Hannsmichel zögert keinen Moment, sein ganzes Gut und den erwirtschafteten Gewinn dem seines Erachtens rechtmäßigen Besitzer zurückzuerstatten. Als ebenso edel erweist sich jedoch auch der Jude; indem er den eben übertragenen Gutshof umgehend Michels Tochter Lisel schenkt, ermöglicht er

75 Bayerische Staatsbibliothek, Cod. germ. 7340 (Stubenberger Gesängerbuch), Teil 2, S. $70 f$. Erstediert und kommentiert bei Ernst, Innviertler Spuren, S. $34 \mathrm{ff}$.

76 Vgl. Kapitel 8.

77 Zur Revision des klischeehaften Judenbilds auf dem Wiener Theater vgl. auch Kurz-Bernardons Die Judenhochzeit oder Bernardon der betrogene Rabiner und Die abgedankten Officiers von Gottlieb Stephanie dem Jüngeren.

78 Der redliche Bauer und großmüthige Jud. oder der glückliche Jahrtag. Ein Lustspiel in drey Aufzügen. Aufgeführt in den kais. königl. privilegirten Theaters. Mit römisch. kais. allergnädigst. Freyheit. Wien, zu finden bey dem Logenmeister. 1774, S. 1f. 
zugleich seinem Buchhalter Prückner nach einer abschließenden Anagnorisis ein glückliches Leben:

PRÜCKNER. Zu großmüthiger Freund!

Richter. D'rum sag' ich: Da wollen wir morgen gleich d'rüber; Aber den heutigen Tag soll mir, zur Ehr der ganzen Judenschaft, unser Schulmeister noch heut mit goldenen Buchstaben in mein Protokoll eintragen.

Peterl. Nein Herr Richter! Das thut er gewiß nicht, dann die Juden seynd seine ärgesten Feinde.

Schmied. Dafür laß du mich sorgen Peterl! Ich werd' dabey seyn, und mockirt er sich nur das mindeste, so schlag' ich ihm mit Gunst die fünf Finger in d'Fressen, daß ihm d'roth Suppe herabrinnen soll.

WAGNER. Und ich secundir' den Herrn G'vattern, das nämlich g'waschen soll seyn.

Michel. Nein meine Herren! Vielleicht wird er von Juden ganz anderst denken, wenn er den heutigen Vorfall hören wird. ${ }^{79}$

In der Druckfassung kommt das von Pauersbach geforderte mundartliche Sprechen nur bedingt zum Ausdruck. Doch mit dem Bauern Hannsmichel scheint der Wiener Autor eine Bühnenfigur geschaffen zu haben, die ein bestimmtes patriotisch-integres Profil abdeckte. Noch 1799 bedient sich der bedeutende Volkstheaterdichter Joachim Perinet (1763-1816) der Figur für ein relativ plattes Agitationsgedicht, das die Vaterlandsliebe und Wehrbereitschaft der österreichischen Bevölkerung während der Koalitionskriege zur Schau stellt. Es zeigt den kaisertreuen Bauern, der zur Jahrtagsfeier des ,Allgemeinen Aufgebots' von 1797, als ein Heer Freiwilliger die anrückende Armee Napoleons zurückschlagen sollte, ${ }^{80}$ mit seiner Familie in die Stadt spaziert und dabei vergangene und gegenwärtige Ereignisse kommentiert, die Franzosen verunglimpft und das Haus Habsburg idealisiert:

1

He, Rosel, auf! Leg' d'Kinder an,

Wir geh'n hinein in d'Stadt;

Geht's, tummelt's euch, was jedes kann,

Sonst kommen wir zu spat.

Heut' vor zwey Jahren war's so noth

Als käm der Antichrist -

Wißt's, daß vom Wieneraufgeboth

Heut der Geburtstag ist?

3

Die hab ich noch vom Seppel her,

Und täglich wird sie 'küßt;

Die Münz' macht mir ein' große Ehr',

Ich hab sie 'kriegt als Christ.

Da hab' ich ein' im Wasser g'fangt,

Das war ein alter Jud',

Den hab' ich noch bey'm Schopf d'erlangt -

Mein G'wissen sagt, s'war gut.

\section{2}

Du Hanns, nimm's rothe Leibel jetzt,

Wo d'Silberknöpfeln drauf,

Weib, nimm den Rock mit Bram besetzt,

Setz' d'Sonntaghauben auf.

Der Sepherl gieb das Mieder 'raus,

Was ihr die Godel g'schenkt;

Ich selber hab als Herr von Haus,

die Kaisermünz' umg'hängt.

4

Hernach hat's Nachbarn Haus gebrennt,

Das hab ich mitsalvirt:

Er hat einmahl mich ausgepfänd't,

Ich hab mich refanschirt.

Der Seppel hat von Wasser 'tropft,

Denn er war nebenbey;

Da hat er mich auf d'Achsel klopft,

Und fragt mich, wer ich sey?

79 Ebda., S. 108.

80 Vgl. Lucjan Puchalski: Imaginärer Name Österreich. Der literarische Österreichbegriff an der Wende vom 18. zum 19. Jahrhundert. Wien: Böhlau 2000. (Schriftenreihe der Österreichischen Gesellschaft zur Erforschung des 18. Jahrhunderts 8) S. 60. 
5

„Er Maistät -“ sag' ich, wascherlnaß:

„Hans Michel heiß ich halt -“

G'sagt hab ich ihm weiß nimmer was,

Laut auf g'weint hätt' ich bald.

Ihr wißt's, wie er so gnädig war,

Da hab' ich 'kriegt die Münz'.

Schaut's her! Er sieht sich gleich auf's Haar,

Ich kenn' ihn noch als Prinz.

[...]

14

Komm Hanns, da schau! Das alles hier,

Gehört jetzt mein, einst dein:

Doch nichts gehöret dir und mir,

Kommt der Franzos herein

$\mathrm{Daß}$ das nicht g'schehen ist, schau Hanns,

Hat viel g'nutzt's Aufgeboth;

Kein Roß, kein Ochs, kein Schaf, kein' Gans,

An Brod und Wein' wär' Noth.

[...]

44

Gieb uns Kuraschi, gieb uns Muth,

Den Größern gieb Verstand,

Wir geben Leben, Leib und Blut

Für unser Vaterland.

Hoch lebe unser guter Herr

Schaut's, ob's ein Bessern findt's -

Hoch sollen's leben! Sie und Er,

Und auch der kleine Prinz!
6

Vom Franzel möcht' ich noch ein Bild

Vom Wiener Aufgeboth,

Denn dort - ich bin Fuchsteufelswild!

Da lag ich auf den Tod;

Mein Knecht, Hanns Adam, der hat ein's

Von unserm jungen Herrn,

Ich alter Esel, ich hab' kein's,

Das thut mich sagrisch scheer'n.

15

Das ist dir gar ein böses G'sind,

Hat kein' Religion:

Hat Vater, Mutter g'mordt, und's Kind,

Und umgestürzt den Thron.

Sie halten gar kein Völkerrecht,

Wie unser Kaiser z'Wien,

Und heißt das Zeug wer immer schlecht,

So köpft ihn d'Gillutin.

\section{5}

Nimm Ihn und Sie hinauf, o Gott!

Recht spat in's Himmelreich,

Nimm auch das ganze Aufgeboth

Ganz Österreich zugleich.

Ja nimm hinauf das ganze Land

Du hast ja Zimmer leer,

Dann sag, und nimm mich bey der Hand:

„Hanns Michel, da komm her!“81

1,1 Leg'... an] zieh an, hilf beim Anziehen 2,6 Godel] Patin, Taufpatin 3,1 Seppel] gemeint ist Joseph II. 4,2 mitsalviert] (lat./ital. salvare) mitgerettet 5,1 wascherlnaß] durch und durch nass 6,8 sagrisch] Fluchwort zum Ausdruck der Bewunderung oder des Zornes 44,1 Kuraschi] (franz. courage) Mut

In den 1780er Jahren hatte Perinet noch zeitkritische Broschüren im Sinne der Aufklärung veröffentlicht; Texte wie die Ärgernisse bzw. Annehmlichkeiten in Wien (17861788) heben sich, so das Urteil Leslie Bodis, durch ihren spielerischen, von Wortwitzen durchtränkten, satirischen Stil hervor und stellen einen „einmaligen Höhepunkt “ 82 der josephinischen Prosa dar. Die Schärfe der Kritik weist aber auch darauf hin, dass „die ganze Reformpolitik Josephs II. für die Wiener Literaten schon in vieler Hinsicht fragwürdig geworden ist “ ${ }^{83}$, wobei das Ideal des ,aufgeklärten Bürgers' selbst satirisch gebrochen wird. 1787 hatte Perinet in einer satirischen Brieffiktion aus den XXIX Geheimen Korrespondenzen den Typus des verbitterten Bauern noch mit konkreten sozialkritischen Absichten gestaltet. Denn die Vorwürfe, die der aufgebrachte „Hanns Michel Dikkopf“ seinem Verwalter macht, werfen kein gutes Bild auf dessen Führung: Die

81 Der Bauer Hanns Michel am Jahrtage des Aufgebothes 1799 den $17^{\text {ten }}$ April. Von Joachim Perinet. Wien, 1799. Gedruckt bey I. C. Schuender im k. k. Taubstummen-Institute.

82 Leslie Bodi: Tauwetter in Wien. Zur Prosa der österreichischen Aufklärung 1781-1795. Frankfurt a. M.: Fischer 1977, S. 377.

83 Bodi, Tauwetter in Wien, S. 384. 
Untergebenen werden rücksichtslos ausgebeutet, während jener sich ein gutes Leben macht; jegliche Kritik aber wird brutal bestraft:

Gestrenger Herr!

Izt kann i nimmer länger halten, es muß alles rein heraus, was mir auf der Seele hokt, und wann mi der G'streng Herr gleich im Bok spannen ließ. Warum hat mi denn der Hr. Verwalter neuli auf den Strafesel reiten lassen, weil i mi hab verlauten lassen, daß Euer G'streng 'm Schinder sein Vetter ist, weil er uns schon gar beim lebendigen Leib schinden thut? .... Muß i deswegen auf dem Esel reiten, weil i d'Wahrheit g'sagt hab? - Das war a saubere Komoedie, wann unser einer nichts reden durft, wann uns der Verwalter mit der Scheibtruch über' d'Nasen fahrt? Izt bin i a mal g'ritten, und izt will i reden, und sollt' i mi[t] n’Wolfen reiten müssen.

Wann's der g'strenge Herr no lang a so treibt, so wird der heilige Barthelme unser Dorfpatron, und auf d' lezt müssen unsere alten Bauern, wie die klein Buben ohne Hosen 'rum lauffen?'s is ja a Spott und Schand, wie er an uns zwikt? Das will d'Herrschaft g'wiß nit hab'n, das kenn' i, aber 'n Herrn Verwalter schlaunt halt 's gute Leben, und da müssen wir'n halt schoppen, daß ihm der Bauch wachst, das is der ganze Handel!

Hohl mi der Fuchs, wann's mi wild macht's, so geh i stante pene zu der Herrschaft, und reib' ihr's unter d'Nasen, was 's für ein Katter zum Beamten hat! - Wann i mein Maul aufmach, so willi mi g'wiß recht auslarn, und den g'strengen Herrn rechtschaffen waschen.

Wann er alle Bauern will auf'm Esel reiten lassen, die ihn nicht leiden mögen, so kann er sie ein eignen B'reiter aufnehmen, der 's ihnen lernt. Komm' i nur einmal zum Herrn Grafen, i will mi g'wiß über den einfältigen Esel beschweren, denn so lang i leb, hab'n wir schon viel Verwalter g'habt, aber no niemals ein Esel. Nichts für ungut, g'strenger Herr.

Hanns Michel Dikkopf. ${ }^{84}$

Strafesel] hölzernes Gestell mit dachartigen Seitenflächen Scheibtruch] Schubkarren Wolfen reiten] sich wund reiten heilige Barthelme] dem Hl. Bartholomäus wurde der Überlieferung zufolge die Haut abgezogen schlaunt] wohlbekommen schoppen] stopfen stante pene] Verballhornung von lat. ,stante pede': stehenden Fußes, sofort auslarn] ausleeren, erleichtern

Der Bauer mag zu ungehobelt sein, sein Sprachgebahren zu erheiternd, um wirkliche Anteilnahme oder Solidarisierung bei der Leserschaft zu erreichen. Doch wird im kommentierenden Schlussabsatz deutlich, dass nicht er das eigentliche Ziel der Satire ist. Denn sein Fehler liegt nicht im durchaus legitimen Zorn, sondern im naiven Vertrauen auf die Gerechtigkeit der ,Herrschaft', das ihm letztendlich zum Verhängnis wird:

Wer ist wohl so wenig in der Welt erfahren, um glauben zu können, der Verwalter habe dem groben Bauern geantwortet? Gott bewahre! Der Flegel kam in's Loch, und nach Verlauf einiger Zeit, wußte es der gestrenge Herr so fein anzustellen, daß der abgeschäzzet wurde. Dreimal gieng der Dummkopf zu seinem Grafen, aber dreimal ward er auch, wie billig, abgewiesen: Der Verdruß und die Noth zehrten ihn allgemach ab, und er starb als Bettler: die Bauern behielten den alten Verwalter, und der Esel blieb bei der Gemeinde. ${ }^{85}$

Ob Perinets in den 1790er Jahren verfasste patriotische Gesänge und dramatische Fragmente als Abkehr von dieser Haltung oder als Weiterentwicklung unter geänderten politischen Bedingungen zu sehen sind, ist schwer zu sagen. Fest steht, dass spätestens mit den ,Jakobinerprozessen` 1794/95 (vgl. S. 228) dezidiert sozialkritische Literatur von

84 [Joachim Perinet:] XXIX Geheime Korrespondenzen. Ainsi fut accomplie cette parole de l'écriture. Et il a été mis au rang des méchans. Erste und lezte Sammlung. Wien 1787. Zu finden bei Lukas Hochenleitter, Kunst- und Buchhändler am Kohlmarkt N. 1180, S. 59 f.

85 Ebda., S. 60f. 
der Zensur nicht mehr geduldet und das Stilmittel der Ironie als geradezu gefährlich eingeordnet wurde. Auch Perinet, der inzwischen eine feste Stelle als Stückeschreiber am Leopoldstädter Theater innehatte, stellte nun seine „treue vaterländische Gesinnung " 86 vielfach unter Beweis. Schon 1792 hatte er gemeinsam mit dem Komponisten Wenzel Müller ein Singspiel mit dem bezeichnenden Titel Der Unterthanen Glück ist auch das Glück der Fürsten auf die Bühne gebracht. Das Stück ist zwar tendentiell standardsprachlich gehalten, doch findet sich eine Vielzahl dialektaler Einsprengsel bzw. ein mündlichkeitsnaher Ton, der sich - so Perinets Vorgabe - ,nach der Landmundart' richtet. Vermutlich war Perinet mit Texten wie diesen auch darauf aus, seine materielle Lage abzusichern, war er doch für seine Unfähigkeit, zu wirtschaften, bekannt. ${ }^{87}$ In Zeiten der verschärften Zensur und einer politisch wenig toleranten Stimmung ging es ihm wohl auch darum, sich öffentlich auf der, richtigen Seite' zu positionieren und damit seine Stellung nicht zu gefährden. Insgesamt reflektieren so diese heute nur mehr bedingt reizvollen Texte die Reaktion auf eine veränderte innen- und außenpolitische Situation.

Im patriotischen Lied vom Bauern „Hanns Michel“ zeigt sich vor diesem Hintergrund ein interessanter Unterschied in der Zeichnung der beiden erwähnten Herrscher, Joseph II. und Franz II. Ersterer wird als Helfer beim Löschen eines brennenden Hauses vorgestellt $(4,5 \mathrm{ff}$.) - ein typischer legendarisierender Topos, der Volksnähe mit Mut, Engagement und Anteilnahme für die Nöte seiner Untertanen verband. Im Vergleich dazu ist sein Neffe Franz deutlich distanzierter charakterisiert: Bleich und blass „aus Gall, und lauter Schmerz" $(36,8)$ grüßt er sein Volk von oben herab; am positivsten erscheint noch, dass er „Vom Seppel was [hat]“ $(36,5)$. Bemerkenswert ist auch die Stelle, an der der Bauer dem Kaiser seine Kinder gewissermaßen , als Opfer' anbietet: „Ich bring ihn selbst, darfst ihn nicht hohl'n, / Dein ist der Hannsel ganz“ (38,7f.). Dass diese Geste dem Kaiser einen geradezu monströsen Anstrich eines Kindsräubers gibt, kann angesichts des bedingungslos obrigkeitstreuen Tenors des Lieds wohl nicht als beabsichtigt angenommen werden, weist aber dennoch im Vergleich mit dem ,hemdsärmeligen' Auftritt, den Joseph II. in dem Lied bekommt, auf eine andere Wahrnehmung des Herrschers hin und erscheint fast wie ein etwas wehmütiger Verweis auf geänderte, schwerere Zeiten.

Eine ähnliche Entwicklung vom aufgeklärten Zeitkritiker zum Systempropagandisten lässt sich auch beim wohl meistgelesenen josephinistischen Unterhaltungsschrift-

86 Puchalski, Imaginärer Name Österreich, S. 224. In Texten wie Die Stimme der Bürger Oesterreichs bey ihrem freywilligen Opfer (1793), Oesterreich über Alles. Eine kleine vaterländische Szene mit Chören (1796), Marschlied für die Freywilligen des Wieneraufgebothes auf der Wieden am siebzehnten April 1798 (1798), Der Sieg über die Franzosen. Ein patriotischer Volksgesang (1799) oder Oesterreichs Ehrentag am siebzehnten April als 2-ten Jahresfeyer des allgemeinen Wieneraufgebothes (1799) findet man „die üblichen Motive, Ideale und Schlagworte des österreichischen Aufgebot-Patriotismus aus der Zeit der Koalitionskriege“ (ebda.).

87 Vgl. Jennyfer Großauer-Zöbinger: Joachim Perinet (1763-1816). In: „Mäzene des Kasperls“ - Online-Edition von 27 Komödientexten und Studie [2008/9], http://lithes.uni-graz.at/maezene-pdfs/bio_perinet.pdf (letzter Zugriff am 12.05.2018), S. 5ff. 
steller beobachten, Joseph Richter (1749-1813). Der ungemein produktive Wiener Autor hatte mit seinen Briefen eines Eipeldauers ein Periodikum geschaffen, das trotz aller satirischer Verzerrung einen unvergleichlichen Einblick ins Alltagsleben der österreichischen Residenzstadt gewährt (vgl. Kapitel 4, S. 329). Das Markenzeichen dieser Briefe war eine stilisierte, für die Lesegewohnheiten eines nicht nur regionalen Publikums entschärfte Mundart. In ganz ähnlicher Weise ist auch sein Gespräch über den Frieden (1795) gehalten, eine Wirtshauskonversation zweier Wiener Handwerkermeister mit einem alten Bürger und einem Kutscher über die jüngsten politischen Ereignisse. Eben erst hat sich Preußen im Frieden von Basel aus dem Ersten Koalitionskrieg verabschiedet und die beiden Handwerker Kneipp und Wetz erhoffen sich dadurch ein Ende des Kriegs und einen wirtschaftlichen Aufschwung. Doch der Bürger bremst die Erwartungen; denn auf Vertragspartner wie Frankreich, wo die Regierung jederzeit wieder gestürzt werden kann, und Preußen, das seine eigenen Interessen im Reich verfolgt, könne kein Verlass sein. Mit dem besonnenen Fiaker bekommt schließlich die Stimme der von oben verordneten politischen Vernunft das Wort:

Kutscher. Ich hab den Herrn zughört; aber ich glaub, d'Herrn habn den rechten Fleck nicht gtroffen - Ich bin einmal durch ein dreyßig Jahrl ein Fiaker gwesen, und wenn ich so über Land gfahrn bin, so habn meine Leut immer gsagt: du Schwager schmeiß uns nicht um - Ey! sorgn Sie sich nicht, hab ich gsagt, Roß und Wagn ghört ja mir zu, und wenn d'Glässer zerschlagen würden, oder der Wagn zerbrechen sollt, so gings ja aus mein Beutl; und da bin ich kein Narr - - und da habn sich d'Herrn und Fraun kuraschirt in mein Wagn eingsetzt, und habn sich ruhig fortführn lassen - - Und, (nehmen S' mir 's Gleichniß nur nicht übel) so meine Herrn, glaub ich, solln 's auch wir braven Unterthanen machen, und solln uns halt ruhig und getrost auf die verlassen, die 's Ruder vom Staat in der Hand führn. Der Wagn ghört ja ihnen zu, und da werden s' gwiß dafür sorgn, daß s' nicht umschmeissen. Ich weiß nicht, ob von Frieden was dran ist, oder nicht: aber wenn s' ein machen, so glaub ich gwiß, daß er zu unserm Besten seyn wird; denn ein guter Hausvater kann ja nur immer 's Beste für seine Kinder wolln. ${ }^{88}$

Schwager] (auch) Bezeichnung für Kutscher

Es war ein deutliches Signal an die bürgerliche Öffentlichkeit, das hier Richter als treuer Diener seines Herrn (der später für seine Dienste auch 30 Gulden Monatspension aus dem geheimen Polizeifonds bezog) ${ }^{89}$ publizistisch setzte. Den Untertanen stand es nicht zu, die Entscheidungen der Regierung in Frage zu stellen, denn - so der ,Burgersmann ' „Es ist wirklich ein Narrheit, wenn wir gmeinen Leut über Ding räsonnirn wolln, die wir nicht einsehn können. “90 Gefragt war kein eigenständiges politisches Bewusstsein, sondern ein kindlich naiver Glaube an die Obrigkeit; die Möglichkeit der Mitbestimmung des Volks sollte erst gar nicht erwogen werden. So endet die kleine Szene mit einem

88 [Joseph Richter:] Gespräch über den Frieden. Deutschland [recte Wien] 1795, S. 12ff.

89 Vgl. Hans Viktor Pisk: Joseph Richter 1749-1813. Versuch einer Biographie und Bibliographie. Wien 1926 [Diss.], S. 37f.

90 Richter, Gespräch über den Frieden, S. 15. 
Hochruf auf den ,Landesvater“ „und mit ihm auf alle braven Unterthanen, die auf Gott und ihren Regenten vertraun!“91

Beinahe noch aufdringlicher ist die patriotische Indoktrinierung in den ,vaterländischen' Stücken, die zur selben Zeit entstanden und in der Idealisierung von Herrschaft und Untertanentum ein unter allen Umständen zu beschützendes Gemeinsames konstruierten. Besonders instruktiv in dieser Hinsicht ist Wenzel Blimas ,Original-Provinzstück' Das Land ob der Enns (1795), das am deutlichsten von seinen Singspielen das dialektale Sprechen auch in die gedruckte Fassung übernimmt. Eigentliches Zentrum dieses vor allem kulturhistorisch bemerkenswerten Dramas ist der oberösterreichische Umgebungsraum selbst, das ,Landl' mit seiner unvergleichlichen Landschaft, Bevölkerung, seinen Sitten und Bräuchen, das auf recht plakative Weise ins allerbeste Licht gesetzt werden soll. Hauptverantwortlich ist dafür der Schiffschreiber Gregori, der als rustikaler Sympathieträger die karge Handlung vorantreibt, die nur eine schnell geklärte Intrige aufzuweisen hat und mit einem Hochzeitsfurioso (fünf Paare finden sich) und einem Landes- und Herrscherlob an der Triumphpforte endet. Positive Figuren sind entweder aus Oberösterreich oder finden hier einen neuen Lebensmittelpunkt, problematischere Rollen wie die Pflegersfrau Klara oder der Friseur Jaques genesen am landlerischen Wesen oder kommen erst gar nicht auf die Bühne wie der Aufklärer Pöchfackel, dessen negativer Charakter sich schon darin zeigt, dass er den Bauern ihre Landessprache abgewöhnen möchte. Denn diese ist in Blimas Lustspiel ein Signum unverfälschter Bodenständigkeit und Sittlichkeit im rousseauschen Sinn und wird in vielen Szenen durchaus wirkungsvoll und humorvoll präsentiert, so etwa, wenn die Wirtstochter Baberl den Schiffsknecht Jodel weckt:

BABERL. (geht auf das Gestad $z$ u, und ruft in das Schiff hinein) Jodl! - Jodl!

JAQues. Par bleu! das ist ein schönes Mädchen!

BABERL. Jodl! - Jodl!

JAQUES. ( $z$ u Johann) Sehen Sie doch das Mädchen an, das ist ein bildschönes Kind.

JoHANN. Nun mich freut es, daß Ihnen doch endlich einmal in diesem Lande etwas auffällt, was für Sie einen Reiz haben kann.

BABERL. Jodl! Liegst auf ain Loser, und hast di mit dem andern zudeckt, daß du mi nit hörst?

JAQUES. Mein schönes Kind! ich will Ihnen den Jodl aus dem Schiff heraus hollen, und ihn munter machen, wenn er schläft.

BABERL. Hats nöt vonnöthen. Is a gar g'fahrli bey ihm nahet z'stehn, wenn er munter wird. Er wird gar wunderli munter. Jodl!

Jodu. (Hebt sich langsam im Schiff in die Höhe, ranzet sich mit der einen Hand, während er sich mit der andern an der Schiffhüte anhält)

BABERL. So! - Hab di guet, Ranzeter! daß du nöt umi fallst. - Ha mein! hast mi denn gar nöt g'hört, wie oft i dir schon g'ruffen hab?

JoDL. Was wollts denn?

BABERL. Iß der Naufährter nöt da?

JodL. Wird leicht drin im Wirthshaus seyn.

BaberL. Na, bey uns drin iß er nöt, drum such i ihn ja. Wo muß ihn denn der Hansl wieder hingeführt haben?

JoDL. Waß a nöt, wo er umer greilt.

91 Ebda., S. 16. 
[BABERL. ] Er soll zum Schöffschreiber eini kumma. Er muß aufs Schiff ain armen Uebersiedler mitnehma mit sein Weib und fünf Kindern, die mein Vada g'wandt, und ihnen a ein Geldl geben hat, daß nach Ungarn reisen können. ${ }^{92}$

Par bleu] (franz., Ausruf des Erstaunens) Donnerwetter! Loser] Ohr ranzet] rekelt, streckt sich Hab di] halte dich Ranzeter] einer, der sich rekelt Naufährter] Schiffsführer bei der Fahrt flussabwärts Waß] weiß umer greilt] herumkriecht, sich herumtreibt eini kumma] hineinkommen

Verweise auf die Mildtätigkeit und Offenherzigkeit der ,Landler' wie dieser finden sich zuhauf, mehr noch: Das Stück entfaltet regelrecht ein Panoptikum der Redlichkeit. Alle hier sind ,brav', wie Georgi nicht müde wird zu betonen, der Lehrer ebenso wie der Pfarrer, die Doktoren und Bader ebenso wie die Arbeiterschicht. Dieser, vor allem den Schiffleuten an der Donau, ist der erste Akt gewidmet. Alle autochthonen Figuren bedienen sich einer vergleichsweise realitätsnahen oberösterreichischen Mundart, der nun auch im Kontext dialektaler Literatur bislang ungewohnte Eigenschaften wie Schlagfertigkeit oder rhetorische Überlegenheit zukommen. Im zweiten Akt wird der Blick auf die nicht minder redliche Beamtenschaft gelenkt, wie schon Namen wie Ehrlieb und Biedermann signalisieren. Ihr einziges Streben ist das Wohl des Landes wie seines Volks - und damit die Umsetzung der Vorgaben des grundgütigen Kaisers. Eigennutz, Korruption oder selbst Nepotismus sind ihnen völlig fremd. Der dritte Akt schließlich endet mit einer standesübergreifenden, auch von Landesfremden angestimmten Eloge auf Oberösterreich, das als pars pro toto für das Habsburgerreich zu verstehen ist:

Knaudenthall. Oberösterreich, und alle Stände und Bewohner desselben verdienen allerdings dieses Lob, und diese Ehre.

ElLRICH. Die Bestättigung der vortreflichen Eigenschaften, die die Stände und Bewohner dieses Landes nicht minder, als das Land selbst haben, ist aus dem Munde dessen, der vom Monarchen diesem Landes vorgesetzt ist, gewiß die sicherste, und für jeden Oberennser die erfreulichste Bestättigung.

Gregori. Derjenige, den das nöt freun soll, der müßt entweder wie a Senkelholz seyn, daß in ainer unsrigen Schwemm z'lang gelegen is, und kain Glut mehr gibt; oder wann er für sein eigenes Vaterland nit gutgsinnt seyn könnt, so wär er nöt mehr werth, als daß ihn, und von allen denjenigen, die uns Landlern nöt gut seyn wollten, ain nach den andern ain unsriger Gamsgeyer in d'Höh hebet, und in Traunfall eini schmiß; dann zum davon tragen in ain andres Land wärs nöt, weil man a ain andres Land kaini bösen Leut wünschen muß. I weis aber, alle rufen mit Freuden: Gott, der Kaiser, und unsre Obrigkeiten sollen an uns immer bravi Oberösterreicher findn. Juhe! es braucht weiter nix, d'Landler seyn brav. ${ }^{93}$

Senkelholz] langes gerundetes Bauholz, Pfahl Schwemm] Schwemme, abgegrenzter Flachwasserbereich Landlern] Einwohner des ,Landls', Oberösterreicher Gamsgeyer] Bartgeier (größter Greifvogel Europas) Traunfall] 12 Meter hoher und 200 Meter langer Wasserfall an der Traun zwischen Steyrermühl und Roitham

Eine derart forcierte Idyllisierung hin zu paradiesischen Zuständen muss das Publikum schon zur Zeit der Entstehung irritiert haben und lässt sich nur im damaligen Bedrohungskontext als chauvinistisches Signal verstehen, das die Verteidigungsbereitschaft

92 [Wenzel Blima:] Das Land ob der Enns. Ein Provinzialstück in drey Aufzügen. Allen Ständen und Bewohnern dieses Landes gewidmet. Linz, [o.V.] 1795, S. 19 f.

93 Ebda., S. 120. 
und den Glauben in die politische Führung stärken sollte. Nach der Linzer Uraufführung (13. Dezember 1795) kam das ,Provinzialstück ${ }^{`}$ - auch bedingt durch die weiteren politischen Entwicklungen - nur mehr selten auf die Bühne.

Ein intentional ähnliches patriotisches Stück widmet 1799 Gottlieb Wetzinger, später Theater-Inspektor am Ständischen Theater in Graz, „Allen braven Steyermärkern“ “94. Der edelmüthige Obersteyrer oder: Hinter den Bergen wohnen auch Leute! ist gleichfalls nach dem simplen Muster der Commedia commovente gestrickt, die mit einer Anhäufung an Tugendbeweisen idealtypisches Menschsein vorexerziert. Die Handlung, die „sich großen Theils auf eine wahre Begebenheit“ ${ }^{95}$ gründet, ist mehr oder weniger auf eine Amtsstunde des menschenliebenden Verwalters Bauernfreund beschränkt, in der ein Liebespaar die Einwilligung des Brautvaters bekommt, zwei Bauern vor dem Bankrott gerettet werden und ein verarmter Offizier ein neues Zuhause findet, jeweils durch moralisch herausragenden Verzicht auf den persönlichen Vorteil. Auch wenn die Rollentexte stark am Standard orientiert sind, macht eine Vorbemerkung im Druck die tatsächliche sprachliche Realisierung unmissverständlich klar: „Außer dem Verwalter, dem Schreiber, und dem Fremden reden alle Personen in Steyerischem Provinzial-Dialecte; so wie sie auch alle in Steyerischer Bauerntracht gekleidet sind. “96 Allzu viele Aufführungen wird aber wohl auch diese dramatische Kleinigkeit nicht erlebt haben.

\section{Brüchige Ordnung: Protest- und Revolutionsgesänge/Wildschützen- und Räuberlieder}

Enkomiastische Dichtung ist keine Literatur, die man lange suchen müsste. Sich für die bestehende Herrschaft zu deklarieren erfordert keinen besonderen Mut, verspricht Förderung und Drucklegungsmöglichkeiten; die künstlerischen Erzeugnisse werden von den Besungenen in der Regel gewürdigt und in Bibliotheken und Archiven aufbewahrt. Dichtung aber, in denen Untertanen sich gegen ihre Herrschaft auflehnen, ihre Entscheidungen oder sogar ihre Legitimität in Frage stellen, bleibt nur selten der Nachwelt erhalten. Kaum ein Verleger geht das Risiko ein, solche Texte zu drucken; findet sich doch ein Drucker für diese gefährliche Tat, bleiben die Schriften zumeist bloß als corpora delicti in den Akten erhalten. Die eigentlichen Adressaten hüteten sich, das belastende Material in den eigenen vier Wänden aufzubewahren, lernten es auswendig und gaben es, nachdem die Quelle wohl vernichtet worden war, mündlich weiter. Meistens aber war diese Dichtung ohnehin nie für den Druck vorgesehen, sondern sollte von Mund zu Ohr weitergetragen werden und so ihre subversive Wirkung entfalten. Diese bewusste Mündlichkeit, die dezidiert orale Konzeption systemkritischer Literatur legt eine beson-

94 [Gottlieb Wetzinger:] Der edelmüthige Obersteyrer oder: Hinter den Bergen wohnen auch Leute! Eine dramatische Kleinigkeit in einem Aufzuge. Grätz, [o.V.] 1799, S. 2.

95 Ebda., S. 3.

96 Ebda., S. 4. 
dere Affinität sowohl zu dialektalen Formen als auch zur musikalischen Gestaltung als Trägermedium nahe. Es ist demnach nicht überaschend, dass nicht wenige der erhaltenen herrschaftsunterminierenden Texte Mundartlieder sind, die sich üblicherweise nur handschriftlich erhalten haben.

Nur aus einer Abschrift für die berühmte ,Sonnleithner-Sammlung' des ,Volksgesangs in den österreichischen Ländern' sind uns die aufmüpfigen Verse des Thomas Hirschbichler, Bauer am Millinggut in Leogang, bekannt, die er etwa in den 1760er Jahren verfasste. ${ }^{97}$ Als einer der wenigen Dialektautoren aus der bildungsfernen Unterschicht, der uns namentlich bekannt ist, überrascht Hirschbichler mit recht unverhohlener Herrschaftskritik, die er allerdings geschickt in eine Kartenspielmetaphorik verpackt. Indem er die einzelnen Abbildungen auf den Karten vom ,Sechser ' bis zur ,Sau' (dem As) bespricht, erlaubt er sich bissige Anmerkungen u. a. gegen König (wohl Joseph II.) und Kaiserin Maria Theresia, die in gedruckter Form sicherlich keine Zensurstelle passiert hätten. Ein Aufruf zum Widerstand findet sich noch nicht; doch macht der Schlussvers klar, dass das Volk selbst Schuld an seiner Lage trägt, da es nichts gegen die Unterdrückung unternimmt.

1

Gott grüß enk beysammen, ihr Herrn und ihr Fraun!

Erlaubt mir ein wenig, die Kart zu durchschaun:

Der Sechser, der Siebner, die send dumme Leut, sö mögnt iehn nix gwinga als was ma iehn geit.

2

Der Achter und Neuner - versteh i die Gmain:

Der Zehner muß Kreutz tragn, die Herrn habnt kains.

Seind 23 Augen - i habs schon durchschaut:

Der langrockát Unter stichts alls mit ain Aug.

3

Aft kommt halt der Ober - á gnädiger Herr,

hat auf á Párocká und gilt schon viel mehr.

Er greift um die Lappen und bhalt s Geld alloan,

er geit nix dem König und strigelt die Gmoan.

4

Oft manicher Bauer wár gscheider als d Herrn,

hat á lichte Augen und siehts recht von Fern;

muß $\mathrm{d}$ augen zuedrucken, darf sagen kain Wort -

sie werden verworfen wie die blinde Kart.

5

Aft kommt denn der König - der höchste im Land,

wann er nit das Spiel gwinnt, so wärs iehm á Schand.

Und hamts iehm koan gworfen, so sticht ihn schon d Sau:

Ja, ja, á so gehts - gilt oft mehrer die Frau.

97 Der Einsender vermerkt 1819, es soll „,vor 50-60 Jahren gedichtet worden seyn“ (zitiert nach der Abbildung in Gerlinde Haid/Thomas Hochradner: Volksmusik in Salzburg. Lieder und Tänze um 1800 aus der Sonnleithner-Sammlung der Gesellschaft der Musikfreunde in Wien mit einem Beitrag von Sabine Veits-Falk und Alfred Stefan Weiß und unter Mitarbeit von Walter Deutsch und Annemarie Gschwantler. Hg. vom Salzburger Volksliedwerk. Wien/Köln/Weimar: Böhlau 2000. (Corpus Musicae Popularis Austriacae 12) S. 218; der dort im biographischen Teil präsentierte Thomas Hirschbichler kann also nicht identisch sein mit dem Autor). 
6

Sö thoant nit lang trachten, sö thoant wenig studirn,

sö mögen gleich schaffen - gehn lieber spatzirn;

und wos sollten strafen, sends selber dábey:

Drum darf má wohl sagn, daß nur gilt d Sauerey.

7

I mags nit dásingen, i mags nit verzähln, glei was jetzt die Herren für á Händl thoant spieln.

Der gmoan Mann muß leiden, is weiter koan Gspoas:

Was s Hándl thoant treibn, dáß der König nix woás.

8

Thiets enks nit $\mathrm{z}$ hárt nehmá, und leidts mit Geduld,

ein jedá kann denká, wir habns wohl verschuldt.

Und schau in dein Busen, so wirst du finden:

Wir thoan uns die Ruthen wohl selber binden. Ende. ${ }^{98}$

1,4 geit] gibt 2,1 Gmain] (bäuerliche) Gemeinschaft, gemeine Leute 3,1 Aft] dann 3,4 strigelt] (eig. mit einem Striegel, einem groben Metallkamm, reinigend durchbürsten) behandelt grob 7,2 thoant] tun

Ein weiteres Beispiel für diese selten überlieferten Lieder ,von unten', also eines wohl tatsächlich in der bäuerlichen Unterschicht entstandenen Protestlieds aus dem 18. Jahrhundert, ist das Weegmacherliedt (1772) aus einer Einzelhandschrift. Die metrisch und stilistisch unbeholfene Dichtung eines unbekannten, wohl auch ungebildeten Autors, der sich möglicherweise hinter dem Kürzel „M. ST. H.“ verbirgt, wendet sich gegen die aufgezwungenen Straßeninstandsetzungsarbeiten, die von den Bauern als Robot oder zur Mautableistung eingefordert wurden. In der oben zitierten Antwort Des Ulri Oestäreichäs von 1744 wurden die Zwangsarbeiten noch als vergleichsweise unproblematischer und letztendlich lohnender Frondienst thematisiert; hier aber bekommt man ein weitaus realistischeres Bild der Willkür und Unterdrückung. Ort der Handlung ist das oberösterreichische (Bad) Hall im Traunviertel, wie aus den angeführten Namen zweifelsfrei zu schließen ist. Als Teil der Hofmarch der landesfürstlichen Herrschaft Steyr unterstand Hall ursprünglich unmittelbar den habsburgischen Landesfürsten, die dem Markt umfangreiche Privilegien der Selbstverwaltung, der Abhaltung von Jahrund Wochenmärkten und des Mautrechts verliehen, die in den folgenden Jahrhunderten erbittert verteidigt wurden. ${ }^{99}$ Eines dieser Rechte war die Zwangsverpflichtung zu Hand- und Spanndiensten für die Erhaltung der Haller Infrastruktur, die bei den umliegenden Bauern selbstredend auf wenig Gegenliebe stieß. Schlimmer noch aber als der unbezahlte Dienst selbst, der bei den ständig durch Witterung, Abwässer und Befahrung belasteten Schotterstraßen unumgänglich war und als Mautersatz verrechnet wurde, schien das überhebliche und rücksichtslose Verhalten der bezahlten Aufpasser und Vorarbeiter. Dementsprechend ergeht sich der Sprecher des Lieds nach der Klage über die Plackerei in Gewaltfantasien gegen die Aufpasser, zunächst lediglich als private Initiative (Str. 6), dann aber als Aufforderung an seine Leidensgenossen:

98 Ebda., S. 218 f.

99 Vgl. Annemarie Schmölzer: Die Handwerkersiedlung Hall. Vorläufer des heutigen Bad Hall. In: Oberösterreichische Heimatblätter 38 (1984), H. 3, S. 271-285. 
1

$\mathrm{Zu}$ Hall ist jezt ainer, stelts weegmacher an, ist mayn ich der sch. Bachmayer, mir kennen in schon, mues halt der tremblhayder ins den Bauren ansagn, vnd mues halt ein Jeder ins weegmacher fahren. 2

Geht nicht der B: tremblhayder da her alß wüe ä Bockh, wüe schwingt er seyn Jöppel, wüe schaut er so grob, Braucht weiter kain fragn, ins weeg macher muest fahrn vnd viervnd zwainzg mahl mus ein Jeder Baur fahrn. 3 Vnd kömmt Man auf Hall, da hats Ein schrankh baum, da sperrens gleich auf, Es da blickhend ain kaum, will ainer durch Raisßen vnd gibt weitter nichts, so thains Jn gleich fragen wos ä schittführer ist. 4 Da Mueß mann gleich dran, mit Roß vnd mit man, ä drey tag must schittführn hast weitter nichts zlohn, wann ainer vill hat, bald fasten bald grabm die narren werden zahlt vnd thain d leuth ä so Plagn. 5 Mueß sich ainer Plagen Beym Mostfigrament, Ich will ein mahl rasten, waß Brennen mich d händ, mueß alle weill grabm, därff mich dannoch nicht klagn, sönst thätens mich gleich ybern Bugel herschlagn. 6 Vnd thuet er mich schlagn, so will ich ains wagn, vnd schlag in hoffer thamerl eini in grabm, da würd er gleich wüsßen vnd Röhrn wüe ä Stier, du magst nih mer auer, es hilft nichts dafür. 7 Jst nicht der Brunhaußer Ein grober flegl, man nihmt kain waichs holz zu Ein scheitter schlögel, daß wär halt sein freud wann er hät z'komendirn vnd möchte d strasßmacher Brigeln, mögn sich ehe nicht mehr Rührn.

8

Jezt habm mir halts weegmacher auch schon Beym Bschlus, wüe wars halt vnd wann Man $\mathrm{n}$ drembelhayder däschusß, in hoffer thamerl thain mir auf Henckhä, vnd in Bach mayr lasßen mir halt wider Rennen.

1,1 Hall] alter oberösterreichischer Markt stelts weegmacher an] stellt das Wegmachen an': ist für den Wegebau verantwortlich 1,2 sch.] scheiß (als abwertendes Epitheton) Bachmayer] in den Matriken vielfach nachweisbarer Name in Hall mir] wir 1,3 tremblhayder] Tremblhaider, seit zumindest 1644 nachweisbare Familie in Hall 1,4 ins weegmacher] zum Wegmachen 2,1 B:] wohl Abkürzung für ,bschissne, beschissene 2,2 Jöppel] Jacke 3,1 schrankh baum] Schlagbaum, Schranke 3,2 Es da blickhend ain kaum] kaum dass sie einen erblicken 3,4 schittführer] Schuttfahrer, Schottertransporteur 4,2 schittführn] Schutt, Schotter fahren 4,4 thain] tun ä so] verstärktes so 5,1 Beym Mostfigrament] Fluch 5,4 Bugel] Rücken 6,2 thamerl] Kurzform für Thomas 6,4 auer] heraus 7,2 scheitter schlögel] schwerer Holzhammer zum Holzspalten 8,2 däschusß] erschösse 8,3 auf Henckhä] aufhängen, aufhenken

Nicht mit physischer Gewalt, sondern mit metaphysischer Strafe droht Maurus Lindemayr in seinem polemischen Zeitkommentar Von dem Kay oder Nebeln (1783), das ein seltenes Naturphänomen als Symbol der allgemeinen prekären Lage deutet. 1783 hat- 
ten hartnäckige trockene Nebel die Sommermonate hindurch das europäische Wetter bestimmt und zu massiven Gesundheitsbeeinträchtigungen und Missernten geführt. ${ }^{100}$ Der zunächst unbekannte Grund war die verheerende Laki-Spalten-Eruption auf Island, die am 8. Juni begonnen hatte und deren klimatische Auswirkungen weltweit zu spüren waren. Etwa $12-15 \mathrm{~km}^{3}$ Lava ergossen sich aus über 130 Kratern im Laufe der nächsten Monate, in bis zu 1400m hohen Fontänen. Dabei wurden geschätzte 122 Millionen Tonnen Schwefeldioxid als giftige Aerosolwolke in der Stratosphäre freigesetzt. In weiten Teilen Europas lagerte sich in kurzer Zeit etwa eine Tonne Schwefelsäure pro Quadratkilometer in Form eines beißenden trockenen Nebels ab - mit fatalen Konsequenzen für Mensch und Natur. ${ }^{101}$

Lindemayr setzt in seinem Lied das natürliche Phänomen eines rätselhaften bedrohlichen Nebels in Beziehung zu den aktuellen Reformen Josephs II., die in paradoxer Umkehrung ihrer ,aufklärenden' Intention nur das Licht der Wahrheit vernebeln würden. Tatsächlich setzten die Eingriffe in Kultus, Priesterbildung und Pfarrgliederung das klösterliche Organisationsmodell zu dieser Zeit massiv unter Druck. Für Kaiser Joseph war der Staat Verwalter der weltlichen Güter der Kirche; dementsprechend erließ er Gesetze, die das Vermögen aller kirchlichen Institutionen in der Monarchie in einem sogenannten Religionsfonds zusammenfasste, aus dem die Ausgaben für den praktischen Gottesdienst bestritten werden sollten. Am meisten zu holen gab es bei den Klöstern, die ihm als Bastionen des Konservatismus und religiösen Aberglaubens ohnehin ein Dorn im Auge waren. Letztlich wurden beinahe zwei Drittel der etwa 900 Klöster der Habsburgermonarchie in diesen Jahren aufgehoben. Offiziell aufbegehren konnten die Orden in dieser Zeit nur bedingt; wer sich zu negativ über die Reformen artikulierte, musste damit rechnen, dass er die Aufhebung seines Klosters damit nur beschleunigte. Auch Lindemayr war durch Dekrete gezwungen, die Vorgaben der Regierung in seinen Predigten bei seinen Schäfchen im guten Licht darzustellen. Seine Dialektdichtung aber gab ihm die Möglichkeit zur Agitation. Denn konzeptionell mündlich und prinzipiell anonym entzogen sich seine ,Bauernlieder ${ }^{c}$ der Zensur, sie appellierten an ein Gemeinschaftsgefühl, konnten durch die musikalische Umsetzung schnell weitergegeben und zur Camouflage verbotener Ideen genutzt werden. So deutet das bäuerliche Rollen-Ich die seltsame Wettererscheinung als böses Omen und zwingende Gottesstrafe für die Auswüchse des aufklärerischen Zeitgeists. Explizit angesprochen werden dabei Eckpunkte der josephinischen Reformpolitik wie die Duldung des protestantischen

100 Vgl. u. a. Manfred Vasold: Die Eruptionen des Laki von 1783/84. Ein Beitrag zur deutschen Klimageschichte. In: Naturwissenschaftliche Rundschau 57 (2004), H. 11, S. 602-608. - Rüdiger Glaser: Klimageschichte Mitteleuropas. 1000 Jahre Wetter, Klima, Katastrophen. Darmstadt: Primus 2001.

101 Allein in Island soll ein Fünftel der Bevölkerung in direkter und weiterer Folge des Ausbruchs zu Tode gekommen sein und auch für andere europäische Länder nimmt man drastisch erhöhte Sterbequoten an. Besonders auffällig waren in den ersten Sommerwochen das kupferfarbene Licht einer Sonne, in die man mit freiem Auge blicken konnte, und spektakuläre Sonnenauf- und -untergänge. Die Trübung der Sonneneinstrahlung durch den aerosolhaltigen sog. ,Höhenrauch führte zu einer merkbaren globalen Abkühlung und bedingte einen der kältesten und schneereichsten Winter, seit es entsprechende Aufzeichnungen gibt. Damit nicht genug: Die Schneeschmelze im folgenden Frühjahr führte in Europa zu gewaltigen Überschwemmungen. 
Glaubens (Toleranzpatent 1781), die Klosteraufhebungen (ab 1782), die Aufhebung und Vermögenskonfiskation des Dritten Ordens (1782), die Ehegesetzgebung (Ehepatent 1783), die Abschaffung des Ablasses, das Wallfahrts- und Prozessionsverbot oder die Beschneidung der Pfarrereinkünfte. Das sei der eigentliche Nebel, der dort auftritt, wo man ,aufzuklären' vorgibt und sich abwendet von Rom:

11

Wie schauts so artlä her

Die Kirchen, d' Klöster wern izt plündert

Dö Gotts Dienst d' Feirtäg halbntheil gmindert

Mä laßt schier Gott kein Ehr

In Pabsten wöllns in allen truzen

Und d Geistlichkeit wie 'n Buxbaum stuzen,

Ja ja so mueß wohl nebli wern

Wann mä ä so alls auf will klärn.

13

Wie haizt mä 'n Pfarrern zu?

d' Stolln lassens mehr als halbs akemmä

Izt wöllns ien d' Gründ und d Wiesen nehmä

Ain Kapellan, ain Kuh;

Thäns prödign, müssens Nebel stüren

Sinst thuet mä's glei klain kritisiren

I möcht bei derä Nöblerei

Kain Pfarrä sein bei meiner Treu.

15

Dö Abläß habn än End

Den ganzen Schatz von dritten Orden

Dö grossen Fähn mit goldän Borten

Hat alls dä Nöbel brennt.

Verstohlnäweis derfst endli bethen

Sinst thuet mä dä ä Straf annöthen,

Wallfahrten gehn, d Prozession

Hat alls dä Toifels Kay väthan.
12

Wer hat denn das dälaubt,

Kässärnä aus 'n Klöstern zmachä

Und das mä raubt die gstiften Sachä

Ja d Geistling selbm ausstaubt?

Was raunzen nöt, wie d' Turteltäubeln

Die aussägsprengten Klosterweibeln?

Wie wirds erst d Kapuziner schern

Wanns müssen Hosenscheisser wern.

14

Woher kimt denn dö Gwalt?

Daß d' Weltling Kirchähandl schlichten

Sogar die Ehverspröchä znichten

Ists Sprichwort nöt uralt?

's Väspröchä soll mä 〈heili〉 halten

Izt will mä nix mehr hörn von alten

Izt nihmt mä si um alls schier an

Was eh dä Pabst allein hat than.

16

Was wird Denn endli draus?

Gott wird schon no in d' Nebel stritten

Dö Kirhä thain so graußlä zrütten

Er macht gwiß no staubaus;

d' Sun wird schon no dö Nebeln tauhä

Was gilts auf d Lezt kimts annäs auä

Dö Nöbelmachä müssen no

Wärns no so aufklärt all ins Lo. ${ }^{102}$

11,1 artlä] seltsam, sonderbar 11,3 Gotts Dienst ... gmindert] die josephinische Reform des Gottesdiensts sah eine erhebliche Reduktion der Feierlichkeiten vor 11,5 truzen] die Stirn bieten, Widerstand leisten 12,1 dälaubt] erlaubt 12,4 ausstaubt] verjagt 12,5 raunzen] jammern, klagen 12,6 aussägsprengten] herausgesprengten, vertriebenen 12,8 Hosenscheisser] heimatlos gewordene Mönche mussten sich, kamen sie nicht anderweitig unter, in das Zivilleben (und in die Zivilkleidung) fügen 13,2 Stolln] Pl. zu Stole: Gebühr bzw. Vergütung für erbrachte kirchliche Handlungen lassens ... akemmä] schaffen sie ... ab 13,5 stüren] stochern, herumstöbern 14,3 znichten] ungültig machen 15,2 dritten Orden] Dritter Orden: entstanden aus Laienbewegungen, die sich aus religiösen und organisatorischen Gründen einem Männerorden (Erster Orden) bzw. Frauenorden (Zweiter Orden) anschlossen 15,6 annöthen] aufzwingen, aufnötigen 15,8 Kay] Nebel 16,2 stritten] stochern, bekämpfen 16,3 zrütten] in Unordnung bringen, verwüsten 16,4 staubaus] Kehraus 16,5 tauhä] (weg-)schieben, (ver-)drängen 16,8 Lo] Loch

Rascher und anders als Lindemayr es sich wohl gedacht hatte, kamen die radikalen österreichischen Aufklärer ein Jahrzehnt später tatsächlich in große Schwierigkeiten, zum Teil ,ins Lo' oder sogar an den Galgen. Denn trotz wiederholter Appelle, die liberalen Leitlinien der leopoldinischen Politik beizubehalten, machte die konservative

102 Lindemayr, Dialektlieder I, S. 80-82. 
Regierung unter Kaiser Franz II. keinerlei Zugeständnisse an die demokratischen Entwicklungen in der Habsburgermonarchie, ganz im Gegenteil: Mit der Re-Installierung der Polizeihofstelle unter Johann Anton Graf Pergen, die ihren Schwerpunkt nicht auf öffentliche, sondern auf die geheimen ,Pflichten legte, entstand ein Klima der Überwachung und Unterdrückung, dessen erklärtes Ziel es war, die Verbreitung revolutionären Gedankenguts zu unterbinden. ${ }^{103}$ In Frankreich war inzwischen die zweite Phase der Revolution angebrochen, mit einer Radikalisierung als Antwort auf die inneren und äußeren gegenrevolutionären Bedrohungen. In Österreich reagierte man mit frankophober Propaganda, vor allem gegen die Jakobiner gemünzt, die sich der Unterstützung des einfachen Volks sicher sein konnten. Auch im Habsburgerreich fürchtete man, dass sich Arbeiter und Kleinbürger auf die Seite der antimonarchistischen politischen Linken schlugen, die eine Lösung der sozialen Fragen versprach. Gezielt wurden deshalb von der Regierung auch dialektale Rollenlieder gegen den Jakobinismus eingesetzt, die aus der angeblichen Perspektive des ,kleinen Mannes` das Zeitgeschehen kommentierten und den politischen Gegner wenig kunstvoll, aber effektiv diffamierten. Im Lied eines Würstelbuben gegen die Jakobiner etwa wurde vordergründig das Schema des Kaufrufs (vgl. Kap.4) aufgegriffen, um antijakobinische Agitation zu lancieren:

1

Gehts! Kaufts mir meine Wuerstel ab, Hessa, Wißts ja, daß ich die besten hab, Tralla, Seynd warm und recht saftig gmacht; Ein Jakobiner, ders veracht. Tralla, Tralla, Tralla. $[\ldots]$

\section{7}

Gehoern wir gleich zur mindern Klaß, Hessa, Seynd doch kein Jakobiner Gfraß, Tralla,

Wir schaemten uns zu leben auch

Nach Jakobiner Sittenbrauch.

Tralla, Tralla, Tralla. ${ }^{104}$

Durch die Inhaftierung französischer Emigranten, den erschwerten Bezug ausländischer Zeitungen und die verstärkte polizeiliche Überwachung öffentlicher Räume wurden oppositionelle Bewegungen sukzessive in den Untergrund gedrängt. So traf man sich in kleinen Gruppen in Privatwohnungen und versuchte das weitere Vorgehen zu organisieren, Aktivitäten abzustimmen. Aber auch die Gegner schliefen nicht. 1793 wurde ein Maßnahmenpaket beschlossen, das revolutionäre Tendenzen im Keim ersticken sollte: keine geheimen Zusammenkünfte mehr, Verbot aller pro-revolutionären Schriften oder Schriften, die demokratische Ideen propagierten und der Monarchie damit gefährlich werden könnten, die Anwerbung von Lohnschreibern für die gezielte literarische Ver-

103 Zum historischen Kontext vgl. Alfred Körner: Die Wiener Jakobiner. [Mit einem Abdruck von:] „Homo hominibus“ (Franz Hebenstreit), übers. und komm. von Franz-Josef Schuh. Stuttgart: Metzler 1972. (Deutsche revolutionäre Demokraten III) - Helmut Reinalter (Hg.): Jakobiner in Mitteleuropa. Innsbruck: Inn 1977. - Bodi, Tauwetter in Wien. - Walter Grab: Ein Volk muß seine Freiheit selbst erobern. Zur Geschichte der deutschen Jakobiner. Frankfurt a. M./Olten/Wien: Büchergilde Gutenberg 1984. - Gerda Lettner/Gilda Pasetzky: Revolutionärer Patriotismus und Friedensforderungen in der Musik des ausgehenden 18. Jahrhunderts. Haydn, Paul Wranitzky, Hebenstreit und Horix: Das historisch-musikalische Umfeld der ,Schöpfung (1793-1800). In: Francia 30/2 (2003), S. 45-71. - Wangermann, Die Waffen der Publizität.

104 Zitiert nach Emil Karl Blümml: Historische Lieder aus Oberösterreich. In: Heimatgaue 1 (1919/20), S. 261-275, hier 265 . 
unglimpfung der Revolution und für systemaffirmative Agitation sowie die Aufspürung der verbotenen Hausdruckereien.

Die Demokraten mussten deshalb eigene Strategien entwickeln, ihre Ideen unters Volk zu bringen. Da es kaum noch Druckmöglichkeiten gab, legte man den Fokus auf mündliche Weitergabe und handschriftliche Vervielfältigung; dementsprechend prägnant sollten die Aufrufe und das politische Informationsmaterial auch formuliert sein. Gerne orientierte man sich dabei an bekannten Textsorten, etwa am Frage-AntwortSchema des Katechismus, das jetzt für politische Grundbekenntnisse genutzt wurde, man fingierte Gebete mit antikirchlichem, antiaristokratischem, aufrührerischem Inhalt oder man dichtete Lieder auf bekannte Melodien bzw. dichtete bekannte Lieder um. So wissen wir etwa von einer revolutionären Fassung des äußerst beliebten dialektalen Kohlbauernbualieds, das ein Pfarrer umstürzlerisch umgedichtet haben soll. ${ }^{105}$ Solche leicht auswendiglernbaren Lieder auf bekannte Melodien garantierten eine schnelle, unauffällige Verbreitung und schützten zu einem gewissen Grad vor Verfolgung, da man nichts Schriftliches in der Hand hatte. Ironischerweise sind uns deshalb diese brisanten Texte, wenn überhaupt, zumeist nur als Abschriften in Prozessakten und Zensurdokumenten überliefert - so auch das radikalste österreichische Revolutionslied des 18. Jahrhunderts, das sogenannte ,Eipeldauerlied', in den Gerichtsdokumenten auch ,Hauerlied genannt. $^{106}$

Das Lied, das in seiner dialektalen Gestaltung offenbar Assoziationen mit Richters populärster Kunstfigur und deren meinungsbildenden Einfluss evozieren wollte, versuchte die weitverbreitete Unzufriedenheit der Arbeiterunterschichten für das Umsturzprogramm der bürgerlichen Intellektuellen zu nützen. Im Fokus der Anklage stehen die

105 Vgl. Körner, Die Wiener Jakobiner, S. 13. Die revolutionäre Umdichtung hat sich aus naheliegenden Gründen nicht erhalten; aber auch die unpolitische Fassung ist derzeit interessanterweise nur in einem späten, sicher nicht in Wien entstandenen Flugschriftdruck überliefert, wo das Bairisch-Österreichische mit anderen Dialekteinflüssen kontaminiert ist:

1

Bin i a schöner Kohlbauern Bua he ra sa,

a schöner Kohlbauern Bua, he ra sa,

Heu und Stroh hobmer gnoug,

bin i nit a schöner Kohlbauern Bua, Kohlbauer Bua.

2

Hob i nit schöini Schöila an, das stait rar,

sind nit schöini Schnella dron, he ra sa,

Heu und Stroh hobmer gnoug,

bin i nit a schöner Kohlbauern Bua, Kohlbauern Bua. [... ]

Die bescheidene Überlieferungslage des sehr sangbaren Lieds verwundert, erwähnt Sonnleithner es doch in seiner Hafner-Gesamtausgabe als Beispiel für eines der allgemein bekannten, von den Liederfrauen verbreiteten Lieder, das - wie „ey, du schwarz Mauserl““ - deutlich älter sein soll als „a Schüsserl und a Rein'l“ (siehe Kap. 7, S. 522). Vgl. Philipp Hafner: Gesammelte Schriften. Mit einer Vorrede und Anmerkungen, vorzüglich über die Oesterreichische Mundart. [Hg. von Joseph Sonnleithner]. 3. Bd. Wien: Baptist Wallishausser 1812, S. 111.

106 Vgl. Walter Grab/Uwe Friesel: Noch ist Deutschland nicht verloren. Eine historisch-politische Analyse unterdrückter Freiheitslyrik von der Französischen Revolution bis zur Reichsgründung. München: Hanser 1970, S. 44-46. - Hans Werner Engels: Lieder und Gedichte deutscher Jakobiner. Mit einem Vorwort von Walter Grab. Stuttgart: Metzler 1971, S. 127f. - Grab, Ein Volk muß seine Freiheit selbst erobern, S. $401-427$. 
privilegierten Stände, die das Volk unterjochen und in ihrer ,Hoffart ${ }^{`}$ die revolutionären Franzosen bekämpfen. Ihnen solle es gleich ergehen wie dem verkommenen Faulpelz Ludwig XVI., der wie die russische Zarin die Rechte des einfachen Volkes massiv beschnitten habe. Das Volk aber hätte auch hierzulande die Macht, würde es sich nicht die Gängelung gefallen lassen. Auch der Kaiser persönlich wird als unmündiges Kind diffamiert, das mit dem Adel gemeinsame Sache macht; das Schicksal des Franzosenkönigs könnte demnach auch ihm drohen. Wer die eigentliche Zielgruppe des Lieds ist, wird in der elften Strophe klar: Lastenträger, Schiffleute und Bergmänner, Holzfäller und Kohlenbrenner, Handwerker und Bauern - also der produktive Teil der Bevölkerung, ohne den die Wirtschaft zusammenbrechen würde und der verachtet und von der Bürokratie an der kurzen Leine gehalten wird. Für diese Abhängigkeitsverhältnisse gebe es nur eine radikale Lösung - die Beseitigung der Regierung und ihrer Getreuen mit Gewalt. Kaum wo findet sich im 18. Jahrhundert ein ähnlich unmissverständlicher, in Verse gefasster Aufruf zur Gewalt an den Oberen.

Das ,Eipeldauerlied‘ entstand im Umfeld eines Wiener Intellektuellenkreises, der enttäuscht vom repressiven Regierungsstil Franz’ II. - mit der Französischen Revolution sympathisierte. $\mathrm{Zu}$ diesem Kreis um den Magistratsrat und früheren Lehrer des Kaisers, Andreas von Riedel, zählten auch namhafte Autoren wie Aloys Blumauer oder Joseph Franz Ratschky. Hauptverfasser des Lieds war der Offizier und Ideologe der Wiener Jakobiner, Franz Hebenstreit (1747-1795), der mit seiner Dichtung die überwiegend analphabetischen unteren Volksschichten ansprechen wollte. ${ }^{107}$ Noch ehe es jedoch Breitenwirkung erreichen konnte, wurden die Wiener Jakobiner verraten und unter dem Vorwurf, eine Revolution zu planen, festgenommen. ${ }^{108}$ In den langwierigen Verhören, die vor allem auf die Frage abzielten, wie verbreitet das Lied bereits war, gestand der Lemberger Polizeikommissar Franz Xaver von Troll, die radikalen Strophen 2 und 3 hinzugedichtet zu haben. Hier nun eine vollständige Fassung, die dem Offizier und Kriegsgerichtsaktuar Kajetan Gilowsky bei seinem Verhör vorgelegt wurde:

1

Was denkts enk denn, daß gar so schreyts

Und alles auf d' Franzosen.

Den Linel haben s köpft - Ja nu mi freut 's, Er war schlecht bis in d' Hosen.

3

Drum fort mit ihm zur Guillotin

Denn Blut für Blut muß fließen,

Hätt man nur a hier so a Maschin,

Müßt's mancher Groskopf büssen.
2

Heut hat ern Volk ain Eyd geschworn, Morg'n hat ern wieder brochen,

D' Freyheit war ihm 'n Augen ain Dorn 'S Volk wollt er unterjochen.

4

Schauts nur die Russisch Kathel an,

Die enk itzt ist so heilig

Hat's nit den Kaiser ihren Mann

abg'setzt und g'mordt abscheulig.

107 Vgl. Alfred Körner: Franz Hebenstreit (1747-1795). Biographie und Versuch einer Deutung. In: Jahrbuch des Vereines für Geschichte der Stadt Wien 30/31 (1974/75), S. 39-62. - Alexander Emanuely: Ausgang: Franz Hebenstreit (1747-1795). Schattenrisse der Wiener Demokrat*innen 1794. Weitra: Verlag der Provinz 2009.

108 Vgl. Grab, Ein Volk muß seine Freiheit selbst erobern, S. 424f. 
5

Wann's Volk anmal ahm nimmer mag

So muss er stille sitzen;

Sonst trift ihn halt der rechte Schlag

Wenn er muß's Blut verspritzen.

7

Schauts enker Kaiser Kind nur an

Mit'n Adel thut ers halten,

Der Ludwig hat 's halt a so than

Drum haben's $n$ ja nit ghalten.

9

Welch manches gutes Mutterkind

Hat elend sterben müssen,

Weil enker Franz von Hoffarth blind,

Will, daß d' Franzosen büssen.

11

Enk, das haßt enk, die er nicht kennt,

Enk Trager, Schifleut, Hauer,

Den, der's Holz hackt, der d' Kohlen brennt,

Den Handwerksg'sellen, den Bauer;

13

Wer nur an wenig ain Titel hat,

Und heißt er nur ain Schreiber

Der zerrt enk schon beym Kettendraht

Als wie ain Bärentreiber.
6

Sie 's ja 's ganz Volk kein Arschpapier

Und darf auf sich wohl denken;

Wer halt nit lernen will Manier

Den Limmel muss man hänken.

8

Was than's denn all die Herren groß,

Die ös so hoch thut's heben;

Da sitzen's halt beim Weiberschooß

Und spielen mit enkern Leben.

10

Was gengen ihn denn d' Franzosen an

Dort hat er nichts zu kehren,

Wär er lieber hier ein rechter Mann

Und hielt enk fein in Ehren.

12

Denn sagt's mir's, ist im ganzen Land

Wer z' finden, der was macht,

Wenn er nit ist mit enk verwandt

Und nit mit enk veracht.

14

Drum schlagts d' Hund'sleut alle todt,

Nit langsam wie d' Franzosen,

Sonst machens enk no tausend Noth

$S^{\prime}$ ist nimmer auf Sie z' losen. ${ }^{109}$

1,1 enk] euch 1,3 Linel] fauler, träger Mensch (auch Kurzform für Leonhard und Wendelin) 3,3 a] auch 4,1 Russisch Kathel] Zarin Katharina die Große 5,1 ahm] einen 7,1 enker] euer 8,2 ös] ihr 10,1 gengen] gehen 11,1 haßt] heißt 11,2 Hauer] Bergleute 14,4 losen] hören, gehorchen

Die besondere Gefährlichkeit des Lieds aus Sicht der Obrigkeit beruhte auf zweierlei: zum einen auf der dialektalen Gestaltung, die ein anti-offiziöses Gemeinschaftsgefühl der Unterschichten suggerierte und Dinge beim Namen nannte, die nie den Weg in den Druck geschafft hätten; zum anderen auf seiner Simplizität, die es ideal zum Auswendiglernen und mündlich Verbreiten macht. Gesungen wurde es, wie andere Spottlieder auch, die sich rasch verbreiten sollten, auf eine bekannte Melodie, die nicht explizit überliefert ist. ${ }^{110}$ Riedel gab im Zuge seiner Verhöre an, dass die Verschwörer bei ihren Zusammentreffen oftmals zur eigenen Unterhaltung bekannte Lieder umgedichtet oder gänzlich neu getextet und mit Klavierbegleitung durch Hohenwart gesungen hatten. ${ }^{111}$

109 Österreichisches Staatsarchiv, Vertrauliche Akten 5, f. 737f. Die ersten Editionen des Lieds bei Grab und Engels greifen zum Teil stark normalisierend in den Text ein, nehmen dialektale Merkmale zurück oder ersetzen sie und kombinieren die verschiedenen Varianten.

110 In der Sekundärliteratur wird zuweilen Hebenstreit als Komponist genannt. Das ist wenig glaubhaft, denn in der Gruppe der Verschwörer gab es etliche andere, die eine deutlich engere Beziehung zur Musik hatten als der Platzoberleutnant - Georg Ruschitschka etwa oder der Student Stanislaus Leopold Graf Hohenwart. Offensichtlich war die erste Verteidigungsstrategie bei den Verhören zur Verfasserschaft des Lieds, dass man einen Hauptmann Beck, der wenige Monate zuvor verstorben war und somit nicht mehr dafür belangt werden konnte, als Textdichter angab. Hebenstreit habe nur die Musik hinzugefügt. Damit aber war mit hoher Wahrscheinlichkeit nicht die Komposition einer eigenen Melodie gemeint, sondern die kontrafaktorische Verwendung einer bekannten Singweise.

111 Vgl. Österreichisches Staatsarchiv, Vertrauliche Akten 9, f. 454f. 


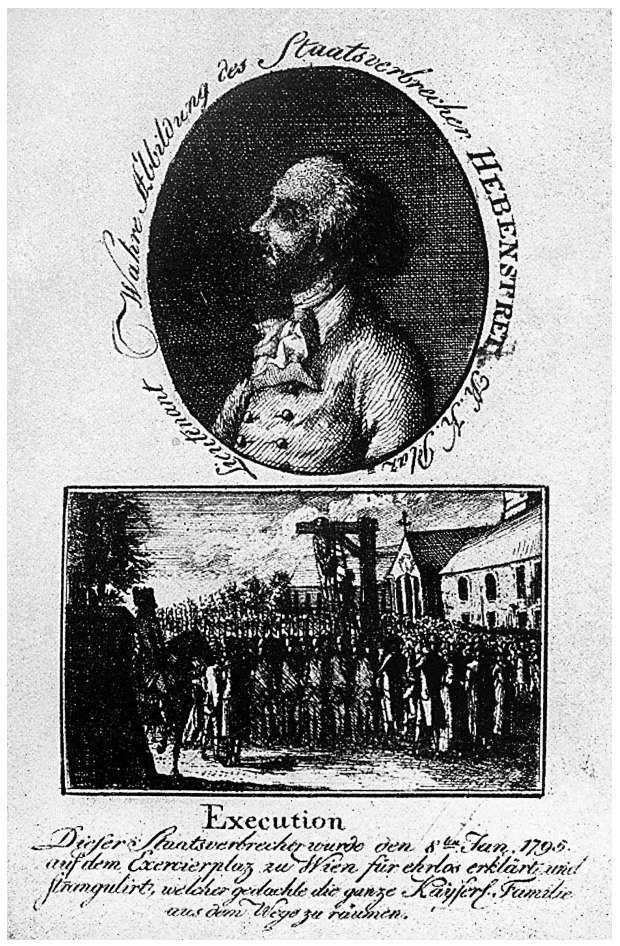

Abb. 20: Flugblatt zur Exekution Franz Hebenstreits (Österr. Nationalbibliothek, Bildarchiv und Grafiksammlung, LW 75464-B).

Die wichtigste Melodie wird in den Prozessakten namentlich genannt: das im Frankreich der Revolutionszeit hochbeliebte, bis heute populäre Marlbrough s'en va-t-en guerre. Auch in Österreich wurde es in unzähligen Kontexten wiederverwertet. So schrieb etwa der spätere jakobinische Mitverschwörer Blumauer 1789 sein Siegeslied auf die Eroberung von Belgrad auf eben diese Singweise. Auch das Eipeldauerlied fügt sich nahtlos in sie ein.

Wie das Lied, das zu den aufrührerischsten seiner Zeit im deutschen Sprachgebiet zählt, tatsächlich in der Öffentlichkeit aufgenommen wurde, lässt sich nur schwer rekonstruieren. Zwar traf es die Stimmung großer Teile der Bevölkerung und soll weite Verbreitung erfahren haben. Doch schon die johlenden Volksmassen bei der Hinrichtung Hebenstreits - der einzige, über den nach dem Militärrecht das Todesurteil ausgesprochen werden konnte - machten deutlich, dass die Wiener Bevölkerung radikalen Gesinnungen und der Aufklärungsbewegung überhaupt höchst reserviert gegenüber stand. Der Staat nahm in der Folge die Jakobiner-Verschwörung zum Anlass für eine strikte Überwachung von Presse, Vereinsleben und Unterricht; die seit den 1780er Jahren blühende gesellschaftskritische Literatur, die auf die Stilmittel der Ironie und Satire setzte, wurde weitgehend unterbunden. Im ,Eipeldauerlied' versuchte die intellektuelle Speerspitze der Habsburgermonarchie gezielt die Arbeiterschicht zu einem gewaltsamen Umsturz aufzuwiegeln; die Bauernschaft - wie es die (wohl ohnehin nicht originale) Benennung vermuten ließe - ist dagegen nicht konkret angesprochen. Riedel hatte be- 
zeichnenderweise bei seinen Verhören zu Protokoll gegeben, dass „derjenige, der es wagen wollte, wider Monarch und Geistlichkeit mit einigem Nachdrucke anhaltend zu predigen, Gefahr laufe[], wo nicht erschlagen, so doch wenigstens mit Gewalt aus dem Dorfe verjagt zu werden“" ${ }^{112}$. Die bäuerliche Aggression wandte sich eher gegen die ,Unterbeamten', die die obrigkeitlichen Befehle zu exekutieren hatten (und nicht selten ihren eigenen Profit suchten). Jakobiner waren im Bauernstand jedoch selten zu finden. Einen hatte Pergens Polizeiapparat zumindest im Verdacht: den etwa 23-jährigen Bauernsohn Johann Pöllinger, Verfasser des Agitationslieds Jetzt nihm ich mein Schaz bei ihrer Hand, das in mehreren, teils fragmentarischen Abschriften in den Polizeiakten überliefert ist und vor allem in Wirtshäusern in der Gegend von St. Lorenzen im Paltental verbreitet wurde. ${ }^{113}$ Pöllinger, „insgemein Lampelgruberhansel“, gab im Verhör an, dass er mit dem Lied, das er „ganz alleinig gedichtet“ hatte, nur konkrete Klagen und aufrührerische Reden der Bauern in Reime gesetzt habe, nach dem Vorbild von Lieber Bruder geh mit mir eines gewissen „Stauchner Simmerl“ ${ }^{114}$. Sein ästhetisch wenig ansprechendes, an traditionelle Bauernklagen anschließendes Produkt lästert ziemlich willkürlich über die ebenso unbarmherzige wie unfähige Herrschaft, das Soldatenunwesen, die Frondienste und die Unzuverlässigkeit der Behörden; im zweiten Teil des Lieds weicht das Lamento immer mehr der offenen Drohung, zunächst metaphysischer, dann aber brachialer Art:

9

Das Geld, daß wird enk Brennen schon,

In der Höll dort werts schon kriegen den Lohn,

Den Himml derfts enk ä so nit hofn,

ös Stet enk so schon, das Höllthor ofn.

10

Beim Welt abmessn, ists ä ä so gwest,

Habts bräf gsträpäziert, jezt is als Umsist,

In die höchstn Baumer hams müssn Schäp aufstekn,

Dort hat ayr könn recht Reu und Laid erwekn.

11

Habn sich müssen begebn, in die gröstn Gfahrn,

Habn müssn ihr Leib, und Leben wagn

Balt das von selben bekom habn ä Rue

Aft habns widä müssn; zum Krieg bräf däzue.

12

Den Krieg, den hat zwar Gott eingesezt,

Aber wer ist dran Ursach, als ihr gewest,

Ihr habt die guten Werk alle abbracht,

Drum hat jezt Gott uns mit den Krieg gestraft.

112 Körner, Die Wiener Jakobiner, S. 121f.

113 Vgl. Österreichisches Staatsarchiv, Vertrauliche Akten 31, f. 623-646, f. 810f. Pöllinger gibt bei seinem Verhör am 3. November 1798 an, „Zwey oder 23 Jahr“ alt zu sein, und stammt aus der „Pfaar St. Lorenzen“ vom Lamplgrubergut, Sonnberg ob Bärndorf gebürtig, vulgo Lampelgruberhansel. Körner sieht die Herkunft Pöllingers fälschlich in Kärnten, vgl. Körner, Die Wiener Jakobiner, S. 51.

114 Österreichisches Staatsarchiv, Vertrauliche Akten 31, f. 601r bzw. Vertrauliche Akten 31, f. 604v. Das Lied des Simon Stauchner selbst moniert die (vor allem josephinischen) Reformen der kirchlichen Feste und Gebräuche, könnte also deutlich früher entstanden sein. Pöllinger hat es spätestens 1795 gehört und formuliert seine abschließenden Anklagen deutlich drastischer. 
13

Von Krieg habt ihr noch nichts empfunden davon,

Habts überal enkern doppelten Lohn,

Habts ä wenig ä Schreibn, ä zwo ä drey Zeil,

aft müssn die Bauern, gley zam in Kanzley.

14

Aft haists halt glei, soltn Kriegssteuer gebn,

Und allerhand ausgabn, wieder dänem,

O Herrn I kenn enkry Falschheiten schon,

Der Kayser der kriegt kain Kreuzer darvon.

15

Das ist für enk Herrn, ä weider nicht schen,

Das dUnköstn müssn Bauern ausstehn,

Müssn Traid und Geld stöln, viel Blut verschwizn,

Und ihr mögts allweil, bei der Tafl sizn.

16

Und wans ä so nit wird balt än End nehm,

Und so muß halt die Rebelion entstehn,

Miterweil mus als Rebelisch wern,

Aft wird halt dä Krieg, über enk meine Herrn.

17

Aft wird enk sHar steign, gen Berg krehn auf

än thail Stech mä enk ab, än thail Henkn mä auf,

Aft wird enker guts Leben, aimal än End nehmä,

Und daß wird enk wohl ä ä mal Selzam für kemä.

18

I Wünsch enk von Herzn, ihr meine Herrn

Und wans nur gley balt Rebellisch dät wern,

Wans schon ä mal Rengt, scheind glei widä Sun,

I schau enk grad an, und steh enk kain um. ${ }^{115}$

9,3 enk] euch 10,1 Welt abmessn] unter Joseph II. wurde für eine einheitliche Besteuerung Grund und Boden der Monarchie vermessen und eingeteilt (josephinischer Kataster); die derart erstellte Steuer- und Urbarialregulierung wurde jedoch nach einem halben Jahr Gültigkeit von Leopold II. wieder abgeschafft ä ä so] auch so 10,2 Umsist] umsonst 10,3 Schäp aufstekn] (Pl. zu) Schaub: Strohbündel zur Markierung der Vermessungspunkte auf den Baumwipfeln aufstecken 11,3 Balt] sobald 11,4 Aft] dann, da 13,2 enkern] euern 13,4 zam] zusammen 14,2 dänem] daneben, dazu 15,3 Traid] Getreide stöln] (zur Verfügung) stellen 17, 1 krehn] gerade 17,2 än thail] den einen Teil mä] wir 17,4 ä ä mal] auch einmal Selzam für kemä] seltsam vorkommen Rengt] regnet 18,4 I schau enk grad] Pöllinger gibt bei seinem Verhör an, er habe - entgegen der ihm vorgelegten Fassung - , I boit enk schon' gedichtet steh enk kain um] mache für keinen von euch Platz, fürchte mich nicht vor euch, vor einer Konfrontation

Auch wenn dieses sozialkritische Lied in Zusammenhang mit den österreichischen Jakobinern ediert wurde, ${ }^{116}$ scheint doch der Unterschied in der Vorstellungswelt beträchtlich zu sein: Das bäuerliche Rollen-Ich nimmt zwar in den letzten Strophen die radikalen Parolen der Revolution auf, doch scheinen die Gewaltszenarien eher in der Nachfolge früherer Bauernrevolten gegen die unmittelbare Obrigkeit zu stehen als in

115 Österreichisches Staatsarchiv, Vertrauliche Akten 31, f. 643r-644v. Erstmals abgedruckt wurde das Lied mit etlichen sinnentstellenden Verlesungen und vielen, zumeist normierenden Eingriffen in Körner, Die Wiener Jakobiner, S. 51f. nach der letztgereihten der acht Fassungen (Vertrauliche Akten 31, f. 810r ff.), die Pöllinger zur Identifizierung und Unterschrift vorgelegt wurde.

116 Vgl. ebda. 
Zusammenhang mit der aufgeklärt-radikaldemokratischen Gedankenwelt der Wiener Jakobiner, die von Freiheit, Gleichheit und Brüderlichkeit aller und der Installation eines neuen Gesellschaftssystems träumten. Aber wie beim ,Eipeldauerlied'sah man die eigentliche Gefahr in der raschen Verbreitung durch die Einfachheit und Sangbarkeit des Lieds. Was mit dessen Autor, der im Verhör geduzt wurde und sich durchaus kooperativ zeigte, passierte, konnte bislang nicht in Erfahrung gebracht werden. Vermutlich büßte er seine dichterischen Versuche, die er „,vor eine Kurzweil“ ${ }^{117}$ und ohne dezidiert politische Hintergedanken unternommen haben will, wie Hebenstreits Mitkämpfer mit schwerer Kerkerhaft.

Ähnlich strenge Strafen hatte auch eine im alpenländischen Raum vielfach besungene und dabei mythisierte und romantisierte Gruppe von Gesetzesbrechern zu erwarten: die Wilderer. Allein die Häufigkeit an entsprechenden Verordnungen und gesetzlichen Bestimmungen zeigt, wie weit verbreitet Verstöße gegen fremdes Jagdrecht waren. Da die Wilderer jedoch in der Bevölkerung einen festen Rückhalt hatten, blieben Verbote und obrigkeitliche Versuche der Kriminalisierung herrschaftswidriger Jägerei in der Regel wirkungslos. Ausschlaggebend dafür war, dass der illegale Abschuss den Unterschichten nicht nur eine Möglichkeit zur Fleischbeschaffung bot, sondern auch die landwirtschaftlichen Schäden mildern konnte, die durch das zahlreiche Wild verursacht wurden und deren Abwehr den Bauern ebenfalls meist verboten bzw. nur sehr eingeschränkt erlaubt war. ${ }^{118}$ Neben solchen wirtschaftlichen Gründen hatten freilich auch Faktoren wie Trotz, Übermut oder soziales Rollenspiel ihren Anteil am Ansehen der Wilderer. Der Jagderfolg der Wildschützen galt als herausragende Leistung, die Trophäen versprachen Anerkennung und Bewunderung. ${ }^{119}$ Auch als Männlichkeitsritual der unteren Schichten lässt sich das Wildern interpretieren, da diese sonst kaum Gelegenheit hatten, sich im eigenen Umfeld zu profilieren und Stärke und Kühnheit zu beweisen. ${ }^{120}$ Schließlich aber kommt dem Wildern auch eine politische Dimension zu, war doch das Luxusgut Wildfleisch den höheren Ständen vorbehalten. Mit der Missachtung des Jagdrechts konnte daher auch eine Form des Protests gegen die Obrigkeit verbunden sein, der allerdings in aller Regel regional, d. h. auf die unmittelbar bekannten Grundherren oder obrigkeitlichen Beamten, beschränkt blieb. ${ }^{121}$ Inwiefern ein solcher Protest freilich tatsächlich

117 Österreichisches Staatsarchiv, Vertrauliche Akten 31, f. 615r.

118 Vgl. Thomas Hochradner: Zur Entwicklung des alpenländischen Singstils am Beispiel des Wildschützenliedes. In: Lied und populäre Kultur/Song and Popular Culture. Jahrbuch des Deutschen Volksliedarchivs 54 (2009), S. 133-151, hier 133f. - Krista Ruehs: Auch „böse“ Menschen haben ihre Lieder. Zur Rezeption von Wilderern in österreichischenVolksliedern des 18. bis 20. Jahrhunderts. In: Jahrbuch für Volksliedforschung 29 (1984), S. 32-57, hier 42f. - Michaela Karl: Sozialrebellen in Bayern. Matthäus Klostermair, Michael Heigl, Mathias Kneißl. Regensburg: Pustet 2003, S. 91ff. - Uwe Danker: Die Geschichte der Räuber und Gauner. Düsseldorf/Zürich: Artemis \& Winkler 2001, S. 187.

119 Vgl. Hochradner, Alpenländischer Singstil, S. 136.

120 Vgl. Karl, Sozialrebellen, S. 91, die sich hier auf eine These der Historikerin Regina Schulte bezieht.

121 Vgl. ebda., S. 91 und Ruehs, Auch „böse“ Menschen, S. 48. 
von den Wildschützen intendiert war oder nicht eher eine nachträgliche Zuschreibung darstellt, muss fraglich bleiben. ${ }^{122}$

In der literarischen Verarbeitung der Wilderer-Thematik entstanden ab dem frühen 18. Jahrhundert auch dialektale Lieder, die grob in zwei Typen unterteilt werden können: Der erste ist der Typus des sozialkritischen Wildererlieds, in dem meist der Triumph des Wilderers über die Jäger im Mittelpunkt steht, die verjagt, bestraft, gedemütigt oder sogar getötet werden. Neben eher realitätsfernen Liedern, in denen Wunschvorstellungen und Aggressionen der Minderprivilegierten auf die idealisierte Figur des Wilderers übertragen werden, finden sich Texte, die nah an den beschriebenen Ereignissen bleiben und diese nicht im Nachhinein verklären. Dementsprechend werden in der Darstellung auch die schweren Lebensbedingungen der Wilderer oder die zu befürchtenden Strafen mit der unerschrockenen Selbstbehauptung des Wilderers und der Kritik bzw. Verspottung der Obrigkeit verbunden. Der zweite Typ kann als idyllisierend-unterhaltendes Wildererlied beschrieben werden, das ab dem späten 18. Jahrhundert reüssierte. Die Konfrontation mit den Jägern und der damit verbundene zumindest latente Protest gegen die Obrigkeit fallen nun weg. Zurückgeführt werden könnte dieser Wandel, so vermutet Hochradner, auch auf die politischen Veränderungen um 1800, die das Wildern mit milderen Strafen belegte und damit der Konfrontation die Schärfe nahm. ${ }^{123} \mathrm{Im}$ Gegenzug findet man in diesen Liedern immer stärker die (auch schon zuvor teilweise anklingende) Verbindung mit - romantisierenden und erotisch eingefärbten - Almenund Sennerinnen-Motiven. Die Verbindung zwischen Sennin und Wildschütz wird vor allem im 19. Jahrhundert zur geradezu prototypischen Konstellation, mit der die romantische Vorstellung „binnenexotischer Naturwüchsigkeit“ ${ }^{124}$ und ein verklärtes Bild promiskuitiver Liebe verbunden wurden.

Während sich stoffgeschichtlich also um die Jahrhundertwende das Gewicht vom ersten zum zweiten Typus verlagerte, sind beide Ausformungen in den Jahrzehnten davor gleichwohl präsent. Schon um 1750 gibt es harmlos-romantisierende Texte und noch aus den 1790er Jahren finden sich deutlich aggressive, beinah revolutionäre Töne. In unserem Untersuchungsbereich aber dominiert die zumindest aufmüpfige, oft auch deutlich rebellische Haltung des Wilderers, der sich nichts aus der Obrigkeit macht und mit Leichtigkeit über die Jäger triumphiert - sei es in populären Liedern der Volkskultur oder auch in ,hochkulturellen' Verarbeitungen. Beispiel für Letzteres ist etwa ein Wildschützenlied aus dem Singspiel Die Hochzeit aufder Alm (1768) von Florian Reichssiegel (1735-1793) und Michael Haydn (1737-1806), in dem ländliche Idylle mit einer grundsätzlichen Aufsässigkeit oder zumindest Sorglosigkeit des Wilschützen verbun-

122 Vgl. dazu insbesonders Danker, Geschichte der Räuber und Gauner, S. 186.

123 Vgl. Hochradner, Alpenländischer Singstil, S. 140.

124 Vgl. Hubert Grininger: Da Weg zu mein Dirndl is stoani ... Liebe und Eros in der alpenländischen Volksmusik von 1800 bis zum Austropop. Graz: Edition Strahalm 1997, S. 7 f. 
den wird. ${ }^{125}$ Das Lied des Polidor, das offensichtlich im Volksgesang aufging, ${ }^{126}$ bedient schon eingangs den Topos des vogelfreien Outlaws, der sich mit der Waffe in der Hand sein eigenes Recht schafft:

1

Wer kann, als ein Wildbrätschütz, lustiger seyn?

Sein Stutzerl, sein Stutzerl und er sind allein.

Er nimmt auf den Buggel sein Stutzerl ins Holtz,

Und geht,

Und dreht

Bald hinum, bald herum sein Stutzerl ganz stolz. ${ }^{127}$

1,3 Buggel] Rücken

Die libidinösen Töne, die später mit Vorliebe an Sennerinnen und Bauernmägde gerichtet sind, gelten hier noch der Waffe, dem ,Stutzerl', dem der Wilderer alleinige Treue schwor und das ihn überall hin begleitet. Wer ihn von seinem „herzige[n] Dieb“ zu trennen versucht, dem droht „ein Loch“ ${ }^{128}$ im Körper. Dieses Motiv der Waffe als Dingsymbol der Freiheit, das gegen die herrschaftlichen Forstbeamten verteidigt wurde, begegnet uns bereits in Flugschriftliedern des frühen 18. Jahrhunderts, allerdings in nur schwach dialektaler Gestaltung, wie zwei Strophen aus dem um 1700 gedruckten Was wollen wir singen, was fangen wir an zeigen sollen. Auch hier fordert der Wilderer ,Urberl` die Jäger lieber zum Duell, als kampflos sein ,Büxerl`auszuhändigen:

4

Grüß dich GOtt mein Herr Urberl, was führest vor ein Leben,

dein wunderschöns Büxerl, das must du uns geben,

und must mit uns gehen ins Richters Wald-Haus,

da bleibst du verborgen, kommst lang nicht mehr heraus.

5

Ins Richter Waldhäusle da geh ich enck nit,

mein wunderschönes Büxerl das geb ich enck nicht,

geht habt es Kurasche, thut eins mit mir wagen,

nach zween und drey Jägern thu ich nicht viel fragen. ${ }^{129}$

5,1 enck] euch 5,3 es] ihr Kurasche] Mut

125 Die Hochzeit auf der Alm, ein Hirtenspiel in zween Aufzügen. In: [Florian Reichssiegel:] Pietas coniugalis in Gismundo et Maria Tragoedia in scenam data ac Almæ Maiori et Academiæ Congregationi Salisburgensi B.V. Mariae in coelos adsumptae dedicata a Poetica Saliburgensi v Calendas Maii. [Salzburg: Mayr 1768], f. A-D. In diesem Text, der Dialekt nur in Ansätzen wiedergibt, wird die Wilderer-Thematik (noch) vorwiegend mit arkadischen Topoi und dem Figuren- und Szeneninventar barocker Idyllik verbunden. Vgl. zur Interpretation auch Hochradner, Alpenländischer Singstil, S. 137f.

126 Vgl. die (etwas stärker dialektal markierte) Fassung der Handschrift 727 der Oberösterreichischen Landesbibliothek, eine Studentenliedersammlung aus dem Salzburger Umfeld der 1770er Jahre, f. 254r-v.

127 Reichssiegel, Hochzeit auf der Alm, f. A2r.

128 Ebda., A2v.

129 Drey schöne neue Weltliche Lieder, Das Erste: Was wollen wir singen, was fangen wir an, es ist ja ein fremder Wild-Schütz in dem Land. Das Andere: Der Tauber der ist in das Holtz hinaus g'flogen. Das Dritte: Ach wie quälen mich meine Gedancken. Jedes in seiner eignen Melodey zu singen. Gedruckt in disem Jahr. [o. O., o. J., um 1700]. 
Wird in Liedern wie diesem der Freiheitswille des furchtlosen Wilderers aus einer relativ schematischen Kontraposition zu den Jägern beschworen, so werden in anderen Texten auch die sozialhistorischen Rahmenbedingungen sichtbar - und damit die obrigkeitskritischen Tendenzen solcher Wildererlieder. So weist etwa Ist nichts Schöners auf der Welt durchaus aggressive Töne auf. Das Verbot der Wilderei durch „große Herrn und Fürsten“ wird als illegitim herausgestellt, laufe doch das Wild „von Gott frey herum“. Beißender Spott trifft die Schonung des Wildes durch die Obrigkeit, die - ohne Rücksicht auf die durch Wildschäden erwachsenden Verluste der Bauern - das Wild verhätscheln und damit erst dafür verantwortlich seien, dass die Unterschichten selbst zum Gewehr greifen:

3

Sagn die Leut es ist a Sünd

Wildprät schiessen, Hasen und Füchsen, Ghört für große Herrn und Fürsten,

Ihr seyd wunderliche Lappen,

Mein wie heissen eure Kappen,

Was von Gott frey herum rennt,

Dem gehört das, ders nieder brennt.

$[\ldots]$
5

Hanz mein wer führt eng dann das Gwild,

Es lauft draust auf den Bauern sein Aker

Frißt sich toll und halt sich waker,

Bis sie hat die Bätschen voll,

Hanz gebts ihnen die Torten und Basteten,

Hengts es an wie dHund an Ketten,

Oder legts ihnen Kinruß an,

So kriegt der Wildschütz nicht davon. ${ }^{130}$

3,4 Lappen] Lapp: einfältiger, naiver Mensch 3,5 Mein] Ausrufepartikel 3,7 nieder brennt] hier: niederschießt 5,1 Hanz] Anredewort, um jemanden aufmerksam zu machen oder Missfallen auszudrücken; im Sinne von: ,he', ,na hör mal' 5,4 Bätschen] Wanst, dicker Bauch 5,6 Hengts es] hängt sie 5,7 Kinruß] schwarzer Farbstoff (hier wohl scherzhaft als Tarnung)

Übermäßige Wildhege und die damit einhergehenden Flurschäden konnten auch durchaus zu größeren sozialen Unruhen führen - wie etwa Jagdunruhen der Jahre 1739/1740 zeigen, die von der Steiermark ausgingen und dann auf die oberösterreichischen Gebiete nördlich der Pyhrngrenze übersprangen. Auf diese Ereignisse bezieht sich ein handschriftlich überliefertes, 33-strophiges Lied mit dem Titel Ein schenes Liedt oder Paurn Discurs Von dem Wiltprädt Schiesßen [Guetten Tag mein Lieba Jodl]. Die topographischen Bezüge weisen - wie Wolfram Tuschner in einem aufschlussreichen Aufsatz ausführt ${ }^{131}$ - auf das Gebiet um Molln in Oberösterreich. Das im zeitgenössischen Kontext höchst brisante Lied ist möglicherweise, so Tuschner, von einem Geistlichen verfasst worden, der sich mit den aufbegehrenden Bauern und ihren Anliegen voll identifizieren konnte. ${ }^{132}$ Der Text verknüpft humoristische Elemente mit jenen der Klage und der An-

130 Drey schöne neue Weltliche Lieder, Am Namenstag der schönen Kätchen. Das Erste: In Schwaben war ein Bauernmädchen. Das Zweyte: Ist nicht schöners auf der Welt. Das Dritte: Lusti mein Führerbue! lusti mein Veitl. Wien zu finden bey Anton Leitner Kupferstichhändler auf den obern Jesuiterplazl oder sogenannten Schulhof. [o. O., o. J, Anfang der 1790er Jahre].

131 Wolfram Tuschner: Ein Wildschützenlied aus dem Mollnertal aus der Zeit um 1740. In: Jahrbuch des Oberösterreichischen Musealvereines - Gesellschaft für Landeskunde 142 (1997), S. 255-268.

132 Vgl. ebda., S. 256f. - Für eine entsprechende Stellung des Verfassers sprechen laut Tuschner der „dialektologisch professionelle schriftliche Umgang mit der eigenen Mundart“ sowie „der durchwegs metrisch einwandfreie Aufbau seines Produkts“ (S. 257). Zudem schließt Tuschner durch offenbar im Schreibfluss gesetzte Sofortkorrekturen auf ein eigenhändiges Manuskript des Autors. Nicht nur hinsichtlich des Stands, sondern vor allem in Hinblick auf den Tenor und die thematische Ausrichtung vergleicht Tuschner das Lied mit den Werken Maurus Lindemayrs. 
klage der Obrigkeit und unterfüttert das typische Ungestüm des Wilderers mit harscher Kritik an aktuellen Zuständen. Besonders deutlich wird die Klage über die landwirtschaftlichen Schäden, für die das Wild verantwortlich ist:

9

Nachä nach dem khünen mä denä, äff dö nächät swilt zam Brennä, das in Winda insä Khaan, offt hat ibä g-haut däs gfran, [...]

13

abä dPan und d arbäß widä, haimb und Brein Stendt Paidy schidä, dä harr wä no Löstlä guett, wan mäs nit dä Hirsch väthuet.
10

Khaan han I. ferdt Bauth 3 Mözen, han woll gmaindt öß solt zuesözen, hat mäs abä swilt vädan, khrieg ga khlebä n samb dauan,

14

mit den Krauth isß ä schan gschechä, ist nimä Khain ausßy sechä, hä wie Kunäts anäs sein, gent mä all nacht dhirschen drein, $[\ldots]^{133}$

9,1 mä denä] wir aber, dennoch 9,2 nächät] Nähe Zam Brennä] zusammenschießen 9,3 Khaan] Korn 9,4 gfran] Frost, Frieren 10,1 ferdt] im vergangenen Jahr, vor einem Jahr bauth] angebaut Mözn] Metzen: Trockenmaß verschiedener Ausmessung, in Süddeutschland zwischen 20 und 31 Liter 10,2 zuesözn] hier: sich vermehren, Ertrag bringen 10,3 Vädan] vertan, geschädigt 10,4 khlebä] schmächtig, knapp (bekomme gerade einmal das Saatgut davon) 13,1 Pan] Bohnen arbäß] Erbsen 13,2 haimb] Heiden: Buchweizen Brein] Hirse schidä] schütter 13,3 harr] Flachs 13,3 Löstlä] letztlich, wenigstens 14,2 ist nimä Khain ausy sechä] es gibt kein Hoffnung mehr 14,3 Kunäts] könnte es anäs] anders 14,4 gent] gehen (3. Ps. Pl. Präs.)

Angesichts dessen scheint die eigenhändige Dezimierung des verhassten Wildes nur legitim. Diese durchaus politische Dimension des Wilderns wird im Text immer wieder deutlich, wenn auch andere Aspekte angesprochen werden, etwa das zu erwartende Fleisch („ist ä no ä nuzä khen / den daß Hirsch fleisch ist ä gern“, Str. 4,3f.) oder auch die Lust am Triumph über die Jäger („wan mäs [d.h. die erlegten Hirsche] ain mahl hamb in Hauß, / Lachän mä dö Jäggä auß“, Str. 23,3f.). Schließlich wird auch relativ deutlich Kritik an der Untätigkeit und Gleichgültigkeit der Obrigkeit geübt, die bewaffnete Landwirte nach ergebnislosen Beschwerden bei der Forstverwaltung nach Gmunden marschieren ließ, wo sie unter anderem einen inhaftierten Wildschützen befreiten. ${ }^{134}$

26

do wäß gfält He Bruedä altä, sangmäs in Herrn Väwaltä, daß ins swiltprät geth ös Thraidt, wierst schan hern offt was ä saith,
27

dherrn sändt hiezt omban gsesßen, wer mit ien will Kerschn ösßn, weffent ain d stingln ös gsicht, wie das alte Sprichworth Spricht,

133 Ein schenes Liedt oder Paurn Discurs Von dem Wiltprädt Schiesßen (handschriftlich, um 1740, 33 Strophen), hier transkribiert nach der Abbildung bei Tuschner, Ein Wildschützenlied, S. 259-263. Im Original ohne Strophennummerierung; anders als bei Tuschner wurden hier die Zeilenumbrüche den Versgrenzen angepasst. - Die Handschrift befindet sich im Oberösterreichischen Landesarchiv/Stiftsarchiv Spital am Pyhrn in der Bestandgruppe IIb, Bd. 699.

134 Vgl. Tuschner, Ein Wildschützenlied, S. 268. 
28

hast äs swiltprät solang grathn, Lastäs öbm no widä Rathn, Lastas Rathn hast Kain gschert, We waiß wie Langs öpa wehrt,
29

$\mathrm{dH}[\mathrm{err}] \mathrm{n} \mathrm{Laßn}$ so nit druzn, Bue väKhäff däfüer dein Stuzn, wilst mä volgn Beß main ichs nit, sist Lasts dä ä so khain fridt, ${ }^{135}$

26,1 do wäß gfält] es wäre falsch/verfehlt 26,2 sangmäs] sagen wir es 26,3 Thraidt] Getreide 26,4 offt] dann, da, also ä saith] er sagt 27,1 Hiezt] jetzt omban] oben 27,3 ös] in das 28,1 grathn] entbehrt 28,2 öbm] eben 28,3 Lastas Rathn] lass es dir raten 28,4 öpa] etwa 28,4 wehrt] währt, dauert 29,1 druzn] trutzen, Widerstand leisten 29,3 Beß] böse

Die Unruhen im Salzkammergut führten allerdings nicht zu einer Verbesserung der Lage und so endet auch das Lied insgesamt in einem fatalistischen Ton: Die Wilderei werde vielleicht noch Haus und Hof - oder gar das Leben - kosten, nur wer sich darum nicht kümmere, könne es weiterhin wagen. Den Strafenkatalog auf das Delikt - vom Pranger und der Konfiszierung des Eigentums über eine Strafe im Zuchthaus oder gar auf der Galeere - führt ein Flugschriftlied aus der 2. Hälfte des 18. Jahrhunderts drastisch vor Augen. Wie der Wildprät-Schütz gefangen worden war wohl als obrigkeitliche Mahnung gedacht, die der Bevölkerung die drohenden Konsequenzen des Wilderns vor Augen führen sollte:

5

Grauset mir schon d'Haut ä bisl, wird mä freyli gschehä weh, nit allein kain faiste Schüßl, es wird heissen auf Gallee, bist ein guter starcker Bruder, da geh her, und nimm ein Ruder, hast schon längst unser g'spott, arbeit fort mein Galioth.
6

Muß mi schon ä Weil drein gebn, gehts mir endlich wie dä will, wann mä führt ein solches Lebn, Männer gelts, das ist ein Spil, etwas hab ich noch vonnöthen, mei thuts halt für mich was betten, villeicht kemmä nimmä z'sam, Schörg fahr fort in dessen Nahm. ${ }^{136}$

5,3 faiste] fette, wohl gefüllt 5,8 Galioth] Galeotte: Ruderer auf einer Galeere 6,2 wie dä will] wie es auch gehen mag

Unmissverständlich aus der Perspektive der Herrschenden ist die Figur des Wilderers auch in einem anonym überlieferten Dialektsingspiel aus dem oberbayerischen Augustiner-Chorherrenstift Beuerberg angelegt. In dem noch heute witzigen, wohl nach der Jahrhundertmitte entstandenen Podagra-Stück, das den Kampf der antiken Götterwelt gegen die personifizierte Stoffwechselkrankheit in herrlich unmanipulierter westmittelbairischer Mundart mit einer Unmenge an bildstarken und hochkomischen idiomatischen Wendungen in Szene setzt, wird das klapperdürre Schulmeisterlein Dolloruki („der dirling, wo nix als haut vnd Pai“ ${ }^{137}$ ) vom grimmigen Götterförster Actaeon auf frischer Tat dabei ertappt, wie es ein Eichhörnchen erlegt:

135 Ein schenes Liedt oder Paurn Discurs Von dem Wiltprädt Schiesßen.

136 Fünf schöne neue Weltl. Lieder. [o. O., o. J.], f. 2r-v. Das einzige uns bekannte Exemplar im Archiv der Stadt Linz (Sammlung Klier: 55/9-143) ist nur fragmentarisch erhalten, das fünfte Lied fehlt. Inhalt: 1: Der Wildprät-Schütz. Hab mein Lebtag sagn hörn. 2: Wie der Wildprät-Schütz gefangen worden. Schaut $n \ddot{a}$, was ich han angfangä. 3: Von denen Aufschneidern, und Ehrabschneidern. Nun wollen wir auf Schneider-Art. 4: Herr Wirth ein guten Tag.

137 Bayerische Staatsbibliothek, Cod. germ. 5719/6a, f. 6v-7r. Erstmals ediert wurde dieses bemerkenswerte Klostersingspiel im Rahmen einer Diplomarbeit von Katharina Steiner: Heft 6a aus der Sammlung Büh- 
AстæON. fit catapultoe fragor, exit ad hunc Actoeon totus flameus.

Pliz! Hunderttausnt sandtgruebn endt, vnd herent!

Was fir ä hundts \& cætera istmä da I mei giaid reigrent?

Das I den örz Cuion nit glei darm rausreiss,

Vnd i taußent fezn daschmeiss.

Wie wer I bey meinä frau dä Diana bstö

Wen mä an iedä Hunts Pernheiter ins giaid thuet reigö?

I waiss scho beyleiffi wo da schuß is herkhemä indagat in quadam latebra

triff I di no o, I will di gwis demmä

fugit ex latebra Dolloruki sed reductus ab Actoene è fuga

Ha, ha! bist äs du froschmaul? sichst da d'Klingä?

Wart, glei Will I dä än Pumpanikhl singä.

foznhued! was genga di d giaida o?

I ho gmaid, du bist schuellmaistä, bist ä sötlä mo?

däxn soll I ahakhä, vnd soll di nauf haua aufn Plossn.

Dolloruki. honi do nix tho herr, ho no an aich-horn gschossn.

ACTæON. Ey Waisch nit, das än aichorn ä duodez-fixl ist?

wer ä so klais schiesst, wirfft ä gross ä nit aufn mist.

döß iß ä bestialitet, wer waiss, wie langst äs scho tribn hast in dein löbnslauf

vo rechts wögn kheret si da scheidähauffn trauf.

bist du ä schuellmaistä, und solst anderi duraus Straffä

was thiena Ihnä deini khindä, fir an Exempl däbey schaffä?

nacha werns ä sötli schlenggln, durstreicha än Wald

vnd, schiessn alls wökh, wass dawischn, warm, vnd Kalt.

hörnä Sunta, vnd feyrtä khoi möss, begöbn si aufs leyrn,

stehln, schlenzn, vnd feyrn. ${ }^{138}$

1 fit ... flameus] (lat.) das Krachen eines Gewehrs ist zu hören, bei dem Actaeon wutentbrannt auftritt 2 endt, vnd herent] drüben und herüben 3 I mei giaid reigrent] in mein Revier eingedrungen 4 Cuion] (franz. couyon oder coïon) nichtswürdiger, verächtlicher Mensch, Lump 5 daschmeiss] zerschmeißen, zerfetzen 6 bstö] bestehen 7 Pernheiter] Bärenhäuter (Schimpfwort) reigö] reingehen, eindringen 8 beyleiffi] beiläufig, ungefähr indagat ... latebra] (lat.) er forscht nach einem bestimmten Versteck 9 triff I di no o] treff ich dich noch an demmä] prügeln 10 fugit ... fuga] (lat.) Dolloruki rennt aus dem Versteck davon, wird aber von Actaeon auf der Flucht zurückgehalten 12 än Pumpanikhl singä] durchprügeln 13 foznhued] Schimpfwort für untüchtigen Mann, Versager genga ... o] gehen ... an giaida] Jagdgebiete, Reviere 14 I ho gmaid] ich habe gemeint ä sötlä mo] ein solcher Mann 15 däxn] die Beine Plossn] bloßen (Rücken, Hintern) 16 honi] habe ich 17 duodez-fixl] Miniaturfuchs 22 was ... schaffä] was für ein Beispiel werden sich deine Kinder daran nehmen 23 sötli schlenggln] solche Schurken 25 hörnä Sunta] hören am Sonntag khoi] keine leyrn] täuschen, betrügen 26 schlenzn] vagabundieren

Dollorukis Verteidigung, seine schwangere Frau hätte es „vnter andern än Aichorn prädl glust“, wird schnell als Lüge entlarvt und auch seiner Ausrede, er habe das „thier hintn ogschossn“ und das sei nach dem „Handtwerkhs Protocoll“ 139 doch sein verbrieftes Recht, wird kein Glauben geschenkt. So wird dem Schulmeister, der nun bereut, die Wildhüter nicht wie üblich bestochen zu haben, letztlich das Podagra an den Fuß gewünscht.

nenstücke und Gedichte aus dem Kloster Beuerberg (1740-86), Cod. germ. 5719: Edition und Kommentar. Graz 2019 [Dipl].

138 Bayerische Staatsbibliothek, Cod. germ. 5719/6a, f. 6v.

139 Ebda., f. 10v. 
Ist diese Lustspielfigur die Erfindung eines kreativen Augustiners, so ist das Treiben und dramatische Ende des wohl berühmtesten Wilderers des 18. Jahrhunderts, des ,Bayrischen Hiasl', vielfach historisch belegt und diente als Vorlage für eine Reihe dialektaler Lieder. Matthias (Matthäus) Klostermayr, 1736 in der Nähe von Augsburg geboren, trieb bis 1771 als Wilderer und Räuber in den Wäldern der bayerisch-schwäbisch-österreichischen Grenzregion sein Unwesen, ehe er mit seiner Bande, die sich in einem Wirtshaus verschanzt hatte, gefangen genommen und schließlich in Dillingen hingerichtet wurde. Bei der Landbevölkerung genoss er hohes Ansehen - nicht nur, da er die von den Bauern beklagte Wildplage bekämpfte, sondern auch wegen seiner Mildtätigkeit gegenüber Armen. Allerdings waren er und seine Gefährten auch für eine Reihe brutaler Verbrechen, darunter neun Morde, verantwortlich. ${ }^{140}$ Schon zu Lebzeiten rankte sich eine Vielzahl an Legenden um seine Person und allein in den zwei Jahrzehnten nach seinem Tod erschienen vier Biographien. Daneben setzte eine breite literarische Rezeption ein, mit lyrischen, epischen und dramatischen Bearbeitungen. ${ }^{141}$ Zwar wurde er, im Unterschied zu anderen populären Räubergestalten, nicht Gegenstand der ,hohen Literatur'; dafür aber wurde der Stoff umso mehr in der populären Literatur vor allem des bayerisch-österreichischen Raums bearbeitet (Frenzel nennt etwa 20 epische Behandlungen und fast 30 Volksliedfassungen bis ins 20. Jahrhundert). ${ }^{142}$ Die stark typisierte ,Hiasl'-Figur in diesen Bearbeitungen hat mit der historischen Persönlichkeit nur mehr wenig gemein. Auch in volkskundlichen oder historischen Darstellungen wurde und wird in ihm bis heute - je nach Zeitgeist, politischer Einstellung und Darstellungskontext - etwas anderes gesehen. ${ }^{143}$

Das wohl bekannteste Lied aus diesem Themenkreis muss in der folgenden Fassung wie sich aus der Angabe des Druckers erschließen lässt - vor 1772 erschienen sein. Das Liedende macht 1771 als Entstehungszeitpunkt wahrscheinlich, also die Zeit nach der Verhaftung des Matthias Klostermayr; vielleicht aber zirkulierte der vordere Teil schon in den Jahren davor eigenständig, bevor die jüngsten Ereignisse eingearbeitet wurden. Mehrmals wird im Text auf den Mythos angespielt, dass der Bayrische Hiasl angeblich

140 Vgl. Karl, Sozialrebellen, S. 16-22. - Waldemar Nowey: Der Bayrische Hiasl als heimatgeschichtliche, volkstümliche und literarische Gestalt. Ein Signal seiner Zeit - ein Signum unserer Heimat? 3. Aufl. Kissing: Selbstverlag Gemeinde Kissing 2003, S. 14-31. - Paul Ernst Rattelmüller: Matthäus Klostermaier vulgo Der Bayrische Hiasl. München: Bruckmann 1971.

141 Vgl. Nowey, Der Bayrische Hiasl, S. 18 und 55ff.

142 Vgl. Elisabeth Frenzel: Stoffe der Weltliteratur. Ein Lexikon dichtungsgeschichtlicher Längsschnitte. 9., überarb. u. erw. Aufl. Stuttgart: Kröner 1998 (Kröners Taschenausgabe 300), S. 336. Diese Verbreitung ist natürlich auch in Verbindung zu setzen mit der Popularisierung von Räuberfiguren durch ,Trivialliteratur und populäre Lesestoffe, die spätestens Ende des 18. Jahrhunderts mit Bestsellern wie Heinrich Zschokkes Abällino, der große Bandit (1793, 1795 als Drama) und Christian August Vulpius' Rinaldo Rinaldini, der Räuberhauptmann (1799) einsetzte, vgl. Ines Köhler-Zülch/Christine Shojaei Kawan: Räuber, Räubergeschichten. In: Rolf Wilhelm Brednich [u. a.] (Hg.): Enzyklopädie des Märchens. Handwörterbuch zur historischen und vergleichenden Erzählforschung. Band 11: Prüfung - Schimäremärchen. Berlin/New York: de Gruyter 2004, Sp. 307-323, hier 311.

143 So etwa Zack/Gerambs ,bajuwarisch-germanisches Heldenideal' (vgl. Viktor Zack/Viktor von Geramb: Die Lieder vom boarischen Hiasl in Deutschösterreich. In: Bayerische Hefte für Volkskunde 6 (1919), S. 134), Noweys ,schuldig gewordenes Individuum (vgl. Nowey, Der Bayrische Hiasl) oder Karls ,Sozialrebell und Kämpfer für Gerechtigkeit‘ (Karl, Sozialrebellen). 
unverwundbar sei und ihm die Kugeln der Jäger nichts ausmachen könnten - eine für den Typus des Räuberhelden und Sozialbanditen, der sich gegen eine ungerechte Ordnung auflehnt, charakteristische Zuschreibung, die als übernatürliche Eigenschaft die Faszination für diese Räuberfiguren verstärkte. ${ }^{144}$ Dass die geächteten Räuber selbst gezielt zu solchen Legendenbildungen anregten, legt - so vermutet Burke - den Schluss nahe, dass in den fingierten Darstellungen unterdrückte Wünsche der Bevölkerung befriedigt werden konnten, sich an jener Obrigkeit zu rächen, die in der Realität die Herrschaft ausübte. ${ }^{145}$

1

Ein Liedlein zum singen, geht kein andern nix an, Als die Jager und die Wildschütz'n, daß man's von einand kenna kann. 3

I bin der bairisch Hirsel gar a lustiger Bua, Steck i a paar Federl aufi auf an grün'n Hut. 5 Ös seyds oft nach mir ganga, ös habts mi oft gesehn, Habts oft auf mi g'schossen, seyds mir ganga auf's Leb’n. 7

Dös wird mir a no taug'n, wanns ös außi gehts in Wald, Da wir is z'samma schirßen, daß alles blitzt und knallt. 9

Ös alle meine Jäger, ein's will i eng no sag'n, Ös könnts schierßen wir's wollts, und ös mögts mir nöt schad'n.

11

Der Hund und der Bua, do lachen grad dazur, Sö denken sö hald grad, no schierßt nur brav zur. 13 In Augsburga Wald drin, und dort hab i mein Gey, Dort schierß i all Wochen, a Hirschal a zwei.
2

I bin der bairisch Hirsel, bin von Augsburg gebohr'n, I bin die ganze Zeit draußt im Wald herum zo'gn.

4

Koan Jager ist im Stand, koan Jager hat kein Schneid, Der mir halt mein Gamsbart von Hut aba reißt.

6

Wanns Büchsal frisch thut knall'n, das Ding thut mir g'fall'n, Mir sand eng're Kügerl, all in Sack eini g'falln.

8

Die Gamsla von den Hochgebirg, die Vögerl von den Bam, Aft wern sie sö halt denka, wann der Hirsl bald wegkam.

10

Das Pulver und das Blei, daß gieb i eng dafür, Koan Jager ist in Stand, der mir auflöst mein G'frir.

12

Wie ärger als schnalzen hörn, wie besser thurt sös g'freun, I bin der bairisch Hirsl, geht ka Kugel nöt ein.

14

Die Haut die verkauf $i$, das Fleisch fress'ma selm, Das Geld, daß versauf'n ma, aft kinna mir schon leb’n.

144 Vgl. Köhler-Zülch/Shojaei Kawan, Räuber, Räubergeschichten, Sp. 308. - Karl, Sozialrebellen, S. $124 f$.

145 Vgl. Peter Burke: Helden, Schurken und Narren. Europäische Volkskultur in der frühen Neuzeit. Hg. und mit einem Vorwort von Rudolf Schenda, übersetzt von Susanne Schenda. Stuttgart: Klett-Cotta 1981, S. 179. 
15

Der alte Schörgen Veitl, mit sein narrischen Kropf, Er hat im verrathen im Augsburger Schloß.
16

Jetzt gengans auf ihm strafa,

a ganz Regiment,

Und wans mi erwischen, aft wir i z'am brennt. ${ }^{146}$

1,4 von einand kenna] auseinanderhalten, unterscheiden 4,4 aba] herunter, herab (,ab-her') 5,1 Ös] ihr 6,3 eng're] eure 7,3 Da wir is] da werde ich sie 9,4 mögts] mögen: vermögen, können 10,4 G’frir] Gefrier: Unverwundbarkeit, Beständigkeit gegen Stiche oder Schüsse; , die Gefrier auflösen': die Beständigkeit, Festigkeit nehmen 12,1 wie ... wie] hier: je ... desto (je ärger sie es schnalzen hören [von den Schüssen], desto mehr freut es sie) 12,2 sös] hier: sie es 13,2 Gey] Gebiet, Bezirk 14,2 selm] selbst 14,4 kinna] können 16,4 z’am brennt] zusammen gebrannt, zusammengeschossen

Vor dem Hintergrund der für die damaligen Verhältnisse hohen publizistischen Aufmerksamkeit, die der Person (bzw. Figur) des Bayrischen Hiasl mit seinem Treiben und nicht zuletzt auch mit seiner spektakulären Verhaftung und Hinrichtung geschenkt wurde, ist die Strophe 11 besonders interessant: Auf zeitgenössischen Stichen wird der Hiasl immer wieder gemeinsam mit einem Jungen und einem riesigen Hund abgebildet. ${ }^{147}$ Diese Darstellung - die in der Flugschrift selbst nicht wiedergegeben wird, aber offenbar gemeinhin bekannt war - wird im Lied hier ganz offensichtlich aufgerufen.

Trotz der Popularität des Bayrischen Hiasl beziehen sich die überlieferten Lieder nur selten in so starkem Ausmaß wie im obigen Beispiel auf sein individuelles Schicksal. Vielmehr zeigt ein Blick auf die Überlieferung, dass sich in ähnlich gestalteten, zum Teil auch früheren Liedern - teilweise als Varianten desselben Lieds - neben dem Namen des Bayrischen Hiasl auch Bezeichnungen wie „Salzburger Bauer“ "148, „SchrägelThomerl“ ${ }^{149}$ oder „Tyroler-Fränzel“ finden. All diese Wildererlieder greifen also auf einen bestehenden Form- und Motivschatz zurück. Dabei lassen sich nach Frenzel zwei wichtige Schemata unterscheiden: Einmal der Typ des Rollenlieds, dem der obige Text entspricht und in dem der Wilderer in der ersten Person die Vorzüge des Wildschützenlebens und seine Taten preist. Der zweite Typ kann mit Frenzel als eine Art „Wildschützenballade“ charakterisiert werden, ,in der der Besuch des Wildschützen bei einer Sennerin, ein Überfall durch die Jäger, deren Niederlage und Verspottung sowie der Abschied von der Sennerin dargestellt wird“" ${ }^{150}$. Auch diesem Schema entsprechen einige

146 Zwei neue Lieder. Das Erste: Der Salzburger-Bauer. Bin a Salzburger Bauer, bei etc. Das Zweite: Der bayrische Hirsel. Ein Liedlein zum singen, geht etc. Druck von Menhardt in Steyr. [o. J.].

147 Vgl. neben Abb. 21 auch das Frontispizblatt in: Leben und Ende des berüchtigten Anführers einer Wildschützenbande, Mathias Klostermayrs, oder des sogenannten Bayerischen Hiesels, aus gerichtlichen Urkunden gezogen [...]. Augsburg, Frankfurt und Leipzig bey Jakob Andreas Friedrich. 1772. - Matthias Brentan, vulgo der Bayrische Hiesel nebst seinem Jungen, und Grosen Hunde. Nach dem Leben gezeichnet, G. P. et I. Lorenz Rugendas, Sc. et exc. Aug. V. [Augsburg], [ca. 1800]. Frankfurt a. M.: Stadt- und Universitätsbibliothek/Einblattdrucke G. Freytag.

148 Siehe die Quellenangabe zum vorigen Lied.

149 Zwey schöne Lustige Lieder. Das Erste von dem Schrägel-Thomerl. Das Anderte von dem Jungen RauffJodel. Gedruckt in disem Jahr. [o. O., o. J., ev. Anfang 18. Jh.]; kein Standort bekannt, Edition bei Konrad Mautner: Zwey schöne Lustige Lieder. Das Erste von dem Schrägel-Thomerl. Das Anderte von dem Jungen Rauff-Jodel. Gedruckt in disem Jahr. In: Bayerische Hefte für Volkskunde 7 (1920), S. 76-107, hier 78f.).

150 Frenzel, Stoffe der Weltliteratur, S. 336. 


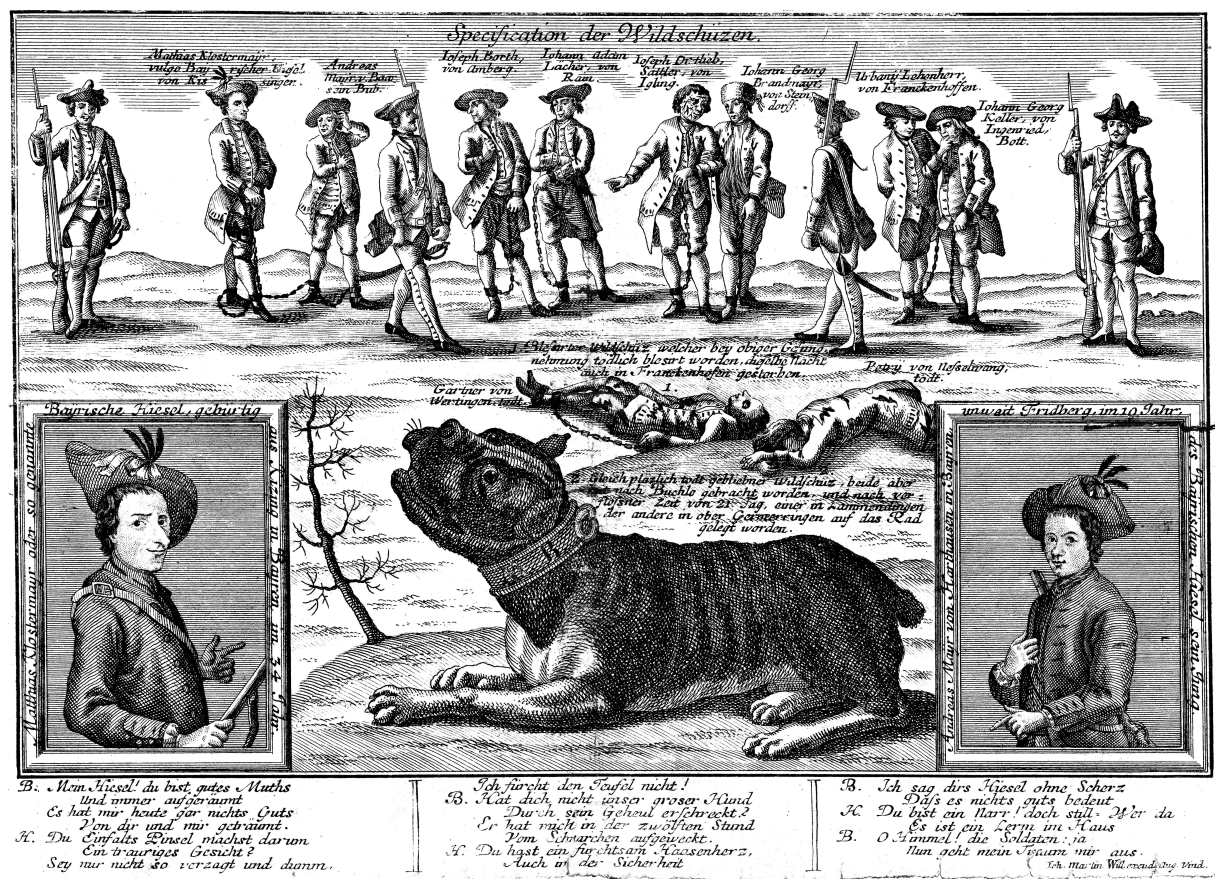

Abb. 21: Einblattdruck zur Festnahme Matthias Klostermayrs und seiner Bande (um 1771/72, Privatbesitz).

dialektale Gesänge aus dem 18. Jahrhundert. Das folgende Lied Von Tyroler-Fränzel kann als Beispiel dafür gelten, mit seinem typischen Wechsel von erzählenden Passagen und Redewiedergabe sowie einem Handlungsbogen, der nach romanzenähnlichem Beginn zum dramatisch inszenierten Showdown übergeht. Dieser endet wenig überraschend mit dem totalen Triumph des Wilderers, hat sich der Erzähler doch inzwischen als autodiegetische Instanz entpuppt:

7

Fruh Morgens wies Tag wurd, da stund sDiendl auf, sie wolt Grapfen bachä, stehn dJäger schon draust, stehn dJäger schon draust.

8

Sieben Jäger, drey Diener habn drey grosse Hund, wie wirds uns jezt gehen, o herzliebstes Kind? o herzliebstes Kind. 
9

Du därfst di nit schröcken, o liebs Reserl mein, i thu mi nit fürchten, wanns no so viel seyn, wanns no so viel seyn.

10

Sie puffen und krallen, und schlagn an der Thür, der Wildschütz muß ausser, es hilft nichts dafür, es hilft nichts dafür.

11

Aft nehmens die Hündl und hetzens auf mich, aft bind ichs zusammen henks zuwi zum Tisch, henks zuwi zum Tisch.

12

Aft nehmens die Flinten, und schiessen auf mich, wie d Jäger habn gschossen, aft schiesset erst ich, aft schiesset erst ich.

13

Ein hab i getroffen, sechs seynd davon grennt, ey ös meini Jäger habts mi no nie kennt, habts mi no nie kennt.

14

Und aften gieng i aufi über dFleischhacker Kram, da seynd mir die Jäger auf d Knye niedergfallen, auf d Knye nidergfalln.

15

Sie bitten und schreyen um Gnad und Pardon, ach laß uns das Leben, ach uns nur verschon, ach uns nur verschon.

16

Aft hab ichs gefraget ob i Gämsel därf jagn, aft habns mir halt glei gsagt, so viel i will habn, so viel i will habn.

17

Möchts ös so gern wissen, wie i hässen thue, bin der Tyroler Fränzl, ä lustiger Bue, ä lustiger Bue.

18

Möchts ös so gern wissen, wo i dähäm bin,

bin ä Tyroler Büberl, bin ja wärlä schlimm, bin ja wärlä schlimm.

19

Ein Liedlein zum singen, ein Liedlein zum Bschluß, wann i aft kommen möcht, so habts kein Verdruß, so habts kein Verdruß. ${ }^{151}$

11,1 Aft] da, dann 11,2 henks zuwi] hänge sie an/dran 14,1 Kram] eig. Verkaufsstand, hier Ortsname (?) 18,2 wärlä] wahrlich

151 Drey schöne neue Weltliche Lieder, Das Erste. Von Tyroler-Fränzel, etc. Das Anderte. So trift mich das Schicksal, etc. Das Dritte. Wie vieles gibt es doch zu denken. etc. Gedruckt in diesem Jahr. [o. O., o. J.; ca. Mitte 18. Jh.?]; 19 Strophen.

Das Lied ist in einer Reihe weiterer, teilweise stärker abweichenden bzw. ausgebauten Varianten mit bis zu 27 Strophen überliefert, in denen der Wilderer auch als, „Maeyr fränzl“ bzw. „Wahrfranzl“ (wohl ein 
Noch stärker die idyllisierende Heiterkeit und Freiheit des Almlebens stellt Lustig ists im Frühling, Juhei sa sa sa! heraus. Das Lied, das in Lorenz Hübners wegweisender Beschreibung des Erzstiftes und Reichsfürstenthums Salzburg mitgeteilt ist, verweist damit schon auf die genretypischen Züge des Wildererlieds im 19. Jahrhundert - vor allem mit dem Natureinstieg, der im übermütigen Ton die Freuden des Frühlings und die Schönheit des Almlebens schildert. Der als wagemutig und - selbstverständlich - treffsicher charakterisierte Wilderer trifft auch hier wieder auf einen Jäger, eine Konfrontation, die wie üblich mit dem Triumph des Wilderers endet.

Lustig ists im Frühling, Juhei sa sa sa!

Die Vögel so schön singen, die Hahna pfalzen a,

Es ist so schön appa, send d'Alma so grün,

Fahren schon die Sendinen gen Alm mit den Kühn.

Es ist ja viel lustiger den Summer bey da Höh,

Da Hoam giebts ja gar koan Freund, send nix als häufig Flöh!

Da Hoam bleib i niema mehr, mags seyn wie da wöll,

Kein Mensch mag mi dahalten, kein Teufl in da Höll.

I geh halt aft der Alm zue, wo öttla Hütten send,

I waß schon wo ich einkehrn muß, wer mi zam besten kennt.

Die Sendin do war hübsch und fein, sie muß mein eigen seyn.

Mecht köma wann i wollt, so gabs ma an Brantwein.

Aft geh i von der Hütten weck und aufi nach der Püersch,

I schau a Boisel hin und her, und sach ein gstreiften Hirsch,

Da han i halt mein Büchsl spannt, und ließ es wacka knalln,

Das Hirschl reißt den Kopf in d'Höch, und ist bald nieder gfalln.

So bald i s'Hirschl an han bracht, laßt's mir ja no koan Rueh,

Mach meinen Weg no weita fort dem hohen Gamsbirg zue.

So bald i bin aufi kema, han i mi nieda glegt,

Untern Kopf an großen Stoan, die Erden zan an Bett.

So bald i mi han schlafen glegt, gehn mir die Augen zue,

Und gschlafen han i die ganze Nacht mit einer süßen Ruh.

So bald i wieder auf bin g'wacht, scheint mir die Sunn schon her;

Aft spring i halt auf meine Füß, und schauat hin und her.

Aft sach ich ein Kartl Gams, Bue das Ding juheisasa.

Gfreute mi wohl sehr, und war wohl so viel rar,

I spann mein Büchs, und schieß fein husig drein:

Zwoa Gams sant husig gfalln, das Ding das that mi gfreun.

Aft waid i halt dö Gamsböck aus, schaut mir da Jäga zue,

Und sagt gschwind: „,erfluchter Kerl!“ was ich da machen thue.

Ich bsinn mi aber nit lang, und nimm ihn bey dem Kragn.

Wart du Jäger, jetzt will i di recht jagerisch daschlagn.

Satzfehler) sowie auch als „Bayrischer Matthiesel“ bezeichnet wird; Fehler und Entstellungen insbesondere dialektaler Wendungen in manchen der Drucke weisen auf eine weitere Verbreitung auch außerhalb des bairisch-österreichischen Raums hin. Wohl auch Grundlage für die eher standardsprachliche Bearbeitung von Arnim/Brentano in Des Knaben Wunderhorn (II 158; „Der Bayrische Hiesel“). 
Wart Jäger, jetzt muest du mir gen die Gamsböck tragn,

Und wirst du mirs nit husig thuen, so will i di daschlagn.

Der Jäger nahm die Gamsböck auf, daß ihm der Ruck hat kracht,

Und i bin ganga hinten nach, und han mi schier z'todt glacht.

Ich kei mi nix um d'Jage, um öena sechs und neun,

Und wann $i$ in die Kirchen geh, so laß i's grad brav schreyn.

Herz und Curasch haben's oanawegs nie ghabt.

Drum fürcht i a koan Jaga, wann mi glei oana datapt. ${ }^{152}$

1,3 appa] aper, unbedeckt, schneefrei 2,2 Da Hoam] daheim, zuhause 2,3 wie da wöll] wie auch immer 3,1 öttla] etliche, einige, mehrere 7,1 Kartl] Herde 7,3 husig] hurtig, schnell, frisch, munter 10,1 kei] bekümmere, schere 10,4 datapt] erwischt

An Liedern wie diesen werden die Übergänge sichtbar zwischen Liedern mit rebellisch-sozialkritischer Ausrichtung und Wildererliedern, in denen die typische Motivik allein für Unterhaltungszwecke genutzt wird. In den folgenden Jahrzehnten treten landschaftliche Idylle und erotische Aspekte immer stärker in den Vordergrund und prägen das Bild der Alm- und Sennerinnenlieder, die von sogenannten ,Nationalsängern' auch außerhalb des süddeutschen Raums populär gemacht wurden. Die Figur des Wilderers konnte dabei auch in den Hintergrund treten und wie etwa in Last sich schon der Frühling sehä durch einen Bauernknecht ersetzt werden. Das Moment des subversiven Gesetzesbruchs verlor sich weitgehend.

Es ist freilich nicht immer ein idealisiertes, da soziale Ungerechtigkeiten ausgleichendes Vergehen, das im Volksgesang zum Thema wird. Auch Verbrechen aus eigennützigeren Beweggründen fanden im Liedgut ihren Ausdruck, wie der gesang von Pachauer dani belegt. ${ }^{153}$ Das Räuberlied beruht auf historischen Begebenheiten und thematisiert die Geschichte des 26-jährigen Innviertlers Anton Honeder (auch Haneder, vulgo Pachauer Dani), der sich mit anderen zu einer Diebesbande zusammentat und nach einem Raubzug über Passau nach Wien floh. Die Wege und Stationen seiner Flucht sind im Lied nachgezeichnet, die Verfolgungsjagden und heiklen Situationen mitunter lebhaft ins Bild gesetzt. Als dem Delinquenten das Beutegeld ausging und er den Heimweg anzutreten gezwungen war, wurde er aufgegriffen, verhört und schließlich ans zuständige Gericht ausgeliefert. In Ungewissheit über sein weiteres Schicksal und mit einer langatmigen Anrufung der Mutter Gottes endet der Gesang:

152 Lorenz Hübner: Beschreibung des Erzstiftes und Reichsfürstenthums Salzburg in Hinsicht auf Topographie und Statistik. Zweyter Band. Das Salzburgische Gebirgland. Pangau, Lungau, Pinzgau. Salzburg: Im Verlage des Verfassers. Gedruckt bey F. X. Oberer 1796, S. 395f. - Bei Hübner unter dem Titel Der Wildbretschütze.

153 Das Lied ist ohne Melodie, in zwei Varianten überliefert: einerseits in 30 Strophen im Stubenberger Gesängerbuch (Bayerische Staatsbibliothek, Cod germ. 7340, Teil 2, S. 96-99), andererseits als 26-strophige Fassung im ,Neuen Schreibbuch der Familie Perner Mondsee‘ von 1827 (mit unklarem Verbleib, möglicherweise in Privatbesitz). Das Lied liegt in mehreren Editionen vor, die teils auch umfassendere Kommentierungen liefern; siehe Ernst (Innviertler Spuren, S. 36ff. zur Fassung der Stubenberger Handschrift), Leopold Schmidt (Eine Mondseer Liederhandschrift von 1827. In: Jahrbuch des österreichischen Volksliedwerkes 13 (1964), S. 12-44, hier 40ff.), Pörnbacher, Bayerische Bibliothek III, S. $1155 f f$. u. S. 1220 zur Fassung der Mondseer Handschrift); für die historisch-biographische Verortung siehe Herbert Klein: Zum Antoni-Honeder-Lied von 1790. Der Wirklichkeitsgehalt einer altsalzburgischen Moritat. In: Jahrbuch des österreichischen Volksliedwerkes 15 (1966), S. 56-62, hier $56 \mathrm{ff}$. 
1

Neun und achtzig hat Man gschribm, da reist ich fordt in die frembde, auf Bärtlme da wirds ä Jahr, käm ich zue raubers Bende, aein halbö stundt von wassä wökh, Bein freybaurn thuedt mans nennä, Beim zimmer Jägl heuslman, dort seind wür zammä kemmä, 2

Da käm der schneider Sepel her, der dät mi angäschieren, der Jägl von hoch-kuchl ä däbe, dö zwen thun Mich verführen, der schündä Man von Pokh in Bach, und speitl-geist zwen Prieder, geh dani sagns geh ä mit uns, geld gnue kriegn mir ä n jeder, 3

So Bald wür uns habm vndteredt, auf Lauffen seind wür eini, da käm uns Endtgögn der hiebl-Pökh, ein Man ist gar ein kleinä, er führt uns hin in das haus, - - und gäb uns Pier und Brodt, und lies uns kochä än guetten schmauss, und leiden gar kein Noth, 4 Zumb schlaffen ham mir Pöthö ghabt, dö rueh dät uns scha daugn, den andern Tag wie Nacht ist warn, da seind wür fordt ins raubm, ein viertl stundt von lauffen wökh, Beim wimbaurn thuedt Mans nenna, beim stadl hind habms ä ein thüer, dort seind mir eini kemmä, 5 So bald als wür in haus drin wärn, gley alsand ham mirs Bunden, und suechten alle truhen aus, kaey geld ham mir nicht gfunden, die Beyrin dät uns selbä sagn, verborgen ligts im kasten, der schneider Seperl fands älaein, der däts gley aussä raschtn, 6 Ich nähm mein geld auf Praunau mit, da bin i gley aufkemmä, wan i hingieng wo ich wolt, - - seind stökh-Brieff nachä kemmä, der Lämpl wirth von obernberg, hat gar ä scheni tochter, Bey der Blib ich drey tag dort, und dät mi Lustig Machä, 7

Den vierdten tag um Neun uhr frueh, seind Sechs Saldatten kemmä, der ambtman knecht ist ä darbey, und woln mi gfangä Nehemä, Bey der thür hind sprung i aus, - - Ren zwey Soldaten nider, und hab mir denkht jezt hets mi ghabt, jezt sechts mi weitter Nimmer, $[\ldots]$

14

In der Wiener stadt da war i drunt, Mehr dan als zöhä wochä, hab hundtert guldä geld verschlagn, und ka mir kaeis mehr Machä, i mues geh wider raeissen $\mathrm{z}$ haus, mein Peutl der hats schwinden, hab kradt Mehr ä Sechs guldä geld, wie werd i aussi finden, 15

$\mathrm{Zu}$ wien und drunt in oesterreich, da wars mir scha guet gangä, so bald i käm ins Rieder gricht, dort wurd i gfangä gnumä, i gäng zum strikhä nanäl hin, zu Ebersperg thuedts Mans Nenä, da sän i und zwaey kerln, weis nöth wie zammä kemmä, $[\ldots]$ 20

Den fünften tag umb acht uhr frueh, da kam der ambtman zwegen, ziech an dein rokh setz auf dein huedt, zumb Pflöger Muest mit gehen, und wie i käm zumb Pflöger hinein, haeist er Mi Nider Sizen, und schaut mi ganz sauer an, mit seinen augen Blizen, 
21

Sag an du kerl, wo kimbst du her, und wer hat di gfangä,

und wer seind deine kammerraden, die mit dir seind gangä,

ach her Pflögä i ken sie Nicht, und kan ä kaein Nehnä,

weil i Bi den kradtn wökh, von Wien erst aussä kemmä,

22

Da Müest i wider ins loch hinein, und zohä wochä sizen,

da habms mi erst auf Braunau gführt, da kämmän mir scha d schüzen,

Beim ambtman hoffer Bleibm mir $\mathrm{z}$ Nacht, den andern tag auf lauffen,

und zuri zu den gräniz grabm, dort daeins mi erst verkauffen,

$[\ldots]$

26

Der her Pflögä hat än wizigä kopff, es ist nicht zumb trauen,

da suech ich meine gröste hilff, bey unsser lieben frauen,

o Muetter gottes steh mir bey, und thue Mi nicht verlassen,

wan ich als-dan sterben Mues, führ Mich dö rechte strassen, $[\ldots]^{154}$

1,2 Bärtlme] Festtag des Hl. Bartholomäus ist der 24. August 1,4 zammä kemmä] zusammengekommen 2,4 dani] Toni 3,1 Lauffen] Laufen in Oberbayern 5,4 aussä raschtn] herausreißen (?) 14,2 kaeis] keines 14,4 aussi] hinaus

Honeder könnte das formal wie stilistisch äußerst ungelenke Lied während seiner Haft zu Laufen im Jahr 1790 selbst verfasst haben; die vielen Details, die Erzählhaltung und künstlerische Anspruchslosigkeit sprechen zumindest nicht dagegen. ${ }^{155}$ Zudem zeichnet der Text kein negatives Bild des nun reuigen Sünders, dessen Schicksal anderen wohl als Lehre dienen sollte. Die Stubenberger Handschrift überliefert mit Steh auf, meine Selle ein weiteres, chronologisch anschließendes Lied aus der Perspektive Honeders. ${ }^{156}$ Es behandelt seine drohende Hinrichtung, streicht seine Reue heraus und berichtet schließlich - nach einem thematischen Bruch - von der Begnadigung durch den Erzbischof von Salzburg, worauf etliche Dankesbekundungen folgen. Das Urteil hätte am 12. April 1791 vollstreckt werden sollen, doch erfolgte angeblich im letzten Moment die Begnadigung zur dauerhaften Inhaftierung; noch im selben Jahr soll Honeder durch das Wirken adeliger Fürsprecher entlassen worden sein. ${ }^{157}$

154 Bayerische Staatsbibliothek, Cod. germ. 7340 (Stubenberger Gesängerbuch), Teil 2, S. 96-99.

155 Vgl. Klein, Zum Antoni-Honeder-Lied, S. 56 und Pörnbacher, Bayerische Bibliothek III, S. 1220. Ernst vermutet dagegen einen Autor, der mit dem Gerichtsfall näher vertraut war, wie den Pfleger oder den Gerichtsschreiber von Laufen. Ob die gebildeten Amtsleute allerdings ein derart holpriges Werklein fabriziert hätten, sei dahingestellt.

156 Bayerische Staatsbibliothek, Cod. germ. 7340 (Stubenberger Gesängerbuch), Teil 2, S. 99-100.

157 Vgl. Ernst, Innviertler Spuren, S. 39. 


\section{LAND- UND STADTLEBEN}

Seit Mundart bewusst als von standardsprachlichen Formen abgehobenes literarisches Mittel im bairisch-österreichischen Sprachraum verwendet wird, dient sie vorrangig zur Charakterisierung eines nicht-privilegierten, unterschichtennahen Umfelds. Durch die dialektale Formulierung konnte hier im Abgleich von Ausdruck und Lebensraum bzw. sozialer Stellung des Sprechers eine weitaus realistischere Szenerie geschaffen werden als mit standardnaher, mündlichkeitsferner Literatursprache. Die autochthone Sprachform signalisierte zum einen die Authentizität des im Fiktionalen Vorgeführten, suggerierte also soziale Lebenswahrheit für einen regional zuordenbaren Kontext. Zum anderen aber (und besonders stark im mehrheitlich katholisch geprägten Süden des deutschen Sprachgebiets) hob sie früh auch bereits komisierend auf die Inkompetenz des Sprechers ab, in gewissen Situationen die angemessene Sprachform zu wählen, also auf das Unvermögen, ,literal' zu denken und sich der (dialektale Varianten überdachenden) Schriftsprache zu bedienen. ${ }^{1}$ Nicht also die Mundart an sich bot den Anreiz zum Lachen; denn diese war im Alltag die bevorzugte Sprachvarietät aller Sozialschichten bis hin zu den Spitzen der Gesellschaft. ${ }^{2}$ Es war die intellektuelle Distanz zu den Usancen der Schriftkultur, die als dominantes Kennzeichen des Dialektsprechers - im pejorisierenden Sinn ebenso wie als positiv konnotierter Mehrwert - in literarischen Texten zur Geltung kam. Dass dies seit den Anfängen im 17. Jahrhundert vor allem bei Figuren aus ländlichen Gegenden zu beobachten ist, kann schon angesichts der damaligen Bevölkerungsverteilung und der äußerst limitierten Bildungsmöglichkeiten im stadtfernen Raum nicht verwundern. Noch im Jahr 1800, nach Jahrzehnten der staatlich geförderten Propaganda gegen die dialektale Alltagssprache, konstatierte der oberösterreichische Benediktiner Matthias Höfer einen alle Schichten umfassenden Gebrauch der Mundart, differenzierte aber drei stratifikatorische Ausprägungen:

Die Sprache an sich selbst betrachtet, richtet sich nach der Verschiedenheit des Standes. Gleichwie die Art, sich zu kleiden, nach dem Ausdrucke des Pöbels, dreyfach ist: 1) städterisch oder herrisch; 2) markisch, wie es unter gemeinen Bürgern in den Marktflecken üblich ist; und 3) bäurisch. Eben so verhält es sich auch mit der Art und Weise, im Reden sich auszudrücken. ${ }^{3}$

$1 \mathrm{Zu}$ der mediengeschichtlichen Differenzierung zwischen oraler und literaler Komposition, der Abgrenzung von Phänomenen der literarischen Mündlichkeit zu jenen der Schriftlichkeit bzw. den bewusstseinstheoretischen Implikationen des Wechsels von einer oralen zu einer, überlegenen literalen Kultur vgl. u. a. Walter J. Ong: Oralität und Literalität. Die Technologisierung des Wortes. Opladen: Westdeutscher Verlag 1987. - Ludwig Jäger: Der Schriftmythos. Zu den Grenzen der Literalitätshypothese. In: Ludwig Jäger/ Erika Linz (Hg.): Medialität und Mentalität. Theoretische und empirische Studien zum Verhältnis von Sprache, Subjektivität und Kognition. München: Fink 2004, S. 327-345.

2 Vgl. Peter Wiesinger: Das Verhältnis von Dialekt und Schriftsprache in Österreich und die literarische Verwendung von Dialekt vom 16. bis zum 18. Jahrhundert. In: Christian Neuhuber/Elisabeth Zehetner (Hg.): Bairisch-österreichischer Dialekt in Literatur und Musik 1650-1900. Graz: Leykam/Universitätsverl. 2015, S. 9-39, S. $16 \mathrm{f}$.

3 Matthias Höfer: Die Volkssprache in Oesterreich vorzüglich ob der Ens, nach ihrer innerlichen Verfassung und Vergleichung mit anderen Sprachen. Wien: Binz 1800, S. 56. 
Im Allgemeinen wird mundartliches Sprechen in der bairisch-österreichischen Literatur vor 1800 mit ,bäurischem' Sprechen identifiziert. Schon die frühesten Beispiele nehmen ihre Protagonisten aus der Bauernschicht, deren Alltagssorgen und -nöte je nach Standpunkt und Intention eher realistisch oder karikierend ins Bild gesetzt werden. Zunächst sind beide Aspekte - Mitgefühl heischende Klage sowie Spott zur Unterhaltung und Disziplinierung - zumeist miteinander verbrämt. Neben die Darstellung klischeehafter Verhaltensformen der Dörfler wie Raufsucht, Trinkfreudigkeit, Unzivilisiertheit oder Engstirnigkeit tritt schon in den frühen Bauernklagen ein weitgehend ungebrochenes Lamento über ungerechtfertigte Abgaben, Dienste und Unterdrückung, wie sie in weiten Teilen des alpenländischen Gebiets zu finden waren. Vieles davon wird durchaus wirklichkeitsnah angesprochen, doch gehören scherzhafte Töne und die topische Sehnsucht nach dem sündhaft-lächerlichen Ordo-Bruch noch lange zum Inventar der gängigen Bauernklagen. Erst bei späteren Beispielen ab der Mitte des 18. Jahrhunderts verliert sich der spöttische Duktus - ein Spott, der natürlich in den beliebten Bauernschelten verabsolutiert wird, aber selbst im gedichteten Bauernlob häufig zu vernehmen ist. Vielleicht waren diese Loblieder, die sich wie Widerrufe der Bauernklagen lesen und Standesstolz suggerieren sollten, gleichfalls gezielt von den Obrigkeiten lanciert, um den Sozialfrieden zu wahren.

Positive Aspekte des bodenständigen Lebens in den Bauernlobliedern werden zumeist im Kontrast zum urbanen Leben vermittelt, dessen Konventionen den grundlegenden Bedürfnissen zuwiderliefen. $\mathrm{Zu}$ den Hauptangriffspunkten der dialektalen Stadtpolemiken gehören Neuerungswut und Modetorheiten, Bildungs- und Repräsentationszwang, aber auch die grotesken Auswüchse der Affektkontrolle. Das unverbildete bäurische Verhalten wird im Kontrast dazu zum Ausdruck der Natürlichkeit und Aufrichtigkeit umgedeutet. Standeslieder für Berufsgruppen, die aus der komischen Abwertung des Fremden (oft auch wieder ironisch gebrochene) identitäre Profile konstruieren, sind in der Dialektkunst häufig anzutreffen. Ob auf Binder, Weber, Schneider oder auch Lumpensammler und Fiakerfahrer gemünzt, stehen diese Lieder in ihrem scherzhaften Ton der Typenkomik des Theaters nahe, wo sie denn auch häufig entstanden, um dann im Volksgesang aufzugehen. Von der Geräuschkulisse des städtischen Alltagslebens ließen sich die beliebten Kaufruf-Quodlibets und ,Tändlmarkt'-Musiken inspirieren; Stadtimpressionen vermitteln auch viele Singspiele, Dialogszenen oder die äußerst beliebten, über Brieffiktion vermittelten Stadtsatiren, die das urbane Volksleben aus dem naiven Blick eines Landmannes bis zur Kenntlichkeit karikierend nachzeichnen. 


\section{Inszenierungen des Bauernlebens: Klage und Lob}

Bauernklagen stehen am Beginn der bairisch-österreichischen Dialektdichtung und bleiben in ihren Variationen weit ins 19. Jahrhundert hinein beliebt. Wie Hermann Strobach in seiner heute noch als Standardwerk dienenden, freilich in vielen Details mittlerweile zu ergänzenden bzw. zu revidierenden Studie zeigte, sind die Gründe für die beinahe genretypische Gestaltungsambivalenz in ihren Ursprüngen zu suchen. ${ }^{4}$ Eine Traditionslinie ist im Theatralen zu finden, bei den närrischen und klugen Bauern des Fastnachtspiels und den manipulativen Darstellungen des gegenreformatorischen Schultheaters, die die Leiden des potentiell revoltierenden Bauern nicht negierten, aber sozialdisziplinär als angestammte Lage des mit komischen Zügen versehenen Landmanns vorführten. Dieser Charakterisierung, von oben', die auf die Unantastbarkeit der gottgegebenen ständischen Ordnung pochte, standen wesentlich mitfühlendere, anklagende Schilderungen in parteiergreifenden Flugschriften entgegen, die für den Bauernstand untragbare Zustände aufzeigten.

Der wirtschaftliche Druck, der auf den Bauern im 17. und 18. Jahrhundert lastete, war tatsächlich enorm. ${ }^{5}$ Gravierend genug waren bereits die oft willkürlich erhöhten landesfürstlichen Steuern (Landsteuer, Rüstgeld und Kopfsteuer), der Zehent für die Grundherrschaft, die vielfältigen Naturalienabgaben und die extrem zeitaufwändigen Robotdienste. Dazu kamen noch - je nach Region - die Freigelder und Veränderungsgebühren (bei Heirats- und Übergabeverträgen, bei Kauf und Schenkung), das Sterbhaupt (d. i. eine Viehabgabe bei Todesfall), die vielfältigen Taxen für Amtshandlungen und der Anfeilzwang, also die Pflicht, Produkte zuerst dem Grundherrn zum Kauf anzubieten. Die leibeigenen Bauern waren oftmals gezwungen, die grundherrschaftlichen Tavernen, Mühlen, Back- und Presshäuser zu verwenden und Erzeugnisse grundherrschaftlicher Betriebe zu erwerben, sie hatten nur ein eingeschränktes Verfügungsrecht über ihren Haus- und Grundbesitz und durften sich in vielen Gebieten nicht mit Umzäunungen gegen Wildschäden schützen. Zumal in Kriegszeiten verschärfte sich die Situation für die Bauern noch durch die Rekrutierung des Arbeitspersonals, die Requirierung von Zugtieren, Verpflegung und Futter sowie die Soldateneinquartierungen bei Truppendurchmärschen, ganz zu schweigen von den Verwüstungen durch feindliche Truppen oder den Folgen von Epidemien.

Schon die älteste uns überlieferte bairisch-dialektale Bauernklage greift viele dieser Aspekte auf. Daß paurn werkh ist ganz nix mehr werth, offenbar in der Nähe von Landshut entstanden, ist ab der zweiten Hälfte des 17. Jahrhunderts belegt und ver-

4 Vgl. Hermann Strobach: Bauernklagen. Untersuchungen zum sozialkritischen deutschen Volkslied. Berlin: Akademie-Verlag 1964.

5 Vgl. u. a. Werner Rösener: Die Bauern in der europäischen Geschichte. München: Beck 1993. - André Holenstein: Bauern zwischen Bauernkrieg und Dreißigjährigem Krieg. München: Oldenburg 1996. - Georg Grüll: Bauernhaus und Meierhof. Zur Geschichte der Landwirtschaft in Oberösterreich. Linz: Oberösterr. Landesarchiv 1975. - Georg Grüll: Die Robot in Oberösterreich. Linz: Oberösterr. Landesarchiv 1952. Sylvia Wurm: Die Bauern im 18. Jahrhundert. In: Adel - Bürger - Bauern im 18. Jahrhundert. Ausstellung des Landes Niederösterreich. Schallaburg '80. 1. Mai bis 2. November 1980. Wien: [o.V.] 1980. (Kataloge des niederösterreichischen Landesmuseums. NF. 96) S. 38-43. 


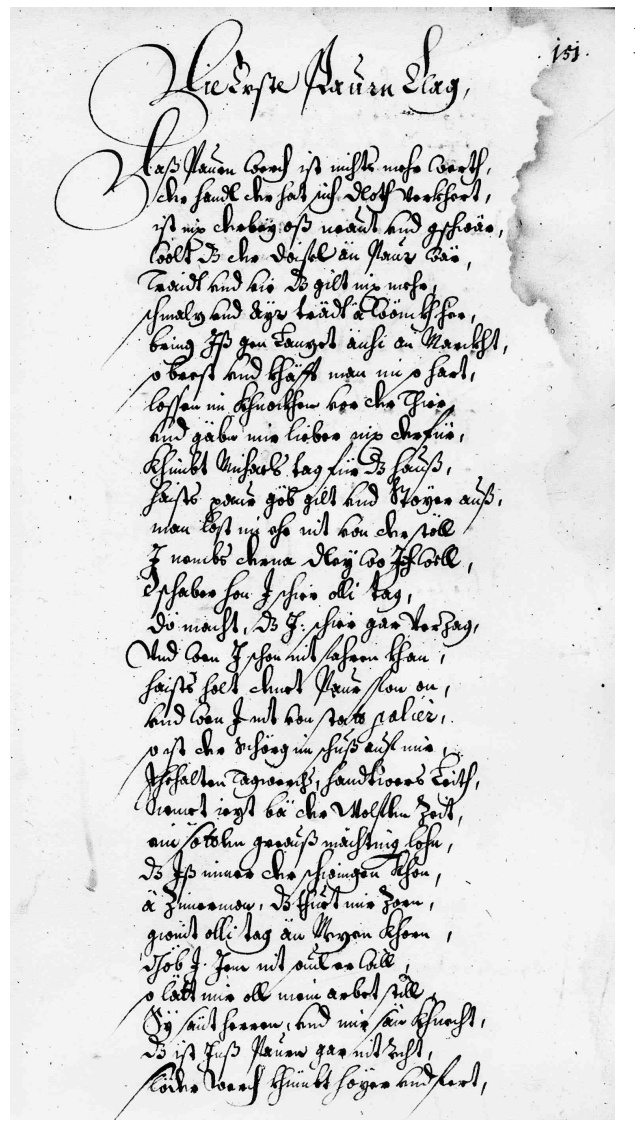

Abb. 22: Handschrift des Andreas Mayr (Universitätsbibliothek Tübingen, Md 290, f. 151r).

gleichsweise breit überliefert; Strobach ediert und vergleicht zwei gedruckte und drei handschriftliche Fassungen - die beiden letzten (D, E) aus jener Handschrift Ms. germ. qu. 1327 der Staatsbibliothek zu Berlin, aus der oben bereits das ,Halleiner Weihnachtsspiel' vorgestellt wurde (vgl. Kap. 1, S. 31). ${ }^{6}$ Die wohl älteste handschriftliche Variante ist bei Strobach jedoch noch nicht erwähnt. Sie stammt aus einem um 1670 in Bayern entstandenen Sammelband des Geisenhausener Pflegekommissars Andreas Mayr und ähnelt in weiten Teilen Strobachs Variante D, die auf eine ähnliche Vorlage zurückzuführen ist (ohne dass sich die Filiation hier mit Sicherheit klären ließe). ${ }^{7}$ Das

6 Strobach, Bauernklagen, S. 103-109. Zu den Varianten im Ms. germ. qu. 1327 vgl. Weinhold, Weihnachtsspiele, S. 173-185, der die wohl aus dem späten 17. Jahrhundert stammende Handschrift unseres Erachtens zeitlich zu früh verortet (Strobach folgt ihm darin).

7 Eine Transkription des Lieds inklusive umfangreicher Stellenkommentare und einer hervorragenden dialektologischen Verortung des Sprachstands findet sich bei Anthony Rowley, „Erste Paurn Clag“ und „,ander Paurn Clag": zwei mundartliche Bauernklagen aus der Mitte des 17. Jahrhunderts. In: Literatur in Bayern 27 (2012), H. 3, S. 20-29, hier S. 22f. und noch einmal (in derselben Fassung) bei Anthony R. Rowley, Was sy zLanzet zue hat tragn“: „Der Bauernsohn in der Kirche“ und die „Baurnklagen“. Drei westmittelbairi- 
Lied ist eine langatmige Aufzählung all der Beschwerden, die das Bauernleben mit sich bringt, mit Redundanzen und Sinnbrüchen, die darauf hindeuten, dass im Lauf der Entstehungs- und Tradierungsgeschichte Textbausteine aus unterschiedlichen Quellen zusammengefügt wurden. So beklagt das Rollen-Ich zunächst ohne komische Brechung den Preisverfall für landwirtschaftliche Produkte, die Steuerlast und Zwangsdienste, die Lohnkosten für Arbeitskräfte und hohen Ausstattungspreise, ehe es bildmächtig den tristen Zustand seiner dürftigen Wirtschaft beschreibt. Gründe dafür scheinen - hier wechselt das Lied in den Bauernspott - auch seine Alkoholsucht und Rauflust zu sein, sehr zum Missfallen der Ehefrau, die in der Folge ausführlich diskreditiert wird. Dann folgt wieder ein Teil mit einem sehr realen Problem, den Schäden durch das herrschaftliche Wild - ein Missstand, den abzustellen die Obrigkeit zumeist nicht gewillt war und der die artikulierten Wilderer-Fantasien nur allzu nachvollziehbar macht. Mit der traditionellen Pointe des lächerlich-unmöglichen Standeswechsels endet das Lied. Ob man es beim Ich des Lieds mit einem Berufsjammerer zu tun hat, mit einem Zerrbild oder mit einem tatsächlich existenziell Bedrohten, lässt sich angesichts dieses Hinundhers nicht eindeutig sagen; alle Facetten klingen an, oder anders gesagt: allen Rezipientenschichten wurde etwas geboten.

Die Erste Paurn Clag

1 Daß Paurn werch ist nichts mehr werth, der handl der hat sich dloth verkhert, ist nix derbey oß neaut vnd gschwär, wolt daß der doifel än Paur wär,

5 Traidt vnd vie das gilt nix mehr, schmalz vnd ayr trädt a wönckh her, bring Iß gen Lanzet änhi an Marckht, so brest vnd khäfft man mi so hart, lossen mi Khnockhen vor der Thier

10 vnd gäbn mir lieber nix derfür, Khimbt Michaels tag für das hauß, haists paur göb gilt vnd Stoyer auß, man lost mi ehe nit von der stöll I nembs derna dley wo Ich well,

15 d schaber hon I schier olli tag, dö macht, daß I: schier gar verzag, Vnd wan I schon nit fahren khan, haists holt denet Paur spon on, vnd wan I nit von statt palier,

20 so ist der Schörg im schuß auf mir, Ehehalten Tagwerch, handtwers Leith, Nemet iezt bä der Wolflen Zeit, ain sottlen greauß mächting lohn,

daß iß nimer der schwingen Khon,

25 ä zimermon, das thuet mir Zorn, gwint olli tag än Mezen Khorn, göb I Iem nit souil er will, so lätt mir oll mein arbet still Sy sänt herren, vnd mir sän khnecht,

30 das ist Ins Paurn gar nit recht, slöder werch khümbt hoyer vnd fert, schier gor derhin auf dritholbn werth, khäf I no schlet än lideres gräs, ä Jopen, Vnd am Ploder gsäss,

35 so geht mir drauf, vnd ist schon hin, än ganz Schof khorn oß clam I bin, Wan I än Khue aufs hechst verkhauf, Vmb Sechs, Sibn Guldn auf ein hauf so bringt der schuester seine schueg,

40 so heau hinauß oß I mein khue, der Mezger vnd der Lederer nüessen s Fleisch, I mueß den schaden biessen, Gölter sözen mir ä nit auß, laffent mir frie vnd spath vmbs hauß,

45 thuen mi stets Jurirn vnd schenden, wölln mir Roß und Khüe auß pfendten

sche Stücke aus der Mitte des 17. Jahrhunderts - Texte und Darstellung des Dialekts. In: Christian Ferstl/ Anthony R. Rowley (Hg.): Was sich in Landshut zugetragen hat - und anderswo. Beiträge zur Schmellerforschung und darüber hinaus. Regensburg: edition vulpes 2013 (Jahrbuch der Johann-Andreas-SchmellerGesellschaft 2012) S. 11-89, hier S. 33-35. Unglücklicherweise berücksichtigt er die ersten beiden Seiten der Handschrift nicht und geht von einem Liedbeginn auf f. 152r aus; somit fehlen diese Seiten auch in seiner Edition. 
der Khnet vnd diern wölln ä ihren lohn, zoll iß nit so läffens der von, Wo afer würdts auf dlest hinkhemen,

50 wo mueß der Paur dmitl nemmen, auf ollen seithen geht holt a, Wo I hin schau ist halt nix da, Waiß ä nit ain Kreüzer zschäzen ließ mi sünst khain gelter dräzen,

55 I hon drey Khüe ist khaini mein, khern oll drey in d Statt hinein, ho droy Roß ist khains nix werth, hinkht ains drinter hoyer vnd ferth, das ander hat kheine zan im Maull,

60 das dritt ist blinkh vnd sünst Stikh faull bin derzue die zway no schuldtig, das macht ain freylin vngedultig, hon Fünff hennan mochen vill gschray lät dernöben khaini khain ay,

65 Im Stodl ist wöder Stro no hey, der holz mist ist mein besti Strey, raucht im hauß vnd rengt mir ein, Iß Khundt ä schier nit lezer sein, woß will I lang vill sagn deruon,

70 Iß steht halt hinten vnd vornen on, sWürthshauß stiendt mir zum besten on, trag afer offt guet büff daruon, vnd ist der Dofferl Schürg ä bue, sözt mir auf allen seithen zue,

75 hon nächten mit mein nachbarn ghäckhlt, hon schlet ä wönckh on dnasen gschnäckhlt,

hat mi der Pfleger vnuerhofft, von statt vmb zway pfundt pfening gstrofft, I waiß nit mocht inß pier oß doll,

80 oder hauß I öppen sünst nit woll, bin in der Musterumb ä derzue, hon holt der lezen händl oß gnue, daß no än moll khain wunder währ, I gieng deruon ließ dhöber lahr,

85 Mein weib ist gar ä häfftigs pain, holt mi oß härth daß I offt main, I wöll mit ihr kurz vmb vnd vmb, gen freysün aufs Cristoricum vnd wöll mi von der leausn fröt,

90 adifitieren lassen ztisch vnd zbött, Ist schon aini auß den olten hat im Gsicht ä hundert Falten, ä kholschwarz har, wie mein schimel, Wär greausy Zeit mit ihr gen himel,

95 zankht vnd greint ä ganze wochen, khan khain guete suppen Khuchen, Plizt vnd dunert vmb im hauß, Ihaidt mi offt ganz vnd gahr hinauß, heint zeuchts mi döß, vnd morgen das,

100 haist für vnd für du schelm du fraß, Räffen offt in äm holbeten ta, dstuben ä vier mall auf vnd a, liesß offt von herzen gern deruon, greifft mi höppin selbm wider on,

105 vnd sözt mir holt oß lang nit auß, biß I ihrn Schedl woll der zauß, I wolt dö broz dö leauß nix werth, läg schon zdüefftist in der Erdt, wolt offten dley än anderi nemen,

110 Mecht I wider ä gelt bekhemmen, Yber das hon y no än blog, vnd ist ä schier mein maiste clog, dhürsch die mochet mi gar der drelt; do lign mir tag vnd nacht im Veldt,

115 frössen mir vmb im Traidt vnd Kraut, oß wenß für sy allain war Paut, gehn zwen greauß horner weith vnd fer, Von oltorff na der heckhen her, der än dickher faister Khnopf,

120 hat vierzechen zuckhen aufm khopf, Ist oben her braun vnd Inten gelb, main offt iß sey der Töifel selb, Springent einher yber dstrasßen, thuen mir schäden yber dmassen, mueß mi Tausent Prauset nüetten, khon holt denet nix der hieten, hon in der Point än Gabes bauth vnd hon zwen tag nit nachi gschaut Ist mirs vnzüfer dryber gsössen, 130 hot mirn mehr oß halb ä gfrössen, ä greausi sä läfft ä dermit, di geit ä ganzi nacht khain Fridt, mocht schlachten änhi, doiff in grundt, daß I mi drein verbergn khundt,

135 hongent an ihr acht Jungi fäckhel, sänt die maisten lauther Präckhel, Stürn vnd wielln im anger vmb, wen I schon schrey, sy göbn nix drumb, Mein Stuzl sözt Ien starckh aufft näth,

140 Iaidt fredi dründter früe vnd späth, der wäckherl oß wie an Polz, der Präntl Stöberts gar ins holz, Sprengens dapfer auf vnd a, Zmorgens sänts schon wider da,

145 hebn schletn Schnobel auf in d he, vnd fressen wider wie vor vnd ehe, Wen I ä moll an Pixen bekhäm, wolt I mi stellen hinder än bäm, vnd wolt aim ainß in dWampen geben,

150 daß er nimmer zwo stundt solt lebn, I honß bän Jägerer offt verclaidt, 
vnd hon ien olli wohret gsait, Sy solten do mit steckhen vnd Spiessen, dö abfröß dapfer nider schiessen,

155 Sy lassens afer fein mit rue, vnd spothent meiner no derzue, Ziglen $ß$ vnziffer fein mit Fleiß, holtens schlet für än Narren weiß, I mueß d hürsch vnd d Sau der nehren

160 sy thuens Fleisch vnd dheit verziehren wolt no än moll bä sötler gschwär, daß der doifel ä Paur wär,

Wär sünst än Mon vnd hets im hiern, khon im gsteifft akhrefodiren,

165 khunt I no schlet lösn vnd schreibn, I wolt nit lang än Paur bleibn, woltn Rockh nahm wötter khern, vnd wolt än Prockherierer wern, da het I zessen und zrünkhen gnue,

170 vnd gäb mir dapfer gelt derzue, mueß holt sehen, wie I yem thue. ${ }^{8}$

2 dloth] glatt (Assimilierung) 3 neaut] Not 5 Traidt] Getreide 6 trädt a wönckh her] trägt auch wenig ein 7 Iß] ich es gen Lanzet änhi] nach Landshut hin(ein) 8 khäfft] schindet 9 Khnockhen] knien 11 Michaels tag] Fest des Hl. Michael am 29. September, in den Bauernregeln Stichtag für Winterwetter und spätester Aussaattermin, Abgabentermin 12 gilt] Abgabe 14 derna dley] dennoch gleich $15 \mathrm{~d}$ schaber] das Scharwerk, der Frondienst 18 denet] dennoch, trotzdem 19 palier] (fälschlich für:) pariere, gehorche 20 Schörg] Gerichtsdiener, Scherge im schuß] sofort 21 Ehehalten] Gesinde, bäuerliche Arbeitskräfte 22 Wolflen] wohlfeil, günstig 23 sottlen] solchen 24 der schwingen] leisten, zahlen 26 Mezen] Trockenmaß, im süddt. Raum zwischen 20 und 30 Liter 28 lätt] liegt 31 slöder werch] das Lederwerk, die Arbeit mit Leder hoyer vnd fert] dieses und voriges Jahr 32 dritholbn] zweieinhalb(fachen) 33 schlet] schlechthin, bloß, nur lideres gräs] lederne Kröse, Halskrause 34 Ploder gsäss] Pluderhose, gepluderte Lederhose 36 oß clam] so klamm, schlecht bei Kasse 43 Gölter] Gläubiger 47 Khnet vnd diern] Knecht und Magd 54 dräzen] necken, peinigen 60 blinkh] Verschreibung für ,blind“ (s. das folgende,Stick') 64 lät] legt 68 lezer] schlimmer 72 büff] Schläge 73 Dofferl] Kurzform für Christoph 75 nächten] gestern ghäckhlt] gestritten 80 öppen] etwa 81 Musterumb] Musterung 82 lezen händl] schlimmen Dinge, Umstände 84 dhöber] die Herberge 88 freysün] Freising Cristoricum] Verballhornung für ,Gericht' 89 leausn fröt] Schimpfwort (lose Fretten) 90 adifitieren] Verballhornung aus ,divideren', trennen 98 Ihaidt] wohl fälschlich für, iaidt': jagt, treibt 99 zeuchts] zeiht sie, wirft sie vor 101 holbeten ta] halben Tag 103 liesß] wohl Verschreibung für ,lief 104 höppin] Kröte 105 sözt mi ... nit auß] hört nicht auf (mir zuzusetzen) 106 der zauß] zersause 107 broz] Kröte dö leauß] die lose, nichtsnutze (oder ,Muttersau'?) 108 zdüefftist] so tief wie möglich 113 mochet mi gar der drelt] bringen mich ganz aus der Fassung, machen mich fertig (,dertrielen') 117 horner] Hirschen 118 oltorff] Altdorf (im niederbayerischen Landkreis Landshut) 120 zuckhen] Zacken, Geweihenden 125 Tausent Prauset] tausendprausend, über alle Maßen (vgl. Greiffenberg, Geburtsbetrachtungen, 1049) nüetten] sich mühen, plagen 127 Point] Beunt: kleines, meist umzäuntes Grundstück, das für einen besonderen Anbau vorgesehen war und so dem Gemeindeviehtrieb verschlossen blieb Gabes] Kraut, Kohl 131 sä] Wildsau, Wildschwein 132 geit] gibt 133 schlachten] Furchen, Schneisen 136 Präckhel] unförmiges, grobschlächtiges Wesen 137 stürn] stochern, stöbern, suchend wühlen 136 Stuzl] Hundename sözt Ien ... aufft näth] setzt sich ihnen auf die Fersen, ist hinter ihnen her 140 fredi] kühn, tapfer 141 wäckherl] Hundename oß wie an Polz] (zu ergänzen: läuft) schnell wie ein Bolzen (einer Armbrust) 142 Präntl] Hundename 145 schletn] nur 151 verclaidt] verklagt, angezeigt 152 olli wohret gsait] die ganze Wahrheit gesagt 154 abfröß] Fresser, Schädlinge 161 bä sötler gschwär] bei solchen Beschwerlichkeiten, bei derart misslichen Zuständen $164 \mathrm{im}$ gsteifft] hervorragend akhrefodiren] latinisierendes Nonsenswort $167 \mathrm{nahm}$ ] nach dem 168 Prockherierer] Verballhornung aus Prokurator, Gerichtsbeamter

Bauernklagen wie diese begegnen uns in den folgenden Jahrzehnten gerade im bairischösterreichischen Raum - vor allem auch in standardsprachlicher bzw. standardnaher Form - zahlreich. ${ }^{9}$ Zuweilen sind sie als Gesangseinlagen im dramatischen Kontext zu finden; nicht zufällig ist eine Variante des oben zitierten Lieds mit Rollenaufteilung auf ,Hauser ${ }^{`}$ und ,Hännsl' in einem Codex mit Weihnachtsspielen überliefert. ${ }^{10}$ Der sein

8 Universitätsbibliothek Tübingen, Md 290 (Beschreibung Etlicher Geist: und Weltlicher Lieder und Sprüch), f. $151 \mathrm{r}-153 \mathrm{v}$

9 Vgl. Strobach, Bauernklagen.

10 Vgl. Daß Paurnwerch ist nichts mehr werth, Staatsbibliothek zu Berlin, Ms.germ.qu. 1327, f. 124ff; ediert bei Strobach, Bauernklagen, S. 103-107. 
hartes Dasein klagende ,Hirten-Bauer' konnte mühelos in die Handlung integriert werden, ja unterstrich in der exponierten Bedürftigkeit noch die frohe Botschaft des Mensch gewordenen Erlösers. ${ }^{11}$ Auch als kontrastiver Akzent ließ sich älteres Liedgut wiederverwerten, wie das Standeslied Das Bauernleben, ich sags grad eben im Traismaurer Krippenspiel belegt.

Bauernklagen konnten aber auch Teile anderer Liedformen sein und funktionale Aufgaben darin übernehmen; so etwa im sozialkritischen Wildererlied (vgl. Guetten Tag mein Lieba Jodl, Kap. 3), wo die existenziellen Nöte der Bauern als Rechtfertigung des Gesetzesbruchs dienen, oder selbst im Liebeslied wie in Alle Leut sehens nicht gern (vgl. Kap. 7), wo Versatzstücke aus diesem Genre den sozialen Kontext umreißen. Ein sehr altes Liedamalgam aus Bauernklage und bramarbasierendem Landsknechtwerbelied ist Wem klag ich Elender Bauer Mein Noth, das uns erstmals 17-strophig 1677 in der ältesten Fassung des Singbuchs Ehrliche Gemüths-Erquickung begegnet, etwas stärker dialektal dann in einer gut ein Jahrhundert jüngeren handschriftlichen Version, ${ }^{12}$ die - mit wenigen Abänderungen - erstaunlich unzersungen erscheint. ${ }^{13}$ Der jammernde Bauer fasst in dieser Klage den Entschluss, sich anwerben zu lassen, um der alltäglichen Misere zu entgehen:

1

WEm klag ich elender Bauer mein Noth/ was muß ich doch anheben? sollt einer lieber seyn tausendmahl todt/ als so elendig leben/

bey Tag und bey Nacht/

der Buckel mir kracht/

und ist das ewig Geben.

3

Sitz in elenden Häusel beym Weib/

die alt hebt an zu gronen/

da wird mir umbkhert der Magen in Leib/

thuet meiner nicht verschonen/

pentzt ewig und greint/

und ist mir so feind/

ich kan mit ihr nicht wohnen.
2

War ich vor Zeiten ein lustiger Bue/ war keiner meines gleichen/ jetzt hab ich ja gar kein Augenblick Ruhe/ das Glück von mir will weichen/ wie wirds mir noch gehn/ ich kann nicht bestehn/ kein Mensch will mir was leichen. 4

Die Höppin gibt mir alle göltige Tag/ nichts als stainharte Knoden/ sie waiß daß ich nichts von Habermel mag/ und seynd kaum halb gesodten/ gar garschtig und sper/ da nimb ich halt her/ und schmitz sie an den Boden.

11 Vgl. auch Leopold Kretzenbacher: Frühbarockes Weihnachtsspiel in Kärnten und Steiermark: Klagenfurter und Grazer Weihnachtsspieltexte des frühen 17. Jahrhunderts als kulturhistorische Denkmäler der Gegenreformation in Innerösterreich. Klagenfurt: Geschichtsverein für Kärnten 1952. (Archiv für vaterländische Geschichte und Topographie) S. 22. - Weinhold, Weihnacht-Spiele, S. 154, 215.

12 Vgl. Wienbibliothek im Rathaus, H. I. N. 215903 (Wem klag ich Elender Bauer Mein Noth).

13 Sprachlich relativ weit entfernt von diesen beiden Fassungen ist das standarddeutsche Wem klag ich armer Bauer meine Noth, das Ditfurth 1875 aus einem alten geschriebenen Liederbuch wiedergibt. Vgl. Franz Wilhelm von Ditfurth (Hg.): Einhundertundzehn Volks- und Gesellschaftslieder des 16., 17. und 18. Jahrhunderts mit und ohne Singweise. Nach fliegenden Blättern, handschriftlichen Quellen und dem Volksmunde gesammelt. Stuttgart: Göschen 1875, S. 237-240; wiederabgedruckt in Strobach, Bauernklage, S. $289 \mathrm{ff}$. 
5

Da fangt das Donnern und Blitzen erst an/ als wolt sie mich grad schlagen/ daß ich im Häusel verbleiben nur kan/ darff ich kein Wörtlein sagen/ und bin noch darzue Ihr Laußiger Bue/ möcht ainer schier verzagen. 8

Hat mich erst nächsten in Kotter gesteckt/ bin drin acht Tag gesessen/ biß ich vor Hunger schier halbet verreckt/ weil ich nicht ghabt zu fressen/ mein Gott und mein Herr/ es gieng mir gar sper/ ich kan ihms nicht vergessen. 9 So mag ich einmahl kein Bauer mehr seyn, ich wills hald rund bekennen/ das Landsknecht Leben fällt mir gar stäts ein/ zum Hauptmann will ich rennen/ ain Thaler ä nein/ so nimb ich gschwind ein/ laß mich ein Landsknecht nennen.
6

Bald kombt der Pfleger und hudelt mich sehr/ man kan ihm nicht gnueg geben/ er schreyt halt immer mein Bauer gib her/ und führt mit mir ein Leben/

bald Steuer von Hauß/

bald Grundrecht darauß/ das Ristgelt noch darneben. 7

Wo sollt ich nehmen gar alleweill Gelt/ hat mir verderbt der Schauer/ der Pfleger dannoch ungütlich anhelt/ er macht mir gar zu sauer.

Wanns Geben so werth/ und nimmer auffhört/ der Teuffel sey ein Bauer.

10

Mein ödes Hüebel ich geren verlaß/ mag mich nicht länger scheren/ das Essen / und Trincken gefallt mir viel baß/ die Arbeit wird auffhören/ afft lig ich in Feld/ hab Zessen und Gelt/ was wolt ich mehr begehren. [... $]^{14}$

1,6 Buckel] Rücken 3,2 gronen] schimpfen, maulen, murren 3,5 pentzt] nörgeln, keifen greint] zankt, streitet 4,1 Höppin] Kröte 4,2 Knoden] Knödel, aus Mehl oder Grieß zubereiteter Kloß 4,5 sper] trocken 6,1 hudelt] bedrängt, setzt zu 6,7 Ristgelt] Rüstgeld: Zwangsabgabe für Ausstattung und Unterhalt des Heeres 7,2 Schauer] Hagel 7,5 werth] anhält, weitergeht 8,1 nächsten] vor kurzem Kotter] Gefängnis, Arrest 9,5 ain Thaler ä nein] etwa 9 Taler 10,1 Hüebel] kleiner Bauernhof (bis etwa 10 Joch) 10,5 afft] dann

Wie lange diese Bauernklagen in verschiedenen Kontexten zirkulierten - ob über gedruckte Flugschriften oder in mündlicher Weitergabe, die zuweilen durch handschriftliche Sammlungen belegt ist -, illustriert die anhaltende Notlage großer Teile der Bevölkerung im süddeutschen Raum. In Österreich etwa brachten erst die nach physiokratischen Prinzipien durchgeführten Reformen Maria Theresias tatsächlich eine Verbesserung der Lebensumstände des Landvolks, das nun eine neue Wertschätzung erfuhr. Da man erkannt hatte, wie wichtig der Bauer als Produzent für die Nahrungs- und Rohstoffversorgung des Reichs, als Steuerzahler für den Staatshaushalt und als potentieller Soldat für die Armee war, bemühte man sich, für günstigere soziale Bedingungen zu sorgen. Hatten die Grundherren in den Jahrzehnten zuvor zur Finanzierung ihres aufwändigen barocken Repräsentationsstils oft genug die Abgaben und Frondienste willkürlich erhöht, ${ }^{15}$ sollte dem Bauernstand nun eine größtmögliche Rechtssicherheit

14 Ediert nach der Fassung der Klagenfurter Ausgabe: Ehrliche Gemüths-Erquickung Welche in sich begreiffet 57. vnderschidliche annembliche Gesänger / Deren Theils Geistlich- theils Weltliche / jedoch mit trostreichen / ehrlich- und sittlichen Lehren vndermischet / und Zu Sondern Ehren Allen ehrlichen Gemüths-Erquickern in 2. Theil zusammen getragen / vnd mit einem kurtzen Register verfasset. Erster Theil / Clagenfurth / Bey Matthias Khleinmayr / Löbl. Landsch. Buchdruckern. Anno 1691, S. 67-69.

15 Vgl. Grüll, Bauernhaus und Meierhof, S. 50-109. 
gegeben werden. Die öffentlichen Funktionen der Herrschaftsbesitzer wurden aus diesem Grund weitgehend den landesfürstlichen Beamten der neu geschaffenen Kreisämter und Distriktskommissariate übertragen (bis dahin konnten etwa Beschwerden über grundherrschaftliche Belange absurderweise nur bei grundherrschaftlichen Behörden eingereicht werden). Weitere Maßnahmen zum Bauernschutz waren u. a. die Aufhebung der Robotpflicht bei Viehkrankheiten, die Abschaffung des Anfeilzwangs im Zuge der großen mitteleuropäischen Hungersnot oder die Robotabolition, also die Möglichkeit, sich von Robotdiensten freizukaufen. Selbst die von den Bauern beargwöhnte theresianische Steuerrektifikation von 1749 hatte insofern positive Auswirkungen, als in einer sechs Jahre später eingeforderten Ergänzung die Gültenbesitzer zur Aufzeichnung aller Hand- und Zugrobote angehalten wurden. ${ }^{16}$ Die Volkszählung und Hausnummerierung von 1770-1772 machte zwar die bäuerliche Jugend für den Armeedienst verfügbar, objektivierte aber auch das zuvor oft willkürlich gehandhabte, korrumpierte Rekrutierungsverfahren. ${ }^{17}$

Ein Umdenkprozess in der Bewertung der bäuerlichen Sozialumstände lässt sich auch im Werk des bedeutendsten Verfassers dialektaler Bauernklagen ablesen. Maurus Lindemayrs Bauernbild ist in der frühen Phase seines Schaffens noch weitgehend beeinflusst vom barocken Bauernspott, wie er im Ordenstheater und auf den höfischen Bühnen der vorangegangenen Jahrzehnte häufig zu sehen war. In seinen frühen Singspielen wie Der von der Hochzeit zurückkommende Hanns wird durch eitle Furcht von der Saufsucht befreyet propagierte auch er noch den Typus des hedonistischen Bauerntölpels, der nur durch Einschüchterung und Gewalt zu einer einigermaßen annehmbaren Lebensführung genötigt werden kann. Auch seine ersten Rollenlieder mit lamentierenden Bauern wie Wann dä Baur Händl hat und Keyerey oder So gar vätoifelt schlecht weisen noch dieselben Brüche auf wie die älteren Vorbilder, mit karikierenden Passagen und der in Aussicht gestellten lächerlichen Unterwanderung des Ordo-Gedankens neben durchaus realistisch geschilderten Elendsszenarien. Zur Unterhaltung der, geistlichen Herrn ' verfasst, diente die Verlachkomik dieser Lieder nicht zuletzt der Stabilisierung bestehender Herrschaftsverhältnisse. Der mundartliche Ausdruck stand hier als soziales Stigma vor allem für den Kontrast zwischen ungebildeter und überlegener gebildeter Schicht, zwischen Beherrschten und Herrschern. Seine Erfahrungen als Seelsorger im bäuerlichen Umfeld aber lassen Lindemayr schon bald neue Töne finden. Vertraut mit den alltäglichen Sorgen seiner Gemeinde weicht nun die lächerliche Verzerrung einer großteils durchaus realistischen Darstellung der Notlage, die mit Einfühlungskraft

16 Vgl. Georg Grüll: Bauer, Herr und Landesfürst. Sozialrevolutionäre Bestrebungen der oberösterreichischen Bauern von 1650 bis 1848. Graz/Köln: Hermann Böhlaus Nachf. 1963, S. 371.

17 Vgl. Anton Tantner: Ordnung der Häuser, Beschreibung der Seelen. Hausnummerierung und Seelenkonskription in der Habsburgermonarchie. Innsbruck/Wien/Bozen: Studien-Verl. 2007. - Michael Hochedlinger/Anton Tantner (Hg.): „... Der größte Teil der Untertanen lebt elend und mühselig“. Die Berichte des Hofkriegsrates zur sozialen und wirtschaftlichen Lage der Habsburgermonarchie 1770-1771. Innsbruck/ Wien/Bozen: Studien-Verl. 2005. (Mitteilungen des Österreichischen Staatsarchivs: Sonderband 8). 
und Glaubwürdigkeit nachgezeichnet ist. Lieder wie I kann mäs unmiglä nöt denkä, Mein Endl hats längst prophizeit oder I wais nöt was mär jezund habm faszinieren mit der Bildlichkeit ihrer Detailbeobachtungen, die den Bauernalltag ohne jegliche Idealisierung, doch mit Anteilnahme vorführen.

In engem Zusammenhang mit seinen frühen Bauernklagen aus den 1750er Jahren steht Lindemayrs Hänts Baurn, wer hets glaubt vor fufzg Jahrn, das gut ein Vierteljahrhundert später entstand und zunächst im Ton des äußerst populären I kann mäs unmiglä nöt denkä gesungen werden sollte (wohl erst nach dem Tod des Autors entstanden zwei eigenständige Vertonungen). Diese musikalische Aktualisierung legt auch den inhaltlichen Vergleich nahe: Tatsächlich hatten sich die Lebensbedingungen des Bauernstands von der Jahrhundertmitte bis zur Entstehungszeit des Lieds um 1776/77 merklich gewandelt, nicht immer aber zum Besseren. Zwar hatten die merkantilistischen Reformen die Ausbeutung durch die Grundherrschaft gemindert und bessere soziale Bedingungen geschaffen. Doch mit den neuen Erfassungsmethoden in Folge der ,Seelenkonskription" waren die Bauern nun dem landesfürstlichen Zugriff direkter ausgesetzt; die erwachsenen Söhne waren für den Militärdienst verfügbar, die Dienstbotenkinder konnten zum Schulbesuch verpflichtet werden. Dazu untergrub die neue Flut an Verordnungen die von staatlicher Seite oft beschworene Freiheit und Eigenständigkeit des Bauern. Wirtschaftlich gesehen war in und nach den Hungerjahren zu Beginn der 1770er Jahre mit Getreide kurzfristig erheblicher Gewinn zu erzielen. Doch führten die Wärmeperiode ab 1771, die intensivierte Agrarwirtschaft in Friedenszeiten und die besseren Produktionsbedingungen in den Folgejahren zu Überangebot und dramatischem Preisverfall. Landwirtschaftliche Erzeugnisse trugen kaum noch etwas ein und der Holzverkauf wurde durch staatliche Verfügungen erschwert. Dazu kamen noch die überzogenen Forderungen und Betrügereien der Mitbürger, die in ihrem Handwerk den jeweiligen Vorurteilen gerecht werden: Müller und Bäcker prellen den Bauern um sein Korn, die Störarbeiter um Tuch, Leder und Arbeitszeit und die Gastwirte lassen sich ihre Dienste viel zu hoch bezahlen.

1

Hänts Baurn, wer hets glaubt vor fufzg Jahrn, Däß ainmal um uns wurd so schlecht Mä het ain grads ghaissen ain Narren Izt glaubm mä's halt dienä wohl recht. Beim Ausgabn kann kainer mehr kleckä Denn d Stoiern wern alli Jahr mehr Mä kann nöt gnue göbm, und gnue strökä Haist alliweil Baur gieb nur her. 3

Mein Weib laßt si ä nimmä blickä In d Stadt wills izt gar nix mehr tragn Ös laßt si ä's Marktmensch nöt schickä ös ließ si eh halbnthail däschlagn; Znächst hat ihr dä Schörg auf dä Brucken In Buedä, und 's Schmalz alls grads weg Drin fahlt $d$ Höpin niedä in Rucken Schmeißt d Air um zween Guldä in Drök.
2

Dös wär dient no alls zum Väwehä $\ddot{A}$ Zeit ließ sichs Traid thoir hin gebm Izt fahlt uns dös ä schon auf d' Zeha 's Geld was mä schätzt, laßt si leicht höbm. Hab nächst ä Fuhr Traid mit vier Rappen Schönmächti in Wochämarkt gführt Hab gmaint i will heufti dätappen I habs kaum in Hosensack gspürt. 4

I het ä Holz, wurden schön Scheiter Und dient derf i gleiwohl kains schlagn I mueß erst in künftingä Freidä In Tanzepfen Pflögä drum fragn. So gehts ain, bei sein aignä Sächel Hat ainär än Pfifferling Gwalt Izt drukt ain ä rozigä Klächel So lang bis ains 's Lebn nimmä gfahlt. 
6

Mein Vieh mag i ä nöt vädändeln

Giebt umädum gnue itzt in Gei

Dä Gwin ist gar schlecht bei den Händeln

's Stroh iß izt so thoir als wie's Heu.

Was seind nöt eh d' Fleischhackä gloffä

Habmt gfratschelt und bötn, wie schön,

Glei habm mä in Leutkäf väsoffä

Izt siecht mä gar selten ain gehn.

7

I tracht wie dä wöll um ä Geldl

So grads mä dös zöhatmal nöt;

Znächst gegnt mä dä Bök in mein Feldl

Der hat mi um Waiz glei augrödt

Wir handeln, vier Guldä aufs beidn

Und führ iehm zwainzg Mezen ins Haus

Neun will er mir izt schon astreitn

Ä so mein Aid ists ja wohl aus.

\section{9}

Dä Schuestä, mein Nachbä dä Schneidä

Dö schneidn doppelt zue auf dä Steer

I gäng mit der Arbät oft weidä

Bei andern gehts ä ä so her.

Zween Tag thains rund zueschneidn und mössen

Aft rennäns haim, thain öpäs holln

Auf d Nacht packen s' zsam nach 'n Frössen

Der ain seine Flöck, der ain d' Solln.

11

Wie 's Heusä bschreibn glei iß aufkemmä

Da hat mä so viel no nöt gfragt

Izt nach und nach kann mä's vänehmä

Warum s' uns den Toixel aufbracht.

Vier Sühn hab i, helfen mir hausen

Seind brav, frum, und treibn kaini Ränd

Kimt Krieg aus: so thains mä s' bräv mausen

Weil d Schlänkeln so groß und schön sänd.

13

Was ist 's für ä Kreuz mit 'n Knechten

Was macht ain das Wechseln für Sprüng

Mä hat izt än guet oder schlechten

Dös iß beim Schullmaister ain Ding.

Izt mueß mä den klain wie den grossen,

Buebm dö vo dä Wiegn aussästeign

Beim Einstehn schon aufschreibn grads lassen

Kain Kruckerl mä derf nit väschweign.
5

Sinst hat ain schier 's Wildprät väfrössen

Von dem habm mä saubä än Fried

Izt fangänd an d' Müllnä zum prössen

Dö fahrn unsern Traidl recht mit.

Mä bringt ien zum Mahln oder Schraden

Söck Traid, dö vä Größt schier zamfahln,

So thuets hinter hundert nit graden,

Däß nöt ä zwai Viertl vämahln.

8

Was lassen ain d Wirthsleut nöt trinkä

Mä iß kaum recht drin no in Haus

Vor lautä zahln möcht mä väsinkä

Dö raithn, ös iß eng ä Grauß.

I, d' Bäurin, dä Hoisl mein Gvadä

Wir drei habms in Beichttag probirt

Viermal griff än iedä in d' Bladä

Dö Toifelsleut habm uns recht gschnürt.

10

Wer hat bei uns eh än Soldaten

Nue übä Nacht ghabt in Quartier

Izt schmökän dö Kärl ön Braden

Mein Aid, ös väfrössen ain schier.

Hat ainr ä Mensch, dös ä weng saubä

Ä Tochtä, dö schön iß vom Leib

So seind s' eng ja drauf als wie d' Taubä

Ös lassen kain Baurn mehr sein Weib.

12

Das Ding thuet mein Seel izt recht schmerzen

I wain oft, daß Rotz davon rinnt

Buebm liebn mi und d Muedä von Herzen

Und uns iß ä jeds ä rechts Kind

I denk mä halt, wern s' heut Soldaten

So seinds morgen vor Schrockä schon hi.

Löbn s' lengä, wann thuet ä das graden

So kriegn s' halt bräv Schuß oder Sti.

14

Kain bössere Zeit ist nöt zhoffä

I sag ieng 's no schlechtä wirds wern

Dö lötzä hat uns no nöt troffä

Do unserö Kinder werns hern;

Von Feirtägn, da habm mä än Trüml

Dö ain habm sö all schon väflogn

Leicht fliegnt dö weng ä no in Himmel

Izt sagts da weil i han engs glogn. ${ }^{18}$

1,1 Hänts] ,he‘, ,hört zu' 1,4 dienä] dennoch, doch 1,5 kleckä] genug haben, sein Auslangen finden 2,1 dient] dennoch Väwehä] verwinden, verkraften, überstehen 2,2 Traid] Getreide 2,7 dätappen] erlangen, (hier:) verdienen 3,3 Marktmensch] Dienstmagd, die an Markttagen die bäuerlichen Waren feilbot 3,4 halbthail] halb,

18 Lindemayr, Dialektlieder I, S. 61-66. 
zur Hälfte 3,5 Znächst] kürzlich, unlängst Schörg] Scherge, Gerichtsdiener 3,7 Höpin] Erdkröte, auch verächtliche Bezeichnung für Frauen 4,4 Tanzepfen Pflögä] (scherzhaft für) Förster, Waldheger 4,5 Sächel] Besitz, Hab und Gut 4,7 Klächel] (eig. Klöppel) schwerfälliger Mensch 5,5 Schraden] Substantivierung zu schroten: grob mahlen, zerkleinern 5,7 graden] (hier:) gelingen, glücken 5,8 vämahln], vermahlen', beim Mahlen verloren gehen 6,1 vädändeln] vertandeln: verkaufen, ein Handel abschließen 6,2 umädum] um und um, rings herum Gei] Land (im Gegensatz zur Stadtgegend), Umland eines Dorfes 6,6 gfratschelt] fratscheln: insistierend fragen, zureden 6,7 Leutkäf] Leitkauf: Anzahlung bzw. auch der gemeinsame Trunk zum Abschluss eines Handels 7,2 grads ... zöhätmal nöt] gelingt es nur selten 7,3 Bök] Bäcker 7,4 Waiz] Weizen 7,5 beidn] warten, zuwarten; , aufs Beiden, Beiten': auf die Bezahlung warten, bei späterer Bezahlung 7,6 Mezen] Pl. zu Metze: altes Hohlmaß für Getreide, in Österreich 61,478 Liter 7,8 mein Aid] bei meinem Eid! 8,4 raithn] (hier:) rechnen, zusammenzählen 8,5 Hoisl] Kurzform für Matthäus 8,7 Bladä] Blase, Geldbeutel 8,8 gschnürt] schnüren: prellen, einen durch List um sein Geld bringen 9,2 Steer] tageweise Arbeit um Lohn und Kost eines (zuweilen ungelernten) Handwerkers 9,6 Aft] dann, danach öpäs] etwas 10,4 Mensch] Mädchen 10,7 Taubä] Täuber, Täuberich 10,8 ös] sie (hier: Personalpron. der 3. Pers. Pl.) 11,1 Heusä bschreibn] Hausnummerierung und Seelenkonskription 1770-1772 11,4 Toixel] Teufel 11,5 hausen] wirtschaften, Wirtschaft führen 11,6 Ränd] Pl. zu Rand: ausgefallene Idee, mutwilliger Streich, lautstarker Spaß 11,8 Schlänkeln] Schlänkel: Schlingel, junger Mann ohne Verpflichtungen 13,2 Wechseln] Wechsel des Dienstverhältnisses, üblicherweise am MariaLichtmess-Tag (2. Februar) 13,7 Einstehn] Dienstantritt, Aufnahme eines Dienstverhältnisses aufschreibn ... lassen] gemeint ist die amtliche Personenerfassung in Folge der ,Seelenkonskription' 1771/72 13,8 Kruckerl] Krüppel, Behinderter 14,3 Dö lötzä] die schlimmste, schlechteste

Das zukunftspessimistische Fazit von Lindemayrs Lied bestätigt sich indirekt in der anhaltenden Beliebtheit des Genres in den letzten Jahrzehnten des 18. Jahrhunderts; nicht nur die bewährten Lieder wurden weitertradiert und verbreitet, auch zahlreiche neue Beispiele entstanden, wie das vor allem in Österreich breit gestreute Mog ich ka Baur nimmer bleiben, das von Lindemayr inspirierte Wer hats ghert vor hundert Jahren, das von Franz Xaver Gruber für die Sonnleithnersammlung eingesandte Nä, nä, $i$ kann mi nimmer verstehen aus der Feder eines Flachgauer Sternsängers oder auch Michael Stockhamers Lieber Schwager, hast kein Kummer, eine ironische „Klage zweyer Zehendmayrn“, die nach dem kaiserlich angeordneten Verlust ihrer Privilegien „wie andre Baurn" ${ }^{19}$ mühsam zu arbeiten und kümmerlich zu leben hatten.

Nicht lange nach den ersten dialektalen Bauernklagen begegnen uns auch erste dialektale Lobeshymnen auf das ländliche Leben, die seine positiven Seiten herausstreichen. Der Verdacht liegt nahe, dass es sich hier - wie freilich auch bei den meisten Lamentos - nicht um Dichtungen aus der Bauernschicht selbst handelt, sondern um Versuche, über die Aufwertung des Standesbewusstseins den sozialen Frieden zu sichern. Ein Teil dieser laudationes agriculturae bedient sich der Topoi bukolischer Dichtung in der Idealisierung des Landlebens, andere argumentieren mit der Ehrwürdigkeit des Stands als ältester Beruf und der moralischen Überlegenheit bodenständiger Arbeit, etliche streichen die Vorzüge im Kontrast zu den Nachteilen anderer Berufe oder Lebensumfelder heraus.

Aus ins Dienstbotenumfeld transponierten arkadischen Elementen, Tanzliedmotiven, Werbeliedkomponenten, erotischen Anspielungen etc. ist das folgende, außergewöhnlich frühe Almenlied All ihr Buebmä treibts zusambä (1703) gestaltet, das in derbrealistischen Tönen die schöneren Seiten des Hüteralltags vorstellt. Mit dem romantischen Naturgenuss in der Freiheit der Berge, mit Musik, Tanz und Liebeleien zwischen

19 Zitiert nach Hans Commenda: P. Wilhelm Paillers Liednachlaß. In: Jahrbuch des österreichischen Volksliedwerkes 13 (1964), S. 45-54, hier 53f. 
Hirten und Sennerinnen gibt es zentrale Motive vor, die im 19. und 20. Jahrhundert zum Grundrepertoire alpenländischer Folklore gehörten, wie sie von den ,Nationalsängern ‘ in weite Teile des deutschen Sprachraums publikumswirksam exportiert wurde. Viel Erfahrung mit Dialektverschriftlichung (bzw. mit dem Bairisch-Österreichischen an sich) scheint der Setzer dieser Liederflugschrift nicht gehabt zu haben, wie die zahlreichen sinnentstellenden Fehler und Inkonsequenzen vermuten lassen:

1

ALl ihr Buebmä treibts zusambä/

Schaaff und Schwein was immer habt/

Auff den schönen kohrn Sambä/

Treib mir auffthe in den Schatt/

Auff der lauga Aelma/

Halt das Roßl Khälma/

Afft kimbt ä dä Jodl krad/

Mit sein grossn Dudl-Sack.

3

Morgens e mir auff thun stehn/

Hörn mir offt von fehrn/

Daß schon dMenscher in dAlma gehn/

Khü und Oxn blährn/

Wann wir auß den Hüttn gehn/

Schwagerin gar vill da stehn/

Wenck i ainer her in Schatt/

Pfeiff ihr ains auffn Dudl-Sack/

5

Wann der Samsta kimbt dahe/

Gehn wir zu den Baurn/

Nehma uns zessn daß wir bstehn/

Und durch dWocha thaurn/

Wann die Nacht am Himmel steht/

Ein jeder zu sein Menschn geht/

Weith gehn / acht ma für kaini Plag/

Wann mir habn den Dudlsack.
2

Wann mä sän in Schatte gelegn/

Daß uns thut der Arsch schier wehe/

Da giebs ehrtä umb da gängn

Glatta Flöh gleich in da hehe/

Unsa Vieh thut grassn/

Mir aber auff den Wassn/

Nimbt ein jeder sein Gredl krat/

Dantzen ains beym Dudl-Sack.

4

Wann i ihr hab pfiffa gnug/

Thut sie sy schö naign/

Sagt zu mir mein lieba Bue/

Kim zu mir in dSchwaign/

Schmalzkho solstu habn/

Darffs dich nit so blagn/

Geh nur nein ohn alle Frag/

Vergiß nur nit den Dudlsack:

6

Kai Fürst kan so lusti löbn/

Auff der langa braidn Welt/

Als wir Hütter-Bubm thun löbn/

Wann mir habn schon weni Gelt/

Schlaff ma in der Ruhe/

Brauchn nit vil Schuhe/

Nehmes Horn und nDudelsack/

Dudln dudln auff den gantzen Tag. ${ }^{20}$

1,3 kohrn Sambä] Kornsamen (?) 1,4 auffthe] wohl Druckfehler für: auffhe 1,5 lauga] wohl Druckfehler für ,langa' 1,6 Roßl] Röschen Khälma] Kälber, Kalbinnen 1,7 Afft] dann ä] auch 2,6 Wassn] Wiese, Rasen 3,3 dMenscher] die Mädchen 3,6 Schwagerin] Sennerinnen 4,4 dSchwaign] Almhütte 4,5 Schmalzkho] Süßspeise aus Gries, Milch und Schmalz 5,4 thaurn] auskommen, genug haben

Noch in der heutigen Volkskultur und volkstümlichen Unterhaltungskultur wirken die Residuen dieser offensichtlich bereits sehr früh lancierten Standesidyllen nach, die Bedürftigkeit als Bedürfnislosigkeit einer ewig jungen Gesindeschicht interpretierten und längerfristige soziale Konsequenzen des propagierten freien Lebens völlig ausblendeten. Diskursiver angelegt sind Kompilationen von Bauernklage und Bauernlob wie Jezund kan Ichs nihmer leydn. In diesem 17-strophigen Zwiegespräch werden Hiesls Klagen und

20 Drey schöne neue Weltl. Lieder / Das Erste: Von deß Bauren Schaaff und Schwein / etc. Das Andere: Ein sehr fröhlich Feld- und Bauren-Liedlein / von einem hertzhafften Bauern-Knecht. In der Melodey: Hänßl geht voller Couraschi ins Feld. Das Dritte: Was denckt ihr doch die Braut / wann kommt ihr HochzeitTag / da ist ihr Kopff / etc. Gedruckt im Jahr/ 1703, f. 1v-2r. 
Alternativlebensmodelle mit Stöphels Auflistung der Vorteile des Bauernstands ganz im Sinne des Ordogedankens gekontert. Da bereits auch physiokratische Argumente für die Aufwertung des Bauernstands anklingen, dürfte das Lied in die zweite Hälfte des 18. Jahrhunderts gehören:

1 Hiesl.

Jezund kan Ichs nihmer leydn, alleweil ein Baur zu seyn, andre lebn stäts in Freudn, Bey mir schlagt alls Unglick ein, nichts als Sterz und Knödl kochen, und kain Rueh die ganze Wochen, Sontag haist es jezt zahl aus, oder fort ins diener haus.

[...]

4 Hiesl.

Adam war allein auf Erden, gab kain Steur und gabn nicht, kunt nit so agschunden werden, war die ganze Zeit mit Fried, jezt haists abä zalt ihr Baurn, zahlt ihr Dieb ihr falsche Lauren, nur fein hurtig oder ich las euch Briglen wie das Vieh.

12 Hiesl.

Kunt ich lesn raitn schreibn, und västundt die Canzley, thät ich Pflegerhandwerch treiben, so wär ich von gaben frey, derf auf kein Robät fahren, kunt mir hüpsch a Geld ersparen, hielt mir Wundä schöni Pferd, wies auf einen Herrn khert.

[...]

17 BEEDE.

Nun so woln wir uns nicht scheren, bleibm wir wer wir gwesen sein. was ist a mit grossen Herren, als ä lährer dunst und Schein, wir mit unsern Baurn Kitl, Brauchen kain Herrn titl, Baur ist Baur, ä gsteiffä Mann, schauts uns Herren wohl drum an. ${ }^{21}$

\section{STÖPHEL.}

Hießl was thuest dich viel quällen, ein Baur ist der erste gwöst, unter allen Menschen Seelen, wie man in der bibel löst, aft sänt erst die Herrn kemä, gros und klain wie mans will nehmä, alls zu Wasser und zu Land Lebt von unsern Baurn Standt.

5 Stöphel.

Nun, so sag mir was wöllst weiter, wanst ä mahl kain Baur mehr bist, Brueder glaub mir, es ist gscheider, Bleib ein jeder wer er ist, Freylich lebn grosse Herrn, als wann sie Gott selbsten wärn, Toll und voll in ihre Kröpf, sänd dabey doch Esels-köpf. [...]

13 Stöphel.

Bruedä Hiesl das laß bleiben, waist wie iezt d-Herrschaften seyn, Leib und Seel must eh väschreiben, sonstn last man dich nicht ein. thuest in deiner Raittung fehlen, haist dä Kerl muß ja stehlen, wans ä noch so redlich seind ist man ihnen dannoch feind.

1,5 Sterz] kleinbröckeliges Armeleuteessen aus Buchweizenmehl, Mais-, Roggen- oder Weizengrieß 2,5 aft] dann 12,5 Robät] Frondienst, Fronarbeit, Dienstleistungen, die der Bauer für die Grundherrschaft zu leisten hatte 13,5 Raittung] Rechnung, Bilanz 17,7 gsteiffä] redlicher, hervorragender

Mit ähnlicher Argumentation operiert auch das wohl etwa zur selben Zeit entstandene Lied Nix ist übern Baurn-Stand, in dessen selbstbewussten Schlussstrophen sich

21 Stiftsbibliothek St. Florian, XI577A, S. 80f., 85f., 88. 
das bäuerliche Ich als intellektuell und moralisch überlegen fühlt. Zudem werde den emporkömmlerischen ,Herren' die Ausbeutung des Bauernstands nach dem Tod zum Verhängnis:

12

Stöckt oft in dä Joppen drin, waß d Herrn hamt käm in Sinn, ich lach mä mein Wampen voll, wann i: dHerrn betroigen kann doll.
14

Laß mich schindten bis äfs Bain, fahr in Himmel no so rain, meini Herrn, dä Baurn-Schwaiß macht enk auf dä Nachfahrt haiß. ${ }^{22}$

12,1 Joppen] einfache Bauernjacke 12,2 hamt käm] haben kaum 14,4 enk] euch Nachfahrt] Aufnahme der Seele im Himmel

Vor allem die irdischen positiven Aspekte stehen im mehrfach überlieferten Juhe! wie lusti iß nöt auf der Baier im Zentrum, das wohl in den 1780er oder 1790er Jahren im oberösterreichischen Raum entstand, wie sich nicht nur aus der Überlieferungssituation, sondern auch aus dem einen oder anderen Hinweis auf josephinische bzw. postjosephinische Reformen vermuten lässt (vgl. etwa 5,5). Zwar werden aus der fingierten Perspektive eines Bauernknechts neben den Vorteilen wie dem reichhaltigen Essen oder dem Arbeiten in der Natur auch Nachteile und Schwierigkeiten, insbesondere die physische Anstrengung, angesprochen. Die Schlussfolgerung des Sängers bleibt aber, dass er nichts wolle als Knecht bleiben - das „Herrnlöbn“ würde ihm gar nicht gefallen. Möglicherweise ist dieses demonstrative Festhalten an der gegebenen hierarchischen Gesellschaftsordnung als Reaktion auf die Französische Revolution mit ihren Forderungen nach Gleichheit und Brüderlichkeit zu sehen. ${ }^{23}$

1

Juhe! wie lusti iß nöt auf der Baier,

i möcht kain Graf und kein Stadtherr nöt seyn;

in aller Früh schon da fressen ma a Seya,

kimmt der Mittag, so giebts Schobern und Brein,

aft uma drey umi kimmt wida d'Jausen,

aft setzen mä uns wida zama zum Tisch,

fressen bis daß mä thun keichä und pfnausen,

und a so sama hübsch rebi und frisch.

2

In da früh, wann unsä Haushann thut krähn,

aft wiri muntä und gametz a mal,

thu i mi ranzen, hübsch gütla umdrahn,

bis i hör d'Ochsen und d'Küeh schreyn im Stall;

aft wann i aufsteh, so thu i mi g'sönga,

daß mä kain Hex und kein G'spenstel nit schadt,

und daß ma a kann kain Trud nöt begegna,

i mag aft ausgehn früh odä spat.

22 Oberösterreichisches Volksliedwerk, HL 379a, f. 5r. Erstediert in Christian Neuhuber: „Mein Gott, warum hast das Rabm Vieh erschafen ... " Lindemayriana et al. in den Liederhandschriften HL 379a und HL $379 \mathrm{~b}$ des Oberösterreichischen Volksliedwerks. In: Streifzüge 2. Beiträge zur oberösterreichischen Musikgeschichte. Hg. vom Oberösterreichischen Volksliedwerk/Volksliedarchiv durch Klaus Petermayr. Linz: Oö. Volksliedwerk 2011, S. 109-124, hier 113f.

23 Vgl. Klier, Linz im Liede. Nachträge, S. 363. 
3

Wann ma ham d'Soya und d'Groimsuppen gessen, aft haists Buem außi zu der Arbeit ins Feld, da singan d'Vögerl, mä möcht si vagessen, wie's da nöt umadum klingelt und helt; aft sing i a meini Tänzel und Liedä, kann i's glei nöt wie's in Notnan thut stehn, so sing ichs gleiwohl bald hoch und bald nieda, d'Menscha sag'n gleiwohl, das Ding iß recht schön. 4

Freyli kimmt d'Arbat hübsch träbi oft aua, 's Ackern und 's Dröschen, das Mahn und das Heig'n machen am warlä dö Stunden recht sauä, daß ain der Schwitz möcht beyn Augnä aussteign; im Frühjahr da hät's halt do launige Nachten, da war's nöt z'kalt, und nöt z'stark und nöt z'hart, aber da hasts halt: Buem richts eng zum beichten, und da vageht an glei wida da G’spaß.

5

Aber ös keman a heiligö Zeiten, d'Kirta und d'Faschingtag bleimd a nöt aus, und auf'n Tendelbas sieht ma vo weiten, da giebts a G'schmaiß und an schmieringa Schmauß; d'Rauhnacht dö wöllns jetzund freili abbringa, und es hat s' do a kain Narr nöt aufbracht, 's Lesseln und's Kraisstehn kann ausbleibm und d's singa, d'Krapfen dö müssen do kema auf d'Nacht.

6

Wann uns a Lust thut zum Tanzen ankemma, aft geh'n ma außi in Kirta zum Tanz, thu i mein grandigi Schwösta mitnehma, d'Nannal nimmt'n Gröga, und d'Lisl da Hanns, und a so than ma narrisch uma springa, und than recht lärma und dümmeln beynand, thans ain den andern so oft umabringä, bis in dä Kandl da Bod'n außäzant. 7

Aft zahln wä d'Zech aus, und than Urla nehmä, scheint uns der Mond nit, so leuchten uns d'Stern, und iß uns z'finstä, und kann ham nit kemma, leiht uns dä Hofwirtd schon a Latern und a so iß halt hübsch lusti beyn Bauern, 's Köstel war g'schmachi, und 's Trünkl war braf, abä das is halt alan zum betrauern, däninga kemman halt einmal z'viel af. 8 Aber i kann mas unmögli gedenka, 's Herrnlöbn thut mi halt anmal nöt g'freun, wann i a Herr wär, wie thats mi nit kränka, i will viel lieber a Bauernknecht seyn; 's G'wissen das hat ja der Geyer schon g'noma, 's Geldel das kleckt tän halt alleweil nöt, 
i bleib bein Bauern und thu mi nichs grimma, wann mi mei Mensch gern hat, löb i mit Freud. ${ }^{24}$

1,1 Baier] Bäuer: Land, ländliches Gebiet 1,3 Seya / 3,1 Soya] Säuer: Säuersuppe; aus Sauermilch, Mehl und Essig angerührte Morgensuppe der bäuerlichen Landbevölkerung 1,4 Schobern] Schober: Germspeise 1,4 Brein] Hirsebrei 1,5 aft] dann, danach 1,7 pfnausen] schnauben, schnaufen, schwer atmen 1,8 rebi] leicht, munter 2,2 wiri] werde ich gametz] gähne 2,3 ranzen] sich rekeln (v. a. nach dem Schlaf) die Glieder strecken und dehnen 2,4 g'sönga] segnen, hier im Sinne von: bekreuzigen 2,7 Trud] weibliches Nachtgespenst 3,1 Groimsuppen] Suppe mit Grieben, Grammeln 3,4 helt] klingt, tönt 3,8 Menscha] Mädchen 4,1 träbi] sehr geschäftig aua] heraus, (hier): daher 4,2 Heig'n] Heu machen, Heu mähen, wenden und einführen 4,4 Schwitz] im Original ,Schwiß` 5,3 Tendelbas] Fest für Mägde, Knechte und Tagelöhner, das im Winter nach Beendigung der Drescharbeiten gefeiert wurde (vgl. Kap. 6) 5,4 G’schmaiß] Unrat, Ekel Erregendes (?) schmieringa] fettig 5,7 Lesseln] Bräuche zur Zukunftsschau, insbesondere in den Rauhnächten um Weihnachten und Jahresende, etwa durch Bleigießen, Schuhwerfen etc. 5,7 Kraisstehn] Brauch zur Zukunftsvorhersage und/oder Geisterbeschwörung, bei dem man zu Weihnachten am Kreuzweg in einem mit einer Rute oder mit Kreide gezeichneten Kreis steht 6,3 grandigi] verdrießliche, mürrische 6,6 dümmeln] ein lautes Geräusch erzeugen, krachen, lärmen 6,7 umabringä] zutrinken 6,8 außäzant] hervorblitzt 7,1 Urla] Urlaub: Abschied 7,8 däninga] Untertänige 8,6 kleckt] reich, langt aus 8,7 grimma] bekümmern, ängstlich sorgen

Auch hier sind die Vorteile des ruralen Lebens beschränkt auf die Vergnügungen der bäuerlichen, unverheirateten Jugend - ein Kunstgriff, der uns in etlichen anderen, ähnlich gestalteten Lobliedern im Dialekt und Standard begegnet. ${ }^{25}$ Obligat ist die abschließende Beteuerung, seinem Stand treu bleiben zu wollen, der katholischen Forderung nach der modestia, der Bescheidenheit folgend.

In der zweiten Hälfte des 18. Jahrhunderts ist am Theater gleichfalls vereinzelt eine Positivierung der Bauernfigur zu beobachten, die sich sprachlich in unterschiedlicher Weise manifestiert. Auf Pauersbachs Der redliche Bauer und großmüthige Jud mit seinem integren Protagonisten Hannsmichel wurde bereits ebenso hingewiesen wie auf Blimas aufdringlich patriotische Bauernfiguren in Das Land ob der Enns. Beide Autoren sprechen sich dezidiert dafür aus, die als vorbildlich gezeichneten bäuerlichen Figuren auf der Bühne auch in ihrer Mundart sprechen zu lassen. Im Gegensatz dazu lässt der Münchner Philosoph, Zensor und Illuminat Karl von Eckartshausen (1752-1803) in Liebrecht und Hörwald oder: So geht's zuweilen auf dem Lande, einem aufklärerisch motivierten Sittenbild gegen die Übergriffe und Gesinnungslosigkeit der Beamtenschaft, gerade die korrupten Reaktionäre in den Amtsstuben, die sich der Modernisierung der Gerichtsbarkeit verweigern und nur ihren eigenen Vorteil suchen, mit deutlich dialektalen Anklängen reden:

Steinern. [...] Die verfluchten Bücher! vor Alters war das Ding alles nicht so. Ein wenig lateinisch g'lernt, die Institutiones und Pandekten durch g'schaut, s'Corpus juris recht r'um g'rissen, und im Praxi praf g'notelt; und g'nug war's, Hab'n doch brafe Leut' g'habt.

BцATt. Ja! ja! Herr Kollega! Itzt will man all zu g'scheid sein. Kommen alleweil mit ihrer Philosophie daher, und können keinen Schergenzettel nicht schreiben. Und so mitleidige Herrn giebts,

24 Drey schöne neue Weltliche Lieder. Zwey Almenlieder. Das Erste: I bin a junger Wildpratschütz, ju ju etc. Das Zweyte: Juhe, wie lusti iß nöt auf der Baier etc. Das Dritte: Die Zeiten Brüder sind nicht mehr etc. Gedruckt in diesem Jahr, f. 2r-3v.

25 Vgl. u. a. das langlebige Lied ,Der vergniegte Baursknecht', das uns in der standardnahen Fassung Es ist fürwahr kein bessers Leben bereits um 1700 in einer Flugschrift erstmals begegnet und mit weitaus stärkerer dialektaler Markierung (vgl. etwa Ist mein Ayd kay scheners Leben) noch ein Jahrhundert später kursierte. 
das ist gleich gar nichts. Was Mitleiden? Dieb' braf g'henkt, und Bauern braf g'straft. Für was wär denn die G'rechtigkeit? Denken's nur, wider die Torturen schreiben's ä alleweil. ${ }^{26}$

Institutiones] oströmisches Rechtslehrbuch Pandekten] spätantike Kompilation aus Werken römischer Rechtsgelehrter Corpus juris] Kodifikation des Römischen Rechts im Auftrag Kaiser Justinians g'notelt] (gebührenpflichtig) gerichtlich aufnehmen und eintragen ä] auch

Die positiv gezeichneten Figuren dagegen - und dazu gehören die unterdrückten, doch moralisch überlegenen Bauern - sprechen hochdeutsch. Diese verquere Registerverteilung basiert wohl auf dem aufklärerischen Ansatz der Sprachreiniger, dass nur recht denken und sich dementsprechend verhalten könne, wer auch richtig - also in einem gepflegten Standard - spricht. $^{27}$

\section{Komisierung und Diskreditierung ländlicher Typen}

Bereits in den oben angeführten Beispielen sind Lob und Tadel des Bauernlebens zumeist auch humoristisch akzentuiert, ohne dass dies die eigentliche identitätskonstitutive oder sozialdisziplinierende Intention konterkarieren würde. Weitaus häufiger freilich begegnet uns der Mensch aus dem ruralen Gebiet als dialektliterarische Figur in einem dominant komischen Kontext. Schon das erste umfangreichere Dokument für literarisierte Bairisch-Österreichische Mundart, das in einer Regensburger Abschrift von 1618 überlieferte Fastnachtspiel Von dem Hänsl Frischen knecht aus dem Wiener Jesuitenumfeld, bringt mit dem ,Bauer als Soldat'-Motiv einen höchst erfolgreichen Typus auf die Bühne (vgl. Kap. 2, S. 267). Als ,miles gloriosus' inszeniert etwa ein 1703 gedrucktes „sehr fröhlich Feld- und Bauren-Liedlein“ den „hertzhafften Bauern-Knecht“ Hanß Felber, dessen großmäulige Ankündigungen erst ihrer Umsetzung harren. Von anderen Werbeliedern dieser Zeit hebt es sich durch deutliche Ironiesignale ab:

1

Fort ihr Buben / von Kraut und Ruben / seyds alle wohl auff/

ich Hanß Felber / geh mein Ayd selber / ins Reich gar hinauff/

schauts der Sommer / geht gleich herumer / he lustig präff Geld/

Wer will lehren / die Büchsen umbkheren / zieh heunt ins Feld.

2

Hauß und Acker / verlaß ich wacker / und ghey mich nichts drum/

greint mein Gredl / ich schlags zum schedl / daß daumelt herum/

gehts auff dSeiten / und stehts von weiten / mein Büchsen gschwind her/

Kugel giessen / zwey dreymahl schiessen / daß donnert so sehr.

26 Karl von Eckartshausen: Liebrecht und Hörwald oder: So geht's zuweilen auf dem Lande. Ein Schauspiel in drei Aufzügen bearbeitet nach Shakespear. München: Johann Bapt. Strobl 1783, S. 17f.

27 Vgl. Ulrich Knoop: Zur Begrifflichkeit der Sprachgeschichtsschreibung: Der ,Dialekt' als Sprache des ,gemeinen mannes' und die Kodifikation der Sprache im 18. Jahrhundert. In: Horst Haider Munske [u. a.] (Hg.): Deutscher Wortschatz. Lexikologische Studien. Ludwig Erich Schmitt zum 80. Geburtstag von seinen Marburger Schülern. Berlin/New York: de Gruyter 1988, S. 336-350, hier 344f. 
3

Veitl pack di / mein Ayd / ich hack di / steh besser hintan/ sechs Frantzosen / ich treib nur Possen / die schlag ich gleich zsamm/ wie Krautstingel / ich acht kein Dingel / wanns Blut gleich herrint/ he curanti / mein Kopff ist hantig / mein Büchsen gar gschwind.

$[\ldots]$

10

Vater und Mutter / mein Schwester und Bruder / so bhüt euch halt GOtt/ keiner kommt woll / biß daß er Säck voll / präff Thaller gnug hat/ afft werds hören / daß wir seynd Herren / und nicht Bauern-Knecht/ Stöß und Gelde / gar keins nicht fehlte / wann man tapffer fecht.

1,2 mein Ayd] bei meinem Eid (Beteuerungsformel) 1,3 herumer] vorüber 2,1 ghey] schere, kümmere 3,4 he curanti] Anfeuerungsruf (Variation zu ,he courage') 10,3 afft] dann

Der Versuch, die Standesgrenzen durch eine militärische Karriere zu überschreiten, damit jedoch gegen Gottes Ordnung zu verstoßen, steht im Zentrum der Bauernschelten, die die ungebührliche bäuerliche Aufstiegssehnsucht ins Lächerliche ziehen. Im Unterschied zu den Klagen und Lobliedern übernimmt der Bauer in diesen Texten meist nicht die Rolle des selbst für sich sprechenden Ich, sondern jene des angesprochenen Spottobjekts oder des verlachten Dritten. Am Beispiel seines versuchten Ausbruchs aus den gegebenen Umständen wird das voraussehbare Misslingen gezeigt, das zur Läuterung führt bzw. die Lächerlichkeit derartiger Bemühungen unterstreicht. Das folgende Beispiel findet sich in einer Ariensammlung zu einem - über die Gesangsteile hinausgehend - nicht überlieferten Singspiel. Darin beklagen Hießl und Stöffl, zwei Knechte, die der Bauer nur durch Schimpftiraden zur Arbeit treiben kann, ihre bedauernswerte Existenz und den harten Arbeitsalltag, sehen aber eine Chance im Soldatenleben und lassen sich anwerben. Bald jedoch müssen sie sich belehrt und bekehrt wieder beim Bauern Hannß einfinden und in reumütigem Ton einräumen, einen Fehler begangen zu haben. Dieser nimmt sie wieder bei sich auf, lässt es sicher aber nicht nehmen, ihnen eine Moralrede zu halten, die rasch in triumphierenden Spott übergeht:

Hannss.

So gehts äm, wann mä zhoh will steign,

Wird mä ga oft bötrogn.

Zerst is dä Himmel vollä Geign,

Und z'lötzt is als dälogn.

Izt stengän d' Limmeln dadä, wies klaini Kind beim Ko,

Erst hams wälln Herrn spilln, und izt hat d'Freud ä Lo.

I mueß nä dribä lachä - ha - ha -

Oes wards schon rechti $\mathrm{He}-$ he - herrn -

Dös Ding is völli gspassi - hi - hi -

Izt fangäns ja an zroho - ho - hozen,

Wies Kindl ohne $\mathrm{Lu}-\mathrm{Lu}-\mathrm{Lu}-\mathrm{Lu}-28$

5 Ko] Koch, Brei 8 Oes] ihr 10 zrozen] zu weinen

28 Stiftsbibliothek St. Florian, II-17-65 W108, S. 13. Da das einzige bekannte Exemplar ohne Titelblatt erhalten ist, sind Handlung, Titel sowie Entstehungsort und -jahr unbekannt. Zentrale Elemente waren neben dem Bauernspott parodistische Typenbilder und eine Variation des beliebten Soldatenwerbethemas. Das Stück dürfte zwischen 1775 und 1785 entstanden sein; die Erwähnung eines Vesuvausbruchs in der elften Arie wird sich auf die Eruption von 1774 beziehen. 
Ein ähnliches Motiv weist ein reich überliefertes Lied in der Tradition der Landsknechtdichtung auf, das - vor dem Hintergrund der Türkenkriege entstanden - bis ins späte 20. Jahrhundert, im Burgenland etwa als Kinderlied, im Umlauf war. ${ }^{29}$ Das Ziel des Spotts ist der Knecht Veitl, der Kavallerist werden will und dafür von seiner Mutter mit notdürftig-provisorischem Rüstzeug ausgestattet wird. Zwar wird für jedes erforderliche Utensil eine Alternative beschafft, doch macht der solcherart gerüstete ,Held' eine alles andere als ritterliche Figur, wie denn auch der spöttische Kehrvers unterstreicht:

1

Vnsser knecht der Veitl, ein Reitter wil er wern, Vnsser knecht der Veitl, ein Reitter wil er wern, er hat ja kaey Ross nicht wie wil er einer wern, da Nimbt sein Muedä än felberstokh Macht im daraus ein Reitter Ross, Reit veitl Reit: es ist kein Naradey,

3 Vnsser knecht der Veitl, ein Reitter wil er wern, er hat ja kein zäm Nicht, wie wil er einer wern, da Nimbt sein Muedä ein kitlbräm, Macht im daraus ein Reitterzäm, reit veitl reit, es ist kein Narädey:

5

Vnsser knecht der Veitl, ein Reitter wil er wern, er hat ja kein Manttel nicht wie wil er einer wern,

da Nimbt sein Muedä kitl-flankhen, Macht im daraus ein reitter Mantel, reit veitl reit, es ist kein Narädey:

7

Vnsser knecht der Veitl, ein Reitter wil er wern, er hat keine sporn nicht, wie wil er einer wern, da Näm sein Muedä distl und dorn, Macht im daraus die reitter sporn, reit veitl reit, es ist kein Narradey:

\section{2}

er hat ja kaein Sattel nicht, wie wil er einer wern,

da Nimbt sein Mueda die offengabel Macht im daraus ein Reitter Sattel, reit veitl reit, es ist kein Narädey:

4

Vnsser knecht der Veitl: ein reitter wil er wern, er hat ka kein säbel Nicht, wie wil er einer wern,

da Nimbt sein Muedä das kreintzenstäbäl, Macht im daraus ein Reitter säbel, reit veitl reit, es ist kein Narädey:

6

Vnsser knecht der Veitl, ein Reitter wil er wern, er hat ja keine stiffel, wie wil er einer wern, da Nimbt sein Muedä ein Riekibl, Macht im daraus die Ritterstiffel: reit veitl Reit, es ist kein Narädey:

8

Vnsser knecht der Veitl, ein reitter wil er wern, er hat ja kein hüetl Nicht, wie wil er einer wern, da Nimbt sein Muedä das Roherthüel:

Macht im daraus das Reitter hüetl, reit veitl reit, es ist kein Narädey: ${ }^{30}$

1,3 felberstokh] Weidenstock, Palmbuschen 2,3 offengabel] Schürhaken 3,3 kitlbräm] Rockborte 4,3 kreintzenstäbäl] Rute für Flechtwerk (Trag- und Wagenkörbe) 5,3 kitl-flankhen] Rockfetzen 6,3 Riekibl] Rühreimer 8,3 Roherthüel] Backrohrtür

Als Begleitphänomen des Ordo-Bruchs ist die ,Hoffart‘ ein gern bearbeitetes Motiv der Bauernschelte. Berufsstandskritik und Mode- bzw. Sittenklage sind in Die hoffart undtern bauern volkh vereint. In anklagendem Ton wird hier getadelt, wie sich das Betragen, Auftreten und Tun der Bauern zum Negativen hin verändert habe. Der angeprangerte Hochmut gehe schließlich so weit, dass sich die Bauern „schon [als] ausgemachte hern“ $(7,2)$ fühlen, ihren Platz im sozialen Gefüge sowie ihre Grenzen verkennen und selbst über Höhergestellte spotten und lachen, da sie sich durch die praktizierte Geldschneiderei offenbar nicht mehr im vormaligen Maße den Regeln der althergebrachten Rangord-

29 Vgl. Deutsch/Haid/Zeman, Das Volkslied in Österreich, S. 210.

30 Bayerische Staatsbibliothek, Cod. germ. 7340 (Stubenberger Gesängerbuch), Teil 2, S. 186. 
nung verpflichtet fühlen. Recht besehen zielt die Kritik freilich lediglich auf die reichen ,Herrenbauern', die so gar nicht mehr den alten Idealen des Bauernstands entsprachen:

1

Die hoffart undtern bauern volkh, die Nimbt jetz überhand, Man kent kein wirth kein Purgers man, von Baueren aus den land dö Ruecher daein si klaeiden, in silber und in seidn, und wan ein beamter wer, lies i aeis aber schneindn, 3

ä Sakhuhr Mues ä Nieder habm, von Silber knopff und schnaln, für bauern ist das schönste tragn, dös Mues ein jeden gfaln, sö frössen fleisch und Prätl, und Richtens anders ein, darzue ein guets Sallätl, drauff Schmökht ä gläsl wein, 5

Sö künänt ja leicht Sauffen, und frössen was aey schmökht, den als was sie verkauffen daeint, kost zwaey geld wans no klökht, das vich ist schrökhlich theuer, der waeitz und auch das korn, wie wers wens erst heuer, so ville sach wer warn, 7

Die Bauern seind bey disser zeit, schon ausgemachte hern, sö spötln krad dö bürgers leuth, wen sie etwas begehrn, sie können ja leicht lachen der Beitl ist schon vohl, o Ihr verdambte Knochen, das enkh der teufl holt: 9

Man trifft zwar noch zu zeitten, ein alten teutschen an, der gwis den armmen leutn, hat etwas guets gethan, der wird auf keine weisse: zu dissen Ruechen zelt, die gott wird einst verfluechen, al dort in jener welt: ${ }^{31}$
2

Sie Bauen jezundt heusser auf, und städl vor laudter Rährn, die schönsten Bögn und zimmer drauff, und das fein No Nöth z klaein, sö bringäns alweil weitter, in haus und in den stahl, weils halt alweil gscheidä wernt, dö limmeln überal:

4

Und kombt ä Kompanie zusam, da Machten sie ä gspil, sie setzen gley die zwölffer zam, ist ihnen gar nöth $\mathrm{z}$ vil, i zwaeinzig dreissig gulden Macht aeiner sich nichts drauss, er Macht darum kaey schulden, und stest kaey loch ins haus,

6

Die scheider dös verkauffen daeint:

die richten sie so schlecht,

ä wengäl daeint ös zammä laein,

das aein verdrissen Mecht, sie Richtens al auf d schneidn, und ä Inwendig hol, so brauchen etlich scheider, so ist die klafftern vol, 8

Vor zeitten wär das bauernkleid, von schlechten tuech und lohn, sö tragn ä häftl in der Pfaeid, und frössen linser knon, und etwan zu heilligen zeitten, frist er ä Pfindl fleisch, dort gäb no den leitn, eps um den rechtn Preiss:

1,5 Ruecher] gierige Menschen daein] tun 1,8 aber] herunter 2,2 vor laudter Rährn] ganz besondere 3,1 ä Nieder] ein jeder 3,5 Prätl] Schweinsbraten 4,3 zwölffer] 12-Kreuzer-Münzen 5,4 klökht] reicht, genug ist

31 Ebda, S. 218. 
6,3 ä wengäl daeint ös zammä laein] ein wenig schlichten sie sie zusammen 6,8 klafftern] Klafter: Hohlmaß 7,8 enkh] euch 8,3 häftl] Häkchen (anstelle eines Knopfs) Pfaeid] Hemd 8,4 linser knon] Linsenknödel 8,6 Pfindl] Pfund (?) 8,8 eps] etwas

Häufiger allerdings als die Modesucht der Bauern wird jene der Stadtbewohner im dialektalen Lied verspottet und das affektierte urbane Leben mit der Simplizität des Dorflebens konstrastiert, so etwa in Lindemayrs bekannten Trutzliedern Vöstung, Schlössä, Märk, und Stödt und Sagnt allweil vom Stadtlöbn. Besonders lächerlich ist das Gehabe, wenn die tatsächliche finanzielle Situation das aufwändige Zurschaustellen eines elitären Status konterkariert und selbst die Grundversorgung für den schönen Schein geopfert wird:

4

Wie oft ist dä Beutl, und d Hosensäck eitl, Leint hungä schier durch dö ganz Wochä Und dennä thaint d' lappen, so stolz daher trappen In Klaidäbracht schimmern, und pochä. Tragnt oft äfn Hut ä Plumäschi Und habnt diernt in Ellbogn s Goräschi Toppe, und Harzopfen, Ös öllendign Tropfn, Häts liebä gnug z’ fressen däfür I schiß äf dö Herrn Manier.
5

Wer fraid um den Blundä, in Gey iß viel rundä Wanns Strohtach gleich z' löchert, und z' rissen Da frist mä schwarz brockä, und bainföstö Nockä

Und hat doch dabey ä grings Gwissen.

Da hört mä niemt gransen, und penzen

Ums Fürgehn, und um Braecedenzen bräf Wind, und groß Sachä Und Schweng däher machä Sey meinthalbn in Städtn d' Manier In Gey ists än unbekannts Thier. ${ }^{32}$

4,2 Leint] leiden 4,3 dennä thaint] dennoch tun 4,5 pochä] sich zur Schau stellen 4,6 Plumäschi] Federschmuck als Aufputz von Hüten (vor allem des Militärs) 4,7 diernt] dennoch, doch Goräschi] Courage, Mut, Beherztheit 4,8 Toppe] Toupet 4,9 Ös] ihr 5,1 Gey] ländliche Gegend (im Gegensatz zur Stadtgegend) 5,4 bainföstö] knochenharte 5,6 gransen] murren penzen] quengeln, jammernd um etwas bitten, (auch:) nörgeln, keifen 5,7 Braecedenzen] Präzedenz: Rangfolge, Vortritt bei offiziellen Anlässen, z. B. bei Prozessionen

Erheblich älter ist das folgende Lied ,Von einem bairischen [i.e. bäurischen] baurn', in dem mit Städterdünkel und Bauerneinfalt gleich zwei Topoi bedient werden. Diese Verknüpfung zweier nur scheinbar widersprüchlicher Motive ist bereits in einer Version aus dem 17. Jahrhundert belegt und konnte sich zumindest ein Jahrhundert lang im Volksgesang halten. ${ }^{33}$ Komische Inversion begegnet uns bereits in der ersten Strophe: Durch den bewusst ambivalenten Ausdruck ,gschlechter Herr', der mit den Konnotationen ,gewöhnlich, gemein' und ,adelig, von Geschlecht' spielt, wird das Verhältnis derer aus dem ,gemeinen Volk' und der , hohen Herren' umgedreht und ,Bauer' gewissermaßen zum Ehrentitel:

1

I bin ä baur vnd bins recht geren

dauschet wol mit kaim gschlechten herren

wollan I wil das bayrische löben

weil I auf Erden bi nimmer aufgöben.

32 Lindemayr, Dialektlieder I, S. $153 \mathrm{f}$.

33 Ich bin halt ä Baur wie muß i denn macha ist sowohl im Druck (Vier schöne ganz neue Weltliche Lieder, Wienbibliothek A 21960, Bd. I, 7) als auch handschriftlich (Bayerische Staatsbibliothek, Cod. germ. 7340, Teil 2, S. 151f.) aus der Zeit um 1790-1800 überliefert und verknüpft in ganz ähnlicher Weise die Kritik an den städtischen Sitten mit einer Komisierung der Bauernfigur. 


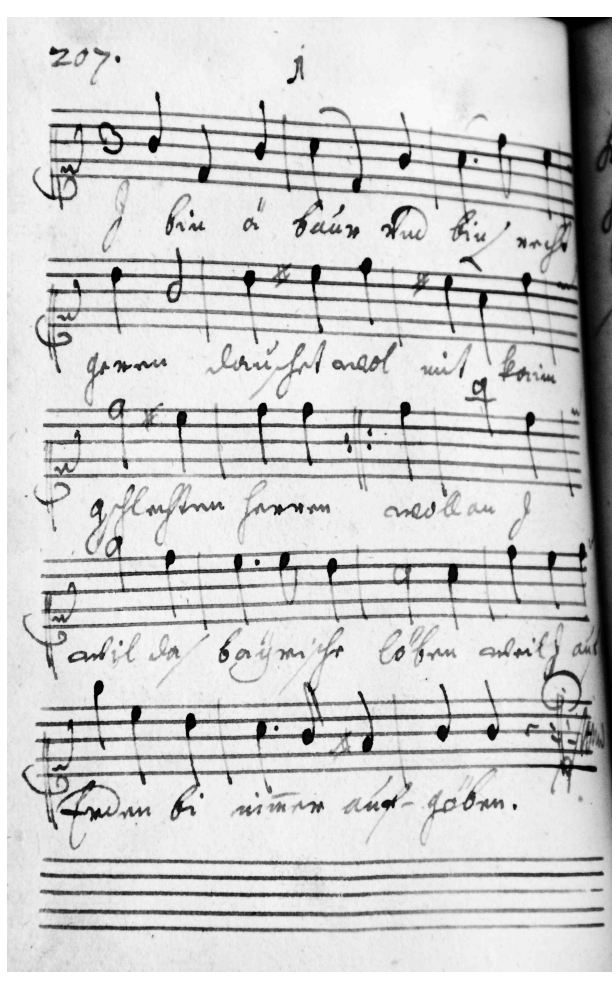

2

Komm i zu iezigen Zeiten in dstatt hat gar vil gassn vergeh i mi kradt bey ins im dorff da geh i nit irr seindt etwan ä haiser ä fünff oder fier. ${ }^{34}$
Abb. 23: Melodie zu I bin ä baur (Staatsbibliothek zu Berlin, Ms.germ.oct. 230, f. 207).

1,2 dauschet] tauschte, würde tauschen gschlechten] gewöhnlichen, einfachen 1,3 bayrische] bäurische (mit bewusstem Doppelsinn, siehe auch Titel) 1,4 weil] solange, dieweil 2,4 ä haiser ä fünff] ungefähr fünf Häuser

In der Folge werden verschiedene Ebenen angesprochen, auf denen sich Land und Stadt und deren Bewohner voneinander unterscheiden, wie etwa Kleidung, Sitten, aber auch Sprache. Dabei wird stets die Selbstverständlichkeit, mit der der Bauer sich ,daheim bewegt und benimmt, in der Stadt in Frage gestellt: Das Pflaster hebe sich unangenehm von den bequemen Dorfwegen ab, die übertriebene Sauberkeit enge das eigene Tun ein und schließlich müsse man in der Stadt auch fürchten, nicht, zierlich' genug zu sprechen. Dies betreffe nicht nur den Umgang untereinander, sondern auch mit amtlichen Instanzen:

34 Staatsbibliothek zu Berlin, Ms.germ.oct. 230, S. 207-212, hier 207f. Erstmals ediert bei Bolte, Der Bauer im deutschen Liede, S. 198-200 (mit geringen Normalisierungen durch Großschreibung der Substantive und bei der Interpunktion), Melodie abgedruckt ebda. im Anhang, S. I. 
8

Bin i da huemma so bin i nit faul sag fei mei sachl wies mir ist vmbs maul bin i beym Pflögä so schaut er mi ah das ihn halt no nit recht Ierzn koh.
9

Drin in der statt so gar der stattbittl will von aim habn sein birenden tittl bey ins im dorff da ist es ai Modl Jäckhl haisst diser der ander schlötß Jodl. ${ }^{35}$

8,3 Pflögä] Pfleger (Gerichts- oder Distriktsbeamter) 8,4 Ierzn] ,ihrzen`, d. h. mit ,Ihr' ansprechen 9,1 stattbittl] Stadtbüttel (Gerichtsdiener) 9,2 birenden] gebührenden 9,3 ai Modl] ein Model, hier etwa: bei allen gleich 9,4 schlötß] schlechthin

Im Verlauf des Lieds allerdings bekommt die anfangs noch relativ neutrale Gegenüberstellung von Lebensbedingungen und Bräuchen eine deutlich ironische Note; im Dorf etwa könne man sich nicht vergehen, da es ohnehin nur vier oder fünf Häuser gebe. Derb wird die Komik, wenn gegen Ende das ungeschliffene bäurische Verhalten mit dem sozialdisziplinierten Stadtempfinden kontrastiert wird:

10

So darff in den Stättn kuen furtz aine thue

Soll in verhaltn, $i$ thues nit Nuä Nuä

ist mir aina noth im dorff lassn fahrn

da thuet mo anandä desstwegn nit gfharn.

12

Nägst gieng i voribä do däts mi astinckhä

das i ai d onmacht darnider miest sünckhä

Wan das ma mir nit gley an khietröckh agstrichä

I mainadt äff meinaid, wer des todts verblichä.
11

Die Appodöggn, die miest i gley Maidn dössl gstanckh kunt i do gar nit völaidn schmöckh liebä an ross oder khie pfifferling als balsm vnd bism frag nichts nach dem ding. 13

Dössl ding hat mar ia gschlagn in glider das mir leichtlich kunt etwas sey zwider mit aim Wort mächt wohnen in stättn nit drin Vil liebä in meiner huemat i bin. ${ }^{36}$

10,4 gfharn] gefährden, etwas Schlechtes tun 11,1 Appodöggn] Apotheke 11,2 dössl] dieser 11,3 schmöckh] rieche 11,3 khie] Kühe/Kuh- 11,3 pfifferling] hier: Mist, Kot 11,4 balsm] Balsam; häufig allgemein für Wohlgeruch 11,4 bism] Bisam: Moschus 12,1 Nägst] kürzlich, neulich, unlängst 12,3 khietröckh] Kuhdreck 12,4 mainadt] meinte, würde meinen meinaid] mein Eid, bei meinem Eid!, wahrhaftig 13,2 zwider] zuwider

Im selben Codex überliefert ist auch ein Lied, dessen eingängiges Grundschema sich in teils stark abweichenden dialektalen und standardsprachlichen Adaptionen über Jahrhunderte im Volksgesang hielt: In einer Gemeinderatssitzung nach Feierabend beratschlagen Bauern „wie die gstudierte Leüth“ ${ }^{37}$ über die Notwendigkeiten des dörflichen Miteinanders. Die einleitende Frage „Was braucht Ma in vnserm dorff“ wird mit scheinbaren Trivialitäten beantwortet, die nicht nur ein pittoreskes Genrebild zeichnen, sondern auch aufschlussreiche Konfliktfelder des Zusammenlebens am Land freilegen können:

\section{6}

Was braucht Ma in vnserm dorff

ä Miln die nit staubt, an Millner der nit raubt, an bottn, der nie hat gelogn an KauffMann, der nie hat betrogn dis braucht $\mathrm{Ma}$ in vnserm dorff.
7

Was braucht Ma in vnserm dorff an schneidä mit der gaiß der vmb kai steln wais an Nodern die ä Jungfrau is ä hebam die vmb d sach woll wist dis braucht Ma in vnserm dorff.

35 Ebda., S. 210.

36 Ebda., S. $210 f$.

37 Staatsbibliothek zu Berlin, Ms.germ.oct. 230, S. 214. 
8

Was braucht Ma in vnserm dorff

an Pfaffä der was ko

der ist ä glehrtha Mo

der selbst thuet haltn was er thuet biettn

vnd vns thuet vor gross schadn hiettn

das braucht Ma in vnserm dorff

10

Was braucht Ma in vnserm dorff.

ä wiegn fürs klai kündt

ä weib das darzue singt

vnd für die fürsorg noch ä wiegn

es mecht die thiern ä ais kriegn

das das braucht Ma in vnserm dorff.

12

Was braucht Ma in vnserm dorff

an Pflegä der nit schindt

an schörgn der braf bindt

an taubn kobl, ä hiener nöst

hät bald vergössn das Allerböst

das braucht Ma in vnserm dorff
9

Was braucht Ma in vnserm dorff

an Mesner der gschwindt lauff

wan es gibt ein kündts tauff.

an gfadä vnd ä gfäderlein

die gern trünckhn an guten wein

dis braucht Ma in vnserm dorff.

11

Was braucht Ma in vnserm dorff

an Jagä mit der bix

der weggschiesst wölff vnd fix

der vns mit frid liess vnser taubn

das gwilt thun wir ihm gern erlaubn

das braucht $\mathrm{Ma}$ in vnserm dorff.

13

Der gmaine rath ist auß

iezt gehmär all nach hauß

dort obn bey der hochn lindn

da würst das gsindl beysammen fündn

Ju! haih spillma mach auf

I bring dir ais, geh sauff. ${ }^{38}$

6,2 Miln] Mühle 7,4 Nodern] Näherin 8,4 biettn] gebieten 9,4 gfadä] Gevatter, Taufpate gfäderlein] Gevatterin, Taufpatin 10,2 klai] kleine 10,5 thiern] Dirne, Magd ä ais] auch eines 11,2 bix] Büchse, Gewehr 11,5 gwilt] Wild 12,4 hiern] Hühner 13,5 spillma] Spielmann 13,6 bring dir ais] Aufforderung zum Trinken (aus dem Glas des Sprechers)

Auch in Gregor Joseph Werners humoristischer Kantate Bauren-Richters-Wahl (1754) wird eine ähnlich verquere Dorfversammlung vorgeführt, in der ein Quintett aus drei (niederösterreichisch sprechenden) Einheimischen, einem Schwaben und einem ,böhmakelnden' Tschechen auf der Suche nach einem neuen Oberhaupt sind: ${ }^{39}$

Obwohl obschon obgleich und sintemall

der leydig krachdürre Tod

mit seinem Pfeil

in schneller Eyl

unsern Richter den Thoma Pökh

den alten Gekh

in oänen hui hat troffen,

und Er

äß wie ä Scheer

in dErden eini gschloffen,

so wär uns do zum Trost

sei höni süesser Most

zu oänen Labsall

auf seinem Todtenmahl.

Nu bräucht mär halt än Man

der uns recht mit Verstand

38 Ebda., S. 216-219. Erstmals ediert bei Bolte, Der Bauer im deutschen Liede, S. 201-203.

39 Vgl. Christian Neuhuber: Werners Werke in Mundart. Weihnachtspastorellen - Der Wiennerische Tändlmarckt - Die Bauren-Richters-Wahl. In: Martin Czernin (Hg.): Gregor Joseph Werner. Eisenstadt 2018 [im Druck]. 
khan gehen an dö Hand

und unsrä gantzen Gmoän

ganz muädä seel alloän

recht gscheidt vorstehen khan. ${ }^{40}$

9 Scheer] Maulwurf 12 höni] Honig 18 Gmoän] Gemeinde, Dorfgemeinschaft

Nach gröberen Querelen, wer denn nun für das Amt tauge, wird schließlich auf der „Bonthätung“ (Banntaiding, i. e. Gemeindeversammlung) der Kompromisskandidat Paul Schnepfendreck zum Dorfrichter gekürt. Wie wichtig für Werner das ästhetische Wirkungspotential phonologischer (und mitgemeint sind natürlich auch morphologische, syntaktische und lexikalische) Differenzen von Sprachvarietäten und Sprachen ist, macht er im ,Avertissement' seines Kantatendrucks von 1754 klar, wenn er „jedem Vocalisten / in seiner Person hauptsächlich die Pronunciation wohl anrecommendiret " 41 .

Vielleicht von Werners Kanate inspiriert ist das kurze Singspiel Die 4 Ratsherrn in Weilheim zur Musik des Steiner Benefiziaten Johann Georg Zechner (1716-1778). Hier ist es keine dörfliche, sondern eine lächerliche kleinstädtische Ratsversammlung, die über das Schicksal eines Delinquenten zu entscheiden hat. Sie wirft kein gutes Licht auf die örtliche Gerichtsbarkeit: Nur einer des Quartetts stemmt sich letztendlich dagegen, einen Unschuldigen aus Pflichtvergessenheit, Inkompetenz und Bequemlichkeit mit der Todesstrafe abzuurteilen. Hier der Beginn des höchst amüsanten Quodlibets für vier Bässe:

1. Consul. Herrn! seidts allö beinandä in Rath?

Wann ainä abgieng, wärs Sünd und wär Schad.

Mörkts auf, was i eng ietzt vorzbringä hab,

übä den Ghenkten heut bröchn mär ön Stab.

D’Sach läßt sie abbröchä nöt übä d'Knie;

um d'Leut is nöt wie um d'Ochsen und Küh!

Mörkts fein auf Herrn was än iedä da thuet.

Menschenfleisch is ja kain kölbernes Blut.

2. Consul. Recht her Kollegä, mä sänd schan beysam;

Was habn mä than znächst ins Teixelspaar-Nahm.

Dös Urthel kann i mein Aid nöt krepiern.

1. Consul. So muß mäs halt hietzt recht examiniern.

3. Consul. Ohne Maßgöbung dä Handl is gfält, dä Herr Collega hat mi übereilt.

I halt dafür, er is unschuldi gwößt.

1. Consul. Das wär dä Teixel hiez sagts ös äf d'Löst.

4. Consul. I han ghört, er is grad falsch angöbn warn, Schlecht is ja d'Zeugenschaft vä hinten und varn.

Sinst is dä Brauch, daßmä d'Sünder anhört.

40 Zwey neue und extra lustige musicalische Tafel-Stücke. I. Der Wiennerische Tändlmarckt. Mit 4. Singstimmen, 2. Violinen und Basso ordinario. [... ] II. Die Bauren-Richters-Wahl. Mit 5. Singstimmen, 2. Violinen und Basso ordinario. [...] Beyde Stücke, sind nach Art der Quodlibete eingerichtet [...]. Von dem Autore des Musicalischen Calenders Gregorio Josepho Werner, Hochfürstlich Estorhasischen Capellmeistern zu Eisenstadt in Ungarn. Augspurg, Verlegt von Johann Jacob Lotters seel. Erben. [1754], Stimmmaterial für Barthlme Zimmermann, S. 1f.

41 Ebda, Avertissement, f. 2r. 
1. Consul. Ei, was kann i dafür hett äs bögehrt. D'Zeit hats nöt glitten, das wißts ja ihr Herrn; I hettn anghert ja von Herzen gern. Is schon Mittag gwößt, wäs Fleisch bald väsodn. Wißts ja nach Zwölfi is Richtn väbothn.

2. Consul. Er is in Kottä drin gsössen lang gnue, hetts ja zän anhern no Zeit ghabt dazue. Z’gleich mueß mä beidö Partheyen anhern.

1. Consul. Han mä denkt, was wölln män Kerl lang schern.

3. Consul. Han ä mahl glösn än altö Legend, s'gros Corpus rurio geht an allö Stend. Sänd lautä Lex drin, dö spröchent s Contrar.

1. Consul. Lex hin, Lex her unsä Kasus is rär. ${ }^{42}$

9 mä sänd] wir sind 10 znächst] kürzlich, neulich, unlängst 13 gfält] gefehlt, fehlerhaft 16 Teixel] Teufel 23 väsodn] versotten 25 Kottä] Kerker gnue] genug 26 zän anhern] zun Anhören 30 Corpus rurio] Verballhornung für Corpus iuris civilis 31 Lex] (lat.) Gesetz 32 Kasus] (lat. casus) Fall

Mitte des 18. Jahrhunderts hatte das bayerische Weilheim in Österreich einen ähnlichen Ruf wie Schilda. Dass die Verunglimpfung aber durchaus austauschbar war, zeigt eine Variante aus dem Besitz der Schwarzenberger, die den närrischen Prozess nach Hirschau, dem ,Schilda der Oberpfalz', verlegt. ${ }^{43}$

Besonders beliebt war in der barocken Unterhaltungsliteratur die Schilderung von Rechtsstreitigkeiten, in denen der ländliche Simpel den gewieften Akademikern hilflos ausgeliefert ist. Verhandelt werden typisch dörfliche Konflikte, der Streit ums Vieh oder entgleiste Wirtshausstreitereien, kleine drastisch-witzige Genreszenen, die man als Intermedien offenbar selbst der höchsten Zuschauerschaft zumuten konnte. 1665 etwa führte die Studentenschaft des Wiener Jesuitenkollegs am Festtag des Ordensgründers das lateinische Huldigungsstück Septennium Romano-Imperatorium Augustissimi Leopoldi Primi auf, das in Anwesenheit Ihrer Majestät den siebten Jahrestag der Kaiserkrönung in Frankfurt feierte. ${ }^{44}$ Zwischen den beiden Hauptteilen der langatmigen Eloge wurde das Zwischenspiel Ein Paur beweist, daß das Schenkhen bey denen doctoren Plus Ultra macht gezeigt, ein auch heute noch unterhaltsames Dreipersonenstück um zwei Bauern, die bei ihrer brachialen Konfliktlösung von einem gerissenen Juristen übervorteilt werden. Der Advokat Krenn ist wie der ,Dottore‘ der Commedia dell'arte

42 Musikarchiv Stift Kremsmünster, G 35/312 (Abschrift P. Ernest Frauenberger).

43 Vgl. Székesegyházi Kottatár, Györ, AMC, Z. 6 (Quodlibeticum 4. Consules Hirschauenses a 4. canti aut bassi e vlne).

44 Vgl. Septennium Romano-Imperatorium Augustissimi Leopoldi Primi, Calendis Augusti Francofurti Coronati Primo Aetatis suae exacto Jubilaeo Anno gloriosè completum: Quod demississima aggratulatione, et votiva gloriosae perennitatis apprecatione Coram Caesarea Ipsa Maiestate In Festo S. Ignatii Loiolae, Celebravit Illustrissima Juventus in Theatro Domus Professae Viennensis, Anno 1665. (Österreichische Nationalbibliothek, Cod. 13225 Han; miteingebunden ist auch die Perioche). Kleine Ausschnitte aus dem Intermedium finden sich bei Johann Willibald Nagl/Jakob Zeidler: Deutsch-Österreichische Literaturgeschichte. Ein Handbuch zur Geschichte der deutschen Literatur in Österreich-Ungarn. Hauptband: Von der Colonisation bis Kaiserin Maria Theresia. Wien: Fromme 1899, S. 673f. - Alexander von Weilen: Das Theater. 1529-1740. Separatabdruck aus Band VI der, Geschichte der Stadt Wien'. Wien: Verl. des Alterthumsvereines zu Wien 1917, S. 28f. Erstedition bei Neuhuber, Dialektale Rede in Wiener Stücken, S. 9195. 
ein opportunistischer Blender, der mit unsinnigen lateinischen Floskeln einzuschüchtern weiß und - wie er im Eingangsmonolog offen bekennt - den Rechtsstreit in die Länge dehnt, um seinen einfältigen Klienten das Geld aus der Tasche zu ziehen. Ein nur zu bereitwilliges Opfer findet er im Bauer Wästl, der glaubt, mit Bestechungsgeschenken den Prozess zu seinen Gunsten lenken zu können. Doch eben das dazu vorgesehene Kalb macht ihm Riepl streitig:

Wästl. Nä mein Keibel gib ich nit her; SKeibel laß ich nit, Ehe ich mein Keibel laß, ehe laß ich haar.

RIEPEL. will nit vill lang gschray machen mit dir.

WÄstl. Auwehe mein Keibel! Lasß da sagi, mein Keibel, No No, warth nur du falscher flögl du, so wirst das Keibel nit da lassen? hat der falsch heider alleweil than, alß wan er mein besster freindt währ, vnd iezt Nimbt er mirs Keibel ohn als gfähr ä so weckh, vnd schlögt mich No darzue. hä! hä! es gfält mir gleichwoll woll, daß ich ihm ä so guets in Pinckhl hab geben dem dieb dem falschen, dem Nichtnuzigen. Ich will dich Schon finden beim richtä.

RiePeL. Ja! Ja! gehe nur hin verkhlag mich.

WästL. Iez han ich die Kroissen ä verlohrn mit dem dieb, wie wirdt ich iez bstehn vor dem doctor? Poz da Kombt er dä doctor. Das ist guett: du warth ain weni mit dem Keiblä! Gstrenger Herr doctor Rättich, der Kärl hat mirs Keibel weg genommen, ich habs dem Herrn doctor Schenckhen wollen, Es ghört dem Herrn doctor zue, wirdt sy ia der Herr doctor drumb annemmä?

RiEPEL. Strenger Herr doctor dö hundtsNasen ist mir Schuldig, SKeibl Ghört mir Zue.

DостоR. Ihr habts villeicht ainem andern Schenckhen wollen? ich haiß nit der doctor Rattich.

Wästr. Jo, der herr doctor ist ia der, der sich alleweill so starckh annimbt vmb Mich?

Doctor. Ich khen euch woll, aber ich haiß nit der doctor Rattich, ich haiß der doctor Krenn.

WÄsтL. No gar recht, der doctor Krenn oder der doctor Rattich, dä deüfel, ich hab ia woll gwisst, daß ä bittere Wurzen ist, vnd hat mir nit ein wölln fahln. Ja schau der her doctor wo das nit wider alle Gerechtigkheit, wider Gott, vnd wider alle seini Zechen Gebott ist, daß er mirs Keibl so leichtfärtiger weiß weegNimbt, vnd ich bin ihms nit Schuldig. gib her SKeibl, siechst den Strengen Herrn doctor da?

RiePEL. Strenger Herr doctä SKeibel gib ich nit her, er ist mirs Schuldig, sein Kue hat mir mein Keibel derstossen, so mueß er mir Ja auf mein Aidt ain anders Keibel geben, Ich khans ia nit einbiessen.

Doctor. es braucht nit vill disputiren, wir wölln baldt wissen; wem das Keibel angehörig ist: wessen ist die Kue, so das Kalb getragen hat?

WästL. Mein ists. Gstrenger Herr doctor.

Doctor. so gehört das Kalb auch Euer.

WästL. Siechst? ich hab ihms ä sagn wölln, er hat mirs aber nit glaubt. Schau wan ich iez des Strengen Herrn doctor nit verschonet, so wolt ich dirs ä so machen; vnd wolt di so Klain aprigln, daß dus Pfaffen begern mögst.

Doctor. Gmach: Gueter freundt ihr habtn handl verlohrn.

RiEPEL. Ja es mögts ain iez vorschmäzen, was wölt; ich gibs Keibel nit her, SKeibl ist mein.

Doctor. Ihr Paurnflögl gibt acht mit wem ihr redt, da will ichs euch auß dem buech aufweisen; daß ihr vnrecht habt. Also. Partus Sequitur Uentrem, das haist wem die Kue zuegehört, dem gehört das Kalb auch zue.

RIEPEL. Ja das ist ain anders wans buech sagt.

WästL. Herr doctor wir wöllen nit lang disputiren mit ihm, wir wölln ihn Nur gleich briglen, vnd was No mehr ist, ist mir ä ins haar vnd in Parth blazt, was derffstu mir in mein Barth greiffen? was geht dich Mein barth an? was hast du in meim barth zsuechen?

Doctor. Ist das ding wahr? so habt ihr 6. daller Straff verfallen; will euchs auch auß dem buech aufweisen, daß euch nit vnrecht gschicht. hörth! qui sentit Commodum; sentiat et onus; das 
ist, so ainer dem Andern auß Zorn in den barth greifft; soll er dem belaidigten zur Straff 6 . daller erlegen; Er hat euch Ja auß Zorn in den barth griffen?

WësTL. Ja ich wolts main, weill er mich gschlagn hat, vnd hat ä söltes grausambs türmisch gsicht gegn mir gmacht.

RiePel. höb ä Paur mit den doctoren an. vnd wan soll ichs gebm?

DостоR. Wan ihr ihms Morgen vmb dise Stundt nit erlegt werd haben, so seith ihr vermög der Rechten, 12. daller verfallen.

Riepel. daß Gott erbarm! wo wirdt ich 6. daller Nemmen? heitt ichs Keibel in GottsNamb gehn lassen.

WästL. gehe hin Schleckh bärtl [... $]^{45}$

Keibel] Kalb heider] kurz für: Bärenhäuter (Schimpfwort) Pinckhl] hier: Rücken Kroissen] Krebse vorschmäzen] vorschwätzen Partus Sequitur Uentrem] (lat.) das Neugeborene folgt der Mutter blazt] geschlagen, unsanft gegriffen qui sentit Commodum; sentiat et onus] (lat.) wer die Vorteile genießt, soll auch die Nachteile tragen türmisch] wild, zornig höb ä Paur] fange ein Bauer Schleckh bärtl] kindlicher Spottruf

Prügeleien sind ohnedies eines der Lieblingsthemen des barocken Bauernspotts. Eine äußerst anschauliche Szene bringt Des Paurn Mündtliche provocation für seinen Pfleger wider deß Gerichtschreibers gegebnen Abschidt, das in genetischer Nähe zu Daß Paurn werch ist nichts mehr werth steht. Es ist ein Prosamonolog, in dem einer der vom Gerichtsschreiber verurteilten Raufbolde seine verquere Sicht der Dinge in einer Weise schildert, die beim damaligen Publikum den Lacherfolg garantierte, dem heutigen Leser zudem aber bei aller satirischen Verzerrung interessante Einblicke in die bäuerliche Geselligkeitskultur gibt. Die Mündtliche provocation ist uns in zwei bereits angesprochenen Quellen überliefert. Die folgende Fassung entstammt wieder dem Codex mit Weihnachtsspielen der Staatsbibliothek zu Berlin ${ }^{46}$ und ist eine für die zweite Hälfte des 17. Jahrhunderts überraschend kompromisslose, standardferne Literarisierung eines westmittelbairischen Dialekts, der mit seinen Vokalisierungen, Assimilierungen und Verschleifungen, mit Apokopen und Synkopen, mit derber Lexik und Idiomatik wesentlich authentischer wiedergegeben ist als in zeitgleichen Werken der Mundartdichtung. So mündlichkeitsnah ist der Scherzmonolog gestaltet, dass offenbar schon die Kopisten dieser wohl im heutigen Innviertel entstandenen Dichtung ihre liebe Mühe hatten und Unverständliches ersetzten oder tilgten:

45 Ebda., S. 93-95.

46 Staatsbibliothek zu Berlin, Ms.germ.qu. 1327, f. 114r-117r. Erstediert wurde das Werk allerdings aus der Handschrift des niederbayerischen Pflegerichters Andreas Mayr (Universitätsbibliothek Tübingen, Md 290), vgl. Rowley, „Erste Paurn Clag“ und „ander Paurn Clag“, S. 38-40 und noch einmal (in derselben Fassung) bei Rowley, ,Waß sy zLanzet zue hat tragn', S. 26f. Keine der beiden Fassungen scheint das Original zu sein; etliche sinnentstellende Abschreib- und wohl auch Verständnisfehler in beiden Texten sprechen dagegen. So muss auch Rowleys Einschätzung, das Werk sei in der Landshuter Gegend entstanden, noch einmal überdacht werden - zumal die Ortsangaben in den nachgetragenen Texten wohl eher ins (damals noch bayerische) Innviertel verweisen. Hagers Vermutung, der Verfasser der Handschrift, Andreas Mayr, habe hier einen Einblick in seinen Berufsalltag gegeben, wird sich wohl kaum verifizieren lassen, vgl. Stephan Hager: „Mießig sein ist nit mein Freud“. Beamtenethos und Poesie im Werk des niederbayerischen Pflegrichters Andreas Mayr im Kontext des oberdeutschen Literatursystems der frühen Neuzeit. In: Verhandlungen des Historischen Vereins für Niederbayern 127-128 (2001-2002), S. 51-210, hier S. 171. 
Vöster herr Pfleger.

I bitt oy vnd der lämöß es iadt mi di greauß neaut änhi, mueß oy anläffen und mueß oy Clagen, waß mir für lözer prozn handl hintert hendt ist gstandten, am Mitichä wie der Stöffl vo Zäll mit Kreschvrschl d'schenkh hat khat, bin I mitm Schuelenzen in allm guetn zum wirth ähi khemä, homä ins ä Maß Pier ein schenkhä lassn vmb inser gelt, vnd homä ä säßl mit einander khröt, Ehat in Ehrn vnd in frinkhet in dendl mährn hat mir mein nachbär der wibman von höckhing vmbän trunkh zuehe gschrien, vnd hat mir ä halbs brat kat auß seim Pier, dem hani ä rödlä bschaidt tho, wie recht vnd billä i[s], vnd hoß vo statt sein gspan Zemmel Bastl wider vmbi brat in alln guatn, vnd ho oß wönkh nichts löz im sinn kat, oß Ir nit, I ho mi ä zum allerwönkhistn nix args von yem bsargt kat, da sait Er afer im hui zu mir, Er gsengs kein schöllmä nit, waß Er sy vmb In keit, er schiß mir in mein trunkh, vnd lät mir holt der frassakh der lözisten rödn an, vnd hält mi oß schmählä, daß Irs nit gläbn kündt, vnd daß oy selbm Zorn tho het, wen Irs kert het an alle schuldt. ist än aydt der wahr ist, hon iem oß würkhli nichts löz tho kat, oß würkli nichts löz da aufm podn lät, fraigt nu nachi, der Schne-Cristl, vnd der Praut Wolfl söndt baidt darbey gwest, do künets oy alle waret sagen, no so bin I afer all mein Lebtag nie khein schelmä holt gwest, ho mi allmall Erlä vnd frinklhä kaltn, ho mi auf alln blazen akhrefediern khina, vnd bin oß runder mo gwest, oß mär ain hat finä mögn, homi ä ains Manß gsteift wiern terfä, vnd ho ä fort zeuserwünckhl am khürchtä dö ganzn tanzbobm allain a krämbt, bin ä säßl in meim sün ä anti warn, hat mir schmä oß weh tho, vnd hat mi der prozn sakh oß Peaußhafftig gmacht, daß ichs nimmer dä lein ho kinä, vnd ho halt bein Sakhament mitm tenkhn feistling hinden am schadernakh yber d'Zill ahi gschlagn, daß erm narsch in alle heh hat kert, vnd wen i mein schnaiter bey mir kat het, so wer dä handl nit guet warn, I hetn z'hackht zu än lautern hodern, I often her vnd sag oy mein Gottseel Kai verlogns wort nit, wan anderst ist, wil ich mi gern strafä lassen, yber dößl ho i mi fein stat davon gmacht, vnd ho zech vnd d'prozenwerch alß ob einander ligen lassen, het si sünst einkrissen, der Peitlpue: vnd dödl, heten sy all anander ghangen, hetn mirg mit erst bleaut vnd ahi beoust, ist affter der Semel-bastl im schuß nachi glifä, vnd ist mir mit vrlä z'khrödn mit baiden hendtn inß gsäß plazt, vnd hot mi vostatt an arsch nider krissen, daß $i$ än pindenger tho hab dlot öhel bey der lackhä bäm saufaltä, ist mein huet vnds gsäsß alß ä lauter drockh warn, kinnt Eus no gschaun lassen wans neaut thät. I afftn her rump in schuß wieder auf, und dä tap ä soßl än guetn Zueggetn pengl, vnd ren in d'wampn damit, daß Er ä guete fahrt nimmer gschnaun hat kinä, wie Er afftn ä wenkh verdleimz hat, da hot mir d'höpin auf ä waus nider schiessn wölln, bin iem afer z'fachtign warn, vnd ho iem in knitl zwischen der Eeaur ähi d'lät, daß er ä der mit agsprungn ist, vnd daß yems bluet yberm holß ä d'liefä ist, hat afer alß weaut tho, vnd ho mi bei golschn nu fraidig stölln müessn, wist wol waß Er für ein höpin ist, vnd waß Er stäts für händl anhebt, wen Er mir Z'ggrat wär warn, het Er mi mit ernst ohi peaust, wär mir oß gwiß gwest alß alle ament. In deml kümbt afn krat dä schergn deperl darzue, zeaucht vostat sein waider auß, hackht nach dä fläch nach inß, stäbt ins auseinander, vnd lät inß all bed in d'halßscheissn, ä sößl sein mir nächstn vorgstantn, vnd ho i in mein sün dapfer kröt kat, ho ä mein rödnen mit ernst braucht, vnd hats alß in der latein fürbracht, hamä afer nichts krichtn khinä, dä krichtschreiber hat eurn vo stat aufm Semelwastl ghangä, hat inß d'luckhn all verzänt, vnd iem auf alle pläzn zue d'lät, mi afer hat Er vo bauchs bebm ausgleglibt, hat mi 2. täg in d'keichn g'schafft, ho baid redner vnd da schiedt alß allain zalln müessen, vnd solt 2 . thallä straf dälögn, daß wär mir nit posierlä, vnd mechts nit ausgstehn, wen Ir mi hanhen liest, ä soßl treibt mi deat für oy, vnd wä bittn halbn, wo Ir holt mit der keichn verguat nämbt, vnd liest mi mit der straf vnkheit, ließ afn mein widersachä ä äzwen täg in ä guets lach ähi werfä, vnd ließ mi ä sößl durchi schiessn, wist Ir ä forth än dienst bei mir etwa mit ä maß hönkh, oder mit äm spänfäckhl, wan mein alte fäckhelt so iß mir ä nit in arsch d'nath, vnd will oy nit an der Pernhaut lign lassn, will oy äfftn mit sötlen leusen scheißhandl alßbolt nimmer kemmen. ${ }^{47}$

Vöster] Ehrenprädikat für Standespersonen oy] euch vnd der lämöß] (Verschleifung für:) um die Erlaubnis iadt] jagt neaut] Not änhi] (,anhin', hier:) her lözer] schlimmer, schlechter prozn handl] Unglücksfall, Sche-

47 Staatsbibliothek zu Berlin, Ms.germ.qu. 1327, f. 114r-117r. 
rerei hintert hendt ist gstandten] geschehen, zugestoßen ist Mitichä] Mittwoch Zäll] wohl Zell an der Pram Kreschvrschl] Ursula Kresch khat] gehabt Schuelenzen] Lenz Schuh khemä] gekommen homä] haben wir ä säßl] so khröt] geredet Ehat] zunächst frinkhet] Redlichkeit in dendl mährn] während dieses Gesprächs höckhing] wohl Höcking im Innviertel ä halbs brat kat] ein halbes gebracht gehabt: jem. ,eines bringen' ist eine Aufforderung, aus dem dargebotenen Krug zu trinken, die man - will man nicht unhöflich sein - mit einem Segen erwidert und annimmt rödlä] redlich bschaidt tho] Bescheid getan: die Einladung angenommen hoß vo statt] habe es sofort gspan] Kameraden Zemmel Bastl] Sebastian Semmel oß wönkh nichts löz] ebensowenig Schlechtes oß Ir nit] wie Ihr bsargt kat] befürchtet sait] sagt gsengs kein schöllmä nit] nimmt es von keinem Lumpen an keit], wirft‘: annimmt, kümmert lät] ,legt‘: hängt an oy selbm Zorn tho het] euch selbst erzürnt hätte kert] gehört hon] habe tho kat] getan lät] liegt baidt] beide frinklhä] redlich akhrefediern] latinisierende Verballhornung runder mo] anständiger Mann finä] finden gsteift wiern] ordentlich wehren zeuserwünckhl] zu Außerwinkel (Ortsname) tanzbobm] Tanzboden a krämbt] abgeräumt ä anti warn] auch missgelaunt, ärgerlich geworden prozn sakh] Schimpfwort (Protz: Kröte) Peaußhafftig] boshaft, wütend dä lein] erleiden tenkhn feistling] linken Faust schadernakh] Winterhut d'Zill] ? (besonders hart, übermäßig?) erm narsch] ihm den Arsch schnaiter] großes Messer zu än lautern hodern] zu einem bloßen Fetzen stat] still d'prozenwerch] die Schererei Peitlpue] Schimpfwort anander ghangen] zusammengeholfen mirg] Sofortkorrektur, wohl zu ,mi‘ bleaut] verbläut ahi beoust] runtergeworfen glifä] gelaufen mit vrlä z'khrödn] mit Verlaub zu sprechen pindenger] Schrei (?) dlot] glatt, direkt öhel] drüben lackhä] Pfütze saufaltä] Schweinegatter afftn] dann in schuß] sofort dä tap] erwische Zueggetn pengl] Prügel mit Zacken d'wampn] den Bauch gschnaun] schnaufen verdleimz] gestöhnt (,gleimazen') d'höpin] die Kröte z'fachtign] voraus, zuvor Eeaur] Ohren ä der mit] in der Mitte d'lät] gelegt d'liefä] gelaufen weaut] ? bei golschn] Fluchwort (?) Z'ggrat] zu hurtig, geschwind ohi peaust] runtergestoßen schergn deperl] Gerichtsbüttel Deperl (Spottwort) zeaucht] zieht in d'halßscheissn] Halseisen, Halsfessel nächstn] kürzlich aufm Semelwastl ghangä] Zum SemmelWastl gehalten d'luckhn all verzänt] die Auswege versperrt auf alle pläzn zue d'lät] seinem Geheule Glauben geschenkt (?) bauchs bebm] in Bausch und Bogen? ausgleglibt] auseinandergenommen, fertiggemacht keichn] Kerker baid redner vnd da schiedt] sowohl Prozess und Schiedsspruch hanhen] henken vnkheit] unberührt, ungeschoren ä äzwen] auch für zwei hönkh] Honig sötlen leusen] solchen

Vielleicht noch älter als diese, Bauernklagen 'sind die frühen dialektalen Verarbeitungen des ,Bauer in der Kirche'-Motivs, wo ein soeben aus Kirche oder Stadt Zurückgekehrter einem daheimgebliebenen Konterpart seine einfältigen Eindrücke schildert. Die naiven Ausdeutungen des Gesehenen dienen dabei weniger der Verspottung des ,tumben Tors als der Erheiterung des Publikums, das von der rührenden Unbedarftheit des Sprechers eingenommen wird. Denn dieser deutet sich das ihm unverständliche Ritual, die liturgischen Zeremonien, vor allem aber die musikalischen Einlagen und das Faszinosum der großen Kirchenorgel in den engen Parametern seines Erfahrungshorizonts unterhaltsam falsch aus. So wird der Taktstock des Regens chori als bedrohliche Waffe oder die karitative Kollekte als Trinkgeld für die erschöpften Sänger verstanden. Manche dieser ,Bauerngespräche` sind monologisch gestaltet, doch wird durch die Vergegenwärtigung des lauschenden Gesprächspartners stets das Bild einer dialogischen Szenerie evoziert. Dies erfolgt mit konventionalisierten Floskeln, die das aufmerksame Zuhören einfordern, den Wahrheitsgehalt beteuern oder das Bedauern, dass das Gegenüber nicht selbst vor Ort war, äußern.

Das früheste erhaltene Beispiel ist Vatter I mueß dir wunder sagn, ein um die Mitte des 17. Jahrhunderts entstandenes Lied, das uns in der Handschrift des Andreas Mayr erstmals vorliegt. ${ }^{48} \mathrm{Da}$ es in der älteren Forschung bereits mehrfach ediert und analy-

48 Eine etwas jüngere Fassung hat sich im vermutlich aus Regensburg stammenden Cod. germ. 5495 der Bayerischen Staatsbibliothek erhalten. Hartmann geht von einer älteren, umfangreicheren Urfassung aus und verweist auf Schmeller, der das Gedicht offenbar nach einer anderen - allerdings nicht eruierbaren - 
siert wurde und auch jüngst wieder Aufmerksamkeit fand, ${ }^{49}$ soll der Beginn hier zur Illustration genügen:
Vatter I mueß dir wunder sagn, waß sy nächten zue hat tragn, Zlanzet dinen in der Statt, am Abent wie man gföspert hat, bin I in ä Khürchen khemen, olli wunder würst vernemmen, da sänt vill manen greauß vnd clain, gern Funffzöhen, wie I vermain, vnd ätlen Schueller ä derbey, wieß mi hat dunckht zween oder drey, hat än yeder ä pfaidt ohn khat, hon khain gsechen der gfeyert hat, sänd machti starckh im handl gwösen, hamet all sant gsungen vnd dlösen, Än langen Schißling in äm Standt, hat stäts on gfuchtlet mit der handt, vnd hinderm Fuchtlen hamet fein, die anderen Zainzing gsungen drein,

\author{
Am Ersten hat schlet ainer ohnghobn, \\ der ander ist stät nachi gstobn, \\ der dritt ist gähling ä her gwischt, \\ Vnnd wie sy der viert hat drinter gmischt, \\ hamets afften auf allen vieren, \\ mit ernst zwitiert, vnd zamen gschrieren, \\ Än yeder trüeg än Zötl her, \\ voll schwarzer häckhen hin und her, \\ der erst hat quikhizt mächti Clain, \\ der ander khundts nit nachi tain, \\ der dritt Stimbt wider gröber Zue, \\ der viert hat blert oß, wie ä Kue, \\ än olter hat än Stekhen khat, \\ vnd wen sy än bue verschnäckhlt hat, \\ So hat ern yberen Schedl gschlogn, \\ daß sy der Steckhen zam hat bogn, \\ $[\ldots]^{50}$
}

2 nächten] gestern (abends) 3 Zlanzet] zu Landshut 4 gföspert hat] die Vesper gehalten wurde 10 ätlen] etliche, einige 11 pfaidt ohn khat] (Chor-)Hemd angehabt 12 gfeyert hat] untätig war 15 Schißling] hoch Aufgeschossener, Bohnenstange 18 Zainzing] hintereinander, einzeln 19 schlet] bloß, nur 20 stat] still 21 gähling] jäh, plötzlich 23 afften] dann auf allen vieren] vierstimmig 24 zwitiert] gezwitschert 27 quikhizt] gequiekt, gequietscht 28 nit nachi tain] nicht nachmachen 33 verschnäckhlt hat] (hier:) versungen hat

Nach diesem ersten Muster aus der Mitte des 17. Jahrhunderts wurde das Motiv in etlichen anderen dialektalen Liedern aufgegriffen - teils in freieren Neuschöpfungen, teils aber auch in Bearbeitungen, die stellenweise sogar Übernahmen einzelner Verse enthalten: so etwa in Aloys Blumauers Vater, hörts nur Wunder an! (um 1785), wo mit dem ,evangelischen Bauernjungen' als Berichterstatter eine antiprotestantische Komponente hinzugefügt wird, oder auch in einem bei Schmeller abgedruckten schwäbischen Gedicht (Vater! hear na Wonder a!), von dem allerdings weder Quelle noch Datierung angegeben werden. ${ }^{51}$ Im Tiroler Raum war das Motiv Hartmann zufolge unter dem Ti-

Quelle gekannt hat und in seiner Grammatik zwei Verse mit dem Titelvermerk Die Vesper von Landshut anführt, die einen Prediger und eine Kanzel erwähnen und die in den vorliegenden Fassungen nicht enthalten sind (vgl. August Hartmann: Ein altes niederbairisches Dialektgedicht. In: Oskar Brenner/August Hartmann (Hg.): Bayerns Mundarten. Beiträge zur Deutschen Sprach- und Volkskunde. Bd. 1. München: Kaiser 1892, S. 225-239, hier S. 238 und Johann Andreas Schmeller: Die Mundarten Bayerns grammatisch dargestellt. München: Thienemann 1821, S. 253). Freilich kann es sich bei der Schmeller vorliegenden Fassung auch um eine spätere abweichende Variante handeln. Auch Blümml zieht das Bestehen einer früheren Fassung in Erwägung, schließt aber die Möglichkeit, dass Mayr der ursprüngliche Dichter ist, nicht aus (vgl. Emil Karl Blümml: Der Bauernsohn in der Kirche. Ein niederbayerisches Dialektgedicht aus ca. 1650. In: Zeitschrift für hochdeutsche Mundarten 6 (1905), S. 228-236, hier 233 und 235).

49 Vgl. Haid/Hochradner, Lieder und Tänze um 1800, S. 281. - Rowley, ,Was sy zLanzet zue hat tragn“.

50 Universitätsbibliothek Tübingen, Md 290 (Beschreibung Etlicher Geist: und Weltlicher Lieder und Sprüch), f. $143 \mathrm{v}-144 \mathrm{r}$.

51 Vgl. Aloys Blumauer's sämmtliche Werke. Dritter Theil. Der Gedichte zweyte Abtheilung. Königsberg: Universitäts-Buchhandlung 1827, S. 118-124. - Schmeller, Die Mundarten Bayerns, S. 547-552. 
tel Die Duxer Möss verbreitetet; ${ }^{52}$ deutliche Parallelen (zugleich aber ebenso wesentliche Unterschiede - v. a. in Struktur und Anordnung) zeigt auch das in der Ebermannstädter Liederhandschrift enthaltene Lied Votta! Lass dir wunder sag'n, was sich nächst hat zugetrag'n (1750). ${ }^{53}$

Eine interessante Variation stellt Der Aufmercksam-alles wohl betrachtend- Und redlich-erzehlende Saltzburger-Baur dar, das die Schilderung eines feierlichen Hochamts in der Domkirche liefert. Die Themenfelder dieses wohl 1751 entstandenen Werks ${ }^{54}$ sind dieselben wie beim älteren Vorbild und ebenso typisch sind der wiederholte Ausdruck großer Verwunderung und die humoristischen Effekte durch die bäuerliche Diktion. Diese ist nicht nur durch Dialekt gekennzeichnet, sondern auch durch mangelnde Kenntnis der gebräuchlichen Bezeichnungen, insbesondere in Hinblick auf die sakrale Umgebung. So bemerkt der mit der Butte in die Landeshauptstadt reisende Sprecher etwa zum prächtigen Deckenfresko Donato Mascagnis und Ignazio Solaris in zwar bewunderndem, doch der Würde des Gegenstands kaum angemessenem Ton: „Gantz obn an da Dilla hotsma machti wohl gfollen, Send Manndl und ollahond Gfraß oni gmohlen“ (7,1f.). Auch ein Verständnis für die Ernsthaftigkeit, die der sakralen Atmosphäre angemessen wäre, zeigt der Bauer nicht und wundert sich über die ernsten Gesichter im Geleit des Erzbischofs: „Leicht übä 20. Manna mit Spitz doher gehn, Sie mochten a so ernsthaffti durmische Fressen, Als hätten sie s'Lachen auf uamahl vergessen“ (10,2ff.). Das unterhaltende Moment verstärkt sich in der vom Rezipienten eingeforderten Re-Interpretation, indem die verzerrte bäuerliche Darstellung zurücktransformiert werden muss in ein dem tatsächlichen Ablauf entsprechendes Szenario. Besondere Aufmerksamkeit wird dem bischöflichen Auftritt gewidmet, der den prächtigen Einzug seiner Untertanen krönt:

14

Gley arschling do kam holt an ernstlicher Mann,

Der hat 2. schneeweisse Bandoffel trogen an,

Gieng Trittla für Trittla botts dochti doher,

Macht wohl mit die Füssa koa bißla koa gscher.

15

A Fuchs-rothi Blocha mit Schnierla vermengt,

Ist ihm übers Gsaß biß auf d'Füß obi ghengt,

An andera hat ihm in neu-gwaschna Kragen,

Zwoa Schritt hinter seina den Schwoaff nachi trogen.

52 Vgl. Hartmann, Ein altes niederbairisches Dialektgedicht, S. $229 \mathrm{ff}$.

53 Staatsbibliothek Bamberg: Msc.misc. 580, S. 82-85. - Edition bei Rolf Wilhelm Brednich/Wolfgang Suppan (Hg.): Die Ebermannstädter Liederhandschrift geschrieben um 1750 von Frantz Melchior Freytag Schulrektor zu Ebermannstadt (Staatsbibliothek Bamberg Msc.misc. 580a). Deutsches Volksliedarchiv Freiburg. Kulmbach: Freunde der Plasseburg E.V. 1972. (Schriften für Heimatforschung und Kulturpflege in Ostfranken 31) S. 129-131.

54 Das im Salzburger Dialekt verfasste Lied mag früher entstanden sein, als die Jahresangabe des überlieferten Drucks vermuten lässt. Denn es behandelt ein Pontifikalamt, dem der Landesfürst „Hanß Ernest“ $(3,2)$ vorsteht - also Johann Ernst Graf von Thun, der in der Zeit von 1687 bis 1709 Erzbischof von Salzburg war. Nach Hartmann könnte das Gedicht daher bereits in dessen Regierungsperiode entstanden sein (vgl. Hartmann, Ein altes niederbairisches Dialektgedicht, S. 230f.; siehe auch Pörnbacher, Bayerische Bibliothek, S. 1201). Möglich ist aber auch eine bewusste Verlagerung des Geschehens in die Vergangenheit, um die spöttisch-distanzierende Beschreibung des Bauern zu ermöglichen bzw. zu entlasten. 
16

Gantz vorn auf da Brust hobi gahling da blickt,

A Creutzl mit Glaßl und Arbes gestickt,

Und wann i nit fahl, so hot a nu grod,

Zwoa gstrichleht bauwollina Faustling oa ghot.

17

Und wo er nu ebba für über ist gruckt,

Hat jedemo s'Füßl vor seina gley zuckt,

Drum hobi ma einbild koa anderer Herr,

Sey eben der Bischoff gewesen als der.

18

Weit hinta, do gienga no vil seiner Gsella,

On jeder aus ihnen hot schöner seyn wölla,

Hobn oghat a Pfoad mitm Handt-broatha Netz,

Wers braucht hett zum Fischen auf oamahl wers letz.

19

Sonst hobi nix bsunders mehr kenna vernehma,

Als wie der Herr Bischoff ind Kircha ist kömma,

Hobns auf der Oltona zom grumplt und kaußt,

$\mathrm{Da}$ mir die gantz Meß durch mein Ohrn hobn gsaußt.

20

Und wie nu mein Hanßl mit oll seina Schar,

Gantz firri ist kömma zum högsten Altar,

So hat er sie gley vor die Seinniga gsellt,

Und untera Sammetos Tachl higstellt.

21

Dort hobns ihn schier gar biß aufs Pfoadl odeckt,

Und wida an schöna Meß-Kittl oglegt.

Und übers lang Hemat hobns ihm no so köhk,

Oghenckt an gantz gfranzleten gelben Brust-Fleck. ${ }^{55}$

14,1 arschling] hinten, rückwärts 14,3 botts dochti] (sehr) andächtig 14,4 koa bißla koa gscher] kein Aufhebens, keinen Lärm 15,1 Blocha] grobes Tuch, (Pferde-)Decke 15,4 Schwoaff] Schwanz 16,2 Arbes] Erbsen 16,3 wann i nit fahl] wenn ich mich nicht irre 16,4 gstrichleht] gestreift 17,1 ebba] etwa 17,2 s'Füßl vor seina gley zuckt] eine Reverenz vor ihm gemacht 18,3 oghat] angehabt 18,3 Pfoad] Hemd 18,3 Handt-broatha Netz] handbreitem Netzstreifen (gemeint sind Chorhemden mit Spitzen) 18,4 letz] unpassend, schlecht 19,3 Oltona] Altan, Empore kaußt] Lärm gemacht 20,2 firri] nach vorne 20,4 Sammetos Tachl] samtenen Baldachin 21,1 odeckt] abgedeckt, ausgezogen 21,2 oglegt] angelegt 21,4 oghenckt] angehängt

Das markanteste Charakteristikum dieser Liedsorte, die unverständig-komische Wiedergabe der musikalischen Umrahmung, ist vom Dichter mit besonderer Liebe ausgestaltet. Sängerknaben, Streichern und den verschiedenen Holzbläsern wird jeweils eine Strophe gewidmet, zwei der obligaten Orgel (die Johann Ernst von Thun stiftete), und auch Dirigent, Blechbläser und Paukist bleiben nicht unerwähnt; wohl kein Zufall, weiß man um die besondere Wertschätzung der Salzburger Erzbischöfe für kirchliche und repräsentative Musik.

55 Der Aufmerksam-alles wohl betrachtend- und redlich-erzehlende Saltzburger-Baur. 1751, f. 3r-v. Edition bei Pörnbacher, Bayerische Bibliothek III, S. 1033-1037. 
23

Drauf hobns ogfanga a Gschroa und a Leba,

Weil koaner dem anderen hat wölla nachgeba,

Bold ohna nix mehr ausm Racha kunt bringa,

Hot missa oan andra statt seina gley singa.

24

Kroth übri do sachi a wunderlichs Gsindt,

Dos war mit da Fingeren so flux und so gschwindt,

Hobn allerley Toantzl mit Geigen aufgmacht,

Das mir hot mei Hertzerl offt über laut glacht.

25

Darneben stundt oaner der war a nit faul,

Nam strox oan Wurch-stichinga Brigel ins Maul,

That alleweil tro sutzla und schlecka so lang,

Biß endla si höra hot lossa a Klang.

26

Ihr ettla die hätta langmachtinga Rohr,

Die hob ma so wunderli brumlet ins Ohr,

Da hobns sies holbat ins Maul eini truckt,

Und gahling lang machti gegen mir ausi zuckt.

27

An andra der saß aufm Stielal gar fein,

Und hota kloas Finger-Broths-Tischel vor sein,

That allmohl wan andri gnug gsunga und gschryen,

Mit all bodi Bratzen drauf ummer regiern.

28

Und wan er zgleich unten und oben dran griffen,

So hots drin im Kasten natirla zam pfiffen,

Als wan d'Meiß und Kotzen, Welff, Zeißl und Bern,

Auf oha mohl mit völlinga Gwolt thatten blerrn.

29

Afft mitten drin sahi an hafftinga Gsella,

Der hat offt allsamma derreissen krot wölla,

Wans auf der Altona gar $\mathrm{z}$ bitter habn gredt,

Hat er mitm Steckl gley gschlaga aufs Bredt.

[...]

33

Wie zletsten der Blunder ist allar auswohren,

Hobns machti zam blasen mit guldeny Horrn,

Der Trummel-Schlager hot si jo braucht wie nit scheidt,

Koa Wunder wers wan er hätt troffa die Leüth. ${ }^{56}$

23,1 Gschroa] Geschrei Leba] Aufheben, Getue 23,3 ohna] einer 25,2 Wurch-stichinga Brigel] wurmstichigen Prügel (scherzhaft für Oboe oder Klarinette) 27,1 Stielal] Stühlchen 27,2 Finger-Broths] fingerbreites 28,3 Zeißl] Zeisige (beliebte Singvögel) 29,1 hafftinga] heftigen, groben 29,3 z bitter] zu viel, zu laut

Das Bauer-in-der-Kirche-Motiv findet auch in einem Anlassgedicht Verwendung, das wohl aus der Feder des Geistlichen Johann Michael Kagerer (1728-1812) stammt. Impulsgebendes Ereignis der in der Mundart des Salzachgaus verfassten Dichtung Gott gseng engs ihr Herrn ist die Jubiläumsweihe der Kirche St. Lorenz bei Mariapfarr 1759 durch Fürsterzbischof Sigismund Graf von Schrattenbach. Das Lied soll im Zuge der

56 Ebda., f. 3v-4v. 
Festlichkeiten bei der Mittagstafel im Anschluss an die kirchliche Feier durch den Geistlichen und Schriftsteller Franz Kaspar Itzlfeldner (1729-1774) in der Verkleidung eines lungauischen Bauern vorgetragen worden sein. ${ }^{57}$ Der Beginn greift mit der nächtlichen Ruhestörung ein topisches Element des Hirtenlieds auf, blendet kurz auch die Vorkommnisse des Siebenjährigen Kriegs ein, um dann wie in den Beispielen zuvor auf Bischof und Musik zu fokussieren. Den Schluss bildet - wie so oft - ein augenzwinkernder Hinweis auf die Trinkfreudigkeit der bäuerlichen Bevölkerung:

1

Gott gseng engs ihr Herrn, und laßts öncks wohl schmökä,

und laßt öngs wegä meiner von Essen nöt schrökä

ich will önck da weil was wundalichs sagen

was si bey da Kierchweyh erst heut hat zutragn.

2

I läg no in Strohbött, aft hör i gäch schiessen,

I ziträt vor Schrökhä auf henden, und Fiessen,

I raith mä Poz tausend, jetz iß mit uns ga,

da Künig aus Preussen ist wirkla scho da.

3

Drauf bin I wohl flux vo mein häußl weg gloffa,

und ho untä wögs schnaps mein Nachban otroffa,

aft fragi hä Nachba, was thut so rebelln,

aft sagt ä dä Fürst weicht d'lenzen Kapelln.

4

Wie i no den Fürsten beym Nama hör nenä

So denk i holla, heut lern in ge kennä

Ist gläb i ä klainä, und ga bräfa Mo

Es kunt Iem kai grossa in gscheidsei nöt dro.

$[\ldots]$

25

aft wie dä ganz handl für übä ist gwösn

da thätens den Fürsten sein lehrbrief volösen,

aft ha i mi flux aus da Kircha weg gstolln

Und thät drunt im Wirthshaus den abloaß abhollen. ${ }^{58}$

1,1 gseng engs] segne es euch 2,3 raith mä] denke mir 3,2 schnaps] Ausdruck eines plötzlichen Ereignisses 3,4 d'lenzen Kapelln] die Lorenz-Kapelle 4,2 ge] gleich, ja (Füllwort)

Die bäuerliche Trunksucht steht auch im Mittelpunkt eines der beliebtesten komischen Stoffe des Barocktheaters: der Eintageskönig. Das narrative Schema, das sich bereits in der Geschichte von Abu el-Hasan oder dem erwachten Schäfer der orientalischen Erzählsammlung Tausendundeine Nacht findet und in der Rahmenhandlung von Shakespeares

57 Vgl. Ignaz v. Kürsinger: Lungau. historisch, ethnographisch und statistisch aus bisher unbenützten urkundlichen Quellen dargestellt von Ignaz von Kürsinger. Mit artistischen Beigaben. Salzburg: Oberer'sche Buchhandlung 1853, S. 559. - Hartmann, Historische Volkslieder und Zeitgedichte III, S. 19. Das Lied ist in verschiedenen Varianten erhalten. Brenner geht von einem direkten Einfluss des 1758 entstandenen Primizlieds Der andächtige Pauer (Incipit: „Gott gseng enckh Essn!“) aus (vgl. Oskar Brenner: Der andächtige Bauer, ein altbairisches Gedicht v. J. 1758. In: Oskar Brenner und August Hartmann (Hg.): Bayerns Mundarten. Beiträge zur Deutschen Sprach- und Volkskunde. Bd. 1. München: Kaiser 1892, S. 295-300, hier 300).

58 Bayerische Staatsbibliothek, Cod. germ. 5985, S. 75-81. 


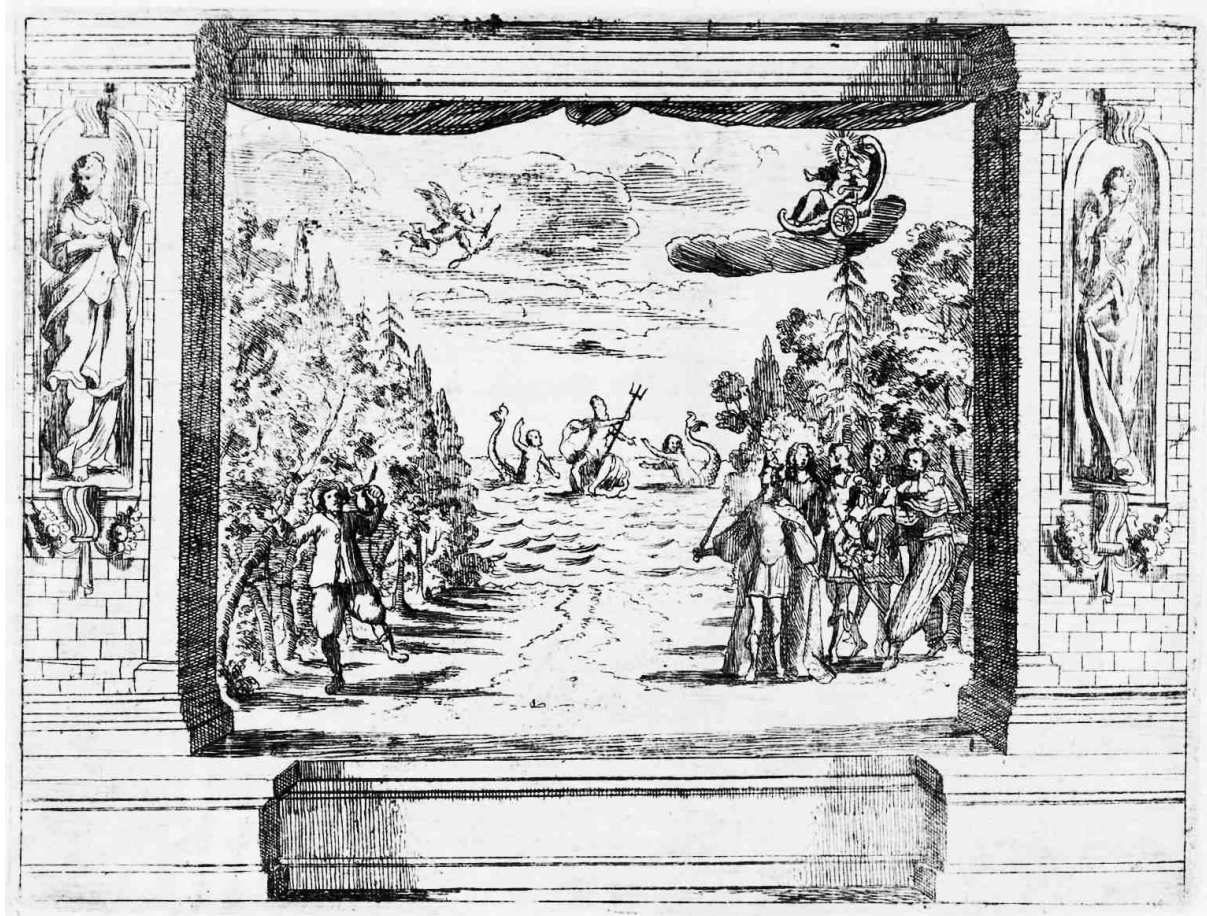

Abb. 24: Kupferstich zu Die Egyptische Olympia (Österreichische Nationalbibliothek/Kooperationspartner Google, Sammlung von Handschriften und alten Drucken, 22043-B).

The Taming of the Shrew (1594) seine wohl bekannteste Interpretation gefunden hat, ist simpel: Ein Betrunkener niederen Stands wird von einer adeligen Gesellschaft schlafend gefunden und auf ein Schloss verbracht, wo ihm nach dem Erwachen vorgespielt wird, er sei Herrscher. Überrascht arrangiert sich der Betrogene mit seiner neuen Situation und nützt haltlos deren Vorzüge, ohne die damit verbundenen Pflichten wahrzuhaben. Als er sich bald darauf zur Besinnungslosigkeit betrinkt, wird er wieder in seine alte Lage versetzt, sodass er am folgenden Morgen nicht mehr weiß, ob das Erlebte nur Traum oder doch Wirklichkeit war. Bereits die erste Adaption in der deutschen Dramatik, das Lustspiel Somnium vitae Humanae (1606) des Mecklenburgischen Pastors Ludwig Hollonius, nützte den Dialekt zur deutlichen Differenzierung der gesellschaftlichen Stände. ${ }^{59}$ Bairisch-österreichische Mundart kommt zur Rollengestaltung erstmals in Die Egyptische Olympia/Oder der flüchtige Virenus zur Verwendung. ${ }^{60}$ Dieses textuell bestüberlieferte Drama der deutschen Wanderbühne im 17. Jahrhundert begegnet uns zunächst 1665, als die berühmteste Truppe ihrer Zeit, die ,Innsbrucker Hofkomödianten', es in Wien auf die Bühne brachte und mit einem opulenten Programmheft bewarb. Der Zweck war offensichtlich: Man wollte Kaiser Leopold, einen bekannten Theaterfreund, beeindru-

59 Vgl. Lowack, Die Mundarten im hochdeutschen Drama, S. 87ff.

60 Vgl. Neuhuber, Dialektale Rede in Wiener Stücken, S. 65-74. 
cken und erhoffte sich weitere Protektion. Wie zwei Handschriften und drei Drucke aus den folgenden Jahren zeigen, redet der betrogene Bauer in der Binnenhandlung des Stücks ein breites Bairisch-Österreichisch und hat damit sofort die Lacher auf seiner Seite. Denn alle anderen Figuren sprechen im genus sublime, dem höchsten Stil, der für das adelige Umfeld der gespreizten Haupthandlung, einer typischen realitätsfernen Liebes- und Intrigengeschichte, vorgesehen war. Die Idee für diesen Stilbruch hatte sich der vermutliche Autor Andreas Elenson (1643-1706), ein Wiener mit bayerischen Wurzeln, wahrscheinlich bei der Commedia dell'arte geholt. Um eine phonetisch authentische Reproduktion eines lokalen Dialekts ging es dabei nicht, wie denn auch der Neuhauser Druck von 1680 eindrucksvoll belegt, wo ostmittelbairische (wienerische) und westmittelbairische Merkmale nebeneinanderstehen, zum Teil auch in bizarrer Entstellung, da der norddeutsche Setzer mit den regiolektalen Formen offensichtlich heillos überfordert war. Diese Unzahl an Fehlern wurde in zwei späteren Regensburger Drucken getreulich reproduziert - eine gewissenhafte Lektorierung war wohl nicht notwendig, sollte der Dialekt doch vor allem die Präsenz des alpenländischen ,Komödienbauern' auf der Bühne markieren, wie der folgende Ausschnitt veranschaulichen soll:

\section{Scena 10}

Baur.

Schentipatz Mist wo bini da y glab es trambt mie / ä wie bini da y daß gsteifft Hauß koma / ßist mit Gold und Silber alles umbhenckt / glei wie y der Saue Gruben y bi a mä troy in grassen Nöthen / a wari do Nöchten Christus heissen hamb ganga / aber ist halt a geschissen voll gewest / mi hetten do ein anda an die Nese griffa.

Scena 11

König mit der gantzen Hoff-Stadt.

TRIPTOLEmus. Ich wünsche Euer Königlichen Majestät einen guten Morgen und lange Gesundheit.

BAUR. Sol dan der Küny da sein.

KöNIG. Haben Euer Majest $\langle$ ät $\rangle$ wol geschlaffen?

BAUR. Oß werd jo nit Narrn sein bini der Küny.

IsıDoro. Was vor Kleider belieben Euer Majestät anzulegen.

Virenus. Von Gold oder Silber / von Samet oder Seiden.

BAUR. A seits mit Narrn / gabt my mey rads wulas Hemmet / und den blauen gefaltaten KirchtagRock / gebts my halt mey Sach / y wil hamb gahn / es derffts an nit lang vor an veitl haben es betrogne Drog.

KöNIG. Bringet Euer Majestät einen Tallar von Gold=Stück sambt den Zugehörungen weilen er das Cyprische Reich regiren sol: Hier Mechtigster König kombt ihr Liebste.

\section{Scena 12}

Asteria.

Asteria. Einen guten Morgen liebster Gemahl / hat mein Lieb wohl geschlaffen.

BAur. Se hi Krupi / daß iß ja a gsteiffti Mad y may mein aid dasi halt kini bi si haist mi Gemahl / von dem Ding het mir nit trämä lassen auer daß runde diende macht daß ichs gläb geschläffä / hab y fein gstaiff mein feines Lieb.

Aventuro. Hie Seynd die Kleider.

KöNIG. Daß man Ihr Majestät bekleide.

Theophrastus. Befinden sich Ihr Majestät noch gesund. 
Baur. Ey Herr Pfaringer / wie du wol singst.

IsIDoro. Ihr Majestät dieser ist kein Geistlicher / sondern ein Doctor der Artzney.

BAur. A wer wolt alle Narrn den kene / es seind encker so viel / daß einer nit weiß wer Pfaff odä Meßnär ist.

PICKelhärIng. Ihr Majestät sein lustig und guter Ding.

BAur. Was ist dan daß vor ein Fretter.

Asteria. Liebster Schatz es ist Euer kurtzweiliger Tischrath.

BAUR. Habts den kein Haußknecht lasts mir Zech macha.

Isidoro. Haben Euer Majestät was zubefehlen ehe sie in die Kirchen gehen?

BAur. Das man den Mist außführt / sag der Dirn / daß sies Vieh wohl versieht.

Aventuro. Es sol geschehen / Gnäd〈iger〉 Herr.

KöNIG. Allo ihr Herrn / begleitet Ihr Majestät nach der Kirchen alle. Abit.

\section{Scena 13 \\ Baur gehet zur Taffel / der König und die Cavallier warten ihn auff.}

KöNIG. Euer Majestät belieben das Wasser zu nehmen.

BAUR. Maist dan daß mi scho dürst / y ho jo no nix gfrassen.

KöNIG. Ich vermeine daß Euer Majest〈ät $\rangle$ ihre Händ nach Gebrauch waschen solten?

BAur. Was waschen / maistu daß y bschißni Hand habe y ho wol 1000mahl gessen / es nie kän vomi graust / und itz / do y Knü bin sol y de Hand waschen.

Triptolemeus. So nehmen dan Euer Majest〈ät $\rangle$ ihren Sitz.

BAur. Ztisch wil y wol gern gahn / äß seid a lenga mit mi y de Kira und Kalast umb ha gschlengelt / äß wän nix zthu wa / y bi mahti hungri darüber waren.

IsıDoro. Hier gebühret Euer Majest〈ät $\rangle$ und hier dero Gemahlin zu sitzen.

BAur. Setzt mi wies wolt / y denck wol ßist a ding wan mü nur gnug zfressen haben du langa y was nit wie du häst / setz di halt nida.

Asteria. Liebster Gemahl dieses seind zwey Vornehme KönigsSohn / last sie auch herzu sitzen.

BAUR. Wieviel fressa werd y no müssa de nehra / wo seids her?

Creonte. Wir seind auß Armenia, und kommen Euer Majestät auffzuwarten.

BAUR. So werds wol hungri sein / setzts enk halt ä nidä. ${ }^{61}$

Schentipatz Mist] Fluch: schänd dich, potz mist bini] bin ich y glab es trambt mie] ich glaub es träumt mir y daß gsteifft] in das schöne, tolle y bi a] ich bin auch mä troy] bei meiner Treu a wari do] ach wäre ich doch Nöchten] gestern abend (fälschlich für ,nächten`) Christus heissen hamb ganga] zum Abendgebet heimgegangen mi hetten do] wir hätten doch Nese griffa] Nasen gegriffen (Nese vermutlich Verlesung des Setzers von: Nasn) Oß] fälschlich für Öß: ihr seits mit] seid nicht, fälschlich für ,nit' mey rads wulas Hemmet] mein rotes wollenes Hemd es derffts an nit] ihr dürft/müsst einen nicht veitl] Diminutiv zu Veit, hier: dummer, leichtgläubiger Mensch Drog] fälschlich für Drög, Dreck Se hi] bäurischer Ausruf, Lockruf Krupi] Ausruf des Erstaunens, wohl zu Krüppel Mad] Maid, Mädchen y may] ich meine mein aid] bei meinem Eid! dasi halt kini bi] dass ich König bin trämä] träumen auer] aber runde diende] hübsche Mädchen, wohl fälschlich für: diendel gläb] glaube gstaiff] gut, tüchtig Pfaringer] scherzhaft für Pfarrer encker] euer, von euch Fretter] einer, der sich mühsam erhält; Habenichts Habts] Habt ihr Allo] allons: (franz.) auf, also jetzt, los geht's Abit] (lat.) geht ab Maist dan] Meinst du denn y ho jo no] ich hab ja noch es nie kän] es (hat) nie keinen (wohl Auslassungsfehler) vomi] vor mir Knü] fälschlich für Künü äß] ihr Kalast] Palast (wohl Druckfehler) umb ha] herum, umher äß wän nix zthu wa] als wenn nichts zu tun wäre (die hellen a wurden falsch verteilt: wan wä) mahti] mächtig, sehr waren] worden (wohl fälschlich für worn) Bist a ding] es ist einerlei wan mü] wenn wir y was nit wie du häst] ich weiß nicht, wie du heißt de nehra] ernähren seids] seid ihr werds] werdet ihr enk] euch ä nidä] auch nieder

61 Freuden-Spiel / Der Egyptischen OLYMPIÆ, Und Deß Flüchtigen VIRENI An Der Durchleuchtigsten / Fürstin und Frauen Frauen / Frauen MARIÆ. HEDWIG AUGUSTÆ. Hertzogin zu Sachsen / Engern und Westphalen / gebohrnen Hertzogin auß Bayern und Sultzbach / etc.etc. den 15. Weinmonats/ 1680. eingetretenen Geburths-Tag Auf Gnädigsten Befehl Ihro Durchl. Herrn und Gemahls / etc.etc. auff der hierzu erbauten grössern Schaubühne in Neuhauß auffgeführet und vorgestellet Von Der Sämbtlichen Hochfürstlichen Nieder-Sächsischen Compagnie COMOEDIANTEN, f. 14v-19r. 
Gut vier Jahrzehnte hat der bedeutende Wandertruppenprinzipal Elenson die regionalsprachlichen Grobianismen des Eintageskönigs mit Erfolg im gesamten deutschen Sprachraum zwischen Schleswig und Laibach, zwischen Aachen und Breslau zur Aufführung gebracht. Und auch nach seinem Tod verschwand das Stück noch lange nicht von den Spielplänen. ${ }^{62}$

1699 gab Elensons Truppe ein Gastspiel in Köln und wird dort wohl auch ihr Paradestück aufgeführt haben. Gut möglich, dass sich dabei der Autor des Printz von Arcadien Anregungen geholt hat. Denn auch diese hervorragende zweiteilige Komödie, die 1701 „von denen Churfürstl. Cöllnischen / Hof-Bedienten“ vermutlich in der bischöflichen Residenzstadt Bonn aufgeführt wurde, verdankt ihre ungemein wirksame Verlachkomik vor allem einem als Prinz verkleideten Bauern-Rüpel, der ständig aus der Rolle fällt. Dass nicht nur er, sondern auch mehr als ein Dutzend weiterer Figuren des hochkomischen Hoftheaterstücks ein erstaunlich realitätsnahes und stilsicheres Westmittelbairisch wiedergeben, mag bei einer Aufführung im Rheinland verblüffen. Doch setzte sich der Hofstaat des in München geborenen Wittelsbacher Kurfürsten Joseph Clemens zu einem Gutteil aus heimischen Untertanen zusammen. Der darunter zu vermutende begabte Autor ist bedauerlicherweise nicht bekannt; es könnte der als kurkölnischer Hofpoet bezeugte „François Mayer" 63 gewesen sein, zu dem derzeit nichts Näheres bekannt ist. Zu bedauern ist zudem, dass sich nur der erste Teil der Doppelkomödie (Das unerwarte Vnglück) erhalten hat; ${ }^{64}$ aus einem ausführlichen, in Bonn gedruckten Szenar sind wir allerdings auch über den zweiten Teil (Das unerwarte Glück) informiert. ${ }^{65}$

Als dem aufgrund einer Prophezeiung von frühester Jugend an in einen Turm gesperrten Prinzen Amynthas mit der Hilfe eines Bauernehepaars die Flucht gelingt, sucht sein Hofmeister Crysippus verzweifelt nach Ersatz, um ihn dem eben eingetroffenen König Aridenus zu präsentieren. So wird kurzerhand der Bauernsohn Peter Mätzpichler in herrschaftliche Kleider gesteckt:

ArIDENus. Ich umbfange dich liebster Sohn, undt schlüesße Jenen in meine Königliche Armb, vm wesßentwillen Ich so Vill nächt Kein aug geschlosßen, Ja, vill Taußent der Thrännen vergosßen habe.

PrInz. Ha Dankh Vada, Eß freyt mi mei oadt vo Herzen - na - eß iß ma Loadt - i mueß gwiß a woana Herr Hoffmoasta, wen da Kini woant?

CrYsippus. (du Stockfisch) Ich glaube, das Kindliche Hertz werde Eur Durchleücht weich genug werden, wan Sie anderst die grosße Liebe Ihres Königlichen Herrn Vatters behertzigen wollen.

Prinz. nit a Breßl Herr Hoffmoasta, gangs ma zherzen, wens nit sein müst, i wolt koan Zaicha vagiesßn. Do walß je sein mueß -

62 Zur Rezeption des Stücks vgl. Christian Neuhuber: $y$ bi a mä troy in grassen Nöthen. Zur kritischen Edition eines Paradestücks des Wandertheaters. In: editio 31 (2017), S. 59-78.

63 Renate Brockpähler: Handbuch zur Geschichte der Barockoper in Deutschland. Emsdetten: Lechte 1964, S. 81.

64 Vgl. Bayerische Staatsbibliothek, Cod. germ. 3168. Ediert von Oskar Brenner: Altbairische Sprachproben aus dem 18. Jahrhundert. In: Oskar Brenner/August Hartmann (Hg.): Bayerns Mundarten. Beiträge zur Deutschen Sprach- und Volkskunde. Bd. 1. München: Kaiser 1892, S. 128-145, 203-222, 336-361 sowie ebda., Bd. 2 (1895), S. 60-73, 161-181.

65 Vgl. ebda., S. 177-181. 
Der Prinz fanget an zu weinen vndt schneitzet ihme in die Handt.

Crysippus. (Du Flögl du Vngezogener) Ey pfui ihr Durchleücht, buzet man di naßen mit der Hand, wie die Bauren?

Prinz. mit wem den? mitn erml?

CRYsIPPUs. Ey noch vill weniger, wie offt habe ich Ihnen schon weisße Tüecher darzue verordnet.

PRINZ. aß wär sunst mei gwandt Leicht guet gnug dazue gwesen, waß soll mar a neys schneitz Tüechl verderben?

Crysippus. (waß ein Einfälltiger haaber Narr)

Aridenus. Vor allem betaure ich mein Prinz, daß ich dich wider meinen Willen so vill Jahr in disem verschlosßenem Thurn gantz verlasßener habe müesßen sitzen lasßen.

Prinz. Bin i do erst heüt - -

CrYsippus. (still Peterl, rede nichts von dergleichen vndt verschwäze dich nicht, Bernhaüter, oder - )

PrInZ. (iß a wahr, i vagiß mi halt schlet alliwall a weni)

Aridenus. Waß redet der Prinz zu Eüch Crysippe?

CrYsippus. Ihr Majestet, der Prinz verwunderet sich über das Majestätische ansechen seines Herrn Vattern.

Prinz. (wie da Karl so schö liegn kan)

CRYsippus. Ihr Durchleücht, Sie belieben auch etwaß gegen Ihre Majestet dem König zu reden und ihrem Herrn Vattern ein schönes Compliment zu machen. (no wie? Wochen Tölppl!)

Prinz. Reden solli mit $\mathrm{n}$ Kini? oja, wema no des Wickal nit alliwall a so ins maull henckat vndt da staub davon in d augen flug afft wolt i scho a wall schmätzen. Vndt vo wem solli reden? Vo da gstaß - -

Crysippus. (willst du dein Maull halten Peterl, von dergleichen posßen, du galgen Vogel! daß dich -$)$

Prinz. (ja wen halt s Hertz voll iß, so geht oam goschn dauon üba)

Aridenus. Aber mein Amynthas -

PRINZ. (scho widar a $\mathrm{n}$ andern noma, $\mathrm{i}$ woaß da deixl selba nima, wer $\mathrm{i}$ als bin.)

Aridenus. Spüherst du auch wohl eine heimbliche freüdt in deinem herzen, da dir das Erste mahl das glückh vergonnet, deinen Vatteren zu sechen?

Prinz. i woaß mei oadt selba nit, wie mar iß, mei herr -

CRYsippus. Ihr Majestet nennet man den König. Nun dan, nennen Ihren herrn Vattern dan also -

Prinz. Ihr Majs - Majs - dreck. $^{66}$

mei oadt] bei meinem Eid! ma Loadt] mir leid woana] weinen Kini] König nit a Breßl] keineswegs, überhaupt nicht koan Zaicha] keine Träne Do walß] doch weil es schlet] bloß, nur Wochen Tölppl] Schimpfwort (etwa: Volltrottel) Wickal] Perücke (pars pro toto für den Hofmeister) alliwall] immer afft] dann a wall] eine Weile gstaß] Kurzform für Anastasia (Geliebte des Peterl) oam goschn] einem der Mund da deixl] beim Teufel!

Große Teile der ersten Komödie sind den Klamaukszenen gewidmet, in denen der stets hungrige Peterl ein Tabu des höfischen Verhaltenskodex nach dem anderen bricht, während Amynthas bei Peterls Eltern, seinen Rettern, Zeuge der Vorbereitungen für den feierlichen Empfang der albanischen Prinzessin Eurenisse wird. Dem königlichen Hofstaat soll - hier scheint Gryphius' Peter Squenz Pate gestanden zu haben - eine lächerliche „Paürische Comedi“ vorgespielt werden, mit der das Stück endet. Im verlorenen zweiten Teil schließlich kann sich Amynthas im Gegensatz zum feigen Peterl als Kriegsheld bewähren, sodass die Täuschung erkannt wird. Mit der Hochzeit von Eurenisse und

66 Zitiert nach Brenner, Altbairische Sprachproben I, S. $214 \mathrm{f}$. 
Amynthas und der Pardonierung Peterls, der als Küchenjunge eingestellt wird, endet die Komödie.

Der Stoff des plötzlich an der Gesellschaftsspitze stehenden Unterschichtlers erfreute sich so großer Beliebtheit, weil er sich durch die Antagonismen von Sein und Schein, von Anspruch und Realität, von Hoch und Niedrig, von Fremd- und Selbsttäuschung über alle komischen Implikationen hinaus als moralisches Exempel ebenso verstehen und verarbeiten lässt wie als Fürstenspiegel, Bauernschelte oder auch als Lebensparabel. Über Elensons Stück könnte er nicht nur Einzug ins Hoftheater, sondern auch wieder zurück auf die kirchennahen Bühnen gefunden haben, wo er schon im 17. Jahrhundert mit Jakob Masens lateinischem Erfolgsstück Rusticus imperans beheimatet war. Denn auch der Salzburger Tuchhändler Ignaz Anton Weiser (1701-1785) mag Zuseher einer Wandertheater-Adaption des Flüchtigen Virenus gewesen sein. Der spätere Bürgermeister der Stadt und Mozart-Librettist machte gemeinsam mit dem Hofkapellmeister Johann Ernst Eberlin ab Mitte der 1740er Jahre mundartliche Intermedien mit derbkomischen Handlungen auf dem benediktinischen Universitätstheater und dem Hoftheater populär und initiierte damit eine äußerst fruchtbare Spieltradition auf den süddeutsch-österreichischen Klosterbühnen. ${ }^{67}$ In seinem witzigen Singspiel Der Wachend-träumende König Riepel (1748) erhöht Weiser noch die derb-drastische Komponente des Stoffs, indem der trunksüchtige Bauer zunächst im handgreiflichen Streit mit seiner entnervten Ehefrau Dreischl gezeigt wird, ehe er sich mit einem vermeintlichen Gift bewusstlos trinkt und von seinem entsetzten Sohn Hansl für tot gehalten wird. Vom ,Tisch-Rath ' Bibax heimlich ins Haus des reichen Germanus gebracht und herrschaftlich gekleidet, glaubt Riepel sich zunächst im Himmel, ehe er von Bibax und seinen Leuten im Verein mit der fürwitzigen Tochter des Trunkenbolds, Gredl, als vermeintlicher König an der Nase herumgeführt wird. Ein Vergleich der entsprechenden Szenen erweist Weiser als Meister seines Fachs, der alle Mittel des komischen Spiels souverän einzusetzen wusste:

\section{Scena III.}

Bibax und die Laquayen richten das Lavor, Glöcklein, die Kleyder und anderes zur Hand, da indessen der Morgen-Seegen geblasen wird, darunter Riepl allgemach erwachet.

Riepl. As hot oach i dar Ewigkoat

Holt a koa rechtö Rue:

I hon a wall scho olsa touda glost,

Woas deart nöt, woß bedeut:

Sands d'Jaga - - oda treibns gehn auß:

Wonn ofar in da Welt da Hieta blost;

So thuets so schö nöt sprecha: Er sihet sich umb

I bi holt, roat i ma, in Himmel aha dopt:

Denn gstueröbm bin i do, dös woas i. Greifft das Beth, und den Schlaff-Rock.

I greiff jo überoll mei wutzl-lindö Seel:

S’Fegfoya honi a duecht i da Welt scho ghobt:

67 Vgl. Boberski, Das Theater der Benediktiner, S. 142. - Christian Neuhuber/P. Altman Pötsch, OSB: Placidus Fixlmillners Dialektsingspiel Astrologus (1746). In: Streifzüge III. Beiträge zur oberösterreichischen Musikgeschichte. Hg. von Klaus Petermayr und Andreas Lindner. Linz: Oö. Volksliedwerk 2013, S. 67-86. 
As mog nöt onascht sey:

Mein Oachl, dös ist doll, do will i bleibm:

Dö Toudn san holt koanö Noan:

As lost si koana mea auf d'Eachtn ohi treibm.

Aria.

Jetz bi i do, wo i sey soll:

Wo d'Halign in ewigna Lebm,

Thien oll Tag an Kieritag gebm:

Ju hey sa! drum ist ma recht wohl:

Do duets jo olls gleissn und glitzln:

Mei Hiebri dö wa nur a Mist:

Längst hett i mi z’toud lossn kitzln,

Wonn is a so ehnda het gwist. Da Capo.

Oas fallt ma, dieschtn solls mi nöt:

Da Holß is no von Stearöbm,

So drucka wier a Bröt.

Zun Glick ist do a Konl:

Lo schau, woß öpan göhn in Himml z'drincka geit: - - Er trinckt auß dem Lavor.

Pfui Doiffl, ist a Wossa.

Wonns koa braus Bie nöt habm;

So was in d'Leng schier a koa rechtö Freud:

Zun Wossa soll si oach

Jo gleiwohl mit an Brondwey kinna lobm:

Hey! - - Hauß-Knecht! - - schloffst denn no?

Hui! - auf a mohl! - an Brontwey heti gean.

No, dös ist schö, koa Hund lost si nöt hearn:

As wean ma leicht nöt beitn wölln:

Wos leit $\mathrm{d}[\mathrm{l}$, woas scho, wos i thue:

Dös wird a Glockn sey, dö brauch i nöt:

As daugt ma zun vasauffn:

I will wohl no wem fintn,

Bey dem is ko vakauffen.

Er probirt auß Vorwitz das Glöcklein, und will es mit sich hinweg tragen, wird aber von denen herein trettenden Bibax, Cammer-Diener, und Laquayen erschröckt.

\section{Scena IV. \\ Bibax mit Obigen.}

RiepL. à parte. Au weh! wos thuer i jetz?

Zu Bibax: Hea Gstreng! Hea Gnodn!

(Jo wonn i wissat, wos i prachtn miet)

Mei, hobts mas nöt varibl:

I woas nöt, wie i hea bi kemma:

Da Toifl mues mi hobm in Himmöl aha gfiet:

BiBAx. Ihr Mayestett! wie mögns so narrisch sey?

Ich sih, sie seyn an mir erschrockn,

Un[d] göbm mir selber s'Zoachn mit der Glockn.

Riepl. à parte. (Wer mues ar öpan sey?

I sihn' fier an wunabolan Halign o:

As geht mar a schon ey,

I glab, Gott Voda lost mi griessen

Und schickt ma durch den Gsondten

An froidlan Guetikomm: 
A fiecht, as mecht mi sist vadriessn.)

Wos will i sogn: - - wea seyts ös?

Bibax. Wos? mi? ihrn ghoam- und offentlichen Rath, Ihrn Stadt-Land-Hof-Mund-Haupt- und Leib-Artzt,

N'Doctor Bibax nimmer kenna?

Dös sicht recht gfarlich auß:

RiePl. Ha ha! n'Docta Wisch-Wosch:

Mier ist dea Nom bekont: - - -

Wea wa denn offtn I?

Bibax. Ihr Majestat! i moan, sö seyn da nit recht z'Hauß?

Sands denn nöt unser Ober-Haupt?

Sands denn nöt unser Herr?

RIEPL. Wos? i bin unsa Hea. à parte. (dea woas guet wer i bi.)

Mey! hau! wie kunt i Hea Gott sey:

Und ho no kam in Himmöl aha gschnopizt?

Wie follts da denar ey?

Bibax. Sie seyn halt dannoch unser Kinig. ${ }^{68}$

Lavor] Waschschüssel oach] einer a wall scho olsa touda glost] schon eine Weile wie ein Toter gehorcht Woas deart] weiß dennoch gehn] etwa, gerade sprecha] klingen roat i ma] denk ich mir aha dopt] hineingetappt, hineingestolpert gstueröbm] gestorben wutzl-lindö] besonders weiche honi a duecht i da] habe ich auch dort in der onascht] anders Mein Oachl] Ausruf der Verwunderung, Beteuerung koanö Noan] keine Narren auf d'Eachtn ohi] auf die Erde hinab Hiebri] Herberge, Behausung ehnda] eher, früher dieschtn] dürsten Konl] Kanne öpan göhn] denn etwa geit] gibt braus Bie] braunes Bier was] wäre es leit] liegt prachtn miet] sagen soll hobts mas nöt varibl] nehmt es mir nicht übel kemma] gekommen aha gfiet] hineingeführt wunabolan] seltsam, wunderlich froidlan Guetikomm] freudiges Willkommen A fiecht] er fürchtet offtn] dann, also aha gschnopizt] hineingeschnuppert

Erstaunlich ist zumal Weisers Virtuosität, durch feinhörig nachgezeichnete regio- und soziolektale Charakteristika ${ }^{69}$ die rhythmisierte und zuweilen reimgebundene Figurenrede mit witzigem Esprit aufzuladen. Riepels Flachgauer Basisdialekt steht neben dem derben Stadtdialekt des lustigen ,Tischrats', der als souveräner Spielleiter die Intrige vorantreibt, die letztendlich zu einer (sehr labilen) Versöhnung zwischen den Eheleuten führt. Noch schlagender wird die aus dem Varietätenkontrast resultierende Sprachkomik in Weisers und Eberlins Singspiel Die Geadelte Bauren / Oder die ihr selbst unbekannte Alcinde (1750), wo sich der Bauer Steffel zum Gelehrten aufschwingen will und im Auftrag seiner Frau Gredel vom blasierten Dorfphilosophen Pompolius hinters Licht geführt wird. Eingewoben ist diese simple Intrige in eine doppelte Wiederfindungs- und Wiedererkennungsgeschichte um Henrich und Alcinde, die mit einer Hochzeit und einem glücklichen Ende für alle Beteiligten schließt. Der besondere Reiz des Werkleins liegt im dialogischen Miteinander der barbarolektalen Protzsprache des Pompolius, der

68 [Ignaz Anton Weiser:] Der Wachend-träumende König Riepel: Auf Gnädigistes Anbefehlen Ihro HochFürstl. Gnaden, Des Hochwürdigist-Hochgebohrnen, des Heil. Röm. Reichs Fürsten und Herrn Herrn ANDREÆ JACOBI, Ertz-Bischoffen zu Saltzburg, Legaten des H. Röm. Apostolischen Stuhls, Primaten von Teutschland, Auß dem Hoch-Reichs-Gräflichen Hauß Von Dietrichstein etc.etc. Auf Dero Hof-Theatro vorgestellet 1749 Poes. J. A. W. Mus. J. E. E. Saltzburg, Gedruckt bey Johann Joseph Mayrs, Hof- und Academischen Buchdruckers seel. Erbin, f. 8r-9v.

69 Zur dialektologischen Verortung und der soziolektalen Differenzierung siehe die Studie von Reiffenstein, Sprachvariation auf dem Salzburger Hoftheater, S. 329-352. 
(nicht selten fehlerhafte) lateinische Floskeln in seine Rede flicht, des Flachgauer Basisdialekts der bäuerlichen Protagonisten, des Hochdeutschen der Höherstehenden und des makkaronischen,Welschelns' des schlauen italienischen Bedienten Bartolino. Nicht zufällig endet das Stück mit einem Chor, der die letztgenannten drei Varietäten noch einmal musikalisch gegenüberstellt:

H.A.P. Dise seynd beglückte Stunden,

S.Gr.H. Dös san recht böglückte Stundn,

BARTOL. Dö san reg beglücke Sdunden,

H.A.P. Wo ein jeder hat gefunden,

S.Gr.H. Wo jetz hot a nieda gfunden,

Bartol. Wo der at ein jeder funden.

H.A.P. Was er sich gewunschen hat.

S.Gr.H. Wos a long si gwunschn hat.

Bartol. Was der so gewunsen at. $[\ldots]^{70}$

Seinen wirkungsmächtigsten Nachfolger fand Weiser in Maurus Lindemayr, der während seines Studiums die Hochblüte des dialektalen Intermediums auf den Salzburger Bühnen miterlebte und - so wie andere Ordensbrüder aus verschiedenen österreichischen und bayerischen Klöstern - sich zu eigenen lyrischen und dramatischen Arbeiten inspirieren ließ. In direktem Zusammenhang mit Weisers Schaffen ist etwa sein Lied Ferten in Hörist zu sehen, in dem ein Bauer seinen wunderlichen Königs-Traum rekapituliert, wobei das eine oder andere Detail noch weiter ins Drastisch-Komische getrieben wird:

3

Grads nöbn dä Böttstatt hibsch unten beym Füssen,

Han i ä silberni Kändl däblickt

Hollä! gedacht i mein Lust will i büssen,

Hat mä dä Himmel zum trinkä was gschickt.

Het um ä Roß gwött äs wär Aschauä

Söltäni Weindl sänd anäs ga gsund,

Wie I han gschlungätzt käms anässtär auä

's Gschirr wär ä Kachel, i spieb wie ä Hund. ${ }^{71}$

3,2 Kändl] Kännchen 3,5 Aschauä] Aschauer Wein (aus dem Weinbaugebiet Aschach an der Donau, der im 18. Jh. aufgrund seines hohen Säuregehalts mehr Spott als Zuspruch fand) 3,6 Söltäni] solche 3,7 gschlungätzt] (gierig) geschluckt anässtär] anders auä] heraus 3,8 Kachel] Topf aus Ton, (hier:) Nachttopf, Nachtgeschirr

Aber nicht nur auf den Klosterbühnen reüssierten im 18. Jahrhundert die dialektsprechenden bäuerlichen Figuren. Auch das professionelle, erstmals im deutschsprachigen

70 [Ignaz Anton Weiser:] Die Geadelte Bauren / Oder Die ihr selbst unbekannte Alcinde: Auf Gnädigstes Anbefehlen Ihro Hoch-Fürstl. Gnaden, Deß Hochwürdigist-Hochgebohrnen / deß Heil. Röm. Reichs Fürsten und Herrn Herrn ANDREÆ JACOBI, Ertz-Bischoffen zu Saltzburg, Legaten des H. Röm. Apostolischen Stuhls, Primaten von Teutschland, Auß dem Hoch-Reichs-Gräflichen Hauß Von Dietrichstein etc.etc. Auf Dero Hof-Theatro vorgestelt 1750. Poes. I. A. W. Mus. von Hrn Johann Ernest Eberlin, Hochfürstl. HofCapell-Meister. Saltzburg, gedruckt bey Johann Joseph Mayrs, Hof- und Academischen Buchdruckers seel. Erbin, f. 40r-v.

71 Lindemayr, Dialektlieder I, S. 40. 
Raum auch ,stehende', also bürgerlich-institutionalisierte Theater in der Reichshauptstadt Wien setzte auf rustikale Mundartrollen als Publikumsmagneten. Schon der berühmte ,Wiener Hanswurst', Joseph Anton Stranitzkys Adaption einer Traditionsfigur der deutschen Lachkultur, nützte als ,Salzburger Sauschneider' das komische Potential regio- und soziolektaler Differenzen. Und auch seine Derivate im süddeutschen Spaßtheater, die im Zuge des von staatlicher Seite erzwungenen Domestizierungsprozesses an ,kreatürlicher' Komik im Sinne Bachtins verloren, setzten in vielen Stücken auf die erheiternde Wirkung von Idiolekten typisierter Dörfler. Ein ausgesprochenes Erfolgsstück in dieser Hinsicht war etwa Johann Joseph Felix von Kurz' Burleske Bernardon der 30 iährige A,b,c, Schütz: oder Hanswurst der reiche Baur und Pantalon der arme Edelmann (1754), das unmissverständlich auf einer Vorlage des Théâtre Italien (Arlequin écolier ignorant) basiert und mit Umarbeitungen mehr als ein Jahrhundert das Publikum begeisterte. ${ }^{72}$ Bernardon, Trademark des Autors, verkörpert hier die Rolle eines 30jährigen Bauernsohns, dessen Vater Hanswurst reich geworden ist und seinen Sohn nun in die bessere Gesellschaft einheiraten möchte. Dieser aber ist nicht an Pantalons Tochter Rosaura, sondern an der Haubenmacherin Colombina interessiert, der er denn auch seine Aufstiegsgeschichte im deutlich bäurischen Idiom erzählt:

Bernardon. [...] wie mir 2 ochsen mit einander hinauß gefahren, und schon ein paarmahl auff und ab spaziert seyn mit dem pflug (der ochs und ich, so habe ich nicht mehr können, so sagt mein Vatter, ich soll nur noch ä paar mahl auff und ab gehen) ich hab g'zogen wie ä ochß damit dem bläsel nicht zu hart geschehe, dan man mus doch auch ein mitleidentliches herz haben, und man weis nicht allzeit was einem noch geschehen kan: Endtlich die zwey ochsen kunten nicht mehr weiter, dan wir seynd an ein stein, da haben wir d'stein wegweltzt: jezt kombts beste: da hat mir g'sehen ein grosße eiserne truhen.

Colombina. voll geld villeicht?

BERNARDON. es waren über 600000 millionen thaler drin: ich hab gleich gemerckhet daß dise truhen schwer seyn wurde, dan ich bin allzeit ohne mich vill zu rümen ein kirniger bue gewe$\operatorname{sen}[\ldots] .{ }^{73}$

mir] wir bläsel] Ochsenname

Zu Bernardons Glück verhelfen ihm der Kaufmannssohn Horatio, der in seine Schwester Angola verliebt ist, und Flavio, Liebhaber der Rosaura. Erwartungsgemäß endet das Stück mit der Ankündigung von drei Hochzeiten nebst Prügelandrohung für Bernardon von Seiten seines Vaters.

Nach Kurz' Abgang aus Wien kam eine (deutlich weniger dialektale) Überarbeitung unter dem Titel Hr. von Eselbank der dreyßig-jährige A. B. C. Schütz in den Druck, die

72 Vgl. Andrea Brandner-Kapfer: Johann Joseph Felix von Kurz: Das Komödienwerk. Historisch-Kritische Edition. Graz 2007 [Diss.], S. 338-365. Zu den Adaptionen vgl. Beatrix Müller-Kampel: Die 30-jährigen ABC-Schützen. In: Kasperls komische Erben. Thaddädl, Staberl, Kratzerl \& Co. Wiener Volkskomödie im Wandel. Von der Typenkomik Anton Hasenhuts bis zur Charakterkomik Ferdinand Raimunds. Graz: LiTheS 2012. (http://lithes.uni-graz.at/0.2pt plus0.2pt minus 0.2pt kasperls_erben, letzter Zugriff am 20.05.2018) - David McShane/Matthias J. Pernerstorfer (Hg.): Der 30-jährige ABC-Schütz. Text, Musik und szenische Praxis im Wiener Volkstheater. 2. Band: Klavierauszug, Wien: Hollitzer 2011. (Don Juan Archiv Wien: Theatralia II).

73 Österreichische Nationalbibliothek, Cod. 13193 Han, f. 49v-50r. 
wiederum 1799 Karl Friedrich Hensler (1759-1825) als Vorlage für sein von Wenzel Müller vertontes Singspiel Taddädl der dreyssigjährige A B C Schütz diente. Die Thaddädl-Figur, ein kindlich-furchtsamer, dümmlicher Lehrjunge mit blecherner Stimme, war eine Kreation des Schauspielers Anton Hasenhut für das Leopoldstädter Theater, das zu dieser Zeit nach seinem größten Star Johann La Roche gemeinhin ,Kasperl-Theater ${ }^{\text {genannt wurde. }}{ }^{74}$ Dieser mimte den neureichen, seine Herkunft verschleiernden Bauern Kasper von Eselbank, dessen Bemühen um sozialen Aufstieg durch Heirat letztendlich vom, vazierenden Instruktor' Schnipp unterminiert wird. Indem er den Ursprung von Kaspers Vermögen entlarvt und eigene Ansprüche vorgaukelt, verhilft er den jungen Paaren zu ihrem Liebesglück. Bezeichnenderweise ist gerade Schnipps Rolle wesentlich stärker mundartlich markiert als alle übrigen, tritt er doch in der letzten Szenen als ,alter Bauer' auf, um den sich krampfhaft vom Bauer-Sein distanzierenden Kaspar in seine Schranken zu weisen. Dass dem aus Württemberg stammenden Hensler dabei nicht immer der Ton des oberösterreichischen Bauern authentisch gelingt, erhöht hier allenfalls die Komik:

Schnipp. Grüß di Gott s’tausendmal, goldna Herr Vetta!

Kennst mi nit - i bin dein Nachber, der Peta.

Komm ja gerad jetzt vom Landlerland her,

Wetter! bist worden ein sackrischer Herr.

Um und um bist ja mit Goldblech beschlagen,

Tragst ja n'Azel, d'Mäus könnten drin nagen.

Und deine Kinder - die schauen ja aus,

Alle so ramplet, als giengen's zum Schmaus.

I und mein Riepel sind eben ankömma,

Gebt's uns die Pratzen und seyd's uns willkömma.

Sie gehen ihm aus dem Weg. Kasperl ist aufgebracht.

Macht's keine Gfrieser, und kloost's nit so auf,

Sonst kriegt's ös eins auf die Goschen hinauf. Sie schauen alle einander an. - Pause.

KASPER. beiseite Das weiß der Teufel, was der Kerl will - ich hab ihn mein Lebstag nit gesehen.

Schnipp. Nun - was schaut's? kennt's mich ebba nit, oder wollt's mi nit kennen? - zu Kaspar, grob Und wie ist's denn mit dir, du Lump von einem gnädigen Herrn - glaubst ebba, weil du so viel Speranzien da machst därfst nix mit mir reden?

KASPER. Seppel! jagts mir den groben Bauern aus dem Zimmer hinaus, ich kenn' ihn nicht. -

ScHNipp. Was? setzt den Hut auf, mit unterstemmten Armen Hinausjagen? Kennt's denn ebba alle, wie ihr da steht's den saubern Herrn da? Fink spricht heimlich mit Rosel, Taddädl mit Katherl. Beyde wollen immer mit dem Lachen ausbrechen.

Kiввutz. Ihro Gnaden - der gnädige Herr von Eselbank.

74 Vgl. Egon von Komorzynski: Hasenhut, Anton. In: Allgemeine Deutsche Biographie. Hg. von der Historischen Kommission bei der Bayerischen Akademie der Wissenschaften. Bd. 50. Leipzig: Duncker \& Humblot 1905, S. 51f. - Gustav Gugitz: Der weiland Kasperl (Johann La Roche). Ein Beitrag zur Theater- und Sittengeschichte Alt-Wiens. Wien: Strache 1920. - Otto Rommel: Die großen Figuren der AltWiener Volkskomödie. Hanswurst, Kasperl, Thaddädl und Staberl, Raimund und Nestroy. Wien: Bindenschild 1946. - Beatrix Müller-Kampel: Hanswurst, Bernardon, Kasperl. Spaßtheater im 18. Jahrhundert. Paderborn [u. a.]: Schöningh 2003, S. 13 und 188. 
Schnipp. Ja - ein saubrer gnädiger Herr - ein Bauer ist er, und heißt Kaspar Pitzel, gebürtig aus Eselbank bey Steyer.

AlLE. in höchster Bewunderung Was? ein Bauer? ${ }^{75}$

Landlerland] Land ob der Enns, das heutige Oberösterreich n'Azel] ein Bisschen, eine Kleinigkeit (hier ironisch: eine ganze Menge) ramplet] herausgeputzt willkömma] reimgeschuldete Fehlbildung Gfrieser] Grimassen kloost's] starrt ös] ihr Goschen] Maul ebba] etwa Speranzien] Sperenzien: Umstände, Mätzchen

Dass auch Rollen, die in der Druckfassung standardsprachlich festgehalten sind, durchaus dialektal angelegt waren oder werden konnten, zeigt das Erfolgsstück Der Bauer aus dem Gebirge in Wien (1767) von Franz von Heufeld (1731-1795). Wie der Titel schon verrät, wird in diesem dreiaktigen Lustspiel ein naiver, aufrichtiger Bauer („Sein Verstand ist durch keine Vorurtheile verderbt; er redet mit einer natürlichen Offenherzigkeit, die von seiner Freyheit zu denken zeiget. ${ }^{\text {(76) }}$ ) mit dem brodelnden Großstadtalltag in der Residenzstadt konfrontiert. Obwohl die auf den alten Prehauser zugeschnittene Rolle des Hans einen Teil ihrer Komik sicherlich aus der Diskrepanz zwischen bäurischer und städtischer Sprache gewann, klingt dieser Aspekt im Druck allenfalls an. Auf dem Stiftstheater Kremsmünster allerdings wurde das Stück wenige Jahre später in einer Bearbeitung von Fratres des Hauses und befreundeter Klöster aufgeführt - natürlich ohne die obligate Liebeshandlung, dafür aber mit einem Protagonisten, der sich als ,Salzburger Bauer's sprachlich deutlich abhebt von seinem urbanen Gastgeber:

Hornschild. Guten Tag, Hannß!

Hannss. a gutn Tag guta Freünd!

HoRnSCHILD. Was machst du? worauf denckst du?

Hannss. I denck, wann i nur schon wida weck wa von hier.

HoRNSCHILD. Warum?

Hannss. Das ist ia a Larm, a Getöß, daß eina möcht närrisch werdn. Die halbe Nacht hab i von Poldern, und rasseln nöt schlaffn könna.

HorNSCHILD. In grossen Städten gehet es nicht anderst zue.

HAnnss. Wie das Getöß aufghört hat, hab i ain Glockn nach da andern leitn ghört, i glaubt würkli, ma gibt s'Zeichn zu ain Land-Sturm, i steh auf, schau beyn Fenster aussi, es rihrt si aba kain Mensch, i leg mi wida nida, bald drauf hör ain Trappen auf da Gassn, a ha! denk i ma, jezt treibt ma s'Vieh aus. I geh' wida zum Fensta, da sieh ich a ganze Schaar Buttn-Weiba vorbey maschieren.

Hornschild. Das waren Leut von Land, die Esß=Wahren zum Marckte brachten, Sie komen fast täglich mit anbrechenden Tage, die Stadt zu versehen.

Hannss. Alle Tag in aina solchn Menge?

Hornschild. Sechsmahl so viel, als du sahest, durch alle Thor der Stadt.

Hannss. Wie ist das mögli? D'Leut in da Stadt müssn erschröckli gfrässi seyn, wann Sie das alles fressen.

Hornschild. Bedencke aber, welche Menge Menschen die Stadt enthält, gegen 200000.

Hannss. I waiß nöt, wie viel das seynd, aba $i$ habs schon gseha, daß ville Leut hier giebt, i bin a wenig d'Gassn hinunter ganga, kaum hab i durchkoma könna, und grob seynd Sie, alß wie d'Hölzer. ${ }^{77}$

75 Taddädl der dreyssigjährige A B C Schütz. Eine Posse mit Gesang in drey Aufzügen, nach einer Burleske für die Marinellische Schaubühne bearbeitet von Karl Friedrich Hensler. Die Musik ist vom Herrn Wenzel Müller, Kapellmeister. Wien, 1799. Gedruckt mit Schmidtischen Schriften. S. 89ff.

76 [Franz von Heufeld:] Der Bauer aus dem Gebirge in Wien. Ein Lustpsiel von drey Aufzügen. Aufgeführt auf dem kais. königl. privilegirten Theater. Wien, im Jahre 1767, S. 7.

77 Stiftsbibliothek Kremsmünster, Ccn 1423, f. 4v-5v. 
Einen besonderen Reiz hatten ,rustikale` Einlagen auf dem Theater, wenn sie aus Kindermund zu hören waren wie in den um die Jahrhundertmitte reüssierenden professionellen Kindertheatertruppen. Mit der altersungemäßen Kunstfertigkeit in Spiel, Tanz und Gesang und launig-naiven Imitationen der Erwachsenenwelt wussten die juvenilen Ensembles das zeitgenössische Publikum zu begeistern. In Kurz-Bernardons Kinderpantomime Arleckin, der glücklich gewordene Brautigam (1756) etwa mit ihren genretypischen rasenden Rollenwechseln verkörperte die neunjährige Tochter des Autors, Antonia Kurzin, die Soubrettenrolle und konnte sich als ,Tyrollerin' (also als Wanderhändlerin) „in 4 Caracteren, und 4. lustigen Arien besonders dinstinguiren “78, darunter mit dieser Einlage:

Liebe Leute schauts mi an,

Ob i enk gefallen kan?

Bin i net ä gsteiftes Mädl?

So schön rund, als wie ä Rädl,

Kurze Füß, und dicke Wädl,

Fäst als wie ä schweine Brätl. ${ }^{79}$

2 enk] euch 3 gsteiftes] hübsches, bildsauberes

Als ehemaliger Tenorist am Kärntnertortheater und somit Künstlerkollege Kurz-Bernardons war auch der Passauer Hofkapellmeister Joseph Friebert (1724-1799) mit solcherlei Arien bestens vertraut. Nicht umsonst findet sich in seinem Singspiel Das Serail (1778) eine ähnlich gestaltete Quodlibetarie, die Kirchenliedincipits, Kindersprüche und Liedeinlagen der Zeit anzitiert und aus dem sprachlichen, thematischen und musikalischen Kontrast komische Effekte erzielt. ${ }^{80}$ Vorgetragen wird sie in diesem Repertoirestück des Kindertruppen-Prinzipals Felix Berner von einer schönen ,Sclavinn` aus dem Landl (Oberösterreich), eine nur mit erheblicher Mühe in das orientalische Setting integrierte Funktionsrolle:

O Himmel! o Erde! O Feuer, Luft und Wasser!

O hät i di, wie wollt i di, ä so, ä so, ä so.

Mein Vatä ist ä brava Mann, Mein Mutta ist ä so:

O Tod! wie bitter bist du nicht,

Wanns heißt, jetzt sey zu Sterben gericht:

Au weh! ich mecht nit denkä dran,

I läffät, läffät glei davan.

Gute Nacht Schneepepperl,

Was thut jetzt mein Sepperl?

Alle gute Ding seynd drey,

Und wanns pascht, so bleibts dabey.

78 Eine neue Tragödie, Betitult: Bernardon Die Getreue Prinzeßin Pumphia, Und Hanns-Wurst Der tyrannische Tartar-Kulikan, Eine Parodie in lächerlichen Versen. Nebst einer Kinder-Pantomime, Betitult: Arleckin/Der glücklich gewordene Bräutigam. Componirt Von Joseph Kurz, Comicus Bernardon. [o. O. 1756], S. 51 .

79 Ebda., S. 55. Beinah dieselben Verse finden sich bereits in der Judenhochzeit (um 1741) aus dem Umfeld von Kurz-Bernardon.

80 Vgl. Christian Neuhuber: I bin halt ä Mädl wie ä Rädl - Anmerkungen zur Figur der ,Sclavinn` in Frieberts Das Serail. In: Matthias Pernerstorfer (Hg.): Das Serail (1778) by Joseph Friebert in historical, sociopolitical and cultural contexts. Wien: Hollitzer 2017. [im Druck]. 
I bin halt ä Mädl, wie ä Rädl, wie ä Schädl,

ä Diendl, wie ä Birndl, wie ä Zwiendl, ä Diendl.

Und alleweil ä weni lusti, ä weni trauri,

ä weni Geld im Sack,

ä weni Schnopftaback,

Und alleweil ä so. ${ }^{81}$

7 läffät] liefe 8 Schneepeperl] scherzhaft für, Joseph 11 pascht] klatscht, kracht 12 Schädl] kleine Schale 13 Zwiendl] Zwirn

So zahlreich und erfolgreich die Komisierungen des Bäuerlichen im 18. Jahrhundert auch sind, entstammen sie nur äußerst selten nachweislich auch der bäuerlichen Kultur selbst, sind also von Autoren verfasst, die in diesem Kontext verankert und ihm nicht durch intellektuelle Bildung oder wirtschaftlichen Aufstieg entfremdet sind. Die meisten Beispiele einer dialektalen ,Volkskunst' aus dieser Zeit sind anonym, regional nur bedingt zuordenbar und durch komplexe Weitergabe- und Überformungsprozesse zumeist nicht auf eine annähernd autornahe Textfassung festlegbar. $\mathrm{Zu}$ den raren Ausnahmen zählen die Lieder des aus Oberplan (Horní Planá) stammenden Schneiders Johann Gabriel (1749 bis um 1810), vulgo ,Koasahansl', dessen satirische Lieder auf Dorfereignisse noch den jungen Adalbert Stifter zu Spottversen inspiriert haben sollen. Der des Lesens und Schreibens nicht mächtige ,Volksdichter' war bekannt dafür, dass er „wie die alten Barden gleich auch eine passende Weise zum Liede erfand und das neue ,Gsonk immer singend vortrug. “ ${ }^{82}$ Eine dieser Dichtungen war der um 1790 entstandene Onspa-Gsonk, der eine Dorfanekdote zum Besten gibt, die ein recht bedenkliches Licht auf die Beteiligten wirft. Denn am 24. Dezember eines schneearmen Winters, der die Holzlieferung aus dem Wald mit Schlitten verhinderte, hatten die Bewohner von Anspan bei Oberplan die halbverfallene Flachsbrechstube des, Kromastefl' zerlegt, um Brennholz für die Feiertage zu haben. Nur die gemauerte Küche, in der ein altes Mütterchen namens Ullana hauste, blieb stehen:

Daß d' Onspa-Laid emsi hant, dos muaß i sog'n,

Sie hombt da Ullana ihr Hoorstub'n weiktrog'n.

Kam hot ma si gschaut um,

Hombt si's weik bis af d' Stum;

Hiatzt hombt's d' Stub'n a davon,

D' Kuchl steht non.

O main liawi Kuchl, wia wiad's da non geihn?

Hiatzt hombt's da in Rouk auszougn und du blaibst steihn!

Kehr du ban Puitla ain,

Er wiad koan Stoan nit sain,

Er wiad da's nit oschlog'n,

Er hot brav trog'n.

In Fostantog vatogs um a drai Uhr

Hombt's af'n Onspa draust ghobt die Baumfuhr.

81 Ein musikalisches Singspiel, genannt: Das Serail. Oder: Die unvermuthete Zusammenkunft in der Sclaverey zwischen Vater, Tochter und Sohn. Botzen: Karl Joseph Weiß, 1779, f. 10r.

82 Johannes Matthias Firmenich-Richartz (Hg.): Germaniens Völkerstimmen. Bd. 3. Berlin: Schlesinger 1854, S. 398 . 
Da Schraml ist auständi blib’n,

Hot si in Kreuz varib'n,

Er wiad's schon bringa ain,

Bis a Bohn wiad sain.

Da Herrndiana Hiesl ruckt aus wia a Bär,

Üwan Grob'n ist a gsprunga, und üwa d'Hoorstub'n glai her.

Wia den ersten Bam thuat heib'n,

Thuat a glai Salva geib'n.

D'Hoorstub'n hot krocht,

Ulli hombt's glocht.

Oana nimmt d' Schweilla, da ondri an Bam,

Oana raißt d' Lodwend weik, der nimmt an Tram,

Der konn nar Schindl kriagn,

Dourt thuat oanr Lott'n ziagn,

$\mathrm{Da}$ ma haint 's Spor siacht non,

Ulls hombt's davon. ${ }^{83}$

1 Onspa-Laid] Bewohner von Anspan, Ortschaft bei Oberplan hant] sind 2 hombt] haben Hoorstub'n] Raum zum Trocknen und Brechen des Flachses 8 Rouk] Rock 9 Puitla] Eigenname 13 Fostantog] 24. Dezember (strenger Fasttag) vatogs] vor Tagesanbruch 15 Schraml] Eigenname 18 Bohn] Schlittenbahn 21 Bam] Balken 22 Salva geib'n] Salve abschießen (i. e. furzen) 26 Lodwend] Bretterwand Tram] Deckenbalken 28 ziagn] ziehen 29 haint] heute 30 Ulls] alles

Dass unrecht Gut nicht gedeiht, mussten die Anspaner freilich bald erkennen, wie die letzten Strophen des Lieds recht nachdrücklich erzählen: Mit dem morschen Holz hatten sie sich auch die Wanzen in ihre Behausungen geholt, „[d]ei uns fost thoant vazeihrn, Kinans nit daweihrn“ ${ }^{84}$.

\section{Berufs- und Standeslieder}

Auch wenn in der sprachlichen Realität Registergrenzen nicht mit Standesgrenzen korrelierten, nimmt in der Dialektkunst vor 1800 doch gerade der Bauer die Stellung des prototypischen Dialektsprechers ein. Neben den typisierenden Verarbeitungen in Dramen und Dialogliedern findet bäuerliches Leben auch im Standeslied seinen Ausdruck, wie an den Bauernklagen und Preisliedern bereits gezeigt wurde. Doch sind in diesem Genre auch andere Gruppen repräsentiert. Schon 1794 gibt Friedrich David Gräter eine recht treffende Beschreibung solcher „Ruhm-, Ehr- und Loblieder der Handwerker“:

Jedes dieser Lieder fängt mit einer Art von Aufruf an, geht dann in das Lob, die Geschäffte und die widerfahrenen Ehren des Standes über, und schließt mit einem allgemeinen Segen für die Zunft oder den Stand. ${ }^{85}$

83 Zitiert nach ebda., S. 398f. Gewährsmann dieses Texts für das Sammelwerk war der aus derselben Gegend gebürtige bedeutende Chemiker Adolf Pleischl.

84 Ebda., S. 399; thoant vazeihrn] verzehren Kinans nit daweihrn] können sie nicht abhalten, können uns nicht erwehren.

85 Friedrich David Gräter: Ueber die teutschen Volkslieder und ihre Musik (kommentiert von Hermann Bausinger). In: Württembergisch Franken 52 (1968), S. 201-226. 
Berufsstandeslieder setzen also Teile der Bevölkerung über die gemeinsame Zugehörigkeit zu einer Berufsgruppe ins Bild und sind üblicherweise durch „[d]ie dominierende Ich-Form, die Selbstdarstellung und die personenbezogene Schilderung des Tuns " ${ }^{86}$ gekennzeichnet. Im Folgenden allerdings wird das Genre - da es an einer verbindlichen systematischen Terminologie mangelt - offener ausgelegt: Zum einen wird die IchForm, auch wenn sie freilich dominant ist, nicht als notwendiges Charakteristikum gesehen; darüber hinaus geht es in den betreffenden Liedern gerade nicht um Personen, sondern um Typen bzw. repräsentative (oder als repräsentativ dargestellte) Vertreter. Die Einzelperson verschwindet geradezu hinter der Gruppe. Das heißt nicht, dass individuell das Leben beeinflussende Aspekte nicht angesprochen werden, wie etwa bereits die Bauernklagen gezeigt haben, doch gilt das Augenmerk dem Berufsstand als Einheit. Vom Genre abzugrenzen ist dabei das Arbeitslied im Sinne einer die Arbeit begleitenden, einleitenden oder rhythmisch strukturierenden Form (siehe Kapitel 6). Anzutreffen sind sowohl Lob als auch Spott, wobei in beiden Fällen zumeist auch eine humoristische Note einfließt. Thematisiert werden dabei einerseits Charakteristika des spezifischen Stands, sein Stellenwert für die Gesellschaft und die Wichtigkeit in jedermanns Alltag; andererseits werden typisierte Klischees verarbeitet, Karikaturen gezeichnet und dem Stand nachgesagte Fehler kritisiert.

Ein Beispiel für ein affirmatives Standeslied mit Außenperspektive ist ein in der Stubenberger Liederhandschrift überliefertes siebenstrophiges Weberpreislied, das die Bedeutung des Stands herauszustreichen sucht. Der inhaltlich wie ästhetisch anspruchslose Text von linkischer, unprofessioneller Bauart beginnt im mahnenden Ton, der mangelnden Respekt vor dem Berufsstand unterstellt und auf dessen Stellenwert aufmerksam macht. Bereits die Eingangsstrophe hebt nicht gerade bescheiden an:

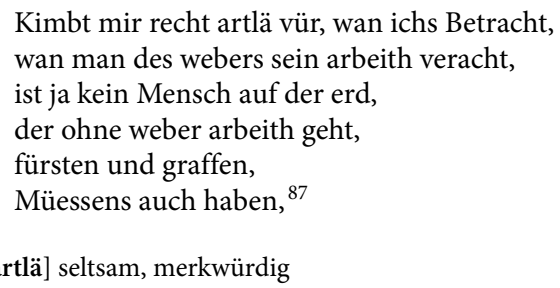

Mit der hier konstatierten Erklärung, dass kein Mensch ohne die Arbeit der Weber auskomme, und dem allgemeinen Tenor des Textes ist auch ohne Ich-Perspektive nahegelegt, dass das Lied aus der Feder eines Standesangehörigen stammt. Neben den Fürsten und Grafen werden im Folgenden auch verschiedene Personen und Gruppen aufgezählt, denen die Arbeit der Weber dienlich bzw. gar unabdingbar ist. Vor allem in Strophe drei wird die umfassende - und quasi das ganze Leben umspannende - Gebrauchsnotwendigkeit der von ihrer Hand erzeugten Produkte angesprochen, indem auf den Einsatz von Gewebtem bei Geburt wie Beerdigung verwiesen wird. Zuletzt wird

86 Deutsch/Haid/Zeman, Das Volkslied in Österreich, S. $65 \mathrm{ff}$.

87 Bayerische Staatsbibliothek, Cod. germ. 7340 (Stubenberger Gesängerbuch), Teil 2, S. 36. 
schließlich sehr eindringlich, deutlich und regelrecht aggressiv die Wertschätzung der Weber eingemahnt:

aber i kan enkhs sagn:

$\mathrm{d}$ weber müests in Ehren habm:

wer $\mathrm{d}$ weber veracht:

der wird von got gestraft. ${ }^{88}$

Es sind also Texte, die auf einem intakten Gemeinschaftsgefühl beruhten, wie es durch die Zunftorganisation gegeben war, und es zugleich stärkten. Denn indem der Gesang die Besonderheit des jeweiligen Stands oder Handwerks, seine Attraktivität und Rolle im alltäglichen Leben herausstreicht, schafft und bestätigt er Identität und zieht Grenzen zu anderen Berufsbereichen. Dass dies durchaus auch heitere und scherzhafte Komponenten umfassen kann, belegt ein Lumpensammlerlied aus derselben Sammelhandschrift, deren Schreiber Philipp Lenglachner (1769-1823) im bayerisch-österreichischen Grenzgebiet eben diesem Lebenserwerb nachging. Vielleicht ist er auch Verfasser des Lieds, in dem ein ,Haderlump sein Dasein und Leben besingt, das von Bekanntheit und Beliebtheit geprägt sei - eine selbstironische Ausdeutung, weiß man um das zweifelhafte Renommee des fahrenden Volks. ${ }^{89}$ Aus dem Straßenbild des 18. Jahrhunderts freilich waren diese Kleinhändler, die ihren Lebensunterhalt durch das Sammeln bzw. Erkaufen von Gewebeabfällen und -resten verdienten, die dann für die Papierproduktion an entsprechende Mühlen verkauft oder gegen Naturalien getauscht wurden, nicht wegzudenken. Da die Papiermühlen auf Nachschub von verarbeitbaren Textilien angewiesen waren, waren ihre schon aufgrund der unhygienischen Bedingungen verrufenen Dienste durchaus gefragt: ${ }^{90}$

1

Ein haderlump Bin ich genant, ein handls-man ganz wohl Bekandt, ein Man von Rären wahren, die weiber wernds erfahren, haderlump ist dä lump, haderlump bleibst ein lump, haderlump haderlump haderlump, ich bin ein haderlump lump lump,
2

Ihr alte weiber in der stadt, glaubts zam wer alti lumpen hat, dö klein und ä dö grossen, die weissen und die schwarzen, haderlump :etc:

88 Ebda.

89 Ähnliche Beteuerungen finden sich etwa auch in den Ölträgerliedern, vgl. Kapitel 5. Rapp spricht im Zusammenhang mit den Wanderhändlertypen von einem „Spannungsfeld von Außenseitertum und Popularität, von Deklassierung und Heroisierung“ (Christian Rapp: Wiener Typen. Zur Erfindung und Karriere eines Soziotops. In: Wolfgang Kos/Christian Rapp (Hg.): Alt-Wien. Die Stadt, die niemals war. Katalog zur Ausstellung im Wien Museum, 25. November 2004-28. März 2005. Wien: Czernin 2004, S. 142-150, hier 143), das letztlich auch das lange Fortleben dieser Figuren förderte.

90 Offensichtlich herrschte zeitweise auch ein derartiger Mangel an ausreichend Hadern, dass mitunter Versuche angestellt wurden, diese durch anderes Material als Grundlage zu ersetzen - vgl. hierzu etwa: Jacob Christian Schäffer: Versuche und Muster ohne alle Lumpen oder doch mit einem geringen Zusatze derselben Papier zu machen. Regensburg [o.V.] 1765. 
3

Ich geh in ganzen dorff herum, alle weiber glaubts dö hadern zam, händ zrissen oder Pschissen, händ denät guet zum Nüzen, haderlump :etc:

5

alle jungfrauen göbts hemeder her, und wan ä gley ein floh drin wer, es hat ja Nix zu sagen, i kan Mirn schan draus jagen, haderlump :etc:

7

Ein jeder kent mich wo ich hinkom, haeist gleich da ist der haderlump, die kinder auf der gassen, dö daeint mich gleich andasten, haderlump :etc:

9 ausn hadern Macht man das Papier, darauf wird gschriben mir und dir, guette zeittung hert man gern, kombt vor die grossen hern, haderlump ist der lump, haderlump bleibst ein lump, haderlump haderlump haderlump, ich bleib ein haderlump Lump Lump, ${ }^{91}$
4

Alle weiber göbts mir dlälachä, i wil enkhs zahln Mechts frey lachä, Nadl häftl Pfeffer, das taugt uns ja vil Pesser, haderlump, ist der lump :etc: 6 Ich bin ja überal Bekandt, wo ich hinkom in ganzen land, wan man hert meinen Nahmen, schreit alles gleich zusammen, haderlump,

8

Ich sueche alle gästen aus, und sueche alle winkhln aus, über d häkhen über d hökhen, wo dö alten lumpen stökhen, haderlump ist der lump :etc:

1,1 haderlump] Lumpensammler 1,3 Rären] seltenen, besonderen 2,2 glaubts zam] sucht zusammen, sortiert aus 3,2 hadern] Stofffetzen 3,3 händ] sind, seien 3,4 denät] dennoch 4,1 dlälachä] die Leinwände 4,2 enkhs] euch 7,4 daeint] tun

Berufsstandeslieder charakterisieren das jeweilige Gewerbe bzw. Handwerk nicht nur, sondern stellen es dabei nicht selten über die anderen Zünfte, da es grundlegender für die menschlichen Bedürfnisse und Voraussetzung für andere Berufsstände sei. Volksliterarisch besonders gern gestaltet wurde etwa die Rivalität zwischen Schustern und Schneidern. Die Hierarchisierung durch genetische Beweisführung ist freilich zumeist nicht ganz ernst gemeint. Ernster gefasste Preislieder, die den Stellenwert des Berufsstands würdigen und forcieren, dürften vermutlich tatsächlich von jeweiligen Mitgliedern des Stands oder zumindest aus dem engen sozialen Umfeld stammen. Lieder dagegen, die vor allem auf Unterhaltung abzielen und in denen der Standesrepräsentant noch stärker typisiert ist, entstammen wohl selten der Feder eines Vertreters der Gruppe selbst. Die stilisierte Darstellung birgt hier ein ausgeprägt komisches Potential, das ihr einen eigenen Platz in der Unterhaltungskultur sichert. Als belustigende Figuren oder überzeichnete Karikaturen verselbständigen sich die Typen-Bilder und werden auch außerhalb ihres eigentlichen Kontexts aufgegriffen, wie etwa in Lindemayrs bekanntem Binderlied:

91 Bayerische Staatsbibliothek, Cod. germ. 7340 (Stubenberger Gesängerbuch), Teil 2, S. 45. 
1

Mit Gunst, i will än Plodrä thain,

Was ist halt nit ä Bindä!

Wer dös nit glaubt, ghört wie i main

Nur unter d Schöps und Rindä;

Gott schickt den Wein, - was hälf ins das

Wanns fehlät an än ghöbign Vaß? -

Und d' Vässer macht, wollt's wissen wer?

Dä Bindä auf der Steer.
2

Was hälfen d Gschirr, um dö i sieg

$\mathrm{Daßd}$ Leut ä so thain strapeln,

Was hälfen alle Kandlkrieg

Mit grossen Bauch und Schnabeln.

Z'erst muß ä Trunk in Vässel sein

Und nachä fühlt mä d Pluzer ein;

Gsezt also, daß kein Binder wär

Blieb nit der Pluzer lär? ${ }^{92}$

1,1 Plodrä] Plauderei, (hier:) Spruch, Erklärung, Aussage 1,4 Schöps] Hammel 1,6 ghöbign] ghöbi(g): fest, stark, gut gebaut 1,8 Steer] Ster, Stör: tageweise Arbeit um Lohn und Kost eines (zuweilen ungelernten) Handwerkers, der in früheren Zeiten damit die Zunftbestimmungen umging 2,1 sieg] sehe 2,2 strapeln] schnell, gierig nach etwas greifen 2,3 Kandlkrieg] Krüge mit Henkel 2,6 Pluzer] dickbauchiger Tonkrug mit engem, verschließbarem Hals

Obwohl sie ihren Ursprung im realen volkskulturellen Alltag haben, sind die literarisierten Standesvertreter in ihrer Stilisierung weitgehend von jeglichen Authentizitätsansprüchen entkoppelt. Diverse Elemente ihrer Gestaltung mögen zwar durchaus der Wirklichkeit entsprechen - dies betrifft vor allem (stets typische!) Arbeitsgegenstände, Utensilien, Kleidung oder Aktionen -, doch stehen diese Komponenten einzig im Dienst der Typenmanifestierung. Stilisierung und Karikierung bedienen in diesem Sinne Klischees, die dem Publikum eine gemeinsame Basis zum Lachen und Verlachen bieten und durch den intersubjektiven Erkennungswert die Belustigungs- und Unterhaltungsfunktion stützen. So überrascht es wenig, dass ebendiese Typen gerade auf der Bühne besonders stark zum Einsatz kommen, wo sie in der Mannigfaltigkeit unterschiedlicher Verkleidungsrollen einen wesentlichen Bestandteil ausmachen. Berufslieder werden in Gesangseinlagen motivisch aufgegriffen oder fließen als Versatzstücke ein; teils weisen bereits die Stücktitel auf entsprechende Typen hin, ${ }^{93}$ teils erschöpfen sich auch ganze Dramen in einem Typenarrangement.

Wie beliebt dieses Genre um die Mitte des 18. Jahrhunderts in Wien war, belegt eine vierbändige Sammelhandschrift mit Arien aus insgesamt 261 Stücken, die zwischen 1737 und 1757 am Kärntnertor-Theater in Wien aufgeführt wurden. ${ }^{94}$ Zwei Beispiele sollen die Vielfalt an typisierten Berufsliedern andeuten, die dort zum Einsatz kamen. In der Komödie Colombina, der Zwilling bringt „Jackerl, ein Schuster Bue“ ein Loblied auf seinen Stand, das Struktur und Motive traditioneller (zumeist standardsprachlicher) affirmativer Standeslieder übernimmt, jedoch mit komischer Gegenbildlichkeit und Grobianismen den Unterhaltungswert steigert:

92 Lindemayr, Dialektlieder I, S. 136.

93 Siehe etwa die für das Wiener Kärntnertortheater belegten Stücke Die eigensinnige Stroh-Schneider-Zunfft, Bernardon Zettel-Trager der Comoedianten von Lion, der nothgezwungene Holippen Bube, und betrogene Vogel-Jäger-Jung, Der durch Ränke glüklich gewordene Wiener als slawakischer Leinwandhändler u. a.m. Anknüpfungspunkte finden sich etwa auch in den in Kap. 5 erwähnten Musikstücken Die Fratschler-Weiber am Schanzel, Der Wiennerischer Tändlmarckt u. a.

94 Teutsche Arien, Welche auf dem Kayserlich-privilegirten Wienerischen Theatro in unterschiedlich producirten Comoedien, deren Titul hier jedesmahl beygerucket, gesungen worden. Österreichische Nationalbibliothek, Cod. 12706-12709; eine zweite Fassung findet sich in der Anna Amalia Bibliothek in Weimar (HAAB Q 592 c). 
1

Nichts ist halt braver als a Schuester!

Wann auf der Welt kein Schuester wär?

Lief jedermann halt barrfuß her

Als wie a Bock, a Ochs, a Schwein,

drum daß wir Menschen Menschen seyn,

das macht der Schuester und sein Bue

Halt durch Pantoffeln, Stiefeln, Schue,

Ei daß di, daß die liebe Leut,

Schauts wie gescheid,

Ist nit a Schuester!

3

Nichts ist halt braver als a Schuester,

dem fallt der Wadel durch den Strumpf;

der hat a Schienbein sichel krump;

der Meister Schuester und sein Bue,

Richt halt zwey steiffe Stiefeln zue,

Und macht durch Leder, Pech und Draht

die Sichel-Füsse kertzen grad.

Ei daß di, daß die liebe Leut,

Schauts wie gescheid

Ist nit a Schuester. ${ }^{95}$
2

Nichts ist halt braver als a Schuester!

die hat an Tapp-Fuß wie a Bär?

Der Schuester und sein Bue ist her,

Und macht den Vor-Fuß wintzig klein,

Schneid a lang mächtigs Quater drein, Und so kriegt halt der plumpe Bär,

A Fusserl, wanns gedrachselt wär.

Ei daß di, daß die liebe Leut,

Schauts wie gescheid,

Ist nit a Schuester.

1,8 daß di] Ausruf (Ellipse für ,Dass dich der Teufel hole!')

Eine andere, etwa um 1738 erstmals aufgeführte Burleske mit dem Titel Der glückliche Hund lässt Kasperl als Tischlergesellen mit einem Loblied auftreten, wobei in der Handschrift explizit angekündigt wird, dass das Lied „lauter Termini Technici dieser Profession“" enthält:

1

Tischler die seynd halt vor anderen Leuten

Mit samt dem Werckzeug vernünffti und gscheid,

Wann mehr Stühl, Bänckerl, und Tischerl arbeiten

So redt a jeds Stuck, es ist nur a Freud,

Erst macht mern Knecht

Just accrat zrecht

da spricht die Rauh-Banck: geh! Kusch di! Kusch di!

dann sagt die Fueg Banck: komm! wisch di! wisch di!

Nach kommt der Stech Beuthel drein

da pflegt der Knüpfel zu platzen: machs fein, machs fein,

Hernacher

verzapft mers, verleimt mers, verschmiert mers,

Verkeilt mers, verputzt mers, verziert mers,

Und so wirds gemacht

daß anem s'Hertz im Leib für Gscheidheit lacht.

2

Kasterl und Trügel die müssen ans singen,

Bett-stätt und Wiegen die pfeiffen darzu,

Thuet mer den Werkzeug in d'Leimzwinge bringen,

Last den Schlicht-Hobel mit leichten kan Ruh;

95 Österreichische Nationalbibliothek, Cod. 12707 (Teutsche Arien 2), S. $299 f$. 
Schraufft mers gar fein

Ins Rössel ein

da singt die Läng-Sag: die Prazschi pratschi!

darauf pfeifft die Schließ-Sag: iß prizschi prizschi!

Nach last mern Dräh Bohrer gehn

dann pfleget die Raspel zu schreyen: fei schön, fey schön!

Hernacher

Verzapft mers, verleimt mers, verschmiert mers,

Verkeilt mers, verputzt mers, verziert mers

Und so wirds gemacht

daß anem s Hertz im leib für Gescheidheit lacht. ${ }^{96}$

1,5 mern] man den Knecht] Zwinge, Klammer 1,7 Rauh-Banck] großer Handhobel, um Bretter zu schlichten Kusch di] verschwinde 1,8 Fueg Bank] Fügebank: langer, schmaler Hobel mit zwei Leisten zum Abhobeln gerader Bretter 1,9 Stech Beuthel] breites Stemmeisen 1,10 Knüpfel] Klüpfel: Holzschlegel zum Schlagen des Stemmeisens platzen] laut schreien 1,12 verzapft] mit Holzzapfen bzw. -stiften zusammenfügen 2,1 Trügel] kleine Truhen 2,4 Schlicht-Hobel] Hobel mit Einfacheisen zum erstmaligen Glätten des Bretts 2,6 Rössel] Spannbank 2,8 Schließ-Sag] feine, mittelgroße Säge 2,10 Raspel] Werkzeug zum Spanabtragen

Bis heute haben Arien wie diese, die mit Fachbegriffen und onomatopoetischer Stimmungsmalerei den Arbeitsprozess bildreich vergegenwärtigen, ihren Unterhaltungswert nicht verloren. Und auch wenn die Tendenz zur Idyllisierung des Werkstattalltags nicht zu übersehen ist, transportiert diese Bühneneinlage doch Aspekte eines wohl auch realen Berufsstolzes. Mundart steht in diesen Gesangseinlagen nicht für Bäuerlichkeit, sondern ist - bei aller Typisierung - soziolektales Merkmal der kleinbürgerlichen urbanen Handwerkerschicht, nicht Stigma der Ungebildetheit, sondern Authentizitätsgarantie und Gemeinschaftssignal.

Frauen stehen in diesen Berufsliedern selten im Mittelpunkt und wenn, dann meistens in etwas zwielichtigem Bild, so etwa im Kellnerinnenlied Lustig ist der Kellnerstand, das ab den 1770er Jahren in Flugschriften zirkulierte. Angesprochen sind berufliche Herausforderungen, wie sie bis heute zu finden sind: die Balance zwischen Attrahierung der männlichen Gäste und Einforderung gesellschaftlicher Schranken, die Schwierigkeiten mit aggressiver, betrunkener und zudringlicher Kundschaft, die Verluste durch Zechprellerei und Anschreibenlassen. Um diesem übel beleumdeten Leben zu entrinnen, bleibt letztendlich nur die Hoffnung, dem ,Richtigen ' zu begegnen:

6

Ey so will ich Kellnerin bleiben, und mit springen Zeit vertreiben, wanns schon heist du Sau, mach ich mir doch nicht daraus, wann sie mich braf machen aus, wer doch einmahl ein Frau. ${ }^{97}$

Ein typisch großstädtisches humoristisches Berufslied ist das in Flugschriften vielfach belegte ,Fiakerlied', das wohl eher nicht von den Lohnkutschern selbst gesungen wurde,

96 Österreichische Nationalbibliothek, Cod. 12706 (Teutsche Arien 1), S. 578.

97 Sechs schöne Neue Lieder. Das Erste: Wir g'nüssen die himmlischen Freuden, etc. Das Andere: O HImmel! O Himmel! wie bist etc. Das Dritte: Alles ist zergänglich, währt ein kurze etc. Das Vierte: O grosser GOtt jetzt ist es aus, etc. Das Fünfte: Ach! was quälen mich meine Gedanken, Das Sechste: Lustig ist der Kellnerstand, sonderbar etc. Gedruckt im Jahr 1772, f. 4v. 
sondern von Straßenmusikanten, die die Figur als Wiener Charakteristikum aufgriffen. Fiaker waren in Wien gegen Ende des 17. Jahrhunderts eingeführt worden und bildeten - neben den Einspännern - die erste Möglichkeit auch für bürgerliche Schichten, in der Stadt einen Wagen zu nutzen. Im Vergleich zu Einspännern galten Fiaker als vornehmer und waren dementsprechend teurer, aber auch für ihre Schnelligkeit bekannt. ${ }^{98}$ Ende des 18. Jahrhunderts gab es in Wien etwa 600 Fiaker. Die Tradition, im Fiaker - der Begriff für den Fahrer fällt hier mit dem des Wagens zusammen - die „Essenz ,wienerischen Wesens' schlechthin“ ${ }^{\text {"99 }}$ zu sehen, entstand zwar erst im Laufe des 19. Jahrhunderts und dann vor allem gegen die Jahrhundertwende hin, als mit der wachsenden ,AltWien'-Nostalgie die Fiaker zu - durch die Modernisierung bedrohten - Verkörperungen des ,Ur-Wienerischen' stilisiert wurden. ${ }^{100}$ Elemente der Typisierung und Mythisierung des Fiakers - Gutmütigkeit und Grobheit, Verschmitztheit und Übermut - finden sich aber auch schon Ende des 18. Jahrhunderts. Der teils dialogisch aufgebaute Text mit vielen lokalen Bezügen und Anspielungen weist keine inhaltlich geschlossene Form auf, sondern konnte wohl beliebig erweitert werden; dies könnte auch die inhaltlichen Ungereimtheiten, Wiederholungen und Lücken in dieser Druckfassung erklären.

1

Und der Herr der steht auf, und geht außi zum Bahrn, und der Bue der spannt ein, und sitzt aufi aufn Wagn.

2

Sitzt aufi aufn Wagn, und fahrt eini aufn Grabn,

und da stellt er sich an, bis er ein Fuhr kann haben.

3

Und wie i aweil steh, da kimmt aner daher,

und der fragt mi a glei, was i auf Hiezing begehr.

4

Auf Hietzing außi, san drey Gulden nit zviel,

und wann sich der Herr halt nit aufhalten will.

5

Ich halt mich nicht auf, und gieb dirs dafür,

aber das sag ich dir, schleuni mußt fahrn mit mir.

6

Und wie i für d'Linna bin ausi kumma,

laß ich meine Rössal ä Trappel renna.

7

Es ist halt a Freud, ist der Haber nit teur,

und da hat a der Herr ja kein Schade nit dabey.

8

Es ist halt a Freud, wann der hat a Schneid,

wann man sieht daher fahrn kann er dRößeln nit dahaltn.

9

Und es ist halt a Freud, um das Fiakerleben,

98 Vgl. Sándor Békési/Martina Nussbaumer: Die Gondolieri Wiens oder die „Wienerischsten aller Wiener“. Zur Karriere der Fiaker im symbolischen Inventar der Stadt. In: Wolfgang Kos (Hg.): Wiener Typen. Klischees und Wirklichkeit. [Katalog zur 387. Sonderausstellung des Wien Museums, 25. April bis 6. Oktober 2013] Wien: Brandstätter 2013, S. 178-187, hier 179.

99 Ebda., S. 178.

100 Vgl. ebda., S. 181. 
und weils allaweil thuta klans Geld abgebn.

10

Weils allaweil thut a klains Geldl abgebn,

und so kann ja der Herr und der Knecht so gschickt leben.

11

Es ist halt a Freud, hann a Geld haben a Schneid,

und da haben dMusikanten kain Schaden nit dabey

12

Z'Mariahilf beym grün Thor, da geht's lästali zu,

und san drey Musikanten, und Fiaker gnue. ${ }^{101}$

1,1 außi] hinaus 1,2 aufi] hinauf 2,1 eini] hinein Graben] Prachtstraße im 1. Bezirk 3,2 a glei] auch gleich Hiezing] Hietzing, früher Dorf bei Wien, heute im 13. Wiener Gemeindebezirk 6,1 für d'Linna] vor die Linie (der Linienwall war eine leichte Befestigung zwischen den Vorstädten und Vororten Wiens) 8,1 Schneid] Mut 12,1 lästali] lästerlich

Die anzügliche Anspielung der letzten Strophe deutet schon an, dass die kursierenden Fassungen des Volksgesangs das Genre auch für Themen erweitern konnten, die über das unmittelbar Berufliche hinausgingen. Den Fiaker als ,Strizzi` zeigt etwa Freunde, habt anjetzo acht (vgl. Kap. 7, S. 510).

Der in vielen Liedern überzogen zur Schau getragene Standesstolz forderte natürlich auch Gegendarstellungen und gezielte Schmähungen heraus. Ein solcher Berufsspott begegnet uns etwa in Neujahrs- und Faschingsliedern häufig, wo Klischeevorstellungen oder zu typischen Merkmalen erhobene Züge in teils harmloseren, teils spitzzüngigeren, stets aber komisch-unterhaltsamen Strophen angeprangert und dem Verlachen preisgegeben werden (vgl. Kap. 6). Das folgende Spottlied ist auf ein Handwerk allein gemünzt und nimmt die angebliche Faulheit, Sittenlosigkeit und Unfähigkeit der Zimmerleute aufs Korn:

1

Wan ich betracht die zimmerleuth, so bin ich schon vohl gall,

ich find ja gar kein vndterschidt, stingfaul seinds überal,

sö kemmänd mir zwie $d$ schnekhen für, mit laudter langsam daey,

es helffen äen oft zam ä vier, däts aeiner leicht a laey,

2

oft aeiner Rent mitn zalstab um, als wie ä wildä stier, er möst den halben tag lang um, in einer Saustahl thür, I wolt ja nachä nu nix sagn, wans nachä Recht dät wern, auf d lötzt feilts um ein Bauernschuech, machst lachä oder Rern, 3

zum össen da seind sö ganz gwänd, da lauffen sö ganz bhend, wan aeiner bey der stumthier ständt, würd aeiner nider grent, oft aeiner lost als wie ä schwein, man waeis nöth was äein felt, das denkh i mir in meinen Sin, er hat sich übereilt,

101 Drey schöne neue Weltliche Lieder, Das Erste: Das Fiackerlied. Das Zweyte: Ein rechtes Theater ist die Welt. Das Dritte. Gott grüß eng meine Herrn allsammt. Gedruckt in diesem Jahr [um 1792]. Erstmals ediert bei Wolkan, Wiener Volkslieder aus fünf Jahrhunderten 2, Nr. XI, S. 27-29. 
4

Wans hammänt Pier und weisses brodt, gots blitz das ist aein gschmauss, wer nit frist und trünkht als wie ein stier, der maeit es ist nöth ghaust, aft aeinä sitz ins scheiss-haus ney, vil lengä als ä stundt, so denkh i mir in meinen Sin, als wan er nöth scheissen kundt, 5

Aft aeiner schleifft den ganzen tag, auf d nacht hat er kaey schneidt, und wan der Bauer ä wertl sagt, so ist der kerl $z$ keit, oft aeiner scherzt dö diennä an greifft aein än kitl sag, so denkh i mir mein zimmerman, wär gscheider du nämbst $\mathrm{d}$ hakh, 6

Es hat au käm Recht Sechsi gschlagn, klaubms scha den werkzeug zam, wans nachä nöth gley zum össen schreint, so ist aein zeit scha lang, Es wär oft aeiner ä darbey, der dätt sein schuldikeit, i kenn ä kradt ä zwen ä drey, und ken vil zimmerleuth, dö Bräffen geht das gsang nix an, dö schlechtn haltn s maul, es ist na kradt das man Rödt davan, zwö seind sö so stingfaul. ${ }^{102}$

1,3 kemmänd] kommen daey] tun 1,4 a laey] allein 2,4 feilts] fehlt es Rern] weinen 3,1 gwänd] geschwind, geschickt 3,2 stumthier] Stubentür 3,3 lost] steht still (und horcht) 4,1 hammänt] haben 4,3 maeit] meint 5,2 z keit] zusammengehauen, beleidigt 5,3 diennä] Mädchen kitl sag] Rocktasche 6,1 käm] kaum klaubms ... zam] zusammenpacken, zusammensuchen 6,4 ä kradt ä zwen ä drey] gerade mal zwei, drei 6,6 ist na kradt] es geht nur darum zwö] weshalb, warum

Auch auf solche gehässigen Pauschalverunglimpfungen wird es wieder gesangliche Erwiderungen gegeben haben, die die Standeswürde herzustellen versuchten. Ein literarisches Indiz dafür ist etwa Lindemayrs Wern d Maister, und Gsölln affrontirt, das auf eine Diskreditierung des Schlossergewerbes zu reagieren vorgibt und diese in einer mehrstufigen Argumentation auf Basis suggestiver Fragen widerlegt. ${ }^{103}$

\section{Kaufrufe}

Krämer, Tandler, Standler und fahrende Händler waren bis ins 19. Jahrhundert präsenter Teil des Straßenbilds der Städte. ${ }^{104}$ Sie deckten einen bedeutenden Teil der Versorgung mit Gütern des täglichen wie auch des längerfristigen Bedarfs ab, waren aber darüber hinaus auch an der Entstehung neuer Konsumgewohnheiten beteiligt, verbreiteten sie doch neue Waren und Moden und konnten stärker als der sesshafte Handel für ein flexibles Angebot an Waren sorgen. ${ }^{105}$ Das - auch mit unterschiedlichem sozialem An-

102 Bayerische Staatsbibliothek, Cod. germ. 7340, Teil 2, S. 219.

103 Vgl. Lindemayr, Dialektlieder I, S. 182-184.

104 Die folgenden Ausführungen sind eine aktualisierte und erweiterte Fassung des Aufsatzes von Elisabeth Zehetner: Kaufrufe und Dialekt in der Literatur. Zwischen Dokumentation, Literarisierung und Typenbildung. In: Neuhuber/Zehetner, Bairisch-österreichischer Dialekt in Literatur und Musik, S. 143-160.

105 Vgl. Susanne Breuss: Kreebs'n und Limonien, Schweewl und Bomad. Alltags- und konsumhistorische Aspekte der Wiener Kaufruf- und Volkstypendarstellungen um 1800. In: Wolfgang Kos (Hg.): Wiener Typen. Klischees und Wirklichkeit. Katalog zur Ausstellung im Wien Museum, 25. April bis 6. Oktober 2013. Wien: Brandstätter 2013, S. 152-157, hier 152f. - Wolfgang Brückner: Der Wanderhandel im 
sehen verbundene - Spektrum beginnt bei Verkäufern und Verkäuferinnen von Lebensmitteln und Haushaltswaren, aber auch Textilien und Waren des gehobenen Gebrauchs: Salami- oder Zwiebelverkäufer, Brezelbuben, Hendlkramer, Froschhändler, Eierweiber, Teppichhändler oder Barometerverkäufer. Daneben gab es ambulante Handwerker und Tagelöhner wie Scherenschleifer oder Wasserträger; Unterhaltung boten Guckkastenund Leierkastenmänner, Gaukler und Musikanten. Schließlich kamen als sozial am tiefsten stehende Gruppe die Trödler, Aschenmänner und Lumpensammler. Sie alle versuchten, ihre Waren und Dienstleistungen auf der Straße unter Verwendung entsprechender - dialektaler - Rufe und Gesänge anzubringen. ${ }^{106}$ Trotz ihrer prominenten und wirtschaftlich relevanten Rolle blieben diese Krämer und Händler häufig gesellschaftlich fragwürdig und wurden oft in die Nähe krimineller oder devianter Personen gerückt. ${ }^{107}$ Vor allem wurde der Straßenhandel selbst über die Jahrhunderte immer wieder Gegenstand von Verboten und Auseinandersetzungen. Gegen umherziehende Händler und Händlerinnen, so hält etwa Brückner fest, gab es im gesamten deutschen Gebiet im 17. und 18. Jahrhundert „die immer wieder gleichen, weil nicht befolgten, ja nicht befolgbaren Mandate, Circulare, Rescripte, Patente, Edicte“, ${ }^{108}$ die solchen ,unbefugten' Handel jedoch nicht einschränken konnten. Mit eigenen Berechtigungsscheinen wurde teilweise versucht, Teile des Straßenhandels zu erlauben und gleichzeitig zu kontrollieren. ${ }^{109}$ Vor dem Hintergrund dieses lebhaften Kleinhandels, der das Straßenbild prägte, und nicht zuletzt der Konkurrenzsituation mit sesshaften Händlern bekamen die Kaufrufe der Tandler, Straßenhändlerinnen und Standelbetreiber besondere Bedeutung und können als „Frühform der Produkt- und Dienstleistungswerbung in einer weitgehend analphabetischen Gesellschaft" ${ }^{\text {110 }}$ gesehen werden. Dabei hatte die Vielfalt dieser Rufe nicht nur eine wirtschaftliche Funktion, sondern auch ästhetische Qualitäten, die in verschiedenen anderen Kontexten aufgegriffen wurden und, wie schon Deutsch hervor-

Diskurs der Aufklärung. In: W. B.: Volkskunde als historische Kulturwissenschaft. Gesammelte Schriften. Bd. 14: Nachträge II. Würzburg: Bayer. Blätter für Volkskunde 2010. (Veröffentlichungen zur Volkskunde und Kulturgeschichte 88/3) S. 229-243, hier 237-239.

106 Vgl. Felix Czeike: Historisches Lexikon Wien. Bd. 3. Wien: Kremeier u. Scheriau 1994, S. 484f. - Gertraud Schaller-Pressler: Volksmusik und Volkslied in Wien. In: Elisabeth Theresia Fritz/Helmut Kretschmer (Hg.): Wien, Musikgeschichte: Volksmusik und Wienerlied: Teil 1. Wien: LIT 2006, S. 3-147, hier 11. Im 19. Jahrhundert begann im Zuge der Industrialisierung der Straßenhandel in dieser Form und damit auch der Kaufruf zu verschwinden; einzelne Rufe - wie der der Lavendelfrau oder des Lumpensammlers - blieben aber bis in die 30er-Jahre des 20. Jahrhunderts erhalten, wie Klier nachweist (vgl. Karl M. Klier: Kleine Volkslied-Studien. I. Alt-Wiener Kaufrufe. In: Das deutsche Volkslied 38 (1936), S. 64-65, hier 64).

107 Vgl. Breuss, Kreebs'n und Limonien, S. 153.

108 Wolfgang Brückner: Die Kolportage im Wirtschaftssystem der Protoindustrialisierung. In: Brückner, Volkskunde als historische Kulturwissenschaft, S. 244-255, hier 236.

109 Für Wien berichtet Deutsch von Verordnungen im 17. und 18. Jahrhundert, die den Wirkungsbereich von „befugten Tändlern“ festlegten und im Gegenzug, unbefugten` Handel - unter Androhung der Konfiszierung sämtlicher Waren - verboten. Dies blieb aber offenbar weitgehend wirkungslos, wie die zahlreich überlieferten Klagen dagegen zeigen. Daneben gab es in Wien aber auch teilweise Sonderregelungen, durch die kleinere „Krämereien“ und „Ständchen“ mit besonderen Befugnissen - dem sogenannten „Hütten-Schein“ - betrieben werden durften und so den Straßenhandel belebten (vgl. Walter Deutsch: Ein ,Wienerischer Tändelmarkt' von 1803 und seine Vorbilder im Wien des XVII. und XVIII. Jahrhunderts. In: Jahrbuch des österreichischen Volksliedwerkes 14 (1965), S. 30-48, hier 30-32).

110 Rapp, Wiener Typen, hier S. 143. 
hob, „nicht nur den ,Marktrichter“ und die Stadtverwaltung, sondern auch die Künste an[regten]“111. Die künstlerische Bearbeitung in literarischer, musikalischer und bildnerischer Form bezog sich auf die Charakteristik einzelner Händler und Händlerinnen sowohl was ihre Rufe als auch was ihr Erscheinungsbild anlangt - und sorgte auch selbst wiederum für die Typisierung dieser Figuren. ${ }^{112}$

Schon um 1620 erschien in Augsburg eine Flugschrift mit einem 17-strophigen Kaufruflied Von allerley Wahren, so man zu Augspurg inn allen Gassen herumbher schreyet. Während das Sprecher-Ich und kommentierende Textteile im (oberdeutsch gefärbten) Standard gehalten sind, werden einzelne Kaufrufe deutlich dialektal inszeniert. Die mundartliche Form wird dabei wirkungsästhetisch genutzt, um die Rufe einerseits als ,Kuriosum ' zu charakterisieren („darob sich mancher Frembdling / sehr verwundert hat"), andererseits sollen aber auch komische Effekte erzielt werden, etwa bei dem Wortspiel mit den im Dialekt annähernd homophonen Wörtern ,Besen - ,bösen ' in der sechsten Strophe („Bo̊sen, bo̊se Weiber“). Schließlich steht vor allem das laute Durcheinander des Markttreibens und die Vielfalt an angebotenen Waren im Zentrum des Lieds. Dialekt ist hier weniger ,Regionalsprache' in Kontrast zu einer - erst in Ausbildung begriffenen - Standardsprache; vielmehr erscheint die dialektale Alltagssprache der Kaufrufe als mündliche Sprachverwendung in Kontrast zur konzeptionell schriftlichen Sprache, die für die einleitenden und kommentierenden Textteile verwendet wird.

$1^{113}$

MErckt auff was ich thů Singen, ihr lieben Biderleüt, von Wunderlichen dingen So man zu Augspurg schreyt, darob sich mancher Frembdling, sehr verwundert hat, wann er dasselbig hơret, allenthalb in der Statt.

111 Ebda.

112 Frühe Beispiele für eine künstlerische Auseinandersetzung sind grafische Darstellungen von Kaufrufen aus Paris (um 1500), Rom (1582) und Bologna (1585/92), die auch allgemein auf die Bedeutung eines lebhaften Straßenhandels für die Stadtentwicklung hinweisen. Im 18. Jahrhundert und dann noch einmal vor allem in der Biedermeierzeit nahm die Zahl dieser Bildserien aus Städten in ganz Europa noch zu; neben Kupferstichen wurden auch Porzellanfiguren beliebt. In Wien wurden vor allem die Kupferstichserien von Johann Christian Brand (Der Kaufruf in Wien, 1775/76) und Jakob Adam (Abbildungen des gemeinen Volks zu Wien, 1789) bekannt (vgl. Karl M. Klier: Wiener Kaufrufe. In: Österreichische Musikzeitschrift 18 (1963), S. 56-68). Auch für das Theater wurden hier Kaufrufe adaptiert, wobei musikalische und grafische Gestaltungen ab etwa 1740 fast gleichzeitig auftraten und sich wechselweise beeinflussten. Die Umsetzung konnte dabei von einzelnen Rufen über Typenarien bis hin zur Gestaltung ganzer Singspiele und Quodlibets zum Thema reichen. Aber auch in kleineren literarischen Formen wie Flugschrift-Liedern finden sich Verarbeitungen von Kaufrufen. Das kann sich auf die Verwendung einzelner Rufe beschränken, die am Anfang eines Lieds für Aufmerksamkeit sorgen sollen; in anderen Fällen werden dagegen Lieder ganz aus Kaufrufen gestaltet, die unverbunden oder nur grob eingebettet nebeneinander gestellt sind. So kann der Eindruck durcheinander klingender Rufe erzeugt und deren musikalische Qualität genutzt werden. Vgl. Brückner, Die Kolportage, S. 245f.

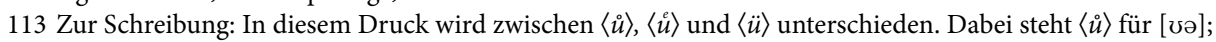
$\langle\dot{u}\rangle$ und $\langle\ddot{u}\rangle$ werden weniger systematisch unterschieden; tendenziell steht $\langle\dot{u}\rangle$ für [y:] oder [Iə] und $\langle\ddot{u}\rangle$ für $[\mathrm{Y}]$ oder [I]. Aufgrund dessen wurde in der Transkription hier ebenfalls die Schreibweise der Umlaute wie im Original übernommen. Nicht wiedergegeben wurden die Virgeln, die hier durch Beistriche ersetzt sind, sowie die Absatzmarkierungen zu Beginn der Strophen. 
2

Saurs Kraut Weyber, hui Riebigskraut,

schreyen die von Lechhaussen, am morgen vberlaut,

Sússe Millich, Butterschmaltz, Sawre Millich, auch,

macht manchen gůten Gesellen, den Hagel in den Bauch.

3

Hammermillich vnd Blaichermillich, die hat man gar für gůt,

kan sich offt begeben, das man darumb reissen thüt,

Sauri Senpff Sur Sura schreyt man auch,

die Bůben mit grossem geschrey, lauffen demselben nach.

[...]

6

Bo̊sen, bo̊se Weiber, ist ein warhafftigs gschrey,

weyl man derselben inn diser Statt, findet so mancherley,

Ofengabeln, Stützen, Stangen groß vnnd klein,

vnnd bey dergleichen Wahren, můssen auch Leüttern sein. ${ }^{114}$

2,1 Riebigskraut] zerriebene und gesäuerte weiße Rüben 2,2 Lechhaussen] Lechhausen: heute Stadtteil im Nordosten Augsburgs, damals Dorf am rechten Lechufer 2,4 Hagel] (metaphorisch für) Unbehagen, Rumoren 3,1 Hammermillich vnd Blaichermillich] wohl nach Örtlichkeiten benannte Milch 3,3 Sur] Salzlösung

Noch stärker im Mittelpunkt stehen in einem Ende des 18. Jahrhunderts gedruckten, aber vermutlich bis zumindest in die Mitte des Jahrhunderts zurückreichenden Lied ${ }^{115}$ die (ostmittelbairischen) Kaufrufe, die nun ganz ohne rahmende Strophen aneinandergereiht sind, um das lebhafte Durcheinander an Rufen und Gesängen auf der Straße nachzubilden.

1

Zunterstain, Zunterstain,

Weiber käfts Besen ein,

habts denn kä Geld,

will enk im Sack hinein thän,

daß seynd gut Zunterstän,

Leibstückl, Hasenbälk, Flederwisch,

heuraths fein frisch.

\section{2}

Hädenbrein, gelben Brein,

käfts Gries und Arbes ein,

Jungfraun kommts all zu mir,

gibs wohlfeil heut,

machts euer Körbel auf,

heut trefts ein guten Kauf,

Hädenbrein, gelben Brein, fein Gries,

Mundmehl,

heuraths fein schnell.

114 Zwey Kurtzweylige Weltliche Lieder. Das Erste: Von drey Weybern, Wie sie einem Holtzhacker sein Agst versoffen haben. Im Thon: Wie man den den Kümmichköhrer singt. Das Ander: Von allerley Wahren, so man zu Augspurg inn allen Gassen herumbher schreyet. Im Thon: Wie man den Rolande singt, etc. [Augsburg, um 1620].

115 Eine verwandte Form ist in der um 1740 entstandenen schwäbischen Ostracher Liederhandschrift überliefert (Nr. 3, schwebel-holz, schwebel holz), vgl. Michael Gerhard Kaufmann (Hg.): Ostracher Liederhandschrift. Kommentiert und mit einem musizierpraktischen Teil versehen. Konstanz/Eggingen: Isele 2006. (Bibliotheca suevica 19) S. 23f. - Kurt Rattay: Die Ostracher Liederhandschrift und ihre Stellung in der Geschichte des deutschen Liedes. Auf Grund der handschriftlichen Liedersammlungen des XVII. und XVIII. Jahrhunderts untersucht. Halle a.S.: Karras 1911, S. $60 f$. 
3

Sauri Rueben, saures Kraut, Köchin wird bald ein Braut, Sallat und Bedersill, was guts und schöns, kommt ein schöns Mädl her, gib ihr ä Würzel mehr, sauri Rueben, saures Kraut, weißen Kelch, heuraths fein schnell. 5 Budämili, Riermili, käfts süß und sauri Mili, Menscher bringts Häferl her, will enk drein thän, trinkts Obas und Caffee, thuts ihn bräf zuckern eh, Budämili, Riermili, sauri Mili, trinkts in dä Still.

7

Alts Eisen, Meßing, Bley,

Glaßscherben ä dabey,

Alte geh geschwind nach Haus,

nimm Butten mit,

Menscher käfts schöne Ring,

gebts obacht, was ich sing,

als Eisen, Huefnägel, Mauerkölln, Grillenhaus, mein Mark[t] ist aus. ${ }^{116}$
4

Sagschäten, Besenstill,

Stubnmädl sagts nicht viel,

könnts kurz und lange habn,

suchts enk än aus,

könnts ein schönes Beserl habn,

hübsch boschet und schön lang,

Schweblhölzl, Feuerstänä, weißen Sand, hab allerhand.

6

Gwand, Besen, Bartwisch,

käfts Schnecken, Krebs und Fisch,

Stockfisch und Häring,

Sartellen, und Schlein,

Jungfraun und Vögerl her,

schwarz Wildprät immermehr, [...]

Rebhendl, Rehböck, Wildgänß,

was guts und schöns.

1,1 Zunterstain] Hammerschlag, d.h. beim Schmieden abspringende Schlacke, die als Feuerstein genutzt wurde 1,6 Leibstückl] Weste, Gilet Hasenbälk] Hasenbälger: Hasenhaut/-fell Flederwisch] Enten- oder Gänseflügel, der als Kehrbesen benutzt wird 2,1 Hädenbrein] Haidenbrein: Buchweizen- oder Hirsebrei 2,2 Arbes] Erbsen 2,7 Mundmehl] feines Weizenmehl 3,7 Kelch] Kohl 4,1 Sagschäten] Sägespäne 5,1 Budämili] Buttermilch 6,1 Bartwisch] Handbesen 6,4 Schlein] Schleie: Karpfenart

Die einzelnen in diesem Lied zusammengestellten Kaufrufe entsprechen - folgt man den Darstellungen von Klier und Deutsch, die die historischen Kaufrufe in Text und Melodie zu rekonstruieren versuchten ${ }^{117}$ - durchaus den üblichen Formulierungen und Stilmitteln. Gleichzeitig werden die Kaufrufe zugunsten von Reim und Rhythmus umgestellt und in eine relativ einheitliche, gebundene Form gebracht. Vor allem bekommt die Zusammenstellung der verschiedenen Rufe in der literarischen Form komische, teilweise auch erotische oder obszöne Nebenbedeutungen. Die regelmäßig eingeschobenen Verweise aufs Heiraten können als Parallelisierung des Marktes mit dem ,Heiratsmarkt verstanden werden, in dem man das Beste und Passendste aussucht - oder ausprobiert.

116 Drey neue weltliche Lieder. Das Erste: Was sollt einen mehr ergötzen etc. Das Zweyte: Schauts mir nur einmahl das etc. Das Dritte: Zunterstain, Zunterstain, etc. Gedruckt in diesem Jahr [o. O., o. J., Ende 18. Jh.]. Vgl. die Edition bei Rudolf Wolkan: Wiener Volkslieder aus fünf Jahrhunderten. Bd. 2: 1800-1914. Wien: Wiener Bibliophilen-Gesellschaft 1923, S. 1-3 nach einer ähnlichen Variante aus einer nicht mehr aufgefundenen Flugschrift (Fünf schöne weltliche Lieder; um 1800). Auszüge des Lieds sind auch bei SchallerPressler, Volksmusik und Volkslied, S. 19 abgedruckt.

117 Klier, Kleine Volkslied-Studien, S. 64f. - Klier, Wiener Kaufrufe, S. 58-66. - Deutsch, Wienerischer Tändelmarkt, S. 38-48. 


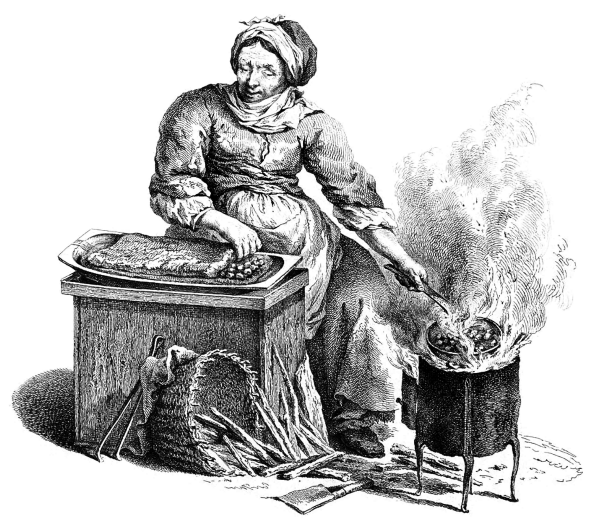

Abb. 25: Johann Christian Brand: Kästenweib (Maroniverkäuferin, Foto: @MAK - Österr. Museum für angewandte Kunst/Gegenwartskunst, KI 2569-16).

Nicht zuletzt vor diesem Hintergrund lassen sich etwa „Besenstiel“ und „Beserl“ wohl als bildhafte Umschreibung für Sexualorgane lesen, ${ }^{118}$ sodass die Aufforderung „suchts enk än aus" doppeldeutigen Witz bekommt.

Neben solchen Flugschriftenliedern wurden Kaufrufe in einer Vielzahl anderer literarischer Texte verarbeitet, sei es als kurze Sequenz oder auch als Gegenstand ganzer Stücke und Singspiele. Vor allem die musikalischen Bearbeitungen sind hier bemerkenswert, zeigen sie doch wieder deutlich die musikalische Qualität der Kaufrufe. Ein Beispiel sind die zwei 1791 anonym gedruckten Singspiele Die Fratschler-Weiber am Schanzel, deren „erstes“ und „Zweytes Stück“ das Wiener Markttreiben mit den Verkäuferinnen und Käuferinnen, den Lieferanten, Kutschern und Kontrolleuren effektvoll und bildhaft in Szene setzen. Trotz der prinzipiell standardsprachlichen Gestaltung sind die Rufe der Marktfrauen dialektal markiert - galten sie doch, wie Karl Julius Weber noch 1827 in seinen Briefen eines in Deutschland reisenden Deutschen aus Wien berichtete, als jene Typen des Wiener Alltagslebens, von denen man den „Volksdialect“119 am besten lernen könne.

Das Theater stellet den Schänzelplatz vor, allwo nebst vielen herumsitzenden Oebstler-Frauen vom Lande, einer Barbierhütte, ein Würstelbratter-Stand, mit angemachten Sallat; dann der Donau-Fluß mit angeankerten Obstzillen zu sehen. Verschiedene Gattungen von Menschen gehen hin und wider spaziren.

Aria.

Erstes Oebstlen-Weib. Kaufts Herrn meine Kirschen, kaufts Birn, kaufts Marillen, Ihr könnt euch den Hunger und Durst damit stillen;

118 Zur erotischen Bedeutung dieses Lieds vgl. Schaller-Pressler, Volksmusik und Volkslied, S. 19, die das Lied in diesen Zusammenhang stellt, ohne jedoch konkretere Anhaltspunkte zu nennen.

119 Karl Julius Weber: Deutschland, oder Briefe eines in Deutschland reisenden Deutschen. Zweiter Band. Stuttgart: Franckh 1827, S. 214. 
Kaufts kreutzerweiß, groschenweiß, büttelweiß ein,

Dieweil meine Früchten ganz frisch gepflükt sein,

Ihr Herren, ihr Frauen, ihr Jungfraun kauft ein. Repet.

2те Oeвstl. Kaufts Ribisel, kaufts Agras, kaufts Erdbeern, kaufts Weichsel,

Ich sitz da, und lös nichts, das ist doch zum Deichsel.

Ich geb all's so wohl feil als immer eins kann,

Und bring meine Waare so hart an den Mann.

Ihr Herren, ihr Frauen, ihr Jungfrauen sehts an. Repet. ${ }^{120}$

2,1 Ribisel] Johannisbeeren Agras] Stachelbeere 2,2 lös] verdiene Deichsel] Teufel

Besonders hervorzuheben ist das Musikstück Der Wiennerische Tändlmarckt des Eisenstädter Hofkapellmeisters Gregor Joseph Werner (entstanden um 1745, gedruckt 1754). ${ }^{121}$ Darin treten vier Figuren - ein „Sagfäller“ (Sägefeiler), ein „Savoiard“ (d. h. ein Händler aus der Savoie, vgl. Kap. 5), ein „Hollähippen-Krämer“ und ein Arzt nacheinander jeweils mit Rezitativ und Arie auf. Die Texte beschränken sich dabei nicht auf das Anpreisen der Waren bzw. Dienstleistungen, sondern verweisen auch auf die Tradition der Lustspielarien mit ihren kurzen, humoristischen Typencharakterisierungen, bei denen sich Werner auch einer jeweils angepassten sprachlichen Gestaltung bedient. ${ }^{122}$ In der Arie des „Sagfällers“ (Basso II) etwa wird dieser - eingerahmt von seinem langgezogenen Ruf - spöttisch als geistig eher beschränkter Mann dargestellt, was nicht zuletzt durch die Vertauschung der Wörter „kapiert“ und „crepirt“ illustriert wird:

Sagfälln

diesi schwäri Kunst

hab i nit glei um sunst

in oänen Tag in oänen Tag crepirt crepirt crepirt crepirt

in oänen Tag crepirt

biß I erst glehrnt hab auf den Tact recht fälln

die Sag die Sag in Zwingär äini spälln

hat mir den Kopf verwürt verwürt

den Kopf verwürt den Kopf verwürt

Sagfälln ${ }^{123}$

7 äini spälln] hineinzuspannen

120 Die Fratschler-Weiber am Schanzel. Erstes Stück. Wien, 1791, S. 6.

121 Zwey neue und extra lustige musicalische Tafel-Stücke. I. Der Wiennerische Tändlmarckt. Mit 4. Singstimmen, 2. Violinen und Basso ordinario. [...] II. Die Bauren-Richters-Wahl. Mit 5. Singstimmen, 2. Violinen und Basso ordinario. [...] Beyde Stücke, sind nach Art der Quodlibete eingerichtet [...]. Von dem Autore des Musicalischen Calenders Gregorio Josepho Werner, Hochfürstlich Estorhasischen Capellmeistern zu Eisenstadt in Ungarn. Augspurg, Verlegt von Johann Jacob Lotters seel. Erben. [1754]. Bereits 1933 nach einem Exemplar des British Museum ediert bei Hans Joachim Moser: Corydon, das ist: Geschichte des mehrstimmigen Liedes und des Quodlibets im Barock. Bd. 2. Braunschweig: Litolff 1933, S. 155-179. - Neuedition (in Partiturform, mit Generalbassaussetzung und angepasster Schreibung) durch Richard Moder (Hg.): Gregor Joseph Werner: Wienerischer Tandlmarkt. Partitur, Stimmen, Klavierauszug (vom Hg.). Wien, München: Doblinger 1961. (Diletto Musicale 81) - Werners Stück wurde bis ins 19. Jahrhundert hinein mehrfach aufgegriffen und bearbeitet (vgl. dazu Deutsch, Wienerischer Tändelmarkt, S. 35ff., Klier, Wiener Kaufrufe, S. 57f. und Neuhuber, Werners Werke in Mundart).

122 Moser konstatiert auch eine musikalische Personencharakteristik in den einzelnen Rezitativen und Arien: „Besonders der Savoyarde bekommt südliches Nationalkolorit (Pizzicato-Begleitung seiner Furlana) und der Arzt einen mondänen Zug." (Moser, Corydon I, S. 89).

123 Werner, Der Wiennerische Tändlmarckt, Basso II, S. 1f. 
Die Mehrstimmigkeit des Markts selbst aber, mit dem Neben- und Übereinander verschiedener Rufe, wird am stärksten im ,Chorus' eingefangen, der in der Art eines Quodlibets den Anfang und Schluss des Stücks bildet und in dem auf die verschiedenen Stimmen verteilt die Rufe der Marktleute wiedergegeben werden: neben dem Sägefeiler („Sagfälln, Sagfälln“) und dem italienischen Schausteller („O söner rarite, o söner Spiliwerckh, wer will seh guckh in die Lokh“) ein Milchverkäufer („Käfts Milli Frau, än Millräm oder än Budä“), ein Sandhändler („Käfts än Sand, käfts än Sand“), ein Bandelkrämer („Bändl, käfts än Zwirn“), ein Rettichverkäufer („rerererererererererererererettich“), weiters ein Schausteller („La laterna magica“), ein Würstelverkäufer („Kafts Säfäladri Würst sänd gantz warm“), ein Hadernsammler („koäni alten Leibstücker zu verkäffä, alti Hüet oder Haasenbalck“) und schließlich ein Kolporteur („Än neue Zeittung um än Creuzer, daß Gott ärbarm"). ${ }^{124}$ Auch musikalisch pointiert werden die Kaufrufe nachgebildet - von den gedehnten „Sag - fälln“-Rufen, die mit den lautmalerischen punktierten Sechzehnteln der Violinen in steigenden und fallenden kleinen Intervallen kontrastieren, bis zum schnellen, rhythmisierenden Sprechgesang des Rettichhändlers oder des Lumpensammlers. Dazu sollen die Instrumentalstimmen mit ihrem hohen, hellen Klang - wie Werner bereits am Titelblatt ankündigt - das sogenannte „Breinglöckl“ imitieren, also die Primglocke bei St. Stephan in Wien, die bis ins Jahr 1784 immer morgens zur ,Prim' (um 6 Uhr früh) läutete und damit auch das Signal für den Arbeitsbeginn der Handwerker und Händler darstellte. ${ }^{125}$

Obwohl Werner insgesamt um eine ,naturalistische sprachliche und musikalische Gestaltung bemüht ist - er schreibt selbst in seinem „Avertissement“, dass „in dem Choro alles natürlich begriffen, wie jedwedere ihre Waaren allda zum Verkauf pflegen auszuruffen“ ", stehen (auch) in diesem Fall die Regeln der Komposition im Vordergrund und die Rufe sind in Harmonie und Rhythmus aufeinander abgestimmt. Sowohl die Übernahme des Dialekts als auch die musikalische Gestaltung der Kaufrufe dürfen daher nicht per se als ,dokumentarisch 'verstanden werden. Es handelt sich bei Werners Stück um bewusst volkstümliches Barocktheater für gehobene Schichten, ${ }^{126}$ das - wie es am Titelblatt heißt - für die Vorführung „bey vornehmen Gastmahlen und anderen lustigen Gesellschaften“ gedacht war. Auch die dialektale sprachliche Gestaltung der Kaufrufe dient in diesem Zusammenhang also als bewusst eingesetzte, stilisierte Sprachform. Dieses Tandlmarkt-Quodlibet von Werner kann als bekanntestes angenommen werden, steht aber nicht allein: Als weitere musikalische Bearbeitungen aus dem 18. Jahrhundert bekannt sind eine Fassung des Wiener Komponisten und Violinisten Karl von Ordonez (Der alte wienerische Tandelmarkt, 1779) ${ }^{127}$ - vermutlich eine Bearbeitung des Stücks von Werner - und ein um 1770 entstandenes Faschings-Quodlibet aus dem Stift

124 Ebda., passim.

125 Vgl. Moder, Wienerischer Tandlmarkt, S. 34.

126 Vgl. Richard Moder (Hg.): Gregor Joseph Werner: Die Bauren-Richters-Wahl. Für 5 Singstimmen (3 Tenöre, 2 Bässe), 2 Violinen und Basso continuo. Erstdruck. Partitur, Streicherstimmen. Wien, München: Doblinger 1968. (Diletto Musicale 171) S. 2.

127 Die Musik gilt als nicht überliefert, der Druck des Textbuchs ist in der Wienbibliothek im Rathaus vorhanden (Mc-55305); einige Textpassagen werden bei Deutsch, Ein ,Wienerischer Tändelmarkt', zitiert. 
Stams, in dem die typischen Figuren des Kaufrufs durch zusätzliche Lustspielfiguren der Zeit ergänzt werden. ${ }^{128}$

In die Anfangszeit der künstlerischen Kaufrufrezeption in Wien weisen zahlreiche Texte aus den oben erwähnten Teutsche Arien-Sammelbänden, die - soweit ersichtlich mit der Handlung der Kärntnertortheaterstücke oft nur sehr lose verknüpft sind. So tritt Colombina in der Komödie Die verhexte Apothecken. Oder Hanns Wurst, der lebendig anatomirte Cadaver als Tiroler Bauchladenkrämerin auf und intoniert zu Beginn ihrer Gesangseinlage einen Kaufruf:

1

Gehts Kauffts von Bandlen was!

Gehts Kauffts von Zwiren was!

Alles ist preiß,

Gehts Kauffts mir Porten ab,

Gehts Kauffts mir Spitzl ab,

Eh' ichs zerreiß;

Tumelts enck, gebts mir Geld,

So mir am meisten fählt,

Weil ich halt all's verkauff,

Geht auch mein Hertzerl drauf. ${ }^{129}$

1,1 Bandlen] Bändern 1,7 Tumelts enk] beeilt euch

Formal ähnlich gestaltet sind zwei Arien des Bernardon aus der Burleske Hanns-Wurst Ein lebendiges Gespenst, wo er sich zunächst „als ein Kohlen-Bauer“ mit dem Ruf „Kafts Kohlen Kohlen! Kafts Sag-Schaten, / Kafts! wer eppes braucht“ zeigt. In einer späterern Szene erscheint er als Pfannenflicker, der seine Künste anpreist. Der Eingang der Arie ist auch Beleg für die Tradition und Stabilität dieser formalisierten Werbesprüche: Dem hier verwendeten Kaufruf sind wir in beinahe wortwörtlicher, jedenfalls aber formal gleicher Gestalt bereits im mehr als hundert Jahre älteren Augsburger Druck begegnet („Schiffelbinden Pfannenflecken“). In diesem Fall tritt auch die insbesondere bei Handwerkerliedern häufig mitschwingende erotische Metaphorik deutlicher hervor: ${ }^{130}$

1

Häfen z’bünden, Pfanna z'flicken,

deckel auf d'Krüg, lasts sehn!

Ist enck Menschern a Häfn zerkloben?

hat a Reinel an Schrick?

Kommts nur z’mir, ös werds mi loben,

s braucht nicks mehr als an Zwick;

Wird der Draht halt umma dreht,

So ist glei der Schrick vernäht,

Glei ist g'schehn;

Häfen z'bünden, Pfanna z'flicken,

deckel auf d'Krüg', lasts sehn!

128 Zisterzienserstift Stams, Bibliothek und Musikarchiv (A-ST/ ohne Signatur).

129 Österreichische Nationalbibliothek, Cod. 12708 (Teutsche Arien 3), S. 458.

130 Vgl. zur insbesondere mit der Figur des ,Pfannenflickers` verbundenen erotischen Konnotation: SchallerPressler, Volksmusik und Volkslied, S. 19 bzw. Klier, Wiener Kaufrufe, S. 64. 
2

Häfen z’bünden, Pfanna z'flicken;

deckel auf d'Krüg, lasts sehn!

Ist a Loch im Einbrenn-Pfännel?

Braucht der Krug a Scharnier?

Ich bin gar a künstlichs Männel,

Menscher drum kömts nur z'mir;

Setz ich halt an Fleck aufs Loch,

Nimm darzu a Steffterl noch

Glei ists g'schehn

Häfen z'binden pp. ${ }^{131}$

1,3 enck Menschern] euch Mädchen Häfn] Topf zerkloben] zersprungen 1,4 Reinel] kleiner, flacher Topf Schrick] Sprung 1,5 ös] ihr 1,7 umma] herum 2,3 Einbrenn-Pfännel] Pfanne für Mehlschwitze 2,10 pp] (Abk. für lat. ,perge perge`) usw.

Weitere musikalische Bearbeitungen des Kaufruf-Themas aus dem 19. Jahrhundert zeugen von der Beliebtheit wie von der musikalischen Kraft der Kaufrufe. ${ }^{132}$

\section{Sitten- und Modelieder}

Literarisch funktionalisierter Dialekt kennzeichnet vor 1800 oft Bruchlinien in einer Gesellschaft, deren Ordnungssysteme sich ausdifferenzierten, sodass traditionelle soziale Rollenvorgaben ihre Selbstverständlichkeit verloren. Der zunehmende Verlust transzendenter Identitätsgaranten und die Infragestellung überlieferter Lebensentwürfe im Zuge der Aufklärung problematisierten die Frage nach dem Selbst und der eigenen Verortung. Als (scheinbar) konservative, beharrende Sprachform des unmittelbaren Alltagslebens wurde Dialekt gerne zur Markierung jener Entwicklungen eingesetzt, die herkömmliche Integrationsmuster aufbrachen und neue Definitionen von Identitäten denkbar machten. Die Intention konnte dabei freilich durchaus verschieden sein und von der brüsken Ablehnung der Modernisierungstendenzen als sündhafter Ordo-Bruch bis hin zur satirischen Aburteilung konservativen Denkens reichen.

Unübersehbar noch dem Orientierungssystem katholischer Morallehre verpflichtet ist das folgende, ab der Mitte des 18. Jahrhunderts weitverbreitete derbdrastische Sittenlied Die sieben Todsünden, das den barocken Vanitas-Gedanken zur Sündhaftigkeit des Lebens koprolalisch überformt. Es beginnt mit einer so unflätigen wie witzigen Gleichsetzung des Lebens mit einem „Baurnschaiß“ (gemeint ist hier die Flatulenz, nicht die Ausscheidung). In weiterer Folge werden die sieben Todsünden, denen je eine Strophe gewidmet ist, behandelt, die für eine allgemeine Kritik der gegenwärtigen Zeit unter

131 Teutsche Arien 1 (Österreichische Nationalbibliothek, Cod. 12706), S. 655f.

132 Vgl. dazu Deutsch, Wienerischer Tändelmarkt, S. 35ff., der eine weitere Bearbeitung von Werners Stück durch den Salzburger Geistlichen und späteren Abt des Stifts St. Peter, Alfred Nagnzaun, unter dem Titel Wienerischer Tändlmarkt/Wiennerischer Tantlmarkt (1803) nennt, sowie Klier, Wiener Kaufrufe, S. 57f., der für das 19. Jahrhundert u. a. das Stück Allerley. Ein Liederspiel des Wiener Komponisten Joseph Weigl (1805) oder die Sammlung Der Wiener Ruf. Deutsche Tänze von Wenzel Plachy (1824) anführt. 
Rückgriff auf geläufige Topoi genutzt werden. Insbesondere die Kritik an der Versessenheit auf aktuelle Mode, an der „Gaillheit“ bzw. dem unbekümmerten Umgang junger Leute miteinander oder an Völlerei und Trunksucht findet sich auch in einer Vielzahl anderer Lieder. Die grundsätzlich geistliche Thematik, die durch das Sündenmotiv gegeben ist und sich auch sonst durch das Lied zieht - in je unterschiedlichem Kontext werden etwa das Jüngste Gericht (Str. 2), der Sündenfall Evas (Str. 3) oder der heilige Petrus (Str. 9) aufgerufen -, schließt in diesem Fall nicht aus, in so gut wie jeder Strophe auf die eine oder andere Weise auf Ausscheidungsvorgänge bzw. damit verbundene Körperteile zu sprechen zu kommen. Diese heute ungewohnte Vermischung wird zweifellos zur Komisierung genutzt, sollte aber keineswegs die durchaus ernst gemeinte moralisierende Botschaft relativieren oder ins Lächerliche ziehen. Vielmehr dienen die derbkomischen Ausschmückungen der Verstärkung der Botschaft, die inhaltlich wie formal durchaus noch barocke Züge aufweist: Den mit der Kritik Angesprochenen wie auch grundsätzlich dem ganzen irdischen Leben wird mit wenig schmeichelhaften Bildern und Vergleichen ein Spiegel vorgehalten, der ihnen ihre Unwürdigkeit zeigen soll:

1

Wann ihs betracht, iß insa Löbn

Nix als a Baurnschaiß

Der gschwind vageht, und stinkt danöbn das ma si kam vawais

bist reich bist arm bist krank bist gsund

O Mensch! betracht es doh

vazappeln mueßt s' wie a Budlhund

Und hätts a Brett fürs Loh.

3

D'Hoffart, und d'Modiklaidapracht

geht mahti hizt in Schwung

dö Eva hatn Anfang gmacht

daweil sie no war jung

dös Weib war gern a Göttin gwößt

den Apfel nahms nöt fäul

hat afa kam dö zend drein gsötzt

schieß ihr da Wurm ins Maul.

5

Wie weit thuts nöt der höllisch Neid

bey insan Zeitn treibn

wann ainer ä bißl bey da Schneid

so will man schon anspeibn

Wann aina na ä weng nöt fäul

Will äf sein Sachl sein

So schaut ma iem schon stark ins Maul

Ma schiß iem lieba drein
2

Gott ist mein Aid, kain Veitel nöt

I sag engs intas Gsicht

Ös hilft kein Flennen und kein Bitt

Wanns kemma werds fürs Gricht

Hann engs oft gsagt, seyds noh nöt frum

seids allö vastokt, und kök,

Walzt eng in altn Sündnan um

äß wie dö Sau in drök.

4

Da schöbi Geitz führt s'Regiment

bey da vadrahtn Welt

Ma schillt beym Tausend schlapprament,

um ain halbpatzen geld.

Ma schind ma schert, ma schabt, ma thuet,

als wollt ma ewig löbn

z’lötzt mueß mas Geld, und Hab und Gut

und alln drök hergebn.

6

Hiezt will ja aus da Gaillheit schon

A ganzi Modi wern

A dirndl, dös kam paperln kann

läft schon, wie d'Sau zum bärn

Wo ist ä Gsellschaft, wo nöt jetzt

d'Sauglokna gengant laut

Vagaft si ainer oft in a Gsicht

das wie ain Arsch ausschaut. 
7

Da Fraß, und d'Füllerey geht an

Wird schir a handwerk draus

Ma frißt ja schir nachm Wochalohn

Und geht zu jeden Schmaus

Ma trinkt, und sauft sö blunznvoll

und schledert als hinein

speibt aina oft an Kibl voll

iß frössens kam ien neun.

9

Dö Trägheit ist ä Toifelsding

Hiezt will a nieda Lapp

$\mathrm{Na}$ allweil af dä Bärnhaut liegn

Was denkst dä, didl tapp

du meinst, da Himmel ghört schon dein

Und lögst kain Hand nöt an

Sankt Peta laßt di gwis nöt ein

Kain Glökl krigst davon.

Ende. ${ }^{133}$
8

Da Zorn regirt hiezt überall

Kain Menschen thut ma recht

A nieda Kühkaß rigelt Gall

daß aina z'springa möcht

Wann ain was übrs Löberl rennt

Und wars na grad a Vist

so bleibt da Zorn schon ohne End

Wannst iem auf d'Nasen schißt.

1,2 Baurnschaiß] Bauernfurz 1,4 si kam vawais] kaum davonkommt, überlebt 1,7 vazappeln] verzappeln, ,den letzten Zucker machen': sterben 1,8 fürs] vor dem 2,1 mein Aid] Beteuerungsformel Veitel] Kurzform für Veit, Vitus, scherzhaft für einen dümmlich-naiven Menschen 2,2 engs] es euch intas] unter's; hier in der Bedeutung von: ,ins (Gesicht) ‘ 2,3 Hann engs] habe es euch 3,5 gwößt] gewesen 3,7 afa] aber zend] Zähne 4,3 schlapprament] Ausruf des Unwillens, verkapptes, Sakrament ${ }^{`} 4,4$ halbpatzen] Batzen: Geldmünze, häufig als Ausdruck für die 4-Kreuzer-Münze verwendet; ein halber Batzen steht dementsprechend für 2 Kreuzer 5,6 Sachl] (bäuerlicher) Besitz 6,3 paperln] plaudern, schwätzen 6,4 Bär] hier: Saubär, d. h. männliches Schwein, Eber 6,6 Sauglockna gengant laut] Unanständigkeiten geredet werden, passieren 7,8 kam ien neun] kaum ihrer neun (könnten es auffressen) 8,3 A nieda] ein jeder Kühkaß] ,Dreikäsehoch rigelt Gall] (,rührt die Galle auf') macht zornig, wütend 8,6 Vist] Furz

Um als Todsünde zu gelten, mussten die Kriterien Schwere, Bewusstheit und Freiwilligkeit erfüllt sein. Vergebung aber konnte durch Einsicht und vollkommene Reue erlangt werden. Auf diesen Erkenntnisprozess zielten die - oftmals im klerikalen Kontext entstandenen - Sittenlieder. Besonders beliebt war die zumeist erstgereihte Sünde der ,Hoffart' bzw. des Stolzes und der Eitelkeit, die sich - wie schon in der dritten Strophe des obigen Lieds angedeutet - an aktuellen Modetorheiten sehr anschaulich explizieren ließen. Spottlieder über Modegewohnheiten sind aufschlussreiche Dokumente zur Alltagskultur, illustrieren sie doch die Reaktionen auf veränderte Kleidercodes, soziale Konventionen oder auch unerwünschte aktuelle Leitbilder. Gegen die kulturelle Vormachtstellung Frankreichs wenden sich bereits die vielen, Alamode-Lieder', mit denen verstärkt seit dem Dreißigjährigen Krieg - gegen ,undeutsche' sprachliche, habituelle, vor allem aber auch vestimentäre Einflüsse polemisiert wurde. ${ }^{134}$ In der bairisch-österreichischen dialektalen bzw. dialektnahen Literatur begegnen uns diese Modespott-

133 Österreichische Nationalbibliothek, Musiksammlung Mus.Hs. 3093 (Fragmentarische Liedersammlung), Bl. 12v-14r [nicht datiert, nach 1791].

134 Vgl. u. a. Alamodische Höllenfahrt / und Geleid zum NobisKrug. [o. O., 1629] (Zu diesen lezten Zeiten hart) - Teutscher Frantzoß. Das ist: Ein newes Allamodo Gesang [...]. Innsbruck: Gäch 1637. (Herzu ein newer Pantalon) - Die Teütsch Frantzösin. Das ist Ein newes Allamodo Gsang [...]. Innsbruck: Gäch 1637 (Der Teutsch Franzoß beklagt sich sehr). Weiteres Material bei John Roger Paas: The German Political Broadsheet 1600-1700. Vol. 4. Wiesbaden: Harrassowitz 1994, S. $291 \mathrm{ff}$. 
gesänge zumindest seit dem frühen 18. Jahrhundert. Vorrangiger Kritikpunkt ist bei einem Großteil der Lieder nicht in erster Linie die Mode selbst als vielmehr der Versuch des sozialen Aufstiegs durch Kleidung bzw. die Aufweichung der sozialen Abgrenzungsmöglichkeit durch die Gesamterscheinung. ${ }^{135}$ So werden in der Schlussstrophe des 1740 erschienenen Flugblattlieds O Himmel, erlaub mir zu klagen mein Leyd Kleidung, Frisur und Schminke als Differenzzeichen der höheren Schicht hervorgehoben („damit man kan spühren, was Herr oder Knecht" ${ }^{136}$ ). Und im 1758 publizierten Nächt hat mich mein Mutter in d'Stadt eini gschickt werden die Unterschichtfrauen, die städtisch-aristokratische Kleidungs- und Pflegegewohnheiten zu kopieren versuchen, davor gewarnt, das hierarchische Sozialsystem und damit den Ordo-Gedanken zu missachten. ${ }^{137}$

Eine besondere Brisanz bekam das Thema für ein leichtgläubiges Publikum durch bedrohliche Andeutungen in den Sibyllinischen Weissagungen, einem Volksbuch, das in verschiedenster Form im Umlauf war und das nahe Weltende aus der überbordenden Eitelkeit der Menschen deduzierte. Als Vorbote des Jüngsten Tags nimmt der Modewechsel in diesem Volksbuch (das an jüdisch-christliche apokalyptische Orakeltexte, die sogenannten Sibyllinen, anknüpft) durchaus einigen Raum ein. In einem Druck aus dem 16. Jahrhundert etwa wird als Endzeitsignal benannt:
Sy tragen Kleider wunderleich
Eins lang / ains eng / ains weit
Und förchten sich zu kainer zeit,
Man sicht an der frawen gewand
Farb und falten mancherhand. ${ }^{138}$

Auch das folgende Flugblattlied aus der Mitte des 18. Jahrhunderts greift diesen Gedanken auf und begründet ihn mit den neuesten Modetrends, die in der Stadt gerade en vogue sind:

135 Zum Phänomen der Kleidung als Zeichensystem vgl. Roland Barthes: Die Sprache der Mode. Frankfurt a. M.: Suhrkamp 1985.

136 Vier schöne neue Weltliche-Lieder, Das Erste: Ein grosser Zanck und Streit von einem versoffenen Mann und einem bösen Weib. Ach du alter Galgen-Schwengel, sauff daß gleich verstickts [sic] daran, etc. Das Anderte: O Himmel erlaub mir zu klagen mein Leyd, ihr Götter etc. Das Dritte: Theilt ein Allmosen einen Blinden, den die Lieb hat blind gemacht, etc. Das Vierdte: Mein Hertz steht offen schau hinein, etc. Gedruckt in diesem Jahr, 1740 [o. O.], f. 3r. - Zu den Modespottliedern vgl. auch Lucie Hampel: Hundert Jahre Kleidermode in österreichischen Liedtexten. In: Jahrbuch des Österreichischen Volksliedwerkes 8 (1959), S. 74-92.

137 Vier schöne Neue Lieder, das Erste: König aus Preussen, was bildest dir ein etc. Das Anderte: O Preuß, du grausamer Tyrann etc. Das Dritte: Nächt hat mi mein Muttern in d'Stadt eini gschickt etc. Das Vierte: Ist einer weil dort wohl in der Stadt darinn etc. Gedruckt in diesem Jahr. [o. O., 1758]; zitiert nach Hampel, Hundert Jahre Kleidermode, S. 77. Vgl. die unten wiedergegebene längere Fassung mit dem Incipit Losts Nachbän, was nächtn mehr talgelts ist gschehn.

138 Von Sibylla Weissagung Und von Künig Salomonis weißhait Unnd was wunders geschehen ist und noch gechehen [sic] sol vor dem jungsten tag. [o. O., o. Verl.], f. 8v. Etwas ausführlicher waren die späteren Prosafassungen, die lange Zeit nur handschriftlich tradiert wurden. In einem Leitomischler Druck heißt es entsprechend: „,in der Kleidung werden sie veränderlich sein, und mit derselben viel Aufwand treiben; die einen werden kurze, die andern wieder lange, die einen enge, die andern wieder weite Kleider tragen, und das von so mannigfacher Farbe und so sonderbar zugeschnitten, daß sie sich selbst darüber wundern werden“ (Die Sibyllinischen Bücher oder die Prophezeihung der Königin Michalda von Saba, der XIII. Sibylle. Leitomischl: Berger 1850, S. 21). 
1

Losts Nachbän, was nächtn mehr talgelts ist gschehn, mä hat ja mei aichl nicht närrisches gsehn, wie hoffärtig d'Leuth bey jetziger Zeit, i glaub halt, es ist der jüngst Tag nit meh weit. 2

Nächt hot mi mei Mudä in d'Stadt ähi gschickt, da honi vo allsgfär ä WeibsBild däblickt, dö wä halt so schö, i kunts net vosteh, sie wüst net vo Hoffart, wies soll dahä geh. 3

Die Leuth auf dä Gassn schauns allesamt an, und sangt halt, jetzt schauts mä [den T]rampltanz an, si steigt ja daher, als wärs waiß nit wer, däweils ists nur gwesn ä gmainer Mist-Bär. 4

Kai Raigä hätt warlä kain so langä Kragn, i rait halt, si hat ihrn vier Monat net zwagn, das Gsicht hats vazwickt, mit Pflästerl vobickt, das hat sie wie Arsch und Fridrich zam gschickt. 5

An Bratzn tragts Rädl als wie ä Schieß-Scheibn, glaub käm daß dähaim gnu zfressn hat Kleidn, damastene Schuh, hoch Steckl dazu, dä Gang wär än Bärn zu voglaichä scho gnu. 6 Der Leib hat a Thali, i kunt encks net sagn, er tauget auf d'Wisn, zu Hirschn vojagn, ihr Ruckgrad ist ja so grad, als wie unser Jodl a Fleisch-Butn hat. 7 Jetzt waiß i warum denn dö Raiff so aufschlagn, weil dMenscha so vil hintän Kidl than tragn, das schö waitzä Mehl steigt auffi no glei, si sträns aufn Schedl, ist Sünd ja mei Treu. 8

Dö Koch-Löffel dö kömma aufn zimlichn Werth, mä kriegts ja schie nimä zu Kuchl und Herd, dö de Hoffart vosteht, brauchts statt än Plansched, offt aini voliehrnt, wanns tantzt ain Mennet. 9

Das Mieder um dMitten geht $z$ [samma so] drang, i glaub hait, es sollt helffe fürn Zwang, ist hinten zamgschniert, daß vorn nix voliehrt, durch seltäni Menschä wird manchä voführt. 10

Du thörrische Trampltanz, was bildst dir den ei, wilst mehr als oft manchi von Adl schö sey, es steht kaum dähi, obst hast so vil Sinn, ä Brenn-Suppn zmacha, dö grecht wä für mi. 11 Mei lasts enck do rathn, legts dHoffart auf dSeit, ös stinckts als wie sLudä, mä schmeckt enck vil zweit, 
mä hat ja oft ahört, wer si übern Stand tragt,

der wird mit dä Präxn in dHöll ani gjagt. ${ }^{139}$

1,1 Losts] Imperativ zu losen: hören, horchen nächtn] gestern, gestern abends talgelts] Albernes, Lächerliches 1,2 mei aichl] Interjektion zum Ausdruck der Bestätigung, der Nachdrücklichkeit 2,1 ähi] hinunter 2,2 honi] habe ich vo allsgfär] von ungefähr, d. h. auf einmal 3,2 Trampltanz] Trampel: ungeschickter Mensch, plumpe Frau 4,1 Raiga] Reiher 4,2 rait] denke, vermute 4,2 zwagn] (mit warmem Wasser und Seife) waschen 5,2 Kleidn] Kleie, Mühlenrückstand als Futtermittel 6,1 Thali] Taille 7,2 Menscha] Mädchen, Frauen 7,3 Kidl] Kittel, Rock 8,3 Plansched] von franz. planchette ,Brettchen: Fischbein für Frauenmieder 8,4 Mennet] Menuett, beliebter Gesellschaftstanz im 17. und 18. Jahrhundert 9,1 drang] fest, eng (von: gedrängt) 9,4 seltäni] solche 10,1 thörrische] taube, schwerhörige 11,2 Ludä] hier: wie hochdt. Luder, d. h. Aas 11,2 schmeckt] riecht 11,4 Präxn] Gewehr (auch spöttisch) ani] hinein

Der Spott über die aktuelle Mode, wie er in dieser und ähnlichen Flugschriften immer wieder auftaucht, lässt sich auf zwei Ebenen lesen, nämlich einerseits als historischer Beleg für die jeweilige Mode selbst, wie es etwa Hampel in ihrem Aufsatz über Kleidermode in Liedtexten zeigt, ${ }^{140}$ andererseits als Dokument sozialer und moralischer Urteile und Leitbilder. Was in den Liedern an modischen Auswüchsen kritisiert wird, überliefert also ein - wenn auch tendenziell polemisch verzerrtes - Bild des gängigen Kleidungsstils: Reifröcke und Glockenärmel (deren Verzierungen hier als ,Radl wie Schießscheiben' interpretiert werden), feine Schuhe und enge Mieder, gepuderte Frisuren und Schönheitspflästerchen. Der Hinweis auf den Gestank der herausgeputzten Frauen lässt sich damit in Verbindung bringen, dass regelmäßiges Waschen im 18. Jahrhundert nicht üblich war - es wurde teilweise sogar abgelehnt, da es die Haut gegen die Witterung empfindlich mache. Körpergerüche wurden daher vor allem mit starken Parfums oder Essenzen übertönt. Nicht allein die Mode aber wird in diesem Lied kritisiert, sondern auch der Versuch, durch Teilhabe an aktuellen Dresscodes einen unangemessenen sozialen Status vorzutäuschen. Modekritik hat in dieser Hinsicht immer auch eine disziplinierende Dimension: Wer sich diese aufwändige Kleidung nicht wirklich leisten kann und Haarpuder durch Mehl oder Fischbein mit Kochlöffeln ersetzen muss, macht sich lächerlich. Insofern unterminiert der aufwändige Putz die soziale Hierarchie, die sich auch über Kleidung ausdrückt bzw. ausdrücken soll.

Interessant ist, dass sich die allermeisten dieser dialektalen Lieder auf Frauenmode beziehen. ${ }^{141}$ Ein Aspekt dieses Genres ist daher wohl auch, nicht nur die Standes-, sondern auch die Geschlechterhierarchie angesichts eines wahrgenommenen ,Sittenverfalls abzusichern. Deutlich scheint das etwa in dem Lied Wie ist die Welt beschaffen, in dem zuerst das unbeständige Leben der jungen Männer, dann die Mode der Frauen kritisiert und abschließend festgehalten wird:

139 Steiermärkisches Landesarchiv, Hs 1395a, VIII.4 (Flugschriften-Fragment ohne Titelblatt, ca. 1755-1760). Eine Variante findet sich in der Flugschrift Vier schöne Neue Lieder (s. o. Fußnote 130); dort beginnt das Lied erst mit der zweiten Strophe des hier abgedruckten und ist weniger stark dialektal wiedergegeben (ediert bei Hampel, Hundert Jahre Kleidermode, S. 76f.; von dort sind auch einige der Wort- und Sacherklärungen übernommen).

140 Vgl. Hampel, Hundert Jahre Kleidermode.

141 Auch z. B. M. Lindemayrs Bauernklage Mein Endl hats längst prophizeit nimmt die eingangs thematisierten Modeveränderungen am Beispiel der „ländlä Tracht“ nur als Aufhänger für eine umfassendere Zeitkritik, vgl. Lindemayr, Dialektlieder I, S. 129-131. 
6

Die Buebm wern jetzt frommä,

sie halten ihren Stand,

die Menscher wern jetzt schlimmä,

sie bringä d'Buebm in d'Schand,

Das Maul, das thäns ain macha,

die Nasen habns an eh,

sie bringen ihn um all sein Sachä,

aft gschicht ihm hart und weh. ${ }^{142}$

6,3 Menscher] Mädchen 6,8 aft] dann

Eines der wenigen Modelieder, die sich explizit auf Männermode beziehen, kommt bezeichnenderweise aus einem rein maskulinen Umfeld: Zum Neujahrstag 1756 mussten sich die Studenten der Kremsmünsterer Ritterakademie, wo dem aristokratischen Nachwuchs eine möglichst breite Ausbildung zuteil werden sollte, ein Spottlied auf ihr affektiertes Getue und ihre kostspielige Modefixiertheit gefallen lassen. Vom Regenschori des Klosters Franz Sparry vertont, diente dieser witzige, leicht höhnische Neujahrsgesang wohl vor allem auch dazu, den künftigen Spitzen der Gesellschaft die Schulhierarchie wieder in Erinnerung zu rufen:

9

schauts, wie si nit S-Röckerl und S-leibl zam reimt,

sänd überall silberne bertl angleimt,

habts täschl und söckl auf alle baid seit,

wärn guet, wans in Kirtag ain bschaidösßen geit.

10

die Köpffl seind abä so zierlä aufbuzt,

d'har seyn eng so schön wie ain budlhund gstu[z]t,

äs ist als mit schmöckäten harbudä gwirzt,

habts eng gwiss ä dreymahl in d'melldrucha gstürzt.

11

dö hietl seind alle von Sammeten Filz,

kost ains gwiss ain anderthalb thallä, was gilt's?

ä silbernes Knöpfl und Portn ä ham,

ä stizköpffl druntä, das reimbt si wohl zam.

12

was wird mit dä Zeit den aus eng no wohl wern?

ös werds mit dä gottshilff grossmächtige herrn,

dö welt wart auf eng schon mit leitn und land,

ös müests es zamhaltn, sonst fallts ausänandt. ${ }^{143}$

9,1 zam] zusammen 9,2 bertl] Borten 9,4 bschaidösßen] bäuerliches Festessen, bei dem üblicherweise die Reste für die Heimreise mitgegeben wurden 10,3 schmöckäten] (gut) riechendem 10,4 melldrucha] Mehltruhe 11,1 hietl] Hütchen 11,4 stizköpffl] Trotzkopf 12,2 ös werds] ihr werdet

142 Fünf Neue Lieder. Das Erste: Ach schlaft denn alles schon | Das Zweite: Es ist wahr wie man sagt, daß / Das Dritte: Wie ist die Welt beschaffen,/ Das Vierte: Ist oft ein schöns Vögerl, kann / Das Fünfte: Weine nicht es ist vergebens. Gedruckt in diesem Jahr. - Ediert bei Wolkan, Wiener Volkslieder I, Nr. XXVI, S. 115-117; seine Datierung um 1700 scheint allerdings wenig realistisch.

143 Musikarchiv Kremsmünster, G44/785. 
Gegen die Tendenzen der bürgerlichen Frauenmode, unreflektiert das kapriziöse aristokratische Kleiderprogramm (mit der europäischen Trendsetterin Marie Antoinette) zu übernehmen, polemisiert Peter Gottlieb Lindemayr in Jezt halt I auf d' Sibilla Weis. Auffälligstes Charakteristikum der Rokokomode war der Reifrock, der im Verlauf des 18. Jahrhunderts sehr unterschiedliche Formen annehmen konnte. In den 1780er Jahren beliebt waren ovale Kuppelformen, die in der zweiten Strophe mit Festungsbauten verglichen werden. Besonders erzürnt den Sprecher, dass selbst Kleinkinder in diese raumgreifenden, natürliche Körperformen ins Extrem verzerrenden Kleider gesteckt werden:

4

Wenns gschäh, daß mit än söltän Gsäßt

Ä Kind gebohrn soll wern,

So hielt mäs für ä Toifels Gfräst,

Wie wurd nit d' Muedä blern?

Jezt daß's Kind dö graden Glieder mit äf d' Welt hat bracht,

Wernd iehm z' Fleis ä graß par Senkel übä d' Hüft hingmacht.

Bei den budäwinzing Kindern

Mit den grassen braiten Hintern,

Wo ist da (I frag nä glei)

Wo ist da Natur dabei. ${ }^{144}$

4,1 Gsäßt] Gesäß 4,3 Gfräst] etw. Ärgerliches, Unnötiges, v. a. auch eine ärgerliche, verachtete Person 4,5 Senkel] Pl. zu Senkel: Bleigewicht zum Beschweren u. a. für Schiffleute, Geschwulst, großes Bündel 4,6 budäwinzing] sehr kleinen

Auch am Theater wurde das Thema verhandelt. In der einfältigen Wiener Posse Was kann ein Buffant nicht thun? (1786) möchte sich eine verwitwete Schlossbesitzerin nicht von diesen heißgeliebten Modestücken trennen und riskiert dadurch ihr eigenes Glück und auch das ihrer Tochter, deren Verehrer - wohl nicht zufällig Sommerfels genannt als Vertreter der Vernunft wenig mit dem Modespleen anfangen kann. Selbst der Bauernstand greift bereits diese Stadtmode auf - sehr zum Amusement, dann auch zum Ärgernis Kasperls, dessen Verlobte gleichfalls ein Bouffant tragen soll:

Kaspar. [...] schau Resel von an Bouffant haben wir g'redt - den tragt z'Wien die erste Dam bis auf's Kuchelmensch.

Röschen. A mein! das wird also a recht hübsches Röckl oder a Klad seyn.

Kaspar. Ey ja wohl.

Röschen. Nun so sag mir was ist den das a Puff - Puff - wie hasts?

KASPAR. Ein Bouffan - no schau, ein Bouffan - no ein Bouffan ist halt ein Bouffan.

Röschen. Ein Bouffan ist halt ein Bouffan Esel - jetzt weiß ichs - du must mir ja erklären, wie er ausschaut.

KASPAR. Ja explicationiren - ein Bouffan der sieht dir halt aus wie ein Mühlrad, nun wie halt unsere gnädige Frau um die Mitte ihres Leibes hat, nur daß er z'Wien noch einmal so groß getragen wird. ${ }^{145}$

Kuchelmensch] Küchenmädchen a Klad] ein Kleid hasts] heißt es

144 P.G. Lindemayr, Lieder in oberösterreichischer Mundart, S. 65.

145 [J. Fr. Gr]: Was kann ein Buffant nicht thun? Ein Lustspiel in drey Aufzügen. Wien, 1786, f. 7f. 


\section{Lokal- und Gesellschaftssatiren}

Generell ist in diesen dialektalen Sitten- oder Modebildern fast immer die Stadt Ausgangspunkt der Dekadenz und Kontrastbild zum (leicht korrumpierbaren) Ländlichen. Aber nicht nur hier dienten die merkwürdigeren Aspekte des urbanen Alltags als Sujet. $\mathrm{Ab}$ den 1770er Jahren kamen auch vermehrt satirische Texte im narrativen oder quasidramatischen Modus auf den Markt, die typischen Mustern des jeweiligen Stadtspezifischen nachspürten und sie zur Belustigung des Lesepublikums aufarbeiteten. Beliebt waren etwa Seitenhiebe auf Emporkömmlinge, die durch Heirat oder Protektion zu Lebensumständen gekommen sind, die ihrer eigentlichen Sozialisation völlig widersprechen, gleichwohl aber eine prononcierte Noblesse an den Tag zu legen. Ein witziges Beispiel stammt aus der Zeit der Broschürenflut (und wird auch in Blumauers Streitschrift gegen die Unzahl an schriftstellerischen Belanglosigkeiten explizit genannt): In Das Lamentabel der gnädigen Frauen über die Fatalitäten der gegenwärtigen Zeit des aus Olmütz gebürtigen Lehrers Johann Strommer (1749-1812) zeigt sich eine, gnädige Frau von N.' begeistert von einem dieser Tagesschreiberlinge und setzt einen Fanbrief auf, der in Ton, Form und Ausdruck in krassem Widerspruch zu ihrem affektierten Getue steht. Nicht nur, dass die Elementaria des Schrifterwerbs beinahe spurlos an ihr vorübergegangen zu sein scheinen, klingt auch in den bemühten Formulierungen der Alltagsdialekt unmissverständlich durch. So unverständlich wirkt das Geschreibsel auf den ersten Blick, dass der fiktive Herausgeber sich bemüßigt fühlte, Erläuterungen und Übersetzung „aus dem Wiener Deutsch - in Deutschland Deutsch“ beizusteuern:

Ser fererlicher man

gnetiger her auder.

$[\ldots]$

neme se mers nit ibl, i hob fon irer schrld kherd, wie doß se sick ter woreit oneme unt die kligadure ter Didel a wenik ausnonter klaupen weln, neme se mers nit in ibel, i sick mai gomermetl um a su a bichel und zuer glan aufmunderunk ires shmis da shig i ine an gremizer Dugoden unt an gultn ih lipe die gellerten besonters die gsheiten und solner gor wenik sain gomen se zmir tuns mer die knot an ih won aufm krapen No. im 00. stok re[k]ter hont swert mer a unentlich fergniken mochn se fan berson zu köne oter wulns irm lefl beimer zmidag obleke so bin ih mid aler hochachdunk

knätiger her auder

win ten

26. Yauni

n. se kumes gwiß mei her is nit zhaus. $\left.{ }^{*}\right)$

ihre zerdliche Frau von Liebstall.

*) Ich will hundert von gegen einen Gnädigen verwetten, daß Mancher diesen Brief, der wohl die beste Stelle im Pöstbüchel hätte, nicht lesen könnte, ohne den Abschreiber so vieler Schreibfehler zu beschuldigen; aber ich betheure es bey meiner Kopistenseele! der Brief war buchstäblich von der gnädigen Frau so geschrieben. Man frage nur einen Hauslehrer; er wirds auf seine Seele abschwören, daß die Kinder lernen, bis ihre Kinder wieder lernen, und wissen doch nichts: heus tu capacitas! - Ich will ihn also aus dem Wiener Deutsch - in Deutschland Deutsch überschreiben. Er mag so lauten:

Sehr verehrlicher Mann, Gnädiger Herr Autor! 
Nehmen Sie mir's nicht übel, ich hab von Ihrer Schrift gehört, wie daß Sie sich der Wahrheit annehmen, und die Karikaturen der Titel ein wenig auseinander klauben wollen; nehmen Sie mirs nicht übel, ich schick mein Kammermädchen um so ein Büchlein, und zu einer kleinen Aufmunterung Ihres Genies, da schick ich Ihnen einen Kremnitzer Dukaten, und einen Gulden. Ich liebe die Gelehrten; besonders die Gescheiten, und 's sollen ihrer gar wenig seyn. Ich wohne auf dem Graben Nro. 000. im 00. Stock, rechter Hand. Es wird mir ein unendliches Vergnügen machen, Sie von Person zu kennen; oder wollen Sie Ihren Löffel bey mir zu Mittag ablecken, so bin ich mit aller Hochachtung

Gnädiger Herr Autor

Wien, den 16. Junii, 1781.

N. B. Sie, kommen Sie gewiß, mein Herr ißt nicht zu Haus. ${ }^{146}$

Ihre zärtliche Frau von Liebsthal.

Doch häufiger noch als die vornehmen Schichten stehen nun die sozialen Unterschichten im satirischen Fokus. In München etwa finden sich ab 1778 mehrere als Gespräche bzw. Folge von Gesprächen gestaltete 4-Kreuzer-Broschüren, die verschiedene niedere Berufsgruppen ins Visier nehmen. Doch anders als bei den Berufsliedern rückt nicht der Beruf an sich oder der Lebensunterhalt der typisierten Figuren ins Bild. Es sind die Hintergrundinformationen, die die Leselust anstacheln sollen: Was die Köchinnen und Stubenmädchen von den Eskapaden ihrer Herrschaften zu berichten wissen oder die Kellnerinnen aus den Beständen ihrer Dienstherren abzweigen, um sich selbst ein schönes Leben zu machen. ${ }^{147}$ Üblicherweise lässt sich dabei jeweils ein am Titelblatt angeführtes vorgebliches Zitat als Paraphrase des im Text zum Ausdruck Gebrachten lesen. In Die Bettelweiber heißt es etwa: „Hütet euch vor den bösen Weibern; denn sie sind ärger, als die giftigsten Schlangen. Buch der Erfahrniß S. 311. “148 Und tatsächlich erweisen sich die Bettlerinnen als selbstgerechte, gierige und durchtriebene Paradebeispiele ,böser Weiber', die in drei ,Gesprächen' ihre Verfressenheit und Sauflust, ihre Rüpelhaftigkeit und Rauflust, ihre Skrupellosigkeit und Durchtriebenheit offenbaren. Im ersten Gespräch beklagen Reßl und Nandl, die sich beim Einkauf am Markt treffen, das immer schlechter werdende Auskommen, lassen aber zugleich erkennen, dass sie sich tatsächlich ein schönes Leben machen können - dies freilich nur im Geheimen und ungesehen von potentiellen Spendern. Im zweiten Gespräch trifft Urschl im Brandweinhaus auf

146 [Johann Strommer]: Das Lamentabel der gnädigen Frauen über die Fatalitäten der gegenwärtigen Zeit. Wien, [Rothscheid] 1781, S. 11-13.

147 Nach der vermutlich in München um 1778 gedruckten Schrift Die Köchinnen fühlte sich deren anonymer Verfasser offenbar durch den guten Erfolg angehalten, entsprechendes Weiteres nachzureichen. So ist dem Folgewerk Die Kellnerinnen eine Satyre in drey Gesprächen die Erklärung vorangestellt: „Wenn mir die salvo Titulo Jungfer Kellnerinnen gleichen Beyfall angönnen, wie die Köchinnen, und um $4 \mathrm{Kr}$. gerne zusprechen, so will ich ihnen zu gefallen über 8 Tage die Koffeejungfern, und über 14 Tage die Mamsell Stubenmägdchen ungesöumt vor Augen stellen [...] wie sie von Natur ohne Schminke sind, müssen sie mir erscheinen“ (f. 1v). Zudem findet sich eine direkte Fortsetzungsbroschüre, Die Vertheidigung der Köchinnen, die nun die Verunglimpften selbst zu Worte kommen lässt, und offenbar den Erfolg dieser Werklein prolongieren wollte.

148 Die Bettelweiber, ein Gespräch. Schrobenhausen nächst der Allmosenstraße 1779, f. [1r]. 
Kathl, die ihr von einer geplanten gewalttätigen Racheaktion gegen einen Verräter erzählt und sie zur Teilnahme anstiftet:

URsCHL. Grüß dich Gott Alte! was machst denn du heute schon so frühe da, hab dich noch nie so frühe da gesehen?

KATHL. Ja das ist eine ganz besondere Ursach heute, ich habe heute was kurioses im Sinne.

URSCHL. Aber nur nichts schlimmes.

KatHL. Wirsts schon sehen, was ich heute für Fotzen austheilen werde; jetzt bleibe ich bis um 8 Uhr sitzen, und sauffe mir einen rechten Rausch an, und dann wirds drauf los gehen, hastn nicht gsehen, und siehstn nicht auch: bif, bif, bif, baf, und wieder unter d'Nasen nauf, daß s'Blut zu der Goschen rab rinnt. ${ }^{149}$

Fotzen] Ohrfeigen Goschen] Maul, Mund

In Einklang mit der stilisierten Darstellung steht auch die sprachliche Gestaltung, sodass die Ausdrucksweise der Figuren zumindest stellenweise einen deutlich gesprochensprachlich-dialektalen Ton trägt. Allerdings ist der Text nicht konsistent auf gleichem Niveau mundartlich notiert; der Autor scheint sich letztlich doch schriftsprachlichen Normen verpflichtet zu fühlen bzw. keine bewusste Abgrenzung von diesen vollziehen zu können oder wollen.

Noch viel bunter und vielfältiger ist das Ensemble prächtig gezeichneter Stadttypen, die uns aus dem Wien des ausgehenden 18. Jahrhunderts überliefert sind. Zu verdanken haben wir dies einem der Meister österreichischer Satire, Joseph Richter, der mit zahlreichen humoristischen Arbeiten zum meistgelesenen Unterhaltungspublizisten des Habsburgerreichs avancierte. Seine Broschüre Wienerische Musterkarte. Ein Beytrag zur Schilderung Wiens erschien von Jänner bis Juni 1785 jeweils einmal pro Monat, insgesamt also in sechs Heften. ${ }^{150}$ Vorgestellt wird eine Reihe von Typen, die wie Waren in der Musterkarte eines (Stoff-)Händlers exemplarisch vorgeführt werden. Richter knüpft damit an die Tradition der Narren-, Moral- und Sittensatire, die nicht zuletzt unter Abraham a Sancta Clara einen Höhepunkt erlebt hatte, an und fügt - zumindest in dieser ersten Auflage - noch einen Schuss Sozialkritik hinzu. ${ }^{151}$ Insgesamt stehen die Broschüren in Stil und Inhalt ganz im Zeichen der (josephinischen) Aufklärung und sind - so Kauffmann - mit ihrer „Dialogisierung und Inszenierung der Wiener Typenbilder" ${ }^{152}$ zukunftsweisend. Indem die verschiedenen Typen miteinander quasiinszenatorisch ins Gespräch finden und ein dem Wienerischen angenähertes Idiom verwenden, werden grundlegende Wirkungseffekte der Wiener Volkskomödie in die Stadt-

149 Ebda., f. [4r]. Im dritten Gespräch dieser Schrift treffen sich Lißl und Miedl im Bierhaus, wo Miedl ihre Verspätung triumphierend damit entschuldigt, dass sie aufgrund einer unter Kollegen nach ihrer Meinung ungerecht geteilten Geldgabe eine Schlägerei begonnen habe, aus der sie durch Bestechung - bemerkenswerterweise in der Höhe des Gesamtbetrags des strittigen Almosens - ungeschoren davon kommt, während die Gegnerin eingesperrt wird.

150 Wienerische Musterkarte, ein Beytrag zur Schilderung Wiens. J[oseph] R[ichter]. Wien 1785. [1. Aufl., ohne Angabe des Druckers.] Vgl. dazu Kai Kauffmann: „Es ist nur ein Wien!“ Stadtbeschreibungen von Wien 1700-1873. Geschichte eines literarischen Genres der Wiener Publizistik. Wien/Köln/Weimar: Böhlau 1994, S. $248 f$.

151 Vgl. Bodi, Tauwetter in Wien, S. 199.

152 Vgl. Kauffmann, Es ist nur ein Wien, S. 250f.; siehe auch Bodi, Tauwetter in Wien, S. 200. 
und Gesellschaftsbeschreibung eingebracht. Insofern ist die Wienerische Musterkarte auch Grundlage für die ebenfalls ab 1785 verfassten (damals allerdings noch nicht als Reihe geplanten) Eipeldauer-Briefe von Richter. Speziell die Sprache wird mehrmals explizit thematisiert als Mittel zur Typisierung, aber auch zur naturalistischen Darstellung. Richter selbst behauptet des Öfteren, dass er seine Gespräche „nach der Natur kopiert“ habe. ${ }^{153}$ In diesem Sinne wird auch immer wieder Dialekt bewusst markiert, zumindest zur Charakterisierung bestimmter Figuren. Dabei bewertet der Autor - ganz dem Aufklärungsdiskurs entsprechend - den Dialekt (die „gemeine Wienersprache“) durchaus als „fehlerhafte“ Sprache, die wohl dem „vernünftigen Ausländer [...] unmöglich gefallen“ könne; ${ }^{154}$ gleichzeitig verteidigt er die Dialektsprecher aber insofern, als dies „nicht zum Maßstab der Aufklärung“ genommen werden dürfe, wie ja auch die Sachsen nicht ,besser denken' könnten als die Preußen, obwohl sie ihnen in der Sprache voraus seien. $^{155}$

1799 wurde eine zweite Auflage gedruckt, die um einige Stücke vermindert ist und nur mehr 39 statt 49 ,Muster ' beinhaltet. ${ }^{156}$ Vor allem die scharfe Kritik an der Geistlichkeit, die sich durch die Stücke der ersten Auflage zieht, ist nun abgemildert oder überhaupt gestrichen; sieben der zehn in der zweiten Auflage nicht mehr enthaltenen Stücke richten sich gegen Aberglauben und Heuchelei von Geistlichen oder von Bürgern und Bürgerinnen, und auch die Änderungen innerhalb der beibehaltenen Stücke stellen nur an manchen Stellen Streichungen etwa von offenbar nicht mehr aktuellen Passagen dar; in den meisten Fällen aber betreffen sie wiederum Kritik an Geistlichen. Damit bilden die beiden Auflagen der Wienerischen Musterkarte auch einen Wandel im öffentlichen Diskurs in den letzten zwei Jahrzehnten des 18. Jahrhunderts ab: Während sich Richter in der ersten Auflage als profilierter Kritiker der antiaufklärerischen Geistlichkeit zeigt - womit er im Rahmen einer Debatte steht, die in den 1780er Jahren lebhaft und wenig zimperlich geführt wurde -, sind alle diesbezüglichen Texte 1799, im achten Jahr der restaurativen und restriktiven Regentschaft Kaiser Franz II., verschwunden.

Als Beispiele für die ästhetische Funktionalisierung dialektaler Formen, zugleich aber auch für die heute noch wirksame Komik von Richters Typisierungen sollen einige seiner ,Muster vorgestellt werden. In Muster eines Oberbeamten. Ausschuß steht der Sprachenstreit der vorangegangenen Jahrzehnte im Mittelpunkt, der durch Johann Christoph Gottscheds Grundlegung einer deutschen Sprachkunst (1748) befeuert wurde (vgl. Kap. 8). Gottscheds auf Basis des ostmitteldeutschen Sächsischen entwickelte Sprachnorm, hatte - durch Gefolgsleute wie Joseph von Sonnenfels auch in Wien propagiert die oberdeutsche Schreibsprache in den 1780er Jahren bereits weitgehend aus der Öffentlichkeit verdrängt. In der Verwaltung war das Gottsched'sche Deutsch seit Regierungsantritt Josephs II. verbindliche Norm; mit seinem Versuch über die Grundsätze des Stils in privat- und öffentlichen Geschäften (1781) prägte Sonnenfels maßgeblich die neue

153 Richter, Wienerische Musterkarte 1785, V, S. 23.

154 Ebda., III, S. 26f. („Muster eines schmähsüchtigen Ausländers“).

155 Ebda.

156 Joseph Richter: Wienerische Musterkarte, ein Beytrag zur Schilderung Wiens. Vom Verfasser der Eipeldauerbriefe. Zweyte abgeänderte Auflage. Wien, In Kommission bey Christoph Peter Rehm. 1799. 
Beamten- und Verwaltungssprache. In der älteren Beamtenschicht freilich hatten die Neuerungen nicht uneingeschränkt Anklang gefunden:

Sitzt auf dem Sopha. Vor ihm steht ein würdiger Konzepist.

Da schau der Herr nur wieder, was der Herr gmacht hat. Hab ich's nit d'n Herrn so oft gsagt, daß man: Befehlshabere, ihme und so weiter schreibt? - Wo sind dann d'e blieben?

KonzePIST. Ich habe mich nach Gotscheds Sprachlehre gehalten.

Oberbeamte. Was ist das für ein Esel, der Gotsched? G'wis ein Sonnefelsianer? Ich sag's d'n Herrn nochmal, laß der Herr das Bücherlesen bleibn. Die Akten brav durchblättert dafür, da kann der Herr lernen, was ein Kanzley-Stylum ist. Das ist ein Kreuz mit eng jungen Leuten. Es wär nöthig unser einer that erst Deutsch lernen, wenn einer enger Konzept verstehen will. Itzt kann der Herr gehen, und folg der Herr mein Rath, sonst wird aus d'n Herrn in sein Lebtag kein Oberbeamter.

Der Konzipist neigt sich, denkt sich seinen Theil, und geht zum Zimmer hinaus.

NB. Dieser Waaren-Artikel ist freylich sehr ausser Mode gekommen; indessen wird er doch hie und da noch angetrofen. ${ }^{157}$

Auch wenn der Dialekt in dieser Szene nicht so sehr im Vordergrund steht, ist er implizit Thema, beharrt doch der alte Oberbeamte nicht nur auf dem überkommenen „KanzleyStylum“, sondern zeigt sich auch außerstande, gehobenen Standard zu sprechen. Bockigselbstbewusst bleibt er bei seinen stark dialektal gefärbten Formen und hält es nicht für nötig, „erst Deutsch lernen“ zu müssen.

Im Muster eines Fleischhackers. Super - Super fein zeichnet Richter ein - am Ende doch nicht gelingendes - Verkaufsgespräch lustvoll nach. Sein Geschick für die Wiedergabe zentraler Eigen- und Feinheiten der Umgangssprache vergegenwärtigt uns das lebhafte Feilschen zwischen dem ruppigen Fleischhacker und der schlagfertigen Köchin als amüsante josephinische Alltagsszene. Wie lange derartige Typen sich in der Wiener Volkskomik hielten, belegt nicht zuletzt die Figur des jähzornigen Viktualienhändlers Vinzenz Chramosta in Karl Kraus' Die letzten Tage der Menschheit (1922).

Fleischinacker. Grüß di Gott! Schwarzi. -

Köchin. Schön guten Morgen, Herr Hansmichel. -

FleischHACKer. Was willst d'haben?

Köchin. Ein saubers Schlegerl hätt ich gern; aber etwan wieder eins, daß schon ein halbs Jahr aufm Eis g'legen ist? D'gnädige Frau hat mich weiter gestern nicht ausgemacht.

Fleischhacker. Dein gnädi Frau ist nicht gscheid. Waßt d'was? Sag deiner Frau, sie soll mirs ehender allzeit sagen lassen, was für ein Fleisch als s'will. I laß ihr ein Maler kommen, der ihr eins malt - oder ein Pudel, der ihr eins - -

Köchin. So mach der Herr Hansmichel nur, daß ich fortkomm, sonst krieg ich wieder ein Greinets.

FleischHACKer. Da! langt einen Schlegel herab Nit wahr das g'rath dir?

Köchin. Geht wohl mit.

FleisCHHACKer. Wart du schlagt sie auf den Hintern.

KöchIN. Nicht so keck Herr Hansmichel! Und was soll's kosten?

FleischHACKer. Kein Kreizer rechter als $1 / 2$ Thaler.

Köchin. Izt geh der Herr! dies Schlegerl da? -

FLeIsCHHACKer. Es ihr aus der Hand reissend Wenn's eng nicht recht ist, so laßts bleiben. -

157 Richter, Wienerischer Musterkarte 1785, I, S. 33. 
KöchIN. Mehr als ein halben Gulden darf ich nicht geben.

FleisChHACKer. Mag d'Jungfer kein Kaß?

Köchin. Um 12 Groschen auch nit?

FleischHACKer. Izt laß di ham geignen. -

Köchin. Nu! So behüt den Herrn Gott! Herr Hansmichel.

FleischHACKer. Geh nur dein schwabischen Gang. -

Es thut mir leid, es offenherzig sagen zu müssen, daß nicht etwan blos die Knechte, sondern wohl auch ein guter Theil der Fleischhackermeister selbst diese grobe pöbelhafte Sprache mit ihren Kundschaften führen. Schon an sich ist es unanständig, und gesezwidrig, Jemandem Injurien zu sagen; aber unverzeihlich ist es, solche Schimpfwörter gegen Leute auszustossen, von denen man lebt.

Wem es etwan auffallen sollte, daß die Magd nicht ganz den Wienerdialeckt rede, der beliebe sich zu erinnern, daß sich die Aussprache der Köchinen, seitdem galante Herrn und wohl auch alte hinkende Kavaliers mit ihnen zu Markt und zur Fleischbank gehen, verfeinert und verbessert habe. ${ }^{158}$

saubers] hübsches, schönes hat mich ... nicht ausgemacht] jem. ausmachen: be-/ausschimpfen (die Rede der Köchin ist hier ironisch zu verstehen) Greinets] Verweis, Schelte das g'rath dir] (geraten: gut ausfallen) das passt dir 12 Groschen] 12 Groschen = 0,6 Gulden (die Köchin versucht also zu handeln und bietet mehr als einen halben Gulden; der Fleischhacker, der einen halben Taler, also einen Gulden verlangt hat, weist sie aber zurück und schickt sie heim) Izt laß di ham geignen] verschwinde Geh nur dein schwabischen Gang] mach dich davon (die Schwaben galten als die ängstlichsten Deutschen, der schwäbische Gang ist also der Rückzug, das Davonlaufen)

Wie sprachbewusst Richter als würdiger Vorläufer von Kraus seine Figuren gestaltet, zeigt sich nicht zuletzt in seinen nachgestellten Kommentaren. Auch beim folgenden Muster eines politischen Kannengiessers. Super fein, das eine „Kafehausscene“ nachstellt, beteuert er, dass er das Gespräch „bis auf unbedeutende Zusäze, so niedergeschrieben habe, wie [er] es mit eignen Ohren anhörte.“:

Ein langer Tisch, an dessen Spitze ein bemittelter und wohl ausgefütterter Bürger das Präsidium führt. Er hat sich bereits der meisten politischen Zeitungen bemächtiget. Der rechte Ellenbogen liegt auf dem Erlanger, mit dem Linken hält er die Frankfurter gefangen; die Wiener-Zeitung hat er in der Hand, und den Regenspurger (Sicherheits halber) unter dem Hintern.

Ein Kaminfeger. Nu! wird noch Krieg?

Der Präsident. Er ist schon so viel als richtig. wieder fortlesend

Der Kafesieder. Glaub nicht, daß's zu was kommt. Das Ding daurt mir schon gar z'lang; denn schaun die Herrn, ich hab das in meinem Kafehaus g'merkt. Da hat's schon oft Handel gebn; wenn s' aber z'lang mit einander gwörtlt haben, so ist's nie zum Raufen kommen.

EIN SCHNeIder. Nun ja - itzt vergleicht der eine Rauferey mit dem Krieg! glaubt der Herr g'wis d'Monarchen zanken wegen einer Partie Billard oder Brandln?

Ein Perǘckenmacher. Ich wett halt auch noch immer drauf, daß wir ein Krieg kriegn - man wird gwis d'Soldaten umsonst so ein weiten Weg gar in's Niederland hinein gehen lassen? Das hieß ja d'Leut g'foppt. -

Der Kaminfeger. Das heißt wohl in Tag hinein g'redt. Wenn der Herr sein Jung in d'Vorstadt Geld einkassiren schickt, und er bringt keins nach Haus, ist er deswegen g'foppt worden? Muß der Diener nicht hingehn; wo ihn sein Herr hinschickt - und sind d'Soldaten was anders als die Diener vom Staat?

158 Richter, Wienerische Musterkarte 1785, II, S. 21-24. 
Perückenmacher. Ich hab halt doch schon einige Soldaten murrn g'hört -

Der Kaminfeger. Schlimm gnug! Das sind aber g'wis keine brave Soldaten g'wesen. Warum giebt man ihnen in Friedenszeiten z'essen, als damit s' im Krieg hingehn, wo man s' hinschickt - ?

Der Kafepräsident. Nu! zweifeln d'Herrn noch ob Krieg wird? Da hörn s' einmal was d'Zeitungen sagn - Der Kaiser von Marocko hat den Holländern 10000. Mann Hilfsvölker versprochen. -

Perückenmacher. So! das ist der Dank, daß wir seinem Gsandten überall nachgloffen sind, wie er z'Wien war, und daß wir ihn an d'Kafehäuser und d'Bierhäuser angmahlt haben?

Der Schneider. Liegt's Marokanerland weit weg von Holländern?

Die Kafehausräthe sehn auf diese Frage einander an, und es folgt eine Pause. Der Präsident faßt sich endlich, und sagt mit wichtiger Staatsmine. Wenn ich mein Landkartn da hätt, so wollt' ich den Herrn gleich zeign, wo Maroko liegt; denn auf meiner Landkartn stehn alle Städt. Es laßt sich aber auch ohne Landkartn errathen. - Was haben wohl d'Marokaner für ein Religion? Blickt die übrigen Räthe mit triumphirenden Lächeln an.

Kaminfeger. Ich glaub halt die Türkische. -

Schneider. Was! Türken sollen s' seyn, und tragn ein weisse Kuttn, wie unsre Karmeliter?

Kafesieder. Freylich sind s' Türken. Sie bethen ja den Mondschein an. ${ }^{159}$

Perückenmacher. Und habn denn d'Herrn nicht g'sehn, daß s' auch ihren Rosenkranz bethen, wie d'Türken?

PRÄSIDENT. So wärn wir also in Clari, und därfen uns weiter kein Kopf z'brechen; denn wenn d'Marokaner die türkische Religion habn, so können s' ja auch nirgends anders liegn, als in der Türkey.

Kaminfeger. Bravo! es leb unser Präsident. -

KafEsieder. Aber wenn s' in der Türkey liegen, so werden s' den Holländern nicht viel nutzen. -

PRÄsIDENT. Warum denn nicht? Sie därfen ja nur zum Kaiser von Konstantinopel stossen, und ins Ungerland einfallen.

SCHNEIDER. Auch wahr. -

Perückenmacher. Meinetwegen mögen s' thun, was s' wollen, wenn nur Krieg wird. Da kommt doch wieder Geld unter d'Leut. -

Kaminfeger. zum Perückenmacher auf den Herrn wird viel springen davon. -

KAFESIEDER. seinen Witz vorher belachend Warum denn nicht? der Kaiser laßt ja seinen Soldaten jetzt lauter Perücken machen, damit s' nicht friert, wenn s' eine Winterkampagnie machen solln. - alle lachen

SCHNEIDER. Spaß à part - Ich hätt' den guten Magn nicht. Ich hätt schon längst drein g’schlagn couti-couti. ${ }^{160}$

KAMINFEgER. In einem Tone, woraus ich schloß, daß er seine Mitkollegen vielleicht blos zum besten habe Ich wüßt schon, was ich thät, wenn ich Kaiser wär. Ich würd' einen kurzen Prozeß mit den Holländern machen; und ließ s' austränken, wie d'Erdmäuß. -

SCHNEIDER. Ja! geht denn das Ding an?

KAMINFeger. Warum denn nicht? Man darf ja nur ein Loch durch d'Mauer machen, die ein holländischer Baumeister dem Meer vor d'Nasn hinbaut hat, so wärn sie auf einmal weg. Vor ein paar Jahrn ist 's g'schehn, da hat d'Maur von freyen Stucken ein Loch kriegt, und da sind viele Millionen ersoffen. -

PRÄSIDENT. Richtig! aber seit der Zeit habn s' ein Wacht hing'stellt. -

159 [Fußnote im Original:] Der katholische Pöbel glaubt noch immer, daß die Türken den Mond anbethen, da sie doch, so wie jeder aufgeklärte Katholik, einen einigen Gott, als den Schöpfer und Erhalter aller Wesen verehren.

160 [Fußnote im Original:] Coute qu'il coute. 
KAFESIEDER. Nein! das wär doch zu stark, alle miteinander zu ersaufen; denn wenn s' gleich Holländer sind, so bleiben s' doch Menschen - und dann wär ja Schad um ihre schön Dukaten. ${ }^{161}$

gwörtlt] wörteln: spitze Reden führen, in einen Wortwechsel geraten Brandln] um Geld gespieltes Kartenspiel ihren Rosenkranz bethen] Anspielung auf die muslimische Gebetskette, die durch ihr ähnliches Aussehen vom Perückenmacher mit dem Rosenkranz verwechselt wird à part] (franz.) beiseite couti-couti] (franz.) coute qu'il coute: koste es was es wolle da hat d'Maur von freyen Stucken ein Loch kriegt] gemeint ist wohl die sog. ,Weihnachtsflut' von 1717, die schwerste bis dahin bekannte Sturmflut an der Nordseeküste mit mehr als 11000 Toten

Der hier durchschimmernde aufklärerische Humanismus Richters äußert sich nicht zuletzt in der Frage nach der Religion der Marokkaner, wie sie in der Runde besprochen wird: Der naiven Behauptung, diese beteten den Mond an, hält Richter in der Fußnote die aufgeklärte Idee der prinzipiellen Gleichwertigkeit der muslimischen und der christlichen Religion entgegen.

Sind die Kommentare der Wienerischen Musterkarte noch tatsächliche Erläuterungen, werden sie in Richters erfolgreichstem literarischem Projekt als unterbemittelte Herausgeberfiktion selbst Teil der Komisierungsstrategie. Die Briefe eines Eipeldauers an seinen Herrn Vetter in Kakran, über d'Wienstadt sind ursprünglich eine 1785 erschienene Broschüre aus 10 ,Briefen', die in Anlehnung an die beliebte Form des Briefromans die naiven Erlebnisberichte eines Eipeldauer Bauern aus der unweit gelegenen Residenzstadt Wien sammelt. Die Handlung folgt, in satirischer Komprimierung, dem Schema der Lettres persanes Montesquieus, bei dem der naiv-erstaunte Blick des Fremdlings die Schwächen der Gesellschaft schonungslos bloßlegt. Die Heimat des gar nicht so ,edlen Wilden' ist im Fall des Eipeldauers freilich nicht weit entfernt: Eipeldau, damals ein für seine Gänsezucht bekanntes Bauerndorf, liegt heute im 21. Wiener Bezirk Floridsdorf. Einmal möchte der Eipeldauer Tölpel die Stadt in der Faschingszeit erleben. Von seinen großspurig auftretenden Wiener Verwandten wird er mit Pomp auf-, doch ebenso rasch beim anschließenden Kartenspiel ausgenommen. Auch die folgenden Einführungen in den Brennpunkten der städtischen Unterhaltung leeren seine Taschen, sodass er seinen Verwandten in Kagran um Geld schreiben muss. Am Aschermittwoch geht es wieder zurück nach Hause. Thematisch finden sich Parallelen zu den Musterkarten, doch fordert die Beschreibung über den naiven Reflektor - der Eipeldauer-Bauer war eine typische Wiener Straßenfigur - die vis comica des Lesepublikums stärker heraus, musste es sich doch die schrägen Beobachtungen zurechtdeuten.

\section{Sechster Brief.}

Ich lauf noch immer mit dem Wiener-Herr-Vetter in der Stadt herum; denn d'Frau Mahm hat mir ja bey meiner Abreis gsagt, daß ein junger Mensch, der in d'Länder geht, überall d' Augen habn muß.

Aber ich könnt gar nicht fertig werden, wenn ich dem Herrn Vettern alles beschreibn wollt, was ich schöns gsehn hab.

Nichts gfallt mir aber besser, als d' Bubn, die d'Lieder ausschrein. Wenn dem Herr Vetter wer was thut, so laßt der Herr Vetter nur gschwind ein Liedl auf ihn machen, das schrein dann d'Bubn aus, und des Herrn Vettern sein Feind wird in der ganzen Wienstadt ausglacht. Der Herr Vetter 
wird vielleicht meinen, daß aus den Bubn mit der Zeit Lumppn und Tagdieb werden? Umkehrt Herr Pfarrer! es werden lauter Soldatn draus. ${ }^{*}$ )

Die Gfangnen, die d'Gassn kehrn, habn mir auch gfallen. Bin ihnen schon oft z'fallen gangn. S'haben recht lustige Einfälle, und mit ihrn Kettn machn s' eine Musik, wie ein Glocknspiel. Wenn s' aber Krampen und Schaufeln in der Hand habn ${ }^{* *}$ ) geh ich ihnen nicht auf d' Haut; s' könnten einen doch damit zum Kopf schlagen.

Gestern hat mich der Herr Vetter auf den Lichtensteg gführt, wo d'Fleischbänk fast alle beyeinander sind. Ich hätts mein Lebtag nicht glaubt, daß d’Wiener so ein guts Gmüth hätten. Aber da hab ich's mit Augn gsehn. Habn ihnen d' Fleischhacker Grobheiten gsagt, daß mir d' Galle aufgestiegen ist. Da habn sich aber d'Wiener Fraun und ihre Menscher nichts draus gmacht, sondern habn ihr Geld hinglegt, und habn 's schlechte Fleisch und d'Grobheiten eingsteckt. ${ }^{* * *}$

*) Der weiß's recht! man hat's gwis nicht probirt, und hat wolln Soldaten aus ihnen machen? Unter hunderten ist nicht einer was nutz dazu.

$\left.{ }^{*}\right)$ Mit was solln s' dann 's Eis aufhacken? Gwis mit den Nägeln? Wenn d'Eipeldauer nur nicht von Dingen redeten, die s' nicht verstehn.

***) Nun da muß ich ihm wieder Recht gebn. Aber kein Wunder ist 's nicht, wenn d' Fleischhacker toll werden. D'Menscher wollen alle gutes Fleisch habn, und wo solln dann d'Fleischhacker 's schlechte Fleisch hinthun? ${ }^{162}$

Mahm] weibliche Verwandte die d'Gassn kehrn] Strafarbeit der Zuchthäusler Fleischbänk] Fleischverkaufsstände Menscher] (Dienst-)Mädchen

Die witzige Schreibsprache des Eipeldauers ist freilich keine Transkription des im Marchfeld gebräuchlichen Basisdialekts; es ist auch nicht der Stadtdialekt der damaligen Zeit. Richter erfindet sich für seine Briefe einen Kunstdialekt, der sich stark am Wienerischen orientiert, doch auch dem nicht des Idioms Mächtigen verständlich sein will. ${ }^{163}$ Als authentische Sprachform kann dieser Jargon, der etwa aus Verständnisgründen die Perfektpartizipia standardnah bildet, nicht dienen. Doch wusste der autochthone Leser, wie die Mündlichkeitssignale umzusetzen waren; dem dialektfernen Publikum aber gab es zumindest eine ungefähre Vorstellung des Klangbilds.

Der Erfolg der Broschüre inspirierte Richter zu einer Fortsetzung 1787, in der der Bauer für einen Prozess in die Hauptstadt kommt, und schließlich zur Weiterentwicklung zu einem Periodikum ab Dezember 1792, in dem die Erlebnisse des Eipeldauers als unfähiger Wiener Beamter im Mittelpunkt stehen. Die Periodizität der Zeitschrift ist nicht konstant; bis 1797 erscheinen pro Jahr 5-8 Hefte, dann bricht die Serie ab, um 1799 mit dem Wiederaufgelebten Eipeldauer neu einzusetzen. ${ }^{164} 1802$ übergibt Richter dem (vermeintlichen) Erstgeborenen des alternden Beamten die Feder, einem verzärtelten Schnösel. Nach dem Tod des Autors 1811 übernimmt Franz Xaver Gewey die Herausgabe des Periodikums für acht Jahre, dann geht die Redaktion an Adolf Bäuerle, der das abgelebte satirische Blatt 1821 einstellt. An die Popularität und Unterhaltsamkeit

162 Briefe eines Eipeldauers an seinen Herrn Vetter in Kakran, über d'Wienstadt. Aufgefangen und mit Noten herausgegeben von einem Wiener. Erstes Heft. Vierte Auflage. Wien, 1785, S. 29-31.

163 Vgl. Eugen von Paunel: Einleitung. In: Eugen von Paunel (Hg.): Die Eipeldauer Briefe 1785-1797. In Auswahl hg., eingeleitet und mit Anmerkungen versehen. 1. Band. München: Müller 1918, S. XI-CXII, hier LXI.

164 Vgl. ebda., S. L. - Kauffmann, Es ist nur ein Wien, S. $253 f f$. 
der ersten Jahrgänge mit dem originalen Eipeldauer reichten die späten Abkömmlinge längst nicht heran. Dennoch: Die Berichte des trotteligen Flaneurs über die Ereignisse und Neuigkeiten der Stadt sind auch heute noch eine unerschöpfliche Fundgrube für das Alltagsleben und historische Geschehen in der Habsburgermonarchie. Dass die implizite Kritik an den sozialen Zuständen im Verlauf der Jahre zunehmend zahnlos wurde, war freilich kein Zufall. Richter, der als begeisterter, scharfzüngiger Anhänger der Aufklärung begonnen und seinen Witz dazu genutzt hatte, verkrustete Strukturen und reaktionäre Geisteshaltungen anzuprangern, war unter Franz II. zum spießigen Propagator der Regierungspolitik und Zuträger der Polizei geworden. Viele andere Möglichkeiten hatte er freilich nicht, denn ohne Arrangement mit der Zensur hätte er seine Zeitschrift nie veröffentlichen können. Ab 1802 wird dem Autor aus geheimen ,Polizeigeldern' eine monatliche Zuwendung von 30 Gulden zugesprochen, denn - so Polizeiminister von Pergen -:

Der Bittsteller hat wirklich Jahre durch in seinen Eipeldauerbriefen [...] auf die Stimmung des Volkes zu wirken getrachtet, und man sich selbst von der Seite der Polizeihofstelle seiner Feder bedienet, um durch dergleichen [...] Flugschriften den Gesinnungen des Staats entsprechende Richtung zu geben. ${ }^{165}$

Auch künstlerisch waren die Eipeldauer-Briefe ausgesprochen einflussreich und so mancher Kollege versuchte, am Erfolg der Figur mitzunaschen. ${ }^{166}$ Bereits als Reaktion auf den Erfolg des ersten Hefts gab ein Autor unter dem Pseudonym Peter Plausch das wenig originelle, aber durchaus witzige ,Trittbrettwerk' Briefe eines Kakraners an seinen Herrn Vetter in Eipeldau über d'Wienerstadt (1785) heraus. Hier besucht nun auch der Vetter aus Kakran die Wienerstadt, wird ähnlich wie der Eipeldauer betrogen, macht seine naiv-entlarvenden Kommentare zum Gesellschaftsleben, bevor er schließlich im achten und letzten Brief seine Rückkehr ins Dorf ankündigt. Manche seiner Erlebenisse decken sich mit denen seines literarischen Vorgängers, manche bringen auch Neues wie sein Bericht aus dem Prater mit Ringelspiel, Musik und Schaustellereien:

Im Prater sind die Leut' nicht so aufgepuzt, wie im Augarten, da sinds viel kommoder, sie schrein, ziehn sich bis aufs Hemd aus, spielen, rauchen Toback, und thun völlig, als wenn's da z'Haus wären.

Die Wiener müssen erschrekliche Liebhaber von Reiten seyn, denn sie sind nicht zufrieden, daß sie überall auf lebendigen Pferden r'um reiten, im Prater reutens sogar auf hölzernen Pferdeln, wie unsers Herrn Verwalter sein kleiner Stepherl; und das die grösten und vornehmsten Leute. Da habns dabei einen Spies in der Hand, da stossen einige auf Türkenköpf, andere fahrn damit mitten in ein kleines Ringel, und sind aufs Treffen abgericht aus der Kunst.

Musik giebts im Prater allerlei, und das sind wunderbare Herrn die Musikanten, sie fragen gar nicht, ob man ihre Musik will oder nicht, ${ }^{*}$ ) und wenn's fertig sind, so gehn's mit dem Teller r'um, und da muß man ihnen was geben, wenn einem auch d'Musik nicht gfallen hat, sonst brummen's, oder sagen einem gar Grobheiten ins Gsicht.

Einer hat mich recht erwischt; Er fragt mich, ob ich wissen will, wie schwer ich bin, ob ich mich will wägen lassen: warum nicht, sag' ich, kanns probirn, und dafür hab ich ihm hernach zahln

165 Pisk, Joseph Richter, S. 37f.

166 Eine erstmalige Übersicht gibt Paunel in seiner Einleitung. 
müssen; das ist mir just so vorgekommen, wie, wenn man d'Schweine wägn läßt, wo man auch für jedes Pfund etwas zahln muß.

*) Das ist sehr vernünftig, weil sonst Niemand ihre elende Musik verlangen würde. ${ }^{167}$

Nach dem Erfolgsmodell der Eipeldauer-Briefe gestrickt sind auch die Briefe eines Przelautschers an seinen Herrn Schwager in Przelautsch über seinen Aufenthalt in Prag (1795). Hier ist es ein Bauerntölpel aus Przelautsch (Přelouč bei Pardubice), der frischverheiratet mit seiner Frau nach Prag kommt, um Kanzlist zu werden, und in seinen naiv-dümmlichen Berichten nach Hause die Prager Gesellschaft, die Modeneuigkeiten, das hiesige Beamtentum, die erotischen Eskapaden seiner Frau und das Zeitgeschehen während der Franzosenkriege komisch gebrochen skizziert. Vom Maskenball etwa berichtet er nach Hause:

Auf d'lezt is mir doch höllisch die Zeit lang worden, und da hab ich meine Frau überal g'sucht, hab sie aber nirgends finden können; bis sie auf emal mit en jungen Herrn zum Vorzimmer, wo ich g'sessen bin, herein spazirt kummt. Da hab ich si gleich g'fragt, wo sie denn war und warum sie so roth is; da hat mir der junge Herr g'antwort, daß er nur is mit ihr im Tualetzimmer g'wesen, weil sie sich beim Tanzen hat e Bisl zerrauft g'habt; da hab ich mich halt bei ihm schön bedankt und er hat ihr die Hand geküßt und drauf sein mer hernach nach Haus gangen. Wir wärn freilich gern g'fahrn, aber denkens nur Herr Schwager 2 fl. haben die Spitzbuben die Fiaker bis auf die Klanseiten verlangt. Zum Glück haben mer so en Bubn mit einer Latern erwischt, und der hat uns um en Siebner ham g'leucht. Aber ang'schaut haben uns die Leut auf der Gassen, daß zwa so schöne Maschkern zu Fuß gehn, ich hab mir aber niks draus g’macht, meine Frau aber hat immer mit mir gezankt und hats bereut daß s'es nit ang'nommen hat, wie sie hat der junge Herr wollen nach Haus fahren lassen, und auch beim Schlafengehn hat sie mir noch immer was von den jungen Herrn vorgeplaudert, daß er hörich so artig, höflich und galant wär, und sie kann ihm auch noch jetzt nit vergessen.

fl.] (Abk. für) Gulden Klanseiten] Kleinseite: Prager Stadtteil Siebner] Siebenkreuzer-Stück ham] heim zwa] zwei Maschkern] Masken, kostümierte Personen

Die Broschüre ist ein rares Beispiel dafür, dass auch in Prag noch Ende des 18. Jahrhunderts eine dialektal gefärbte Umgangssprache gesprochen und rezipiert wurde. Sprachkritischer Purismus und eine bewusste Abwendung vom österreichischen Sprachgebrauch ließen hier zwar in der gebildeten Oberschicht ein prononciertes Prager Deutsch entstehen, das wegen seiner weitgehend dialektfreien Aussprache als reinste deutsche Sprechweise in der Habsburgermonarchie galt. ${ }^{168}$ Dieses gehobene Prager Deutsch wurde allerdings nur von einer kleinen Bevölkerungsschicht gesprochen und war niemals mit dem allgemeinen, volkstümlichen Prager Deutsch identisch. Die Sprache der deutschen Kleinbürger war das Kleinseitner Deutsch, ein mit tschechischer Phraseologie infiltrierter vulgärösterreichischer Mischjargon. ${ }^{169}$ Der Autor des Werkchens ist unge-

167 Briefe eines Kakraners an seinen Herrn Vetter in Eipeldau über d'Wienerstadt. Aufgefangen, und mit Noten herausgegeben von Peter Plausch, einem Wiener. 1785, S. 25-27.

168 Vgl. Christian Neuhuber/Lenka Vodrážková: Mundartenliteratur. In: Peter Becher [u. a.] (Hg.): Prager deutsche Literatur im regionalen Kontext. Ein Handbuch. Stuttgart: Metzler 2017, S. 398-403, hier 398.

169 Vgl. Pavel Trost: Das späte Prager Deutsch. In: Acta Universitatis Carolinae. Germanistica Pragensia II (1962), S. 31-39. 
nannt; etliche Indizien aber deuten darauf hin, dass der Publizist und Theatermann Karl Franz Guolfinger, Ritter von Steinsberg (1757-1806) hinter dem Werk stehen könnte. Noch im selben Jahr wird auch sein ausgesprochen erfolgreiches Singspiel Hanns Klachel von Przelautsch (Musik von František Vincenc Tuček) in Prag uraufgeführt. Weitere Singspiele, die den dümmlichen böhmischen Bauern in den Mittelpunkt setzten, folgten.

Auch in Wien griff der ständig in finanziellen Schwierigkeiten steckende erfahrene Bühnenautor Ferdinand Eberl (1762-1805) den Bauer-in-der-Stadt-Stoff auf und versuchte erst gar nicht, die Anleihen zu kaschieren. Sein Der Vetter von Eipeldau bey seiner Frau Mahm in Wien (1796), der erste Teil einer Trilogie um den reichen Eipeldauer Bauern Lorenz, dem einzigen Dialektsprecher dieser Stücke, ist eine simple, aber effektvoll gebaute Liebes- und Verwicklungskomödie. Lorenz, der seine Tochter Röschen zu seiner Verwandten, der über ihre Verhältnisse lebenden, borniert-blasierten ,Mahm', in die Kost gegeben hat, findet bei seinem Besuch in Wien schließlich den ersehnten Sohn wieder und ermöglicht seinen Kindern ihr jeweiliges Liebesglück. Der Erfolg des Sujets inspirierte u. a. auch Emanuel Schikaneder zu seinem immens populären Tyroler Wastel (1796) (vgl. Kap. 5). Beide Werke wiederum wurden für die Briefe des Tiroler Wastels an den Schulmeister in Kaduschl (1800), von einem Fixeldauer' ausgeschlachtet; da das derbe Tirolerisch geschickt wiedergegeben ist, scheinen Richter und Schikaneder als Autoren des Spin-off eher auszuscheiden:

Luschti lebendi! Der Tirolerwastl ischt ze Wean! Das ischt a Stadtele so groß als unser Landele! Und in dem Stadtele huken viel tausend Millionen Leut aufeinonda. Und der Stöffensthurim i[]scht um gute zween Köpf höcher als der Thurim an unsrer Johanneskapelln. - Koz Velten! Schulmaster, du host an Schädel wie a Woßerschof, aber da stund dir der Verstand still! Wie ma ins Stadele san einigsprungen, do hon ma g'jugazt, und das klani Menschli, die Seffeln ischt für Wohlthat so roth worden, als wenn ihr aner a Schmozli gschnipft hätt.'. ${ }^{170}$

Koz Velten] Fluch (Velten Kurzform für Valentin, oft auch Euphemismus für Teufel) Woßerschof] Wasserschaff, wannenförmiger Behälter hon ma g'jugazt] haben wir gejuchzt Seffeln] Diminutiv für Josepha Schmozli] Kuss gschnipft] gestohlen

Selbst der damals berühmteste ,regelmäßige` Dramatiker des Habsburgerreichs, Cornelius Hermann von Ayrenhoff (1733-1819), der sonst keinerlei Affinität zur ästhetischen Überformung regiolektaler Sprechweisen zeigte, griff 1795 bei einer Polemik gegen das in Wien äußerst populäre Balletttheater Salvatore und Maria Viganòs zu Richters Kunstfigur:

Aber gnug schon! d'Frau Mahm muß das Alles mit ihren eigenen Augen und Ohren beurtheilen, und ich weiß gewiß, Sie wird hernach nicht mehr so sehr für der Frau Godel ihr Krippelspiel eing'nommen bleiben, obwohl ich der Frau Mahm eing'stehen will, daß die Pantomimi der klein Mandeln bey der Frau Godel verständlicher ist, weil doch dort bey jeder Scen den Leuten laut g'sagt wird, was d'Mandeln deuten und vorstellen. Uebrigens muß sich d'Frau Mahm nicht wundern, daß ich itzt ein so passionirter Viganoist bin, was ich doch bisher nicht war.

170 Briefe des Tiroler Wastels an den Schulmeister in Kadurschl, erstohlen und mit Noten ans Licht gestellt von einem Fixeldauer. Wien: Hohenleitter 1800, S. [3]. 
Nach und nach wird man halt g'scheiter, und 's giebt doch hier z'Wien so viel feine Kenner der schönen Künste, daß man mit Zeit und Fleiß was lernen muß, wenn man der ungelehrigste Eselskopf ist. ${ }^{171}$

Mahm] weibliche Verwandte Godel] Taufpatin klein Mandeln] Marionetten

Sprachlich weit weniger versiert ist eine andere Theaterpolemik „,im Geschmack des lustigen Eipeldauers" 172 eines anonymen Autors: Das Sendschreiben von Hannswurst aus dem Reich der Todten, an seine würdigen Nachfolger bey den Wiener-Vorstädt-Theatern (1795) geißelt die angeblich indiskutablen Zustände an den Wiener Vorstadttheatern, deren Schauspieler allesamt legitime Nachfolger des Hanswursts seien. Weniger dialektal akzentuiert als Richters Original, aber doch deutlich regionalsprachlich sind auch die Briefe eines Bürgers in Laibach an seinen Gvatter in Laaß, die einen naiv-opportunistischen Bericht über den Einmarsch und Aufenthalt französischer Truppen in Krain (28. März - 8. Mai 1797) während der Koalitionskriege geben.

171 Cornelius von Ayrenhoff: Sämmtliche Werke. Hg. von Joseph Friedrich Freyherrn von Retzer. 3. neu verb. und vermehrte Auflage. 5. Bd. Wien: Schmidt 1814, S. 332 f.

172 Sendschreiben von Hannswurst aus dem Reich der Todten, an seine würdigen Nachfolger bey den Wiener-Vorstädt-Theatern im Geschmack des lustigen Eipeldauers abgefaßt. Wien, 1795. 


\section{FREMDES UND EIGENES}

Stärker als dem Standard ist dem Dialekt die Differenzierung zwischen ,fremd' und ,eigen' inhärent, ist ihm doch regionale Zuordnung und damit eine potentielle, wenn auch variabel ansetzbare Grenze konstitutiv eingeschrieben. Das zeigt sich nicht zuletzt bei den verschiedenen Definitionsversuchen. Denn im Gegensatz zur dezidiert überregionalen Schriftsprache, einer ,Kunstsprache', die auf einen kommunikativen Ausgleich abzielt, ist die Beschreibung eines Dialekts immer nur in der Distanz zum Nicht-Dialektalen möglich. ${ }^{1}$ Die identitätsstiftende Funktion des Dialektalen operiert dementsprechend wesentlich mit verschiedenen Arten der Fremderfahrung, in der man sich wiederum des Eigenen versichert. ${ }^{2}$ So kann es nicht wundern, dass Dialektliteratur, die rasch mit einer selbstgewählten Beschränkung auf das Eigene, das ,Eigentliche‘ assoziiert wird, auch ein nicht zu unterschätzendes Sensorium für das Andere zeigt, das vorrangig im Fremden als nicht zur eigenen Gruppe Zugehörigen in den Blick rückt.

Thematisch bzw. funktional lassen sich bei der Auseinandersetzung mit Fremdem in bairisch-österreichischen Texten vor 1800 drei - zuweilen auch interferierende - Perspektiven differenzieren: 1. die abgrenzende Fremdsetzung, 2. die Verständigung über das Eigene und 3. die Dichotomienaufhebung. In Texten der ersten Kategorie werden Grenzen zwischen Eigenem und Fremdem gezogen, wobei mit der Andersartigkeit sowohl positive als auch negative Konnotationen verbunden sein können, aber auch immer wieder eine zunächst neutrale Neugier auf das Kuriose und Exotische. Dominantes Merkmal ist hier die sprachliche Differenz, die sich von der minimalen regiolektalen Abweichung bis hin zur Anderssprachlichkeit erstrecken kann. Zentral ist sowohl auf mündlich-klanglicher wie auch auf graphematischer Ebene immer wieder das Spiel mit dem Verstehen/Nicht-Verstehen und der Dechiffrierlust des Publikums. Dazu kann der Fokus auf das mit der fremdländischen Herkunft verbundene Aussehen kommen, aber auch Waren, Dienstleistungen oder Verhaltensweisen werden gerne ins Blickfeld gerückt. Mit dem Staunen über das unbekannte Andere geht oft das Lachen darüber einher. Je deutlicher mit der Darstellung des Fremden eine Abgrenzung verbunden wird, je mehr also das Fremde ausdrücklich als völlig Anderes inszeniert wird, desto stärker rücken Verhandlungen über das Eigene in den Vordergrund, die sowohl negativ (kritisch) als auch positiv (affirmativ) ausgerichtet sein können: Kritische Aussagen über das Eigene können mit einer tendenziell eher positiven Darstellung des Fremden verbunden sein, die der eigenen Kultur den Spiegel vorhält. Häufiger wird mit der Darstellung des Fremden aber eine positive Bestätigung des Eigenen verbunden, was in bewusst politisch-propagandistischer Weise genutzt werden kann (wie bereits im 2. Kapitel aus-

1 Vgl. Löffler, Dialektologie, S. 8.

2 Vgl. Corinna Albrecht: Fremdheit. In: Alois Wierlacher/Andrea Bogner (Hg.): Handbuch interkulturelle Germanistik. Stuttgart/Weimar: Metzler 2003, S. 232-238, hier 233-235. - Andrea Leskovec: Einführung in die interkulturelle Literaturwissenschaft. Darmstadt: Wissenschaftliche Buchgesellschaft 2011. (Einführung Germanistik). 
führlich zur Sprache kam). In beiden Fällen wird die literarische Darstellung Fremder als Folie und Gegenbild genutzt, über die das Eigene und damit verbundene Ansprüche und Werthaltungen konturiert werden können. Überall dort freilich, wo Fremde zur Bestärkung des Eigenen dienen, wird tendenziell die Grenze zum Eigenen durchlässig. Fremde sind nicht mehr nur Gegenbild, sondern können zum Teil des Eigenen werden das Gemeinsame rückt in den Mittelpunkt. In diesem Zusammenhang spielt die Verwendung dialektaler Formen eine zentrale Rolle, die auf verschiedenen Ebenen Aspekte des Eigenen wie Alltag, soziale Nähe oder auch Regionalität ausdrücken können.

Nur selten in der sprachlichen Differenzierung, sondern über weit verbreitete Vorstellungsbilder modelliert sind die in der Dialektliteratur beliebten österreichischen Volksstereotype, die sowohl im abwertenden als auch im positiven Gebrauch verfestigte Gruppenzuweisungen des öffentlichen Bewusstseins zum Thema haben. Das Fremde ist hier zumeist nur ein dem Eigenen nicht unvertrautes, simplifizierendes Herausstellungsmerkmal, das es abgrenzt vom intendierten Zielpublikum. Nur zu oft tendiert freilich die undifferenzierte Übergeneralisierung in der Unterhaltungsliteratur auch zum wertenden Vorurteil, das negative affektive Einstellungen bestätigt, so etwa beim dumpfen steirischen ,Raufjodel', beim derben Salzburger Sauschneider oder beim versoffenen oberösterreichischen Mostbauern. Besonders viele Stereotype weist interessanterweise Tirol auf, vom heimatliebenden Schützen über Straßenhändler wie den Zillertaler Ölträger oder den ,Lemoni-Mann' bis hin zum ,witzigen` Naturburschen. Eine reiche Quelle für historische Ressentiments sind die untergriffigen Reisebeschreibungsfiktionen, bei denen Ethnophaulismen die einzelnen Stationen markieren und in der Abwertung anderer Volksgruppen das eigene Umfeld implizit positiviert wird. Manche ethnonymischen Zuordnungen sind auch heute noch gängig (z. B. der eifersüchtige Italiener, der eitle Franzose), andere inzwischen obsolet (so etwa der ,vertürkte ${ }^{c}$ Ungar). Sprachgeschichtlich besonders interessant sind ,makkaronische Figuren, in deren mündlich angeeigneter Umgangssprache die Muttersprache durchklingt, wie beim italienischen Tandler, dem kroatischen Soldaten oder dem ungarischen Heubauern. Das Erstaunliche, dass in dieser Literatur Fremde dialektal sprechen, eröffnet einen breiten, disziplinenübergreifenden Fragenhorizont zum rein mündlichen Spracherwerb, zum Verhältnis von Sprachgebrauch und sozialer Stellung, zur Identitätskonstitution und Selbstinszenierung. Nur selten finden sich dagegen explizite Selbstreflexionen, in denen die Konstituenten des eigenen Seins - unironisiert - präsentiert werden. Diesen subjektiveren Ton finden erst spätere Dialektautoren wie Anton Schosser, Franz Stelzhamer oder Karl Adam Kaltenbrunner. 


\section{Nachhaltige und sporadische Volksstereotype}

Regionenbezogene Typisierungen, wie sie auch heute immer wieder gerne vor allem in belustigender, aber etwa auch politisierender Absicht verwendet werden, haben eine lange und selten rühmliche Tradition. ${ }^{3}$ Als erkenntnisökonomische Reduktion komplexer Sachverhalte geben Stereotype ein schematisiertes und schablonisiertes Orientierungsmuster für die Beurteilung einer sozialen Gruppe, wobei vermeintliche oder tatsächliche Eigenarten, Auffälligkeiten oder Schwächen die Basis der pauschalisierenden Typenkonstrukte bilden. ${ }^{4}$ Diese Kategorisierungen zur Erleichterung im Beurteilungsprozess, die über kleinste Lokalgruppen ebenso zu finden sind wie über Großethnien, sind Teil der Sozialisierung und können als Autostereotype mit Selbstzuschreibungen oder als von außen applizierte Heterostereotype wesentlich und nachhaltig das Vorstellungsbild prägen. ${ }^{5}$ Die Beständigkeit dieser Typen ist dabei im Allgemeinen freilich an historische Gegebenheiten und deren Wandel gebunden; nicht alles ist heute noch verständlich und so manches nur mehr in der Rekonstruktion der sozialen, wirtschaftlichen und politischen Umstände nachvollziehbar.

In diesem Sinne finden sich auch in der bairisch-österreichischen Dialektliteratur des 17. und 18. Jahrhunderts zahlreiche Beispiele, in denen Volksstereotype literarisch verarbeitet werden, sei es in harmloser Form für den Belustigungseffekt oder als feindselige, desavouierende Spitze in kriegspropagandistischen und agitatorischen Schriften. Es sind Stilisierungen, an denen sich die „Existenz eines frei verfügbaren Formen- und Formelschatzes" ${ }^{\text { }}$ nachweisen lässt, die in Form literarischer Versatzstücke bzw. Topoi etwa über bestimmte Sitten und Lebensweisen, Aussehen oder Charaktereigenschaften - immer wieder auftauchen und auch anderen Gruppen zugeschrieben werden können. ${ }^{7}$ Welche Heterostereotype im Habsburgerreich en vogue waren, wird aus der bekannten Steirischen Völkertafel ersichtlich, die Anfang des 18. Jahrhunderts mit bildnerischen Darstellungen und tabellarischen Eigenschaftszuschreibungen die wichtigsten

3 Vgl. Franz K. Stanzel: Zur literarischen Imagologie. Eine Einführung. In: Franz K. Stanzel (Hg.): Europäischer Völkerspiegel. Imagologisch-ethnographische Studien zu den Völkertafeln des frühen 18. Jahrhunderts. Unter Mitwirkung von Ingomar Weiler und Waldemar Zacharasiewicz. Heidelberg: Winter 1999, S. 9-39. - Ruth Florack: Bekannte Fremde. Zu Herkunft und Funktion nationaler Stereotype in der Literatur. Tübingen: Niemeyer 2007.

4 Vgl. u. a. Hans Henning Hahn (Hg.): Stereotyp. Identität und Geschichte. Frankfurt a. M.: Lang 2002. Lars-Eric Petersen/Bernd Six: Stereotype, Vorurteile und soziale Diskriminierung. Theorien, Befunde und Interventionen. Weinheim: Beltz 2008.

5 Ein gern gegebenes Beispiel für die Langlebigkeit von Zuschreibungen an Volksgruppen sind die bei Melissantes explizierten Stereotype, vgl. Carsten Berndt: Melissantes: ein Thüringer Polyhistor und seine Berufsbeschreibungen im 18. Jahrhundert. Leben und Wirken des Johann Gottfried Gregorii (1685-1770) als Beitrag zur Geschichte von Geographie, Kartographie, Genealogie, Psychologie, Pädagogik und Berufskunde in Deutschland. 3. Aufl. Bad Langensalza: Rockstuhl 2015, S. 96-103, S. 113.

6 Ingomar Weiler: Ethnographische Typisierungen im antiken und mittelalterlichen Vorfeld der „Völkertafel“. In: Franz K. Stanzel (Hg.): Europäischer Völkerspiegel. Imagologisch-ethnographische Studien zu den Völkertafeln des frühen 18. Jahrhunderts. Unter Mitwirkung von Ingomar Weiler und Waldemar Zacharasiewicz. Heidelberg: Winter 1999, S. 97-118, hier 101.

7 Vgl. ebda., S. 97. 
zehn europäischen Völker charakterisiert (bzw. desavouiert). ${ }^{8}$ Die Funktionalisierung dieser Stereotype für die Kriegspropaganda wurde bereits im zweiten Kapitel am Beispiel der ,türkischen Teufel' und ,französischen Schelme' besprochen. Binnenethnische Vorstellungsbilder, die uns etwa bereits in poetischen Arbeiten zum Stadt-Land-Kontrast begegnet sind, sollen im Folgenden vorgestellt werden. Im Mittelpunkt stehen Typen, die als beispielhafte Exemplare ihrer Gruppe präsentiert werden und durch die Betonung kurioser Trachten, ungewohnter Sprachformen und anderer Verhaltensweisen eine gewisse mit der jeweiligen Region assoziierte Binnenexotik aufweisen. Ob am Beginn dieses Stereotyps eine konkrete Person stand oder einzelne Gruppenmerkmale zu einer prototypischen Figur gebündelt wurden, die das Vorstellungsbild prägte, ist zumeist nicht mehr zu entscheiden. Manche dieser stereotypen Figuren tauchen eher sporadisch auf und verloren sich wieder aus dem kollektiven Gedächtnis, andere dagegen wurden $\mathrm{zu}$ festen Typen, die in unterschiedlichen Kontexten funktionalisiert wurden und noch heute Nachwirkungen zeitigen.

\section{Steirische Raufbolde und Kropfträger}

Einer der ersten Regionalstereotype, die uns in der bairisch-österreichischen Dialektliteratur begegnen, ist der ,Raufjodel'. Die Figur, die im süddeutschen Raum des 18. Jahrhunderts zum Inbegriff des provokanten Radaubruders und Kampfhahns werden sollte, begegnet uns zuerst als Protagonist eines populären Rollenlieds ${ }^{9}$ in der Liedersammlung Ehrliche Gemüths-Erquickung, die in verschiedenen Auflagen aus der 2. Hälfte des 17. Jahrhunderts vorliegt. ${ }^{10}$ Als Steyermarcktischer Rauffjodel sind seine bramarbasierenden Anekdoten dezidiert regional verortet. Völlig aus der Luft gegriffen ist der Typus des gewaltbereiten steirischen Jugendlichen nicht. Bereits 1661 beschreibt Matthias Abele im zweiten Band seiner vielgelesenen Metamorphosis telae iudicariae, oder Seltzame Gerichts-Händel nicht ohne ironischen Unterton die Spezies der selbsternannten

Räiffinger oder frische Buben / welche oft einem zu Gefallen / so ihres Gleichens seyn will/ 1. 2. 3. ja 4. Meilwegs / auf die Täntz oder Hochzeiten / nachgehen / und als dann Gelegenheit suchen / mit dem anderen / vermittels der Fäustwechslung / bekand zu werden.

8 Vgl. Stanzel, Europäischer Völkerspiegel.

9 Vgl. die Editionen bei Paul Nettl: Das Wiener Lied im Zeitalter des Barock. Wien: Passer 1934, S. 3840 und Karl Weinhold: Steyermarckischer Raufjodel. In: Zeitschrift des Vereins für Volkskunde 4 (1894), S. 335f. Eine kürzere Fassung (11 Str.) des Lieds aus einer nicht näher beschriebenen „alten Handschrift“ ist bei Ditfurth, Deutsche Volks- und Gesellschaftslieder, S. 343f. abgedruckt. Zur allgemeinen Einordnung siehe Leopold Schmidt: Volksliedlandschaft Obersteiermark. Die Frühzeit ihrer Kenntnisnahme und Erforschung. Vom ,Rauffjodel' bis zum ,Gams-Urberl'. In: Österreichische Musikzeitschrift 28/9 (1973), S. 371-389.

10 Bislang nachgewiesen sind Drucke von 1677 (o. O.), 1686 (Wien), 1687 (Wien, identisch mit 1686) und 1691 (Klagenfurt); die ersten drei Drucke sind mit einem Notenteil für Singstimme und Basso continuo in Hufnagelnotation mit beweglichen Lettern ausgestattet. Die textuell erheblich erweiterte Klagenfurter Fassung (heute: Bibliothek am Landesmuseum Kärnten, II 9001) ist bislang weitgehend unbeachtet geblieben und wurde nach ihrer Entdeckung 1963 nur kurz vorgestellt, vgl. Oskar Moser: Die ,Ehrliche Gemütserquickung. Eine neuentdeckte Liedersammlung von 1691 aus der Offizin Kleinmayr in Klagenfurt. In: Die Kärntner Landsmannschaft 1963, Nr. 7 (Juli), S. 4f. 
Zwar lokalisiert er den Typus ins „Land ob der Enns“, also nach Oberösterreich, führt jedoch umgehend auch ein Äquivalent für das „Land Steyr“ an und fügt ein exemplarisches Streitgespräch bei:

sonderlich in Ober-Steyr-Marck / tragen dergleichen Fäust-Helden oder Räiffer auf ihren Hüten eine Kranich-Feder / alsdann muß er sich auf zween seiner Gegner wagen / und ihnen / wie sie es nennen / Bescheid thun.

Man findet auch etliche unter den Schiffleuten / welche ihren Unwillen mit dergleichen schlag mich ins Gesicht / wiederum versöhnen; wie mancher sagt: Ich hätte eine Lust / ich wolte dir eine Goschen geben / und dich ins Fraß schlagen; schlag her / du Mauskopff/ (wird der ander sagen) ich geheu mich umb dich keinen Pfifferling / du Hundskrot; alsdann gehet der Handel an / wird aber bald wiederum durch etliche halbe Weinkandeln abgewaschen und vergessen. ${ }^{11}$

Goschen] Ohrfeige Fraß] (verächtlich für) Gesicht geheu] schere, kümmere

Die hier angesprochenen ritualisierten Auseinandersetzungen zur Generierung einer hierarchischen Ordnung der Kampfwilligen legen nahe, dass auch die Figur des Raufjodels nach dem Leben gestaltet war, wenn auch publikumsgerecht zugespitzt und satirisch überzeichnet. Als rustikale Variante des miles gloriosus fantasiert er sich im zweiten Liedteil einen rechtsfreien Raum für seine Gewaltexzesse, bei dem auch Totschlag keine Rolle zu spielen scheint. Die Gegner werden zerhackt und zerhauen, verfaulen im Graben oder werden ,zum Grind' geschlagen; juridische Konsequenzen werden dabei nicht bedacht. Authentisch scheint die niedrige Frustrationstoleranz und Hemmschwelle zu sein: Wie man aus volkskundlichen Berichten weiß, reichte oft schon die kleinste Geste, um als Provokation ausgelegt zu werden.

Durch die konkrete regionale Zuordnung wäre zu vermuten, dass man den steirischen Dorfburschen auch in seiner eigentlichen Sprache zu Wort kommen lässt. In den älteren Drucken aus Ehrliche Gemüths-Erquickung finden sich allerdings nur dialektale Anklänge in der Einschüchterungsrede, insgesamt aber ist das Lied noch am oberdeutschen schriftsprachlichen Standard orientiert:

1

Herzu ihr Buben / hat einer ein Lust

mit mir ein Gang zu wagen/

Da steh ich fertig / da habt ihr mein Brust/

mein Freud ist rauffen / schlagen/

Vor keinen mir graust/

ich hab auch mein Faust/

darff umb kein Menschen fragen. ${ }^{12}$

11 Continuatio Metamorphosis telæ iudiciariæ. Oder: Ander Theil Seltzamer Gerichts-Händel / Und hierauf gleichfalls seltzam erfolgter Aussprüche. Zusammengetragen / und mit lustigen Anmerckungen ausgeführt und gefüttert. Durch Matthiam Abele / von Lilienberg / der hochlöbl. Fruchtbringenden Gesellschafft unwürdigen Mitglieds. Nürnberg / In Verlegung Michael Enters / Im Jahr 1661, S. 90f. Vgl. auch Mautner, Zwey schöne Lustige Lieder, S. 86f.

12 Ehrliche Gemüths-Erquickung / Das ist: Unterschiedliche annehmliche Gesänger / Mit Trostreichen sittlichen Lehren untermischet / Sambt beygesetzten Melodeyen / von neuen gemacht und zusammen getragen. Cum licentia Superiorum. Gedruckt zu Wienn / bey Susanna Christina Cosmerovin / K. K. M. Hoffbuchdruckerin/ 1686, S. 151. 


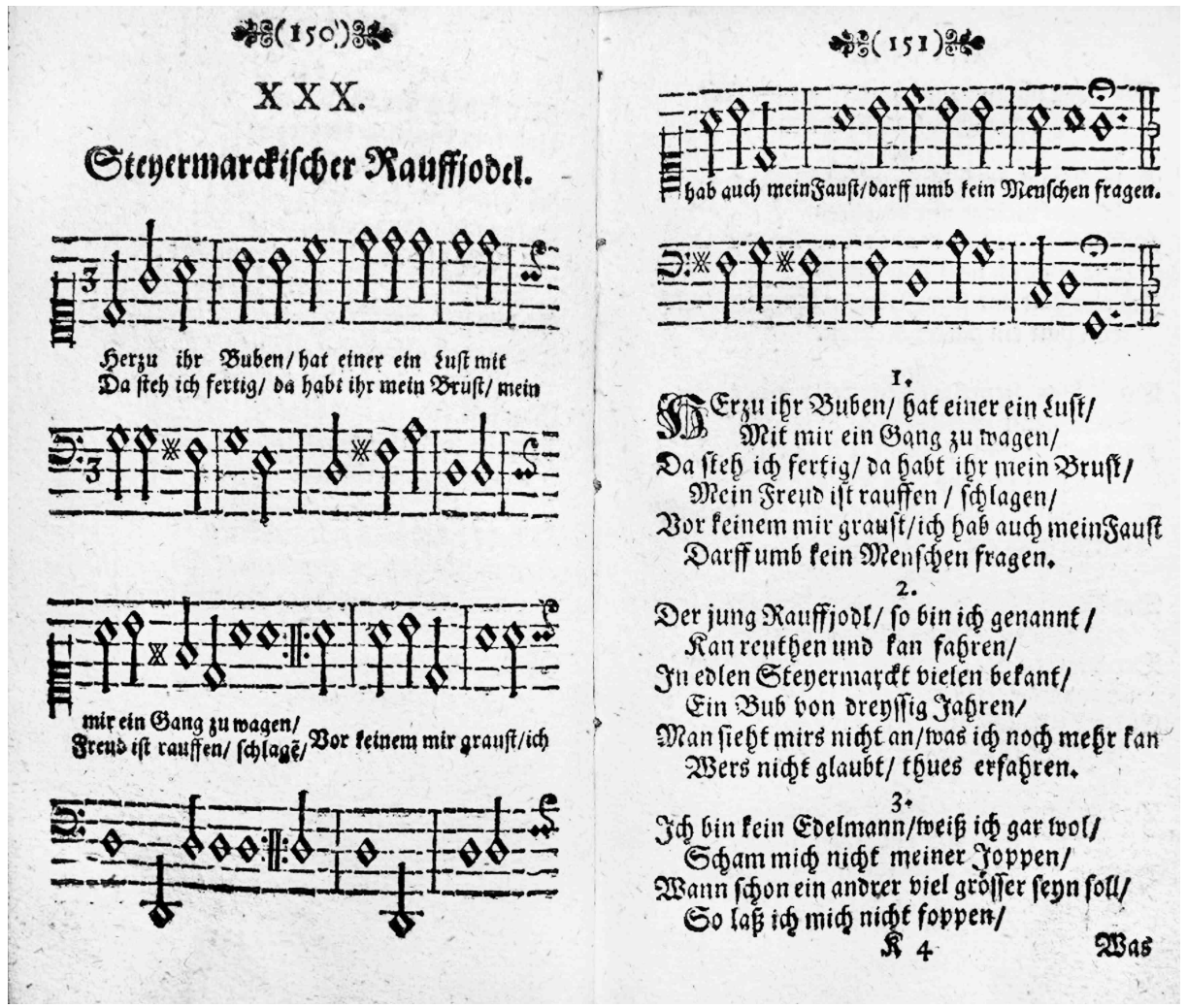

Abb. 26: Auszug aus Ehrliche Gemüths-Erquickung (Wien, 1686, Universitätsbibliothek Graz, SOSA, Rara 1; I, 29572).

Relativ zeitnah allerdings - wenn man den Vermutungen Konrad Mautners folgt wurde das Lied in einer dialektaler gestalteten Fassung auch als Flugschrift veröffentlicht. ${ }^{13} \mathrm{Da}$ die Formulierungen der älteren Fassung ohne wesentliche Veränderungen in die Mundart übertragen werden konnten, werden wohl auch die älteren Versionen stärker dialektal realisiert worden sein, sodass schon dort zur inhaltlichen Typisierung der so markant gestalteten Figur die sprachliche trat. ${ }^{14}$

13 Nach Mautner deutet der detailliert beschriebene, aber nicht abgebildete Holzschnitt auf das 17. Jahrhundert - „es sei denn, daß ein schon vorhanden gewesenes Holzstöckel, wie dies ja so oft geschah, nachträgliche Wiederverwendung fand“ (Zwey schöne Lustige Lieder, S. 77). Eine genauere Überprüfung ist zurzeit nicht möglich, da die Quelle als verschollen angesehen werden muss.

14 Ein weiteres Indiz ist das Incipit einer Flugschriftfassung von 1686, das Hartmann (Historische Volkslieder II, S. 110) folgendermaßen zitiert: „Anbey Der Steurmärckische Rauff-Jodl, Herzu ihr Buben hat einer ein Lust, mit mir ein Gang zu waga, etc.“. Ist das „waga“ kein Druckfehler, würde es wohl auch bedeuten, dass das Lied in dialektaler Form schon früh auch im westmittelbairischen Raum, möglicherweise auch darüber hinaus bekannt war. 
1

HErzu ihr Buemä hat ainä än Lust/ mit mir ein Gang zu wagen: da stehe ich fertig / da habt ihr mein Brust/ Mein Freud ist Rauffn und Schlagen: vor keinen mir graust/ ich hab auch ein Faust/ darff umb kein Menschen fragen. 3

I bin kein Edelmann weiß i gar wol/ scham mi nit meiner Joppen/ wann schon ein andrer vil grösser seyn soll/ so laß i mi nit foppen/

was frag i noch ihm/ so klein als i bin/ will ihm das Maul verschoppen. 5 Du Oxen-Liendl großkopffeta Bue/ Mei Faust wird dir nit schmeckä/ hast du Curäschi so mach di herzu/ was frag i umb dein Steckä/ du Simändl auch/ mit deinem Schmer-Bauch/ solst mir gar nit erschrökä. 7

Der Becken Hänßl hat d'Suppen versaltzt/ thut mir ins Hertz einschneiden/ hat mir in Würths-Hauß unsinnig eingschnaltzt/

er hats noch auf der Kreiden/

hat gjuchzet darzu/

der trutzige Bue/

das mag i gar nit leyden. 9

Auf offner Strassen mach i mi an ihn/ es wird groß Fetzen geben/ ein gute Schmitzen hat er zum Gewinn/ solts kosten auch mein Leben/ so starck es kan seyn/ so schlag i darein/ warum darff er anheben. 11

Wann er sein Leben gelassen im Stich/ verfault er dann im Graben/ da muß er streckä all viere von sich/ sonst fressen ihm die Raben/ seh Hänßl mein Knecht/ es gschicht dir so recht/ du hasts selbst wollen haben.

\section{2}

Der jung Rauff-Jodl bin ich genannt/

kan reuthen / und kan fahren/ im edlen Steuermarckt gar vilen bekannt/ ein Bue von 30. Jahren/ man sicht mirs nit an/ was ich nun mehr kan/ wers nicht glaubt thuets erfahren. 4

Kein Flögel ißt in unser Revier/ wanns meiner nur begehren/ offt starcke Buemä drey oder ä vier/ die jag ich weith von feren/ i hau halt und sti/ schlag mächtig umb mi/ bin halt ä harter Kerren.

6

Der Mörtl hat mi gfordert herauß/ hab ihm die Haut voll gschlagen/ den Narren hat man ganz blutig ins Hauß/ von mir haimb müssen tragen/ er kunt nicht mehr gehn / er kunt nicht mehr stehn/ jetzt ligt er an den Schragen. 8

Soll er nur einmohl mir kommen ins Gsicht/ flux wolt i mit ihm fechten/ das soll er wissen / i weich ihm gar nicht/ er find an mir den Rechten/ ey potz Saffrian/ i weiß was i kan/ trutz allen starcken Knechten.

10

Bald er an mir nur ein wenig anstöst/ mein Bletzer will i zucken/ zerhauen will i den Bubn aufs best/ die trutzige Hunds-Lucken/ afft ligt er zerhaut/ an Bein und Haut/ zu vier und zwarnzig Stucken.

12

Der Bue der Riepl ist geltig nix nutz/ hebt an vil schlimme Possen/ hat nächsten mir und mein Gespänen zutrutz/ mein Hund mit Füssen gstossen/

da bin i nit faul/ und schlag ihn aufs Maul/ das Blut ist hergeschossen. 
13

Erst gestern hab i ihn ertappt/ zu nächst bey unsern Hueben/ hat er bey sich ein Säbl gehabt/ und noch zwey andere Buben/ da hab i dreinghaut/ als wie in ein Kraut/ zerhackt als wie die Ruben.

15

Znächst wie die Gredl ihr Hochzeit hat ghabt/ mit unsers Jägers Frantzen/ hab i ihn auf dem Tantz-Boden erdappt/ wolt gschwind bei mir anschantzen/ der dalcketa Knoll/ war dämisch und voll/ wolt nur allweil vort tantzen.

17

Da Pfarrä Hießl dä gstrobletä Narr/

hat a mit mir angfangä/

hab ihm außgriffen groß Schüpl vom Har/

seynd dreymal zambä gangä/

und hab ihm haimb gleucht/

biß nunter zum Teicht/

mit einer Hopffen-Stangä.

19

So bleib i halt der Rauff-Jodl so wert/

all Buemä mi schon kennä/

wer mich zum Rauffen und Schlagen begehrt/

mit Lust werd i zurennä/

so bräff als ichs mach/

thus einer mir nach/

will ihn ein Meister nennä. ${ }^{15}$
14

Dem Lentzl-Müllner i schuldig eins bin/

i kan ihms ja nit schenckä/

mei Präxen will i no wetzen an ihm/

er muß auf mi gedenckä/

so bald $i$ ihn find/

schlag i ihn zum Grind/

will ihm ä Guts anhenckä.

16

Da bin i hurtig / und gib ihm präff Stöß/

wirds haben wohl empfunden/

zersetzt ist worden sein Joppen und Kröß/

sein Schedl voller Wunden/

und hät ihn noch mehr/

geployet / wann er

nit wär bey Zeit verschwunden.

18

Fang Hießl morgen fein widerumb an/

hast Lust wohl bey der Linden/

dein Meister bin i du kenst mi ja schon/

laß mir die Händ nit binden/

bekomm ich dich mehr/

und kombst du mir her/

was suchst das wirst du finden.

4,1 Kein Flögel ißt in unser Revier] möglicherweise entstellte Zeile; in der Fassung von 1686 verständlicher: „Keim Flegel weich ich in unser Refier" 2,4 Bue] im ländlichen Bereich: unverheiratetet Mann 4,5 sti] (ich) steche 4,6 Kerren] Kern, d. h.: ,ich bin schwer zu knacken` 5,1 Liendl] Kurzform für Leonhard großkopffeta] übertrieben stolzer, angeberischer 5,3 Curäschi] von franz. courage: Mut 5,5 Simändl] Verkleinerungsform für Simon 6,6 Schragen] (als Kranken- oder Totenbahre verwendetes) Holzgestell 7,3 eingschnaltzt] mit herausfordernden Lauten provoziert 7,4 er hats noch auf der Kreiden] er ist es noch schuldig (redensartlich von der Kreide, mit der man eine Schuld aufschreibt) 9,3 Schmitzen] Striemen 9,7 warum darff er anheben] hier: warum muss(te) er anfangen 10,1 Bald] hier: sobald 10,2 Bletzer] (spöttisch für) bäuerlicher Säbel bzw. altes, rostiges Messer 12,1 Riepl] Kurzform für Ruprecht oder Rupert geltig] rein, allein (gar nichts nutz) 13,2 Hueben] Hube, Hufe: kleineres bewirtschaftetes Acker- oder Weidegrundstück 14,1 Lentzl] Kurzform für Lorenz, Laurenz 14,3 Präxen] säbelähnliches Messer, verächtlich für Schwert 14,6 Grind] (Kopf-)Schorf, hier für Schädel 15,4 anschantzen] spielen, einsetzen, wagen, von Schanz (vgl. franz. chance: Glücksfall, Vorteil); d. h. hier in etwa: ,sein Glück versuchen' 15,5 dalcketa] alberner, lächerlicher 16,1 präff] tüchtig, anständig, ansehnlich 16,3 Kröß] Halskrause 16,5 geployet] gebläut, d. h. blau geschlagen 17,1 gstrobletä] struppelige (wohl auch bildlich für Wirrkopf) 17,3 Schüpl] Büschel 17,4 zambä] zusammen 18,1 Hießl] Kurzform für Matthias $18,5 \mathrm{mehr}]$ hier: wieder, ein andermal

15 Ediert nach Mautner, Zwey schöne Lustige Lieder, S. 89-91, da seine Quelle, eine Flugschrift in Privatbesitz (Adolph Krodth, Graz), verschollen ist. Titelzitat: Zwey schöne Lustige Lieder. Das Erste von dem Schrägel-Thomerl. Das Anderte von dem Jungen Rauff-Jodel. Gedruckt in disem Jahr. [o. O., o. J.]. 
Volkstümliche Raufereien, die auf einem differenzierten System aus Rangfolgen, Signalen und Herausforderungsgesten beruhten, hatten im alpenländischen Raum eine jahrhundertelange Tradition. ${ }^{16}$ Als nicht zu duldende Beleidigung konnte etwa schon die Missachtung einer vorgegebenen Reihenfolge beim Tanzen aufgefasst werden, wie sie im Lied in Str. 15 anklingt, ein falscher Blick oder eine unangemessene Handlung. Diese ständige Überempfindlichkeit gegenüber tatsächlichen oder angeblichen Herausforderungen und die Bereitschaft, sich mit jedem zu messen, verbunden mit exzessiv erscheinender Gewalt werden in diesem Lied durchaus mit einer gewissen spöttischen Distanz beschrieben.

Ob zunächst das Lied war oder die Redewendung, lässt sich bei der derzeitigen Quellenlage nicht sagen. Fest steht, dass der „Rauff-Jodel aus Steyermarck“ ${ }^{17}$ bzw. der „Steyrmärckische Rauff-Jodel “ ${ }^{18}$ in den folgenden Jahrzehnten eine wohlbekannte Gestalt war, wie sich etwa an den satirisch-unterhaltenden Arbeiten Franz Callenbachs oder auch an diversen homiletischen Schriften ablesen lässt. Dann aber scheint sich die unmittelbare Verbindung der Figur mit der Steiermark langsam aufzulösen. Ein 1734 bei Christoph Lercher in Wien veröffentlichtes Curieus- und Lustiges Bauerngespräch des Steyerischen Rieppel und so genannten Saltzburgerischen Rauff-Jodl, das die Kampfbereitschaft der aus allen Teilen des Reichs kommenden Soldaten im Polnischen Erbfolgekrieg illustrieren sollte, stellt dem rauflustigen Steirer bereits ein Pendant aus dem Erzbistum gegenüber. Im Motto des Titelblatts allerdings finden die Attribute noch einmal zueinander:

I der Steyrisch Riepel genannt

Und Rauf-Jodel wohl bekannt

Will rauffä mit dem Franzosen;

Kann nur auf mi wohl losen.

Wenn die Schlacht wird gehen an,

Rauff i bis am letzten Mann. ${ }^{19}$

Ab Mitte des 18. Jahrhunderts finden sich nur noch Belege, in denen der ,Raufjodel ${ }^{\star}$ ohne Regionalbezug als Synonym für Raufbold verwendet wird. Viel nachhaltiger war dagegen ein anderes Klischee, das - obwohl sich auch hier das Phänomen in vielen anderen Alpengegenden in ähnlicher Weise manifestierte - zum „monostereotypen Cha-

16 Vgl. Mautner, Zwey schöne Lustige Lieder. Im Lauf der Jahrhunderte wurde von den jeweiligen Obrigkeiten immer wieder versucht, diese ritualisierten Schlägereien zu verbieten oder zumindest die Rauflust in sportliche Wettkämpfe zu kanalisieren, wo das Kräftemessen nach Regeln und unter Aufsicht vonstatten ging.

17 [Franz Callenbach:] Genealogia Nisibitarum Deß Uhralten NISI-Stamm-Baum Geburths-Brieff [... ]. Gedruckt im Jahr 1714, S. 128.

18 [Franz Callenbach:] Puer centum annorum sive Heteroclitus repuerascentis mundi genius, der vor Augen liegend-handel-und wandlenden Welt täglich anhaltendes Kinder-Spiel, den in Jahren erwachsenen beyderley Geschlechts / was stands sie auch seynd, zu trewmeynender Nachricht. [...] Herauß gegeben: Auff der jetzigen an Jahren zimblich uralten / an Sitten aber verjungten Welt-Kinderstuben. Im Jahr / Da die Welt alt und Kindisch war. [1715], S. 47.

19 Zitiert nach Hartmann, Historische Volkslieder II, S. 325 (ohne dessen eigenwillige Kennzeichnung der Nasalierung). Ein Exemplar der bei Hartmann teilweise edierten Flugschrift konnte bislang nicht gefunden werden. 
rakteristikum der Steirer im Völkerpanoptikum der europäischen Literaturen “ ${ }^{20}$ wurde: der Kropf. Als Topos der Unterhaltungskunst begegnet es uns etwa im Reiselied Jetzt bin ich mir schon satt gnug graist, auf das später noch explizit eingegangen wird (vgl. S. 366). Hier der entsprechende Abschnitt in der Gegenüberstellung zweier Varianten: eine (wohl in Steyr gedruckte) Flugschriftfassung aus der Mitte des 18. Jahrhunderts und eine relativ zersungene, wohl etwas jüngere Fassung aus einer in Graz überlieferten Einzelabschrift:

3

Der Luetenberger steigt in Kopf/ und macht in Ohren-Sausen, fast jeder Steyrer hat ein Kropf, das thät mich schon z’viel graussen, wann aina hat än G’wächs in Halß, so groß als ä Lemoni, den schätzt man dorten über alls, und solten oben ohni.

4

Und wann man ainä fragen will/ wo hin da geht die Strassen/ da reissens oft die Wind-Mühl auf/ thain ihre Kröpf aufblassen/ aft reissen erst die Goschen auf/ so groß als wie a Stadl, aft gebns än endlich Antwort drauf/ sonst waiß ich gar kein Tadl. ${ }^{21}$
3

Der Lurden werger steigt in Kobf, und macht in ohren sausen, ä ihter stei[r]er hot ein Kropf, das tuth mir schon z:vill grausßen, und wer ein Kres dragt um den hals, so gros als wie d:lemoni, den schezt man dort schan über als, und sezt ihm oben öhni

4

Vnd wan mär einen fragen will, wohin da geth die strasßen, da zihens auf das wind Ventill, Bis ihre Kröpf anblasßen, aft Reysßens Erst die goschen auf, so gros als wie ein Stall, und göwen Endlich d:antwort drauf, sunst weis i gahr Kein dall, ${ }^{22}$

3,1 Luetenberger] Luttenberger: Weinsorte aus der Gegend um Luttenberg (heute Ljutomer in Nordslowenien) 3,6 Lemoni] Zitrone 3,8 solten] wohl für: selten (oder verderbt für stölten: stellt ihn?) 4,4 thain] tun 4,5 aft] dann Goschen] Mund 4,6 Stadl] Scheune 3,1 Lurden werger] Luttenberger, s. o. 3,5 Kres] Kröse: Halskrause (scherzhaft für Verwachsungen)

Gerade am Beispiel des imagologischen Kropfs zeigt Franz K. Stanzel, wie elementar stereotype Vorstellungsbilder die eigene Wahrnehmung beeinflussen können, zumal wenn dadurch eigene Ideen bestätigt werden. Als 1748 David Hume von Wien kommend durch die Steiermark reiste, zeigte er sich in seinen Briefen entsetzt über deren Bevölkerung:

But as much as the Country is agreeable in its Wildness; as much are the Inhabitants savage \& deform'd \& monstrous in their Appearance. Very many of them have ugly swelld Throats: Idiots, \& Deaf People swarm in every Village; \& the general Aspect of the People is the most shocking I ever saw. ${ }^{23}$

20 Franz K. Stanzel: Telegonie - Fernzeugung. Macht und Magie der Imagination. Wien/Köln/Weimar: Böhlau 2008, S. 256-265.

21 Drey schöne Weltliche Lieder, Das Erste: Jetzt bin ich mir schon satt gnug graist, hab etc. Das Anderte: Last sich schon der Frühling sehä, Bue das bringt etc. Das Dritte: O Frühlings-Zeit, auf grüner Hayd, schönstes etc. Gedruckt in disem Jahr. [o. O., o. J.], f. 1v.

22 Steiermärkisches Landesarchiv, Hs 1109 (Jetzt bin i mi schan sat gnueg, greist), f. 1r.

23 J. Y. T. Greig (Hg.): The Letters of David Hume. Vol. 1 (1727-1765). Oxford: University Press 2011, S. 130. 
Abb. 27: ,Kropferter' im Reiner Musterbuch (Österr. Nationalbibliothek, Sammlung von Handschriften und alten Drucken, Cod. 507, f. 9v).

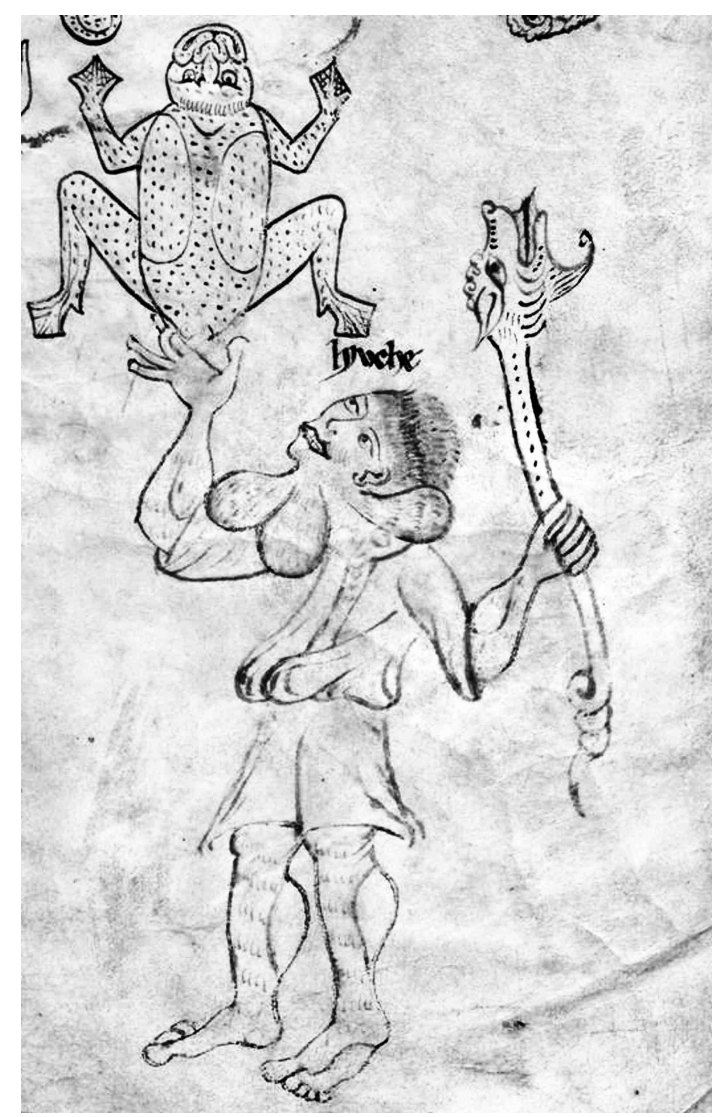

Überraschen konnte den berühmten Philosophen und Diplomaten das vermehrte Aufkommen der Struma freilich nicht; seit der Antike wird über derartige Entstellungen bei der Alpenbevölkerung berichtet. Erstmals bildhaft dargestellt ist der ,kropferte Steirer im ,Reiner Musterbuch ' aus dem frühen 15. Jahrhundert; der folgenreichste Bildspender aber war der ,Vater der Völkerkunde' Johannes Boemus, der in Omnium gentium mores, leges et ritus (1520) die Steirer als „strumosi“ abqualifiziert und mit dem - nicht aus eigener Anschauung gewonnenen, aber äußerst wirkungsmächtigen - Bild der säugenden Mutter, die ihren Kropf zum Stillen auf den Rücken werfen muss, garniert. ${ }^{24}$ Multipliziert wurden solche Vorstellungen durch Unterhaltungslieder wie Was find man dan in steuer, wo das ganze Land auf den körperlichen Defekt reduziert wird:

$24 \mathrm{Vgl}$. „mulier lactans illam post tergum perinde atque saccum reijciat [sic], (si fama vera est) ne infanti impedimento sit“, in: Mores, leges et ritus omnium gentium, per Ioannem Boëmum Aubanum, Teutonicum ex multis clarissimis rerum scriptoribus collecti. Cum Indice locupletissimo. Lugduni, Apud Ioan. Tornæsium, \& Guliel. Gazeium. 1561, S. 295. Vgl. auch Stanzel, Telegonie, S. 263. 
1

Was find man dan in steuer,

Nichts als hohe schöpff, und grosse kröpff,

wan man meint sie habm nur zwey,

so ist der dritt schon auch darbey:

hohe schöpff: und grosse kröpff:

dSteuerer habm die Meresten kröpff: ${ }^{25}$

1,1 steuer] Steiermark 1,2 schöpff] hohe, auftoupierte Frisuren (wohl eher dem Reim geschuldete Behauptung) 1,6 Meresten] meisten

Da kaum eine Reisebeschreibung auf despektierliche Anspielungen auf die (zumeist nicht autopsierten) Deformationen verzichtete, genügte der Anblick einiger Betroffener, um auch Hume in seinen Vorurteilen zu bestätigen.

\section{Tiroler Schützen, Händler und Unterhaltungskünstler}

Wie stark Erwartungshaltungen die eigene Beobachtung beeinflussen können, zeigt Stanzel an Humes Eindrücken aus Tirol, wo er bei der Weiterreise nach Trient ein ganz anderes Bild gewann: „The Inhabitants are there as remarkably beautiful as the Stirians are ugly. An Air of Humanity, \& Spirit \& Health \& Plenty is seen in every face. "26 Auch hier determinierte offensichtlich das Stereotyp den Blick. Denn im europäischen Diskurs des 18. Jahrhunderts waren die Vorstellungsklischees zu Tirol und seinen Einwohnern äußerst positiv besetzt. Vor allem galten die Tiroler schon damals als Patrioten und Freiheitshelden, die im Bayerischen Rummel 1703 als aufrechte, treue und todesmutige Untertanen im Gebirgskrieg die überlegenen Invasionstruppen des Kurfürsten Maximilian II. Emanuel zurückschlagen konnten - ein Bild, das nicht unwesentlich von den aus Wien lancierten dialektalen Agitationsliedern (siehe Kap. 2) mitgestaltet und verbreitet wurde. Im Mittelpunkt stand dabei der Schütze, dessen Treffsicherheit, Wagemut und Heimatliebe bei potentiellen Feinden gefürchtet waren. Durch das Landlibell von 1511, das die Landstände zu Verteidigungsleistungen verpflichtete, hatte ja jeder Tiroler Wehrfähige das Recht, eine Waffe zu tragen; auf zahlreichen Schießplätzen konnten die entsprechenden Fertigkeiten geübt werden.

Wie man den Mythos des wehrhaften Alpenbewohners gezielt über fiktionale - und damit auch unsterbliche bzw. ewig loyale - Identifikationsfiguren erweiterte und verbreitete, wurde bereits am Lustigen Muster-Platz der Tyrolischen Bauern (vgl. S. 118) gezeigt. Ein weiterer Puzzlestein dieser Mythisierung war ein Propagandaflugblatt, das Crischtel Troyling / Uber 40. Jahr / und Anführer seiner Mit-Bauern in Tyrol zwischen Felsen im Laufschritt mit angelegter Flinte zeigt, seinen im Bild nicht sichtbaren Feinden martialisch-dialektal drohend:

25 Bayerische Staatsbibliothek, Cod. germ. 7340 (Stubenberger Gesängerbuch), Teil 2, S. 201.

26 Greig, The Letters of David Hume, S. 131. 
Halt ir bluents Kaerl

seiths ir knoagt odr ih Haerll. ${ }^{27}$

1 bluents Kaerl] feige, schlappe Kerle 2 seiths ir knoagt] (seid ihr geneigt) ergebt euch ih Haerll] ich lasse es krachen (?)

Es ist wohl ein fingiert urwüchsiges Tirolerisch, mit dem der erfundene ,Treuling seine Gegner anwettert, sich zu ergeben, sonst würden sie erschossen. Wirksam aber war diese Medialisierung auf alle Fälle, wie auch die internationalen publizistischen Reaktionen zeigen. $^{28}$

Welchen Status die Tiroler Schützen in diesen Jahrzehnten europaweit hatten, lässt sich selbst noch in der Verballhornung dieser Propaganda erahnen. Die ebenso berühmte wie gesuchte Kupferstichsammlung Il Callotto resuscitato. oder Neü eingerichtes Zwerchen Cabinet, die um 1710 in Augsburg erstmals erschien und ab 1716 zahlreiche holländische (und wohl auch englische bzw. französische) Raubdrucke nach sich zog, ${ }^{29}$ bringt als 39. Blatt Christl Pestnbalkh, Bürg Schütz bey der Tyrolischen Steinfalle im Französisch Bayrischen Einbruch, der sich dem amüsierten Publikum folgendermaßen vorstellt:

Lod i mein Büchsa schorff, und sez a mohl ohn wong,

So gnod dir Gott Franzoß, bey Gott du lebscht nit long,

Du bischt mir gfunda nur, i schatz di vill zu gring,

Dost mir entlauffn solscht, i kenn schoan deine Spring. ${ }^{30}$

1 Lod i] lade ich ohn wong] an die Wange 4 Dost] dass du Spring] Schliche, Tricks

27 Germanisches Nationalmuseum Nürnberg, Graphische Sammlung, Inv.-Nr. MP 24263. In der Subscriptio ist zu lesen:

Von Stand ein schlechter Baur / doch Commendant im Feld/

Einfältig von Geburth / von Hertz doch wie ein Held/

Streit vor das Vatterland / nach vierzig Jahren witzig/

Nimmt Degen / Bandellier / Bley / Pulver / Büchsen hitzig/

Zielt / schlägt mit Bauren-Kunst die Feind so aus Tyroll/

Daß sie mit Blut und Geld ihm musten geben zoll;

Und da der Anfang ihm nun ist so wol gerathen/

Will er / was ferner kommt / hiernechst lebendig braten.

Beigefügt war dieser Kupferstich auch der manipulativen Darstellung der Ereignisse an den Pässen Leutasch und Scharnitz in: Copia-Schreiben Von Brixen in Tyrol / Wovon der eygentliche und authentische Bericht enthalten der jüngsten Action Der Kayserlichen Soldaten und Tyrolerischen Bauern / In wiederRecuperierung deren zwey vesten Päß / Luitasch und Scharnitz / Wie auch die Retirierung des Chur-Fürsten in Bayern aus Tyrol. Samt dem eigentlichen Contrefait des über 40. Jahr alten Tyrolerischen Bauern Crischtel Troyling / welcher im letzten Treffen wider den Chur-fürsten in Bayern / die Bauern commandirt hat. Wien / zu finden im rothen Ygel. [1703].

28 Vgl. u. a. die aufgelisteten Schriften bei W. Drugulin (Hg.): Atlas Historique Drugulin. Catalogue d'une précieuse Collection de Feuilles volantes, estampes allégoriques et satyriques, livres d'entrées, etc. pour servir à l'histoire publique et intime de tous les pays pendant les quatre derniers siècles. Leipzig: KunstComptoir 1867, S. 317, darunter etwa auch ein heute verschollenes, niederländisch betiteltes Blatt.

29 Vgl. Günther G. Bauer/Heinz Verfondern: Barocke Zwergenkarikaturen von Callot bis Chodowiecki. Hg. vom Kulturamt der Stadt Salzburg anläßlich der Ausstellung in der Galerie der Stadt Salzburg von 1. August bis 1. September 1991. Salzburg 1991.

30 Il Callotto resuscitato. oder Neü eingerichtes Zwerchen Cabinet. [Augsburg, um 1710], Bl. 39. 


\section{Srifhtel צrowling/

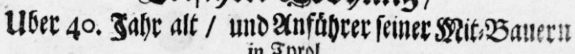 in Evrol.}

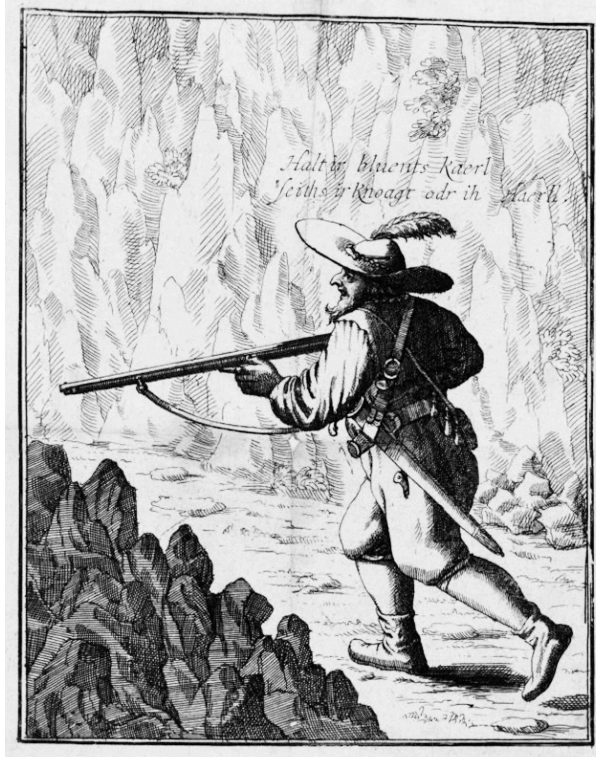

Abb. 28: Crischtel Troyling (Germanisches Nationalmuseum Nürnberg, MP 24263).

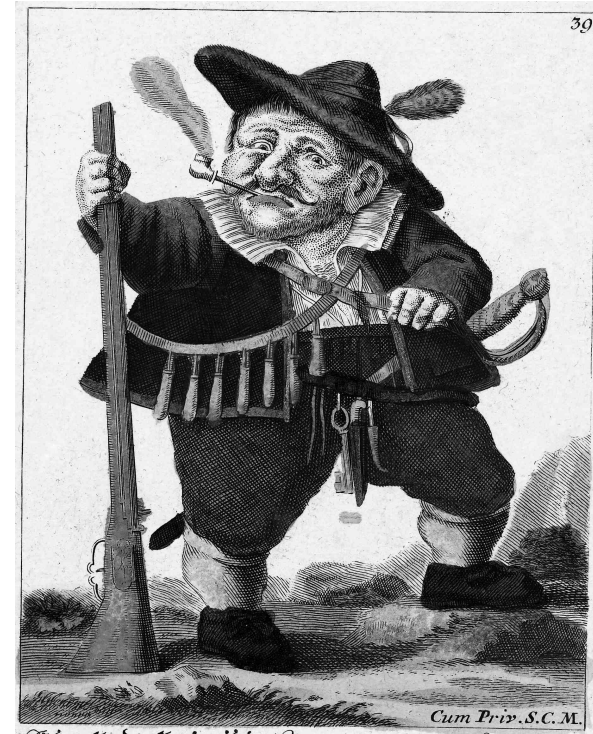

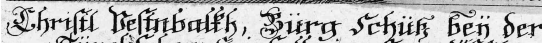

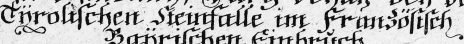

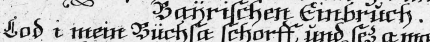

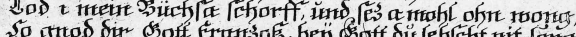
Sil thich of

Abb. 29: Christl Pestnbalkh aus: Il Callotto resuscitato (Rijksmuseum, FMH 3695-a39).

Wer die sprachsensiblen Alexandriner verfasste, die für diese Zeit ungewöhnlich geschickt auch regiolektale Nuancen (wie hier etwa den typischen postalveolaren Frikativ ,sch') berücksichtigen, ist bislang noch nicht geklärt. Dass der Autor aus dem süddeutschen Raum stammt, ist angesichts seines Dialektrepertoires allerdings offensichlich. Im Unterschied zum steirischen ,Raufjodel' sind die Drohungen des Christl Pestnbalkh nicht als leere Prahlhans-Attitüde zu verstehen. Vielmehr ist selbst in der Karikatur der damals europaweit grassierenden Zwergenmode noch der Respekt zu spüren, der den selbstbewusssten Schützen entgegengebracht wurde. Mit ihrem präzisen Einzelfeuer waren sie in der vertrauten Gebirgsumgebung, wo man die gegnerischen Truppen in aussichtslose Lagen locken konnte, dem gedrillten Salvenfeuer überlegen und schufen damit einen Mythos, der noch fast ein Jahrhundert später in den Koalitionskriegen (und in weiterer Folge in den Befreiungskriegen) dankbar aufgegriffen wurde. Auf Johann Friedrich Primisser und Peter Paul Staudacher wurde in diesem Zusammenhang bereits hingewiesen (vgl. Kap. 2). 1797 ließ sich auch P. Rogerius Schranzhofer (1746-1816) aus dem Stift Stams zu seinem bellizistischen Beitrag Die Tiroler Schützen hinreißen, mit dem er die (leicht modifizierte) Melodie von Mozarts Kanon Oh du eselhafter Martin (KV 560b, 1788) unterlegte. $^{31}$

31 Vgl. Walter Senn: Mozartiana aus Tirol. In: Festschrift Wilhelm Fischer. Zum 70. Geburtstag überreicht 
Juhe! Tiroler wäxe Schüzn,

Mier wölln inser Ländl beschüzn.

schaut, der Fränzoß

geät äf ins loß.

ä Tiroler Bue fürcht nix.

Nehmt änieder nur sein Stuzn,

die weärn die Fränzöslen sauber puzn.

Döß ist ä Gschosß,

äf dLäit und Roß,

flux mueß alls purzlen,

aft der Täifl sie hollen kann.

Nehmt nur änieder mit sain Bläy sain Mann,

Und springs nur nit wie dHasen gläi darvon.

spannt an! schlagt an! göbt fuir!

aft mäinaät ists gschöchn schon.

Solt ä däs Bläy nit klöckn,

so miests ins Roär gar Staän dräin stöckn.

Nur präff: piff, päff, piff, päff.

Wix, wäx, wäx wix. ${ }^{32}$

1 wäxe] tapfere 2 Mier] wir 6 änieder] ein jeder 9 äf dLäit] auf die Leute 11 aft] dann (im Sinn von: damit) 15 mäinaät] mein Eid (Beteuerungsformel) 16 klöckn] ausreichen 17 miests] müsst ihr Staän dräin] Steine hinein

Explizite Anweisungen zur Aufführung lassen darauf schließen, dass der Kanon im Stift auch tatsächlich gesungen wurde. ${ }^{33}$

Doch nicht nur als Patriot und Schütze zählte der Tiroler zu den beliebtesten unter allen ,Regionaltypen' des 18. Jahrhunderts im bairisch-österreichischen Raum, auch das Stereotyp als Wanderhändler war im 17. und 18. Jahrhundert tief in der Bevölkerung des deutschen Raums verankert. ${ }^{34}$ Die Illustrierung des Stadt-Land-Kontrasts und die pittoreske Binnenexotik, die auch mit einer mehr oder weniger konsequent umgesetzten sprachlichen Charakterisierung einhergehen konnte, garantierten auch in der Unterhaltungskultur den Erfolg dieser Figuren, die immer wieder in verschiedenen Kontexten aufgegriffen wurde. Einer Tiroler Bauchladenkrämerin sind wir bereits in einer Wiener Hanswurstburleske begegnet (vgl. Kap.4). Die ältesten Belege für die literarische Typisierung des Tiroler Wanderhändlertums beziehen sich auf die ,Ölträger ' - konkreter häufig: ,Zillertaler Ölträger`. Schon ab 1538 finden sie als typisierte Figuren in höfischen Festveranstaltungen Verwendung, etwa bei den sogenannten ,Bauernhochzeiten', wie sie im Barock im habsburgischen Raum beliebt waren (vgl. Kap. 6); im 16. und 17. Jahrhun-

im Mozartjahr 1956. Innsbruck: Im Selbstverlag des Sprachwissenschaftlichen Seminars der Universität Innsbruck 1956. (Innsbrucker Beiträge zur Kulturwissenschaft, Sonderheft 3) S. 49-59. - Hupfauf/Erber, Liedgeschichten, S. 87-89.

32 Bibliothek und Musikarchiv Stift Stams, 7346-7348 (alte Sign. L VI 24). Abbildungen bei Senn, Mozartiana, S. 53f. und Hupfauf/Erber, Liedgeschichten, S. 89.

33 Sandra Hupfauf: Lieder der ,Freiheit': politisch, symbolisch, kommerziell. In: Jahrbuch des österreichischen Volksliedwerkes 59 (2010), S. 243-257, hier 248.

34 So tritt etwa auch in Goethes Jahrmarktsfest zu Plunderweilern ein Tiroler Wanderhändler mit seinem typischen Werberuf auf. 
dert sind entsprechende Rollen auch in Volksschauspielen belegt. ${ }^{35}$ Die Ölträger-Figur fand auch später - bis über den deutschsprachigen Raum hinaus - weite Verbreitung und war noch im 19. Jahrhundert als (literarischer) Typus weithin bekannt. ${ }^{36}$

Grundlage des literarisierten Stereotyps waren die vor allem aus dem Zillertal stammenden Ölträger (bzw. Olitätenhändler, Buckelapotheker oder Balsamträger), die als umherziehende Händler verschiedenartige Arzneien verkauften - hausierend oder auf Märkten. Prädestinierend für die Ausprägung eines Typenbilds war die auffällige, durch die spezifische Zillertaler Tracht vergleichsweise einheitliche Erscheinung dieser Wanderhändler, die oft auch als Laienheiler tätig waren: blauer Kittel, Tuchgamaschen, ausladender Hut und vor allem eine am Rücken getragene Truhe bzw. Kraxe, in der die Arznei- und Haushaltsmittel transportiert wurden. Dieser hohe visuelle Wiedererkennungswert kommt auch in so manchen Liedern zum Ausdruck, die eingangs gerne auf die Bekanntheit des Rollen-Ich verweisen. ${ }^{37}$ Der Olitätenhandel unterlag im 17. und 18. Jahrhundert immer wieder Verboten; die Bevölkerung aber - unabhängig von sozialer Schicht - schätzte die vagierenden Händler und ihre Mittel, leisteten die Ölträger doch einen nicht zu unterschätzenden Beitrag zur Sicherstellung der medizinischen Versorgung am Land. ${ }^{38}$ Umgekehrt stellte die Tätigkeit für die Bewohner des Zillertals vor dem Hintergrund schwieriger wirtschaftlicher Bedingungen - etwa durch den Niedergang des Bergbaus in der Gegend - eine einträgliche Verdienstmöglichkeit dar. Bereits aus dem Jahr 1683 ist eine landesfürstliche Befugnis zum Verkauf selbstverfertigter Arzneien erhalten. ${ }^{39}$

Als literarische Figur tritt der Tiroler Ölträger ${ }^{40}$ in einer Reihe von Liedern und Theaterstücken auf, gemäß der Typencharakteristik und zur sozialen bzw. regionalen Verortung auch gerne als Dialektsprecher. Zumeist ist er als lustige Figur angelegt, mit Hanswurstanklängen in seinem Auftreten und Sprachwitz, der - wie in der Schulkomödie Pavonius ${ }^{41}$ - so in seinem Register verharrt, dass sich auch sein ansonsten rein standardsprachliches Gegenüber zu mundartlichen Anklängen verleiten lässt:

35 Vgl. Karl Mair: Die Öltrager des Zillertals. In: Tiroler Heimatblätter. Monatshefte für Geschichte, Naturund Volkskunde 11 (1933), H. 7/8, S. 263-265. - Anton Dörrer: Zillertaler Volksschicksale, gesehen an den Schicksalen ihrer Schauspiele. In: Herbert Seidler (Hg.): Festschrift. Moritz Enzinger zum 60. Geburtstag. Innsbruck: Wagner 1953. (Schlern-Schriften 104) S. 25-52. - Anton Dörrer: Volksdichterische Charakteristik aus dem Ahrntal. In: Österreichische Zeitschrift für Volkskunde. 50 (N.F. 1) (1974), S. 28-66. - Otto Kostenzer: Die Zillertaler Ölträger. In: Das Fenster. Tiroler Kulturzeitschrift 14 (1974), S. 1451-1457.

36 So finden sich in der wichtigen Volksliedsammlung von Süß insgesamt drei Ölträgerlieder, vgl. Maria Vinzenz Süß (Hg.): Salzburgische Volks-Lieder mit ihren Singweisen. Salzburg: Verlag der Mayrischen Buchhandlung 1865, S. 88ff.

37 Siehe dazu die Beispiele unten bzw. auch das von Süß aufgezeichnete Lied Dar Zillachtålar Öhltrågar, das mit der Formel beginnt: „Griaß enk Gött, ös kennt mi schun, / I bin dar Zillachtålar-Mun, / Herausse aus Tyröl.“ (Süß, Salzburgische Volks-Lieder, S. 90).

38 Vgl. Büchner, Tiroler Wanderhändler, S. 108f.

39 Vgl. Mair, Die Öltrager des Zillertals, S. 263ff. - Konstanzer, Die Zillertaler Ölträger, S. 1451ff.

40 In Abb. 30 das Titelkupfer zu: Die lustige Melankolie, oder der mit sich selbst allein redende, über die vorgegebene Sympathie-Kraft speculierend- und nichts umschneidende Oeltrager. Gott, und seiner Kirche zu lieb ausgearbeitet [... ]. AMberg geDrVCkt Von Caspar HeXengLaVber [1775].

41 Das ohne Angabe von Autor, Ort und Jahr überlieferte, in die Mitte des 18. Jahrhunderts zu datierende Stück ist vermutlich im Klosterumfeld entstanden. Geboten wird eine lehrhafte, moralisierende Handlung, 
Abb. 30: Titelkupfer zu:

Die lustige Melankolie (1775,

Bayerische Staatsbibliothek,

P.O.germ 924).

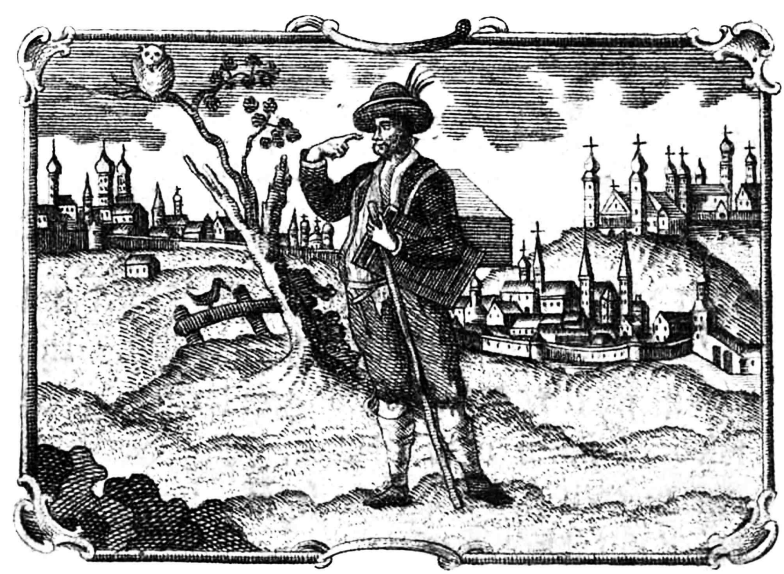

Tyroller. Herr Burgermäister braucht ihr nit vo meinä waar, i ho woß köstlichs Haupt Pulver. PAvonius. scher dich Cannalien! unsterbliche Götter haben keine medicin und solcher schmierereyen vonnöten - aber halt du bist doch ein wackerer Fädl [...] [Laß] dich recht betrachten. TYroller. ho holt ä d-Nosn mittn in gsicht

PAvonius. iß ä wahr, aber halt, gelt du bist gwis immer mitleydiger Samaritan [... ${ }^{42}$

i ho woß] ich habe etwas Fädl] armer Mensch, Habenichts ä] auch

Der zweite Auftritt des Tirolers ist als - sicherlich komische - Improvisationsszene ausgeführt und textuell nicht festgehalten.

Mehr Platz wird der populären Figur im Admonter ,Drama musicum ' Phoenix e funere vivus eingeräumt, das zu einem besonderen Anlass gefertigt worden war. Der damalige Abt Matthäus Offner war nach schwerer Krankheit 1775 bereits voreilig für tot erklärt worden. Zur Feier seiner unerwarteten Genesung inszenierte man einen Festabend mit einem zehnteiligen allegorischen Stück, einer Festansprache und einem Gedicht. Nach diesen in Latein gehaltenen Unterhaltungen gab es offenbar noch einen Auftritt von mehreren Bauernfiguren (Hieserl mit seinen Freunden Moeliboeus Heischinck, Menalcas Kröpfl und Tityrus Langhans sowie schließlich dem Zillertaler Ölträger Jodl). Ihre vier dialektalen Liedeinlagen - mit Regionalbezug und Verweisen auf den Gesundheitszustand des Abts - sind im selben Kodex überliefert. Ein Autor ist nicht genannt; aufgrund des Zusammenhangs mit dem Festspiel lässt sich aber vielleicht der damalige Rhetorikprofessor Petrus Rinn (gest. 1810) vermuten. Das Lied des Zillertaler Ölträgers ist das dritte in dieser Folge und bringt ein recht anschauliches Bild, wie das Warenrepertoire angepriesen wurde. Diverse Mittelchen werden präsentiert, ihre Nützlichkeit gerühmt und der Preis verraten - all dies in heiterem Ton und mit schelmischem

indem der geizige und hoffärtige Pavonius, der von sich glaubt, „mehr göttlich als menschliches an sich zu haben“, durch verschiedene Streiche seines Sohns die Lehre erfährt, wie sehr er von seinem Reichtum und seiner Hoffart verblendet war.

42 Bayerische Staatsbibliothek, Cod. germ. 3175a (Pavonius: Superbus et Avarus Sed utrobique delusus. Das ist. Der Geiz- und hoffärthige doch beyderseyts lüstig hintergangene Pavonius), f. 13r. 
Witz, der wohl auch im wirklichen Leben dem Verkaufsgespräch nicht fehlte. Zuletzt wird mit dem Verweis auf das nächste Ziel St. Gallen (eine Pfarrei von Admont) auch das Wanderleben angesprochen. Dass in der Aufzeichnung in der fünften Strophe zwei Wörter fehlen, könnte darauf beruhen, dass hier ein - im Vortrag gewiss umgesetzter eher derberer Spaß in der Niederschrift ausgespart bleiben sollte.

1

Grüß euch Gott! os kennts mi schon,

Bin der Zillerthaller Mann,

Aussä aus Tyroll,

drum bin i ä, wie ihr wist,

Än ausgeschrirnä gutä Christ,

Oda do seyn soll.

3

Terpentin, Cathräinenöel,

Stehn da in der möttern Stöll, sänd ä bauchweh Chur,

Vm zehn Kräiza gieb ichs her,

Ich steh guet, du kömmst nöt mehr,

kauf, probier es nur.

5

Scorpigonöel hani ä

Wunderbalsam allerlä,

vnd Schneberger - - -

$\mathrm{Daß}$ sänd Sachä nur glei rär,

Es hats nöt leicht ä jeda Bäyr,

Glaubts mä sichä - - -
2

Stainöll hani desmal viell,

ß'gläsl acht Kreuzä, wer ains will,

Schlechts hani gwis kains,

Schmier di, odä trincks glat auß,

Hilfts di nöt, so mach nix draus,

kauf dä wiedä ains.

4

Daß ist Kaznkreutl Geist,

Ist guet, wann ä Hund di beist,

Hailt di wunden zue,

Wanst ofä nöt bissen wirst,

Odä sönst kein Mängl gspierst,

Hast dei Lebtag gnue.

6

Pillerl groß und klaiin für d'Kröpf,

Spiritus für gschwollne Köpf,

Hünneraugen Schmier;

Schwundpölsterl für d'krumpe füsß,

Rosmärin Essenz für d'flüs,

taugt für alles schier.

Hier gehet der Jodl ab nach Sct. Gallen. ${ }^{43}$

1,5 ausgeschrirnä] berüchtigter, berühmter 2,1 Stainöll] Steinöl: aus Ölschiefer gewonnenes, schwarzes, stark riechendes Öl hani] habe ich 3,1 Cathräinenöel] Katharinenöl: wurde als Sekundärreliquie gehandelt; Arzneiöl, das angeblich aus den Knochen der Heiligen Katharina von Alexandria floss (bzw. mit ihren Gebeinen oder Stücken davon in Kontakt war) 3,2 in der möttern Stöll] am mittleren Regal 4,1 Kaznkreutl Geist] Baldriantinktur 4,4 ofä] aber 5,1 Scorpigonöel] Skorpionöl: Öl, das gewonnen wird, indem lebende Skorpione in Öl eingelegt werden, die im Todeskampf Gift ausstoßen 5,3 Schneberger - - -] vermutl. Schneeberger Schnupfpulver, ein Pulver aus fein zermahlenen Kräutern, Blüten und Wurzeln, das Niesreiz auslöst und Schwindel vertreiben, Gedächtnis, Sehkraft und Geruchssinn stärken sollte 6,5 für d'flüs] bezieht sich vermutlich auf die durchblutungsfördernde Wirkung, die Rosmarin haben soll

Der Eingangsruf, der auf die Bekanntheit und Beliebtheit des Motivs referiert, scheint zum festen Formelschatz der Tiroler Wanderhändler gehört zu haben - sowohl in der literarischen Verarbeitung als auch (vermutlich) im Alltag. Bereits in Wolfgang Rinswergers um 1697 am Salzburger Universitätstheater aufgeführter lateinischer Schulkomödie Potinus ist eine Arie enthalten, die im Handlungskontext von einem aus Tirol stammenden Straßenhändler gesungen wird und ein ganz ähnliches Incipit aufweist. ${ }^{44}$ Hier ist der „Circumforaneus ex Tyroli“ allerdings ein Zitrusfrüchte- und Maroniverkäufer, der seine Ware feilbietet und gleichfalls (illegal) ins Baderhandwerk hineindilettiert:

43 Stiftsbibliothek Admont, Cod. 35/45 (Phoenix e funere vivus), f. 12v-13r.

44 Zur zeitlichen Einordnung der Aufführung vgl. Boberski, Das Theater der Benediktiner, S. 257. 
1

Guetn Abed, kents mi scho,

Bin halt ä Leemoni mo,

Afftn aus Tyroll.

Schwartz ums Maul, in Gwissn weiß,

Mit ain halbn dreysger leiß

Bin i z'fridn woll.

3

Ins weiß Bier seynds träffli gut,

Wen mä Safft und Schöll drein thut.

Z'Freysing pflegt märs hie.

Vorauß ists ä gute Sach

Wen das Bier bleibt gar zlang schwach,

in der Holler Blieh.

5

Bämeränschen hab ich vill,

S'par 8 Kreutzer: wer ai will.

Der lust hat, der zahls.

Käffts, so wird mein Karb bald lär,

Dan i trag no dechter schwär,

Mit der Frucht an Halß.

7

Köstn gibt's ä Säcklä voll,

Wie mä d'Sau möst in Tyroll,

Brings ins Bayrland rein,

Den da gibt's äs nach der Wahl,

Gley z'negst ins Potini Stall.

Find i gwis ä Schwein.
2

Braucht ihr öppät sottläs G’fräß,

Taugt gar hibsch in d'Aderläß,

Zum än Gläßl-Wein.

Gfalt euch waß, klaubt rauß i bitt,

Liebe Leuth, verschweigt märs nit,

Seint wohl hibsch und fein.

4

Der Potinus, wie es scheint,

Will ihm z'Ader lassen heunt,

Kaufft gar gwiß was ein.

Will g'schwind sechn (weiß scho s'Hauß)

Wo d'Sau schaugt zum Fenster rauß

Dortn geh i nein.

6

Pergämoth, wan bliebt ihr Herrn,

Sänt so marb, i sags nit gern,

Bin ä guter Tropf.

Aini um än Kreutzer gley,

Muß ernöhrn Kind, und s'Weib

Hat ain jeds än Kropf

8

Spältl, Kletzl hab i no,

Giest mä saure Milli dro,

Daß laxirt bey Zeit,

Wer purgier vo mir gern hett,

Trifft mi oh hindt auf der Gredt,

Lebts wohl liebe Leuth. ${ }^{45}$

1,1 Abed] wohl Druckfehler 1,2 ä Leemoni mo] ein Zitronenmann, Zitrusfruchtverkäufer 1,3 Afftn] hinten 1,5 dreysger] kleine bayerische Maßeinheit (32. Teil eines Metzen, ca. 1 3/5 Liter) leiß] Läuse 2,1 öppät] etwa, zufällig sottläs G'fräß] solches Fressen, derartiges Essen 2,4 klaubt rauß] sucht es euch heraus 2,5 märs] mir es 3,1 träffli] trefflich 3,2 Schöll] Schalen 3,3 Z'Freysing] bayerische Bischofsstadt (auch zuständig für Rinswergers Heimatkloster Tegernsee und sein Tätigkeitsort nach der Salzburger Zeit) 3,6 Holler Blieh] Holunderblüte 5,1 Bämeränschen] Orangen, Apfelsinen 5,2 ai] welche 5,5 dechter] dennoch, trotzdem Frucht an Halß] bildlich für Kropf (vgl. die Parallelstelle im Reiselied, S. 348) 6,1 Pergämoth] Bergamotte (Citrus limon bzw. bergamia), Hybrid aus Limette und Bitterorange wan bliebt] wenns beliebt 6,2 marb] mürbe 7,1 Köstn] Kastanien 7,2 möst] mästet 7,5 z'negst] in der Nähe 8,1 Spältt] getrocknete Apfelspalten Kletzl] Dörrbirnen 8,2 Milli] Milch 8,3 laxirt] führt ab 8,4 purgier] Abführmittel 8,5 oh] an Gredt] hölzerne oder gepflasterte Stufe, vor allem bei Bauernhäusern (von der auch die Notdurft verrichtet werden konnte)

In Rinswergers Besserungskomödie versucht Sobrina, Ehefrau des Trunkenbolds Potinus, mit Hilfe ihrer Söhne und fünf Studenten, ihren Mann von seinem Laster zu

45 Wolfgang Rinswerger: Potinus. In: E funere Phoenix. Sive Operis posthumi Dramatum Pars III. Complectens Dramata Paschalia olim in Scenam data A Reverendissimo, Perillustri, ac Amplissimo. Domino Domino Wolfgango Rinswerger p. m. Exempti nostri Monasterii Michaelfeldensis Abbate Vigilantissimo, nec non Reverendissimorum ac Celsissimorum Principium Archi Episcopi Salisburg. \& Frisingensis Episc. Consiliario Ecclesiastico. Nunc verò opera \& studio in ordinem redacta, \& annotationibus, ac triplici indice aucta in usum studiosæ Juventutis aliorumque operum Comicorum Amatorum. â P. Joanne Evangelista Heigl. Benedict. \& ejusd. Exempti Monast. Michaelfeldens. in Palatinatu Superiori Professo. Cum Facultate Superiorum. Pedeponti typis Joannis Francisci Hanck, 1730, S. 181-252, hier 247-249. - Kommentierter Abdruck der Arie auch in Pörnbacher/Hubensteiner, Bayerische Bibliothek II, S. 540-542. 
befreien; dieser aber fällt von Akt zu Akt wieder in seine alten Gewohnheiten zurück. Möglich gemacht werden die Täuschungsaktionen, weil Potinus sich immer in den Schlaf säuft (vgl. das rusticus-imperans-Motiv in Kap. 4). Erwacht und konfrontiert mit seinem vermeintlichen Unglück, jammert er dann seinen running gag , $\mathrm{O}$ vinum, o vinum', ohne aber nach der Errettung tatsächlich die Finger vom Alkohol lassen zu können. Im vierten Akt stürzt ihn sein Versprechen, keinen Fuß mehr ins Wirtshaus zu setzen, in eine tiefe Melancholie, die mit einem Aderlass behandelt werden soll. Hier fügt sich der Auftritt des Tiroler Händlers ein, der seine Stärkungsmittel - wie die Szenenankündigung erläutert - für die therapeutische Nachbehandlung an den Mann bringen will („Distrahuntur fruges, pro phlebotomis comparandæ“ ${ }^{46}$ ). Das Tirolerische des ,Lemoni-Manns' ist freilich auf seine Rollenanlage beschränkt; denn sprachlich gesehen ist sein Lied dem Westmittelbairischen des aus München gebürtigen Autors verpflichtet.

Trotz aller Drolerie klingt in Rinswergers Arie auch das beschwerliche Leben der vazierenden Händler an: der Druck, mit den Einnahmen Frau und Kind ernähren zu müssen, und die körperlichen Beschwerden (interessanterweise wird hier der Kropf als allgemeines Signum der Gebirgsbewohner gesehen, nicht nur der Steirer). Noch konkreter tritt der harte Arbeitsalltag des Ölträgers in einem Lied aus dem ,Stubenberger Gesängerbuch` zu Tage, wo dieser eine Hilfskraft sucht und sich über das schlecht gehende Geschäft beklagt, da die Kundschaft zwar gerne das Öl für Notfälle zu Haus hat, doch nur ungern Geld dafür erübrigen will:

1

Geh Bauer geh leih mir dein knecht, der wär mir zumb öltragn krad recht: so wöln mir Miternander geh:

äm ständt das trühäl sche:

das öl tragn schlagt ä scha was aus:

hat mir 4 jahr 5 f: dähaust:

3

dö weiber dö daein sö Beklagn:

sö sangt halt kaey geld daeins Nöht habm:

so woln mir den bauern fragn:

wo er thuedt ä kaeis habm:

der bauer der hat si bedenkht:

und er sagt das geld ist vil zwenkh:
2

O Bauer dein knecht gfiel mir wohl:

äm ständt das trühäl ganz dol: wan uns dö leuth däeint [fragn]: was mir darin daein habm: oft sagn mir halt lauter guetö sach: gehts weiber gehts kaufts uns was ab: 4

Schau Bauer und las dir nur sagn:

ä n öl solst alweil im haus habm: es wird oft aeis krankh im haus: derfs nöth gehn lassn aus: ä glässl voll öl gib i dir: du gäst mir än zwaeingä dafür: $[\ldots]^{47}$

1,4 äm ständt das trühäl sche] ihm stünde die Warentruhe gut an 1,5 schlagt ä scha was auf] trägt schon auch was ein 1,6 5 f: dähaust] 5 Gulden eingebracht 2,3 däeint] tun 3,2 sangt] sagen 3,4 ä kaeis] auch keines 4,3 aeis] eines, einer 4,6 zwaeingä] Zweier (halber Kreuzer)

Beide Figurentypen - der patriotische Tiroler Schütze und der charismatische Tiroler Händler - verbanden sich Ende des 18. Jahrhunderts zu einem der erfolgreichsten Volksstereotype dieser Zeit: dem ,Tyroler Wastel', der ein drittes, bis heute wirksames tirolerisches Stereotyp idealtypisch verkörperte: die ,Lustigkeit', worunter je nach Per-

46 Ebda., S. 238.

47 Bayerische Staatsbibliothek, Cod. germ. 7340 (Stubenberger Gesängerbuch), Teil 2, S. 136. 
spektive unverstellte Aufrichtigkeit, kindliche Naivität oder natürliche Witzigkeit verstanden werden konnte. Der spätere Lemberger Universitätsprofessor Joseph Rohrer, ein Pionier der österreichischen Volkskunde, beschrieb in seiner Studie Uiber die Tiroler (1796), dem „Resultat einer durch mehrere Jahre in Tirol fortgesetzten Menschenbeobachtung“, diesen typischen - exotischen - Wesenszug und dessen Aufnahme in der habsburgischen besseren Gesellschaft folgendermaßen:

Wenn sich aber der größere Theil der deutschen Tiroler auch nur mit wenigem Glücke auf das Tonspiel verlegt, so gelingt ihm das Gedankenspiel um so besser. Ich meine hiermit die Gabe ohne vieles Kopfbrechen durch Witzeinfälle zu unterhalten, mit welcher dies Bergvolk reichlich ausgestattet ist. Unter der Regierung weiland Theresiens wurden wandernde sonnenverbrannte Tiroler öfters von dem erbländischen hohen Adel in Sold genommen, um melancholische Damen zur Lustigkeit zu stimmen, und die Eingeweide hypochondrischer Herren heilsam zu erschüttern. In die adelichen Zirkeln zu Prag wird noch jetzt der handelnde Tiroler-Bauer als Mittelpunkt hineingelassen, und die ganze Gesellschaft durch seine Scherze zusehends aufgeweckter. Eben so werden von Böhmischen Landedelleuten und Ungarischen Magnaten die vorbeyreisenden Tiroler zur Tafel geladen, um sich an ihrem Witze zu ergötzen. Die nicht seltene Naivetät dieser Alpensöhne erzeugt bey dem wohlhabenden Adel dieser Länder ein gutherziges Lächeln, das gewöhnlich bey den Damen mit einem wohlthätigen Gefühle der Zärtlichkeit gegen diese arme exotische Menschenrace verbunden ist, welcher erst nach einer Reihe von Jahren Verstellungskunst zur zweyten Natur wird - worauf sich wohl auch die bekannte Redensart beziehen mag, daß die Tiroler erst mit 40 Jahren gescheid werden. ${ }^{48}$

Es war wieder ein Geniestreich - oder zumindest eine geschickte Geschäftskalkulation des Zauberflöten-Librettisten Emanuel Schikaneder (1751-1812), die Wesensmerkmale der bestehenden Tiroler-Klischees im Protagonisten seiner 1796 uraufgeführten Erfolgsoper Der Tyroler Wastel (Musik: Jakob Haibel) zu bündeln. So geschickt profilierte er den heimatliebenden, witzigen Handschuhhändler im Wiener Großstadtambiente, dass die Figur eine regelrechte Patrioten-Mode auslöste mit einer der nachhaltigsten Rezeptionen in diesem Kontext.

Gattungsgeschichtlich kann das Stück als Prototyp des Volksstücks gelten: Im Zentrum stehen bürgerlich-familiäre Verhältnisse des publikumsnahen Wiener Alltags, verbunden mit Merkmalen der Hanswurstiaden und mit solchen des aufklärerischen Sittenstücks. ${ }^{49}$ Dabei lebt es insbesondere stark vom Kontrast ${ }^{50}$ zwischen den zwei ,natür-

48 Joseph Rohrer: Uiber die Tiroler. Ein Beytrag zur Oesterreichischen Völkerkunde. Wien, im Verlag der Dollischen Buchhandlung 1796, S. 75 f.

49 Vgl. Anke Sonnek: Emanuel Schikaneder. Theaterprinzipal, Schauspieler und Stückeschreiber. Kassel [u. a.]: Bärenreiter 1999. (Schriftenreihe der Internationalen Stiftung Mozarteum Salzburg 11) S. 225. Aust/Haida/Hein, Volksstück, S. 105. Die Verbindung dieser verschiedenen Aspekte zum ,Volksstück' wurde zwar nicht durch Schikaneder begründet - als Muster kann eher Hafners vierzig Jahre früher erschienenes Stück Die bürgerliche Dame gelten -, verhalf ihm aber durch die Figur des Tyroler Wastels zu ungeheurer Popularität (vgl. ebda.).

50 Vgl. dazu: Wendelin Schmidt-Dengler: Polarisierung als Gestaltungsprinzip auf dem Alt-Wiener Volkstheater. In: Jahrbuch der Grillparzer-Gesellschaft 10 (1973), S. 41-63, insbes. 50ff. - Wendelin SchmidtDengler: Das Kontrastschema Stadt-Land in der Alt-Wiener Volkskomödie. In: Jürgen Hein (Hg.): Theater und Gesellschaft. Das Volksstück im 19. und 20. Jahrhundert. Düsseldorf: Bertelsmann 1973. (Literatur in der Gesellschaft 12) S. 57-68. 
lichen', kräftig zupackenden Tirolern und der Wiener Gesellschaft, deren Überempfindlichkeit, künstliche Höflichkeit, vor allem aber auch Hochmütigkeit und Standesdünkel kritisiert werden. Die Krise, durch die sich die Handlung entspinnt, ist denn auch die Liebe zwischen Louise von Tiefsinn, deren Eltern jüngst in den Adelsstand erhoben wurden, und dem jungen Bäckermeister und Hausbesitzer Joseph, einem Bürgerlichen. ${ }^{51}$ Die dünkelhafte Stiefmutter ist von dieser Verbindung entsetzt; der Vater dagegen und insbesondere dessen Bruder - eben der aus Tirol gemeinsam mit seiner Frau angereiste Wastel - unterstützen das Paar. Bei einem gemeinsamen Ausflug in den Prater eskaliert die Situation, alle trennen sich im Streit. Frau von Tiefsinn hat nun vor, Louise zwangsweise mit einem alten Buchhalter zu verheiraten, während ihr Mann, der sich von ihr tief gedemütigt fühlt, verschwunden bleibt. Erst das Eingreifen des unerschrockenen Tirolers löst die Situation: Er lässt kurzerhand einen Advokaten rufen, um die Verbindung zwischen Louise und Joseph zu schließen, und am Ende versöhnen sich - recht plötzlich - sogar Herr und Frau von Tiefsinn wieder.

Einen Eindruck vom Stück und von der Figur des, Tyroler Wastels' kann die folgende Szene aus dem ersten Akt geben, in der das Tiroler Paar zum ersten Mal auftritt. Die Naturverbundenheit und Unverfälschtheit der Tiroler wird bereits hier in deutlichen Kontrast zum städtischen Leben gesetzt:

Herr von Tiefsinn. Nur herein lieber Bruder, nur herein liebe Base.

WASTEL. Aber sogt's mir nur ihr Wiener Leut, warum bauts eng denn engere Häuser gar so hoch? bei eng muß man ja steigen, als wenn man bei uns in Tyrol auf die Alma nauf gieng.

Herr von Tiefsinn. Lieber Bruder, um der schönen Aussicht willen übersieht man kleine Ungemächlichkeiten. Das ist also deine zweite Frau?

WASTEL. Bei uns in Tyrol wissen wir nichts von Frauen, wir haben nur Weiber. Schau, bist selbst ein geborner Tyroler und redst so dappisch. Du Liesel sez di nieder.

Liesel. (setzt sich.)

WAStel. Aber jetzt sag mir du, wo ist denn dein Weib, daß ich sie noch nit g'sehn hab'?

Herr von Tiefsinn. Vermuthlich auf ihren Zimmer, aber sie wird bald kommen.

Wastel. Hats a so guts Herz, wie dein erstes Weib?

Herr von Tiefsinn. (seufzt.)

WAStel. Ja seufzen mußt mir nit, sonst geh i dir gleich aus dem Haus. Hats a saubres Gefries?

Herr von Tiefsinn. So, so!

Wastel. Hats Geld g'habt?

HerR von Tiefsinn. Nicht einen Kreuzer! sie war Kammerjungfer und machte mich durch diese Heyrath zum Amtssekretär.

WASTEL. A solche hast g’nommen? nu die wird dir die Brennsuppen weiter nit hart einbrocken.

51 In dieser Konstellation ist neben dem mit der Figur des Wastel eingebrachten Stadt-Land-Kontrast ein weiterer Gegensatz dargestellt: Die Familie Tiefsinn gehört im Stück zu jenen ehemals bürgerlichen Händlern und Handwerkern, die - oft durch Spekulationen - ein gewisses Vermögen erlangt haben und damit in die höhere Gesellschaft aufgestiegen sind; deren neu erworbener Geltungsdrang wird in der Figur der Frau von Tiefsinn parodiert, die alles ,Bürgerliche` abzulegen versucht. Einem solchen neuadeligen Reichtum stellt Schikaneder das idealisierte Bild eines ehrlichen und biederen, wenngleich ebenfalls materiell abgesicherten Handwerks gegenüber, das durch den jungen Bäcker Josef repräsentiert wird. Vgl. u. a. Eva-Maria Ernst: Zwischen Lustigmacher und Spielmacher. Die komische Zentralfigur auf dem Wiener Volkstheater im 18. Jahrhundert. Münster/Hamburg/London: LIT 2003, S. 257. 
LieseL. (hat sich indessen mit der Toilette beschäftigt und sich angestrichen, läßt sich aber mit dem Gesichte nicht eher sehen, als jetzt, da sie den Hut, der auf den Tische lag, aufgesetzt hat.) Du Wastel! schau mi amal an!

WAStel. Ha ha ha! jetzt siehst du just aus, wie unsere alte Gräfin, wenns in die Stadt eini fahrt. ${ }^{52}$

dappisch] ungeschickt, plump Gefries] Gesicht (häufig abwertend)

Der Unterschied zwischen den ,natürlichen', grob-aufrichtigen Tirolern und der Wiener Gesellschaft, die im Zentrum des Stückes steht, schlägt sich auch deutlich in der Sprache nieder: Wastel und seine Frau sprechen starken Dialekt, die Wiener verwenden Standardsprache. Die regiolektale Markierung der ,Tiroler ' Repliken soll vor allem Direktheit und Ungekünsteltheit signalisieren. Gleichzeitig aber dient der Dialekt im Stück auch durchaus traditionell der Markierung des sozialen Stands - wobei er auch abwertenden Charakter hat - sowie zur Komisierung der Figuren: So spricht etwa Jodel, ein Bediensteter von Joseph, der explizit als „dumm“ (S. 9) bezeichnet wird, Wiener Dialekt; ebenso der zwielichtige Wirt im Prater. Insgesamt wird im Stück mit der Figur des Tiroler Wastel das alte Motiv des Bauern in der Stadt (vgl. Kap. 4) auf charakteristische Weise umgeformt: Es geht nun nicht um die Lächerlichmachung eines weltfremden Tölpels; das Publikum soll vielmehr am Anderssein des Protagonisten, das die bewahrte natürliche Identität ausdrückt, „die eigene Verformung durch konventionellen, großstädtischen, von der Natur isolierten Zwang kennen[lernen] “ ${ }^{53}$. Die ,lustige Figur ' erlebt im Tyroler Wastel ihren Aufstieg zu einer respektablen Bürgersperson, deren Hauptaufgabe nicht mehr (nur) darin besteht, Komik zu vermitteln, sondern Bodenständigkeit und Redlichkeit - Eigenschaften, die insbesondere mit dem ,Tirolerischen' in Verbindung gebracht werden. ${ }^{54}$

Lieder aus dem Stück, zumal die dialektalen, wurden schon bald nach der Uraufführung über Flugschriften im gesamten deutschen Sprachraum verbreitet und später auch - insbesondere Die Tyroler sand often so lustig so froh - in diverse Volksliedsammlungen aufgenommen. Sie zeichnen ein simplizistisches, reduziertes Bild einer unschuldigen Kreatürlichkeit in einem idyllisierten Umfeld:

Die Tyroler sand often so lustig so froh,

Sie trinken ihr Weinel und tanzen a so

Früh legt man sich nieder

Früh steht man dann auf

52 Der Tyroler Wastel. Eine komische Oper in drei Aufzügen von Emanuel Schickaneder. Die Musik ist vom Herrn Haibel Mitglied des k. k. privil. Wiedner Theaters. Leipzig bei August Geers 1798. - Zur Quellenlage siehe Andrea Brandner-Kapfer (Hg.): Der Tyroler Wastel. Eine komische Oper in drei Aufzügen von Emanuel Schikaneder. Die Musik ist vom Herrn Haibel Mitglied des k. k. privil. Wiedner Theaters. Leipzig bei August Geers 1798. Anmerkungen. Graz 2011, http://lithes.uni-graz.at/kasperls_erben/pdfs_erben/ doku_schikaneder_tyroler_wastel.pdf (letzter Zugriff am 14.05.2018).

53 Aust/Haida/Hein, Volksstück, S. 105; vgl. ähnlich auch Ernst, Zwischen Lustigmacher und Spielmacher, S. 258f.

54 Vgl. Sonnek, Schikaneder, S. 227. Daneben dienen auch die Figuren Mariane und Jodel - als Liebespaar der Nebenhandlung auf der , niedrigeren' Ebene - der Darstellung einer einfachen Lebensart. Dieses Ideal wird also nicht ausschließlich, wie beim Tyroler Wastel und seiner Frau, anhand von ,von außen kommenden Figuren gezeichnet, sondern auch an dezidiert Wiener Figuren - von denen eine „Aura des ,Hier-bei-uns aus[geht], in der sich das Publikum eingeschlossen fühlt“ (Aust/Haida/Hein, Volksstück, S. 106). 
Klopfts Madl aufs Mida

Und arbeit brav drauf.

Und kommt denn a Kirta, so schaut man zum Tanz,

Der Jodel führt die Nannerl, die Gretel den Hans

Da dreht sichs, denns Weibl, da dreht sich der B[ua],

Er nimmt sie beim Leibel und juchazt dazu.

Die Tyroler sand often so lustig so froh etc. etc.

Sie sorgen für die Stadtleut mit Milli und Kaß,

Sie treiben die Kühen auf die Almer ins Gras.

Sie jodlen und singen und thun sich brav um

Und hüpfen und springen wie die Gemsen herum.

Die Tyroler sand often etc. etc.

Hat aner a Schazerl, so bleibt er dabei,

Und giebt ihn a Schmazerl und liebt sie recht treu,

Da kriegens denn Kinder, wie die Kugeln so rund,

Die zappeln und springen, wie die Hechten so gesund. ${ }^{55}$

1,1 often] eben, nun mal 1,5 Madl] Mädchen 1,7 Kirta] Kirchweihfest, Kirmes 2,2 Milli] Milch

Ausgegliedert aus dem spezifischen Kontext des Theaterstücks trieb die stereotype Figur des redlichen, lebensfrohen Tirolers die ab etwa 1800 einsetzende romantische Verklärung des, Alpenländischen' voran, die auch mit einer neuen Wertschätzung des Dialekts verbunden war. ${ }^{56}$ In den ersten Jahren des Bühnenerfolgs aber war es noch vor allem das vaterländisch-agitative Potential des Wastels, das in Zeiten der immer stärkeren Bedrohung durch Frankreich zur Konstruktion eines Zusammenhalts der Habsburgertreuen genützt wurde. Als der prototypische, gute Untertan' wird er in einer ganzen Serie von ,Trittbrett-Liedern zum „Scharfschütz wider die Franzosen“ stilisiert („Auf, frische Tyroler, auf, spannt euer Büchs, schießt nieder Franzosen wie die Haasen und Füchs“), oder zum Gratulanten „an Kaisers Namenstag“:

1

Auf lustig ihr Bubn, jetzt dreh ich den Hut, der Kaiser soll leben, er ist uns all'n gut; der Franzel, der lebe, der ists ja wohl werth, daß man durch a Liedl sein Andenken ehrt. Juhe! 2

Sei Rösel ist ja auch so gut und so schön,

für sie muß a jeder durchs Feuer grad gehen;

i hob an der Rösel a kindischa Freud,

und nur gr[ad] ihr Nama der macht mir a Schneid. Juhe!

55 Schickaneder, Der Tyroler Wastel, S. 43f.

56 Vgl. Otto Holzapfel: Die Entstehung des alpenländischen Mundartliedes um 1800 als Spiegelbild einer neuen Wertschätzung des Dialekts. In: Zeitschrift für Dialektologie und Linguistik 69 (2002), H. 1, S. 3852 . 
3

Die Wiena, die braven, die sind auch getreu,

sie sind für den Kaiser gleich alle dabey;

sie machen mei Aid schon sich alla a Ehr,

sie denken halt redli, was brauchts sonsten mehr. Juhe! ${ }^{57}$

1,3 Franzel] Kaiser Franz II. von Habsburg-Lothringen 2,1 Rösel] Maria Theresia von Neapel-Sizilien 2,4 Schneid] Mut (durch die Erinnerung an ihre gleichnamige große Vorgängerin und Großmutter) 3,3 mei Aid] bei meinem Eid! (Beteuerungsformel)

Wie gezielt der Vorzeigepatriot von der Obrigkeit funktionalisiert wurde, um in der kritischen Zeit vor dem Frieden von Campo Formio Loyalität mit dem Herrscherhaus zu demonstrieren, zeigt nicht zuletzt Das herzliche Lied des Tyroler Wastels, und seiner Liesel, das bei einer Prager Huldigungsvorstellung gesungen wurde. In der Königsstadt an der Moldau hatten sich während der unsicheren Monate große Teile der kaiserlichen Familie aufgehalten. Nun, kurz vor dem Abschied, blieb keine Gelegenheit ungenutzt, ihnen den Rückhalt und die Anhänglichkeit des böhmischen Volks zu versichern. Wastels dialektale Ovation sollte demonstrieren, dass man den Tirolern um nichts an Vaterlandsliebe nachstand. Die neunstrophige Eloge wurde - so berichtet zumindest die Hofpresse - zur euphorischen Treuekundgebung: „Jede Strophe des Lieds, die innigen Bezug auf ihre Majestäten, und die anwesenden sämmtl. höchste Herrschaften hatte, wurde so zu sagen mit Ungestüm applaudirt, und mit einem herzlichen Vivat! begleitet. Da die aufrichtigen Wünsche des Publikums in demselben gleichsam vereinigt waren, so mußte dasselbe auf unabläßliches Verlangen wiederholt werden. “58

1

Ey schaut doch die Liesel is komma,

Das freut uns Tyrola gar sehr;

Sie hat von enk Praga vernomma,

Oes halts auf des Koasas san Ehr'.

Oes liebts ja die Prinza von Herza

Unds Koasas schön blühenden Stomm,

O d' Liebe, die brennt wie a Kerza,

Und lodert in d' Höh' wie a Flomm.

[...]

8

Brav seyds ös, ihr redlichen Praga;

Der Burger, der Fürst, und der Graf,

Die Künstler, so wie d'Kaufmannsdiena',

Kurz: alles was z Prag ist, ist brav.

Brav seyds ös, ihr Landleut, unn Baura,

Ihr schützet das Land in Gefahr;

Der Ruhm eures Muthes wird daura

Auf d' Enkel in d' spätheste Jahr!
7

Gott's Lohn wird enk Praga schon komma,

Die Ihr enk habt g'rüstet zum Streit!

Wir hobn in Tyrol schon vernomma,

Wie ehrlich und tapfer ihr seyd,

Brav seyds ös Beamte und Stända!

Wir drucken enk dankbar die Hand:

Brav seyds ös, ihr Pragastudenta!

Oes liebts unsern Franzel unds Land!

\section{9}

Der Franzel und d'Resel soll leben;

und Karl unser Retter dabey,

Und, was nur Soldat ist, soll leben,

Sie waren den Koasa stets treu!

Und kracha d'Kanona beym Frieda,

So trinkt man auf Resel und Franz:

Dann draht, statt dem Rauffa, sich wieda

Der Wastel und d'Liesel beym Tanz. ${ }^{59}$

57 Sieben ganz neue Lieder aus dem Tyroler Wastel [o. O., o. J.].

58 Denkmal wahrer Bürgertreue. Oder Sammlung aller Gedichte, welche bei höchster Anwesenheit Ihrer königlichen Hoheiten der durchlauchtigsten Erzherzoginnen und Erzherzoge erschienen sind. Herausgegeben von A. E. Prag: Franz Gerzabeck Sohn 1797, S. 30.

59 Ebda., S. 38, 40f. 
1,1 Liesel] Erzherzogin Maria Elisabeth von Habsburg-Lothringen, streitlustige Äbtissin des Adeligen Damenstifts in Innsbruck; im Volksmund wurde die korpulente, durch Pockennarben entstellte einstige Schönheit ,kropferte Liesl' genannt 1,3 enk] euch 1,4 Oes] ihr 9,2 Karl] Karl von Österreich-Teschen, Oberbefehlshaber der Reichstruppen an der Rheinfront; die Siege bei Amberg und Würzburg 1796 brachten ihm große Popularität, mehr noch aber die Schlacht bei Aspern 1809, wo er Napoleon die erste Niederlage zufügte

Patriotismus ist generell ein dankbares Spielfeld für die Literarisierung von verschiedenen Volks- und Regionalstereotypen, denen - wie bereits im zweiten und dritten Kapitel gezeigt - mehr oder weniger distinktive Eigenschaften zugeschrieben wurden. Positive Reduktionen beschworen die Einheit des Reichsverbands, der als politischer gemeinsamer Nenner Heterogenes verband; negative Reduktionen schürten den Hass auf den ,fremden' Gegner und legitimierten die Aggression über das Inkommensurable der Religionen, Sprachen oder Haltungen. Ein instruktives Beispiel für propagandistische Funktionalisierung stereotypisierter Figuren sind die, vaterländischen' Spiele wie etwa Wenzel Blimas Der gestrige Tag (vgl. S. 201), das schon im Vorwort „Thathandlungen“ verspricht, „welche redende Beweise sind, wie bieder, wie patriotisch, und wie edeldenkend die Bewohner des Erzherzogthums Oesterreich ob der Ens gegen ihren Landesfürsten bey allen Gelegenheiten sich auszeichnen “60. Dementsprechend schablonisiert sind die Protagonisten, die als verallgemeinernde Repräsentationen der ,Vaterlandsliebe obrigkeitlich gewünschte Verhaltensweisen vorzeigen.

Nicht weniger verkürzt, doch im Negativen, sind in derselben Zeit des Ersten Koalitionskriegs die Gegnerbilder. Als diffamierende Kontrastfolien des Eigenverständnisses, die ,nationalen Hass' generieren sollen, ${ }^{61}$ greifen sie Topoi der Unmenschlichkeit auf und skizzieren Horrorszenarien, um zum Abwehrkampf zu mobilisieren. Als letztes Beispiel sei in diesem Zusammenhang das berühmte, vielgesungene Spingeser Schlachtlied (1797) genannt, das als Flugschrift zirkulierte, die offensichtlich auf ein breiteres, koalitionäres Publikum abzielte, versuchte man doch mit Erläuterungen allzu tirolerische Formulierungen verständlich zu machen. Kontrafaktorisch auf die Melodie der humoristischen, Schwazer Predigt' Jaz wöll ma ge $n$ heilig'n Geist singa gedichtet, prangert der (vermutliche) Autor Franz Karl Zoller (1748-1829/39) zu Beginn die Gräueltaten der Franzosen in drastischen Bildern an: ${ }^{62}$

Jez wöll'n mär gien n’Französen zü gög’n gien,

Mei, wos hobn's denn do bey üns herinn z'thien?

Es hot sie einär plangt ${ }^{(a)}$

Mär hobens nit verlangt

So käm an jedär Narr,

Fräß üns mit Haut und Haar:

Dös geat do nit, eyawohl

in Tyrol

60 Blima, Der gestrige Tag, S. [-4].

61 Vgl. Joep Leerssen: Nation, Volk und Vaterland zwischen Aufklärung und Romantik. In: Alexander von Bormann (Hg.): Volk - Nation - Europa. Zur Romantisierung und Entromantisierung politischer Begriffe. Würzburg: Königshausen \& Neumann 1998, S. 171-178, hier 172f.

62 Zur Kontextualisierung und Rezeption des Lieds vgl. Hupfauf/Erber, Liedgeschichten, S. 95-117. 
Di Brixner öper ${ }^{(b)}$ dö lärmen ${ }^{(c)}$ wohl fast,

Do hobens plündert, wos geist und wos hast ${ }^{(\mathrm{d})}$

Gsoffen aus den Wein,

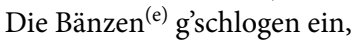

Die Kästen augehackt,

Die Kreuzar ${ }^{(\mathrm{f})}$ ausser zwackt:

Und gnommen krod s'Allerböst

Dös seyn Göst!

Z'Michael ${ }^{(\mathrm{g})}$ unten, Bue, do hob’n die (mi graußt,)

Wenn ich drun denk'n thue) dö Lumpen recht g'haußt:

Den armen Patern droant,

Ja gor die Kirch nit g'schoant,

S'Zibori ausser g'riss'n,

Die Hostien umher g'schmiss'n:

Ist dös nit a Gspöttä(h), pfui!

Meiner Trui!

Oes Gitschelen $^{(\mathrm{i})}$, und ös Weiber göbt acht!

Daß enk öper der Franzos nit aufocht ${ }^{(\mathrm{k})}$,

Er suecht enk aus die Söck,

Reißt enk den Brustich ${ }^{(1)}$ wöck,

Treibt Kühe und Goas darvun,

Z'löscht zündt er d'Häuser un:

Und zueher laß’n sölla Hund,

$[\ldots]$

Wär mär z’rund.

(a) Sie sehnten sich herein zu kommen. (b) etwa. (c) jammern. (d) was der Brief vermag. (e) die Fässer. (f)

das Geld. (g) zu Wälsch-Michael im Kloster. (h) Gespött. (i) Mädchen. (k) auffangt. (l) Schnürbrust. ${ }^{63}$

1,1 mär gien] wir rasch zü gög'n gien] entgegengehen 1,2 z'thien] zu tun 2,2 wos geist und wos hast] so viel wie möglich 2,6 ausser zwackt] herausnehmen 3,1 Z'Michael] St. Michael an der Etsch/San Michele all'Adige: 1807 aufgehobenes Augustiner-Chorherrenstift 3,5 Zibori] Ziborium: Speisekelch zur Aufbewahrung der konsekrierten Hostien 4,3 enk] euch 4,5 Goas] Ziegen 4,7 zueher] herzu, näher her sölla] einen solchen

Im zweiten Teil des Lieds, das weniger ein Schlachtgesang als ein Siegeslied ist, wird ein lebhafter Kampfbericht gegeben, der die Tapferkeit der Tiroler als Vorbild und Ansporn für die übrigen Völkerschaften der Allianz recht eindimensional herausstreicht. Recht besehen unterscheiden sie sich in ihrer mörderischen Kompromisslosigkeit nur in dem einen vom Gegner - dass sie ihr Eigenes verteidigen.

\section{Reiselieder, Reiseerzählungen, Länderklischees}

Beständigere Stereotype als anlassbezogene, für die Agitation funktionalisierte ,Kriegsklischees', deren Gültigkeit rasch durch geänderte politische Konstellationen in Frage

63 Kriegslied eines Tyrolers im Landsturm. An. 1797. Nach der bekannten Melodey: Jez wöll’n mier gien den heilign Geist singen u.s. w. Innsbruck gedruckt mit Wagnerschen Schriften, f. 2r-3v. Bereits ediert bei Bauer, Tiroler Kriegslieder, S. 104-107, ohne nähere Quellenangabe. Zuletzt abgedruckt in Hupfauf/Erber, Liedgeschichten, S. 95f., allerdings mit irritierendem diakritischem Ring (für das superskribierte ,e') als Markierung des hellen ,a'. 
gestellt werden konnten, finden sich in jenen Liedern und Erzählungen, in denen meist im Rahmen eines fiktiven Reiseberichts - die verschiedenen Charakteristika unterschiedlicher Länder und Regionen bzw. ihrer Bewohner aufgezählt und vergleichend gegenübergestellt werden. Nicht die unmittelbare Erfahrung und Begegnung bestimmen das wiedergegebene Bild, sondern Attribute aus „einer Art literarischer Requisitenkammer, einem schriftlich fixierten Fundus der geläufigen Vorstellungen von fremden Völkern“ ${ }^{64}$. Literatur war tatsächlich der eigentliche Träger nationaler und regionaler Stereotype und sorgte für ihre Prolongierung, selbst wenn manche Attribute bereits obsolet geworden waren. Zahlreiche, Nationalcharaktere', deren Komponenten sich in der öffentlichen Meinung bis heute erhalten haben, wurden bereits in den Epithetalisten und Poetiken der Frühen Neuzeit verzeichnet und somit für die Literatur verfügbar gemacht, wobei Fremd- und Eigenzuschreibungen weniger differieren, als man vermuten würde. ${ }^{65}$ Was uns an Stererotypen in der Literatur vor 1800 begegnet, sind Eigenschaftskonglomerate, die ihr Material aus Ständeklischees ebenso gewinnen können wie aus der Humoraltypologie oder aus extrapolierten Individualcharakteren und diese Attribute ethnisieren bzw. regionalisieren. ${ }^{66}$ In der komischen Literatur spielen darüber hinaus auch die kirchlichen Sündenkataloge, die von lässlichen bis ,himmelschreienden ' Verfehlungen reichten, eine wesentliche Rolle.

Besonders beliebt scheint im österreichischen Raum das Reisescherzlied Jetzt bin ich mir schon satt gnug graist gewesen zu sein, das uns in je zwei gedruckten bzw. handschriflichen Fassungen ab der Mitte des 18. Jahrhunderts überliefert ist, aber durchaus älter sein könnte. In diesem Lied berichtet ein Sprecher aus dem Wiener Raum von seiner Reise durch Mitteleuropa und gibt dabei (oftmals bis heute geltende) Vorurteile und Ressentiments zum Besten. Wieder in Niederösterreich angekommen und kurz vor dem Ende seiner Fahrt rekapituliert er die verschiedenen Stationen: Zunächst war er längere Zeit bei den Steirern, auf deren Kochkünste und körperliche Defekte er besonders genau eingeht, ein ähnliches Bild zeigt sich in Kärnten, dann gehts zu den bitterarmen Windischen, den verbrecherischen Krainern, den eifersüchtigen Welschen, den eitlen Franzosen, den stockfischessenden Holländern, den standardsprechenden Sachsen, den eselhaften Schlesiern, den diebischen Böhmen, den feigen und verlausten Schwaben, den versauten Bayern, den viehverschneidenden Salzburgern, den schussgewaltigen Tirolern, den versoffenen Oberösterreichern, den türkischbeeinflussten Ungarn, um schließlich wieder bei den niederösterreichischen ,Fläschl-Tragern` zu landen. Viele der negativen Zuschreibungen finden wir leicht variiert auch in anderen dialektalen Arbeiten wieder.

Im Folgenden ist die ältere der Flugschriftfassungen wiedergegeben, auf der auch der zweite Druck fußen dürfte, der manche Schreibung modernisiert, aber dabei auch komische Feinheiten nivelliert, so etwa den bis heute beliebten Scherz, was zwischen den niederösterreichischen Städten Stein und Krems liege:

64 Franz K. Stanzel: Europäer. Ein imagologischer Essay. 2., aktual. Aufl. Heidelberg: Winter 1998, S. 18.

65 Vgl. Florack, Bekannte Fremde, S. 66.

66 Vgl. Stanzel, Europäer, S. 21. 
1

JEtzt bin ich mir schon satt gnug graist/ hab gsehen fremde Länder, bleib gleich wohl noch beyn alten Laist/ auf Teusch ein Narr wie ehender. Auf Stain, Und, Krembs will ich noch gehn, will ich mein Vorwitz biessen/ aft wann ich kom hinab auf Wienn, will ich mein Raiß beschliessen.
2

In Steyermarck bin i 3. Jahr gwest/ da hats mir ä nicht gfallen, än Stertz auf d'Nacht / än Stroh ins Beth, sonst nicht als Bohna z'fressen, der Strugl solt ä parte seyn/ danck dirs mit deiner Mutter/ alle liebe Tag än Haiden-Brein, ist nur a Gimpel-Fuetter. ${ }^{67}$

1,3 beyn alten Laist] bei den alten Gewohnheiten 1,4 auf Teusch] auf Deutsch; kurz und gut 1,5 Stain] Stein an der Donau (heute Stadtteil von Krems) Und] 1796 aufgehobenes Kapuzinerkloster und Ortsname (heute zu Krems an der Donau gehörig) 1,6 biessen] büßen 2,2 ä] auch 2,3 Stertz] kleinbröckeliges Getreidegericht 2,5 Strugl] Strudel ä parte] (franz. à part): in ungewöhnlicher Weise geschmackvoll 2,7 Haiden-Brein] Haiden: Buchweizen/Brein: Brei aus Hirse oder Buchweizenmehl; Haiden-Brein oder auch Haiden-Sterz stellte bis ins 18. Jahrhundert ein Grundnahrungsmittel dar und wurde erst im 19. und 20. Jahrhundert durch ,Türken (Mais), Kartoffeln und Weizen verdrängt

Bei aller satirischen Verkürzung und Abwertung spricht das Stereotyp doch auch tatsächliche Sachverhalte an. Bis heute gelten Hülsenfrüchte (Käferbohne) und Getreidegerichte (Sterz) als Spezifika der steirischen Küche. Auf das physische Charakteristikum der Struma, das in den folgenden Strophen 3 und 4 angesprochen wird, wurde bereits oben eingegangen (vgl. S. 348). Ganz ähnliche Vorstellungen galten zur Entstehungszeit des Lieds auch noch für Kärnten, das gleichfalls über körperliche und geistige Deformationen bzw. über seine Kulinarik definiert wird:

5

In Kärndten bin ich auch schon gwest/

dort han ich schon erfahren,

was drinen geht aufs allerbest/

gibts nichts als Kröpf und Narren/

die Kost vor ordinari schier,

ist Brein, Talken / und Blenten,

darzu von Stain das saure Bier,

seyn ihr vier Elementen. ${ }^{68}$

5,5 vor ordinari] für gewöhnlich 5,6 Talken] Teig, teigige Masse Blenten] Plenten: Brei aus Buchweizenmehl (von ital. ,polenta') 5,7 von Stain das saure Bier] Steinbier (bei der Erzeugung wird das Bier mit glühenden Steinen erhitzt)

Bezeichnend für den satirischen Duktus ist, dass die negativen Seiten verallgemeinernd hervorgehoben, die zweifellos gleichfalls vorhandenen positiven aber verschwiegen werden. Dass sich negative Erfahrungen auch charmanter darstellen ließen, zeigt etwa eine vergleichbare Stelle aus einer zeitgenössischen Reisebeschreibung: „Man trinkt also in Kärnten vorzüglich steyersche, und italienische, auch tyrolerische Weine [...], besonders da man im ganzen Lande eine Art Bier braut, das nicht zu trinken ist; es heißt das

67 Drey schöne Weltliche Lieder, Das Erste: Jetzt bin ich mir schon satt gnug graist, hab etc. Das Anderte: Last sich schon der Frühling sehä, Bue das bringt etc. Das Dritte: O Frühlings-Zeit, auf grüner Hayd, schönstes etc. Gedruckt in disem Jahr, f. 1r.

68 Ebda. 
Steinbier, und wird aus Hafer mit etwas Hopfen bereitet. “69 Doch um ein gerechtes Urteil war es dem Autor ohnehin nicht zu tun, wie schon die nächsten Ziele unmissverständlich klar machen. Die Reise geht weiter in den Süden Innerösterreichs, in die bettelarme Windische Mark (heute Ost-Slowenien) und das westlich davon gelegene Krain, deren Einwohner wenig einnehmend geschildert werden: Macht man den einen das Sprachenwirrwarr zum Vorwurf, unterstellt man den anderen eine notorische Kriminalität.

6

In Windisch gibts recht bräffe Leuth, und haben schier nichts z'nagen, ihr Land ist käm ä Händl breit/ vor Hunger schier verzagen, die Sprach ist schelmisch ä darbey/ von jedem Land zam g'stollen/ halb Teutsch, halb Böhmisch / ungarisch halb Wällisch / was nur wolln.

\section{7}

In gantzen Crain da bauens auf vast alle Meil än Galgen, wer dort ä Kind hebt aus der Tauff, muß gleich die B'stattung zahlen/ dann selten kommens unter d'Erd, drum brauchens nicht viel Grüfften, wanns stellen än baar Jährl gwehrt/ verstickens gleich in Lüften. ${ }^{70}$

6,5 schelmisch] unehrenhaft 6,8 Wällisch] Italienisch 7,6 nicht viel Grüfften] Gehenkte wurden zur Abschreckung hängen gelassen, bis sie abfaulten, und durften nicht begraben werden 7,7 stellen] Stehlen 7,8 verstickens gleich in Lüften] werden sie gehenkt

Sind diese äußerst abwertenden Stereotype heute völlig vergessen, so sind uns die folgenden romanischen ,Nationalcharaktere' in ihren Grundzügen gar nicht fremd. Der genießerische, aber auch eifersüchtige und heißblütige Italiener ist auch heute noch ein ebenso dankbares künstlerisches Sujet wie der leichtlebige, selbstverliebte Franzose bzw. die eitle, modebewusste Französin.

8

In Wällisch Land ist der Muscat, ein rechte Stärck des Magen/ doch seyn mir d'Leut als z'rabiat, thut Eyfer-Sucht starck plagen/ und was mich hat am meisten gschröckt, ich muß nur frey bekennä, ich han die Leut nicht anderst g'hört, als Kätzlmacher nennä.

10

Wie ich bin kemma auf Pariß, dort han ich erst erblicket, daß dort a jeds Schmarafl-Gfriß, 30 Fleckl ins G'sicht bicket/ dort tragt än jede Madamsel än Rock als wie ä Glocken, än Kopf als wie a Lambl-fell/ als gstessen voll mit Locken.

\section{9}

In Franckreich bin ich ä schon gwest, hab gsehen räre Sachen/ wer in den Land vil gelten will, der muß Wind können machen/ und weil sie seyn von Haaren krumm, die Hoffart nicht bedencken/ so muß ein jeder Hader-Lump/ die Haar in Beitl hencken.

8,1 Wällisch Land] Italien Muscat] hochgeschätzter Wein aus der Muskateller-Traube (im 18. Jahrhundert berühmt waren die Muscatelli di Monte Fiascone bzw. di Monte Alcino) 8,8 Kätzlmacher] abschätzige Bezeichnung für Italiener (wohl von spätlat. cattia: hölzerner Schöpflöffel (Gatzel), die fahrende ladinische

69 Benedikt Franz Hermann’s Reisen durch Oesterreich, Steyermark, Kärnten, Krain, Italien, Tyrol, Salzburg, und Baiern, im Jahre 1780. In Briefen an den Herrn Hofrath v.S. ... in M. ... Erstes Bändchen. Enthält die Reise durch Niederösterreich, Steyermark, und Kärnten. Wien: Wappler 1781, S. 149.

70 Drey schöne Weltliche Lieder, f. 1v. 
Holzschnitzer zum Kauf anboten) 9,8 die Haar in Beitl hencken] der Haarbeutel war „unter Ludwig XIV. Mode, bestand aus einem wattirten Beutel von schwarzem Taffet und sollte ursprünglich den zusammengelegten Zopf oder das Hinterhaar einer Beutelperücke aufnehmen." (Herders Conversations-Lexikon 1855, S. 193f.) 10,3 Schmarafl-Gfriß] hier wohl: abwertende Bezeichnung für eine Frau 10,4 Fleckl] Schönheitspflaster (Mouches) aus gummiertem Taft und Samt als Kennzeichen französischer Mode und Lebensart bicket] klebt 10,5 Madamsel] Scherzbildung aus Madame und Mademoiselle 10,6 än Rock als wie ä Glocken] Anspielung auf den Reifrock, ein mit einem Gestell aus Gerten, Fischbein oder Ähnlichem gespreizter Rock 10,8 gstessen voll] übervoll

Besonders die frankophoben Charakterisierungen hatten im deutschen Sprachraum schon damals eine ebenso lange wie fruchtbare literarische Tradition. Auf die ,AlamodeLieder', die die kulturelle Dominanz Frankreichs im deutschen Sprachraum anprangerten, wurde bereits hingewiesen (vgl. Kap. 4). Auch die vielen ,Teutsch-Franzos'-Satiren, mit denen , undeutsche' Einflüsse dem Verlachen preisgegeben wurden, operieren mit denselben abwertenden Simplifizierungen. ${ }^{71} \mathrm{Zu}$ den (seit 1714 österreichischen) Niederlanden und Sachsen scheinen ähnlich gängige desavouierende Vorstellungsbilder gefehlt zu haben, denn hier wird das Lied-Ich - das sich ja eingangs als Narr vorgestellt hat - selbst zum Objekt des Verlachens:

11

Ins Holland hab ich mich ä gwagt, und wie ich bin hinkemmä, so han ich fleissig nachi gfragt, wo sie den Stockfisch fangä, allein dort ging es mir schier für/ sie möchten mich ansehen, wohl vor ein solches Wunder-Thier/ da thät ich widä gehen.
12

Von dorten bin ich weck geraist, hab gesehen andere Strassen, in Sachsen, oder wie mans haißt, das Ding kunt ich nicht fassen/ dorten die Leuth seyn so geschickt, und höflich ä darneben/ mein Baurn-Sprach sich nicht da schickt, müßt alln än Narrn abgeben. ${ }^{72}$

11,4 Stockfisch] durch Trocknung haltbar gemachter Fisch verschiedener Art (Dorsch, Seelachs etc.) 11,5 ging es mir schier für] kam es mir vor 12,6 ä darneben] noch dazu

In beiden Fällen entlarvt sich der Sprecher als ungebildeter Tölpel, ob er nun einen Begriff (Konservierungsmethode statt Gattung) missversteht oder unfähig ist, sich standardsprachlich auszudrücken. Sollte diese Strophe mit der geänderten satirischen Zielrichtung nicht nachträglich hinzugefügt worden sein, könnte sie Hinweise auf die Entstehungszeit des Lieds liefern. Denn ganz offensichtlich ist das Minderwertigkeitsgefühl des Ich im Kontext des barocken Sprachenstreits zu sehen, der um die Frage tobte, an welchen Sprachvarietäten sich die schriftsprachliche Überdachung der Dialekte zu orientieren habe. Gottsched als maßgebliche Autorität seiner Zeit positionierte das ,sächsische' (ostmitteldeutsche) Meißnerdeutsch, während seine Gegner wie der Gengenbacher Benediktiner Augustin Dornblüth vehement die Berücksichtigung regionaler Sprechgewohnheiten des süddeutschen Raums urgierten. Zum Zeitpunkt der Entstehung der ,Sachsen'-Strophe scheint die Ablösung der oberdeutschen Schreibsprache als Leitvarietät durch die ostmitteldeutsche Schriftsprache bereits beschlossene Sache zu sein. Ab

71 Vgl. u. a. Ruth Florack: Tiefsinnige Deutsche, frivole Franzosen. Nationale Stereotype in deutscher und französischer Literatur. Stuttgart/Weimar: Metzler 2001. - Florack, Bekannte Fremde.

72 Drey schöne Weltliche Lieder, f. 2 r. 
Mitte des 18. Jahrhunderts intensivierte sich auch die Pejorisierung des Dialekts und die soziale Stigmatisierung seiner Sprecher, die in der Rekapitulation des sächsischen Aufenthalts anklingt. Ein Indiz für eine nachträgliche Erweiterung ist freilich, dass sie in einer Grazer Einzalabschrift zu 18 Strophen fehlt. ${ }^{73}$

Wieder mit der gewohnten Verunglimpfung geht es dann in den folgenden Strophen weiter. Das reiche Schlesien wird über Grobianismen in ein schlechtes Licht gerückt, seine Einwohner als Eselfresser verlacht (ein Spottname ungeklärter Herkunft, der sich bis weit ins 19. Jahrhundert hielt). Den grobschlächtigen Böhmen wird hier nicht ihre sprichwörtliche Musikalität, sondern eine unersättliche Diebeslust nachgesagt, den Schwaben eine sagenhafte Feigheit, wie sie in Schwänken, Spottliedern und Märchen (Die sieben Schwaben) seit dem 16. Jahrhundert vielfach thematisiert wurde; dazu auch noch Verlaustheit.

13

Aft dacht ich her / aft dacht ich hin, wo aus ich solte gehen/ da komts mir endlich in den Sinn, das Schlesien zu besehen, dort habens alls in Abundänz, Käß, Kuh-Dreck / Milch und Butter, wann man betracht die gantz Substantz, kommts alls von einer Mutter.

15

Die Böhmen haben Köpf wie Stier, und seynd fast all leibeygen/ die Kerl sauffen vast nichts als Bier, bis Gerben ausser speyben/ das Stellen habens ä schon g'wohnt, sie seyn als wie die Katzen/ kein Nagl steckt nicht in der Wand, sie thun in ausser kratzen.

17

Wie ich bin kemmä aus den Land, müst ich mich schier Tod kratzen, Leiß hab ich kriegt für s'Vatterland/ von ihren G'sind und Fratzen, wie Zecken fangens z'kriechen an, ich hät schier schelten mögen, beym Schlapprament, und Mordion/ sie nahmen mir schier s'Leben. ${ }^{74}$
14

Aber eins ist was mich hat g'schröckt, das kan ich nicht verhalten, än Esel sey in Land verreckt, man hörts von Jung und Alten, sie zäpften ihn von hinten an/ das Bier heraus zu pressen, und was sie noch mehr haben gethan, den Esel habens gar g'fressen.

16

In Schwaben bin ich auch marschiert, weil ich hab ghört erzehlen/

wie nämblä Schwaben so guräschiert, daß 9. von 10. Ellen/ mit einen Spieß sich haben gwagt, wohl über einen Haasen, und haben sonsten nichts erjagt, als nur ein lange Nasen.

13,1 Aft] dann 13,5 Abundänz] (lat. abundantia): Überfluss, Reichtum 14,8 den Esel habens gar g'fressen] seit dem 16. Jahrhundert finden sich zahlreiche legendarische Begründungen dafür, warum die Schlesier als Onophagen verschrien waren; u. a. dienen dabei Dummheit, Arbeitskraft oder Geiz als Motivation 15,2 leibeygen] abhängig von einem Leibherrn, der zu Frondiensten, Abgaben und weiteren Zwängen verpflichten konnte 15,4 Gerben] Oberhefe des Bieres; hier auch: Erbrochenes ausser] heraus 16,3 nämblä] nämlich guräschiert] mutig, verwegen 16,4 von 10. Ellen] Längenmaß (Wiener Tuchelle =0,776m); aus der Entfernung von

73 Vgl. Jetzt bin i mi schan sot gnueg, greist (Steiermärkisches Landesarchiv, Hs 1109), f. 1r. Es fehlen im Vergleich mit der Flugschriftfassung die Berichte über Slowenien, Sachsen, Schlesien und Salzburg. Die Strophenfolgen 1-5 sowie 16-18 sind identisch, 6-15 entspricht 7, 20, 8, 9, 10, 16, 17, 18, 15 und 11.

74 Drey schöne Weltliche Lieder, f. $2 \mathrm{v}-3 \mathrm{r}$. 
10 Ellen haben sich die Schwaben an den Hasen herangewagt 17,4 G'sind und Fratzen] Gesinde und Kindern 17,7 Schlapprament] Ausruf des Unwillens, vermutlich als verkapptes ,Sakrament ${ }^{`}$ Mordion] der mittelalterlichen Gerichtspraxis entstammender Ruf nach Hilfe (Zetermordio)

Dezenter sind die Anspielungen bei den unmittelbaren Nachbarn. Ein Symbol Bayerns außerhalb seiner Grenzen war die Rennsau, ursprünglich wohl der Trostpreis beim Münchener Jakobi-Dult-Pferderennen, dann vermutlich spöttischer Ausdruck der Provinzialität und Ruralität, aber auch des Reichtums des Herzogtums. Vergleichsweise respektvoll ist der Rückblick auf das prächtige Salzburg, das - um dem Bericht eine komische Wendung zu geben - mit den vorzugsweise aus dem Pinzgau und dem Lungau kommenden Sauschneidern in Verbindung gebracht wird.

18

Wie ich ins Bayrland kemmä bin, da lauft ma d'Sau entgegen, da dacht ich mir in meinen Sinn, möcht auch ä Sau aufheben, da macht ich mich gantz in der Still bald wieder auf die Strassen, die Brad-Würst von der ersten Fill hab ich in Bayrland lassen.

\section{9} In Saltzburg bin ich auch schon gewest/ hab grosse Wundä gsehen, dort gfalt mir wohl ihr schöne Tracht/ weil sie so gsteift hergehen, da ließ ich bald das Land in Stich, und thät mich retiriren/ sie möchten mich wie s'arme Vieh auch schneiden, und kastriren. ${ }^{75}$

18,2 d'Sau] im übertragenen Sinn Schimpfwort für den Bayer 18,4 ä Sau aufheben] sprichwörtlich für: einen Fehler machen 18,7 von der ersten Fill] von der ersten Füllung: aus Darminhalt; vielleicht hier auch sexuelle Anspielung 19,4 gsteift] prächtig, schön 19,6 retiriren] zurückziehen

Der im gesamten Habsburgerreich mit Privileg herumreisende Viehbeschneider, der entgeltlich zu Domestizierungs- und Mastzwecken Nutztiere kastrierte, gehört zu den beliebtesten literarischen, dezidiert dialektal angelegten Stereotypen in der bairischösterreichischen Unterhaltungskultur. Die Sauschneiderei ist das Handwerk des von Joseph Anton Stranitzky kreierten ,Wiener Hanswursts ' ebenso wie des Jöri in Maurus Lindemayrs Ernsthaften Spaß, es steht im Mittelpunkt des populären Scherzlieds Acht Sauschneider müssen sein, das u. a. von Valentin Rathgeber, Joseph Haydn und Wolfgang Amadeus Mozart bearbeitet wurde. Schon in der ersten Ausgabe des Callotto resuscitato ist ihm ein Blatt gewidmet; hier ist es Riepl Gleichdron, dessen Schneidefreudigkeit die Sorge des Rollen-Ich im Reiselied verständlich macht:

Ju huy! woß brauchts denn vil vom oltn Riepl-gsc[h]lecht, kem i holt hea und bin sauschneiders oba-knecht, dopp i umbs messa hea, so schneid i grechats drein, mog Stier, sau, Roß, und hundt, mein brueda selbma sei. ${ }^{76}$

1 kem i holt hea] komme ich eben herbei 3 dopp] tappe grechats] gerade, geradewegs, schnurstracks 4 selbma] selbst

Wenig überraschend kommen beim Tirolbericht die beiden Stereotype vom wehrfähigen Bauern und unterhaltsamen Kindskopf zur Anwendung. Kräftig ausgeteilt wird zum Schluß noch gegen die Oberösterreicher, die auch heute noch als ,Mostschädel' geneckt werden, und gegen die türkisierten Ungarn.

75 Drey schöne Weltliche Lieder, f. $3 r$.

76 Il Callotto resuscitato. oder Neü eingerichtes Zwerchen Cabinet. [Augsburg, um 1710], Bl. 2. 


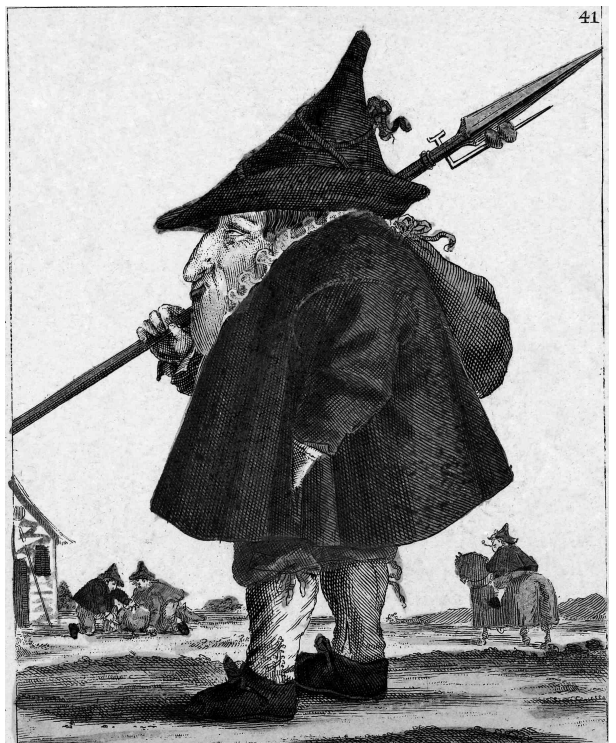

(9)

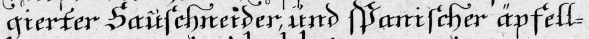
Abaldator.

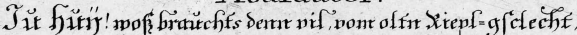

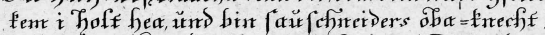

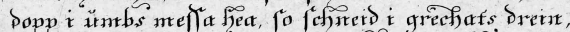

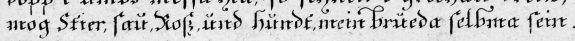

\section{0}

Wie ich bin kemmä ins Tyrol, auf Innsprug und auf Brixen, da gfiellen mir die Bauren wohl/ weils gut verstehn die Büchsen; allein dort hats mich auch nicht gfreit, ich hab schon gschmeckt den Braten, vor 40. Jahr wurd ich nicht gscheit, wär noch ä Gfahr thäs graten.

22

Aft schwum ich auf der Donau weck, grad abi ins Crabaten, in Ungarland beyn Gewernick, da möchts mir besser gratten, dort tragens Hosen wie die Frösch, darzu ein krummen Säbel, kein gutes Hemmet in der Wäsch, das Fressen miserabl.
Abb. 31: Riepl Gleichdron aus Il Callotto resuscitato (Rijksmuseum, FMH 3695-a41).
21

Aft schwum ich auf den Inn wie d'Gänß, wolt lehrnen die Rechts-Händel, da kam ich ins Land ob der Ens, sonst haist mans halt das Ländl. Allein dort ich vor mich nichts fund/ als Apfl-Most zu sauffen, man sagt ein Ländler sey ein Hund/ da ließ ich mich nicht tauffen.

20,7 vor 40. Jahr ... gscheit] Redensart unbekannten Ursprungs, siehe S. 359; nicht umsonst wurde etwa der fiktive Kriegsheld ,Crischtel Troyling' (siehe S.350) mit ,Uber 40. Jahr ' beworben 20,8 thäs graten] täte es gelingen, würde es so ausgehen 21,4 Ländl] volkstümliche Bezeichnung für das oberösterreichische Kernland, insbesondere das Hausruckviertel mit Teilen des Traunviertels 22,2 abi] hinab Crabaten] Kroatenland 22,3 Gewernick] eig. ung. köpönyeg: ,Umhängemantel', von türk. kepenek: ,ungenähter, ärmelloser Filzüber- 
wurf' (der anatolischen Schäfer); hier metonymisch für Türke bzw. die Einwohner des türkischen Vasallenstaats 22,4 gratten] ergehen 22,7 Hemmet] Hemd

Die letzte Strophe schließlich bringt in der Conclusio die Versicherung des Eigenen, das im Kontrast zu den vorgeführten Ethnophaulismen desto lebens- und liebenswerter erscheint. Der Spottname des ,Flaschltragers wird derart zum stolz getragenen Ehrentitel, sodass auto- und heterostereotypische Zuschreibung verschmelzen.

23

So bleib ich halt in Oesterreich/

dort schlag ich auf mein Lager,

von enck ich nimmer hinweg rais/

bleib halt ein Fläschl-Trager/

der Luft ist gsund, die Leuth seynd prav,

das thut mich recht ergötzen,

von enck ich nimmer hinweck raiß,

bis mich mit Hund aushötzen.

23,1 Oesterreich] unter Österreich wird hier nur das Erzherzogtum ,Österreich unter der Enns` verstanden, das etwa dem heutigen Niederösterreich entspricht 23,3 enck] euch 23,4 Fläschl-Trager] Spottname der Niederösterreicher, im Speziellen der Wiener; in seinen Oesterreichischen Volksmärchen (1822) verknüpft Franz Zischka die Entstehung mit der Salzburger Stierwascher-Legende: dort habe man den schwarzen Stier so verbissen weißwaschen wollen, dass sich das Wasser der Salzach, dann des Inns und der Donau weiß färbte; die Wiener liefen daraufhin mit Flaschen zum Strom, weil sie dachten, es wäre süße Milch

So kulturhistorisch und imagologisch interessant diese Reiselieder sind, wirkt die auch in der sprachlichen Gestaltung stark musterhafte Abhandlung verschiedener Länderstereotype für heutige Leser in der ganzen Länge etwas ermüdend. Die negativen Befunde bleiben äußerst eindimensional und sind vor allem dazu da, den jeweiligen Reisefortschritt zu motivieren und die Heimkehr zu überhöhen. Im 18. Jahrhundert aber, in dem Nachrichten über andere Länder und erst recht das Reisen selbst durchaus Seltenheitswert hatten, übten sogar diese reduzierten Informationen über mehr oder weniger exotische Destinationen große Faszination aus.

Das Reisen steht auch im Mittelpunkt der mehrfach aufgelegten Lustigen Reyß-Beschreibung aus Saltzburg in verschiedene Länder; die wohl als Neujahrsgabe ${ }^{77}$ erstmals um 1717 gedruckt wurde und den fiktiven Werdegang des Wiener Hanswurst in einem Narrenepos gestaltet. Als ,Herausgeber' der Schrift firmiert Joseph Anton Stranitzky. Ihr Autor war er - so die Erkenntnisse der neueren theaterhistorischen Forschung nicht; ihm dürfte wohl der Weltpriester Johann Valentin Neiner (1679 bis um 1748) zur Hand gegangen sein, dessen Curiose Narren-Calender auffällige stilistische Ähnlichkeiten aufweisen. ${ }^{78}$ In späteren Drucken aus den 1780er Jahren wird dieselbe Schrift unter dem Namen von Stranitzkys Nachfolger in der Rolle des Hanswurst, Gottfried Prehauser, wiederabgedruckt. Als Persiflage auf die damals blühende Reiseliteratur konzipiert,

77 Vgl. Richard Maria Werner (Hg.): Der Wiener Hanswurst. Stranitzkys und seiner Nachfolger ausgewälte Schriften. 1. Bd.: Lustige Reyss-Beschreibung aus Saltzburg in verschiedene Länder von J. A. Stranitzky. Wien: Konegen 1883. (Wiener Neudrucke 6) S. VIII.

78 Vgl. Rommel, Die Alt-Wiener Volkskomödie, S. 339. - Kauffmann, Es ist nur ein Wien, S. 109. - Otto G. Schindler: Stranitzky, Joseph Anton. In: Rudolf Flotzinger (Hg.): Österreichisches Musiklexikon. 5: Schwechat - Zyklus. Wien: Verl. der Österr. Akad. der Wissenschaften 2006, S. $2324 f$. 
berichtet der einfältige Salzburger Knecht, wie er hoffnungsfroh Abschied vom Bauern Riepel nimmt, um die Welt zu bereisen. Die Unternehmung stellt sich jedoch als komplikationsträchtig heraus: Nur zu oft bitter enttäuscht, zweifelt er immer wieder an seinen Reiseambitionen, um letztlich doch weiterzuziehen, am nächsten Reiseziel erneut sein Glück zu versuchen - und abermals zu scheitern. Seinen Weg skizziert er, in komischer Übertreibung ambitionierter Reiserouten und in bewusst absurder Reihenfolge, folgendermaßen:

erstens nimm ich den kürtzisten Weeg von Saltzburg aus nach Moscau/ von dannen schnur gerad in Thyroll / von Thyroll in Schweden / von Schweden in Steurmarckt / von Steuermarckt in Schwaben / kom ich einmahl in Schwaben-Land / hab ich Croaten gleich an der Hand / darauff wend ich mich auff die lincke Seit / so hab ich in Holland auch nimmer weit / von Holland gehe ich in Westphalen / aus Westphalen geht die ebene Strassen in Italien / von dar kom ich in Böhmen und in die Türkey / endlich zu Wienn in Oesterreich kehr ich ein $[\ldots]^{79}$

Endlich, „nach so vielen Kummer und Hunger / Klagen und Plagen / Hitz und Schwitz / und tausenderley Gefahren / die ich in allen Landen / so Heldenmüthig hab außgestanden“ ${ }^{80}$, kommt er in Wien an, wo er feststellt, „daß jederman an meiner wenigen Person ein geneigtes Gefallen truge " 81 und so beschließt er zu bleiben - und zwar im Dienst des Theaters als ,komischer Bauer'.

Stets werden im Verlauf des Umherziehens bekannte Länderklischees eingebracht, stereotype Motive eingesponnen und Volkstypen - ein Moskauer Zobelbauer, ein schwäbischer Schneckenhändler, ein kroatischer „Hünner-Jubilier“, ein italienischer „Hächlmacher und Mauß-falln-Kramer“ ${ }^{82}$ etc. - karikiert. Dabei wird in hanswurstischverdrehender Manier mit dem Wissen des Publikums um stereotypische Charakteristika gespielt, sodass sich Pointen aus dem Bruch aufgebauter Erwartungshaltungen und Hanswursts daraus resultierenden Widrigkeiten ergeben. Die mit Reimen durchsetzte Erzählsprache bleibt großteils standardsprachlich, doch mit ausgeprägten Merkmalen regiolektaler Mündlichkeit. Diese wird akzentuiert, wenn lokale Umstände und Gebräuche in den Blick rücken, so etwa in der Beschreibung der Erlebnisse in Tirol, wo uns wieder der Ölträger begegnet und - wie fast in allen Kapiteln - bäuerliche Arbeit und Mahlzeit das Thema sind:

[D] a kame just unter der Thür / wieder ein anderer Thyroler zu mir / der truge in einer Schachtel einige lateinische Kuchl wider allerhand Zuständ und Gebrechen / wie man aus dem gedruckten Zettl könt lesen / aber wider den Hunger ist nichts darinn gewesen / diesen batte ich / er möcht sich doch bequemen / und mich in seine Diensten auffnehmen / das war dem Kerl just recht / dann er brauchete eben einen Knecht / aber O Elend! bey diesem feindseeligem Mann / da fieng sich erst die Arbeit recht an / Holtz klieben nach der Läng und über zwerg / Dung tragen auff die allerhöchsten Berg / denen Dirnen die Spän reuspern beym Ruben-Schaben / und sonsten noch

79 Lustige Reyss-Beschreibung aus Saltzburg in verschiedene Länder. Herausgegeben von Joseph Antoni Stranitzky / Oder Den so genannten Wiennerischen Hannß Wurst. In: Richard Maria Werner (Hg.): Der Wiener Hanswurst. Stranitzkys und seiner Nachfolger ausgewälte Schriften. 1. Bd.: Lustige Reyss-Beschreibung aus Saltzburg in verschiedene Länder von J. A. Stranitzky. Wien: Konegen 1883. (Wiener Neudrucke 6) S. 4.

80 Ebda., S. 39.

81 Ebda., S. $41 f$.

82 Ebda., S. 23 und 30. 
Abb. 32: Hanswurst und Tiroler Ölträger in Lustige Reyss-Beschreibung (um 1717).

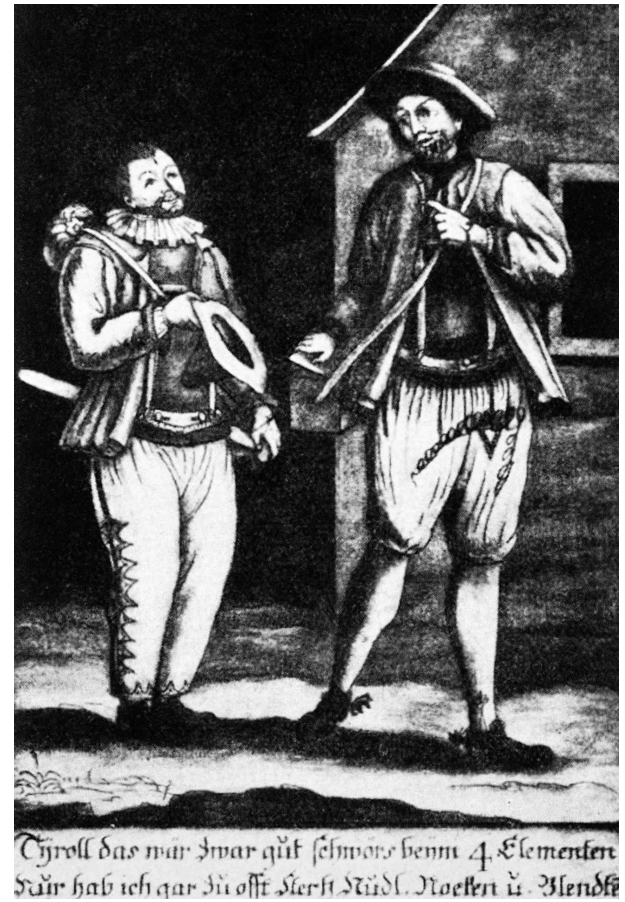

allerhand Sachen / daß einem die Rippen möchten krachen / darbey nichts zu essen als Stertz und Nudl / oder dalkete rockene Strudl / bey einer eintzigen Nocken / blieb ich offt ein gantze Stund hocken / wie hats mir nicht so angst gemacht / biß ichs recht hab hinunter gebracht / endlich wo ich mich nur hin thät wenden / so sah ich nichts als überall Plenden / und wär ich noch länger verblieben an dergleichen Orthen / wär ich zur lauterer Plenden worden. ${ }^{83}$

Kuchl] hier im Sinne von: Arzneien klieben] spalten über zwerg] quer Dirnen] Mägden reuspern] wegzupfen dalkete] blöde, dumme rockene] aus Roggenmehl Plenden] Polenta (aus Maisgrieß)

Diese harmlosen Stereotypenwitzeleien scheinen fixer Bestandteil des Wiener Theaterrepertoires geblieben zu sein, wie nicht nur aus den Neuauflagen des Heftchens über Jahrzehnte hinweg zu sehen ist. ${ }^{84}$ Einige zentrale Figuren - wie der ,Crabatische Hühner-Krammer' (vgl. S. 394) - begegnen uns etwa auch in der (Joseph Felix Kurz-Bernardon zugeschriebenen) Burleske Die Zauber Trommel, die 1737 am Kärntnertor-Theater aufgeführt wurde. ${ }^{85}$

Auch das in einer Handschrift von 1724 aus dem bayerischen Kloster Baumberg überlieferte Schuldrama Glikh-Vndt Vnglikhseelige Rais des Hanswurst greift das Thema

83 Ebda., S. 10f. Abbildung aus Rommel, Alt-Wiener Volkskomödie, S. 349 (dort allerdings mit fälschlicher Beschreibung).

84 Zur Filiation vgl. die detaillierte Aufstellung bei Werner, [Einleitung zu] Lustige Reyß-Beschreibung, S. X$\mathrm{XX}$.

85 Vgl. Max Pirker: [Einleitung]. In: Pirker, Teutsche Arien I, S. IX f. 
des ,Länderreisens' auf, allerdings in nachdrücklich belehrender Absicht: ${ }^{86}$ Die - eigentlich tragische - Haupthandlung bringt das Schicksal eines Schülers mit dem bezeichnenden Namen Peregrinus, der von seinen Eltern eine Reise erbittet, zu der er als Begleiter seinen Hofmeister und den Bedienten Hanswurst mitnimmt. Die Kavalierstour verläuft aber wenig glücklich, die verschiedenen Personen verlieren sich aus den Augen und Hanswurst tötet schließlich aus Unverständnis sogar den Hofmeister. Von Peregrinus verstoßen, wird er angeklagt und zum Tode verurteilt, um am Schluss im letzten Moment durch einen Kammerdiener befreit zu werden. Die simple Lehre des Stücks, sein Glück nicht in der Ferne zu suchen, nimmt sich letzten Endes auch Peregrinus zu Herzen: „Wan ich die so manigfältige verdrüessliche reisens immcommoditeten hätte vorsechen könen, würdte ich mich woll eines anderes besonnen haben. " 87 Gegenbild der als Ideal vermittelten ,stabilitas' ist Hanswurst, dessen anarchische Komik und opportunistische Unverständigkeit das Gefahrenpotential psychischer ,Unbehaustheit symbolisiert. Dialekt dient dabei als Signal des ,Aus-der-Rolle-Fallens', mit dem Hanswurst auch höherstehende, sonst standardsprachlich gezeichnete Figuren wie Peregrinus oder sogar den Richter affiziert. In der Ignoranz sprachlicher Konventionen spiegelt sich seine Verweigerung sozialer Normen. Diese komischen Elemente haben, anders als die didaktische Ausrichtung des Stückes, auch heute ihren Reiz nicht verloren, wie das ,Mordgeständnis' des Hanswurst belegt:

Peregrinus. wo ist dan der hoffmeister, das er sich heundt niemahlen sehen last, ist er villeicht krankh?

Hanswurst. Nä, iezt fählt ihm wiedä nix mehr, aber göstern ist ä ga grob ybl auf gwön.

Peregrinus. Von disen hab ich kein wordt gewust, wer hat ihm wider geholffen?

Hanswurst. i han ihm gholffen.

Peregrinus. wie da?

HANSwURST. in den langä waldt göstern istn S:grümmä ga starkh a kembä nachä ha i mi halt däbarmbt, vndt han ihm S:mössä in bauch gstochä, däss grimmä hat auffä kört, vndt dass ä fei warmmb hat ghabt, han in vnter einen mist hauffen begrabn, iezt würdt ihm nix mehr wehe thain.

Peregrinus. hans wurst, du hast eines theills ybel angefangen, hat dich niemandt gesehen?

HANSwurst. kai mensch nöt 2 handtwerchs pürschl sändt vo bey gangä, dö habn mi abä nöt sechen könä, den i ha d:augen vöst zuethan.

Peregrinus. O vnuerstendiger tropff: ergo habn sye dich nit sechen könen, weill du die augen geschlossen?

Hanswurst. ia ha do i sö ä nöt gsechn.

Peregrinus. iezt fangt mein reis recht an verdrüesslich zu werdten. warumb hast du nit vorhero von disen vngeschikhten vnterfangen mir etwas verthrauet? beede seindt wür nunmehro in grester gefahr, verathen, vndt in die harte gefangenschaft hinwekh geschlepet zu werdten. wo ist dan das gelt, so der hoffmeister für meine reis mit sich geführet.

86 Der Charakter des Stücks als Schuldrama wird besonders daran deutlich, dass etwa im zweiten Akt eine lateinische Szene mit einer Gelehrtendiskussion, die mit der Handlung kaum in Verbindung steht, eingefügt ist (II,4). Auch in Szenen wie einer Gerichtsverhandlung (I,6) oder einem Monolog des Diogenes (II,1) scheinen weniger die Handlung des Stücks als die Demonstration rhetorischer Fertigkeiten im Zentrum zu stehen.

87 Bayerische Staatsbibliothek, Cod. germ. 4396 (Glikh- Vndt Vnglikhseelige Rais des Hanswurst Vorgestellet in einer Action auf offentlichen Theatro von denen Seminaristen in Baumburg. 1724.), f. 16v. 
Hanswurst. hat ä den ä gelt ä ghabt?

Peregrinus. O vnglikh verdambte bestia, du hast ia selber gesehen, das ihme mein Pa Pa 2000 Ducaten eingelifferet.

Hanswurst. 2000 Ducaten? das ist 2000 Mahl fein saubä dä logn.

Peregrinus. wie? soltest du noch zu meinen vnglikh spotten du bestia. augenblickhlich mach dich forth von mir, ich verlange den vngeschikhte bauern dienst nit mehr.

Hanswurst. ha ha, wie so granti herr Peregrin.

Peregrinus. gehe mir von den leib, oder ich lass dir dieses kalte eisen durch den leib pahriren. NB Peregrin stost mit den degen nach den hanswurst.

Hanswurst. iezt bin i hin, maus dodt bin i.

Peregrinus. das ist dein verdienter lohn du canallia. ich bin des lebens müedt, ich mues denselben ein Endt machen. diser Dolche soll mir den weeg zeigen zu einer langen vnglikhseeligen reis, welche mein hoffmeister allbereith durch vnbesonnenes verfahren meines verfluechten dieners angetretten.

et abiit.

Hanswurst. geh hin mei Peregrin geh hin. alls wan mä den narrn nit grathen kuntn, stirb dir meinentwegn ä guetts genüegen. iezt löb ich erst gern, iezt will erst $i$ ä herr wern. abä wie du armä nar? I wais scho was i thue. den hoffmaister grab i aus, lög seine klaider an, 2000 ducaten hat er ä bey ihm. la no gehen, es hat schon grathen. guraschi madam, wer suecht der findt. ${ }^{88}$

gwön] gewesen $\mathrm{i}$ han ihm gholffen] die Verwendung von ,helfen` spielt hier mit der möglichen negativen Konnotation des Verbs (,ich werd' dir schon helfen!') grümma] Zwicken, Kneipen, Bauchschmerzen a kembä] bekommen, befallen auffa kört] aufgehört (Schreibversehen?) dass ä fei warmmb] damit er es schön warm saubä dä logn] schön erlogen granti] mürrisch, verdrießlich hin] (verächtlich:) tot et abiit] (lat.) und geht fort/ab grathen] (hier): entraten, entbehren la no] lass nur es hat schon grathen] (hier): es ist schon gelungen, mir wurde schon geholfen guraschi] (franz. courage) Mut

\section{Grenzgänger der Sprachen}

Nicht nur stereotypisierte Figuren aus dem bairisch-österreichischen Sprachraum kommen in dialektalen literarischen Texten vor, sondern auch ,Fremde', die als Nicht-Muttersprachler gezeichnet und sprachlich durch ein typisches Kauderwelsch charakterisiert werden, das durch Abweichungen in Aussprache, Wort- und Satzbau bzw. durch das Einfügen fremdsprachiger Wörter gekennzeichnet ist. In der komischen Dichtung hat die Sprachmischung als Stilmittel eine lange Tradition ${ }^{89}$ mit dem Makkaronismus als eigener, auch im deutschsprachigen Raum äußerst beliebter Gattung. ${ }^{90}$ Das Besondere an den Figuren, wie sie im Folgenden vorgestellt werden, ist, dass ihre Muttersprache

88 Ebda., f. 17v-18v.

89 Vgl. etwa Paul Goetsch: Fremdsprachen in der Literatur: Ein typologischer Überblick. In: P. G. (Hg.): Dialekte und Fremdsprachen in der Literatur. Tübingen: Narr 1987. (ScriptOralia 2) S. 43-68, insbes. S. 55f. (für das englische Drama). - Manfred Schmeling/Monika Schmitz-Emans: Einleitung. In: Manfred Schmeling / Monika Schmitz-Emans (Hg.): Multilinguale Literatur im 20. Jahrhundert. Würzburg: Königshausen \& Neumann 2002.

90 Vgl. Hermann Wiegand: Makkaronische Dichtung. In: Harald Fricke (Hg.): Reallexikon der deutschen Literaturwissenschaft. 3., neubearb. Aufl. Bd. 2: H-O. Berlin/New York: de Gruyter 2000, Sp. 527-530. 
nicht mit der Standardsprache des Gastlands interferiert, sondern mit einer regiolektalen Variante. In den Fokus rückt damit ein weiteres Mal der Aspekt der Mündlichkeit: Dialekt und fremdländischer Akzent summieren sich in diesen mündlich markierten Texten nicht nur; die spezifische Mischung weist auch darauf hin, dass das Erlernen der deutschen Sprache gerade in den Unterschichten - nicht nur im 17. und 18. Jahrhundert - häufig nicht schriftlich, sondern im Wesentlichen mündlich erfolgte, und damit auf einer mündlichen - dialektalen - Varietät des Deutschen im süddeutschen Raum basiert.

Dabei können mit einer solchen Darstellung von Fremden in (dialektalen) Texten unterschiedliche Funktionen verbunden sein: die Nutzung komischer, ,entautomatisierender' und aufmerksamkeitssteigernder Effekte, die mit der Sprachmischung verbunden sind, ebenso wie die Steigerung von Anschaulichkeit oder die Suggestion von Authentizität. Nicht zuletzt aber wird auf diese Weise dezidiert auch Fremdes und Eigenes verhandelt, wobei die Figur des Anderen sowohl als negative als auch als positive Vergleichsfolie dienen kann. Jene Konstellation, in der eine positiv gezeichnete ,fremde Figur in kritischer Absicht dem Eigenen gegenübergestellt wird, lässt sich häufig mit dem Motiv des ,edlen Wilden' in Verbindung bringen, das im 18. Jahrhundert insbesondere im Kontext der Aufklärung breit rezipiert wurde und u. a. auch im Wiener Spaßtheater in verschiedenster Weise verarbeitet wurde. ${ }^{91}$ Auch Schikaneders Tyroler Wastel liegt etwa dieses Muster zugrunde. Doch öfter noch ist der ,Wilde“ nicht edel, sondern in seiner exotischen, lächerlichen oder auch abstoßenden Andersartigkeit vor allem dazu geschaffen, sich der Vorzüge des Eigenen zu versichern. Dass dieses ästhetische Konzept zumal in politisch-propagandistischen Texten zur Anwendung kommt, kann nicht verwundern. ${ }^{92}$

\section{Romanische Wanderhändler und Lohnarbeiter}

$\mathrm{Zu}$ den ältesten bilingualen Figuren in der bairisch-österreichischen Dialektliteratur zählen fahrende Krämer, die uns in ihren ,autochthonen` Pendants mit den charakteristischen Kaufrufen, Lockgesängen und Standesliedern bereits an anderer Stelle begegnet sind (vgl. Kap. 4). Im Unterschied zu diesen reindialektalen Rollen aber wird hier der Exotismus zudem durch Phänomene der Sprachmischung, der Interferenz und des Codeswitchings verstärkt und zumeist für komische, aber auch latent bis dominant xenophobe Wirkeffekte genützt. Besonders im süddeutschen Raum waren Fahrende aus Italien kein ungewöhnlicher Anblick. Mit südländischen Viktualien oder Heilmitteln,

91 Vgl. Matthias Mansky: Nachwort. In: Gottlieb Stephanie der Jüngere. Die abgedankten Officiers oder Standhaftigkeit und Verzweiflung. Ein Lustspiel von fünf Aufzügen. Hg. von Matthias Mansky. Hannover: Werhahn 2015, S. 131-159. - Matthias Mansky: Der ,edle Wilde` als lustige Figur? Funktionalisierung und Transformation bei Franz von Heufeld und Joseph Felix von Kurz-Bernardon. In: Franz M. Eybl (Hg.): Nebenschauplätze. Ränder und Übergänge in Geschichte und Kultur des Aufklärungsjahrhunderts. Bochum: Winkler 2014. (Das achtzehnte Jahrhundert in Österreich 28) S. 193-207.

92 Ausführlicheres zur Darstellung von Fremden in literarischen Texten vgl. Elisabeth Zehetner: Dialekt und die literarische Darstellung von Fremden vor 1800. Untersuchungen zum Verhältnis zwischen Eigenem und Fremdem. Graz 2016 [Dipl.]. 
mit Schnitzkunst oder Kleinwaren, mit Guckkästen oder Skioptika, mit Hilfsdiensten im heilkundlichen oder handwerklichen Bereich brachten sie willkommene Abwechslung in den ruralen und urbanen Raum, von Publikum und Kauflustigen argwöhnisch beäugt und belustigt bestaunt.

Dies wird in einem Lied deutlich, das als Der walsche Kramer bereits in einer 45-strophigen Fassung aus dem späten 17. Jahrhundert (mit Melodie) überliefert ist; ${ }^{93}$ Teile dieses Lieds finden sich noch einmal um 1740 in einer wohl in Wien entstandenen Handschrift ${ }^{94}$ bzw. in der oberschwäbischen Ostracher Liederhandschrift. ${ }^{95}$ Es bietet eine seltsame Mischung verschiedener Motive und Gattungen, die eine Kompilation unterschiedlicher Quellen vermuten lässt, denn das Spektrum reicht vom Kaufruf und dem Anpreisen verschiedener, kurioser Waren über Soldatenlied bzw. Soldatenklage bis zur heftigen Frauenschelte.

Zu Beginn der umfangreichsten älteren Fassung (Str. 1-9) gibt der Händler einen mit Kaufaufforderungen garnierten ersten Überblick über sein reiches, aus Italien importiertes Warenangebot, das Haushaltsgegenstände ebenso umfasst wie Galanteriewaren, vor allem aber unterschiedliche Heilmittel, Devotionalien und Andachtsgegenstände, deren italienische Herkunft offensichtlich für das ,echt Katholische' bürgen soll. Angeboten werden Rosenkränze, Ablässe, die gegen bösen Zauber helfen sollen, gedruckte Andachtsbilder und wächserne gesegnete Reliefbilder, die als Heilmittel gegen Kopfweh und Fallsucht angepriesen werden. Für komische Effekte sorgen in diesem Kontext nicht nur die geschickte Markierung des italienischen Akzents des Händlers und die witzige Verdrehung bis heute verwendeter Verkaufsfloskeln („schadts nit so hilffts doch nit ${ }^{\text {“96), }}$ sondern vor allem auch der durch und durch profane Umgang mit heiligen Dingen, der heuchlerische Frömmigkeitspraxen und einen allseits tief verankerten Aberglauben offenlegt.

Schon mit den ersten Versen wird das Rollen-Ich unmissverständlich als Fremder gekennzeichnet - und das nicht nur durch Herkunfts- und Ortsbezeichnungen, sondern auch durch sein sprachliches ,Kauderwelsch'. Nirgends ist dieser aus dem 16. Jahrhundert stammende Begriff passender als in diesem Kontext, verbindet er doch ,kaudern', d. i. Handel mit Kleinwaren zu betreiben, mit der alten deutschen Bezeichnung für romanische Sprachen. ${ }^{97}$ Diese verworrene Sprechweise, die alle verfügbaren sprachlichen

93 Staatsbibliothek zu Berlin, Ms. Germ. Oct. 230 [Papierhandschrift ohne Titel, um 1650-1690], f. 96-110. 45 Strophen. Vgl. zur Datierung u. a. Bolte, Der Bauer im deutschen Liede, S. 28. - Für eine zusammenfassende Beschreibung und weiterführende Angaben zur Handschrift vgl. Ikonić, Von dem Entsaz wien, S. $117 \mathrm{f}$.

94 Wienbibliothek im Rathaus, H. I. N.-4623 (Papierhandschrift ohne Titel: Schlüssel für Geheimschriften, Lieder, Arien aus Wiener Hanswurstkomödien; vermutl. Wien, um 1740). Die Cantilena Gä soldat mag ig nimmer say (S. 459f., 9 Strophen) übernimmt die Strophen 10-15 des oben genannten Lieds, die Cantilena O du mein Treuer Gott (S. 463f., 8 Strophen) die Strophen 29, 32, 33, 36, 38, 40, 41 und 44.

95 Vgl. Rattay, Die Ostracher Liederhandschrift, S. 81f. - Michael Gerhard Kaufmann (Hg.): Ostracher Liederhandschrift. Kommentiert und mit einem musizierpraktischen Teil versehen. Konstanz, Eggingen: Isele 2006. (Bibliotheca suevica 19).

96 Staatsbibliothek zu Berlin, Ms.germ.oct. 230, S. 99.

97 Vgl. Etymologisches Wörterbuch des Deutschen. Erarbeitet im Zentralinstitut für Sprachwissenschaft, Berlin, unter der Leitung von Wolfgang Pfeifer. 2. Aufl. München: dtv 1995, S. 639. 


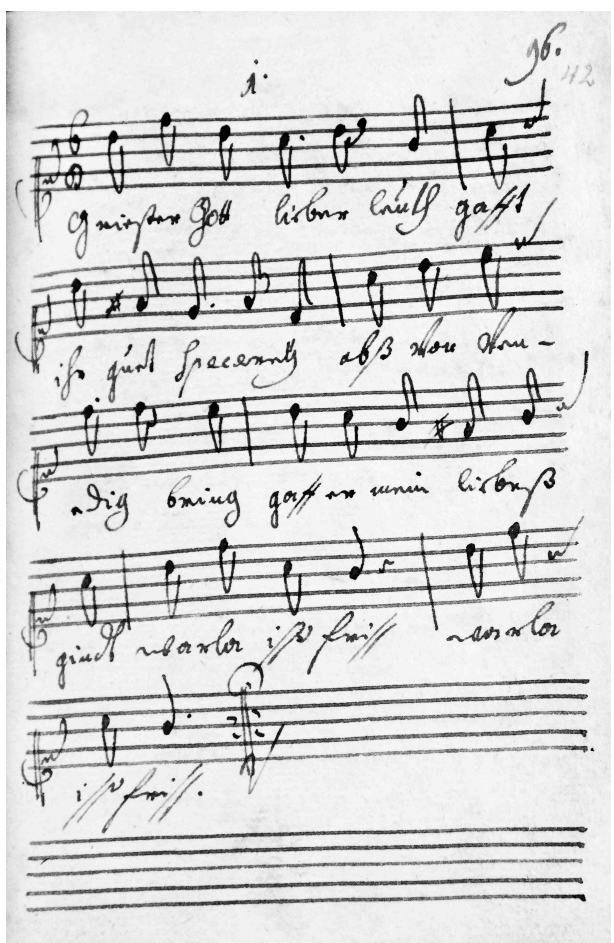

Abb. 33: Der walsche Kramer (Staatsbibliothek zu Berlin, Ms.germ.oct. 230, f. 96).

Mittel einbringt, um zum kommunikativen Ziel zu gelangen, ist im Walschen Kramer vergeichsweise stark phonetisch wiedergegeben, um ein möglichst wirksames Klangbild des kuriosen Radebrechens literarisch nachzuschaffen:

1

Griester Gott lieber leuth gafft ihr guet specerey $\mathrm{ab} ß$ von venedig bring gaff er mein liebeß gindt warla isst friss warla isst friss. 3

Ab Roman andtsuech auch wie da mennß hat in brauch berl vnd ohren g'henckh gaufft mir ab halb verschenckh, warla sein fein.

5

Wan sie das gopff mag weh braugt er das agnus De wird es si helffen bald das es nit aber fald Sondern bleibt stehn.

\section{2}

Wollt ihr das Messer steckh wollt ihr un gugl fleckh abter sau rockh darin kindt ihr schwindt ausserbring warla buzt wol.

4

Hört ihr Catholisch leuth laufft su von aller seith saut nur mein ware an die i ab bragt von Rom ganz warm vnd friss. 6 Wolt ihr ins himmel komb miest ihr sein lammel frommb betten dis Rosenkranz nit alb theyl sonder ganz bis alls aus iss. 
7

Ab I. a ablas feng wie Manns an better heng, abt ihr gfress hexerey oder sonst zauberey treibt gschwindt als weckh. 9 $\mathrm{Ab}$ au ein gwises öl das sterckht das leib vnd seel schadts nit so hilffts doch nit wan ihr abt finger schnitt oder ins fus. ${ }^{98}$
8

Bilder von aller andt für Mann vnd weiber standt seindt magdt in Niderlandt babt es auf an das wandt taugt für altar.

1,2 gafft] kauft 1,5 warla isst friss] es ist wahrlich frisch 2,1 Messer steckh] Stechmesser (langes Messer für Schlachtung oder Jätarbeiten) 2,2 gugl fleckh] Küchenfleck, Kochschürze bzw. Putztuch 2,3 abter] habt ihr sau rockh] Schweinedreck (?) 2,4 kindt ihr schwindt ausserbring] könnt ihr geschwind herausbekommen 3,1 Ab Roman andtsuech] ich habe römische Handschuhe 3,2 da mennß] das Mensch, Mädchen 4,2 su] herbei, herzu 4,4 bragt] gebracht 5,1 gopff mag weh] Kopf schmerzt 5,2 agnus De] agnus Dei (lat. Lamm Gottes), hier: kleine, zu Ostern in Rom gesegnete Reliefbilder aus Wachs mit dem Symbol des Lamm Gottes 5,4 aber fald] herunterfällt, umfällt (wirksam gegen Fallsucht) 7,1 Ab I. a ablas feng] Ich habe auch Ablassfänger (?) 7,2 an better heng] an die Betten hängt 8,1 aller andt] allerhand 8,4 babt] pappt, klebt

Sowohl die Markierung des fremdsprachigen Akzents als auch die Verwendung dialektaler Formen sind hier Zeugnis einer oralen Sprachkultur, in der sich die in den deutschsprachigen Raum ziehenden Händler und Händlerinnen bewegten. Dies bezieht sich nicht zuletzt auf den Spracherwerb: Im Rahmen einer Gesellschaft, die weit von vollständiger Literalisierung entfernt war und deren Alltag von mündlicher Kommunikation geprägt war, erfolgte auch der Erwerb von Deutsch als Fremd- und Zweitsprache in den meisten Fällen - und jedenfalls in den sozialen Schichten, von denen hier die Rede ist in mündlicher Form. Dieser Aspekt der Mündlichkeit prägt auch die literarische und formale Gestalt der Texte, in diesem Fall bis hin zur teils stärker an phonetischer Wiedergabe denn an orthographischen Konventionen orientierten Schreibung. Trotz dieser Überlegungen wäre freilich die Vorstellung, dass hier ein tatsächlich genuin mündlicher (oder gar: authentischer) Ausdruck eines Wanderhändlers festgehalten wurde, ein Kurzschluss. Mündlichkeit ist hier vielmehr - auch wenn reale Vorbilder den unbekannten Autor zur Darstellung inspiriert haben mögen - fingiert und dementsprechend als Mittel literarischer Stilisierung zu begreifen. Nicht zuletzt spielt hier auch die eigenwillige, teilweise schwer zugängliche und gerade darum eigenen Reiz entfaltende Schreibweise eine wichtige Rolle.

Noch deutlicher ist die mündliche Rede im zweiten Überlieferungsträger markiert, der auf die im 18. Jahrhundert üblichen Konventionen der Dialektverschriftung - insbesondere die Markierung von /a/ durch 〈ä $\rangle$ - zurückgreift. Aus dieser Wiener Handschrift soll im Folgenden eine als Cantilena betitelte Soldatenklage wiedergegeben werden, die in der älteren Quelle (Ms. Germ. Oct. 230) in das Wanderhändlerlied einmontiert ist (Str. 10-15), sich inhaltlich jedoch nicht recht einfügt. Das verbindende Element ist der fremdländische Akzent durch fehlerhafte Aussprache, Grammatikfehler und Wortstel-

98 Staatsbibliothek zu Berlin, Ms.germ.oct. 230, f. 96-99. 
lung, der Assoziationen zu kindlicher Redeweise weckt und der Klage einen ,weinerlichen' Tonfall verleiht, der weniger zur Identifizierung einlädt als zu einer distanziertspöttischen Haltung gegenüber der Figur.

1

Gä soldat mag ig nimmer say

firdt mig daß Teüffl drey

wi ig ap mag stick todt

umiläff in dy noth

armi Pondidt.

3

Ops der Gän guedter guandt

Gäzo iß grosser Sandt

emedt iß volli leiß

alwey mey Bugl beiß

Cospedo.

5

Saubtmann iß ä mauß gopff

alpey mey Bugl glopff

Tildt geldt armer Soldat

Alpeyl sön menzn adt,

Grosser Gojo

7

sener sack ipser Sack

opster in mey land mack

seny räridedy findt

sä sä mey lieper Gind

sener Spilperck.

9

Oder gier Rauckfanck aus

Gumpster fey frie in aus

Dapst das mens in das Bedt

Gäzo guet sackn edt

Späzä gämin. ${ }^{99}$
2

Wi ig von äsß weg läff

oz mir Soldtadt gläptäff

Gips mi agt gulti dron

engs mir muß gedn an

mags mir Soldat.

4

Strümpff obm ä gä Bodtn

Seynds mag auß Bauern lodtn.

Sue lauffs basser ayn

pans gumdt das schwiz dareyn

pärlä schmeck slim

6

Ezter nur bißl geldt

wolzter bald läff aus feldt

wolzter ips gäßl gäff

in dy weldt umi läff

wolzter ips frey

8

Oder due maußfal mackh

in die Weldt umy drackh

äckl saü ä dapey

Gäff Gäff mey Lieper ley

warley seyn guedt.

1,1 Gä] kein 1,3 wi ig ap mag stick todt] als ich jemand erstach 1,4 umiläff] bin ich weggelaufen 1,5 Pondidt] Bandit 2,1 von äsß] von zuhause 2,2 gläptäff] ,aufgeklaubt': mitgenommen 2,4 engs mir muß gedn an] hängt mir eine Muskete um 3,1 Ops der Gän guedter guandt] ich habe kein gutes Gewand 3,2 Gäzo] (ital. cazzo: Penis): Äquivalent zu ,Scheiße!' oder ,Fuck!' iß grosser Sandt] das ist eine große Schande 3,3 emedt] Hemd 3,4 Bugl] Rücken 3,5 Cospedo] Cospetto! (ital. Gegenwart [Gottes]): Ausruf der (eher negativen) Verwunderung oder Empörung 4,1 obm ä gä] haben auch keinen 4,2 mag] gemacht lodtn] Loden: verfilzter, wetterfester Wollstoff 4,3 Sue] in die Schuhe 4,4 pans gumdt] wenn kommt 4,5 pärlä schmeck slim] riecht es wahrlich schlimm 5,2 alpey] alleweil, immer 5,3 Tildt] stiehlt 5,4 sön menzn adt] hat schöne Mädchen 5,5 Gojo] (von ital. coglioni: Hoden): Arsch, Trottel, Lump 6,1 Ezter] hätte ich 6,2 wolzter] wollte ich 6,3 ips gäßl gäff] hübsche Guckkästchen kaufen 6,4 umi] herum 7,1 sener sack ipser Sack] schöne Sachen, hübsche Sachen 7,2 opster] habe ich mack] gemacht 7,3 seny räridedy] schöne Raritäten 7,4 sä sä] Lockruf (Komm!, Los!) 8,3 äckl] Hecheln (kammartiges Arbeitsgerät zum Reinigen von Flachs- und Hanffasern) saï a] sind auch 9,1 gier Rauckfanck] kehre Rauchfang 9,2 Gumpster fey frie] komme ich recht früh 9,3 Dapst] ertappe 9,4 Gäzo] s. o. 9,5 Späzä gämin] (ital. spazzacamino) Rauchfangkehrer

Negative Vorstellungsbilder, die schon im Reiselied angesprochen wurden, finden sich auch hier im ersten Liedteil wieder: Der heißblütige Italiener macht sich nach einem Tö-

99 Wienbibliothek im Rathaus, H. I. N. 4623, S. 459 f. 
tungsdelikt aus dem Staub, lässt sich in seiner Naivität anwerben, ohne für das harte Soldatenleben geschaffen zu sein, und lamentiert über schlechte Montur - kaputte Schuhe, löchrige Strümpfe, verlauste Hemden - und brutale Behandlung. Im zweiten Liedteil phantasiert sich der Soldat wider Willen ein besseres Leben, indem er Berufsfelder aufruft, die gleichfalls als typisch für italienische und auch savoyardische Vaganten galten: ein Leben als Guckkästner, der Sehens- und Berichtenswertes aus aller Welt gegen Entgelt in die entlegensten Gebiete brachte, als Mausfallen- und Hechelkrämer oder als Rauchfangkehrer.

Diese drei komischen Rollenbilder sind Fixpunkte der süddeutschen Unterhaltungskunst im 17. und 18. Jahrhundert. Nicht zufällig eröffnet der Callotto resuscitato mit dem Typenblatt Nicolo Cantabella, Savoyardischer Wurmschneider, wo dieser seinen Guckkasten mit Bildern zum aktuellen Zeitgeschehen und deutlich dialektalem Einschlag anpreist:

Ey schöna spilawerkh! Ey söna Margarit!

So söner ots in Welt ka Menß nok seha nit,

Ganz söner natural Campania prasentir,

Wie auß der Welßer Land Franzoß muß retirir,

Wie kum die Prinz Eugen, oh sena rarité,

Sau, sau wie von Turin ots lauffen, Ey wie seh! ${ }^{100}$

2 ots] hat es 3 Campania] (ital. campagna) Feldzug 4 Welßer Land] Italien 5 sena rarité] schöne Rarität 6 sau] schau Turin] am 7. September 1706 konnten kaiserliche Truppen unter dem Oberbefehl von Prinz Eugen in der Schlacht von Turin das französische Heer schlagen; nach dieser Niederlage musste Ludwig XIV. im Spanischen Erbfolgekrieg durch die Generalkapitulation 1707 Italien aufgeben seh] schön

Das Motiv des Italieners als Gaukler, Nachrichtenkolporteur und Spielmann taucht auch in Gregor Joseph Werners Wiennerischem Tändlmarckt ${ }^{101}$ auf, wo der bereits erwähnte ,Savoiard' seine Jahrmarktsattraktionen - Spielwerk, Guckkasten, Laterna Magica, Musik - mit einer Werberede voll dialektaler Anklänge anpreist. ${ }^{102}$ Auch hier begegnen wir wieder dem prototypischen Ruf „söner Raritè“ ${ }^{103}$ :

100 Il Callotto resuscitato. oder Neü eingerichtes Zwerchen Cabinet. [Augsburg, um 1710], Bl. 2.

101 Zwey neue und extra lustige musicalische Tafel-Stücke. I. Der Wiennerische Tändlmarckt. Mit 4. Singstimmen, 2. Violinen und Basso ordinario. [...] II. Die Bauren-Richters-Wahl. Mit 5. Singstimmen, 2. Violinen und Basso ordinario. [...] Beyde Stücke, sind nach Art der Quodlibete eingerichtet [...]. Von dem Autore des Musicalischen Calenders Gregorio Josepho Werner, Hochfürstlich Estorhasischen Capellmeistern zu Eisenstadt in Ungarn. Augspurg, Verlegt von Johann Jacob Lotters seel. Erben. [um 1750]. Bereits 1933 nach einem Exemplar des British Museum ediert bei Moser, Corydon, S. 155-179. - Neuedition (in Partiturform, mit Generalbassaussetzung und angepasster Schreibung) durch Richard Moder (Hg.): Gregor Joseph Werner: Wienerischer Tandlmarkt. Partitur, Stimmen, Klavierauszug (vom Hg.). Wien, München: Doblinger 1961. (Diletto Musicale 81).

102 So singt er etwa im Recitativo: „ä nide so stärk“ (ein jeder so stark) (Der Wiennerische Tändlmarckt, Tenore I, Recitativo, S. 2).

103 Vgl. dazu die Zusammenstellung von literarischen Belegen vom Ende des 18. Jahrhunderts bei Deutsch, Ein ,Wienerischer Tändelmarkt', S. 45. Siehe aber auch Texte wie eine 1730 gedruckte anti-protestantische Schmähschrift, die den bekannten Ruf im Titel als Catch-Phrase nutzt: Schöne Rareté! Schöne SpihleWerck! Schöne Murmlethier! Allons, feiff Murmlethier, feiff! Das ist: Catholische Replic, Oder GegenAntwort Auf die so betitult: Unwiderlegliche etc. Widerlegung disseithiger Apologiae [...]. Constantinopel [wohl Augsburg] 1730. 
Ick gom auß die Savoier Länd

mit söner Raritè

die Spilliwerg bellè gallant

will si vor Creutzer seh? ${ }^{104}$

Schon in Zedlers monumentalem Lexikon wird unter dem Stichwort ,Raritäten-Kasten vermerkt, dass „gemeine Leute, so mehrentheils Italiäner von Geburth [...] die Messen in Deutschland zu besuchen, auf den Gassen herum zu lauffen und durch ein erbärmliches Geschrey: Schöne Rarität! Schöne Spielwerck! Liebhaber an sich zu locken“ 105 pflegten. Auch Maurus Lindemayr lässt in seinem Dialektsingspiel Die durch die Todesfurht Vertriebene Sauffsucht des liederlichen Hansen einen, Medicus Italus' auftreten, der in einer radebrechenden ,Cantilena' seine Heilkünste anpreist und seine Kundschaft für einen Kreuzer auch einen Blick in seine „Buttn“ gewährt. ${ }^{106}$ Dass das Gewerbe kein einfaches war und nicht immer ein Auskommen garantierte, lässt eine Gesangseinlage aus einem anonym überlieferten Singspiel der 1770er Jahre anklingen, wo der Guckkästner Niggerl sein detailliertes Bildangebot mitleidheischend mit diesen Versen einleitet:

Igg binsi armer Wellscher leyd viel und harter Noth,

Igg hab si keiner Pfennig Geld, und hab si keiner Brod.

Kann vor Hunger kaum mehr stehen

Kann nicht mehr hausiren gehen.

Hab si viel und grosser Leiß,

Magg jugg, jugg und allweil beiß.

Hab igg oft mit schöner Saggen

Spillwerk viel Geld begom:

Thuet si nicht mehr viel drausmaggen,

Wenn igg in der Deutschland kom. ${ }^{107}$

Wie eng in der Kunst die Verbindung zwischen den romanischen Guckkästnern auf der einen und den Mausfallen- und Hechelkrämern auf der anderen Seite gesehen wurde, belegt ein weiteres Zwergenkarikaturenblatt, 1720 in Augsburg von Elias Baeck gestochen, das die beiden Typen gegenüberstellt. Gemeinsam ist ihnen der kauzige Akzent, mit dem sie die Vorzüge ihrer Waren anpreisen:

104 Werner, Der Wiennerische Tändlmarckt, Tenore I, S. 1.

105 Grosses vollständiges Universal-Lexikon aller Wissenschafften und Künste. Dreyßigster Band Q und R-Reh. Leipzig und Halle: Johann Heinrich Zedler 1741, Sp. 891.

106 Zitiert nach: Moriz Enzinger (Hg.): Zwei Singspiele von P. Maurus Lindemayr. In: Euphorion 31 (1930), S. 31-95, hier 54 .

107 Stiftsbibliothek St. Florian, II-17-65 W108 [Flugschriftfragment ohne Titelblatt], S. 8. 
Hechell Maus-Fall-Macher.

Wann der Mauß nein gombt, mit der Gobff,

Gan ni mehr rauß die arme Tropff,

Gan nit mehr dring, gan nit mehr iss,

Ister stirb todt, und als vergiss.

3 dring] trinken
O. SCHÖNA RARIDE.

O. rahra spilawerck, O. sehna Raride,

Ih loß dy um ein greitz, vill in mein gastel seh,

Do gan man schau die Türg, dy König in die Preiß,

Wie garll mit dy Flod, ind Welßer Lande reiß. ${ }^{108}$

2 greitz] Kreuzer 4 garll] Kaiser Karl VI. ind Welßer Lande] nach Italien (wohl Anspielung auf den Sieg über die spanische Flotte in der Seeschlacht vor Kap Passero 1718)

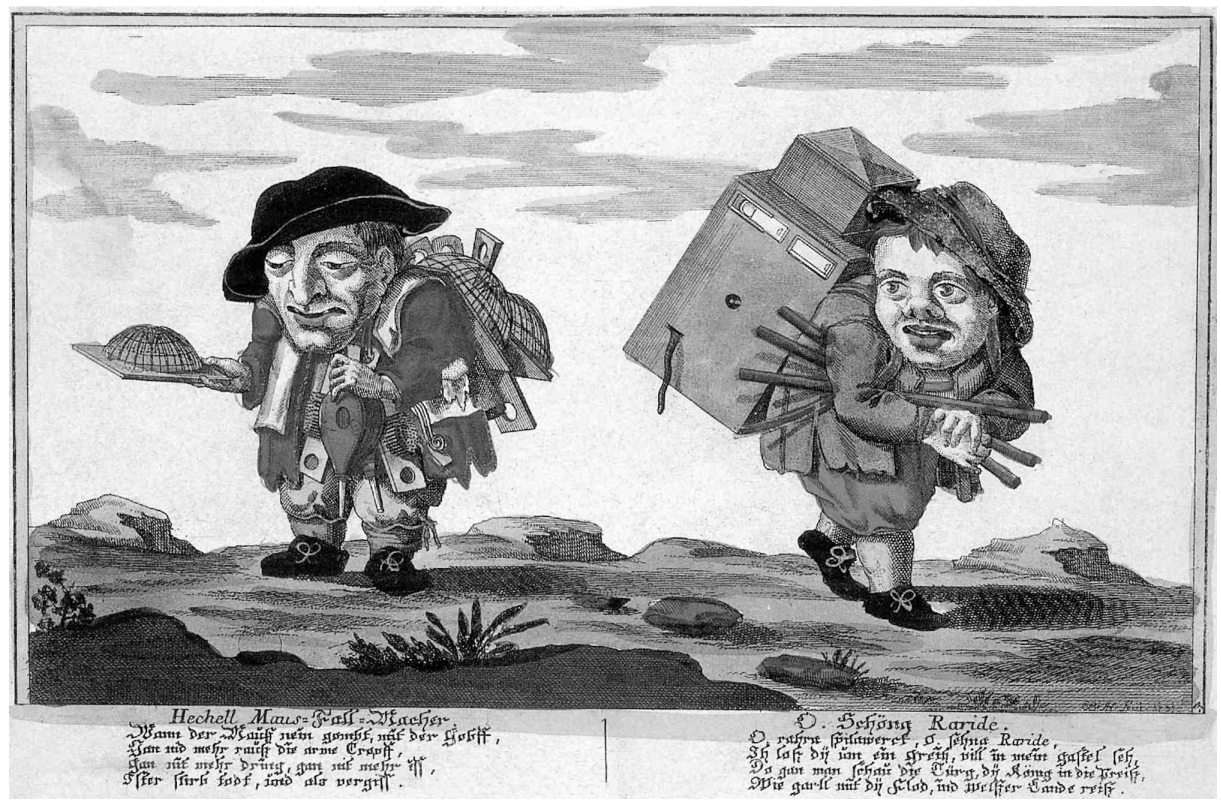

Abb. 34: Elias Baeck: Hechell Maus-Fall-Macher/O Schöna Raride (Augsburg, 1720).

Der gleichfalls breit belegte Kaufruf „Hechel, Mausefall“ ${ }^{109}$ ertönte etwa auch im Wiener Kärntnertortheater, wie schon der Titel Die lustige Bauren-Hochzeit zwischen Han-

108 Zitiert nach der Abb. in Bauer/Verfondern, Barocke Zwergenkarikaturen, Tafel 17. Eine etwa zeitgleich von I. A. Müller gestochene einfigurige Kaufrufserie des Augsburger Verlagshauses Leopold zeigt „Pier Cacciasorcio. Vorgesetzter deß Blaßbälg, Heckala u. Mausfalla appalto“, der seine Waren folgendermaßen anpreist (ebda., S. 53):

Kofft Mausifall, o Leüth! Cospetto gute Sacken,

Schön Blaßbälg, Heckala, wird dick gewiß nit reü;

Bin redlich Savojard, kans künstlik z’samma macken,

In mei Land weiß ma wohl, wer Cacciasorcio sey.

109 Als Beleg für diesen Kaufruf bzw. die zugrundeliegende typische Verbindung von Hechel- und Mausfallenverkauf vgl. etwa die Beispiele in Grimms Deutschem Wörterbuch unter dem Stichwort „Mausefallenkrämer“ (Bd. 12, Sp. 1823) und „Hecheljubilierer“ bzw. „Hechelmann“ (Bd. 10, Sp. 737). U. a. wird dort auch die Bezeichnung „heckelemeusefallenmacher“ genannt, die sich an dem „ruf, mit dem sie in mangelhaftem deutsch ihre waare anbieten“, orientiere (ebda.). 
ßel und Gredel, oder Hanns-Wurst der verliebte Maus-Fallen-Krämer erwarten lässt. ${ }^{110}$ Komische Effekte werden hier verstärkt mit Code-Switching erzeugt - immerhin war Italienisch noch immer die führende Kultursprache in der Residenzstadt:

Chi vol Hechel, Mause-Fall,

Chi vol was comprare?

In der Kuchel, in der Stall

Er kann aplicare.

Ist vielleicht in eurem Haus

Uno razzo, oder Maus?

Liebe Herren, kauffet doch

Eh der Maus springt in der Loch. ${ }^{111}$

1 Chi vol] (ital.) wer will 2 comprare] (ital.) kaufen 4 aplicare] (ital.) anbringen 6 razzo] (fälschlich für ital. ratto) Ratte

Auch im Volksgesang scheint die Figur fest verankert gewesen zu sein, wie das folgende Rollenlied aus einer um 1760 vermutlich in Oberbayern verfassten Handschrift nahelegt, das im sprachlichen Duktus den bereits behandelten Texten entspricht:

1

I bin si braff kerl, bin wärli kein narr,

I bring si aus welschland vil hübsch und schön wahr,

gut hacherl, mausfall, der welschen kunst, dran

der Teutschland nit kan.

2

I bin si braff kerl, kan handwerckh wohl fein,

hab glehret 3 wochen, bis i han ergriffen;

er macht dir, läst geld und ist dir schön kunst;

lehr niemand umbsunst.

3

Du hast dir daheimb beym teüffl vil meus.

sie stilt dir vil korn und frißt dir vil spei[s]

gauff nur den mausfall und bsin dir nit lang;

wirst warli maus fang.

4

du thust ihr darein ein bisserl speckh,

kombt nacher der maus, macht alleweil schmeckh,

110 Vgl. Österreichische Nationalbibliothek, Cod. 12707 (Teutsche Arien), S. 117-125. - Edition bei Pirker, Teutsche Arien II, S. 57-61, hier 57.

111 Ebda., S. 61. - Vgl. auch die Anm. und den Textabdruck bei Ulf Birbaumer: Das Werk des Joseph Felix von Kurz-Bernardon und seine szenische Realisierung. Versuch einer Genealogie und Dramaturgie der Bernardoniade. Wien: Notring 1971, S. 85f. - Das Lied wurde aber auch außerhalb des Theaterkontexts überliefert, wie eine zweite Fassung in der Ostracher Liederhandschrift (mit Noten) beweist (vgl. Ostracher Liederhandschrift, Teil 2, Nr. 44, S. 148 (originale Blattzählung: 33b)). Hier nach der Edition bei Rattay, Die Ostracher Liederhandschrift, S. 70:

ab ein hechel, mausefall, mausefall,

gib wohl, was Campare,

in der Kuckhel, in der stall in der stall

Sewu applicare.

Der Text entspricht weitgehend der oben angeführten Version, verweist aber mit den entstellten bzw. teilweise durch deutsche Ausdrücke ersetzten italienischen Wendungen deutlich auf seinen mündlichen Überlieferungskontext sowie einen des Italienischen offenbar nicht kundigen Schreiber. 
gröbl über, gröbl ummer, bis endli kombt drein; nacher ist er schon dein.

5

und wan $[\mathrm{m}]$ ir dein weib will teüfflbös sein, kanst machen der fozen, in mausfall spör ein, gib nacher zu freß nicht, das hunger leiden thuet; wird warli bald guet. ${ }^{12}$

1,3 hacherl] Hechel 4,3 gröbl] krabbelt 5,2 fozen] (verächtlich-figurativ für) Frau

Bleibt noch der italienische Rauchfangkehrer, der uns u. a. auf einem der in den Wiennerischen Beleuchtungen beschriebenen illuminierten Sinnbilder begegnet, die aus Anlass der Geburt Josephs II. in Wien aufgestellt wurden (vgl. Kap. 3, S. 177). Es ist zugleich ein instruktives Beispiel für den Fremdenhass, mit denen Gastarbeiter konfrontiert waren. Die einheimische Wiener Bevölkerung hatte - zumindest in der literarischen Zuspitzung - kein Verständnis dafür, dass auch Untertanen aus weiter entfernten Teilen der Monarchie an den Geschenken des Herrscherhauses partizipieren wollten:

Der obere Jesuiter-Platz / oder Hof / mit der gewesten Triumph-Pforten der Stadt- und übrigen Beleuchtungen / sonderbar die Bühne / wo rot- und weisser Wein sprunge / auch Brod und Brättel ausgeworfen / und die Trompeten und Paucken gehöret wurden; unten eine Menge Leute / deren einige mit Stangen / und Ampern den rinnenden Wein auffiengen / einige denen anderen die Krüge zerschlugen / wiederum einige voll da lagen: Auf einem anderen Haus darneben schauete ein Rauchfangkehrer bey dem Rauchfang heraus / welcher mit einem Amper auf der Stangen nach dem Wein langte:

Ick pover Teifl kans auf Gäßl kän Platz finden.

Probir alt per Camin / ob mi kans auffi winden.

Puo far! ja das is kut / kans perfetman wol sehen/

Will ick halt ä bräf lusti seyn / e droben bleiben stehen.

Unten schlugen ihm die Leute die Stangen hinweg / und die Buben warfen mit Steinen nach ihme / sagend:

Du Kätzelmacher pack dich fort.

Sonst zeig'n wir dir ein anderes Ort/

Rinnt Wein / und wirft man Brätl aus/

So g'hörts allein zu unsern Schmaus. ${ }^{113}$

Brättel] Schweinsbraten Amper] Eimer pover] armer alt] halt, eben auffi] hinauf Puo far] (ital.) kann machen, sinngemäß: es funktioniert perfetman] (franz. parfaitement): perfekt, tadellos ä] auch e] (ital.) und Kätzelmacher] abschätzige Bezeichnung für Italiener (wohl von spätlat. cattia: Gatzel, hölzerner Schöpflöffel)

Werfen wir noch einmal einen Blick zurück auf das zuerst zitierte, älteste Lied dieser Kategorie. In seinem dritten Teil setzt das Rollen-Ich nach dem Soldatenlied-Intermezzo sein Anpreisen der umfangreichen Produktpalette fort, deren einzelne Posten wie Glaspulver gegen Zahnweh oder Mithridat als Antidot heute sehr fremd anmuten:

112 Universitäts- und Landesbibliothek Tirol, Cod. 980, Bl. 48v. Hier nach der Edition bei Blümml, VolksliedMiszellen, S. 51. Die Handschrift wurde um 1760 wohl in der Gegend um Ingolstadt und vermutlich in einem Kloster - darauf deuten u. a. die lateinischen Liedtitel - verfasst.

113 Wiennerische Beleuchtungen 1741, S. 46f. 
16

I thu ey schreyen nagg

ach mein wahr nit veragg

gaff er es is gut wahr

aug was von Perdergar

$\mathrm{ab}$ is darbey.

18

San bulver abß sie guett

Wan dir Mundt stinggen thuet

reibter bis rauslaff bluet

sag nit wan weh dir thuet

iss gleig vertreib.

20

I bring aus welscher landt

seiden vnd daffet bandt

schnupp tobackh augenbrill

wan er gaff sigt er vill

wan nit iss blindt

22

Wan der du san weh hast

gaffter Venedi glast

beister bis Pulver geit

dreibt er in gurser seith

warla probier.

24

Friss balsam absi bragt

gafft er du nit veragg

wen den die kopf thuet weh

streigt er nur an die schlöff

iss gleig vertreib.

26

Wan I dan griegte gelt

wolt i schrey in der welt

lusti allegro seydt

iez iss mein grester freydt

$a b$ dwahr vergaff.
17

Afften san ä darbey

gaffter mein alter wey

siben aggt oder nein

söz dar in mieder nein

warla ebt starg.

19

Ab schön flor ä mit bring

gaff er mein ypscher gindt

steht schön auf weisen leib

gaffter mein junger weib

warla iss glar.

21

Dawagg abß ä mit bragg

von gosmen angemagg

abs a von Rosamen

negel öel vnd simmen

warla stinckh woll.

23

gaffter bommranz mein err

gib dir ein nag begehr

swey duz vmb ein guldt

magt das wein vnd Speis gut

$\mathrm{ab}$ offt probier.

25

Abter friss Medritat

wan der gifft leib drin att

nimbt er ein Messer Spiz

degt er sue das er schwiz

nimbt alls gifft wegg.

27

Wan i deng an Mein landt sittert mein osen bandt

das es so weit ist aim

wan i nur mohl gam aim

wo bin begant. ${ }^{114}$

16,2 veragg] verachtet 16,4 Perdergar] ? 17,1 Afften] Hafteln, Schließen 17,2 wey] Weib, Frau 17,3 aggt] acht 17,5 ebt] hebt: hält 18,1 san] Zahn 18,3 rauslaff] rausläuft 19,1 flor] dünnes Gewebe, Schleier 20,2 daffet] Taffet: leichter, glatter Seidenstoff 21,1 Dawagg] Tabak mit bragg] mitgebracht 21,2 gosmen] ? 21,3 Rosamen] Rosmarin 21,4 negel öel] Nelkenöl simmen] Zimt 22,2 Venedi glast] venedisches Glas, Glas aus Murano be Venedig 22,3 geit] gibt 22,4 gurser seith] kurzer Zeit 23,1 bommranz] Pomeranze, Bitterorange 24,1 balsam] allgemein für wohlriechende Mittel oder lindernde Heilmittel 25,1 friss Medritat] frisches Mithridat: nach dem sagenhaften König Mithridates (um 100 v. Chr.) benanntes Arzneimittel aus verschiedenen Zutaten, das als Gegengift und Heilmittel für verschiedenste Zwecke galt 27,4 mohl gam aim] einmal heimkäme

In der letzten Strophe klingt das Heimweh an, das diese Weitgereisten sicherlich oftmals quälte. Auf sich alleingestellt in der Fremde machten den reisenden Händlern auf den langen Wegen nicht nur die vielen Gefahren zu schaffen, sondern wohl auch Einsamkeit und fehlende Gemeinschaft. Mit diesem Hintergrund gewinnt eine witzige Gesangseinlage in Wolfgang Rinswergers bereits angesprochener Besserungskomödie Potinus eine

114 Staatsbibliothek zu Berlin, Ms.germ.oct. 230, f. 101-105. 
tiefergehende Dimension, die über den Schulspott und die Trunkenboldsatire hinausgeht. Denn hier ist ein ,Institor Italicus', ein italienischer Händler, auf der Suche nach Ersatz für seinen geliebten, kürzlich verendeten Esel. Als er den schlafenden Eselskopf Potinus sieht, glaubt er ihn gefunden zu haben:

1

O bitter Leyd! O grosser Schmertz! wie mi thuts wehe, und steck;

Wie voll ist Traur, wie schlag si Hertz, mein Esel hat verrökh.

ä scheider Thier, ä lieber Vich, wansi scho braf hab schlagt, Hats tragen wie sein Bruder mich, ä gantze Tag nix sagt.

3

Jetz fallt dahin, und stirbts mir Tod, Mach si kein Testament;

ä gansen Freundschafft steckts in Noth!

Gibts Esel vil wer kennt:

$\mathrm{Laß}$ ruhen doch in ander Welt,

Swar fürchts mir groß darbey

Wan si werd Geist bey Nacht anmeld,

So gimbts sum Brüdern gley. 5

I bin si im Welsch Andlsman,

Abs vil und schöne Wahr;

Wans Esel nit begomen gan,

So bins än armer Narr,

Was aber denck si grad jetz sruck,

Im Schuell da ganß gnug find,

Oder i warts auf Esel Brugg,

Da wils gehe suchen schwind.

7

Wie hats mi schröck der Wunder Friß,

Waiß nit aus Forcht wo bin;

Lebendig Teufl (glaubts gar gwiß)

In Esel ist sitz drin.

Wans ausser fahrt, und greiffts mi an,

Nämbs mi in Höll mit sich,

Läff schwind voraus, was läffen gan,

Bieth GOtt! ä schlimmer Vich. ${ }^{115}$
2

Habs offt sue spröch, drauf Esel, drauf,

Mach schwinde gang, I will;

Ganst in der Stall scho wider schnauf,

Aufs Nacht gibs dir friß vill:

Da hats mein Thier gut Hoffnung macht,

langspanne Ohren Spitz;

Voll Freud von Ertz nach Fuetter lacht,

Wan ich schon bin drauf sitz.

4

Waß dan mach sie, sags lieber Leuth!

Gibs mir ä nutzlich rath;

Ain Esel brauch si halt bey Zeit,

Sonst gimbts mein Sach su spat;

Muß her und hin raiß auf dö Marck,

Gost mi vil Geld und Miehe,

Wansi mi nit tragt bräf Esel starck,

Sitz auf, haist, und bleibts hie.

6

Aber schau! schau! was sicht si dort,

Da findts mein grosser Glück,

Lebendig Esel ligts an Orth,

Wanst nit hat schon verstick:

Oldtseelig schlafft mein gute Freund,

Mit Ohren zupf aufwacht:

Auf Esel! Sonn sum Fenster scheint,

Stehts auf! und schlaffs bey Nacht.

1,5 ä scheider] ein gescheites 1,6 wansi] (auch) wenn 2,1 sue spröch] zugeredet 2,2 schwinde] geschwinderen 2,6 langspanne Ohren Spitz] spitzte die langen Ohren 5,5 sruck] zurück 5,6 ganß gnug] kann man 6,1 sicht si] sehe ich 7,1 Wunder Friß] Wundergesicht, Schreckbild 7,5 ausser] heraus 7,6 Nämbs mi] nähme er mich 7,8 Bieth] behüte

115 Rinswerger, E funere Phoenix, S. 207-209. 


\section{Kroaten und Ungarn - Krämer, Krieger, Heubauern}

Überwiegt bei den Stereotypen der italienischen Handelsreisenden und Lohnarbeiter bei aller liebenswerten Kauzigkeit die abgrenzende Fremdsetzung, finden wir bei literarischen Typisierungen von Kroaten bzw. Ungarn ausdifferenziertere Formen der Darstellung des Andersseins von der abwertenden Distanzierung bis zur Herausstellung des Gemeinsamen bzw. Verbindenden. Als Beispiel für eine noch vorwiegend negative Zeichnung des Fremden kann Philipp Hafners Der Kroatische Bauer und das Wiennermädgen gesehen werden, das erstmals 1763 im ersten Teil seiner Lyriksammlung Scherz und Ernst in Liedern abgedruckt wurde. Anders als die zuvor vorgestellten monologischen Lieder wird hier Fremdsein im Dialog verhandelt. Die Gegenüberstellung der jeweils, eigenen' und ,fremden' zugeschriebenen Charaktereigenschaften soll vor allem die Unvereinbarkeit zwischen beidem zeigen, wobei die fremde Lebensart als eindeutig defizitär dargestellt wird.

1 KroAT.

Schöni liebi Wiena Madel!

Muiß si dir was Guits vertrau:

Mei Herz brat wie Schweinabratel,

Möchs si werda nit mei Frau;

Mach mi heurath! thui nit bsinna,

Sey mei Weibel, schau mi an,

Habs viel Geld in Säckel drinna, Bin krawatisch reichi Mann.

3 Kroat.

Will si Schatzel dir nit gfallen,

Warum bin is nit brav Mann,

Kan dir guiti Sacha zahlen,

Die dir andri geba kann:

Bin dir redli, thui nit zweifel,

Hab mi schön, und sey mi guit,

I! du mach Gsicht wie das Teufel,

Sag: was di nit gfallen thuit.

5 Kroat.

Hab si ja nit Gsicht so übel,

Hab si zimli groß Verstand,

Kenn das Knobel, und das Zwibel

Und Kapäunel vonanand;

Hab si schwarz Bart, blaui Gwandel,

Rothi Zischma, rundi Huit,

Hab mi liebel, wie dein Mandel,

Schöni Lelki sey mi guit.

7 KroAt.

I was Menschel liebi Schatzel!

Glaubs nit, das Krabat guit is?

Erteck! wann i dir gib Schmatzel

Bleib di Loth Taback in Gfriß,

Kann i glei nit Prallhanns macha,

Fopp di nit, wie Deutschi thuit,

Lieb di, daß mir Herz thuit kracha,

Und hab treu krawatisch Bluit.
2 Wiener Mädgen.

Deine so geschwinde Fragen

Sollen gleich entschieden seyn;

Ich will dir gar nicht viel sagen,

Nur ein Wort, und dieß heißt: nein!

Niemals könnte mir es träumen,

Einem solchen wilden Mann

Herz und Alles einzuräumen,

Den ich gar nicht lieben kann.

4 Wiener Mädgen.

Alles, was ich an dir sehe,

Alles, was in deinem Land,

Und daß ich es kurz gestehe,

Deine Sitten, der Verstand:

Deine Kleider, deine Blicke,

Deine Sprache, dieser Bart,

Deines Leibes grobe Dicke,

Und die rohe Lebensart.

6 WienER MädgEN.

Zärtlich ist der Deutschen Liebe,

Deine Art gleicht ihrer nicht;

Ihre Küsse, ihre Triebe

Sind bezaubernd eingericht:

Deutschland ists, wo ich gebohren,

Deutsche sind es nur allein,

Denen ich es zugeschworen:

Niemal ungetreu zu seyn.

8 Wiener Mädgen.

Alle Worte sind vergebens,

Alles Bitten ohne Frucht,

Weil die Tage meines Lebens

Deutsche Art mein Herze sucht.

Ein Salopp und Schmuck in Haaren,

Strickrock, Sack, und Palatin,

Sind ganz andre Kleider Waaren,

Als bey einer Ungarin. 
9 Kroat.

Je! kannst tragen, was dir gfallen,

Von di Schedel bis zur Schuih,

Langa Sack von Stanling Schnallen,

Und schwarz Rockolor dazui;

Ohrenglasel, Sammetstützel,

In di Gsicht brav schwarzi Fleck,

Und von Haar an Heilingstritzel,

So fallt nix von Freyla weck.

11 Kroat.

Bin nit schleck! mei liebi Madel,

Geld macht mi zum Edlimann:

Was frag du denn nach di Adel,

Wann i dir alls schaffa kann:

I hab Roß, und hab a Wagen,

Wills nit fahren mehr mei Weib,

Laß si auf die Buckel tragen,

Hab Laquey, der Vieh austreib.
10 Wiener Mädgen.

Nicht allein die schönen Kleider,

Machen, daß ich spröde bin;

Nein! mein Herz gedenkt viel weiter,

Und zielt einzig nur dahin,

Mich recht vornehm einst zu paaren,

O! wie läßt es doch so schön,

Wenn man kann im Wagen fahren,

Und die Diener rückwerts stehn.

12 Wiener Mädgen.

Und gesetzt ich thät es wagen,

Und ich wollt die Deine seyn,

Müßt ich dir gleich Anfangs sagen,

$\mathrm{Daß}$ mein Lieben nur ein Schein;

Zwar würd ich dich Schatzerl nennen,

Ich wär Frau, du wärst mein Mann,

Heimlich aber würd ich brennen,

Für das, was ich lieben kann. ${ }^{116}$

5,3 Knobel] Knoblauch 5,6 Kapäunel] Kapaun: kastrierter, gemästeter Hahn 5,6 Zischma] (ungar. csizma) Halbstiefel 5,7 Mandel] Mann 5,8 Lelki] (ungar.) Seele 7,1 Menschel] Mädchen 7,3 Erteck] (ungar. ördög) Teufel Schmatzel] Kuss 7,4 Loth] Maßeinheit (in Österreich 17,5 Gramm) 9,3 Stanling Schnallen] Schuhschnallen aus Sterlingsilber (?) 9,4 Rockolor] eine Art Reise- oder Regenmantel 9,5 schwarzi Fleck] Mouche, Schönheitspflaster 9,7 Heilingstritzel] zopfförmig geflochtenes Hefegebäck als traditionelles Geschenk zu Allerheiligen 11,7 Buckel] Rücken

Abb. 35: Notenteil zu Der kroatische Bauer.

\section{Der Kroatifae 2aute,}

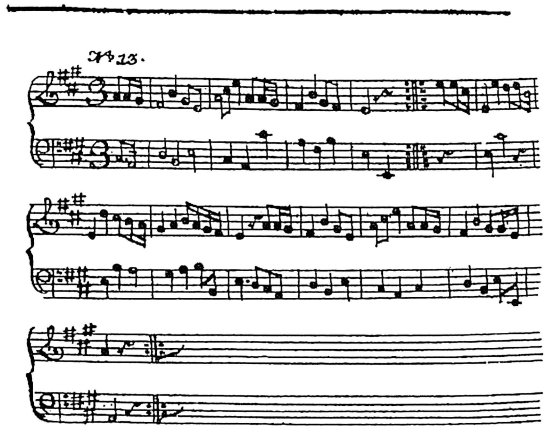

Obwohl Hafners Lied Fremdheit zum Thema macht, lässt sich diese nicht an klaren nationalen oder ethnischen Grenzen festmachen, sind doch die Konzeptionen von Nation, Staat und Sprachgemeinschaft im 18. Jahrhundert noch relativ ambivalent. Dies spiegelt sich auch im vorliegenden Text wider, in dem offenbar nur von einer Gegenüberstellung zwischen ,Deutsch' und ,Nicht-Deutsch` ausgegangen werden kann. Konkrete Abgren-

116 Scherz und Ernst in Liedern verfaßt von Philipp Hafner. [Erster Teil.] Wien, gedruckt und verlegt bey Joseph Kurzböcken, Universitätsbuchdruckern in der Bognergasse im hofglaserischen Hause. 1763, S. 4448. - Reprint: Philipp Hafner: Scherz und Ernst in Liedern. Neu herausgegeben und eingeleitet von Emil Karl Blümml. Wien/Prag/Leipzig: Strache 1922. 
zungen der nicht-deutschen Bevölkerungsteile nach Sprachnation oder Ethnie, wie sie sich im 19. Jahrhundert mit zunehmender Rigidität ausbildeten, ${ }^{117}$ lassen sich dagegen nicht feststellen - im Gegenteil: Obwohl der Bauer hier explizit als Kroate bezeichnet wird, weisen die fremdsprachlichen Begriffe, die er verwendet, eindeutig ins Ungarische. Deutlich wird diese Unschärfe auch in der Entgegnung der Wienerin, sie wolle nicht wie eine „Ungarin“ (Str. 8,8) gekleidet sein. Diese Vermischung der ethnischen Zuordnung, die schon Blümml konstatierte, ${ }^{118}$ wurde mit der Gruppe der Burgenland-Kroaten begründet, die in damals zu Ungarn gehörigen Gebieten lebten. ${ }^{119}$ Doch sind derartige Zuschreibungen, die von rezenten nationalen Vorstellungen ausgehen, mit Vorsicht zu genießen. Letztendlich dient die Rolle des Kroaten (oder Ungarn) im Text vor allem als Platzhalter für einen Fremden, dessen konkrete ,nationale', ethnische und eben sogar sprachliche Einordnung im zeitgenössischen Diskurs schlicht nicht von Relevanz war. Der Dialog zwischen dem werbenden Kroaten/Ungarn und dem ablehnenden Wiener Mädchen arbeitet letztlich unüberbrückbare Differenzen auf verschiedenen Ebenen heraus. Thematisiert wird etwa die Sprache, die in der Aufzählung der Hindernisse dezidiert genannt wird und zugleich die formale Gestaltung des Lieds prägt: Der Kroate wird durch ein Kauderwelsch aus Dialekt ${ }^{120}$ und fremdländischen Sprachmerkmalen gekennzeichnet, während für den weiblichen Part interessanterweise nicht etwa Wiener Dialekt, sondern Standardsprache verwendet wird. Damit wird in diesem Fall neben einer ,nationalen' auch eine soziale Grenze markiert: Der Mann wird nicht nur als Kroate, sondern auch als Bauer positioniert, also der Unterschicht zugeordnet.

Auch Kleidung und Aussehen, vor allem aber Sitten und Lebensart werden als trennend herausgestellt, wobei Hafner das Wiener Mädchen gleich mehrmals betonen lässt, dass es einen solchen Kroaten gar nicht lieben könne. Während sie die „Deutschen“ als „zärtlich“ und „bezaubernd“ beschreibt, werden ihm seine - negativ zu verstehenden - stereotypen Eigenschaften in vorgeblich verteidigender Weise selbst in den Mund gelegt. So will er seinen Verstand mit seiner Expertise bei Knoblauch, Zwiebel und Kapaun belegen - eine deutliche Anspielung auf die Vorliebe für Zwiebel und Knoblauch in der osteuropäischen Küche sowie auf die Figur des ,kroatischen Zwiebelkrämers', die u. a. auch in Kaufruf-Darstellungen des 18. Jahrhunderts zum Typeninventar

117 Vgl. Leerssen, Nation, Volk und Vaterland, S. 171 und 177.

118 Vgl. Emil Karl Blümml: [Nachwort]. In: Hafner, Scherz und Ernst [Reprint], S. 77.

119 Vgl. Kurt Nemetz-Fiedler: Die Lyrik Philipp Hafners. Wien 1927 [Diss.], S. 87. Blümml, der die Figur als „ungarischen (kroatischen) Bauern“ bezeichnet, weist auf die Bauern aus dem Ödenburger und Eisenburger Komitat hin, die damals vor allem Heu und Stroh auf den Wiener Markt lieferten, und stellt damit eine Verbindung zu der ,Heubauern'-Figur her (Blümml, [Nachwort], S. 77f.). Auch Karl M. Klier verfolgte in einem nicht mehr publizierten Projekt eine ähnliche These, die alle zu ,Ungarn' und ,Kroaten überlieferten populären Lieder mit dieser Volksgruppe in Beziehung setzte. Vgl. dazu Jakob M. Perschy: „Echter“ Heubauer und „falscher“ Krowod: Das letzte Projekt des Volksliedforschers Karl Magnus Klier. In: Archivar und Bibliothekar. Bausteine zur Landeskunde des burgenländisch-westungarischen Raumes. Festschrift für Johann Seedoch zum 60. Geburtstag. Eisenstadt: Amt d. Burgenländ. Landesregierung 1999. (Burgenländische Forschungen, Sonderband 22) S. 330-335.

120 Neben einzelnen Begriffen und Dialekteinfluss auf Ebene von Morphologie und Syntax fällt vor allem die Verwendung der ui-Form auf, die für einzelne ostösterreichische bzw. westungarische Regionen typisch ist und für die sprachliche Charakterisierung ,ungarischer' Figuren im 18. Jahrhundert häufig herangezogen wurde; vgl. etwa auch unten die Heubauern-Lieder. 
gehört. ${ }^{121}$ Ähnlich stereotypisiert war die angebliche Vorliebe von Kroaten und Ungarn für Tabak, ${ }^{122}$ der ihnen lotweise im Bart hinge. Auch die Erwiderungen auf die modischen und sozialen Ansprüche der Wienerin rücken den Kroaten in ein ungünstiges Licht. Nur an wenigen Stellen dagegen werden ihm tatsächlich positive Eigenschaften zugestanden - und zwar insbesondere seine Redlichkeit und Treue, die der deutschen Unaufrichtigkeit gegenübergestellt werden. Parallel zu dieser Abwertung des ,Fremden lassen sich aber auf einer zweiten Ebene auch ironische Wendungen gegen die Wienerin feststellen, die sich vor allem auf die modischen Eitelkeiten und die hohen (sozialen) Ansprüche des Mädchens beziehen, das „einzig“ nur daran denkt, sich „recht vornehm einst zu paaren“ $(10,5 / 6)$. Auch die letzte Strophe, in der sie freimütig zugibt, selbst im Falle einer Heirat zwar so zu tun, als würde sie den Kroaten lieben, in Wirklichkeit aber für andere zu „brennen“ (12,7), lässt sich nicht nur als endgültige Festschreibung einer unüberwindlichen Differenz lesen, sondern stellt der Aufrichtigkeit des Mädchens ein schlechtes Zeugnis aus.

Eine weitaus positivere Rolle spielen Fremde dort, wo sie literarisch als Soldaten auf Seiten der österreichischen Armee kämpfend dargestellt werden und dazu dienen, als Patrioten und treue Bürger des Reichs die Loyalität aller Untertanen zum ruhmreichen Haus Habsburg zu bekräftigen. Als besonders unerschrocken und kampfbegierig galten die Kroaten, wie schon in Kapitel 2 am Beispiel von Curioser Crabatischer Discurs (1717) gezeigt wurde, wo ein kroatischer Soldat seinem Kameraden Jurco einen Augenzeugenbericht zur Schlacht von Belgrad gibt (vgl. S. 111). Dezidiert hervorgehoben wird die Kompromisslosigkeit der eigenen Truppen: „[... ] wärlä häbn mir kein Perdon / Müsten springä über Klingä / Janischären alli samb/“123. Und auch die Loyalität zum Herrscherhaus wird stolz betont:

Seyn wir nie Corutzen gwesen / seyn wir allzeit treu verblieben/

Wird kein Mensch von uns was lesen / wird ä solchs von uns nie gschrieben. ${ }^{124}$

1 Corutzen] antihabsburgische Aufständler im Königreich Ungarn

Vor diesem Stereotyp des unerschrockenen wilden Kämpfers muss natürlich eine andere Spielart dieser beliebten Figur umso lächerlicher wirken. Sie findet sich im Lied vom ,armen Kroatl', das bereits 1737 in der Burleske Die Zauber Trommel am Wiener Kärntnertortheater zum Einsatz kam. ${ }^{125}$ Die vierstrophige Fassung, die Hanswurst als

121 Vgl. u. a. Kroatinn mit Zwiebel. Croate, qui vend des oignons. In: Zeichnungen nach dem gemeinen Volke besonders Der Kaufruf in Wien. Etudes prises dans le bas peuple et principalement Les Cris de Vienne. 1775. Nach dem Leben gezeichnet von J[ohann] Brand Professor der bildenden Künste [o. S.].

122 So etwa auch in Karl Marinellis Der Ungar in Wien (Der Ungar in Wien. Ein Originallustspiel in drey Aufzügen. Von Marinelli dem ältern, einem deutschen Schauspieler. WIEN, gedruckt mit Schulzischen Schriften. 1773, S. 3f.).

123 Curioser Crabatischer Discurs, Str. 3, 2-3. - Die Janitscharen waren eine Elitetruppe der osmanischen Infanterie.

124 Ebda., S. 2r.

125 Österreichische Nationalbibliothek, 12706 (Teutsche Arien I), S. 15ff., hier 22f. - Edition bei Pirker, Teutsche Arien I, S. 11. - Erhalten ist wie üblich nicht der Text des ganzen Stücks, sondern nur die Arien. Darin tritt jeweils Hanswurst in verschiedenen Verkleidungen - als steirischer Bauer, schwäbischer Schneckenhändler, Husar, Pole, Kroate, Schuster etc. - auf, wobei diese Typen auch jeweils sprachlich charakterisiert 
„Crabatischer Hühner-Krammer" singt, ${ }^{126}$ ist wohl kaum das ,Original", sondern vermutlich eine Theateradaption eines geläufigen Lieds. Wo auch immer dessen Ursprung liegen mag - spätestens um 1800 scheint es größere Beliebtheit erlangt zu haben, wie mehrere erhaltene Flugschriftendrucke der Zeit mit einer 9-strophigen Fassung belegen. ${ }^{127}$ Hier rückt die Figur des infantilen Pantoffelhelden in den Mittelpunkt, der von seiner bösen Frau schikaniert wird:

1

Arm Kroatl, nichts zu leben, nichts mehr Madel Bratzel geben, nichts mehr tanzen kroatisch, nichts mehr tanzen hop hop, frisch. 3

Muß alleweil mit leere Magen

Hündl Buckerl, Kraxel tragen, möcht oft schmeißen Teufel weg, mit die trecke Geberneck. 5 Giebst mir Hündl viel zu schaffen, laß nit bey der Nacht ein schlaffen, schreyen, alleweil Kikriki, und in aller Früh zwick auf mi. 7 Teufel mach bey Weib mehr bleiben, der mich aus die Haus will treiben, möcht oft laufen i armer Mann von dir Hund auf und davon. 9

Kroatl nichts mehr Weiberl kaufen, weil er wie die Teufel raufen, lieber, allein lustig spring, und dazu kroatisch sing. ${ }^{128}$
2

Weib hat arm Kroatl schlagn, und hat aus die Häuserl jag'n, hat die Gati aufgehebt, und aufs Arscherl Fick, Fick gebt. 4 Muß alleweil wie Narr umlaufa, schreyen: a Zwiefel a Knoffel kaufa; is nit guti mehr wie eh, arm Kroatl thut Baucherl weh. 6 Kann kain Speck kain Zwifel krigen, muß wie Oxel Wagen ziehn, nichts ist schlechters unter Tag unter Heuwagen Betterl mach. 8 In die Weib hat Teufel drinna, weilen wie die Waskodina, wan schlug Teufel ab das Knack, vor Kroatl tobre tak.

1,2 Bratzel] Hand 2,3 Gati] (Unter)Hose 2,4 Fick, Fick] (onomatopoetisch für) Schläge 3,2 Hündl] Hühner Buckerl, Kraxel] auf dem Rücken 3,4 trecke Geberneck] dreckigen Übermantel (eig. ung. köpönyeg: ,Umhängemantel', von türk. kepenek: , ungenähter, ärmelloser Filzüberwurf`' der anatolischen Schäfer) 8,2 Waskodina] ? 8,3 Knack] Genick 8,4 tobre tak] (kroat.) gut so, in Ordnung

werden. Einige der Arien sind daher eher standardsprachlich orientiert, andere markieren fremdsprachigen Akzent und einige Dialekt. Eine spätere, durch einen Theaterzettel von 1766 belegte Fassung des Stücks schreibt Brandner-Kapfer - allerdings mit Zweifeln - Joseph Felix von Kurz zu, der jedoch wohl eher nur als Bearbeiter der älteren Fassung zu gelten hat. Vgl. Brandner-Kapfer, Johann Joseph Felix von Kurz, S. 13 f. und 634.

126 Die Arie umfasst neben einer zusätzlichen Anfangsstrophe (Incipit: „Schaut er an, daß unsr än“) die 1., 2. und 4. Strophe des Lieds.

127 Der älteste bekannte Flugschriftendruck ist um 1800 entstanden: Vier schöne neue Weltliche Lieder. Das Erste. Arm Kroatl, nichts zu leben, nichts / Das Zweyte. Schwerin, bist wirklich todt, kommst / Das Dritte. Wahres Lieben, süßes Leben, wo zwey / Das Vierte. So trift mich das Schicksal, so soll / Gedruckt in diesem Jahr. [9 Strophen] - Vier weitere undatierte oder spätere Drucke (bis 1823) führt Wolkan in seiner Sammlung historischer Wiener Volkslieder an, vgl. Wolkan, Wiener Volkslieder 2, S. 351f.

128 Vier schöne neue Weltliche Lieder, f. 1v-2r. 
Komisierungseffekte wie der weinerliche Tonfall, die demonstrative Hilflosigkeit oder die mit Diminutiva akzentuierte Kindlichkeit verband man zu dieser Zeit mit der damals populärsten lustigen Figur, dem (von Johann La Roche verkörperten) Kasperl. Nicht umsonst findet sich eine umgearbeitete Variante des Lieds auch in einem (parodistischen) Kasperl-Stück von 1781 (Armer Kasperl, nix zu lebn). ${ }^{129}$

Der Fremde als lustige Figur im Typeninventar des Theater- und Liederkorpus begegnet uns schließlich auch in den ,Heubauer'-Liedern, die in mehreren ab 1796 in Wien gedruckten Flugschriften überliefert sind. In ihnen wird der Andere - trotz der deutlichen sprachlichen Markierung als Ungar und einer dementsprechenden Kostümierung - eher als Wiener Typus und volkstümliche Figur inszeniert, die für Unterhaltung in diversen Wirtshäusern sorgte und bei Bedarf auch für patriotische Zwecke herangezogen werden konnte, wenn es galt, einen Sieg oder den Geburts- oder Namenstag von Angehörigen des Herrscherhauses zu besingen. Der Heubauer wird dabei einerseits als exotische Figur gezeichnet, andererseits aber auch dem Figureninventar der Wiener Typen einverleibt und als ,urwüchsig' und ,original' wienerisch/österreichisch markiert. ${ }^{130}$ Eigenes und Fremdes gehen damit eine für diese Figur charakteristische Verbindung ein. Sozialhistorisch lässt sich die Heubauern-Figur wohl auf jene Bauern aus der Region des ,Heidebodens 'östlich des Neusiedlersees im damaligen Wieselburger Komitat zurückführen, die die Stadt Wien bis weit ins 19. Jahrhundert „fast monopolartig mit Heu als Pferdefutter" ${ }^{131}$ versorgten. Freilich waren es keineswegs die Heubauern selbst, die unter dieser Bezeichnung auftraten, sondern Volkssänger, die sich dieses im Stadtbild wohl bekannten Typus und seiner ,Farbigkeit' in Kleidung und Aussprache bedienten. ${ }^{132}$ Entsprechend verweist der Jargon der Figur, der durch Fehler in Phonologie, Morphologie und Syntax, mehr oder weniger ungarische Wendungen und häufig auch durch ui-Mundart charakterisiert ist, eher auf die „gängigen Vorstellungen des deutschsprachigen Wiener Publikums vom slawischen [bzw. ungarischen] Radebrechen “ ${ }^{\text { } 133}$ hin als auf einen wirklich gesprochenen Dialekt. Die Sprachmischung dient dabei der Figurencharakterisierung, erfüllt aber auch einen anderen poetischen Zweck: Das Spiel mit Betonungsverschiebungen ermöglicht erst die Einhaltung des Versmaßes, falsche Wortstellungen ,retten` sonst unmögliche Reime, Enjambements brechen das sonst eintönige

129 Im Anhang des 1781 gedruckten Anti-Kasperl-Pamphlets Etwas für Kasperls Gönner findet sich das als boshafte Parodie gestaltete Kasperlstück Das Spiel der Liebe und des Glücks, oder Kasperl, der geglaubte Printz der Insul Csiri Csari, in der als Arie des Kasperl Teile der ersten und vierten Strophe dieses Lieds verwendet werden: „Armer Kasperl nix zu lebn,/ Nix den Madeln Pratzl gebn,/ Nichts mehr sagen als wie eh / Armer Kasperl hat Baucherweh." (Etwas für Kasperls Gönner. Wien 1781, bey Sebastian Hartl. burgl. Buchbinder, in der Singerstrasse neben St. Stephansthor, S. 11f.; Edition bei Gugitz, Der Weiland Kasperl, S. 91). - Vgl. dazu auch Kap. 8.

130 Vgl. dazu auch Rapp, Wiener Typen, S. 146. - Kos, Einleitung, S. 16.

131 Michael Joseph Gmasz: Das traditionelle Hochzeitslied auf dem burgenländischen Heideboden. Unter besonderer Berücksichtigung handschriftlicher Liederbücher und Privatchroniken. Wien 2013 [Dipl.], S. 14.

132 Perschy weist in diesem Zusammenhang darauf hin, dass nur der ungarische bzw. auch kroatische, nicht aber der deutschsprachige Heubauer vom Heideboden, den es ja auch gab, zur Figur stilisiert wurde, was „sicher im mangelnden Exotismus des Letztgenannten begründet“ liegt, vgl. Perschy, „Echter“ Heubauer und „falscher" Krowod, S. 333.

133 Ebda., S. 332. 
Versmaß auf. Damit wird nicht nur in der inhaltlichen, sondern stärker noch in der sprachlichen Gestaltung der Figur das Spielerische und Humorvolle unterstrichen - ein wohl nicht unwesentlicher Faktor für ihre Beliebtheit.

Obwohl die Heubauern-Figur in verschiedenen Darstellungen mit einem bestimmten Sänger in Verbindung gebracht wurde, ${ }^{134}$ lässt sie sich wohl kaum auf einen Autor zurückführen, zumal sie aufgrund des Erfolges auch rasch von anderen Sängern aufgegriffen wurde. Dies macht etwa das 1797 gedruckte Lied Recht nothwendigi Zuwaag' deutlich: Denn mit diesem Druck antwortet ein zweiter Dichter auf eine - leider nicht erhaltene - Streitschrift des Schöpfers der Heubauernfigur, der offenbar den Epigonen angriff und ihm u. a. vorwarf, kein echter Ungar zu sein. ${ }^{135}$ Der explizite Bezug auf einen ,echten Heubauern' spricht für die Popularität der Figur, die schnell zu einer festen Größe geworden zu sein scheint und zur Nachahmung animierte. Das Lied macht mit seinem Untertitel Noch di G'wicht von seini agni Numero außerdem deutlich, dass nicht nur die Figur, sondern auch die Melodie fest etabliert war. In späteren Flugschriften, die eher Reklame-Charakter haben, ${ }^{136}$ aber auch im Theater wurde die Figur schließlich das ganze 19. Jahrhundert über aufgegriffen. ${ }^{137}$

Im folgenden Liedausschnitt besingt der Heubauer das Ende des Faschings, wobei, wie für diese Lieder typisch, der Auftrittskontext im Wirtshaus stark präsent ist. Als

134 Häufig wird in Zusammenhang mit der Heubauern-Figur der Volkssänger Lajos Komlosyj/Ludwig Komlóssy genannt, der etwa auch im Katalog der Österreichischen Nationalbibliothek als Interpret angegeben ist. Der Name wird öfters in Darstellungen aus dem 19. Jahrhundert genannt (vgl. insbesondere Constant von Wurzbach: Biographisches Lexikon des Kaiserthums Österreich. Bd. 12: Klácel - Korzistka. Wien: Verlag der k. k. Hof- und Staatsdruckerei 1864, S. 404. - Moritz Bermann: Alt- und Neu-Wien. Geschichte der Kaiserstadt und ihrer Umgebungen. Wien, Pest, Leipzig: Hartleben 1880, S. 1084). Ein aus Ungarn stammender Sänger dieses Namens soll etwa zwischen 1800 und 1820 in Wiener Gaststätten aufgetreten sein und dabei „ungeheureres Aufsehen“ (Bermann) erregt haben und „bald eine volksthümliche Figur“ (Wurzbach) geworden sein. Nähere biographische Angaben zum Sänger bleiben aber vage und scheinen mehr der literarischen Fantasie entsprungen als auf belegten Daten zu basieren. Sollten die bei Bermann ohne Quelle angegebenen Lebensdaten 1784-1856 stimmen, kann Komlossy nicht als eigentlicher Urheber der Heubauern-Figur gelten, wäre er doch bei den ersten Drucken von 1796 erst 12 Jahre alt gewesen. Vgl. Sepp Gmasz: Mundart zur Haydnzeit: historische, literarische und musikalische Quellen. Mit besonderer Berücksichtigung des burgenländischen Raumes. In: Jahrbuch des österreichischen Volksliedwerkes 59 (2010), S. 202-218, hier 214f.

135 Recht nothwendigi Zuwaag' zu di Promemori von di Gewissi Mann der allan will rechti Heubauer seyn. Noch di G'wicht von seini agni Numero; Mit Anmerkungen von ani scheideri, als rechti und linki Heubauer is. Wien, 1797. Auf Kosten des vormahligen Buchdruckers Weimar, und in Kommission in der Rehm'schen Buchhandlung am Kohlmarkt. - Namen werden auch in diesem Druck nicht genannt, allerdings wird der Schöpfer des Heubauern als „gebohrne[r] Ungar“, dessen Name aber „kein ungarisches Gepräge hat", bezeichnet (ebd., Bl. 2v).

136 In einer größeren Anzahl an Flugschriften ab etwa 1808 tritt die Heubauern-Figur als gewissermaßen institutionalisierte Werbefigur auf, die für bestimmte Veranstaltungen, Gaststätten oder Theaterstücke wirbt. Die sprachliche Gestaltung wird sehr viel schwächer, die Wiedergabe des Akzents bzw. Dialekts beschränkt sich auf einige wenige feste Wendungen und Formen. (Vgl. etwa: Nagelneui Lid, was di ungrischi Heubauer von di neui Wiener-Apollo-Saal in Pesth sungen hat. Zum singen im Tone der gewöhnlich beliebten Heubauern-Arie. 1808. - Heubauern-Lied über das lustige Faschingsstückel, genannt: Der Rochus Pumpernickel.1809. - Ganz besondri Naglneui Lid, was di bekannti ungrischi Heubauer von di unverbrennbari Spanier, Nicolaus Isidor Roger, seini mit großi Beyfall z’Wien beym Sperl gmachti Experiment von der Unverbrennbarkeit, in Pesth sungen hat. 1809).

137 Vgl. dazu die Hinweise bei Perschy, „Echter“ Heubauer und „falscher“ Krowod, S. 332. 
(trink)lustige und spendable Figur fordert er die Zuhörer zum Trinken auf und spricht Wirt, Wirtin oder einzelne Gäste an:

\author{
Heubauer tritt ein \\ Semper lusti! nix in Trauer! \\ Secht's, no amal kummt Heubauer, \\ Bill helf Fasching gar begrab'n; \\ Brüder! boll'n uns heunt no letzen, \\ Morgen thuit's Brennsuperl setzen, \\ Morgen Quarklkaß aschab'n. \\ Zum Wirth \\ Wirth! bring' hurti aus dem Keller, \\ Grüntziger und Muskateller, \\ Heunt geht alles unter'nand; \\ Gieß’ den Sauern untern Süssen, \\ Heunt mer libi Fasching b'sliessen, \\ Dazu brauch' mer nit Verstand.
}

\author{
Zur Wirthin \\ Wirthin! thui di produziren, \\ Heunt muist narrisch uns traktiren, \\ Koch uns heunt a Quodlibet; \\ Kraut und Ruiben, Artischoken, \\ Thui, was d'hast im Haus, h'nein broken, \\ Daß heunt alles ran aufgeht. \\ Zur Kellnerin \\ Lelkem! thui dir d'Schüecherl schmieren, \\ Wirst di heunt no müssen rühren, \\ Heunt muß's tanzt seyn, das is g'wis; \\ Ober zeitli müst's anheben, \\ Daß's no Tanzl gnui thuit geben, \\ Puncto zwölf der Kehraus is. [... $]^{138}$
}

1,1 Semper] (lat.) immer 1,4 letzen] (zum Abschied) vergnügen, meist durch Essen, Trinken und Tanz 1,6 Quarklkaß] Quargel, Sauermilchkäse 2,3 Quodlibet] (lat.) was beliebt: Kombination der beliebtesten Dinge 3,2 Grüntziger] Grinzinger: Weißwein aus dem Wienerwald 4,2 Lelkem] (ungar.) meine Seele (als Kompliment)

Nach diesem Grundmuster aufgeräumter Feierlaune wird der Heubauer zum prototypischen Überbringer guter Botschaften in der Wiener Unterhaltungskunst um 1800. Dass dieses Muster rasch auch für agitatorische bzw. affirmative Zwecke eingesetzt wurde, liegt zur Zeit der Koalitionskriege auf der Hand. Dem obligaten Auftritt im Wirtshaus folgt im Lied was hot auf di Karoli-Tag ein ungarischi Heubauer zu Wien sungen dementsprechend die patriotische Schilderung eines Sieges unter Erzherzog Karl. Die Figur des Heubauern scheint nicht zuletzt auch deswegen so geeignet, weil sie gewissermaßen den Zusammenhalt innerhalb der Monarchie ,verkörpert ${ }^{\text {‘ }}$ - und entsprechend auch explizit betont, dass „teitsch und ungarisch Soldat“ die Franzosen gemeinsam zurückgeworfen hätten:

1

Liebi Teitschi Pajtàsch! gehnmer

In die Birtshaus, trinks ein Emmer,

Zahli alli allein aus;

Habi meini Heu verkaufen,

Willi alli glei versaufen,

Und geh ohni Kraitzar z'Haus.

$[\ldots]$
2

Ober bringi ham die Portre

Von Prinz Karli seini Ordre,

Die Er hot bei Birzburg mogt;

Bird mein Beib und Ginder bunder,

Bie die grossi Held zu Plunder

Hot verflugti Franzos jogt.

138 Lied was hot auf di Sterbtog von di Fasching, di bekannti ungarischi Heubauer z'Wien sungen. In Gesellschaft eines Fleischhackers, Müllers, Bäckers, Greislers, Lehenkutschers, und eines Friseurs. Wien, Auf Kosten des vormahligen Buchdruckers Weimar, und in Commißion in der Rehm'schen Buchhandlung am Kohlmarkt. 1798. 
7

Bie si olli Nasionen

Bundern, daß Er sik nicht schonen,

Ein so grossi Majestät!

Bie si olli Hasen schomen,

Mog nit sogen ihri Nomen,

Die hom sogen: Nem-lehet!

9

Birst bald, Teitschi Pajtàsch! heren,

Bie hot Karli Reich ausleren

Bon die Franzos Raubgepack;

Nocher herst du nimmer trummeln,

Sondern bie sik ummertummeln

Die Soldat bei Dudellsack.
8

Mog die Franzos kanoniren,

Thuit doch Karli komandiren,

Allibeil und überall;

Mog si schneiben, mog si regen,

Karli reitet mit di Degen

Ueber Berg und über Thall.

10

Bie si bird die Sundheit tringen,

Und aus volli Hals bird singen:

Lebe Karli Teitschlands Held!

Unser Voter Kaiser lebe!

Und uns Bauern bider gebe

Mit die Fried auch Bissel Geld! ${ }^{139}$

1,1 Pajtàsch] (ungar. pajtás) Kamerad, Genosse 1,2 Emmer] Eimer: Maßeinheit (in Österreich 56,5 1) 2,2 Von Prinz Karli seini Ordre] im Lied wird der Sieg Erzherzog Karls (1771-1847, jüngerer Bruder Kaiser Franz' II.) über die Franzosen bei Würzburg im Jahr 1796 besungen 2,5 zu Plunder] davon, zum Teufel 7,6 Nem-lehet] (ungar.) nicht möglich, kann nicht sein

Der Heubauer ist hier nicht mehr als jemand gezeichnet, der von auswärts kommt, als An- oder Durchreisender - er ist Wiener. Mag man seiner Sprache auch anhören, dass er aus Ungarn stammt: Mit den Deutschen verbindet ihn das Reich, der gemeinsame Feind und über allem der „Voter Kaiser“, der für diese völkerübergreifende Einheit stand.

\section{Selbstreflexionen}

So nachhaltig das Fremde in der bairisch-österreichischen Dialektdichtung vor 1800 in all seinen Spielarten zum Thema wird, so sehr das Typische im Eigenen und Anderen zur Sprache kommt, so selten findet sich der Blick auf das Individuelle, die - ironisch ungebrochene - Reflexion über die Konstituenten des eigenen Seins. In der Mundartliteratur dieser Zeit ist die Identitätskonstitution noch nicht zum Problem geworden; man sieht sich also noch in einer Welt, die trotz aller Unbilden klare Ziele und Bezugspunkte kennt. Die wichtigsten Bezugssysteme sozialer Identität im 18. Jahrhundert, Religion, Stand und Staat, sind als Rollenvorgaben noch weitgehend intakt, auch wenn die Diskurse der Aufklärung die Loslösung von dogmatischen Vorgaben bereits unübersehbar vorantreiben. Den Autoren der uns überlieferten Dialektliteratur muss die Poesie nicht Mittel zur Selbstkonstitution werden, weil sie die Welt noch nicht als kontingent erfahren haben. ${ }^{140}$ Finden wir poetische Selbstreflexionen, so verortet sich das Ich bei aller Abgrenzung

139 Lied was hot auf di Karoli-Tag ein ungarischi Heubauer zu Wien sungen. Wien, Auf Kosten des vormahligen Buchdruckers Weimar. 1796, f. 1r-4v. - Das Lied ist darüber hinaus handschriftlich überliefert, nur mit der ersten Strophe, aber mit Melodie und Klavierbegleitung: Lied, was hot auf die Karoli-Tag zu Wienn ein ungarisch Heubauer sungen (Österreichische Nationalbibliothek, Musiksammlung, Mus.Hs. 18778).

140 Vgl. Karl Eibl: Die Entstehung der Poesie. Frankfurt a. M.: Insel 1995, S. 60. 
zum Anderen doch immer in einem als verbindlich verstandenen (metaphysisch legitimierten) Sinnzusammenhang. Das Gedicht als Reflexions- und Diskussionsraum legt dem potentiellen Leser also keine Neuorientierung in einer problematisierten Umwelt nahe, sondern zeigt Möglichkeiten der Integration bzw. des Beharrens im Bestehenden auf.

In diesem Sinn ist etwa auch Peter Gottlieb Lindemayrs Mein Gemüth- und Denkensart (1780) zu verstehen, eine vergleichsweise simple Eigencharakterisierung, in der sich das Ich als anständiger, lebenslustiger und gottesfürchtiger Mensch vorstellt, der gleichwohl um seine kleinen Schwächen weiß und zu diesen steht. Die zahlreichen Züge des Typischen und Allgemeinen verweisen auf einen ,mittleren Charakter', wie er seit der Antike in der Tugendethik diskutiert wird. Gemäß der aristotelischen Mesotes-Lehre soll man zur Erlangung von Tugend das Mittel zwischen zwei Extremen suchen, wobei dieses Mittlere individuell vom jeweiligen Charakter abhängig ist. Anzustrebende Tugenden sind Klugheit, Gerechtigkeit, Tapferkeit und Mäßigung, auch Freigebigkeit, Seelengröße, Hilfsbereitschaft, Sanftmut, Wahrhaftigkeit, Höflichkeit und Einfühlsamkeit. Sie zu erlangen ermöglicht dem Menschen die Harmonie mit sich selbst. Thomas von Aquin fügte dem Katalog klassischer Tugenden noch die theologischen Tugenden Glaube, Liebe und Hoffnung hinzu. Beinahe alle diese Tugenden sind hier mehr oder weniger explizit angesprochen:

1

Ih bin halt schon ä so:

Ä Freund dä ganzen weiten Welt, Välang mä weitä nöt viel Gelt, Ä weng wünsch ih mä doh, Ih bin halt schon ä so.

$[\ldots]$

4

Ih bin halt schon ä so:

Nöt z’höflih, afer äh nöt z'grob, Hör gern der andern Leut iehn Lob; Mein's gleihwohl liebä noh.

Ih bin halt schon ä so.

[...]

7

Ih bin halt schon ä so:

Ih bin gleih härb, und bi gleih gut, Danah mä mi ansuchä thuet:

Mein Rechten ghalt ih doh.

Ih bin halt schon ä so.

9

Ih bin halt schon ä so:

Geht's gut; so denk ih: waiß nöt, was?

Geht's afä schlecht; so tröst mih das:

Der alti Gott lebt noh.

Ih bin halt schon ä so.
2

Ih bin halt schon ä so:

Wer mih gern hat, den lieb ih äh

Und wenn mär ainr schan ghäßi wä;

So liebet ihng halt doh,

Ih bin ämal ä so.

[...]

6

Ih bin halt schon ä so:

Ih gieb gern aus und nimm gern ein;

Müßt afer ih dä Narr just seyn:

So scherets mih schan doh.

Ih bin halt schon ä so.

8

Ih bin halt schon ä so:

Wo's lusti zugeht, halt ih mit,

Wo's trauri aussiecht, bleib ih nit,

Mitleidi bin ih doh,

Ih bin halt schon ä so.

[...]

11

Ih bin halt schon ä so:

Ih denk mein Thail hübsch in dä Still

Ih loß däbey und röd nöt viel

Ä Kennä han I do -

I bi halt schon ä so! 
12

Ih bin halt schon ä so:

Glaubn thue ih währlä nöt ga leicht,

Wenn afä was dä Wahrhät gleicht,

So glaub ih d'Sach schan doh.

Ih bin halt schon ä so.

14

Ih bin halt schon ä so:

Was recht und Gott lieb thu ih gern

Und thue mih aft um Niemden schern

'N G'horsam laist ih doh,

Ih bin halt schon ä so:
13

Ih bin halt schon ä so:

Ih friß und trink gern öppas guts

Bin kreuzwohlauf und guten Muths

Beim Mittel bleib ih doh.

Ih bin halt schon ä so.

15

Ih bin halt schon ä so:

Nöt bloß ä Mensch, ä Krist däbey,

Gott und 'n Kaisä ewi treu.

Was will mä mehrä no?

Ih bin und bleib ä so! ${ }^{141}$

1,1 ä so] (verstärktes) so 2,3 ghäßi] gehässig: (hier in ursprünglicher Bedeutung) hassend, feindlich gesinnt 4,3 iehn] ihr 7,2 härb] böse, zornig 11,3 loß] höre zu 11,4 Kennä] Kennen, das: Wissen, Kenntnisse, Überblick, Durchblick 13,2 öppäs] irgendetwas 14,3 aft] dann, also

In der ,Gemüth- und Denkensart' des Ich finden sich allgemeine Dispositionen eines Menschen, der nach dem Maßstab christlicher Tugendvorstellungen sozialisiert wurde. Da es dem (männlichen) Rezipienten ohne Schwierigkeiten möglich war, sich mit den Aussagen zu identifizieren, konnte das Lied über den privaten Gebrauch hinaus auch in den Volksgesang eingehen.

Derber, doch mit derselben intentionalen Ausrichtung und transzendenten Absicherung („,es löbt no der alti gott") präsentiert sich ein ,Seelenbild“, das der Kremsmünsterer Kapitular Franz Sparry Mitte des 18. Jahrhunderts auf Basis einer beliebten Weihnachtsliedmelodie vertonte. Auch hier dominiert ein Konservatismus im unerschütterlichen Vertrauen auf eine höhere Gewalt:

1

Solt i woana, odä lachä?

gfreyt mi warlä koäns gar vill, I lasß bliz’n, i lasß krachä,

i denk halt nur auf mei Zill;

waß soll i mein Kopff vill zreisß’n,

was i will, das denk i mir,

mi kann gwiß kän unglück beisß’n,

i waiß scho, was is däfir.

3

thuet mi scho vill arbeith Qualln,

denk i halt, äs muaß scho seyn,

muasß dä hund in beit'l Pell'n,

gib i mi ganz willi drein;

thät i woanä, thät'ns lachä,

na das wär mä oämahl z'schlecht

I mag ien dö freid nit machä,

mag nöt thoän, was ien is recht.
2

Sagts mä do, was soll i scheich'n, hoäts! was soll mä machä bang, mögn mi andrö waiß was zeich'n, mach i halt mei feig'n lang; i denk mir, laßts nur d'leuth sag'n, auf dä welt hat nix än bstand, lasßts ös beisß’n, laßts ös nag’n, bin Zum leyd'n no in stand.

4 wanns mä all mei säch'l nemä, denk i wohl, groß iß mei Noth, kanß do widä alls bekemmä, es löbt no der alti gott; meintwögn thoän scho andri sag'n, dwelt muesß wer'n nag'l neü, soll do nix mei herz mehr blag'n, bin der alt und bleib däbey.

141 P.G.Lindemayr, Lieder in oberösterreichischer Mundart, S. 54-57. 
5

mi kann nix mehr iezt däschröck'n,

wan scho dwelt gar zamä fallt,

mi lasßt gwiß mei gott nit stöck'n,

i fall nöt, wan er mi halt;

greiff'n dfeind zu ihr'n waff'n,

kämäns gwisß in schand und Spott,

i will süsß und sicha schlaff'n,

bin wohlauf und hoff auf gott. ${ }^{142}$

1,1 woänä] weinen 2,1 scheich'n] scheuen 2,3 zeich'n] zeihen, beschuldigen 2,4 mach i halt mei feig'n lang] zeige ich ihnen die Feige (obszöne Geste mit dem durch die Finger gestreckten Daumen) 2,7 lasßts ös] lasst sie 3,3 muasß dä hund in beit'l Pell'n] kürzer treten, zurückstecken (?) 5,2 zamä] zusammen

Als letztes Beispiel dieses beliebten Typus sei ein Lied vorgestellt, das anstelle einer transzendentalen Begründung des eigenen Verhaltens einen durch und durch hedonistischen Standpunkt einnimmt. Gleichgültig gegenüber den Meinungen, Erwartungen und Urteilen seiner Umgebung, betont das Ich, sich vollkommen frei und unabhängig nach Lust und Laune zu verhalten. Was anderen gefällt bzw. was andere für gut und richtig oder schlecht und falsch halten, zählt für den Sprechenden nicht. Ob es um genussvolles Essen und Trinken, einen vermeintlich verwerflichen Tagesrhythmus, Arbeitsscheue, Streitereien oder Gejammer geht - stets wird selbstbewusst im redundanten Credo eingangs und abschließend konstatiert: ,ich bin und bleib ä so'.

1

Ich bin und bleib ä so,

ich las mich gwiss nicht Mahlen:

was anderen nicht sol gfahlen

ich bin und bleib ä so,

es Mag mich einer loben,

auch tadlen wie er wil,

werd doch zu solchen sachen:

nur alle auslachen,

ich bin und bleib ä so:

3

Ich bin und bleib ä so:

geh abends gar bald schlaffen:

thue Morgens spädt aufwachen

ich bin und bleib ä so:

ich hüet mich vor der arbeit:

und liebe mehr die rueh:

das gschicht als derentwegen:

das ich meiner gsundheit Pflegen

ich bin und bleib ä so
2

Ich bin und bleib ä so:

ist es was mir thuedt schmekhen:

wans anders nur thuedt khlekhen:

ich bin und bleib ä so:

ich thrinkhe guetten wein:

zu zeiten auch ein Pier:

und is guettes Prätl:

darzue ein guets Salätl:

ich bin und bleib ä so

4

Ich bin und Bleib ä so:

ich lasse jene Bellen:

die mir stets schaden wöllen:

ich bin und bleib ä so:

ich las die zankher zankhen:

die greiner greinen gnueg:

ich aber thue nur lachen:

$\mathrm{zu}$ allen dissen sachen:

ich bin und bleib ä so: 
5

Ich bin und bleib ä so:

ich rede gern was wahr ist:

ich trinke gern was klahr ist

ich bin und bleib ä so:

ich bleib bey meiner Modi:

Mag gfahlen wem es wil

wens aber nicht wil gfahlen:

der kan ims anders Mahlen:

ich bin und bleib ä so: ${ }^{143}$

2,3 khlekhen] reichen, genügen 4,6 greiner] Jammerer

143 Bayerische Staatsbibliothek, Cod. germ. 7340 (Stubenberger Gesängerbuch), Teil 2, S. 60. 


\section{BRAUCHTUM UND GESELLIGKEIT}

Ein weites Betätigungsfeld für künstlerische Dialektverwendung bieten Formen der Geselligkeit und des Brauchtums, die sich schon zwischen bäuerlich-ländlichem und bürgerlich-urbanem Bereich deutlich unterscheiden konnten und darüber hinaus im aristokratischen Umfeld ihren ganz eigenen Ausdruck fanden. Es ist zugleich jener Bereich, wo dialektale Kunst die deutlichsten Kontinuitätslinien aufweist; manche dieser Texte scheinen bereits in der beginnenden Frühen Neuzeit zu wurzeln und sind in adaptierter Form bis heute in Verwendung. ${ }^{1}$ Erste systematischere Beschreibungen der volkskulturellen Unterhaltungsformen fernab der Ballungszentren finden sich gegen Ende des 18. Jahrhunderts in aufklärerischen statistischen und topographischen Darstellungen, die - teils von physiokratischen Theorien geleitet, teils bereits als touristische Handhabe gedacht - bestimmte ländliche Regionen zumeist mit empirischer Sorgfalt, doch subjektivem Blick und selektivem Interesse präsentierten. Die sogenannten ,Volksbelustigungen' der unteren Schichten dienten dabei als Illustrationen der unterschiedlichen (in der kursorischen Erfassung natürlich auch typisierten) Lebensweisen. Als genuine Sprachformen der jeweiligen Region fanden dialektale Brauchtumstexte schon in diesen ersten Studien besondere Beachtung. Die fundiertesten Informationen vor $1800 \mathrm{zu}$ unserem Untersuchungsbereich mit zahlreichen Beispielen aus Volksgesang und Volksdichtung bringt der bayerische Publizist Lorenz Hübner in seiner bemerkenswerten dreibändigen Beschreibung des Erzstiftes und Reichsfürstenthums Salzburg (1796). Hübner schildert das Brauchtum zu den kirchlichen Festen und Heiligen Zeiten, zu Hochzeiten und Begräbnissen, Almtrieb und Freizeit, um dann das Liedreservoir der Gebirgsbevölkerung anhand von Beispielen in drei Gruppen zu ordnen: Gstanzl, Gasslreime und „Gesänge, die theils religiösen Inhalts sind, und geistliche Gänger genannt werden; theils, und zwar meistens einen erotischen Inhalt, oder auch das Wildschießen, das Alpenleben, das Soldatenleben, und dergleichen Gegenstände zum Stoffe haben. “2 Das 1819 im Zuge der von Joseph Sonnleithner initiierten Sammlung eingesandte Liedmaterial aus den Salzburger Kreisen scheint Hübners Beobachtungen in dieser Hinsicht recht gut zu bestätigen. ${ }^{3}$

Dass Dialekt freilich bereits im 18. Jahrhundert auch in anderen Brauchtumsbereichen eine wesentliche Rolle spielt, weiß man nicht zuletzt aus den verschiedenen ,Idiotika', in denen Provinzialismen gesammelt und sprachtheoretisch ,ursprüngliche

1 Vgl. u. a. Andreas C. Bimmer: Brauchforschung. In: Rolf W. Brednich (Hg.): Grundriß der Volkskunde. Einführung in die Forschungsfelder der Europäischen Ethnologie. Zweite, überarbeitete und erweiterte Auflage. Berlin: Reimer 1994, S. 375-395. - Hinrich Siuts: Brauchtumslied. In: Rolf Wilhelm Brednich/ Lutz Röhrich/Wolfgang Suppan (Hg.): Handbuch des Volksliedes. Bd. I: Die Gattungen des Volksliedes. München: Fink 1973, S. 343-362.

2 Vgl. Lorenz Hübner: Beschreibung des Erzstiftes und Reichsfürstenthums Salzburg in Hinsicht auf Topographie und Statistik. Zweyter Band: Das Salzburgische Gebirgland. Pangau, Lungau und Pinzgau. Salzburg: Oberer 1796, 392f.

3 Vgl. Haid/Hochradner, Lieder und Tänze um 1800. 
Ausdrücke als mögliche Ergänzungen zum Wortschatz der ,Hochsprache aufgewertet wurden. Andreas Zaupser etwa, der 1789 die erste bedeutende bayerische Idiotismensammlung nach Johann Ludwig Praschs ein Jahrhundert älteren Pionierarbeiten vorlegte, gibt nicht nur einen Anhang mit „Sprichwörtern und Volksliedern“4 aus Bayern und der Oberpfalz, sondern fügt bei zahlreichen mundartlichen Lemmata ethnologisch bemerkenswerte Erläuterungen zu traditionellen volkskulturellen Handlungsmustern hinzu. ${ }^{5}$ Ebenso aufschlussreich für das Brauchtum in der Habsburgermonarchie sind die umfangreichen sprachwissenschaftlichen Arbeiten des Sprach- und Naturforschers Johann Siegmund Valentin Popowitsch, dessen Wörterbuchprojekt allerdings erst vor wenigen Jahren ediert wurde. ${ }^{6}$ Auch Hübner erstellte für den dritten Band seiner Landesbeschreibung eine umfangreiche Liste mit Salzburger Mundartausdrücken. Schon früh wurde dabei auf den ursächlichen Zusammenhang zwischen Regiolekt und identitätsbildenden bzw. integrationsstiftenden Bräuchen hingewiesen.

Neben der allgemeinen Brauchtumsdichtung im Jahreslauf, die in regelmäßig wiederkehrenden, ritualisierten Kontexten zum Einsatz kam (und zuweilen bis heute in variierter Form vorkommt) wie Arbeitslieder, Ansingelieder oder Glück- und Segenswünsche, stehen kontextbezogene Gelegenheitstexte, die zu konkreten individuellen Ereignissen und Schwellensituationen im Lebenslauf gedichtet und aufgeführt wurden zu religös motivierten Anlässen wie Taufe, Hochzeit, Primiz oder Kirchweih oder zu profanen Feiern wie Geburtstag, Promotion oder auch zu einem Jagderfolg. Etliches davon wurde bereits in den Kapiteln zuvor angesprochen und muss hier nicht mehr vorgestellt werden. An keine konkreten jahreszeitlichen, biographischen oder beruflichen Fixpunkte gebunden sind Freizeit- und Unterhaltungslieder, die das gesellige Beisammensein am Land und in der Stadt thematisieren und zugleich zu dessen damals wichtigsten Konstituenten zählen. Aber auch Tanzformen, Spiele oder Geschicklichkeitsbewerbe sind mit dialektalen Elementen überliefert. In der Inszenierung solch ,bäuerlichen' Zeitvertreibs und Brauchtums fand schließlich bürgerliches, klerikales und hochadeliges Publikum wiederum seine eigene Belustigung.

4 Andreas Dominikus Zaupser: Versuch eines baierischen und oberpfälzischen Idiotikons. Nebst grammatikalischen Bemerkungen, über diese zwo Mundarten, und einer kleinen Sammlung von Sprichwörtern und Volksliedern. München, bey Joseph Lentner 1789.

5 Zu den Idiotika-Sammlungen vgl. Walter Haas: ,Die Jagd auf Provinzial-Wörter'. Die Anfänge der wissenschaftlichen Beschäftigung mit den deutschen Mundarten im 17. und 18. Jahrhundert. In: Klaus Mattheier/Peter Wiesinger (Hg.): Dialektologie des Deutschen. Forschungsstand und Entwicklungstendenzen. Tübingen: Niemeyer 1994, 329-365. - Walter Haas: Provinzialwörter. Deutsche Idiotismensammlungen des 18. Jahrhunderts. Berlin/New York: de Gruyter 1994.

6 Vgl. Johann Siegmund Valentin Popowitsch: Vocabula Austriaca et Stiriaca. Nach der Abschrift von Anton Wasserthal hg. und eingeleitet von Richard Reutner. 2 Tle. Frankfurt a. M.: Lang [u. a.] 2004. 


\section{Allgemeine Brauchtumstexte}

Als regelmäßig wiederkehrende soziale Handlungen einer Gemeinschaft dienen Bräuche der Konstitution, Erhaltung und Vermittlung eines Gruppengefühls. ${ }^{7}$ Im Gegensatz zu kultischen Handlungen (in denen sie oft wurzeln) sind Brauchtumsformen nicht explizit auf einen metaphysischen, höheren Endpunkt hin ausgerichtet; ihr symbolischer Wert ist stärker lebensweltlich orientiert und bietet Orientierungsfunktion in gewissen sich wiederholenden sozialen Situationen einer dadurch Zusammenhalt gewinnenden Gemeinschaft. Eine wesentliche Grundlage der gemeinschaftsbildenden Traditionen, die sich durch ein ritualisiertes, über lange Zeiträume relativ stabiles Formeninventar ausbilden, sind textuell gestützte Kommunikationsprozesse. ${ }^{8}$ Dass bei der Ausbildung regionaler Besonderheiten gerade auch, verfestigten' regiolektalen Formulierungen eine besondere Bedeutung zukommt, versteht sich von selbst. Gängige Klassifizierungsmodelle von Brauchtumskomplexen über Jahreslauf, Lebensverankerung oder berufliche Gruppenzugehörigkeit sind in unserem Zusammenhang allerdings nur bedingt zielführend, da - auch wenn es zahlreiche Hinweise auf den ritualisierten Einsatz dialektaler Brauchtumstexte gibt - die Quellenlage nur einen unzulänglichen Einblick in die mündlichkeitszentrierte Praxis erlaubt. Im Folgenden sollen deswegen drei repräsentative Bereiche vorgestellt werden, in denen der mundartliche Ausdruck schon vor 1800 schriftlich festgehalten wurde: Arbeitslieder, Ansinglieder (bzw. Glück und Segenswünsche) und Hochzeitsdichtung. Dass viele dieser Texte und Formulierungen nach Erwachen des ethnologischen Interesses für sprachliche Kulturgesten bei diversen Sammelunternehmen des 19. und 20 Jahrhunderts in annähernd selbem oder variiertem Wortlaut aufgezeichnet wurden, bestätigt die Stabilität ihrer sinn-, identitäts- und integrationsstiftenden Funktion für die jeweilige Gruppierung.

\section{Arbeitslieder}

Lieder zur Arbeit können prinzipiell in zwei Gruppen unterteilt werden: Arbeitslieder im eigentlichen Sinn dienen durch Rhythmussynchronisierung zur Koordination von kraftintensiven Arbeitsabläufen. ${ }^{9}$ Üblicherweise zusammengesetzt aus einem zentralen, regelmäßig wiederholten Arbeitsruf und variierbaren Zwischentexten, erleichtern sie zum einen die monotonen, ruckweise verlaufenden Bewegungsmuster mehrerer Beteiligter und machen zum anderen mit unterhaltsamen Abschweifungen oder verbindenden Klagen die harte körperliche Betätigung erträglicher. Besonderes Interesse haben in der volkskundlichen Forschung des bairisch-österreichischen Raums Lieder und Sprüche zum Pilotenschlagen (Einrammen von Pfählen) und Drischeldreschen gefunden. ${ }^{10}$

7 Vgl. Bimmer, Brauchforschung, S. $375 \mathrm{ff}$.

8 Vgl. Hans Blumenberg: Die Lesbarkeit der Welt. Franfurt a. M.: Suhrkamp 1986, S. 374f.

9 Vgl. die materialreichen Untersuchungen von Karl Bücher: Arbeit und Rhythmus. 5. verbesserte Aufl. Leipzig: Reinicke 1919. - Josef Schopp: Das deutsche Arbeitslied. Heidelberg: Winter Universitätsverl. 1935.

10 Vgl. Karl M. Klier: Österreichische Pilotenschläger-Lieder. In: Jahrbuch des Österreichischen Volksliedwerkes 1 (1952), S. 19-33. - Deutsch/Haid/Zeman, Das Volkslied in Österreich, S. $67 \mathrm{ff}$. 
Von diesen - mit Schopp zu sprechen - ,echten ' Arbeitsliedern heben sich Arbeitstaktlieder ab, die traditionelles Liedmaterial mit (oftmals onomatopoetischen) Zusatzversen in charakteristischen Arbeitsrhythmen verbinden. ${ }^{11}$ Diese konnten zwar auch während der Arbeit zur Unterhaltung und Verkürzung der Zeit gesungen werden, kamen aber wohl viel häufiger außerhalb der entsprechenden Tätigkeiten zum Einsatz.

Von der ersten Gruppe haben sich aus dem 17. und 18. Jahrhundert in bairischösterreichischer Mundart einige Beispiele erhalten, allerdings nur in literarischer bzw. musikalischer Überformung, die jedoch in einigen Fällen mit später aufgezeichneten, tatsächlich im Arbeitsprozess eingesetzten metrorhythmischen Arbeitsliedern korrespondieren. Teils waren es Quodlibets, wo sich diese Alltagsgesänge bearbeitet erhalten haben. Schon das früheste textuell überlieferte Arbeitslied aus dem österreichischen Raum, das ebenso häufig wie falsch zitierte Vaß ziehen in Osterreych, findet sich in einer entsprechenden Sammlung von Melodiefragmenten, die der aus der Oberpfalz stammende Pfarrer und in den 1540er Jahren im Wiener Schottenstift als Schul- und Chormeister tätige Wolfgang Schmeltzl (um 1500 - um 1564) 1544 veröffentlichte. Die vierstimmige Bearbeitung weist etliche dialektale Elemente auf, die vielleicht schon bewusst als Unterstützung der musikalischen Deskription durch eine mündlichkeitsnahe Form deutlich weniger sprachlich ausgeglichen wurden als in anderen vergleichbaren Liedern. Im Folgenden ein Ausschnitt aus der Diskantstimme, der auch die authentischen Arbeitsrufe wiedergibt:

so Thomel/

leich uns her den dremel/

das man das vaß

recht ruck nit zuck/

so gegenknecht puck dich

schaw auff dich halt an dich/

das vaß ligt auff dem höhel höhel/

schaw das es bleib/

leg an die seyl/

steht gleich an/

nu wolan in Gottes nam/

ziecht all gleich/

Jo sehin/

Jo sehin/

halt vest ir lieben geselln/

halt vest. ${ }^{12}$

1 Thomel] Kurzform für Thomas (in der Bassstimme reimbedingt naheliegender ,temel'] 2 leich ... her] gib, reich her dremel] Knüppel, Prügel 5 puck] bücke 7 höhel] Hügel, Erhebung 13 Jo sehin] ja, nimm hin (Zugkommando, in den anderen Stimmen auch, Jo ha' bzw. ,ho ha')

Das stark rhythmisierende, oftmals daktylische Metrum der Arbeitslieder ist auch noch in einer Arie eines anonymen Singspiels bewahrt geblieben, von dem lediglich die Gesangseinlagen als Flugschrift überliefert sind. Die Erwähnung eines Guckkastenbilds

11 Vgl. Schopp, Das deutsche Arbeitslied.

12 [Guter / seltzamer / vñ künstreicher teutscher Gesang / sonderlich ettliche Künstliche Quodlibet / Schlacht vñ der gleichen / mit vier oder fünff stimmen / biß her / im truck nicht gesehen.] Discant. Gedruckt zu Nuernberg durch Io. Petreium. M.D.XLIIII, f. 73r-v. 
mit dem Ausbruch des Vesuvs lässt eine Entstehungszeit des Stücks knapp nach 1774 vermuten; sprachlich tendiert es ins Westmittelbairische. Soweit es sich aus den quodlibetartigen Einlagen rekonstruieren lässt, dreht sich die Handlung um die Knechte Hießl und Stöffl, die sich der harten Arbeit am Hof entziehen möchten, indem sie sich rekrutieren lassen, schließlich aber reumütig zu ihrem Bauern Hannß zurückkehren (siehe Kap. 4, S. 268). Dieser gibt zu Beginn des Stücks das folgende Arbeitslied zum Besten, in dem im zweiten Teil die ursprünglich koordinierenden Aufgaben der Versbetonung noch gut nachvollziehbar sind:

Frisch hurti Buem laßts eng nä d'Arbät schmöckä,

Zwö gäb i eng denn sinst s'Frössn und Lohn!

Rührts all engri Glidä, so kinnä mä glöckä,

Sinst jag i eng wälä grad all zween dävon.

Nehmts d' Mostln stehts nidä

Höbts auf, und steßts widä:

Daß pumpert,

Daß schlumpert

Das schlöglt,

Das klögelt

Kotz Kruzen kain End!

Oes Krennfikrament. ${ }^{13}$

1 eng nä] euch nur 2 Zwö] weswegen 3 engri] eure glöckä] etwas erfolgreich zu Ende bringen 4 wälä] wahrlich 5 Mostln] Stampfer (zum Obstzerquetschen) 7 pumpert] klopft laut 8 schlumpert] Analogiebildung zu,pumpert' 9 schlögelt] pocht 10 klögelt] hämmert, klopft 11 Kotz Kruzen] Fluch (zu Kuruzen: antihabsburgische Aufständische im Osten des Reichs) 12 Krennfikrament] Fluch (Verballhornung von ,Sakrament')

Ohnedies scheint die bäuerliche Arbeit in diesem leider nicht näher verortbaren Singspiel das eigentliche Thema zu sein, denn es schließt auch mit einem Arbeitslob, wieder in markanter Metrik.

Die künstlerisch hochwertigste Verarbeitung historischer bairisch-österreichischer Arbeitsrufe in einer quodlibetartigen Komposition stammt aus der Feder des St. Florianer Chorherrn Franz Joseph Aumann (1728-1797). In seinem Hochenauer Gschray für vier Stimmen, zwei Violinen und Kontrabass ließ sich der Regenschori des Augustinerklosters von den Rufen der Arbeiter beim Rücktransport der ,Hochenauer ' bzw. ,Hohenauer' inspirieren. Diese riesigen Lastschiffe (auf der Donau etwa 46m lang) fuhren an der Spitze des ,Gegenzugs', der mit einem gewaltigen, an der ,Hohenau' fixierten Seil durch kräftige, von den ,Schiffreitern' gerittene Pferde flussaufwärts gezogen wurde. ${ }^{14}$ Als grobe Kerle verschrien, führten die ,Jodln' genannten Reiter die Zugpferde unter lautem Geschrei über das Uferterrain, immer wieder auch in Kommunikation mit den Schiffleuten hinter ihnen, die die Schiffe zu manövrieren hatten:

13 Stiftsbibliothek St. Florian, II-17-65 W108 [Flugschriftfragment ohne Titelblatt], S. 4.

14 Vgl. Carl Victor Suppan: Die Donau und ihre Schiffahrt. Wien: Selbstverl. 1917, S. 82ff. - Rudi Palla: Verschwundene Arbeit. Ein Thesaurus der untergegangenen Berufe. Frankfurt a. M.: Eichborn 1995, S. 277280 . 
Tauch an, tauch an, mein liebä Schifmann, sunst kemmä nöt weitä, wie d'spanischen Reitä, tauch an, tauch an mein liebä Schifmann! Tauch an, tauch an mein liebä Schifmann, sunst kemmä nöt weitä wie d'spanischen Reitä, tauch an, tauch an mein liebä Schifmann. Holl aus - holl aus tauch an tauch an. ${ }^{15}$

3 kemmä] kommen wir d'spanischen Reitä] hölzerne Annäherungshindernisse aus x-förmig zusammengebundenen Stangen zur Lagerbefestigung und Angriffsabwehr

Weitaus häufiger als diese Lieder mit quasi-authentischem Rufmaterial sind solche Lieder überliefert, die während kollektiver Beschäftigung oder nach getaner Arbeit zum Zeitvertreib gesungen wurden. Dass diese nicht ursächlich mit der Beschäftigung im Zusammenhang stehen mussten, belegt etwa eine witzige Szene aus Anton von Buchers Geistlichem Vorspiel (vgl. Kap. 1), wo die Zimmerleute sich beim Bau der Arche sehr zum Missfallen Noahs mit recht unpassenden Liedern unterhalten. Mit dem liebenswerten Grüß dich Gott, mein liebe Regerl stimmen sie ein Lied an, das sich bis weit ins 19. Jahrhundert im Volksgesang hielt, es folgen Liebesleidlieder und ein Rätsellied, bevor ihr Arbeitgeber sich ein geistliches Lied ausbedingt. ${ }^{16}$

Lieder, die die jeweilige Arbeit nicht nur mehr oder weniger explizit thematisieren, sondern Arbeitsabläufe auch klanglich imitieren und das Ergebnis präsentieren, gehören zu den beliebtesten Arbeitsliedern und wurden nicht nur im ländlichen Kontext vom Volk gesungen, sondern auch auf den Bühnen gerne gesehen. Beispiele aus dem Umfeld des Kärntnertortheaters wurden bereits in Kap. 4 vorgestellt; hier ein weiteres aus der Burleske Der weibliche Satanas, in der Bernardon - vermutlich also Joseph Felix von Kurz, der vielleicht auch als Autor verantwortlich zeichnet - einen standesstolzen Weber verkörpert:

15 Musikarchiv Stift Kremsmünster, G 35/311. Erstmals abgedruckt bei Moser, Corydon, S. 186-198. Zu den weiteren Überlieferungsträgern vgl. Peter Dormann: Franz Joseph Aumann (1728-1797). Ein Meister in St. Florian vor Anton Bruckner. Mit thematischem Katalog der Werke. München/Salzburg: Katzbichler 1985, S. 418.

16 Vgl. Bucher, Geistliches Vorspiel, S. 160-163. 
1

Lustig Weber auf dem Stuhl! du darfst dich nicht rantzen; Laß dein Eintrag von der Spuhl durch den Zettel Tantzen; Tritt den Schammel! wirf das Schif, Ruck den Anschlag gschwind im Grif, Allo! zif zif!

Frisch drauf! pif pif!

Heysa! zif zif! Juch he! pif pif!

Schleunig, daß die Läus wegfliegen, Hurtig, daß wir Krätzen kriegen,

Allo! zif zif!

Frisch drauf! pif pif!

Heysa! zif zif!

Juch he! pif pif!

$\mathrm{O}$ Vergnügen.
2

Schleuer, Zwillich, Bomeßin, Leinwand fürs Weiberl, Kannefaß und Musßelin, Barchent auf a Leiberl, Wird vom Weber so gemacht, daß ans Hertz im Leibe Lacht, Allo! zif zif!

Frisch drauf! pif pif!

Heysa! zif zif!

Juch he! pif pif!

Schleunig, daß die Läus wegfliegen,

Hurtig, daß wir Krätzen kriegen,

Allo! zif zif!

Frisch drauf! pif pif!

Heysa! zif zif!

Juch he! pif pif!

O Vergnügen. ${ }^{17}$

1,2 rantzen] sich räkeln, aus Faulheit oder Müdigkeit strecken 1,4 Zettel] Kettfaden 1,5 Schammel] Tretholz zum Antreiben des Webstuhls 2,1 Schleuer] Schleier, dünnes Gewebe Zwillich] derbes, doppelfädiges Gewebe Bomeßin] Pomesin, grobe Gewebart 2,3 Kannefas] ungebleichte Leinwand, Segeltuch Musßelin] feinfädriger, glatter Stoff 2,4 Barchent] Mischgewebe aus Baumwolle und Leinen

Ein stilistisch ähnliches Arbeitslied findet sich auch in der Klosteroperette Tendlbaß des Seitenstettener Paters und Priors Norbert Pambichler (1716-1768), die in der Vertonung des Stiftsorganisten Christian Widmann (1724/27-1788) im Todesjahr des Autors uraufgeführt wurde. Ob der Ordensmann Liebe Rupfen, Laß di zupfen, das von der Bäurin Kundl während des Spinnens gesungen wird, extra für das Stück geschaffen oder auf ein bereits vorliegendes, populäres Lied zurückgegriffen hat, ist bei derzeitiger Quellenlage nicht mit Sicherheit zu sagen. Eineinhalb Jahrzehnte später bereits für Oberösterreich belegt, ${ }^{18}$ wendet es sich launig direkt an Arbeitsmaterial und -gerät. Die Alliterationen und Haufenreime des Refrains im Verein mit den Rhythmisierungen und Wiederholungsfiguren der Melodie imitieren dabei lautmalerisch den Arbeitsvorgang, das Schnurren des Spinnrads und das Betätigen des Fußtritts:

1

Liebe Rupfen

Laß di zupfen

spin di fein, und bleib nit dick

sinsten wirst ä kreuzer strick.
2

Dräh dich spiellerl steh mein Stühlerl Mach mit mir ä solchö gspunst dö mi lobt, und ä mei Kunst.

zieh di, zähr di, zupf di, zauß di, zritt di, zräf di, repet. zieh di, zähr di $p$.

laß di sauber puzen.

Fleissigs Mädl, dräh dein Rädl, spin ä Fädl,

kriegst ä pfaidl zun än klaidl.

so kanst nacher truzen.

17 Österreichische Nationalbibliothek, Cod. 12709 (Teutsche Arien 4), S. 155-157.

18 Vgl. Neuhuber, Lindemayriana, S. $115 f$. 
3

mehr än Knotten.

und än Knotten

Ey du häbrer, rupfrer Mist, wan den das Ding g hächtlt ist? repet. zieh di, zähr di $p$. 5

Du mei Rocken

bleibst mein Docken

bist mir liebä als ä Man.

weil i di bräf rupfen kan.

repet. zieh di, zähr di $p .{ }^{19}$
4

Agn, und gräden

zrissne Fäden

bleibts mir auß, i brauch eng nit

weils mirs Rüpfel nur zerritt.

repet. zieh di, zähr di $p$.

1,1 Rupfen] Rohmaterial (hier Flachs) zum Verspinnen 1,4 kreuzer strick] minderwertiger Strick 1,5 zähr di] dehn dich zritt di] geht auseinander zräf di] zerrauf dich 1,8 pfaidl] Hemd(chen) 1,9 truzen] hier: stolz sein 2,1 spiellerl] kleine Spule 2,2 Stühlerl] Trageteil des Spinnrads 2,5 repet.] (lat. repetitur) wird wiederholt p.] (lat. perge) usw. 3,3 häbrer] widerspenstiger rupfrer] grob zersauster 3,4 g hächelt] durch die Hechel (Metallkamm) gezogen, gekämmt 4,1 Agn, und gräden] Abfall beim Flachsbrecheln 4,4 Rüpfel] Diminutiv zu Rupfen zerritt] durcheinanderbringt 5,1 Rocken] Spinnrocken, an dem die unversponnenen Fäden befestigt sind 5,2 Docken] Puppe, Spielzeug

Kontextuell nicht eingebunden ist ein zweites Arbeitslied, das Pambichler möglicherweise erst im Zuge der Aufführungsvorbereitungen als wirkungsvollen dramatischen Auftakt der Handlung hinzugefügt und in der Perioche aufgezeichnet hat. Das dreistimmige Lied der Drescher aufn Tenn im Dreivierteltakt, das nun die Reimhäufungen noch intensiver auskostet, ist ein kunstvolles Beispiel, wie die als Arbeitshilfe konzipierten Muster für ein weitaus komplexeres musikalisches Ganzes adaptiert werden. ${ }^{20}$ Der Wechsel der Singstimmen, die variable Rhythmisierung, die ausgefeilte Melodieführung machen einen tatsächlichen Einsatz bei der kräfteraubenden, staubigen Drescharbeit äußerst unwahrscheinlich. Als Vorführkunst zur Unterhaltung und symbolischen Aufwertung bäuerlicher Arbeit freilich war ein solch artifizielles Drescherlied (mit der damals klostertypischen Begleitung durch zwei Geigen, Viola, Kontrabass und zwei Hörner) ideal:

1

Auf?

Heb auf!

Schlag nieder, heb auf!

auf ein Streich zween drauf!

Wan Triescheln sich schwingen,

und s'Ringerl dran glanzt;

Wan d'Körner bräf springen,

und s'Ströberl schön tanzt:

da schmuzt dir der Baur.

Da wird ihm kein bucken, kein ducken,

kein drucken, kein lucken, kein mucken,

kein schlucken, kein Stucken, kein Zucken

Kein Arbeit nicht saur.
2

Auf!

Heb auf!

Schlag nieder, heb auf!

auf ein Streich zween drauf!

Geh Stephel sey munter

bleib nit immer stehn.

Hinauf und hinunter

fein langsam mußt gehn.

sonst drescht nur lährs Stroh.

Wans aber bräf dumpert, und gumpert, und humpert, und lumpert, und klumpert, und pumpert, und sumpert, und schlumpert:

Da ist der Baur froh.

19 Stiftsarchiv Seitenstetten, Theatralia 33 G (Textheft). Erstmals ediert bei Karl Heinz Huber: Pater Norbert Pambichlers, Tendlbaß. Textwiedergabe, Wort- und Sacherklärung sowie Interpretationsversuche. In: Jahrbuch des Wiener Goethe-Vereins 97/98 (1993/94), S. 205-267, hier 220f.

20 Zur Analyse des Drescherlieds vgl. Huber, Pater Norbert Pambichlers, Tendlbaß`, S. 250. 
3

Auf?

Heb auf!

Schlag nieder, heb auf!

auf ein Streich zween drauf!

Ihr drescher euch tumelt,

kein Hälmel auslasst,

und wacker auftrumelt,

biß alls ausgepasst.

das gibt ein schön Klang.

Es ist ja der Halbpaß, der Auspaß,

der Waizpaß, der Traidpaß, der Schallpaß,

der Bierpaß, der Weinpaß, der Tennlpaß,

das allerschönst Gsang.
4

Auf?

Heb auf!

Schlag nieder, heb auf!

auf ein Streich zween drauf!

Wan d'Flegeln regieren,

und in der Höch seynd,

die Baurn florieren,

und ihre Sonn scheint,

da werdens enck stolz.

Da sieht man dirs falzen, und malzen, und pfalzen, und schmalzen, und salzen, und schnalzen, und um und um walzen, alß wie ein Runds Holz. ${ }^{21}$

1,5 Triescheln] Schlagteil der Dreschflegel 1,6 Ringerl] metallenes Verbindungsstück zwischen Stiel und Flegel 1,8 Ströberl] Diminutiv zu Stroh 1,9 schmuzt] schmunzelt, lächelt 3,5 tumelt] beeilt 3,8 ausgepasst] ausgedroschen, ausgeschlagen 3,10 Halbpaß] Halbschlag (hier und in der Folge ein lautmalerisches Spiel mit dem Wort ,Bass') 3,11 Traidpaß] Getreideschlag

\section{Ansingelieder}

Etwas besser dokumentiert, was den authentischen Textbestand betrifft, sind dialektale Umzugs- und Ansingelieder - Lieder also, mit denen zu verschiedenen Zeiten des jahreszeitlichen Brauchtums bestimmte Personen oder Gruppen mit Glück- und Segenswünschen, Spaßversen oder auch kleineren Provokationen angesungen wurden; als Gegengabe erhofften bzw. erwarteten sich die Sänger Geld, Naturalien oder freie Bewirtung. ${ }^{22}$ Neben dem Heische- bzw. Tauschwunsch ist den Ansingeliedern der Hang zu formelhaften Wendungen im Bausteinsystem gemeinsam, von denen sich thematisch und formal freier gefügte Liedteile abheben, die Raum zur Variation und situativen Anpassung boten.

Die im alpenländischen Raum wichtigste Gruppe dieser Heischelieder, die vor allem von den ,Sternsingern' vorgetragenen Gesänge zum Weihnachtskreis, wurde bereits behandelt (vgl. Kap. 1). Ein anderer kalendarischer Fixpunkt zu dieser Jahreszeit, der nicht die Erneuerung des Glaubens durch ein neues Kapitel der Heilsgeschichte feierte, sondern sein Brauchtum stärker aus der (herbeigesehnten) Erneuerung von Natur und sozialer Gemeinschaft gewann, ist der Jahreswechsel, zu dem gleichfalls auffällig viele Lieder entstanden. ${ }^{23}$ In der Singtradition haben sich religiöse und profane Themen oftmals vermischt, wie sich u. a. an entsprechenden einleitenden oder abschließenden

21 Stiftsarchiv Seitenstetten, Theatralia 33 G (Perioche). Erstmals ediert bei Huber, Pater Norbert Pambichlers ,Tendlbaß', S. 235f.

22 Vgl. Hinrich Siuts: Die Ansingelieder zu den Kalenderfesten. Ein Beitrag zur Geschichte, Biologie und Funktion des Volksliedes. Göttingen: Schwartz 1968.

23 Vgl. Arne Holtorf: Neujahrslied. In: Rolf Wilhelm Brednich/Lutz Röhrich/Wolfgang Suppan (Hg.): Handbuch des Volksliedes. Bd. I: Die Gattungen des Volksliedes. München: Fink 1973, S. 363-389. - Gerlinde Haid: Neujahrssingen und Neujahrslied in Niederösterreich mit besonderer Berücksichtigung des Piestingtales. 2 Bde. Wien 1974. [Phil. Diss]. 
Segenswünschen für das neue Jahr in Weihnachtsliedern zeigt, z. B. in der Anfangsstrophe eines Hirtengesangs, der am Neujahrstag 1773 im steirischen Stift Rein zu hören war:

1

Grüeß di Gott, mein liebes Kindlein, wünsch dir glück zum neuen Jahr; liegst halt no in z'rissnen Windlein, leidest Kält' in größter G'fahr.

Kombt dann Niembt, der helfen kinnte dir mit einem Fetzen G'wand, ach, das is fürwahr a Sünde, und der Welt a großi Schand. ${ }^{24}$

Hier sollte wohl die Schilderung der Armut des Gottessohns die Zuhörer auch für die Not der Sternsinger sensibilisieren, die mit dem Heischesingen mehr schlecht als recht über die sonst verdienstlosen Wintermonate zu kommen versuchten. Nicht umsonst werden in der vierten Strophe die mitleiderregenden Umstände des Hirten beschrieben und die ,Reichen indirekt in die Pflicht genommen, zumindest eine Kleinigkeit zu spenden, „daß a wenk kunst besser leben “25. Auch Zaupser überliefert einen von den „armen Knaben“ am Neujahrstag vorgetragenen Spruch, der Neujahrs- und Weihnachtsbrauchtum zusammenführt: „Glückseligs neus Jahr, und a Christkindl im krausten Haar.“ ${ }^{\text {“6 }}$ Noch heute ist dieser Spruch in der Steiermark zu hören.

Prinzipiell weisen Neujahrslieder im Vergleich zu den Weihnachtsliedern eine konkretere Ansprache auf, die das Zielpublikum stärker einbindet. Nicht der Bericht des Vergangenen, sondern die Beurteilung des Gegenwärtigen im kleinen und größeren Rahmen steht im Mittelpunkt. So können die einzelnen Personen des Haushalts mit Segenswünschen und Lobsprüchen bedacht werden oder auch Berufsstände und soziale Gruppen. Eine mehrteilige kleinformatige Sternsinger-Gebrauchshandschrift aus dem frühen 17. Jahrhundert (mit zurückhaltender dialektaler Transkription) zeigt, wie formelhaft diese Brauchlieder mit ihren stehenden Eingangsphrasen, fixen Strophenelementen und gleichförmigen Bildern waren. Ob nun Schüler, Schreiber, Hausknechte, Kellner, Bäckermeister, Kaufleute, Wirte, Köchinnen, heiratsfähige Jungfrauen oder Bräute angesungen wurden, die lobenswerten Eigenschaften (Fleiß, körperliche Vorzüge, besondere Fertigkeiten) und Szenarien (frühmorgendliches Gebet, Arbeitsgänge) variieren nur im Detail. Als Einleitungen dienen u. a. folgende Bausätze, die die Singkonstellation mitansprechen:

24 Zitiert nach Karl M. Klier (Hg.): Schatz österreichischer Weihnachtslieder. Aus den ältesten Quellen mit Weisen. 3. Heft: Weihnachtslieder und Hirtenspiele aus Steiermark. 1: Verschiedene Orte. Klosterneuburg: Augustinus-Druckerei [1936-40]. (Thesaurus Austriacus) S. 52. Vgl. auch den dort zitierten Bericht eines Beiträgers zur Sonnleithner-Sammlung aus dem Judenburger Kreis, wo „in der Nacht vor dem Neujahrstag [... zu den angeseheneren Bauern Musikanten“ kamen. Sie begannen mit einer charakteristischen Melodie, dann brachte „ein Spaßmacher sowohl in Knittelreimen als Prosa die drolligsten Neujahrswünsche, für die Bewohner des Hauses anwendbar, vor“. Abschließend „werden entweder einige Krippellieder gesungen oder auch steyrische Tänze gespielt“. Vgl. ebda., S. 53f.

25 Ebda.

26 Zaupser, Versuch eines baierischen und oberpfälzischen Idiotikons, S. 28. 
Ihr Lieben meine Singer laft nit daruon wier haben noch weiter zu singen an. Ihr lieben meine singer fachts widerum an, wier haben noch weider zu singen an. Ihr Lieben Meine Singer drets ein den Ring, wier haben ein schene Braut herin.

Wier Komen mit grossen Freuden dar, Wier wünschen euch Allen ein neues Jahr. ${ }^{27}$

1 laft] läuft 3 fachts] fangt 5 drets] tretet

Als Eingangsstrophe oder in Kombination mit den vorigen findet sich oft auch der folgende Zweizeiler mit einer uralten (vielleicht schon damals kryptischen) Formulierung und dem entsprechenden Platzhalter für die angesungene Person:

Der dag der Reiß wol durch den Thron,

die Jungfrau $\mathrm{N}$ : singen wier an. ${ }^{28}$

Volksliedhaft romantische Elemente wie „ein schlißl von Etlgestain“, der „wol an ein gultes Ketelein“ geheftet war, waren bei einem Dienstbotenlob ebensowenig deplatziert wie märchenhafte sprechende Tiere:

Sagt mier Ein Klains walt Vögelein wie das ein fleissig Kellner sey. ${ }^{29}$

Den unverheirateten jungen Männern wird „ein schene Jungfrau in goltfarben har, Ein frume vnd ein Reiche, ein schene vnd ein Seiberliche “30 gewünscht, den Kaufleuten guter Handel, den Bräuten eine gute Ehe. Drei Beispiele für die Schlusssequenz:

hiermit habts ihrs vernumben,

wier haben Euch angesungen.

mit disen gesang zum neuen Jar,

Gott bewar euch vor leit vnd groser gefar.

Vnd last Enckh daß nit verdriessen,

duet vns ein neues Jor her schiessen. ${ }^{31}$

Dieses sehr starre Formelinventar traditioneller Neujahrssprüche und -lieder wurde bald auch mit humorvollen Anspielungen und satirischen Spitzen kontrapunktiert. Schon in der oben zitierten Sammlung findet sich gegen Ende ein Spruch, der wohl auch regelmäßig angewendet wurde:

Der Papst sprach ich bet für Enck al, der Kaisser sprach Ich Regier für Enk al,

der Purger sprach Ich ret für Enck al,

der Pauer sprach Ich dernör Enck al,

der lanzkhnecht sprach Ich khrieg für Enk al

27 Folgen Etliche neue Jor gesanger vnd h. drey Khönig Tag (mehrteilige Handschrift in Oktav von verschiedenen Händen ohne Foliierung, Privatbesitz Christian Neuhuber), f. 4r, 11r, 19r, 41r.

28 Ebda., f. $11 \mathrm{v}$.

29 Ebda., f. 5v.

30 Ebda., f. $24 \mathrm{r}$

31 Ebda., f. 19r, 22v. 
der Dot sprach Iich fris Enck al

Al 1629 Jar

hab ich gelt so zal ich bar. ${ }^{32}$

1 Enck al] euch alle 4 dernör] ernähre

Mit gutmütigem Spott zur moralischen Ermahnung wartet ein Neuer Jahres-Wunsch des bedeutenden oberfränkischen Benediktinermusikers Valentin Rathgeber auf, den er 1737 in seinem für die Unterhaltungskultur im süddeutschen Raum so einflussreichen Tafel-Confect veröffentlichte. Eine um zwei Strophen erweiterte, dialektal und satirisch zugespitzte Adaption von Text und Melodie ist der Neu Jahrsgsang pro Tabula des Kremsmünsterer Konventualen Franz Sparry, der Begleitstimmen für 2 Violinen und Cello ergänzt:

1

ä glücksälligs Jahr

dis wölln wir anwünschen dem klein und dem grosßen, es ist von dem glückwunsch kein menscheit ausgschlossen; wir wünschens ein jeden, wers imma seyn soll, hams zwar nit vädient all, ey wüsts es ja wohl, ja gelts äß is wahr. ä glücksääligs Jahr. 2

ä glücksälligs Jahr

beym schustern ist wiz und ingenium zfinden, thuens hirn alls mit lödernen rüemen verbinden; sie machen auf d'Modi fein gspizige Schue, da rennen vill weibä dä höll damit zue. ja gelts äß is wahr. ä glücksääligs Jahr. 3

ä glücksälligs Jahr die herrn Klaydermacher seynd spizfindig Kunden sie haben vill modi in Klaydern erfunden; weil aber die Modi schier jedermann tragt, der Toifel vill schneidä in bockstall verjagt, ja gelts äß is wahr. ä glücksääligs Jahr. 4 ä glücksälligs Jahr die bierbrey und weinwürth seind sonst nit die lösten, sie richten ain schmaus umb leidliche Kösten; wans gwerb nur dähalten, so ists ien scho gnue, vill lasßen krumbs grad seyn und lachen dazue, ja gelts äß is wahr. ä glücksääligs Jahr. 5 ä glücksälligs Jahr die Maurä, und zimmäleuth ehrliche Mannä ham harte und gfärliche arweit beynannä; sö müesßen hoch steigen, sänd vill schon däfalln, doch arweitens halbet, und ganz mues mäs zahln, ja gelts äß is wahr. ä glücksääligs Jahr.

32 Ebda., f. 53v. 
6

ä glücksälligs Jahr

die fuhrleuth, und botten ham zraisen und zlauffä,

sö kunten den himmel glei buttenweis kauffä;

do förcht i swird manchä danöben ausfliegn,

dö fuhrleith mit schelten, dö botten mit liegn.

ja gelts äß is wahr. ä glücksääligs Jahr.

7

ä glücksälligs Jahr

die Jäger ham vill zthain mit schiesßen und hözen,

verdirns wohl, wans müed sänd, daß d'gurgl einnözen;

bisweiln läfft västollnä ain hirschl ins haus,

kan ä nit so sünd seyn, zwö zahlt mä iens aus,

ja gelts äß is wahr. ä glücksääligs Jahr.

8

ä glücksälligs Jahr

die herrn Musicanten mit Pfeiffen und geigen

sänd ehr und lobwürdig, mä kans nit väschweigen;

sö singen stäts ahni, und bleiben beym trump,

doch werffens den wagen auf ainmahl offt umb

ja gelts äß is wahr. ä glücksääligs Jahr.

9

ä glücksälligs Jahr

die herren Studendten thun tag und nacht wachen

durch glehrtheit ein staffel der Ehren zu machen;

sie stöcken in büechern, wernd wissenschaft reich,

ain ding is do schad dran, äs seind nit all gleich,

ja gelts äß is wahr. ä glücksääligs Jahr.

10

ä glücksälligs Jahr

den Kürschner den hätt i beym härl vagössen

thuet brustflöck und schlieffä den leuthen anmössen;

buzt Fuxbälgg, und schafffehl, so vill er nur hat,

ey näm er nur d'Kazen, wär ä nit drumb schadt,

ja gelts äß is wahr. ä glücksääligs Jahr.

11

ä glücksälligs Jahr

den adl soll $\mathrm{i}$ ja auf dlözt no ansingen,

i wais nit, wies öppä in ohren wird klingen;

där adl is wacker, i sag engs ganz frey,

nur aber wan gottsforcht und weisheit däbey,

ja gelts äß is wahr. ä glücksääligs Jahr. ${ }^{33}$

1,5 ey] wohl Verschreibung für ,es‘ 3,2 Kunden] Leute, Kerle 4,2 bierbrey] Bierbräuer 5,4 däfalln] zu Tode gestürzt 6,5 schelten] Fluchen liegn] Lügen 7,4 läfft ... haus] unterschlagen sie Wildpret 7,5 zwö] warum 10,3 schlieffä] Muffe, Handwärmer

Nur mehr Anlass für eine schelmische Satire auf die Studenten der 1744 nach Ettaler Vorbild gegründeten Kremsmünsterer Ritterakademie war das „Neüjahrsgsang von den heikelichen und windmacherischen Muterkindl ${ }^{“ 34}{ }^{34}$ das Mitte der 1750er Jahre an meh-

33 Musikarchiv Stift Kremsmünster, G 44/787.

34 Ebda., Vermerk Sparrys, der bei der Textquelle (G 44/785) fehlt. 
reren Neujahrstagen mit leichten Modifikationen und Ergänzungen vorgetragen wurde (vgl. Kap. 4). Die tatsächlichen Bezüge auf den Jahreswechsel beschränken sich auf kurze Floskeln zu Beginn und am Ende des Lieds:

13

iezt mues i aufherrn, mein gsängl is aus,

i bin halt ganz närrisch, mei machts nur nix draus,

villeicht han i glogn, vileicht is nit wahr,

i wünsch eng mit ain wort ä glücksäligs jahr. ${ }^{35}$

Während Sparrys Neujahrslieder von besoldeten Stiftsmusikern vorgetragen wurden, ist das Neujahrslied des bereits erwähnten Leoganger Bauern Thomas Hirschbichler eines der raren aus dem 18. Jahrhundert erhaltenen Beispiele eines tatsächlich im Dorfkontext entstandenen und verwendeten Brauchtumslieds, das aus der Feder eines namentlich bekannten ,Volksdichters' stammt. Es beginnt mit einer selbstreflexiven Ausdeutung der Aufgabe eines ,Ansingers', der aus nachvollziehbaren Gründen sein Publikum nicht gegen sich aufbringen kann, will er entsprechend entlohnt werden, der aber zugleich aus dem Aufzeigen von Fehlverhalten Unterhaltung schaffen soll:

1

Nach all mein Fürnehmä, so bin i jetzt da,

i wünsch enk halt recht gern viel Zoig zum noin Jahr.

Wann i nur grad wissat, was jeder gern hett,

damit i bey an jeden a Ehr aufhöbn thet.

2

Was will i mi kümmern, obs jeden thut gfalln,

sonst möchtens mi gar in den Faschingsbrief mahln.

Ist nie kainer gwesen, dem alls gfalln hat recht;

i mach mein Wunsch fort, gfallts enk wohl oder schlecht. ${ }^{36}$

1,1 Fürnehmä] Absicht, Ansinnen 1,3 wissat] wüsste 1,4 Ehr aufhöbn] Beifall finden 2,2 in den Faschingsbrief mahln] als Narr zum Faschingsgespött werden

Die nächsten 14 Strophen nehmen sich einzelne Berufsgruppen und Charaktere vor, die mit Lob und zuweilen auch mit leisem Spott bedacht werden, und wurden wohl auf das jeweilige Publikum abgestimmt. Vom aufmüpfigen Unterton seines KartenspielLieds (siehe Kap. 3) lässt Hirschbichler hier wenig anklingen. Witziger wird es, wenn die Sprache auf den Ansinger selbst kommt:

17

Mir extra wünsch i än Stadl voll Geld -

die halb Welt zum Wiesách, die halb Welt zum Feld.

Gut $z$ essen, gut $z$ trinken viel Freud und kain Neid

und daß mir koan Mensch koan schlechts Wort niemá geit. ${ }^{37}$

17,1 Stadl] Scheune 17,2 Wiesách] (Berg-)Wiese 17,4 geit] gibt

35 Musikarchiv Kremsmünster, G44/785.

36 Wien, Gesellschaft der Musikfreunde VI/27.474, Oberösterreich, VII. Heft, Salzkreis, 33.c.; zitiert nach Haid/Hochradner, Lieder und Tänze um 1800, S. 209.

37 Ebda., S. 211. 
Gleichfalls zum Brauchtum rund um die Weihnachtsfeierlichkeiten gehören die Lieder und Sprüche, die beim sogenannten ,Anglöckeln' an den Donnerstagen im Advent gebräuchlich waren. Mit aufwändig gestalteten, von innen beleuchteten Lichtkappen aus buntem Papier und an einem Gürtel befestigten Glocken und Schellen zogen weiß gekleidete Männer durch den Ort, symbolisch Licht in die dunklen Winternächte bringend. Hübner bemerkt zum Sinngehalt darüber hinaus: „Man hält es für ein Vorzeichen eines fruchtbaren Jahres, wenn sich viele Anglöckler melden“, und gibt das folgende Beispiel für ein traditionelles Ansinglied aus der Gegend von Werfen:

Ihr meine lieben Brüder stehts zusamm in a Scheib’n,
Und so woll'n ma ein bois uns mit n’Singa verdreibn,
So gehn ma daher halt a bey da Strassen,
Daß ma nit zuekehrn, das mögn ma nit lassen.
Wohl unter der Hausthür steht dort der Hauswirth,
So griessn ma zum Ersten halt den ehrsamen Hauswirth.
Wohl an den fruh'n Morgen da fallet der Tau,
Und griessen zum Andern die ehrbare Hausfrau,
Wir griessen die Knecht', wir griessen die Dirn,
Wir griessen das Kindlein wohl inner der Wiegn.
O du lieber Hauswirth das griessen ist aus,
Wann du uns nit aufthust, gehn wir zu an anderen Haus.
Wird nun aufgethan, dann wird weiter gesprochen:
Wir wünschen dem Hauswirth viel Glück in das Haus;
Das Unglück muß weit über d'Berge hinaus.
Wir wünschen ihm Glück, wir wünschen ihm Segen,
Wir wünschen ihm fruchtbaren Thau, und auch Regen.
Wir wünschen ihm Glück, wir wünschen ihm Heil,
Damit ihm das Glück werd' alles zu Theil,
So wünschen wir Glück ihm halt überall,
Wir wünschen ihm Glück zu den Vieh in dem Stall.
Nun wollen wir das Wünschen beschliessen,
Es möchte dich o Hauswirth das Zulosen verdriessen.

2 bois] Zeitraum, Zeit 22 Zulosen] Zuhören

Auch hier finden sich dieselben Anfangsverse wie bei den Neujahrsgesängen, die eine konkrete Aufführungssituation kreieren und die Rollenverteilung klarstellen. Dass dieser Austausch von formelhaften Einstiegssätzen nicht nur bei den thematisch sehr ähnlichen Ansingliedern des Weihnachtskreises zu beobachten ist, zeigt das folgende Abschiedslied aus der Gegend um Mammendorf, das Lorenz von Westenrieder 1792 in seinen volkskundlichen Beyträgen zur vaterländischen Historie, Geographie, Statistik, und Landwirthschaft (ohne Melodie) abdrucken lässt. Das ,uralte Lied, das einem Wandersburschen beim Abschied von seiner Geliebten und Familie in den Mund gelegt ist, „erweckt“ - so der bedeutende bayerische Aufklärer - „immer einige Thränen der Zuhörenden, und selbst den Sängern gebricht die Stimme“" ${ }^{\text {39 }}$. Die - im generell sehr feh-

38 Hübner, Beschreibung des Erzstiftes und Reichsfürstenthums Salzburg, S. 387f; seine Quelle bzw. Übermittlungsperson gibt Hübner nicht an.

39 Lorenz Westenrieder (Hg.): Beyträge zur vaterländischen Historie, Geographie, Statistik, und Landwirthschaft, samt einer Uebersicht der schönen Litteratur. Vierter Band. München: Joseph Lindauer 1792, S. 410. 
lerhaften Druck leider verderbte - Anfangsphrase finden wir auch bei etlichen Wildererund Hieslliedern (vgl. Kap. 3). Wo sie tatsächlich ihren Ursprung nahm, wird wohl nicht mehr zu klären sein. Doch ist zu vermuten, dass damit auch eine fixe Melodie übernommen wurde:

Au Liedlan zu singa, an Liedlau au neus,

I wills Iena bringa wohl ins Estereich.

Dienle jetzt pfieti Gott, wane i mues raisen fort

„Raisn kanscht schon, bleib aba nit lang aus

In zwai oda drey Jahren kom widerum nach Haus. “

Pfieti Gott Gschwistert, laschts mar a Meß lesen glei

Wann i auf da Raisschaft sterb'n mues frei.

Pfiet eng Gott ös Vata, und Mueta beysama

Vergelscht Gott um ales, was ma guets habts gethan

$\mathrm{Daß}$ mi habts Krischstli habts aufgezog'n

Pfieti Gott liebe Leiten, habschts ma nix für unguet.

Wann i der Raisschaft hald sterben mues.

Wen i do sitz ausi aufs Mier

Kom i meina loba lang nima ins Boarland her. ${ }^{40}$

3 Dienle] Mädchen pfieti] behüte dich

\section{Hochzeitsbrauchlieder und -sprüche}

Westenrieders dokumentarischem Interesse für ältere Volksdichtung verdanken wir auch einige Beispiele von stehenden Hochzeitsbrauchtumstexten aus der Dachauer Gegend, die alle an die Person des Hochzeitsladers gebunden und (zumindest intentional) teils bis heute noch anzutreffen sind. Der ,Prograder ' begleitet nicht nur moderierend die Hochzeit selbst, sondern wird schon im Vorfeld der Feierlichkeiten tätig, indem er die Einladungen in lyrischer Form und persönlichem Vortrag übermittelt. Dabei begibt er sich - so Westenrieder ,gewöhnlich zu Pferd, nicht nur zu den nächsten Anverwandten, sondern zu allen Dorfleuten und herumliegenden Nachbarn, und vollbringt bey jedem, mit großem Geschrey, folgenden Spruch“:

Ich kumm daher von dem ehrsammen Bräutvolk und von Gottes Gnadn,

So will ich euch im Namen Maria und der allerheiligsten Dreyfaltigkeit in die Hochzeit ladn.

Durch Gottes Gnadn, und durch Gott in Ehren,

$\mathrm{Daß}$ zu uns bis heut acht Tag zu Willen und Ehren

$\mathrm{Zu}$ den ehrsammen Hochzeiter sollts euch fleißi stelln ein,

$\mathrm{Zu}$ den Auszug, zun braun Bier, und Brandtwein.

Ich will euch aber weida einladn in das lobwürdige Gottshaus,

Nachdem wir san zogen dahoamer aus;

Da sollts beywohna dem Amt der heiligen Meß,

Gleichwies der Priester vor dem Altar singt oder Lest.

Da sollts uns helfa das Opfer legn,

Nachdem wird uns der Priesta den geweichtn St Johannes Wein zu trinka geben.

Jezt will aber euch noch weida ladn zu den ehrgeachten Herrn

Wirth und Gastgeber in seine Behausung, und offne Tafern;

40 Ebda., S. $410 f$. 
Da wird man zur Tafl gesezt, da sollts uns helfa das Hochzetmahl vozöhren,

Und däs soll von jedn gschegn in allen ehrn.

Da giebt man uns a Suppn, und a Kraut,

Wies halt in alln Hochzetn ist da Brauch;

A Suppn und a Kraut däs nöt allain

Ich hoff, a guets Bier und andrö guetn Speisn wern a noch dabey seyn.

Das Hochzetmahl ist paktirt wordn $1 \mathrm{fl} .4 \mathrm{kr}$., oder 16 Batzn

Jezt seyds infelirt und eingeladn. ${ }^{41}$

21 paktirt] abgemacht 1 fl. 4 kr.] 1 Gulden 4 Kreuzer 16 Batzn] $=64$ Kreuzer $(60$ Kreuzer $=1$ Gulden $) 22$ infelirt] invitiert, eingeladen

Das seltsame Mischmasch aus offiziöser formelhafter Ansage und dialektaler persönlicher Rede kennzeichnet auch den Abschiedsgruß, der vom Hochzeitslader stellvertretend für das in die Ehe gehende Kind beim Verlassen des elterlichen Hauses vorgetragen wird. Dabei wird der Akt des ,Urlaubnehmens' durch die Verbalisierung in feierlichem Prozedere gleichsam performativ-symbolisch vollzogen. Der Text liegt in zwei weitgehend normierten und je nach Bedarf zu gebrauchenden Varianten vor: Die kürzere Variante wird verwendet, wenn beide Eltern des Bräutigams oder der Braut noch am Leben sind; in der längeren wird dem verstorbenen Elternteil mit einer zusätzlichen Passage gedacht. Verabschiedung, Dankesworte und Wertschätzungsbekundungen sind die zentralen Momente, die im soziokulturell determinierten Kontext ,Heirat' zum Ausdruck gebracht werden. Dabei wird der mit der Verehelichung verknüpfte Akt, die sozial Nahestehenden zu verlassen, in der Inszenierung als Neuordnung des familiären Gefüges noch einmal in seiner Bedeutung hervorgehoben. Der an sich steife zeremonielle Charakter der Rede (der vor allem in religiösen Belangen zutage tritt) wird durch die Tendenz zur mundartlichen ,Nähesprachlichkeit' emotional unterwandert:

Still ab a kloane Weil! ihr sollt all a weni stiller sey.

Es ist so gar nöt von meintwegn,

Sondern es ist dem ehrsammen Hochzeiter dran gelegn.

Und weil es sih aufn heutigen Tag also thuet begebn,

Daß der ehrsamme Hochzeiter für sih selber nöt gern thuet redn,

So hat er mih wolln an die Seitn stelln;

Er hat mir a wenigs vorgesagt, oder in den Kopf eigebm,

Er hat mih laßn in der Gstalt seiner allhier herkömma,

Daß ih sollt statt ihm a freundligs Urlaub nehma.

So bald der ehrsamme Hochzeiter in der Frieh aufgestandn,

So ist er glei hinter den heitern Himmel naus ganga,

Er hat Gott bettn also gleich.

Daß heunt Niemet koa Schand oder Herzenleid geschegn mag;

Es sey glei im Gehn, Reitn, oder Fahrn,

Als wie oft mancher Vöta, oder Basl thuet sagen,

Ach hätt mih der ehrsame Hochzeiter nöt in d'Hochzet glatn!

So wär ih in koa selches Unglück nöt grathn.

Däs hätt ih und der ehrsame Hochzeiter nöt gern,

Sondern er hat euch all geladn in Ehrn.

Ihr sollt aber heut braucha koan Pracht und Uebermueth;

41 Westenrieder, Beyträge zur vaterländischen Historie, S. 412. 
Dann Christus der Herr hat selber gsagt, es thuet koan Menschn koa Guet;

Denn Luzifer hat sich durch Hoffart aufgethan,

$\mathrm{Da}$ ist er verstürzt wordn von hochn Himmelsthron,

Und durch den heilinga Erzengel Michael

Ist er geschlagn worden in den tiefisten Abgrund der Höllen ganz schnell.

$[\ldots]$

Dieweil sich dann iezt der ehrsamme Hochzeiter zu den Sakerment der Eh will kehrn,

So nimmt er Urlaub von seinen Herzliebsten Aeltern in Ehrn,

Und dankt ihna um alle Guetthatn,

Dieweil sie ihn aus dem Koth erzogn hattn,

Und habm ihm gewonna das liebe Stücklein Brod,

Dankt er dafür ihna, und dem großn Gott,

$\mathrm{Daß}$ sie alles habm geschickt her,

Deßwegen dankt er noch vilmehr.

Er sagt, er will sie a gwis nöt verlassn,

Und wenn sie wärn in Feur und Wassa,

Und wenn sie wärn in Angst oder Noth,

So wollt er mit ehna thoaln an jeds Stücklein Brod;

Er nimmt iezt Urlaub von Oedl und Andl auch zu gleich

Durch Gott den Vader im Himmelreich.

Nimmt Urlaub von Schwestern und Brüeder,

Weil sih scheidn mueß an jeder.

Er bitt, sie solln ihm alls verzeicha,

Und dafür viel Guets voleicha.

Er nimmt Urlaub von Fre[u]nd und Schwager,

Nimmt Urlaub von Knecht und Diern,

Und nimmt Urlaub von kloan Kind in der Wiegn;

Von dem kloan Kind zwar nöt aloa,

Sandern er nimmt Urlaub vo der ganzn Gmoa;

Dä in die Hochzeit ganga san.

$[\ldots]^{42}$

15 Vöta, oder Basl] Verwandte männlichen oder weiblichen Geschlechts 37 thoaln] teilen 38 Oedl und Andl] Ahnfrau, Großmutter / Ahnherr, Großvater 48 Gmoa] Gemeinde, Dorfgemeinschaft

Dass solche stark ritualisierten und stereotypisierten Brauchtumstexte eine beliebte Folie für Parodien abgaben, liegt auf der Hand. Zumal bei Faschingsfeierlichkeiten und im Fastnachtspiel war das Thema Hochzeit ausgesprochen beliebt. ${ }^{43}$ Diesem Kontext entstammt auch eine gereimte Scherzrede, die zumindest auf den ersten Blick auch als humoristisches Einsprengsel auf einer tatsächlichen Vermählungsfeier verstanden werden könnte:

Kombt geschwind ihr hochzeit geste, man wird euch aufs allerbeste, Tractamente stellen vor, vor das erste gibts spökh-Pastadten, von getrenkh wil ich nicht reden, dan da heists schenkh genssewein, vor die geste Tapffer ein, Ich franz Nahr hunds Bacher, kazenfangen von Weidenfeld, ohne Bar geld, gebürtig in Lekhfeldner Pfahr, Meines handwerkhs ein stokh-nar, thue zu wissen insgemein, allen nahren gross und klein die den Prieff Lessen, oder Lessen hören, und hierinen

42 Westenrieder, Beyträge zur vaterländischen Historie, S. 413-416.

43 Schon das früheste überlieferte bairisch-österreichische Fastnachtspiel mit dialektalen Passagen, das in Regensburg wiederaufgeführte Wiener Spiel Von dem Hänsl Frischen knecht (vgl. Kap. 2) endet mit einer Hochzeit. 
Benenet werden, auch allen Blinden die in angreiffen, sambt allen dennen, die eine scher könen schleiffen, und die schmalle wahrheit gestudiert haben, auch allen dennen, den disser offene heyrahts Brieff Bekandt wird, das ich die Ehrbahre, und wohlgebutzte Jungfrau, welche ist noch keine frau habe Zur Ehe genohmen, aber wür seind noch nicht zussamgekommen, ihr nahm heist kundl feldschmeis, ihr heyrathguet ist fleh und leus, die bringt mir zue ein heyrathguet, ein Neugewesten, jetz wohl alten Vilzhuedt, mit einer ströhenen schnur, zwey dölpische hend, und zwey krump füess, zwey lang degen, und ein kurzen spiess, ein Kupffern schleiffstaein, 12 hölzerne Pfannen, gross und klein, 4 wägen ohne reder, 2 Beder ohne feder, 10 Stükh sternen zwilch, 8 grosse zöger vohl riemühl, drey duzät löffl hat keiner kein stil, ein Lälach ohne hül, 5 Neue käss von küehflökh ein mühlstein zu einer überdökh, Ithem mehr hat mir meine rozige zodterte Jungfrau Braudt, die eben auf die andere Bueben schaut, ein Braudt-Pfaeid verehrt, welche ist nicht vil wehrt, schön aufgenäht, schön schwarz und weis, mit fleh und leus, aufzändlt mit Nissen, schwager du hast mich mit der tochter Bschissen, mehr hats mir treulich vermacht ein Bösser tag, ein schlechte Nacht, sie ist in armueth wunderreich, und einer achtzigjährigen Jungfrau gleich $[\ldots]^{44}$

genssewein] Gänsewein = Wasser Beder] Betten (Federbetten) zwilch] Zwillich (grober Leinenstoff) zöger] Körbe riemühl] Rührmilch, Buttermilch Lälach] Leintuch Ithem] (lat. item) ebenso zodterte] mit ungepflegten langen Haaren Braudt-Pfaeid] Hochzeitshemd aufzändlt] geschmückt (mit zahnförmigem Muster)

Zwar fehlen die nötigen Belege, doch wird dieser derb-komische „heyraths Contract“ aus einer Sammelhandschrift wohl gern vorgetragener Teil von Faschingsunterhaltungen gewesen sein. Mit seinen Tabubrüchen und der forcierten Ekelkomik steht er in einer Reihe mit den damals beliebten ,Bäurische Hochzeit'-Liedern (vgl. Kap. 7), die wiederum Überzeichnungen von Dialektliedern waren, die einen etwas realistischeren Blick auf das damalige Hochzeitsbrauchtum gewährten. Ein sehr frühes Beispiel ist die Steyerische Hochzeit, der einzige ausdrücklich dialektal gestaltete Beitrag aus der bedeutenden Liedersammlung Ehrliche Gemüths-Erquickung, in deren Klagenfurter Ausgabe von 1691 es erstmals aufgenommen wurde. Als bewusst ,volkstümliche', unterhaltsame Schilderung für gehobene Schichten konzipiert, werden in Jäckl loß mein lieba Bue Eckpunkte der Hochzeitsvorbereitungen und -feierlichkeiten am (obersteirischen) Land aus Sicht der unmittelbaren Nachbarschaft anschaulich aufbereitet. Vieles hat sich dort bis heute gehalten: Böllerschießen, Krapfenbacken, Brautaufwecken, ,Absperren' mit zu erledigenden Aufgaben, Musikbegleitung, Brauttanz und zuweilen auch eine Rauferei:

1

Jäckl loß mein lieba Bue/

was i dir muß soga/

wirst di nämla wunern gnue/

vnd der Muetter kloga/

insäs Nochba Lentzel schau/

thut die Sopherl nömä/

hast scho nägstn allweil gmait/

daß dus wilst bekömä.
2

Schau wie dos ä Toiffels Bue/

thuet so gar nichts soga/

wärs wann i ihn gschänden thue/

will ihn wärlä froga/

ha du Lapp er hat scho gsagt/

will ins all zwien ladn/

he wann wir auff d'Haitzet gien/

thuets ins halt no gradn.

44 Bayerische Staatsbibliothek, Cod. germ. 7340 (Stubenberger Gesängerbuch), Teil 2, S. 49 f. 
3

Jäckl butz dein Buffa recht/ wöllmä halt nit klöschn/ äs wann lautä grossi Knecht/ thätn zämä tröschn/ inser Ruep der barstet Bue/ hot ä gstaiffi Bixn/ affer lodn kan ers nit/ thuet so lang umbwischn. 5 Jodl waist du ninderst nit/ gar än gstaifftn Spilmo/ der ins über d'Alm mit/ gar ä schiens auffschneidn ko/ laß den Mair in hintan Berg/ er hat ä schiene Diern/ er ko wärlä äff mein Ayd/ gstaiff die Fitl riern.

7

Inser Grell der nagstn stätz/ ist in Garstn gschloffn/ hatn inser Bue der Kaintz/ in än Schincka troffen/ offtn hamän than in d'Möst/ mit den grössern Brieling/ habmern wärlä stattla gmöst/ biß her äffm Frühling.

9

Riepl lod dein Buffa schnell/ mir san schoin beysamma/ Vrschl stöck nur an den Grell/ wann mör wärn köma/ werma schoissn vorm Hauß/ wirst futar hörn/ trag än Krapffä gschwind herauß/ daß die Braut thust ehrn. 11 Riepel halt di tapffer an/ laß die Braut nit falln/ müssest wärlä sinstn schon/ wol än Talla zahln/ O Herr Pfarra göbt ä Lehr/ daßn junga Lappn/ wärlä s'Mensch ist gwalti starck/ geit ihm gwiß ä Schnappn.
4

Insers Göttn Christä kimbt/ mit der grossn Diern/ wann er d'Schlisselbixn nimbt/ wöllmä halt nit ziern/ insern Kirchgang mächti schien/ wärn d'Leuth nit sponna/ wärn aber dörffn Knecht/ thäten d'Braut anzonna. 6 Göstern hat schoin inser Bue/ zu der Haitzet gschlang/ gar ä schieni roithe Kueh/ hat schoin Meel haim tragn/ Krapffn bachen wers ä/ Schmoltzkoch ä / ä Höfä voll/ kochä werns allerley/ wermä habn nit ä Moal. 8

Wästl holl die Dierna all/ daß mä gien in Kircha/ offtn laß ma gien än Knall/ in den longa Bircha/ foider aussa no die Braut/ sie ist in langen Hoff/ öper melcht sie insre Küeh/ oder fuettert no die Schof.

10

$\mathrm{Nu}$ sä giehma halt nä furst/ Jäckl puff ä mal her/ wärlä mein Ayd mich schon durst/ hiet i truncka halt eher/ Spilmo fidl halt eins auff/ gar ä schienes täntzl/ wann die Braut wird bröcha auff/ schenckts dir ä ein Kräntzl.

12

$\mathrm{Nu}$ sä giehmä widä haim/ Spilmo fidl halt eins auff/ Hänßl läff vm insä Maimb/ wag ä gstaifftes Tantzel drauff/ hap ju heu du Jäckl Bue/ laß die Bixen knallen/ wird dem Brautham vnd der Braut/ häfftig wol gefallen. 
13

Heut sän mir banander all/

wöllmä halt nit springa/

Jodl setz di halt nä bald/

thue mir ains zubringa/

nun mein Braut du gstaiffte Diern/

sey nur frölä disen Tag/

nach den össn wöllmä hupffn/

hörst ja wol was i da sag.

15

Ha das Schmaltzkoch ist schoin da/

giema no bald tantzn/

Riepel greiff nä zu der Sach/

thue die Braut anschantzn/

hab sie her gstaiff bey der Mitt/

machs nä tapffa springa/

hap ju he mein stoltze Diern/

muest mit mir ains ringa.
14

Nun du Köchin richt nur an/

gibs de grossn Diern/

wen ma faisti Krapffn han/

wöllmä s'Moul nit schmiern/

afft an Scheibel Biern=Most

wöllma ä schoin trincka/

habn nächt ä wieni kost/

thät mi ja guet düncka.

16

Afftn Jäckl ahi geh/

vmb deß Göttn Diern/

führs nä alli offn hie/

thus nä tapffa rührn/

schmier den Jodl an den Kopff/

wann ä vil thuet mochä/

räffn auß sein rothen Schopff/

wöllmä halt nicht lacha. ${ }^{45}$

1,1 loß] hör zu, horch 1,3 gnue] genug 1,5 Lentzel] Kurzform für Laurenz/Lorenz 1,7 nägstn] unlängst allweil gmait] immer geglaubt 2,3 gschänden ] (hier) verprügeln 2,6 zwien] beide 2,7 Haitzet] Hochzeit 2,8 gradn] glücken, passen, zum Guten ausgehen 3,1 Buffa] Böller 3,2 wöllmä] wir wollen klöschn] Lärm machen 3,3 äs] als 3,4 zämä tröschn] gemeinsam dreschen 3,5 Ruep] Kurzform für Ruprecht/Rupert barstet] bärtige 3,6 gstaiffi Bixn] tolles Gewehr 4,1 Göttn] Taufpaten 4,2 grossn Diern] Großdirn, ranghöchste Magd 4,3 Schlisselbixn] improvisiertes Böllerschießgerät aus einem Schlüssel 4,5 schien] schön 4,6 sponna] beobachten 4,8 anzonna] angrinsen, anlächeln 5,1 ninderst] nirgends 5,2 Spilmo] Spielmann 5,4 ä schiens auffschneidn ko] etwas Schönes vortragen kann 5,8 Fitl riern] Geige spielen 6,1 Bue] unverheirateter Knecht 6,2 gschlang] geschlachtet 6,5 wers ä] werden sie auch 6,6 Schmoltzkoch] Schmalzkoch: Süßspeise aus Grieß, Milch und Schmalz Höfa] Topf 7,1 Grell] Ferkel nagstn] vor Kurzem 7,2 Garsten] Garten 7,3 Kaintz] Kurzform für Konrad 7,5 offn hamän] dann haben wir ihn in d'Möst] zum Mästen 7,6 Brieling] schlachtfertiges Schwein 8,4 Bircha] ? 8,5 foider aussa] fordern, rufen heraus 8,7 öper] vielleicht 9,1 Riepl] Kurzform für Rupert 9,6 futar] lärmen, poltern (?) 10,1 giehma] gehen wir nä furst] also fort 10,4 hiet] hätte 11,8 geit] gibt 12,3 Maimb] Mume, eig. Schwester der Mutter, Tante (allerdings wurden darunter alle älteren weiblichen Verwandten verstanden) 13,3 Jodl] Kurzform für Jodocus 13,4 ains zubringa] zuprosten (und einen Schluck anbieten) 14,5 Scheibel Biern] alte Mostbirnensorte 14,7 nächt] gestern abend ä wieni] ein wenig 15,2 giema] gehen wir 15,5 hab] halte 16,1 ahi] hinunter 16,2 des Göttn Diern] die Mägde des Taufpaten

45 Ehrliche Gemüths-Erquickung Welche in sich begreiffet 57. vnderschidliche annembliche Gesänger / Deren Theils Geistlich- theils Weltliche / jedoch mit trostreichen / ehrlich- und sittlichen Lehren vndermischet / und Zu Sondern Ehren Allen ehrlichen Gemüths-Erquickern in 2. Theil zusammen getragen / vnd mit einem kurtzen Register verfasset. Erster Theil / Clagenfurth / Bey Matthias Khleinmayr / Löbl. Landsch. Buchdruckern. Anno 1691, S. 153-156. - Ähnlich in Titel (Die Steyerische Hochzeit) und Incipit ist das einige Jahrzehnte später gedruckte Jackerl komb mein lieber Bue. Inhaltlich scheint das (nur fragmentarisch erhaltene) Lied jedoch nur im letzten Teil zu entsprechen; den weitgehend verlorenen Hochzeitsvorbereitungen und -beschreibungen geht ein komisches Vater-Sohn-Gespräch um die Kunst des Handanhaltens voraus. 


\section{Gelegenheitspoesie}

Neben Texten, die zuweilen jahrhundertelang in relativ gleichbleibender Form kursierten und in ritualisierten, jahreszeitlich definierten oder biographischen Kontexten zum Einsatz kamen, stehen dialektale Gelegenheitstexte, die für bestimmte individualisierte Anlässe und konkrete Personen - oft auch auf Bestellung und gegen Bezahlung - eigens verfasst wurden. Die Palette ist dabei groß: $\mathrm{Zu}$ den Feiern mit religiösem Hintergrund wie Taufe und Hochzeit wurden bereits im dritten Kapitel mundartliche Dichtungen vorgestellt, die vor allem zu Repräsentationszwecken entstanden waren und die dynastischen Schlüsselmomente der jeweiligen Herrscherhäuser in ein entsprechend glorifizierendes Licht setzten. Nicht staatstragend, dafür aber persönlicher und situationsgebundener schildern die folgenden Gelegenheitslieder zu Kindlmahl und Hochzeit, zu Primiz, Profess und Abtwahl, zu Promotion, Aderlass oder auch zur Feier einer geglückten Bärenjagd freudige Feierlichkeiten im bäuerlichen, bürgerlichen oder klösterlichen Umfeld.

\section{Taufmahl- und Hochzeitslieder}

Meister dialektliterarischer Momentaufnahmen des bäuerlichen und bürgerlichen Alltags waren die ungleichen Brüder Maurus und Peter Gottlieb Lindemayr, wie bereits an einigen Kostproben in den vorangehenden Kapiteln gezeigt wurde. Besonders authentisch, detailfreudig und realitätsnah zeigen sich ihre Arbeiten dort, wo Vorkommnisse aus dem Familien- oder Freundeskreis für diverse Brauchtumsfeierlichkeiten aufgearbeitet werden. Hier wird die mundartliche Sängerfigur nicht - wie sonst zumeist - als naiver, satirisch gebrochener Bauernkommentator markiert, sondern rückt näher an das Autor-Ich, dessen Anteilnahme und Mitgefühl deutlich zu spüren ist.

Als Unterhaltungseinlage für ein traditionelles ,Kindlmahl', das nach Ende des Wochenbetts zusammen mit Paten, Verwandten und Honoratioren im Elternhaus des Neugeborenen feierlich begangen wurde, entstand Maurus Lindemayrs reizvolles Freudenlied Was giebts denn z' Traunkirha heut a. Anlass war die glückliche Geburt der später auch auf der Stiftsbühne aktiven Nichte des Autors, die am 19. August 1763 unter dem Namen Maria Barbara Thekla aus der Taufe gehoben wurde. Dass der Vater Joseph Gotthard Lindemayr, Hofrichter zu Traunkirchen, der Entbindung mit besonderer Unruhe und Sorge entgegen sah, ist verständlich: Denn Ende 1761 war wenige Tage nach seinem erstgeborenen Kind Maria Anna auch seine erste Frau Maria Theresia im Kindbett gestorben. Nur sechs Monate später heiratete der Hofrichter erneut: Maria Barbara Hörttenhueber, Tochter des Hofrichters zu Peuerbach. Nur drei Strophen sind uns von diesem Lied überliefert. Das Fragment beginnt wie so oft mit einer Simultanbeschreibung der Feierlichkeiten, blickt zurück auf die Ängste des werdenden Vaters, der sich in den Wochen vor der Geburt ins Gebet flüchtet, um schließlich auf die Patin Maria Barbara Desselbrunner, geborene Pösch, zu blenden. Diese war erst im Mai mit einem Gmundner Gastwirt verehelicht worden; offenbar etwas spät nach Meinung der Kindsmutter: 
1

Was giebts denn $\mathrm{z}$ 'Traunkirha heut a? Sänd, glaub ih, dö Gfadäsleut da.

Ih waiß schan, ih bild mä's schier ein, Äs wird halt ä Kindelmahl seyn.

Den Schmauß, dö Mahlzeit thain s' kochä, Denn heut sänd aus dö sechs Wochä; d' Streng Frau iß va Rom wiedä da: Den Gspaiß giebts z' Traunkiehra heut a. 3

Wie ist dä Streng Frau sünsten gschehng, So oft's Pöschen Bäberl hat g'sehng? Dä Himmel waiß's was s' ihr hat dacht, Und was s' ihr für Fausen hat gmacht? Und kam (was das für ä Wunä!)

Wär's d' Frau von Herrn Desselbrunä;

So thuet Sih d' Streng Frau gleih bekehrn:

d' Frau Bäberl muß Gfäderin wern. ${ }^{46}$
2

Wie hat dä Streng Herr sih nöt grimmt, däß glücklä d' Streng Frau niedä kimmt; Wie’s nahät mit ihr kämm äf d' Zeit, Da hat 'n kain Rand nimmä gfreut. Der Grummä thät 'n oft netten, Zum Wain, zum Seufzen und bethen; Stellt allerlai Andachten an: Schaut's! was für ä heiligä Mann!

1,1 giebts ... a] passier, ist los Traunkirha] Traunkirchen: Ort am Westufer des Traunsees 1,2 Gfadäsleut] Taufpaten (Göd und Godn) 1,4 Kindelmahl] Festessen zu Ehren der Taufpaten direkt nach der Taufe bzw. nach Ende des Wochenbetts der Kindsmutter 1,7 Streng Frau] Frau des ,Strengen Herrn' Hofrichters, s. u. va Ram wiedä da] von Rom wieder zurück: Kindern wurde die längere Abwesenheit einer Wöchnerin aus dem öffentlichen Leben scherzhaft mit einer Fahrt nach Rom erklärt 2,1 Streng Herr] Titulatur für einen höheren Beamten ohne Rats- oder Adelstitel grimmt] Sorgen gemacht 2,4 Rand] ausgefallene Idee, mutwilliger Streich 2,5 Grummä] Kummer, Gram netten] nötigen, zwingen 3,2 Bäberl] Kurzform für Barbara 3,4 Fausen] Einbildung, Phantasterei

Vielleicht war es ja der um 18 Jahre jüngere Peter Gottlieb Lindemayr - damals noch Schreiber in der Traunkirchener Kanzlei seines Bruders und ein gesuchter Sänger -, der das Lied im Kreis der Familie vortrug. Dass er es zweifellos kannte, belegt auch sein eigenes, nach diesem Vorbild gestaltetes Freudenlied Was gäts denn in Stadl heut mehr für än Rand, das zu einem ähnlichen Anlass entstanden war und zumal in der Anfangsstrophe deutliche stilistische und sprachliche Parallelen aufweist. Verfasst hatte er es auf die glückliche zweite Entbindung seiner 39-jährigen Frau Susanne, die ihm die einträgliche Stelle als Salzstadelschreiber in Stadl-Paura verschafft hatte. ${ }^{47} 1766$ hatte eine Totgeburt sie beinahe ins Grab gebracht. Da sie in der Folge fürchtete, kinderlos zu bleiben, wollte sie zunächst auch den ersten Anzeichen für eine erneute Schwangerschaft nicht recht Glauben schenken, hegte sogar die Besorgnis, von einem weiteren Ödem genarrt zu werden, bis endlich die Bewegungen des Kinds im Mutterleib zu spüren waren. Bei der komplikationsfreien Geburt am 11. Oktober 1768 brachte sie schließlich ein Mädchen zur Welt:

46 Lindemayr, Dialektlieder I, S. 177f. - Zu Ernest Frauenbergers Arrangement des Lieds für Pianoforte vgl. Peter Deinhammer/Christian Neuhuber (Hg.): Maurus Lindemayr/Ernest Frauenberger: Klavierlieder in oberösterreichischer Bauernsprache. Kommentierte Ausgabe. Weitra: Bibliothek der Provinz 2015, S. $248 f$.

$47 \mathrm{Zu}$ den näheren Umständen dieser Stellenvergabe im kirchlichen Einflussbereich vgl. Christian Neuhuber: und ein besonderer Liebhaber der Dichtkunst. Zum Leben und Werk Peter Gottlieb Lindemayrs. In: Peter Gottlieb Lindemayr: Lieder in oberösterreichischer Mundart. Kritische Ausgabe. Hg. und kommentiert von Christian Neuhuber. Wien: Praesens 2010, S. 93-141, hier 100-105. 
1

Was gäts denn in Stadl heut mehr für än Rand,

Ös ist, glaub I, mehr die ganz Freundschaft bänand?

I bild mäs schier ein, was öppern wird sein,

Ä schöns saubers Dirnderl,

Als wie ä gschölts Pirnderl,

Das wirds ä so gfreun.

2

Ä Zeit her hamts schon alli Hofnung välohrn,

Bis endli d'Frau Sändel hübsch braschäd ist warn.

Aft wärs glei ä Freud, selbm anäri Leut

Hamt grads dävon gsprochä;

D’Frau Sändel thät pochä

Und schrieb's gar in d'Weit.

3

In Anfang hats gmaint zwar, ös mächt si betroign,

Und hätt liebä gflennt schon, wenn d'Hoffnung soll loign;

Äft d'löst wärs no rär, da hätts schier ä Gfähr,

Ös möcht si ä schickä,

daß alli dö Dickä

Ä Wassäsucht wär.

4

I han wohl vo Herzen zu alli dem glacht.

Oft aini wurds schmerzen, han I mir gedacht,

Dö Sucht ist ä Gift, wanns Jungfraunä trift,

I wollts gar nöt rathen,

$\mathrm{Da}$ ainä thät graten

Und kämm ihr in d'Hüft.

5

In Engltag hat äs si ainwög däkennt,

Da hats öppäs ungfähr in d'Seit inhi grennt;

$\mathrm{Nu}$ sagäts kain Wart, weils nämlä so hart

Mit ganzen Välangä

Und völlingä Plangä

Än Rumplä hat g'wart.

6

Dräf gängs übä d'Arbät von Frueh bis in d'Nacht,

Hamt Fäschen und Pölster und Kindsböttä gmacht.

Und dös I was haiß, ist dös dä gröst Gspais,

$\mathrm{Daß}$ dö das maist than hat,

Dö selbm no kain Kind ghat,

Und do schon alls waiß.

7

Und endlä so hats üns, Gott Lob und Dank! glückt,

$\mathrm{Daß}$ ünsä Frau Sändel in Wochän da liegt.

Vo Herzen und Mund wünsch I eng ön Gsund,

Und wann d'Frau nöt stutzät

Was a geht äfs Duzät,

Ä so wärs halt rund! ${ }^{48}$

1,1 gäts] gibts, gibt es Stadl] (heute) Stadl-Paura: Ort an der Einmündung der Ager in die Traun, als Umschlagplatz Knotenpunkt des damaligen Salzhandels Rand] lautstarker Spaß, ausgelassene Festlichkeit 1,2 Freund-

48 P.G. Lindemayr, Lieder in oberösterreichischer Mundart, S. 79f. 
schaft] (hier) Verwandtschaft, Familie 1,3 öppern] etwa, vielleicht 1,4 Dirnderl] Mädchen 1,5 Pirnderl] Birnchen 2,2 Sändel] Kurzform für Susanna braschäd] dick, (hier im Sinne von:) schwanger 2,3 Aft] dann, also 2,5 pochä] backen, ausbacken, (hier) ein Kind austragen 4,5 graten] passieren, geschehen 5,1 Engltag] Fest des Erzengels Michael (29. September) ainwög] dennoch, trotzdem däkennt] erkannt 5,2 öppäs] irgendetwas ungfähr] plötzlich, unversehens inhi] hinein grent] gestoßen 5,5 Plangä] (übermäßiges) Verlangen, Lust 5,6 än] auf den Rumplä] ungestüme, heftige Bewegung 6,3 dös I was haiß] Formulierung zur Bekräftigung eines Sachverhalts Gspais] Spaß, witzige Sache 7,2 in Wochän da liegt] im Wochenbett liegt 7,3 Gsund] Gesundheit

In den wenigen Jahren, die ihr beschieden waren, sollte Maximiliana Barbara Lindemayr in Lustspielen ihres Onkels Maurus zum Publikumsliebling des Lambacher Stiftstheaters aufsteigen.

Auch das Hochzeitslied Grieß enk Gott! da bin I wiedä des Stadelschreibers bedient sich - anders etwa als Han heut früh schon lang hin und her graitt (1752) seines Bruders Maurus - nicht der traditionellen distanzierenden bäuerlichen Reflexionsfigur. Es ist vielmehr das poetische ,Protokoll‘ eines Berichts, den eine „Mademoiselle M. E. P.“ von einer Hochzeit in Lauffen gab, an der der Stadelschreiber aus unbekannten Gründen nicht teilnehmen konnte. Wer sich hinter dem Kürzel verbirgt, konnte noch nicht eruiert werden. Doch muss es eine Angehörige der bürgerlichen Oberschicht aus dem Umfeld des Gmundner Salzoberamts gewesen sein, deren launige Schilderung der Hochzeit zwischen dem Wildensteiner Amtsschreiber Johann Baptist Schibl und der Salzfertigerswitwe Katharina Wiesmayr P.G. Lindemayr 1789 zum Gaudium des gemeinsamen Freundeskreises in Verse fasste. Diese gewähren einen aufschlussreichen Einblick in die damaligen bürgerlichen Hochzeitsbräuche. Nach der durch Lawinenabgänge erschwerten Anreise eines Teils der Hochzeitsgäste von Gmunden per Schiff und Schlitten wurden sie vor Ort von der restlichen Gesellschaft und von Braut und Bräutigam empfangen. Quartier wurde im Haus der Braut, einem stattlichen Salzfertigerhaus direkt unterhalb der Kirche, bezogen, wo bereits am Abend vor der Hochzeit das Fest begann:

6

Aften sän mä ruehi gsössen, Bißs hat ghaissen, an iß gricht. Und nachdem mä gnue habn gessen, Ham mär übers Tänzen gricht. Das hat daurt bis zway fruh maring, Wo dä Bräuckä haim ist gfahrn: Gleiwohl derfts enk ga nöt saring, daß mä sän marodi warn.

8

Ihr Herr Pfarrä, dä Herr Schreinä

Hat dö Brautleut cupulirt.

Iß ä brävä Mann, ä feinä:

der hat iehns ga schön probirt,

Was das sagn will in dä Bibel,

Wachset, und vermehret euch:

daß än jedä jungä Schibel

Schan iß bstimmt fürs Himmelreich.
7

Wie dä Tag, und Stund anbrochä zu dä Kupelgäzigan

Sän mär aus'n Bethern krochä,

Und das glei um ailfi schan.

Sän in d'Kirä eini trötten, Ehrbar, züchti, vollä Scham, Ham den lieben Himmel bötten, Für die Braut, und Bräutigam. 9 Wies sänd aus dä Kirä gangä Sässens zam in Hahzetsaal. Fluchs hams zum vexirn angfangä, das hat daurt das ganzi Mahl. Leut sänd gwösen beinänanä, d'Fraunä glei so bräf, als d'Herrn; Ja wohl zanken! ja wohl granä! Hams där an änand viel z'gern. 
10

Däß soll s Essen bössä schmöckä

Hamms ä schöni Musi gmacht.

Und aft vo dä Tafel wöckä

Ham mä tanzt die ganzi Nacht.

Und da iß nöt viel agangä

daß dä Schitel nöt än Gspais

Untern Jungfern an hat gfangä:

Ain, und andern wurd schan hais.

12

Untä Scherzen, Tanzen, Springä

Bräch dä helli Tag glei an.

I hätt solln - und kunt nöt - singä

Weil mä hat dä Hals weh than.

Gab ä so gnue Umätreibä;

Gleiwohl hieß: (äs iß wahr ä)

Wenn nä glei dä Stadelschreibä,

Wenn ä dößmal dadä wä.
11

Daßs än Eifäsucht iß gwösen,

Werds enk glei selbm ei ham bildt.

Zwar ös iß ä traurigs Wösen,

Wenn ä fremdi mehrä gilt.

Und das werds ham öftä gfunden:

Haigli ist ä Jungfrau gern

No weit mehr mit ihren Kunden,

Als ä Frau mit ihrem Herrn.

13

Und gleiwie seit Adamszeiten

Alli Brautleit an sänd brennt,

$\mathrm{Daß}$ mäs schan von allä weiten

An iehn Thain, und Lassen kennt

Giengs ä ohni Steurästückeln

Nöt bei unsern Brautbar a

Was i wais von den Artikeln:

Red i in dä Ghaim nur da. ${ }^{49}$

6,4 gricht] sich zugewendet 6,5 maring] Morgen 6,7 saring] sorgen 6,8 marodi] schlapp, matt 7,2 Kupelgäzigan] (lat. copulatio) Trauung, Heiratsakt 7,5 Kirä] Kirche (i. e. die Wallfahrtskirche Maria Schnee in Lauffen) 8,1 Schreiner] Pfarrer Johann Schreiner aus Goisern 8,2 cupulirt] getraut 8,4 probirt] bewiesen, ausgelegt 8,7 Schibel] Name des Bräutigams und seiner zu erwartenden Kinder 9,3 vexirn] Späße machen 9,7 Ja wohl] (hier im Sinne einer Verneinung) kein Gedanke daran, keine Rede davon granä] murren, mürrisch sein 10,5 iß ... agangä] hat gefehlt 10,6 Schitel] Teufel 11,2 ei ham bildt] eingebildet, erahnt haben 11,6 Haigli] heikel 11,7 Kunden] Liebhaber, Verehrer 12,5 gnue] genug Umätreiber] Stimmungsmacher, Spaßmacher 13,2 an sänd brennt] angebrannt sind, (hier) vor Liebe verrückt sind 13,4 iehn] ihrem Thain] Tun 13,5 Steurästückeln] Schildbürgerstreich, Narretei (wohl im Zusammenhang mit dem beliebten Volkstanz ,Steirischer')

Das angesprochene, Steirerstückl' war ein Unfall, den Schibl, wohl nicht nur trunken vor Liebe, auf der Rückreise in Ischl verursachte, wobei seine frisch Angetraute einen Schuh verlor und offenbar auch ein Kirchbesucher zu Schaden kam. Die Erzählerin aber gewinnt auch aus diesem wohl nicht allzu schwerwiegenden Unglück noch Komik, indem sie den Fahrer aufgrund der Umstände aus dem Vertrauensgrundsatz ausnimmt und dem Opfer die Schuld anlastet. Nach zwei Anekdoten, die zu Spekulationen Anlass gaben, wer denn nun das Sagen im Haus habe, endet der Bericht mit der Heimreise der Gäste und guten Wünschen für das junge Ehepaar.

Während hier der Bericht einer Dame von einem männlichen Dichter in Verse gebracht wird, legt die einzige namentlich bekannte Dichterin in einer bairisch-österreichischen Mundart vor 1800, Therese von Artner (1772-1829), ihre Hochzeitsimpressionen und -wünsche durchaus konventionell einer treu-naiven Bauernfigur in den Mund. Interessant neben der weiblichen Autorschaft ist auch der konfessionelle Hintergrund, denn der ,Glückwunsch zu dem fröhlichen Ehrentag' entstand zur Feier der Verehelichung des Predigers der evangelischen Gemeinde Harkau (Harka) Samuel Schiller mit Anna Maria Fabri und wurde vermutlich am 9. Oktober 1798 nach der Ankunft des Brautpaars aus Güns (Köszeg) vorgetragen. Warum Artner diese vor allem katholisch assoziierte Liedform des dialektalen Simultanberichts wählt und als Broschüre

49 Ebda., S. 46-48. 
drucken lässt, ist nicht bekannt; in einer späteren Werkausgabe verweist sie nicht auf eines der zahlreichen österreichischen Vorbilder, sondern auf Hebel (dessen Alemannischen Gedichte freilich erst Jahre später erscheinen). ${ }^{50}$ Es sollte das einzige veröffentlichte Dialektgedicht der später unter dem Künstlernamen ,Theone' bekannt gewordenen Lyrikerin bleiben. Na Vader, heund verkaf eng d'Linß ist in Hianzisch gedichtet, einer damals „Von dem deutschen Landvolk im Eisenburger, Oedenburger, Wieselburger und Preßburger Comitat ${ }^{\text {“51 }}$ gesprochenen ui-Mundart, die heute noch im Burgenland zu hören ist. Sprachlich durchaus geschickt gestaltet, bleiben die verwendeten Bildfelder weitgehend traditionellen dialektalen Elogen verhaftet. Interessanterweise verwendet der Drucker (wohl aus Ödenburg/Sopron) zur Verschriftung des hellen a-Lauts nicht wie im 18. Jahrhundert noch üblich den a-Umlaut, sondern - analog zum Ungarischen ein akzentuiertes ,á, wie er sich in der Mundartdichtung des frühen 19. Jahrhunderts durchsetzen sollte.

1

Na Vader, heund verkaf eng d'Linß wer will und mag, i nit! Heund kimt der geistlich Herr von Günß, und bringt sein Frauerl mit. 3

Es meine Leuteln, wißts Es was?

Es sáchts sie á recht gern; stellts Eng mit mir an d'Günßer Straß, da g'wahrn mirs schon von fern. 5

Hiez geht der Staub auf - tummelts Eng! da fahrens schon herzui.

Hansmichel, duck di nur á weng, das i’s á segen thui.

7

Nit umasunst habens d'Leut so g'lobt, s'is d'Wahrheit meiner Treu! Habts gsegn, wie's hat so freundlih g'nopt, Und gschmaundelt á derbei? 9

Z’wegen meiná! San mir ihna zschlecht, mir laßens á unkeit.

Á Freundlichi, nur de ist recht, für armi Bauersleut.

11

Kumts! Trinkn mir ihná z'lieb án Wix uns von den besten Wein ná! warts á wenig! - das is nix, mir fallt was G'scheiders ein.
2

I muiß si segn, die Jungfer Braut, der Fürwitz sticht mi z'sehr. er hat sich g'wis nix schlechts ausgschaut, der liebi geistlich Herr.

4

Gebts Achting wenn der Wagen kimt, vergeßts nit af'n Gruiß,

das jeder schön sein Huit animt, und auskrazt mit'n Fuiß.

6

Hiez hab i's g'segn - der Deigel n'ein,

Das Bräutel das is rár!

Á solchi müßt die meine sein, wann i was herrets wár.

8

Grüßts ánmal d'Jungfern in der Stadt, was gilts, se haltens Gnáck so steif als wann án Eisendrath in Buckel drinná stáck.

10

Heund wird ihr no mein Gáß hing'führt, (giebt alli Tag fünf Halb!)

Und wann mein Kuih mehr traged wird kriegt sie das ersti Kalb.

12

Schliefts jeder in sein Suntagsrock, und gehts zur Pfarr mit mir, staubts d'Zischma ab, und láhnts in Stock und Huit hübsch vor die Thür.

50 Vgl. Therese von Artner: Gedichte. Gewählt, verbessert, vermehrt. Tl. 1. Leipzig: Hartleben 1818, S. 185.

51 Ebda. 
13

I wás á Hahzetsprüchel fein, und führ für Eng das Wort. au weh! du Steffel, sag mir ein! i kan in Spruch nit fort.

15

Treuherzi druck i Eng die Hand, und wünsch: Lebts lange Jahr So froh und glückli mit ánand als wie á Täuberlpaar.

17

Des sag i nur, das Enger Zucht g'wiß frumm und brav muiß wern, denn wie der Bám, á so die Frucht das wás mir nah und fern.

19

Des is mein Wunsch. - És Stadtgäst, hörts,

dás mi niembs kritisirt! -

Denkts das és á nix gscheider wärts,

hätts nit so lang gstudiert. ${ }^{52}$
14

Was schadts! es braucht kän glernten Spruch, i will mein Herz nur fragn.

Dir, braves Paar, is zierlich gnug

was das mir wird einsagn.

16

Und segnt Eng halt der liebi Gott

bald, wie i hoffen will -

Die Jungfer Braut wird feinlá roth scho recht - i schweig schon still.

18

Bleibts nur den Harkern ferner treu, und liebts es für und für.

Halts no á fröhlichs Jubilei nach fufzig Jahren hier.

1,1 eng] euch 1,3 Günß] dt. Name der ungar. Stadt Köszeg an der Grenze zu Österreich 3,1 Es] ihr 3,2 sáchts] sähet á] auch 4,4 auskrazt] einen Kratzfuß macht, eine Reverenz erweist 5,1 tummelts Eng] beeilt euch 6,1 Deigel] Teufel 6,4 was herrets] ein Herr 7,3 g'nopt] genickt 7,4 gschmaundelt] gelächelt 8,2 Gnáck] Genick, Nacken 8,4 Buckel] Rücken 9,1 Z’wegen meiná] von mir aus 9,2 unkeit] in Ruhe, in Frieden 10,1 Gáß] Geiß, Ziege 11,1 Wix] Rausch 12,1 Schliefts] schlüpft 12,3 Zischma] (ungar. csizma) Halbstiefel 16,3 feinlá] sehr, wirklich 17,1 Enger Zucht] (hier) euer Nachwuchs 17,4 wás] weiß 18,1 Harkern] Bewohnern von Harkau/Harka

\section{Primiz-, Profess- und Prälatenwahllieder}

Wie bei den weltlichen Hochzeiten wurden auch zur , geistlichen Hochzeit ${ }^{53}$, der Primiz, im Zuge der Feierlichkeiten gerne launige, zumeist auf den Primizianten abgestimmte Lieder vorgetragen, von denen sich aus dem 18. Jahrhundert auch einige in bairischösterreichischer Mundart handschriftlich erhalten haben. ${ }^{54}$ Die erste Eucharistiefeier, in der er allein konsekriert, ist im Leben jedes neugeweihten Priesters ein besonderer Moment. Üblicherweise in der Heimatgemeinde gehalten, gab die Primiz früher Anlass

52 [Therese von Artner:] Glückwunsch zu dem fröhlichen Ehrentag des Wohlehrwürdigen geistlichen Herrn Samuel Schiller mit der Wohlgebohrnen Jungfrau Anna Maria Fábri von einem Harker Pfarrkind am 9ten Oktober 1798.

53 Dementsprechend nimmt Franz Friedrich Kohl in seiner Sammlung Tiroler Hochzeitslieder unter dem Kapitel ,Geistliche Hochzeitlieder' auch zwei Primizlieder auf, vgl. Franz Friedrich Kohl: Die Tiroler Bauernhochzeit. Sitten, Bräuche, Sprüche, Lieder und Tänze mit Singweisen. Wien: Ludwig 1908. (Quellen und Forschungen zur deutschen Volkskunde 3) S. 86-88.

54 Vgl. u. a. die von Sparry komponierte Aria pro Tabula ad Primitias R.P. Romualdi Grasbovel oder das bereits von Brenner edierte Gott gseng enckh Essn (1758) aus dem Kloster Baumburg (vgl. Brenner, Der andächtige Bauer, 295-300). 
zu umfangreichen, hochzeitähnlichen Feierlichkeiten der gesamten Gemeinde, die mit Stolz dem Beginn der geistlichen Tätigkeit eines Seelsorgers aus ihren Reihen beiwohnte. Der Neugeweihte wurde von einem befreundeten Priester, der auch die Primizpredigt hielt, zunächst unter Glockengeläute in feierlicher Prozession zur Kirche geführt, wo er als Hauptzelebrant die Messe feierte. Bei der anschließenden Primiztafel für den engeren Kreis der Familie und Ehrengäste wurden diese heiteren Gesangseinlagen von den $\mathrm{Mu}$ sikern, die zuvor schon die Messe begleiteten, aufgeführt; zum Gaudium des Publikums konnten dabei durchaus auch Parallelen zu den,weltlichen 'Hochzeiten und den Vorzügen der jeweiligen ,Bräute gezogen werden, wie in diesem 14-strophigen Lied zur Feier der ersten Messe, die der Weltpriester Michael Stainer in der Steyrer Stadtpfarrkirche am 29. Juni 1778 hielt:

1

Ihr Herrn, und Frauen! väzeichst mä mei Singa,

I wir eng bän ößn da gar nit lang irrn:

Öß derfts mä kai ößn, kain trunk nit zuebringa,

I mus in $\mathrm{H}$. Bräutigam ä gratulirn,

Ös iß ja bän Hazäten ä sinst da Brau

Wans Dirnl än Man kriegt, und s Biebl ä Frau.

2

Wer will si bän heutign föst aftn aufhalten,

den ä nandrö Hazät vo weitn nit glei

der Priestä sein Wei kriegt sei löbta kai Falten

Bleibt alliweil gstaltö, recht schön und rund reih

Der hat iem ä rundögö Glöngät ausgschaut;

dö katholisch Kirä iß selmä sei Braut.

3

Ä sölchänä Brautgä hat währlä guet handeln, ä sölchänä iß scho auf ewö aufghebt

der allita Gott in än Mensch thuet väwandeln, der täglö mit Gott, und sein Heilingä Geist löbt der irrögö Schaf ö den rechtn Stall weißt der mitn Wart Christi ganz eifarö speißt.

4

So macht halt Gott Wundä mit fleißingä Leutn dö andächtö, frum, und fei fleißi studiern:

Aft schikt ä ien sölchänä sälögö zeitn,

Und thuts zu sein geistlingä dingä anführen.

So hams vo dä Freundschaft än ötlä däfahrn,

Weil scho iena 7. lautä Geistling seind warn. ${ }^{55}$

1,2 I wir eng bän ößn] Ich werde euch beim Essen 1,3 Öß derfts mä] ihr müsst mir 1,5 bän Hazäten ä sinst] bei der Hochzeit auch sonst

Mit viel Laune schildert der Dichter in den folgenden Strophen die familiären Verhältnisse des Primizianten; immerhin ist es bereits der dritte Sohn der ,Frau Jobstin', der den geistlichen Stand ergreift. Auch dem kleinen Bruder Hans wird eine ähnliche Zukunft prognostiziert, ein älterer Bruder ist Wirt, die Tochter gut verheiratet. Die ob-

55 Oberösterreichische Landesbibliothek, Mappe 779, 117, f. 1r. 
ligaten Wünsche für das Erleben einer goldenen Primiz (50 Jahre später) und ein Vivat beschließen das Lied:

12

Ains mues i no wünschn, ains mues i no singa,

Wan Gott den 3. Geistlöng 50. J. no that göbm

Daß kuntn dös 50 jahrö Meßopfä bringä

da sollt dä herr, und d'Frau Jobstin no löbm,

Und i, wan hin wär, stund glatt widär auf,

Sungs Amt väher - nachä ä Taflgsang drauf.

13

Das wünsch i, ihr Herrn, und Frauen vä Herzen

I wißat no hauftö, i mues abä schweign:

Seitz öbm rundö lustö, thuets lachä und scherzen

Mir thain dä weil draustn ä Sinfäni geign.

Wans gößn habt, und vo da Tafl aufsteht,

So macht dä herr Blumä schö saubrö Minett.

14

Ains mues i no bittn, ains mues i no plodern,

Mei schlagts mä um dößmal mei bittn nit a

Mi tham in herr Brautigam itzt aussä fodern,

Nehmts Glößä in d' Händ, und schreits rund lautö na,

Göbts achting, i will gehn schön güetlä anhöbm:

He! Vivat dä geistlö H. Staina soll löbm!

he! Vivat, dö Stainerisch Freundschaft soll Löbm! ${ }^{56}$

12,6 Sungs Amt väher] sänge vorher im Hochamt 13,6 Minett] Menuette 14,1 plodern] sagen, sprechen 14,3 Mi tham] wir tun 14,5 gehn] (Expletiv zur Bekräftigung eines Vorhabens, im Sinne von) jetzt, also, dann, gleich güetlä] einfach, ohne Anstrengung 14,7 Stainerisch Freundschaft] Familie Stainer

Die vielen Interna aus den Familienverhältnissen ebenso wie das Wissen um religiöse Feinheiten lassen einen geistlichen Autor aus dem Umfeld des Geehrten vemuten. Vielleicht war es ja der Garstener Benediktiner Leander Kremser selbst, in dessen Sammlung sich das Lied erhalten hat.

Ähnliches ist wohl auch zur Autorschaft des nächsten Primizlieds zu vermuten, das ein Konventuale oder Bediensteter des Augustiner-Chorherren-Klosters Baumburg im nördlichen Landkreis Traunstein (aus dem uns aus dieser Zeit auffällig viele dialektale Arbeiten überliefert sind) verfasst haben dürfte. Am 29. April 1770 feierte der Bartholomäer Weltpriester Sebastian Stadler in der Stiftskirche seine erste Messe. Die komische Laudatio für den „Städl Wastl“ besorgte bei der anschließenden Tafelmusik eine bäuerliche Figur aus seiner Heimatgemeinde, die gleich zu Beginn gleichfalls auf die, geistliche Ehe' zu sprechen kommt, wobei die ,Braut' des neugeweihten Priesters anders definiert wird:

56 Ebda., f. 2 r-v. 
1

Vozeyhmas, Wastl, das i kim von Eggenfeln herein!

da Marckt, die Gmain, das ganze Gricht

dö thüen si all erfreun,

das du so wacka drauf gstudirt,

bist worn Sanct Bärthlmee,

erwöhlt die heillig Priesterweyh

und nöt die heilig Eh.
2

Dein Mueta freyd dös Ding äso -

sieh! wies dort aussa schaut, danckt Gott demüthig, denkt dabey: „,ietzt hat mei Sohn ä Brauth, dö braucht kain Essen, Trinkä nöt“". das Ding ligt mir im Sinn; mein! wer wird dann dö Frau wohl seyn? die Himmelskönigin. ${ }^{57}$

1,2 Eggenfeln] Eggenfelden in Niederbayern, Heimatort des Primizianten 1,3 Gmain] Gemeinde 1,6 Sanct Bärthlmee] fälschlich für ,Bartholomäer', der Gemeinschaft der Bartholomiten Angehöriger (vgl. Hartmann) 2,2 aussa] heraus

Zwei weitere wichtige Brauchtumskomponenten werden in diesem Primizlied angesprochen: Zum einen wird die ,Primizbraut' vorgestellt, die in Analogie zur Brautjungfer den Primizianten in die Kirche begleitet. Zum anderen rückt der eigentliche Höhepunkt der Primizmesse ins Bild: der Primizsegen am Ende des liturgischen Teils, dem eine besondere Kraft zugesprochen wurde und der derart bei der ländlichen Bevölkerung sehr begehrt war:

8

Dö Kräntzlbraut dö hofft auf di; wanst habn solst Glick und Stern, ä Pfarrä odä gnädig Herr, möcht si dein Köchin wern und dir aufwarthen früh und spath. was wilst denn habn mehr? I aber förcht und gläb für gwis: ihr Mueta lasts nöt her.
9

D’Hofwirthin last ä grüessen di und hat aufgebn mir, du solst än heilign Seegen auch ind d'Kuchl schicka ihr.

Sie hat mir gsaid, es sey da Segn für das Fegfoia guet.

I ha kain Sack, kain Rantzen nöt; bitt: gib mirn in mein Huet! ${ }^{58}$

8,1 Kräntzlbraut] Brautjungfer, hier: Primizbraut 9,5 gsaid] gesagt

Eines der gelungensten Beispiele für diese Liedgattung, Maurus Lindemayrs Grüeß di Gott mei liebä Gfadä, ist als Duett zweier bäuerlicher Wanderer auf dem Weg nach Ischl gestaltet. Der szenische Einstieg zeugt von Lindemayrs Gespür für dramatisch wirksame Genrebilder: Ein ortsfremder Wanderer, der offenbar eine Pause eingelegt hat, um sich ein Pfeifchen zu stopfen, hält einen an ihm Vorbeieilenden an, um ihm nach dem Grund des Tumults in Ischl zu befragen. Informationen werden ausgetauscht, die Labungen eingenommen und gemeinsam geht es weiter zur Messe, denn den Segen will man auf keinen Fall versäumen:

57 Bayerische Staatsbibliothek, Cod. germ. 4402; zitiert nach: August Hartmann: Baumburger Dialektgedichte. In: Oskar Brenner/August Hartmann (Hg.): Bayerns Mundarten. Beiträge zur Deutschen Sprachund Volkskunde. Bd. 2. München: Kaiser 1895, S. 305-313, hier 311.

58 Ebda., S. 312. 
1

Grüeß di Gott mei liebä Gfadä!

Läf di nöt von Aden! bait!

Sagmä do, was habts denn da dä

Bän enk z' Ischl für ä Gjaid?

Han schon nächtn d' Glocken surmä,

Und dö Böllä krachä ghert;

Heut thains no viel örgä sturmä,

Denn ös rigölt si ja d' Erd.

[...]

6

Los! ös thaint schon in dä Kihrä

Orgeln, blasn, Bauckenschlag'n;

Nimm den hintern Fueäs iezt fürä,

$\mathrm{Daß}$ mä d' Prödi no däfrag'n.

Sinst'n möcht dä Sögn nöt gelten,

Wann mä nöt 's Wort Gottes hern,

Und das wär, mein Aid! zum schelten,

Thät mi gwis mein Löbtä schern.
2

Hudri, Gfadä! thue nöt sämmä,

zünd dä gschwind dein Pfeifferl an!

Heut will ins von Art Niemd gämmä,

Allsamt läft, was kroichä kann.

Kem mä z' spat, so kimst nöt z' schmeiß’n,

Und i han mei Löbtä ghert:

Nagelnoie Stifel z' reiß’n

Wär dä Sögn allani schon werth.

7

Chor:

Dort sieh ihn von weiten,

Ä kreuzbräfa Mann.

Sein Herz ist voll Freud'n,

I kenn iehms schon an.

Viel Glück solls enk rögnä

Beym geistlingä Breat.

Thiets ens nä braf sögnä,

Auf lembdi und tead. ${ }^{59}$

1,1 Gfadä] Taufpate; häufiger ist die Verwendung als Anredeform gleichrangiger Personen, v. a. der Nachbarschaft 1,2 bait] warte 1,4 Ischl] Marktgemeinde im Zentralsalzkammergut (heute Bad Ischl) Gjaid] Lärm, Aufregung, Trubel 1,5 nächtn] gestern (abends) surmä] sumsen, summen 1,6 Böllä] Geschütze kleineren Kalibers für Festschießen 1,7 sturmä] Sturm läuten 1,8 rigölt] rührt, bewegt sich 2,1 Hudri] (Aufforderung, sich zu beeilen) Geschwind! 2,3 gämmä] zu Hause bleiben, das Haus hüten 2,4 Allsamt] alles, alles zusammen 2,7 Nagelnoie Stifel z' reiß'n] früher Beleg für den bis heute gebräuchlichen Spruch, der Primizsegen wäre es wert, ein Paar Schuhsohlen durchzulaufen 6,1 Los] Horch!, gib Acht! ös] sie (hier: Personalpron. 3. Pers. Pl.) 6,3 fürä] nach vor, nach vorne 6,7 mein Aid] bei meinem Eid! 7,6 geistlingä Breat] geistliches Brot, im Sinne von: geistlicher Beruf

Für Ordenspriester wie Lindemayr war vor der Primiz schon das Ablegen der Gelübde ein einschneidendes Erlebnis, das in den Klöstern dementsprechend feierlich zelebriert wurde. Das öffentliche Versprechen eines Novizen, sich an eine Ordensgemeinschaft zu binden, ist ein ritueller Abschluss des bisherigen weltlichen Lebens. Mit dem Versprechen, die im Matthäusevangelium genannten Ratschläge der Armut, ehelosen Keuschheit und des Gehorsams zu beherzigen, weiht er sein neues Leben fortan dem Dienst an Gott und den Menschen. Diese Gelübdetrias beleuchtet auch ein von Franz Sparry vertontes Professlied eines unbekannten Autors (der wohl unter seinen Kremsmünsterer Mitbrüdern Nonnos Stadler, Johannes Weylgoune oder Theophil von Dückern zu suchen sein wird). Der Liedanfang hat es in sich: eine literarische Totenbescheinigung mit dem spröden Vanitas-Trost, dass im Diesseits ohnehin kein Heil zu erwarten und der Exitus folglich die einzig richtige Entscheidung sei:

59 Lindemayr, Dialektlieder I, S. 52 und 53f. 
1

Liebi Fratres grües enckh Gott! nu seits heint auf oämahl Todt: nix thuet mehr in enckh iezt löb'n, haut und Kopf habts scho vägöb'n, mey lasts gehn, äs ligt nix dran habts in Himmel do än lohn; schauts heint habts was guetts angfangä, seits dä weldt fein recht entgangä, liebi Fratres grües enckh Gott! nu seits heint auf oämahl Todt.
2

o wie gscheid habts ös heint gmacht, habts dö ganzi weldt välacht: si kan nix als allwaill lieg'n, hint und for'n thuets betrieg'n, wölts ös wiss'n, was d'welt sey, nix als ber'n heiterey; auf dä weldt kan mir nix gfal'n, thäts mäs no so schön abmahl'n, o wie gscheid habts ös heint gmacht, habts dö ganzi weldt välacht. ${ }^{60}$

1,1 Fratres] (lat.) Brüder; Konventsmitglieder ohne Priesterweihe enckh] euch 1,2 heint] heute 2,3 lieg'n] lügen 2,5 wölts ös] wollt ihr 2,6 ber'n heiterey] Bärenhäuterei (Schimpfwort): Schwachsinn

Was so düster beginnt, ist freilich - wie bereits die volksnahe Sprachgebung verrät - zur Erheiterung und Erbauung eines Festpublikums gedacht. Gefeiert wurde eine doppelte Profess und der gewählte Tag, Allerheiligen 1750, legte morbide Witzeleien nahe. Gerade für solche Grenzgänge des guten Geschmacks hatte sich im Klosterkontext die Präsentationsfigur des singenden Bauern etabliert, der in ungeschliffener ,bäurischer' Sprache auch Grobheiten sagen konnte, die freilich oft einen wahren Kern hatten. Vorgetragen üblicherweise von einem Stiftssänger, waren die Mundartgesänge fixer Bestandteil der klösterlichen Unterhaltungskultur dieser Zeit. Es waren keine unbedeutenden Konventualen des Klosters an der Krems, die an diesem Tag ihre Gelübde abgelegt hatten: Ulrich Öttl wurde einer der führenden katholischen Rechtsgelehrten seiner Zeit und fungierte als Subregens der Ritterakademie, dann als Dekan der höheren Schulen in seinem Stift; auch als Theaterdichter trat er mehrfach hervor. Die Bühnenmusik dazu schrieb zum Teil sein Professbruder Georg Pasterwiz, der als bedeutendster Komponist seines Klosters gilt. ${ }^{61}$ Welche Konsequenzen die Verpflichtung auf die Evangelischen Räte für die beiden Professen hat, wird in den folgenden Strophen noch einmal expliziert, indem es die Vorzüge mit stoizistischen Argumenten und Sentenzen herausstreicht. Der Schluss des Lieds empfiehlt die Hingabe an Gott, nachdem der feierliche Schritt ohnehin bereits mit der Tonsurierung als sichtbarem Zeichen und dem Schwur als kirchenrechtlichem Akt vollzogen wurde.

60 Musikarchiv Stift Kremsmünster, G 44/793 (Abschrift von Georg Pasterwiz), f. 1r-v. In derselben Mappe erhalten ist eine jüngere (standardsprachliche) Variante zur Profess von Berthold Höger, Leonhard Holzermayr und Roman Böhm (1759). Auch die dialektale Fassung erlebte zumindest zwei weitere Aufführungen: $1762 \mathrm{zu}$ Ehren von Anton Holl, Prokop Richter, Jakob Copisi und Wolfgang Leuthner; etwas später für die Novizen Franz und Carl, jeweils mit neuen personalisierten Liedstrophen. Sparrys Autograph findet sich unter Sign. G 44/792.

61 Während seines Studiums in Salzburg hatte Pasterwiz Kompositionsunterricht bei Johann Ernst Eberlin genommen, wirkte nach Sparrys Tod als Regenschori und vertonte etliche, auch dialektale Singspiele seines Mitbruders Beda Plank (1741-1830). Als Stiftshofmeister in Wien empfahl er Mozart seinen Schüler Franz Xaver Süßmayr. Vgl. zu Leben und Werk der in musicis engagierten Konventualen Kellner, Musikgeschichte des Stiftes Kremsmünster. 


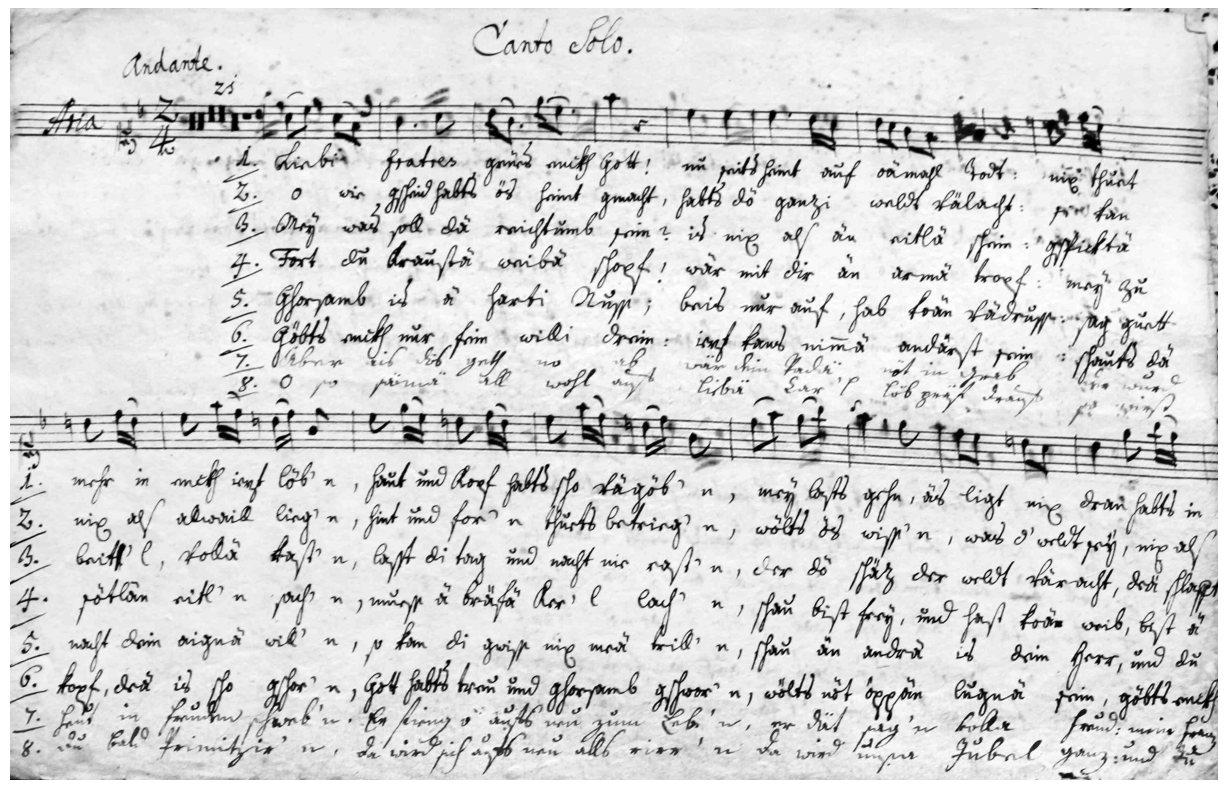

Abb. 36: Profess-Gesang (Musikarchiv Stift Kremsmünster, G 44/793).

3

Mey was soll dä reichtumb sein? is nix als än eitlä schein: gspicktä beit'l, vollä kast'n lasst di tag und nacht nicht rast'n, der dö schäz dä weldt väracht, deä schlafft guett ä ganzi nacht; hast nöt vill, derffst nöt vill sorg'n, wo koä schuldnä, gibts koän Porg’n mey was soll dä reichtumb sein? is nix als än eitlä schein.

5

Ghorsamb is ä harti Nuss;

beis nur auf, hab koän vädruss: sag guett nacht dein aig’nä will'n so kan di gwiss nix meä trill'n, schau än andrä is dei Herr, und du kanst nöt fäll'n mehr, thue di nur a weni zwingä, so kanst leicht in Himmel gwingä, Ghorsamb is ä harti Nuss, beis nur auf, hab koän vädruss.
4

Fort du kraustä weibä schopf! wär mit dir än armä tropf: mey zu sötlän eitl'n sach’n muess ä bräfä Ker'l lach'n, schau bist frey, und hast koän weib, bist ä Eng'l mit'n leib; der'n Ehestand recht thuet kennä, last si leicht mit iem nöt brennä fort du Kraustä weibä schopf, wär mit dir än armä tropf. 6

Göbts enckh nur fein willi drein: iezt kans nimmä andärst sein: schauts dä kopf, deä is schon gschor'n, Gott habts treu und ghorsamb gschwor'n, wölts nit öppän lugnä sein, göbts enckh nur geduldi drein; thiets enckh ganz und gar Gott göb'n, gibt er enckh das ewi löb’n, Göbts enckh nur fein willi drein, iezt kans nimmä andärst sein. ${ }^{62}$

4,1 kraustä] gelockter 4,3 sötlän] solchen 5,4 trill'n] plagen, zusetzen 5,6 fäl'ln] fehlen 6,5 öppän] etwa 6,7 thiets] tut

62 Musikarchiv Stift Kremsmünster, G 44/793, f. 1r-v. 
Die ,harte Nuss' der Gehorsamkeit in der Nachfolge Christi ist ein wesentlicher Bestandteil monastischen Lebens. Den Willen Gottes möglichst gut zu verwirklichen implizierte auch, den Dispositionen der Oberen in allen Lebensfragen zu folgen. Insofern war die Wahl des Oberhaupts einer Ordensgemeinschaft von zentraler Bedeutung für alle, die ihm Gehorsam schuldig waren. Dementsprechend feierlich wurde die richtungsgebende Entscheidung im 18. Jahrhundert üblicherweise zelebriert, nicht nur im Heimatkloster. Als etwa der frischerwählte Kremsmünsterer Abt Erenbert Meyer im Juni 1771 auf der Heimreise von seiner Infulierung in Passau im Kloster Lambach Halt macht, wurde ihm zu Ehren auch der dialektale Kurzweilige Hochzeit-Vertrag aufgeführt, den Maurus Lindemayr für die Verabschiedung der Erzherzogin Maria Antonia im Jahr zuvor verfasst hatte.

Nicht zuletzt diese Festkultur war eines der Argumente im ,josephinischen Klostersturm', das Benediktinerstift für einige Jahre unter Administration zu stellen. Als der kunst- und wissenschaftsaffine Abt Amand Schickmayr 1794 starb, brachte eine durch Sperrkommissare durchgeführte Inventur finanzielle Verhältnisse zutage, die beim Konvent Entsetzen hervorriefen und die Wiener Obrigkeiten veranlassten, einer Wahl nicht zuzustimmen, solange die wirtschaftliche Situation nicht geklärt war. Erst Monate später wurde sie mit der Auflage erlaubt, dass sich der gewählte Abt zur Veräußerung der Kupferstich- und Münzsammlung und zur Umsetzung der verordneten Wirtschaftsreform eidlich verpflichtete. Die Wahl des Lambacher Kapitels fiel wenig überraschend auf den begabten Prediger und ausgebildeten Astronomen Julian Ricci, der zuvor bereits als Mitadministrator die Geschicke des Stifts geleitet hatte. Von seinem ausgleichenden Wesen versprach man sich eine Versöhnung der Diskrepanzen im Konvent, aber auch die notwendige Konsequenz, um die dringend erforderlichen Reformen durchzusetzen. Diese Punkte spricht auch Peter Gottlieb Lindemayrs Freudenlied Ju he sä! heut freuts mi an, das am Wahltag zur Abendtafel und am folgenden Tag zur Mittagstafel abgesungen wurde:

4

Zwar schmutzt ä ga friedli, und lächelt ain an,

Mä meinet, daß er ga nöt ernstli seyn kan;

Do wichtigi Sachä

vätreibnt iehm schon 's Lachä;

da iß ä ganz anäs, schickt si in d'Zeit

Und wenns ä so seyn muß; so zaigt er ä Schneid.

5

Z'erst hat ä dä Wahl si ä Weil widäsetzt,

Wiewohl ä si endli noh gebn hat auf d'letzt:

Äs kämm iehm schier auä,

Ä wär da nöt z'brauä:

Di Demuth hat afä aus iehm ä so gröd:

Drum hälf ä sein ganzi Entschuldigung nöt.

6

I halts Kain für Übel; äs will schon was sagn:

Ä sölterä Herr muß den ganzen Last tragn.

Das macht ain schon schwitzen,

Und lehrnt ain stät sitzen: 
Do glei wohl! äs iß halt ä bsunderi Ehr:

Und I wurd mit Freuden ä sölterä Herr.

7

I ließ bein än gleichä dä Sach ihren Lauf,

Und that mä halt iebel än guten Tag auf.

Thät fahrn, und thät reiten,

Thät mit sölchern Leuten,

Dö aufrichti denken, und mir ä gut wölln,

Ä Recration und ä Mahlzeit anstölln.

8

Ä so thät halt I und i find das für gut:

Ä so blieb mä bößä bei Kräften, und Muth:

I wollt $n$ Prälaten

das gutherzi rathen.

Daduri dähält ä si längä beim Lebn;

$\mathrm{Nu}, \mathrm{nu}$ ! äs wird alls von iehm selbä si gebn.

9

Potz tausend! Dort iß ä: - itzt wird mär erst hais;

Was iß denn? - ä kennt, und västeht ia än Gspais:

Äs gilt schon Ihr Gnaden!

$\mathrm{Daß}$ d'Reihsthallä grathen!

Gott laß enk regirn durch ä halbshundert Jahr!

Ju vivat, und fiat! So wird mein Wunsch wahr. ${ }^{63}$

4,1 schmutzt] lächelt, schmunzelt 4,6 Schneid] Mut, Courage 5,3 auä] heraus 5,4 z'brauä] zu brauchen, zu gebrauchen 6,2 sölterä] solcher 6,4 stät] still, ruhig, bewegungslos 7,2 iebel] manchmal, ab und zu, zuweilen 7,6 Recration] (lat. recreatio: Wiederherstellung) Rekreation, Erholung 8,5 daduri] dadurch dähält] erhält 9,2 Gspais] Spaß 9,4 grathen] gedeihen, in reichem Maß zuteil werden 9,6 vivat] (lat.) er lebe! fiat] (lat.) es geschehe!, es werde!

Den hohen Ansprüchen allerdings konnte Ricci aufgrund widriger Umstände nie gerecht werden. Eine nachhaltige Konsolidierung verhinderten vor allem die turbulenten Ereignisse während der Franzoseninvasionen 1800, 1805 und 1809 mit den Plünderungen, Einquartierungen, Abgaben und Diensten, mit den Requirierungen der Klosterräumlichkeiten für die kaiserlichen, dann auch französischen Lazarette und - symbolträchtig genug - mit der dreimaligen Flucht und mehrmonatigen Abwesenheit des Abts. Dieser reagierte auf die allgegenwärtigen Probleme mit zunehmender Lethargie, sodass das komische Zerrbild, wie es das Rollen-Ich in den Strophen 6-8 ganz im Stile eines rusticus imperans ausmalt und dem frischgewählten Julian anempfiehlt, in späteren Jahren der Wahrheit bedenklich nahe kam.

Zur Ehre eines neuerwählten Klosteroberhaupts entstand auch Die Prob der Gratulation oder der Dorf Schulmeister des Chorregenten des Tiroler Benediktinerstifts Fiecht, Edmund Angerer (1740-1794). Das witzige Singspiel (wohl auf einen eigenen Text des seinerzeit hochangesehenen Kirchenmusikers) wirft einen Blick hinter die Kulissen des geschäftigen Probenbetriebs unmittelbar vor den Feierlichkeiten. Ein Schulmeister, selbst sprachlich und musikalisch überfordert mit der lateinischen Kantate, die ihm der ,Geistliche Herr' Oswald zum Einstudieren überlassen hat, versucht die „krumme Bauer

63 P. G. Lindemayr, Lieder in oberösterreichischer Mundart, S. 69f. 
Tochter“ Lisl und ihren halbwüchsigen Bruder Jäckerl noch rasch zu instruieren. Als ,Probe` der daraus entstehenden Komplikationen möge der Anfang genügen:

Schulmeister. So kömant dFrazn no nöt! Was gilts sö kinän nix? Es ist abä scho woltlä hart ä, i waiß nöt, dä Geistli Herr maint grad, es kanns ä jedä gschwind, was ihm nöt hart für kimmt, das wird ä schöns Graulieren wern. Dä Bue kanns nöt, das Diendl nöt und i kanns selber ä nöt recht. Da da da du da do do Surgite grathiæ serta connectite optimo Præsuli optimo piano Sol fa mi Sol mi forte Optimo Præsuli so gehts recht wen mä ihm no helfä kan, Surgite grathiæ Serta connectite forte Optimo Præsuli, das geht schon aba iez zaha - - - - harmina zanite der Lauf hat halt ä höb grad wögns Athn Surgite grathiæ Serta connectite optimo Præsuli.

LisL. die unterdessen vor der Thür draussen steht. Grüß Gott Herr Schulmaista!

SChulmeister. bist da ä mal, wo bist den so lang.

LIsL. i wär scho ehndä kemmä abä d'Mudä iß so lang nöt firtig worn mitn Koch kocha Herr Schulmaista.

Schulmeister. du grossi Droll kanst nie vo haim kemma, bevorst nöt ä Pfann voll Koch ausfrist - Nu Nu äs iß scho recht, kanst öppäs?

LisL. ä Bißl.

Schulmeister. ä Bissl, wan wärst es den dä lerna? Laß sehn, höb an!

LisL. zieht die Stim heraus. Surgite gratiæ Serta connectite -

Schulmeister. halt! du Fozn! han i dirs ä so glernt? sprich mäs recht aus, sunst schlag i drein, Surgite grathiæ -

LisL. Surgite grathiæ gratiæ -

SCHUlmeister. grathiæ daß iß än Esel, sey mä still iß ja ä T, kanst nöt Buchstabiern. ${ }^{64}$

kinän] können woltlä] wirklich, sehr für kimmt] vorkommt Surgite grathiæ ... optimo] (lat.) erhebt euch, den Dankeskranz bindet für den besten Oberen (gratiæ wird falsch ausgesprochen) Sol fa mi Sol mi] Tonsilben der Solmisation zahaharmina zanite] (lat. carmina canite) singt die Lieder (hier spricht der Schulmeister die Anlaute falsch aus) ehndä kemmä] früher gekommen Droll] Schimpfwort öppäs] etwas höb an] fang an Fozn] derbes Schimpfwort

Bei der Kontrollvisite des Komponisten freilich stellt sich heraus, dass der Schulmeister selbst die lateinischen , $\mathrm{t}^{\mathrm{t}}$ und , $\mathrm{c}^{\mathbf{c}}$ falsch ausspricht. Frustriert verwirft er die Kantate und studiert mit seinen Schülern sein „aigns Gsang“ ein, denn „der gnädi Herr iß ä brafä Mann, und hat liebä öppäs gmains, dös vo Herzen geht, als öppäs künstlis das nöt zam

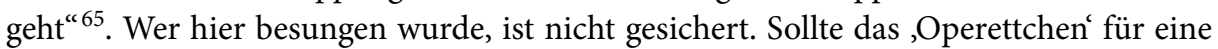
Fiechter Feier entstanden sein, wird der solcherart Geehrte wohl der 1790 erwählte Abt Alfons Pacher gewesen sein.

Eine besondere Ehre wurde dem bedeutenden Göttweiger Abt Gottfried Bessel bei seinem fünfzigjährigen Priester- und Doktorjubiläum 1746 zuteil, als mit Maria Theresia und Franz Stephan das regierende Herrscherpaar und der Kaiserbruder Prinz Karl den Festlichkeiten beiwohnten. ${ }^{66}$ Der aus Buchen im Odenwald gebürtige Bessel, ein bedeutender Historiker, Diplomat, Hoftheologe und 1714-1716 auch Rektor der Universität Wien, hatte das Kloster nach dem verheerenden Brand von 1718 glanzvoll wiederaufbauen lassen und eine wertvolle Bibliothek darin errichtet. Was sich bei seinem goldenen Primizfest ereignete (bei dem auch zwei Mitbrüder geehrt wurden), hielt der Hauspoet

64 Österreichische Nationalbibliothek, Musiksammlung, Mus.Hs. 5144, f. 2r und 9r-10r.

65 Ebda., f. 13v.

66 Vgl. u. a. den Bericht im Wienerischen Diarium vom 25. Juni 1746 (Nr. 51, S. 9f.), der im Wesentlichen mit den Angaben des unten besprochenen Lieds übereinstimmt. 
P. Rupert Krenner (1722-1782) aus der topischen Perspektive eines naiven Bauern in einem launigen 60-strophigen Gedicht fest: Die Ehrengerüste und Triumphbögen für Bessel und seine Gäste, die aus Wien beorderte Kürassiergarde als Begleitschutz der Herrschaften, der Empfang, bei dem der Jubilar, ein „steinalter Datl“67, symbolisch die Stiftsschlüssel überreichte, die übliche Verballhornung der Kirchenmusik, all das wird gekonnt ins Bild gesetzt, bevor konkret auf die Erneuerung der Ordensgelübde (Ablesung der Formel und Unterzeichnung), rituelle Waschung und Friedenskuss eingegangen wird:

34

Da Mehrist beim Altar fiel nieder auf d'Füaß, und löst in an Zettl ganz safti und süaß; aft gang er auf d'Seitn und schrieb was drein, wer kann mas daratn, was gwesn muaß sein. 35

Drauf bringans an Seßl, da sitzt er si drauf, aft sagn zwoa andre a Blattl voll auf; die gangan z'letzt a aufs Platzl hintan, und kratzn s'Papierl mit Kreuzstrichln an.

[...]

40

Drauf fahrns in der Arbeit schön stad wieda fort,

Aft muaßt er si waschen und redat kein Wort;

ma tuat ihm an guldenan Weidling fürhebn,

der kunt schier a halberte Roßschwemm abgebn.

41

Würs aba schier ausgwest, da riglt sich alls und fahrn inananda gar fein um an Hals; dem Kaiser und Kaiserin habns a danebn, a guldenes Kastl zum Ableckn gebn. ${ }^{68}$

34,1 Da Mehrist] der Ranghöchste 34,4 mas daratn] es mir erraten 40,1 stad] ruhig 40,3 Weidling] große Rührschüssel mit Henkeln 41,1 riglt] rührt, bewegt 41,4 Kastl] Kästchen (gemeint ist das Pazifikale zur Weitergabe des Friedenskusses)

Mit einem Bericht über die Besichtigung von Raritätenkammer und Bibliothek, das abschließende opulente Festessen und die Verabschiedung lässt der gebürtige Salzburger Krenner sein Gedicht ausklingen. Dass es allein für die Unterhaltung des Göttweiger Konvents gedacht war, lässt sich dabei u. a. auch an einer Spitze gegen den bekannt genussfreudigen Karl von Lothringen erkennen, der dem Burgunder offenbar ausgiebig zugesprochen hatte.

67 Zitiert nach: Ludwig Koller: Mundartdichtung auf den kaiserlichen Besuch in Göttweig 1746. In: Das Waldviertel 5 (1956), Nr. 9/10, S. 162-170, hier S. 164. Koller ediert die ältere der beiden erhaltenen Abschriften aus dem fünften Band von Gregor Schenggls handschriftlichem Diarium Gottvicense (Stiftsarchiv Göttweig).

68 Ebda., S. 167f. 


\section{Profane Anlasslieder: Defensio, Aderlass, Bärenbegräbnis}

Die auffällige Dichte an Dialektdichtern in Klöstern und die traditionell besseren Möglichkeiten der schriftlichen Fixierung und Archivierung dieser flüchtigen Kunst im monastischen Umfeld lassen Liedgut zu sakralen, liturgischen oder klosterinternen Anlässen möglicherweise stärker ins Licht treten, als ihm anteilsmäßig zukommen würde, da sich profane Gelegenheitslieder seltener in Quellen vor 1800 erhalten haben. Aber auch im Klosterumfeld sind Dichtungen zu rein weltlichen Ereignissen entstanden, wie schon an Liedern zu Ehren illustrer Gäste wie Marie Antoinette (vgl. Kap.3) gezeigt wurde. Auch das pädagogische Engagement der Schulorden bot zahlreiche Gelegenheiten, wie etwa das Beispiel des folgenden Promotionslieds zeigt. Es entstand anlässlich der öffentlichen Dissertationsverteidigung Joseph Ferdinand Seyringers an der Kremsmünsterer Akademie. Seyringer stammte aus einer bayrisch-österreichischen Juristendynastie, die mit dem Stift Kremsmünster schon über Jahrzehnte hinweg durch Rechtsberatung und Anwaltstätigkeiten verbunden war. 1733 in Linz geboren, ging Seyringer an die frisch errichtete Ritterakademie, wo er auch Vorlesungen zur Rechtswissenschaft besuchte. Sein Studium schloss er am 28. November 1752 mit der Verteidigung seiner (auch gedruckten) Abschlussarbeit De civili felicitate mit Bravour ab und wurde noch am selben Tag in einer Abschiedsfeier geehrt. Das dabei vorgetragene Festlied, wiederum in der Vertonung Franz Sparrys, gibt zu Beginn noch einen anschaulichen Bericht von der beanspruchenden Prüfungssituation, wechselt dann jedoch rasch zu einer recht harschen Advokatenschelte, die die Redlichkeit des Berufsstands aus humoristischem Blickwinkel gehörig in Zweifel zieht - nicht unpikant, bedenkt man, dass der Vater des Prüflings anwesend war:

1

auweh! das hoäst disputiert! aus'n Jure thains heint rauff'n, last si koänä do väkauff'n bräff defendens hast di gwirrt; söxi habn an di anbisß'n, ham do nit'n kopff wöckgrisß'n, selbst dei Vadä gibt koä ruhe, er sagt, halt di wohl mei bue. 3 freili tragts offt thaller ein, sän d'wort ausänandä zog'n, wird do zahlt än ieda bog'n, wie schaut aber sgwisß'n drein. thuest dein beit'l freili Spick'n, und dein gwiss'n thut di zwick'n, in dä truch'n hast 'n hundt, pelt zum gwiss'n alli stund. [...]
2

abä wälst bald wöckä roäst, mues i dir ä lehr no geb’n, dö dä taugt für all dei leb’n, flieh'n Advocat'n laist, sunst hats ghaisß'n all Jurist'n, sän mein oäch'l schlechti Christ'n was is offt der Advocat, is halt umä dum väträt. 4 nimbst di umb vill händl an, kanst dä freili gar vill gwingä, abä sgwisß'n wird nit ringä, all'n niembt recht dienä kan. umb än silbern, goldern rog'n, wird offt dwarheit greili bog'n, wilst än ied'n dienä recht, wirst nit gar lang bleib'n grecht. 
6

bist ä schlauch'r Advocat, muest auf boäd'n achsl'n trag'n, anderst denck'n anderst sag'n, nä sonst di niembt acht'n thät. muest in scherz'n und in lach'n, ausß'n recht än unrecht mach'n, laugnä mues der Advocat, wan dä han schon 6 mahl krät.
7

freili sän nit alli gleich, gibt ja frummi, gibt ja grechti, aber öppä no mehr schlechti, i do gar niemd übl zeich. wer den gfahr'n will entfliech'n, mues si von den stand wöckziech'n, meintwegn wir än advocat, i dirs gwisß nit rath’n thät. ${ }^{69}$

1,2 thains] tun sie 1,4 defendens] (lat.) sich verteidigend gwirrt] gewehrt 1,5 söxi] sechs 2,4 laist] Leisten 2,6 mein oäch'l] (Beteuerungsformel) bei meinem Eid! 2,7 offt] dann umä dum] rundherum, durch und durch 4,1 händl] Streitfälle 4,3 ringä] leichter 4,5 rog'n] Vorteil, Gewinn 4,6 greili] gräulich 6,6 ausß'n] aus dem 6,8 han] Hahn 7,4 übl zeich] beschuldige 7,7 wir] werde

Der abschließende unmissverständliche Ratschlag, nicht die Advokatenlaufbahn einzuschlagen, da dabei kaum einer redlich bleiben könne, war wohl einem der Oberen zu viel des Guten, denn für die Aufführung wurde noch rasch eine lobhudelnde achte Strophe eingefügt, die dem frisch Promovierten das Vorbild des Vaters anempfahl. Nach einem Fortsetzungsstudium in Salzburg wurde dem frisch ernannten kaiserlichen Pfalzgrafen 1756 an der Universität Innsbruck die Doktorwürde verliehen. Als Hof- und Gerichtsadvokat der Landeshauptmannschaft im oberösterreichischen Zentralraum tätig, starb Seyringer nur 39-jährig 1773 in seiner Geburtsstadt.

Auch im Unterhaltungsprogramm der alljährlichen Aderlasstage kamen nachweislich dialektale Scherzlieder zur Verwendung. Der Spott richtete sich dabei freilich nicht gegen die heute befremdliche medizinische Behandlungsmethode, die noch bis ins frühe 19. Jahrhundert durchaus gängige Praxis war. Als ausleitendes Verfahren der Humoraltherapie, die im Gleichgewicht der Körpersäfte den Schlüssel zur Gesundheit sah, kam der Aderlass bei einem umfangreichen Krankheitsspektrum zum Einsatz, nicht nur bei akuten Leiden, sondern auch als Maßnahme zur Gesundheitsvorsorge. An astrologisch bestimmten Tagen wurden die Venen von einem Bader mithilfe eines Schneppers geöffnet und etwa 100 bis $500 \mathrm{ml}$ Blut entnommen. Sogenannte ,Aderlass-Männchen', wie man sie auch in den damaligen Kalendern abgebildet sah, gaben an, welche Körperzonen unter welchen Tierkreiszeichen bevorzugt behandelt werden konnten. Dass diese Therapie als geselligkeitsfördernde Prophylaxe durchaus ihre angenehmen Seiten haben konnte, ist Thema diverser Aderlaß-Gsängl. Ein im salzburgischen Hallein 1721 gedrucktes Beispiel eines unbekannten Autors, der es dem bürgerlichen Lesepublikum seines Rätselbuchs als Zugabe angedeihen ließ, singt ein (weitgehend standardsprachliches) Lob auf die Gesundheit, ehe es die Phlebotomie-Patienten in den letzten Strophen deutlich dialektaler zum Genuss aufruft:

69 Musikarchiv Kremsmünster, G44/795. Ediert wurde die ursprüngliche, in der Mappe zweitgereihte Fassung (die weitgehend deckungsgleich ist mit dem Dichterautograph der Strophen 2-7). Differenzen und Überarbeitungen der anderen Fassung lassen vermuten, dass das Lied mit entsprechenden Adaptionen noch zumindest zweimal zum Einsatz kam. 
10

Ey so seyts wol auff beysammen/

Leib und Seel mit Freuden labt/

Ests vnd trinckts in GOttes Nahmen/

Leyds kein Mangl wanns was habt/

Dann ja hier auff diser Erden/

Besser vns nichts z'Theil kan werden/

Als was etwann / s'Maul erdapt.

[...]

15

Ey so höbts dann auff die Böcher/

Nembts mein treuen Rath in acht/

Trinckts einmal ains gsund der Löcher/

Die vns hat der Bader gmacht;

Seyts fein munter / thuets nit schlaffen/

Wists ja was Doctores schaffen/

Ist verbotten biß auff d'Nacht. ${ }^{70}$
14

Wann fürs Blut so herauß gflossen/

Lieber / mein betracht nur das/

Widerumb Wein wird hinein gossen/

Für ain Tropfen / nur zwey Maß;

Und ich hab sechs Untzen glassen/

So klöckt ja / ist leicht zu fassen/

Kaumb das Heidelberger Vaß.

14,6 klöckt] genügt, reicht 14,7 Heidelberger Vaß] berühmtes Riesenfass im Heidelberger Schloss 15,3 gsund] auf die Gesundheit

Den Aufruf zum hedonistischen Auskosten der arbeitsfreien Zeit und leiblichen Genüsse legt Maurus Lindemayr in Dort schier um sankt Jöring aui einem faulen Bauern in den Mund, der als komisches Gegenbild zu den therapierten Konventualen während der ,Lass-Tage ' Ende April herhalten musste. Die Realität sah freilich anders aus, konnte es sich doch kein Bauer der damaligen Zeit leisten, die betriebsame Frühlingszeit nicht zu nutzen und sich wie die geistlichen Herren den Tag mit Ergötzlichkeiten der Rekreation zu vertreiben.

1

Dort schier um sankt Jöring aui,

Wann dä Mayschein thuet eingehn,

Wenn dä Frühling kimmt da schau i,

Wies mächt in Kallena stehn:

Steht ä ganz reoths Köpfel drinä, geh i flux zum Badä hin;

Laß ä Schüssel Bluet herrinnä,

Bis i schier ohnmächti bin.

3

Ja wohl Säür, und schwarzi Brockä

Bädi Semmel mues i habn,

Nix da Knödl, Sterz und Nockä,

Fleisch und Brätel mues mi labn:

Thue beym össen starki Greistä

Trink än ötlä Bluzä Most,

Aften kemänd endli d'Geistä,

Was macht halt ä gueti Kost.
2

Aft thue i schön stät ausströckä,

In än Winkel alli Vier;

Das mi leichtlä Niemt kann wöckä, mach i d' Lien fürs Fenstä für.

Da thue i fein sacht auspfnausen

Schlaf dähin in Lust und Freud,

Lig ä so in Walln, und sausen,

Bis mä d' Gresch zum össen schreut.

4

Lusti is halt 's Aderlassen,

Da blagt ain kain Arbät nit,

Tröschen, mähn, und Mist auffassen,

Hat vo mir dort gueten Frid:

Trag 'n Arm fein in dä Schlingä

Thue schön güetlä umspaziehrn,

Ließ mi vo kain Doifel zwingä,

Daß i d' Trischel an sollt rührn.

70 Viertzig Rätzel in ain Nest. Und Ein Zuegab auch zulest. Dem Curiosen Leser für ein Frühlings=Lust verehrt. Zu finden bey Joseph Wolffgang Kriner / Buchhandler am Hällein / nächst Saltzburg / Anno 1721, S. $40-42$. 
5

Rain Söchs Wochä ghalt i 's Bäuschel,

D’ Adern is ä häiglichs Glid;

Trink all Tag än angnems Räuschel,

Däs mä käm mehr halt ä Trit:

Thue mi nöt stark übäzappeln,

Ranz mi rund ä guetiweil,

Bis $i$ aus 'n Böth thue grappeln,

Und vom Duchät auä greill.

7

Liebi Herrn Adäläßä,

Wünsch enk tausend Glück däzue;

Füllts mit Wein, und nöt mit Waßä,

Heut dö anzäpft Adern zue:

Wie dä Doktä's Bluet hat zschniten,

Hat iehm währlä d' Wahl weh thann,

Ainä doh hats Prae haimgriten.

Nenn ä nöt, ös kennts 'n schan. ${ }^{71}$
6

's Hächelleckä schmöckt 'n Budl,

Wie mir d'Arbät nah dä Läß,

Da haists widä Prein und Nudl,

Blendtn, Sterz, und anärs Gfräß:

Denk mär oft, und bstürz mi drüba,

Das alls wert ä kurzi Zeit,

Gueti Täg gehnt ä vorübä,

Ist halt alls än Eitelkeit.

1,1 sankt Jöring] Georgitag (23. April) 1,2 Mayschein] Neumond im Monat Mai eingehn] (hier:) beginnen, anfangen 1,5 Köpfel] günstige Aderlasstage waren mit roten Köpfen markiert 2,1 stät] still, ruhig, bewegungslos 2,4 Lien] Fensterbalken 2,5 auspfnausen] ruhig ausatmen, tiefe Atemzüge machen, besonders im Schlaf 2,8 Gresch] Kurzform für Margarete 3,1 Ja wohl] (hier ironische Verneinung) nein, kein Gedanke daran Säür] Sauersuppe aus saurer Milch, Mehl und Essig; Frühstück der bäuerlichen Bevölkerung 3,2 Bädi] gebäht, in der Pfanne geröstet 3,3 Sterz] gerösteter Teig aus Maisgrieß oder Buchweizenmehl 3,5 Greistä] Stöhnen, Ächzer 3,6 Bluzä] dickbauchiger Tonkrug 4,3 auffassen] auflegen, aufheben 4,8 Trischel] Dreschflegel 5,1 Rain] sicher, nicht anders, genau so 5,2 haiglichs] heikles 5,5 übäzappeln] überanstrengen, sich verausgaben 5,6 Ranz] recke, dehne 5,8 Duchät] Tuchent, Federbett auä greill] herauskrieche 6,1 Hächelleckä] Lecken an der Hechel (brettförmiges Arbeitsgerät mit Metallspitzen zum Reinigen des Flachses) 6,4 Blendtn] Buchweizen, Heidenkorn bzw. der daraus hergestellte Brei 7,7 Prä] Vorrang, Vortritt

Auf ein besonders merk- und denkwürdiges Ereignis bezieht sich ein ,sehr altes Lied von einer Bärenjagd', das uns zurzeit bedauerlicherweise nur über die Forschungsliteratur zugänglich ist. Deren einzige Vorlage ist einem handschriftlichen Altausseer Liederbuch von 1855 entnommen und soll vom Großvater des Schreibers überliefert worden sein. ${ }^{72}$ Die Entstehungszeit von Juheisa viktoria, guete Zeitung kommt an lässt sich über Umwege erschließen. Denn das „derbe[] Spottgedicht auf einen erlegten Bären in der Form einer ironischen Begräbnisbeschreibung ${ }^{\text {" } 73}$ bringt genügend Hinweise auf Handlungsort und beteiligte Personen, um es einem konkreten Ereignis zuzuordnen, von dem u. a. auch in der Linzerischen Freitags ordinari Zeitung berichtet wird. Ein Bär habe über 18 Jahre im Gebiet zwischen Attersee und Mondsee „dem Publico einen unbeschreiblichen Schaden zugefüget“, ohne dass man seiner habhaft werden konnte. Am 14. Mai 1778 aber „war endlich jener beglückte Tag, an welchem dieses Raubtier von den hiesigen Bürgjägerssöhnen, Martin und Mathias Flachberger, an dem Steinbacher Gebirge erschlichen, und nach 6 in dessen Balg hineingejagten Kugeln, auf die Haut

71 Lindemayr, Dialektlieder I, S. 36-38.

72 Vgl. Hans Commenda: Bärenbegräbnis. Ein alter Jägerbrauch aus dem Salzkammergut. In: Oberösterreichische Heimatblätter 2 (1948), H. 3, S. 267-272, hier 268. - Karl M. Klier: Eine Bärenjagd. In: Heimatgaue 5 (1924), S. 141-144, hier 143.

73 Ebda. 
gelegt worden ist" ${ }^{74}$ Nicht lange danach wird auch das literarisch auffällig unbeholfene, doch brauchtumsgeschichtlich umso interessantere Lied entstanden sein. Der Jagderfolg selbst wird vom Erzähler nur kurz gestreift, um rasch auf das eigentliche Thema zu kommen:

3

O mein Bue, das Bärenjagen ist alles schon vorbey,

Dö Stainbacha Jaga hambt g'schossn eahna drey,

Sö hambt ihm umbs Löbn bracht, das will ich dir wohl sagn,

Jetzt führend ihn ahi auf Camma, dort toans ihn halt begrabn.

3,4 ahi auf Camma] runter nach Kammer (Ort am Attersee, damals Khevenhüllerische Herrschaft)

Nach einem Überblick, wer den Bären an seinen Bestimmungsort transportieren darf, wird über die Beschreibung der Beteiligten das feierliche Begräbnis mit Kreuz- und Fahnenträger, Totenliedsängern und Bläsern, Sarg, Bahrtuch und Windlichtern, mit fingierter geistlicher Begleitung und angeblich 400 Bärenschützen gleichsam performativ inszeniert. Bei der Totenzehrung wird der letzte Wille des erlegten Räubers verkündet, dann die Grabverzierung in die Wege geleitet, bevor die Schützen mit freiem Umtrunk belohnt werden. Weit über ein Dutzend namentlich genannter und über Anekdoten oder Aussehen charakterisierter Teilnehmer unterstreichen den Volksfesteindruck und lassen ein sehr lebendiges Bild des Klamauks entstehen:

6

Jetzt hab i dö vier Trager, i muaß no a zween habn,

Das Kreuz muaß der Lambach See Jagaknecht tragn,

Oen Fahn tragt der Stöffl, er kann eahms schon toan,

Der Lambach See Jagaknecht, der war ihm viel z' kloan.

7

Jetzt gehn ma noch a zween Singabuam a,

I waiß nit amal, wo i hin sollt gehn darna,

Da Forstmoasta hat ain, und dem Goisara sein Knecht

Dö zween muaß i nehma, sand justament recht.

8

Dö ortnerischen Jagaknecht, und Stumma all zween,

Dö kinnand mitananda nachn Fahn nachi gehn,

Posaun müssens blasen, den Prim und Sekund,

Hiezt bist amal g'schossen, du zoterter Hund.

9

Der Schloßa und der Stierndl Schneida, und noch zween sand eingl'aden,

Der Reisenbichler und der Fellner Wirt, dö toant d'Windlichter tragn.

Der Herr Lehrer muaß Schulmoaster seyn, er kann lateinisch röden,

Der Amtmann ist der Ebenseewirt, der richt sich schon zum Spörn.

74 Zitiert nach ebda., S. 141. Klier gibt zudem ein Ölbild aus Weißenbach wieder, das den Bären beim Wildern mit der Inschrift zeigt: „Das Wild hat bei 20 Jahren in hiesiger Umgebung gehaust und durch Reißen des Hornvieh um viele tausend Gulden Schaden zugefügt. Anno 1778 ist es von den Birgsjägersöhnen Martin und Matthias Stachberger in Aurwald beim Aurikar durch 5 Kugelschüsse erlegt und die Gemeinde von diesem befreit worden. Hat eine starke Wiener Klafter in der Länge und 3 Schuh in der Höhe und 5 Zentner 25 Pfund gewogen“ (ebda., S. 144f.). Commendas Abschrift (Bärenbegräbnis, S. 267) unterscheidet sich zum Teil beträchtlich. 
10

Den Sigmund Stüger muaß i a no was sagn,

Voran hilft er dem Fellnerwirt den Uibertan tragn.

Den Weigglhoffern ihr Knecht, den Lippl nach der Traun,

Dö kinnand ihm hinten in das rauch Loch nachi schaun.

11

Der Lambachsee Jager ist gar a kloaner Mann,

Der tragt ihm das Rauchfassel, den zwingt er leicht an,

Der Weißenbach Jager hat die Mößner Stell,

Der Stummä mueß Pfaff seyn, mag seyn, was er will.

12

Er nimmt anstatt an Wedl an Kühschwaif in d'Händ,

Und tuet ihm so einspritzn zu seyn letzten End,

Weil er in seyn Leben dö Kühschweif gern ghabt,

So hat er a dadurch den Garaus daschnappt.

13

Bärenschützen, was die andern sand, toant hinten nachi gehn,

Seynd vierhundert an der Zahl, der Grabgang wird gar schön,

Oes wird zum Eßn und Trinka wern, tue sich nur Koana wehrn,

Der Ramb-Lipplmann sticht Katz ab, wirds Bratl gnueg abgeben.

14

Der Traunkircha Bräu hats Bier herg'richt, ös wern drey Eima seyn,

Der Hofwirt gibt her Kas und Brot, aufn Tisch a Kandl Wein.

Der Gartner gibt her häufig Rättich und dazu Salat,

Daß a jeder Schütz zum Mudlbratl noch a Zuspeis hat.

15

Da Hofmaura hat zu mir erst g'sagt, er tat ihm's nit versagn,

Er hat dem Bärn die Ehr antan und tat'n guat vergrabn,

Zum Singa hat er a koa Stimm, das weiß ma schon vorher,

Es liefn d' Schütz'n all davon, tat gröber als der Bär.

16

Der Bär laßt bitten um Vergeben im Land jetzund bey all'n,

Dö vor lauter Zaghaftigkeit über Stöck und Stein seyn g'falln,

Er laßt ihn sagn a guatö Nacht, Goraschi zu ihn' Stand,

Er sagt, es g'freut 'n nix als das, daß d'Hüt hint lassen hambt.

17

Da Bär hat recht von Herzen g'lacht, a Jahr vor seinem End,

Daß Wallfahrta und der Bader Franz so g'schwind davon sand g'rennt,

Hambt an moderign Stock von weiten gsehn, hambt ihn für'n Bärn ang'schaut.

Hambt Ebenseer Schützen auffö müssen, hätten ihn’ sinst nit hoamb traut.

18

Da Renna und der Ziller hambt zu mir g'sagt: Bua, laß gehn,

Hietzt geht ins no da Grabstein ab, an den lassn's mir nit stehn;

Da Renna sagt: er haut'n ihm zua, da Zilla macht dö Schrift,

Da Hoffschmied hat das eisna Kreuz schon auf dem Stain herg'richt.

19

Hietzt wern dö Bauern recht lustög seyn und sagn viel tausend Dank,

Und gebn den', dö ön Bärn daschossn hambt, viel Kreuzer zu an G’schank,

Vivat! es soll da Jaga löben, Vivat! schreyts all mit mir,

Und der das Lied jetzt g'sunga hat Bezahlts brav Kas und Bier. ${ }^{75}$

75 Zitiert nach Klier, Eine Bärenjagd, S. 141-143. 
6,3 Oen] den (zu ,der Fahn') 7,1 Singabuam] Sängerknaben 8,4 zoterter] mit langen Haaren, dichtem Fell 9,2 toant] tun 9,4 Spörn] Sperren: nach Todesfall verhängte Sperre der Erbmasse 10,2 Uibertan] Bahrtuch 12,1 Wedl] Aspergill, Weihwassersprenger 12,4 daschnappt] erwischt 14,4 Mudlbratl] Mürbbraten (aus mit Gewürzen und Salz gebeiztem, geräuchertem Fleisch) 16,3 Goraschi] (franz. courage) Mut 17,4 auffö] hinauf hoamb] heim

Der ironische Grundtton des Lieds lässt unklar, ob sich das Lied auf ein tatsächlich in dieser Weise zelebriertes Ereignis bezieht oder dieses nur zur Erheiterung der Zuhörerschaft imaginiert. Zwar sind rituelle Begräbnisse von Bären in der volkskundlichen Forschung seit dem Neolithikum nachgewiesen. Für Commendas Annahme, dass es sich um einen „alten Jägerbrauch aus dem Salzkammergut “ ${ }^{\text {“7 }}$ handle, gibt es jedoch nur wenige Belege, so etwa eine Briefstelle zu einer Bärenstrecke von 1837, in der von einem „Totenmahl des Bären“ ${ }^{77}$ die Rede ist. Ob sich daraus ein kontinuierliches Brauchtum ableiten lässt, sei dahingestellt.

\section{Freizeitdichtung}

Nicht konkrete Anlässe oder Ereignisse, sondern das gesellige Beisammensein an sich und die zwanglose Unterhaltung sind der produktive und performative Kontext für Freizeitdichtungen aller Art, die uns als Trink-, Gemeinschafts- oder Werbelieder, als Begleittexte für Tanzformen, Spiele oder Geschicklichkeitsbewerbe oder aber auch als umfangreichere dramatische Arbeiten überliefert sind. Beim vergnügten Miteinander im Freundes- oder Familienkreis ist die Verwendung des Dialekts nur allzu naheliegend - auch wenn dies in der Verschriftung oftmals nicht zu Tage tritt. Eine geradezu für den regiolektalen Vortrag prädestinierte Textgattung wie der Witz etwa zeigt in den verfügbaren handschriftlichen Quellen überraschenderweise nur sehr zurückhaltende Spuren konzeptioneller Mündlichkeit. Die Witze in der zwischen 1700 und 1729 angelegten, heute leider verschollenen siebenbändigen Sammelhandschrift Olla potrida des Linzer Juristen Johann Carl Seyringer (den wir als stolzen Vater schon kennengelernt haben) weisen - soweit dies Gugenbauers Auszügen zu entnehmen ist $-{ }^{78}$ nur zarte Spuren dialektaler Mündlichkeit auf, so etwa in den folgenden beiden Beispielen:

32

Es schickte ein Bauer dem Pfarrer durch seine Tochter eine Schlachtschissel. Als sich nun der Pfarrer deretwegen höflichst bedankte mit Vermelden, es wär gar zu viel, gab ihm das Mädl zur Antwort: Ja, es hats mei Muetter wohl auch gsagt, es wär zuviel, es hat ihr aber der Vater zur Antwort geben: Ja, wohl zuviel; wer weiß wann wir etwa des Schelmen von Nöten haben.

76 Commenda, Bärenbegräbnis, S. 267.

77 Zitiert nach Klier, Eine Bärenjagd, S. 143.

78 Vgl. Gustav Gugenbauer: Linzer Witz vor 200 Jahren. Aus den Sammlungen von Johann Carl Seyringer. In: Heimatgaue 12 (1931), S. 69-83, 158-173. - Gustav Gugenbauer: Linzer Witz vor 200 Jahren. In: Heimatgaue 16 (1935), S. 68-78. Zum Verbleib der Bände vgl. Gernot Barnreiter: Johann Carl Seyringer. Leben und Wirken eines frühneuzeitlichen Rechtsgelehrten. Wien 2012. [Dipl.], S. 22, Fn. 72. 
36

Als ein Mutter hörte, wie der Präceptor ihrem Sohn einen wohlverdienten Schilling gab, lief sie mit feimendem Maul voll des Zorns hinzu und sprach: Hui, Trescher!, wie gibts Treschen aus? Antwort: Frau, gar schlecht, lauter Stroh, lauter Stroh, kein Traid!

Ja, wohl zuviel] (ironische Verneinung) keine Rede von zu viel Präceptor] Schulmeister Schilling] (hier) Prügel feimendem] schäumendem Traid] Getreide

Man geht sicher nicht fehl in der Annahme, dass zumindest die direkten Reden im Vortrag wesentlich mundartlicher klangen. Konserviert wurde die mündlichkeitsnahe Vortragsdimension solcher Juxe am ehesten noch in der Verbindung mit Musik.

\section{Trink- und Gesellschaftslieder}

Wie nahe so mancher Trinkliedtext am authentischen Ausdruck blieb, illustriert eine Anekdote, die der spätere Hofkapellmeister Joseph Eybler (1765-1846) auf die letzte Notenzeile seiner heute vielleicht populärsten Komposition notierte: „Als Michael Haydn und ich an einem heissen Sommerabend spatziren giengen, hörten wir beym rothen Turm von einem betrunkenen Bauer gegenwärtiges Liedchen singen, worauf er mich einen Canon zu machen animirte; dieß die Veranlassung dazu. “79 Das künstlerische Ergebnis dieses Vorsatzes von 1798 war ein 6-stimmiges Musikstück auf die wenig tiefsinnigen Worte:

Wann i a Räuscherl hab, ist ma sauwohl, wann i a Räuscherl hab ist ma sauwohl, Ey wie ist mir sauwohl wann i a Räuscherl hab, sauwohl, sauwohl, Dudl dudl dudl du, dudl du, dudl dudl dudl du, dudl du, wann i a Räuscherl hab, ist ma sauwohl. ${ }^{80}$

Natürlich ist hier ein gewisser Grad der Stilisierung in Rechnung zu stellen, schon allein durch die topische Figur des ,betrunkenen Bauern; zudem waren Eybler und Michael Haydn selbst für ihre Trinkfreudigkeit bekannt. Doch kann wohl angenommen werden, dass tatsächlich zahlreiche ähnlich simple Trinkliedchen im Volksgesang kursierten. Lediglich den Text von mehreren volkstümlichen Trinkliedern überliefert uns Zaupser in seinem Wörterbuch:

XIV

Trinklied.

O du lieba Gerstensaft,

Gibst mein gliedern so viel Kraft!

Fall i s'Tags wohl neunmal nieda:

Steh ollemal auf, und sauf glei wieda.
XV

Noch ein Trinklied.

Jetzt hob i no drey Kreuza, ghörn mein und dein,

Drah di Waberl, drah di, versuffa müeßens seyn!

79 Österreichische Nationalbibliothek, Musiksammlung, Mus.Hs.16599, f. 2v.

80 Ebda. 
XVI

Noch eines.

Sauf, Brüederl, sauf,

Da Thala geht schon drauf.

Bald kummt die heili Magdalena,

Bringt an Sack von Siebazehna.

Sauf, Brüederl, sauf,

Da Thala geht no drauf.
XVII

Noch ein Trinklied.

Vor da Mittanocht geh i nöt hoam:

Wos macht dös braun Bier für an Foam!

Vor da Mittanacht geh i nöt weck,

Weil mir dös braun Bier so wohl schmeckt. ${ }^{81}$

15,2 Drah di Waberl] dreh dich, Waberl (Kurzform für Barbara) 16,3 heili Magdalena] Fest der Hl. Maria Magdalena am 22. Juli 16,4 Siebazehna] Siebzehn-Kreuzer-Stücke (ab 1750 nach dem Konventionsfuß zu 120 Kreuzern) 17,2 Foam] Schaum

Zwar ist anzunehmen, dass Zaupser die Nr. 16 nach der Melodie von Schlaf, Kindlein, schlaf (vielleicht schon in der Fassung von Johann Friedrich Reichardt von 1781) kennengelernt hatte. Notiert aber wurden diese Trinklieder zu dieser Zeit zumeist nur in musikalischen Erweiterungen, in denen volkstümliche Elemente (wie etwa die Jodlerbestandteile in Eyblers Kanon) erhalten blieben. ${ }^{82}$

Vielleicht war auch das offensichtlich einige Jahrzehnte zuvor entstandene witzige Quartett Gehn mä haimb odä nit, das als Terzett mit Kontrabassbegleitung bereits im thematischen Musikalienkatalog des Lambacher Stiftsorganisten Anton Obermayr von 1768 verzeichnet ist, ${ }^{83}$ von einem volksmusikalischen Vorbild inspiriert; die simple Melodie der Führungsstimme spricht zumindest nicht dagegen. In diesem Trinklied (das in einer späteren Terzett-Fassung Michael Haydn zugeschrieben ist) ${ }^{84}$ versichern sich die illuminierten Gäste gegenseitig, warum so gar nichts für das Heimgehen spricht:

Gehn mä haimb odä nit

Nä nä nä nä heunt nit

Bleimä da oda nit?

ja ja heunt bleima da.

Waß seyn ma denn da haimb Nutz?

Niemand nix thuet geben

allerley zu essen guet,

da ist guet zu leben,

da gebns bratn zu sauffen her,

sant gar hüpsche Leute

d'gläßl stehn da niemals leer,

ja da bleibma heute

ha ha, wir bleim ja da,

ha ha, ha ha, ha ha, ha ha,

wir bleim ja da, wir bleim ja da.

81 Zaupser, Versuch eines baierischen und oberpfälzischen Idiotikons, S. 100f.

82 Vgl. Leopold Nowak: Ein Bauernkanon von Joseph Eybler. In: Jahrbuch des österreichischen Volksliedwerkes 8 (1959), S. 10-12.

83 Anton Obermayr: Catalogus musicalium et instrumentorum ad chorum Lambacensem pertinentium. The Lambach thematic catalogue (1768) Facsim. ed. / with annotations and commentary by Charles H. Sherman. Hillsdale, NY: Pendragon 2002, S. 223, Nr. 1527. Das hier bezeichnete Notenmaterial „â 3 Vocj é Basso" ist verschollen; das bei Obermayr verzeichnete musikalische Incipit weicht auffällig ab und scheint keine der Singstimmen wiederzugeben.

84 Vgl. Schweizerische Nationalbibliothek, Literaturarchiv, MLHs 126/6/2. 
Wir wolln die deutsche Treu

hier suechen keck und frey

wan ma glei hiez haim thain gehn,

kema spat noch Hause,

bitten wir um Herberg schön,

da bey guetten Schmause,

ha ha, wir bleim ja da,

hier ist ja guet zu sein

weil uns die deutsche Treu

mit ihrer Lieb und Gunst

giebt alles her umsunst,

I sag engs rund und köck

heunt geh i woll nit wöck

wir gehn wohl ja kein Tritt,

denn schon der Abend wird,

so bleima alle da

ja ja, ja ja, wir bleim ja da,

ja ja, ja ja, wir bleim ja da,

und wollen lustig seyn,

trinkä ä glaßl Wein,

der Wein is guet,

macht frischen Mueth

schenkts ein, schenkts ein,

schenkts ein, schenkts ein. ${ }^{85}$

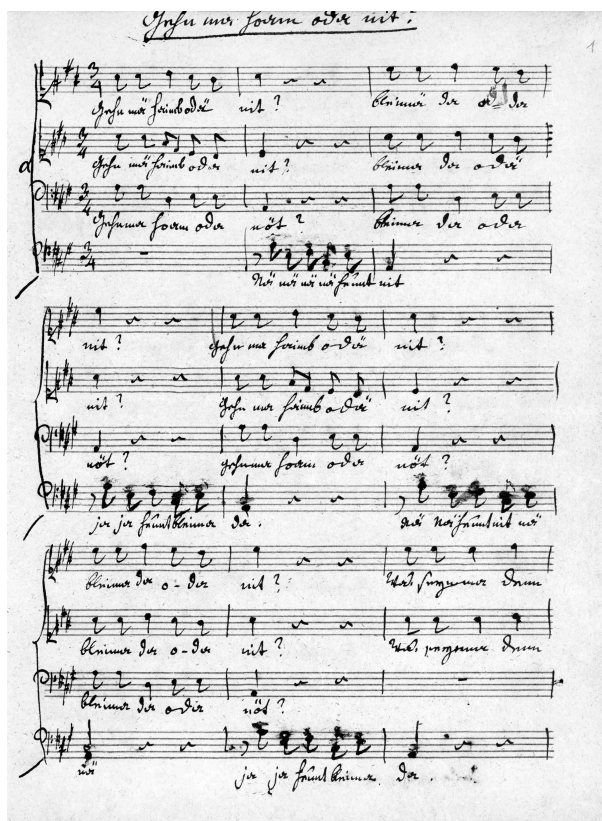

Abb. 37: Quartett Gehn mä haimb odä nit (Österreichische Nationalbibliothek, Musiksammlung, Mus.Hs. 18989, f. 1r).

Besonders witzig wirkt der Wechsel vom Pathos des deutschen Treueklischees, das natürlich im Standard beschworen wird, zum hedonistischen dialektalen Scheinargument.

85 Österreichische Nationalbibliothek, Musiksammlung, Mus.Hs. 18989f. 1r-4v. 
Gefinkelte Argumentationen für die bacchantischen Leidenschaften, wie man sie in anakreontischen Liedern der Zeit oder später etwa in diversen Kommersliedern finden kann, sucht man hier vergeblich. Im Mittelpunkt dieser Dialekttrinklieder steht zumeist der versoffene Landmann, der triebhaft seinen Gelüsten ausgeliefert ist, wie im textuell wenig inspirierten, aber umso sangbareren Kanon des St. Florianer Chorherrn Franz Joseph Aumann:

Brudä, dä Tiofel holl mi, thut mi heut so stark dürst'n.

Sauf bräv, so wird dih nimmä dürst'n.

Holl mi dä Tiofl Brudä

thut mih heut so stark dürsten;

Sauf Brudä sauf brav, so wird di nimmä dürst’n. ${ }^{86}$

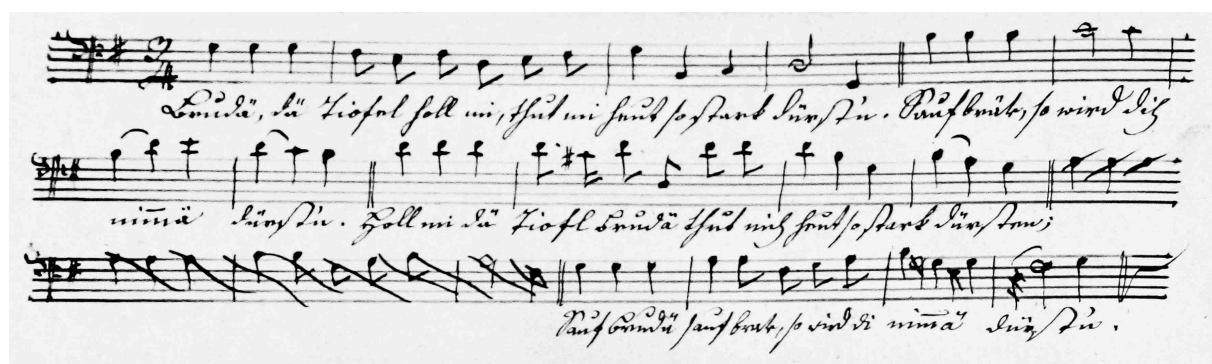

Abb. 38: Franz Joseph Aumann: Brudä, dä Tiofel holl mi (Musikarchiv Stift Kremsmünster, G 44/755).

Ähnliche Typen finden sich in den Liedern Marcellinus Sturms, etwa in seinem Lumpenlied Kellnerin bring z'saufa!, in dem das trinkfreudige Ich seinen problematischen Stammbaum präsentiert, der trotz oder vielmehr gerade wegen der exzessiven Flüssigkeitszufuhr beinahe vollständig verdorrt ist. Die im heiteren Ton vorgetragenen abschreckenden Beispiele aus der Familiengeschichte hindern freilich den fröhlichen Zecher nicht daran, dem Alkohol weiterhin zuzusprechen - mehr noch: selbst nach dem Ableben wünscht er sich in dessen nächste Nähe:

1

Kellnerin bring z'saufa!

Heut hab i n'Durst z'samm g'spart,

Lauf, was kannst laufa,

Eh' d'Leber ganz daharrt.

O Schatzerl so kumm!

Der Durst bringt mi um, -

$\mathrm{Ha}$, s'Teuxel! s'Bier ist guet,

Kauf mir no koan neua Huet.

Chor. Ha s'Teuxels! s'Bier ist guet,

Kauf mir no koan neua Huet.

[...]
4

Mein schöna Stammabaum

Ist ganz vor Hitz ausdorrt,

Dem Tod entrinn i kaum,

Außer i gieß ewig fort -

Bis früh oder spät

Der Zieglstoan z'geht,

Drum frisch wieder eing'schenkt,

Oder Kellnerin aufg'hängt -

Chor. Drum frisch wieder etc.

86 Musikarchiv Stift Kremsmünster, G 44/755 (Abschrift Ernest Frauenbergers mit fehlerhafter Namensnennung). Erstmals ediert bei Dormann, Franz Joseph Aumann, S. 407. 
6

Tröst Gott mein Urahnherrn,

Den hat um Mitternacht

Der Durst, sein Unstern,

Hart neben dem Zapfen umbracht.

Ihm machten zwölf Maaß

Kaum s'Zapfl recht naß,

s'Mein wird a nöt leicht

Mit sechsen ang'feucht.

Chor. s'Mein wird etc.

8

Sein rothe Lisl

War so ausg'selcht und dürr,

Wie an Ochsenfisl,

s'Gießen half nichts an ihr -

Erquick sie, o Herr,

In deinem Reich mehr;

Denn der Durst ist a Pein!

Ach Schatzerl! schenk ein.

Chor. Denn der Durst etc.

10

Mein Mueda (a kreuzbravs Wei)

Wie halt a Wei sein sollt,

hat sich den Brandwein glei

In größten Maßkrügn g'holt.

Dieß ist a (teutsch z'redn)

Ihre letzte Oelung g'wedn.

s'Braun Bier wird die mein,

Ehs g'storbn muß sein.

Chor. s'Braun Bier etc.

[...]
7

N' durstigen Maxen,

Mein Oedel, (dös denk i noh)

Sein Binsen g'wachsen,

So voll goß er sich o;

Ist denna vodorbn,

Am Lungabrand g'storbn.

A Rausch ist mir lieba

Als a hitzigs Fieba.

Chor. A Rausch etc.

9

Meins Vodans früher Tod

War s'hitzi Temperament,

d'Wirthsleut hättn sich (woaß Gott)

d'Füß aus'n A- bald g'rennt;

Er hat vor seim End

Vor Durst Niemd mehr kennt.

$\mathrm{O}$ i fürcht a recht sehr

Dieß schreckli Malör.

Chor. O i fürcht etc.

17

Sollt i auf dieser Welt

Wirklich austrunka hobn,

Thuets mi um 's übri Geld

In Merzenkeller grobn.

Wohl unter a Bierfaß

Lieg i allweil schön naß;

Ja unter a Bierfaß

Lieg i allweil schön naß.

Chor. Ja unter etc. ${ }^{87}$

1,4 daharrt] endgültig hart wird 1,7 s'Teuxel] des Teufels 6,4 Zapfen] Zapfenstreich (hier im Spiel mit der ursprünglichen Bedeutung des ,Streichs auf den Zapfen' als Zeichen der beendigten Ausschank) 6,6 Zapfl] Gaumenzäpfchen 7,2 Oedel] Großvater 8,3 Ochsenfisl] Ochsenziemer 17,4 Merzenkeller] Keller für untergäriges Vollbier

Das Grab unterm Fass besingt auch der angeheiterte Jucundinus in einem deutschlateinischen Lazarusspiel Theophil von Dückerns, das 1752 von den Kremsmünsterer Ritterakademikern zwar während der Fastenzeit aufgeführt wurde, dennoch aber zahlreiche komische Szenen enthält:

i laß mi in Kellä eingrabn,

so kan i mi immä zue lab’n,

denn unter Bier Vaß

isß alliweil naß,

da schmeckts mä je lenger, je baß. ${ }^{88}$

Gut möglich, dass Dückern mit dieser limerickähnlichen Strophe ein gängiges Volkslied verarbeitete.

87 Sturm, Lieder zum Theil in baierischer Mundart, S. $115 \mathrm{ff}$.

88 Stiftsbibliothek Kremsmünster, Ccn 1387 (Beata Lazari \& infausta Epulonis Mors, Tragœdia), f. 2v. 
Von den gängigen Freizeitbelustigungen in der Residenzstadt zeugen heute noch Wolfgang Amadeus Mozarts (1756-1791) berühmte Kanons. Gleich drei der größten Attraktionen bringen die beiden mit 2. September 1788 datierten vierstimmigen Kanons KV 556 und 558 ins Spiel: den Prater, ein seit 1766 sich stetig entwickelnder Vergnügungspark mit seinen drei Jahre zuvor eröffneten beliebten Kaffeehäusern an der Hauptallee, das 1755 von Carl Defraine errichtete hölzerne Amphitheater mit seinen Raubtierhatzen und den von Johann La Roche verkörperten Kasperl am Leopoldstädter Theater. Im dialogisch gestalteten Grechtelt's enk treffen Vorfreude auf den Ausflug in die Vorstadt auf Missmut und Verweigerung:

Grechtelt's enk, grechtelt's enk,

wir gehn im Prater.

Im Prater? im Prater?

izt laß nach,

i laß mi net stimma.

Ei beileib. Ei jawohl,

mi bringst nöt aussi:

was blauscht der? was blauscht der? -

izt halt's Maul!

I gib' d'r a Tetschen. ${ }^{89}$

1 Grechtelt's enk] richtet euch zusammen, macht euch fertig 4 laß nach] gibt Ruh 5 stimma] überstimmen, überreden 6 Ei beileib] und ob 7 aussi] hinaus 8 blauscht der] redet er daher 10 Tetschen] Ohrfeige

Gründe für seine Verweigerungshaltung reicht der Spielverderber im zweiten Kanon Gehn wir im Prater nach (der in späteren Fassungen deutlich dialektaler transkribiert ist als im Autograph):

Gehn wir im Prater, gehn wir in d'Hetz, gehn wir zum Kasperl, zum Kasperl, zum Kasperl.

Der Kasperl ist krank,

der Bär ist verreckt,

was tät' ma in der Hetz drauß, in der Hetz drauß?

Im Prater gibt's Gelsen

und Haufen voll Dreck,

im Prater, im Prater gibt's Dreck. ${ }^{90}$

6 ma] wir 7 Gelsen] Mücken 8 Dreck] Kot, Exkremente

Die Texte dieser vor allem für den engeren Freundeskreis gedachten musikalischen Späße stammen wohl sämtlich von Mozart selbst. Deutlich wird dies vor allem bei seinen multilingualen Arbeiten, allen voran natürlich sein vielleicht berühmtester Kanon Bona nox! bist a rechta Ox (KV 561), der in der derben Originalfassung („scheiß ins Bett daß' kracht; gute Nacht, schlaf fei g'sund und reck' den Arsch zum Mund“"91) dialektale und standarddeutsche Elemente mit Brocken aus Latein, Französisch, Italienisch und Englisch mischt. Ähnliches gilt für das fragmentarische Quartett Caro mio

89 Wolfgang Amadeus Mozart: Neue Ausgabe sämtlicher Werke. Serie III: Lieder, mehrstimmige Gesänge, Kanons. Werkgruppe 10: Kanons. Vorgelegt von Albert Dunning. Kassel [u. a.]: Bärenreiter 1974, S. 38.

90 Ebda., S. 43.

91 Ebda., S. 62. 
Druck und Schluck (KV 571a), ein weitgehend sinnfreies, beinah dadaistisch anmutendes Mischmasch aus italienischen, deutschen und salzburgisch-dialektalen Wendungen und Satzteilen, deren klangliche Nuancen auf komische Wirkung abzielen. Zur Illustration daraus die Rolle, die sich Mozart selbst zugedacht hat:

Cara mia bagatellerl, cara mia bagatellerl, io parto, tu resti, Spitzignas, oh Dio! tu resti, Spitzignas, Che pena! che tormento! wenn's regn't, ist's naß. Quello l'adira, wir können nix dafüra, wir können nix dafüra, cara Cobochti! pietà, pietà, es ist schon achti, un pò di carità, sonst machen ma... ${ }^{92}$

Das Quartett war - wie schon Constanze Mozart meinte - ein Pendant zum in Mozarts Freundeskreis besonders geschätzten Bandel-Terzett. Diese „typisch wienerische Miniaturposse ${ }^{\text {"93 }}$ entstand aus einer Alltagssituation heraus und gewann ihren Reiz wie schon das Inhaltsverzeichnis der Oeuvres complettes (1799) hervorhob - durch die bewusste Akzentuierung der Nähesprachlichkeit:

Mozart vermisste einst, als er sich sehr schnell ankleiden wollte, ein gewisses Band, und rief daher seiner Gattin aus einem Wiener Volksliede im gemeinsten Dialekte zu: Wo ist's Bandel? Sie antwortete sogleich aus demselben Lied: Drinn im Zimmer u.s.w. Dies gab ihnen und einem Freunde [Gottfried von Jacquin], der dazu kam, Veranlassung zu einer Schäkerey, und Mozart sezte sich und schrieb für sich, seine Konstanze und jenen Freund dieses Terzett, das, wenn es seine komische Wirkung gehörig thun soll, im gemeinsten Wiener Dialekte gesungen werden muß, den Mozart persiflieren wollte und ihn deshalb so herausgehoben hat. ${ }^{94}$

Auch hier also gibt ein Volkslied, im gemeinsten Dialekt' den Impuls für eine großartige Komposition der Elitekunst. Ob dabei tatsächlich der Dialekt selbst persifliert werden sollte, darf zumindest angezweifelt werden, weiß man doch um die Vorliebe des „Musikwie Sprachgenies Wolfgang Amadé “95, Sprachmaterial mit all seinen sozio- und regiolektalen Färbungen für eine ungemein lebensnahe, spielerisch-kreative Schreibweise auszureizen. Es ist vielmehr die herausgestellte Diskrepanz zum Normativen, die er hier (ebenso wie etwa in seinen Briefen an das Bäsle) ${ }^{96}$ für komische, charakterisierende oder

92 Mozart, Neue Ausgabe sämtlicher Werke III, Werkgruppe 9, S. 64-66.

93 Ebda., S. IX.

94 Ebda.

95 Luc de Grauwe: Wolfgang Amadé Mozart. In: D. Alan Cruse [u. a.]: Lexikologie/Lexicology. Ein internationales Handbuch zur Natur und Struktur von Wörtern und Wortschätzen. 2. Halbbd. Berlin/New York: de Gruyter 2005. (HSK 21.2) S. 1524-26, hier 1524. - Zur Sprache Mozarts vgl. auch Luc de Grauwe: Sie sehen also, daß ich schreiben kann wie ich will. W. A. Mozart. In: Studia Germanica Gandensia (NF) 24 (1996), H. 1, S. 223-243. - Ingo Reiffenstein: Sprachvariation in den Briefen der Familie Mozart. In: Klaus Mattheier [u. a.] (Hg.): Vielfalt des Deutschen. Festschrift für Werner Besch. Frankfurt a. M. [u. a.]: Lang 1993, S. 361-381.

96 Vgl. Joseph Heinz Eibl/Walter Senn: Mozarts Bäsle-Briefe. Kassel [u. a.]: Bärenreiter 1978. 
auch provokative Wirkeffekte zu nützen weiß. Die - wie Polenz meint - „postnormative, intellektuelle Reaktion auf bereits etablierte und routinierte Sprachnormen “ ${ }^{\text {97 }}$ impliziert demnach keinerlei Abwertung des, unmodernen' Mundartlichen, sondern unterminiert die Allgemeingültigkeit des Regelhaften - der Sprache ebenso wie der sozialen Konventionen, wie nicht zuletzt seine (mit der Familie und seinen Freunden geteilte) Freude an koprolalischer und sexueller Komik zeigt (vgl. Kap. 7). Im um 1786 komponierten Bandel-Terzett ist neben dem Ehepaar Mozart (Sopran und Tenor) noch der Freund des Hauses Gottfried von Jacquin als Bass verewigt, der sich in das häusliche Liebesgezänk einmischt: ${ }^{98}$

Constanze. Liebes Manndel, wo ist's Bandel?

Mozart. Drin im Zimmer glänzt's mit Schimmer.

Constanze. Zind' du mir, zind' du mir!

Mozart. Ja, ja, ja, ja, ich bin schon hier und bin schon da.

JACQUIN. Ei was Teufel tun die suchen, ein Stück Brodel? - od'r ein' Kuchen?

Mozart. Hast es schon?

Constanze. Ja - an Dreck!

Mozart. Nu, nu, nu, nu, nu, nu, nu, nu! $\mathrm{Nu}, \mathrm{nu}, \mathrm{nu}, \mathrm{nu}, \mathrm{nu}, \mathrm{nu}, \mathrm{nu}, \mathrm{nu}$ !

JACQUIN. Das ist zu keck! das ist zu keck! Liebe Leuteln, darf ich's wagen, was ihr sucht euch zu befragen?

Constanze/Mozart. Schmecks! Schmecks!

JACQUin. Ei pfui! ei pfui! Ich bin so'n gutherzig's Dingerl, könnt's mi umwinden um a Fingerl!

Constanze / Mozart. Itzt geh! itzt geh!

JACQUin. A nöt! A nöt!

Schaut's, ich wett, ich kann euch diena, denn ich bin a geborner Wiena.

Constanze / Mozart. Unser Landsmann, unser Landsmann? Ja, dem muß ma nichts verhehlen, sondern alles klar erzählen.

JACQuin. Ha, ha, ha, ha, ha!

Ja, das glaub ich!

$\mathrm{Nu}$ - laßt einmal hören!

Ei verflucht, laßt einmal hören

Constanze / Mozart. Nur Geduld - nur Geduld!

JACQUIN. ... od'r ihr könnt euch alle zwei zum Teufel scheren!

Constanze / Mozart. Guter Lapas, wir suchen's schöne Bandel.

97 Peter Polenz: Deutsche Sprachgeschichte vom Spätmittelalter bis zur Gegenwart. Bd. II: 17. und 18. Jahrhundert. Berlin/New York: de Gruyter 1993, S. 206.

98 Zur Neudatierung des Terzetts vgl. Wolfgang Amadeus Mozart: Kritische Berichte. Serie III: Lieder, Mehrstimmige Gesänge, Kanons. Werkgruppe 9: Mehrstimmige Gesänge (C.G. Stellan Mörner). Vorgelegt von Holger M. Stüwe. Kassel [u. a.]: Bärenreiter 2007, S. a/9. 
JACQUIN. 's Bandel? Hm!

$\mathrm{Nu}$, da hab ich's ja in mei'm Handel!

Constanze / Mozart. Lieber Jung,

JACQUIN. Halt's die Zung'!

Constanze/Mozart. aus Dankbarkeit

JACQUIN. ich hab nicht Zeit,

Constanze/Mozart. werd' ich dich lieben allezeit!

JACQUIN. es ist schon spät,

ich muß noch weit!

Constanze/Mozart/Jacquin. Welche Wonne, edle Sonne,

z'leb'n in caritatis camera,

und das schöne Bandl hamera,

ja, wir habn's, wir habn's, ja! ${ }^{99}$

1 Manndel] Männchen, Mann Bandel] Bändchen, Band 5 Zind'] leuchte 9 Brodel] Scherzdiminutiv zu Brot 17 Schmecks!] Komm doch selbst drauf! 34 Lapas] Scherzbildung zu ,Lapp؛ naiver Mensch 45 in caritatis camera] (lat.) im Zimmer der Liebe 46 hamera] haben wir auch

Ganz im Stil dieser Unterhaltungskunst ist auch ein Kanon gehalten, der in zwei handschriftlichen Quellen Mozart zugeschrieben ist. Das Thema, eine Kegelpartie unter Freunden, lässt an das (Jacquins Schwester Franziska gewidmete) Kegelstatt-Trio und die „untern kegelscheiben “ 100 entstandenen Hornduos denken. Auch der dialektale Text mit seiner stimmungsvollen Bildlichkeit und den amikalen Spötteleien könnte durchaus aus Mozarts Feder stammen. Trotz seiner offensichtlichen musikalischen Qualitäten hält die Mozart-Forschung allerdings an der Einschätzung fest, dass sich eine Autorschaft „in keiner Weise belegen oder auch nur untermauern “101 lässt. Gleichwohl ist Gehn wir auf d'Kögelstadt ein äußerst gelungenes Beispiel für die in den letzten Jahrzehnten des 18. Jahrhunderts beliebten dialektalen Gesellschaftskanons zum fröhlichen Zeitvertreib und verdient es, hier erstmals abgedruckt zu werden:

Gehn wir auf d'Kögelstadt

he! Bue setz auf

gilts a zwölferl wer mehr scheibt

fümfe viere steht

a Loch! potz dausent saperment

ich scheib jä wie a'n Ochs

wie a'n Ochs wie a'n Ochs

wie a'n Esel wie a'n Ochs

wie a'n Esel

itz scheib du

ha ha ha ha

das Anwandln gilt nöt

gilt nöt gilt nöt

99 Mozart, Neue Ausgabe III, Werkgruppe 9, S. 7-18 (längere Repetitionen sind zum Teil nicht wiedergegeben).

100 Wolfgang Amadeus Mozart: Neue Ausgabe sämtlicher Werke. Serie III: Kammermusik. Werkgruppe 21: Duos und Trios für Streicher und Bläser. Vorgelegt von Dietrich Berke und Marius Flothuis. Kassel [u. a.]: Bärenreiter 1975, S. XXII.

101 Mozart, Kritische Berichte III, Werkgruppe 9, S. b/39. 
zwegn meiner zwegn meiner

mags gelten

also gilts? also gilts?

also gilts? also gilts?

Gehts gehn mä, gehn mä gehn, gehts. ${ }^{102}$

3 zwölferl] Zwölfkreuzer-Münze scheibt] Kegel umschießt 12 Anwandln] über die Bande spielen 14 zwegn meiner] wegen mir, von mir aus

Abb. 39: Mozart zugeschriebener Kanon Gehn wir auf d'Kögelstadt (Musikarchiv Stift Kremsmünster, G 43/717).

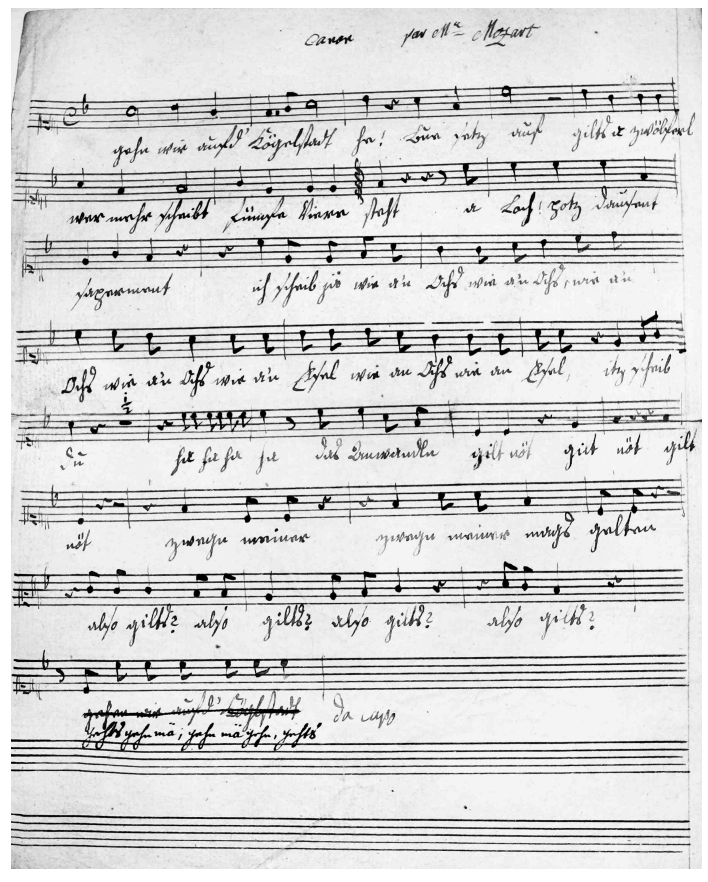

\section{Gassllied und Tanz}

$\mathrm{Zu}$ den beliebtesten Freizeitbeschäftigungen der männlichen Jugend am Land zählte das ,Gasslgehen'. An schönen Abenden zogen Burschenrunden - selten zur Freude der restlichen Bevölkerung - mit Jauchzen, Klatschen und Gesang von Bauernhof zu Bauernhof, vor allem, um die Aufmerksamkeit der Mädchen auf sich zu ziehen. Mit poetischen Kleinformen wie den zwei- bzw. vierzeiligen Schnaderhüpfl und Gstanzln, aber auch umfangreicheren Gasslreimen wurden dabei erotische oder satirische, klagende oder provozierende, witzige oder ernste Töne angeschlagen, manchmal auch mit verstellten Stimmen und aus einem Versteck. Zuweilen reagierte das weibliche Gegenüber vom Fenster aus auf die Liebesbeteuerungen oder Spottverse und forderte mit ihren Antworten ein fröhliches Wort- und Singgefecht heraus, zuweilen bewirtete es die Besucher und unterhielt sich mit ihnen. Blieb die derart Angesungene aber stumm und zeigte 
sich nicht, riskierte sie, dass man ihr das Arbeitsgerät versteckte oder durch Lärmen das Haus weckte. Um die Belästigungen nicht überhand nehmen zu lassen, wurde über die Jahrhunderte hinweg immer wieder mit Erlässen und Verboten behördlich gegen das Brauchtum eingeschritten. ${ }^{103}$ Aber auch auf diese Anfeindungen reagierte man wieder in Spottliedern wie dem folgenden, das Zaupser überliefert:

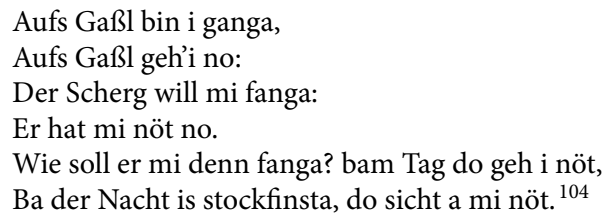

Das umfangreiche Repertoire dialektaler Lieder und Sprüche, von denen jeder Gasslgeher Dutzende parat hatte, ist dank solcher frühen volkskundlichen Sammelbemühungen auch im 18. Jahrhundert in einigermaßen repräsentativen Auszügen überliefert, auch wenn natürlich in Rechnung zu stellen ist, dass anstößigere oder zu kritische Verse nicht den Weg in den Druck fanden. Den ausführlichsten Überblick zu diesen volkskulturellen Formen und ihrer Aufführungspraxis gibt Lorenz Hübner, der mit einigen „Pröbchen von den Dichtertalenten des hiesigen jungen Volkes“ ${ }^{105}$ verschiedene Konstellationen des Miteinanders umreißt:

Lobgedicht auf die Geliebte

Mein Dienal hat kohlschwarze Aeugelein, und wie a Zeiserl schauts her;

Wann i beyn Fensta an Schnagla thue, wutzalts in Pfoadal daher.

Liebes-Antrag

Zwo blitz-blabö Täuberl fliegn über ain Thal;

Diendl magst mi liebn, oder nit, hast dö frisch Wahl.

Antwort hierauf an einen Unbeständigen

I mecht ga nit tauschn, i kalt krat döß mein,

Mecht no oans beköma, mecht no fölscha seyn.

Liedchen eines Mädchens im Betreffe der nächtlichen Besuche

Itzt hat a ma Bueß aufgebn unser Pater:

Sollt nit so lang herstehn beyn Fenstergatter.

Lied eines spröden Mädchens

Geh weck von mein Fenster, Bue! laß mir an Fried!

Bin a frische Bösdirn, auf thue i dir nit.

Liedchen auf einen Gasselbuben, der das Kammerfenster des Mädchens nicht wußte

Drey Stund bin i ganga, dös ist ma a Gspoas,

Itzt han i erst aufdenkt, daß i's Fenster net woaß.

103 Vgl. das Beispiel Salzburg in Haid/Hochradner, Lieder und Tänze um 1800, S. $76 f f$.

104 Zaupser, Versuch eines baierischen und oberpfälzischen Idiotikons, S. 94.

105 Hübner, Beschreibung des Erzstiftes und Reichsfürstenthums Salzburg, S. 382. 
Lied eines Jungen, der sich auf dem sogenannten Gassel verspätete

Auf's Gassel bin i ganga, und han mi verspat,

Und wie i hoam zue bin ganga, haben d'Mada schon gmahd.

Aft zoich i mein Rock aus, und hengan für's Gsicht,

Und han ma glei denkt, a so kennen's mi nit. ${ }^{106}$

1,1 Zeiserl] Zeisig 1,2 Schnagla] Schnalzer, Geräusch mit dem Mund oder den Fingern wutzalts] kommt sie geschwind Pfoadal] Hemdchen 3.1 i kalt krat] ich behalte eben 4,1 hat a ma] hat er mir 5,2 Bösdirn] unverheiratetes Mädchen 6,1 Gspoas] Spaß 7,2 d'Mada] die Mäher 7,3 zoich] ziehe hengan für's] hänge ihn vor

In welch unterschiedlichen Formen dieselbe Strophe auftreten konnte, belegt etwa die erstzitierte, die Zaupser wenige Jahre zuvor im Bayerischen folgendermaßen gehört hatte:

Meind Diendl hod Aeuglein,

Wie a Täubelein,

Und wie an Engl schauts her;

Und wenn i beym Fensta an Wischpla thue,

So pfutscheilts im Pfaideil daher. ${ }^{107}$

4 Wischpla] leisen Pfiff 5 pfutscheilts] hüpft Pfaideil] Hemdchen

Eine merkwürdige Sonderform waren die Gasslreime, die die Burschen unter dem Fenster der begehrten Schönen „mit vielfältig sehr veränderten Tönen, unter allerley Gezische mit der Zunge, oder auch Schnalzen mit den Fingern (Schnackeln genannt) herzusagen pflegen: sie dauern oft eine Viertelstunde lang, und ohne sie darf sich kein Bursche bey dem Kammerfenster seiner Geliebten einfinden “ ${ }^{108}$. Hübner zitiert als Beispiel den Pinzgauer Fopper, der ein reiches Spektrum volksliterarischer Topoi aufweist, vom klausulierten Simultanbericht bis hin zu gesuchten Absurditäten, die die Angesprochene ,foppen', also täuschen sollten. Hier der erste Teil dieses Reims, der später in veränderter Form im Volkslied aufging: ${ }^{109}$

I geh her von unt und von oben.

Von Grund und vom Boden,

Vom Berg und von Thal,

Itzt kim i z’an enkern Dienerl Fenster aber a mal.

Und soviel Stingey daß a Mader abmahd,

$\mathrm{Daß}$ a Samann aussat,

Und soviel Trüpfl daß ins Wasser fließen,

Saperments Weiberleut! will i enk heunt grießen.

Itz Weiberleut deitz a bißl meine Rödn vanema,

Oder a bißl oane z'an Fensta zuera köma.

That gern a Wort a zwoa sagn,

Und a wenk oane ums heurathn fragn.

106 Ebda., S. 383f.

107 Zaupser, Versuch eines baierischen und oberpfälzischen Idiotikons, S. 96.

108 Ebda., S. 687.

109 Vgl. Thomas Hochradner: Der Fopper. Ein Beispiel thematischer Wanderschaft. In: Peter M. Krakauer/ Christoph Khittl/Monika Mittendorfer (Hg.): Der Diskurs des Möglichen. Musik zwischen Kunst, Wissenschaft und Pädagogik. Festschrift für Wolfgang Roscher zum 70. Geburtstag. Anif b. Salzburg: MüllerSpeiser 1999, S. 200-224. 
I wuscht enk öpa saperisch daschröckn,

Wann i that über's Heurathn stöckn? -

Hint ahi han i a saperische Leiten, sand 900 Tagbau,

Wachst nix als lauter guets Zoig drauf.

Varum Distel und Döern.

Agraments Weiberleut theits heunt gar nit hörn?

Kuchelgarten seynd a 7 Tagwerkbau,

Wachst nix als grüens Kraut darauf,

Schnittlauch, Knoblauch, Petersill. -

Schau was die saperaments Weiberleut lachen vastill!

Abi hinter d'Hüll.

Hennen und Hahner hab i anghengt,

Schafl und Gaiß hab i einspengt,

Zwölf Roß hab i im Pflueg, 6 in der Arn,

Zugehn thuets bey mir vor lauter rarn.

Achtzehn Gäul han i a da hoam in Stall;

Knecht und Dirnen nach der Wall.

Die Böthl thüen bey mir das ganze Jahr dräschen,

$S$ ' weiß Brad mögn a nit alls da essn,

Hunga därfn ma Tag und Nacht nit leiden,

A bißl Kurzweil thuen ma alleweil treiben.

Jetzt Bösdirn! mögst d'Werktag a harbene Pfoad tragn:

Und a Schöns Federmesser a in Sack habn,

Thät's dich nit freun,

Wann's d' magst so a brave Bäuerin seyn? -

Bei mir magst es a leicht erleidn,

Thue mehr als 100 Kühe gen Alm treibn.

Z'essen hat ma ja nix als a bisl a Kraut und ötlernö Raner.

Z'Abends gangen ma zeitla schlafn mitananer

Und a so vertreibn ma uns den frischen Mueth;

Beyananer liegn ma uns gnueg.

Der Bauknecht ist zu der Arbeit und zum ani regiern

Wohlwachs; aber thuen thuet er a wohl mit der Dirn! -

Und der Werfer ist soviel a brave Paschan,

Dort hangen um und um d'Weiberleut dran,

Und das Ding thuet'n wohl saperisch freun;

Gern thuet er auf'n jeden Finger neun.

Der Stadler thuet a grad bey der Mueßpfann am besten rauma.

Und im Sumer thuet er'n Werfer in Stadl alleweil sauma.

Und im Aufschlager han i mi gar nit dapascht,

Densn hen i rone nit verschaarscht.

Der Roßknecht ist soviel lustig, und soviel gscheid,

Und aufs Gassl hat er a wolter weit.

Er hat si nit lang bschlossn, nit lang bsuna,

$----$

$---$

$----$

110

4 z'an enkern] zu eurem Dienerl Fenster] Fenster der Mägdekammer a mal] einmal 5 Stingey] Stängel, Halme Mader] Mäher 9 deitz] tut 10 zuera köma] herzukommen 11 a Wort a zwoa] ein, zwei Worte 13 I wuscht enk

110 Hübner, Beschreibung des Erzstiftes und Reichsfürstenthums Salzburg, S. 688f. 
öpa] ich würde euch vielleicht 15 Hint ahi han i] hinten runter habe ich saperische Leiten] verflixten Hang Tagbau] Fläche, die mit 4 Pferden an einem Tag bestellt werden kann 17 Varum] vor allem 18 Agraments] verfluchte 22 vastill] heimlich 22 Abi hinter d'Hüll] raus aus der Bettdecke 25 Arn] Egge 29 Böthl] Bettler, Kinder (?, vgl. Schmeller I, 224) 33 Bösdirn] unverheiratete Magd harbene Pfoad] feines Leinenhemd 39 ötlernö Raner] etliche rote Rüben 44 Wohlwachs] kompetent 45 Werfer] Knecht, der Wagenfuhren (Heu, Getreidegarben) ablädt Paschan] Person 49 Stadler] Scheunenknecht 51 Aufschlager] Knecht, der mit der Aufschlaggabel Heu nach oben gibt dapascht] gekümmert (?) 52 Densn ... verschaarscht] im Druck verderbter Vers 54 wolter] wirklich, sehr 55 bsuna] besonnen, überlegt

Die vier fehlenden Verse brachten wohl Derbheiten, die Hübner selbst oder die Buchzensur nicht abdrucken lassen wollte. Neben diesen erotischen, ja teils sogar pornographischen Aspekten (vgl. Kap. 7) war der jugendliche Kräftevergleich ein beliebtes Thema der Gassllieder. Den Brauch, mit der Feder am Hut Raufbereitschaft zu signalisieren, hat Abele schon 1661 für die Obersteiermark beschrieben (vgl. Kap. 5). Zaupser bringt die entsprechenden ,Trutzgsangln' mit Erläuterung:

A frischa Bue bin i, ho d' Feder aufgsteckt,

In Raafa und Schlogn hod mi koana daschreckt.

Anmerkung. An den Gränzen Tyrols haben die baierischen Bauernbursche den Gebrauch, so viele Federn von Nutzhehern oder andern grossen Vögeln auf den Hut zu stecken, als sie Pursche zu prügeln im Stande sind. Eifert nun einer entweder wegen überlegener Stärke oder wegen Liebeshändeln mit einem andern, so singt er dieses Liedchen. Ist ein anderer zugegen, der sich mehr Kräfte zutrauet, so singt er folgendes, und dann ists gewiß gerauft:

A frischa Bue bin $i$,

Ho d' Feda auf mi!

Is a frischera do,

So rahm i n' brav o. ${ }^{111}$

Viele dieser Lieder und Sprüche fanden sich auch bei Tanzveranstaltungen wieder, waren doch die Gstanzlstrophen musikalisch gesehen „integrierte Bestandteile der instrumental ausgeführten Ländlermusik“112. Ihre in der Runde zumeist mehrstimmig ausgeführten Melodien abstrahierten den harmonischen Gehalt der Tanzmusik, die freirhythmischen Möglichkeiten des Metrums wurden für die effektvolle Präsentation der Pointen genützt. Eine der frühesten Aufzeichnungen einer Schnaderhüpfel-Melodie ist die ,Galanteriefuge' (op. 17/6) des aus Klosterneuburg gebürtigen Komponisten und Musiktheoretikers Johann Georg Albrechtsberger (1736-1809), der darin das aus seiner Jugendzeit bekannte Der Lipp und der Lenz verarbeitete. Der derbe Wortlaut des Vierzeilers ist uns nicht aus dem 18. Jahrhundert, aber aus zahlreichen Aufzeichnungen späterer Jahre bekannt, so etwa aus Deutsch-Mokra (Nimezska Mokra) in der heutigen Westukraine, das 1775 von angeworbenen Holzarbeitern aus dem oberösterreichischen Salzkammergut gegründet wurde. ${ }^{113}$ Richard Wolfram notierte in dieser transkarpatischen Sprachinsel, wo mittelbairische Dialektkultur des 18. Jahrhunderts lange konserviert wurde, noch 1930:

111 Zaupser, Versuch eines baierischen und oberpfälzischen Idiotikons, S. 99.

112 Deutsch/Haid/Zeman, Das Volkslied in Österreich, S. 139.

113 Vgl. Stephan Gaisbauer/Hermann Scheuringer (Hg.): Karpatenbeeren. Bairisch-österreichische Siedlung, Kultur und Sprache in den ukrainisch-rumänischen Waldkarpaten. Mit Fotographien von Hans Kumpfmüller. Linz: Adalbert-Stifter-Institut des Landes Oberösterreich 2006. 
Da Lipp und da Lenz

håmb an oantuttlats Mensch

und da Lenz håt's net g'wißt,

daß's Mensch oantuttlat ist. ${ }^{114}$

2 oantuttlats Mensch] Mädchen mit einer Brust

Es ist nachvollziehbar, dass die Obrigkeiten mit verschiedensten Mitteln versuchten, solche Gesänge - und mit ihnen oft auch die Tänze selbst - zu unterbinden. Abgesehen von genehmigten Anlässen wie auf Hochzeiten, an Zunfttagen, bei Vertragsabschlüssen, Kirchweihfesten oder im Fasching war Tanzen deshalb nur zu bestimmten Zeiten, in lizensierten Lokalen und mit rigiden Auflagen (die freilich selten eingehalten wurden) erlaubt. ${ }^{115}$ Das erste Lied, das der Vorsänger auf eine bekannte Melodie sang, gab den Tanz vor, den die Musikanten übernahmen und variierend weiterführten. ${ }^{116}$ Wie die choreographische Ausführung aussah, deutet Hübner in seinen Beobachtungen aus dem Lungau an: „Es wird [...] unter wechselweiser Anstimmung der aus dem Stegreif fabrizirten Tanzliedchen rechts und umgekehrt im Kreise herumgewalzet, wobey alle Theile des Körpers in Bewegung sind, und die Mädchen besonders ihre Reitze sehr geschickt zu entfalten wissen. "117 Auf das Klatschen und Stampfen weisen etwas spätere Quellen hin.

Aus den einzelnen Schnaderhüpfeln bildeten sich bald auch Lieder mit einem $\mathrm{Zu}$ sammenhang der Strophen, die die Hauptmelodie des Tanzes tragen. Bedauerlicherweise ist diese bei der ältesten bekannten Aufzeichnung einer bairisch-österreichischen Variante des hier so bezeichneten ,Hühnertanzes` nicht eingetragen; dass sie mit jener übereinstimmt, die Erk und Irmer in den Deutschen Volksliedern wiedergeben, darf zumindest angezweifelt werden: ${ }^{118}$

1

Wanst zu mein Schazerl kimst, sag I Laß grüssen,

wan's dich fragt, wies mä geht, sag aufn Füssn, wanns di thuet fragen heut oder morgen, sag, I bin frisch und gsund, bin no nit, bin no nit, bin no nit gstorben.

\section{2}

Bin bey meim Dienerl gwöst

ist schon 8 Tag,

han ihn 3 Bußl göbn

han nöt mehr ghat,

hät I mehr ghat,

hätt I iehm mehr göbn, wünsch I iehm glück auf d'Raiß, und ä langs, und ä langs, und ä langs löbn.

114 Richard Wolfram: Volkstänze aus Deutsch-Mokra. In: Das deutsche Volkslied 41 (1939), S. 30-33, hier 33. $\mathrm{Zu}$ weiteren, teils auch abgeschwächten Fassungen des Vierzeilers vgl. Deutsch/Haid/Zeman, Das Volkslied in Österreich, S. $26 \mathrm{f}$.

115 Vgl. Haid/Hochradner, Lieder und Tänze um 1800, S. 63f.

116 Vgl. ebda., S. 38f.

117 Hübner, Beschreibung des Erzstiftes und Reichsfürstenthums Salzburg, S. 536.

118 Vgl. Ludwig Erk/Wilhelm Irmer (Hg.): Die deutschen Volkslieder mit ihren Singweisen. Bd. I, Viertes Heft. Berlin: Plahn 1843, S. 23; als Quelle für den Text wird auf Nicolais Feyner kleyner Almanach (1778) verwiesen, der gleichfalls nur eine Strophe wiedergibt. 
3

Wann mein Schatz wandern thut

bleib I nöt da,

wans aufn wassä fahrt,

fahr I iehm nach

fahrt sy aufn wassä

fahr I aufn land,

I und mein tausend Schatz,

kemän scho, kemän scho,

kemän scho zam,
4

Daß ist dä Hennä Tanz,

Bue, Bue, Bue, Bue,

wer nit kan, fang nit an,

sue, sue, sue, sue,

Hennä Tanz hy

und Hennä tanz her,

so liebt mi sey lebtä kain

söltä nä, Bue, Bue, Bue,

Bue, Bue, Bue, mehr. ${ }^{119}$

2,3 Bußl] Küsse 3,9 kemän scho zam] kommen schon zusammen 4,8 söltä nä, Bue] solcher Bursche, Junge

Neben diesen Tänzen für das Allgemeinvergnügen stehen Tanzformen, die bei feierlichen Anlässen von Spezialisten aus verschiedenen Zünften aufgeführt wurden. Ein bis ins 19. Jahrhundert verbreitetes Brauchtum war der Schwerttanz, bei dem zur Musik von (üblicherweise) Flöte und Trommel kunstvolle Bewegungen mit Schwert oder Degen ausgeführt wurden. Die Waffen dienten dabei als „Bindeglied von Mann zu Mann“, sodass sich eine Kette bildete, „die sich verschlingt, entwirrt, ein- und ausdreht, ohne daß die Fassung gelöst wird“ ${ }^{120}$. In den komplexeren Ausformungen dieses im süddeutschen Raum seit dem späten 15. Jahrhundert belegten Waffentanzes trat zur choreographierten, musikalisch unterstützten Bewegung noch das dramatische Moment hinzu, in dessen Mittelpunkt zumeist ein auf verschiedene Weise malträtierter Tölpel steht. ${ }^{121}$ Die in verschiedenen Überlieferungen (u. a. auch wieder aus Deutsch-Mokra) zu findenden Handlungselemente des oft auch dialektal gehaltenen Spiels umfassen scheinbare Tötung und Wiederauferweckung, außerdem die scherzhafte Darstellung von Rasieren und Zähneziehen. ${ }^{122}$

Im Nachlass von August Hartmann hat sich eine Spielfassung aus dem oberösterreichischen Salzkammergut erhalten, die neben dem Text auch Abbildungen und drei Melodien für Piccoloflöte („Tympano Tambour accompagnirt nach Belieben“123) um-

119 Stiftsbibliothek St. Florian, XI 577 A, S. 103-105.

120 Richard Wolfram: Ein neugefundenes Schwerttanzmanuskript des 18. Jahrhunderts aus dem Salzkammergut. In: Jahrbuch des österreichischen Volksliedwerkes 32/33 (1984), S. 147-166, hier 147.

$121 \mathrm{Zu}$ den Schwerttänzen vgl. u. a. Kurt Meschke: Der Schwerttanz im germanischen Kulturkreis. Leipzig/ Berlin: Teubner 1928. - Richard Wolfram: Schwerttanz und Männerbund. Kassel: Bärenreiter 1936-1938. (3 Lieferungen) - Otto G. Schindler: Über Schwert- und Reiftänze in Wiener Neustadt. Ein Beitrag zu niederösterreichischen Volkskunde. In: Jahrbuch des Österreichischen Volksliedwerkes 22 (1973), S. 3639. - Gerlinde Haid: Schwerttanz. In: Rudolf Flotzinger (Hg.): Oesterreichisches Musiklexikon. Bd. 5: Schwechat - Zyklus. Wien: Österr. Akademie der Wissenschaften 2006, S. $2180 \mathrm{f}$.

122 Vgl. Wolfram, Schwerttanzmanuskript, S. 147, der auf die „bemerkenswerte Einheitlichkeit“ der überlieferten Schwerttänze vom Böhmerwald bis in die Steiermark hinweist, denen „ein und dieselbe Textfassung zugrunde“ liege (ebda., S. 151, 159, 161ff).

123 Bayerische Staatsbibliothek, Nachlass August Hartmann, Supplement zur Kiste 20 (Beschreibung der in dem Salzkammergute ob der Enns, dann im Herzogthume Steyermark, üblichen National-Faschingsbelustigung, oder des sogenannten Schwert-Tanzes), zitiert nach der Abbildung in Wolfram, Schwerttanzmanuskript, S. 149. Die Handschrift ist nicht datiert, wird von Wolfram aber auf Grundlage des Schriftbildes, der Abbildungen sowie einzelner inhaltlicher Elemente, etwa der „Vertrautheit des Schreibers mit Figuren des Kontratanzes“ in die 2. Hälfte des 18. Jahrhunderts datiert, jedenfalls „keinesfalls jünger als 1800“ (ebda., S. 150). 
fasst. In der Tradition eines fastnächtlichen Reihenspiels präsentieren sich 10 Tänzer, die zu fünft einander gegenüberstehen. Die Gasse zwischen ihnen ist der Spielraum des witzigen Kommentators Arlequin, der in einem typischen Hanswurst-Kostüm, allerdings mit stilisiertem Hut, auftritt. Er ist es, der das Publikum anspricht und um eine Spende bittet, ihm fällt auch die Wiedererweckung des wie folgt zu Tode gekommenen Tänzers Rubein zu:

VORTÄNZER. Herein Rubein!

Rubein. Warum heißt du mi in Rubein?

Laß die Bauern gottlosi Buabm seyn.

Hab in Nacht versoffn bey den sauren Wein

ARLequin. Du bleibst halt a gern sitzn

Rubein. Ho gmaint, i hon an Holzschlögl gössen.

Is mir mei Magn so lausig und so ring,

I hof er wird no drina ling.

Mit dem Grünewald kann i mi nimma votragen.

ArLequin. Höbts ma koani Handl o sag i.

Rubein. I muß ihm zu schlakrawald über d' Kapp’n schlagn, ihr Herrn.

ARLEQUin. Das magst wöng meina thuen.

VORTÄNZER. Herein Rexmaul!

ArLequin. Hast weita kain saubrs Maul a nit du.

Der Vortänzer, Rubein und Rexmaul gehen im Zirkl herum, unter welcher Zeit die übrigen auf der Seiten stehn.

Rexmaul. Warum heißt du mi 's Rexmaul?

Rubein! zu deinen Reden bist du nit faul,

Du hast mir nachts abends spat ein Röd gethan

$\mathrm{Daß}$ ich muß führen in Zorn in meiner Hand.

ArLequin. Ös werds ma nu Handl ohöm, ös werd nöt aussözn!

Rexmaul. Rubein, i will dir an Hakabraden göbm auf deinen Leib,

Arlequin. Still sey!

Rexmaul. Das du must klagen Kind und Weib,

Kind und Weib zu jeder Zeit,

Rubein! auf d' nachst last du mi unkeit.

ArLeQuin. Statt seyds! höbts ma koani Handl o!

Rexmaul. Rubein! i will dir a Blattn schern

Und will dich auf dem Tanzbodn kehrn, ihr Herrn.

Rexmaul schlägt den Rubein mit dem Degen zu Boden, wobey Arlequin zu weinen anfängt, doch dem ungeachtet wird das Auf- und Abgehen um den auf dem Boden liegenden Rubein fortgesetzt.

VORTÄNZER. Fried, Fried! ainer den andern schädigts nit,

D' Herrn möchtn ins dron denka

Möchtn ins d' Straff a nit schenka.

Ey, ey - wer ha mir mein liebm Rubein derschlagn.

Rexmaul. I hab ihn gschlagn zu Hauffm

Daß sein Seel in mein Degenspitz muß herumlauffen,

I hab in g'schlogn zu Todt,

Oll meine Herrn und Nachbarn, helfts mir aus der Noth!

VortänZER. Aus der Noth wölln ma da schon helffen,

Was legst uns ein? 
Rexmaul. An Eimer Wein,

A foasti Schwein,

Dabey wölln mir brav lustig seyn. ${ }^{124}$

in] den i hon] ich habe ring] leicht, gering ling] liegen Höbts ma koani Handl o] fangt keine Streitereien an schlakrawald] (Fluchwort) Verballhornung von ,Sakrament ' wöng meina] meinetwegen Ös werds] ihr werdet Hakabraden] Hackbraten (?) unkeit] ungeschoren, in Frieden statt] ruhig, still Blattn] Glatze legst uns ein] zahlst du uns

Die holprigen, in ihrer Formelhaftigkeit archaisch anmutenden Knittelverse verweisen auf die lang andauernde Spieltradition, die in ihren Grundlagen noch im Fastnachtspiel des 16. Jahrhunderts zu wurzeln scheint.

\section{Inszeniertes Brauchtum}

Dramatische Formen spielten im Brauchtum eine wesentliche Rolle, wie bereits an verschiedener Stelle gezeigt wurde - sei es im volkstümlichen Weihnachtsspiel, in Fastnachtsburlesken oder in Heischespielformen. Besonders gerne wurde in Oberbayern zur Zeit der, Drischelleg Theater gespielt, also nach Beendigung der schweren Drescharbeit zu Beginn der winterlichen Ruhepause. August Hartmann hat - heute überwiegend verschollene Handschriften mit mündlichen Mitteilungen ergänzend - eine ganze Reihe dieser beliebten Drischellegspiele überliefert, die er großteils (mit zuweilen wenig überzeugenden Argumenten) dem legendären, aus Salzburg stammenden , ausgejagten Studenten ' Ferdinand Joly (1765-1823) zuordnet. ${ }^{125}$ Die Dichtungen und Lieder des im bayerisch-österreichischen Grenzgebiet vazierenden ,Scholi‘ waren im Volk äußerst beliebt; mit Sicherheit zuordnen lassen sich allerdings bislang keine Arbeiten von ihm, die vor 1800 entstanden wären. Das thematische Spektrum dieser von Laien in Scheunen oder Wohnstuben aufgeführten, weitgehend anspruchslosen Drischellegspiele war offenbar recht breit: Sagendramatisierungen (,Die Unterberger') und Bibelszenen (,Der verlorene Sohn'), Hirtenspiele und Liebespossen, Jahreszeitenspiele oder auch Überrumpelungsschwänke wie sie schon Scholtz von Scholtzenberg im ersten Interludium zu Widerwertig- und glückselige Liebe Cambises (siehe Kap. 2) verarbeitet. Großteils scheint hier also sehr altes schauspielerisches Traditionsgut für die bäuerliche Unterhaltung aufgegriffen oder neu in Szene gesetzt worden zu sein.

Doch auch das Brauchtum selbst konnte wieder in dramatischen Brauchtumsformen thematisiert werden. In Norbert Pambichlers bereits angesprochenem Singspiel Tendlbaß steht der personifizierte Brauch des Arbeitsabschlussfestes selbst im Mittelpunkt. Geliebt von der Landarbeiterschaft, den Gewerbetreibenden und Spielleuten, aber angefeindet von denen, die keinen wirtschaftlichen oder gar moralischen Nutzen in den mit Essen, Trinken, Tanz und zuweilen eben auch Theaterspiel begangenen Feierlichkeiten sahen, werden in den Figuren von Kleinem und Großem Tendlbaß die Vorzüge und Nachteile der ländlichen Unterhaltungstraditionen diskutiert. Dass das Drischelleg- bzw. Tendlbass-Fest eine wichtige (nicht nur materielle) Form der Entlohnung für

124 Zitiert nach Wolfram, Schwerttanzmanuskript, S. 156f.

125 Vgl. Hartmann, Volksschauspiele, S. 179-282. 
die schwere Drescharbeit darstellte, wird ebenso angesprochen wie dessen Kehrseite: die Unwirtschaftlichkeit, Geschäftemacherei, Verschwendung und hinterlistige Verführung zu den Lastern der Völlerei, Trunksucht oder sonstigen amoralischen Verhaltensweisen. Gleichwohl kommen in dieser Seitenstettener Klosterkomödie - gleichsam als Sinnbild der Hartnäckigkeit etablierter Brauchtumsformen - der Tendlbaß und mit ihm das Landvolk mit einer hinterlistigen Intrige zu ihrem überlieferten Recht. Der entschiedenen Festgegnerin Kundl wird weisgemacht, dass den Verächtern des Tendlbaß das Vieh sterben würde, „weils ä so än uralten Brauch habn abbringä wölln“126. Als sich tatsächlich drei tote Schweine auch in ihrem Stall finden, bereut die Bäurin des Schmalzhofs ihre Ablehnung traditioneller Schenkrituale, die ihr der noch unerkannte Tendlbaß vorwurfsvoll aufzählt:

Grosser Tendlbass. Mä gibt 'n Kindern das gottengwand, den gotten Kindern das roth ayr, den allerheilling strüzl: Mä schickt der gväderin das weisät: mä last alle Jahr dö faist Raunacht mit all ihrn Feyrenden unternächten kemä: mä gibt n Mistfassern dö Dung Krapfen, den Schnittern die Waizknoden, alln gibt mä: nur n Tendlbaß, dem alten Tendlbaß, dem liebn Tendlbaß, dem ehrwürdigen Tendlbaß, dem will mä sei uralte gab abbringä, und azwickä. wie soll ä glick dabey sein?

KundL. Häts mei! soll denn döß Ding gar so grob unrecht seyn? i habs mei lebtä nit ä so außgraith.

SpIllman. Und wie mögn do d' Leuth selbst so vill Razen, und Mäuß in d' Häuser zigeln, wans 'n spöck, 's gselcht Fleisch, und 's Schmalz ä so aufspahrn, den schädlichen Gästen kunt mä als das nit leichtä entzoiha, als wan mäs 'n Tendlbaß geit.

Grosser Tendlbass. No nit gnue, das mä iem nix geit: er muß no dazue ein Schmalzdieb, ä Bratldieb, ä mehldieb, ainer über den andern haissn. wan das kaini ungrechtigkaiten sänd, und alle Straf verdienän, so waiß is ä nit.

KundL. ö mei, hörts öß! Döß Ding hani do mein Lebtag ni ä so außlögn ghört... . Eß roit mi afer alls, waß i gredt, und gsait ha.

Jagerl. Schmalzfoger, und Kainz laufen herbey.

JAGERL. Muedä! D’Säu lign alle drey toder in Stall draust.

Schmalzhofer. es ist nit andert ... Da haben wirs jezt.

Kundl. Wie iss den geschehä?

KAINZ. Mä sieht nix. es muss halt trofä habn, oder es müssn umgfalln seyn.

Schmalzhofer. Das hast jezt va deinä Zusserey.

Grosser Tendlbass. habts den öß 'n Tendlbaß no nit ghabt?

Schmalzhofer. Döß ist ebn mei Klag... . Da habn wir jezt das sauber unglick.

KundL. Ja, i muss däkenä: $i$ hab iem nix verguhnt, $i$ han iem ä ä so glästert, und außgmacht... . es roit mi afer: i bitt iems a, öß seyts all meine Zeugn. Und wen er da wär, und käm, wan immer dä wöll, 's ganz hauß gäb i iem. und so lang mir d' Augn offen stehn, solt er alle Jahr kemä, und gut ghalten wern. ${ }^{127}$

gottengwand] Kleid, das der Taupate / die Taufpatin dem getauften Kind einige Jahre später machen lässt und gewöhnlich zu Ostern schenkt gotten Kindern] Patenkindern roth ayr] rotes Osterei (als Erinnerung an den Opfertod Christi) allerheilling strüzl] Allerheiligenstriezel: zopfförmig geflochtenes Hefegebäck guäderin] Taufpatin weisät] Geschenk zur Geburt eines Kindes (Naturalien, Stoff, Geld etc.; unklar, warum hier in die andere Richtung geschenkt wird) faist Raunacht] Feiste Raunacht (üblicherweise vom 5. auf den 6. Jänner): letzte Raunacht, die mit ausgiebigem Essen begangen wurde last ... unternächten kemä] gewährt Einlass

126 Zitiert nach Huber, Pater Norbert Pambichlers ,Tendlbaß', S. 227.

127 Ebda., S. 228. 
Dung Krapfen] Mehlspeise für die Stallknechte Waizknoden] Knödel aus Weizenmehl Häts mei] Ausruf: Je nun mei lebtä] zeitlebens außgraith] bedacht zigeln] züchten entzoiha] entziehen geit] gibt hörts öß] hört ihrs hani do] hab ich doch gsait ha] gesagt habe es] (hier 3. Pers. Pl.) sie es muss halt trofä habn] es muss sie der Schlag getroffen haben Zusserey] Jammerei, Raunzerei däkenä] erkennen außgmacht] beschimpft öß seyts] ihr seid wan immer dä wöll] wann auch immer

Was Kundl nicht wissen konnte: Die Schweine waren schon zuvor heimlich geschlachtet worden und dienen beim folgenden Tendlbaß-Fest zum Schmaus. Mit der Mechanisierung bäuerlicher Arbeitsprozesse ist dieser Brauch in Vergessenheit geraten, im Gegensatz zu vielen anderen, die Pambichler hier und in weiteren Teilen des Spiels kundig ins Bild setzt und die bis heute zu finden sind.

Nicht nur in der Klosterkultur war das bäuerliche Brauchtum als Sujet beliebt; auch in allerhöchsten Kreisen amüsierte man sich mit und über bäuerliche Alltagsunterhaltung. 1684 etwa spielte Kaiser Leopolds Halbschwester Eleonora, verwitwete Königin von Polen, mit ihren Hofdamen und jenen der Kaiserin eine „Mayerin mit allen 14 Menschern" ${ }^{128}$ im dialektalen Faschingssingspiel Rocken stuben, vnd Mayrhoff, das uns in der Handschrift des Christoph Leopold Reichsgraf von Thürheim (1623-1689) überliefert ist. Ob er auch der Verfasser ist, ist wohl nicht mehr zu klären (eine ,ui'-Form spricht eher für einen Dichter aus dem ostmittelbairischen Gebiet). Dem aufgrund von Pest- und Türkengefahr nach Linz verlegten kaiserlichen Hof wurde in dieser theatralen Einlage ein kleiner Blick auf die weiblichen Aufgabenbereiche in einem landwirtschaftlichen Betrieb geboten; aufgelockert wurde das Spiel mit Tanz und Balletteinlagen. Es beginnt mit einer Befehlsausgabe der, Mayerin` Eleonora von Österreich an ihre Mägde:

1

Menscher khumbt Einmahl heran,

habt ihr Entlich ausgeschlaffen,

hebts Einmahl die arbeit an,

last das hin vnd wider gaffen,

Gehts Ihr wol gebuzte dockhen,

luzel, Ändel, nembst den rockhen,

wan Ihr gspunnen Eiren strenn

dan könt ös zum fenster gehn.
2

Rosel bring die hiendel her, vnd thue solche fleissig schoppen, würstu sie verfietern mehr, du weist, Ich laß mich nit foppen, du muest solche mir bezallen, khaterl du muest pfeffer mallen, vnd reib dan in einen huy, auch ein Achtel salz darzuy.

128 Oberösterreichisches Landesarchiv, Weinberg, Akten-Nr. 1406, L VII (Rocken stuben, vnd Mayrhoff welche Ihr mais. der Kaiserin Eleonora vnd deren hohen, vnd liebe Gästen in einem Cammerfest von Ihr mai. der Königin in polen vnd beeder Ihr mais. der Kaiserin vnd kenigin hofdammen vorgestelt. Im fasching 1684 $z$ u Linz.), f. 2v. In Auszügen erstediert wurde das Stück von Hans Commenda: Adelige Lustbarkeiten in Linz vom 16. bis zum 18. Jahrhundert. In: Historisches Jahrbuch der Stadt Linz 1958, S. 141-180, hier 156-158. Die auffällig fehlerhafte Transkription des arrivierten Forschers lässt sich wohl - auch wenn die Handschrift tatsächlich nicht leicht entzifferbar ist - nur mit Commendas Arbeitstechnik erklären: Auch hier wird er wohl das Original zumindest zum Teil mit stenographischen Kürzeln festgehalten und für die Edition rekonstruiert haben. 
3

Niemb das ober fleissig ab,

frondel gschwindt zum butter rühren,

machts das kheine klag Ich hab,

oder Ich wil Euch curiren,

lisel gschwindt zu deinem Nähen, schikhe dich Christel meel zu fähen, wäberl sez das vrhet an, das man heüt noch pachen khan.

5

Miedel richt die ratenfaal,

duderl schau, das Ayr khanst findten,

bring das kleine garen all,

das Es khumb einmall zum windten,

was gewunden mues man sechteln,

sopherl thue die schäffer dechtlen,

vnd seith fleissig vmb vnd vmb,

dan Ich khürzlich wieder khumb. ${ }^{129}$
4

Schau, wo d'khüe im staal schon seyn gröschel, vnd thue solche melchen, Vrschel salz das fleischlein Ein, vnd richt solches zue zum selchen, wie thuestu hervmb so wächeln, trautel gschwindt den haar thue hächeln, Madel stosse for die schwein, gelb: vnd weisse rueben Ein.

1,1 Menscher] Mädchen 1,3 hebts ... an] fangt an 1,5 dockhen] Püppchen 1,6 luzel] Kurzform für Lucia Ändel] Kurzform für Anna rockhen] Spinnrocken, an dem die unversponnenen Fäden befestigt sind 1,7 strenn] Strähn: Maßbezeichnung für Anzahl gehaspelter Fäden 1,8 ös] ihr 2,1 hiendel] Hühner 2,2 schoppen] stopfen (für die Mast) 2,3 verfietern] durch das Füttern ruinieren, beim Stopfen töten 2,6 katherl] Kurzform für Katharina 2,7 in einen huy] geschwind 3,1 ober] Süßrahm, Sahne 3,2 frondel] Kurzform für Veronika 3,6 fähen] fein sieben 3,7 wäberl] Kurzform für Barbara vrhet] Uret, Urhab: Sauerteig 4,2 gröschel] Kurzform für Margarete 4,4 Vrschel] Kurzform für Ursula 4,5 wächeln] fächeln, wedeln 4,6 haar] Flachs hächeln] mit der Hechel bearbeiten, durchkämmen 4,7 Madl] Kurzform für Magdalena 5,1 Miedel] Kurzform für Maria 5,2 duderl] Kurzform für Ottilie 5,5 sechteln] mit Lauge bleichen 5,5 schäffer] Bottiche, Wassergefäße dechteln] einweichen, wässern (um sie dichter zu machen)

Sechs der Mädchen freilich denken nicht daran, die befohlenen Aufgaben sofort auszuführen, sondern nützen die Abwesenheit der Chefin um ein „minuet, vnd als dann eine bourrée“ zu tanzen. Auch die übrigen acht lassen sich trotz Prügelandrohung für die „nichtsnuzigen heppinnen“ nicht davon abhalten, ein „tröschs ballet“ zu beginnen, in dessen Pausen sie das folgende Arbeitslied mit typisch rhythmisierender Metrik singen:

1

wie gfalt vns das kleschen in tröschen so guet, wans gströbich so krachet vns machet den mueth, die tröschel hoch schwingen, khan bringen vil freidt verdriest schon vil leith.

2

wer wolt nur so sizen, vnd schwizen beym rat, stets offen hitz leiden, vil freyden nicht hat, nach starkhen bewegen, sich legen ins beth, vil Vnlust vergeht.

129 Oberösterreichisches Landesarchiv, Weinberg, Akten-Nr. 1406, LVII, f. 1r. 
3

beyr arbeit so singen, vnd springen darbey,

so dunkht vns dis keillen ein spillen nur sey,

so so vnser ruckhen vmbs puckhen nichts fragt,

sa sa noch eins gwagt. ${ }^{130}$

1,1 kleschen] Krachen, Lärm 1,2 gströbich] Stroh, ausgedroschenes Getreide 3,2 keillen] angestrengtes Arbeiten

Von wem die (verlorene) Musik für Singeinlagen und Tanzeinlagen der kurzen Szene stammte, wissen wir nicht - im Gegensatz zu einer Musica zu deren Hochadelichen Hoff Dämen Comedi, die 1686 von „Ihro May. dem Kayser“"131 Leopold I. (1640-1705) höchstpersönlich komponiert wurde. Das textuell nur in den italienischen und deutschen Singeinlagen überlieferte höfische Unterhaltungsstück mit seinem genretypischen Liebesgeplänkel wird von einem beschwingten Tanzlied beschlossen, bei dem Mägde allerlei Holz für ein Brauchtumsfeuer zu ergattern versuchen. Der Dichter ist unbekannt, doch finden sich auffällige Ähnlichkeiten zum oben zitierten Auftrittslied der Mayerin; der dialektale Duktus ist nun allerdings stärker in der Verschriftung bewahrt worden.

1

Träxlä Tischlä pranget wol

wan ihr nur habt holz

alles ist mit trimer voll

aichen holz macht d'bintä stolz.

Becken Köch die bachen braten

nu mit holz hoätz imä fort

Könts oän scheitel no woll kraten

bey dem hert loänt oänes dort.

Nämlä homä trimä gnue zum foir zam bracht sämä zimlä lang drum umäkrent

hupfmä halt

wies ins gfalt

nembts enck in acht

das nu koäni d'iopen nit verbrent.

3

Luzl woäst wan Krapfen bachst

und du has darbey

kloäni scheitl gelt du lachst

gib ein Kleines steht dir frey.

Urschel wan thust Kösten rösten

brauchst doch Kollen imä hin

thue uns ä mit oänä trösten

wird sein schon nach unsrem sin.
2

Bintä Wagnä die ihr hir

stats mit holz umgeht

ziechet dort ein block herfür

hinten oäns in Winckl steht.

oäches buches ist uns eben

es mag sein hart oder weich

latten trimä tiets uns geben

es gilt uns schon alles gleich.

Danzmä umä gmälä fort hipsch umä dum nu fein gietlä läf niembts äsm ring

ist als oäns

das nu koäns

nit dani kum

und ein iedi moäd fein laut mit sing.

4

Mädl gib nu bald was her

hast nächt s'holz verschwent

wie du ghoäzt hast gar zu ser

woäst wie d'hast dein belz verbrent.

du wirst in dem gwölbel hinten

Putten testen sein ä guet

no oän alti Wannä finden

uns in Kram schon taugen thuet. ${ }^{132}$

1,1 Träxlä] Drechsler 1,4 bintä] Binder 1,5 Becken] Bäcker 1,6 hoätz] heizen sie 1,7 kraten] entbehren 1,8 loänt oänes] lehnt eines 1,9 Nämlä homä trimä gnue] denn wir haben genug Trümmer zam] zusammen 1,10 sämä] wir sind umäkrent] herumgerannt 1,13 enck] euch 1,14 d'iopen] die Joppe, Jacke 2,5 oäches] aus Eiche buches] aus Buche 2,7 tiets] tut 2,9 Danzmä umä] tanzen wir herum gmälä] gemächlich, gemütlich umä dum]

130 Ebda., f. 2 r.

131 Österreichische Nationalbibliothek, Musiksammlung, Mus.Hs. 16003, f. 1 r.

132 Ebda., f. 16v-18r. 
drum herum 2,10 gietlä] sachte läf niembts äsm] laufe niemand aus dem 2,13 dani kum] raus-, hinauskommt 2,14 moäd] Maid, Magd, Mädchen 3,1 Luzl] Kurzform für Lucia 3,5 Urschel] Kurzform für Ursula Kösten] Esskastanien, Edelkastanie, Maroni 4,1 Mädl] Kurzform für Magdalena 4,2 nächt] gestern (Abend) 4,6 Putten] Butten, größere Holzgefäße testen] kleinere hölzerne Gefäße (zur Aufbewahrung und zum Transport von Lebensmitteln) 4,7 oän alti Wannä] eine alte Wanne

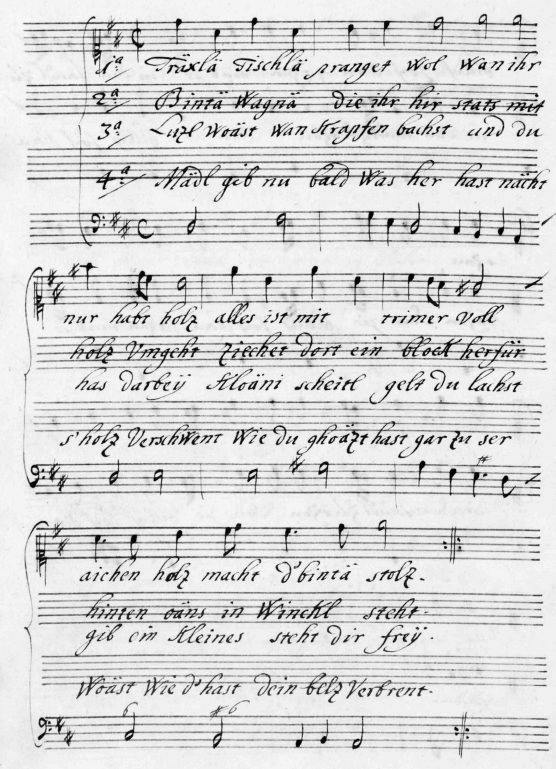

Abb. 40: Österr. Nationalbibliothek, Musiksammlung, Mus.Hs. 16003, f. 16v).

Dass der musik- und theaterbegeisterte Monarch Dialektkunst durchaus zu schätzen wusste, wurde u. a. schon im Zusammenhang mit Elenson, Scholtzenberg und den Wiener Jesuiten angesprochen. Generell gehörte das Rollenspiel in bäuerlicher Verkleidung seit dem frühen 16. Jahrhundert zu den beliebtesten höfischen Unterhaltungsformen, bei denen alle vornehmeren Mitglieder der Hofgesellschaft ihren Beitrag zu leisten hatten. ${ }^{133}$ In den als Festmahl inszenierten,Wirtschaften ' und ,Bauernhochzeiten' kleideten sich Aristokraten als gewöhnliche Leute und mussten zum Teil auch in entsprechende Sprachmasken schlüpfen, die freilich nicht immer gelangen. Der Musikgraf Prinz Pius von Savoyen etwa wird als ,Marktschreyer" einer „Wirthschaft am Kayserl. Hofe“ vom 29. Februar 1724 mit einer 11-strophigen Wiegenlied-Adaption zitiert, die etliche gravierende Dialektmängel aufweist:

133 Vgl. vor allem Claudia Schnitzer: Höfische Maskeraden. Funktion und Ausstattung von Verkleidungsdivertissements an deutschen Höfen der Frühen Neuzeit. Tübingen: Niemeyer 1999. (Frühe Neuzeit 53) S. 220-249. Von einer weiteren beliebten Faschingsunterhaltung, der zeremoniellen Schlittenfahrt, bringt das wohl noch in den 1680er Jahren verfasste Bauernlied Wie i nägst vo Grinzing in dstatt eichö kam einen amüsanten Bericht, vgl. Staatsbibliothek zu Berlin, Ms.germ.oct. 230, f. 85v-90r. 
1

Häiä Pupäiä mein Kindlein schlaff ein,

Laß dä mein Singä nit unlustä seyn,

Miä soäe hie in Wirthehaus, wo koänä was fehlt,

Miä fressä, miä sauffä, und kost uns koä Gelt.

Heidl. Häiä, Pupäiä.

2

Dein Vodä, deä bräfdä, deä tapfäri Wirth,

Duit Ins meä Ehr an, als immä gebirt,

Miä hüpfä, miä springä, eä hilft Ins däzui,

Laß dä liebs Kindl, nit steäre die Ruhi,

Heidl. häiä, Pupäiä.

3

Dein Mämä dö Schöni, dö wäckäri frau,

Aes lacht mä das Heärz schon, so oft auf Sä schau,

Dö wart Ins so stätlä und guitheärze auf,

Schlaff mein liebs Kindl. und schlaff nuä bräff dräuf.

Heidl. Häiä Pupäiä.

$[\ldots]$

11

So wird oft in weid-broäden Welt-Croäs herum,

Von deie grossen Wirthshauß stäts klingä dä Ruhm,

Und ä däß Gesproäch von dir werdee geführt,

Däß du mein Oäd seyst, da mächtigsti Würth,

Heidl. häiä, Pupäiä. ${ }^{134}$

1,3 Miä soäe] wir sind koänä] hier: keinem 2,2 Duit Ins] tut uns 2,4 steäre] stören 11,1 Welt-Croäs] Weltenkreis

Angesungen wurde das noch ungeborene Kind, mit dem Kaiserin Elisabeth Christine hochschwanger war. Doch entband sie nicht den herbeigesehnten Thronfolger, sondern zur herben Enttäuschung Karls VI. mit Maria Amalia ihre jüngste Tochter. Unklar ist, welche der zahlreichen sprachlichen Ungereimtheiten der Überlieferung und welche dem ungewohnten Registerwechsel geschuldet sind. Schon Nagl/Zeidler merken dazu an: „,Mia soan ' [... ] spricht kein Bauer, sondern nur ein bäuerisch redender Städter, welcher glaubt, dass er alle seine hohen Dialekt-á in bäuerische oa ,vergröbern' müsse. “135

Bauernspiele, aktiv und rezeptiv, hatten ihren fixen Platz im höfischen Festzeremoniell. Als besonderer Liebhaber galt Kaiser Franz Stephan, der noch wenige Tage vor seinem Tod 1765 Maurus Lindemayrs Saufsucht sah, die im Tiroler Stift Wilten im Rahmen der Hochzeitsfeierlichkeiten für Erzherzog Leopold vor der kaiserlichen Familie gespielt wurde. Seine Tochter Marie Antoinette, die dieses Faible für das BäuerlichDörfliche teilte, wurde 1770 bei der letzten Station ihrer Brautreise auf heimatlichem

134 Francisci Ernesti Brükmanni, D. Centuriae Tertiae Epistola Itineraria XXVIII Exhibens Memorabilia Viennensia [...]. Wolffenbüttel: [o.V.] 1751, S. 351f., 354. Schon Karl Friedrich Flögel, auf den sich fast alle folgenden Quellen beziehen, zitierte das Lied in seiner wegweisenden Geschichte des Groteskekomischen (1788) nach dieser Fassung, nicht nach dem angeblich im Wienerischen Diarium abgedruckten Original (der entsprechende Jahrgang des Wiener Diariums fehlt in der Österreichischen Nationalbibliothek). Vgl. auch Jakob Zeidler: Ueber Feste und Wirtschaften am Wiener Hofe während des 16., 17. und 18. Jahrhunderts. In: Jahrbuch der Oesterreichischen Gesellschaft vom weissen Kreuze 1890, S. I-XVIII, hier XV.

$135 \mathrm{Nagl} /$ Zeidler, Deutsch-Österreichische Literaturgeschichte, S. 698. 
Boden im Stift Lambach mit Lindemayrs Kurzweiligem Hochzeit-Vertrag verabschiedet. Das Mundartstück um die Hochzeit der Bauernkinder Jodl und Treinsch, das Vorbereitungen und Bräuche wirkungsvoll in Szene setzt, sollte der Dauphine in der Spiegelung der eigenen Situation wohl moralische Unterstützung geben. Denn Treinsch ist eine glückliche Braut, die ihre neue Rolle als Nachfolgerin akzeptiert und selbstbewusst ihre Vorzüge nennt:

Hanns. [...] Und, Treinsch, västeh mi recht:

Du gäst dä weil dö Dirn, dä Jodl gät’n Knecht.

I halt enk avä do, als meini rechten Kinä:

Du hast dös Bread, dös i: du kannst di drübä b’sinä.

Vägaimäz i ä mal; so seyd ös HErr, und Frau:

ä sodl is bän inns von Altäs he dä Brau.

Treinsch. Waist wohl, mir is ja recht: la gehn, i wills schon machä.

I han mein Arbät glernt, kann dreschen, mähn, und bachä,

Kann stöppen aufn Kiß, kann nähn mit Seidn, und Zwirn,

Kann mehlä Küh, und Gaiß, und hexisch Budä rührn.

Das kann i.

Margareth. Ja das kanns.

TReINSCH. Da wird mäs niemt a gwingä.

JoDL. Und tanzen.

Treinsch. Kann i ä.

Hanns. Kannst öppern ä schön singä?

TREINSCH. Recht ga klain kann ichs nöt.

Margareth. äs hat halt grad sei Gschäll.

JoDL. Geh sing!

TREINSCH. I wills probiern.

Hanns.

Spilleut hebts an däwäll. ${ }^{136}$

2 gäst dä weil] gibst derweil, du hast die Rolle 4 Bread] Brot (hier im Sinne von Unterhalt) 5 Vägaimäz] sterbe 6 ä sodl] so 10 mehlä] melken 12 a gwingä] etwas vormachen 15 öppern] vielleicht 20 hebts an däwäll] fangt gleich an

Das Stück endet mit der Aufforderung des Amtmanns an alle Hochzeitsgäste, in der Tracht nach Lambach zu gehen und dort den hohen Gast gebührend zu begrüßen. Tatsächlich hatten unmittelbar vor der Theateraufführung „60 baar von ledigen Bauren Bueben und Menschern“ ihre typischen Tänze zum Besten gegeben - inszeniertes Brauchtum als Abschiedsgeschenk und Souvenir für eine 14-Jährige, die ihre Heimat nie wieder sehen sollte. Ob sie das Libretto, das Mundartrede und standardsprachliche Prosaübertragung synoptisch gegenüberstellt, in Frankreich jemals wieder in die Hand nahm, ist nicht überliefert.

136 Kurzweiliger Hochzeit-Vertrag nach der natürlichen ob der Ennserisch-Bäurischen Mund- und Denkungsart, in gebundener Rede, zu Unterhaltung Ihro Königl. Hoheit der Durchlauchtigsten Frau, Frau Maria Antonia Erzherzoginn von Oesterreich, Dauphine von Frankreich; Als höchst dieselben den 23. April 1770. in dem Stifte Lambach übernachteten. Steyr: Gregor Menhardt [1770], f. 20f. 


\section{KÖRPER UND SINNLICHKEIT}

Als wesentliches ästhetisches Mittel konzeptioneller Mündlichkeit ist der Dialekt prädestiniert, Intimität auszudrücken und somit auch jene Dinge anzusprechen, die der normative Aufklärungsdiskurs aus der Literatur zu eliminieren versuchte. Denn obwohl die aufkommende Anthropologie im 18. Jahrhundert das Wissen über den Menschen und seine psychischen und physischen Funktionen in den Mittelpunkt des Erkenntnisinteresses rückte, tat man sich schwer, allzu betonte Sinnlichkeit und Kreatürlichkeit als imaginative Kompensate in einer Schriftkultur zu akzeptieren. ${ }^{1}$ Erst nach 1800 wird die postulierte Harmonie von Körper und Seele immer deutlicher als Utopie dekuvriert, die einen realistischen Blick auf die tatsächlichen Erscheinungsformen des Menschlichen blockiert. Hatte man mit der Darstellung von Brutalität weniger Hemmungen, waren Körperlichkeit, Anzüglichkeiten und ausschweifender Sinnesgenuss allenfalls in toposgeschichtlich gerechtfertigter mythologischer Einkleidung und Tradition akzeptabel. In der fingierten Mündlichkeit der Dialektliteratur allerdings hatte das Nichtaufschreibbare oder Nichtaufschreibenswerte stets ein Refugium. Ihre implizite Logik des Transitorischen, des flüchtigen Worts, entzog sich dem Anspruch des Bewahrens- und Verbreitenswerten, den Literalisierung vermittelt, und stellte somit ein Ventil dar für den Druck, der sich mit den Lern- und Transformationsprozessen der Sozialdisziplinierung in der Frühen Neuzeit stetig steigerte. ${ }^{2}$ Verstärkt durch die soziolektale Stigmatisierung der Protagonisten als eben jenen, die sich dem Projekt bürgerlicher Erziehung und Selbstoptimierung auch sprachlich verweigerten, war hier ein ästhetischer Gegenraum gegeben, in dem das Tabuisierte, Abstoßende und Obszöne seinen gleichsam , momenthaften' Ausdruck finden konnte. Als obrigkeitlich geahndeter Verstoß gegen Geschmack und Sitten der jeweiligen Zeit blieben freilich wenig überraschend nur marginale Bruchstücke dieser als minderwertig und anstößig erachteten ,Gegenkunst' in authentischen Quellen schriftlich erhalten. Auch in der Forschung fanden diese Dichtungen als ,apokryphe', nicht anerkannte Volkskunst in weiterer Folge nur wenig Beachtung; erst die mutigen Arbeiten von Friedrich S. Krauß, Emil Karl Blümml oder Gustav Gugitz zu Beginn des 20. Jahrhunderts präsentierten das Material für ein realistischeres, ideologisch unverfälschtes Gesamtbild der Volksdichtung. ${ }^{3}$

Eine zentrale Domäne des Dialektalen war die Verbalisierung des Kreatürlich-Triebhaften, das in der nähesprachlichen Formulierung die Pädagogisierungs- und Ratio-

1 Grundsätzlich dazu Wolfgang Iser: Das Fiktive und das Imaginäre. Perspektiven literarischer Anthropologie. Frankfurt a. M.: Suhrkamp 1992. - Hans Jürgen Schings (Hg.): Der ganze Mensch. Anthropologie und Literatur im 18. Jahrhundert. DFG-Symposion. Stuttgart, Weimar: Metzler 1994.

2 Vgl. Winfried Schulze: Gerhard Oestreichs Begriff der ,Sozialdisziplinierung in der Frühen Neuzeit‘. In: Zeitschrift für Historische Forschung 14 (1987), S. 287-317.

3 Vgl. dazu u. a. Rolf Wilhelm Brednich: Erotisches Lied. In: Rolf Wilhelm Brednich/Lutz Röhrich/Wolfgang Suppan (Hg.): Handbuch des Volksliedes. Bd. I: Die Gattungen des Volksliedes. München: Finke 1973, S. 575-615. 
nalisierungsbestrebungen der Aufklärung (die ja auch Verschriftlichung und Standardisierung vorantrieben) unterlief. Der karnevaleske Körper der grundsätzlich dialektal angelegten lustigen Figuren wie Hanswurst oder Bernardon und ihre Machtlosigkeit, ihn unter Kontrolle zu halten, entlasteten den Rezipienten vom Domestizierungsdruck und bescherten ihm die Lust des Tabubruchs, die Freude am Despektierlichen, das Lachen über die momentane Aufhebung aller Konventionen. ${ }^{4}$ Michail Bachtins groteskes Körperkonzept einer karnevalistischen Lachkultur mit ihren omnipräsenten Motiven des Verschlingens, Ausscheidens und des Sexuellen findet - trotz aller Hemmnisse bei Verschriftlichung und Überlieferung - auch im dialektalen Textkorpus seine Bestätigung. ${ }^{5}$ Ein nicht unbeträchtlicher Teil daraus wurde tatsächlich auch für die normunterwandernde Faschingszeit geschaffen. Koprolalische, also vulgär- und fäkalsprachliche Lieder zum standesaufhebenden Exkretionsdruck oder Krankheitsklagen wie die Bauer-BaderWechselgesänge um Verstopfungs- oder Dysenterieprobleme waren auch im Klosterumfeld aufführbar; Ekellieder, die mit Unappetitlichkeiten aller Art Schauer hervorrufen sollten, erfuhren im Lauf der Jahrzehnte ständige Umgestaltungen und konnten mit Fress-, Sauf-, und Fäkalkomik angereichert werden; Flohlieder brachten eine gequälte Leiblichkeit im Kampf mit dem Ungeziefer ins Bild.

Am seltensten findet sich freilich Libidinöses in schriftlicher Form, explizit Sexuelles, das über einen mehr oder weniger zweideutigen Anspielungshorizont hinausgeht. Die bekannt derben Vulgarismen eines noch nicht domestizierten Hanswurst sind nur in den seltensten Fällen tatsächlich auch textuell fixiert, waren sie doch üblicherweise Teil des Improvisationsspiels (und damit nicht zuletzt auch außerhalb des Zugriffs der Zensur). Deftigeres klingt auch in Camouflageformen diverser Textformate an, wo es sich als Lebensbeichte oder quasi-dokumentarische Berichterstattung über Nötigungsvorfälle tarnen kann. Dass es aber schon im 18. Jahrhundert auch dezidiert pornographische Literatur im bairisch-österreichischen Dialekt gegeben haben muss, legen handschriftliche Liedersammlungen aus dem zweiten Jahrzehnt des 19. Jahrhunderts nahe, deren Inhalt zumindest zum Teil schon in den Jahrzehnten zuvor im Umlauf war.

Vergleichsweise umfangreicher ist dialektale Literatur, die sich Liebe, Sinnlichkeit und die Beziehung der Geschlechter in etwas unverfänglicherer Weise zum Thema macht. Anrührend wirkt dies in simplen Liebesliedern nach alten volkstümlichen Mustern, anzüglich in anakreontischen Dichtungen mit ihren frivolen Sujets. Einen wichtigen Themenkreis stellen Werbedialoge dar, bei denen der Dialekt im Wechsel mit oberdeutscher Umgangssprache soziale Differenzierung markieren oder als homogene Sprechlage für ritualisierte Flirtformen im ländlichen Bereich dienen kann. Liebesverwirrungen sind ohnehin das Herzstück unzähliger Lustspiele, so auch im Bereich der Dialektburleske. Aber auch das Ende so mancher Liebesbeziehung im wüsten Ehe-Streit

4 Vgl. Müller-Kampel, Hanswurst, Bernardon, Kasperl.

5 Vgl. Michail Bachtin: Rabelais und seine Welt. Volkskultur als Gegenkultur. Aus dem Russischen von Gabriele Leupold. Hg. und mit einem Vorwort versehen von Renate Lachmann. 2. Aufl. Frankfurt a. M.: Suhrkamp 1998. 
ist ein Dauerbrenner auf den Bühnen und Stoff für Frauen- und Männerschelten in unzähligen Variationen.

\section{Kreatürliches, Krankhaftes und der Reiz des Ekelhaften}

Das ,lange' 18. Jahrhundert mit seiner tiefgreifenden Neumodellierung des gesellschaftlichen Miteinanders gilt als eine der prägendsten Epochen für Verhaltensweisen und Selbstverständnis des westlichen Menschen. Die ineinandergreifenden Prozesse der Disziplinierung, Pädagogisierung und Rationalisierung, die das öffentliche und private Leben in Europa determinierten, schufen verbindliche Vorstellungen davon, wie sich der angepasste Untertan im frühmodernenen Staat zu verhalten habe. ${ }^{6}$ Die mentalitäts- und identitätsgeschichtliche Überformung kultureller und sozialer Heterogenität bedingte allerdings, dass elementare Bedürfnisse des Individuums durch Fremd- und Selbstkontrolle immer stärker unterdrückt werden mussten. Die Teilhabe an einer ,zivilisierten Gesellschaft setzte Selbst- und Körperbeherrschung ebenso voraus wie Affektkontrolle und Hygienebewusstsein; in direkter Folge weiteten sich die Grenzen des Scham- und Ekelgefühls erheblich. Und diese Grenzen mussten auch sprachlich, zumal im öffentlichen Diskurs, eingehalten werden.

So groß der Anpassungsdruck aber auch war, bot Literatur immer wieder Gelegenheit, im Fiktionalen gesellschaftliche Bruchlinien aufzuzeigen, wo das Verdrängte, Verbotene, Unterdrückte wieder zum Vorschein kam. Zumal in der Lachkultur kamen solche Freiräume zur Geltung, in denen die repressive Macht der Disziplinierungsdiskurse für den Moment der ästhetischen Erfahrung keine Wirkung zeigte und das Abstoßende als Komisches zu einem provozierenden Gelächter gegen den Normierungsdruck anregen konnte. ${ }^{7}$ Bevorzugt wurden dafür Gattungen, die das Anomale, In-sichWidersprüchliche, Ambivalente, Inkommensurable wirkungsvoll und situationsflexibel herausarbeiten konnten. Dialektale, für die mündliche Verbreitung konzipierte Lieder waren besonders beliebt, entzogen sie sich doch ebenso wie die Extempores der lustigen Figuren leichter dem Zugriff der Zensurinstanzen, die sich im Verlauf des 18. Jahrhunderts immer gezielter auch auf Unterhaltungskunst konzentrierten. Im mündlichen Vortrag konnte Leiblichkeit noch vergleichsweise frei ausgelebt werden; hier vermochte das Sprechen über unmäßiges Fressen und Saufen, hemmungsloses Ausscheiden, zügellose Triebbefriedigung und groteske Tabubrüche das rigide sozialmoralische Korsett zumindest für einen kurzen Moment zu sprengen und dem disziplinierten Körper seine verlorene Freiheit zumindest für die Dauer des künstlerischen Erlebnisses zurückerstat-

6 Vgl. u. a. Norbert Elias: Über den Prozeß der Zivilisation. Soziogenetische und psychogenetische Untersuchungen. Bd. 1-2. 14. Aufl. Frankfurt a. M.: Suhrkamp 1989. - Philippe Ariès: Geschichte der Kindheit. Übersetzt von Caroline Neubaur und Karin Kersten. 12. Aufl. München: dtv 1996. - Michel Foucault: Dispositive der Macht: Über Sexualität, Wissen und Wahrheit. Berlin: Merve 2008.

7 Vgl. Michail M. Bachtin: Literatur und Karneval. Zur Romantheorie und Lachkultur. Frankfurt a. M.: Fischer 1990. 
ten. Wie sehr diese Art der Literatur tatsächlich im Alltag verankert war, lässt sich kaum mehr sagen; nur ein Bruchteil kam verschriftlicht auf uns.

\section{Der unzivilisierte Körper}

Schon die Überlieferungsgeschichte mancher dieser karnevalesken Texte verrät uns, wie sehr sie wider die Schicklichkeit verstießen. Ein Beispiel dafür ist etwa Maurus Lindemayrs Die zwey wüchtigsten Dinge, das mit einem gängigen derben Sprichwort als Refrain den ebenso alltäglichen wie konsensuell ,unbeschreibbaren' Vorgang des Ausscheidens zum Thema macht. Dass dieses Lied voll ausgelassener Fäkalkomik zweifelsfrei dem Benediktiner aus Neukirchen zugeordnet werden kann, ist nicht selbstverständlich. Denn die Differenz zwischen anlassgebundener Performanz und schriftlicher Tradierung, vielleicht auch der sich wandelnde Zeitgeschmack oder spätere Bedenken des Autors hatten eine Überlieferung seiner grobianistischen Frühwerke großteils unterbunden. Sie fehlen in den Liederbüchern seines Bruders Peter Gottlieb Lindemayr ebenso wie in den Konvoluten aus seinem näheren Umfeld. Immerhin scheint sie sein früherer Schüler, der Lambacher Regenschori Koloman Fellner, für charakteristisch und auch gelungen genug erachtet zu haben, dass er sie für seine geplante Werkedition auswählte und 1817 an den Linzer Verlag Eurich schickte. So konnten so urwüchsig-brachial komische Arbeiten wie Der kranke Bauer und der Dorfbader auf uns kommen, um ein anschauliches Bild der spätbarocken Unterhaltungskultur im Studenten- und Klosterbereich (zu Faschingszeiten) zu geben. In den Druck aber gelangten diese Lieder damals noch nicht. ${ }^{8}$ Zwar hatte die Zensur 1821 dem Duett zwischen Bauern und Bader die Imprimatur erteilt, nachdem sie ihm drei Jahre zuvor die Veröffentlichungstauglichkeit abgesprochen hatte, doch schreckte der Herausgeber offenbar selbst vor der Vulgarität zurück und nahm es nicht in das Textkorpus auf. Die zwey wüchtigsten Dinge scheint Fellner sogar selbst aus seinem Mundum gestrichen zu haben, denn hier fehlt sowohl der Beginn des Lieds als auch ein Zensurvermerk. Zum Glück ließen sich in anderen Sammlungen weitere Belege finden, die zwar (in den letzten Strophen) etwas von Fellners Fassung abweichen, im Allgemeinen aber nicht allzu weit vom Original entfernt sein dürften:

1

Was brauchts denn das Fratscheln, was brauchts denn das Fragn;

Ih will enk ja dWahrat schön rund auha sagn.

Wie oft saits mein Vata,

Da Hansel mein Gfata:

Mensch gib dih na gutwilli drein;

Denn g'schissen und g'storbn mußs seyn.

2

Fragts Köni, fragts Kaiser, fragts d'Herrn von Stand,

Fragts dLeut, dö in Stadtn, und dö aufn Land.

Wie wurds dirs niht reißen;

8 Maurus Lindermayr's [sic] Dichtungen in ob der ensischer Volksmundart. Von Verehrern seiner Muse gesammelt. Linz: In der k. k. priv. akademischen Kunst-, Musik- und Buchhandlung 1822. 
Wenns niht thatn scheißen;

Da thut sih kains spreizen, kains schreyn;

Denn g'schissen und g'storbn mußs seyn.

3

Z’Wien gibts enk Nachtköni, dö handln mit Dröck,

Sö führn enk dö grössesten Fässa voll weg.

Gehn auhi in d' Kamma,

Und scheissen braf z'samma;

Aft därft enks kain Mensch niht anschreyn.

Denn g'schissen und g'storbn mußs seyn.

4

In Klöstern gibts Scheishäusl grad nah da Wahl;

Steht ains an den andern, oft zwanz'g in air Zahl.

Bald fressen, bald saufa,

Aft scheißen fort laufa;

Sö thain sih aufs Alösen gfreun.

Denn g'schissen und g'storbn mußs seyn.

5

Beim Bauern haißts auf d'Gredn, wenn ma scheißn will gehn:

Wenn anders in Hof thut kain Scheishäusel stehn.

Aufs Schaf muß ma sitzen,

In Mist danhi spritzen.

Thain dKinder niht Gagerln a schreyn?

Denn g'schissen und g'storbn mußs seyn.

6

Ih wais's wie ain is, wenn mas Scheißn niht kann,

Da müssn enk d'Bader mit Spritzen geich d'ran;

Das Ding thuts aft zamma,

'n Dröck auha z'ramma;

Da Krank thut aufs Scheißn sih gfreun,

Denn g'schissen und g'storbn muß seyn.

7

Um dStadl da is's enk mit Haufen so voll;

's gibt Lenni, s'gibt Trümmer mit aileft halb Zoll.

Da lernt ainer s'Springa,

Wann ain d'Neoth thut zwinga;

Da laft ma zun Stadln, zun Zäun;

Denn g'schissen und g'storbn mußs seyn.

8

Bist groß oder klain, oder wild, oder schön,

Bist reich oder arm, mußt halt scheißn fort gehn.

Thut üns der Tod schmeißn

Haißts aufghört vom Scheißn,

Aft gebn ma üns gutwilli drein,

Denn g'schissn und g'storbn mußs seyn. ${ }^{9}$

1,1 Fratscheln] Gerede 1,2 enk] euch rund auha sagn] ungeschminkt sagen 1,3 saits] sagt es 1,4 Gfata] Gevatter, Taufpate 3,1 Nachtköni] Euphemismus für Toilettenreiniger, Kloakenräumer (der die Abortfässer entleerte) 4,1 Scheishäusl] Toilettenanlagen (in Klöstern üblicherweise bereits mit Wasserablauf) 5,1 Gredn]

9 Wienbibliothek im Rathaus, MH 6254 (Sammlung verschiedener Bauern-Lieder meistens von Rev. D. Pater Maurus [mit Bleistift von späterer Hand ergänzt: Lindemayr], Ordinis Sti Benedicti im Kloster Lambach, und Pfarrer zu Oberneukirchen. Siegmundi Diemberger), f. 3v-4r [mit Melodie]. 
hölzerne oder gepflasterte Stufe, vor allem bei Bauernhäusern (von der aus auch die Notdurft verrichtet werden konnte) 5,3 Schaf] hier wohl: Holzgerüst 5,4 danhi] weg, von einem weg 5,5 Gagerln] den Darm entleeren 6,3 thuts aft zamma] hilft dann dabei 7,2 Lenni] weiche, von weicher Konsistenz, beinah flüssige aileft] elf Zoll] Längeneinheit (nach dem Allgemeinen Maßpatent von 1754 entsprach das österreichische Zoll etwa $2,63 \mathrm{~cm}$ ) 7,4 d'Neoth] die Not 7,5 Stadln] Scheunen

Noch heute ruft das fäkalkomische Lied ähnliche Irritationen hervor wie damals. Zu rigide sind die Belange der Defäkation aus dem öffentlichen Diskurs ausgeschlossen, als dass man nicht über die dreiste Offenheit der Thematisierung verblüfft wäre, und nicht wenige werden sich wohl dabei ertappen, sich für ihr Belustigtsein zu schämen. Schon das Lachen über den grotesken Konventionsbruch selbst wird also als Konventionsbruch empfunden, da es die Berechtigung des kulturellen Wertesystems in Frage stellt, ob man es nun - mit Bachtin - als befreiendes Lachen empfindet oder - mit Kayser - als abgründiges Lachen, das an das Grauen grenzt. ${ }^{10}$ Die Komik als Vereinigung von Inkongruentem resultiert dabei aus der Attraktion des tabuisierten Abstoßenden. Natürlich ist die Rede auch hier einem Bauern in den Mund gelegt, dessen Stand man traditionell weniger ernste Zivilisationsbemühungen unterstellte. Die Botschaft ist bei aller Drastik aber eine simple Wahrheit: In ihrer Leiblich- und Endlichkeit sind alle Menschen vom ,Nachtkönig' bis zum Monarchen im Wesentlichen gleich - dies ist auch die Voraussetzung für ein gemeinschaftliches, normunterwanderndes Mitlachen, das sich abhebt vom disziplinierenden Lachen über jemanden.

Dass solche anspruchslosen Scherze quer durch alle Gesellschaftsschichten beliebt waren, versteht sich von selbst. Niedergeschrieben wurden sie aber wohl nur, wenn sich damit ein Mehrwert verband, z. B. jener einer interessanten, notierenswerten Melodie. Mit viel Glück bleiben diese Niederschriften erhalten, so etwa ein Notenblatt aus der Feder des Wiener Komponisten Johann Baptist Henneberg (1768-1822), der im letzten Jahrzehnt des 18. Jahrhunderts Kapellmeister am Freihaustheater war und dort u. a. maßgeblich an der Einstudierung von Mozarts Zauberflöte beteiligt war. Auch die beiden auf dem Blatt notierten Kanons über Harndrang und Flatulenz sollen im Beisein Mozarts entstanden sein, wie der Vorbesitzer dieses einzigen Überlieferungsträgers, Aloys Fuchs, vermutet. ${ }^{11}$ Viel Wahrheitsgehalt scheint diese Information aus verschiedenen Gründen nicht zu besitzen. Die Lieder - nach eigener Auffassung „gut in nassen Gesellschaften zu gebrauchen“ - zeigen Merkmale des Improvisatorischen und schnell zu Papier Gebrachten; Henneberg verfasste die Musik wohl zu eigenen Worten, die im Prozess der Niederschrift noch überarbeitet wurden.

10 Vgl. Wolfgang Kayser: Das Groteske. Seine Gestaltung in Malerei und Dichtung. Oldenburg/Hamburg: Stalling 1957.

11 Vgl. den Zusatz am Schutzblatt: „3 sehr laszive Canons nicht vor Jedermanns Einsicht geeignet - wohl aber bei nassen Gesellschaften unter Männern gut zu gebrauchen. 1. die beiden Canons auf der $1^{\text {ten }}$ Seite sind von + Theaterkapellmeister Johann v Henneberg (intimmer Freund von Mozart - componirt u geschrieben." (Staatsbibliothek zu Berlin, Mus.ms.autogr. Henneberg, J. B. 2M). 


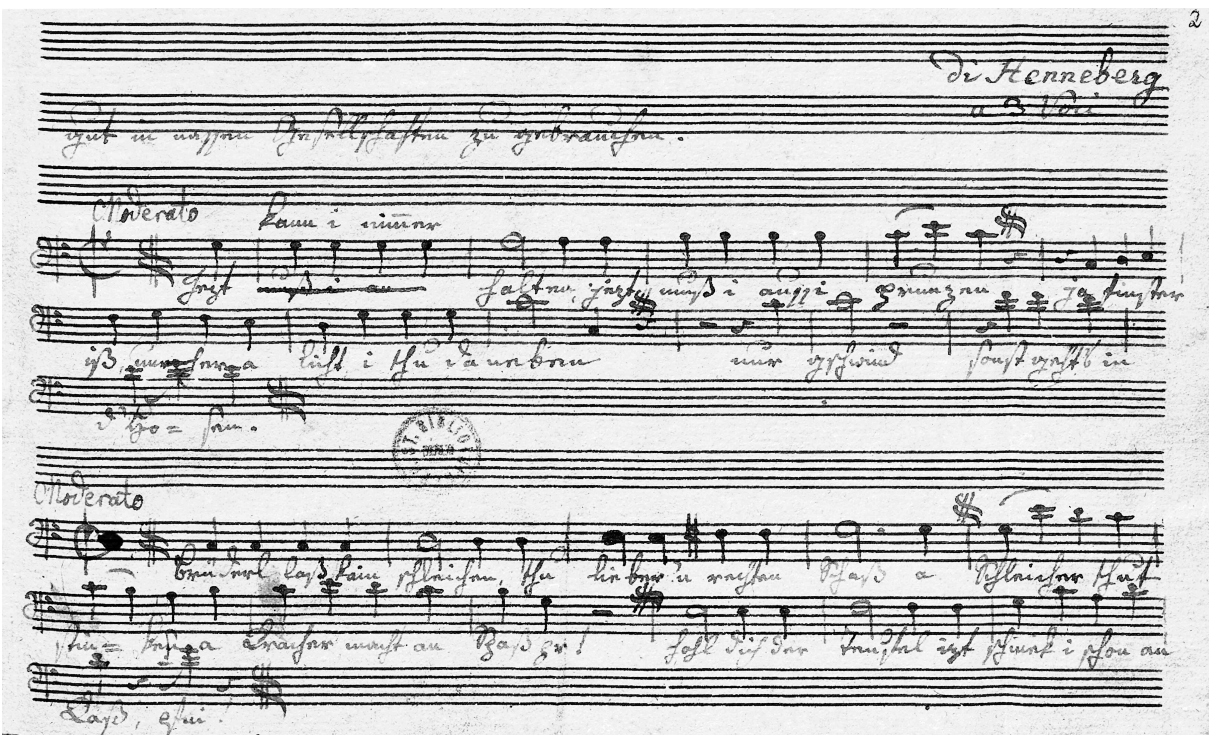

Abb. 41: Notenblatt mit zwei Kanons von Henneberg (Staatsbibliothek zu Berlin, Preußischer Kulturbesitz, Musikabteilung mit Mendelssohn-Archiv), Mus.ms.autogr. Henneberg, J. B. 2M, f. 2r).

1

Jetzt kann i nimmer halten, jetzt muß i aussi prunzen ja finster iß, nur her a Licht $i$ thu daneben nur gschwind sonst geht's in d'Hosen.
2

Brüderl laß kain schleichen, thu lieber 'n rechten Schaß a Schleicher thut stinken a Kracher macht an Spaß pr! hohl dich der Teufel izt schmek i schon an Kaß, pfui! ${ }^{12}$

1,2 aussi prunzen] hinausurinieren 2 Schaß] Furz

Der wohl fälschlich erstellte Konnex dieser Kanons zu Mozart ergibt sich aus der Freundschaft Hennebergs und der bekannten Vorliebe des Salzburger Genies für derbe sprachliche und musikalische Späße, von denen er genügend selbst fabrizierte. ${ }^{13}$ Bis heute gern gesungen wird etwa sein pseudolateinischer Kanon Difficile lectu mihi mars (1786/87, KV 559), dessen skatologische Komik sich erst in der dialektnahen Umsetzung entfaltet. ${ }^{14}$ Mozart schrieb ihn als Schabernack auf Kosten seines Freundes, des Baritons Johann Nepomuk Peyerl, dessen starker niederbayerischer Akzent und Aussprachegewohnheiten die Vulgarismen beim ersten Probesingen zum Amüsement der

12 Ebda., f. 1r.

13 Berühmt sind vor allem die koprolalischen Witzeleien in Mozarts Bäsle-Briefen, wo Formulierungen wie „ich scheiss dir auf d' nasen, so rinds dir auf d'koi [= Kinn]“ (Brief vom 5. November 1777, vgl. http:// dme.mozarteum.at/DME/briefe/letter.php? mid=928\&cat=, letzter Zugriff am 14.05.2018) eher die Regel als die Ausnahme sind. Vgl. de Grauwe, Sie sehen also, daß ich schreiben kann wie ich will.

14 Vgl. Gottfried Weber: Ueber eine Originalhandschrift von Mozart. In: Cäcilia. Eine Zeitschrift für die musikalische Welt I (1824), S. 179-182, hier $179 f$. 
Zuhörerschaft besonders deutlich hervortreten ließen. Unter Gelächter sang dann der Freundeskreis - so will es zumindest die Anekdote - den bereits auf der Rückseite desselben Notenblatts notierten Spottkanon $O$ du eselhafter Peierl (KV 560a). ${ }^{15}$ Interessanterweise wurde in der Forschung der erste Grobianismus, der sich durch die damals ungebräuchliche Aussprache des lateinischen , $c^{c}$ vor hellem Vokal mit [k] ergibt (,di fick $\mathrm{i}^{\prime}=$ dich ficke ich), bislang nicht wahrgenommen, obwohl derartige Scherze gerade im katholischen Umfeld beliebt waren (vgl. in der Umkehrung etwa Angerers Prob der Gratulation, Kap. 6). Dazu kam die an Goethes Götz gemahnende Aufforderung ,leck du mi in Ars'; abgerundet wurde der Scherz durch die aus den Wiederholungen resultierende Betonung des italienischen Tabuworts ,cujoni' (coglioni = Hoden, Eier).

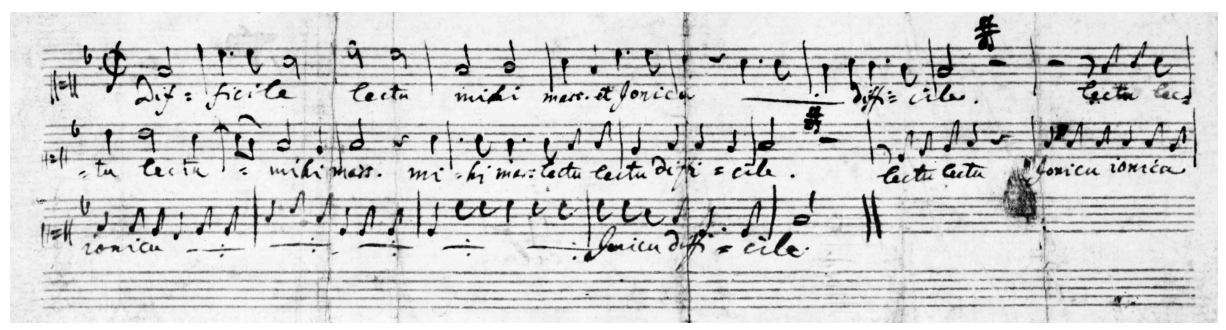

Abb. 42: Autograph Mozarts zu Difficile lectu mihi mars (@ The British Library Board, Zweig MS 58).

Mit der Lust am koprolalischen Tabubruch spielen auch Vexierlieder wie Hört was ich will verkün- kün- künden, dessen Reimschema jeweils im zweiten Vers eine Erwartungshaltung beim Publikum aufbaut, die zwar verbatim nicht eingelöst wird, doch keinerlei Zweifel an der eigentlichen Aussage und Intention lässt. Die Reimverweigerung bzw. ostentative Ablenkung, die bewusst in banale, unverfängliche oder völlig zusammenhanglose Bereiche führt, bietet nicht nur einen zusätzlichen wirkungsästhetischen Reiz, sondern stellt auch einen gewissen Schutz vor obrigkeitlichen Konsequenzen dar (nicht zuletzt deswegen wurde sie gerne auch im politischen Kontext verwendet).

1

Hört was ich will verkün-kün-künden, wann ich hätt Augen hin-hinhin und her durch das Vexirn, fahrt man manchen durch das Hirn, durchs Vexirn.

3

Laß dir ein Zahn ausrei-rei-reissen, und in die Lucka schei-scheiScheider kliebn, in Ofn schiebn, daß wir ein warmes Stübel kriegn, Ofen schiebn.
2

Ich stund bei einer Ai-Ai-Aichen, und thät als wolt ich sai-saiSaiten-Spiel und Vogl-Gsang, klinget schön und wärt nicht lang, Vogl-Gsang. 4

Auf die Bratt-Wurst und Blun-Blun- Bluntzen, muß man schier allzeit brun-brun-

Brunnen-Wasser lassen seyn, trinken einen guten Wein, lassen seyn.

15 Vgl. Mozart, Neue Ausgabe III, Werkgruppe 10, S. XIV. 
5

Wann ich iß Rättich-Wur-Wur-Wurzen, muß ich gleich darauf fur-furFurchen machen mit dem Pflug, und hab noch nicht geessen gnug, mit dem Pflug.

7

Wann ich thät einen la-la-lassen, wer will der kann ihn fa-fa-

Fasten ist vor vil nicht gut, macht ein melancholisch Blut, vil nicht gut.

9

Jetzt möcht ich noch eins wi-wi-wissen, wer ein möcht hinten kü-kü-

Kisel-Stein und enge Schuh, macht im Podagra vil Fluch, enge Schuh.

11

Ich kann nicht länger bleib-blei-bleiben, Ich muß ein wenig spei-speispeisen, sonst komm ich zu spat, essen muß man, wann mans hat, sonst ists z'spat.
6

Wann man frißt harte Spei-Spei-Speisen, ist gut wann man thut schei-scheiScheiben-schiessen ist schon fein, wanns nur kein geht hint hinein, ist schon fein.

8

Jetzt thuts ein wenig lo-lo-losen, obs nicht kracht in die Ho-HoHollehippen iß ich gern, wann sie nur neubacken wärn, $\mathrm{i} ß$ ich gern.

10

Ich muß zum alten Ge-Ge-Gecken, muß ihn ein wenig le-le-

Lecker-Bißl seynd schon gut, stärkt das Herz, und frischt das Blut, seynd schon gut.

12

Jetzt legt sich Köchin ni-ni-nider, und streckt aus ihre Gli-GliGlider seynd bald brochen ab, wann man fallt die Stiegen ab, brochen ab. ${ }^{16}$

1,3 Vexirn] (lat. vexare: schütteln, plagen) Necken, Ärgern 2,2 sai-] (Reimerwartung) saichen: urinieren, harnen 3,3 kliebn] (Holz) spalten 4,1 Bluntzen] Blutwurst 4,2 brun-] (Reimerwartung) brunzen: urinieren, harnen 6,3 Scheiben-schiessen] Zielschießen auf Schussscheiben 8,1 losen] zuhören 9,4 Podagra] Fußgicht (schmerzhaftes Großzehengelenk)

Das Lied scheint in dieser Flugschriftfassung (vermutlich aus Oberösterreich, 2. Hälfte des 18. Jahhunderts) bereits einigermaßen zersungen und erweitert, mit einer relativ schwachen dialektalen Ausgestaltung, die in Verbindung mit einer für oberdeutsche Bereiche zuweilen ungewohnten Lexik vermuten lassen, dass sein Ursprung nicht im Überlieferungsgebiet liegt.

$\mathrm{Zu}$ den bekanntesten lyrischen Arbeiten der Wiener Spaßliteratur des 18. Jahrhunderts gehört Philipp Hafners Der lächerliche Philosoph, das nicht nur in seine Gedichtsammlung Scherz und Ernst in Liedern aufgenommen ist, sondern sich auch als Einlage im Lustspiel Die dramatische Unterhaltung unter guten Freunden (1763) findet. Es kombiniert im dreimaligen Wechsel eine barocke Vanitas-Elegie mit der derben Unverschämtheit des Schnaderhüpfels und spielt als zusätzliche Pointe im jeweils letzten Vers der Dialektstrophe mit Erwartungshaltungen; am auffälligsten in Str. 3 und 4:

In stiller Einsamkeit

Herrscht ungestöhrte Freud;

Gesundheit, Ruh, Betrachtung,

Der eitlen Lust Verachtung

16 Drey neue Weltliche Lieder. Das Erste. Hört was ich will verkün-kün-künden, wann ich etc. Das Zweyte: Lusti Guraschi, jetzt ist mein Jahrl aus, Bauer richt etc. Das Dritte: Armes Herz hör auf zu etc. Gedruckt in diesem Jahr. [o. O., o. J.], f. 1v-2v. 
Und Kenntnis dieser Welt

Die Mancher in Städten für seinen Abgott hält.

Des Hannsgörg sein Mensch is a garstiger Bär

Und er nihmts beym Kragen und halßts no prav her

$\mathrm{Na}$ ! das weis i gwiß

A so a wilds Gfris

Die thät i nit halsen

Wanns Reichsthala hät. ${ }^{17}$

4,2 halßts ... her] umarmen und küssen 4,4 Gfris] (hässliches) Gesicht

Weitgehend der Vorstellungskraft des Publikums überlassen war der Konventionsbruch in einem populären Scherzlied, das - zuweilen unter dem Titel Über das Wort Thun - in handschriftlichen Sammlungen und Flugschriften seit den 1770er Jahren überliefert ist. Hier eröffnet die verzögerte Informationsvergabe im ersten Strophenteil im Zusammenspiel mit dem Refrain einen weiten Bedeutungsspielraum, der je nach Intention genutzt und in der Zielrichtung beliebig erweitert werden konnte. Hier der Beginn einer 12-strophigen Fassung aus Oberösterreich:

1

Brüedä seits lusti, frisch, und rund,

Thaimä präf zamä, daß is gsund,

Seits lusti, und nit trauri.

I thue däs meini, du thuest däs deini, än jedä thuet däs seini.

3

Dä Genäräl thuet mit allen Gwalt, Er thuet so stark, däß donnert, und knalt, mit Pumern heraus schiessen.

I thue $p$

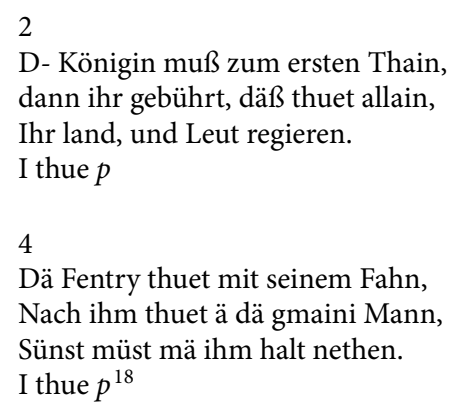

1,2 Thaimä] tun wir (es) zamä] zusammen 2,1 Thain] tun 2,4 p] (Abk. für lat. perge: fahre fort) usw., etc. 3,1 Pumern] Kanonen 4,1 Fentry] Fähnrich 4,3 nethen] zwingen

Dominiert bei den ältesten bislang bekannten Fassungen noch die Freude an koprolalischen Tabubrüchen, sind in den verschiedenen Adaptionen des 19. und 20. Jahrhunderts die Anspielungen, was denn die verschiedenen Standesvertreter so ,tun', immer öfter auch sexuell konnotiert.

\section{Verlachte Krankheit}

Die unverhohlene Präsentation des Degoutanten, dessen Thematisierung aus dem zivilisierten Diskurs ansonsten ausgeschlossen ist, stellt eine affektive Sensation dar, ist Ekel doch eines der elementarsten menschlichen Gefühle, das nicht nur moralische oder ästhetische Abwehrreaktionen provoziert. ${ }^{19}$ Auch körperliche Auswirkungen kann

17 Scherz und Ernst in Liedern, Zweyter Theil. Verfaßt von Philipp Hafner. Wien, gedruckt und verlegt bey Joseph Kurzböcken, auf dem Hofe. 1764, S. 22.

18 Oberösterreichisches Volksliedwerk, HS 379a, f. 10v-11r. Vgl. Neuhuber, Mein Gott, warum hast das Rabm Vieh erschafen, S. 116f.

19 Vgl. Winfried Menninghaus: Ekel. Theorie und Geschichte einer starken Empfindung. Frankfurt a. M.: Suhrkamp 1999. 
das Überschreiten der Ekelschranken zeitigen: Konvulsionen, Würgereflex und Brechreiz ebenso wie Abwehrlachen, ja sogar - wie Sigmund Freud gezeigt hat - Erregung. ${ }^{20}$ Worauf wir so stark reagieren, ist freilich stark kulturell geprägt und orientiert sich dementsprechend am jeweiligen Lebensraum und den sich ändernden Verbotsdimensionen. Die Tabuisierung und moralische Verurteilung des Abstoßenden ist ein Signum des fortschreitenden Zivilisationsprozesses. Den Ästhetikern des 18. Jahrhunderts war das Ekelhafte in erster Linie das Gegenteil des Schönen, das als Genuss am Unendlichen das allzu Natürliche als Ausdruck des hässlichen, verfallenden, verfaulenden Lebens schlechthin ausblenden muss. Als genuin eklig identifizierten sie körperliche Zeichen des Alterns, Körperöffnungen und ihre Ausscheidungen sowie Verwesung. ${ }^{21}$ Auch Kant konnte sich der irritierenden Faszination des Ekelhaften nicht entziehen, das als vernunftbedrohende „starke Vitalempfindung “22 die höchste Aufmerksamkeit einfordere und zu dem er in seinen Reflexionen zur Anthropologie (neben einigen anderen kuriosen Vermerken) ,[g]erade zu das faule und excremente des thierischen Korpers überhaupt. Ekle Krankheiten ${ }^{\text {“23 }}$ zählte.

In der Kunst kommt dem Widerwärtigen als Wirklichkeitsanker für den schönen Schein gleichwohl eine wichtige Rolle zu, indem es lustvoll die abstoßende Differenz zum Ideal herausarbeitet. Gerade in einer Zeit, in der von Theoretikern wie Winkelmann, Herder oder Lessing der formvollendete Körper am Leitbild der antiken Kunst zum Inbegriff des Schönen stilisiert wurde, übernimmt die ästhetische Gestaltung des defizitären Körpers eine wesentliche Entlastungsfunktion vom Druck der immer rigider formulierten gesellschaftlichen Normen. Naheliegend war dafür die Thematisierung der von Kant angeführten, eklen Krankheiten' in grobianistischen Spaßliedern, die den Körper als fehleranfälliges System zeigen, das mit den beschränkten Mitteln der Heilkunst am Land nur selten zufriedenstellend wiederhergestellt werden konnte. Eine kontextuelle Einbettung für das Vergnügen an koprolalischen Normverstößen boten die beliebten Bauer-Bader-Dialoge um Verdauungsprobleme kleinerer oder größerer Natur. Ein besonders derb-skatologisches, in der dramaturgischen Gestaltung der Ekelrede aber auch hochkomisches und kulturhistorisch höchst aufschlussreiches Beispiel stammt mit Der kranke Bauer und der Bader (um 1750) wieder vom Lambacher Benediktiner Maurus Lindemayr. Die Lust an der Zurschaustellung des Kreatürlichen, an der Inszenierung des durch den Zivilisationsprozess Verdrängten, am Tabubruch einer öffentlichen Befreiung des unterworfenen Körpers garantierte offensichtlich auch in höheren Bildungsschichten den Lacherfolg; im Volksgesang hielt sich der Wechselgesang nachweislich bis ins 20. Jahrhundert: ${ }^{24}$

20 Vgl. ebda., S. 275-332.

21 Vgl. Stephanie Bölts: Krankheiten und Textgattungen. Gattungsspezifisches Wissen in Literatur und Medizin um 1800. Berlin/Boston: de Gruyter 2016, S. 127.

22 Zitiert nach Menninghaus, Ekel, S. 173. Vgl. dazu auch Jürgen Vogt: Starke Gefühle. Zu den prärationalen Grundlagen ästhetischer Erfahrung. Teil 1: Kants Ekel. In: Zeitschrift für Kritische Musikpädagogik (2007), S. 54-71, http://www.zfkm.org/07-vogt.pdf (letzter Zugriff am 20.05.2018).

23 Zitiert nach Menninghaus, Ekel, S. 188.

24 Vgl. Tiroler Volksliedwerk A 2712. 
1

Der Bauer.

Mein liebä Maistä Badä, mein Hof ist übel dran

Der Bue, der Knecht, und i sein krank, da schau dös Gsaichät an!

Der BADER.

Mein liebä Nachbä Veitl, wo hast denn dein Västand

Hast all drei Brunzät zsamagschüt, wie glaub ichs aussänand?

2

Der Bue, der nahm das Glasl, und brunzät zersten drein

In d' Mitten hat der Knecht drein gsaicht, das öbrist ist das mein.

I derf dein Gsaich nit kosten, i siech mä so schon gnue

d Franzosen hast du wirklä schon, d Pedetschen kriegst dazue.

3

Wär i än Apotheckä, wär i ä gscheidä Mann

d Leut gäbn mirs Geld fürs Scheissen gehn, sö hätn än Drök davon.

Geh laß dir d Puls gschwind greiffä, du schaust galhänti drein

Wann dir ä Hehn auf d' Nasen schiß, kuntst ä nöt gelber sein. 4

Ob i thue hänti scheissen, das hast ja nöt väkost

Mein Lo brennt mit mortalerisch, i main, es ist verroßt.

Das ist dö goldä Ader, da taugt än Eglläß

Dö zuzeln bräv dein Arschloch aus, aft kriegst ä saubäs Gsäß.

5

Hab i dö goldä Ader: so derfst mi nöt kurirn

I kann ja mit Dukaten Dröck mein Weib und Kind dänihrn.

Dö goldä Ader tragt dä mein Veidl gar nix ein;

dö Gall, dö ist ä lauter Dröck, bei dir mueß gschissen sein.

6

Ja wann i nur kunt scheissen, i het schon lengst purgirt

Mein Dröck ist wie än Eisenkeil, so schwär und pumpähört.

Friß Mana sauf Rhebarbara, mit foli seni Brüh

Das schwaibt dän Dröck glei Emmaweis und Supenleen von dir.

7

Es war schon recht das scheissen, thät aber ä gern speibm

So kunt män Drök halt unt und oben, auf einmal aussi treibn.

Friß Springkern, vitri moni, tartari medici

Aft speibst ön Dröck per vomito auf deutsch haißts übäsi.

8

O lieber Bader Christl, du bist ä glehrtä Mann

Kannst allen Dröck lateinisch sagn, und steht dir recht gut an

Da hast ä Vomitivi, ist für ä Roß ä Chur

Das schwaibt dä 'n Drök und Tröbern aus, und riegelt dä d' Natur.

9

Wie mueß i mi vähalten, wie mueß ichs nehmä ein

Daß d' halt mein Maistä Badä, zum Dröck kannst Gvader sein.

Da nihm, und friß das Stüpl, und leg di glei ins Beth

Aft scheißt, und speibst ä Lackä drein, zwölf Dröscher fressens nit.

10

Der Bue, der fangät znächsten, zum fantasirn an

Mir hat er aufn Buckel gsaicht, und d Muedä schiß er an.

Der Bue hat Dissenteri, und braucht än fösten Spund

I mueß iem halt sein Lo väkeiln, aft wird er wieder gsund. 
11

Du machst mir än Vertrauä, i hab auf di Kredit

In Buebm, den thuest du 's Loch väkeiln, für 'n Knecht giebst ä was mit.

Was thuet dä Knecht denn ahnden, was thuet iem denn so weh

Du muest män Dröck vätraulä sagn, sonst scheiß i drein von eh.

12

Der Knecht der ist so gfährli, das uns schon wirkli graußt

Denn 's Gröb, und Därm und d Kudlfleck, des hengt iem alls heraus.

Der Knecht hat ä Rupturum, und hat iehms 's Nözel zsprengt

Weil iehm die ganz Viserio in Scrotum aussähengt.

13

Waist wohl der Knecht hat schmerzen, und liegt auf allen Viern

Er schreit ganz Täg und Nächt wie ä Sau, wir möchtens Ghör verliern.

Sag hats 'n gar nie brochä, wie schaut sein sedum her

Auf deutsch haißts, wie ä scheissen thuet, aft frag i nimmermehr.

14

Sein Arschlo kann izt rasten, das ist ä noier Gspaiß

Der Dröck geht iem beim Maul izt aus, als wie ä Glut so haiß.

Da mueß i niedä sizen, das macht mi erst studirn

Da haißts halt, gschissen ist nöt gmahln, Der Knecht wird abmäschirn. ${ }^{25}$

1,1 Bader] vor allem im ländlichen Bereich tätiger Heilkundiger für kleinere chirurgische Eingriffe, Wundversorgung, Knochenbruchbehandlung, Zahn- und Augenheilkunde u. a. 1,2 Gsaichät] ,Gesaichté: Harn, Urin 1,3 Veitl] Diminutiv zu Veit, Vitus 1,4 Brunzät] ,Gebrunzé: Harn, Urin 2,1 Glasl] gemeint ist hier das Uringlas (Matula), in dem der Morgenharn gesammelt und dem Bader zur Harnschau vorgelegt wurde brunzät] urinierte zersten] zuerst 2,2 drein gsaicht] hineinuriniert öbrist] oberste 2,3 derf] muss 2,4 Franzosen] Franzosenkrankheit (Morbus gallicus), Syphilis Pedetschen] (franz. petechie, neulat. petechia) punktförmige kapillare Haut- oder Schleimhautblutung; unter Petetschen verstand man zumeist das mit dieser Symptomatik verbundene Fleckfieber (Petechialtyphus), aber auch Typhus oder Blattern 3,2 Drök] Exkremente, Kot 3,3 galhänti] gallenbitter; auch verzwickt, grämlich 4,1 hänti] bitter, herb, von ekelhaftem Geschmack väkost] verkostet: die orale Kotdiagnose war allerdings auch in der Volksmedizin nicht üblich 4,2 mortälerisch] mordsmäßig, ungeheuer, furchtbar 4,3 goldä Ader] goldene Ader (Euphemismus für Hämorrhoiden) Eglläß] Blutabnahme mittels Blutegeln 4,4 zuzeln] saugen 5,2 dänihrn] ernähren 6,1 purgirt] (lat. purgare: reinigen) ausgeschieden, entleert 6,2 pumpähört] sehr hart 6,3 Mana] Manna: manitolhaltiger Blutungssaft der MannaEsche (Fraxinus ornus), der bis heute Abführmitteln beigegeben wird Rhebarbara] Rhabarber (aufgrund der Anthranoidhaltigkeit zuverlässiger Stuhlganganreger) foli seni] (falscher Plural zu lat. folium sennae) Extrakt aus Blättern der Sennapflanze (senna alexandrina), regt im Dünndarm die peristaltischen Bewegungen an und den Stuhlgang; auch heute noch eines der zuverlässigsten Abführmittel 6,4 schwaibt] schwemmt Supenleen] weich, beinahe flüssig 7,1 speibm] erbrechen 7,2 aussi] hinaus 7,3 Springkern] Pl. zu Springkorn: Samen der kreuzblättrigen Wolfsmilch, der stark abführend und brechreizend wirkt vitri moni] (entstellend für lat. vitrum antimonii) Spießglanz, in der Heilkunde u. a. als Hauptbestandteil des ,Brechweinsteins‘ eingesetztes Halbmetall tartari medici] (falsche Pluralform zu lat. tartarus medicus) medizinischer Weinstein, eines der gebräuchlichsten Brechmittel in der Volksheilkunde 7,4 Aft] dann per vomito] (lat. per vomitum) durch Erbrechen, durch das Erbrochene übäsi] von unten nach oben hin 8,3 Vomitivi] (fälschlich für) Vomitivum: Brechmittel, Emetikum 8,4 Tröbern] Residuum von ausgepressten oder ausgekochten Dingen, hier: Speiseabfälle, Verdauungsreste rigeln] lockern, aufrütteln, in Bewegung bringen 9,2 Gvader] Taufpate 9,3 Stüpl] (Diminutiv zu Stupp) Staub, (Arznei-)Pulver 9,4 Lackä] Lache, Pfütze Dröscher] Knechte, die für die kräfteraubende Drescharbeit eingesetzt wurde und deswegen erhöhter Nahrungszufuhr bedurften 10,1 znächsten] kürzlich, neulich 10,2 Buckel] Rücken 10,3 Dissenteri] Dysenterie: Ruhr (schwere Durchfallerkrankung) 11,1 i hab auf di Kredit] ich vertraue dir 11,3 ahnden] sich beschweren 11,4 von eh] von vornherein 12,1 gfährli] gefährdet 12,2 Gröb] Organe, die durch die Atmung in Bewegung sind, auch die Lunge selbst Kudlfleck] Kuttelfleck (hier:) Innereien 12,2 Rupturum] (fälschlich für lat. ruptura: Riss) Einriss, Durchbruch eines inneren Organs Nözel] (Diminutiv zu Netz) Bauchfell 12,4 Viserio] (fälschlich für lat. viscera) Eingeweide Scrotum]

25 Lindemayr, Dialektlieder I, S. 132-135. 
(lat. scrotum) Hodensack 13,3 sedum] (fälschlich für lat. sedes) Stuhlgang, Stuhl 14,1 Gspaiß] Spaß 14,2 Der Dröck ... aus] bei Darmverschluss staut sich der Darminhalt bis in den Magen, bis es zum Erbrechen kommt 14,4 abmäschirn] abtreten, sterben

Trotz aller sprachlichen Drastik (oder vielleicht gerade wegen ihr) gibt das Lied ein instruktives Bild der Behandlungsmöglichkeiten, die sich der bäuerlichen Bevölkerung im Krankheitsfall boten. So bizarr das Renommieren des Dorfbaders mit entstellten lateinischen Krankheitsbezeichnungen und Heilmitteln auch anmuten mag - die vorgeführten medizinischen Anamnese-, Diagnose- und Behandlungsmethoden zeigen ihn auf der Höhe seiner Zeit, auch wenn die exzessive Behandlungsweise oder die bedrohliche Häufung der anempfohlenen hochwirksamen Remedien Schlimmes vermuten lassen. Nach der Uroskopie auf Basis der Galen'schen Humoralpathologie, der Patientenbefragung und der Pulsdiagnose werden Vomitiva und Klistiere zur Entgiftung des Körpers ebenso in Erwägung gezogen wie ein Aderlass zur Kreislaufkorrektur und eine Blutegelkur zur Gefäßbehandlung bei Hämorrhoidalleiden. Heilmethoden also, die auch in der Alternativmedizin wieder zunehmend Akzeptanz finden. Auch die verschiedenen namentlich empfohlenen Mittel sind vielfach heute noch in Gebrauch oder zumindest Bestandteil naturmedizinischer Präparate.

Es ist also weniger der medizinische Kenntnisstand der Zeit, dem hier die Kritik galt. Zum Lachen gebracht werden sollte das Publikum vor allem durch die rigorose Benennung der Ausscheidungsprozesse und durchaus bedenklichen Krankheitsbilder, die im Behandlungsgespräch zwar sinnvoll sein konnte, doch schon zu dieser Zeit nicht nur im öffentlichen Diskurs kaum tolerabel war. Selbst der Bader hat seinen Anteil daran, dass in die an sich emotionslos zu gestaltende Pathographie wieder der Ekel Einzug erhält, wenn er ungustiöse Vergleiche („zwölf Dröscher fressens nit“) ins Spiel bringt. Einen besonderen Reiz aber musste das Lied für das durchwegs lateinkundige Zielpublikum (vermutlich bei einer Faschingsaufführung des Lambacher Konvents) durch die Diskrepanz von tatsächlicher medizinischer Terminologie und deren Verstümmelung in der Rede des akademisch ungebildeten Baders haben. Ein Küchenlatein, das gleichwohl mächtigen Eindruck auf den Bauern macht und ihm Vertrauen einflößt - ein Phänomen, das sich bis heute beobachten lässt.

Mehrfach überliefert ist ein weiterer brachialkomischer Wechselgesang nach diesem Muster, der wie eine direkte Fortsetzung zu Lindemayrs Duett anmutet, kommt hier doch ein Bauer zum Bader, weil die Abführmittel der letzten Behandlung hartnäckigen Durchfall hervorgerufen haben. Auch die charakteristische metrische Form der elf Wechselstrophen lassen an ein Abhängigkeitsverhältnis denken. Die sprachlich und inhaltlich deutlich simplere Durchführung mag jahrzehntelangen Umsingeprozessen geschuldet sein. Hier der Beginn einer Fassung aus einer Handschrift, die im Anschluss ein weiteres Lindemayrlied überliefert:

1

Willkomb mein Lieber Badä Bist schon ä Gscheidä man, mit mir wills halt nit Bösser wern, was fang ich wohl noch an?

Lippl lieber Nachber was fehlt dir den schan mehr,

Bist z nägstn ja erst dadä gwöst kimmst heut schan wider her. 
2

Ja schau mein Lieber Bader, ös ist hallt d'sach ä so,

Seith dem däs du mir ein hast göbm so han ich d'scheissn noch,

Lippl sey kain Läppl los du den Ding sein gang

Den wanst du nimmä scheissn kanst, so wird dir widä Bang.

3

Es wär schan recht mein Badä ös ist halt doch ä Laid,

schau wan ich nur än schais will thain, so geht der Tröckh in d'Pfaid

Lippl las bräf krachen, und mach dier da nix draus,

vnd wan der tröckh in d'hosn geht, so wischn wider aus.

4

Schau nur mein liber Bader da han ich halt ains than,

und han heut in dös gläsl Brunzt, geh schaus ä wenig an,

Lippl lieber Nachber das Ding sicht gfärhlä aus,

ich will dir ä Mixtur ein göbm, wan dir nur nit dran graust.

5

Nä nä mein Lieber Bader nä grausn thuet mir nit,

wan ich nur krat wie andre Leuth von scheissn hätt än frid

so Bist Bräf mein Lippl, wan du wilst Bösser sein,

So scheis nur in dein käppl, und nimbs hibsch warmer ein.

[...]

7

No itzt mein lieber bader hab ich än trunkh schan than,

Er schmöckht mir nit, ich glaub ja nit däs ih mehr trinkhn kan.

Lippl sey kain Läppl thue nur än zukher dran,

und immä nur gschwind eini, und schaun nit lang an. ${ }^{26}$

1,4 z nägstn] kürzlich, neulich dadä] hier 2,3 Läppl] Dummkopf 3,2 schais] Furz, Darmwind Pfaid] Hemd 4,2 Brunzt] uriniert

Abb. 43: Willkomb mein liebä

Badä (Österr. Nationalbibliothek, Musiksammlung, Mus.Hs. 19180, f. 1r).

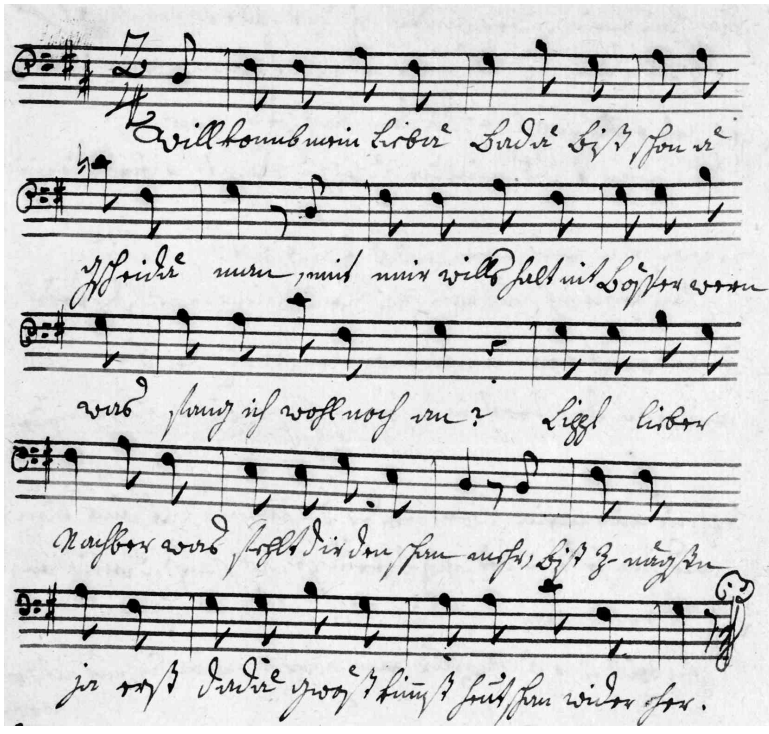

26 Österreichische Nationalbibliothek, Mus.Hs. 19180, f. 1r-2r. 
In dieser Tonart geht es weiter; Lippl wird als Therapie zur Autokoprophagie genötigt und vom Bader mit der ordinären Empfehlung entlassen: „fris, Sauf, Brunz scheis und

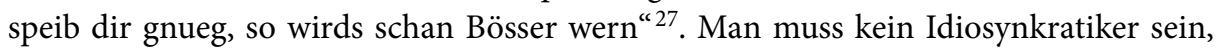
um hier die Ekelgrenze massiv überschritten zu sehen.

Wird hier Widerwillen durch den Fokus auf Fäkalien erzeugt, steht beim nächsten Beispiel die facettenreiche Symptomatik einer ekelerregenden Krankheit im Mittelpunkt. Lindemayrs wohl bekanntestes Lied Der kranke Bauer, das sich mehr als zwei Jahrhunderte im Volksgesang hielt, begegnet uns erstmals in seinem Lustspiel Herr von Storax, das Molières Ballettkomödie Monsieur de Pourceaugnac (1669) klosterbühnengerecht bearbeitet. Eingebunden in eine scharfe Ärztesatire, erhöht hier das sicherlich schon früher entstandene Lamento das Lachpotential durch die drastische Schilderung des bisherigen Leidenswegs des Bauern, der in der Behandlung durch einen selbstverliebten, aber völlig unfähigen Medikus prolongiert wird. Zuvor schon hatte er erfolglos andere Möglichkeiten der Linderung gesucht: Nach der Kur mit den Heilpflanzen eines Wurzelsammlers und den fruchtlosen Ratschlägen eines Sauschneiders vertraut er sich einem Heiler an, der ihm jedoch mit seinen Zaubersprüchen und Amuletten keine Linderung verschaffen kann. Auch die lebensgefährlich häufig angewendeten, da einträglichen Vomitiva und Aderlässe des Baders verschlimmern lediglich den Zustand des Patienten, der als letzten Ausweg - so zumindest der Handlungsverlauf im Storax nun doch die teuren Behandlungen eines studierten städtischen Mediziners in Anspruch nehmen will:

1

Hänts ist denn kain Docter anz'kemä,

Der ain ä Recept kunt väschreibm.

Der d' Krankät in Strigel recht nehmä, und 's Fiebä kunt glücklä Vätreibm.

Bald druckts mi, bald beists mi,

Bald stichts mi, bald reists mi,

Bald Schludert, und schlögelt mäs hien.

Bald thut mä's Herz zitern,

Bald brennts mi in Glidern,

I mueß no bey Zeiten crepirn.

3

Bald möcht i von Huesten Dä stickä, äs röckt mi in d' weit, und in d' leng.

Kan käm ä waichs Bread ahi schlickä,

I raitt halt, dä Posag ist z' eng.

ins Maul steigts oft anhi

ganz Fezen floignt danhi,

Und 's Kägäzen hat nie kain End.

Thuet einwendi rodeln,

mueß Tag und Nacht strodeln,

Denn d' Lumpel, und 's Gröb ist Väbrennt.
2

In Wintä da spengts mi in Fläxen,

In Frühling Kimmts anher in d' Hüft.

In Sumä da z'schrickänd mä d' Häxen

Kriegnd Fingädick Schrammer, und Klüft.

ä wilds Toifel weri,

ä grieni Maderi

Rinnt auer alls dicks Tag und Nacht.

Bin fra, däsß thut rinnä,

wanns blib in mir drinnä,

dä brand hätt mi lengst schon umbracht.

4

In Kiritag z'nächsten obm z' Schwanä

Hats Wei beyn WaldHänsl was Käft.

Än Schwiz Trunk und Stupp untränanä, und allä lay Wurzen und Säft.

Drauf käms mär in d' Waihä,

kunt käm mehr für spaihä,

hat alli Kröß ädern välögt,

Dä Magn hat si aufblät,

's Gedüräbm alls umdrät,

I wär bän ain Haar bald väröckt.

27 Ebda., f. 2v. 
5

Drauf Hambts mär än Doctä värrathen

Der d' Pfin und 'n Schölm guet västeht,

Der z'toiffest gar drin in Krawaten

Sein Sau Schneidä Handel nageht.

Guet rund sagt er auä,

Fürs Fäderl mueßt brauä,

Denn d' Würämb und d' Wind thaind dih plagn.

Stehts no an Söchs wochä,

So kriegst ä langs Sochä,

und leztlä s Vägift gar in Magn.

7

In HundsTägen hat mä dä Badä,

än achtmahl zum Bröchär eingebm,

Und liesß mär ä zwölläf mahl Adä

Das hätt mi bald gar bracht ums Lebm.

Sither han ichs Dempfen,

und s Keichär, und 's kempfen,

'S Herz Dogäzt, und d' Löbärn schnurt ein,

D' Füsß sänd wie ä Spelten,

Dä Bau wie ä Zelten,

In Gotts Nahm, wanns Tead glögn mueß seyn. ${ }^{28}$
6

Aft han ichs Guräschi gar gnummä, und dösthalbm än Wahrsagä gfrait,

Der hat mär erst Schröckär, und Kummä, mit sein hockes Pockes eingiait.

Hat Gärten abrochä,

und n Fiebä Sögn gsprochä,

Und lang öppäs brumt in än Kraiß.

und hät mär anghangä,

Wirs nix hat väfangä,

Ä Binckerl Für d' Hinfallät Fraiß.

1,1 anz'kemä] zu finden, anzutreffen 1,3 in Strigel ... nehmä] hart zusetzen, (erfolgreich) bekämpfen, überwinden 1,7 Schludert] schlottert, zittert schlögelt] zuckt, pocht 2,1 spengts] drückt, spannt es Fläxen] Sehnen 2,2 anher] heran, herauf 2,3 z'schrickänd] bersten, zerspringen 2,4 Klüft] Akk. Pl. zu Kluft: Ritze, Spalt 2,5 Toifel weri] Teufelswerk 2,6 Maderi] Eiter 2,7 auer] heraus 2,8 brand] Absterben von Gewebeteilen aufgrund bakterieller Fäulnis 3,3 ahi schlickä] hinabschlucken, hinunterschlucken 3,4 raitt] denke, vermute Posag] eig. Blinddarm, (übertragen auch) Wanst, Bauch 3,5 anhi] hinan, hinauf 3,6 danhi] hinweg, weg 3,7 Kägäzen] Hüsteln, Räuspern 3,8 einwendi] innen, drinnen rodeln] geräuschvoll atmen, röcheln 3,9 strodeln] rasseln (beim Atmen), röcheln 3,10 Lumpel] Lunge Gröb] Organe, die durch die Atmung in Bewegung sind, auch die Lunge selbst 4,1 Schwanä] Kurzform für Schwanenstadt 4,3 Stupp] Staub, (Arznei-)Pulver 4,5 Waihä] weicher Teil des Rumpfs in der Körpermitte, Taille 4,6 für spaihä] vorangehen 4,7 Kröß ädern] Blutgefäße des Gekröses, der Eingeweide 4,9 Gedüräbm] Gedärme 5,2 Pfin] Finnen: Jugendstadium des Bandwurms, so etwa des Rinder- oder des Schweinebandwurms Schölm] (Vieh-)Seuche, gefährliche Krankheit 5,4 Sau Schneidä Handel] Handwerk des ,Sauschneidens', des Kastrierens von Tieren zu Mastzwecken 5,6 Fäderl] Kolik, Bauchgrimmen brauä] gebrauchen, (hier:) Medizin anwenden 5,7 Würämb] Pl. zu Wurm 5,9 Sochä] Siechtum, andauernde Krankheit, Schwindsucht 6,1 Aft] dann, danach, also Guräschi] Mut, Beherztheit 6,2 dösthalbm] deswegen gfrait] gefragt 6,4 eingiait] eingejagt 6,5 Gärten] Pl. zu Gart: Treibstecken, (Zauber-)Gerte (zum ,Austreiben' der Krankheit durch Schläge) 6,6 Fiebä Sögn] mit christlichen Glaubensinhalten versetzte beschwörende Sprachhandlung zur Krankheitsheilung 6,7 öppäs] irgendetwas 6,9 väfangä] nützen, Wirkung zeigen 6,10 Binckerl] (hier:) Päckchen, kleines Bündel mit unterschiedlichem Inhalt, das in der Volksmagie vom Kranken als Amulett um den Hals getragen wurde Hinfallät Fraiß] Fallsucht, epileptischer Anfall 7,1 HundsTägen] Tage zwischen 24. Juli und 23. August Badä] vor allem im ländlichen Bereich tätiger Heilkundiger (im Unterschied zum ,medicus', dem studierten Arzt) 7,2 zum Bröchär eingebm] ein Brechmittel verabreicht 7,5 Dempfen] das Dampfen haben: an Engbrüstigkeit, Atemnot leiden 7,6 kempfen] Hustenkrampf, Hustenanfall 7,7 Dogäzt] klopft, pocht, hämmert 7,8 Spelten] Holzspaltstück, Schindel, Zaunbrett 7,9 Zelten] flacher Kuchen 7,10 Tead glögn] totgelegen, gestorben

Die Zurschaustellung mangelhafter Physis war im Barock ein populäres Komisierungsmittel. In der autopathographischen Detailliertheit des grausigen Krankheitsverlaufs mit

28 Lindemayr, Dialektlieder I, S. 73-76. 
all seinen Absonderungen, Ausdünstungen, Ausschlägen oder offenen Wunden wurden aber zudem auch gezielt Ängste angesprochen, dass sich die Krankheit über ,Miasmen' (starke üble Gerüche) ausbreiten könnte. Da darunter nicht nur (damals ohnedies noch nicht genauer erklärbare) biologisch-medizinische Effekte angesprochen waren, sondern auch psychisch-emotionale Phänomene, ${ }^{29} \mathrm{kam}$ dem befreienden kathartischen Lachen eine besondere Wirkung für die,Psychohygiene $z u$.

Weniger brisant ist der Krankheitsbericht im wohl einige Jahrzehnte später entstandenen, anonym überlieferten Scherzlied Her Docter $i$ bit eng, mey göbts mir ein raht. Denn im Verlauf der 12 Strophen wird klar, dass das angebliche Leiden des Patienten im Wesentlichen ,nur' eine zunehmende Unfähigkeit zur ehemals gargantuesken Gefräßigkeit und Trinkfreudigkeit oder zur jugendlichen Kraftmeierei ist. Der ausschweifende Lebenswandel des Knechts fordert nun im fortschreitenden Alter seinen Tribut - auch der geschickteste Arzt wird hier kein Remedium finden:

5

Kommt etwann nach diesen ein Spanferkl her,

kaum halb kann ichs essen, so schmeckt mir nichts mehr;

Bratwürstl, die hab ich ganz klafterweis gmessen, jetz kann ich kaum etlich mehr Ellenweis essen, zwölf Mäßl Wein thäten vor Zeiten mir wohl, jetzt trink ich kaum $6 \mathrm{Maß}$, so bin ich schier voll. 6

Vor Zeit hätt ich gschlaffen mit Ratzen in dwet, jetzt kann ich kaum acht Stund mehr zählen in Bett, und wenn eim das Schlaffen am besten thät schmecken, so thut mich der Bauer zum Dröschen aufwecken, und wann ich demselben kein Ghör geben thue, da jodlt er, da haust er, er laßt mir kein rueh. 7

Wann ich jetzt mein Stärck, und vor Zeiten betracht, so ists halt natürlich, wie Tag, und wie Nacht; die größten Krüg hab ich ganz ernsthaft angriffen, und hab dazu allzeit mein Leibstückl pfiffen; im Rauffen da hab ich mich ritterlich gwagt, daß ich oft ganz Tischvoll mit Fäusten verjagt. 8 Jetzt bring ich vor zittern den Krug kaum zum Maul, Knie brechen mir wie ein ausgmerglten Gaul: ich fürcht, wenn ich mich nicht so wacker könnt zeigen, es därft mich der Meister vom Wasen bald kriegen, doch glaub ich nicht, daß er mich d'schinden begehrt, ist d'Haut voller löcher, wär nicht der Müh werth. ${ }^{30}$

5,3 klafterweis] zu Klafter: Längenmaß; etwa die Länge, die ein Mensch mit ausgebreiteten Armen umfassen kann (in Österreich 1,9m) 5,4 Ellenweis] zu Elle: Längenmaß (Wiener Maßelle $\sim 77,7 \mathrm{~m}$ ) 5,5 Mäßl] Maß: Raumeinheit (in Österreich 1,4 l) 6,1 in dwet] um die Wette 6,6 jodlt] (hier) schreit, lärmt haust]

29 Vgl. Alain Corbin: Pesthauch und Blütenduft. Eine Geschichte des Geruchs. Aus dem Französischen von Grete Osterwald. Berlin: Wagenbach 2005.

30 Zwey schöne ganz neue Lieder. Das erste. Herr Docta, i bitt euch, mein göbt mir än Rath, etc. Das zweyte. Nichts schlimmers ist auf Erden, als eine Weibsperson, etc. Gedruckt in diesem Jahr. [o. O., o. J.], f. 2v-3r. 
(hier) schimpft, poltert 8,4 Meister vom Wasen] Wasenmeister: Schinder, Abdecker (verantwortlich für die Beseitigung und Verwertung von Tierkadavern)

Die dialektale Gestaltung des witzigen Krankheitsberichts ist in dieser Fassung nur schwach markiert. Wie der Vergleich mit einer handschriftlichen Fassung nahelegt, ${ }^{31}$ wurde sie bei der Aufführung jedoch deutlich mundartlicher realisiert. Wohl nicht zufällig erinnert die ironische laudatio temporis acti in ihrem leichten Couplet-Ton an Einlagen des Wiener Volkstheaters.

Zweifellos für dialektale Bühnenfiguren wurde eine Krankheit literarisiert, die wie kaum eine andere im 18. Jahrhundert zur Generierung komischer Effekte eingesetzt wurde. Im bereits angesprochenen reindialektalen Beuerberger Podagra-Stück (vgl. Kap.3) belästigt die personifizierte Fußgicht selbst die unsterblichen Götter mit ihren mannigfaltigen Symptomen:

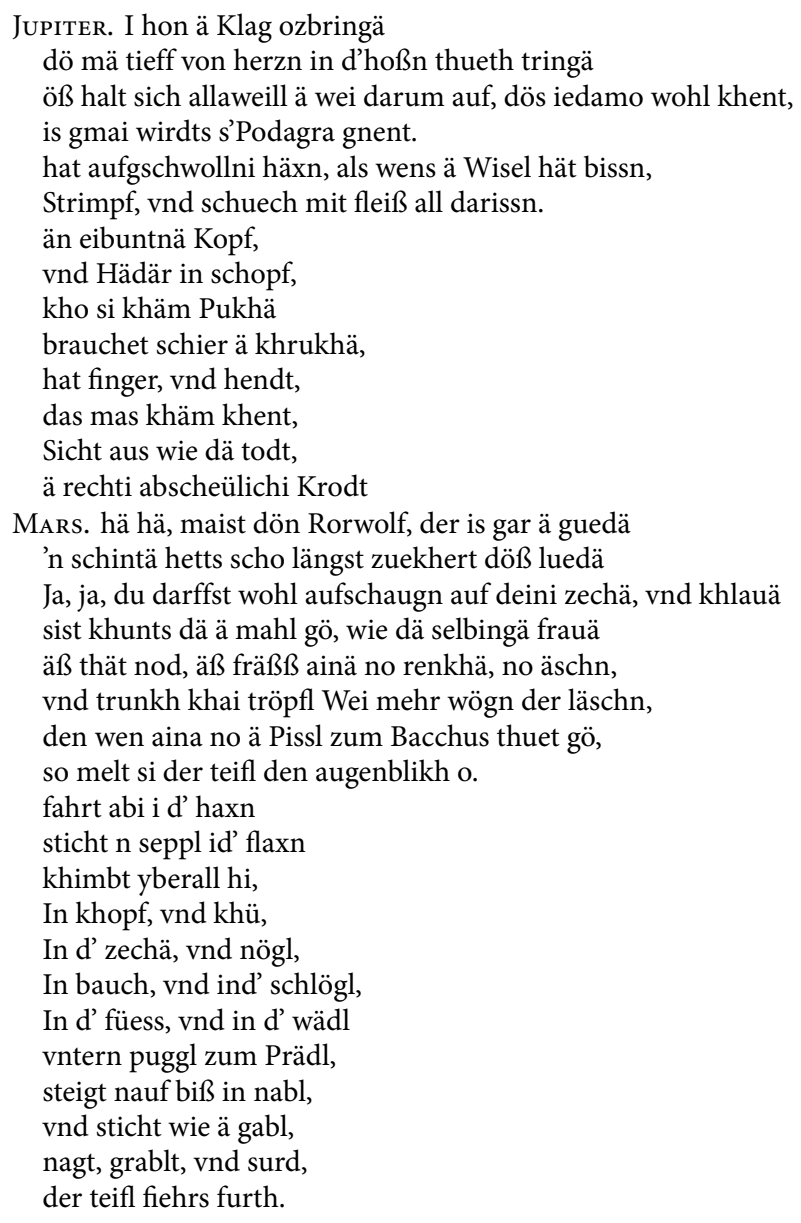

31 Vgl. Bayerische Staatsbibliothek, Cod. germ. 7340 (Stubenberger Gesängerbuch), Teil 2, S. 58f. 


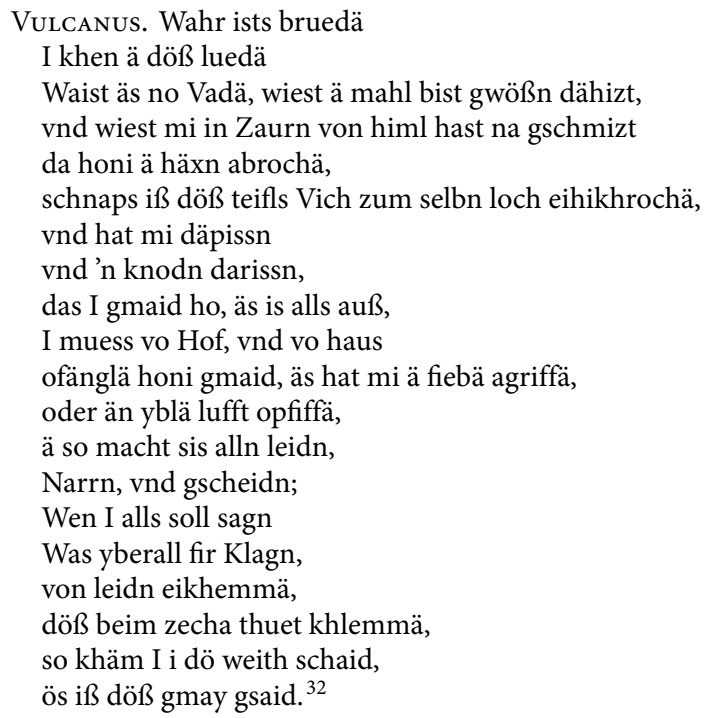

3 iedamo] jedermann 4 is gmai] insgemein 5 häxn] Beine 6 darissn] zerrissen 7 eibuntnä] eingebundenen 9 khäm Pukhä] kaum bücken 14 Krodt] Kröte 15 maist] meinst Rorwolf] Schreckgespenst (überfällt kleine Kinder) 15 schintä] Schinder, Abdecker zuekhert] zugehört (ist für den Schinder gerade recht) 18 renkhä] Reinanke (forellenartiger Speisefisch) äschn] Äsche (forellenartiger Speisefisch) 19 läschn] Lasch, (verächtlich für) Frau 22 abi] hinab, runter 23 id' flaxn] in die Flechse, Sehne 25 khü] Kinn 27 schlögl] (hier) Schenkel 28 wädl] Wade 29 Prädl] Fleisch des Beins 32 grablt] juckt krabbelnd 33 fiehrs] führe 36 wiest ä mahl] wie du einmal 37 Zaurn] Zorn na gschmizt] hinuntergeschmissen 38 honi] habe ich abrochä] abgebrochen 39 schnaps] lautmalerisch für einen sehr kurzen Vorgang eihikhrochä] hineingekrochen 40 däpissn] zerbissen 42 gmaid ho] gemeint habe 44 ofänglä] anfänglich 45 yblä lufft opfiffä] ,üble Luft' (Miasma) angehaucht 50 eikhemmä] herein-, daherkommen 52 i dö weith schaid] (sinngemäß) vom Hundertsten ins Tausendste 53 gmay gsaid] allgemeine, übliche Rede

Mit den Vorwürfen konfrontiert, zeigt sich die streitlustige Podagra freilich alles andere als mundfaul (hat „ä losi goschn“), droht den Olympiern mit Prügeln („dälogn iss, Khembtsma in Kirchtä ös drey/I fircht ench allsamt nit, wenns glei göttä seit, vnd I no a wei $^{\text {“33) }}$ ) und rechtfertigt ihr Treiben als Rettung, da es jugendlichen Übermut unterbinde. Auf die Erde verbannt, nimmt sie schließlich die Wildschützen ins Visier. Vielleicht verhalf ja diese burleske Krankheitsallegorie dem einen oder anderem im Publikum dazu, sich sein Leiden für kurze Zeit wegzulachen.

\section{Ekellieder}

Koprolalische und pathographische Unterhaltungslieder wie die oben angeführten, die den Blick fast ausschließlich auf die ansonsten peinlich verschwiegenen Ausscheidungsprozesse bzw. auf eine abstoßende oder schmerzhafte Symptomatik lenken, sind aus naheliegenden Gründen nicht allzu oft überliefert. Häufiger anzutreffen sind Lieder,

32 Bayerische Staatsbibliothek, Cod. germ. 5719/6a, f. 1v-2v.

33 Ebda., f. 5r und 4r. 
die sich im kulinarischen Bereich die schon von Mendelssohn, Herder und Lessing erkannte Nähe des Ekels zum Geruchs- und Geschmackssinn, ${ }^{34}$ die sonst von den Künsten kaum affiziert werden, zunutze machen. Diese Ekellieder spielen mit der Stimulation des Brechreizes, einer evolutionär wichtigen Reaktion, die uns vor dem Konsum verdorbener und somit gefährlicher Lebensmittel schützen soll. In der Auflistung von Dingen, die den herrschenden Essregeln widersprechen, soll ein gemeinsames Verlachen des Widerwärtigen erreicht und im wohligen Grausen vor dem Tabuisierten Gruppenidentität bestätigt werden.

Besonders beliebt waren in diesem Zusammenhang Beschreibungen eines abstoßenden Festmahls im bäuerlichen Bereich. Als parodistische Gegenmodelle zu den opulenten Schauessen der barocken Festkultur zielt diese Groteskpoesie nicht auf die ästhetische Sättigung des beeindruckten Publikums, sondern auf dessen angewidert-belustigte Abkehr vom Berichteten. Ein Beispiel ist das Lied Von der beschmiessenen Baurn Hochzeit, das sich in vielen Variationen über Jahrhunderte im Volksgesang hielt, hier etwa in einer österreichischen Flugschriftfassung aus der Mitte des 18. Jahrhunderts:

1

Nagsten homer a Hochzeit g'habt, Jagel mirk dirs wohl; da sand wohl unser dreyßig g'west, hamb g'fressen, g'soffen aufs allerbest, Jagel mirk dirs wohl, Jodel wies seyn soll. 3

Aft brachtens uns a Rindfleisch her, Jagel mirk dirs wohl,

das hat dir g'stunken wie a Schmer, hamb Ommassen krochen hin und her, Jagel mirk dirs wohl, Jodel wies seyn soll.

5

Das Einmachfleisch hab ich gleich kennt, Jagel merk dirs wohl, der Jagel hat sichs Maul verbrennt das er glei ist im Tisch weggrennt, Jagel merk dirs wohl, Jodel wies sein soll.
2

Aft brach[t]ens uns zur ersten Speis, Jagel mirk dirs wohl, g'sottne Nuß und bratne Leiß, und aft an g'spiegner Gerstenreis, Jagel mirk dirs wohl, Jodel wies seyn soll. 4 Das saure Kraut hab i nit g'mögt, Jagel mirk dirs wohl, das hat so susla sausla g'schmekt, als wans war in an Kühdreck g'steckt, Jagel mirk dirs wohl, Jodel wies seyn soll.

6 Oft hambd dir d'Vögeln ummerdrat, Jagel merk dirs wohl, da hambs dazu a Semmel bat, oft hambs dir Kretzen auffi gsad, Jagel merk dirs wohl, Jodel wies seyn soll. ${ }^{35}$

1,1 Nagsten] kürzlich, neulich, unlängst homer] haben wir 1,2 Jagel] Kurzform für Jakob 1,6 Jodel] Kurzform für Georg oder Jodokus 2,1 Aft] dann, da 2,3 Nuß] Teil des Hinterbeins von Nutztieren (v. a. zum Braten geeignet) bratne Leiß] gebratene Läuse 2,4 g'spiegner] gespiebener: erbrochener 3,3 Schmer] Tierfett, vor allem Schweinefett 3,4 Ommassen] Ameisen 4,3 susla sausla] wohl für angegärt (zu susen: gären), mit unangenehmen Geschmack 5,1 Einmachfleisch] Fleisch, das mit Pökelsalz haltbar gemacht wurde 6,1 ummerdrat] herumgedreht 6,3 bat] gebäht (in Scheiben geschnitten leicht geröstet) 6,4 Kretzen] Krätzmilben als Erreger der Krätze (Hautausschlag) auffi gsad] raufgesät

34 Vgl. Menninghaus, Ekel, S. 149.

35 Vier schöne neue Weltliche Lieder. Das Erste. Disputation vom Wein und Wasser etc. Das Zweyte. Von der beschmiessenen Baurn Hochzeit etc. Das Dritte. Sollt ich dann sterben bin ich noch jung etc. Das Vierte. Schönster Engel mein Vergnügen, etc. Gedruckt in diesem Jahr [o. O., o. J., um 1750), f. 2v-3r. 
Entomophagie, Verzehr von Erbrochenem, Verdorbenem, Verpökeltem, dazu noch ekelerregende Gerüche und degoutanter Geschmack - in der detaillierten Inszenierung des Unappetitlichen versichert man sich der Differenz zur akzeptierten Normalität, deren alltägliche Langweile unterlaufen und mit neuem Reiz aufgeladen wird. Der simple Aufbau derartiger Ekellieder - ein grausiger Gang nach dem anderen wird bei einem Mahl aufgetragen - erlaubte beliebige Erweiterungen und Variationen, die nicht zuletzt auch als Modifikationen des Ekelempfindens im Zivilisationsprozess gelesen werden können. Schon aus dem späten 17. Jahrhundert hat sich mit Nägstn ist ä Malzeit gwest eine 14-strophige handschriftliche Variante mit einer etwas klareren Redesituation im Refrain erhalten. Obwohl länger, ist diese älteste überlieferte Fassung im Angebot der aufgetischten Speisen noch weniger differenziert und beschränkt sich großteils auf das Aufzählen von stinkendem oder besonders hartem und schwerem Essen wie in den folgenden Strophen:

6

Afftn kam ä fleisch an tüsch

Lippl merckh mi wol

Dössl wa fey ganz vnd frisch

wie ä zrissnä flädawisch

Lippl wie sei soll.

8

Afftn habns vns knödl bracht

Lippl merckh mi wol

warn vo gstunckhna spöck agmacht

stai föst das mä zändt habn kracht

Lippl wie sey soll

10

Afft habns Ins an höchtn göbn

Lippl iez schrey Ju

Ja der stünkhat merckhs fey ebn

macht krad speibn vnd ybergöbn

lippl iez friss du
7

Skraut hat gar kai Mensch nit gmögt

Lippl daugt für di

hat so laidla grausam gschmögt

alß wam mas ey press hett glögt

Lippl friss fir mi

9

Ha mi auf bastettn gspart

lippl merckh mi wol

o dö war so föst vnd hart

hörta als ä schlissl bart

Lippl gfalts da wol

11

Sbradl soll i aft traniern

Lippl merckh mi wol

Lauta bai kai ross mächts führn

häntä wie ä bitträ birn

Lippl gfalts da wol ${ }^{36}$

6,1 Afftn] dann 6,2 Lippl] Kurzform für Philipp 6,3 Dössl] das, dieses fey] wirklich 6,4 zrissnä flädawisch] zerrissener Flederwisch 7,3 laidla] ziemlich, leidlich 7,4 wam mas] wenn man es 8,4 stai föst] steinhart mä] mir 9,4 schlissl bart] Schlüsselbart 10,1 höchtn] Hecht 10,3 stünkhat] stinkt 10,4 speibn] erbrechen 11,1 Sbradl] den Braten traniern] wohl (unbeabsichtigt) fehlerhaft für: tranchieren, zerlegen 11,3 Lauta bai] nur Knochen kai] kein 11,4 häntä] hantig, bitter

In der zumindest ein halbes Jahrhundert jüngeren Fassung werden dagegen die verschiedenen Gänge des Hochzeitsmahls abwechslungsreicher in der Evozierung des Ekelreizes beschrieben: Neben grausigem Gestank und unappetitlicher Konsistenz nimmt die ,Zubereitung' bzw. Verunreinigung mit verschiedenem Ungeziefer (Läuse, Ameisen, Kretzmilbe etc.) relativ großen Platz ein. Am Schluss wird der Braut noch ein dem Mahl entsprechender Ausrutscher zugeschrieben, der die ekelhafte Geruchsbelästigung nun auch auf einer interpersonellen Ebene thematisiert:

36 Staatsbibliothek zu Berlin, Ms.germ.oct. 230, S. 177-182 (mit Melodie). 
7

Von Wein kann i dir sagn eben, Jagel merk dirs wohl,

kann Tropfen hambs auf Tafel geben das kann i sagen bey mein Leben, Jagel merk dirs wohl, Jodel wies seyn soll.

9

Oft hambs an Drirum Drarum gmacht, Jodel merk dirs wohl,

An drirum drarum i thue drein, daß mueß a b’schissne Hochzeit seyn, Jodel merk dirs wohl, Jagel wies seyn soll. ${ }^{37}$
8

Oft müssmer halt von Tisch aufstehen, Jodel merk dirs wohl, da last die Braut an lauden gehn, hat g'schmeckt in d'Nasen wie a Kren, Jagel merk dirs wohl, Jodel wies seyn soll.

7,3 kann] keinen 8,3 last ... an lauden gehn] flatulierte laut 8,4 Kren] Krenn, Meerrettich 9,3 Drirum Drarum] wilder Tanz (auch euphemisch für Prügelei, in anderen Scherzliedern als Abschluss belegt)

Ein lächerlicher Bauerntanz, der wohl in eine Prügelei ausartet (auch dies ein Fixpunkt barocker Unterhaltungsdichtungen), beschließt innerfiktional das als Gemeinschaftsereignis bzw. -erregnis angelegte Geselligkeitslied, bei dem der rhythmisch akzentuierte Refrain wohl von allen Anwesenden gesungen wurde.

Überblickt man das Korpus der Dialektlieder, die karnevaleske Körper, Ekelreize und despektierliche Konventionsverletzungen als komische Stimuli in den Mittelpunkt stellen, überwiegen freilich Scherzlieder, die Tabubrüche und Schamgrenzenüberschreitungen aus verschiedenen Bereichen kombinieren, um so ein abstoßendes Panorama gesellschaftlichen Fehlverhaltens zu demonstrieren - natürlich vor allem am Beispiel der unzivilisierten unteren Schichten. Der heute zum Teil nicht mehr nachvollziehbare Reiz dieser grausigen Schock-Kunst kann verschieden gedeutet werden; manche werden ihr Normbewusstsein bestätigt gesehen oder dessen kurzzeitige Aufhebung genossen haben, anderen war es vielleicht Hilfe, eigene Phobien zu kontrollieren, für viele werden quasi-voyeuristische Motive zur schaurigen Unterhaltung beigetragen haben. In manchen Fällen aber wird es auch eine bewusste Provokation des Gegners gewesen sein. Wohl nicht zufällig wird deshalb in der aus Oberösterreich überlieferten Bayerischen Hochzeit schon im Incipit ein Regionalbezug gegeben und vielleicht auch bewusst auf die bekannte Steyerische Hochzeit (vgl. Kap. 6) angespielt. Hier sollte wohl der ,verfreundete' Dauerfeind durch skatologische Ausfälle, die Aufzählung von Ekelspeisen und Demonstrationen asozialen Verhaltens in der gemeinsamen Sprache gründlich desavouiert werden. Ob der nur mit Gedankenstrichen wiedergegebene fünfte Vers verbale oder anderweitige Grobheiten enthielt, kann bei heutiger Quellenlage nicht gesagt werden:

37 Von der beschmiessenen Baurn Hochzeit, f. 3r. 
1

Zu Straubing Bey dem Fäckl Wirth da wär a Hochzeit doll, Wo lauter bauer wie man gespirt In aller Frueh stern voll.

- - - -

Mit schunckn, Blunzen und Bradwürst Tracktirn sie Tröfli wohl.

3

Dä Breutgä und Braut Vadä,

Dö sässn obn an,

Dä Veit, dä Procuradä

ist gar ä gsteiffä Mann

- - - -

Erst hat er iem das loch ausgwischt, jezt fangt ern braut-trunck an.

5

Dä Braut ihr alti Muedä,

die fienge an zu wain, sie sagt mi treibt dä Budä, in Kidl mueß i thain.

sie schisß halt über d-Fersn a, das hamä jezt zum Lohn.

7

Ä Weib fangt an än Handl,

ös war ja recht ä grauß,

sie thät halt in ain Kandl

und guß zum Fenster aus,

- - -

sie thät än grossen Schais dazue,

Man hört in ganzen Hauß.
2

Die Köchin mit der Supn grent, die wär ja mächtig hais, aft hat iem ä jedä d'Fotz-Maul brennt

Dieweil no kainer wais.

Sie spibn all in d'Schissl 'nein und thät ein jeder än Schais.

4

Der Breuer käm geloffn

Mit einer Bitschen Bier,

er hatn toixl troffen

ist schon die recht Purgir,

$----$

sie lauffen alli scheissen aus

bißweiln ä 3 ä 4 .

6

Aft wär ä Sau Kopf aufgetragn,

das war die lezte Richt,

dä wischtn ainä bey dem Kragn,

die andern Kriegn nix,

Er frääs den ganzen Sau-Kopf weg,

das iem bäm Arsch aubricht.

8

Ä Bue fangt an zum Kreisten,

sagt iems der Wirt fein keck

hä Höppin, muest so feistn,

Du stinckst als wie ä tröck;

$----$

wans du dein Arsch nöt halten wilst, vätreibst mä d-Hochzeit gäst. ${ }^{38}$

1,1 Straubing] oberbayerische Stadt an der Donau Fäckl] Ferkel 1,5 Blunzen] Blutwurst 1,6 Tracktirn] bedienen 2,3 d'Fotz-Maul] (grämlich verzogener) Mund 2,6 Schais] Furz 3,1 Breutgä] Bräutigam 3,3 Procuradä] Prokurator, Hochzeitslader 3,4 gsteiffä] toller, hervorragender 3,5 iem] sich 4,2 Bitschen] Gefäß aus Kupfer, Zinn oder Blech mit Deckel und Henkel für den Transport von Flüssigkeiten 4,3 Toixl] Teufel 4,4 Purgir] Abführmittel 5,2 ä] auch 5,4 thain] tun 5,6 hamä] haben wir 6,2 Richt] Gericht, Speise(ngang) 6,3 dä wischtn] erwischt 8,1 Kreistn] vor Anstrengung, Schmerz stöhnen 8,3 Höppin] Kröte feistn] stinken (?)

Zu den bekanntesten Liedern dieses Genres gehört ein derb-beschwingter Tanzbericht, der wohl auch zum Tanzen selbst gesungen wurde. Die situative Einbettung bietet ein Nachbartreffen, wo witzige und pikante Details der vorabendlichen Veranstaltung ausgetauscht werden. Bildstarke Schilderungen, hyperbolische Elemente, Kunstredundanzen, komische Pointen, vor allem aber der lebhafte Rhythmus machen verständlich, warum sich das handfeste Lied in seinen vielen recht unterschiedlichen Ausformungen so lange im Volksgesang halten konnte. Die vorliegende Fassung Die kropfete Marieannl stammt aus einem um 1800 entstandenen Singbuch des Tegernseer Klosterschülers Markus Seitz, in dem sich neben zeitgenössischen Gesellschaftsliedern aus gedruckten

38 Stiftsbibliothek St. Florian, XI 577 A, f. 37v-39r. 
Sammlungen auch ,bodenständigere' Gesänge finden, sodass sich ein guter Überblick über das Spektrum weltlicher Lieder, die im Klosterumfeld ihren festen Platz hatten, ergibt. ${ }^{39}$ Diese oberbayerische Adaption, in der Dialekt und Rhythmus des Lieds sieht man von der lückenhaften letzten Strophe ab - besonders gut wiedergegeben sind, steht neben einer größeren Anzahl anderer Überlieferungen aus dem gesamten Dialektraum, die ab dem späten 18. Jahrhundert in Flugschriften und handschriftlich auf uns gekommen sind. Noch im 20. Jahrhundert wurde das Lied im Zuge von Volksliedaufzeichnungen erfasst. ${ }^{40}$

1

Grieß di Gott mei lieba Nachbas Nachba

Kömma a scho wida zsam

Mei, wie stehts mit deina Tochtas Tochta

Ursl hoast si mit Nam;

Nachtn sama gwösn, mei hasts a glösen

Bey ain gar hurtinga Tanz,

Habn a tanzt, und gsunga,

Habn a pfiffa, gsprunga

Wie I hör, so wars ganz.

3

Der Schustakristl, und der Stoffl-lenzl, und der Seppl mitn Schnauzbart

Habn a d'Annamiedl mitn Anderedl

Zum tanzn eini gnart,

Untern bösten Tanzn thatn si si ranzen, röckten dHaxn in $\mathrm{dHöh}$

fielen um $\mathrm{u}[\mathrm{n}] \mathrm{d}$ uma

thatn gar an Brumma

War ja a nicht gar recht.

\section{5}

Endla kam halt a da Bindabachl

Mit seinen grossn Huet daher,

Und dazue der Dunners klichl klachl

Justament von der Stehr,

Wir wolltn alle wissn Wer denn also gschmissn

Denn es stunk als wie dHöll

Da thatns uma fragn,

Da that aina sagn:

sKüechlbachers sei Gsöll
2

Endli, endli, bin I ganga ganga

Und derentwögn bin I da

Daß I euch was nuis erzöhlen will,

Daß I euch was nuis sag:

Daß da Kramahiesl und da Taschn-Veidl

Habn a geigt beim grünen Kranz

Und die Annamiedl

mitn Anderedl

habna a dabey tanzt.

4

Die kropfet Mariannl Mitn kurzn Gwandl

Bildt si a an flöck ei

D Strimpf hatts auffa bundn Mit an

Zwirmbandl

Und da Kidl wa bramt ei

Mit lauta Schnecknhaüsl War er eingebreislt

Und das Gflecht war vom Strick,

In der Ochsenhaut

da sie uma schaut

Tanzt si denna braf mit.

6

Endla kam a der Lackapatscha

Mit seinen schönen Wei,

Ainen Fueß hats wie a Schnitersichl

Und der ander steht auf d'Seit,

Auf ain Aug that si nit sehn

Aufn andern iß blind

An Hals ißs volla Dippldippll

Aufn Kopf hats ain Gründt.

39 Vgl. Robert Münster: Zwei Singknaben-Liederbücher aus den letzten Jahren des Klosters Tegernsee. In: Sänger- und Musikantenzeitung 38/3 (1995), S. 141-145. - Robert Münster: Zwei Liederbücher der Tegernseer Singknaben Caspar Aiblinger und Marcus Seitz. In: Sixtus Lampl (Hg.): Tegernseer Jubiläumsreihe 746-1996. Bd. 1: Klingendes Tal. Zur Musikpflege von der Benediktinerabtei über den Kiem Pauli bis zur Gegenwart. Valley: Schloßverlag Valley 1996, S. 144-153.

40 Vgl. Karl Reiterer: Lustige altsteirische Gsangeln, Vierzeiler und Lieder aus dem Ennstal und dem Ausseer Landl. Aussee: Grill 1906. 
7

Endla nahm I halt a Urlaub,

Und gieng a glei nach Haus

I gieng auffi auffi bey da Schlömauer

that mit föst oni loan

That mi umareibn fangtn an zu speibn

Unsa 5 mit einand,

Habs a so furt tribn,

Bis habn alle gspibn,

Ist ja a, a schir a Schand.
8

Endla samma wida wida ganga

Alle zsam mitanand

gieng über Stög,

fielen all in Dröck

Glei als wie die Plunznsöck,

San glei lign blibn,

Habn a wida gspibn,

Habn a gmoant ös iß bött. rep ${ }^{41}$

1,5 Nachtn] gestern, gestern abends 2,5 Kramahiesl] Hiesl: Kurzform für Matthias Taschn-Veidl] (eig. Taschenmesser) Wortspiel mit Eigennamen (Kurzform für Vitus) 2,7 Annamiedl] Annemarie, Anna Maria Anderedl] Andreas 3,1 Stoffl-lenzl] Lenzl: Kurzform für Laurenz, Lorenz 3,5 ranzen] sich rekeln, die Glieder strecken und dehnen; hier wohl für , unanständige oder unnütze Bewegungen', auch mit sexueller Konnotation 4,2 Bildt ... flöck ei] eingebildet sein 4,3 auffa] herauf Zwirmbandl] Zwirnfaden 4,4 bramt ei] eingebrämt, mit einem Samt- oder Pelzstreifen eingefasst (hier mit Schneckenhäusern statt dem teuren Randband) 4,5 eingebreislt] gesäumt, geschnürt 5,4 Stehr] Stör: handwerkliche Arbeit (z. B. von Nähern, Schneidern, Schuhmachern etc.), die in der Wohnung der Bestellenden gegen Kost und Logis verrichtet wird 5,5 gschmissn] abschwächend für ,geschissen' (Exkremente ,ausgeworfen') 6,1 Lackapatscha] Spottname, im Jenischen (einer Rotwelsch-Variante, gesprochen vor allem von Wandermusikanten) für ,Ente' 6,7 Dippldippll] Beulen, Pickeln 6,8 Gründt] Exsudat, (Wund-)Schorf 7,2 Urlaub] Abschied 7,3 Schlömauer] schlechte Mauer (spöttisch für Ort, wo man sich erleichtert) 7,4 föst oni loan] fest anlehnen 7,5 umareiben] herumreiben speibn] erbrechen 8,5 wie die Plunznsöck] (Blunzen: Blutwurst) stockbesoffen 8,8 ös iß bött] ,es ist das Bett' rep] (lat. repetitur) wird wiederholt

Auch über den Umweg der (angeblichen) moralischen Belehrung konnten Ekelbilder zum Einsatz kommen, wie etwa Marcellinus Sturms bereits angesprochenes Schrecklied Die Hölle drastisch belegt. Die Vergegenwärtigung ekelerregend-traumatisierender Strafen hatte in den barocken Schreck- und Bußexempeln, die die Gläubigen durch psychische Erschütterung zur Abkehr von den angeprangerten Lastern bewegen sollten, eine ebenso reiche wie unheilvolle Tradition. Die ausgelassene Fabulierungsfreude Sturms, die karnevalistische Komik der infernalen Szenen und nicht zuletzt auch ihre dialektale Gestaltung als Ironiesignal verraten allerdings, dass die Einschüchterungsrhetorik der überkommenen Homiletik im Zeitalter der Aufklärung weniger epistrophischen als unterhaltenden Effekten dient:

19

Galante und zuckasüß’ Bübeln

Vergessen a s'Scherzen und Liebeln,

Statt Torten fürs Mäulerl

Kriegns Brozn auf Tällerl,

Eins wird Ihnen gar nicht viel taugn,

Dem Luzifer d'Nasen aussaugn.
20

Die hohen und g'schupften Frisuren,

Die wird euch der Teufel anschnuren,

Ihr eitle Koketten

Aus Dörfern und Städten,

Er wird Euch mit Pech pomadiren,

Mit Würmer und Schlangen frisiren.

41 Bayerische Staatsbibliothek, Ms.mus. 7098 (Handschriftliches Liederbuch des Singknaben Markus Seitz aus seiner Schulzeit im Kloster Tegernsee), S. 28-32. Ein Abdruck mit einer normalisierten Textfassung findet sich in Münster, Zwei Singknaben-Liederbücher, S. 143; das Blatt mit den Noten ist bei Münster, Zwei Liederbücher, S. 152 als Faksimile abgedruckt. 
21

Die mit den lockenden Blicken, Man wird euch kurios da ausflicken, Ihr werdet zu Katzen An Augen und Bratzen, Drauf nimmt enk a feuriga Mon, Beim Kragen, jetzt schnufelts brav dron.

23

Ich will enk a Beispiel aufführn, Vielleicht möchts enk s'Herz a weng rührn, Was kriegts für $\mathrm{A}$ - prella

Die stolze Jezabela!

Ist nöt das a sakrische Bueß, Wenns Teufl in A - lecka mueß?
22

Und ihr mit den ang'schmirten Wangen,

Was werdet ihr dorten anfangen,

Wenn (mit salva veni)

Ins Häusel a weni

Den Kopf euch der Luzifer steckt,

Daß ihr auf zehn Meilen schon schmeckt.

24

Jetzt sag mir noch einmal a Sünda,

Es wär in der Höll nichts dahinter,

Gelt, jetzt kommt enks Rotzn,

Jetzt hängts enka Fotzen!

So machts hat g'schwind Reu und Leid,

Thuets Bueß und werds a mal g'scheit. ${ }^{42}$

19,4 Brozn] Kröten 20,1 g'schupften] gekünstelten, gezierten 20,3 Koketten] (franz. cocotte: Hühnchen) übertrieben modische Person 21,4 Bratzen] Hände 21,5 enk] euch 21,6 schnufelts] schüffeln, schnuppern 22,3 salva veni] (entstellend für lat. salva venia) mit Verlaub (zu sagen) 22,4 Häusel] Toilette, Klo 22,6 schmeckt] riecht, stinkt 23,4 Jezabela] Isebel, Frau König Ahabs von Israel, wird im Alten Testament verantwortlich für die Missetaten ihres Mannes gemacht

Nicht metaphysische, sondern sehr irdische Qualen sind Thema eines komischen Klagelieds, das der Flohplage ein literarisches Denkmal setzt und das noch 2001 bei volkskundlichen Feldforschungen im Kärntner Gurktal aufgezeichnet werden konnte. ${ }^{43}$ Mit ausgeprägtem Sinn für Situationskomik und drastischer Bildlichkeit wird in diesem Dialektbeitrag zur beliebten Flohliteratur der Kampf gegen die ekelhaften, schlafraubenden Parasiten geschildert, der in der langgezogenen Wehklage des Refrains musikalisch noch akzentuiert wird:

1

Es wär in meinem Bett ä schon gut schlafen, aber die Teufels-Fleh göbm halt kein Rueh, hab oft ä ganzi Nacht mit ihnä zschafen, zreissen mir d-Tuchet, und s-Lälach darzue, haist alliweil kratz, und kreill, im Hemmet alleweil, Pissen, pissen, pissen muß seyn.

2

Wann ich mich nur ä weng lög auf die seiten, und will ausweichä den schindtmässing Vieh, da kemänts dutzetweis wieder anzreiten, will nur ein jeder anhenken ein Stich, zwickänt bald hint, bald forn, und hamt mich für ein Narrn, Piss[en] $p p$

3

Wann ich aft main ich will schlaffen am Besten, da kimt das Teufels Vieh gleich wieder an,

42 Sturm, Lieder zum Theil in baierischer Mundart, S. $80 \mathrm{f}$.

43 Vgl. Kärntner Volksliedwerk IDN 53030 sowie u. a. die verschiedenen Fassungen in den Beständen des Österreichischen Volksliedwerks. 
will sich ein jeder von mein Leib faist mästen,

daß sie oft können kaum springä darvon,

können mich execiren,

kann mich oft kaum däwören,

Piss[en] $p p$

4

Mein Gott, warum hast das Rabm Vieh erschafen,

daß meinen Leib ahso peinigt, und quält,

hät mi ja können mit andern Ding strafen,

immerzu mit einen Beutl voll Geld,

hast von den Vieh kein Lob,

weils zwickt, und peist so grob,

Piss[en] $p p$

5

Warts alli Teuxls Fleh, will engs schon machä,

weils meinen Leib habt ä so exequiert,

ich werd zu engern $U[n]$ tergang lachä,

wann eng der Teufel in d-Höll abi führt,

da werd ich seyn mit Rueh,

da kints mir nimä zue,

gschlafen, gschlafen, gschlafen muß seyn. ${ }^{44}$

1,4 Tuchet] Tuchent: Bettdecke, Federbett Lälach] Leintuch 1,5 alliweil] immer kreill] kreilen: kratzen, zerkratzen 1,7 Pissen] gebissen 2,2 schindtmässing] für den Schinder, verfluchten 2,3 kemänts] kommen sie 2,7 pp] (p Abk. für lat. perge: fahre fort) usw., etc. 3,6 däwören] erwehren 5,1 Teuxls] Teufels engs] es euch 5,2 exequiert] gequält 5,3 engern] euren 5,4 abi] hinunter 5,6 kints] könnt ihr

Eine andere, melodielos überlieferte 6-strophige Fassung des Flohlieds aus einer Liederhandschrift aus dem Nachlass des Garstener Benediktiners Leander Kremser (17511829), die in Salzburger Studentenkreisen um 1775 angelegt wurde, wartet mit etlichen gravierenden Textabweichungen und einer erotischen Zusatzstrophe auf:

5

Wär mir viel lieber ein Floh auf 2 Füssen,

wär mir viel ruhiger in meinem Beth,

$\mathrm{Daß}$ ich nicht bständig so kratzen darft müssen,

zreißet mir Duchet und Leilach auch nit,

Ein floh der hatt 2 Füß

Sich gern fangen ließ,

bissen 3. muß seyn. ${ }^{45}$

5,4 Duchet und Leilach] Tuchent (Bettdecke) und Leintuch 5,8 bissen 3.] dreimalige Wiederholung

44 Oberösterreichisches Volksliedwerk, Hs 379a, f. 15r-16r. Erstmals ediert bei Neuhuber, Mein Gott, warum hast das Rabm Vieh erschafen, S. 118f.

45 Oberösterreichische Landesbibliothek, Hs. 727, f. 6v. 


\section{Liederliche Lieder und andere anstößige Texte}

Es ist kein Zufall, dass sich sexuelle Anspielungen und erotische Phantasien in Kontexten versteckten, in denen man sie nicht vermuten würde. Die von Kirche und Staat propagierte Sexualitätsfeindlichkeit hatte über Jahrhunderte hinweg einen offenen Diskurs über Lust und körperliches Verlangen zu verhindern gewusst und den natürlichen, existenziellen Akt als animalische, dem Moralisch-Vernünftigen zuwiderlaufende Triebhaftigkeit stigmatisiert. ${ }^{46}$ Würde man die Bedeutung von Sexualität für den Menschen im deutschen Sprachraum allein nach ihrer Thematisierung im gedruckten Schrifttum bemessen, müsste man davon ausgehen, dass die massive Repression sich tatsächlich auch in der Mentalität und Vorstellungswelt des Volkes libidofeindlich verankert habe. Das weitgehende Fehlen entsprechender Texte zeichnet freilich ein völlig falsches Bild. ${ }^{47}$ Zwar waren die öffentlich zugelassenen Ausdrucksformen aufgrund der äußerst restriktiven Gesetzeslage tatsächlich marginal, ${ }^{48}$ doch in der obrigkeitlich nur schwer gängelbaren Mündlichkeitskultur fand das menschliche Grundbedürfnis nach geschlechtlicher Beziehung und Befriedigung hinlänglich Beachtung, wie zahlreiche wütende Verordnungen und Polemiken gegen Schamperlieder, Zoten, Zweideutigkeiten und andere unzüchtige Unterhaltungen belegen. ${ }^{49}$ Verschriftlicht wurden sie freilich nur selten und die meisten Spuren davon hat Prüderie oder die Angst vor Entdeckung im Lauf des Überlieferungsprozesses getilgt. Die wenigen Texte mit eindeutig sexuellen Motiven, die erhalten blieben, vermitteln das Tabuisierte zumeist über Camouflageformen geduldeter Textformate.

\section{Camouflierte Wollust}

Einen simplen Trick, das eigentlich tabuisierte Sprechen über Sexualität dennoch zu ermöglichen, haben wir bereits im ersten Kapitel mit Liedern zum Beichtsakrament kennengelernt, wo erst mit der Benennung der Verfehlung Vergebung erlangt werden kann. Dass die Sprechsituation der Lieder dabei mit einer impliziten Aufhebung des Beichtgeheimnisses spielt, verleiht den Bekenntnissen zusätzlichen Reiz. Eines der gewagtesten

46 Vgl. Michel Foucault: Sexualität und Wahrheit. Der Gebrauch der Lüste. Bd. 2. Frankfurt a. M.: Suhrkamp 1986, S. 81.

47 Vgl. für den - freilich nur bedingt vergleichbaren - angelsächsischen Bereich die erhellende Studie von Faramerz Dabhoiwala: Lust und Freiheit. Die Geschichte der ersten sexuellen Revolution. Aus dem Englischen von Hainer und Esther Kober. Stuttgart: Klett-Cotta 2014.

48 Vgl. zu den Verhältnissen in der Habsburgermonarchie Sabine Scholz: Die Entwicklung der österreichischen Pornographiegesetzgebung seit 1740. Frankfurt a. M. [u. a.]: Lang 1999, bes. Kap. 3 und 4.

49 Als Beispiel sei hier nur das ,Norma-Edikt ' Maria Theresias genannt, das ,jede équivoque und der Ehrbarkeit zuwiderlaufende unfläthige Redensarth [... ] bei schwerster Bestrafung “ am Theater untersagte (zitiert nach Karl von Görner: Der Hans Wurst-Streit der österreichischen Aufklärung 1781-1795. Wien: Konegen 1884, S. 4f.); parallel dazu wurde auch das Buchwesen durch die ,Bücher-Censurs-Hofcommission' reglementiert. Vgl. Beatrix Müller-Kampel: Disziplinierter Körper, reglementierter Spaß. Zur politischen und zivilisatorischen Zurichtung des Hanswurst im 18. Jahrhundert. In: Oswald Panagl/Robert Kriechbaumer (Hg.): Stachel wider den Zeitgeist. Politisches Kabarett, Flüsterwitz und subversive Textsorten. Wien/ Köln/Weimar: Böhlau 2004, S. 47-58, hier 47. 
Beispiele dieser tabubrechenden Beichtparodien stammt wohl aus der Feder des Ex-Jesuiten Aloys Blumauer. Wie schon bei Der evangelische Bauernjunge in der katholischen Kirche und Petrus und Malchus greift er auch hier vermutlich auf eine ältere Vorlage zurück, die er poetisch überformt und mit Provokationen gegen die Geistlichkeit zuspitzt. Thema ist die Ohrenbeichte eines liederlichen Bauernburschen, der mit Freude am Detail seine sexuellen Abenteuer, seine triebhaften Exzesse, seinen Widerstand gegen Regeln und Autoritäten ganz ohne jede Spur ehrlicher Reue erzählt. Eigentliches Ziel, das wird bald klar, ist nicht die Absolution, sondern die Brüskierung des Priesters, dem durch das Schweigegebot die Hände gebunden sind. Dass Die Beichte auch nach ihrer Erstedition durch Leopold Schmidt ${ }^{50}$ bislang nicht dem Gesamtwerk des bedeutenden österreichischen Satirikers zugeschrieben wird, kann - abgesehen von der unsicheren Quellenlage - auch angesichts der reihenweisen Tabubrüche nicht verwundern; die ästhetische Qualität und souveräne Gestaltung aber hebt das Lied ab von ähnlichen im Volksgesang des 19. Jahrhunderts aufgezeichneten Spottbeichten. ${ }^{51}$

Der erste Teil des Lieds bewegt sich noch in einigermaßen konventionellen Bahnen und erinnert im kaum verhohlenen Stolz des Ich auf das eigene Lotterleben an Sturms Reumüthige Beicht (vgl. Kap. 1), setzt aber auch schon erste perfide Nadelstiche gegen den Beichtvater:

1

Herr Pater! Recht an's Gade an

Mit engri langi Ohren

Wenn's ös nit seits der helf'n kann

So bin i eng verloren.

3

Da war i a Kerl nit Kren

So sauber grad zum freßen

Jetzt bin i aber wieder schön

In alten Dreck h'nein gseßen.

5

Han g'sündigt, was a Mensch nur kan

Nix beth nur ghurt und trunken

Han denkt die Pfaffen scheiß i an

Das san die wahr'n Hallunken.

7

Han in der Meß oft gelacht und g'schwäzt

Und d'Menscher grüßt wie a ledi

Han gröpaßt, g'hust, und noch auf d'letzt

Laut g'farzt in engrer Predi.
2

Seit Ostern is, jetzts grad a Jahr

das mußts vor allen wißen

$\mathrm{Daß}$ i dort drunten beim Altar

Recht ausgmist han mein Gwißen.

4

Drum gebt's mir zu mein Seelenheil

Jetz z'erst an weng 'n Segen

Und nacher will i 'n größten Theil

A mahl auf d'Seiten fegen.

6

Mir hat den ganzen Tag nix kränkt

Als d'Menscher, Wein und Karten

Und vor der Kirn han i denkt

I laß den Lendl warten.

8

Kan Arbat hat mi a nit g'schmeckt

I bin in Lahnstull gseßa

Han alli vieri von mir g'streckt

Und gar nix than als gfreßa. ${ }^{52}$

50 Vgl. Leopold Schmidt: Ein unbekanntes Mundartgedicht Blumauers. In: Germanisch-Romanische Monatsschrift 29 (1941), S. 147-150. Schmidt gibt als Quelle eine aus dem ersten Jahrzehnt des 19. Jahrhunderts stammende, verschollene Handschrift mit Blumauer-Gedichten an, die Gustav Gugitz einsah; dessen Abschrift ist auch die Grundlage des edierten Texts. Unsere Edition ist einer anderen Sammelhandschrift entnommen und weicht orthographisch und zuweilen auch lexikalisch von der Fassung Schmidts ab.

51 Vgl. Emil Karl Blümml: Schottkys Volksliedernachlass. Wien: Ludwig 1912. (Quellen und Forschungen zur deutschen Volkskunde VII) S. 6 und 60f. Auch die Sprache des Lieds verweist auf eine weiter westliche Entstehung, als es die beiden Wiener Handschriften vermuten ließen.

52 Wienbibliothek im Rathaus, H. I. N.-55795, Teil 2, f. 100v-101r. 
1,1 Gade] verderbt für Gader: Zaun, (hier) Gitter im Sichtfenster des Beichtstuhls 1,2 engri] euren 1,3 ös] ihr 1,4 eng] euch 3,1 Kren] Meerrettich (bei Schmidt: ,wie a Kren') 5,4 san] sind 6,2 d'Menscher] die Mädchen 6,3 Kirn] Kirche 6,4 Lendl] dummer, träger Mensch (auch Kurzform für Leonhard und Wendelin) 7,2 wie a ledi] wie ein Lediger, Unverheirateter (?) 7,3 gröpaßt] gerülpst 7,4 engrer] eurer 8,1 Kan] keine

Der zweite Teil des Lieds ist dem Geschlechtsleben des Pönitenten gewidmet, der es in einer Unverblümtheit schildert, die (nicht nur) im 18. Jahrhundert ihre schockierende, aber auch entfesselnd komische Wirkung wohl kaum verfehlte. Mit obszöner Lexik, einer nur allzu eindeutigen Metaphorik, mit Details aus der sexuellen Praxis und zu schlechter Letzt noch mit einem blasphemischen Affront bringt der Bauernbursche seinen Beichtvater wohl in größte Verlegenheit - und mit ihm der Autor ein Publikum, das (aus welchen Gründen auch immer) diese Unflätigkeiten und Zoten nicht entlastend witzig finden kann. Schon zu Beginn dieses Abschnitts finden wir einen interessanten Querverweis auf , unkeusche Lieder', deren Melodie offenbar so bekannt war, dass sie auch gepfiffen schon gegen die Konventionen verstießen. Ob auch dieses Lied eine derart signifikante Melodie besaß, ist beim derzeitigen, rein textuellen Quellenstand nicht $\mathrm{zu}$ sagen. Ist es aber Zufall, dass das Lied metrisch ganz ähnlich gebaut ist wie das berüchtigte ,Eipeldauerlied' (vgl. Kap.3) und das eine oder andere Schlüsselwort mit diesem teilt (vgl. etwa ,Lendl')? Wohl nicht ganz ohne Grund wurde ja auch Blumauer verdächtigt, an der Entstehung des revolutionären Texts federführend beteiligt gewesen zu sein.

9

I han, kam war die Meß vorbey

Unkeusche Liedl pfiffa.

Und unsrer Anamiedl dabey

An Arsch und Dutteln griffa.

11

Du lieber Gott was fang i an

Was muß i von alls leiden

Herr Pader glaubts mir nur, i kann

Mein Annamidl nit meiden.

13

Ey hat's Mensch an Hintern g'hat

Und mit an Straf an schwarzen

Zwa Dutteln wie a Kuh nur hat

Und rosenbraune Warzen.

15

I nim den Rosenkranz heraus

und damit hab ihn bogen

O herr! da sah'n zum Laden aus

Die Krallerln alle g'flogen. ${ }^{53}$
10

Ja, d'Unkeuschheit die reißt mi[r] halt

Viel Löcha in mein Gwißen

Und hat mir a scho oft mit Gwalt

A Loch in d'Hosen grißen.

12

Letzt bin i bey ihr auf'n Heu

In hintern Stadl gseßen

Dann han ihr so aus Narrethey

Auf'n Arsch zwa Praker g'meßen.

14

Wie hat mir da mein Brunzer than

Mir is ganz g'spasi woren

Is gwest, als mußt i um 'n Lohn

A Dutzend Brunnröhr bohren.

9,3 Anamiedl] Kurzform für Anna Maria 9,4 Dutteln] Brüste 12,2 Stadl] Scheune 12,4 Praker] Schläge 13,2 Straf] Streifen 14,1 Brunzer] Penis (eig. Organ zum Urinieren) 15,3 sah'n] wohl verderbt für ,san ' (sind) Laden] Fensterbalken 15,4 Krallerln] Korallen (beliebtes Material für Rosenkranzperlen)

53 Ebda., f. 101r-102r. 
Im abschließenden Teil kehrt das Lied wieder zurück in die Bahnen einer launigen confessio vitae, mit Ekelkomik, Rüpelszenen und Protzreden. Deftiger aber als in vergleichbaren Liedern (etwa bei Sturm) sind die eingestandenen Blasphemien, die zu dieser Zeit wohl ein ähnliches Schockpotential hatten wie zuvor die Sexgeständnisse. Eine unerhörte Frechheit ist es freilich auch, dem Beichtvater die Vergebung eines persönlichen Übergriffs gegen ihn zuzumuten und ihn zugleich spüren zu lassen, wie wenig man im Allgemeinen von der Lossprechung hält. Dass ihm diese rein kirchenrechtlich gar nicht erteilt werden kann, weil sämtliche Voraussetzungen für die Wiederherstellung der Taufgnade im katholischen Sinn - Gewissenserforschung, Reue, guter Vorsatz, Bekenntnis und Wiedergutmachung - fehlen, versteht sich von selbst und ist zentraler Teil der komischen Strategie des Lieds.

16

Mir hat den ganzen Tag nur durst

Nach Wein und gutn Bißen

I hab in d'Plunz, und Leberwurst

Verzeih mers Gott! nur g'schißen.

18

Glebt han i wia a Graf so rar

Han selbst 'n Amtmann trutzet

Und an an Kiritag sogar

N'Arsch an d'Semmeln putzet.

20

In Zorn, da was i gar nit z'leb’n

Z'nächst hätt i bald in Zorn

Gott Vater selbst a Faunzn gebn

Wann i wa Master worn.

22

Nur so a gmaner Sacrament

Den kon ja gar nix schaden

I fluch gleich daß sie d'Erden trennt

Wie d'Unger und Krowaten.

24

Herr Pfarrer denkts nur nima dran

Sonst kunts ma's nit vergeben

Auf d'Faunzen, die i z'nächst eng han

Beym Wirth auf'n Kiritag geben.
17

Beym Tanz da hab' i wie a Mähr

Ausgschlagn mit allen Vieren

Und than als ob i narrisch wär

In Podex und in Hirn.

19

Und rauschi bin i often gwest

Bin z'Nacht in Wind und Regen

Oft mehr in Saustall als in Bett

Und in die Graben glegen.

21

Z'nachst hans mir halt verlegt mein Pfoad

$\mathrm{Un}[\mathrm{d}]$ a mein grüne Hauben

Da han i gflucht als wie a Hoad

I kans ös derfts mirs glauben.

23

Jetz falt mir was Entsetzlichs

Es dreht sich um mein Gwißen

I han es wird 8 Tag jetz seyn

Recht stark in d'Hosen gschißen.

25

Jetz han i alles wörtln klagt

das andre erraths ös

Denn was i gwust han, han i gsagt

Jetz sied's ös, oder brat's ös. ${ }^{54}$

16,3 Plunz] Blunze, Blutwurst 20,1 was] weiß 20,2 z’nächst] vor kurzem, unlängst 20,3 Faunzn] Ohrfeige 20,4 Wann ... worn] wenn ich es geschafft hätte 21,1 Pfoad] Hemd 21,3 Hoad] Heide 21,4 ös derfts] ihr dürft es 22,1 gmaner] gemeiner, normaler, einfacher 24,2 kunts ma's] könntet ihr es mir 24,3 eng] euch 25,1 wörtln] bei Schmidt sinnvoller ,wörtli‘

Eine simple Transposition einer gängigen Vorlage ins Obszöne begegnet uns in einer Flugschrift aus dem ausgehenden 18. Jahrhundert, das mit den unverfänglichen Incipits zweier Lieder und dem Holzschnitt eines spielenden Kindes eine Harmlosigkeit vorgaukelt, die der Blick ins Innere rasch dekuvriert. Denn der erste Gesang entpuppt sich als rüde Frauenschelte mit der expliziten Legitimierung ehelicher Gewalt. Und auch das

54 Ebda., f. 102r-v. 
Abb. 44: Titelblatt einer Flugschrift, um 1790 (Foto/Quelle: Archiv der Stadt Linz, Sammlung Klier 55/4-33).

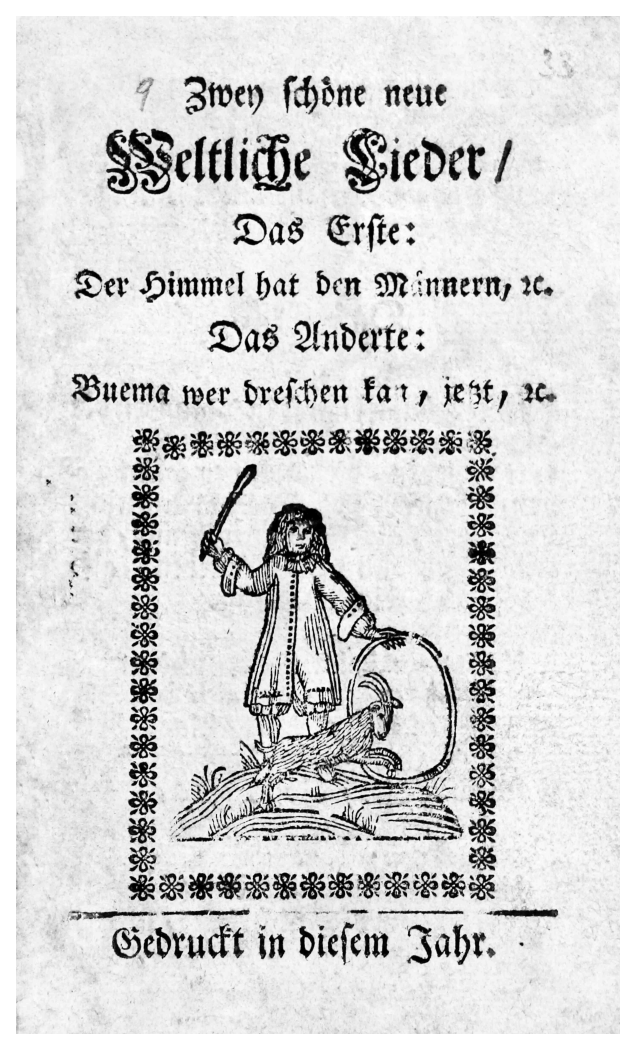

zweite Lied ist nur vordergründig das Arbeitslied, das man erwartet: Buema wer Dreschen kann bewahrt zwar grundsätzlich die Form des Hypotexts, eines traditionellen Drescherlieds, das uns durch die Sonnleithner-Sammlung von 1819 aus dem niederösterreichischen Thernberg bekannt ist. ${ }^{55}$ Die Szenerie der Drescharbeit bleibt ebenso erhalten wie die ausgeprägte Rhythmik, die die Arbeitsbewegungen regeln soll, wie vor allem im weitgehend sinnfreien Refrain deutlich wird. Doch rasch wird klar, dass es inhaltlich um Handfesteres geht:

1

Buema wer Dreschen kan, jetzt geht das dreschen an, gema ins Nachbarn Haus, dreschen den Habern aus, gelt du drescht ä, halt ja i moan ä, ey dasti halt ä.

\section{2}

Die Bäurin hat 2. Diern, thamas in Stadl führen,

die Brüst seynd hoch erhoben, die Buema thans selbst loben, gelt du drescht ä, halt ja i moan ä, ey dasti halt ä.

55 Vgl. Deutsch/Haid/Zeman, Das Volkslied, S. 68f., die das Lied mit Noten abdrucken. 
3

Gsichter seynd kugelrund, und in Leib frisch und gsund, kurze Füß dicke Wädl, die taugen just recht in d'Städl, gelt du drescht ä, halt ja i moan ä, ey dasti halt ä.

5

Die oän, die ist recht nett, sacht alle Tag ins Beth, aft komt ihr hint was aus, Buema das war ä Schmaus, gelt du möchst ä, halt ja i moan ä, ey dasti halt ä.

7

Buema jetzt tummelts eng, aft thama no ä weng, aft wann ma 11. läut, da ist zum Fressen Zeit, gelt du frist ä, halt ja i moan ä, ey dasti halt ä. 9

Hiesel hat ä so gschwitz, i hab mi recht derhitzt, s'Hemmet beyn Arsch ist naß, geh sey so gut und blas, gelt du blast ä,

halt ja i moan ä, ey dasti halt ä. ${ }^{56}$
4

Die oän die rührt sich recht, unter uns Baurnknecht, sie arbeit um in Streih, fast wie ä Sau darbey, gelt du schmeckst ä, halt ja i moan ä, ey dasti halt ä. 6

Buema drescht nur braf drauf, hebts nur die Dreschln auf, schlagt es recht tief hinein, das Stroh muss sauber seyn, gelt du drescht ä, halt ja i moan ä, ey dasti halt ä.

8

Buema jetzt läutens schon, habst acht, daß mas hören kann, jetzt sama alle froh, werfts Dreschl hin aufs Stroh, gelt du wirfst ä, halt ja i moan ä, ey dasti halt ä.

1,1 Buema] Buben, Jungs 1,3 gema] gehen wir 1,4 Habern] Hafer 1,5 ä] auch 1,6 moan] meine 1,7 dasti] Ausruf der Verwunderung, vermutlich von der Ellipse ,dass dich ...'2,1 Diern] Mägde 2,1 thamas] tun wir sie 3,4 Städl] Scheune 4,1 oän] eine 4,3 Streih] Streu, Einstreu im Stall 5,2 sacht] pisst, uriniert 5,3 aft] dann 6,2 Dreschln] Dreschflegel 7,1 eng] euch 7,2 thama] tun wir 9,3 Hemmet] Hemd

Unmissverständlich ist die Arbeitslied-Parodie sexuell konnotiert, wobei die Mehrdeutigkeiten des ,Arbeitens im Stall‘ wie auch das Motiv des Dreschens anspielungsreich ausgenutzt werden. Dabei bleibt es in diesem Fall nicht bei eher harmlosen erotischen Anspielungen, vielmehr können derb-sexuelle, eventuell sogar gewalttätige Bilder assoziiert werden, wenn von den heftigen Bewegungen (Str. 4) und den tief reingeschlagenen Drescheln (Str. 6) die Rede ist. Bezeichnenderweise aber lassen sich diese Anspielungen nicht eindeutig festmachen, ja verschwinden geradezu, je genauer man den Text vor der Folie des zugrunde liegenden Musters betrachtet. Eine einseitig erotische Interpretation scheint dementsprechend nicht möglich, die zitierten Stellen könnten auch jederzeit rein auf die Arbeit des Dreschens ohne sexuelle Anspielung bezogen werden. Gerade das

56 Zwey schöne neue Weltliche Lieder, Das Erste: Der Himmel hat den Männern, etc. Das Anderte: Buema wer dreschen kann, jetzt, etc. Gedruckt in diesem Jahr [o. O., o. J., ca. 1760-1800], f. 2v-3v. 
macht einen Text wie den vorliegenden - bei aller Derbheit und Banalität - mit Blick auf soziale Normvorgaben und Zensurdruck auch spannend. ${ }^{57} \mathrm{Ab}$ der Mitte verlegt sich das 20-strophige Lied mit der Beschreibung unterschiedlicher Ausscheidungsprozesse sowie eines ekelerregenden Mahls ganz auf die weniger tabuisierte Fäkal- und Ekelkomik, wie wir sie bereits kennengelernt haben:

10

Jakel geh gschwind wo bist, da scheiß i aufn Mist, d'Suppen steht auf den Tisch, wart bis ichs Loch auswisch, gelt du wischt ä, halt ja i moan ä, ey dasti halt ä.

12

Aft kriegts än Millireis, sän Kern wie Bettlerläus, ä Saufleisch ä dazu, aft hommä gfressen gnue, gelt du frist ä, halt ja i moan ä, ey dasti halt ä. $[\ldots]^{58}$
11

Buema frests was eng schmeckt, der Hund ist erst verreckt, d'Bäurin hatn hais abgsotten, frest darzu Semelknotten, gelt du frist ä, halt ja i moan ä, ey dasti halt ä.

11,1 eng] euch 11,4 Semelknotten] Semmelknödel 12,4 hommä] haben wir gnue] genug

Subtiler als in der parodierten Offenlegungssituation der Ohrenbeichte oder durch die Brachialmetaphorik von Arbeitsliedern werden sexuelle Inhalte in Textsorten zum Publikum geschmuggelt, die sich das Mäntelchen der neutralen Berichterstattung und moralischen Entrüstung umhängen, um das Tabu der Thematisierung des Obszönen zu umgehen. Besonders gewieft operiert hier die unter dem Akronym „A. v. M.“ erschienene antiklerikale Streitschrift Neuester Hexenproceß aus dem aufgeklärten heutigen Jahrhundert (1786), die einen authentischen (?) Mordfall im niederbayrischen Neuberg zur Agitation gegen den von konservativer katholischer Seite noch immer geförderten Hexenglauben nutzt. Eine junge Bäuerin habe auf Anraten eines ,Hexenpaters' die Großmutter ihres Mannes erschlagen, da deren Kühe im Gegensatz zu den ihren reichlich Milch gaben. Zuvor aber habe dieser P. Benno aus dem Franziskanerkloster zu F. die naive Neubergerin zu sexuellen Handlungen genötigt - eine Szene, die ohne großen Erkenntnisgewinn, doch zur Unterhaltung der Leser, lustvoll' detailliert rekonstruiert wird. Dass die leichtgläubige Genötigte dabei als Dialektsprecherin inszeniert wird, soll ihre Simplizität unterstreichen, die ihr zum Verhängnis wird.

Die junge Bäuerin begehrte also den Hexenpater, den man ihr herab rief, und welcher sie in ein dazu besonders bereitetes Zimmer führte, und mit Bier bediente. Anfänglich hörte man den jungen Pater wenig sie unterbrechen - Als aber das liebe Weibchen ausgeredt, und ihre Noth wegen der Zauberey geklagt hatte - fieng er an: -

57 Vgl. zu diesem Zusammenhang etwa Rudolf Schenda: Volk ohne Buch. Studien zur Sozialgeschichte der populären Lesestoffe 1770-1910. Frankfurt a. M.: Klostermann 1970, S. 368f.

58 Zwey schöne neue Weltliche Lieder, f. 3v. 
Bäuerin! Bäuerin! Da muß was anders als die Alte Schuld seyn - wie meynts ihr! - B. Ich? Ja mein Gott! Wo solls dann fehlen? P. Habt ihr euern Mann treulieb? ? B. O ja von Herzen gern! P. Seyd ihr mit ihm zufrieden? B. Ja! Ihr Hochwürden! P. Thut er seine Schuldigkeit, seyd auch ihr zufrieden? B. Ja! P. Versteht mich wohl! Ich meyn's so, ob er bei der Nacht im Bette thut, wie ihr es verlanget, so lang und viel? B. Aber ey! - (voll Scham) Ihr Hochw - P. Ja nur heraus mit der Sprache, denn da kommt viel darauf an - also? B. Ja! Ihr Hochwürden. P. Hm! Hm! (ergreift ihre Hand) Weib! Weib! beinahe komme ich auf andere Gedanken! B. Aber, Ihr Hochwürden, ich bitt enk um Gotteswillen - werds ja mich für kai Hex halten? P. Das nicht, Weible, - aber - wie! Macht 'nmal eur Mieder auf! - B. Ihr Hochwürden! Was denken's? ist ja ä Schand! P. Ich kann euch nicht helfen - Ich komm sonst nicht auf die Spur - Nun - B. In Gottesnamen! Aber Herr! P. So! - schon wieder nähere Spuren (indem er die volle Brust streicht - drückt - und zulezt saugt) B. Aber, Ihr Hochwürden, was ist denn das? O jeges! Wenns ay Mensch sehet - P. Halt dich, Närrin! (saugt immer fort) B. Nu was zeigt sich denn? P. (Voll Feuer) Ja, Mütterchen! Ich spüre zwar, daß eine Hexerey in eurem Leib ist - aber noch weis ich nit, kömmts von eurer Alten, oder gar von eurem Manne her - und um das zu finden, müßt ihr euch schon da niederlegen. B. Ja! Was woll'es dän thai mit mir? P. Das werdet ihr schon sehen - Gelt, ihr seyd schwanger? B. Ja! Ihr Hochwürden! P. Nun schaut! Das Kind ist verhext, und da wird euch ein schöner Bankert Freud machen, und einmal auf dem Scheiterhaufen brinnen, (brennen) wenn ich euch nicht helfe - und es geben euch die Kühe keine Milch, bis da geholfen ist - gebt euch also nur willig, und legt euch nieder - B. Nun, wanns Ihr Hochwürden befehlen! (die Arme stand während voriger Rede da, und wußte nicht, wie ihr geschah - willig legte sie sich auf den Boden, und der Franciskaner fährt fort) P. Nun hebt die Röcke weg! B. Aber, Ihr Hochwürden! Ich schäm mich ja! P. Ey was schämen! - Fällt mit räuberischer Wollust über die arme Betrogene hin, und - Eine schauderhafte Scene für ehrliche Männer. Nachdem er sie geschändet hatte, sprang er hastig in die Höhe, und macht die schändlichsten Sachen. ${ }^{59}$

O jeges] Ausruf zum Ausdruck der Bestürzung (Verballhornung von ,O Jesus') woll'es] wollt ihr thai] tun

Geschickt wird hier unter den Fahnen der Aufklärung Lust-Kontrebande betrieben, die zur Erheiterung der Lesenden die sexuelle Nötigung mit den narrativen Mitteln der Schwankliteratur bzw. in Nachfolge von Bocaccios Decamerone (mit dem es die antiklerikale Ausrichtung teilt) vermittelt. Mit einem scheinheiligen Kommentar zur ,schauderhaften Scene' des Geschlechtsakts versichert der Autor den ,ehrlichen Männern` ihre eigene überlegene Moral, während zuvor Lust und Befriedigung der Frau als widersinniger Hexenbeweis genüsslich vorgeführt werden.

Wenn von weiblicher Sexualität im öffentlichen Diskurs die Rede war, dann am ehesten noch im Zusammenhang mit den Diensten des ältesten Gewerbes, wie im folgenden Doppellied über den Graben und seine ,Nymphen'. Die Prachtstraße in der Wiener Innenstadt zwischen Stephansplatz und Kohlmarkt galt im 18. Jahrhundert nicht nur als gesellschaftlicher Treffpunkt, an dem man, wie Pezzl in seiner Skizze von Wien (1788) schreibt, „stets vornehme und schön geputzte Leute beiderlei Geschlechts in Wagen, zu Pferde und zu Fuß vorüber gehen“ 60 sehen konnte. Sie war auch ein Ort volkstümlicher Belustigungen und, insbesondere seit der josephinischen Zeit, „Tummelplatz der Prostituierten “61. Wie man sich die Anlockung der Freier durch die Straßendirnen in diesen

59 Neuester Hexenprocess aus dem aufgeklärten heutigen Jahrhundert. Oder So dumm liegt mein Bayrisches

Vaterland noch unter dem Joch der Mönche und des Aberglaubens von A. v. M. [o. O.] 1786, S. 5.

60 [Johann Pezzl:] Skizze von Wien. Fünftes Heft. Wien/Leipzig: Krauss 1788, S. 717.

61 Vgl. Felix Czeike: Der Graben. Wien/Hamburg: Zsolnay 1972, S. 62f. 
Abb. 45: Prostituierte und Freier (aus: Richter, Taschenbuch für Grabennymphen, Österr. Nationalbibliothek/ Kooperationspartner Google, Sammlung von Handschriften und alten Drucken, 294206-A, S. 4).

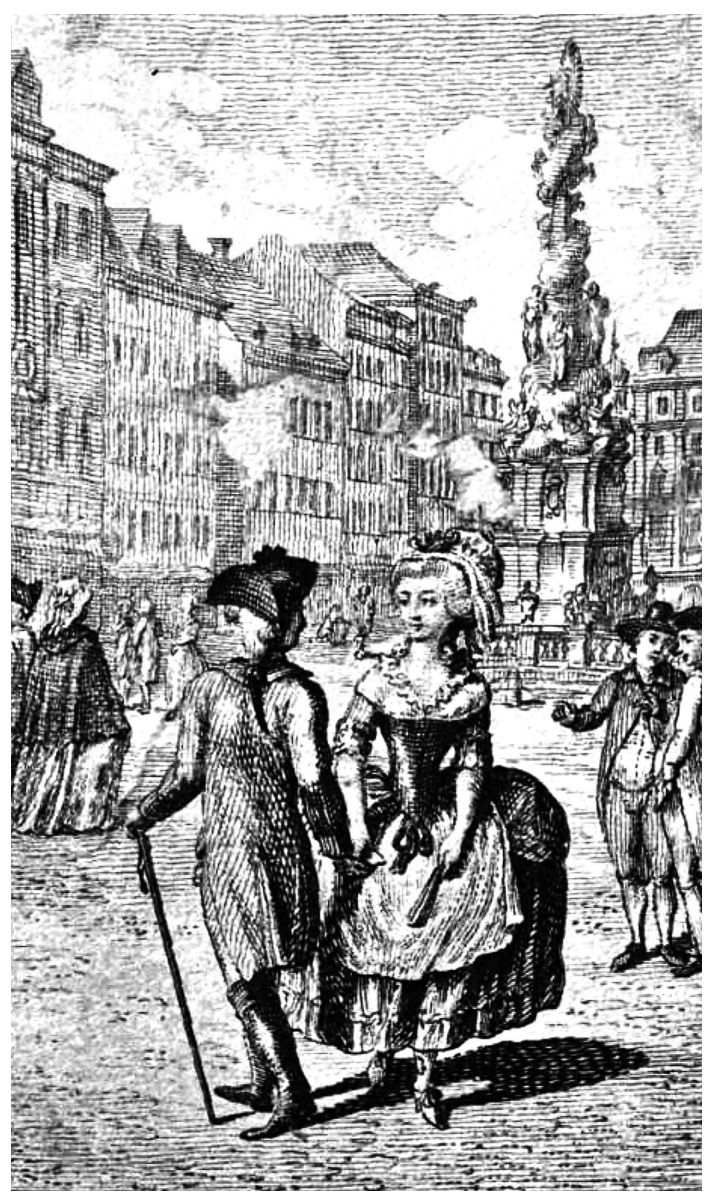

prüden Zeiten vorstellen muss, verrät Joseph Richters amüsantes Taschenbuch für Grabennymphen auf das Jahr 1787, ein ,Jahresplaner' für horizontal Erwerbstätige und ihre Kundschaft aus libertinistisch-ironischer Perspektive. Frei von der üblichen Moralisiererei wird hier Prostitution als notwendiges Geschäftsmodell präsentiert, dessen Problematik nicht darin besteht, dass es existiert, sondern dass es von einer heuchlerischen Gesellschaft verleugnet und behördlich mit Schikanen belegt wird. ${ }^{62}$ Die Bewahrung des schönen Scheins bedingte eine Heimlichkeit, die durchaus auch gesundheitliche Folgen haben konnte, wie die Bildbeschreibung einer Illustration dieser Broschüre klarstellt: „Eine Grabennymphe druckt einem Fremden im Vorbeygehen ihre Addresse in die Hand. Einige Herumstehende lachen, weil sie wissen, daß eine Addresse von dieser bekannten Grabennymphe zugleich eine Anweisung an die Apotheke seye. " ${ }^{63}$ Auch im vorliegenden, anonym überlieferten,Grabenlied` ist das Verbergen des Unschicklichen

62 Vgl. Puchalski, Imaginärer Name Österreich, S. $162 \mathrm{f}$.

63 [Joseph Richter:] Taschenbuch für Grabennymphen auf das Jahr 1787. [o. O.], S. 78. 
dominantes Thema; im ersten Teil werden zunächst die verschiedenen Orte und Gelegenheiten der Geschäftsanbahnung vorgestellt:

1

Freunde habt anjetzo acht, Es wird was Neu's gebracht, s'Thema ist vom Graben, Was man da alles kann haben, Kurz von der Wienerstadt, Wies zugeht früh und spat. [...]

6

Wenns schon bald Mittag wird,

Wird schon ausspekulirt,

Gecken stehn hauffenweis,

Drunter manch junger Greis,

Lauren dort auf d'Mamseln,

Thun sich hübsch nahe stelln.

8

Gassen ein, Gassen aus,

Werfen sie s'Netzgarn aus,

Bis Jemand hinten zupft,

Ein paarmal aufi tupft,

Wenns ein wenig finster wird.

Da wird erst negozirt.

10

Was nutzt das lange Frag'n

Nehmens ein Lehe-Wag'n,

Kutscher fahr! führe uns dort,

Führ uns hübsch langsam fort,

ja so gehts alle Tag,

Wie ich da sing und sag. ${ }^{64}$

\section{2}

In der Früh, wenns kaum graut,

Wird schon ums Frühstück g'schaut,

Die Menscher rucken an,

Passen auf Kerln schon,

Wenns ein wenig spater wird,

Wird d'Herrschaft niederg'führt.

7

So gehts den ganzen Tag,

Eins lauft den Andern nach,

Wenn dann die Nacht anruckt,

Da wird erst doppelt guckt,

D'Madeln, die fliegen rum,

haben oft kein Tüchel um.

9

Bey der Limonadi-Hütten,

Darf man just nicht viel bitten,

Gefrornes de l'arlequin,

Reißt manche Jungfer hin,

Da wird erst accordirt,

Bis man ganz einig wird.

2,3 Menscher] Mädchen 8,4 aufi tupft] anstupst 8,6 negozirt] verhandelt 9,3 Gefrornes de l'arlequin] Harlekin-Eis (beliebtes Speiseeis) 9,5 accordirt] vereinbart, verabredet 10,2 Lehe-Wag'n] (wohl fälschlich für ,LehnWag'n') Mietkutsche

Die in der zehnten Strophe angesprochenen Mietkutschen, die gewissermaßen als Stundenhotel Verwendung finden, stehen im Mittelpunkt des zweiten Teils, der das Spiel mit dem Aussprechen und Verschweigen, dem Andeuten und Verhüllen weitertreibt. Das pikante Thema des Geschlechtsakts in der Kutsche wird hier lapidar als ,Weib-und-MannSpiel` umschrieben, während der darauf folgende Streit zwischen Freier und Kutscher ausführlich, ja beinah geschwätzig geschildert wird. Das Feilschen um den angemessenen Fahrtpreis aber dient dazu, das Geschehene, ohne es explizit zu benennen, der Phantasie der Zuhörer stets präsent zu halten. Diese Differenz zwischen Wissen und Erzählen wird auch in der situativen Rahmung des Lieds angesprochen, wenn der Sänger auf all das verweist, was eigentlich noch zu erzählen wäre, aber nicht gesagt werden darf.

64 Zwey schöne Lieder. Das Erste. Frisch auf Kameraden zu Fuß und zu Pferd. Das Zweyte. Der Viacker in Wien. [o. O., o. J.; Wien, um 1800], f. 2r-3r. Erstmals abgedruckt in: Wolkan, Wiener Volkslieder II, S. 3-9. 
1

Jetzt ist die Laune hier

Wo ich beym Gläschen Bier,

Es weiter singen will

D'rum Freunde nur hübsch still,

Ich will euch Etwas sagen

Und zwar von Leh'n-Wagen.

3

Jetzt sizt das Paarl d'rinn

Im aller froh'sten Sinn,

Jetzt geht d'Negoz erst an

Sie spielen Weib und Mann,

Und wie's noch weiter geht

Weiß Jeder, der's versteht.

5

Kurzum die beyden Leut

Haben halt ein rechte Freud,

Der Kutscher fahrt nicht schlecht

Schwager! just so geht's recht,

Und so geht's immer fort

Bis der Wagen kommt an's Ort.

7

Was ey! warum nicht gar

Kerl, du bist ein Narr,

Haben wir nicht akkordirt

Hast uns umsonsten g'führt,

Ey das geht mich nichts an

Kurz, ihr Gnaden wissen's schon.

9

Es wärts die rechten Narren

Möchts gern langsam fahren,

Aber 's zahlen wer enk z'viel

Was man begehren will,

Hat enk mein Wagen g'fallen

So denkts jetzt auch an's zahlen.

11

So G'schichteln giebt's sehr viel

D'rum schweig ich lieber still,

Wollt man z'viel Wahrheit sagen

Wurd man auf d'Goschen g'schlagen,

D'rum hör ich lieber auf

Und sing ein anders d'rauf. ${ }^{65}$
2

Es heißt fahr langsam fort

Im ersten Lied ein Wort,

Der Kutscher sagt gleich ja

Ih: Gnaden ich bin schon da,

Ja er ist noch so fein

Und hebt's in Wagen hinein.

4

Der Kutscher den Spaß kennt

Schaut, daß kein Roß nicht rennt,

Und weil er's gut versteht

Schaut er, daß langsam geht,

Was da im Wagen geschieht

Davon schweigt itzt mein Lied.

6

Nachher steigt's Paarl aus

Und zahlen den Kutscher aus,

Der Kutscher schaut's Geld an

Ihr Gnaden wissen's schon,

Sie müßen was spendiren

$\mathrm{Nu}$ ja! für's langsam führen.

8

Und machen's mir kein Spaß

Denn sonst verrath ich was,

Kerl! was willst du sagen

Ey, was geschehen im Wagen,

Gebens noch drey Zwölfer her

nachher sag ich nichts mehr.

10

Nun Kerl sey nur stat

Und red nicht gar so pfad,

Da hast drey Zwölfer noch

Kerl ist's recht nun so

Ja jetzt bedank ich mich

Und fahre fort, wie hi.

3,3 Negoz] (ital. negozio) Handel, Geschäft 5,4 Schwager] Bezeichnung für einen Lohnkutscher 8,5 Zwölfer] seit dem frühen 16. Jh. geprägte 12-Kreuzer-Stück (ab 1795 mit geringerem Gehalt geprägt) 10,1 stat] still 10,2 pfad] (fälschlich für) fad (?) 11,4 Goschen] (verächtlich für) Mund, Maul

Mit Allusionen und Elisionen Schlüpfrigkeiten zu fabrizieren, gelingt auch auf sehr unterhaltsame Weise dem (pseudonymen?) Broschürendichter Joseph Hochberger, der in Wiener Krankheiten am Aschermittwoch (1784) die frivolen Aspekte des Faschings in

65 Zwey schöne Lieder, f. 3v-4v. 
der Residenzstadt aufs Korn nimmt. Als 11. Kapitel montiert er als Beispiel, „welche grosse Fortschritte die Rechtschreibung, Sprachlehre, und der Briefstyl in unserer Stadt gemacht habe“, eine witzige Brieffiktion, die ihr komisches Potential nicht nur aus der Diskrepanz von Mündlichkeit und Schriftlichkeit bzw. Brieffloskel, Alltagsformulierung und Sprachfehlern schöpft, sondern mit perfiden Bildwechseln die Vorbereitungen für den Maskenball sexuell konnotiert:

füllgeliptester!

in Ahler Eule mach ich innen zu Wiesen, das mi dfrau Mama häut auf Dredut mit nimt. justament frisirt's der Schan, Hab im schon an Gulden gschenkt, nur damit er si mit der Mama recht tumelt; und wan er mit der Mama firti is, so kumt er ibermi.

Schan! - hab i gsagt - stoß er mi nur gschwind zsam, und trag er hernach das Billiedl zum Herrn von ... Damit sö mi aber glei kenne, so will i ina sagn, wie i wir masakrirt sein.

aus dem Harn künens mi nöt kene, weil mi der Schan so erschreklich durchbuttert, aber blumeranfarbeni Schuech hab i an, und an bremte Dam farben Rog, mit saitenen Franzeln, und a piss farbi Kasaten mit Schwedlaren farbn maschen. Um den Hals hab i mein brülliantes Greiz - sö kennens ja, sö haben's erst neuli in der Hand ghabt, aber wartens [n] ur - kömmens mir no amahl a so, sö Bosheit, sö!

Hiezt bfiet ina God, und ich verhaare

dero

immer und ewig getreue und geborne

von S.

NB. nehmens ineri staglen Schnallen, daß i ina glei kenn, und lassens ina ihn senfzer Gangel segn. Adies. Adies.

auf Dredut] auf die Redoute, den Ball Schan] Jean tumelt] beeilt ibermi] über mich Billiedl] Billet wie i wir] wie ich werde masakrirt] fälschlich für ,maskarirt', maskiert aus dem Harn] an den Haaren durchbuttert] durchpudert (,budern/pudern' bair.-österr. auch für ,koitieren') blumerant] (franz. bleu mourant: ,sterbensblau') fahlblau, bläulich bremte Dam farben] (franz. brun de dame) braun für die Dame Kasaten] Bluse (?) Schwedlaren] (?) Hiezt] jetzt bfiet ina] behüte sie ineri] ihre i ina] ich Sie staglen Schnallen] Stöckelschuhe mit Schnallen (?) senfzer Gangel] Seufzergang (?) segn] sehen

\section{Obszöne und pornographische Lieder}

Auch wenn über gelebte Sexualität großteils nur in übertragener, moralisierender oder satirisch indirekter Weise öffentlich gesprochen werden konnte, heißt dies nicht, dass keine literarischen Produkte entstanden wären, die die Dinge beim Namen nannten. Doch weitgehend ausgeschlossen von der Drucklegung und den Zwängen innerer und äußerer Zensur ausgesetzt, hat sich kaum ein originales Dokument aus dem 18. Jahrhundert erhalten. Dass die wenigen, teils auch späteren Quellen, die uns einen bescheidenen Blick auf die zeitgenössische Verbalisierung von Lust erlauben, in vielen Fällen dialektale Merkmale aufweisen, kann nicht verwundern. Nicht nur signalisierte die Nähesprachlichkeit eine dem Thema angemessene Intimität, die sich abhob von der distanzschaffenden, in diesem Kontext umso mehr, uneigentlich ' wirkenden Schreibsprache. In der fingierten Mündlichkeit konnte auch das leichter transportiert werden, was als nicht aufschreibbar und nichtig galt. Doch aus dem mündlichen Privatgebrauch, der sich in den dialektalen Formen widerspiegelt, fand nur bedauernswert wenig in die Schrift und kaum etwas davon hat die Zeiten überdauert. Eine Zufallsüberlieferung ist ein nur 
schwach mundartlicher Kanon des aus Benediktbeuern stammenden Bassisten, Komponisten und Regisseurs Sebastian Mayer (1773-1835), der das lächerliche Lamento eines Tripper-Kranken in Noten setzte:

Ich möcht gern vögeln hab aber 'n kranken Schwanz

ich möcht gern vögeln, find keinen Jungfern Kranz.

Was hilfts probieren, ich kann halt nimmermehr.

Mein Schatz hat d'Paucken, und ich das Rehrlgschwer. ${ }^{66}$

4 Paucken] Venerische Geschwüre Rehrlgschwer] Röhrengeschwür: Tripper, Gonorrhoe

Pornographische Texte im eigentlichen Wortsinn, also aufgezeichnete ,Hurenlieder (griech. pornē: Dirne), sind uns in zwei Sammlungen erhalten, die unter teils abenteuerlichen Umständen die verschiedenen Zensurmechanismen überdauerten. Die eine ist der Forschung unter dem Sammelbegriff ,Spittelberger Lieder ' bekannt und wurde erstmals 1924 von Emil Karl Blümml und Gustav Gugitz publiziert, deren dafür gewählte Pseudonyme K. Giglleithner und G. Litschauer sie vor weiterem Ungemach behüten sollte. ${ }^{67}$ Denn schon 1908 hatte der Volksliedforscher Josef Pommer gegen Blümmls Sammlung Erotische Volkslieder aus Deutsch-Österreich gerichtliche Schritte eingeleitet und mit einer perfiden, auch antisemitisch motivierten Kampagne eine weitere akademische Karriere seines bedeutenderen Konkurrenten unterbunden. ${ }^{68}$ Die Vorsichtsmaßnahme ist nachvollziehbar: Noch heute sind die Lieder aus Spittelberg, dem einstmals berühmt-berüchtigten Vergnügungsviertel mit Dutzenden Lokalen und Winkelbordellen, in ihrer drastischen Direktheit nichts für Zartbesaitete. Gewährsmann für die deftigen Vierzeiler war der Wiener Feuilletonist Friedrich Schlägl, der aus einer heute verlorenen Sammlung des bibliophilen Gastwirts Franz Haydinger (des bedeutendsten Viennensia-Sammlers des 19. Jahrhunderts) von $1812^{69} 71$ Vierzeiler kopierte, obwohl er in Wiener Luft (1875) noch beteuerte: „Meine Feder würde erröten, wenn ich versuchte, nur eine Zeile niederzuschreiben “70.

66 Staatsbibliothek zu Berlin, Mus.ms.autogr. Henneberg, J. B. 2M, f. 2v. Der Vorbesitzer Aloys Fuchs vermerkt: „Der 3te Canon auf der Rückseite, ist von dem Hofopernsänger Sebastian Mayer (+) Schwager Mozarts aufgeschrieben; und das Ganze höchst wahrscheinlich an einem lustigen Abend in Mozarts Beisein, componirt worden. “ Mayer, der 1797 eine Schwester Constanze Mozarts heiratete, war bei Mozarts Tod erst 18-jährig und wird ihn kaum persönlich gekannt, geschweige denn mit ihm anzügliche Lieder gesungen haben. Die Entstehungszeit ist wohl in die Mitte der 1790er Jahre zu setzen.

67 Vgl. K. Giglleithner/G. Litschauer [i. e. Emil Karl Blümml/Gustav Gugitz]: Der Spittelberg und seine Lieder. Wien: Privatdruck 1924, S. 56. - Siehe dazu auch Alexander Sixtus von Reden/Josef Schweikhardt: Eros unterm Doppeladler. Eine Sittengeschichte Altösterreichs. Wien: Ueberreuther 1993, S. 45ff. - Susanne Mauthner-Weber: Venuswege. Erotischer Führer durch das alte Wien. Wien: Promedia 1996, S. 165188. - Ernst Weber: Spittelberg-Lieder. In: Rudolf Flotzinger (Hg.): Oesterreichisches Musiklexikon. Bd. 5: Schwechat - Zyklus. Wien: Österr. Akademie der Wissenschaften 2006, S. 2265f. - Roger Stein: Das deutsche Dirnenlied. Literarisches Kabarett von Bruant bis Brecht. Köln/Weimar/Wien: Böhlau 2007, S. $245 f$.

68 Ein ähnliches Schicksal ereilte 1921 Leo Schidrowitz mit seiner Sammlung Das schamlose Volkslied, vgl. Brednich, Erotisches Lied, S. 589.

69 Der Versteigerungskatalog zum Nachlass Haydinger verzeichnete 1876 „Lieder: Ein Band Manuscript. Enthält: Harfenisten-Lieder, Politische auf Napoleon und auf die 3 Allirten, Quodlibets, 181 Spitelberger-Lieder, 4zeilige usw. Gesammelt in Jahr 1812. $8^{\circ} .185$ S. (Sehr pikant.)“. Zitiert nach Giglleithner/ Litschauer, Der Spittelberg und seine Lieder, S. 56.

70 Ebda., S. 55. 
Es ist davon auszugehen, dass ein Großteil dieser Lieder, die in der Frühzeit zumeist begleitet von zwei Violinen und einem ,Bassetl' (Kontrabass) von Beleg- und Kundschaft der Wiener Etablissements und natürlich auch anderswo gesungen wurden, schon im 18. Jahrhundert entstanden sind, nicht nur im urbanen, sondern sicherlich auch im ländlichen Raum. So konstatiert Lorenz Hübner in seiner Beschreibung der Volkslieder des Pfleg- und Landgerichts Werfen, dass es neben den von ihm als Beispiele angeführten „sogenannten Gsängl, oder Schnödahüpfl, wovon jeder Bursche und jedes Mädchen eine Menge auswendig weiß, singt, oder mit pfeifen ausdrückt, [... ] noch mehrere, aber sehr schmutzigen Inhalts" ${ }^{\text {"71 }}$ gebe (ohne dass er dies belegen würde). Eine Ahnung vermittelt zumindest der Abtenauer Schuhmachermeister Thomas Braun, Einsender für die Sonnleithner-Sammlung von 1819 (wo allzu Schlüpfriges üblicherweise schon vorweg von den jeweiligen Behörden aussortiert wurde) mit einer Handvoll „Volksliedl oder sogenante Schnöderhöpfl“ ${ }^{72}$, in denen über eine mehr oder weniger explizite Metaphorik von sexuellen Wünschen die Rede ist. Auf die Zeit um 1790 bzw. 1800 datiert Braun die folgenden beiden Gstanzl, die noch im 20. Jahrhundert gesungen wurden:

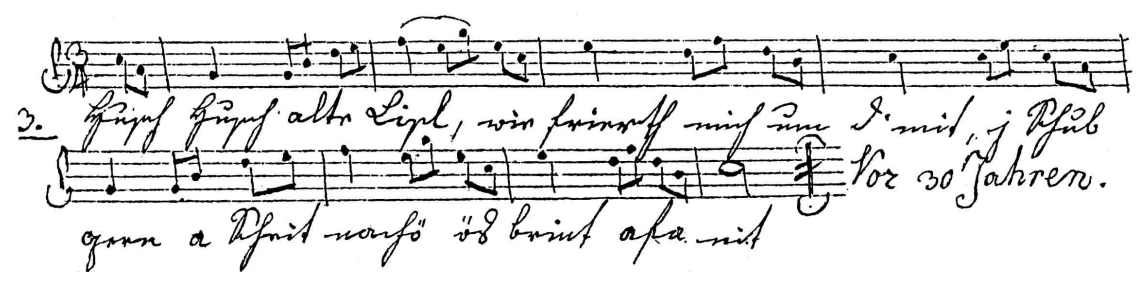

Husch Husch alte Lisl, wie frierth mich um d'mit, j Schub gern a Scheit nachö ös brint afa nit.

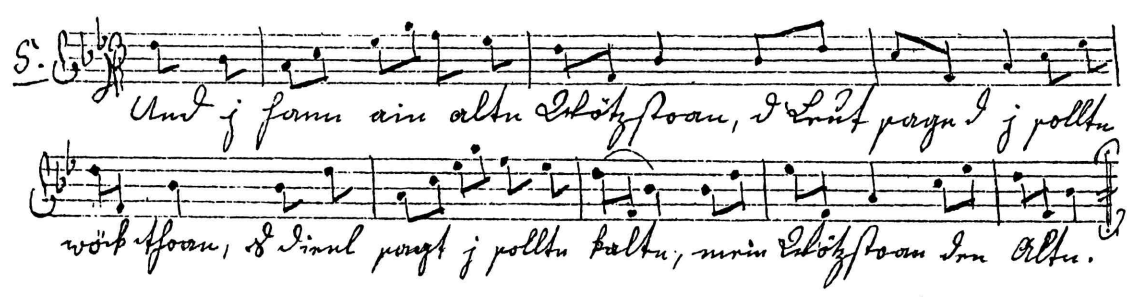

Abb. 46 und 47: Autograph Thomas Brauns (Gesellschaft der Musikfreunde, VI/27.474, VII. Heft/35).

Und $\mathrm{j}$ hann ain altn Wötzstoan, d'Leut sagnd j solltn wök thoan, $s$ dienl sagt I solltn kaltn, mein Wötzstoan den Altn. ${ }^{73}$

71 Hübner, Beschreibung des Erzstiftes und Reichsfürstenthums Salzburg II, S. 391

72 Wien, Gesellschaft der Musikfreunde, VI/27.474, VII. Heft/35. Vgl. den Abdruck und die Wiedergabe der ersten Seite bei Haid/Hochradner, Lieder und Tänze um 1800, S. 240-248.

73 Wien, Gesellschaft der Musikfreunde, VI/27.474, VII. Heft/35. 
Wie die meisten alpenländischen ,Gstanzl' oder ,Schnaderhüpfel‘ sind auch die ,Spittelberger Lieder ' dialektale Gesänge, vorwiegend im Drei-Viertel-Takt mit einem Hang zur komischen Zuspitzung und epigrammatischen Pointe, in denen eine agonale oder übertrumpfende Singsituation anklingt. ${ }^{74}$ Das Ich (oder besser das , $\mathrm{I}^{\mathrm{I}}$ ) kann weiblich oder männlich sein oder auch wechseln (wobei in diesem Themenkreis die Geschlechtszuordnung aus naheliegenden Gründen wesentlich einfacher fällt als in anderen Lyrikformen). Angesprochen werden zahllose Aspekte der Sexualpraxis aus beiderlei Perspektive, als Selbst- oder Fremdbeschreibung, wobei besonders die zur Schau gestellte Libido der Frau gegen alle gesellschaftlichen Konventionen verstieß. Obszön wirken diese kurzen Texteinheiten vor allem, weil ihr Bilderreichtum (anders als etwa in den Erotika der arkadischen Dichtung) sich weniger aus der verhüllenden Metaphorik der sexuellen Handlung denn aus dem entblößend-konkreten Ausdruck für Geschlechtsorgane und Sexualakt ergibt. Dem Dialekt kommt dabei - abgesehen von einer soziolektalen Stigmatisierung - v. a. die Funktion des (scheinbar) unverstellten, archaisch-unkultivierten Ausdrucks zu, der der unsublimierten Triebhaftigkeit des Dargebotenen entspricht:

1

Die Klan san ma liaba

Als wia die Großn,

Sie san ja viel gschickta

Zum einilassn.

63

Jetzt tröpfeln ma d'Dutteln, Jetzt rinnt ma mei(n) Fud,

Jetzt laß i an drüba

Und wars glei a Jud.
23

Tua ma'n eini, tua ma'n eini,

Tua ma's net zreissn,

Steck ma'n eini ins vordre Loch, 's hintre ghört zum Scheißn.

66

Du Spitzbua, wannst pudern willst, Puder mi gschwind,

Bevor ma da Saft

Aus da Fotz aussarinnt. ${ }^{75}$

1,1 Klan san ma] Kleinen sind mir 23,1 Tua ma'n eini] steck ihn mir rein 63,1 Dutteln] Brüste 63,2 Fud] Vagina 63,4 wars glei] wäre es auch 66,1 pudern] vögeln, koitieren

Dem pornographischen Mythos von der Frau als hypersexueller, stets williger und unersättlicher Koituspartnerin, der vor allem der Enttabuisierung und sexuellen Stimulation dient, entspricht ein auf das Phallische reduziertes Männerbild, das in Prahlreden zur Größe und Leistungsfähigkeit des stolz präsentierten Geschlechtsorgans seinen auffälligsten Ausdruck findet:

22

Und sagst alleweil, sagst alleweil,

Es ist dir alls z'groß

Und jetzt hastn ja drin

Auf an anzign Stoß.
25

Und auf da Ofnbank nimm i d'Nudl in d'Hand Und aufn Kanape steht ma d'Nudl in d'Höh Und auf da Bettlastiagn wirstn einigkriagn, Fud, Nudl, ja, an Papp a.

$74 \mathrm{Zu}$ den Gattungsausformungen vgl. u. a. Klaus Beitl: Schnaderhüpfel. In: Rolf Wilhelm Brednich/Lutz Röhrich/Wolfgang Suppan (Hg.): Handbuch des Volksliedes. Bd. I: Die Gattungen des Volksliedes. München: Finke 1973, S.617-677. - Gerlinde Haid: Gstanzl. In: Rudolf Flotzinger (Hg.): Oesterreichisches Musiklexikon. Bd.2. G - Kl. Wien: Österr. Akademie der Wissenschaften 2003, S. 641. - Beatrix Müller-Kampel: Komik in Vers und Reim. Am Beispiel von Gstanzln aus dem Salzkammergut. In: Christian Neuhuber/Elisabeth Zehetner (Hg.): Bairisch-österreichischer Dialekt in Literatur und Musik 1650-1900. Graz: Leykam/Universitätsverl. 2015, S. 161-174.

75 Giglleithner/Litschauer, Der Spittelberg und seine Lieder, S. 65, 76. 
61

I gib da mei(n) Nudl,

Mein Beutl dazua,

Wann dei(n) Fud das alls frißt,

Hats ihr Lebitag gnua.
67

So a gwiß Sardellngrüchl,

Dös is ma schon 's Liabsti,

Da steht ma glei da Schwaf auf,

Nimmts Kappl a(b) und grüaßt mi. ${ }^{76}$

22,1 alleweil] immer 25,2 Kanape] Sofa 25,3 Bettlastiagn] bis 1887 mehrstöckige Stiegengasse vom Spittelberg zur Laimgrube (heute nivelliert unter dem Namen Königsklostergasse) 25,4 Papp] klebrige Masse (hier wohl: Ejakulat) 61,4 gnua] genug 67,3 Schwaf] Schweif, Penis 67,4 Kappl] Käppchen

Zuweilen klingen in den derben Aufforderungen zum Geschlechtsverkehr und der Darstellung des sexuellen Miteinanders aber auch die existenziellen Nöte der Prostituierten an, deren Geschäftsgrundlage durch Menstruation, ungewollte Schwangerschaften, Krankheiten oder schlicht das Altern gefährdet ist:

4

Mei(n) Buberl geh weg

Und laß mi ungheit,

Sunst mach i di schmutzi,

I hab heunt mei(n) Zeit.

27

Tuan eini, tuan eini,

Tuan halt net danebn

Und i bin an alts Dirnderl,

I muaß davo(n) lebn.
24

Zipl net, zapl net,

Greif ma mein Nabel net,

Greif ma mei(n) Ding net a(n),

San Krätzn dra(n).

31

$\mathrm{Kla}(\mathrm{n})$ zsammgschlagne Glasscherbn

Und an Mitridat,

Das gibt ma mei(n) Büabl,

Daß ma’s Schuastern net schadt. ${ }^{77}$

4,2 laß mi ungheit] lass mich in Ruhe 27,1 Tuan eini] tu ihn rein 27,3 Dirnderl] Mädchen, hier auch Diminutiv von Dirne 31,2 Mitridat] nach dem sagenhaften König Mithridates (um 100 v. Chr.) benanntes Arzneimittel aus verschiedenen Zutaten, das als Gegengift und Heilmittel für verschiedenste Zwecke galt 31,4 Schuastern] Koitieren

Andere Vierzeiler wiederum sind aggressive Herabwürdigungen des Gegenübers, die auch nicht vor sexueller Verspottung und koprolalischen Ausfällen zurückschrecken. Dieses gerade im pornographischen Kontext nicht ungewöhnliche Ausagieren von Dominanz und Kontrolle spiegelt nur bedingt tatsächliche Machtverhältnisse wider, bot aber formelhaftes entlastendes Abwehrmaterial, wohl nicht nur im rhetorischen Hin und Her des Gstanzl-Agons.

3

I mag di net liabn,

Hast gar an kurzn,

Du klengst ma net auffi

An d'Nabelwurzn.

21

Und i greif da net dra(n)

Und du bist mar alls z'alt,

Hast patzwache Dutteln

Und 's Fuderl is kalt.
12

Du alte Runkunkel,

Du zahnluckerts Tier,

Hast viel Haar auf da Pumpel

Und kampelst di nia.

43

I scheiß dir ins Gsicht

Und i brunz dir in d'Augn,

Du kannst ma die Beberln

Vom Arsch abaklaubn. ${ }^{78}$

76 Ebda., S. 65, 76.

77 Ebda., S. 65, 69f.

78 Ebda., S. 65, 67f., 72. 
3,3 klengst] reichst auffi] hinauf 12,1 Runkunkel] altes, keifendes Weib 12,3 Pumpel] Vagina 12,4 kampelst] kämmst 21,3 patzwache] sehr weiche 43,2 brunz] pisse, uriniere 43,3 Beberln] Beeren, (hier:) Kotstücke

Melodien sind zu diesen frivolen bis vulgären Gstanzln nicht überliefert, doch lassen sich den charakteristischen metrischen Schemata traditionelle Melodietypen zuordnen, die eine musikalische Wiederaufführung ermöglichen. ${ }^{79}$

Während die 68 ,Spittelberger Lieder ' heute durch diverse Wiederabdrucke und Einspielungen zumindest in Auszügen wieder eine gewisse Bekanntheit erlangt haben, ist eine größere Sammlung mit einer breiteren Palette anzüglicher, erotischer und pornographischer Texte bislang in der Forschung so gut wie unbeachtet geblieben. ${ }^{80}$ Nur Rudolf Wolkan hatte sie für seine Wiener Volkslieder (1923-1926) in Händen, fand allerdings ,auf fast 400 Seiten nur ein einziges Lied, das man ohne Bedenken veröffentlichen kann" ${ }^{\text {"81. }}$. Auch diese zweiteilige Handschrift, die gegen Ende der 1810er Jahre angelegt wurde, enthält zum Großteil Beiträge, die bereits im 18. Jahrhundert nachweislich oder vermutlich im Umlauf waren. Dass Wolkan das Manuskript auf 1785 datiert und aus Ottakring stammen lässt, ist einer Camouflage geschuldet, die wohl auch die Wiederentdeckung des brisanten Inhalts bislang verhindert hatte. Denn dem ersten Teil der Sammlung ist mit Der Gräuel der Verwüstung (1785) ein Klassiker der josephinischen Predigtsatiren vorangestellt (vgl. Kap. 8), der auf den ersten Blick unverfänglich klerikal wirkt, erst bei genauerer Lektüre sich als böse Parodie auf die konservative katholische Homiletik entpuppt. Im Schutze dieser 61 handschriftlichen Seiten folgen zahlreiche standardsprachliche, teils schlüpfrige Beiträge in arkadischer Tradition. Brisanter ist der zweite Teil, der nun viel Dialektales bringt. Auch hier wird mit der Abschrift der Rosenkranz-Predigt (1780) - ein weiteres Stück der indizierten antiklerikalen Spaßliteratur, diesmal aus Bayern (vgl. Kap. 8) - die Überfülle der folgenden Frivolitäten leidlich getarnt. Unterhaltsame, auch aus zeitgenössischen Anthologien bekannte Arbeiten im Standard (u. a von Joseph Franz Ratschky und Carl Arnold Kortum) stehen neben mundartlichen, darunter bereits angesprochene Werke wie Blumauers Petrus und Malchus und Die Beichte, Sturms Die himmlischen Freuden, die Pinzgauer Wallfahrt oder der eklige Hochzeitsschmaus; beliebte ,Harfenistenlieder' wie Der hat nix g'sehen, der nit in Wien war (das einzige Lied, das Wolkan übernahm) oder Brüder seyds lustig hopsasa wechseln mit pikanten Parodien auf Schikaneders Vogelsängerarie oder Bürgers Pfarrerstochter von Taubenhain; ein witziges Hirtenlied (Ey mein Nachbars leuten) findet sich ebenso wie ein rotzfreches Paradieslied (I will eng was singen), diverse Fäkalgesänge wie Bin z'nachst in der Stadt drina gwest, Vexier- und Spottlieder, ein Ecce quam bonum mit dialektalen Zwischenstrophen, Scherzrechnungen, laszive Anekdoten oder auch eine detaillierte und nicht nur soziologisch aufschlussreiche Angebotsliste der (wohl kaum historischen) Prostituierten ,Theresia Lustfeld‘. Vor allem aber bein-

79 So etwa präsentiert der Wiener Schauspieler und Musiker Stephan Paryla-Raky seit 2000 in seinem Programm Hur \& Moll - Lieder nach der Sperrstund' Auszüge aus der Sammlung in verschiedener musikalischer Besetzung.

80 Vgl. die unbetitelte Sammelhandschrift H. I. N. 55795 der Wienbibliothek im Rathaus. Eine kommentierte Edition ausgewählter Texte wird zurzeit von Beatrix Müller-Kampel und Christian Neuhuber vorbereitet.

81 Wolkan, Wiener Volkslieder I, S. XXII. 
haltet die Handschrift insgesamt 380 Gstanzl ganz im Stil der Spittelberger Lieder, von denen sich einige dort auch wiederfinden; andere haben sich, wörtlich oder variiert, bis heute im Volksgesang erhalten. Kaum eine Spielart der (heterosexuellen) Sexualität wird ausgespart, Laszives ungeniert mit Fäkalzoten und witzigem Unsinn kombiniert:

177

Wann i wissat daß der Bue kam, dat i s'Pumperl waschen

Und wann i wißat daß er nit kam that ihs drecki laßn.

183

So leg di nur zuha, so leg di nur her

Und z'erst wuzel nur d'Duterl oft geig mi recht her.

269

Und wanst mirs nit glaubst und meinst ih treib ein Scherz

So zündt beim Arsch ein Lüftl an und schau mir in mein Herz.

373

Das Mensch hab i beym Arsch ertappt

Die litt es ganz geduldig

Drei Seitl Wein hab i g'habt

Herr Wirth was bin i schuldig. ${ }^{82}$

177,1 wissat] wüsste dat] täte Pumperl] Vagina 183,1 zuha] herzu 183,2 wuzel] drücken und drehen Duterl] Brüste

Besonders beliebt waren, weil sie die Autorität der Kirche und deren wütenden Kampf gegen diese Auswüchse der Spaßsubkultur ${ }^{83}$ unterminierten, untergriffig-ordinäre Pfarrer-Gstanzl wie diese:

193

Und unser Pfarrer haust a nit übel

dann er fögelt sein Köchin und scheist auf d'Bibel.

194

Der Pater Vikari der machts nit a so

Denn der vögelt z'erst d'Köchin oft leckt er ihrs Lo.

195

Oft steckt er ihr'n a no von hinten hinein,

Und da schreit eng d'Köchin was soll denn das sein? ${ }^{84}$

194,1 Vikari] Vicarius, Vikar: Inhaber eines kirchlichen Hilfsamtes, Stellvertreter des Pfarrers 194,2 oft] dann, danach 195,1 a no] auch noch 195,2 eng] euch (hier im Sinne einer Bekräftigung)

Bei all der geballten Drastik dieser - wie Müller-Kampel pointiert formuliert - „,Lustspiele` en miniature ${ }^{\text {“ } 85}$ überraschen Strophen, die etwas zartere Töne anschlagen und sexuelle Handlungen nicht nur als lustvollen physischen Vorgang, sondern auch als Ausdruck einer liebevollen Paarbeziehung zeigen:

82 Wienbibliothek im Rathaus, HIN 55795, Teil 2, f. 135v, 136r, 158r, 175r.

83 Vgl. etwa für den Salzburger Raum die Ausführungen und Belegstellen bei Thomas Hochradner: Musikalische Volkskultur in Salzburg vom späten 18. Jahrhundert bis 1848. In: Gerlinde Haid/Thomas Hochradner: Volksmusik in Salzburg. Lieder und Tänze um 1800 aus der Sonnleithner-Sammlung der Gesellschaft der Musikfreunde in Wien. Mit einem Beitrag von Sabine Veits-Falk und Alfred Stefan Weiß und unter Mitarbeit von Walter Deutsch und Annemarie Gschwantler hg. v. Salzburger Volksliedwerk. Wien/Köln / Weimar: Böhlau 2000. (Corpus Musicae Popularis Austriacae 12) S. 13-155, hier $76 \mathrm{ff}$.

84 Wienbibliothek im Rathaus, H. I. N.-55795, Teil 2, f. 37r.

85 Müller-Kampel, Komik in Vers und Reim, S. 172. 
98

Mein Dirndl iß schwanga, das is eng a Freud

hab'n g'sagt i kan nix und jetzt loben mi d'Leut.

129

Zimpimperl, Zimpimperl wird d'Hochzeit bald wern,

Wie freut sie mein Pumperl daß narrisch möcht wern. ${ }^{86}$

\section{Fensterln, Gasslgehen, Werben in Lied und Schauspiel}

Die Vorfreude auf ein gemeinsames Kind oder auch nur auf ein gemeinsames eheliches (Liebes-)Leben, wie sie in den letzten beiden Vierzeilern anklingt, war im ländlichen Bereich, dem Ursprungs- und Traditionsgebiet der Gstanzl und Schnaderhüpfel, keine Selbstverständlichkeit für jedermann/frau. Gerade im alpinen Raum waren nicht-eheliche sexuelle Beziehungen (unter anderem, wenn auch nicht nur) zwischen Knechten und Mägden relativ häufig - insbesondere in durch Viehwirtschaft geprägten ländlichen Gebieten mit gesindereichen Höfen. ${ }^{87}$ Die sogenannten ,Unbehausten', also Hausgesinde, Dienstboten oder auch Handwerksgesellen, machten etwa in Tirol um 1766 rund ein Drittel der Bevölkerung aus, womit ein großer Teil der Bevölkerung von der Ehe ausgeschlossen war. Über die Hälfte der Männer und Frauen zwischen 20 und 40 waren in Österreich im 18. Jahrhundert ledig; sehr viele blieben überhaupt unverheiratet. ${ }^{88}$ Die relativ große Häufigkeit vor- bzw. nicht-ehelicher Sexualität lässt sich (mangels anderer Quellen) an der Zahl der unehelich geborenen Kinder dokumentieren ${ }^{89}$ die bereits im 17. und 18. Jahrhundert in manchen Gebieten bis zu $10 \%$ betrug und ab Ende des 18. bis Mitte des 19. Jahrhunderts in Bayern und Östereich besonders hoch war, mit ca. 20\% in Bayern und Oberösterreich, 30\% in Niederösterreich, Salzburg und der Steiermark und bis zu $45 \%$ in Kärnten. ${ }^{90}$ Ohne Möglichkeit, zu heiraten, mussten die Liebschaften also

86 Wienbibliothek im Rathaus, H. I. N.-55795, Teil 2, f. 127r, 130r.

87 Vgl. Michael Mitterauer: Familienformen und Illegitimität in ländlichen Gebieten Österreichs. In: Archiv für Sozialgeschichte 19 (1979), S. 123-188, hier 180.

88 In der Steiermark ergab etwa die Konskription von 1754, dass 42\% der Bevölkerung, in der Obersteiermark sogar 54\% unverheiratet blieben (vgl. Birgit Leuchtenmüller-Bolognese: Bevölkerungspolitik zwischen Humanität, Realismus und Härte. In: Herbert Matis (Hg.): Von der Glückseligkeit des Staates. Staat, Wirtschaft und Gesellschaft in Österreich im Zeitalter des aufgeklärten Absolutismus. Berlin: Duncker \& Humblot 1981, S. 177-208, hier 183f.).

89 Zwar lässt sich die Zahl der unehelich geborenen Kinder nicht in einen direkten Zusammenhang mit vorehelicher Sexualität bringen und eine Berechnung vorehelicher Sexualität aus Illegitimitätsraten ist seriöserweise nicht möglich. (Vgl. dazu auch Peter Becker: Leben und Lieben in einem kalten Land. Sexualität im Spannungsfeld von Ökonomie und Demographie - das Beispiel St. Lambrecht 1600-1850. Frankfurt a. M./New York: Campus 1990. (Studien zur historischen Sozialwissenschaft 15) S. 220.) Man kann aber, davon wird hier zumindest ausgegangen, immerhin aus den Illegitimitätsraten auf das Vorhandensein von nicht-ehelicher Sexualität in größerem Ausmaß und - mit Vorbehalt, da der Faktor der Empfängnisverhütung nicht unbedingt als konstant angenommen werden kann - auch auf ein ,mehr' oder ,weniger schließen.

90 Vgl. Mitterauer, Familienformen und Illegitimität, S. 180 und 123f. - Hintergrund war eine neuerliche Verschärfung der Heiratsbestimmungen im 19. Jahrhundert, einhergehend mit einer Milderung der Sank- 
heimlich bleiben, wurden moralisch verurteilt und konnten unangenehme Konsequenzen nach sich ziehen. Dennoch, auch darauf weist die Vielzahl an dialektalen Liedern zum Thema hin, waren sie wohl gang und gäbe.

\section{Liebeslieder}

Liebeslieder im engeren Sinne, also romantisch-innige Lieder als unmittelbarer Ausdruck einer seelisch-geistigen und weniger sexuell-körperlichen Beziehung, die sich direkt an den Partner richten und nicht in mehr oder weniger scherzhafter Weise an Dritte, sind in der Dialektliteratur des 18. Jahrhunderts selten. Manche Beispiele wirken mit ihren Archaismen und gezierten Bildern, als wären sie erst im Lauf jahrzehnte- oder gar jahrhundertelanger Singtradition aus einem standardsprachlichen Original in eine mündlichkeitsnähere Fassung übertragen worden. Hierher gehört etwa das durchaus anrührende Schozerl du bist mei, das uns nur in einer verderbten, möglicherweise auch nicht im bairisch-österreichischen Raum gedruckten Version einer Liederflugschrift erhalten ist, weshalb hier auch etliche sprachliche Ungereimtheiten den Gesamteindruck trüben.

1

Schozerl du bist mei

i bin auch ganz dei,

i kauf dir halt ein Schnirn bald,

wann i dir nit bin zu alt,

thu mir redli sogn,

ob du mi willst hobn

fein, recht i mögt,

wann i dir nit bins schlecht.

3

Schozerl reich mir die Hand, der Heurath hat a Bstand, hundert Gulden und a Kuha und a stattlis Gwand dazua laß i dir halt macha, da wird Höpin lacha, fein schön dort steh, mit mir zum Pfarrer geh
2

Dann i hab ein Wunden empfunden, die seyn von deiner Hand, du hast dein Liebsbogen zogen, tapfer ouf mi gespannt, $i$ bin verwund, mach mich gesund, muß renna wi a Budelhund, i will dir stets na renna, als wie der Hahn der Henna, von fern, verehrn, i hab die halt so gern.

4

Thu mirs Pratscherl recka, strecka, gleich a Ringerl dro, wir solln uns zama flicka, stricka, i loß di nimmer oh, du bist mei Weib und i dei Mo, i bleib dir treu, es bleib dabey, ich will dir halt na renna, als wie der Hahn der Henna, von fern, i hab di halt so gern. ${ }^{91}$

1,3 Schnirn] wohl für Geschnür: Halsschmuck einer bürgerlich gekleideten Dame 3,6 Höpin] Kröte, auch grobes Kosewort für eine Frau 4,1 Pratscherl] Pratzerl, d. h. Hand.

tionierung unehelicher Sexualität in rechtlicher wie in moralischer Hinsicht, und zwar insbesondere dort, wo durch die Agrarrevolution und den dadurch bedingten Arbeitskräftemangel in der Landwirtschaft das Gesinde eine gestärkte (ökonomische) Position erlangen konnte. Beides zusammen darf wohl als Grund für die hohen Illegitimitätsraten um 1850 herangezogen werden (vgl. ebda., S. 182ff.).

91 Neun schöne weltliche Lieder. Das Erste. Ich bin a so a Kerl und geh a so rahr etc. Das Andere: In dem Winter Vögel fangen etc. Das Dritte: Bin i gestern spot ausi ganga, etc. Das Vierte: Sag mir, o Schönste, was 
Wie immer man den Blocksatz des Drucks auch in Verszeilen auflöst - ein einfaches Strophenlied scheint hier nicht vorzuliegen, weichen doch Strophen- und Versbau der ungeraden und geraden Liedteile so weit voneinander ab, dass hier auch bis zu einem gewissen Grad ein Melodiewechsel vorgelegen haben muss (der auffälligerweise nicht mit einem Sprecherwechsel verbunden ist). Die barocke hochliterarische Metapher des Liebesbogens der zweiten Strophe will zudem nicht recht in den bäuerlichen Kontext der dritten passen; vielleicht fanden auch hier Abschnitte zweier unterschiedlicher Gesänge zusammen.

Eine Kompilation von ursprünglich separaten Teilen war wohl auch das populäre Liebeslied Das Wuzerl, dessen abschließendes Gstanzl - Nestroy arbeitete es auch in Das Mädl aus der Vorstadt ein - an das bekannte erste Gattungsbeispiel in deutscher Sprache (Dîu bist mîn, ich bin dîn) erinnert:

Mei Herzerl, mei Herzerl ist treu

A Schlösserl, a Schlösserl dabei.

An einziger, einziger Bue,

Hats Schlüsserl, hats Schlüsserl dazue. ${ }^{92}$

Viel häufiger freilich als das ungebrochene Liebesbekenntnis im Sinne einer - zumindest ansatzweisen - Erlebnisdichtung wird Liebe in der bairisch-österreichischen Dialektkunst vor 1800 in typisierten Rollenliedern und zumeist in scherzhafter Form verhandelt. Die Typisierungen von Protagonisten und die Schematisierung der Situationen im Liebesgeschehen begünstigten offenbar auch hier ein ,Bausteinsystem', wie wir es bereits bei den Weihnachtsliedern kennengelernt haben. Material unterschiedlicher Herkunft wurde (zumeist auf Basis metrischer und damit musikalischer Kompatibilität) kombiniert, sei es - oft wohl auch ungewollt - im mündlichen Überlieferungsprozess, sei es für die Drucklegung, um ein neues Produkt vermarkten zu können.

Ein instruktives Beispiel ist eines der heute (zumindest dem Titel nach) bekanntesten Dialektlieder des 18. Jahrhunderts, A Schüsserl und a Reindl, das die Forschung vor allerlei Probleme stellt. Denn obwohl sich gegen Ende des Jahrhunderts zahlreiche Belege für die Popularität und Volksläufigkeit des Lieds finden, verfügen wir weder über eine annähernd verbindliche Textfassung aus dieser Zeit, noch lassen sich der ,eigentliche' Ursprung und das Alter einigermaßen exakt feststellen. Spätestens im Zuge der Tiroler-Mode nach Schikaneders und Haibels Erfolgsoper Der Tyroler Wastel wurde es im süddeutschen Raum als Tirolerlied bekannt. Eine der frühesten Aufzeichnungen dafür ist der Reise durch Oestreich und Italien (1802) des Schriftstellers und Diplomaten Johann Isaak von Gerning entnommen und dort auf das Jahr 1797 datiert. ${ }^{93}$ Da

hab ich dir etc. Das Fünfte: Wie ist es möglich dann, daß ich dich etc. Das Sechste: Schozerl du bist mei und i bin au ganz etc. Das Siebende: Wie quälet mich also die Lieb, die mich etc. Das Achte: Willst du dein Herz mir schenken, so etc. Das Neunte: Als ich einmal spazieren gieng da war etc. Gedruckt in diesem Jahr [o. O., o. J., um 1770], f. 3v.

92 Zitiert nach Wolkan, Wiener Volkslieder I, S. XXIV. Vgl. auch die weiteren Beispiele zur Singtradition in Deutsch/Haid/Zeman, Das Volkslied in Österreich, S. 39 f.

93 Ein bei Feurzeig/Sienicki als früheste Quelle erwähnter Brief von 1779 beruht auf einem Druckfehler bei Lechthaler/Moissl/Schnabel, die den Reisebrief Gernings fälschlich auf den „31. Oktober 1779“ da- 
Gerning dabei auch die Melodie des Lieds anspricht, wird er sich das Lied wohl auf Basis eines mündlichen Vortrags notiert haben; auch die ungewöhnliche Schreibung des (Pseudo-)Tirolerischen, die den damaligen Konventionen der Dialektverschriftlichung kaum entspricht, und die zahlreichen Ungenauigkeiten aufgrund von Verständnisproblemen deuten darauf hin: ${ }^{94}$

1

Ä Schisserl un ä Rainerl,

Ä Sächter un ä Millitopf,

Is oll mei Kuchelg'schirr;

Un won i hold on di gedenk

So main I, so main I,

So main I, wär bey dir.

3

Wie soll i di dann nemma

Un won i di nit mog

De bistht ze wild von Angesicht

Verzeih mersch Gott I mo di nit.

Geh schar di, geh schar di

Un komm mehr nimmermehr.
2

Hoschst g'sad de wullst mi nemma

Sebald de Summa kummt

De Summa de is kumma

De hoschst mi do nit k'numma.

Geh nimmi, geh nimmi,

Gelt ja de nimmscht mi do.

4

Do han mer no sechs Kreitzer

Di g'hera mei un dei

Do kafe mer Schlambascher Wein

A Kuckelhopf un Kropfa drein.

O Hanserl - o Lenerl!

Versoffa muß es sei! ${ }^{95}$

1,1 Rainerl] Kasserolle 1,2 Sächter] kleinerer Bottich mit einem Griff 1,2 Millitopf] Milchtopf 2,1 Hoschst g'sad] hast gesagt 3,3 wild] hier: hässlich 3,4 mersch] mirs 4,1 han mer] haben wir 4,3 Schlambascher] Verballhornung für Champagner (?) 4,4 Kuckelhopf] Gugelhupf Kropfa] Krapfen

Ein weiterer früher Beleg des Lieds in dialektaler Form findet sich in einer Flugschrift, die vermutlich um 1790 zum ersten Mal gedruckt wurde. Die einzelnen Strophen entsprechen grob Gernings Fassung, sind jedoch anders gereiht: Am Beginn stehen die beiden Strophen, in denen es um das Versprechen geht (vgl. die Strophen 2 und 3 der oben abgedruckten Fassung); die bekannte Anfangsstrophe folgt in dieser Form nach:

A Schüßel a Reinl, ist unser Kuchelgschirr,

A Schüßel a Reinl, ist unser Kuchelgschirr

und wann i halt an di gedenk

und wann i halt an di gedenk,

so mein $i$, so mein $i$, so mein i wärst bey mir,

so mein i, so mein i, so mein i wärst bey mir. ${ }^{96}$

tieren. Vgl. Lisa Feurzeig/John Sienicki: Quodlibets of the Viennese Theater. Middleton: A-R Editions 2008. (Recent Researches in the Music of the Nineteenth and Early Twentieth Centuries 47) S. 297 - Josef Lechthaler/Gustav Moissl/Sigismund Schnabel: Lieder fürs Leben. Ein Sing- und Musizierbuch für die Jugend. 9. Aufl. Wien: Hölder [u. a.] 1949, S. 214.

94 Damit ist freilich nicht gesagt, dass es sich dabei um eine besonders authentische Fassung handelt - ob Gerning in die Textgestalt eingegriffen hat, lässt sich weder belegen noch ausschließen.

95 J[ohann] I[saak] Gerning: Reise durch Oestreich und Italien. Erster Theil. Mit einem Titel-Kupfer. Frankfurt a. M.: Wilmans 1802, S. 89 f.

96 Vier schöne neue Weltliche Lieder. Das Erste: Von Wurmser ein Husar, fiel. Das Zweyte: Soldat ist gut zu seyn, sie etc. Das Dritte: Hab glaubt du willst mi nemma, Das Vierte: Loß auf mein liebe Mutter i muß. Gedruckt in diesem Jahr. [o. O., o. J., Wien, bei Anton Leitner, um 1790]. Ein Nachdruck von Ignaz Eder ist um etwa $1800 \mathrm{zu}$ datieren. 
Die hier erstgereihten Strophen beruhen auf dem wesentlich älteren - nicht dialektalen Lied Du hast mich wollen nehmen, das bereits seit dem späten 16. Jahrhundert belegt ist ${ }^{97}$ und in vielen Versionen mit unterschiedlicher Reihenfolge der einzelnen Teile auftaucht. Thema ist ein Heiratsversprechen, das von der Frau eingefordert wird und vom Mann je nach Fassung - entweder wieder zurückgewiesen oder aber bekräftigt wird. Die dialektale Variante und insbesondere die Verknüpfung mit dem humoristischen Motiv des ärmlichen Haushalts sind dagegen erst gegen Ende des 18. Jahrhunderts belegt und zeigen, wie sich aus sogenannten, Liedformeln' bzw. ,Wanderstrophen - auch zum Nachteil der inhaltlichen Konsistenz - neue, höchst erfolgreiche Schöpfungen kreieren ließen. ${ }^{98}$ Eine um 1800 entstandene Flugschrift, die offenbar auch Armin und Brentano als Vorlage für ihre - sehr freie - Nachdichtung in Des Knaben Wunderhorn diente, ${ }^{99}$ bietet schließlich eine verhältnismäßig geschlossene Komposition. In der um vier Strophen erweiterten Fassung A Schüssala, a Häfala spannt sich ein nachvollziehbarer inhaltlicher Bogen von der Liebeserklärung über den Streit zwischen den Liebenden bis hin zur Versöhnung. ${ }^{100}$ Eine zweite Fassung in derselben Flugschrift (A Höfala, a Schüssala) zeigt dagegen die Sprecherin als junge Ehefrau, zufrieden mit dem liebevoll geschilderten Wenigen, das die beiden besitzen. Neben einer intensiven Rezeption am Wiener Theater, wo es in Schikaneders Singspielen Der Tyroler Wastel und Die Kaufmannsbude (Musik: Henneberg, 1796) ${ }^{101}$ sowie in Friedrich Karl Lipperts Einakter Der Marktschreyer (Musik: Franz Xaver Süßmayr, 1799) ${ }^{102}$ wiederverwertet wurde, etablierte sich das Lied um die Jahrhundertwende geradezu als Pflichtübung für Komponisten, die damit ihre Variationskunst für verschiedene Instrumente unter Beweis stellten. ${ }^{103}$ Vor allem Beethovens Op. 105/Nr. 3 für Flöte und Klavier erfreut sich auch heute noch großer Beliebtheit.

97 Vgl. Philip Vilas Bohlman/Otto Holzapfel: The folk songs of Ashkenaz. Middleton: A-R Editions 2001. (Recent researches in the oral traditions of music 6) S. 41. - Deutscher Liederhort. Auswahl der vorzüglicheren Deutschen Volkslieder, nach Wort und Weise aus der Vorzeit und Gegenwart gesammelt und erläutert von Ludwig Erk. Neubearbeitet und fortgesetzt von Franz M. Böhme. Bd. 2. Leipzig: Breitkopf u. Härtel 1893, S. 376f. (Nr. 552a).

98 Vgl. Bohlman/Holzapfel, The folk songs, S. 41.

99 Des Knaben Wunderhorn. Alte deutsche Lieder. Gesammelt von L. Achim v. Arnim und Clemens Brentano. Heidelberg/Frankfurt: Mohr u. Zimmer 1806, S. 373f. (Hast gesagt du willst mich nehmen).

100 Vier lustige Tanz- und Opernlieder: 1) A Schüssala, a Häfala is all etc. 2) A Häfala a Schüssala (auf eine andere Art.) 3) Ihr Männer nehmt euch mit den Weibern etc. 4) Hab ih a Weib und bin a Moh etc. [o. O., o. J.]. Dass hier die verschiedenen Sprecherrollen deutlich bezeichnet werden, stellt ebenso wie der Titel der Flugschrift und die Weiterentwicklung in der Fassung , auf eine andere Art' die Herkunft aus dem Theater klar.

101 Vgl. Feurzeig/Sienicki, Quodlibets of the Viennese Theater, S. 287. Dieses Stück selbst und damit auch die dort verwendete Variante dieses Lieds sind offenbar nicht überliefert. Die Verbindung zwischen Lied und Singspiel ist nur über weitere musikalische Bearbeitungen gegeben, die sich auf Die Kaufmannsbude berufen, so etwa die Sei variazioni sull'aria „A Schisserl und a Reindl“ des aus Italien stammenden Gitarristen Mauro Giuliani.

102 Hier wird nur die erste Zeile des offenbar bereits bekannten Liedes zitiert: „A Schüßerl, und a Reindl / A Spinnrad und an Hut, Und meines Vaters Bräun'l / Ist all mei Hab und Gut. ... “ ([Friedrich Karl Lippert:] Der Marktschreyer. Ein komisches Singspiel in einem Aufzuge. In Musik gesetzt von Hrn. Franz Xaver Süßmayr. Wien: Christoph Peter Rehm 1799, S. 62).

103 Variationen für Violine legten u. a. Franz Krommer (František Vincenc Kramár), Peter Fuchs und Dominik Langer vor; für Flöte bzw. Traversflöte Joseph Richter, Franz Bühler und Karl Kreith, für Gitarre Mauro Giuliani, für Klavier Johann Baptist Vanhal, Paul Maschek (Pavel Mašek), Ludwig Gall, Johann Pe- 


\section{Affären, Verführung, voreheliche Beziehungen}

Häufiger Topos in dialektalen Liebesliedern des 18. Jahrhunderts ist das ,Fensterln', das sich bis heute als Bild für volkstümliche Werbepraxis im kollektiven Gedächtnis erhalten hat. Die heimlichen Besuche und Treffen in der Nacht, die dem Flirten - und mehr - dienen konnten, werden in vielen Liedern besungen. Dabei ist die verwendete Perspektive nicht die Du-Form, die Lieder richten sich also nicht direkt an die Angebetete; vielmehr handelt es sich dabei in der Regel um gemeinschaftlich gesungene Lieder, ${ }^{104}$ die entsprechend an Dritte adressiert sind, denen die Vorzüge des Mädchens und die eigenen Abenteuer geschildert werden (vgl. dazu schon Kap. 6). Mehr oder weniger stark können dabei auch moralische und gesetzliche Verbote und die damit verbundenen Gefahren für die jungen Burschen in der bäuerlichen Gesellschaft thematisiert werden. Im folgenden populären Gassllied, das auch selbst das Motiv des ,Gassengehens` aufgreift, begegnen wir dem typischen Figureninventar: Bauernknecht, Magd als Geliebte, Bauer (hier nicht als Gegner, sondern tendenziell als verständnisvoller Mitwisser), Bäuerin als Hüterin der Sitten. Den jungen Knecht sticht die „Lieb hind und vorn“, der Magd geht es nicht viel anders, sie treffen sich nächtlich „mit Lust und Freud“. Dass die Bäuerin die Magd schilt und der Bauer vom Knecht wissen will, wo er in der Nacht war, macht ihnen weiter nichts aus:

1

Lusti mein Führerbue!

Lusti mein Veitl!

hab ich kein Kreuzer Geld

mehr in mein Beutel,

sticht mi d'Lieb hint und vorn,

und das ist wärlä wahr,

das hat mich triebn,

sonst wär ich dähäm blieben.

\section{2}

Das Knäberl auf der Gassen

fangt auch an zu singen,

das Mäderl im Kämmerl

fangt auch an zu springen,

nimmt das Pfäderl in die Hand,

ist mir entgegen g'rennt

auffi in Angä,

da hats mich empfangä.

ter Heuschkel, Johann Bernhard Hummel, Ambros Rieder, Gotthelf Heinrich Kummer, Katharina Bauer u. a.

104 Vgl. Ilka Peter: Gaßlbrauch und Gaßlspruch in Östereich. Salzburg: Müller 1953. - Deutsch/Haid/Zeman, Das Volkslied in Österreich, S. 51f. - Gisela Rösch: Kiltlied und Tagelied. In: Rolf Wilhelm Brednich/ Lutz Röhrich/Wolfgang Suppan (Hg.): Handbuch des Volksliedes. Bd. I: Die Gattungen des Volksliedes. München: Finke 1973, S. 483-550. - Hochradner, Musikalische Volkskultur, S. 76ff. - Gerlinde Haid: Fensterllied. In: Rudolf Flotzinger (Hg.): Oesterreichisches Musiklexikon. Bd. 1: A - F. Wien: Österr. Akademie der Wissenschaften 2002, S. 434. 
3

Löst mir mein Schüherl auf, und die Strumpfbändel, zieht mir die Strümpferl aus, henks auf ein Stängel, däweil wir schlafen gehen, werden d'Strümpf schon trucken wern, lieber mein Schatzerl, geh er in mein Kammer schlafen. 5 Suppen habens g'fressen, das Koch habens noch g'habt, die Bäurin hat g'scholtn, der Bauer hat g'lacht, der Bauer ist ein brafer Mann, er kennt schon den Buema an, er weiß schon wie es geht, und wann man lang nit aufsteht. 7

Die Schuh an Füssen seynd auch schon mehr z'rissen, wo ich bey der Nacht hingeh, wills mein Herr wissen, du bist Bauer ich bin Knecht, wann i dir bin nit recht, därfst es grad sagen, i will di ä nit lang fragen. Du bist Bauer, ich bin Knecht, wann i dir bin nit recht därfst es grad sagen, i will di ä nit lang fragen. ${ }^{105}$
4

Wir mit Lust und Freud, seynd beynander, aft wann der Tag hergeht, so scheiden wir vonander, lusti im freyen Feld, frag wann i kemma soll, Samstag auf die Nacht da möcht dich haben. 6

Das Gässerl ausgehen laß ich mir nicht wehrn, wann ich im Sommer geh, darf mi niemd sperrn, wann ich im Winter geh, schneibt mir den tiefen Schnee, kann schier nit waden, kanns gleichwohl nit graden.

1,6 wärlä] wahrlich, sicher 2,3 Pfäderl] Hemd(chen) 4,3 aft] dann 5,6 Buema] Buben, Jungen 6,8 graden] entbehren, lassen

Während Lieder wie das genannte insgesamt eine fröhlich-scherzhafte Stimmung beibehalten, teilweise sogar - wie Es ist fürwahr kein bessers Leben ${ }^{106}$ - mit Klamaukszenen und einem dezidierten Bauernlob verbunden sein können, wird in anderen Liedern die Situation der Bauernknechte und -mägde auch stärker problematisiert, zumal hinter der oft verklärten Praktik des ,Fensterlns' und der heimlichen Liebschaften ein sozialhistorisch nicht unbedeutendes Problem stand:

105 Vier Neue Lieder. Das Erste: Ich weiß nicht wies kimmt, etc. Das Zweyte: Bin i ä rundä Hießl, etc. Das Dritte: Lusti mein Führerbue, etc. Das Vierte: Willikum Brudä bist da, etc. Gedruckt in diesem Jahr [o. O., o. J.].

106 Mehrere gedruckte und handschriftliche Belege vor 1800, hier: Sieben schöne neue Weltliche Lieder, Das Erste: Und wann ich betrachte die eitle Welt, wie sie etc. Das Zweyte: Die Freyheit ist verschwunden, Cupido stellt sich etc. Das Dritte: Es ist fürwahr kein besser Leben, als der edle Bauren= etc. Das Vierte: I bin a so a Kerl, und geh a so rar daher etc. Das Fünfte: Oft mancher muß leiden, und hats nicht etc. Das Sechste: Es wolt ein Jungfer in Closter gehn, die Welt etc. Das Siebende: O schnelle Freud, O kurze Zeit, wie bald bist etc. - Vgl. auch Blümml, Schottkys Volksliedernachlass, S. 62. 
1

Alle Leut sehens nicht gern, daß du mein Schäzerl sollst wär'n, sehn sie's gern oder nicht, von mein Schaz laß ich nicht, so lang ich ein Ater kan rühr'n, thu ich mein Schazerle lieben.

3

Ein Thaler den thät ich spentiren, wenn ich mein schön Schazerl könnt griechen; wollt gleich ein mehrers wagn, wollt' s gleich den Pfarrer sag'n, das er uns z'samma thät geben, so könnt man das Lieben nicht wehren. 5

Kein Bauernknecht gieb ich nicht Oh, muß alleweil scheyen Hottoh müßen in Wald naus fahr'n müssen die Stöck raus graben, kein Bauernknecht mag ich nicht seyn, muß alleweil Hottoh braf schreyn. ${ }^{107}$
2

Dienterl schwarzaugete Gret, hast mich zum Lieben bewegt, hast Schneeweiß Zähn im Maul, zum Lieben bist auch nicht faul, bist so schön kurz und so dick, und auch schön röthlicht im G'sicht. 4 Unsern Herrn Amtmann sein Bub, der schaut uns beym Lieben oft $\mathrm{zu}$, wenn ers den Herrn Amtmannt, sagt] daß ich beym Dientel schlaf, dann hlift kein Bitten und kein Gnad,] und muß gleich werden ein Soldat.

1,5 Ater kan rühr'n] Ader rühren kann, lebendig bin 2,1 Dienterl] Mädchen 3,2 griechen] kriegen (als Reimwort auf ,spentiren' muss die Aussprache [krı:en] lauten) 5,1 gieb ich nicht Oh] will ich mehr sein 5,2 Hottoh] Kommandoruf zum Weitergehen für Pferde oder Ochsen

Auch wenn sich im Lied ein relativ selbstverständlicher Umgang mit vorehelicher Sexualität ausdrückt, wird gleichzeitig auch eine drohende Sanktionierung angesprochen. Die im Lied genannte Strafe - nämlich als Soldat eingezogen zu werden - entspricht dabei durchaus den historischen Tatsachen, wurde doch die Praxis der Kriminalisierung unehelicher Sexualbeziehungen zumindest bis unter Maria Theresia fortgeführt; Männer, die wiederholt der Unzucht bezichtigt wurden, konnten bei Zahlungsunfähigkeit zwangsrekrutiert werden. ${ }^{108}$ Wie Frauen bestraft wurden, klingt im Bauerngespräch O Riepl da kemm mir recht z'sammen an, in dem zwei Burschen über die Vernaderung am Dorf lamentieren, die ihnen das „Gäßl-gehen“ verleidet:

\section{7}

Vier Menscher die seynd ä schon drinnä/ die müssen in Schörgen-Haus spinna, bis sie die Straf recht habn abdient/ aft lassens erst wider haim gehn.

\section{8}

Ihr fünfe die müssen noch kemmä/ wo wärn sie das Geld ä hernehmä/ wann sie die Straf nicht können gebn/ wird man ihn die Geigen anlegn.

107 Fünf schöne neue Weltliche Lieder, Das Erste. Cupido ich schwöre dir, keine andre nehm etc. Das Zweyte. Stax donnerte vom Predigtstuhle, es sey etc. Das Dritte. Ich bin kein Epicurer nicht, schein ich gleich etc. Das Vierte. Alle Leut sehens nicht gern, daß du Schäzerl etc. Das Fünfte. Recht unglücklich ist das Lieben, weil es so etc. [o. O., o. J., ca. 1770], f. 2 v-3r.

108 Vgl. Becker, Leben und Lieben in einem kalten Land, S. 254f., der in dem Zusammenhang auf drei Patente Kaiser Karls VI. aus den Jahren 1737-1740 hinweist, die sich gegen das ,Laster der Unzucht' unter dem ledigen Bauernvolk richteten. 
9

Pfui Stöfl ist das nicht ä Schand/ mein Ayd ich bleib nicht in dem Land/ der Teufel holl alleweil Straffen, wann ainer bey Dienl wolt schlaffen.
10

O Hießl was thust mir dann rathen/ wie mainst / könn mir s'Gäßl-gehn grathn/ das Gäßl-gehn wär ja ä Freud/ vertreibt man oft maniche Zeit. ${ }^{109}$

7,1 Menscher] Mädchen 7,2 Schörgen-Haus] Unterbringung des Schergen (Gerichtsdieners) mit Haftzellen 7,4 aft] dann 8,4 Geigen] Halsgeige, Schandgeige: hölzerne Fessel um Hals und Handgelenke zur demütigenden Abbüßung von Ehrenstrafen (v. a. von Frauen) 9,2 mein Ayd] (Beteuerungsformel) bei meinem Eid! 9,4 Dienl] Mädchen 10,2 grathen] entbehren, lassen, verzichten

Insgesamt erscheinen derartige Klagen - trotz der prinzipiell typisierten Rollen - durchaus als aus dem Leben gegriffene literarische Artikulation der Probleme junger Leute am Land. Ernste Klage über Unfreiheit und Zwänge ebenso wie scherzhafte Rede, erotische Anspielung und gemeinschaftliches Singen: All diese verschiedenen Aspekte finden sich in solchen Liedern und erklären damit wohl erst ihre Beliebtheit, die über die idyllisierende Darstellung des ,Fensterlns' in späterer Zeit deutlich hinausgeht.

Dass das ,Fensterln' nicht nur ein ländliches Phänomen war, sondern auch im urbanen Gebiet praktiziert wurde, legt eine heitere Szene aus Perinets Erfolgssingspiel Die Schwestern aus Prag (1794, Musik: Wenzel Müller), eine Adaption der Hafner-Posse Der von dreyen Schwiegersöhnen geplagte Odoardo, nahe. ${ }^{110}$ Inhalt des Stücks ist ein Verwirrspiel mit vielen Verehrern: Der Tochter der Familie, Mitzerl, steigen gleich drei Männer nach, die Mutter Kunigunde ihrerseits versucht sich einen der Verehrer zu angeln und der Vater Odoardo - der es selbst auf Mitzerls Dienerin Lorchen abgesehen hat - hat alle Hände voll zu tun, die Männer von seinem Haus fernzuhalten. Mitzerl selbst freilich hat sich mit dem Marquis Kletzenbrod bereits einen Verehrer auserwählt, der sich auf verschiedene Weise an Odoardos dümmlichen Diener Kaspar vorbeizustehlen weiß:

Kaspar. Weil ihr Gnaden g'schaft haben, daß ich soll Obacht geben, daß niemand in's Haus kommt, so hab ich gestern auf d' Nacht Obacht geben; und wie ich hab Obacht geben, so ist mir die Zeit lang worden, und da hab ich mir unsern großen Hund den Sultel mitgenommen, damit ich gleichwohl eine Ansprach gehabt hab. Na, und der hats auch g'sehen, wie der Franzos hat einsteigen wollen, und sie därfen ihn nur fragen, so wird er's ihnen erzählen, wann er anders ein rechtschaffener Hund ist, der Ehr im Leib hat.

109 Fünf schöne Neue Lieder. [Das Erste: Auf, auf mit Freud, ihr Schäfers-Leut. Das Anderte: O Vatter laß vor allen, die liebe Kinder-Zucht. Das Dritte: Ihr Eheleut! ach hört mich doch an. Das Vierte: Ihr liebe meine Männer, was müß ma anfangä. Das Fünfte: O Riepl da kemm mir recht z'sammen. (o. O., o. J.)], f. 4v.

110 Perinet übernahm den Inhalt zu großen Teilen und teilweise fast wörtlich, ergänzte aber Lieder und veränderte einige Figuren, Konstellationen und Szenen. Mit der Bearbeitung gewinnt insbesondere auch der Dialekt eine größere Bedeutung: Die komischen, ,niedrigen' Figuren (besonders die Kasper-Figur) sprechen fast durchwegs mehr oder weniger stark Wiener Dialekt. Diese sprachliche Markierung spricht Perinet schon in der Vorrede des Stücks entschuldigend, aber zugleich den lokalen Charakter bestärkend, explizit an: „Daß die Ausdrücke und die Sprache im österreichischen Dialekte sind, entschuldiget nur die Bestimmung, daß es in und für Oesterreich geschrieben wurde.“ (Die Schwestern von Prag. Als Singspiel in zwey Aufzügen, nach dem Lustspiele des Weyland Herrn Hafner, für dieses Theater neu bearbeitet von Joachim Perinet, Theaterdichter, und Mitgliede dieser Gesellschaft. Die Musik ist von Herrn Wenzel Müller, Kapellmeister dieser Bühne. Wien, gedruckt bey Mathias Andreas Schmidt, kaiserl. königl. Hofbuchdrucker. 1794, S. [3]). 
Odoardo. O du dummes Rindvieh! Wie soll denn ich mit dem Hund reden?

KaSPAR. Na ohne Spaß! Es ist ein seelenguter Mensch der Hund; fragen sie ihn nur.

Odoardo. Die Hundssprache versteh ich nicht. Aber wie hat denn der Chevalier einsteigen können?

KASPAR. Er ist halt auf's Gatter zu ebner Erd g'stiegen, da hat er sich oben an G'sims ang'halten, und hat hinauf kraxeln wollen.

OdoARdo. Und was hast denn du dabey gemacht?

KasPar. (lacht) Ich? Ich hab's gar fein g'macht. Ich hab g'schrieen, „He! he! Der Herr kann sich ja zersprageln, oder gar den Hals brechen, wann er so herumkraxelt: Was brauchts denn die Talkerey da? Wann der Herr expressi einsteigen will, so kann ich ihm ja eine Leiter hohlen?"“Dictum factum, ich geh her, bring ihm d' Feuerleiter, und da ist er ganz kommod eing'stiegen.

Odoardo. Was! der Franzos hat über Nacht in meinem Haus kampirt?

Kaspar. Die Fräula Mitzerl hat ihn ja nicht hineing'lassen, und es ist ja besser, daß einer spienzelt, als daß er ein Krüppel wird?

OdoARDo. Hab ich dir nicht befohlen, keinen Menschen in's Haus zu lassen?

KASPAR. Sie haben g'sagt; Stell dich vor die Thür, und laß mir keinen Menschen hinein, aber vom Fenster haben sie nichts gesagt; das können Sie nicht reden als ein braver Mann: und ich hab all mein Lebtag ghört, Fensterln därf man aber nicht thürln. ${ }^{111}$

Talkerey] Dummheit expressi] vorsätzlich Dictum factum] (lat.) gesagt, getan spienzelt] liebäugelt, flirtet

Mit einer Verkleidungsintrige (der Marquis als Arzt und sein Bedienter Johann als Odoardos Schwester) und Erpressung (die außerehelichen Liebesabsichten der Eltern zu verraten) bekommt das Liebespaar schließlich doch noch die Erlaubnis zur Heirat.

Liebesverwirrungen - mit dem gattungstypisch glücklichen Ende - sind auch Thema des Nachspiels Die Bauren, in dem nach Nachbarschaftsstreitigkeiten, Konkurrenz, Eifersucht und Liebeshändel zwei Bauernkinder zueinanderfinden. Im Eingangsmonolog beklagt Görgel seine leidige Situation: Noch unerhört hegt er den Wunsch, Urschel, die Tochter des Nachbarn, zu heiraten, sieht seine Chancen allerdings mehr und mehr schwinden, da ein militant geführter Nachbarschaftskrieg zwischen Urschels Vater Jockerl und Görgels Erbonkel Bartel einer Vereinigung im Wege steht. Denn die Opponenten begreifen die Feindschaft weniger als individuelle Causa untereinander, sondern erheben den Zwist gleichsam zur generationenumgreifenden Familienangelegenheit. Zudem gibt es noch den Liebeskonkurrenten Hiesel, der von der geldgierigen alten Intrigantin Aschevettel angestachelt wird, die abweisende Urschel mit Gewalt für sich zu gewinnen; Görgel dagegen, dem Urschel tatsächlich zugetan ist, empfiehlt sie, die Angebetete zu vergessen, da diese ihn nur zum Narren halte, und bringt sich selbst als Braut ins Spiel. Ein Ende gesetzt wird all dem durch einen Urteilsspruch des Pflegers Wilhelm, der Jockerl, Bartel, Hiesel und Aschevettel drakonische Strafen auferlegt und für Görgel und Urschel bestimmt, dass sie vermählt werden sollen. Doch da dem unterhaltsamen Nachspiel ein solch ernsthafter Ton nicht ansteht, besteht die Buße der zänkischen Sippe letzten Endes nur im Schrecken, mit dem sie davonkommen. Denn als auch das jungvereinte Paar sich für eine Begnadigung der Verurteilten einsetzt, erlässt

111 Ebda., S. 7f. 
Wilhelm die Strafen, mahnt allerdings zur Besserung - und resümiert: „also mus man denen bauren mores lehrnen“"112.

Die Handlung mag manchem bekannt vorkommen: Es ist eine simplifizierende Bearbeitung von Andreas Gryphius', Scherzspiel' Die geliebte Dornrose (1661), eines der bedeutendsten Werke der deutschen Dialektkunst. Von wem die gut ein Jahrhundert jüngere, handschriftlich und anonym überlieferte bairisch-österreichische Adaption stammt, ist ungeklärt. Bisweilen wird sie Joseph Felix von Kurz zugeschrieben, ${ }^{113}$ doch lässt sich dies nicht stichhaltig verifizieren. Das Stück komprimiert die vier Akte der Vorlage zu einem und ersetzt den schlesischen Dialekt des Ursprungstextes duch ein lokal angepasstes Idiom - wenn auch, wie so oft, nicht in stringent realisierter Notation und mit durchaus widersprüchlichen Einsprengseln. ${ }^{114}$ Relativ nahe an der Vorlage bleibt die Bearbeitung zu Beginn, wo die Nachbarschaftsaggressionen in regelrechte Schädigungswut ausarten, an der Görgels Glück zu zerschellen droht. Dabei ist die Streitepisode nicht nur handlungsrelevanter Hintergrund, sondern auch brachial-komisches Element, dessen burleske Züge den Schauspielern Gelegenheit gab, in ihrem Rollenfach zu brillieren. Um die textuellen Umarbeitungen, vor allem aber die Übertragung vom schlesischen in einen ostmittelbairischen Dialekt entsprechend einschätzen zu können, vorweg ein kleiner Abschnitt aus Gryphius' Vorlage:

Bartel Klotzmann bringet einen Hahn unter dem Arme mit sich / welchem der Fuß entzwey geschmissen.

Bartel. Ja es gleebts ke Mensch ufm lichten breiten Gots Boden / wos das für e Kroitze iß / wen me en sulchen leechtfertigen Jhrvargaßenen Nookber hott.

Gregor. O siß Klotzman! Mey Vetter ha wird wider uff Durnruses Nanne rasen. Jch will a bisseln hie hinger da Boom traten unde hüren wasse draus warden wird.

Bartel. O Mey Haan! O mey Haan! O du armer Haan siß key Haan in dam gantze Fürstenthum dar dam Hahne die woge helt.

Jockeldreyecke kommet von der andern Seiten und träget einen mit sidendem Wasser verbrandten Hund.

JocKel. Hulß der hänger. Jche kans nimme leiden / ha macht mer dar Pussen de länge ze vill. Jch steche em noch e mohl e Masser in Bauch / dos em der dräck zur Wunde raus fährt!

Gregor. Nu saht wos der Teufel kon? da brenget e Durnrusens Vetter och har. Wu se nu enander begähnen se wirds an gihn.

Jockel. Meine arme Lusche! O du arme Lusche! Se han dich verbrand ase wen de e Püleweesser werst.

BARTEl. O mey armer Haan! dan Schaden verwingest du unde iche nimmer mir!

JocKel. Du arme Lusche! hett Jch doch garne weln behandeln unde bezahlen was de gefrassen hust: wen dich die heellusen Leutte nich su getribeliret hetten. Nu ich schwere! Se hans nicht dihre / ober wull mir gethan.

112 Österreichische Nationalbibliothek, Cod. 13193, f. 113r.

113 So etwa auch im Katalog der ÖNB, die über das einzige bekannte Textzeugnis verfügt (vgl. ebda., f. 105r113r). Erstmals ediert wurde das Stück bei David G. John: The German Nachspiel in the Eighteenth Century. Toronto/Buffalo/London: University of Toronto Press 1991, S. 118-139.

114 Auch hier geht es nicht um eine spezifische Lokalisierung, sondern vielmehr um die Distinktionsfunktion der Mundart an sich bzw. um eine Umsetzungsrichtlinie, die zu einer entsprechenden Realisierung auf der Bühne animieren soll. 
BARTEL. O du armer Han. Jch schwere: ich wil nich ruhn / biß ich Jockels Cuntzens Been wider e zwie geschlain ha.

Jockel. Jch schwere! Jch will mäy Häytt nich sanffte leen / biß ich Bartels Gritte wider da Kupff verbrüht ha / das er de Wulle stüben soll. ${ }^{115}$

Dieselbe Szene (und etwas mehr) zum Vergleich, der schon hier eine Reduktion der barocken Wortgewalt und der vergleichsweise radikalen Dialektverschriftlichung für theaterpraktische Zwecke zeigt. Unsicherheiten in der mundartlichen Gestaltung zeugen einerseits von einer nur unzureichend überwundenen Nähe zur unmittelbaren schlesischen Quelle, die immer wieder durchschlägt, und andererseits von standardsprachlichen Interferenzen:

BARTEL. Es glaubts kein mensch aufm lichten breiten gotsboden, was das für ä kreüz ist, wan me en sulchen leichtfertigen ehrvergesßenen nachbar hat.

GöRGL. das ist der bärtel, mein zukunfftiger schwiger vatter wans grath! ich will ä wengerl auf d'seythen tretten, und heren was drauß werden wird.

BARTEL. o mei hahn! o du armer hahn! o du krumper hahn, s'is kein hahn in dem ganzen viertl der meinem hahn gleich gewesen wäre.

JOCKERL. hols der hencker: i kans nimmä leyden, mä macht mir der possen in d'läng zu vill: ich stech dem bärtl noch ä mahl ä mesßer in baug daß iem der pfifferling zur wunde rausfährt. o mein armer budel, wie haben dich d'schelmen verbrennt.

BARTEL. o mein armer hahn!

JOCKERL. warum haben dich heilose leüth so getribilirt. nu ich schwere, sie habens nit dir, aber wohl mir gethan.

BARTEL. wer raset dan dorth?

JOCKERL. wer macht sich dorten so breit?

BARTEL. hoho! es ist der jockl selber.

JOCKERL. gott grüsße euch nachbahr Bärtl, und geb eüch so vill glück, alß ihr werth seyt.

BARTEL. und eüch Jockel so vill ihr verdienet.

JOCKERL. ich denck allzeit, ich verdien besßer glück alß du.

BARTEL. was hat dir mein hahn gethan, daß ihms beyn entzwey gschmisßen.

JOCKERL. da soll mein budel antworten: ich wird dir d'goschen so verbrennen, das der bart aussehen soll, wie meinen budl d'haar.

BARTEL. du darfftest mihr nit vill wesens machen, so will ich dir alle beyde hiexen in kleine trümmer zerschlagen, daß du auf denen finger heim kriechen solst: wan mei hahn so schlecht wech das ben zerbrochen, so wolte ich nicht ä solches leben machen.

JOCKERL. ich schmis dir auf dei hahn, was is um ä hahn, mein budel ach! mein budel, der hat sich allzeit wacker mit den anderen hunden im dorff herumbisßen: er hat bey der nacht besßer g'wacht alß zehen muschketierer: nur schad is, das er nit teüsch reden können: o du armer budel.

BARTEL. mei hahn hat mer verstand im hirn g'habt, alß mancher kalender macher: ich schmisße dir auf deinen schäbigen hund.

JOCKERL. du hast vill zu schmeisßen? wirds ämahl herauskämen, das du meine zäun zerbrochen, und niderg'risßen hast: du wirst wohl sehen, wies dir gehen wird.

115 Andreas Gryphii Verlibtes Gespenste / Gesang-Spil. Die gelibte Dornrose. Schertz-Spill. Beyde auffs neue übersehen und zum andern mahl gedruckt. Breßlaw / Bey Esaie Fellgibeln / Buchhändl. Leipzig / Druckts Christian Michael/ 1661, S. 9f. 
BARTEL. wie wirds dir aber gehen, der mir d'junge bäumer unten abgeschelt, daß sie haben ausdörren müsßen? wars nicht du? he!

JOCKERL. wer war der, der der herrschafft d'forellen ausm bach g'stohlen, und hernach dieselbe in der stadt verkaufft, wars nicht du? he!

BARTEL. wer war der, der mir alle bougerdin piren g'stohlen, und hernach in der stadt verkaufft. wars nicht du? he!

JOCKERL. hat nit dein bui meinen pferden die schweif ausgeraufft und hutschnür daraus gemacht? he!

BARTEL. hat nit dein weib kalck in teich g'worffen, daß der grosße hecht hat müsßen abstehen? he!

JOCKERL. hast mir vill vorzustesßen.

BARTEL. halts maul, sonst nieth ich dich. ${ }^{116}$

wans grath] wenn es gelingt ä wengerl] ein wenig getribilirt] zugesetzt, in Bedrängnis gebracht goschen] Maul hiexen] (wohl fälschlich für) ,häxen': Beine bougerdin piren] besondere Birnensorte bui] (unverheirateter) Knecht nieth] verprügle

Je weiter sich das Spiel im Verlauf der Handlung von der weitaus umfangreicheren Vorlage entfernt, desto stärker emanzipiert sich auch die sprachliche Überarbeitung von der schlesischen Vorlage, von der gleichwohl Bruchstücke erhalten bleiben. Interessanterweise übernimmt der Bearbeiter von Gryphius auch die sprachliche Isolierung der Dornrose, die - hier wie dort ganz gegen das Rollenprofil - in einem gestelzten Hochdeutsch spricht und selbst in so hochemotionalen Momenten wie Nötigung und Rettung nicht ganz auf das „,herrisch reden “ 117 vergisst:

Hiesel. glück zu mein schaz, wie stehts?

URSCHEL. es gehet mir ärger, alß zu erdenckhen.

Hiesel. au wehe wie traurig, weil ihr den görgel nicht kriegen kunt. i bin so gut alß er, und wohl no anderthalb centner besßer.

URSCHEL. das kan seyn: gott behüt eüch. will gehen.

Hiesel. nei, nei, wir müsßen mit einander was reden, ihr habt mi lang gnui bey der nasen herumg'führt, nu g'schwind d'brazen her. auf d'zusag.

URSCHEL. ich bin nicht vor eüch, und ihr nicht vor mich gebohren, drum suchet eine andere aus, die eüwer besßer würdig.

Hiesel. ihr bildet eüch groili vill ein: ich geh nit vom fleck, bis ir mi nit nembt, i weis daß mein zaplndes herz aussiht, wie ä welcker rättig: $i$ kan mi nimmer zum narren halten müsßen.

URSCHEL. geht von hier, wohin ir gehört.

Hiesel. gib d'brazen her, sonst - -

URSCHEL. was? mit mir, he! nachbahr, freund, vatter, helffts, rettets.

Hiesel. halt d'goschen, sunst wirds nit gut werden mit uns zwey. du stelst di nur so bös, du wirst wol wieder gut werden.

Sechster Auftrit.

Iörgel. Urschel. Hiesel.

GörGEL. du leichtfertiger, redlichkeit vergesßener, treüloser landlaufferischer schelm und dieb.

URSCHEL. nur zu, errettet mich von disem galgenvogel.

Hiesel. du lugner, du kirchdieb, wart nur, ich will di schon no niäten.

GörGEL. gehe nur, i will di schon verklagen, du schelm, du hießlicher hiesel.

116 Österreichische Nationalbibliothek, Cod. 13193, f. 106r-v.

117 Ebda., f. 108r. 
das ist mein glück, das i der urschl z'hilff kommen bin, wan is nit gethan hätt, so wärs wohl g'sungen g'wesen. jezt will i vor d'lange weil [z] u der frau aschevettl gehen, und - just kumbts raus. ${ }^{118}$

gnui] genug brazen] Hand rättig] Rettich müsßen] fälschlich für ,lassen` (vgl. Gryphius) goschen] Maul niäten] verprügeln, verdreschen hießlicher] dummer $[\mathbf{z}] \mathbf{u}], \mathrm{du} \mathbf{u}^{\prime}$ emendiert

Dass Frauenfiguren auch im Spaßtheater des 18. Jahrhunderts weitaus seltener und weniger ausgeprägt Dialekt sprechen als ihre männlichen Pendants, steht nicht zuletzt im Zusammenhang mit der zunehmenden Stigmatisierung des regionalen Idioms als ,unfeine` und im öffentlichen Umgang gerade für das schöne, zarte Geschlecht nicht passende Kommunikationsform. ${ }^{119}$ Eine wichtige Liedgattung allerdings, die das Konfliktpotential zwischen Werbendem und Umworbener literarisch verarbeitet, setzt gezielt auf dialektales weibliches Sprechen, um unterschiedliche soziale Schichten herauszuarbeiten. Im Buhlen eines Höherstehenden um ein Bauernmädchen wird durch die sprachliche Gestaltung der Standesunterschied zusätzlich markiert. Während das Mädchen Dialekt (in mehr oder weniger ausgeprägter Form) spricht, ist dem Adeligen oder Bürger eine stärker schriftsprachlich geprägte Varietät (in zuweilen auch elaborierterer Metrik) zugewiesen. Ein frühes Beispiel dafür ist die 41-strophige ,Heyraths-Abrede Halt still mein schöne Baurn-Dirn, wo ein ,Cavalier` einem Bauernmädchen das Blaue vom Himmel nebst Liebe und Ehe verspricht. Der Verlauf einer Beziehungsanbahnung dieser Art endet üblicherweise in einer bloßen Kurzaffäre und einer Enttäuschung des naiven Mädchens. So verfolgt man den Verlauf bereits von Beginn an in der Erwartungshaltung, dass dem Mädchen letztlich das Herz gebrochen wird oder sich gar schlimmere Konsequenzen ergeben - ob man nun Mitleid dabei empfindet oder Naivität und Aufstiegsgelüste bestraft sehen will. In diesem Fall aber erweist sich die Prognose als falsch und es kommt zu einer überraschenden Wendung am Ende des Lieds:

1

Halt still mein schöne Baurn-Dirn, ich hab dir was zu sagen, du sollst all Gunst und Lieb verspüren, laß dir mein Qual nur klagen, bis in den Tod bin ich verwundt, ach komm und hilf, mach mich gesund sonst muß ich gar verzagen.

\section{2}

$\mathrm{Daß}$ die potzschende was ist dir geschehen, hast nit ä wintzlen und winßlendes Geschrä, sag mirs rund heraus sonst muß ich gehn, ein hurtiges Mädel das bleibt nicht lang stehen. $[\ldots]$

118 Ebda., f. 108v-109r.

119 So moniert etwa Samuel Riedl: „Es ist ein recht auffallender unangenehmer Kontrast, wenn ein schöner Mund die Sprache des niedrigen Pöbels spricht, und wenn die mit der besten Wahl gekleidete Dame, so pöbelhaft, als ihre Küchenmagd redet“ (Der wienerische Sekretär auf alltägliche Fälle. Zum Gebrauch Jener, welche in Geschäftsaufsätzen Anweisung verlangen. Dritte veränderte, durchaus verbesserte, und vermehrte Auflage. 2 Bde. Wien: Gerold 1787, S. 12). Freilich war es selbst für hochadelige Frauen durchaus üblich, im familiären Umfeld Dialekt zu sprechen, wie eine launige Anekdote über Maria Theresia belegt: Diese habe bei einer Gelegenheit das ,blabe Buich` (blaue Buch) verlangt und damit ihr sächsisches Kammerfräulein vor ein Rätsel gestellt. Vgl. Peter Wiesinger: Die sprachlichen Verhältnisse und der Weg zur allgemeinen deutschen Schriftsprache in Österreich im 18. und frühen 19. Jahrhundert. In: Andreas Gardt/Klaus J. Mattheier/Oskar Reichmann (Hg.) Sprachgeschichte des Neuhochdeutschen. Gegenstände, Methoden, Theorien Tübingen: Niemeyer 1995. (Reihe Germanistische Linguistik 156) S. 319367 , hier 321. 
9

O Schönste quäle mich nicht so sehr, vergrößere nicht mein Schmerz, o reiche ein Erbarmnuß her, vor Lieb verbrinnt mein Herz, die Lieb ist gegen dir gericht, ein Gegenlieb verlangts zur Pflicht, o treib nicht länger Scherz.

11

So bin ich armer Cavalier, ja ganz glücklos geboren, so ich kein Gunst empfang von dir, indem ich dich erkohren, mein Herz hat dich allein erwählt, zu einer lieben Braut bestellt, sey doch nicht so verlohren.

\section{9}

Du g'fallest mir mein liebes Kind, ewig sollst bleiben mein, auf ewig ich mich dir verbind, und will gehören dein, hier reich dir meine treue Hand, nihms hin zu ein gerechten Pfand, das unverfälschlich soll seyn.

31

Ein Ring von lauter Diamantstein, so werthreich ich anhab,

sammt zwey Herschaft soll dein seyn, zu einer Morgengab,

noch hundert tausend und so viel, in Gold und Silber schenken will, und lieben bis ins Grab.

\section{3}

Kein Spieler bin ich glaub du mir, kein Sauffer auch insgleich, viel Wein trink ich nicht von Natur, den Rausch ich höchstens scheu, so werd ich wie ein Göttinn dich, verehren, lieben inniglich, bis ich in Tod verbleich.

\section{7}

Wann er die Sichel schon geht irr, ists doch von keinem Gewalt, du laß ihm die Kuh und s'Kalb dafür, so ist es ihm bezahlt, dein Lidlohn und was du sonst hast, ihm um die Sichel verlaßt, o geh gehe bald.
10

Dasti was frag i wol um deine Schmerzen, bhüt di Gott pack di und laß mich unkeit. meinstdu wohl daß ich die Zeit hab zu scherzen,

bey solchen Schwätzen da suche kein Freud, laß mi mit Frieden und mich nicht betrüb, dann ich verstehe noch nichts von der Lieb. [...]

12

Ey mein geh pack di was steckt dir im Hirn, suchst du ein Braut, so geh such fein recht, ich bin grad nur ein Bauern-Dirn,

solchene Menscher seynd für dich viel z'schlecht,

schopfete Diendl gibts für dich gar gnug, suche nur solche und laß mich mit Ruh.

[...]

20

Hässa so seys, da hast's Patschhändl, aber geh sag was giebst mir dann dran, käf mä ja neue Schuhe und grüne Bandel, rothe Strümpf, gefältetes Kreß das hab ich schon,

endlich mein Kittel ist a gut genue, aber sein kein Börtl hab i nit mein Bue. [...]

32

Ey so seys aber noch eins mußt versprechen, mußt mir zusagen versteh mich fein wohl, mich mußt fein lieben, die Treu mir nit brechen, mußt mir nit spielen und sauffen dich voll, sonst kunst du mir werden ein grober Narr, thäst mi aft schlagen, und nähmst mich beym Haar.

34

Nun du mein Lieber setz dich derweil nieder, ich thu mein Gramet heimtragen voneh, hohlen mein Binkel, und komm dir flux wieder,

aber sag niemand daß ich mit dir geh, unseren Buben den g'fall ich ä wohl, sie thäten dich [] dreschen und abprügeln voll. [...]

38

Ey so gehen wir zu deinem Wagen, weil du mich liebest so gehe ich mit dir, laß in gheim nur zwey Wörtlein sagen, ich bin eine Dame vor dich Cavalier, wann schon die Kleidung als Baurendirn, ist doch darunter ein Adel verhüllt. 
39

Wie da mein Kind verhalt mir nicht, wie sollt dieß möglich seyn, ich bitt die Wahrheit mir bericht, dein Gestalt giebt mir ein Schein, daß du von keinem g'meinen G'schlecht, so geh mein Schöne sag mirs recht, du bist ja gänzlich mein.
40

$\mathrm{Da}$ ichs mit wenig Wort dir offenbar, oft hab ich gesehen dich, und wurde verwund, also die beste Gelegenheit wäre, $\mathrm{da} ß$ ich verkleideter mit dir reden kunnt, wartete ich bis du gingst auf d'Jagd, und stellt mich zu Diensten als ein

Baurenmagd. ${ }^{120}$

2,1 Daß die potzschende] dass dich, potz schänd dich! (derbe Fluchformel) 2,2 wintzlen] Winseln 10,1 Dasti] dass dich (der Teufel hole, etc.) 10,2 laß mich unkeit] lass mich in Frieden 12,4 Menscher] Mädchen 12,5 schopfete Diendl] Mädchen mit kunstvollen Frisuren 20,1 Patschhändl] zartes Händchen 20,4 Kreß] Kröse, Halskrause 20,5 Börtl] Borte 32,6 aft] dann 34,2 Gramet] Kram, Zeug 37,5 Lidlohn] Arbeitslohn für Gesinde

Das Werben mit verführerischen Verlockungen führt freilich nicht immer zum Erfolg, wie das folgende Lied um ein „dickwampets baure Madl“ zeigt, das eher ein Zankgespräch denn eine Affärenanbahnung ist. Die exotischen Leckereien, deren Genuss der hohe Herr dem Mädchen nächtens in Aussicht stellt, sind ihr unbekannt und daher uninteressant. Zufrieden mit ihrer Lebenssituation verwehrt sie sich, als Objekt amouröser Abenteuer eines Adeligen missbraucht zu werden, der in seiner beleidigten Reaktion keinen guten Eindruck hinterlässt:

1

Komm du mei dickwampets baure Madl! komm du mit mir in mei Schloss.

I gib dir zucker und Mandel Kern, setz di a weni mei schooss.

Chocolade, Lemonade

diess findest allezeit auf meinem Tisch. 3

$\mathrm{Ob}$ du schon nicht meines gleichen bist

Zieh ich dich andern doch vor

Wenn ich ein jung zartes Mädchen küss

gieb ich mein herzchen davor

Artige schöne du dich nit schäme

Wenn dich ein zärtlicher Edelman Küsst

5

Geh nur du dickwampets baure Madl

Geh nur zu deinem groben Hans

$\mathrm{zu}$ deinem schmutzigen, zu deinem truzigen

zu deinem stinckend verächtlichen hans.

\section{2}

Geh Er nur geh Er nur wegg von mir,

Er ist für Mi ja viel z’rahr.

I bi ja nur an arms ba[u]rendienl

A Fräuli für ihn bessa war.

Schockolawatschi, Lemonadri,

Diess weiss I nit a mol, was es nur sey.

4

Mei hansl steht mir viel besser a

Als ein so jung frisches blut.

Mit meim Hansen, kan i braf tanzen

O Wenn doch nur eimol d'hochzeit bald wär.

6

Potz tausend, potz tausend, wea mussa sey,

Das eh mein Hanso veracht?

Er muss ma a scho der rechte sey

Das Er ist kömt bey der Nacht

Wenn Er mi will nehma, müss er bey tag köma

Sinst ist Er allezeit von mir veracht. ${ }^{121}$

120 Ein neues weltliches Lied, worinn zweyer verliebten Personen in Diskurs eine ganze Heyraths-Abrede begriffen. Gedruckt in diesem Jahr. [o. O., o. J.], f. 1r-4v.

121 Österreichische Nationalbibliothek, Musiksammlung, Mus.Hs. 19029 (Das Unschuldige Vergnügen, Bestehend in LX Ausserlesten, Ernst und Schertz Haften, doch Jedesmal Sehr Eingerzogennen Lieder, gesammelt undt zwahr auff die Harpfen Eingericht undt Mäistens mit Neuen arien versehen, auch zu größerem Nach-truck mit zwey Violinen versterckhet von F. M. Gölle, der H. Gottes Gelehrtheit undt geistlichen Rechten Beflißenen, in saltzburg. Ihm Jahre MDCCLXXVII), f. 73v-74r. Eine Edition dieser 
1,1 dickwampets] dickbäuchig, mollig

Noch drastisch-witziger fallen sprachlicher Kontrast und zwischenmenschliche Differenzen in einem etwas späteren Gesprächslied zwischen einer Kuhmagd und einem ,Stadtherrn' aus, dessen abgeschmacktem Süßholzgeraspel eine äußerst derbe Abfuhr erteilt wird:

1

Lieber kleiner schöner Engel

Dich als Göttin beth ich an,

Denn du kannst geben

Mir das Leben

Lösche meine Liebesflamm!

Trudel haß i

Und nit was $i$

Was a Göttin is für a Thür.

Sagst, dein Herz brinnt -

hast es anzündt -

treibst den Narren gar mit mir

Für an Lappen, willst ihm foppen

Willst mi hab'n is das dein Gruß

I thus dir rathen

Spar dir den Athen

Weil i an Affen di heißen muß.

[...]
5

Nun so höre

Was ich schwöre

Du bist Schuld an meinen Tod

Ich muß sterben

Und verderben

In der bittern Liebesnoth.

Halt di Goschen

Und laß dein Plauschen

Du bist ja no recht frisch und gsund

Willst mi bethören

Mit deinem Schwören,

Daß du krepirst als wie a Hund.

Kannst di hänken

Und ertränken

Mir liegt ja gar nix dran

Mein großer Peter

Potz Donnerwetter

Der pakt di Sach ganz anders an. ${ }^{122}$

1,6 haß] heiße 1,7 was] weiß 5,7 Goschen] (derb für) Mund, Maul 5,8 Plauschen] Gerede

Der Zorn des Mädchens über die hohlen Liebesphrasen ist nicht ganz unverständlich, immerhin war die ,Unschuld' in einer Gesellschaft mit rigiden Sexualnormen oft das einzige Kapital, das es in eine potentielle Ehe einbringen konnte. Natürlich versuchte man auch mit Liedern der Verführbarkeit entgegenzusteuern, indem man abschreckende oder motivierende Beispiele benannte. Eine Warnung, sich vor zu schnellen Zusagen $\mathrm{zu}$ hüten, bringt der angeblich aus dem Zillertal stammende, in recht unterschiedlichen Fassungen im gesamten Alpenraum verbreitete Bürgäl gesang, in dem die Magd Notburga ihrem Dienstgeber von ihren Enttäuschungen in Liebes- und Geldhändel berichtet:

7

Ist das der dankh für das Bändl hossen waschen, wie viel kiertä wökhl hab ich im scha geben, $\mathrm{z}$ letz thuedt er mir an den allergrösten spodt, solchä dingä machän aeinä verwegen,

8

Fassung mit Noten liefert Emil Karl Blümml (Hg.): Die Liederhandschrift des Weingartner Benediktiners P. Meingosus Gaelle aus dem Jahre 1777. Als Beitrag zur Geschichte des geistigen und studentischen Lebens an der Benediktiner Universität Salzburg. Wien: Ludwig 1912, S. 71, führt dabei allerdings nur die Singstimme an.

122 Wienbibliothek im Rathaus, H. I. N. 55795, Teil 2, f. 39r-v, 41r. 
hab im z Negst ä zwaey wochäläl geben,

kund er ja nit aeis zahlen

wan er hat gethan wie er thun hete soln,

etwan weren noch ein Par gröschlein gfahlen,

9

jezt las i mi von kein Lother voppen Nimmehrmehr,

jetz hab ichs schon erfahren,

wan mir aufs negst aeiner aufs fenstel kombt,

wil i mi ä Bräff äschling haben, ${ }^{123}$

7,1 Bändl hossen] Bänderhose, Kniebundhose 7,2 kiertä wökhl] Kirchtagwecken, Mehlspeise 8,1 z Negst] vor kurzem wochäläl] Wochenlöhne 9,1 Lother] unehrenhafter Mann 9,4 äschling haben] den Rücken zukehren

Dass es sich lohnt, dem Drängen eines potentiellen Partners nicht vorschnell nachzugeben, demonstriert das beliebte ,Laterndl'-Lied, das seinen Reiz aus der metaphorischen Umschreibung der Jungfräulichkeit (bzw. allgemein Sexualität) gewinnt. Das Bild der heilen bzw. zerbrochenen Laterne war im Volksgesang weit verbreitet. ${ }^{124}$ Mit seinem charakteristischen Refrain wird das Lied darüber hinaus in den Kontext bäuerlicher Spinnstuben eingebettet, die als Orte des Zusammenseins der unverheirateten Dorfbevölkerung keineswegs nur der Arbeit dienten, sondern auch als Fixpunkte jugendlicher Unterhaltung galten. ${ }^{125}$ Obwohl seit dem 16. Jahrhundert mit Verboten und Erlässen gegen deren ,Unsittlichkeit ' angekämpft und auf den Ausschluss unverheirateter junger Männer gedrängt wurde, konnten sich die Spinnstuben gegen alle Einschränkungen bis weit ins 19. Jahrhundert hinein zäh behaupten. ${ }^{126}$ Dabei standen sie nicht nur als Orte möglicher erotischer Annäherung zwischen den Geschlechtern in der Kritik, sondern auch als Kommunikationsräume, in denen die Verspottung Erwachsener oder die Tradierung magisch-irreligiöser Bräuche ihren Platz hatte, aber eben auch „der spielerische Ausdruck jugendlicher Sexualkultur selbst in Form von sexuellen Anspielungen, Anzüglichkeiten und derben Späßen, vor allem durch Scherzrede, Lied und Gedicht “127. Im Fall des vorliegenden Lieds ist allerdings weniger anzunehmen, dass es tatsächlich aus dem Umfeld solcher ländlicher Spinnstuben stammt. Auffällig ist jedoch, dass bei allem Versteckspiel mit der Metapher des ,Laterndls‘ und dem Bild des ,Spinnradl tran' (Spinnrad drehen), das in allen möglichen Zweideutigkeiten ausgereizt wird - das Thema der Sexualität zwischen unverheirateten jungen Leuten - oft nur halbherzig verdeckt durch die Metaphorik - erstaunlich offen und freimütig verhandelt wird:

123 Bayerische Staatsbibliothek, Cod. germ. 7340 (Stubenberger Gesängerbuch), Teil 2, S. 18 [11 Strophen]. In einer um zwei Strophen kürzeren Fassung erstmals ediert bei Johann Nepomuk Georg Strolz: Bürgall, ein Zillerthaler Volkslied. In: Der Sammler für Geschichte und Statistik von Tirol (1807), Bd. 2, S. 57-69. Die Entstehungszeit des Lieds ist nicht genau zu eruieren; Strolz gibt nur vage an, das Lied sei „ziemlich alt, wenigstens erinnern sich alte Leute, es schon in ihrer Jugend gehört zu haben“" (S. 57f.).

124 Vgl. Wolkan, Wiener Volkslieder II, S. 347f. So findet sich etwa auch in Schottkys Volksliedernachlass ein „Laternengsangl“ vom Ende des 18. Jahrhunderts mit derselben Metaphorik, vgl. Blümml, Schottkys Volksliedernachlass, Nr. IX.

125 Hans Medick: Spinnstuben auf dem Dorf. In: Gerhard Huck (Hg.): Sozialgeschichte der Freizeit. Untersuchungen zum Wandel der Alltagskultur in Deutschland. 2. Aufl. Wuppertal: Hammer 1982, S. 19-49, hier 19f. und 22.

126 Vgl. ebda., S. $23 \mathrm{ff}$.

127 Ebda., S. 28. 
2

Ausn Arbeitshaus is käma erst gestern auf d'Nacht,

A Madel dö hat a Laterndl mitg'bracht;

Zum Spinradl tran [Spinradl tran Spinradl tran tran ]

3

I sog glei mein Dirndl erfüll mein Begehren,

I zohl dich recht gut leich ma g'schwind dein Latern:

Zum Spinradl tran etc.

4

Mein saubers Laterndl das gib i nöd her,

Du mägst mirs zombrachen nachdem hat i kans mer;

Zum Spinradl tran etc.

[...]

6

Mein Mutta dö hot mirs oft Wanata g'sogt

Gib Acht das dir niemand s'Laterndl zomschlogt;

Beim Spinradl tran etc.

[...]

9

Mein Nachbarn sein Dürndl hobns s'Laterndl brocha,

Drum san in da Finsta z'viel zuchi grocha;

Zum Spinradl tran etc.

[...]

13

I gib dir an Rath geh in d'Stadt nein an Graben,

Da kannst um an Gulden Laterndl genug habn;

Zum Spinradl tran etc.

14

Um an Gulden a Laterndl was falt die den ein,

I kriegs um 30 kr. auf den Schottenbastein,

Zum Spinradl tran.

15

A solche Latern dö man gleich habn kann,

Trifft man unter Hundert kein gute nöd an;

Zum Spinradl tran etc.

16

Tritt ich mit an Mann sogts in ehlichen Stand

Nachdem habn mirs Laterndl allzwa mit a nand;

Zum Spinnradl tran etc.

17

I sog gleich wons so is mein Dirndl schlag ein

Du wirst jetzt mein Weiberl s Laterndl gehört mein;

Zum Spinradl tran etc.

18

Drum heiraths ihr Männer von ledigen Stand,

Nacha habts a Laterndl und is eng kein Schand,

Zum Spinradl tran etc. ${ }^{128}$

2,1 käma] gekommen 2,3 tran] drehen 6,1 Wanata] weinend 9,2 zuchi grocha] hinzugekrochen 13,1 Graben] gemeint ist der Graben in Wien, der für seine Prostituierten (,Graben-Nymphen') bekannt war 14,2 Schottenbastei] Gasse beim Wiener Schottentor, ebenfalls ein für Prostitution bekannter Ort

128 Lied vom Spinnradl tran tran. Zur Belustigung der Jugend. Hat eine bekannte Melodie. Gedruckt in Neusaal. [i. e. wohl Wien, o. J.]. Abgedruckt in Wolkan, Wiener Volkslieder II, Nr. III, S. 9-12. 
Die Sexualnormen, deren mögliche und auch tatsächlich gehandhabte Umgehung das Lied explizit thematisiert, werden im (etwas forciert moralischen) Ende bestätigt. Während der junge Mann voreheliche sexuelle Erfahrungen an den entsprechenden Lokalitäten ohne Sanktionierung sammeln kann, ${ }^{129}$ muss ein Mädchen sein ,Laterndl' unbeschädigt in die Ehe bringen, wo man dann die Lust ohne Schande gemeinsam auskosten kann.

\section{Ehedramen}

Nicht immer freilich verläuft das gemeinsame Leben harmonisch. Spottlieder auf Frauen oder Männer in der Ehe oder auf den Ehestand im Allgemeinen scheinen soziokulturell über die Zeit hinweg eine konstante Traditionslinie aufzuweisen. Sarkasmus und Satire, Hohn und Häme, Stichelei und Spitzfindigkeit - all dies lässt sich auch heute noch immer trefflich auf einzelne Geschlechter oder deren Beziehungen anwenden, um Lacher zu ernten. Ob Stammtischwitz, Kabaretteinlage oder Rollensatire im Film, humoristische Frotzeleien dieser Art - teils harmlos und neckisch, teils scharf und derb - taugen zur Erheiterung und Belustigung wie vor über 200 Jahren (wenn sie auch nicht stets allseits goutiert sein mögen).

Ein typisches Beispiel aus dem 18. Jahrhundert ist etwa das handschriftlich überlieferte Spottlied Ist dan die hen Mehr als der han, das zunächst den Mann ins Visier nimmt, diesen letztlich aber - der althergebrachten Ordnung gemäß - triumphieren lässt. Mit dem Incipit stellt es sogleich das punctum saliens im Dissens der Geschlechter vor, wobei freilich eine Negation der - rhetorischen - Frage impliziert ist. Zentrales Thema des Lieds ist also der Konflikt um die rechte Ordnung im Ehestand, der in humorvoller Weise behandelt wird. Der Text gibt sich als Warnung an einen unverheirateten oder jungverheirateten Mann und wird wohl auch als scherzhafte Hochzeitsfest-Einlage aufgeführt worden sein. Denn in lebhaften Bildern werden Szenarien gezeichnet, in denen der Mann die häusliche Befehlsgewalt an eine reiche, schöne, herrische oder böse Frau verliert und bildlich in den Hühnerkäfig schlüpfen muss. Die empfohlene Lösung für das Problem verkehrter Machtverhältnisse ist brachialer Natur:

1

Ist dan die hen mehr als der han,

ist dan das weib mehr als der man,

wo hat man das ding erhört,

wie sich hat die welt verkehrt,

das die hen den han so weit thuedt treiben,

129 Vgl. Franz S. Hügel: Zur Geschichte, Statistik und Regelung der Prostitution. Wien: Zamarsky/Dittmarsch 1865, S. 71: „Die verrufensten Gegenden Wiens, wo die Freudenmädchen ihre Venustempel ehemals aufgeschlagen hatten, waren die Schottenbastei, Naglergasse, Krugerstraße, der Elephant, die Mohrenapotheke, das Belvedere (wenn Musik war), die Theater, der Prater, die Hetze, der Augarten, der Graben, Kohlmarkt und Hof." 
das er mues schlieffen, in die hennersteigen,

[...]

9

Jezund wolt ich wünschen das dissen raht, ein jeder Braffer man nachlebe[n] dat,

wan das weib zufriden nicht wil sein,

so nim ein ochsen zen, und schlag Bräff drein,

wer dissen ernst sein weib wird zeigen,

der darff nicht mehr schlieffen in die henersteigen,

10

Wan die hen wil krehen vor den han,

und das weib reden vor den man,

so mues man die hen an den Pradtspiess jagen,

und das weib in die goschen schlagen,

so ist die hen todt und das weib mues schweigen,

und die mues selbst schlieffen, in die henersteigen, ${ }^{130}$

1,6 schlieffen] schlüpfen, kriechen 9,4 ochsen zen] Züchtigungsinstrument aus dem zu einer Art Gerte gedrehten, gedörrten Bullenpenis bzw. dessen Haut 10,4 goschen] Mund, Maul

Das beliebte Motiv, das die Dominanzverhältnisse zwischen Ehepartnern sehr anschaulich ins Bild setzt, findet sich in einer Vielzahl anderer Lieder, so etwa in der Arie In der Hüner-Steigen aus der Wiener Kärntnertor-Burleske Hanns-Wursts gedoppeltes Probund Meister-Stuck:

Da sitz ich im Nest,

So machens die Weiber,

Die Schuld hat der Schreiber,

Ich werd bald erlöst,

Viel Männer seynd Lappen,

Die bhalten ihr Kappen,

Und schreyen braf ki kri ki,

Viel tausendmal ärger als i. ${ }^{131}$

Dominante, böse Frauen, die ihren angestammten Pflichten im gemeinsamen Haushalt nicht nachkommen und den Mann demütigen, sind generell ein äußerst beliebtes Thema in dialektalen Flugschriften des 18. Jahrhunderts. Oft ist es der Alkoholmissbrauch, der als Wurzel des Übels identifiziert wird und - weil er zu dieser Zeit üblicherweise als männliches Laster gilt (vgl. etwa Ach du alter Galgen-Schwengel) - bei Frauen noch viel schockierender wirkt:

1

Sey mir willkomm mein lieber Peter,

i hab ghört du hast gheyrath wie thuts dir denn gehn,

muß dir nicht recht gut gehn, bey deiner Lenä,

schaust doch ganz trozig aus, thu dirs ankennä.

130 Bayerische Staatsbibliothek, Cod. germ. 7340 (Stubenberger Gesängerbuch), Teil 2, S. 80-81. Zum selben Thema und mit gleichem Tenor kommen in Ach mein got was hab ich gethan (ebda. S. 55-56) zwei Ehepartner zu Wort, wobei der Mann als verängstigter, unterwürfiger Part von seiner herrischen Frau in die Hühnersteige gesperrt wird.

131 Österreichische Nationalbibliothek, Cod. 12707, S. 382. Erstmals ediert bei Pirker, Teutsche Arien II, S. 175. 
2

Sag mir von gut gehn nicht, mein lieber Thomä,

schau mir nur an mein Pfaid, muß mich recht schämä,

mein Weib das Mustä thut nicht gern waschen,

sie braucht kein Saifen nicht, und ä kein Aschen.

3

Waschen thut sie zwar gern, aber mit der Goschen,

wanns nur was zsauffä giebt, da steht ihr s'Maul offen,

einwaikä thuts ä gern, ihrn Hals mit Brandwein,

wanns ä drey Seitel hat, thuts doll und voll seyn.

$[\ldots]$

6

Wann i sag mein liebs Weib, must nicht ä so trinka,

bey unsern Häusel schau laßt sich nichts gwinna,

da macht mich aus das Weib, mit ihrn bösen Schnabel,

sagt grad gehst gleich du Hund, springt um d'Ofengabel.

7

I hör schon mein Peta, es geht dir gar übel,

dein Weib hat d'Hosen an, und du den Kitel,

wann i ä solchs Weib bekemma solt, i wolt dirs curirn,

ja ihr versoffne Haut wolt i einschmirn.

8

Weißhäßlä Stekä die wärn gut zu brauchä,

Ochsenzehn, Mannäfäust du darfst mirs glaubn,

beym Haaren nehmä, in der Stubm umazoiha,

als wie ein Stokfisch muß mäs recht bloiha.

9

Poz tausend mein Thomä mußt nicht ä so redn, wanns mein Weib hörn thät, thäts Handel abgebn, sie fiel dir in d'Haar, thät mit dir rauffä,

wie oft hab ich müssen schon von ihr entlauffä.

10

Mein lieber Peter ich will dir noch ein Rath gebn, wanns mir den folgen thust, wirst habn ä guts Lebn, zahl dein Weib Brandwein gnug, thue ä mit ihr sauffä, wanns alles vertrunkä habts, mögts baarfuß lauffa.

11

Mein lieber Thomä es wird ä so gschehä,

es ist schon drum und dran, $i$ thus schon seha,

ey was scher mich drum, wann alles ist versoffa,

vielleicht stirbt der alte Hund, hab i ein junge zu hoffä. ${ }^{132}$

1,4 ankennä] anmerken 2,2 Pfaid] Hemd 2,3 Mustä] liederliche Frau 2,4 Aschen] Lauge aus Wasser und Asche war ein typisches Reinigungsmittel für Wäsche und Fußböden 3,3 einwaikä] einweichen 6,3 macht mich aus] beschimpft mich 6,6 Ofengabel] Schürhaken 8,1 Weißhäßlä Stekä] (Weiß-)Haselstecken 8,2 Ochsenzehn] Ochsenziemer, d. h. Rute aus dem getrockneten Penis eines Ochsen 8,3 umazoiha] umherziehen, umherschleifen 8,4 bloiha] schlagen, prügeln

Das zynische Fazit, auf ein Ende der Ehemisere durch den baldigen Tod des Partners zu hoffen, findet seine konsequente Fortsetzung in bösartigen Liedern, die mit dem durch

132 Drey neue weltliche Lieder, Das Erste: Ich weiß nicht, wie mir ist schon etc. Das Zweyte: Boz tausend hundert schlaperment, etc. Das Dritte: Sey mir willkomm mein lieber Peter, etc. Gedrukt in diesem Jahr. [o. O., o. J.; Steyr?, 2. H. 18. Jh.]. 
und durch ungebührlichen Verhalten der frisch Verwitweten komische Effekte erzielen. In Iezt geh i zu mein Nachbän ist es ein Ehemann, dessen anfängliches Lamento plötzlich in ein höhnisches Freudenlied voll rüder Pietätlosigkeiten umschlägt. Nur noch der Refrain zitiert als sarkastischer Kontrapunkt das Formelinventar des konventionellen Klagelieds:

1

Iezt geh i zu mein Nachbän, und klag ihm halt mein Noth, wie das mein Weib nie Kranck ist gwöst, und iezt ist würckly todt, I armer Mann, Was fang I an, I armer mann, Was fang I an. 3

Da kämä auf Freydthoff hin, da war das grab schon gmacht, da hät I a bißl waina solln, ha liebä ä wengerl glacht. I armer etc.

5

Jezt schauts mä um än grossen Stain und waltzts män auf das grab, das dö alt nöt häimä kümt, was hät I für a Blag.

I armer etc.
2

Gehts schauts mä um än Schubkarn um, und werft die alt hinaus, führts ös für tausend Teixel, so kumt aus mein Haus, I armer Mann, was fang I an I armer Mann, was fang i an. 4 Es käm dä Pfarrer mitn Flederwisch und dunkht ins Simperl ein, aft sprichtä ä par wärtl und spricht die Höppin ein. I armer etc.

6

Jezt Hamä no 6 Kreutzer die kern mein und dein, drady wäberl drady väsoffä müessens seyn, I armer etc. ${ }^{133}$

2,3 ös] sie Teixel] Teufel 4,1 Flederwisch] (hier:) Aspergill, Weihwasserpinsel 4,2 Simperl] flacher Brotkorb, (hier:) Weihwasserschale 4,4 Höppin] Kröte, derbes Schimpfwort für Frau 6,1 drady wäberl] dreh dich, Waberl (Barbara, ursprünglich Aufforderung zum Tanz)

Einzelne thematische Bausteine wie das beschwerte Grab finden sich bereits im erstmals um 1535 in einem Nürnberger Druck belegten Spottlied Die alte Trumpel, das in den folgenden Jahrhunderten in verschiedenen Dialekten neu ausgestaltet wurde. ${ }^{134}$ Mit Und weil $i$ znächsten aus bin gang hat sich noch eine weitere bairisch-österreichische Adaption dieses weitverbreiteten Lieds erhalten. ${ }^{135}$ Ein ähnlich herzloses Verhalten kann freilich auch der weiblichen Seite unterstellt werden, wie das nicht minder maliziöse, bis ins 20. Jahrhundert weitverbreitete Lied von einer vergnügungssüchtigen Bäurin zeigt:

1

Bäurin sollst ham gehn,

Dein Mann ist krank,

Legts'n auf d'Bank.

Lieber Franz

No an Tanz

Nachher wolln ma hamgehn.

\section{2}

Bäurin sollst ham gehn,

Dein Mann liegt in Zügen

Liegt er in Zügen?

Laßts'n liegen,

Lieber Franz $p p$.

133 Stiftsbibliothek St. Florian, XI 577 A, S. 101-103.

134 Vgl. Zwey newe Lieder / Das Erst / Wol auff wir wöllens wecken. Das ander / Die alte Trumpel / Im Thon /

Es het ein biderman ein weyb / ir dück wolt sie nit lan etc. [o. O., o. J., Nürnberg, um 1535].

135 Vgl. Haid/Hochradner, Lieder und Tänze um 1800, S. $229 f$. 
3

Bäurin sollst ham gehn,

Dein Mann griegt d'letzt' Ölung.

D'letzt' Ölung?

Mein Empfehlung,

Lieber Franz $p p$.

\section{5}

Bäurin sollst ham gehn,

Ein alter Freyer ist im Haus.

Ist er im Haus?

Werfts'n raus!

Lieber Franz pp.
4

Bäurin sollst ham gehn,

Bäurin sollst ham gehn,

Dein Mann ist tod,

Ist er tod?

Tröst' ihn Gott!

Lieber Franz $p p$.

6

Bäurin sollst ham gehn,

Ein junger Freyer is im Haus.

Ist er im Haus?

Laßts'n nit raus!

Lieber Franz, jetzt kan Tanz,

Denn jetz muß i z'haus geh'n. ${ }^{136}$

1,1 ham] heim 2,1 in Zügen] im Sterben 3,5 pp] (lat. perge perge: fahre fort, fahre fort) usw., etc.

Besonders beliebt war das Ehestreit-Thema auch auf den Klosterbühnen. Maurus Lindemayr belieferte das Lambacher und befreundete Stiftstheater mit entsprechenden brachialkomischen Szenen in seinen Klosteroperetten wie Jodel, der Friedensstifter, Saufsucht oder Der ernsthafte Spaß. Aber auch das nicht weit entfernte Benediktinerstift Kremsmünster kann auf eine ausgeprägte eigenständige Tradition verweisen, die wiederum von den Produktionen Weisers und Eberlins auf der Salzburger Universitätsbühne inspiriert war. Ein frühes Beispiel ist das zweiteilige Singspiel Astrologus des aus dem südböhmischen Beneschau (heute Benešov nad Černou) stammenden Gymnasialdirektors und Pater comicus Johannes Weylgoune (1708-1760). ${ }^{137}$ Die Musik zu dem als Zwischenspiel einer lateinischen Finalkomödie 1746 aufgeführten Stück stammte von P. Placidus Fixlmillner (1721-1791), der seinen Zeitgenossen vor allem als Astronom von Weltrang bekannt war. Im ersten Teil wollen der tölpelhafte Bauer Hänsl und sein Sohn Pärtl bei einem ,Sterngucker in Erfahrung bringen, „ob nit bald umädum ä vöstä frid wiäd weän "138, doch noch bevor sie eine vernünftige Antwort erhalten, werden sie von Greschl, Hänsls rabiater Ehefrau, unter wüsten Beschimpfungen nachhause geprügelt:

MuetTer. hänsl mein man! Pärtl mein bue! hansel! Pärtl, wo seits voan odä hintn; i suech enk umädum, und kan enk do nöt findtn.

VATter. Gelt Pärtl hon is nöt gsoät. iez ist d'muedä ä da. Dö wiäd uns gö recht glokä.

SoHN. Vadä halt goschn, sö mechti öppä heän, ös sänd ia insa 3, was bist den so däschrokä.

Astrologus. Disß ist gewis ein sternseherin: sye hat den tubum in der hand zum sternsehen, wann sye beyn raufang durch in d'höhe thuet abgehen.

Muetter. Aria.

Woächt hänsl i will di scho kriegn,

i will da dein schedl scho biegn,

Woächt Partl ös bleibt da nit auß,

136 Wienbibliothek im Rathaus, HIN 55795, Teil 2, f. 26v-27v. Unter dem Titel Der Weltlauf (Wai, wai, sollst hoam gehň) wurde eine Variante bereits 1819 in der ersten namhaften Volksliedersammlung aus Niederösterreich mit Noten abgedruckt, vgl. Franz Ziska/Julius Max Schottky (Hg.): Oesterreichische Volkslieder mit ihren Singweisen. Pesth: Hartleben 1819, S. $165 f$.

137 Stiftsbibliothek Kremsmünster, Ccn 1373, S. 63-77.

138 Ebda., S. 66. 
i zdruk eng all zway wiä ä lauß.

dö künä dö thoän dä hoämb reän

dö frazn dö thoän ämb recht scheän.

da Vada dea last ins alloän

i zschlag eäm gwis all seine boän.

VATter. auwehe! auwehe! Poz selament z'schlagn alle Poän und z’trukä wiä laus? Partl wie gfalts dä? gelt döß ist ä grauß.

Muetter. seits da öß gassen schlänggl, geh geh hoämb, i nimb di beim schibl.

VATTER. auwehe! moästä! Pärtl! hellffts mä hellffts mä.

\section{Aria à 4}

MuetTer. gehts nöt haimb ös schläggl! was tiets so lang aus?

SoHn. Mueda! halt goschn, ös wiäd gwiß nix drauß.

VATTER. Greschl du höppin, wie schaust heunt mea auß.

Astrologus. hab ich Kein ruhe in hauß.

Muetter. geh nu gley scheädi

SoHn. Vada i wie mi,

VATTER. d'mueda is wini,

Astrologus. Pakt euch nur all hinaus. ${ }^{139}$

Pärtl] Kurzform für Bartholomäus Bue] Bub, Junge enk] euch hon is nöt gsoät] habe ich es nicht gesagt glokä] klopfen, verprügeln goschn] Maul mechti öppä heän] könnte dich vielleicht hören tubum] (Akk. zu lat. tubus) Röhre, (Fern-)Rohr raufang] Rauchfang, Kamin Woächt] warte zdruk eng] zerquetsche euch künä] Kinder thoän] tun dä hoämb] daheim reän] weinen ämb] einem boän] Beine (i. e. Knochen) öß gassen schlänggl] ihr Gassenschlingel schibl] Haarbüschel Greschl] Kurzform für Margarete höppin] Kröte scheädi] scher dich, verschwinde wini] tollwütig

Im zweiten Teil erbitten Hänsl und Pärtl vom Astrologen ein Mittel gegen Greschl, nicht ahnend, dass die beiden gemeinsame Sache machen. Als ihnen vorgeschlagen wird, mit Sternzeichen-Hokuspokus Greschl umzubringen, sind sie begeistert dabei:

Astrologus. [...] iezt ist euer weib gestorben, seit nun ganz wohl getrost, iezt habt ihr im hauß den friden erworben.

Aria.

VATTER. Juhe hapsäsßä mei Greschl ist scho hü. iezt Pärtl las krachä thua kudan thuä lachä Juhe hapsäsßa mei greschl is scho hi, dös ding dös thuät mi gfreyn so war i hänßl bin,

SoHN. iezt muest gen än andäs weib nehmä

VATTER. hän sagmäs wo wier is bekemmä.

SoHN. ä Jungi, ä reichö ä schöni, ä guä ä dollö dian i köni $\mathrm{Ju} J u$ he hapsäsßa di muäs mei mueda seyn. ${ }^{140}$

hü] hin kudan] kichern, lachern gen] schnell, also (Füllwort) hän sagmäs] he, sag mir wo wier is] wo werde ich sie ä dollö dian i köni] ein tolles Mädchen kenne ich 
Doch der Anblick der scheinbar Toten und das Entsetzen der Kinder und Verwandten lassen sie ihre Tat rasch bereuen. Mit einem weiteren ,Zauberspruch ' wird Greschl wiederbelebt und zumindest für den Moment wissen alle wieder, was man aneinander hat.

Nicht weniger derb geht es in Simmel bekommt eine Ohrfeigen zu, einem weiteren durchkomponierten Intermedium für das Kremsmünsterer Schultheater anonymer Herkunft (Matthias Pregg?). Das Spiel beginnt publikumswirksam mit einer Ohrfeige, die der versoffene Bauer Simmerl von seiner zweiten Frau bekommt, während er sie mit unterwürfigen Schmeichelreden zu beruhigen sucht. Aber erst als ihr Sohn aus erster Ehe, Amico, auftritt, lässt sie von Simmerl ab, der wiederum von seinem Sohn Bieberl getröstet wird. Als ihn die Furie - trotz der Einwände des Wirts - aus dem Wirtshaus prügeln will, wird sie mit einer List kampfunfähig gemacht; an einen Tisch gebunden kann Simmerl sie schlagen, wie er möchte:

Bieberl. he Vadä

SimMerL. ha.

WiRTH. he Nachbä.

BIEBERL. gschwind steh auf! Wir habn da mit da Mueda

SimMERL. ä döß lueda

BIEBERL. an artlichn Rand angfangä.

Simmerl. Na, döß liess si endli horen

WIRTH. itzt wirds enk gwiß no dasi wern, ma habn's Rosoli glaß von ihr däwischt, da habn wir an Schlaftrunk drunta gmischt, öß hat schon trunkä ä davon izt geh ma gehn, und bindens föst an Tafel an da kanst du nacha was d'willst mit da fotzen machä, du bist izt herr im hauß.

Simmerl. Die Erste straf ist die izt trink mä den Rosoli ihr bey än tropfen auß

WIRTH. izt greifts nur an, mä wölln dhöppin recht föst Binden.

SimmerL. no oäns: $n$ Carbätsch nim ä zu dir auwe i fürcht ma do schier Sünden

WirTh. Nachbä dö Weibä soll mä zohln, und alli soll ma schindn, die ihren aignä Mann kain trunk vägunä wölln, du kannst äs priegeln und halbs daschlagn, sie derf kein Wörtl sagen. ${ }^{141}$

Rand] Spaß, Streich enk] euch dasi] kleinlaut Rosoli] Likör, meist auf Basis von Kirschensaft öß] sie gehn] schnell, gleich (Füllwort) dhöppin] die Kröte Carbätsch] Karbatsche, Peitsche mit kurzem Holzstiel vägunä] vergönnen

Unter den Schlägen Simmerls gibt die Ehefrau schließlich klein bei - ein kurzer Triumph freilich nur.

In Theophil von Dückerns (1718-1774) dialektalem Interludium zum Schulstück Floridus (1757) weigert sich der versoffenene Hänsl, seinem Sohn Riepel zu folgen und nach Hause zu gehen; denn dort wartet nur seine Frau mit Schimpfen und Prügeln. Riepel soll ihr deshalb ausrichten, er sei in einen Vogel verwandelt worden:

Allweil brummä, allweil grannä,

Mi als wie än Hund anzahnä.

Nä; das wird mä währla z’vill.

Hann i abä aimal d'Flügl;

Kimmt mei Weib, und will mi schröckä;

Zaig i d'Feign, und floig ihr wöckä.

Dortn thue i, was i will. ${ }^{142}$

141 Musikarchiv Stift Kremsmünster G 13/35, f. 8v-9r.

142 Stiftsbibliothek Kremsmünster, Ccn 1348, f. 7v. 
1 grannä] murren, seine Ungeduld zu erkennen geben 2 anzahnä] die Zähne zeigen, fletschen 6 d'Feign] beleidigende, obszöne Geste (Daumen zwischen Zeige- und Mittelfinger)

Im zweiten Teil des von Georg Pasterwiz vertonten Zwischenspiels finden wir Hänsl in einen Käfig eingesperrt, ansonsten ist nichts Vogelhaftes an ihm. Verzweifelt fleht er Riepel an, ihn aus seinem Gefängnis zu befreien, doch dieser hält es für eine gerechte und lehrreiche Strafe; überdies lässt sich keine Tür finden.

In Kremsmünster wurde auch Michael Haydns beliebtes Zweipersonenstück Der Bassgeiger von Wörgl (um 1775) nachweislich aufgeführt, dessen Text möglicherweise aus der Feder des dortigen, aus Tirol gebürtigen Kapitularen P. Leo Peternader (17341808) stammt und einen Ehestreit mit witzigen dramatischen Wendungen behandelt. Die schlichte Handlung ist schwankhaft: Da Liesl ihrem betrunkenen Mann Bärtl den Zutritt zum Haus verweigert, täuscht dieser vor, sich im nahen Bach ersäufen zu wollen. Während Liesl verzweifelt nach ihm sucht, schleicht er hinterrücks ins Haus, um nun selbst seine Partnerin auszusperren:

BärTL. Hä! hä! was willst? I bi no nit däsoffn

Hast gmoät, i sey scho hi. Oägl oägl

Bring däs Weib, da geits no ä Noägl

LiEsL. Gottlob! Gottlob! weil nu du da bist!

Han gmoät du seyst däsoffn.

I bin woäs wie weit nachn Bach gloffn.

Trinck zue was d'magst und laß mi ein

BärTL. Mä! wie thuest denn iezt so fein!

Zigeinerinn, häst du mi z'erst einglassn?

Probiers nur iezt, wie guets is auf dä Gassn.

LiesL. Välang vo mir dö Alläbesten Speisn

BärTL. Fopp anre du loß Zankeisen

LIESL. Es is ja kalt: i muß dafrirn

BÄRTL. Tränk di meintwegn, wennd' so nit willst krepiern

LIESL. Wär denn nit recht Schad um mi?

BärTL. Du Bärr, was haltst nit no auf di?

Jetzt han i ä koä Ghör, wie du, zu oänä Bitt.

Scherr di nu fort, i brauch di nit. ${ }^{143}$

2 Gmoät] gemeint Oägl] Spottwort, -reim 3 Bring däs] Trinkspruch (,auf dein Wohl') geits] gibt es ä Noägl] einen Rest 6 woäs] weiß 17 koä] kein

Mit einem virtuosen Bitt- und Spott-Duett klingt dieser Ehestreit ungelöst aus.

Das Motiv des ausgesperrten Ehepartners war im Ordenstheater offenbar ein beliebtes, denn es begegnet uns auch in einem anonym überlieferten Griseldis-Spiel aus den Beständen des Benediktinerstifts Marienberg in Südtirol. ${ }^{144}$ Laut Titelblatt „zu Meran

143 Musikarchiv Stift Kremsmünster, G 28/56, Partitur, f. 7v-8r. Vgl. dazu die gedruckte Fassung (mit modernisiertem Text) Johann Michael Haydn: Der Bassgeiger zu Wörgl - ein Lustspiel in der Musik von einem Aufzuge. Hg. von Werner Rainer. Partitur. Wien: Doblinger 1995.

144 Vgl. Toni Bernhart: Griseldis (1713). Ein Neufund aus dem Stiftsarchiv Marienberg und die Geschichte des Schultheaters am Benediktinergymnasium Meran. In: Nestroyana 37 (2017), H. 3/4, S. 175-187. Bernhart inszenierte das Stück gemeinsam mit Janina Janke 2016 im Neubau der Abtei Marienberg. 
Exhibiert Anno 1713“, bringt das Stück die seit Boccaccios Decamerone bekannte Geschichte der tugend- und duldsamen Bauerntochter, deren Leidensfähigkeit von ihrem adeligen Mann so lang geprüft wird, bis sich ihre Ergebenheit und Loyalität als über alle Zweifel erhaben erweist. Die rurale Herkunft der Protagonistin wird im Stück, das ausführlich den Alltag von Bauern und Handwerkern schildert, auch sprachlich markiert. So lamentiert Griseldis Vater auf gut Tirolerisch über die vielen (typisch weiblichen) Kleinarbeiten, die er nach dem Abgang der Tochter alleine verrichten muss: „mueß allain holz- vnd strëb harken, stroh schneiden, das khielel bsëchen, trenckhen, melchen, aufseichen, abrämen, s khibele schlagen, das ainer ëpper ä gmächet hat die nud[1] oder ein plentn zu schmëlzen“" ${ }^{145}$. Noch stärker dialektal gestaltet ist das Zwischenspiel, in dessen erstem Teil der aus dem Wirtshaus heimwankende Mann von seiner Frau mit einer Schimpftirade empfangen wird:

du schlänggl, du schliechtl, du lackhendrischer, du wäsch pluyer, du spihlpue das enckh der gugger nit ä mall die khart[en] vertragt. aber Er treibt enckh wohl iehm[er] an, das er vns weiber dësto mehr zum Zorn anraizt, und auch darzue zwingt, Aber was achtest dus, wan ich zu hauß drweil verdärb und stärb, wurd dir die schellsau no lieber sein als jch. Du lueder, schäm di do du tag dieb, [...] du bist ä sauberer gsëll. ä saubers muster, ä formal lugner, hast du mir das verhaissen, wie du 10 mall vmb mich gloffen bist? dort hast du mir wol andere worth gëbn, als iezt. [...] gehe du hin iber nacht ligen, wo du in tag bist gwësen, [... I Ich wintsch dir ein guete nacht. ${ }^{146}$

schlänggl] Taugenichts, Schlingel schliechtl] Nichtnutz lackhendrischer] (besonders) ungeheuerlicher wäsch pluyer] Schlagholz zum Wäschewaschen spihlpue] Spielbub enckh] euch gugger] Kuckuck, hier Synonym für den Teufel ä mall] einmal formal lugner] Paradelügner

Als Zerrbild der geduldigen und unterwürfigen Griseldis reißt hier der Frau (angesichts der Eskapaden ihres Manns durchaus nachvollziehbar) der Geduldsfaden. Doch in der Logik des Volkshumors muss sie im zweiten Teil des Interludiums für ihre Unbotmäßigkeit büßen, wenn sie sich als Ausgesperrte und vom Mann Verspottete wiederfindet.

145 Zitiert nach ebda., S. 185.

146 Ebda., S. 186. 


\section{FEHDEN UND FEINDSCHAFTEN}

Ihre suggerierte Mündlichkeit und Lebensnähe prädestinieren Dialektliterarisierungen nicht zuletzt auch für alle Facetten des Manipulativen, Agitatorischen, Polemischen und Provokativen. Mundart begegnet uns in öffentlichen und privaten Auseinandersetzungen als gezielt eingesetztes ästhetisches Mittel, um den konkreten Kontext abzustecken, eine bestimmte Zielgruppe anzusprechen, Gegner zu charakterisieren oder Authentizität und Emotionalität zu vermitteln, wie schon an vielen Beispielen in den vorangegangenen Kapiteln gezeigt wurde. Nicht selten aber ist die Mundart selbst eigentliches Ziel des Angriffs. In diesem Fall dient der zumeist überzeichnete oder deplatzierte regiolektale Ausdruck als Signum einer defizitären Sprachgebarung, die sich aus diversen Gründen normativen Ansprüchen in verschiedenen gesellschaftlichen Bereichen verweigert, sei es in der Literatur, dem Theater, der Kanzelrhetorik oder der ritualisierten Alltagskommunikation. In vielen Fällen - und beileibe nicht nur in offensichtlich konfessionell motivierten Streitigkeiten - spielte bei dieser Art der Funktionalisierung eine Differenzierung eine bedeutende Rolle, die eben nicht im alltagssprachlichen Gebrauch gründete, sondern den jeweiligen ideologischen Leitparadigmen geschuldet war: Der bairisch-österreichische Dialekt (und mit ihm der als ,Jesuitendeutsch' verunglimpfte oberdeutsche Standard) galt als genuin katholisch, während mit dem ab Mitte des 18. Jahrhunderts auch in süddeutschen Regionen etablierten Standard ostmitteldeutscher Prägung (dem ,Lutherdeutschen') protestantische Lebenswelten und Kultursysteme assoziiert wurden. ${ }^{1}$ Mit der zunehmenden ökonomischen und sozialen Überlegenheit der protestantischen Territorien und der damit verbundenen Oberhoheit im Gelehrtendiskurs (die ja mutatis mutandis noch heute ihre Auswirkungen zeigt) ${ }^{2}$ verband sich damit bald eine Diskreditierung des Bairisch-Österreichischen als Rückständigkeitsmerkmal - eine Verunglimpfung, die nicht nur von Protestanten, sondern auch von etlichen katholischen Aufklärern vorangetrieben und literarisch verarbeitet wurde, wie u. a. am Beispiel Anton von Buchers (vgl. Kap. 1) bereits gezeigt wurde.

Vor dem sukzessiven Machtverlust der katholischen Reichsstände ab dem Österreichischen Erbfolgekrieg hatte die autochthone katholische Kultur in Bayern, Salzburg und Österreich allerdings noch durchwegs selbstbewusst ihre spezifischen Sprachvarietäten auch in den konfessionellen Auseinandersetzungen eingesetzt. Davon zeugt die

1 Vgl. u. a. Peter Wiesinger: Zur bairisch-oberdeutschen Schriftsprache des 16. und frühen 17. Jahrhunderts in Österreich unter dem Einfluss von Reformation und Gegenreformation. In: Walter Hoffmann [u.a.] (Hg.): Das Frühneuhochdeutsche als sprachgeschichtliche Epoche. Werner Besch zum 70. Geburtstag. Frankfurt a. M. [u. a.]: Lang 1999, S. 241-273. - Peter Wiesinger: Die Entwicklung der deutschen Schriftsprache vom 16. bis 18. Jahrhundert unter dem Einfluß der Konfessionen. In: P. W.: Das österreichische Deutsch in Gegenwart und Geschichte. 3., aktual. und neuerlich erweit. Aufl. Wien/Berlin: LIT 2014. (Austria: Forschungen und Wissenschaft. Literatur- und Sprachwissenschaft 2) S. 301-312.

2 Vgl. Dieter Breuer: Die protestantische Normierung des deutschen Literaturkanons in der frühen Neuzeit. In: Heinz-Gerhard Haupt/Dieter Langewiesche (Hg.): Nation und Religion in der deutschen Geschichte. Frankfurt a. M./New York: Campus 2001, S. 84-104. - Haefs, Zur Literatur und Theologie, S. 32-36. 
große Anzahl an Texten, die in Zusammenhang mit der Herabwürdigung oder Vertreibung von (Krypto-)Protestanten entstanden. Im klösterlichen Umfeld lässt sich diese Traditionslinie der Funktionalisierung von Dialekt für propagandistische und diffamierende Zwecke im Glaubenskampf sogar bis weit in die Regierungszeit Kaiser Josephs II. verfolgen.

\section{Konfessionelle Agitationstexte: Salzburger Emigration, theresianische Transmigration, Toleranzpatent}

Die konfessionelle Spaltung des deutschsprachigen Raums hatte in der ersten Hälfte des 17. Jahrhunderts in die Katastrophe des Dreißigjährigen Kriegs geführt, ohne dass sich nach dessen Ende am Kräfteverhältnis Wesentliches geändert hätte. Auf der Grundlage des Augsburger Religionsfriedens von 1555, wonach der Landesherr über die Konfession seiner Untertanen zu entscheiden habe (cuius regio, eius religio), versuchten die Habsburger, Protestanten durch erzwungenen Konfessionswechsel oder Vertreibung aus ihrem Machtbereich zu entfernen. ${ }^{3}$ Im Verlauf der Jahrzehnte wurden so viele bedeutende österreichische Dichter ins Exil gezwungen (u. a. Johann Wilhelm von Stubenberg, Wolf Helmhardt von Hohberg, Catharina von Greiffenberg). Die europaweit meistbeachteten Aktionen gegen protestantische Minderheiten im katholischen Süden des deutschen Sprachraums wurden allerdings im Fürsterzbistum Salzburg gesetzt, das mit drastischen Zwangsmaßnahmen den evangelischen Glauben endgültig aus dem Herrschaftsgebiet zu eliminieren versuchte. ${ }^{4}$ Diese medial vielfältig ausgeschlachteten Protestantenvertreibungen ${ }^{5}$ fanden auch im kursierenden Liedgut Niederschlag, wobei sich von beiden Seiten des Konflikts themenbezogene Texte auch in dialektaler Form erhalten haben. Viel mehr allerdings, vor allem aus dem Bereich des oral konzipierten Pasquills und der aggressiven Propagandaschrift, dürfte unwiderbringlich verloren sein.

Sanftere Töne finden sich zunächst noch im - ursprünglich standardsprachlichen Klage- und Gebetslied Ich bin ein armer Exulant. ${ }^{6}$ Es entstand im Kontext des durch

3 Vgl. u. a. Erich Buchinger: Die ,Landler“ in Siebenbürgen. Vorgeschichte, Durchführung und Ergebnis einer Zwangsumsiedlung im 18. Jahrhundert. München: Oldenbourg 1980. (Buchreihe der Südostdeutschen Historischen Kommission 31) - Ernst Wangermann: Emigrationen und Transmigrationen österreichischer Protestanten im 18. Jahrhundert. In: Sylvia Hahn/Andrea Komsloy/Ilse Reiter (Hg.): Ausweisung Abschiebung - Vertreibung in Europa. 16.-20. Jahrhundert. Wien: Studienverlag 2006, S. 73-86. - Rudolf Leeb/Martin Scheutz/Dietmar Weikl (Hg.): Geheimprotestantismus und evangelische Kirchen in der Habsburgermonarchie und im Erzstift Salzburg. Wien/München: Böhlau/Oldenburg 2009. - Hans Krawarik: Exul Austriacus. Konfessionelle Migrationen aus Österreich in der frühen Neuzeit. Münster [u. a.]: LIT 2010.

4 Vgl. Astrid Schlachta: Die Emigration der Salzburger Kryptoprotestanten. In: Leeb/Scheutz/Weikl, Geheimprotestantismus, S. 63-92. - Krawarik, Konfessionelle Migrationen aus Österreich.

5 Vgl. u. a. Angelika Marsch: Die Salzburger Emigration in Bildern. Mit Beiträgen von Gerhard Florey und Hans Wagner und einem Verzeichnis der zeitgenössischen Kupferstiche. Weißenhorn: Konrad 1977.

6 Vgl. Raymond Dittrich (Hg.): Die Lieder der Salzburger Emigranten von 1731/32. Edition nach zeitgenössischen Textdrucken. Tübingen: Francke 2008. (Mainzer Hymnologische Studien 22). 
Erzbischof Max Gandolf von Kuenburg veranlassten Landesverweises von etwa 800 Salzburger Protestanten aus dem damals zu Salzburg gehörenden Osttiroler Defreggental und aus Dürrnberg bei Hallein - eine Zwangsmaßnahme, die in der protestantischen Publizistik als Beispiel der Standhaftigkeit ihrer Glaubensbrüder angesichts katholischer Willkür auführlich besprochen wurde. Der Autor des Lieds, Joseph Schaitberger (16581733), ein Dürrnberger Bergmann und protestantischer Glaubenskämpfer, verfasste es möglicherweise bereits 1686 auf dem Weg nach seinem Emigrationsort Nürnberg - erstmals im Druck erschienen ist es allerdings erst 1691 in einem Sendbrief Schaitbergers. Es transportiert die Sorgen und Nöte der Vertriebenen, betont zugleich aber auch ihr Einstehen für den rechten Glauben. Dass das Exulantenlied (auf die Melodie des Kirchenlieds Ich dank dir schon durch deinen Sohn) in den protestantischen Gebieten des deutschen Reichs große Verbreitung gefunden hatte, belegen nicht zuletzt etliche Adaptionen, darunter auch eine dialektale, pseudo-bairische Variante, die in der Mundart der Vertriebenen verfasst sein soll. Diese Fassung wurde, als die konfessionellen Spannungen mit der Vertreibung von über 20.000 Protestanten unter Fürsterzbischof Leopold Anton Freiherr von Firmian zu Beginn der 1730er Jahre erneut aufflammten, mehrfach in protestantischen Blättern abgedruckt, „damit man auch ihre Sprache einigermassen daher kennen lerne "7 . Dialektkundige waren bei der propagandistisch intendierten Drucklegung offensichtlich keine beteiligt, so unbedarft ist die Wiedergabe der oberdeutschen Mundart in sämtlichen erhaltenen Fassungen. Denn selbst wenn man mögliche Übertragungsfehler und Zersingungseffekte in Rechnung stellt, dürfte das (auch zeitlich nicht genau bestimmbare) Original nicht in der Mundart aus der Halleiner Gegend verfasst worden sein. Dies belegt auch die 11-strophige Fassung des Lieds aus der Auserlesenen Theologischen Bibliothec von 1733 mit ihrem irritierend inkonsistenten, mehr schwäbischen denn bairischen Dialektprofil:

1

I bin ein armer Exulant, Also thu i mi schreiba, Ma thuet mi aus dem Vatterland Um GOttes Wort vertreiba.

3

Ei Pilgrim bin i halt numehr, Muß rasa fremde Strosa,

Das bitt i di, mein GOTT und HErr,

Du wirst mi nit verlosa.

5

Ketta un Banda wor mir mein Ehr,

Um JEsu willa zdulta,

Un dieses mocht die Glaubens Lehr,

Un nit mein böß Verschulda.
2

Daß waß i wohl, HErr JEsu Christ, Es ist dir ah so ganga, Itzt will i dein Nachfolger seyn, HErr, machs nach deim Verlanga. 4 Den Glauba hob i frey bekennt, Des darf i mi nit schäma; Wenn mo mi gleig ein Ketzer nennt Un thuet mirs Leba nehma.

6

Muß i glei in das Elend fort, Wil i mi do nit wehra, So hoff i do, GOTT wird mi dort Och gute Fründ beschera.

7 Nöthiges Supplement zu der Auserlesenen Theologischen Bibliothec. Dreyzehendes Stück. Leipzig: Brauns sel. Erben 1733, S. 127. 
7

HErr, wie du wilt, so gib mi drein,

Bey dir will i verbleiba,

I will mi gern dem Wille dein

Gduldig unterschreiba.

9

So mues i heut von meinem Hauß,

Die Kindel mues i losa,

Mein GOtt es treibt mi Zährer aus

$\mathrm{Zu}$ wandern fremde Strosa:

11

Soll $\mathrm{i}$ in diesem Jammerthol

Noch länger in Armuth leba,

So hoff i do, GOtt wird mir dort

Ein bessre Wohnung geba. ${ }^{8}$
8

Mues i glei fort, in Gottes Nam,

Un wird mir alls genomma,

So woaß i wol die Himmel Cron

Wer i onmal bekomma.

10

Mein GOTT führ mi in ane Stodt,

Wo i dein Wort kan hoba,

Darin will i mi früh un spot

In meinen Hertzel loba.

2,2 ah so ganga] auch so gegangen 3,2 rasa] reisen 4,3 mo mi gleig] man mich gleich 9,2 losa] lassen 9,3 Zährer] Tränen

In dieser dialektalen Gestalt wurde Schaitbergers (trotz ihrer zweifelhaften Genese bis heute vielzitierte) Hymne in einer gehässigen Entgegnung von katholischer Seite parodiert, die im Vergleich zur Vorlage sprachlich authentischer gestaltet ist und einen Perspektivenwechsel vollzieht. Indem der Exulant hier nicht selbst der Sprechende, sondern der Angesprochene ist, erscheint das Lied als direkte Antwort (besonders deutlich in der letzten Strophe). Dabei wird der Vertriebene nicht nur mit bissigem Spott bedacht (der zugleich auch Luther treffen soll), sondern als Irrläufer auch für sein Schicksal selbst verantwortlich gemacht und in seinem Unglück verlacht. Der Text ist, soweit bekannt, lediglich durch den Salzburger Landeskonservator Vinzenz Maria Süß (18021868) überliefert, der ihn in die nur im Manuskript erhaltene Nachlese zu seiner Volksliedsammlung aufnahm:

1

Hiaz bist an årmar Exilon

Muaßt fort auf frembda Stråssen

Hättst böttn ehnda Gott und Hean

Ea sollt di nit valåssen.

3

Hättst du no g'folgt, so woaß i g'wiß

$\mathrm{A} ß$ wa da nit so gånga;

Kunst ein Nachfolga Christi seyn,

Und dås wa sein Valånga.

5

Daß du des Luthers Lehr bekent

Darfst di wol billa schama,

Drumb wann ma di an Ketza nennt

Låß da nix åndas trama.
2

Ea wa schon keman en da Noth

Hättst du di eam dageben

Du durfst nit leid'n an sötlan Spott

Und hättst a ruaögs Leben.

4

Hiaz muaßt åls wie $r$ a Pilgeramb

Armbselig furt maschiaren,

Wast blieben eh' ban rechten Weg

Du megst di nit verirren.

6

Kettn und bandl, a schenö Ea

Umb Luthers Willen dulden

dås håt gemåcht dein falschö Lea

Fråg neama nåch Vaschulden.

8 Ebda., S. 127-129. 
7

Von deinen Haus muaßt hiaza weck

Dö Kinda muaßt valåssen;

Gelt Schelm dås treibt da Zacha aus

Daß'd hiaz bist so valåssen.

9

Wülst du mit uns Rechtgläubigen

(Viel Glück!) nit länga leben,

Låß dia von Martin Luther auch

Sein Thoal im Himmel geben.
8

Geh fort en eine Stådt wost wülst

Wos Praedicanten håben,

dö werden dia den Leib zwår wol

da Seel nåch wenig låben.

10

Der Nårr der dieses Liad håt gmåcht

Schambt sich, sich hia zu nenna,

Weil ea des Pabsten Lehr varåcht,

Sich zu Luthers thuat bekenna. ${ }^{9}$

1,1 hiaz] Jetzt 1,3 ehnda] früher 2,1 wa] wäre 2,2 eam] ihm dageben] ergeben 2,3 sötlan] solchen 2,4 ruaögs] ruhiges 4,1 wie $\mathbf{r}$ a] wie ein 4,3 Wast] wärest 5,2 billa] billig, mit Recht 7,2 valåssen] verlassen (Kinder unter 12 durften nicht mitgenommen werden und wurden katholisch umerzogen) 7,3 Zacha] Tränen 8,2 Praedicanten] evangelische Prediger 9,4 Thoal] Teil

Gleichfalls der Süß'schen Nachlese entnommen ist ein katholisches Spottlied, das abermals eine Führerpersönlichkeit der Salzburger Protestanten angreift und direkt auf Ereignisse im Herbst 1731 Bezug nimmt, die dem berüchtigten Emigrationspatent Bischof Firmians vom 31. Oktober vorangingen. ${ }^{10}$ In einem humoristischen, aufgrund erzähltechnischer Schwächen etwas wirren, Bauerngespräch berichtet der soeben aus der Stadt Salzburg zurückgekehrte Jodl seinem Freund Stöffl von den dort beobachteten Vorfällen. Zentrales Ereignis war der neugierig erwartete Empfang eines auswärtigen, aus dem Gebirge stammenden „Bischofs“, der stark bewacht auf die Festung Hohensalzburg geführt wurde. ${ }^{11}$ Natürlich steckt auch hier hinter dem naiven Bauerndiskurs das textsortenspezifische Spiel mit Fehlinterpretationen, die die Protestanten und insbesondere den Führer der ansässigen Gemeinschaft, Rupert Stullebner, in ein lächerliches Licht stellen sollten. Stullebner war Schmied zu Hüttau (Pongau/Salzburg) und ein begabter Volksprediger, dessen Wirken vielleicht auch damit in Zusammenhang stand, dass 1730 in seinem Heimatort die Kirchensinger abgeschafft wurden, weil sie ,verdächtige ' Lieder sangen. ${ }^{12}$ Stöffels in bewunderndem Ton vorgebrachte Beschreibung Stullebners ist vom Rezipienten selbstverständlich ironisch zu deuten - immerhin handelte es sich (wie auch aus den skeptischen Entgegnungen Jodls rasch klar wird) beim Einzug des ,Bischofs' in Wirklichkeit um einen Gefangenentransport, wobei die Delinquenten nichts Gutes zu erwarten hätten.

1 JodL.

Jä Stöffl wänn du en da Städt z'nagst wast g'wes'n

Wäs hät'st du nit g'sech'n für ein narrösch Wes'n

Aus allen den Häusern u. Gäss'n send d'Leut

Z'samm g'loff'n und gschrien äls warn sö nit g'scheidt.

Und äls i that frägn, wäs dös that bedeut'n,

So sägt'n sie: Limbl geh nur g'schwindt auf dö Seit'n,

9 Archiv des Salzburg Museums, HS 4055-3 (Maria Vinzenz Süß: Nachlese), f. 126r-v [Manuskript zu: Süß, Salzburgische Volks-Lieder].

10 Erstmals ediert bei Hartmann, Historische Volkslieder, S. 282-284 (in verfälschender Transkription).

11 Vgl. ebda., S. 284f.

12 Vgl. Hermann F. Wagner: Die Volksdichtung in Salzburg. Salzburg: Mayr 1882, S. 10. 
Woaßt denn nit daß en birgan ean bischof kimbt hea

An ieda wollt seg'n, wea dann dea Mann wea.

2 STÖFfl.

Ah Jodl wäs säg'st ma, a bischof is kemma,

Mein säg mirs do a no wia thuat män denn nenna?

Sö sägt'n ea wa vo da Hüttau da Schmied,

Und hält äll seinö Kapitularen a mit.

Ea war a rötha und kropfata Männ,

Vül mechtögö Sächn ea wärla hät thän;

En birg wär ea bischof, hät alle regirt,

Däs gantzö Kommando alloan hät ea g'führt.

3 JodL.

Han Stöffl, däs kan i ma bildtn nit ein,

daß en da Städt Sälzburg zwon bischöf solln seyn.

Nur oana war ällzeit Äll oana regiascht,

Wo hät denn da Toifl den ändan hea gfüascht?

A bischof von Sälzburg wann oana wül wean,

Davon müaßn wißn gär vül großö Hean.

$A ß$ bleibt schon dabey, aß geht ma nit ein,

Dä muaß schon dahinta a Schelma-Stück seyn.

4 STÖFfl.

Han Jodl, wia narrösch, häst denn nit recht gfäßt,

I hons jä selbm g'sehen, wiar älls auf eam paßt.

So mörk da fein Älles und gieb nu recht ächt,

Sö habmt'n göschloß’n mit Schwertern bewacht.

Dö Hearn send g'ritt'n und g'fähren dö Fraun,

$A ß$ wollt hält an iodes den bischof änschaun.

Hint und voran dö Dragona ze Pferdt,

Däs is jä a Zoach’n, gwiß äller Ehr'n werth.

5 JodL.

I glabs nit mein Stöffl, a bischof is's nit,

$A ß$ war jä a gänga dö Geistlakeit mit.

I känns hält nit glabm, aß schickt sö a nit,

Z'gleich seyn a bischof, und z'gleich seyn a Schmied.

Da bischof von Sälzburg steht gär hoch en Ehra

Eam stehen zu Diensten wol gär großö Heara.

Da bischof trägt d' Infel, en Stäb en da Handt,

Da Schmied hät nu Hämma, dö Zäng en da Wandt.

6 STÖFfl.

Äfa Jodl, dös hätt i mein Lebtäg nia gmoant,

$\mathrm{Da}$ du so vastockt wast und gär so vapoant,

Schau nu dar Einzug wär bey dunkla Nächt

Alls hät seyn müass'n en gär schärfa Wächt.

Mit Kösch'zn und Foia vül g'loff'n send zua

$A ß$ hät oana kinna nit seh'n älls g'nua.

Glabs nu kräd Jodl daß vül is drän g'legn,

Daß en Sälzburg bökömman den Män anzusehn.

7 JodL.

bey äll denä Sächn is's mia hält nit recht

Denn äll diesar Einzug, fürn bischof is z'schlecht.

Wa dös da rechtmässögö bischof und Hear,

Wo send denn wol g'stand'n d'musikalischen Chör,

Trompetar und Paukn und dö nit allein 
Sinst kunts jä koa fürstlichar Einzug nit seyn;

An bischof empfänga und begloat'n en d'Städt

Vül schenö und machtögö Sächn mit hät.

8 STÖFFL.

So mecht i dia währla wol gär nix mea säg’n,

Du Esl geh hin und thua selba nächfräg'n.

Hoch häbm's 'n g'scholt'n und hoch promoviascht

Und zwär en dö föstung gär hoch auffö g'füascht.

En G’schlössarn da wohnen ja äll großö Hearn

Hiaz känst schon ahnemma was eam g'schegn füar Ehrn;

Von Änfang da Welt, koa Mensch häts nia g'seg'n,

Daß dös einen bischof von Sälzburg wa g'scheg'n.

9 JodL.

Mein Stöffl däs häst du nit recht übalögt

I glab eppas ändas is unta da döck:

Denn schau nue a, oana wird hoch promoviascht

Wan ihn da Henka zon Galgn aussö füascht.

Ein anders is d'föstung mit Ehren zu segn

Ein anders wenns oanen mit G’wält einö legn.

Sey äfa hiaz stat, i wül nix mea wiss'n

A Schelm muß a seyn ohnö Gott u. Gewissn.

Zwoa bischöf en Landt, niar oana hät denkt,

So glab i währhäftög da Schelm wird no g'henkt. ${ }^{13}$

1,1 z'nagst] gestern, jüngst wast] wärest 1,7 en birgan ean bischof] der Bischof der Gebirgsleute 2,1 kemma] gekommen 2,2 a no] auch noch 2,3 ea wa] er wäre Hüttau] Gemeinde im Fritztal im Salzburgerland 2,4 Kapitularen] Priester, die als Mitglieder eines geistlichen Kapitels die vom Bischof übertragenen Aufgaben erfüllen 2,5 rötha und kropfata] rotköpfiger (?) und kropfiger (mit vergrößerter Schilddrüse) 2,6 wärlä] wahrlich, fürwahr 2,7 En birg] im Gebirge 3,1 Han] Interjektion: He 3,2 zwon] zwei 3,3 regiascht] regiert 3,4 gfüascht] geführt 3,7 ma nit] mir nicht 4,2 eam] ihn 5,2 a gänga] auch gegangen 5,3 glabm] glauben 5,7 Infel] Mütze eines Bischofs oder Abtes 6,2 vapoant] engstirnig, unverständig 6,5 Kösch'zn und Foia] Kerzen und Feuer 8,3 g'scholt'n] betitelt, geehrt promoviascht] promoviert, befördert 8,5 G’schlössarn] Schlössern 9,2 eppas ändas] etwas anderes unta da döck] unter der Decke 8,4 aussö füascht] hinausführt 9,6 einö] hinein 9,7 äfa hiaz stat] aber jetzt still

Der Prediger ,Ruep' Stullebner, der allgemein als Oberhaupt der evangelischen Bewegung im Fürsterzbistum galt, stand wohl auch hinter zwei Gesandtschaften, die Bittschriften an das ,Corpus Evangelicorum' nach Regensburg brachten, damit die Vertreter der evangelischen Reichsstände als Schutzinstanz protestantischer Interessen im Reich bei Erzbischof Firmian u. a. Glaubensfreiheit für die Salzburger Untertanen erwirkten. Eine erste Eingabe im Mai 1731 war weitgehend folgenlos geblieben, ${ }^{14}$ so beschloss man Anfang August, eine weitere Gesandtschaft zu schicken, um die Unterstützung der evangelischen Stände für 18.000 namentlich angeführte Kryptoprotestanten zu erreichen. Die 24 Männer aus den sieben Pongauer Pflegegerichten wählten eine Route über den Pass Gschütt nach Oberösterreich, wurden allerdings in Wildenstein bei Ischl aufgegriffen. 21 (oder - wie im Lied - 22?) von ihnen, die keine Pässe besaßen, kamen in Untersuchungshaft und wurden nach Gmunden, dann nach Linz gebracht, von wo sie

13 Archiv des Salzburg Museums, Hs 4055-3 (Maria Vinzenz Süß: Nachlese), f. 121r-122r.

14 Vgl. Gerhard Florey: Geschichte der Salzburger Protestanten und ihrer Emigration 1731/32. Wien/Köln/ Graz: Böhlau 1977, S. 85. 


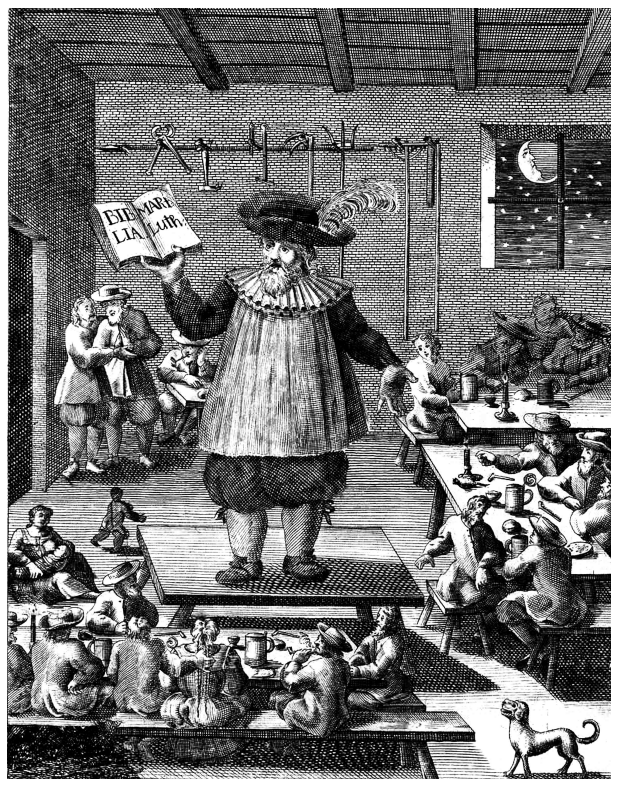

Abb. 48: Frontispizstich zu den fingierten Controvers-Predigten (1733, Österreichische Nationalbibliothek/Kooperationspartner Google, Sammlung von Handschriften und alten Drucken, 227286-B).

schließlich durch kaiserliche Truppen nach Salzburg überstellt und in der Festung Hohensalzburg verwahrt wurden. ${ }^{15}$ Drei Abgesandte mit gültigen Pässen kamen über die bayerische Grenze und zwei von ihnen schafften es schließlich bis nach Berlin, wo sie den preußischen König für ihre Sache einnehmen konnten und den zur Emigration gezwungenen Schicksalsgenossen damit eine Zukunftsperspektive eröffneten. Wie rasch in diesem Konflikt auf neue Ereignisse literarisch reagiert wurde, zeigt ein katholisches Schmählied aus dem Salzburger Umfeld, das sich im Musikarchiv des Stifts Kremsmünster handschriftlich erhalten hat und die beschriebenen Vorkommnisse kurz vor dem Einmarsch der kaiserlichen Soldaten Mitte September höhnisch abhandelt.

1

Jetzt geht mir mein aichl der traumb wohl Recht auß, iezt alln Birgern Paurn schan zue geht der grauß

schleichen ganz zag Herumb alß wanß main Laith währn stumb iezt würth iehn wohl auf d:Leng $\mathrm{d}$ :Hosßen schier z:eng.

2

Daß Haben erfahren die 22 man

so aufs ney auf Regnspurg Haben wohlen kommen an, zaigten sih unter d:Leith voll drost und fröhlichkeit iezt wurd ihn d:Freidt verbuzt Und d:Feder gstuzt.

15 Vgl. Florey, Geschichte der Salzburger Protestanten, S. 100. 
3

Der Graff Keffenhiller der hat iehns Bräff zaigt,

Er ist ohne: dem Södlen Leithen ganz gnaigt

Er gibt ihn Spendt darneben

Hats auf Linz abigeben,

Dort seinds auf aller Böst

vöst in ärrest.

4

Meine Birger Pauren ich wintsch Enckh vill Glickh

der Herr Martin Lutter Hilfft Enckh Balt zumb Strickh

weills Habt zu seiner Ehr

z:thimblkhamb gfrösßen Herr

Ein grosße schissl voll

schniten ganz voll.

5

Und wan der H. Lutter ist ein gsteiffter man

so wurd er Enckh auß der noth wohl Helffen schan

Wan er das ding nit thuet,

so ist er wohl nit z:gueth

daß man van ihm weicht Balt

nichts auf ihm Halt.

6

Zwahr der Martin Lutter Hat öffter wohl glogen

Er und sein Pibl Hambt vill Leith Betrogen

ihr Birger seiths nit z:guth

Habts doch Kein tropfen Bluth

der Redlich unter d:Leith,

darff ieder Zeith.

7

Waß mueß nit für Undrey der fürst iezt der Leben waß habts nit für Lugn zu Regnspurg eingeben

pfuy schambts Enckh ist ein Spott

drumb Straff Enckh iezt schan Gott.

waß gilts öß Kembt umb Köpf

all Birger Tropf.

8

mir ist Enckh schan kommen Recht auf den Betrug

zu Regnsburg dort wisßens schan Enkher lugn

waß dorten vor Habt gwendt

Habts wider selbst bekhendt,

Und bey Gricht bstandten frey

daß derlogn sey,

9

Darzue wißt wohl waß Enckher schuldigkheit ist waß Gott Hat befolhen ein Rechtschaffnen Christ daß er sein fürsten und herrn trey gehorsamb soll verehren wieß andere Vnthathan

Haben than.

10

Und ihr verschambte Leith Habt wider Gott

und wider die Kürchen g:röth mit schant und Spott glogn wider d:obrigkheit 
veracht die geistlichkheit

sagts ob ein solcher ist

ein rechter Christ,

11

Von Feckhfeuer wolt öß auch wüsßen khain warth

Und d:schrifft sagt Ja selbst daruan van dißen arth

glaubs schan daß nichts drumb wist

waß ein mahl S:teifls ist

khert schnur-grath forth in d:Höll

seys wie der wöhl.

12

Und iezt khent man d:Vögl infödern schan Recht

Es ist gradt ain Lumpper Hundt der Pauer und sein khnecht.

Wan Pauren Rebellieren

noch dazue S-Volkh verfihrn

Lient man gley Södla tröpf

danzen auf Köpf.

13

so Recht meine aichern Knöpf farths noh ä so forth

mechts maull nit lang z:reisßen ich sag gar khein worth

d:Spöckh Knödl dies Habt g:habt

mit den Brödl Enckh d:wamppa glabt,

Wirndt Enckh schan z-Salzburg zalt

Kombts noh fein Balt. ${ }^{16}$

1,1 mein aichl] Interjektion zum Ausdruck der Bestätigung 1,2 Birgern Paurn] (protestantische) Gebirgsbauern 1,4 main Laith] fälschlich für die Beteuerungsformel ,mein Aid` (,bei meinem Eid`) 3,1 Graff Keffenhiller] gemeint ist wohl der berühmte spätere Feldmarschall Ludwig Andreas von Khevenhüller, der die kaiserlichen Truppen befehligte, die Kaiser Karl VI. auf Bitten Bischof Firmians nach Salzburg entsandte 3,2 Södlen] solchen 4,1 Enckh] euch 4,4 z:thimblkhamb] zu Timelkam (Ort im Hausruckviertel, Kontext unklar) 7,5 öß Kembt] ihr kommt 8,1 mir] man (wohl fälschlich für ,mär') 11,5 seys wie der wöhl] wie immer es auch sei 12,4 Lient] lehrt 13,1 aichern Knöpf] Eichenknöpfe 13,2 mechts] ich möchte

Auch Stullebner emigrierte, nachdem er mit 32 weiteren ,Rädelsführern' am 28. September auf Hohensalzburg eingesperrt worden war, schwer gezeichnet von den Haftbedingungen am 6. Mai 1732; in der Folge wurde die von den Gegnern als ,Superintendent verspottete Symbolgestalt der Salzburger Exulanten zur Zielscheibe etlicher katholischer Kampfschriften. ${ }^{17}$

Polemisch wird das Thema auch in Form eines fiktiven Briefwechsels abgehandelt, wobei beide erhaltenen Texte von September/Oktober 1731 bzw. vom folgenden Jahreswechsel in Flugschriftform Verbreitung gefunden haben dürften. Wie viele Stücke diese literarisch durchaus ansprechende, inhaltlich perfide mundartliche Propaganda-

16 Musikarchiv Stift Kremsmünster, C 57/45, f. 1r-2r.

17 Vgl. etwa die fingierte Predigtsammlung: Des ehemaligen Saltzburgischen Superintendenten, und Kunstreichen Schmid zu Hüttau, Ruep Stullebner, In dasigem Gebürg gehaltene und in einer Volck-reichen Versammlung abgelegte Controvers-Predigten, Zu welchen / wegen Abgang einer Gloggen / das Zeichen mit Drommlen / Musqueten-Schuß / Küh-Hörner / ausgehenckten weissen Leilachen oder dem Dach des Wirths-Hauses, und anderen andächtigen Ceremonien gegeben worden: Mit sonderbar-curieuser Mühe und Nachforschung gsammlet, zusammen geklaubt und in etwas bessere Ordnung gebracht: Wie auch mit Catholischen Anmerckungen erläuteret / von einem Hoch-wohl-gebohrnen Mit-Glid der Hochwürdigsten Geistlichkeit in Ober-Teutschland. [o.O, o.V.] 1733. 
serie enthielt, ist ebenso unbekannt wie ihr Autor. Im chronologisch vorzureihenden, nur handschriftlich überlieferten Brieflied Herr Vetter grieß Gott! (in dem wiederum ein früheres Schreiben erwähnt wird) wendet sich der sorgenvolle Verfasser ,Wahrmund Christlich', ein „haußknecht in dem Catholischen Pfarrhoff Salzburg heraußern gebürg “ ${ }^{18}$, in mahnendem Ton an seinen in der Gebirgsgegend ansässigen Vetter, der zum Protestantismus übergetreten sei und nun zur Vernunft gerufen werden soll. Als Argumente dienen gerade jene Vorwürfe, mit denen man auch von offizieller Seite gegen die Kryptoprotestanten Stimmung machte: Sie seien gewaltbereite Rebellen, die sich gegen den Landesherren auflehnten, die katholische Bevölkerung bedrohten und beschimpften, aufwieglerische Predigten hielten, Heiligenbilder und -statuen zerstörten, evangelische Lieder sängen und zentrale Punkte der katholischen Glaubenslehre ins Lächerliche zögen. Vor untergriffigen Verunglimpfungen der gegnerischen Seite freilich scheute man selbst keineswegs zurück. Luther etwa sei „als ein schwein / in garten herein / der Christlich catholischen kirchen gfalln ein "19 (Str. 9/1-3). Höhnische Kommentare galten auch Stullebner, den in Oberösterreich gefangenen Gesandten und Verhaltensweisen der Kryptoprotestanten, die den repressiven Maßnahmen geschuldet waren, wie Begräbnisse in ungeweihter Erde. Der zweite Teil des 30-strophigen Lieds zielte offensichtlich auf die Einschüchterung der evangelischen Bauern ab, indem detailliert die fürstlichen und kaiserlichen Truppen aufgelistet wurden, die zur Unterdrückung der Evanglischen entsendet wurden.

6

Was hat euch Johann

von Nepomuc than,

das ihr Ihn so kezerisch griffen habt an,

in Diernberg obn gibts auch so luterisch strickh,

Sanct Augustin bildnuß waiß auch ein Vnglickh, da hofft ihr nur gsteifft,

wans d-heilign angreifft,

Im himmel wirds haissen, ist d-höll na schier zseifft.

[...]

10

Was z-hütta der schmidt, das glaubt man gar nit,

für kezerischer Dieb ist, vnd halten vill mit, Man sagt ia, das zahl von ä 19. sey,

recht schelmisch aufrührer, Spionen darbey,

ihr zehlt gar vngfehr

von zehen grichter her,

bey sibenzehentausendt, sibenhundert, schie mehr.

11

Der würth zu bischofhoff,

zgleich Mezger der goff

hat etlich birg oxen mit ihm tribn, wie d-schoff,

es wären in alle bey ain vnd zwainzig sein,

18 Archiv der Erzabtei St. Peter, Akt 617,1, Bl. 4, f. 5v.

19 Ebda., f. 2r. 
allein vnter gmundtn, da spörte mans ein, seind nit lang dort blibn, auf linz hat mans tribn, i glaub, es wern-s alle bräf hezn, sambt ihn. 12

sandts vnten gnueg ghezt,

(hör ich) werns zu lezt

Auf Salzburg hergliefert, ins gschlosß auffigsezt, habn schon gsagt, die bürger wolln z-Salzburg sogar vmb Micheli speisen, wird dannoch halt wahr, hinab giengen d-Narr, vnd herauf werns fahrn, wern doch darbey s-fuehrlohn vnd zöhrung erspahrn. 13

Verdients ia ein blauß, löscht aim sein leben auß, so grabts ihn im garten krat ein hintern hauß, dort khönts ihren traurigen seelen zu ehren, das wasßer abschlagen, zum trost d-hosen vmbkhern, fahret ia auf mein ayd, ohne rey, ohne layd, schnur grat der höll zue, wie an andarä hayd. 14

Ain thaill habn khain scheuh, gilt ihnen alß gleih, Sie predign, vnd tauffen, hat khainna khain weih, drumb wern ihnen d-soldaten zum geistlichen lebn, wenigist vmbä kopf die minores drauf gebn, die blaten ä schern thuens ohne dem gern, z-nächst bey der khoi, so waxen d-haar nimma gern. 15

Zwee vornemme herrn, i nen nur khain gern, habn z-wien vntn, khaysa alls anbracht in ehren, er hat ä vasrpocha, er dempfft die Rebelln, die-n fridn habn brocha, väführt so vill Seeln. Vor last er eüch mahn, wer sich will verschon, soll abstehn, sonst tragt er ein leckher daruon.

16

Es khamen bereit

Sanct Irgische leüth, sänt kherl, wie teiffl, begierig auf beüth,

ia woll a schott suppen, khäsß, schmalzkoch, vnd brod, bräff gelt her, wirds haisßen, lebt ös in der noth, die zeitung ist schlecht, do gschicht enkh so recht, öß dickhischen köpf, sowoll baurn, als khnecht.

17

Dästi figrament, wie hat er aini gnent, Graff Sauerer (main i) steht ä zum den endt 
mit 6. Compagni von Radstatt nitt weit,

gibt acht auf ain winckha, ist fertig allzeit;

hats khaysers Patent,

der schaut enckh auf d-hendt,

wird enckh d-suppen salzen mit lauter elendt. ${ }^{20}$

6,3 griffen habt an] gemeint sind die Hl. Nepomuk-Statuen, die vereinzelt - so etwa in Saalfelden - von den Brücken gestoßen wurden 6,4 Diernberg] Dürrnberg bei Hallein strickh] Lumpen, Galgenstricke 6,5 Sanct Augustin bildnuß] eine Augustinus-Statue wurde in der Nacht auf den 26. Juli 1731 in einer Dürrnberger Kapelle beschädigt 6,6 gsteifft] besonders, inständig 6,8 zseifft] ? 10,1 z-hütta] zu Hüttau 11,1 bischofhoff] Bischofshofen: Stadt im Pongau 11,2 goff] Dummkopf 11,3 birg oxen] Gebirgsochsen d-schoff] die Schafe 12,4 bürger] (protestantischen) Gebirgler 12,5 Micheli] Michaelistag: 29. September 13,1 blauß] Applaus, Beifall 14,5 minores] ordines minores (lat.) = niedere Weihen 14,6 blaten] Platte, Glatze, Tonsur 14,8 khoi] Kinn (?) 15,8 leckher] Schaden 16,2 Sanct Irgische leüth] Leute aus St. Georgen 16,4 schott suppen] Rahmsuppe mit Brotstücken 16,5 ös] ihr 15,8 dickhischen] tückischen 17,1 Dästi figrament] Fluchwort 17,3 Graff Sauerer] Graf Saurau 17,4 Radstatt] Radstadt: Stadt im Pongau

Die Replik, die der „wohlmeritierte Organist, Kürchen-Sünger, Zechbrobst“ „Paull Bekherung“ - inzwischen „(Gott Lob) widrumb Catholischer Schuellmaister" - seinem wohlmeinenden Freund schickt, gibt sich den Anschein eines ,Insider'-Berichts. Formal ist sie zunächst als Neujahrsglückwunsch gestaltet, um dann nach dem Muster des vorangehenden Briefs die Ereignisse um die Inhaftierung führender Protestanten zusammenzufassen und diese samt ihrer Leitfigur Luther zu verunglimpfen. Nun aber sind die Diffamierungen noch pauschaler und boshafter, zumal wenn sie die legitimen Anliegen und Forderungen der Evangelischen übergehen und diesen dafür eine besondere Lüsternheit unterstellen, die auch der eigentliche Beweggrund für die Glaubensspaltung gewesen sei. Um der infektiösen Amoralität Herr zu werden und die verbliebenen Katholiken vor diesen Ausartungen zu schützen, sei Firmians Emigrationspatent (das gegen geltendes Recht Tausende binnen kürzester Zeit und bei widrigster Witterung ins Ausland zwang) unumgänglich gewesen.

1

Ein glückseelig Neues Jahr!

Was dem gerechten GOTT zu Ehren/

Von ihm kanst, und wilst begehren/

Ja dem Himmel selbst so gar

Wünsch i dir von Grund meins Hertzen/

Lieber Vetter / thuet mi schmertzen/

$\mathrm{Daß}$ i draussen nit mit dir/

In der Still khan redn dafür.

[...]

12

Gibt öppän ä Keibl auf/

Wann dä Weth so hoch ist gloffen/

Und ä bessere Frund zu hoffen/

Oder ä paar Fäickl drauf/

In dem Fall will von äm gwissen/

Weder Mann: no Weib was wissen/

Wann endlö dä Sau-Marckt auß/

Treibt ein jedä sVich nach Hauß.
11

Sündign geth an nach der Pausch/

dJugend lebt nach ihen Gedancken/

dEheleuth springen aufm Schrancken/

Khimbt scho aufm Weiber Tausch/

Hat ä sötlä Stier / vertrossen/

An sein alter Khue a gschossen/

Tauscht er um ein jüngere grad/

Dö ein schönern Nutzen hat/

13

Macht gar vill das sechst Gebott/

Dem will khainer recht parieren/

Zriß dem Luther auch sein Hürn/

Lid ebm an der Gaiß-Bocks noth/

Wie ihm habm die Venus Funcken/

Auß sein gaillen Hertzen gstuncken/

Da hieß glei / den Glauben mutiert/

sCäthärl auß dem Closter gfiehrt.

20 Ebda., f. 1v-3v. 
14

Endlö do/was ihn betrüfft/

Wüst er noch sein schwinnern Leben/

Ein umkherten Mantl zgeben/

Mit verfölschtter heilign Schrüfft/

Aber unsere tumbe Piffl/

Habn ja gar khai schölbmen Griffl/

Was ihen speibt der Fezl ein/

Das soll Evangelisch seyn.

20

GOtt woll uns no gnädig schohn/

Wann ä mall dö Sodomiten/

Gommorer / und Niniviten/

Nimmermehr bey uns thuen wohn/

Mir thuen drundter nur die Armen/

Und geduldign Schaaf erbarmen/

Die sich habm so weith geirrt/

Und von Wölffen worn verfiehrt.

[...]
15

Nu mä hats so threulich gmohnt/

Weils aber umsonst ist gwesen/

Habns ein langs Patent verlesen/

Und dö Truzer nimmer gschont/

Hat ihn fürgstöllt gwissen Fürsten/

Daß zu Emigrieren wüßten/

Ist hint nach gwest / wie voran/

Habn än Straich ins Wasser than.

[...]

36

Es sey aber / wie ihm wöll,

Wir wollen dannoch fleißig betten/

$\mathrm{Daß}$ sye GOtt in lesten Nöthen/

Wenigst rötte von der Höll/

Und erleuchte ihre Gwissen/

Auf daß bin i stetts beflissen/

Wünsch von Hertzen immerdar/

GOtt geb ihen ein gescheides Jahr!

$[\ldots]^{21}$

11,1 nach der Pausch] im großen Stil 11,2 ihen] ihren 11,5 sötlä] solcher 12,1 öppän] etwa ä Keibl] ein Kälbchen 12,2 Weth] Wert 12,3 Frund] Pfründe (?) 12,4 Fäickl] Ferkel 13,4 Lid ebm] litt eben 13,8 sCäthärl] gemeint ist Katharina von Bora, die 1523 mit Luthers Hilfe aus dem Kloster floh und ihn 1525 heiratete 14,3 umkherten Mantl] umgekehrten Mantel, Tarnmantel 14,5 Piffl] Büffel 14,6 khai schölbmen Griffl] nicht den geringsten Begriff, nicht die geringste Ahnung 14,7 Fezl] böser Mensch, Teufel 15,1 gmohnt] gemahnt 15,3 langs Patent] das engbedruckte Emigrationspatent Bischof Firmians im übergroßen Format 82 x $60 \mathrm{~cm}$ umfasste 122 Zeilen 36,1 wie ihm wöll] wie auch immer

Es wären hier noch weitere Lieder als Beleg dafür zu nennen, dass die katholische Seite ihren infamen Propagandafeldzug vor allem über Mundartkunst führte, so etwa das Trutzlied Hiaz is üns a Liad vo Sälzburg hea kema, in dem die katholischen Gebirgsbauern aus dem oberpinzgauer Bramberg beteuern, dass sie sich auch mit Waffengewalt gegen die lutherische Vereinnahmung zur Wehr setzen würden. ${ }^{22}$ Solche Texte richteten sich an die eigene Gefolgschaft, die eingeschworen werden sollte auf den Hass gegen die abweichlerischen Lutheraner, und erschienen zumeist im Fürsterzbistum Salzburg bzw. in den habsburgischen Ländern, wo ein Übergreifen der Bewegung verhindert werden sollte. Eine Ausnahme ist der umfangreichste dialektliterarische Beitrag in diesem Zusammenhang, ein Freundliches Gespräch zwischen zwey Saltzburger / Hiesel einen Catholischen Land-Bauren / und Riepel einen halb Luthrischen Bürg-Knecht, welche in einer vornehmen Schwäbischen Reichs-Statt einander ungefehr angetroffen haben. ${ }^{23}$ Ganze 72

21 A Monssie Monssie Warmund Christlich Meus Amatus Cognatus, et Indignus Domus Servus in Catholicus, Parochie Aula Salzburgum Extra Montibus. Francko. [o. O., o. J., 1731/32], f. 1v, 2v-3r, 4v.

22 Archiv des Salzburg Museums, HS 4055-3 (Maria Vinzenz Süß: Nachlese), f. 123r-123v; vgl. Hartmann, Historische Volkslieder II, S. 280f.

23 Cadmus Teuto-Phoenix, Seu Palingenesia Islebio-Juvaviensis: Vel potiùs Secudinae, Et Superfoetatio Jezabel: Oder Späte Nachwehen Und Nach-Geburth / Der Luthrisch-Evangelischen Kirchen, Mit einem Unförmlichen Mutterkalb (Mola Carnea genant): Zwischen Hiesel / einem noch Catholischen Saltzburger Bauren / Und Riepel, einem abgefallenen Bürg-Knecht: Gespräch weise vorgestellt / und in müssigen Neben-Stunden / Zum Unterricht sonderheitlich des Bayrischen Landmannes; Entworffen von einem Vor- 
Seiten stark ist dieses bemerkenswerte siebenteilige Zwiegespräch, in dem der glaubensfeste Katholik Hiesl den kritisch-verständigen Exulanten Riepel, der seine Entscheidung bereits zu bereuen scheint, mit ungewöhnlicher Spitzfindigkeit, argumentativer Kraft und Beredtheit wieder zur Rückkehr zum rechten Glauben ermutigen möchte. Die Desavouierung ist in dieser im Umfeld der Dillinger Jesuiten-Universität entstandenen Schrift subtiler als in vergleichbaren Texten, doch im Detail nicht weniger verleumderisch. Immerhin aber werden nun auch Missstände auf katholischer Seite angesprochen, genusssüchtige und pflichtvergessene Pfarrer gescholten, Unterlassungen in der Seelsorge aufgezeigt. Zudem rücken Probleme ins Blickfeld, die durch die Massenvertreibung in den Zielländern tatsächlich entstanden waren. Wurden die ersten Emigrantenzüge der ,Unangesessenen ' um die Jahreswende 1731/32 zunächst noch bejubelt und die Glaubensgenossen freudig aufgenommen, zeichneten sich bald logistische Probleme ab. Die Aufnahmekapazitäten der freien Reichsstädte in Bayern und Schwaben waren bald erschöpft, die Spenden blieben aus und die Hilfsbereitschaft der Bevölkerung nahm angesichts des unerwartet großen Andrangs von Flüchtlingen, die Arbeit und Unterkunft suchten, rasch ab: ${ }^{24}$

RIEPEL. GOtt Lob! das i di no ontriff und Obschid nehma kon.

Hiesl. Ey i wolt / das der Himmel voller Geigen hieng / und lauter Bratwürst regnen thötte.

RIEPEL. Worumb bist so ungedulti mei Hiesl? Worumb mochst so finsters Gfriß? host keine guete Nocht ghobt? wer hot dir etwas leyds gethon? oder wos ist dir sonst über d'Zecha grochen?

HiEsL. Nichts dergleichen: Ihr schwarmerische Bürger und neugeborne holb Luthrische verursocht holt olles Unglikh / und Unstern / wo ihr nur hinkommet.

RiEPEL. Wos hobn don die orme Bürger scho wida Böses stüfften müessen? hob wida uns von niemond Luthrischen no klogn hörn, so long i bey meinen Herrn in Diensten bi.

HIEsL. Nichts Gutes hobt ihr gstüfft / weil wegen enkh heunt die Stott-Thor nicht geöffnet werden. Mueß olso wider meinen Willn länger hiebleiben, und neue Unköstn mochen. Solls einen ehrlichn und häußlichen Monn nicht rechtschoffn vertrießn?

RIEPEL. Wos soll mon long d'Thor gspehrt holtn, seynd wir doch schon herein? und won wir wida davo gehn möchtn oder woltn, gabs jo no ondere Tög in der Wochen, und werden die Thor destwegen durchs gontze Johr nicht können vorspehrt bleiben.

HiesL. Eben dorumb weil scho so vil aus enkh hereinkommen, will mon keinen mehr aus den gestert Obends ongekommenen hereinlossn, sondern sollen gleiwohl umb ein Haus weiter gehen: die Cotholische Herren thuen sich gwolti drüber beschweren, und sogn, es geb scho gnueg Orme, und ondere vile Freßnorren in der Stott; wo mon don mehr dergleichen poßirn liesse, warens der gemeinen Stott nur ein Uberlost: mon könne und solle denen ungehorsomen Rebellen, und verwegnen Rumorstüfftern nicht wohltrauen etc.

Riepel. Wer sogt vo uns sötle horte Ding? wird gwiß no grobe Handl obsetzn; die Thöre müessn holt mit Gwolt aufgsprengt werden, won guete Wort nicht helffen wolln. ${ }^{25}$

Gfriß] (abwertend für) Gesicht d'Zecha] die Zehe Bürger] Gebirgler enkh] euch häußlichen] wirtschaftlich, sparsam Rumorstüfftern] Aufständischen sötle] solche Handl obsetzn] Streitereien geben

nehmen, Hochadelichen Mit-Glid der Hochwürdigsten Geistlichkeit in Ober-Teutschland. Dillingen, Mit Genehmhaltung und Gutheissen der Oberen. 1732. [Der oben zitierte Titel ist dem eigentlichen Text auf $\mathrm{f}$. $2 \mathrm{r}$ vorangestellt].

24 Vgl. Florey, Die Entwicklung des Protestantismus, S. $25 f$.

25 Freundliches Gespräch, S. 53f. 
Die zweite Emigrationswelle ab April 1732 hatte bereits ein klares Ziel: Auf Einladung und mit tatkräftiger Unterstützung des Preußenkönigs Friedrich Wilhelm I. ließen sich Tausende ,Ansässige in Ostpreußen und Preußisch-Litauen nieder. Die Dürrnberger Emigranten, die als Schlüsselpersonal der wirtschaftlich so wichtigen Salzgewinnung zunächst Ausreiseverbot hatten, verließen gegen Ende des Jahres ihre Heimat Richtung Niederlande, manche von ihnen suchten in der (damals noch britischen) Kolonie Georgia ihr Glück. ${ }^{26}$

Setzten also katholische Agitationstexte vorwiegend auf dialektale Ästhetik, war die Lieddichtung der Salzburger Emigration, die in den folgenden Jahren in zahlreichen Drucken im gesamten protestantischen Deutschland verbreitet wurde, dagegen dezidiert standardnah gehalten. Lieder wie In Gottes Namen tret ich an, Ach wann wir das recht bedenken, In Gottes Namen so heben wir's an!, Mit Gott wollen wir anheben oder Von Gott will ich nicht lassen richteten sich offensichtlich an ein evangelisches Publikum fernab des bairisch-österreichischen Sprachraums und stellten die Ungerechtigkeit der Verbannung, das Leid der Vertriebenen, aber auch ihr unerschütterliches Gottesvertrauen in der Not in den Mittelpunkt; der aggressive glaubenskämpferische Ton der katholischen Pendants fehlt ihnen weitgehend. ${ }^{27}$

Auch in den folgenden Jahrzehnten scheint diese Taktik der dialektalen Stimmungsmache gegen den Kryptoprotestantismus wiederholt zur Anwendung gekommen zu sein, auch wenn kaum Textmaterial überliefert ist. Von Maurus Lindemayr, in Salzburg akademisch sozialisiert, hat sich ein Lied erhalten, das in der postumen Erstausgabe einem „katholische[n] Bauer[n] bei Anfang der freigegebenen akatholischen Religionsübung “ 28 in den Mund gelegt wurde. Doch steht der Bezug zu den josephinischen Reformen im deutlichen Widerspruch zum Liedbeginn, der ein religiöses Treffen der Kryptoprotestanten vor der Legalisierung solcher Zusammenkünfte schildert. Durch das Toleranzpatent von 1781 war es für Protestanten nicht mehr nötig, sich , heimlich in Häuser zu schleichen', um dort der Auslegung der lutheranischen Lehre zu lauschen. Lindemayrs Wie lusti gehts izt auf dä Welt wird deshalb wohl Erfahrungen aus seiner Missionarstätigkeit in Aichkirchen verwerten: ${ }^{29}$ Zur Bekämpfung des Kryptoprotestantismus hatte Kaiserin Maria Theresia 1752 die Deportation jener Männer und Frauen nach Siebenbürgen angeordnet, die sich weigerten, ihren evangelischen Glauben aufzugeben. Alle Seelsorger der betroffenen oberösterreichischen Gemeinden hatten damals der Häresie verdächtige Personen einem ,Religions-Concessus` zu melden, der daraufhin in einem Verhör die Rechtmäßigkeit der Anschuldigungen überprüfte und hartnäckig bei ihrem Irrglauben Bleibende zur Deportation bestimmte. Im Zuge dieser theresianischen ,Transmigrationen' wurden zwischen 1752 und 1757 insgesamt 2042

26 Vgl. Florey, Die Entwicklung des Protestantismus, S. 27-32. - Florey, Geschichte der Salzburger Protestanten, S. $158 \mathrm{ff}$.

27 Vgl. Hartmann, Historische Volkslieder II, S. 287-310.

28 Maurus Lindermayr's Dichtungen, S. 184.

$29 \mathrm{Zu}$ den näheren Umständen der Aichkirchener Missionierung vgl. Neuhuber, „Ehrbar will man ergetzt werden ...", S. 24-29. 
oberösterreichische Lutheraner nach Siebenbürgen verbracht. ${ }^{30}$ Lindemayrs Aufgabe als ,missionarius' war eine durchaus schwierige, denn die lutherischen Bauern machten es wie er in einem Brief an seinen Abt berichtet - „endlich so derb, daß es nicht ärger seyn kunte. " ${ }^{31}$ Tatsächlich trat die kryptoprotestantische Bewegung in der Hoffnung auf Hilfe durch den Regensburger Reichstag immer offensiver mit ihrer Forderung nach Religionsfreiheit an die Öffentlichkeit und wiederholt kam es zu Zusammenstößen. Sichtlich eingeschüchtert vom selbstbewussten Auftreten seiner Gegner, empfiehlt deshalb Lindemayr ein konsequentes Vorgehen, da seine Sicherheit wie auch die der katholischen Bevölkerung nicht mehr gegeben sei. Sein Lied formuliert geläufige Vorwürfe einer 200-jährigen Tradition: Die protestantische Lehre verkünde einen allzu leichten Weg zu Gott, der der Bequemlichkeit des Menschen verpflichtet sei, sie entwerte das Mysterium von Wandlung und Beichte, sei sich uneins bezüglich der Sakramente, verkenne die Bedeutung der Heiligen und sei nur deswegen so begehrt, da sie den Menschen nach dem Mund rede und jeder sie zu begreifen glaube.

1

Wie lusti gehts izt auf dä Welt

Giebt alleweil was neus

Znächst habm sö d' Baurn bei 's Nachbärs Feld

Väsamelt Duzetweis

Aft schlichäns haimli in ä Haus

Dort säß ä Bauersmann

Der lögt ien d luthrisch Bibel aus

Alls hört 'n fleissi an.

3

Dö gueten Werk und d' Fastenzeit

Dö habn s' glei z'erst wegpuzt

Mä plagt nur glei umsonsten d' Leut

Und z'lözt het alls nix gnuzt;

Der Petä, der Äpostel Fürst

Der hat viel Fasttäg gmacht

Der Luthä ißt viel liebä d Würst

Hats wieder all abracht

5

Dö zehn Geboth, Dö habm mä schon

Oft grossi Engsten gmacht

Izt wann ichs ä nöt halten kann

Ists gnue, wann ichs betracht.

Izt mag i stolpern, wie i will

So schad mä do kain Sünd

Wann i nur nöt in Glaubn vähüll

Bin i ä säligs Kind.

[...]
2

Dö Prödi war, wie schön nur glei

I hab von Herzen glacht

Den schmalen Weg ins Himmelrei

habns izt viel breäda gmacht

Dö Dorn und Distel, dö ain z’ krailn

Die gfärling Stein, und Stög

Dö sinsten Dort ain oft väwailn

Dös Gfräßt habns saubä weg.

4

Ganz leichtli kann mä izt spazirn

Bis zue der Himmelsthür

Mä kann so leicht si nimmä irren

Kain Gadern steht mehr für

Willst einkehrn, geh schön frisch und toll

Es gät Wirthshäusä gnue

Dort frißst und saufst Di plunzenvoll

Aft fahlst in Himmel zue.

6

Die haimli Beicht, und d' Sünden sagn

Wo d' Menschä und wo d Buebm

Schon vor dä Fasten Sori tragn

Dös räffens weg wie d Ruebm

Izt Derfst nur sagn, hab gsündigt Herr

Es thuet mä schmerzli weh

So sagt ä, thues fein nimmer mehr

Bist weisser als dä Schnee.

30 Martin Scheutz: Die lutherischen bauren machen es endlich so derb, daß es nicht ärger seyn kunte - Geheimprotestantismus und Transmigration im Schatten der Benediktiner von Lambach um die Mitte des 18. Jahrhunderts. In: Klaus Landa/Christoph Stöttinger/Jakob Wührer (Hg.): Stift Lambach in der Frühen Neuzeit. Frömmigkeit, Wissenschaft, Kunst und Verwaltung am Fluss. Tagungsband zum Symposion im November 2009. Linz: OÖLA 2012, S. 391-427, S. 311-349.

31 Brief vom 30. Mai 1752, zitiert nach Neuhuber, „Ehrbar will man ergetzt werden ... “, S. 64f. 
15

Ist das nit recht ä himlisch lebn

Und Do ganz leicht dabei

Derfst nix um Papst und d' Pfaffen gebn

Bist Sünd und Gwissen frei;

Kimst abä zu der Himmelsthür

Herbei von Luthersland:

So spreizt der Toifel d Larwend für

Und macht di kontrawand
16

Ei nun so sei's, izt wern mä schaidn

Bleibn d Schaaf, und d Böck allain

Izt kinnän d Schaaf sö bössä waidn

Dä Schaafstall wird izt rain.

Bleibt nur ain Gott, ain Glaubn: so wird

Ain Hirt, ain Schaafstall sein

Drum spört mä d rauding Schaaf, und Hirt

Zsam in än Bockstall ein. ${ }^{32}$

1,3 Znächst] kürzlich, unlängst 2,5 z'krailn] zerkratzen 2,7 väwailn] (hier:) aufhalten, verzögern 2,8 Gfräßt] eig. (Futter-)Abfall: ärgerliche, unnütze Sache 3,8 abracht] abgeschafft 4,4 Gadern] Absperrung vor Ein- und Durchgängen 4,7 plunzenvoll] vollgestopft wie eine Blunze (Blutwurst), randvoll 6,1 haimli Beicht] heimliche Beichte, i. e. Ohrenbeichte (von den Protestanten lange Zeit bekämpft) 6,3 Sori] Sorge 6,4 räffens weg] wegräffen: ausreißen 15,7 Larwend] Bretterverschlag 15,8 kontrawand] (zu franz. contrebande: Schmuggelware) ungesetzlich 16,1 wern mä schaidn] werden wir trennen 16,7 rauding] räudigen

Tatsächlich wurden in den nächsten Jahren aus Aichkirchen zumindest 23 Erwachsene und Kinder exuliert. Das harte Vorgehen der Behörden zeigte Wirkung bei den verbliebenen Protestanten, die ihren Glauben nun bis zum Toleranzedikt wieder im Verborgenen lebten bzw. zum Katholizismus konvertierten. Vielleicht wurde ja Lindemayrs Lied nach der Kundmachung des Toleranzpatents reaktiviert, als Flugschrift verbreitet und so einer breiteren Öffentlichkeit vorgestellt. Dem Autor, der bis zuletzt vehement gegen die Legitimierung der Protestanten im Habsburgerreich Stellung bezog, wurden auch andere antilutherische Lieder zugeschrieben, die als Flugblätter im Umlauf waren. Zwei dieser Pasquille, Ich weis was neus, was ich enk will sagn und Zu Alkofen da wollens die Straßkapelln haben, teilt der protestantische Aufklärer Friedrich Nicolai (17331811) in seiner wirkungsmächtigen Beschreibung einer Reise durch Deutschland und die Schweiz im Jahre 1781 mit aufrichtiger Entrüstung mit. Sie sind ihm Belege dafür, dass „die Reformation in Österreich [...] das Werk des Kaisers“ sei und nur durch seine unmittelbare Macht gegen die „katholische Klerisey“ verteidigt werden könne. Diese Schmählieder würden „auf einen halben Bogen gedruckt, öffentlich verkauft, und in vielen österreichischen Städten und Dörfern, besonders in Oesterreich ob der Ens, wo die mehresten Protestanten wohnen, öffentlich abgesungen [...], um den Widerwillen gegen die Protestanten zu unterhalten und zu vermehren“. ${ }^{33}$

1

Ich weis was neus, was ich enk will sagn,

dö Bauern im Landl thun sö berathschlagn,

den Glaubn thuns verlaugna, thun lutherisch wern,

i wais nöt zum Plunda, was no draus wird wern.

2

Zu Wels beym Geimayr da kommens zusamm,

da thuen sos einschreiben mit Tauf= und Zunam,

32 Lindemayr, Dialektlieder, S. 189-191, $195 f$.

33 Friedrich Nicolai: Eine Untersuchung der Beschuldigungen, die Herr Prof. Garve wider diese Reisebeschreibung vorgebracht. [Anhang zu:] Friedrich Nicolai: Beschreibung einer Reise durch Deutschland und die Schweiz, im Jahre 1781. Nebst Bemerkungen über Gelehrsamkeit, Industrie, Religion und Sitten. 12 Bde. Bd. VII. Berlin und Stettin: Nicolai 1786, S. 125. 
empfangens ganz freundlich, und wünschen enk Glück, das dank enk der Teufel, ich halts gar nöt mit.

3

Auftragens enk sFressen, dö Gänß schmeckt ma wohl, habn Wein dazu gsoffen, seynd worden sternvoll, oft habns sös haimgführt, wie d'Säu auf den Wagen, habs nie ä so gsehen, kanns warlä wohl sagen.

4

In Samarey ist ä Weber, der ist der Pastor, der kann gar gut predigen, und stellt eins gleich vor, daß sie das wahre Licht habn, und nacher ists aus, aft steigt von der Kanzel die Weberfilzlaus.

5

$\mathrm{Daß}$ sie das wahre Licht haben, wies glauben und sagen, sie habens aus allerhand Länder z'samtragen, sie sehen aufgehen den helliechten Stern, weil ihr Martin Luther hat than in d'Latern. 6 Jetzt habns no kain Templ und a kein Betthaus, geht kainer in Kirchä, bleibn alle zu Haus, zu Haus habens a Predig, und a falsche Lehr, vom Teufel und Luther kommt alles daher. 7

Die Bibel thuns lesen als wie a klainer Bue, mein Bruder es ghört noch was mehrers dazu, thun d'Bibel verfälschen, zletzt glaubts kainer mehr, thun d'Heiligen verachten, und lassen ien kain Ehr. 8 Ich will nur gern sehn, ob sie so wern bleiben, es wern halt das Gspiel aufs höchste no treiben, bis dä Kaiser wird sehen, das Ding ist nöt recht, aft meine liebe Baurn wirds seyn mit enk schlecht. ${ }^{34}$

1,1 enk] euch 1,2 Landl] volkstümliche Bezeichnung für das oberösterreichische Kernland, etwa zwischen Wels, Vöcklabruck und Gmunden 1,4 zum Plunda] Bekräftigungsfloskel 2,1 Wels] oberösterreichische Stadt an der Traun Geimayr] Wirthaus in Wels, im Dezember 1781 Sammelpunkt der Protestanten zur Registrierung 3,3 oft habns sös] dann haben sie sie 4,1 Samarey] St. Marien (Dorf südlich von Linz) 4,4 aft] dann

Die beiden Lieder von bescheidener literarischer Qualität stammen sicher nicht von Lindemayr; sowohl inhaltliche wie formale Gründe sprechen deutlich gegen seine Autorschaft. Dass der Lambacher Mönch von Nicolai genannt wird, unterstreicht jedoch seine Bekanntheit als Verfasser von Schmähgedichten im Dialekt mit Protagonisten aus dem bäuerlichen Umfeld. Gerade in den Anfängen der freien Religionsausübung scheinen viele davon im Umlauf gewesen zu sein, um gegen den Übertritt zum evangelischen Glauben Stimmung zu machen und den unveränderten Vorrang der katholischen Kirche herauszustreichen. Spottlieder wie das gleichfalls im oberösterreichischen Raum entstandene Heundt mues ich enkh ja nu was neues däzöln belegen eindrucksvoll die anhaltende Diskriminierung der, Akatholischen', indem es über das fehlende Geläute 
der evangelischen Gotteshäuser, die bis 1848/49 nicht als Kirchen kenntlich gemacht werden durften, lästert.

1

Heundt mues ich enkh ja nu was neues däzöln:

was dö Lutherrischen Bauern: von kaeisser habm wölnt:

er sol ihen nur ein glockhen Beschern:

er sols nur erlauben sö zalns ja ganz gern:

2

Der kaeissä der Binst sich und denkht was ist das:

drauf Last er ihnen giessen ein glokhen von glass:

ein Eyssenen schwenkhl den henkht er ihnen drein:

da kinäns Bräff Leuthen, Bräff singä und schrein:

3

Gehts Meini Lutheraner das ding ist recht dol:

weils habt ein glokhen das gfalt enckh recht wohl:

daeits aber nit gar zu starkh leitn und ziegn:

das eng nicht der schwenkhl, die glokhn duet zkliemb.

4

Wan glokhen dät bröchä: was wär das für ein löbm:

was wurds den öss nachä mit den schwenkhl anhöbm:

der schwenkhl älaein der klingt ä nimermehr:

oft wärds dö altn nahrn: als wie halt vorher: ${ }^{35}$

1,1 enkh] euch däzöln] erzählen 1,2 habm wölnt] haben wollten 2,1 Binst] Schreibversehen für ,bsint 2,4 kinäns] können sie 3,3 daeits] tut 3,4 duet zkliemb] tut zertrümmern 4,2 öss] ihr anhöbm] anfangen, beginnen

\section{Aus dem Kontext der Predigtkritik im Josephinismus}

Es kann nicht verwundern, dass die katholische Seite im Glaubenskampf massiv auf regiolektale Waffen setzte. Schon in den Jahrzehnten davor finden sich in der katholischen Homiletik umgangssprachliche und dialektnahe Formulierungen zuhauf, um das großteils illiterale Zielpublikum zu erreichen. Noch in den für den überregionalen Buchmarkt von Autor und Drucker überarbeiteten barocken Sammelbänden von Predigt- und Erbauungsliteratur ist dieses Element einer dezidiert regionalen Oralität, die die performativen Bedingungen der Darbietung und Wahrnehmung geprägt hat, unübersehbar. Das homiletische Ziel einer seelsorgerischen Ausdeutung der christlichen Heilslehre forderte um 1700 den Einsatz aller sprachlich-inszenatorischen Mittel, die die Lebenswirklichkeit der Adressaten trafen und literarisch verwerteten. Als größter Meister dieser Popularisierung der Kanzelrhetorik gilt bis heute der Augustinermönch und Wiener Stadtseelsorger Abraham a Sancta Clara (Ulrich Megerle, 1644-1709), dessen wortgewaltige volkstümliche Predigten sich vor allem an die städtische Mittelschicht

35 Bayerische Staatsbibliothek, Cod. germ. 7340 (Stubenberger Gesängerbuch), Teil 2, S. $45 f$. 
wandten. ${ }^{36}$ Wie sehr auch seine Literatursprache noch von Mündlichkeitsmerkmalen geprägt war, zeigte bereits Curt Blanckenburg. ${ }^{37}$ Tatsächlich Dialektales findet sich im Schriftlichen vor allem im Wortschatzbereich; phonetische, morphologische und syntaktische Eigenheiten begegnen uns darüber hinaus auch in vielen zitierten Sprichwörtern und Volksliedstrophen, die sich der stilistischen Überformung bei der Drucklegung entzogen und erahnen lassen, wie stark sich die gesprochene Predigt an den Sprachgewohnheiten des ,gemeinen“ Volks orientierte. ${ }^{38}$ Noch ganz der „Psychodynamik der Oralität“ ${ }^{39}$ verpflichtet sind auch die beliebten Stilmittel der Redundanz und Bildhäufung, wie sie etwa in einer Strafpredigt gegen übermäßiges Trinken zur Anschaulichkeit und Komisierung auf Basis gängiger Kinderreime eingesetzt werden:

damalen wann Herodes der König einen solchen Rausch hat von Wein / daß er

Ein Kachl für ein Bier-Glaß/
Ein Mehl-Sack für ein Wein-Faß/
Ein Kersch-Baum für ein Besen-Stihl.
Ein Flederwisch für ein Wind-Mühl/
Ein Katz für ein Wachtl/
Ein Stärl für ein Schachtel/
Ein Hackbretl für ein Löffl/
Den Hänsel fürn Stöffl/

anschaut / dazumal ist Gelegenheit / wann ihm die Augen gläntzen wie ein glässener Wammes Knopff / wann ihm die Wangen aussehen wie ein Preußisches Leder / wann ihm das Maul säffert wie ein schmutziger Faum-Löffel / wann ihm die Händ zittern wie der Schweif von Bachsteltzen / wann ihm die Füß wancken / wackeln wie ein schwache Haßl-Nuß-Stauden / dazumal wird Gelegenheit seyn/wann Herodes wird ein Narr seyn / wann wird aber das geschehen? ${ }^{40}$

Kachl] Nachttopf, Nachtgeschirr Stärl] Star (Diminutiv) säffert] sabbert, geifert Faum-Löffel] Schaumlöffel, Schaumkelle

Viel stärker als die protestantische Kanzelrede ist die gegenreformatorische Predigt an das Konzept der kirchlichen Autorität gebunden. ${ }^{41}$ Erst in der Auslegung durch den Prediger offenbare sich der eigentliche Gehalt der göttlichen Rede. Dementsprechendes Gewicht kam deshalb der Inszenierung und unterhaltsamen Präsentation durch die Sprecherinstanz zu, deren persönliche Perspektive zur vermittelnden Richtschnur der verhandelten Themen wird. Die Selbstdarstellung des katholischen Kanzelredners umfasste demgemäß ein breites Rollenrepertoire und orientierte sich nicht zufällig an

36 Vgl. Franz M. Eybl: Abraham a Sancta Clara. Vom Prediger zum Schriftsteller. Tübingen: Niemeyer 1992. Allgemein zur katholischen Homiletik: Urs Herzog: Geistliche Wohlredenheit. Die katholische Barockpredigt. München: Beck 1991.

37 Vgl. Curt Blanckenburg: Studien über die Sprache Abrahams a S. Clara. Ein Beitrag zur Geschichte der deutschen Drucksprache im 17. und 18. Jahrhundert. Halle (Saale): Niemeyer 1897.

38 Vgl. Nagl/Zeidler, Deutsch-Österreichische Literaturgeschichte I, S. 633ff., 650.

39 Vgl. Ong, Oralität und Literalität, S. 37f.

40 Abraham à S. Clara: Abrahamisches Bescheid-Essen Soll man wohl nicht vergessen / Er hat es hinterlassen / Mit gfallt es über die massen / Wer nicht will glauben diß / Steck Brillen auf und liß. [...] vorgesetzt und aufgetragen von P. Fr. Alexandro à Latere Christi [...]. Wien, Brünn: Lehmann 1717, S. 330. Textbausteine finden sich noch im Anhang zu Des Knaben Wunderhorn (vgl. Clemens Brentano: Sämtliche Werke und Briefe: Des Knaben Wunderhorn. Lesarten. Stuttgart [u. a.]: Kohlhammer 1978, S. 573).

41 Vgl. Eybl, Abraham a Sancta Clara, S. 214ff. 
performativen Techniken des Theatralen zur Unterhaltung und Belehrung seines sozial breit gestaffelten Publikums. Ganz gezielt wurden dessen Emotionen stimuliert; auch das Lachen war nicht verpönt, solange es der moralischen Unterweisung dienlich war. Das zeigt etwa ein derbdrastisches Predigtexempel Leo Wolffs (1640-1708), eines Zeitgenossen Abraham a Sancta Claras. Die kleine Szene mit dialektaler Figurenrede und Pointe aus der Predigtsammlung Rugitus Leonis (1702) des aus München stammenden Franziskanerpaters sollte die Tugend- und Vorbildhaftigkeit Saras als Abrahams Gattin herausstreichen, indem der Zuhörerschaft das andere Extrem als Witz vor Augen geführt wurde:

Gleichwie jene Bäurin ist beschaffen gewesen / als dieser ihr Mann / der Baur mit sambt seinem Knecht zu Morgens in aller Fruhe in den Wald umb Holtz gefahren / in dem Heim-Weeg aber geschehen / daß der geladene Wagen in einem Hohl-Weeg umbgefallen / und also den nebenher gehenden Bauren erschlagen hat; Ist der Knecht von dem Wagen und Pferdten nach Haus geloffen / jämmerend und schreyend: O wehe! O wehe! O wehe! O wehe! Die Bäurin voll Schrecken hebt die Händ auf / und fragt: Was ist gschehä? Bods Regiment! Hänßl / was ist gschehä? O wehe! O wehe! O daß Gott erbarm! Der wagen voll Holtz ist im Hohl-Weeg umbgfallen / und hat den Baurn todt gschlagn! draust ligt er / ist Mauß-todt / O wehe! O wehe! O du Narr/ (sagt sie) daß dirs GOtt verzeyh / hast mich nicht erschröckt / i hab gmeint / es sey ein Rad / oder gar der Wagn brochä. Närrischer Hänßl / thue no nit sodä! ${ }^{42}$

thue no nit sodä!] Tu doch nicht so! (,no' wohl fälschlich für ,do', ,sodä: verstärktes ,so')

Mit Einlagen wie diesen konnte sich Wolff der Aufmerksamkeit seiner Schäflein sicher sein. Institutionalisiert waren komische Predigtteile zum Osterfest, wo der ,risus paschalis' (Ostergelächter) als fester Bestandteil des katholischen Brauchtums seit dem Mittelalter die Freude über das Ende der Fastenzeit und die Auferstehung des Herrn signalisieren sollte. ${ }^{43}$ Trotz vielfacher theologischer Anfeindungen nicht nur aus dem protestantischen Lager konnte sich die Tradition des ,Ostermärleins', das über das Possenhafte das Sakrale affirmierte, bis weit ins 18. Jahrhundert halten. Die Lacher auf seiner Seite hatte sicher auch Clemens von Burghausen (Clemens Harderer, 1693-1732/34) mit seinem in den narrativen wie dialogischen Teilen teils dialektal gehaltenen Gedicht / und geschicht anstatt eines Oster-Märl, in dem der beliebte oberbayerische Kapuzinerprediger eine burleske Szene um den Bauern Jacka mit eingelegten Anekdoten und Witzen wie folgendem anreicherte:

Es hatte nun diser Baur seinen jüngsten Sohn bey sich / der schmeichlete dem Vatter / daß er einen so vortrefflichen Spitz-Bart habe / und wolte zu ihm sagen / sein Bart sehe aus / wie ein Bocks-Bart / doch getrauete er sich nit dis zu sagen / sonder sprache: Vattä / Vattä / du hast än Bart als wie ä Löw. Mein Kind / sprach der Vatter: du hast ja kein Löw nie gesehen. Jo / sagt der

42 Leo Wolff: Rugitus Leonis, Geistliches Löwen-Brüllen. Das ist: Eingriffige Sonntags-Predigen / Durch ein gantzes Jahr. Aus klaren Sprüchen der H. H. Vätter / raren Antiquitäten / schönen Symbolischen Gleichnussen / bewehrten und beweglichen Historien etc. zum Schröcken und Trost der Sünder verfasset / auch mit unterschidlichen Registern wohl versehen. Augsburg: Georg Schlüters 1702, S. $78 \mathrm{f}$.

43 Vgl. Elfriede Moser-Rath (Hg.): Predigtmärlein der Barockzeit. Exempel, Sage, Schwank und Fabel in geistlichen Quellen des oberdeutschen Raumes. Berlin: de Gruyter 1964. - Werner Röcke: Ostergelächter, Körpersprache und rituelle Komik in Inszenierungen des ,risus paschalis‘. In: Otto Langer/Klaus Ridder (Hg.): Körperinszenierungen in mittelalterlicher Literatur. Berlin: Weidler 2002, S. 335-350. 
Sohn / da auf der Schantz gehen etliche. Das seynd Böck / und kein Löwen. O! das hab ich ä gemeint / sagt der Sohn. ${ }^{44}$

Als Motivreservoir der Ostermärlein dienten häufig Schwänke oder Komödien, die ins Narrative transferiert wurden, so etwa in der Annehmliche[n] Geschicht aus Andreas Strobls (1641-1706) Sammlung Ovum Paschale Novum Oder: Neugefärbte Oster-Ayr (1710). Dieses Oster-Mährl des Laufener Kollegiatskanonikus ist eine höchst anschauliche Zusammenfassung des ,rusticus imperans'-Motivs, die zwar auf Jakob Bidermanns Prosaversion in Utopia (1640) fußt, in den dialektalen Anklängen jedoch interessante Parallelen zu Elensons populärer Wandertheaterfassung aufweist (siehe Kap. 4). Es ist freilich nur ein Beispiel unter vielen, die das unterhaltsame Moment in der Kanzelrede hochhielten und eine regionalsprachliche Ausgestaltung in der Praxis zumindest erahnen lassen. Manchmal bleiben diese Regionalismen auch in der Druckfassung als volksnahe Inszenierungsmittel erhalten; so belegt die folgende Stelle aus Christoph Selhamers (1636-1708) Sammlung von ,Gei-Predigen' (d.h. ländlichen Predigten) Tuba rustica (1701), dass in vereinzelten Fällen sogar dem leidenden Messias selbst dialektale Worte in den Mund gelegt werden konnten:

als aber die frommen Weiber häuffig ihre zäher vergossen / da er sein groben Creutz-Block auf den Calvari-Berg geschlept, da wolt er nicht / daß sie vil pflenen solten. Nolite flere, schrye er zuruck. Was habts hinter mir für ein Wimslen? Hörts auf das Wuislen / das Hechetzen / das Wainen. ${ }^{45}$

zäher] Tränen Nolite flere] (lat.) weint nicht Wimslen] Wimmern Wuislen] Winseln Hechetzen] Schluchzen

Gegen Mitte des 18. Jahrhunderts aber hatte sich - inspiriert von der jansenistischen Reformbewegung und der protestantischen Aufklärung - auch in den katholischen Ländern des Heiligen Römischen Reichs Deutscher Nation ein Erneuerungsdiskurs etabliert, der die religiösen Ausdrucksformen der Gegenreformation kritisch hinterfragte und eine Neuausrichtung der Kirche nach rationalen Leitbildern einmahnte. Sinnentleerten Frömmigkeitsformen, Profanierungen liturgischer Elemente, Ausartungen der Volksfrömmigkeit bzw. der Prunkentfaltung als Selbstzweck und anderen Auswüchsen des Barockkatholizismus wurde nun auch von theologischer Seite der Kampf angesagt. Im Habsburgerreich setzte der Wiener Erzbischof Kardinal Johann Joseph von Trautson 1752 mit einem Hirtenbrief ein vielbeachtetes Zeichen für einen Reformprozess, der sich besonders gegen die Missstände im Predigtamt wandte. ${ }^{46}$ Dieses solle sich auf die Vermittlung der Heilslehre, nicht auf Heiligengeschichten, Ablässe, Wallfahrten oder

44 Clemens von Burghausen: Seraphisch Wald-Lerchlein Ansingend Hohe / und Nidere / Das ist: Hundert Sonn- und Feyertags-Predigen / An sowohl hoch- als nidere Stands-Persohnen / Stadt- und Dorffs-Leuth. [...] Opus posthumum. Zweyter Jahr-Gang. Augsburg: Martin Veith 1734, S. 132.

45 Christoph Selhamer: Tuba Rustica. Das ist: Neue Gei-Predigen / Worinnen auf alle Sonntäg des Jahrs Wundersame Lieb- und Lebens-Thaten / Deren / So vor disem fromb und heilig auf dem lieben Gej gelebt / solches auch mit ihrem hell-glantzenden Tugend-Wandel ansehnlich erleucht / Predig-weiß verfasset / mit sittlicher Glaubens und Lebens-Lehr reichlich eingericht / den lieben Bauren zu sonderbarem Trost / in gegenwärtige Form gebracht/ordentlich vorgetragen werden. [... ] Im Jahr Christi/ 1701, S. 308.

46 Vgl. Peter Wiesinger: Dialekt im Urteil der Aufklärung. Über Wiener Dialektpredigten von 1782. In: Albrecht Greule [u. a.] (Hg.): Die bairische Sprache. Studien zu ihrer Geographie, Grammatik, Lexik und Pragmatik. Festschrift für Ludwig Zehetner. Regensburg: Ed. Vulpes 2004. (Regensburger Dialektforum 5) 
Gnadenbilder konzentrieren und dürfe das Volk nicht gegen die Autoritäten aufwiegeln; vor allem aber wettert Trautson gegen Prediger, die „den Predigt-Stuhl zu einem SchauPlatz, und das Wort GOttes, wovor man erzittern sollte, zu einem Gelächter machten, [... und den muthwilligen gemeinen Pöbel bis zum Laut-Lachen erlustigten " ${ }^{\text {47 }}$. Um einer derartigen „Entheiligung des Göttlichen Worts“ ${ }^{48} \mathrm{zu}$ begegnen, setzte der spätere Kardinal auf eine bessere theologische und rhetorische Schulung, die nicht zuletzt auf eine elaborierte, moderne deutsche Sprache achtete.

Als Norm galt seit 1750 auch im Habsburgerreich Johann Christoph Gottscheds Grammatik, wie er sie in seiner Grundlegung einer deutschen Sprachkunst (1748) auf Basis des ostmitteldeutschen Sächsischen entwickelt hatte. Mit dieser dezidierten Abwendung von der oberdeutschen Schreibsprache ging in den folgenden Jahrzehnten eine drastische Abwertung des Dialekts als schichtenübergreifende Alltagssprache einher. ${ }^{49}$ In der Öffentlichkeit den mundartlichen Ausdruck zu wählen, galt nun für die gebildeten Schichten zunehmend als unschicklich. Die Elitenschmieden übernahmen rasch die Vorgaben und richteten ihren Deutschunterricht nach Gottscheds Regelwerk aus. An der Ritterakademie des Stifts Kremsmünster etwa engagierte sich der Konventuale Rudolph Graser, der mit dem Leipziger Professor im Briefwechsel stand, ${ }^{50}$ für Gottscheds Sprachlehre. Auch seiner Vollständigen Lehrart zu Predigen (1768) - ein richtungsweisendes Werk der Reformhomiletik ganz im Sinne Trautsons - legte er sie zugrunde. Für die normale Sonntagspredigt, zumal auf dem Lande, empfahl Graser die „natürliche Schreibart“, die allerdings nicht „pöbelhaft, niederträchtig, grob, bäurisch “ ${ }^{51}$ sein dürfe. Freilich war es für die Landgeistlichen in der Praxis nicht einfach, ein hohes, standardnahes Sprachniveau zu halten. In der Predigtsituation empfahl es sich deshalb, das geschriebene Konzept an die Hörgewohnheiten des großteils ungebildeten Publikums anzupassen, wollte man verstanden werden.

Ganz in diesem Sinne argumentiert auch Maurus Lindemayr, der zu Grasers Praktischer Beredsamkeit der christlichen Kanzel (1769), einem praxisorientierten Kompendium vorbildlicher Predigten mit exemplarischen Analysen, neben sechs eigenen Arbeiten auch ein Vorwort, an die jungen Herren Prediger' beisteuerte. Der Lambacher Mönch, selbst ein berühmter Redner, nützte die Gelegenheit zu einer Spezifizierung seiner Vorstellungen einer wirkungsvollen Kanzelrhetorik; diese erfordere eine „Einfalt des

S. 143-161. - Ulrike Katrin Freitag: Geputztes Blumwerk und buntschäkkiger Wörterkram. Sprachkritik in den Wöchentlichen Wahrheiten (1782-1784). Frankfurt a. M. [u. a.]: Lang 2007. (Schriften zur deutschen Sprache in Österreich 38).

47 [Johann Joseph von Trautson]: Hirten-Brief an seine Geistlichkeit, und insonderheit die Prediger / in seinem ersten Lateinischen Laut, und in das Teutsche übersetzt. [Wien: oV.] 1752, f. 4v.

48 Ebda., f. 5r.

49 Vgl. Wiesinger, Das Verhältnis von Dialekt und Schriftsprache.

50 Vgl. P. Konrad Kienesberger OSB: Der Gottschedianer P. Rudolf Graser OSB und seine Fluchtreise nach Paris (1760/61) im Spiegel des überlieferten Briefwechsels. Eine Episode aus der Zeit der Aufklärung in Kremsmünster. In: Studien und Mitteilungen zur Geschichte des Benediktinerordens und seiner Zweige 109 (1998), S. 291-464.

51 Rudolph Graser: Vollständige Lehrart zu predigen oder wahre Beredsamkeit der christlichen Kanzel nach der Vorschrift der berühmtesten Redner Frankreich und Deutschlands in gründlichen Regeln. Augsburg: Matthäus Rieger und Söhne 1768, S. 617. 
Ausdrucks“, der sich nach den Kenntnissen und der Rezeptionsfähigkeit der Zuhörer richtet, eine „Freimüthigkeit“ ${ }^{52}$, die Dinge beim Namen zu nennen, und den Verzicht auf theatralischen Pathos des Redners. Kritik übt er am Gebrauch der ,sächsischen Schriftsprache durch österreichische Prediger, denn es sei gewiss, „daß man, da hier in Österreich, fast leichter Pferde und Ochsen, auf sächsische Rüfe, als die Bauren, auf eine sächsische Sprache abrichten könne " 53 . Und so empfiehlt er der jungen Predigergeneration: „Im Schreiben, sollen wir Sachsen; im Predigen aber, Oesterreicher seyn “ 54 . Der berühmte Dialektdichter meinte damit allerdings wohl kaum, dass von der Kanzel tatsächlich mundartlich geredet werden sollte, sondern dass man die regionale Herkunft im Sprechduktus nicht verleugnen und die Vielfalt der sprachlichen Möglichkeiten nützen sollte. Kurz vor Lindemayrs Tod sollte die Frage der Legitimität von dialektaler Rede in der Kanzelrhetorik mit großer Vehemenz und unter anderen Vorzeichen noch einmal aufgeworfen werden.

Angestoßen wurde dieser Diskurs auf publizistisch-öffentlicher Ebene durch das Erscheinen einer Schriftenreihe, die bewusst Zündstoff lieferte: die Wöchentlichen Wahrheiten für und über die Prediger in Wien. Herausgegeben wurde die Wochenschrift durch den Schriftsteller und Freimaurer Leopold Alois Hoffmann (1748-1806), der nach einer Karriere als Universitätsprofessor für deutsche Sprache in Pest und Wien vor allem durch seine Spitzel- und Denunziationstätigkeit in unrühmlicher Erinnerung blieb. Sein aufklärerischers Zeitschriftenprojekt, nach eigenen Angaben „[b] earbeitet von einer Gesellschaft Gelehrter“"55, rezensierte Predigten im Umkreis Wiens, teils mit Wiedergabe des Wortlauts. Vorbildliche Predigten wurden wohlwollend erläutert, schlecht beurteilte Predigten kritisch demontiert und als Negativbeispiele an den Pranger gestellt. Lob wie Kritik betrafen sowohl Inhaltlich-Argumentatives als auch Sprachliches und Formales. ${ }^{56}$ Bereits in der ersten Ausgabe seiner Wöchentlichen Wahrheiten Mitte April $1782^{57}$ spricht Hoffmann wörtlich von einer Fehde und erklärt einleitend seine programmatischen Ansatzpunkte und Beweggründe, indem er die einflussreiche, oft unterschätzte Stellung des Predigers als „Gesandter Gottes“ hervorhebt, dessen Mund „fast allgemein

52 Rudolph Graser: Praktische Beredsamkeit der christlichen Kanzel, in Regeln, Exempeln, und vollständigen Mustern; mit einer Vorrede begleitet von P. Maurus Lindemayr, Benedictinern und ehemaligen Priorn zu Kloster Lambach, dermalen Seelsorgern zu Neukirchen. Augsburg: Matthäus Rieger und Söhne 1769, S. XXII.

53 Ebda., S. XXI. Zu Lindemayrs Kritik am Gebrauch der sächsischen Schriftsprache im oberdeutschen Sprachgebiet vgl. Peter Wiesinger: Die sprachlichen Verhältnisse und der Weg zur allgemeinen deutschen Schriftsprache in Österreich im 18. und frühen 19. Jahrhundert. In: Andreas Gardt/Klaus Mattheier/Oskar Reichmann (Hg.): Sprachgeschichte des Neuhochdeutschen. Gegenstände, Methoden, Theorien. Tübingen: Niemeyer 1995. (Reihe Germanistische Linguistik 156) S. 319-367.

54 Graser, Praktische Beredsamkeit, S. XXII.

55 Leopold Alois Hoffmann (Hg.): Wöchentliche Wahrheiten für und über die Prediger in Wien. Bearbeitet von einer Gesellschaft Gelehrter. Zwote verbesserte Auflage. Wien und Prag, bei J. Ferd. Edlen von Schönfeld 1782, [Titelblatt].

56 Im Zusammenhang mit dem vorliegenden Text interessant sind vor allem die Bände von 1782 und 1783. $\mathrm{Zu}$ dieser Wochenschrift vgl. Bernhard M. Hoppe: Predigtkritik im Josephinismus. Die „Wöchentlichen Wahrheiten für und über die Prediger in Wien“"(1782-1784). St. Ottilien: EOS 1989. (Studien zur Theologie und Geschichte 2).

57 Vgl. Bodi, Tauwetter in Wien, S. 129. 
für eine Quelle von Heiligkeit und Wahrheit “58 gelte. Umso schockierender sei die mangelhafte Qualität der Predigten:

Mit einem Worte: das Predigerwesen scheint so vielen ein bloßes Gedächtniswerk, eine förmliche Tagwerkerei, eine althergebrachte Gewohnheit, mit der man es halten kann, wie man will, ein Leisten, darüber jeder nach eigenem Gutbefinden seinen Schuh ziehen darf; und wie ich vorhin sagte: ein Handwerk geworden zu sein, in welches jeder nach Belieben, wachend oder schlafend, nüchtern oder besoffen, mit und ohne Kopf pfuscht, und pfuschen darf, wie und so viel er will, $-{ }^{59}$

Ideologischer Ausgangspunkt der Auseinandersetzung ist die Annahme der Aufklärer, dass die Seelsorger und Prediger maßgeblichen Einfluss auf das Volk hätten und demnach Verfügungen des Monarchen sowohl erleichtern als auch erschweren bzw. in diesem Sinne auch für die Aufklärung des Volkes wirksam sein könnten. ${ }^{60}$ Zudem sollte einer teils von der Kanzel ausgehenden Agitation gegen die josephinischen Reformen publizistisch entgegengewirkt werden. In diesem Kontext sind die am Reformkatholizismus orientierten Wöchentlichen Wahrheiten zu sehen, die das unkontrollierte, unzensierte Wirken der Kanzelredner kritisch unter die Lupe nehmen. Die ,Gesellschaft Gelehrter' (Mitwirkende sind neben Hoffmann auch Joseph Maria Weissegger und Johann Rautenstrauch) will somit als öffentliche Kontrollinstanz fungieren, um reformfeindlichen Predigten entgegenzuwirken und Prediger $\mathrm{zu}$ inhaltlichen und formellen Verbesserungen zu motivieren. ${ }^{61}$

Trautsons Nachfolger, Kardinal Christoph Anton von Migazzi, der um das Ansehen der Geistlichkeit bangte und ein Erstarken der kritischen Stimmen unter den Gläubigen befürchtete, beantragte nach dem erstmaligen Erscheinen ein sofortiges Verbot der Zeitschrift, das jedoch nicht zustande kam. Dafür aber wurde mit dem jansenistischen Theologen Marc Anton Wittola ein Vertrauensmann der Regierung in die, Gesellschaft Gelehrter' eingebunden, der sicherstellen sollte, dass das Wort Gottes in der Wochenschrift nicht infrage gestellt werde, und der für eine theologische Fundierung der Kritik Sorge trug. Nutznießer der als Entgegenkommen signalisierten Intervention war freilich die staatliche Führung, schließlich erhielt man auf diese Weise Informationen darüber, was gepredigt wurde, und konnte fallweise dem Kardinal die Verwarnung beschuldigter Prediger nahelegen. ${ }^{62}$ Auch auf Ebene der breiten Öffentlichkeit wurden die stark rezipierten Wöchentlichen Wahrheiten kontrovers aufgenommen, wie die zahlreichen Reaktionen nicht nur von politischer und klerikaler, sondern auch publizistischer Seite belegen. ${ }^{63}$ Kritik und Gegenkritik befeuerten sich gegenseitig, sodass der Wochenschrift ein reger Absatz über eine beachtliche Zeitspanne beschert war. 113 Predigtbesprechungen waren es letztendlich, die später in neun Bänden ediert wurden. Somit markieren

58 Hoffmann, Wöchentliche Wahrheiten I, S. 4f.

59 Ebda., S. $8 f$.

60 Vgl. Wangermann, Die Waffen der Publizität, S. 85f.

61 Vgl. ebda.

62 Vgl. ebda., S. $86 f$.

63 Kauffmann sieht die Wöchentlichen Wahrheiten als Auslöser für eine dritte Welle der Broschürenflut, nachdem die Schrift Über die Begräbnisse in Wien eine erste und das Pamphlet Was ist der Papst? eine zweite Welle ausgelöst hatten (vgl. Kauffmann, Es ist nur ein Wien, S. 172). 
die Wöchentlichen Wahrheiten auch eine entscheidende Entwicklung in den literarisch ausgetragenen Kontroversen dieser Zeit: „[H]ier wird punktuelle Kritik in Periodizität übergeleitet, wird ein fortdauernder Wille bekundet, den kirchlichen Diskurs im aufklärerischen Medium kritisch zu begrenzen. " ${ }^{4}$

Die Dynamik des Konflikts zeigt sich in diversen - schriftlich und öffentlich ausgetragenen - Konfrontationen. Ein instruktives Beipiel liefert der Prediger Joseph Pochlin (1735-1801), der als Lehrer der geistlichen Beredsamkeit am Wiener erzbischöflichen Seminar tätig war. ${ }^{65}$ Als Gegner der aufklärerisch-progressiven Seite wurde er aufgrund seiner konservativen bzw. reformfeindlichen Haltung rasch zur Zielscheibe der Predigtkritiker, zumal er diese noch vor dem Erscheinen der ersten, vorab angekündigten Ausgabe aufgefordert hatte, ihn bei einer seiner Predigten anzuhören und diese zu rezensieren. ${ }^{66}$ Die am 23. Mai 1782 erschienene Rezension einer Predigt, die Pochlin elf Tage zuvor in Vösendorf gehalten haben soll, ${ }^{67}$ fiel - wie zu erwarten - negativ aus und machte sich über die dürftigen Fähigkeiten und das übersteigerte Selbstwertgefühl des Gottesmannes lustig. Der derart Verhöhnte wiederum setzte sich mit der dialektalen Spottschrift Guetdunkn des Fleischhakermaster z'Vösendorf zur Wehr. ${ }^{68}$ Als Verfasser der beleidigt-polemischen Schimpftirade gibt sich Pochlin freilich nicht offen zu erkennen, auch wenn seine Autorschaft bekannt gewesen sein muss. Er verschanzt sich hinter der Figur des Fleischermeisters Bartlme Uhatzi als einem repräsentativen Vertreter seiner vom Rezensenten verspotteten „dummen “69 Vösendorfer Anhängerschaft, der seine Gedanken über die rechte Art zu predigen im (auch schriftlich umgesetzten) starken ostmittelbairischen Dialekt vorbringt. Pochlin selbst predigte zwar, wie aus der Rezen-

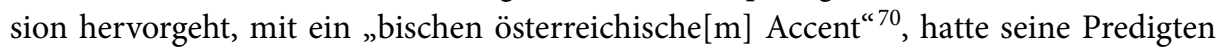
aber sicherlich konzeptionell schriftsprachlich gestaltet. Generell scheint die Annahme, in den 1780er Jahren sei es noch „durchaus selbstverständlich [gewesen], daß die Geistlichkeit und das selbst in der Domkirche St. Stephan im Dialekt predigte “71, nicht zu halten. Wäre dem so, fänden sich weitaus mehr Belege in den Wöchentlichen Wahrheiten. Auch damals waren durchgehend mundartlich gehaltene Predigten wohl eher die

64 Franz M. Eybl: Hanswurststreit und Broschürenflut. Die Struktur der Kontroversen in der österreichischen Literatur des 18. Jahrhunderts. In: Wendelin Schmidt-Dengler/Johann Sonnleitner/Klaus Zeyringer (Hg.): Konflikte - Skandale - Dichterfehden in der österreichischen Literatur. Berlin: Schmidt 1995, S. 24-35, hier S. 33 .

65 Vgl. Wangermann, Die Waffen der Publizität, S. 88f.

66 Vgl. Franz Stephan Rautenstrauch: Ueber das Betragen der Bischöfe in den k. k. Staaten, in Rücksicht der landesherrlichen Verfügungen in geistlichen Sachen. Wien: In Kommission bey Sebastian Hartel in der Singerstraße 1783, S. 17. - [Anonym]: Briefe über den gegenwärtigen Zustand der Litteratur und des Buchhandels in Oesterreich. [Zürich] 1788, S. 40.

67 Vgl. Hoffmann, Wöchentliche Wahrheiten I, S. 97-120.

68 Anregung, seine Gegenschrift mundartlich zu gestalten, dürfte die Rezension selbst geliefert haben, da Pochlin vorgeworfen wurde, seine beim Predigen verwendete Sprache sei nicht angemessen für das Vösendorfer Bauernpublikum (vgl. ebda., S. 111).

69 Ebda.

70 Ebda.

71 Peter Wiesinger: Die Stadt in der neueren deutschen Sprachgeschichte V: Wien. In: Werner Besch [u. a.]: Sprachgeschichte. Ein Handbuch zur Geschichte der deutschen Sprache und ihrer Erforschung. 3. Bd. 2. vollständ. neu bearb. u. erw. Aufl. Berlin, New York: de Gruyter 2003. (HSK 2.3) S. 2354-2377, hier 2367. 
Ausnahme, auch wenn davon auszugehen ist, dass gerade auch in religiösen Zentren die breite sprachliche Palette zwischen Basisidiom und ostmitteldeutscher Standardsprache an bestimmten Stellen effektvoll zum Einsatz kam.

Der Dialekt in Pochlins Spottschrift ist demnach als bewusst eingesetztes ästhetisches Mittel zu verstehen, als eine dem Typus Fleischhacker zugeordnete, diesen auszeichnende und stilisierende Sprechweise, die die Verspottung der gelehrten Herren aus Wien auf die Spitze treibt, wenn ihnen ein einfacher, der Standardsprache nicht mächtiger Dörfler ihr Unverständnis vor Augen hält und die Leviten liest. ${ }^{72}$ Das Werk, für das - ganz dem Zeitgeist entsprechend - die Briefform gewählt wurde, beginnt mit zwei dialektalen Zuschriften, eine an den Buchdrucker des eigenen Texts mit der Bitte um sorgfältige Erledigung der Drucklegung, die andere an jenen des Anstoß gebenden Texts mit der Bitte, den Verantwortlichen die nunmehr vorliegende Entgegnung bekannt zu machen:

so hab i glaubt, weil sö do wissen müssn, wo's wohnen, damit sö 'sAuszügl hintragn könna, i that an besten, wann i sö bittat, daß sö’s den Hernern, dö niembst kenna soll, sagtn, sö könten hietzt mein Manung drukter lesn, weil 's ihna meine Gedankn nit a so habn wolln eindruckn lassn, und daß 's ihna sagten, weil i in Pader Puchlin sain Gnadnbrief g'lesen hab, daß 's lauter arme Narn in der G'selschaft sayn ${ }^{73}$

do] doch Auszügl] kleine Schrift, eig. Auszug aus dem Rechnungsbuch eines Handwerkers Hernern] Herren niembst] niemand hietzt] jetzt drukter] gedruckt a so] verstärktes ,so', genau so

Danach erst folgt der an die Herausgeber der Wöchentlichen Wahrheiten gerichtete Textteil, eine spöttische Erwiderung auf das „dumi Zeigs“ ${ }^{74}$ und die Kritikerschelte, die bis zur Drohung geht: Die Wiener sollten das nächste Mal doch lieber in der Stadt bleiben, denn „wans nomal kuma, so könas d'Polizey a mitnema, sonst möcht ihna der Landluft, der ihna, wie's sagen, lieber als Predi gwesn ist, Kreuzweh machen, dan es möcht just ein scharfer Luft gehn. “75 Das Verhalten der angesprochenen „Herner“ wird mit denselben Argumenten kritisiert, wie sie auch andere konservative und aufklärungskritische Verteidiger der angegriffenen Geistlichkeit, wie M. Wild oder Patricius Fast, in ihren Gegendarstellungen verwendeten. Dass sie ihre Namen nicht preisgeben, mache sie verdächtig; mit den Verunglimpfungen suche man nur den ökonomischen Erfolg; vor allem aber sei die rezensierte Predigt falsch dargestellt, teils aufgrund mangelnder Gedächtnisleistung („weils ihna aus der Predi niks merken habn könna“), teils durch bewusste

72 Dass der Dialektgebrauch auf bestimmte Schichten beschränkt sei, soll hier allerdings nicht impliziert werden - jedoch wäre in diesem Fall eine schriftsprachliche Gestaltung konventionsgemäß, wodurch die Unkenntnis des angemessenen Sprachgebrauchs bzw. das Unvermögen, diesen anzuwenden, die Stilisierung erlaubt. Eine detaillierte Analyse des Dialektgebrauchs in Pochlins Schrift gibt Freitag, Geputztes Blumwerk, S. 95-170.

73 [Joseph Pochlin]: Guetdunkn des Fleischhakermaster z’Vösendorf über d'hoglerti G’selschaft der Predigerkridi z'Wien, di si naili übern Pader Puchlin herg'macht hat, mit ainer Zuschrift an Buchdruker Schmid und ain klain Schreib’n an gnädig'n Herrn Buchdruker bein Karnertor. Selbst aussagebn, g'offenbart und ins Licht g'setzt von Bartlme Uhatzi, Fleischhakermaster z’Vösendorf. Wien: Mathias Andreas Schmidt 1782, S. $8 f$.

74 Ebda., S. 12.

75 Ebda., S. 14. 
Wirklichkeitsentstellung („daweil bringens lautr Lugn übr d'Prediger auf ${ }^{\text {“76) }}$ ). Entgegen der Behauptungen der Kritiker habe die Predigt Pochlins sehr wohl ihren Zweck erfüllt und sei exakt auf das Zielpublikum zugeschnitten gewesen:

Wer hats g'sagt, daß der Pader Puchlin uns nit gnue than hat, wer? Das sollns uns ins G'sicht sagn, da wurdetens ain kujose Antwort drauf kriegn, d'Herner wissn ja nit ainmal, was er predit hat, er hat ja kain Suntapredi, sondern ain Lobpredi g'halten, er hat uns ja nur zaigt, wiema den heil. Joannes nachfolgn solln, daß ma guti Kristn sayn, er hat ja in zwoa Theiln g'sagt, daß der Joannes si fleisi dö kristliche Lehr aign g'macht hat, und daß er mit der kristlichen Lehr die Gottlosn z'schandn g'macht hat; er hat uns ja für katholische Kristen angsehn, die so wissn, was glaubn müssn, dena er nur ain Muith mitn Heilign sein Beispiel hat machn wolln. Wann er für g'wis g'wust hät, daß d'Herner auf sein Einladung, übr die i recht g'lacht hab, wie is g'hört hab, kuma, die a so voller Zweifl sayn, und die auf d'Heilign nit vill haltn, so hätt er freyli anders predign müssn, aber das hama an den Tag z'Vösendorf nit braucht, wir kenna schon unsern Glaubn, und lassn uns von alln den Hernern, die z'Wien drinn von der Duleranz, Pabsten, Ablas, und Geistlichn so wunderbarli schreibn, heraust kain neuen Glaubn vorschreibn.

Ja ja es zaigt si freili so klar, daß’s gar d'Bauern z'Vösendorf mit’n Fäusten hättn greifen könna, daß unsre Regligion in manche Schedel schon von Kindsbanern an nit einiganga ist, weil ma so verwirte z'ritte Sacha allerweil a so gar von ainigen Geistlichn hört; schau ma nur die Lukna an, die sö so boshaft in ihna G’wissn grissn habn, und wie sö non alliweil umerfetzen, bis gar kain Stükl G’wissn mehr habn.

Sö sagn, unsr Predigr waiß niks als von G'heimnußglaubn, und i hab do in der ganzn Predi ain ainzigsmal das Wort G'heimnuß g'hört, wie er g'sagt hat, daß ma nit drüber grübbln, sundern demüti anbethn solln, 'S Predign von Glaubn mögn d'Herner fraili nit hörn, aber unser ainer wohl; i glaubs gern, daß sös nit wissn, was glaubn haist, sö glaubn vielleicht gar, daß a Luederaner, oder Kalfiner, oder Zwiklianer, oder a Türk, und a Jud den selimachendn Glaubn habn; bey ihna stekt freili der ganze Glaubn in Kopf, weils allerweil was z'stichln, und z'nekn habn, aber der Unglaubn togerzt in Herzn, wovon die schlima Gedankn in Kopf aufisteign; es ist ihna hart zu verdaun, wan der Prediger ain rechten Brokn ihna von der Kanzl abiwirft, der's recht auf d'Nasen trift; und i glaubs gern, daß ihnre Köpf von ihrn Glaubn schwindli wern, und daß selbst nit wissn, was glaubn; besonders wans auf d'Nacht ausn Birhäußl haimkuma, und Glaubnsartikln schreibn wolln. ${ }^{77}$

wurdetens] würden sie kujose] kuriose, seltsame d'Herner] die Herren Suntapredi] Sonntagpredigt wiema] wie wir ma] wir hama] haben wir Kindsbanern] Kindesbeinen einiganga] hineingegangen z'ritte] zerrüttete, wirre Lukna] Lücke umerfetzen] herumreißen Kalfiner] Calviner, Calvinisten Zwiklianer] Zwinglianer togerzt] klopft, pocht abiwirft] hinabwirft

Punkt für Punkt wird die Kritik der ,Herner ' zerpflückt; Vorwürfe werden als haltlos abgetan, niedrige Motive und Bildungslücken unterstellt. Auch komisches Talent verrät die eine oder andere Verhöhnung, so etwa die Ausdeutung des Blattnamens damit, „daß [die Kritiker] d'Wochn do anmal d'Warheit redn “78. Zum Schluss werden die Predigtkritiker aufgefordert, sich beim ,Pader Puchlin' für ihre Entgleisungen zu entschuldigen; mit einer kurzen Lobeshymne auf ihn wird im trotzigen Ton geschlossen. Der Text muss einen gewissen Bekanntheitsgrad gehabt haben, wie diverse Referenzen in anderen Texten bezeugen. So wird auf Pochlins Schreiben etwa auch in Perinets fingierter Briefsammlung

76 Ebda., S. 13.

77 Ebda., S. 15-19.

78 Ebda., S. 11. 
XXIX Geheime Korrespondenzen ${ }^{79}$ Bezug genommen, in der ein Brief dem reform- und aufklärungskritischen Patricius Fast, Priester der Metropolitankirche Migazzis, in die Feder gelegt ist. Perinet lässt Fast hier die Angriffe durch Kritiker und ,Neuerer ' beklagen und sich selbst in seinen Anstrengungen für die Kirche loben, worunter unter anderem auch sein Einsatz für Pochlin fällt, indem er „die Uhazzische Hezpachtung vertheidiget" ${ }^{80}$ habe. Auch in Richters Wienerischer Musterkarte findet sich ein Bezug: im „[Muster] einer Dame, die oft zur Beicht geht“ rät ein aufgeklärter Geistlicher seinem Bruder davon ab, seine Frau zu einer geistlichen Bruderschaft, und zwar „in die Herzjesu, oder in die neue Dreifaltigkeits-Bruderschaft, durch den P. Pochlin, P. Hell oder P. Niklas" gehen zu lassen, da diese nur Aberglauben verbreitete und eigentlich verboten sei. ${ }^{81}$

Schon Jahre zuvor hatte auch in Bayern eine dialektale Predigt von angeblich konservativer, antiaufklärerischer Seite für Aufregung gesorgt. Verfasser der RosenkranzPredigt im ganzen Ernste gehalten zu Bogenhausen nächst München den 3. October 1779 soll ein unter dem Pseudonym,Wiesenpater aus Ismaning' bekannter Kleriker gewesen sein, nach unterschiedlichen Quellen ein Kapuziner und Eremit der Kolomansklause, der nach dem Erscheinen der Schrift Predigtverbot erhalten habe. Schon die zeitgenössische progressive Literaturkritik wusste nicht recht, was es mit diesem 1780 erschienenen Werklein auf sich hatte, nahm aber gerne die Gelegenheit wahr, es als besonders infames Beispiel antiaufklärerischer Predigtexzesse zu zitieren. So beteuert man in den Annalen der Baierischen Litteratur von 1781, wo Auszüge wiedergegeben wurden, die Predigt sei „wirklich keine Satyre, so sehr sie es auch zu sein scheinet. Einige lustige Köpfe, welche bei derselben in der Absicht zugegen waren, sie, so viel es möglich wäre, im Gedächtniß zu behalten, beförderten sie zum Druck“ ${ }^{82}$ Freilich: Auch wenn hinter dem Text ein reales Vorbild gestanden haben mag, war die eigentliche Intention der Drucklegung zweifelsohne die Diffamierung der traditionellen katholischen Kanzelrede, deren aggressive Rhetorik, extensiver Metaphernreichtum und emotional-irrationale Argumentation lustvoll überzeichnet werden. Mit volksmissionarischer Ambition versucht der ,Wiesenpater', die Macht, Wirkkraft und Bedeutung des Rosenkranzes herauszustellen, der als zentrales Volksgebet der Katholiken bereits im Vorwort als Waffe gegen alles Böse, alle Verführung, alle Verfehlung inszeniert wird. Dabei schreckt die Predigt auch vor hetzerischen Tönen nicht zurück; immer wieder werden Attacken gegen die Protestanten bzw. Luther sowie auch gegen verpönte ,neumodische' Geistliche und deren Anliegen gefahren und mit hanebüchenen Exempeln im launigen Erzählduktus veranschaulicht:

79 [Joachim Perinet]: XXIX Geheime Korrespondenzen. Ainsi fut accomplie cette parole de l'écriture. Et il a été mis au rang des méchans. Erste und lezte Sammlung. Wien 1787. Zu finden bei Lukas Hochenleitter, Kunst- und Buchhändler am Kohlmarkt N. 1180.

80 Ebda., S. 37.

81 Vgl. J[oseph] R[ichter]: Wienerischer Musterkarte. Ein Beytrag zur Schilderung Wiens. Wien 1785. [1. Aufl.]. 3ter Theil. Nr. 27.

82 Annalen der Baierischen Litteratur vom Jahr 1778. Nebst einer vorläufigen Geschichte der Aufklärung und Litteratur in Baiern unter Maximilian Joseph. Ersten Bandes erstes Stück. Nürnberg: Grattenauer 1781, S. 234 . 
Die heilige Beicht, und den heiligen Rosenkranz last euch nicht nehmmen, liebe Christen! aber ihr habt halt nicht alle Tag Zeit, sagt ihr? nicht Zeit? aber Schniderhipfel, aber Saugsangl könnts singen auf d'Nacht, mein! last's den Pfiferling seyn, und bett's dafür einen Rosenkranz, dan der überwältigt d'Höllen-Schanz. Zum Beweis will ich euch ein gar auferbauliches Exempl erzählen: In einem gewisen Frauenkloster ist einmal eine gewise Klosterfrau gewesen, und die ist Portnerin worden, und da ist alleweil ein junger Geistlicher dazuekommen, Sie haben von Anfang weiter nichts Böses im Sinn g'habt, aber wie’s halt geht, wenn man's Feuer zum Stroh legt, der Teufel ist halt ein Schölm, man därf ihm halt nicht trauen, denn schaut's, nachdem's so eine zeitlang b'ständig zusammen kommen seind, verlieben Sie sich endlich gar ineinander und was g'schicht? er ist jung gewessen, Sie ist jung gewessen, Sie entschliessen sich also mit einander auf, und davon zu gehen. Das ist schön, das ist brav! ich wünsch Glück auf d'Reiß, und ein schön's Wetter auf'n Puckel, das wird ein schöns Leben werden, Sie ein Klosterfrau, er ein Geistlicher, daß Gott erbarm wär das ein Geistlicher, wär das ein Klosterfrau! und wo werden's dan hingehen, ins Luterthum halt, was werdens anfangen? dörft's ia nicht zweifeln, ein Lueder-Leben halt, ia, ia, es ist schon so, Sie seyn würcklich miteinander zum Blunder gangen, sieben ganze Jahr seinds miteinander in der Weld herumvagiert, endlich hat der geistlose Geistliche sein saubere Klosterfrau (verzeich mirs Gott! ich hätt's lieber einen Schlepsack g'nennt) sitzen lassen, und ist ihr auf, und davon. Bedanck mich s'Truncks, wie wird ihr ietz gangen seyn? Könnt's euch's wohl einbilden, wie es bey einem solchen Gepack gehet, Sie hat halt ihre Fleisch-Banck aufg'schlagen, und hat von ihrem Körper g'lebt; Pfui der Schand! ist das ein Sauleben! aber wart's nur ein Bisel, wie müessen uns nicht übereilen. Merckt's auf, was g'schechen ist. Auf d'letz hat Sie sauber gar nichts mehr g'habt, weill Sie ihr mit ihrem Sau-Handl nichts mehr hat verdienen können, dann durch ihr LuederLeben kranck worden, und in ihrer Kranckheit ist's endlich zum Kreuz g'rochen. So gehts, wenn man nicht mehr luedern kan, fangt man s'betten an. In Gott's Nahm, wenn's nur nicht bisweillen schon z'spatt wär. Aber die Andacht des H. Rosenkranz lüegt halt selten, und dieser Andacht ist die gute Beatrix (so hat die Klosterfrau geheissen) alleweil ergeben gewessen, und so gar wi's durchgangen ist, so hat's ihre Schlüssel der Mutter Gottes unter'n Kreuz ang'henckt, und hat g'sagt: Mein liebe Muetter Gottes, ich hab dir bis dato treulich gedient, aber ietzt, kan ich nicht mehr, versich du meine Portner-Dienst, ich kan's einmal nicht mehr versehen. Und die MuetterGottes ist ihrem Begehren auch getreulich wilfahren, hat die Portner-Dienst die ganze Zeit, die unsre Beatrix ausgewessen ist fleisig versehen, dan nachdem unsre Land-Streicherin wider g'sund worden ist, hat Sie sich entschlossen, wider in ihr Kloster zuuckz'kehren, und wie's beym Kloster ang'langt, geht's zu der Porten hin, in Willens, sich durch Portnerin bey der gnädigen Frau melden z'lassen, und um eine heilsam Straf zu bitten, und Besserung ihres Lebens zu versprechen. Aber o Wunder über Wunder, wie die Portnerin die Thür aufmacht, überfahlt unsre Büesserin ein Schrecken, und ein Schauder, daß Sie nicht mehr g'wust hat wo Sie ist, die Portnerin aber geht auf Sie zue, und sagt: mein liebe Schwester, mein liebe Beatrix, sey ohne Sorgen, es weiß im ganzen Kloster kein Mensch, daß du so lang ausg'wessen bist, ich hab unterdessen dein G'stalt angenohmmen, hab deinen Habit anglegt, und deine Dienst versehen, nihm ietzt deine Schlissel wider zu dir, leg deinen Habit an, es wird dir kein Mensch kein Haar krümmen, sey künftighin frömmer, bett' fleisig deinen $\mathrm{H}$. Rosenkranz, und sey wider meine Dienerin wie zuvor. ${ }^{83}$

Schniderhipfel] Schnaderhüpfel, Gstanzl: kurze, gereimte alpenländische Gesangsform, zumeist im 3/4-Takt, oft auch improvisiert und mit Pointe im Wechselgesang vorgetragen Saugsangl] wie Schnaderhüpfel Portnerin] Pförtnerin Puckel] Rücken herumvagiert] herumgezogen Schlepsack] eig. Fischnetz, im übertragenen Sinn: liederliche weibliche Person Bedanck mich s'Truncks] Dankesformel für ein Freigetränk Fleisch-Banck] Verkaufsstelle für Fleisch, metaphorisch für Prostitution luedern] sündigen, ein liederliches Leben führen Habit] Ordenstracht

Völlig zu Recht vermutet der Rezensent der Allgemeinen deutschen Bibliothek hinter solcher Brachialrhetorik einen Spötter, der „damit die abgeschmackte Art des Kan-

83 [Anonym]: Rosenkranz-Predigt im ganzen Ernste gehalten zu Bogenhausen nächst München den 3. October 1779 von dem sogenannten Wiesenpater aus Ißmaning. [o.O, o.V.] 1780, S. 9-13. 
zelvortrages mancher katholischer Prediger lächerlich machen “ ${ }^{84}$ wollte - um diesen Ansatz allerdings umgehend zu verwerfen. Dabei verweist schon die Widmung an die kurfürstlich-bayerische Gelehrtengesellschaft „zur Beförderung der geistlichen Beredsamkeit und Katechetik in München " 85 auf die satirische Absicht; unmissverständlich wird sie dem unvoreingenommenen Publikum vor allem aber durch die pointiert-ironische Verwendung dialektaler Formen, die hier weniger als Zeichen der Volkstümlichkeit denn als Beleg der intellektuellen, theologischen und rhetorischen Unbedarftheit des ,Wiesenpaters' dienen.

Bezeichnenderweise werden diese mundartlichen Formulierungen zwei Jahre später für einen Neudruck unter dem Titel Funckelneue Rosenkranzpredigt noch erheblich intensiviert. Diese zweite Fassung ist „[d]en Herren Predigtkritikern zu Prag zugeeignet“, also jener Gruppe um den Prämonstratensermönch Ägid Chladek und den Herausgeber Karl Guolfinger von Steinsberg, die 1782 mit der Geißel der Prediger (ab dem 5. Stück unter dem Titel Predigtenkritik) homiletische Aufklärungsarbeit leisteten und den Wiener Wöchentlichen Wahrheiten als Vorbild dienten: ${ }^{86}$

Liebe Herrn Kridiker!

Seyts nit harb, daß ich enck meine Predig zug'eignet; ich hab in Zeitung g'lesen, und ist auch ein Wander G'sell aus Prag ausse kume, der hat mir verzehlt, daß ös a ganz Bandl b'samen seyts, und auf die Prager Prediger braf schimfts und losziehts; Schon recht, nur zue, warum predigens nit besser; in meiner funckelneuen Rosenkranz Predi, da werds wohl nix z'tadeln finden. - - Net wahr, so mueß ma s'Wort Gottes fürtragen. Die Predi hat si g'waschen; Oes werds mich wohl a Bißl lobn? - Nur net z' viel ich bin net hoffärti. Auf Laurenzi geht der Bader Michl auf Prag eini wohlfarten, da werds mein Predig wohl schon g'lesen, und a was drüber druckt habn; Schickts mir a paar solche Wisch mit ausse, daß ichs mein Bauern fürlesen kan, was 's kost, wers schon zahln. Wenns a mahl Zeit habts, kommts zu mir ausse, i hab a guets Bier, und fette Damfnudeln sollts a kriegn. - -

Nu lebts derweil g'sund.

Bogenhaußen den 1. Juny 1782.

Wiesen-Pater. ${ }^{87}$

harb] verärgert enck] euch ausse kume] herausgekommen ös a ganz Bandl b'samen] ihr eine ganze Bande beisammen hoffärti] eitel, ruhmsüchtig Auf Laurenzi] am Laurenzitag: 10. August sollts a kriegn] sollt ihr auch bekommen

Spätestens mit dieser durchtriebenen Widmung sollte klar geworden sein, dass der ,Wiesenpater' bloß eine provokante Stellvertreterfigur für jene rückständigen katholischen Kontroversprediger war, deren Ungebildetheit, Ignoranz und Blasiertheit man auf diese Weise bloßzustellen versuchte. Das hinderte freilich den Aufklärer und verbissenen Kämpfer wider den süddeutschen Barockkatholizismus Friedrich Nicolai in seiner Beschreibung einer Reise durch Deutschland und die Schweiz nicht, das polemische Kunstprodukt 1785 als Beispiel für den verkommenen Zustand der Religion im Raum

84 Allgemeine deutsche Bibliothek 44/1 (1780), S. $344 f$.

85 Rosenkranz-Predigt, S. [3].

86 Vgl. Hoppe, Predigtkritik im Josephinismus, S. $69 \mathrm{ff}$.

87 [Anonym]: Funckelneue Rosenkranzpredigt gehalten zu Bogenhausen nächst München von dem sogenannten Wiesen-Pater aus Ißmaning. Den Herren Predigtkritikern zu Prag zugeeignet. [o. O, o. V.] 1782, S. 2 . 
München bzw. in Bayern zu bemühen und teilweise abzudrucken. ${ }^{88}$ Noch im 19. Jahrhundert würdigte man die literarischen Qualitäten der Mystifikation oder prangerte die anekdotisch überlieferten Eskapaden des ,Wiesenpaters' an, ohne die satirische Absicht zu erkennen. ${ }^{89}$ Wer der Verfasser dieser literarisch durchaus bemerkenswerten und unterhaltsamen Predigtparodie war, ist wohl nicht mehr zu rekonstruieren; eine Nähe zu katholischen Aufklärern um Anton von Bucher oder Joseph Milbiller (1753-1816) lässt sich zumindest vermuten. ${ }^{90} 1781$ hatte vermutlich derselbe Autor mit den Predigten zum Lachen in den Stunden der Langeweile ein unspektakuläres Nachfolgewerk vorgelegt, das auf glaubenskämpferische Töne weitgehend verzichtet. Der Titel allein signalisierte nun bereits den unterhaltsamen Charakter der Schrift, unterstützt durch die Urheberfiktion auf dem Titelblatt: „Von Wiesen-Pater zu Ißmaning, aus seinem Pulte entwendet, getreu abgeschrieben, und zum Muster für alle Prediger in Druck gegeben “91.

Auch die 1785 anonym mit dem fingierten Druckort,Weisheitsburg' erschienene ,Missions- Buß- und Sittenpredigt' Der Gräul der Verwüstung, die zu Ottakring am 24. November 1782 von einem ,Operarius Katechetikus' gehalten worden sein soll, bediente sich einer Herausgeberfiktion, die sich allerdings gleich eingangs von Form und Inhalt der mitgeteilten Rede distanziert. Diese habe der Herausgeber selbst mitangehört und könne „zum Lobe des Herrn Pfarrers, in dessen Kirchspiel diese Bußpredigt gehalten ward, nur hinzusetzen, daß er, sammt seinem Vikar, gar nicht im Stande ist, eine Predigt, wie diese, zu halten, und wenn er Jahr und Tag drauf studirte ${ }^{\text {“92 }}$. Der vermeint-

88 Nicolai, Beschreibung einer Reise durch Deutschland 5, S. 722f., Beilage 5, S. 90-92.

89 So etwa in Webers Möncherei, wo der Vergleich mit dem Kapuzinerpriester Martin von Cochem hergestellt wird (vgl. Carl Julius Weber: Sämmtliche Werke. Eilfter Band: Die Möncherei oder geschichtliche Darstellung der Klosterwelt und ihres Geistes. Stuttgart: Hallberger 1836, S. 183f.), oder in Corvins Pfaffenspiegel: „Eins der originellsten Predigertalente war aber wohl der sogenannte Wiesenpater zu Ismaning in Bayern, der vor hundert Jahren lebte. Seine Rosenkranzpredigt: ,Der heilige Rosenkranz überg'waltigt d'Höllenschanz' und seine Schwanzpredigt sind höchst komisch. Die letztere sollte bewirken, daß die Bauernburschen sich nicht mehr, wie sie zu thun pflegten, Sauschwanz schimpften, sondern beim Namen nannten. In ihr kommt folgende Stelle vor: ,Warum, meine Christen, ist gewachsen dem Hund sein Schwanzerl? Dem Hund sein Schwanzerl ist gewachsen, damit er wedle und wackle, daß ihm nicht fahren die Mucken ins Loch. - Wir Geistlichen sind aber die wahren Schwänzerl, wir müssen wedeln und wackeln, damit nicht fahren die Seelen der gläubigen Christen ins Loch des Teufels!' Wenn nun auch einzelne Spötter über solche Mönchspredigten lachten, so waren sie doch von Wirkung auf das Volk und dem Bildungsgrade desselben angemessen." (Otto v. Corvin: Pfaffenspiegel. Historische Denkmale des Fanatismus in der römisch-katholischen Kirche. Zweite neu durchgesehene Aufl. Stuttgart: Vogler \& Beinhauer 1869, S. 337).

90 Der geweihte Priester Milbiller war einer der Herausgeber der gesellschaftsreformerischen Monatsschrift Der Zuschauer in Baiern (1779-1782/84), wo er mit frechen Satiren gegen die konservative Geistlichkeit anschrieb. Ließ er diese im dialektalen Duktus zu Wort kommen, sollte dies nicht Volksverbundenheit signalisieren, sondern Rückständigkeit. So trauert einer dieser verzopften Landpriester in einem fingierten Brief der alten Zucht nach, als „d'Buben mehr so g'haut wurden, daß d'Fetzen davon vielen“ (Der Zuschauer in Baiern 3 (1781), XXXIIII. Stück, S. 442).

91 [Anonym]: Predigten zum Lachen in den Stunden der Langeweile. Auf alle Sonntage des ganzen Jahres, von Wiesen-Pater zu Ißmaning, aus seinem Pulte entwendet, getreu abgeschrieben, und zum Muster für alle Prediger in Druck gegeben. [o. O., o.V.] 1781.

92 Der Gräul der Verwüstung, eine Missions- Buß- und Sittenpredigt der Gemeinde zu Ottakring, ein Pfarrdorf westwärts Wien, den 24. Nov. 1782 gehalten von einem Operarius Katechetikus. Weisheitsburg, 1785, S. [4]. 
lich originale Predigttext selbst weist durchwegs einen gesprochensprachlichen Ton auf, einzelne Stellen bzw. Passagen sind darüber hinaus deutlich dialektal (tendentiell niederösterreichisch, wie lautliche Merkmale wie etwa in "Schui“ - ,Schuh', „suichen“ ,suchen' etc. nahelegen). Bezeichnenderweise finden sich die markantesten mundartlichen Stellen vor allem in Zusammenhang mit Ermahnungen, appellativen Passagen und Redewiedergaben, betonen also - wie generell - Situativität, Nähe und Emotionalität. Freilich wird schon mit den Eingangsformulierungen rasch deutlich, dass die Authentizität der Predigt nur vorgeschützt ist, um das perfide Spiel mit den Grundmustern der Textsorte umso komischer zu gestalten:

Euer Lieb und Andacht stehen auf, und bezeichnen sich mit dem Zeichen des heiligen Kreuzes, und sprechen mit Andacht: Im Namen Gott des Vaters, und des Suhns, und des heiligen Geistes Amen, und hören an die Worte des heiligen Evangeliums - He, Buben dort im Winkel, wollts Ruhe geben, oder ich schick den Schulmeister über euch. - Druckts nit, stehts fein still, und gebts acht. -

Ja, meine lieben Kristen, wann wir an das schreckliche Druber und Drunter denken, von welchem der Heiland sagt, so sollt uns billig scheußangst werden. Nit wahr, wenn unausstehliche abscheuliche Hitz einen so martert, daß man den ganzen Tag hindurch wie eine Sau schwitzt, wie mirs selber oft genug geschicht $-{ }^{93}$

Es sind nicht nur sprachliche und situative Entgleisungen, die den Text als Parodie dekuvrieren. Haarsträubende theologische und logische Irrtümer reihen sich aneinander, lateinische Phrasen werden entstellt und missbräuchlich verwendet, mit leicht zu entschlüsselnden Zweideutigkeiten und sogar mit sexuellen Eindeutigkeiten wird nicht gegeizt. Im Fokus der Lächerlichkeit steht der fingierte Katechet, der sich konzeptlos von einer Assoziation zur nächsten treiben lässt, während seiner Predigt Gewalttätigkeiten androht, flucht, Sexstellungen auf der Kanzel nachahmt („Stehend - ruckwärts - vorwärts“94) und andere empfiehlt, Schnupftabak nimmt oder auch mit religösen Druckwerken handelt:

Von diesem schrecklichen Uibel könnts euch aber leicht wieder loskaufen. Schauts Leut, ich hab Katechismes beimer, sie habn mirs um einen Kreuzer theurer geben wollen, die Bücherkramer in der Stadt, das sind rechte Wucherer, drauf bin ich halt fortgangen. Endlich hat er mir nachgeschrien: So gengen Ihro Hochwürden her da, weil Sie's sind, und so hab ich's doch um sechs Kreutzer kri[e]gt; mithin Schenk ich euch so ein Seelenschatzerl. Ihr müßt mir aber 12 Kreutzer dafür geben, fürs Einbinden und Zurichten, hab selber kaum einen Kreutzer dabei. - Wer das Büchel liest, hat hundert, und wer's lesen hört fünfundzwanzig Tag Ablaß. Ist das nicht ein Bagatelgeld für die ewige Seeligkeit? ${ }^{95}$

Katechismes] Katechismus-Schriften beimer] bei mir Wucherer] auch Name eines berüchtigten Wiener Buchdruckers gengen] gehen

Mehr Wutrede als Ermahnung, Belehrung oder Erbauung, zeichnet der satirische Text ein denkbar ungünstiges Bild der katholischen Kanzelrhetorik, deren Wirkungsästhetik - nimmt man die Karikatur ernst - wesentlich auf Anschuldigungen, Drohungen und Einschüchterungen zu fußen schien:

93 Ebda., S. $5 f$.

94 Ebda., S. 51.

95 Ebda., S. $29 f$. 
Item, Kinder sollen der Andacht ergeben seyn, in der Weisheit brav zunehmen, und hübsch Gehorsam leisten. Die Kinder sollen zeitlich in der fruh aufstehen, und fleißig arbeiten; aber da heißts gemeiniglich: „Voda, i mog nit, is gor z'kolt. - No warts a weni, mon wird enk 'sBeth, oder d Streu auswarma. ${ }^{\star}$ ) Da ranzen sie sich erst, wie die Säu im Kindelbeth von einer Seite auf die andere. Nachher wenn's aufgestanden sind, da heißts: Wo is mai Schui? - Wer hot main Brustflöck?" - Da sollt der Vater den Ochsenzahm nehmen, oder s'Staberl, und soll enks suichen, da wurds ös schon finden. Wanns angelegt sayn, da könnens einen Riencken Brod herfressen, daß nur eine Freud zu zu schaun ist; aber zur Arbeit seyds nichts nutz. - Gelts Buben und Menscher, da lachts, weil ich euch brav trief? - Eure Eltern sind die nämlichen Stöck, wie ihr, nur um ein paar Jahr älter! die Wahrheit kommt ihnen selber lacherlich vor. - No hobens halt auch in ihrer Jugend nit anders g'macht! Aus Zaunstöcken wachst kein Weinstock. ${ }^{96}$

*) Diese und die folgenden Reden wurden von dem Herrn Prediger mit der gehörigen Kinderstimme, sowie die ganze Predigt, im österreichischen Tone affektiert, worauf immer ein allgemeines Gelächter entstand.

Voda, i mog nit, is gor z'kolt] Vater, ich mag nicht, ist gar zu kalt No warts a weni] Na, wartet ein wenig enk] euch auswarma] auswärmen, warm machen ranzen] sich recken und dehnen Schui] Schuh Brustflöck] bäuerliches Kleidungsstück, Weste Ochsenzahm] Ochsenziemer: die gedehnte, zu einer Art Gerte gedrehte, gedörrte Haut eines Bullenpenis bzw. dieser selbst diente als Züchtigungsinstrument enks] es euch wurds ös] würdet ihr es Riencken] größeres Stück Brot, Brotlaib

Ein hastig gedruckter Warnzettel, der sich bei einem Exemplar der Wienbibliothek im Rathaus nachgebunden erhalten hat, warnte erfolglos vor der Schrift, die „nach genauer Untersuchung falsch, und sehr schmähsüchtig befunden worden, und [...] ein unterschobenes Werk eines ehr- und gewissenlosen Verfassers" sei. ${ }^{97}$ Dieser wird wohl Johann Strommer gewesen sein, der während der ,Broschürenflut' als Autor anonym, unter Pseudonym, aber auch unter eigenem Namen mehrfach mit religions- und gesellschaftskritischen Werken hervorgetreten war. Neben der Verunglimpfung religiöser Inhalte waren es wohl vor allem auch die unverblümten sexuellen Anspielungen, die seine Predigtparodie selbst in Zeiten der ,erweiterten Preßfreiheit' unter Joseph II. unverzüglich auf den Index verbotener Bücher brachten. ${ }^{98}$ Trotzdem oder wohl eher gerade deswegen avancierte sie zu einem Hauptwerk der klandestinen Spaßliteratur im Habsburgerreich, die in mehrfachen Nachdrucken ${ }^{99}$ und Abschriften ${ }^{100}$ jahrzehntelang zirkulierte.

96 Ebda., S. 20f.

97 Wienbibliothek im Rathaus, A 75422 - Teil I.

98 Vgl. Catalogue des livres défendus par la commission impériale et royale, Jusqu'à l’année 1786. Bruxelles: [o.V.] 1788, S. 36.

99 Vgl. u. a. die mehrfach aufgelegte Sammlung: [Anonym]: Predigten zum Todtlachen. Allen Hypochondristen und Grillenfängern zur Erheiterung empfohlen von einem lustigen Bruder. Konstantinopel: Auf Kosten des Türkischkaiserlichen Oberkonsistoriums [i. e. vermutlich Leipzig: Sommer] 1802, S. 1-48. Darin enthalten ist auch die Rosenkranz-Predigt des ,Wiesenpaters'.

100 Vgl. etwa die im Kap. 7 vorgestellte brisante Sammelhandschrift H. I. N.-55795 der Wienbibliothek im Rathaus, die mit ebendieser Predigtsatire beginnt. 


\section{Hanswurststreit}

Zentrum der Wiener Spaßkultur im 18. Jahrhundert war das Lachtheater, das europäische Spieltraditionen und autochthone Elemente zu einer publikumswirksamen, impulsgebenden Bühnenform verdichtete. Ihr Aushängeschild war die Wiener Spielart des Hanswurst. Er war es auch, an dem in der älteren Forschung ein Konflikt festgemacht wurde, der ab der Jahrhundertmitte den theater- und literarästhetischen Diskurs prägte - ein Konflikt, der noch immer unter dem Begriff ,Hanswurststreit' gehandelt wird, auch wenn dieser Streit deutlich über eine Kritik an dieser lustigen Figur allein hinausgeht. Die Auseinandersetzungen, die damit gemeint sind, haben vielmehr den Rang eines sich abzeichnenden Paradigmenwandels, erfolgte hier doch ein „Wechsel des Bezugsrahmens zwischen der allgemeinen verbindlichen Normästhetik und der Bildung ästhetischer Schulen, die jeweils um Zustimmung werben “ ${ }^{101}$. Der Wiener Hanswurst ist somit vor allem als pars pro toto für die vielfältigen Streitpunkte einer poetologischen und theaterpraktischen Diskussion um die gesellschaftliche Aufgabe des Schauspiels zu sehen.

Die Figur - von Joseph Anton Stranitzky geprägt, wenn auch nicht von ihm erfunden - trug Charakteristika der alten Pickelhäringrolle, erweitert um Elemente verschiedener romanischer Theatertraditionen, ohne allerdings die starren Typenbilder der Commedia dell'arte beizubehalten. Stranitzkys Kreation ist ein aus Salzburg stammender Bauer, Sauschneider oder Diener, er ist „Narr und Galgenstrick, Fresssack und Säufer, Zankteufel und Raufbold, Frauensammler und Sexualphantast, Analphabet und Illiterat, Feigling und Prahlhans, Hosenscheißer und Windmacher und immer auch aufs Geld aus" ${ }^{102}$. Sein charakteristisches Kostüm ist eine fiktive Tracht, bestehend aus roter Jacke, blauem Brustfleck, Hosenträgern, gelber knöchellanger Hose, derben Schuhen, Krause und grünem Spitzhut, ergänzt durch eine Holzpritsche. Typischerweise trägt er einen kurzen, in dünnen Koteletten zum Haar hin laufenden Bart; seine Haare sind straff zu einem nach oben stehenden Büschel gebunden. ${ }^{103}$ Was den Hanswurst Wiener Prägung aus der Vielzahl an komischen Typen auf den Bühnen der damaligen Zeit hervorheben und zu seiner europäischen Bekanntheit verhelfen sollte, war seine bewusste Institutionalisierung, Regionalisierung und mediale Vermarktung. Als Stranitzky 1711 das Wiener Kärntnertortheater übernahm, eröffneten sich der künstlerischen Gestaltung durch das stehende Theater und die fixen Rezeptionsverhältnisse völlig neue Möglichkeiten. Die allein auf den Tageserlös angewiesenen Schauspieler der verschiedenen umherziehenden Theaterbanden konnten bei ihren Auftritten eine bestimmte Publikumserwartung ebenso wenig voraussetzen wie entsprechende Vorkenntnisse. Durch die Lokalisierung der Herkunft des Hanswurst, seine konsequente berufliche Festlegung im Bauernstand (signalisiert durch ein konkretes, unabänderliches Kostüm) und eine signifikante regiolektale Sprechweise differenzierte Stranitzky seine Figur von weni-

101 Eybl, Hanswurststreit und Broschürenflut, S. 25.

102 Müller-Kampel, Hanswurst-Stranitzky, S. 5.

103 Vgl. ebda. 
ger präskriptiv angelegten komischen Konkurrenzfiguren. Darüber hinaus wurde durch kleinere literarische Arbeiten die Popularität der Figur sowohl finanziell verwertet als auch erweitert.

Noch Nicolai würdigte - wenngleich in einem allgemein eher angriffigen Kommentar - dieses beständige Erfolgsrezept, ${ }^{104}$ das alle Publikumsschichten unabhängig von Stand, Beruf und Geschlecht ansprechen wollte - und dies vorrangig im Dialekt, auch wenn sich dies für die Anfangszeit nur mit vergleichsweise wenigen Quellen belegen lässt. Schon im bereits angesprochenen ,vaterländischen' Hanswurststück Türckisch-bestraffter Hochmuth aus Stranitzkys Umfeld verrät so manche Replik des Protagonisten, dass dieser sich auf der Bühne auch durch die regionalsprachliche Markierung - und in der Aufführungspraxis sicher deutlicher als in der Verschriftlichung belegt - von seinem Umfeld abhob, so etwa, wenn er die Verpflegung der Knechte bei der landwirtschaftlichen Arbeit Revue passieren lässt: „ä Grieß-Schmarren, Nocken, Linßen, ä Brein und was halt die Bauern ins Feld mit auße geben“, oder wenn er gegen eine schnippische Kammerzofe ausfällig wird:

HANs wURST. Du Strudel-Gesicht und ich mag dich auch nicht, unsere Jodeln daheim haben wohl hübschere Mädel, das sind Menscher, Fuß habens so weiß wie ä Gold, laß schauen ob die deinigen so weiß sind.

Sophia. Du ungeschliffener Esel, du Flegel wart, jetzt will gleich den Haußknecht laßen über dich kommen, daß er dir den Puckel voll anprügeln soll. Gehet $a b$.

Hans wURST. Du Schneebruntzerin ich verlang dich nicht, unsere Buben daheim, wann sie ihrem Diendel ä Schmatzel geben, und nicht zwey finger dick ein Rotz dran sitzen thät so meynten Sie es wär nicht gesund, ja diese da wär wohl geschickt darzu, wann sies sehen würden, daß es solche schopffete Menscher geb, Sie dächten es wären Fledermäuß oder MeerWunder, und sol der Haußknecht sich unterstehen mich zu prügeln, ich wolt ihm ä Stoß geben, daß man ihn zu Preßburg wieder suchen müst. ${ }^{105}$

Jodeln] Kurzform für Jodokus oder Georg; hier: junge, grobe Männer aus bäuerlichem Umfeld Menscher] Mädchen Puckel] Rücken Schneebruntzerin] derbes Schimpfwort (brunzen = urinieren) ä Schmatzel] einen Kuss schopffete Menscher] Mädchen mit (übertrieben) eleganter Frisur

Auch der sichtlich an der Kunstfigur des universitär approbierten ,Zahnbrechers` Stranitzky orientierte „Hans Sausakh von Wurstelfeld, Berühmter Zahnluken-Architekt u. Zotten Professor auff der hohen Baurn Schuhl“ stellt sich in der bereits mehrfach genannten Augsburger Kupferstichsammlung Il Callotto resuscitato. oder Neü eingerichtes Zwerchen Cabinet grob mundartlich - wohlgemerkt nicht wienerisch - vor:

I bin holt wie I bin, bin wia maß hobm will,

Bins gleichwohl nit alloan, da Norn gibts holt gar vill,

Reiß i an Zohtn hear, so thoan holt d'Norrn locha,

Ma kon a Leüthn jo da possn nit gnua mocha,

104 Nicolai hält fest: „Er fand mit dieser Neuerung viel Beyfall, und sie war in der That ein Schritt zur Verbesserung, weil wirklich der Charakter eines einfältigen und dabey possirlichen Bauern der Natur gemäß, und also mehreres Interesse fähig ist, als der Bloße Charakter eines Narren, der Narrenstreiche macht, um sie zu machen." (Nicolai, Beschreibung einer Reise durch Deutschland und die Schweiz 4, S. 568ff.).

105 Wienbibliothek im Rathaus, H. I. N. 160870 (Türckisch-bestraffter Hochmuth oder das ANNO 1683. von denen Türcken belagerte und von denen Christen entsetzte WIENN Und Hans Wurst die kurzweilige Salve-Guarde des Frauen-Zimmers, lächerlicher Spion und zum Tode verdamter Mißethäter), S. 19. 
Bikemmt a moncha schon dabey an plumpm stich,

Lekt Ers zum bestn auß, und sogt daß ghert fia dich. ${ }^{106}$

1 maß hobm] man es haben 2 alloan] allein da Norn] der Narren 3 Reiß i an Zohtn] mache ich einen unanständigen Witz thoan] tun locha] lachen 4 Ma kon a] man kann auch gnua] genug 5 Bikemmt a moncha] bekommt auch mancher 6 Lekt Ers] legt, deutet er es (Wortspiel mit, leckt') ghert fia] gehört für, zielt ab auf

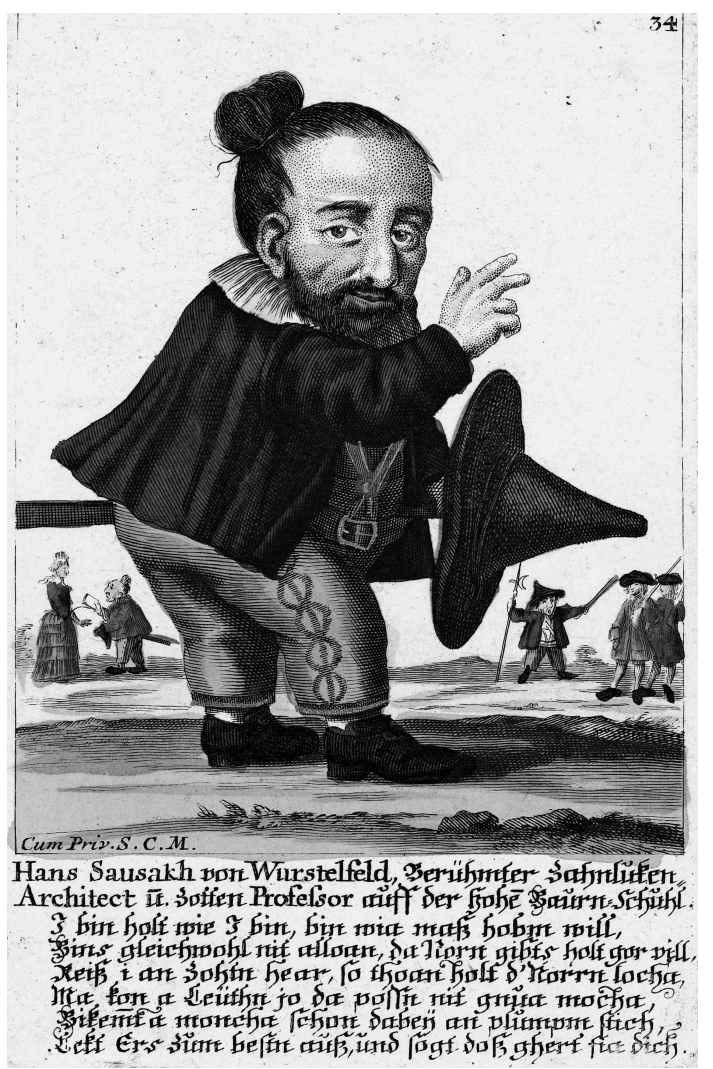

Abb. 49: Hans Sausakh von Wurstelfeld aus: Il Callotto resuscitato (Rijksmuseum, FMH 3695-a34).

Die Sammlung grotesker Spottfiguren, ein Beitrag zur seit Callots Gobbi beliebten Zwergenmode im Barock, wird nach neuestem Forschungsstand dem Augsburger Kupferstecher Martin Engelbrecht (1684-1756) zugeschrieben. ${ }^{107}$ Von wem die sprachlich bemerkenswerten Alexandrinerstrophen stammen, ist unklar. ${ }^{108}$

106 Il Callotto resuscitato. oder Neü eingerichtes Zwerchen Cabinet. [Augsburg, um 1710], Bl. 39.

107 Vgl. Günther G. Bauer/Heinz Verfondern: Barocke Zwergenkarikaturen von Callot bis Chodowiecki. Hg. vom Kulturamt der Stadt Salzburg anläßlich der Ausstellung in der Galerie der Stadt Salzburg von 1. August bis 1. September 1991. Salzburg 1991).

108 Gleichfalls im Augsburger Umfeld entstand wohl auch das Pasquill Bucephalus, Das Faßnacht-Roß, zweiter Teil einer katholischen Streitschrift gegen den bedeutenden evangelischen Aufklärungstheologen Christoph Matthäus Pfaff, der zuvor Jakob Reysings untergriffige Apologia detailliert widerlegt hatte. Wie schon im gleichfalls nur vordergründig als ,Fasnachtspiel' gestalteten ersten Teil Schöne Rareté! Schöne Spihle-Werck! Schöne Murmlethier! Allons, feiff Murmlethier, feiff! eines unbekannten Verfassers wird hier die Figur des Sauschneidersohns Hanswurst (auch Arlequin, Kilian Brustfleck) zum Angriff gegen den 
In seinen Anfängen weitgehend alleinverantwortlich für eine grobianistische, parodistische Akzentuierung der pathosschwangeren Haupt- und Staatsaktionen, wandelte sich der Wiener Hanswurst unter Stranitzkys Nachfolger Gottfried Prehauser zu einer weitaus facettenreicheren, flexiblen Figur, die viele Wesenszüge des Arlecchino/Arlequin aufgesogen hatte. ${ }^{109}$ Zur Seite standen ihm in den durchgängig komischen Stücken mit ihren Rollentypen, fixen Handlungsmustern und Lazzi weitere lustige Akteure traditionelle wie Pantalon, Scapin oder Colombina und auch neu geschaffene wie der ,Bernardon', von Joseph Felix Kurz kreiert und als umjubelter shapeshifter Namensgeber einer eigenen Burleskenform, der phantastisch-totaltheatralen ,Bernardoniade‘. Gespielt wurden seit den 1730er Jahren auf den Wiener Bühnen teilextemporierte Burlesken, die unmittelbar oder mittelbar der Formenwelt der Commedia dell'arte entstammten; über Wandertruppen verbreiteten sie sich wiederum in großen Teilen des deutschen Sprachraums. ${ }^{110}$ Von diesen Burlesken mit Improvisationselementen sind aus dieser Zeit üblicherweise nur Szenare oder Gesangseinlagen überliefert, die uns das Bühnengeschehen lediglich in seinen Umrissen vorstellen. Das geübte Personal der professionellen Truppen konnte die Handlungsvorgaben mit dem je eigenen Repertoire an sprachlichen und körperlichen Mitteln vergleichsweise frei, aber natürlich in Übereinstimmung mit der Figurenanlage ausgestalten, wobei weniger die geistesgegenwärtige Erfindung an sich als das gekonnte Arrangement erprobter Textbausteine, die Variation publikumswirksamer Effekte und die Integration von Lazzi und Musikeinlagen im Vordergrund standen. Über den spezifischen Gebrauch von Sprachvarietäten in den Extempores weiß man generell nur wenig; in den Szenaren finden sich wenig Spuren und in den raren ausformulierten und gedruckten Libretti dieser Zeit begegnet uns das Spiel üblicherweise

protestantischen Gegner funktionalisiert, indem er eingeschobene Expertisen, Argumente, Darlegungen etc. im Gespräch mit dem ,Choragus` räsonierend bis grobianistisch kommentiert. Dialekt spricht auch dieser Arlequin bzw. Hanswurst nur fallweise, dann aber ausgesprochen explizit:

ARLEQIN. Ihr möchts jetzunder nemmen / für was ihr es wolt / mir gilt alles gleich / vor Zeiten ist es wohl a mahl a Rooß gwest / und hat Bucephi geheissen / was es aber dermahlen seye, das waiß ich nit.

Maister Hannss. Nu was ist dann dein Verlangen darmit?

ArLeQIN. Ja was woaß I/ wo - und was ihm alles fehlt / und ob er noch curabel seyn möchte! schaugt ihr gleich wohl / müests besser verstehen dann ich.

Q.V.S.J.S.D.C.R.Z.F: Bucephalus, Das Faßnacht-Roß, Wormit Der Arlequin verschidene curieuse Avanturen gehabt: Das ist: Catholische Replic, Oder Gegen-Antwort Auf die Uncatholisch so betitult Unwiderlegliche etc. Widerlegung disseithiger Apologiae vor das Allerdurchleuchtigste Ertz-Hauß Oesterreich, Die Religion betreffend, Anderer Theil, Continuirt in der Form eines Schau-Spihls. [o. O., o.V.] 1730, S. 40.

109 Vgl. Asper, Hanswurst. Studien zum Lustigmacher. - Müller-Kampel, Hanswurst, Bernardon, Kasperl.

110 Vgl. u. a. Rommel, Die Alt-Wiener Volkskomödie. - Gustav Zechmeister: Die Wiener Theater nächst der Burg und nächst dem Kärntnerthor von 1747 bis 1776. Graz/Wien/Köln: Böhlau 1971. - Franz Hadamowsky: Wien. Theatergeschichte. Von den Anfängen bis zum Ende des Ersten Weltkriegs. Wien, München: Jugend und Volk 1988. - Herbert Zeman: Alt-Wiener Volkskomödie. In: Horst Albert Glaser (Hg.): Literatur. Eine Sozialgeschichte. Bd. 4. Reinbek/Hamburg: Rowohlt 1992, S. 323-329. - Johann Sonnleitner: Hanswurst, Bernardon, Kasperl und Staberl. In: Johann Sonnleitner (Hg.): Hanswurstiaden. Ein Jahrhundert Wiener Komödie. Salzburg, Wien: Residenz 1996, S. 331-389. - Johann Sonnleitner: Die Wiener Posse. Begriff und Wirkungsästhetik um 1770. In: Franz M. Eybl (Hg.): Nebenschauplätze. Ränder und Übergänge in Geschichte und Kultur des Aufklärungsjahrhunderts. Bochum: Winkler 2014. (Das achtzehnte Jahrhundert in Österreich 28) S. 137-150. 
literarisiert, zensurbedingt gereinigt und an Lesegewohnheiten bzw. einen breiteren Absatzmarkt ausgerichtet.

Wie Hanswurst und consortes in den Wiener Stücken des Kärntnertortheaters der 1740er Jahre tatsächlich sprachen, davon geben Bühnenmanuskripte aus der ehemaligen Schwarzenberg'schen Residenzstadt Krumau (Český Krumlov) Aufschluss. Fürst Joseph Adam hatte hier die Theatertradition wiederaufleben lassen, nicht durch Bühnenprofessionisten, sondern als Haustheater, an dem sich das Fürstenpaar selbst und befreundete Adelige beteiligten. ${ }^{111}$ Die Spielvorlagen besorgte man sich in Wien: populäre Hanswurst-Burlesken des Kärntnertortheaters. Da es aber Laiendarstellern nur schwer möglich gewesen wäre, ihre Charaktere auf Basis der lapidaren Vorgaben in den Szenaren überzeugend all'improviso zu gestalten, sind in den Krumauer Manuskripten die Repliken für die adeligen Akteure und ihre Mitspieler detailliert ausgeschrieben, und zwar in einer Weise, die auch die sprachlichen Eigenheiten der verschiedenen Typen viel deutlicher zu Tage treten lässt. Sie erlauben somit Rückschlüsse auf Spielkonventionen, über die man ansonsten nur spekulieren konnte, und dokumentieren das per se Transitorische des Improvisationstheaters, so auch das kunstfertige Spiel mit dialektalen Formen. Dialektsprecher in den Krumauer Burlesken sind (wenn nicht der Handlungsverlauf eine andere Sprechweise verlangt) Hanswurst, Scapin und diverse Dienerfiguren; auch in Colombinas Repliken finden sich des Öfteren dialektale Wendungen. Der am Kärntnertortheater von Prehauser verkörperte Hanswurst wurzelt sprachlich freilich nicht im Salzburgischen; er spricht Ostmittelbairisch in seiner Wiener Variante, die sich am auffälligsten durch eine Monophthongierung des mittelhochdeutschen Diphthongs $e i$ vor Nasalen und bestimmen Konsonanten zu einem langen, hellen $a$ von den umliegenden Dialekten abhebt - so etwa in ,hast ' für mittelbairisch ,hoast' (= heißt) oder ,was' für ,woas' (= weiß).

In der Burleske Baron Wurstelsprung ein Zum Edelmann gewordene Strohschneider, einem der neun handschriftlich erhaltenen, aus dem Kärntnertortheaterrepertoire stammenden Stücke ${ }^{112}$ des aristokratischen Laientheaters in Krumau, zeigt sich die Evolution der Figur in den ersten Jahrzehnten des 18. Jahrhunderts: Zu Beginn entspricht Hanswurst noch vorwiegend der dümmlich-naiven Opportunistenfigur stranitzkyscher Prägung, die ihre Triebbefriedigung sucht, solange man sie nicht daran hindert; im Verlauf der Handlung aber tritt immer mehr der sprachgewaltige und wandlungsfähige Hochstapler prehauserschen Zuschnitts zu Tage. Hier ein Ausschnitt aus dem ersten Akt:

111 Vgl. Otto G. Schindler: Die erlauchten Komödianten des Herzogs von Krumau. Der oberösterreichische Adel gastiert am Schloßtheater der Fürsten zu Schwarzenberg. In: Blickpunkte Oberösterreich 44 (1994), S. 32-39. Eine weitgehend wortgleiche Übersetzung ins Tschechische bietet Otto G. Schindler: ,Arlequin`a ,Don Quichotte‘ na Šumavě. Rakouské pramenÿ ke krumlovskému zámeckému divadlu knížat ze Schwarzenbergu. In: Jihočeský sborník historický 63 (1994), S. 61-68. - Christian Neuhuber: Ein Wurstelsprung von Wien nach Český Krumlov. Zur kritischen Erstedition der Krumauer Hanswurst-Burlesken. In: Nestroyana 38 (2018), H. 1-2.

112 Eine kommentierte Edition mit Studie ist im Erscheinen, vgl. Lisa Erlenbusch/Marko Ikonić/Christian Neuhuber (Hg.): Vom Wiener Kärntnertortheater nach Schloss Krumau. Die Hanswurst-Burlesken von Český Krumlov. Wien: Lehner 2018. 
Stopherl. Han sag mer nur Hannßwurst: was faulenzt den du a so, hast mer das Strohschneiden, wan mer nicks als singt.

Hansswurst. Du bist halt a alleweil wunderli mein Lieber Vatter: als wann mer nit kunt Strohschneiden und singen zugleich

Stopherl. I kenn di schon du fauler Schlanckl: der seiter I di hab in d' Frembd gschickt will die halt s arbeiten gar nimer schmecken, du manst halt wanstu etli Französische Brocken ausspeyest die der Teifel in der Höll nit versteht, so ist schon gnue, aber wart nur I wir dir schon anmahl Stroh auf dein Buckel schneiden.

HANsswurst. No, no, mein Vatter zürn di nur nit I wir mi schon bessern: Schau du must es do selber gstehen, daß I der brawest unter dein Söhnen.

StOpherL. Es hat mir Geld gnue kost bis du so braw worden: Aber hör anmahl I wir jetz [Lücke] da seÿn, und wir umi gehn zum Hißl Stroh kauffen bleib du derweil z haus, arbeit fleißi, und gieb mir auf die klein Kinder achtung.

HANSSWURST. Es ist schon recht Vatter geh nur.

STOPHERL. I wir bald wieder zu Haus seÿn (gehet $a b$ )

Scena II

Hannßwurst allein.

Geh, geh, du alts Brumeißen, daß dir Hals und Kragen brichst: aber bin I nit a rechter Narr daß I mi a so schern lassen: I bin a so greister Kerl I kann vier oder fünf sprachen, aber kann nit recht: parle vu fraß gern vui Monsieur wann I was hab, I bin in allen grossen Städten von Europa gwest $\mathrm{z}$ Paris da bin I gar lang gwest: daß is an ort, ja wann I no dran denck, so vergeht mer aller Lust zum Strohschneiden, I bin a zu Wienn zu Prag zu Leipzig, zu Linz, zu Przisnitz, zu Durkowiz, in allen den grossen Städten gweßen: und I soll a so da knotzen, und mi a so da hudeln lassen, $\mathrm{Na}$, na das thu I nit, mein resolution is gnumen Adieu mon cher Schneidstock: di sih I nimmer: Jez ist just die beste zeit, weil mein Vatter nit zu Haus ist so wil I derweil einigehen, und will a kleine visitation unter sein Geld halten, was braucht er so viel Geld, er is a so an ertz Geitz Hals, und I wirs besser anbringen: I hab kein Seitel wein trunken seiter daß I zu Haus bin, und I bin den champagner, monte pulcianer, und Burgunder so gwont, dann zu Paris trinckt mer die wein wie es Wasser: Alle Brün sein voll darmit: Eh bien I will geschwind nein lauffen ehe mein vatter haim kumt will an Geld zu mir nehmen und in die Stadt gehen, an gscheider bin I, wer weis was no aus mir wird (singt) Fortune favorisir mir pauvre Strohschneider. $(\text { gehet } a b)^{113}$

Han] Interjektion: He hast mer das] nennt man das a alleweil] auch immer Schlanckl] Taugenichts, Schlingel manst] meinst I wir] ich werde Buckel] Rücken gnue] genug umi] hinüber Hißl] Kurzform für Matthias Brumeißen] Maultrommel; schimpfender Mensch Przisnitz] Prisnitz, tschech. Přísečná, Dorf 3km nordöstlich von Krumau Durkowiz] Turkowitz, tschech. Dobrkovice, Dorf 2km westlich von Krumau knotzen] herumhocken, zuhause bleiben hudeln] etwas in Eile verrichten resolution] Entschluss mon cher] mein lieber di sich I nimmer] dich sehe ich nicht mehr einigehen] hineingehen monte pulcianer] toskanischer Rotwein aus Montepulciano Fortune] Glück pauvre] arm

Beide Konzepte dieser Hanswurst-Komik - das kreatürlich-karnevalistische ebenso wie das polymorph-variable - widersprachen allerdings den theoretischen Vorstellungen des ,praeceptor germaniae', wie sie in der Critischen Dichtkunst (1730) expliziert wurden. Gottscheds Verständnis des Theaters als weltliche Verkündigungsanstalt zielte auf die Erziehung des deutschen Bürgertums ab, das nach seinem materiellen Aufstieg nun auch

113 Christian Neuhuber: Der Baron Wurstelsprung. Kontextualisierung, Analyse und Edition einer Krumauer Hanswurstburleske. Praha: Institut umění - Divadelní ústav v Praze 2015. (Beilage der Zeitschrift Divadelní revue 26/2) S. 40f. 
verstärkt gesellschaftlichen Einfluss für sich forderte. ${ }^{114}$ Erster Schritt dazu war es, der äußerst heterogenen Klasse durch eine rational begründete, allgemein verpflichtende Moral ein Gefühl der Gemeinsamkeit zu vermitteln. Entscheidende Bedeutung kam hier der belustigenden ,Erbauung ' der Komödie zu, die Gottsched in Anlehnung an Aristoteles, jedoch moralpädagogisch akzentuiert, „als eine Nachahmung einer lasterhaften Handlung, die durch ihr lächerliches Wesen den Zuschauer belustigen, aber auch zugleich erbauen kann" ${ }^{115}$, definiert. Moral wird dabei als eine aus vernünftigen Prinzipien deduzierbare Kategorie gedacht, deren elementaren Wert die ,Fabel' des Stücks herausarbeiten soll. Indem ein ,Laster' als verstandeswidriger Bruch des moralischen Konsenses in aller Deutlichkeit vorgeführt und als „allgemeine Thorheit“"116 belacht wird, kann bürgerliche Identität über das Einvernehmen in moralischen Fragen eingeübt werden. Eine zweckungebundene Komik, die rein unterhaltend sein will, hatte in diesem Konzept keinen Platz. ${ }^{117}$ Dementsprechend finden „die deutschen Narren [... ] wie Hans Wurst oder Pickelhering“ Gottscheds heftige Ablehnung; denn da sie „kein Muster in der Natur haben "118, ist das Verlachen ihres anormalen Verhaltens ohne jegliche pädagogische Relevanz. Verlacht werden sollte in der ,regelmäßigen` Komödie lediglich, was von einem eingeforderten vernunftgegründeten Standard gesellschaftlichen Normverhaltens abweicht. Das Theater war in diesem Sinn als Erziehungsanstalt zu verstehen, in der das Disziplinierungsinstrument Lachen zur Identitätsbildung funktionalisert werden sollte.

In Wien setzt die Debatte um die Bühnen und darüber, was diese zeigen sollen, in den späten 1740er Jahren ein und verläuft in weiterer Folge über mehrere Jahrzehnte. Ihr prominentester Vertreter ist Joseph von Sonnenfels, der „wirkmächtigste Poetologe der mariatheresianisch-josephinischen Zeit" ${ }^{119}$. Nur mehr vordergründig aber betrifft nun die Kontroverse die Ästhetik des Theaters; auch die bürgerliche Selbstdefinierung war nicht länger das vorrangige Ziel. Der Wiener ,Hanswurststreit' hat eine deutliche politideologische Note, indem „die ,Verregelmäßigung ' des Theaters letztlich auf die ,Verregelmäßigung ' der Untertanen “120 abzielte. Die 1750er und 1760er Jahre sind durch die Opposition von Bemühungen um die Etablierung eines regelmäßigen Theaters einerseits und dem ungebrochenen Erfolg des extemporierten Spiels andererseits geprägt. 1751 wurde von Maria Theresia im Rahmen einer Verwaltungsreform die ,Bücher-Censur-Hofcommission“ eingerichtet und somit die Zensur „zu einem potentiellen Instrument der Aufklärung umfunktioniert" ${ }^{121}$, doch befasste sich die Kommission zu-

114 Vgl. Christian Neuhuber: Das Lustspiel macht Ernst. Das Ernste in der deutschen Komödie auf dem Weg in die Moderne: von Gottsched bis Lenz. Berlin: Erich Schmidt 2003, S. $24 \mathrm{ff}$.

115 Johann Christoph Gottsched: Versuch einer Critischen Dichtkunst. Unveränderter photomechanischer Nachdruck der 4., vermehrten Auflage, Leipzig 1751. 5., unveränderte Auflage. Darmstadt: Wissenschaftliche Buchgesellschaft 1962, S. 643.

116 Ebda., S. 640.

117 Vgl. Gottscheds Diktum: „Vieles ist auch lächerlich; wie zum Exempel die Harlekinspossen der Italiener: aber darum ist es doch nicht lasterhaft." Ebda., S. 643.

118 Ebda., S. 654.

119 Müller-Kampel, Hanswurst, Bernardon, Kasperl, S. 156.

120 Marion Linhardt: Kontrolle - Prestige - Vergnügen. Profile einer Sozialgeschichte des Wiener Theaters 1700-2010. Graz: LiTheS 2012. (LiTheS Sonderband 3) S. 13.

121 Müller-Kampel, Hanswurst, Bernardon, Kasperl, S. 153. 
nächst ausschließlich mit Druckwerken, erst ab 1760 auch mit Handschriften und Szenarien. Am Kärntnertortheater, der bedeutendsten Bastion des Improvisationstheaters im deutschsprachigen Raum, wurde nach der Aufhebung des kaiserlichen Privilegs 1752 auch Einfluss aufs Personal genommen, indem Darsteller verpflichtet wurden, die nicht aus der Stegreiftradition stammten; zudem war eine bestimmte, festgelegte Anzahl von Spieltagen regelmäßigen Stücken vorbehalten. ${ }^{122}$ Ein Faktor der Beständigkeit des extemporierten Spiels lag dabei auch darin, dass die Pächter nicht auf diese Vorführungen verzichten konnten: einerseits aus wirtschaftlichen Gründen, andererseits aus Mangel an spielbaren regelmäßigen Stücken. Im Februar 1752 erließ Maria Theresia das sogenannte Norma-Edikt, das definierte, an welchen Tagen keine Vorstellungen stattfinden durften. Außerdem sah es eine Einschränkung des Repertoires vor. So sollten vornehmlich Stücke französischer, italienischer oder spanischer Autoren gespielt werden, aber auch konforme deutsche Dramen, die allerdings einer vorausgehenden Prüfung zu unterziehen seien; explizit verboten wurden Bernardoniaden und ähnliche Stücke. Auch diese Maßnahmen zeigten vorerst nur bedingten Erfolg.

Als sich nach dem Tod Friedrich Wilhelm Weiskerns (1768) und Prehausers (1769) mit dem nach Wien zurückgekehrten Kurz-Bernardon ein neuer Aufwind für das Stegreif-Theater ankündigte, reagierte Sonnenfels mit einem Promemoria und einer Resolution und konnte eine Verschärfung von Zensur und Extemporierverbot erwirken. Im Fokus war eine Kontrolle dessen, was den Bürgern präsentiert wurde, da sich improvisierte Stegreif-Szenen freilich auch jeglicher Zensur vorab entzogen. Ähnlich dem Konflikt um die Predigten befürchtete man einen schlechten Einfluss des Theaters vor allem auf die unteren Schichten. ${ }^{123}$ Sonnenfels' Anliegen, sämtliche Regelungen auch auf die Wandertruppen und Vorstadt-Theater auszuweiten, wurde allerdings von Joseph II. abgelehnt. Da diese noch bis in die frühen Neunzigerjahre über viel größere Freiheit verfügten, verlagerte sich „das Spaßtheater alten Schlages, wenn auch aufklärerisch-rationalistisch überformt, " 124 in die Vorstadt-Theater.

Dem Kontext dieses Konflikts entspringt ein 1761 in Pressburg erschienenes aufklärerisches Tendenzstück mit dem lapidaren Titel Hannswurst. Die als Hanswurst-Spiel gekleidete persiflageartige Streitschrift richtet sich in ihrer ironisierenden Überspitzung gegen die burleske Spieltradition und die Vernarrtheit des Publikums in die lustige Figur. Autor des Stückes war wohl nicht, wie oft in der Forschung vermutet, Joseph

122 Vgl. u. a. Zechmeister, Die Wiener Theater nächst der Burg und nächst dem Kärntnerthor. - Hilde HaiderPregler: Des sittlichen Bürgers Abendschule. Bildungsanspruch und Bildungsauftrag des Berufstheaters im 18. Jahrhundert. Wien/München: Jugend und Volk 1980. - Sonnleitner, Die Wiener Posse.

123 Sonnenfels schreibt: „Giebt es nicht mehrere Classen der unteren Bürger, welchen der Staat nach durchgearbeitetem Tage eine Erholung zu verschaffen verpflichtet ist? Wäre es nun aber gleichgiltig, diesen Theil Bürger entweder in eine Gauklerbude hinzuschicken, wo sie die Albernheiten eines Possenreißers und seine Unfläthigkeiten mit Ekel anhören müssen, oder ihnen ein gesittetes Vergnügen zu verschaffen, wo sich ihre Stirne, ohne den Anstand schamroth zu machen, aufheitern kann? Der Mann aus der mittleren Classe bedarf es sogar noch weit mehr, dass der Staat ihm eine anständige Ergötzung zu verschaffen suche, als der Adel.“ In: Joseph von Sonnenfels: Briefe über die Wienerische Schaubühne. Hg. von Hilde HaiderPregler. Graz: Akademische Druck- und Verlagsanstalt 1988. (Wiener Neudrucke 9) S. 411.

124 Müller-Kampel, Hanswurst, Bernardon, Kasperl, S. 160. Vgl. auch Linhardt, Kontrolle - Prestige - Vergnügen, S. 16ff. - Bodi, Tauwetter in Wien, S. 163ff. 
Leopold Petrasch, sondern der Pressburger Autor und Sonnenfels-Anhänger Karl Gottlieb von Windisch (1725-1793), Mitbegründer der dortigen Gesellschaft der Freunde der Wissenschaften. ${ }^{125}$ Schauplatz seines Lustspiels ist das Schloss des Herrn von Hammelwitz, dessen Schwiegersohn in spe Eraste und Freund Klugendorf sich Sorgen um den guten Ruf der adeligen Familie machen. Denn diese ist dem - inzwischen von allen vernünftigen Aristokraten abgelehnten - Possenspiel verfallen und will selbst eines als Haustheater inszenieren. Als besonders ärgerlich erscheint dabei, dass ein Herr von Einfaltshausen die tragische Handlung von Sophokles' Antigone als Hanswurst durchkreuzen soll, denn, so argumentiert Hammelwitz: „wenn man nichts dabey zu lachen hätte; zu was wäre der Plunder?“" ${ }^{126}$. Bevor es dazu kommt, sollen nach dem Schema der sächsischen Typenkomödie die fehlgeleiteten Theaterliebhaber gebessert werden, indem ihnen das unmögliche Verhalten eines ,realen' Hanswurst vor Augen geführt wird. Verkörpert wird dieser vom Kammerdiener Heinrich, den Klugendorfs Stiefsohn Leander in Diensten hat. Heinrich spricht in seiner Rolle stark dialektal, wobei die verwendete Mundart - ganz im Sinne der spielinternen Funktion - mehr Kunstprodukt denn spezifische Varietät ist, dient doch der betonte Dialektgebrauch zur Überzeichnung seiner Derb- und Verdorbenheit; schließlich soll sich der Spaßmacher sowohl den dramatis personae als auch den Rezipienten gegenüber unmöglich machen:

Herr von Einfaltshausen. Du bist, wie mich dünkt, ein lustiger Kerl, und hast ohne Zweifel auch gute Einfälle; Kannst du mir nicht etwas lächerliches vormachen? denn dieß höre ich gern.

HeinRICh. Jo, fir mey Hearn moch ih scho Gspoas, so viel alsr wihl; obr an niedn Norrn ko ih nit aufwoartn.

Herr von Einfaltshausen. Ich habe geglaubt daß du durchaus voller Schnacken und Possen wärest?

HeINRICH. An solichn, der mr nix zfressn gibt, moch ih oa koan Gspoas; ös mechts mr oa dr bormherzigy Gaflier sey!

Herr von Einfaltshausen. auf die Seite Der Kerl scheint mir grob. laut Hast du gehört: ich habe die Hannswürste jederzeit gern gehabt, und ich werde auch jetzt bey einer Gelegenheit selbst den Hannswurst vorstellen.

HeinRich. So sanmr Briedar! Ha, ha, Norrn hon ih wuol gnuy unter eng gsegn, ober koan Honntzwuerst gleywuolstr nit.

Herr von Einfaltshausen. Sey nicht so grob, und denke doch, mit wem du redest.

HeInRICH. Sagstdes do selmr, daßd a Honntzwuerst wern willst; bist den mer als ih? Hoa?

Herr von Einfaltshausen. Du Flegel! rede höflicher, oder ich will dir gleich...

125 Vgl. Otto G. Schindler: Hanswurst in Preßburg/Bratislava. Deutsche Lustigmacher auf den ältesten Theaterzetteln Ungarns. In: Horst Fassel/Paul S. Ulrich/Otto G. Schindler (Hg.): Deutsches Theater im Ausland vom 17. zum 20. Jahrhundert. Interkulturelle Beziehungen in Geschichte und Gegenwart. Münster: LIT 2008, S. 95-122, hier 109. Windisch war u. a. auch Ehrenmitglied der Olmützer societas incognitorum, die Petrasch bereits 1746 als erste deutsche Gelehrtengesellschaft in den habsburgischen Ländern ins Leben gerufen hatte, vgl. Anton Schlossar: Petrasch, Josef Freiherr von. In: Historische Commission bei der königl. Akademie der Wissenschaften (Hg.): Allgemeine Deutsche Biographie. Bd. 25: Ovens-Philipp. Leipzig: Duncker \& Humblot 1887, S. 516-517.

126 [Karl Gottlieb von Windisch]: Hannswurst, ein Lustspiel in einem Aufzuge. Preßburg: Johann Michael Landerer 1761, S. 14. - Vgl. auch Hedvig Belitska-Scholtz/Olga Somorjai: Das Kreuzer-Theater in Pest (1794-1804). Eine Dokumentation zur Bühnengeschichte der Kasperlfigur in Budapest. Wien/Köln/ Graz: Böhlau 1988. (Maske und Kothurn, Beiheft 12) S. 96. 
HeInRICH. Wos schär ih mih um dih, du Liendl! du mueßt selmr a solicher sey! und wandst mr nit gley d'Goschn holst: so gy ih dr a Faunzn, daß dih verwundarn wirst.

Herr von Einfaltshausen. Was Henker ist das für ein abscheulicher Kerl? Ich werde noch die Leute ruffen müssen, die dich hinaus prügeln.

Heinrich. A ondry Monier is vo ondrn prüglt wern, und a ondry, wonn mr von Honntzwuerst prüglt wird. Ih by a Kommadienr, daßdes woast, du Riepl! vrstöhst den gor koan Gspoas nit? und wilst an Honntzwuerst mochn! wondsta Honntzwuerst bist, so muesst selmr prügln.

Herr von Einfaltshausen. Ich verstehe zwar Spaß, aber von dir nicht. Auf der Bühne bin ich ein Bauer, aber nicht hier.

Heinrich. Guet, so derfst nuer in dr Kumedy Prügl austhaln, ih obr überoll, und wons mr einkimt. Ih by ollywaal dr Honntzwuerst.

Herr von Einfaltshausen. Mich wirst du doch nicht prügeln? denn ich bin ein Edelmann.

HEINRICH. Wondst koan prügln wirst, der a großr Hear is, wem wirst den zprügln kriegn?

Herr von Einfaltshausen. Ja auf der Bühne prügle ich wohl auch den König Kreon.

Heinrich. Bißt den hietz mear ols dr Kiny durt is? O du tolketr Hiesl! du wilst a Kumödy hobn. A Norr und a Honntzwuerst mochn gley a Kumödy.

Herr von Einfaltshausen. Ich sage es dir zu guter letzt: verliere den Respect nicht, den du mir schuldig bist!

HeInRICH. Wort du verfluechtr Kearl, ih will der gley dey Respect geabn! er prügelt den Hrn. v. Einfaltsh. der hinaus läuft. Nun mit einem bin ich fertig. Das Ding soll einen Lärm absetzen, der gewiß nicht klein seyn wird. ${ }^{127}$

fir mey Hearn] für meinen Herrn Gspoas] Späße an niedn Norrn] einem jeden Narren ko] kann oa koan] auch keinen ös mechts mr oa] von mir aus könntet ihr auch sanmr] sind wir hon ih wuol gnuy unter eng gsegn] habe ich wohl genug unter euch gesehen gleywuolstr] gleichwohl Sagstdes do selmr] du sagst es doch selbst Liendl] Wiener Spottwort für einen dümmlichen Menschen d'Goschn holst] den Mund hältst gy ih dr a Faunzn] gebe ich dir eine Ohrfeige wonn $\mathbf{m r}$ ] wenn man daßdes woast] damit du es weißt Riepl] Kurzform für Rupert, Ruprecht; Spottwort für einen groben Menschen wondsta] wenn du ein austhaln] austeilen wons mr einkimt] wenn es mir einfällt ollywaal] alleweil, immer Wondst koan] wenn du hietz] jetzt tolketr] dummer Hiesl] Kurzform für Matthias; Spottwort für einen naiven Menschen

Nachdem den Komödienliebhabern durch weitere in die Realität transponierte absurde Possenhandlungen die Schändlichkeit und Schädlichkeit solcher Spiele vor Augen geführt wird und Eraste zu einem resümmierenden Plädoyer für die Verbannung des Burlesk-Possenhaften von der Bühne ausholt, wird das Täuschungsmanöver aufgeklärt. So muss sich schließlich auch Hammelwitz durch die Intrige zur Einsicht gebracht zeigen („heute noch soll die ganze Bühne zerbrochen, und sammt den Scenen ins Feuer geworfen werden. Künftighin aber soll man auch gewiß in meinem Hause nichts von dergleichen Narrheiten mehr, weder hören, noch sehen “128); mit Überlegungen zur „Einrichtung einer Bühne von gutem Geschmacke“ ${ }^{129}$ klingt das Spiel aus. Gottsched selbst beklagte in einer Rezension zu Windischs Stück die anhaltende Dominanz der Hanswurst-Figur auf den Wiener Bühnen, setzte seine Hoffnung aber in diejenigen, die den „verdorbenen Geschmack“ ${ }^{130}$ des Publikums auszutreiben versuchen, denn es sei

127 Windisch, Hannswurst, S. 30-32.

128 Ebda., S. 50.

129 Ebda., S. 52.

130 Johann Christoph Gottsched: [Rezension zu:] Hanswurst, ein Lustspiel in einem Aufzuge. Presburg bey J.M. Landerer 1761. 52. S. in 8. In: Das Neueste aus der anmuthigen Gelehrsamkeit 12 (1762), S. 199-213, hier 200 . 


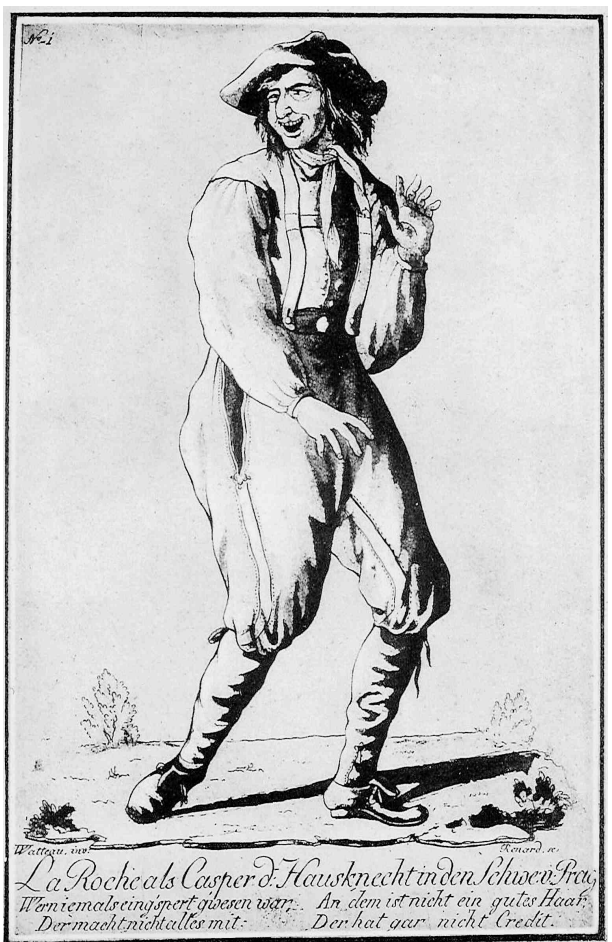

Abb. 50: Rollenbild La Roches als Kasperl (1794).

„l̈̈cherlich und schädlich, solche närrische Komödien, worinn der Hanswurst erscheint, und mit seinen Unflätereyen und hirnlosen Possen den Pöbel und seinesgleichen zum Lachen zwingt, in einer wohleingerichteten Republik zu dulden “ ${ }^{131}$. Doch noch zwanzig Jahre später trieb die lustige Figur höchst erfolgreich auf einer Wiener Vorstadtbühne ihr Unwesen, wenn auch in domestizierter, weniger kreatürlicher Form: Johann Joseph La Roches liebenswert-infantile Kasperl-Figur machte das Leopoldstädter Theater zur bekanntesten Bühne im süddeutschen Raum. ${ }^{132}$ Selbst Joseph II. soll ein begeisterter Besucher gewesen sein, wie eine Anekdote des Komponisten Karl Ditters von Dittersdorf überliefert:

Der Kaiser gieng eines Abends ins Marinellische Theater in der Leopoldstadt. Kasperl sang, als Nachtwächter, eine Arie außerordentlich komisch. Der Kaiser, dem sie sehr gefiel, ließ sie sich abschreiben und, da er eine gute Baßstimme hatte, so sang er sie bey seiner Kammermusik. Er wiederholte diese Arie einige Male und legte allmählich immer mehr die Lazzi’s des Kasperl hin-

131 Ebda., S. 212.

132 Auch in diesem Fall ist der prominente Schauspieler nicht Erfinder der Figur, jedoch wurde sie erst durch ihn zum „überregional bekannten Typus spezifischen komischen Profils“, vgl. Müller-Kampel, Hanswurst, Bernardon, Kasperl, S. 13. - Andrea Brandner-Kapfer: Kasperls komisches Habit. Zur komischen Gestalt und zur Gestaltung der Komik in Erfolgsstücken des Leopoldstädter Theaters um 1800. In: Andrea Brandner-Kapfer/Jennyfer Großauer-Zöbinger/Beatrix Müller-Kampel: Kasperl-La Roche. Seine Kunst, seine Komik und das Leopoldstädter Theater. Graz: LiTheS 2010. (LiTheS. Zeitschrift für Literatur- und Theatersoziologie. Sonderbd. 1) S. 56-104. 
ein. „Nun, was meynt Er?“ fragte er einmal den Greybig [Franz Kreibich, Musikdirektor und Violinist], „habe ich die Arie so vorgetragen, wie Kasperl?“ - O! O! O! versetzte Greybig mit seiner gewöhnlichen Begeisterung; bey meiner armen Seele! Ew. Majestät sind der leibhafte Kasperl! ${ }^{133}$

Doch auch diese so harmlos erheiternde Rolle forderte noch Kritiker zu literarischen Fehdeschriften heraus, so etwa den anonymen Verfasser des 1781 erschienenen Pamphlets Etwas für Kasperls Gönner, der vor allem gegen die Zuseher und ihren unauslöschlichen Wunsch nach komischer Unterhaltung wettert:

Vielen, denen das Andenken weyland Hannswurstes (dessen Anhänger Kasperls Parthey zugewachsen sind) so werth ist, daß sie mit einem ihre ganze Seele ausdrückenden Blicke versichern, sie hätten von der Zeit kein Spektakel besuchet, als die Schaubühne einen so großen Verlust erlitten, und der Ort des Ergötzens sich in einem Platz des Weinens, seufzens, und Moralisirens ungewandelt hat, und kaum ein, oder ein paar Akteurs was spaßiges hervor bringen können. Warum, sagen sie, soll ich mein Geld für Weinen ausgeben, da die Welt ein Sammelplatz des Jammers, und des Weinens ist? ${ }^{134}$

„Es wäre zu wünschen“, so das tendenziöse Fazit, „daß der denkende Theil wenigstens dem Geschmack nur die einzige Gewogenheit erweiste, und solches Vernunft, und Anstand entehrendes Gezeug mit ernster, Merkmale seines Unwillen, ausdrückender Miene aufnähme" ${ }^{135}$. Im Anhang der Schmähschrift findet sich als Beleg für diesen üblen Geschmack ein Kasperlstück, betitelt Spiel der Liebe und des Glücks, oder Kasperl, der geglaubte Printz der Insul Csiri Csari. Das ,Spiel' ist vielmehr eine exemplarische Szene und will in satirischer Weise die als besonders anstößig geltenden Konstituenten der Kasperliaden La Roches aufzeigen. Wohl nicht erst für den heutigen Leser aber macht dieses Beispiel - völlig gegen die eigentliche Intention - die Faszination der frühen Kasperl-Stücke verständlich und lässt Rückschlüsse auf performative Eigenheiten zu, die aus erhaltenen Spieltexten nur bedingt zu rekonstruieren sind. ${ }^{136}$ Charakteristisch sind Exotismus (der Schauplatz der „Insul Csiri Csari“, auf den Kasperl als PrinzErsatz versetzt wird), Verkleidungs- und Kostümierungsfreude (Kasperls Auftritt „in kalikutischer Kleidung“ ${ }^{137}$ etc.), Maschinenzauber (vgl. die Ankündigung „mit [...] Maschinen, Flugwerken, Versenkungen, Verschwindungen “ ${ }^{138}$ ), Handlungsbrüche, groteske Elemente, körperbetontes Spiel und übertriebene Mimik. ${ }^{139}$ Vor allem aber zeigt die durchaus witzige Szene, dass auch die Dialektverwendung des Protagonisten - in deutlichem Kontrast zu den anderen Figuren - zu den Charakteristika der Kasperlia-

133 Karl von Dittersdorf: Lebensbeschreibung. Seinem Sohne in die Feder diktirt. Leipzig: Breitkopf und Härtel 1801, S. 240.

134 Etwas für Kasperls Gönner, S. 3f.

135 Ebda., S. 6.

136 Vgl. Ernst, Zwischen Lustigmacher und Spielmacher, S. 205.

137 Etwas für Kasperls Gönner, S. 14.

138 Ebda., S. 7f.

139 Vgl. Ernst, Zwischen Lustigmacher und Spielmacher, S. 205. 
den zählt, auch wenn die Mundart in der Verschriftlichung nicht unbedingt authentisch wirkt. ${ }^{140}$

VALERIo. Wie hast du den Brief an Angeolina bestellet? Rede, sage, wo ist die Antwort?

Kasperl giebt ihm eine Maulschele.

VALERIO. lauft nach den Degen. Diese Verwegenheit kostet dich dein Leben! richte deine zerraufte Seele in Ordnung, du must sterben!

KASPERL. fält ihm zu Füssen schreit erbärmlich O jeges! o jeges! verschonts mai jungs Lebn, i bin jo meiner Mueder ihr schönster Sun, si hot jo gar kan ondern ghobt.

VALERIO. Sprich Bestie, wo du nicht willst, daß deine Spitzbübische Seele auf der Spitze meiner Klinge zittere.

KASPERL. jo jo i will als bstehn.

VALERIO. Rede Elephanten Schlingl', antworte Mißgeburt.

KASPERL. No ös hobts gsogt nit wohr, ös hobts gsogt, wos gsogt hobts.

VAlerio. Wie du Hauskanalie, du erkühnest dich zu spaßen. Greift nach dem Degen.

KASPERL. Auwe! Auwe! i sog schon i sog schon. No, i bin holt hingongn, und do bin i durt gwest, und do begegnet mit anr in anr Parukn, ols wons Dschwobn abgsuzlt hädn, er hot su gonz a Hausmasterisch Gsicht ghobt, und wal ös gsogt hobts, i soll im Brief ihm Hausmastr gebn, so hobi gfrogt ob er der Hausmastr is? Nu sogtr, worum frogtr? Narrischer Norr sogi, doaß is ihna wir, i mus in Hausmastr an Brief von Hr. Valerio gebn, und er mußn dr Fräula Anschula bringn, und dos derf kan Mensch wissn. No sogter iß schon on rechtn Mon giebr nur in Brief her. Ich frogn, ob i nid soll auf auf [!] d'Ontwort wortn, do gibt er mir a Por Tetschn, doaß i d'Nosen auf der Erd gsucht hob, do host d'Ontwrt, brings dein Herrn.

VALERIO. Himmel das wahr ihr Vater!

KASPERL. Das mus gwis amol a Schmolztrager gwest sayn.

VALERIO. Ich bin verlohren! ${ }^{141}$

O jeges] genretypischer Klageruf, schon für Hanswurst und Bernardon belegt ös hobts gsogt] ihr habt gesagt anr] einer ols wons Dschwobn abgsuzlt hädn] als wenn die Küchenschaben sie abgeleckt, ausgesaugt hätten wal ös] weil ihr hobi] hab ich sogtr] sagt er Mon] Mann a Por Tetschn] ein Paar Ohrfeigen Schmolztrager] Schmalzträger (alpenländische Butter- und Käsehändler galten als besonders kräftig)

Wie schon in der Hanswurst-Parodie sollte auch hier der Dialekt lediglich als Mittel der Verächtlichmachung und übertriebenen Typisierung der geschmähten Figur dienen. Gleichwohl vergegenwärtigen die Repliken in dieser nicht für die Drucklegung geglätteten Form einen Teil des besonderen Reizes, der sich aus der Differenz der Sprachvarietäten ergab. Sie sind somit wohl sogar authentischer als die ohne verunglimpfende Absicht abgedruckten, für ein größeres Lesepublikum gedachten Texte. Inhaltlich wird schlicht eine Aufeinanderfolge typischer Motive geboten, ohne einen schlüssigen Bogen zu spannen: Kasperl wird von seinem Herrn aufgrund eines schwerwiegenden Fehlers verjagt, dann von der Hexe Megära auf eine exotische Insel versetzt, wo er die Stelle des Prinzen einnimmt, und bekommt schließlich die Prinzessin zur Frau versprochen. Dieses unverknüpfte Possen- und Zoten-Allerlei soll den „Marionetten Geschmack“142 illustrieren,

140 Vgl. zur Dialektverwendung von La Roche auch Gustav Gugitz: Der Weiland Kasperl (Johann La Roche). Ein Beitrag zur Theater- und Sittengeschichte Alt-Wiens. Wien, Prag, Leipzig: Strache 1920, S. 257 und 264f. Gugitz, der das Pamphlet inklusive Stück 1920 ediert, verweist auf eine Entgegnung zu diesem Pamphlet, in der dessen Autor angegriffen wird: „bald schreibt er wie ein Jude, bald wie ein Deutsch-Böhm und nicht ein Wörtchen nach der bäurischen Mundart, die er lächerlich und verächtlich machen will“" (Gugitz, Der Weiland Kasperl, S. 302 bzw. 106).

141 Etwas für Kasperls Gönner, S. 9 f.

142 Ebda., S. 3. 
den der Kasperl wieder salonfähig gemacht habe, zumindest für jenen unverständigen Teil des Publikums, dem es in Wirklichkeit mehr um gesellschaftlichen Austausch und Tratsch gehe, denn um ein Theater, das eigentlich „eine Schule der edlen Sitten, und des guten Geschmacks" ${ }^{143}$ zu sein habe. Gustav Gugitz, der die Schrift als erster edierte, hatte wenig Verständnis für diese „leere[n] Wichtigtuereien eines Pseudoliteratentums, das alles mißverstand und mit angelesenen Phrasen des Gottschedianismus punktete“ ${ }^{144}$.

\section{Literatursatirische Dialektfunktionalisierung}

Das Kasperl-Pasquill war nur eines von Tausenden Druckwerken, die unter den nur kurz herrschenden liberalen Bedingungen der josephinischen, erweiterten Preßfreiheit ${ }^{\text { }} \mathrm{ab}$ 1781 den anonymen Buchmarkt fluteten und einen Wettbewerb der Meinungen widerspiegeln, an dem nun auch Neo-Autoren partizipieren konnten, die unter den früheren restriktiveren Bedingungen kaum eine Möglichkeit zur Publikation vorgefunden hätten. Dass darunter auch viele Unberufene waren, die mit wertlosen Tageserzeugnissen rasches Geld machen oder ihren kruden intellektuellen Ergüssen typographisches Gewicht verleihen wollten, wurde schon rasch wiederum in Broschüren reflektiert, die die ästhetische Qualität der kritisierten Schriften kaum übertrafen und selbst zur Widerrede reizten. In der 1781 erschienenen, mehrfach aufgelegten Spottschrift Die neue Gestalt der Narrenversorgung in St. Marx etwa sieht der ungenannte Verfasser - möglicherweise Aloys Blumauer, der mehrfach mit literarischer Kritik an der Broschürenflut hervortrat $^{145}$ - etliche seiner Schreiberkollegen reif für die Irrenanstalt und empfiehlt ihnen, bei ihrem Leisten zu bleiben:

Seyd's nit so bissig auf einander, verderbt's ja Einer dem Andern den G'spaß, was will das sag'n? S' kommt nichts r'aus. Seyd's gute Kletz'n, so gebts süss'n Most. Muß denn gleich s' Feuer im Dach seyn, wenn Einer, oder der Andere einen Fehltritt mit seinem Steckenpferd macht, müßt nit gleich so harb herfahrn, als wenn schon dem Himmel der Bod'n aus wär; will halt Jeder sein Kramm aufn Markt trag'n, muß den Leuten auf all'n Eck'n, und Gass'n lang gnug vorurgeln, und sich halbtod schrey’n: Schöne Rarität! - schöne Spilewet! - gibsi Kreuzer! guksi mein Loch; ${ }^{146}$

Kletz'n] Birnen harb] böse, wild Kramm] Ware, Jahrmarktattraktion vorurgeln] vororgeln: mit der Drehorgel spielen Schöne Rarität!] typischer Ausruf eines Jahrmarktanbieters Spilewet] Spielwerk (Nachahmung des gebrochenen Deutschs der Marktfahrer) gibsi] geben Sie (s. vorne) guksi mein Loch] schauen Sie in mein Loch (bei Schaukästen, Camerae obscurae etc.)

143 Ebda., S. 20.

144 Gugitz, Der Weiland Kasperl, S. 280.

145 Vgl. unter anderem das Gedicht Die Wiener Büchl-Schreiber nach dem Leben geschildert von einem Wiener (1783), das gleichfalls dialektale Anklänge nicht scheut und von Nicolai auszugsweise in der Allgemeinen deutschen Bibliothek (1784, 57/1, S. 590) abgedruckt wurde.

146 Die neue Gestalt der Narren-Versorgung in St. Marx. Drite Auflage. Wien, Gedruckt, und verlegt in der Jahnschen Universitätsbuchdruckerey, in der grossen Himmelspfortgasse, im kleinen Romhof, Nro 981. im ersten Stock. 1781, S. $28 \mathrm{f}$. 
Empört von den Angriffen dieses Werkleins - und der gewählten mündlichkeitsnahen Sprachgebung - zeigt sich der Autor der Gegenschrift Die Gelehrten im Nasenland, der den Verfasser als Repräsentanten all jener sieht, die ihre eigentliche Bestimmung vergessend und ohne entsprechende Bildung zur Feder griffen. Herzstück der Schrift ist ein Traum über das ,Nasenland', ein Paradies der Gelehrten, wo sich die Geistesgrößen der Vergangenheit und jüngeren Gegenwart - erkennbar an ihren besonderen Nasen - vergnügen, als plötzlich ein Hanswurst Einlass fordert, auf einem Esel sitzend, „beyde ganz mit Manuskripten, und Postbücheln, und Hetzzetteln, und Brochüren überdeckt, und behängt " ${ }^{147}$. Auch er beansprucht, im tiefsten Wiener Dialekt, für sich, „a Glerter“ ${ }^{\text {148 }} \mathrm{zu}$ sein; wird aber nach der Lektüre seiner mitgebrachten Schriften von den Geistesgrößen verjagt:

Diese Worte, diese Ausdrücke, und Gedanken! - Wie, Niederträchtiger, du wagst es das Land der Gelehrten durch deine Gegenwart zu entheiligen, eines Rechts dich ihres Wohnhauses, so für Männer unsers gleichen gemacht ist, mit deinem Geschmir anzumassen, für Männer, die - Was? i war kan Glerter? Gift saferment, muß anner ia vor Gall fast zu ein Eßigfassel wern, schauts, oes kömts mir Quanti Verdrati vor, i bin an Autor, und der mit sein langspitzigen Ohrwascheln mein Mithelfer, mein Dugatsbruader, hab'n mitsam den Diogenes, d'trauerfers, und alle Hetzzetln vor Zeiten gemacht, eh no die Friseer dran zu pfuschen angefangt. - Saferment, hättn Herrn eher kennt, hättn meiner Six in mein unsterblichen Werk nach St. Marx verschrieben. - Ich erstaunte über die Frechheit des Kerls, und noch mehr über den Maulesel, der sich da zu bäumen, und allerhand Grimassen zu machen anmaß. - Fort von hier sprach ein edler ehrwürdiger Mann jagt ihn vor unser Nasenland hinaus, die Händ am Rücken gebunden. ${ }^{149}$

i war kan] ich wäre kein anner] einer oes kömts] ihr kommt Quanti Verdrati] ganz verdreht (italienisierende Scherzwendung) Dugatsbruader] Duzbruder (Verballhornung) Diogenes] Kurztitel für die (verschollene) Schrift Diogenes in der Maske d'trauerfers] die Trauerverse (auf den Tod der Kaiserin Maria Theresia), möglicherweise Blumauers Beitrag zu den Leichengedichten auf den Tod Marien Theresiens Hetzzetln] Programme des Wiener Hetztheaters kennt] gekannt meiner Six] Bekräftigungsfloskel St. Marx] ehemaliges Bürgerspital im heutigen 3. Gemeindebezirk, vor Eröffnung des ,Narrenturms 'im Allgemeinen Krankenhaus 1784 auch Unterbringungsort für psychisch Kranke

Bildung, darin lässt dieser uninspirierte Hickhack keinen Zweifel, drückt sich vorrangig in der Sprachgebarung aus. Wer es nicht versteht, sich gewählt im Standard auszudrücken, oder diesen verweigert, wird mit Spott aus der Gelehrtenwelt verstoßen. Die Figur des Dialekt sprechenden Hanswurst unterstreicht insofern die gründliche Desavouierung der Substandardsprache im gelehrten Diskurs. Allenfalls als literarische Waffe, mit der diese Verunglimpfung vorangetrieben werden konnte, hatte die Mundart noch ein Recht, gedruckt zu erscheinen.

Was sich allerdings in den 1780er Jahren bereits als communis opinio gab, galt einige Jahrzehnte zuvor im deutschsprachigen Raum noch längst nicht als ausdiskutiert. Springender Punkt des Normierungsdiskurses war zweierlei: zum einen die Frage, an welchem sprachlichen Vorbild sich die gemeinsame deutsche Schriftsprache orientieren sollte, zum anderen, inwieweit regionale Eigenheiten (Provinzialismen) in diesen neuen

147 [Anonym]: Die Gelehrten im Nasenland, ein Traum, und Erzählung des allda erlittenen Schicksals der beyden Verfasser der neuen Gestalt der Narrenversorgung in St. Marx. Wien, [o.V.] 1781, S. 29.

148 Ebda.

149 Ebda., S. 30f. 
Standard zu integrieren wären. ${ }^{150}$ Energische Befürworter einer Integration von Provinzialismen - und damit in Kontraposition zu Gottscheds Konzept einer exklusiven Hochsprache nach meißnischem Vorbild - waren die Zürcher Kunsttheoretiker Johann Jakob Bodmer und Johann Jakob Breitinger. Beide waren der Überzeugung, dass eine Sprache nicht über eine konstruierte Norm, sondern auf Basis ihres konventionellen Gebrauchs bestimmt werden müsse, da sie an eine konkrete Sprachgemeinschaft gebunden sei. Die anfangs durchaus amikale Diskussion, die Bodmer und Breitinger mit dem Leipziger Sprachrichter und seinen Anhängern führten, nahm im Lauf der Jahre immer schärfere Töne an, da die Schweizer die Vorbildlichkeit des ostmitteldeutschen Meißnischen entschieden in Frage stellten und für eine gegenseitige Bereicherung von Hochund Regionalsprachen eintraten. ${ }^{151}$ Die Aufgabe lexikalischer Eigenheiten, wie Gottsched sie forderte, würde nach Bodmer zum Verlust volkskultureller Autonomie führen und die Identifikation mit der eigenen Herkunft erschweren. ${ }^{152}$ Jedes Volk solle deshalb seinen Dialekt verbessern, indem die Vorzüge der anderen Regionalsprachen integriert, eigene Stärken aber selbstbewusst verwendet und gepflegt werden. Die Notwendigkeit einer Vereinheitlichung der Schriftsprache stellte Bodmer somit niemals in Frage; ihm war es vielmehr um das Recht auf regionalspezifische Färbung zu tun. ${ }^{153}$ Was die Gottschedianer als Makel und Gefährdung einer wünschenswerten gemeinsamen Sprache sahen, verstanden die Schweizer Konkurrenten vielmehr als Chance und Gewinn.

Dieser regionalistische Ansatz konnte bei den Anomalisten nur auf Ablehnung stoßen und wurde in der weiteren Diskussion nicht selten als Versuch, das Hochdeutsche durch den jeweiligen Dialekt zu ersetzen, spöttisch abgehandelt. Die wohl boshafteste zugleich aber eine ästhetisch grandiose - Auseinandersetzung ist die ,Traktatsammlung'Volleingeschancktes Tintenfäßl in (pseudo-)tirolerischer Mundart, eine aberwitzige Briefpoetik mit weiteren fingierten Korrespondenzen im , meißnischen' Standard und in Plattdeutsch. Die Verve des Rundumschlags, die Vielseitigkeit der punktgenauen Angriffe und die Kunstfertigkeit der sprachlichen Travestie machen die Satire mit ihrer bizarren barocken Titulatur zu einem der interessantesten Werke (nicht nur) der bairisch-österreichischen Dialektliteratur vor 1800, auch wenn die ältere Forschung es noch

150 Vgl. u. a. Katja Faulstich: Konzepte des Hochdeutschen. Der Sprachnormierungsdiskurs im 18. Jahrhundert. Berlin: de Gruyter 2008. - Wiesinger, Das Verhältnis von Dialekt und Schriftsprache.

151 Vgl. Gesine L. Schiewer: Bodmers Sprachtheorie. Kontroversen um die Standardisierung und pragmatische Fundierung des Deutschen. In: Anett Lütteken/Barbara Mahlmann-Bauer (Hg.): Bodmer und Breitinger im Netzwerk der europäischen Aufklärung. Göttingen: Wallstein 2009, S. 638-661.

152 Vgl. Johann Jakob Bodmer: Vorrede. In: Johann Jakob Breitinger: Fortsetzung der Critischen Dichtkunst, worinnen die poetische Mahlerey in Absicht auf den Ausdruck und die Farben abgehandelt wird. Zürich/ Leipzig: Orell 1740, f. 2r-6v - Johann Jakob Bodmer/Johann Jakob Breitinger: Der Mahler der Sitten. Von neuem übersehen und starck vermehret. 2 Bde. Zürich: Orell 1746.

153 Vgl. Stefan Sonderegger: Aspekte einer Sprachgeschichte der deutschen Schweiz. In: Werner Besch [u. a.] (Hg.): Sprachgeschichte. Ein Handbuch zur Geschichte der deutschen Sprache und ihrer Erforschung. 3. Tlbd. 2., vollst. neu bearb. u. erw. Aufl. Berlin/New York: De Gruyter 2003 (HSK 2.3) S. 2825-2888. Emanuel Ruoss: Von Sprachrichtern und Provinzialismen. Zu Johann Jakob Bodmers Position im Normierungsdiskurs. In: Sprachspiegel 71/2 (2015), S. 34-40. 


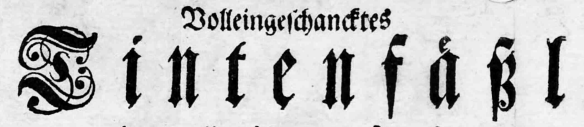 \\ eines allezeit parat fenenden \\ פrieff SECRETARY, \\ gefiulft \\ mit foblruesrabenped) ichwarker Iinten wider unire Feeind, \\ mit rotber gegen unire Freino, mit gelber voller $\Re$ ied \\ nit brauner und mit blauer, wies d' willit, fíes ono fauer. grins ige vno bindige

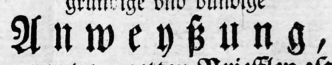 \\ wie man aflerhand Sortimenta von netten Briefflen z fammen butedffectirn fan:

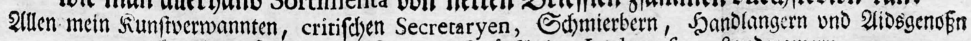 aud') andern Seuten, als SJandwercfspirf(b)ln, Lackeyefen, Eanocramern, Beolerrid,tern ercat. \\ Damafen Frauenzifern vnd in Dieferben verfchamerierten vno von Der \&ieb hart abgepriegeften Bemuicthern mit eim 2 Sớrtl allen vnd iben

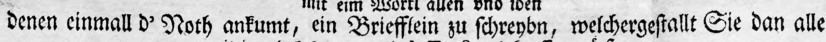 miteinanber gegenwartigß Traetxtel fauffn múe

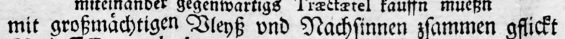 \\ vito mit etweliden 3 Brieff Formuln bes erwurdigen Serrn Authoris widitiac Sadies uns Jandein betreffend, infonderlid) aber mit critifchen. Sance = vnd Stbimpffir $\mathfrak{B r i e f f l e n}$ \\ R. D. VIT O BLA R R O E C K E L I O Theol. Mor. \& S. S. Can. Candidat. Sacerdot. Kufftteinienfi. \\ Suffffein auf Roften Des erwúrdigen Şertn Aurhoris I745*
Cum permifu Superiorum.

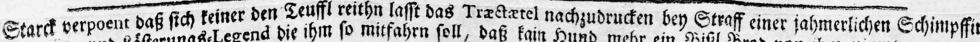

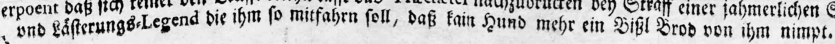

Abb. 51: Titelblatt zu Volleingeschancktes Tintenfäßl (1745, Bayerische Staatsbibliothek, Epist. $814 \mathrm{n}$.).

für „wohl das pöbelhafteste Produkt der deutschen Litteratur“ ${ }^{154}$ hielt, dessen einzelne Teile „ungesittete Possenreißerei“ ${ }^{155}$ von „unglaublicher Gemüthsrohheit“ ${ }^{156}$ belegten.

Das Volleingeschanckte Tintenfäßl, eine durch und durch bösartige Kampfschrift gegen Gottscheds Gegner - allen voran die erklärten Dialektverteidiger und Befürworter sprachlicher Variation Bodmer und Breitinger, aber auch weitere Kritiker des Leipziger Sprachprofessors wie Jakob Immanuel Pyra, Christian Ludwig Liscow, Johann Ulrich von König, Johann Christoph Rost oder auch Johann Matthias Dreyer - ist eine satirische Beweisführung, welche Konsequenzen die Forderung der Schweizer Theoretiker, Regionalsprachliches und Sinnlichkeit in die Schriftsprache einfließen zu lassen, nach

154 Gustav Waniek: Gottsched und die deutsche Litteratur seiner Zeit. Leipzig: Breitkopf und Härtel 1897, S. 478.

155 Friedrich W. Ebeling: Geschichte der Komischen Literatur in Deutschland seit der Mitte des 18. Jahrhunderts. Erster Band: 2. Hälfte des 18. Jahrhunderts. Leipzig: Haynel 1869, S. 165.

156 Waniek, Gottsched, S. 479. Zur Genese des Werks vgl. v. a. Herbert Schauer: „Das pöbelhafteste Produkt der deutschen Litteratur“. In: Meinhard Knigge (Hg.): Zwischen Zettelkasten und Internet. Ein Feststrauß für Susanne Koppel zum 31. Oktober 2005. Unter Mitwirkung von Renate Lempart und Detlev Gerd Stechern. Eutin: Lumpeter und Lasel 2005, S. 39-50. 
sich ziehen würde. ${ }^{157}$ Als Verfasser des 132 Seiten starken Pamphlets zeichnet der fiktive Tiroler Kleriker Vitus Blauroeckelius verantwortlich, der sein angeblich in Kufstein gedrucktes Machwerk dem ,Herrn Wolfgang Erlenbach' (ein den Zeitgenossen durchaus geläufiges Pseudonym Bodmers) widmet. Schon die ebenso langatmigen wie kurzweiligen Ausführungen der Dedikation und Vorrede geben ein recht plastisches Bild des bornierten Klerikers, dessen dümmliche Selbstgefälligkeit, Ahnungslosigkeit und Sinnenlust genüsslich zelebriert werden, perfiderweise in hochkomischer Verzerrung des rhetorischen Duktus, wie er uns auch in den sprach- und bildmächtigsten katholischen Barockpredigten begegnet. Auf allen sprachlichen Ebenen werden mit ausgelassener Fabulierfreude Mündlichkeitsmerkmale verabsolutiert, Schrift- und Sozialkonventionen gebrochen und die Kunst, Gedanken zu Papier zu bringen, zum Problem gemacht. Noch die Einleitung zum ersten Teil ist ein Lamento über die Schreibblockade, die Blauröckel hindert, seine Briefpoetik mit etwas Geistreichem beginnen zu lassen:

Drey Tag gang ich schon umer wie ein ungarischer Ochssen-Prælat, dem der Metzker mit seiner gschlieffenen Hacken-Complesanz ein klains Nota Bene fürs Sägspantriegerl gebn hat. Es geht mir halt wie eim Budel, der das Apetits Bröckel so schlecht nach dem verjungten Maaß-Stab abgmessen hat, daß ihm drüber in Halß ist steckn bliebn, Kutz! Kutz! Kutzauß, Melackel, Kutzauß! Ja es wil halt nit ausser, das Bröckel geth weder hinterschi noch fürschi, und wan er sich ztodt kotzet. Justiment so geths mir. Wo ich seit gestern geh und steh; so sagn dLeuth: Ey um tausend gots willn, wie fallt ihr Erwürden vom Fleisch: segn ja nit anderst auß, alß wie ein gspyben AepffelMändel. Und ich glaubts bey meiner Treu wol: ich hab itze schon 3. Tag und Nacht verstudiert, wie ich mein critisch Tintnfäßl soll anhebn, daß ein Bißl ingenios ausser kumt. Ja und da steh ich wie d'Ochssen am Laimberg, und es thet mir ninx einfalln, wan ich d'Frayß krieget. Ich sinnet hinum, ich sinnet herum. Ich studiert, daß ich auß Angst mögt den Durchfall kriegn. Hilfft alles ninx. Ingenium habe ansunst wie ein Saltzstadl, spitzig bin ansunst wie ein Zwilch-Nadl. Alles umsunst. Ich betet, ich fluchet, ich schmählet, ich flennet, ich stampffet, ich krohnet. Hilfft alles ninx, und wan ich an der Mauern auffikriechet, wie ein Muck: so fiel mir halt kain Treckl ninx ein. Wie mueß das Ding kumen? Ihr Erwürden Herr Blauröckl rantz dich auß ein Bißl, sag ich, hast ja sunst Einfäll, wie ein alt Capellen. Ja ich hätt halt kain Einfall, und wan ich zberstn thet. Es ist mir ninx anderst, als wan ich ein Bret fürs Loch vernagelt hett. Was tausent sa sa, wie geth das Ding zu? Glaub steiffist bey meiner priesterlichen Weych, daß das Ding von ninx anderst herkumen thuet, alß von dem vermaledeyten Titul-Bladt. Ich hab über das ehrvergessne Tittul-Bladt

157 [Friedrich Melchior Grimm:] Volleingeschanktes Tintenfäßl eines allezeit parat seyenden Brieff Secretary, gefüllt mit kohlrueßrabenpechschwartzer Tinten wider unsre Feind, mit rother gegen unsre Freind, mit gelber voller Neyd, mit grüener voller Freud, mit brauner und mit blauer, wies d’willst, süeß vnd sauer. Das ist gründige vnd bündige Anweyßung wie man allerhand Sortimenta von netten Briefflen zsammen buechstebirn kan: allen mein Kunstverwannten, critischen Secretaryen, Schmierbern, Handlangern und Aidsgenoßn auch andern Leuten, als Handwerckspürscheln, Lackeyesen, Landcramern, Bedlerrichtern etcæt. wie auch, Damasen Frauenzifern vnd in dieselben verschamerierten vnd von der Lieb hart abgeprüegelten Gemüethern mit ein Wörtl allen vnd iden denen einmall d'Noth ankumt, ein Briefflen zu schreybn, welchergestallt Sie dan alle miteinander gegenwartigs Træctatl kauffn müeßn mit großmächtigen Vleyß vnd Nachsinnen zsammen gflickt vnd mit etwelichen Brieff Formuln des erwürdigen Herrn Authoris wichtige Saches und Händeln betreffend, insonderlich aber mit critischen Danck- und Schimpffir Briefflen auch hertzbrechenden Caresir Brieffen mit vnder vergezierrathet von R.D. Vito Blauroeckelio Theol.Mor. \& S.S. Can. Candidat.Sacerdot. Kuffsteiniensi. Kuffstein auf Kosten des erwürdigen Herrn Authoris 1745. Cum permissu Superiorem. Starck verpoent daß sich keiner den Teuffl reithn lasst das Træctatl nachzudrucken bey Straff einer jahmerlichen Schimpffir vnd Lästerungs-Legend die ihm so mitfahrn soll, daß kain Hund mehr ein Bißl Brod von ihm nimpt. 
wie ein Narr gsunnen, und mueßt einer wärtzing ein Schedel habn wie ein Rind-Viech, wan er eim nit brembssn solt, wan man soliche nachdenckliche Saches auffsetzn thuet.

Scham mich allßo billichist ins Hertz eini, daß ich mit ninx ingeniosen den Anfang machn kan, wie ansunst mein Gewohnheit ist. Ist aber daß mein aintziger Trost, daß die teutschglahrte Welt schon waiß, daß ich ein so schelmischen Kopff hab, wie ein Woll-Haspel, und waiß ich gwiß, daß kain christcatholischer Leser (müesst dan ein Türck oder ein Leyptziger seyn) von mir præsentirn wird, daß ich mich um der etlichen Creutzer willn, die er für mein Tintnfäßl ausgiebt, zum Narrn studiern solt. ${ }^{158}$

umer] herum Ochssen-Prælat] Zugochse, dann auch Schimpfwort für einen begriffsstutzigen Menschen Hacken-Complesanz] (französ. complaisance) Willfährigkeit (?) Nota Bene] (lat.) merke wohl Sägspantriegerl] Sarg Melackel] beliebter Hundename (nach dem berüchtigten französischen Offizier Ezéchiel de Mélac) ausser] heraus weder hinterschi noch fürschi] weder zurück noch nach vor gspyben Aepffel-Mändel] ausgespieenes Äpfelmännchen (Mehlspeise) ausser kumt] herauskommt, wird ninx] nichts wan ich d'Frayß krieget] und wenn ich die Frais (Fallsucht, epileptischer Anfall) bekommen würde Saltzstadl] Lagerhalle für Salzhandel Zwilch-Nadl] Nadel für Zwillich (strapazierfähiges Gewebe) krohnet] gronen: murren, seine Ungeduld lautlich zu erkennen geben auffikriechet] hinaufkröche Muck] Fliege rantz dich auß] ruh dich aus wärtzing] wahrlich eini] hinein glahrte] gelehrte præsentirn] wohl fälschlich für pressieren (drängen)

Richtig instruktiv wird die Poetik der Briefkunst ohnehin nie, ganz im Gegenteil. Der erste Beispielbrief, den Blauröckel endlich im dritten Kapitel vorlegt, ist natürlich von ihm selbst und wird folgendermaßen gerechtfertigt: „Potz tausend fickremech sag ich, halts das Maul zum Loch und thets mir nit in Crahm, eh ich ausglegt hab. Kan dan ich nacher was dafür, daß kaine schönere Exempel zfindn seyn, alß wie meine. “159 Das lächerlich antiquierte, ungelenke Schreiben ist bezeichnenderweise an Bodmer gerichtet, den er um seine Meinung zum beigelegten Alexandriner-Gedicht Der rasende Ulrich eine Persiflage auf Königs Lyrik - bittet. Drei fingierte Briefe an Bodmer von anderer Hand, die vor affektierten Französismen nur so strotzen, sind ebenfalls eingerückt. Dann folgt überraschenderweise eine Trauerrede in kompromisslosem Plattdeutsch, die Dreyer in die Schuhe geschoben wird, eine Taktlosigkeit, an deren Ende das Fazit gezogen wird:

Da was enmal en Mann, dei heet Pyra, dei leet en grooten Huupen Versch utgaen, dei wurd Kanzler von Germanien und Conrecter in Berlin, dei lewde in grooten Ansehent by dei Schweizers; dei Leipziger honackten ein sehr, un dei Hällischen Mögmakers tärgden em so lang, de Hey up de Stell bumps dood bleef. ${ }^{160}$

Das vierte Kapitel bietet grotesk dämliche Liebesbriefe, wettert gegen wissenschaftliche Methodik und Hermeneutik („Zitiererei“) und preist das ,ingenium', das fünfte bringt u. a. einen Wutbrief an einen Salzburger Freimaurer, bevor Blauröckel in der ,Außläutung' mitleidheischend aufstöhnt: „Kans sagn, daß mich das Tintfäßl so ausgmergelt hat, daß ich wie ein schmurglete Tobacs-Pfeiffn außsich. Glaub gar ich werd kranck, leg mich nieder und stirb, nacher hats die glart Welt. " 161 Schluss ist freillich trotzdem nicht. Zunächst folgt noch ein ,Kierauß' mit einer (hochdeutschen) Rede Daß ein guter

158 Ebda., S. 1f.

159 Ebda., S. 19.

160 Ebda., S. 49.

161 Ebda., S. 78. 
Redner ein Schweizerianer seyn müsse, bevor mit einer Werkliste bizarrer Traktate, die Blauröckelius noch zu schreiben gedenkt, tatsächlich geendet wird.

Autor dieser Streitschrift, einer idiomatischen Fundgrube („Es schickts enck zu der Critica wie der Igl zum Arschwisch “162) und Preziose der komischen Literatur, ist der Regensburger Friedrich Melchior Grimm (1723-1807), später einer der renommiertesten Intellektuellen Deutschlands und Herausgeber der handschriftlichen (damit auch unzensurierten) Correspondance littéraire et philosophique. Verfasst auf Anregung Gottscheds, der schon Grimms satirischen Lebenslauf von Bodmer und Breitinger in Johann Joachim Schwabes Sack-, Schreib- und Taschen Allmanach auf das Schalt-Jahr 1744 zu schätzen wusste, erschien das Volleingeschanckte Tintenfäßl recte bei Hemmerde in Halle. Der Leipziger Sprachrichter hatte wohl auch eingeschobene Texte vermittelt: Einer seiner Parteigänger, Johann Daniel Denso, hatte die plattdeutsche Leichenrede beigetragen; die satirische Rede im ,Kierauß stammt von seiner Frau, Louise Adelgunde Victorie Gottsched. ${ }^{163}$

Das Argument der Natürlichkeit als Richtlinie des guten Geschmacks, das von Bodmer und Breitinger wiederholt für eine Integration dialektaler Formen in die Literatursprache eingebracht wurde, ließ Gottsched nicht gelten. ${ }^{164}$ Denn unter ,Natürlichkeit verstand er keine Orientierung an der Natur selbst, sondern an den bewährten Leitbildern der Tradition, die das Ideal eines kontrollierten Ausdrucks vernünftiger Gedanken vorgaben. In diesem Ansatz folgt ihm auch der Salzburger Benediktiner Florian Reichssiegel, der sich in den späten 1760er Jahren mit Horazens und Gottscheds Poetik beschäftigte und sie in seinem, dramatischen Scherz- und Lehrgedicht ' Die Wahrheit der Natur (1769) verarbeitete. Das Schulsingspiel, das heute vor allem durch die hochwertige Vertonung Michael Haydns in Erinnerung ist, wollte (so der Dichter im Vorwort) „,in allen Zügen die Natur mit der Vernunft und Kunst [... ] vereinigen“165 - ein hochgestecktes Ziel, dem die simple Handlung kaum Genüge tun konnte. Im Zentrum steht Mentor, die personifizierte Vernunft, der mithilfe der drei Grazien Euphrosina, Aglaia und Thalia (als Allegorien der Musik, Poesie und Malerei) die von schlechter Kunst in Bande geschlagene Mutter Natur befreien möchte. Gemeinsam machen sie sich auf, der Menschheit rechte Kunst zu lehren, doch treffen sie auf ihrer Reise nur unbelehrbare Dilettanten und Kunstbanausen: den Schulmeister Bockstolz, seine Frau Urschel und den Poeten Vollstreich (die nicht zufällig den ,pöbelhaften' Dialekt als gemeinsames Stigma haben) sowie den Maler Wurmstich. Am versoffenen Schulmeisterehepaar, das sich am jämmerlich gekratzten Marsch der Spielleute delektiert, wird der schlechte Zustand der zeitgenössischen Unterhaltungsmusik exemplifiziert und implizit mit der

162 Ebda., S. 11.

163 Vgl. Schauer, Das pöbelhafteste Produkt, S. 46f.

164 Vgl. Jesko Reiling: Die Genese der idealen Gesellschaft. Studien zum literarischen Werk von Johann Jakob Bodmer (1698-1783). Berlin/New York: de Gruyter 2010, S. 80ff.

165 [Florian Reichssiegel]: Die Wahrheit Der Natur In den Drey irdischen Grazien, Nämlich in der Dichtkunst / Musik und Malerey / Ein dramatisches Scherz- und Lehrgedicht, Von den Schülern der Dichtkunst In Salzburg aufgeführet 1769. Salzburg, Gedruckt bey Johann Joseph Mayrs, Hof- und Akademischen Buchdruckers sel. Erbinn [1769], f. 2r. 
Streitszene auch ein Beispiel für das niedrige Niveau der damals auch in Salzburg noch beliebten musikalischen Dialektpossen gegeben:

BоскsтоLz. Gehts, gehts! was stimm'ts so lang? fangts einmal an zu wainen:

Doch gehts fein grad daher; sonst möchten d'Leute mainen, Ihr hättet einen Rausch.

Die Spielleute geigen den Marsch, worüber sich Euphrosina heftig entsetzet.

Da bleibts ein wenig stehn;

Ich sieh dort fremde Leut, die uns vieleicht zu sehn

Daher geraiset seynd. Du Urschel! magst nit tanzen?

URSCHEL. Nä Ma! Äs thuäts nit meahr.

Bocкstolz. Du bist ein fauler Ranzen!

Ich bin ganz lämmpig noch: ich wollt' die ganze Nacht

Noch tanzen. Hey! nur frisch ein Tänzlein aufgemacht!

Die Spielleute geigen einen Tanz auf, bey welchem H. Bockstolz mit einem kleinen Mädchen tanzet: aber Euphrosina nimmt dem Baßgeiger die Grundgeige.

Euphrosina. Ihr Stümper! schweiget still! sonst schlage ich den Bogen

Euch um das Angesicht. Bey raschen Wasserwogen,

Wo Schiff und Ruder knarr't, läßt es so häßlich nicht,

Wie bey der tollen Hand die falsche Geige spricht.

BоскsтоLz. Hey! Jungfrau! was ist das? wer hat euch das erlaubet,

Daß ihr dem Spielmann Hanns gleich seine Geige raubet?

Das Ding, beym Dattrament! das Ding, das geht nit an;

Ihr habt dadurch mir selbst iniurus angethan.

Euphrosina. Wie, Thörichter! dem schon das Hirn vom Weine schwitzet,

Und das Pedantenaug mit Afterbildern blitzet,

Hat dein verstimmtes Ohr gar keine Fühlung mehr?

Bockstolz. Das heißt zuviel geredt! das trift mein pont honär!

Weib! Urschel! schau nur grad, wie dieses Flitscherl schwätzet!

Sie hat mein hohes Amt, und mich und dich verletzet.

URSCHEL. Mordfetzen! was ist dös? du Lueder! giebst es her

Die Geige oder nit? ich falle wie ein Bär

Auf deine Borsten los!

Sie reißt der Euphrosina die Baßgeige und den Bogen aus der Hand, und giebt selbe dem Spielmanne wieder.

Du Fetzen schlechter Zeiten!

Ist dieses der Respekt für hohe Obrigkeiten,

Wie wir seynd? Soll ich dich $-{ }^{166}$

Nä Ma] nein, Mann lämmpig] lebendig iniurus] (fälschlich für lat. iniuria) Unrecht Afterbildern] täuschendes Abbild, Halluzination pont honär] (franz. point d'honneur) Ehrenstandpunkt, Ehre Flitscherl] Schimpfwort für eine Frau, Flittchen

Nicht besser als die Musik kommt die vom eitlen Reimeschmied Vollstreich repräsentierte zeitgenössische Salzburger Dichtkunst weg. Die Kostproben aus seinem Cuvre sind selbstredend dialektal und entsprechen der gängigen unterhaltsamen Flugschriften-

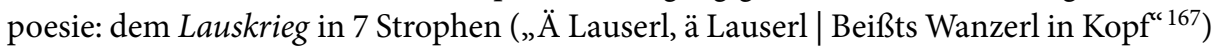

166 Reichssiegel, Die Wahrheit der Natur, f. 10v-11r.

167 Ebda., f. 13r. 
folgt zum großen Missfallen der mythischen Zuhörerinnen das Trauerlied vom todten Trutzerl:

1

Der Trutzerl war ä wakärä Hund,

War wutzelfaist, und war kugelrund:

Auf einmal aber bellt er nit meär,

Will nimmer frössen, geht ihm ganz speär;

Drum, drudl drum drum!

Da Trutzl kimmt um.

3

Der Budel stihlt ä Brätel vom Rost,

Und bringt es Straks dem Trutzerl zum Trost.

Der Trutzerl aber mag nix davon;

Drum frists der Budel, stirbt aber dran:

Pum, Budl pumpum!

Dä Budl kimmt um.

5

Der Trutzerl macht drauf säi Testament,

Und höbt in d'Hech säi zottiges End;

Er setzt ä Merkmal, und sagt: I bin

A Zeug deär Liebe, und stirbt dahin:

Drum, drudl drum drum!

Dä Trutzl kimmt um. ${ }^{168}$
2

Der Moperl geht zum Trutzerl glei hin,

Und bring ä Maaß Laxiermedicin.

Der Moperl aber selber wird krank,

Und stierbt an Fiebä, wird vollä Gstank.

Mum, mudl mumm um!

Dä Mopl kimmt um.

4

Der Bumerl sicht dö äussersti Noth,

Und bringt geschwind den Trutzerl ä Brodt;

Lauft übän Müllstög, und deä bricht ein,

Und reißt-n untäs Müllrad hinein.

Pum, pumpl pumpum!

Dä Bumml kimmt um.

1,2 wutzelfaist] fett 1,4 speär] elend, miserabel 2,2 Laxiermedicin] Abführmittel 5,2 d'Hech] die Höhe

Den Höhepunkt der Kunstlosigkeit bildet schließlich ein Beispiel aus Vollstreichs Odendichtung, sein Streitgespräch zwischen Alexander und Philotas, das das entgeisterte Publikum „krank und zum zerschnellen lachen“ machen soll und den Richtspruch über den illoyalen Heerführer mit einem lächerlichem Chronogramm enden lässt:

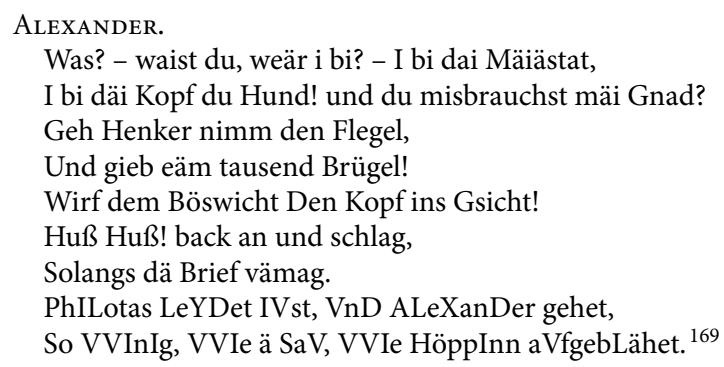

Unnötig zu sagen, dass auch der Maler Wurmstich sich als aufgeblasener Möchtegern entpuppt, sodass die Grazien Mentor desillusioniert in dessen Studierstube folgen, wo sie seine talentierten Versuche in Malerei, Musik und Dichtung würdigen und mit konstruktiver Kritik zu verbessern trachten. Welche Vorbilder Reichssiegel seinen Schülern anempfiehlt, wird dabei explizit genannt: die moralisch-lehrhaften Fabeln Christian Fürchtegott Gellerts und Daniel Trillers, die ethischen Schriften Alexander Popes, die

168 Ebda., f. $14 \mathrm{v}-15 \mathrm{r}$.

169 Ebda., f. 16r. 
Lyrik von Justus Friedrich Wilhelm Zachariae und Friedrich Gottlieb Klopstock. Dezidiert abgelehnt dagegen werden natürlich die anakreontische Dichtung und - durch die gegebenen Beispiele - die Dialektdichtung. Es entbehrt nicht einer gewissen Ironie, dass der ,öffentliche Lehrer der Dichtkunst' an der Benediktineruniversität Salzburg weniger für seine geschraubten Alexandriner oder seine gottschedianische Poetik als gerade durch seine - gut gemachten - Abschreckungsbeispiele als Dialektdichter in Erinnerung blieb.

Schon zu dieser Zeit freilich waren die Auswirkungen der gottschedschen Sprachreform absehbar und fanden nicht überall Befürworter. Johann Gottfried Herder etwa konstatierte in seinen wegweisenden Fragmenten Ueber die neuere Deutsche Litteratur ernüchtert, dass „, [k] eine Parthei [...] dem wahren Genie der Deutschen Sprache so sehr geschadet [habe], als die Gottschedianer “ ${ }^{170}$, da sie mit der Propagierung einer ,vernünftigen' Sprache die sinnliche Dimension und die eigentlichen Grundlagen des Deutschen beschnitten und diese damit, entmannt' hätten. Ganz in der Nachfolge Bodmers plädiert er deshalb für eine antipuristische Spracherneuerung durch eine Rückbesinnung auf archaische und dialektale Formen, die es wiederzuentdecken und fruchtbar zu machen gelte. Um an die Wurzeln des Volksgeists zu gelangen, suchte er nach mündlichen Literaturtraditionen, deren volkshafte Sinnlichkeit ein Überleben fernab der Verschriftlichung möglich machte. Im Volkslied - ein Begriff, den er selbst erstmals prägte - glaubte er eine von Literarizität und Konventionen unberührte Ausdrucksform gefunden zu haben, die für Authentizität und Unberührtheit stand und zurückführte zur eigentlichen ,Muttersprache. ${ }^{171}$ „Je entfernter von künstlicher, wissenschaftlicher Denkart, Sprache und Letternart das Volk ist: desto weniger müssen auch seine Lieder fürs Papier gemacht, und todte Lettern Verse sein “172, konstatiert Herder im Auszug aus einem Briefwechsel über Oßian und die Lieder alter Völker (1773). Es ist bezeichnend, dass gerade die OssianGedichte, die er als Beispiel für die zeitenüberdauernde poetische Kraft der Volksdichtung inszenierte, sich als rezente Fälschung des Schotten James Macpherson entpuppten.

Die medien- und zivilisationkritischen Widersprüchlichkeiten in der Begriffsbildung von Herders Versuch, diese Volkspoesie zu sammeln, boten denn auch eine breite Angriffsfläche. Den Druck seiner ersten Anthologie Alte Volkslieder (1774) stellte Herder nach Kritik von verschiedenen Seiten bereits nach einigen Bögen frustriert ein. Besonders schmerzhaft aber war Nicolais perfide Sammlung Eyn feyner kleyner Almanach, mit dem der Berliner Aufklärer Ende 1776 Herders editorische Bemühungen um die Volkskunst und die Schützenhilfe, die er dabei durch Gottfried August Bürgers Aufsatz Herzensausguss über die Volks-Poesie (1766) erhielt, persiflierte. Die beiden hatten

170 Johann Gottfried Herder: Ueber die neuere Deutsche Litteratur. Fragmente. Erste Sammlung. Zweite völlig umgearbeite [sic] Ausgabe. Riga: Hartknoch 1768, S. 75.

171 Vgl. u. a. Matthew Gelbart: The Invention of ,Folk Music' and ,Art Music'. Emerging Categories from Ossian to Wagner. Cambridge: University Press 2007. - Nils Grosch: Über das Alter der Populären Musik und die Erfindung des,Volkslieds'. In: Sabine Meine/Nina Noeske (Hg.): Musik und Popularität. Aspekte zu einer Kulturgeschichte zwischen 1500 und heute. Münster [u. a.]: Waxmann 2011. (Populäre Kultur und Musik 2) S. 59-76.

172 Johann Gottfried Herder: Auszug aus einem Briefwechsel über Oßian und die Lieder alter Völker. In: Johann Gottfried Herder: Von deutscher Art und Kunst. Hamburg: Bode 1773, S. 12. 
1774 nach Jahren des freundschaftlichen Briefverkehrs miteinander gebrochen, da ihre kunsttheoretischen Positionen - Herder als Proponent des Sturm und Drang, Nicolai als dessen rationalistischer Gegner - immer mehr divergierten. Nun verhöhnt Nicolai mit seiner Parodien-Sammlung Herders Aufruf zur Bewahrung des Überlieferten in der Herausgeberfiktion: Die Lieder seien dem Dessauer Bänkelsänger Gabriel Wunderlich abgelauscht, der nach seiner Ablehnung bei der Fruchtbringenden Gesellschaft 1619 am unterdrückten Liedgut erstickt sei und fortan als Geist „bey heyterm Mondscheyn [...] altteutsche Volckslieder" singe; niedergeschrieben habe sie der Ritzmücker Schuster Daniel Seuberlich. Die geschickt komponierte Mischung aus 64 nach gängigen Vorlagen gebildeten, zum Teil auch authentischen Liedern verschiedener Genres karikierte mit überspitzt-antiquierter Orthographie die Altertumsbegeisterung der Stürmer und Dränger und hatte deren Sammelbemühungen sogar einen wesentlichen Punkt voraus: Sie präsentierte die Texte mit Melodien, darunter volksläufige Singweisen, aber auch identifizierbare Liedkompositionen, u. a. von Johann Friedrich Reichardt. ${ }^{173}$ In einem Brief an Lessing expliziert Nicolai seine Beweggründe:

Mein Almanach hat freilich eine sehr ernsthafte Absicht, nemlich einige der Toren, die jetzt thun, als ob alle Weisheit und Gelehrsamkeit nicht eines Bißchen Mutterwitzes (das sie Genie taufen), und alle Poesie nicht der Tyroler und Hechelträger wert wäre, wo möglich, klug zu machen, oder diesen Herren, welche wähnen, es dürfe sich niemand an sie wagen, gerade in die Zähne zu lachen. ${ }^{174}$

Unter den rustikalen Liedern, die als Widerlegung der These vom poetischen Mehrwert der Volksdichtung abgedruckt wurden, findet sich auch ein pseudodialektaler Scherzgesang: Eyn steyrisch Lyd, von alten Weybern. Vom bairisch-österreichischen Dialekt hatte Nicolai freilich zu diesem Zeitpunkt keine Ahnung - erst bei seiner , Reise durch Deutschland und die Schweiz im Jahre 1781' wird er sich intensiver mit ihm auseinandersetzen und sogar ein kleines Idiotikon anlegen. Dementsprechend unzulänglich sind hier noch - wie auch in einem weiteren Beitrag Wyr g'nüszen dj hymmlischen Frewden (Nr. XIX, S. 88 im 2. Jahrgang von 1778) - die Versuche, einen alpenländischen mundartlichen Ton zu simulieren:

'S is nichts mit den alten Weybern,

bin fro dz ich keyne hab

Liber frey'ch mir'n junges Maydel.

Do ich Frewd darob hab.

Miff! Muff! geets ym Hause,

Den gantzen tag herum,

Junge Maydel geen halt grade

Alte Weyber geen krumm.

173 Vgl. u. a. Johann Nikolaus Schneider: Ins Ohr geschrieben: Lyrik als akustische Kunst zwischen 1750 und 1800. Göttingen: Wallstein 2004, S. 32-45. - Miriam Noa: Volkstümlichkeit und Nationbuilding. Zum Einfluss der Musik auf den Einigungsprozess der deutschen Nation im 19. Jahrhundert. Münster [u. a.]: Waxmann 2013. (Populäre Kultur und Musik 8).

174 Friedrich Nicolai: Brief an Lessing vom 5. Juni 1777. In: Gotthold Ephraim Lessing: Werke und Briefe. Bd. 12: Briefe von und an Lessing 1776-1781. Hg. von Helmut Kiesel. Frankfurt a. M.: Dt. Klassiker Verl. 1994, S. 82. 
Wer so 'nen alten Schimmel

Ynn seynem Stalle hat,

Friszt sich ab sein libes Leben,

Unndt kommt fru ins Grab. 
Drum libe Jungkgesellen,

Freyt ia keyn' Alte nicht,

Denn ir muszt s' feyn behalten,

Biß der tod ir's Hertze bricht. ${ }^{175}$

Um Authentizität war Nicolai freilich nicht bemüht, sollte das Lied doch gerade die ästhetische Minderwertigkeit des Dialektalen zur Schau tragen. Dass seine sprachkundlichen Beschäftigungen von 1781 allerdings nicht auf unfruchtbaren Boden gefallen sind, belegt eine Besprechung des ersten Bands der Eipeldauerbriefe, eines „schnurrigen Originals“, die er im ungelenk nachgeahmten Idiom der populärsten Erfindung Joseph Richters einleitet: „Ain halt recht spaßerlichs Ding, so herzig und eigens beschrieben, daß sich Rec. in d'Wienstadt zu seyn getra'mt hat." ${ }^{176}$ Dem Reiz des Dialektalen als ästhetisches Mittel konnte sich offenbar sogar der gestrenge Aufklärer nicht gänzlich entziehen. Auch Herder profitierte letztendlich von Nicolais Almanach-Invektive: Verärgert und herausgefordert von dieser „Schüssel voll Schlamm“177 nahm er die Arbeit an seinem Sammelprojekt wieder auf, zwar ohne den Enthusiasmus der Geniezeit, dafür jedoch kritischer in der Auswahl und pointierter in der soziologischen und ästhetischen Begründung. ${ }^{178}$ So konnten die Stimmen der Völker in Liedern (ursprünglich: Volkslieder) wegweisend für die Erfassung, Edition und Erforschung der Volkspoesie werden.

175 [Friedrich Nicolai]: Eyn feyner kleyner Almanach vol schönerr echtem liblicherr Volckslieder, lustigerr Reyen vnndt kleglicherr Mordgeschichte, gesungen von Gabriel Wunderlich weyl. Benkelsengernn zu Dessaw, herausgegeben von Daniel Seuberlich, Schusternn zu Ritzmück ann der Elbe. Erster Jahrgang. Berlin/Stettin: Nicolai 1777, S. 142f.

176 Allgemeine deutsche Bibliothek, Bd. 70 (1786), 1. Stück, S. 259.

177 [Johann Gottfried Herder]: Von Aehnlichkeit der mittlern englischen und deutschen Dichtkunst, nebst Verschiednem, das daraus folget. In: Deutsches Museum 1777, Bd. 2, Stück 11 (November), S. 421-435, hier 430 .

178 Vgl. Heinz Rölleke: Über Volks- und Geistliche Lieder bei Herder. In: Martin Keßler / Volker Leppin (Hg.): Johann Gottfried Herder: Aspekte seines Lebenswerkes. Berlin/New York: de Gruyter 2015, S. 115-128, hier 121 . 


\section{EDITIONSKRITERIEN}

- Die Groß- und Kleinschreibung der Handschrift wird beibehalten, sofern sie deutlich unterscheidbar ist. Zweifelsfälle bei mangelnder Unterscheidbarkeit von Majuskel und Minuskel (d/D) oder Größenvarianz (a/A, f/F, g/G, o/O, u/U, v/V, z/Z) werden unmarkiert der heutigen Schreibung angeglichen.

- Die Getrennt- und Zusammenschreibung richtet sich grundsätzlich nach der Vorlage; in Zweifelsfällen bei geringem Spatium wird die Schreibung an die orthographischen Gewohnheiten der Zeit angepasst.

- Die Interpunktion folgt, auch bei offensichtlichen Kopisten- oder Druckfehlern, der Vorlage; Punkte am Satzende werden jedoch stillschweigend ergänzt.

- Die Silbentrennung am Zeilenende der Vorlage wird nicht übernommen.

- Im Fließtext wiedergegebene Verse mit regelmäßigen Metren werden rekonstruiert.

- Schreibökonomische Abkürzungen im Text werden, sofern sie sich eindeutig aus dem Kontext erklären, prinzipiell unmarkiert aufgelöst. Dies gilt für:

Suspensionen mit Punkt bei Eigennamen, Konjunktionen, Präpositionen, Regiebezeichnungen / geschwänztes End-e als Abbrechungszeichen für -en / $d$ in Kombination mit einem dem $z$ ähnelnden Zeichen für das bzw. daß (kontextuell angepasst) / $d$ mit zusätzlicher nach oben gezogener Schleife für der / Nasalstrich als Doppelungszeichen bei $n$ und $m$.

- Umfangreichere Auflösungen werden mit eckigen Klammern markiert.

- Rollenbezeichnungen werden in Kapitälchen wiedergegeben und einheitlich vom Sprechtext mit Punkt und Spatium getrennt; Abkürzungen werden aufgelöst, unterschiedliche Schreibweisen gemäß dem Rollenverzeichnis normalisiert.

- Regieanweisungen werden kursiv gesetzt.

- Die mit |: und :| gebildeten Klammern zur Abhebung einer Parenthese vom übrigen Satzteil werden mit ( ) wiedergegeben.

- Einfügungen, Korrekturen und Auslassungen von Editorenhand werden mit eckiger Klammer [ ] markiert.

- Das überwiegend mit $\ddot{a}$ bzw. mit superskribiertem $e$ wiedergegebene helle [a] des historischen Sekundärumlauts (im Gegensatz zu den verdumpften $a$-Lauten des Bairisch-Österreichischen) wird in der Druckfassung in der gleichen Weise wiedergegeben.

- Schaft-s und rundes $s$ werden als Allographe einheitlich mit $s$ wiedergegeben.

- Die mit Antiqua oder lateinischer Schreibschrift von der deutschen Kurrente abgehobenen Fremdwörter werden in der Edition nicht hervorgehoben.

- Doppelpunkte nach Szenen- und Akteinteilung wurden einheitlich getilgt.

- Die Schrägstriche (Virgeln) des Drucks werden konsequent ohne Spatium davor und mit Spatium danach wiedergegeben.

- Die Glyphe = als Verbindungszeichen wird einheitlich mit Bindestrich ersetzt. 
- Strophenzahlen werden einheitlich ohne Punkt wiedergegeben, bei genauer Zuordenbarkeit unmarkiert ergänzt.

- Typographische Einrückungen werden nicht übernommen. 


\section{ABBILDUNGSVERZEICHNIS}

Cover: Egbert van Heemskerk: Genreszene (Privatbesitz)

Abb. 1: Huy liebe meine buebn (Staatsbibliothek zu Berlin - PK Handschriftenabteilung, Signatur: Ms.germ.oct. 230, f. 197)

Abb. 2: Titelblatt der Flugschrift Vier schöne neue Weyhnacht-Lieder (Archiv des Österreichischen Volksliedwerkes/Österreichische Nationalbibliothek, ÖC Kotek 1331, http://data.onb.ac.at/rec/ dtl_2848292)

Abb.3: Klavierliedfassung Joseph Giehrls zu Sturms Die Erbsünde (aus: Lieder zum Theil in baierischer Mundart, Bayerische Staatsbibliothek München, 9351154 Mus.pr. 617-2, S.2, urn:nbn:de:bvb:12-bsb11139972-7)

Abb. 4: Singstimme zu Schmalnauers Die halb zwölfer Messe in Linz (Privatbesitz)

Abb. 5: Beginn von Vetterl was wilst geistlich werden (Österr. Nationalbibliothek, Musiksammlung, Mus.Hs. 19029, f. 61v, http://digital.onb.ac.at/rep/access/open/10026B43)

Abb. 6: Partiturausschnitt zu Aumanns, Schulmeister-Messe‘ (Österr. Nationalbibliothek, Musiksammlung, Mus.Hs. 15905, f. 7v, http://digital.onb.ac.at/rep/accesss/open/1001851C)

Abb. 7: Flugschrifttitelseite (Staatsbibliothek zu Berlin - PK, Abteilung Historische Drucke/Signatur: Ye 7971)

Abb. 8: Titelvignette aus Oesterreichisches Freuden-Lied (Staatsbibliothek zu Berlin - PK, Abteilung Historische Drucke/Signatur: Ye 8101)

Abb. 9: Titelblatt zu Lustiger Bauren-Discurs (Österr. Nationalbibliothek/Kooperationspartner Google, Sammlung von Handschriften und alten Drucken, 303956-B, http://data.onb.ac.at/ABO/\% 2BZ2583160X)

Abb. 10: Kupferstich zu Muster-Platz der Tyrolischen Bauern (Staats- und Universitätsbibliothek Dresden, Digitale Sammlungen, Hist.Austr. 198,1.p)

Abb. 11: Titelblatt von Ländlä Sittlä (Oberösterr. Landesarchiv, Flugschriftensammlung, Schachtel C2)

Abb. 12: Titelkupfer zu Denck- und Lobwürdiger Land-Tag (Oberösterr. Landesarchiv, Flugschriftensammlung, Schachtel C2)

Abb. 13: Ausschnitt aus Ein kurtzweilig Faßnachtspill (Archiv des Historischen Vereins für Oberpfalz und Regensburg, MS.R 161, f. 46r)

Abb. 14: Beginn des Zwischenspiels aus Der Teutsche Sultan (Bayerische Staatsbibliothek München, Slg. Her 2198, f. 3v, urn:nbn:de:bvb:12-bsb00055150-6)

Abb. 15: Titelblatt zu Bäurisches Oster-Märl (Österr. Nationalbibliothek/Kooperationspartner Google, Sammlung von Handschriften und alten Drucken, 308956-B, http://data.onb.ac.at/ABO/\% 2BZ114761209)

Abb. 16: Titelblatt zu Letztliche Continuation (Wienbibliothek im Rathaus, Druckschriftensammlung, A-11527)

Abb. 17: Titelkupfer zu Curioses Gespräch zwischen Hänsel und Lippel (Wienbibliothek im Rathaus, Druckschriftensammlung, E-11689)

Abb. 18: Kupferstich zum kaiserlichen Maskenball vom 12.1.1744 (Johannes Andreas Pfeffel nach Giuseppe Galli Bibiena, Wien Museum, Inv.Nr. 31.600)

Abb. 19: Zweytes Kassazionslied (Oberösterr. Landesbibliothek, I 4966)

Abb. 20: Flugblatt zur Exekution Franz Hebenstreits (Österr. Nationalbibliothek, Bildarchiv und Grafiksammlung, LW 75464-B, http://data.onb.ac.at/rec/baa10312373)

Abb. 21: Flugblatt zur Festnahme Matthias Klostermayrs und seiner Bande (um 1771/72, Privatbesitz)

Abb. 22: Handschrift des Andreas Mayr (Universitätsbibliothek Tübingen, Md 290, f. 151r)

Abb. 23: Melodie zu I bin ä baur (Staatsbibliothek zu Berlin - PK, Handschriftenabteilung, Signatur: Ms.germ.oct. 230, f. 207) 
Abb. 24: Kupferstich zu Die Egyptische Olympia (Österr. Nationalbibliothek/Kooperationspartner Google, Sammlung von Handschriften und alten Drucken, 22043-B, http://data.onb.ac.at/ABO/ \%2BZ84621207)

Abb. 25: Johann Christian Brand: Kästenweib (Maroniverkäuferin, Foto: @MAK - Österr. Museum für angewandte Kunst/Gegenwartskunst, KI 2569-16)

Abb. 26: Auszug aus Ehrliche Gemüths-Erquickungs (Wien, 1686, Universitätsbibliothek Graz, SOSA, Rara 1, I 29572)

Abb. 27: ,Kropferter' im Reiner Musterbuch (Österr. Nationalbibliothek, Sammlung von Handschriften und alten Drucken, Cod. 507, f. 9v, http://digital.onb.ac.at/rep/access/open/100480FF)

Abb. 28: Crischtel Troyling (Germanisches Nationalmuseum Nürnberg, MP 24263)

Abb. 29: Christl Pestnbalkh aus: Il Callotto resuscitato (Rijksmuseum, FMH 3695-a39)

Abb. 30: Titelkupfer zu: Die lustige Melankolie (1775, Bayerische Staatsbibliothek München, P.O.germ 924, S. 1, urn:nbn:de:bvb:12-bsb10114679-9)

Abb. 31: Riepl Gleichdron aus Il Callotto resuscitato (Rijksmuseum, FMH 3695-a41)

Abb. 32: Hanswurst und Tiroler Ölträger in Lustige Reyss-Beschreibung (um 1717, aus Rommel, AltWiener Volkskomödie, S. 349)

Abb. 33: Der walsche Kramer (Staatsbibliothek zu Berlin - PK, Handschriftenabteilung, Signatur: Ms.germ.oct. 230, f. 96)

Abb. 34: Elias Baeck: Hechell Maus-Fall-Macher/O Schöna Raride (Augsburg, 1720, aus: Bauer/Verfondern, Barocke Zwergenkarikaturen, Tafel 17)

Abb. 35: Notenteil zu Der kroatische Bauer (aus: Reprint: Philipp Hafner, Scherz und Ernst in Liedern, S. 44)

Abb. 36: Profess-Gesang (Musikarchiv Stift Kremsmünster, G 44/793)

Abb. 37: Quartett Gehn mä haimb odä nit (Österr. Nationalbibliothek, Musiksammlung, Mus.Hs. 18989, f. 1r, http://digital.onb.ac.at/rep/access/open/100184F6)

Abb. 38: Franz Joseph Aumann: Brudä, dä Tiofl holl mih (Musikarchiv Stift Kremsmünster, G 44/755)

Abb. 39: Mozart zugeschriebener Kanon Gehn wir auf d'Kögelstadt (Musikarchiv Stift Kremsmünster, G 43/717)

Abb. 40: Arienvertonung Kaiser Leopolds (Österr. Nationalbibliothek, Musiksammlung, Mus.Hs. 16003, f. 16v, http://digital.onb.ac.at/rep/access/open/10044258)

Abb. 41: Notenblatt mit zwei Kanons von Henneberg (Staatsbibliothek zu Berlin - PK, Musikabteilung mit Mendelssohn-Archiv, Signatur: Mus.ms.autogr. Henneberg, J. B. 2M, f. 2r)

Abb. 42: Autograph Mozarts zu Difficile lectu mihi mars (๔ The British Library Board, Zweig MS 58)

Abb. 43: Willkomb mein liebä Badä (Österr. Nationalbibliothek, Musiksammlung, Mus.Hs. 19180, f. 1r)

Abb. 44: Titelblatt einer Flugschrift, um 1790 (Foto/Quelle: Archiv der Stadt Linz, Sammlung Klier 55/4-33)

Abb. 45: Prostituierte und Freier (aus: Richter, Taschenbuch für Grabennymphen, Österr. Nationalbibliothek/Kooperationspartner Google, Sammlung von Handschriften und alten Drucken, 294206-A, S. 4, http://data.onb.ac.at/rec/AC10248344)

Abb. 46 und 47: Autograph Thomas Brauns (Gesellschaft der Musikfreunde, VI/27.474, VII. Heft/35, aus: Haid/Hochradner, Lieder und Tänze um 1800, S. 240)

Abb. 48: Frontispizstich zu den fingierten Controvers-Predigten (1733, Österreichische Nationalbibliothek/Kooperationspartner Google, Sammlung von Handschriften und alten Drucken, 227286-B, http://digital.onb.ac.at/rep/access/open/100012A5)

Abb. 49: Hans Sausakh von Wurstelfeld aus: Il Callotto resuscitato (Rijksmuseum, FMH 3695-a34)

Abb. 50: Rollenbild La Roches als Kasperl (1794, Abdruck einer Postkarte zum Musiktheaterfest der Stadt Wien 1924, Privatbesitz)

Abb. 51: Titelblatt zu Volleingeschäncktes Tintenfäßl (1745, Bayerische Staatsbibliothek München, 829762 Epist. 814 n, f 1r, urn:nbn:de:bvb:12-bsb10403932-3) 


\section{LITERATUR}

Abel-Struth, Sigrid: Die Texte weihnachtlicher Hirtenlieder. In: Rolf Wilhelm Brednich/Lutz Röhrich/Wolfgang Suppan (Hg.): Handbuch des Volksliedes. Bd. 1: Die Gattungen des Volksliedes. München: Fink 1973, S. 419-444.

Achim von Arnim/Clemens Brentano: Des Knaben Wunderhorn. Kommentierte Gesamtausgabe. Hg. von Heinz Rölleke. Bd. 1. Stuttgart: Reclam 1987.

Adrian, Karl: Das Halleiner Weihnachtsspiel. Ein Beitrag zum Volksschauspiel in Salzburg. In: Zeitschrift für österreichische Volkskunde 9 (1903), S. 89-107, 142-150.

Albrecht, Corinna: Fremdheit. In: Alois Wierlacher, Andrea Bogner (Hg.): Handbuch interkulturelle Germanistik. Stuttgart, Weimar: Metzler 2003, S. 232-238.

Andres, Jan/Geisthövel, Alexa/Schwengelbeck, Matthias (Hg.): Die Sinnlichkeit der Macht. Herrschaft und Repräsentation seit der Frühen Neuzeit. Frankfurt a. M./New York: Campus 2005.

Arend, Stefanie [u. a.]: Anthropologie und Medialität des Komischen im 17. Jahrhundert (15801730). Amsterdam/New York: Rodopi 2008. (Chloe. Beihefte zum Daphnis 40)

Ariès, Philippe: Geschichte der Kindheit. Übersetzt von Caroline Neubaur und Karin Kersten. 12. Aufl. München: dtv 1996.

Arneth, Alfred von: Maria Theresia's erste Regierungsjahre. 2. Bd.: 1742-1744. Wien: Braunmüller 1864.

Asper, Helmut G.: Hanswurst. Studien zum Lustigmacher auf dem deutschen Theater im 17. und 18. Jahrhundert. Emsdetten: Lechte 1980.

Aust, Hugo/Haida, Peter/Hein, Jürgen: Volksstück. Vom Hanswurstspiel zum sozialen Drama der Gegenwart. München: Beck 1989. (Arbeitsbücher zur Literaturgeschichte)

Bachtin, Michail M.: Literatur und Karneval. Zur Romantheorie und Lachkultur. Frankfurt a. M.: Fischer 1990.

Bachtin, Michail: Rabelais und seine Welt. Volkskultur als Gegenkultur. Aus dem Russischen von Gabriele Leupold. Hg. und mit einem Vorwort versehen von Renate Lachmann. 2. Aufl. Frankfurt a. M.: Suhrkamp 1998.

Barnreiter, Gernot: Johann Carl Seyringer. Leben und Wirken eines frühneuzeitlichen Rechtsgelehrten. Wien 2012. [Dipl.]

Barthes, Roland: Die Sprache der Mode. Frankfurt a. M.: Suhrkamp 1985.

Bauer, Günther G. / Verfondern, Heinz: Barocke Zwergenkarikaturen von Callot bis Chodowiecki. Hg. vom Kulturamt der Stadt Salzburg anläßlich der Ausstellung in der Galerie der Stadt Salzburg von 1. August bis 1. September 1991. Salzburg: Kulturamt der Stadt Salzburg 1991.

Bayerisch-Tirolische G'schichten ... eine Nachbarschaft. Bd. 1: Katalog. Innsbruck: Landesmuseum Ferdinandeum 1993.

Beall, Karen F.: Kaufrufe und Straßenhändler / Cries and itinerant trades. Eine Bibliographie. Dt. von Sabine Solf. Hamburg: Hauswedell 1975.

Becker, Peter: Leben und Lieben in einem kalten Land. Sexualität im Spannungsfeld von Ökonomie und Demographie - das Beispiel St. Lambrecht 1600-1850. Frankfurt a. M./New York: Campus 1990. (Studien zur historischen Sozialwissenschaft 15)

Beisbart, Ortwin/Maiwald, Klaus: Dialekt in der Literatur - Ein Aspekt von Regionalität im Zeitalter der Globalisierung? In: Regionalität als Kategorie der Sprach- und Literaturwissenschaften. Hg. vom Instytut Filologii Germanskiej der Univ. Opolski. Frankfurt a. M.: Lang 2002, S. 123-140.

Beitl, Klaus: Schnaderhüpfel. In: Rolf Wilhelm Brednich/Lutz Röhrich/Wolfgang Suppan (Hg.): Handbuch des Volksliedes. Bd. 1: Die Gattungen des Volksliedes. München: Finke 1973, S. 617677.

Békési, Sándor/Nussbaumer, Martina: Die Gondolieri Wiens oder die „Wienerischsten aller Wiener“. Zur Karriere der Fiaker im symbolischen Inventar der Stadt. In: Wolfgang Kos (Hg.): Wiener Ty- 
pen. Klischees und Wirklichkeit. Katalog zur 387. Sonderausstellung des Wien Museums, 25. April bis 6. Oktober 2013. Wien: Brandstätter 2013, S. 178-187.

Belitska-Scholtz, Hedvig/Somorjai, Olga: Das Kreuzer-Theater in Pest (1794-1804). Eine Dokumentation zur Bühnengeschichte der Kasperlfigur in Budapest. Wien/Köln/Graz: Böhlau 1988. (Maske und Kothurn, Beiheft 12)

Bencker, Georg: Das deutsche Weihnachtsspiel. Greifswald 1933. [Diss.]

Benthien, Claudia: Barockes Schweigen: Rhetorik und Performativität des Sprachlosen im 17. Jahrhundert. München: Fink 2006.

Bermann, Moritz: Alt- und Neu-Wien. Geschichte der Kaiserstadt und ihrer Umgebungen. Wien/ Pest/Leipzig: Hartleben 1880.

Berndt, Carsten: Melissantes: ein Thüringer Polyhistor und seine Berufsbeschreibungen im 18. Jahrhundert. Leben und Wirken des Johann Gottfried Gregorii (1685-1770) als Beitrag zur Geschichte von Geographie, Kartographie, Genealogie, Psychologie, Pädagogik und Berufskunde in Deutschland. 3. Aufl. Bad Langensalza: Rockstuhl 2015.

Bernhart, Toni (Hg.): Johannes Ulrich von Federspiel. Hirlanda. Durch falschheit zu feir verdamte unschuld: Edition des Legendenspiels nach der Laaser Handschrift von 1791. Wien/Bozen: Folio 1999.

Bernhart, Toni: Griseldis (1713). Ein Neufund aus dem Stiftsarchiv Marienberg und die Geschichte des Schultheaters am Benediktinergymnasium Meran. In: Nestroyana 37 (2017), H. 3/4, S. 175187.

Bimmer, Andreas C.: Brauchforschung. In: Rolf W. Brednich (Hg.): Grundriß der Volkskunde. Einführung in die Forschungsfelder der Europäischen Ethnologie. 2., überarb. und erw. Aufl. Berlin: Reimer 1994, S. 375-395.

Birbaumer, Ulf: Das Werk des Joseph Felix von Kurz-Bernardon und seine szenische Realisierung. Versuch einer Genealogie und Dramaturgie der Bernardoniade. Wien: Notring 1971.

Birlinger, Anton: Zur Kunde der süddeutschen Mundarten des 17. und 18. Jahrhunderts. In: Archiv für das Studium der neueren Sprachen und Literaturen 23 (1868), H. 43, S. 221-236.

Bittmann, Sandra: Der mediale Diskurs um die zweite Türkenbelagerung Wiens zwischen 1683 und heute. Wien 2008. [Dipl.]

Blanckenburg, Curt: Studien über die Sprache Abrahams a S. Clara. Ein Beitrag zur Geschichte der deutschen Drucksprache im 17. und 18. Jahrhundert. Halle a. d. S.: Niemeyer 1897.

Blöchl, Arnold: Melodiarium zu Wilhelm Paillers Weihnachts- und Krippenliedersammlung herausgegeben in den Jahren 1881 und 1883. Unter Mitarbeit von Annemarie Gschwantler und Walter Deutsch. Hg. vom Oberösterreirischen Volksliedwerk. 2 Halbbde. Wien/Köln/Weimar: Böhlau 2000. (Corpus musicae popularis Austriacae 13)

Blumenberg, Hans: Die Lesbarkeit der Welt. Frankfurt a. M.: Suhrkamp 1986.

Blümml, Emil Karl: Der Bauernsohn in der Kirche. Ein niederbayerisches Dialektgedicht aus ca. 1650. In: Zeitschrift für hochdeutsche Mundarten 6 (1905), S. 228-236.

Blümml, Emil Karl: Volkslied-Miszellen. In: Archiv für das Studium der neueren Sprachen und Literaturen 59 (1905), Bd. 115, S. 30-66.

Blümml, Emil Karl (Hg.): Die Liederhandschrift des Weingartner Benediktiners P. Meingosus Gaelle aus dem Jahre 1777. Als Beitrag zur Geschichte des geistigen und studentischen Lebens an der Benediktiner Universität Salzburg. Wien: Ludwig 1912.

Blümml, Emil Karl: Schottkys Volksliedernachlass. Wien: Ludwig 1912. (Quellen und Forschungen zur deutschen Volkskunde VII)

Boberski, Heiner: Das Theater der Benediktiner an der alten Universität Salzburg (1617-1778). Wien: Verl. der Österr. Akademie d. Wissenschaften 1978. (Theatergeschichte Österreichs VI: Salzburg 1)

Bodi, Leslie: Tauwetter in Wien. Zur Prosa der österreichischen Aufklärung 1781-1795. Frankfurt a. M.: Fischer 1977.

Bodmer, Johann Jakob: Vorrede. In: Johann Jakob Breitinger: Fortsetzung der Critischen Dichtkunst, worinnen die poetische Mahlerey in Absicht auf den Ausdruck und die Farben abgehandelt wird. Zürich/Leipzig: Orell 1740, S. [III-XIII]. 
Bodmer, Johann Jakob/Breitinger, Johann Jakob: Der Mahler der Sitten. Von neuem übersehen und starck vermehret. 2 Bde. Zürich: Orell 1746.

Bohlman, Philip Vilas/Holzapfel, Otto: The folk songs of Ashkenaz. Middleton: A-R Editions 2001. (Recent researches in the oral traditions of music 6)

Bölts, Stephanie: Krankheiten und Textgattungen. Gattungsspezifisches Wissen in Literatur und Medizin um 1800. Berlin/Boston: de Gruyter 2016.

Bolte, Johannes: Der Bauer im deutschen Liede. 32 Lieder des 15.-19. Jahrhunderts nebst einem Anhange. In: Acta Germanica I (1890), H. 3, S. 175-303.

Boruth, Peter: Die Krankengeschichte des Kurprinzen Joseph Ferdinand von Bayern (1692-1699). Textedition mit Übersetzung. München 1985. [Diss.]

Brandner-Kapfer, Andrea: Johann Joseph Felix von Kurz: Das Komödienwerk. Historisch-Kritische Edition. Graz 2007. [Diss.]

Brandner-Kapfer, Andrea: Kasperls komisches Habit Zur komischen Gestalt und zur Gestaltung der Komik in Erfolgsstücken des Leopoldstädter Theaters um 1800. In: Andrea Brandner-Kapfer/Jennyfer Großauer-Zöbinger/Beatrix Müller-Kampel: Kasperl-La Roche. Seine Kunst, seine Komik und das Leopoldstädter Theater. Graz: LiTheS 2010. (LiTheS. Zeitschrift für Literatur- und Theatersoziologie. Sonderbd. 1) S. 56-104.

Brandner-Kapfer, Andrea (Hg.): Der Tyroler Wastel. Eine komische Oper in drei Aufzügen von Emanuel Schikaneder. Die Musik ist vom Herrn Haibel Mitglied des k. k. privil. Wiedner Theaters. Leipzig bei August Geers 1798. Anmerkungen. Graz 2011. http://ithes.uni-graz.at/kasperls_erben/pdfs_erben/doku_schikaneder_tyroler_wastel.pdf (letzter Zugriff am 14.05.2018).

Brandstetter, Herbert G.: Der bayerische Volksaufstand im oberen Innviertel. In: G'wunna hat z'letzt nur unseroans. Der bairische Volksaufstand 1705/1706 im Spanischen Erbfolgekrieg. Vom Innviertel nach Tölz, zur Sendlinger Mordweihnacht und zur Schlacht bei Aidenbach. Hg. von Marktgemeinde Kopfing, Marktgemeinde Aidenbach, Bund der Bayerischen GebirgsschützenKompanien. Ried im Innkreis: Moserbauer 2005, S. 71-81.

Brednich, Rolf Wilhelm/Suppan, Wolfgang (Hg.): Die Ebermannstädter Liederhandschrift geschrieben um 1750 von Frantz Melchior Freytag Schulrektor zu Ebermannstadt (Staatsbibliothek Bamberg Msc.misc. 580a). Deutsches Volksliedarchiv Freiburg. Kulmbach: Freunde der Plasseburg E.V. 1972. (Schriften für Heimatforschung und Kulturpflege in Ostfranken 31)

Brednich, Rolf Wilhelm: Erotisches Lied. In: Rolf Wilhelm Brednich/Lutz Röhrich/Wolfgang Suppan (Hg.): Handbuch des Volksliedes. Bd. I: Die Gattungen des Volksliedes. München: Finke 1973, S. 575-615.

Brenner, Oskar: Altbairische Sprachproben aus dem 18. Jahrhundert. In: Oskar Brenner/August Hartmann (Hg.): Bayerns Mundarten. Beiträge zur Deutschen Sprach- und Volkskunde. Bd. 1. München: Kaiser 1892, S. 128-145, 203-222, 336-361 sowie ebda., Bd. 2 (1895), S. 60-73, $161-$ 181.

Brenner, Oskar: Der andächtige Bauer, ein altbairisches Gedicht v. J. 1758. In: Oskar Brenner / August Hartmann (Hg.): Bayerns Mundarten. Beiträge zur Deutschen Sprach- und Volkskunde. Bd. 1. München: Kaiser 1892, S. 295-300.

Brenner, Oskar/Hartmann, August (Hg.): Bayerns Mundarten. Beiträge zur Deutschen Sprach- und Volkskunde. 2 Bde. München: Kaiser 1892/95.

Brenner, Oskar (Hg.): Altbairische Possenspiele für die Dachauer Bühne bearbeitet. München: Kaiser 1893.

Bretholz, Bertold: Geschichte Böhmens und Mährens. Bd. 3: Dreißigjähriger Krieg und Wiederaufbau bis 1792. Reichenberg: Sollor 1924.

Breuer, Dieter: Die protestantische Normierung des deutschen Literaturkanons in der frühen Neuzeit. In: Heinz-Gerhard Haupt/Dieter Langewiesche (Hg.): Nation und Religion in der deutschen Geschichte. Frankfurt a. M./New York: Campus 2001, S. 84-104.

Breuss, Susanne: Kreebs'n und Limonien, Schweewl und Bomad. Alltags- und konsumhistorische Aspekte der Wiener Kaufruf- und Volkstypendarstellungen um 1800. In: Wolfgang Kos (Hg.): Wiener Typen. Klischees und Wirklichkeit. Katalog zur Ausstellung im Wien Museum, 25. April bis 6. Oktober 2013. Wien: Brandstätter 2013, S. 152-157. 
Brewer, Charles E.: The Instrumental Music of Schmeltzer, Biber, Muffat and Their Contempories. Farnham: Ashgate 2011.

Brockpähler, Renate: Handbuch zur Geschichte der Barockoper in Deutschland. Emsdetten: Lechte 1964.

Browning, Reed: The War of the Austrian Succession. Stroud: Alan Sutton 1994.

Brückner, Wolfgang: Der Wanderhandel im Diskurs der Aufklärung. In: Wolfgang Brückner: Volkskunde als historische Kulturwissenschaft. Gesammelte Schriften. Bd. 14: Nachträge II. Würzburg: Bayer. Blätter für Volkskunde 2010. (Veröffentlichungen zur Volkskunde und Kulturgeschichte 88/3) S. 229-243.

Brückner, Wolfgang: Die Kolportage im Wirtschaftssystem der Protoindustrialisierung. In: ebda., S. 244-255.

Brukner, Fritz (Hg.): Joseph Anton Stranitzky: Türckisch-bestraffter Hochmuth, oder Das ano 1683. von denen Türcken belagerte und von denen Christen entsetzte Wienn, und Hans Wurst, die kurzweilige Salve-Guarde des Frauen-Zimmers, lächerlicher Spion, und zum Tode verdamter Mißethäter. Innsbruck/Wien/München: Tyrolia 1933.

Bücher, Karl: Arbeit und Rhythmus. 5. verb. Aufl. Leipzig: Reinicke 1919.

Buchinger, Erich: Die ,Landler' in Siebenbürgen. Vorgeschichte, Durchführung und Ergebnis einer Zwangsumsiedlung im 18. Jahrhundert. München: Oldenbourg 1980. (Buchreihe der Südostdeutschen Historischen Kommission 31)

Buchmann, Bertrand Michael: Türkenlieder zu den Türkenkriegen und besonders zur zweiten Wiener Türkenbelagerung. Wien/Köln/Graz: Böhlau 1983.

Burke, Peter: Helden, Schurken und Narren. Europäische Volkskultur in der frühen Neuzeit. Hg. und mit einem Vorwort von Rudolf Schenda, übersetzt von Susanne Schenda. Stuttgart: KlettCotta 1981.

Busch, Michael: Der Bauer als Soldat. Ein gescheitertes Konzept der Heeresaufbringung? In: Ralf Pröve (Hg.): Klio in Uniform? Probleme und Perspektiven einer modernen Militärgeschichte der frühen Neuzeit. Köln/Weimar/Wien: Böhlau 1997, S. 143-166.

Busch, Werner: Nachahmung als bürgerliches Kunstprinzip. Ikonographische Zitate bei Hogarth und in seiner Nachfolge. Hildesheim/New York: Olms 1977.

Carpani, Giuseppe: Le Haydine ovvero Lettere su la vita e le opere del celebre maestro Giuseppe Haydn. Milano: Buccinelli 1812.

Commenda, Hans: Bärenbegräbnis. Ein alter Jägerbrauch aus dem Salzkammergut. In: Oberösterreichische Heimatblätter 2 (1948), H. 3, S. 267-272.

Commenda, Hans: Adelige Lustbarkeiten in Linz vom 16. bis zum 18. Jahrhundert. In: Historisches Jahrbuch der Stadt Linz 1958, S. 141-180.

Commenda, Hans: P. Wilhelm Paillers Liednachlaß. In: Jahrbuch des österreichischen Volksliedwerkes 13 (1964), S. 45-54.

Commenda, Hans: Ein oberösterreichisches Notburga-Spiel. In: Oberösterreichische Heimatblätter 23 (1969) H. 1/2, S. 36-40.

Corbin, Alain: Pesthauch und Blütenduft. Eine Geschichte des Geruchs. Aus dem Französischen von Grete Osterwald. Berlin: Wagenbach 2005.

Corvin, Otto v.: Pfaffenspiegel. Historische Denkmale des Fanatismus in der römisch-katholischen Kirche. 2. neu durchges. Aufl. Stuttgart: Vogler \& Beinhauer 1869.

Czeike, Felix: Der Graben. Wien/Hamburg: Zsolnay 1972.

Czeike, Felix: Historisches Lexikon Wien. Wien: Kremeier u. Scheriau 1994.

Dabhoiwala, Faramerz: Lust und Freiheit. Die Geschichte der ersten sexuellen Revolution. Aus dem Englischen von Hainer und Esther Kober. Stuttgart: Klett-Cotta 2014.

Dainat, Holger: Der Siebenjährige Krieg in den Medien. In: Wolfgang Adam/Holger Dainat (Hg.): „Krieg ist mein Lied“. Der Siebenjährige Krieg in den zeitgenössischen Medien. Hg. in Verbindung mit Ute Pott. Göttingen: Wallstein 2007. (Schriften des Gleimhauses Halberstadt 5) S. 926.

Danker, Uwe: Die Geschichte der Räuber und Gauner. Düsseldorf/Zürich: Artemis \& Winkler 2001. 
de Grauwe, Luc: Sie sehen also, daß ich schreiben kann wie ich will. W. A. Mozart. In: Studia Germanica Gandensia (NF) 24 (1996), H. 1, S. 223-243.

de Grauwe, Luc: Wolfgang Amadé Mozart. In: D. Alan Cruse [u. a.]: Lexikologie/Lexicology. Ein internationales Handbuch zur Natur und Struktur von Wörtern und Wortschätzen. 2. Halbbd. Berlin/New York: de Gruyter 2005. (HSK 21.2) S. 1524-1526.

Deinhammer, Peter/Neuhuber, Christian (Hg.): Maurus Lindemayr/Ernest Frauenberger: Klavierlieder in oberösterreichischer Bauernsprache. Kommentierte Ausgabe. Weitra: Bibliothek der Provinz 2015.

Deutsch, Walter: Ein ,Wienerischer Tändelmarkt' von 1803 und seine Vorbilder im Wien des XVII. und XVIII. Jahrhunderts. In: Jahrbuch des österreichischen Volksliedwerkes 14 (1965), S. 30-48.

Deutsch, Walter/Haid, Gerlinde/Zeman, Herbert (Hg.): Das Volkslied in Österreich. Ein gattungsgeschichtliches Handbuch. Wien: Holzhausen 1993.

Ditfurth, Franz Wilhelm von (Hg.): Die historischen Volkslieder des Bayerischen Heeres von 16201870. Aus fliegenden Blättern, handschriftlichen Quellen und dem Volksmunde gesammelt und herausgegeben. Nördlingen: Beck 1871.

Ditfurth, Franz Wilhelm von (Hg.): Einhundertundzehn Volks- und Gesellschaftslieder des 16., 17. und 18. Jahrhunderts mit und ohne Singweise. Nach fliegenden Blättern, handschriftlichen Quellen und dem Volksmunde gesammelt. Stuttgart: Göschen 1875.

Ditfurth, Franz Wilhelm von (Hg.): Die historischen Volkslieder der Zeit von 1648 bis 1871. Bd. 1: Die historischen Volkslieder der Zeit von 1648 bis 1756: Die historischen Volkslieder vom Ende des dreißigjährigen Krieges, 1648, bis zum Beginn des siebenjährigen Krieges, 1756. Heilbronn: Henninger 1877. Bd. 2: Historische Volkslieder der Zeit von 1756 bis 1815: I. Die historischen Volkslieder des siebenjährigen Krieges, 1756-1763. II. Die historischen Volkslieder vom Ende des siebenjährigen Krieges, 1763, bis zum Brande von Moskau, 1812. Berlin: Lipperheide 1871/72.

Dittersdorf, Karl von: Lebensbeschreibung. Seinem Sohne in die Feder diktirt. Leipzig: Breitkopf und Härtel 1801.

Dittrich, Raymond (Hg.): Die Lieder der Salzburger Emigranten von 1731/32. Edition nach zeitgenössischen Textdrucken. Tübingen: Francke 2008. (Mainzer Hymnologische Studien 22)

Dormann, Peter: Franz Joseph Aumann (1728-1797). Ein Meister in St. Florian vor Anton Bruckner. Mit thematischem Katalog der Werke. München/Salzburg: Katzbichler 1985.

Dörrer, Anton: Hundert Innsbrucker Notendrucke aus dem Barock. Ein Beitrag zur Geschichte der Musik und des Theaters in Tirol. In: Gutenberg-Jahrbuch 14 (1939), S. 243-268.

Dörrer, Anton: Zillertaler Volksschicksale, gesehen an den Schicksalen ihrer Schauspiele. In: Herbert Seidler (Hg.): Festschrift. Moritz Enzinger zum 60. Geburtstag. Innsbruck: Wagner 1953. (Schlern-Schriften 104) S. 25-52.

Dörrer, Anton: Volksdichterische Charakteristik aus dem Ahrntal. In: Österreichische Zeitschrift für Volkskunde 50 (N.F. 1) (1974), S. 28-66.

Drexel, Kurt/Fink, Monika: Musikgeschichte Tirols: Von den Anfängen bis zur Frühen Neuzeit. Innsbruck: Wagner 2001.

Drobesch, Werner: Bodenerfassung und Bodenbewertung als Teil einer Staatsmodernisierung. Theresianische Steuerrektifikation, Josephinischer Kataster und Franziszeischer Kataster. In: Reto Furter, Anne-Lise Head-König, Luigi Lorenzetti (Hg.): Les migrations de retour. Rückwanderungen. Zürich: Chronos 2009. (Geschichte der Alpen/Histoire des Alpes/Storia delle Alpi 14) S. $165-183$.

Drugulin, W. (Hg.): Atlas Historique Drugulin. Catalogue d'une précieuse Collection de Feuilles volantes, estampes allégoriques et satyriques, livres d'entrées, etc. pour servir à l'histoire publique et intime de tous les pays pendant les quatre derniers siècles. Leipzig: Kunst-Comptoir 1867.

Ebeling, Friedrich W.: Geschichte der Komischen Literatur in Deutschland seit der Mitte des 18. Jahrhunderts. Bd. 1: 2. Hälfte des 18. Jahrhunderts. Leipzig: Haynel 1869.

Edler, Stefanie: Mündlich Verwurzeltes schriftlich konserviert. Überlegungen zur schriftlichen Repräsentation in der Überlieferung von Dialektliteratur des 17. und 18. Jahrhunderts. In: Christian Neuhuber/Elisabeth Zehetner (Hg.): Bairisch-österreichischer Dialekt in Literatur und Musik 1650-1900. Tagungsband. Graz: Leykam/Universitätsverl. 2015, S. 39-59. 
Eibl, Joseph Heinz/Senn, Walter: Mozarts Bäsle-Briefe. Kassel [u. a.]: Bärenreiter 1978.

Eibl, Karl: Die Entstehung der Poesie. Frankfurt a. M.: Insel 1995.

Elias, Norbert: Über den Prozeß der Zivilisation. Soziogenetische und psychogenetische Untersuchungen. Bd. 1-2. 14. Aufl. Frankfurt a. M.: Suhrkamp 1989.

Engels, Hans Werner: Lieder und Gedichte deutscher Jakobiner. Mit einem Vorwort von Walter Grab. Stuttgart: Metzler 1971.

Emanuely, Alexander: Ausgang: Franz Hebenstreit (1747-1795). Schattenrisse der Wiener Demokrat $^{*}$ innen 1794. Weitra: Verlag der Provinz 2009.

Enzinger, Moriz: Die Entwicklung des Wiener Theaters vom 16. bis zum 19. Jahrhundert (Stoffe und Motive). 2 Teile. Berlin: Selbstverlag der Ges. für Theatergeschichte 1918/19. (Schriften der Gesellschaft für Theatergeschichte 28/29)

Enzinger, Moriz (Hg.): Zwei Singspiele von P. Maurus Lindemayr. In: Euphorion 31 (1930), S. 31-95.

Enzinger, Moriz: Der Engelsturz. Fastnachtspiel in Tiroler Bauernreimen von Joseph Sieberer S. J. In: Maske und Kothurn 10 (1964), S. 324-375

Erichsen, Johannes/Heinemann, Katharina (Hg.): Brennpunkt Europas 1704. Die Schlacht von Höchstädt/The Battle of Blenheim. Begleitbuch zur Ausstellung in Schloss Höchstädt an der Donau, 1. Juli bis 7. November 2004. Stuttgart: Thorbecke 2004.

Erk, Ludwig/Irmer, Wilhelm (Hg.): Die deutschen Volkslieder mit ihren Singweisen. Bd. 1. Viertes Heft. Berlin: Plahn 1843.

Erlenbusch, Lisa/Ikonić, Marko/Neuhuber, Christian (Hg.): Vom Wiener Kärntnertortheater nach Schloss Krumau. Die Hanswurst-Burlesken von Český Krumlov. Wien: Lehner 2018.

Ernst, Eva-Maria: Zwischen Lustigmacher und Spielmacher. Die komische Zentralfigur auf dem Wiener Volkstheater im 18. Jahrhundert. Münster/Hamburg/London: LIT 2003.

Ernst, Willibald: Innviertler Spuren im sogenannten Stubenberger Gesängerbuch. In: Der Bundschuh 11 (2008), S. 27-43.

Ernst, Willibald (Hg.): Geistliches Zeitten Buch worin die Schönsten gebether Sambt den gesänggern, auf Alle Hohe Fest und andere untterschiedliche heillige zeitten des ganzen Jahr hindurch beschriben seind. Gesammelt und geschrieben von Phillipp Lenglachner $\left({ }^{*} 1769, \dagger 1823\right)$. Edition der Handschrift Cgm 7341 der Bayerischen Staatsbibliothek München. Transkribiert von Willibald Ernst. München: Institut für Volkskunde der Kommission für bayerische Landesgeschichte bei der Bayerischen Akademie der Wissenschaften 2012 (Stubenberger Handschriften 1. Quellen und Studien zur musikalischen Volkstradition in Bayern 4)

Etymologisches Wörterbuch des Deutschen. Erarbeitet im Zentralinstitut für Sprachwissenschaft, Berlin, unter der Leitung von Wolfgang Pfeifer. 2. Aufl. München: dtv 1995.

Externbrink, Sven: Einleitung: Der Siebenjährige Krieg - ein europäischer Weltkrieg im Zeitalter der Aufklärung. In: Sven Externbrink (Hg.): Der Siebenjährige Krieg (1756-1763). Ein europäischer Weltkrieg im Zeitalter der Aufklärung. Berlin: Akad.-Verl. 2011, S. 9-26.

Eybl, Franz M.: Abraham a Sancta Clara. Vom Prediger zum Schriftsteller. Tübingen: Niemeyer 1992.

Eybl, Franz M.: Hanswurststreit und Broschürenflut. Die Struktur der Kontroversen in der österreichischen Literatur des 18. Jahrhunderts. In: Wendelin Schmidt-Dengler/Johann Sonnleitner/ Klaus Zeyringer (Hg.): Konflikte - Skandale - Dichterfehden in der österreichischen Literatur. Berlin: Schmidt 1995, S. 24-35.

Eyer, Ingrid: Das lyrische und dramatische Werk Philipp Hafners. Seine weltanschauliche und stilistische Position in der österreichischen Literatur der Maria-Theresianischen Ära. Wien 1986. [Diss.]

Faulstich, Katja: Konzepte des Hochdeutschen. Der Sprachnormierungsdiskurs im 18. Jahrhundert. Berlin/New York: de Gruyter 2008.

Feurzeig, Lisa/Sienicki, John: Quodlibets of the Viennese Theater. Middleton: A-R Editions 2008. (Recent Researches in the Music of the Nineteenth and Early Twentieth Centuries 47)

Firmenich-Richartz, Johannes Matthias (Hg.): Germaniens Völkerstimmen. Bd. 3. Berlin: Schlesinger 1854.

Florack, Ruth: Tiefsinnige Deutsche, frivole Franzosen. Nationale Stereotype in deutscher und französischer Literatur. Stuttgart/Weimar: Metzler 2001. 
Florack, Ruth: Bekannte Fremde. Zu Herkunft und Funktion nationaler Stereotype in der Literatur. Tübingen: Niemeyer 2007.

Florey, Gerhard: Geschichte der Salzburger Protestanten und ihrer Emigration 1731/32. Wien/Köln/ Graz: Böhlau 1977.

Flotzinger, Rudolf (Hg.): Wolfgang Schmeltzl: Guter, seltzsamer und kunstreicher teutscher Gesang. Graz: Akademische Druck- u. Verlagsanstalt 1990. (Denkmäler der Tonkunst in Österreich 147/148)

Flotzinger, Rudolf: Ländler. In: Rudolf Flotzinger (Hg.): Oesterreichisches Musiklexikon. Bd. 3: Km N. Wien: Verl. der Österr. Akademie der Wissenschaften 2004, S. 1219.

Forcher, Michael: Bayern-Tirol. Die Geschichte einer freud-leidvollen Nachbarschaft. Wien: Herder 1981.

Foucault, Michel: Sexualität und Wahrheit. Der Gebrauch der Lüste. Bd. 2. Frankfurt a. M.: Suhrkamp 1986.

Foucault, Michel: Dispositive der Macht: Über Sexualität, Wissen und Wahrheit. Berlin: Merve 2008.

Freitag, Ulrike Katrin: Geputztes Blumwerk und buntschäkkiger Wörterkram. Sprachkritik in den Wöchentlichen Wahrheiten (1782-1784). Frankfurt a. M. [u. a.]: Lang 2007. (Schriften zur deutschen Sprache in Österreich 38)

Frenzel, Elisabeth: Bauer wird König für einen Tag. In: Kurt Ranke (Hg.): Enzyklopädie des Märchens: Handwörterbuch zur historischen und vergleichenden Erzählforschung. Bd. 1. Berlin, New York: de Gruyter 1977, S. 1343-1347.

Frenzel, Elisabeth: Stoffe der Weltliteratur. Ein Lexikon dichtungsgeschichtlicher Längsschnitte. 9., überarb. u. erw. Aufl. Stuttgart: Kröner 1998. (Kröners Taschenausgabe 300)

Fromberg, Thorsten: Fronleichnamsprozession und Sternsingen. Zwei barocke Volksschauspiele aus dem Schreybbuech Phillipp Lenglachners (Niederbayern um 1800). Kiel 2012. [Diss.]

Fuhrmann, Mathias: Alt- und Neues WIEN, Oder Dieser Kayserlich- und Ertz-Lands-Fürstlichen Residentz-Stadt Chronologisch- und Historische Beschreibung Beschreibung Von den mittleren Biß auf gegenwärtige Zeiten. Anderter Theil. Wien: Prasser 1739.

Füssel, Marian: Der Siebenjährige Krieg. Ein Weltkrieg im 18. Jahrhundert. München: Beck 2010.

Gaisbauer, Stephan/Scheuringer, Hermann (Hg.): Karpatenbeeren. Bairisch-österreichische Siedlung, Kultur und Sprache in den ukrainisch-rumänischen Waldkarpaten. Mit Fotographien von Hans Kumpfmüller. Linz: Adalbert-Stifter-Institut des Landes Oberösterreich 2006.

Gelbart, Matthew: The Invention of ,Folk Music' and ,Art Music'. Emerging Categories from Ossian to Wagner. Cambridge: University Press 2007.

Gerhartl, Gertrud: Belagerung und Entsatz von Wien. Wien: Österr. Bundesverlag 1983.

Gerning, J[ohann] I[saak]: Reise durch Oestreich und Italien. Erster Theil. Mit einem Titel-Kupfer. Frankfurt a. M.: Wilmans 1802.

Gessinger, Joachim: Sprache und Bürgertum. Sozialgeschichte sprachlicher Verkehrsformen im Deutschland des 18. Jahrhunderts. Stuttgart: Metzler 1980.

Giglleithner, K. / Litschauer, G. [i. e. Blümml, Emil Karl/Gugitz, Gustav]: Der Spittelberg und seine Lieder. Wien: Privatdruck 1924.

Glaser, Rüdiger: Klimageschichte Mitteleuropas. 1000 Jahre Wetter, Klima, Katastrophen. Darmstadt: Primus 2001.

Gmasz, Michael Joseph: Das traditionelle Hochzeitslied auf dem burgenländischen Heideboden. Unter besonderer Berücksichtigung handschriftlicher Liederbücher und Privatchroniken. Wien 2013. [Dipl.]

Gmasz, Sepp: Mundart zur Haydnzeit: historische, literarische und musikalische Quellen. Mit besonderer Berücksichtigung des burgenländischen Raumes. In: Jahrbuch des österreichischen Volksliedwerkes 59 (2010), S. 202-218.

Goetsch, Paul: Fingierte Mündlichkeit in der Erzählkunst entwickelter Schriftkulturen. In: Poetica. Zeitschrift für Sprach- und Literaturwissenschaft 17 (1985), S. 202-218.

Goetsch, Paul: Fremdsprachen in der Literatur: Ein typologischer Überblick. In: Paul Goetsch (Hg.): Dialekte und Fremdsprachen in der Literatur. Tübingen: Narr 1987. (ScriptOralia 2) S. 43-68. 
Goetsch, Paul: Vorwort. In: Paul Goetsch (Hg.): Dialekte und Fremdsprachen in der Literatur. Tübingen: Narr 1987. (ScriptOralia 2) S. 7-10.

Golzar, Elisabeth: Bilder führen durch den Klang der Stadt. Die Entwicklung der europäischen Kaufrufgrafik. In: Wolfgang Kos (Hg.): Wiener Typen. Klischees und Wirklichkeit. Katalog zur Ausstellung im Wien Museum, 25. April bis 6. Oktober 2013. Wien: Brandstätter 2013, S. 32-39.

Görner, Karl von: Der Hans Wurst-Streit der österreichischen Aufklärung 1781-1795. Wien: Konegen 1884.

Gottsched, Johann Christoph: Versuch einer Critischen Dichtkunst. Unveränderter photomechanischer Nachdruck der 4., vermehrten Aufl., Leipzig 1751. 5., unveränderte Aufl. Darmstadt: Wissenschaftliche Buchgesellschaft 1962.

Gottsched, Johann Christoph: Hanswurst, ein Lustspiel in einem Aufzuge. Presburg bey J.M. Landerer 1761. 52. S. in 8. In: Das Neueste aus der anmuthigen Gelehrsamkeit 12 (1762), S. 199-213.

Grab, Walter/Friesel, Uwe: Noch ist Deutschland nicht verloren. Eine historisch-politische Analyse unterdrückter Freiheitslyrik von der Französischen Revolution bis zur Reichsgründung. München: Hanser 1970.

Grab, Walter: Ein Volk muß seine Freiheit selbst erobern. Zur Geschichte der deutschen Jakobiner. Frankfurt a. M./Olten/Wien: Büchergilde Gutenberg 1984.

Gräfe, Florian: Dialektliteratur in Deutschland und Italien. Konstanz und Wandel von Bewertungsmustern. Marburg: Tectum 2004.

Graser, Rudolph: Vollständige Lehrart zu predigen oder wahre Beredsamkeit der christlichen Kanzel nach der Vorschrift der berühmtesten Redner Frankreich und Deutschlands in gründlichen Regeln. Augsburg: Matthäus Rieger und Söhne 1768.

Graser, Rudolph: Praktische Beredsamkeit der christlichen Kanzel, in Regeln, Exempeln, und vollständigen Mustern; mit einer Vorrede begleitet von P. Maurus Lindemayr, Benedictinern und ehemaligen Priorn zu Kloster Lambach, dermalen Seelsorgern zu Neukirchen. Augsburg: Matthäus Rieger und Söhne 1769.

Gräter, Friedrich David: Ueber die teutschen Volkslieder und ihre Musik (kommentiert von Hermann Bausinger). In: Württembergisch Franken 52 (1968), S. 201-226.

Greig, J. Y. T. (Hg.): The Letters of David Hume. Vol. 1 (1727-1765). Oxford: University Press 2011.

Greule, Albrecht: Dialekt als Theolekt? Überlegungen aus der Perspektive der Variationslinguistik. In: Elisabeth Frieben/Ulrich Kanz/Barbara Neuber/Ludwig Zehetner (Hg.): Dialekt und Religion. Beiträge zum 5. dialektologischen Symposium im Bayerischen Wald, Walderbach, Juni 2012. Regensburg: edition vulpes 2014, S. 29-36.

Greverus, Ina-Maria: Der territoriale Mensch. Ein literaturanthropologischer Versuch zum Heimatphänomen. Frankfurt a. M.: Athenäum 1972.

Grininger, Hubert: Da Weg zu mein Dirndl is stoani... Liebe und Eros in der alpenländischen Volksmusik von 1800 bis zum Austropop. Graz: Edition Strahalm 1997.

Großauer-Zöbinger, Jennyfer: Joachim Perinet (1763-1816). In: „Mäzene des Kasperls“ - OnlineEdition von 27 Komödientexten und Studie [2008/9]. http://lithes.uni-graz.at/maezene-pdfs/bio_ perinet.pdf (letzter Zugriff am 12.05.2018).

Grosch, Nils: Über das Alter der Populären Musik und die Erfindung des ,Volkslieds'. In: Sabine Meine/Nina Noeske (Hg.): Musik und Popularität. Aspekte zu einer Kulturgeschichte zwischen 1500 und heute. Münster [u. a.]: Waxmann 2011. (Populäre Kultur und Musik 2) S. 59-76.

Grosses vollständiges Universal-Lexikon aller Wissenschafften und Künste. Bd. 30: Q und R-Reh. Leipzig und Halle: Johann Heinrich Zedler 1741.

Grüll, Georg: Die Robot in Oberösterreich. Linz: Oberösterr. Landesarchiv 1952.

Grüll, Georg: Bauer, Herr und Landesfürst. Sozialrevolutionäre Bestrebungen der oberösterreichischen Bauern von 1650 bis 1848. Graz/Köln: Hermann Böhlaus Nachf. 1963.

Grüll, Georg: Bauernhaus und Meierhof. Zur Geschichte der Landwirtschaft in Oberösterreich. Linz: Oberösterr. Landesarchiv 1975.

Gugenbauer, Gustav: Linzer Witz vor 200 Jahren. Aus den Sammlungen von Johann Carl Seyringer. In: Heimatgaue 12 (1931), S. 69-83, 158-173. 
Gugenbauer, Gustav: Linzer Witz vor 200 Jahren. In: Heimatgaue 16 (1935), S. 68-78.

Gugitz, Gustav: Der weiland Kasperl (Johann La Roche). Ein Beitrag zur Theater- und Sittengeschichte Alt-Wiens. Wien: Strache 1920.

Haas, Walter: Franz Alois Schumachers ,Isaac'. Eine Volksschauspielparodie aus dem 18. Jahrhundert. Luzern: Rex 1975.

Haas, Walter: Dialekt als Sprache literarischer Werke. In: Werner Besch [u. a.]: Dialektologie. Ein Handbuch zur deutschen und allgemeinen Dialektforschung. 2. Halbbd. Berlin/New York: de Gruyter 1983. (HSK 1.2) S. 1637-1651.

Haas, Walter: ,Die Jagd auf Provinzial-Wörter`. Die Anfänge der wissenschaftlichen Beschäftigung mit den deutschen Mundarten im 17. und 18. Jahrhundert. In: Klaus Mattheier/Peter Wiesinger (Hg.): Dialektologie des Deutschen. Forschungsstand und Entwicklungstendenzen. Tübingen: Niemeyer 1994, S. 329-365.

Haas, Walter: Provinzialwörter. Deutsche Idiotismensammlungen des 18. Jahrhunderts. Berlin/New York: de Gruyter 1994.

Hadamowsky, Franz: Wien. Theatergeschichte. Von den Anfängen bis zum Ende des Ersten Weltkriegs. Wien/München: Jugend und Volk 1988.

Haefs, Wilhelm: „Charfreytagsprocession“, „Sündfluthspiel“ und „Monachologie“. Zur Literatur und Theologie der Katholischen Aufklärung. In: Hans-Edwin Friedrich/Wilhelm Haefs/Christian Soboth (Hg.): Literatur und Theologie im 18. Jahrhundert. Konfrontationen - Kontroversen Konkurrenzen. Berlin/New York: de Gruyter 2011, S. 32-63.

Hafner, Philipp: Scherz und Ernst in Liedern. [Reprint.] Neu herausgegeben und eingeleitet von Emil Karl Blümml. Wien/Prag/Leipzig: Strache 1922.

Hager, Stephan: „Mießig sein ist nit mein Freud“. Beamtenethos und Poesie im Werk des niederbayerischen Pflegrichters Andreas Mayr im Kontext des oberdeutschen Literatursystems der frühen Neuzeit. In: Verhandlungen des Historischen Vereins für Niederbayern 127-128 (2001-2002), S. 51-210.

Hahn, Hans Henning (Hg.): Stereotyp. Identität und Geschichte. Frankfurt a. M.: Lang 2002.

Hampel, Lucie: Hundert Jahre Kleidermode in österreichischen Liedtexten. In: Jahrbuch des Österreichischen Volksliedwerkes 8 (1959), S. 74-92.

Haid, Gerlinde: Neujahrssingen und Neujahrslied in Niederösterreich mit besonderer Berücksichtigung des Piestingtales. 2 Bde. Wien 1974. [Diss.]

Haid, Gerlinde/Hochradner, Thomas: Volksmusik in Salzburg. Lieder und Tänze um 1800 aus der Sonnleithner-Sammlung der Gesellschaft der Musikfreunde in Wien mit einem Beitrag von Sabine Veits-Falk und Alfred Stefan Weiß und unter Mitarbeit von Walter Deutsch und Annemarie Gschwantler. Hg. vom Salzburger Volksliedwerk. Wien/Köln/Weimar: Böhlau 2000. (Corpus Musicae Popularis Austriacae 12)

Haid, Gerlinde: Fensterllied. In: Rudolf Flotzinger (Hg.): Oesterreichisches Musiklexikon. Bd. 1: AF. Wien: Österr. Akademie der Wissenschaften 2002, S. 434.

Haid, Gerlinde: Gstanzl. In: Rudolf Flotzinger (Hg.): Oesterreichisches Musiklexikon. Bd. 2. G-Kl. Wien: Österr. Akademie der Wissenschaften 2003, S. 641.

Haid, Gerlinde: Schwerttanz. In: Rudolf Flotzinger (Hg.): Oesterreichisches Musiklexikon. Bd. 5: Schwechat - Zyklus. Wien: Österr. Akademie der Wissenschaften 2006, S. $2180 f$.

Haider-Pregler, Hilde: Des sittlichen Bürgers Abendschule. Bildungsanspruch und Bildungsauftrag des Berufstheaters im 18. Jahrhundert. Wien/München: Jugend und Volk 1980.

Härter, Karl: Early Modern Revolts as Political Crimes in the Popular Media of Illustrated Broadsheets. In: Malte Griesse (Hg.): From Mutual Observation to Propaganda War. Premodern Revolts in Their Transnational Representations. Bielefeld: transcript 2014, S. 309-350.

Hartmann, August (Hg.): Volksschauspiele. In Bayern und Österreich-Ungarn. Mit vielen Melodien, nach dem Volksmund aufgezeichnet von Hyacinth Abele. Leipzig: Breitkopf und Härtel 1880.

Hartmann, August: Zum 2. September 1886. In: Allgemeine Zeitung (München), 2. September 1886, Nr. 243. 
Hartmann, August: Ein altes niederbairisches Dialektgedicht. In: Oskar Brenner/August Hartmann (Hg.): Bayerns Mundarten. Beiträge zur Deutschen Sprach- und Volkskunde. Bd. 1. München: Kaiser 1892, S. 225-239.

Hartmann, August: Baumburger Dialektgedichte. In: Oskar Brenner/August Hartmann (Hg.): Bayerns Mundarten. Beiträge zur Deutschen Sprach- und Volkskunde. Bd. 2. München: Kaiser 1895, S. 305-313.

Hartmann, August (Hg.): Historische Volkslieder und Zeitgedichte vom sechzehnten bis neunzehnten Jahrhundert. Bd. 2: Von Mitte des siebzehnten bis zu der des achtzehnten Jahrhunderts. München: Beck 1910.

Hastaba, Ellen: Das Volksschauspiel im Oberinntal. Innsbruck 1986. [Diss.]

Hastaba, Ellen: Komische Szenen in geistlichen Tiroler Spielen des 17. Jahrhunderts, aufgezeigt am Beispiel der ,Comedia Barbara', Fließ 1644. In: Max Siller (Hg.): Fastnachtspiel - Commedia dell'Arte. Gemeinsamkeiten - Gegensätze. Akten des 1. Symposiums der Sterzinger Osterspiele. Innsbruck: Wagner 1992, S. 75-101.

Hein, Jürgen: Darstellung des Dialektsprechers in der neueren deutschen Dichtung. In: Werner Besch [u. a.]: Dialektologie. Ein Handbuch zur deutschen und allgemeinen Dialektforschung. Bd. 1/2. Berlin/New York: de Gruyter 1983, S. 1624-1636.

Heller, Karin: Barocke Dichtung aus den 7 Gemeinden: Zimbrische Texte aus dem 17. und 18. Jahrhundert. Wien: VWGÖ 1988.

Henne, Helmut: Hochsprache und Mundart im schlesischen Barock. Studien zum literarischen Wortschatz in der ersten Hälfte des 17. Jahrhunderts. Köln/Graz: Böhlau 1966. (Mitteldeutsche Forschungen 44)

Hennig, Mathilde: Grammatik der gesprochenen Sprache in Theorie und Praxis. Kassel: kassel university press 2006 .

Hennig, Mathilde: Thesen zur Erforschung historischer Nähesprachlichkeit. In: Maria Balaskó/Petra Szatmári (Hg.): Sprach- und literaturwissenschaftliche Brückenschläge. Vorträge der 13. Jahrestagung der GESUS in Szombathely, 12.-14. Mai 2004. München: Lincom 2007, S. 13-26.

Herder, Johann Gottfried: Ueber die neuere Deutsche Litteratur. Fragmente. Erste Sammlung. Zweite völlig umgearbeite [sic] Ausgabe. Riga: Hartknoch 1768.

Herzog, Urs: Geistliche Wohlredenheit. Die katholische Barockpredigt. München: Beck 1991.

Hippel, Wolfgang von: Armut, Unterschichten, Randgruppen in der frühen Neuzeit. 2., aktual. u. um einen Nachtrag erw. Aufl. München: Oldenbourg 2013. (Enzyklopädie deutscher Geschichte 34)

Hochedlinger, Michael: Oberösterreich im Spanischen Erbfolgekrieg 1702-1706. Wien: ÖBV 1993. (Militärhistorische Schriftenreihe 66)

Hochedlinger, Michael: Austria's Wars of Emergence. War, State and Society in the Habsburg Monarchy 1683-1797. London [u. a.]: Pearson Education 2003.

Hochedlinger, Michael/Tantner, Anton (Hg.): „... Der größte Teil der Untertanen lebt elend und mühselig“. Die Berichte des Hofkriegsrates zur sozialen und wirtschaftlichen Lage der Habsburgermonarchie 1770-1771. Innsbruck/Wien/Bozen: Studien-Verl. 2005. (Mitteilungen des Österreichischen Staatsarchivs: Sonderband 8)

Hochradner, Thomas: Der Fopper. Ein Beispiel thematischer Wanderschaft. In: Peter M. Krakauer/ Christoph Khittl/Monika Mittendorfer (Hg.): Der Diskurs des Möglichen. Musik zwischen Kunst, Wissenschaft und Pädagogik. Festschrift für Wolfgang Roscher zum 70. Geburtstag. Anif b. Salzburg: Müller-Speiser 1999, S. 200-224.

Hochradner, Thomas: Musikalische Volkskultur in Salzburg vom späten 18. Jahrhundert bis 1848. In: Gerlinde Haid/Thomas Hochradner: Volksmusik in Salzburg. Lieder und Tänze um 1800 aus der Sonnleithner-Sammlung der Gesellschaft der Musikfreunde in Wien. Mit einem Beitrag von Sabine Veits-Falk und Alfred Stefan Weiß und unter Mitarbeit von Walter Deutsch und Annemarie Gschwantler hg. v. Salzburger Volksliedwerk. Wien/Köln/Weimar: Böhlau 2000. (Corpus Musicae Popularis Austriacae 12) S. 13-155.

Hochradner, Thomas: Zur Überlieferung des ,Halleiner Weihnachtsspiels. In: Jahrbuch des Österreichischen Volksliedwerks 50 (2001), S. 41-62. 
Hochradner, Thomas: Zur Entwicklung des alpenländischen Singstils am Beispiel des Wildschützenliedes. In: Lied und populäre Kultur/Song and Popular Culture. Jahrbuch des Deutschen Volksliedarchivs 54 (2009), S. 133-151.

Hofer, Anton: Sprüche, Spiele und Lieder der Kinder. Wien: Böhlau 2004. (Corpus Musicae Popularis Austriacae 16)

Höfer, Matthias: Die Volkssprache in Oesterreich vorzüglich ob der Ens, nach ihrer innerlichen Verfassung und Vergleichung mit anderen Sprachen. Wien: Binz 1800.

Hofmann, Hasso: Repräsentation. Studien zur Wort- und Begriffsgeschichte von der Antike bis ins 19. Jahrhundert. Berlin: Duncker \& Humblot 1998.

Holenstein, André: Bauern zwischen Bauernkrieg und Dreißigjährigem Krieg. München: Oldenburg 1996.

Holland, Hyacinth: Sturm, Nikolaus. In: Allgemeine Deutsche Biographie 37 (1894), S. 45-48.

Holtorf, Arne: Neujahrslied. In: Rolf Wilhelm Brednich/Lutz Röhrich/Wolfgang Suppan (Hg.): Handbuch des Volksliedes. Bd. 1: Die Gattungen des Volksliedes. München: Fink 1973, S. $363-$ 389.

Holzapfel, Otto: Die Entstehung des alpenländischen Mundartliedes um 1800 als Spiegelbild einer neuen Wertschätzung des Dialekts. In: Zeitschrift für Dialektologie und Linguistik 69 (2002), H. 1, S. 38-52.

Huber, Karl Heinz: Pater Norbert Pambichlers, Tendlbaß`. Textwiedergabe, Wort- und Sacherklärung sowie Interpretationsversuche. In: Jahrbuch des Wiener Goethe-Vereins 97/98 (1993/94), S. 205267.Huber, Nikolaus: Die Literatur der Salzburger Mundart. Salzburg: Eigenverl. 1878.

Hübner, Lorenz: Beschreibung des Erzstiftes und Reichsfürstenthums Salzburg in Hinsicht auf Topographie und Statistik. Zweyter Band. Das Salzburgische Gebirgland. Pangau, Lungau, Pinzgau. Salzburg: Im Verlage des Verfassers. Gedruckt bey F. X. Oberer 1796.

Hügel, Franz S.: Zur Geschichte, Statistik und Regelung der Prostitution. Wien: Zamarsky/Dittmarsch 1865.

Hupfauf, Sandra: Lieder der ,Freiheit': politisch, symbolisch, kommerziell. In: Jahrbuch des österreichischen Volksliedwerkes 59 (2010), S. 243-257.

Hupfauf, Sandra/Erber, Silvia Maria: Liedgeschichten. Musik und Lied in Tiroler Politik und Gesellschaft 1796-1848. Hg. von Thomas Nußbaumer und Brigitte Mazohl. Innsbruck: Wagner 2013.

Ikonić, Marko: Von dem Entsaz wien. Ein dialektales Propagandalied aus der Liedersammlung Ms. germ. oct. 230 der Staatsbibliothek zu Berlin. In: Christian Neuhuber/Elisabeth Zehetner (Hg.): Bairisch-österreichischer Dialekt in Literatur und Musik 1650-1900. Tagungsband. Graz: Leykam/Universitätsverl. 2015, S. 118-132.

Iser, Wolfgang: Das Fiktive und das Imaginäre. Perspektiven literarischer Anthropologie. Frankfurt a. M.: Suhrkamp 1992.

Jaeger, Monika: Theorien der Mundartdichtung. Studien zu Anspruch und Funktion. Tübingen: Bissinger 1964.

Jäger, Ludwig: Der Schriftmythos. Zu den Grenzen der Literalitätshypothese. In: Ludwig Jäger/Erika Linz (Hg.): Medialität und Mentalität. Theoretische und empirische Studien zum Verhältnis von Sprache, Subjektivität und Kognition. München: Fink 2004, S. 327-345.

Jäger, Ludwig/Linz, Erika (Hg.): Medialität und Mentalität. München: Fink 2004.

Jäger, P. Albert: Tirol und der baierisch-französische Einfall 1703. Aus archivalischen und andern gedruckten und ungedruckten Quellen bearbeitet. Innsbruck: Wagner 1844.

Jahn, Bernhard: Die Medialität des Krieges. Zum Problem der Darstellbarkeit von Schlachten am Beispiel der Schlacht von Lobositz (1.10.1756) im Siebenjährigen Krieg. In: Wolfgang Adam/Holger Dainat (Hg.): „Krieg ist mein Lied“. Der Siebenjährige Krieg in den zeitgenössischen Medien. Hg. in Verbindung mit Ute Pott. Göttingen: Wallstein 2007. (Schriften des Gleimhauses Halberstadt 5) S. 88110.

Janke, Pia: Die Wiener Haupt- und Staatsaktionen des frühen 18. Jahrhunderts. In: Jahrbuch der österreichischen Goethe-Gesellschaft 108/109/110 (2004/2005/2006), S. 259-271.

John, David G.: The German Nachspiel in the Eighteenth Century. Toronto/Buffalo/London: University of Toronto Press 1991. 
Kantorowics, Ernst H.: Die zwei Körper des Königs. Eine Studie zur politischen Theologie des Mittelalters. Aus dem Amerikanischen übersetzt von Walter Theimer. Stuttgart: Klett-Cotta 1992.

Karl, Michaela: Sozialrebellen in Bayern. Matthäus Klostermair, Michael Heigl, Mathias Kneißl. Regensburg: Pustet 2003.

Kauffmann, Kai: „Es ist nur ein Wien!“ Stadtbeschreibungen von Wien 1700-1873. Geschichte eines literarischen Genres der Wiener Publizistik. Wien/Köln/Weimar: Böhlau 1994.

Kaufmann, Michael Gerhard (Hg.): Ostracher Liederhandschrift. Kommentiert und mit einem musizierpraktischen Teil versehen. Konstanz/Eggingen: Isele 2006. (Bibliotheca suevica 19)

Kayser, Wolfgang: Das Groteske. Seine Gestaltung in Malerei und Dichtung. Oldenburg/Hamburg: Stalling 1957.

Kellner, Altman: Musikgeschichte des Stiftes Kremsmünster. Kassel/Basel: Bärenreiter 1956.

Kienesberger, P. Konrad OSB: Der Gottschedianer P. Rudolf Graser OSB und seine Fluchtreise nach Paris (1760/61) im Spiegel des überlieferten Briefwechsels. Eine Episode aus der Zeit der Aufklärung in Kremsmünster. In: Studien und Mitteilungen zur Geschichte des Benediktinerordens und seiner Zweige 109 (1998), S. 291-464.

Kirchmair, Fritz: Die Gefechte an der Pontlatzer Brücke 1703 und 1809. Wien: Österreichischer Bundesverlag 1983. (Militärhistorische Schriftenreihe 48)

Klein, Herbert: Zum Antoni-Honeder-Lied von 1790. Der Wirklichkeitsgehalt einer altsalzburgischen Moritat. In: Jahrbuch des österreichischen Volksliedwerkes 15 (1966), S. 56-62.

Klier, Karl M.: Eine Bärenjagd. In: Heimatgaue 5 (1924), S. 141-144.

Klier, Karl M. / Seemann, Erich: Kunstlieder im Volksmunde. Nachweise. In: Jahrbuch für Volksliedforschung 2 (1930), S. 156-160.

Klier, Karl M.: Kleine Volkslied-Studien. I. Alt-Wiener Kaufrufe. In: Das deutsche Volkslied 38 (1936), S. 64-65.

Klier, Karl M. (Hg.): Schatz österreichischer Weihnachtslieder. Aus den ältesten Quellen mit Weisen. 1. Heft: Weihnachtslieder und Hirtenspiele aus Niederösterreich. Klosterneuburg: AugustinusDruckerei [1936-40]. (Thesaurus Austriacus)

Klier, Karl M. (Hg.): Schatz österreichischer Weihnachtslieder. Aus den ältesten Quellen mit Weisen. 3. Heft: Weihnachtslieder und Hirtenspiele aus Steiermark. 1: Verschiedene Orte. Klosterneuburg: Augustinus-Druckerei [1936-40]. (Thesaurus Austriacus)

Klier, Karl M.: Österreichische Pilotenschläger-Lieder. In: Jahrbuch des Österreichischen Volksliedwerkes 1 (1952), S. 19-33.

Klier, Karl M.: Linz im Liede. In: Jahrbuch der Stadt Linz (1954), S. 553-580.

Klier, Karl M.: Innsbrucker Lied-Flugblätter des 17. Jahrhunderts. In: Jahrbuch des österreichischen Volksliedwerkes 4 (1955), S. 56-77.

Klier, Karl M.: Historische Lieder des 18. Jahrhunderts aus Österreich. Zugleich ein Beitrag zur Metrik des Volksliedes. In: Jahrbuch des österreichischen Volksliedwerkes 8 (1959), S. 22-51.

Klier, Karl M.: Ein Ehestreitlied des 18. Jahrhunderts und seine Verbreitung. In: Jahrbuch des Österreichischen Volksliedwerkes 10 (1961), S. 21-35.

Knoop, Ulrich: Zur Begrifflichkeit der Sprachgeschichtsschreibung: Der ,Dialekt' als Sprache des ,gemeinen mannes' und die Kodifikation der Sprache im 18. Jahrhundert. In: Horst Haider Munske [u. a.] (Hg.): Deutscher Wortschatz. Lexikologische Studien. Ludwig Erich Schmitt zum 80. Geburtstag von seinen Marburger Schülern. Berlin/New York: de Gruyter 1988, S. 336-350.

Koch, Peter/Oesterreicher, Wulf: Sprache der Nähe - Sprache der Distanz. Mündlichkeit und Schriftlichkeit im Spannungsfeld von Sprachtheorie und Sprachgeschichte. In: Romanistisches Jahrbuch 36 (1986), S. 15-43.

Kocka, Jürgen: Weder Stand noch Klasse. Unterschichten um 1800. Bonn: Dietz 1990.

Kohl, Franz Friedrich: Die Tiroler Bauernhochzeit. Sitten, Bräuche, Sprüche, Lieder und Tänze mit Singweisen. Wien: Ludwig 1908. (Quellen und Forschungen zur deutschen Volkskunde 3)

Kohler, Alfred: „Tu felix Austria nube...“. Vom Klischee zur Neubewertung dynastischer Politik in der neueren Geschichte Europas. In: Zeitschrift für historische Forschung 21 (1994), S. 461-482.

Köhler-Zülch, Ines/Shojaei Kawan, Christine: Räuber, Räubergeschichten. In: Rolf Wilhelm Brednich [u. a.] (Hg.): Enzyklopädie des Märchens. Handwörterbuch zur historischen und verglei- 
chenden Erzählforschung. Bd. 11: Prüfung - Schimäremärchen. Berlin/New York: de Gruyter 2004, Sp. 307323.

Koller, Ludwig: Mundartdichtung auf den kaiserlichen Besuch in Göttweig 1746. In: Das Waldviertel 5 (1956), Nr. 9/10, S. 162-170.

Komorzynski, Egon von: Hasenhut, Anton. In: Allgemeine Deutsche Biographie. Hg. von der Historischen Kommission bei der Bayerischen Akademie der Wissenschaften. Bd. 50. Leipzig: Duncker \& Humblot 1905, S. 51-52.

Körner, Alfred: Die Wiener Jakobiner. [Mit einem Abdruck von:] „Homo hominibus“ (Franz Hebenstreit), übers. und komm. von Franz-Josef Schuh. Stuttgart: Metzler 1972. (Deutsche revolutionäre Demokraten III)

Körner, Alfred: Franz Hebenstreit (1747-1795). Biographie und Versuch einer Deutung. In: Jahrbuch des Vereines für Geschichte der Stadt Wien 30/31 (1974/75), S. 39-62.

Koschatzky, Walter (Hg.): Maria Theresia und ihre Zeit. Zur 200. Wiederkehr des Todestages. Katalog zur Ausstellung 13. Mai bis 26. Oktober 1980 Wien, Schloss Schönbrunn. Salzburg/Wien: Residenz 1979.

Koschorke, Albrecht: Körperströme und Schriftverkehr: Mediologie des 18. Jahrhunderts. München: Fink 1999.

Koschorke, Albrecht: Paradoxien der Souveränität. In: Albrecht Koschorke [u. a.] (Hg.): Der fiktive Staat. Konstruktionen des politischen Körpers in der Geschichte Europas. Frankfurt a. M.: Fischer 2007, S. 113-119.

Kostenzer, Otto: Die Zillertaler Ölträger. In: Das Fenster. Tiroler Kulturzeitschrift 14 (1974), S. 14511457.

Krawarik, Hans: Exul Austriacus. Konfessionelle Migrationen aus Österreich in der frühen Neuzeit. Münster [u. a.]: LIT 2010.

Kretzenbacher, Leopold: Frühbarockes Weihnachtsspiel in Kärnten und Steiermark: Klagenfurter und Grazer Weihnachtsspieltexte des frühen 17. Jahrhunderts als kulturhistorische Denkmäler der Gegenreformation in Innerösterreich. Klagenfurt: Geschichtsverein für Kärnten 1952. (Archiv für vaterländische Geschichte und Topographie)

Krieger, Dorette: Die mittelalterlichen deutschsprachigen Spiele und Spielszenen des Weihnachtsstoffkreises. Frankfurt a. M. [u. a.]: Lang 1990. (Bochumer Schriften zur deutschen Literatur 15)

Krummholz, Martin: „Zu unaussprechlicher Freude allerhöchsten Herrschaften wie auch zum höchsten Troste allhiesiger Inwohner." Zwei Illuminationen vor dem Wiener Stadtpalais Schwarzenberg anlässlich der Geburt der ältesten Söhne Maria Theresias. In: Jiří Kroupa/Michaela Šeferisová Loudová/Lubomír Konečný (Hg.): Orbis artium. K jubileu Lubomíra Slavíčka. Brno: Masarykova univerzita 2009, S. 539-553.

Kürsinger, Ignaz von: Lungau. historisch, ethnographisch und statistisch aus bisher unbenützten urkundlichen Quellen dargestellt von Ignaz von Kürsinger. Mit artistischen Beigaben. Salzburg: Oberer'sche Buchhandlung 1853.

Küther, Carsten: Menschen auf der Straße. Vagierende Unterschichten in Bayern, Franken und Schwaben in der zweiten Hälfte des 18. Jahrhunderts. Göttingen: Vandenhoek \& Ruprecht 1983. (Kritische Studien zur Geschichtswissenschaft 56)

Lechthaler, Josef/Moissl, Gustav/Schnabel, Sigismund: Lieder fürs Leben. Ein Sing- und Musizierbuch für die Jugend. 9. Aufl. Wien: Hölder [u. a.] 1949.

Leeb, Rudolf/Scheutz, Martin/Weikl, Dietmar (Hg.): Geheimprotestantismus und evangelische Kirchen in der Habsburgermonarchie und im Erzstift Salzburg. Wien/München: Böhlau/Oldenburg 2009.

Leerssen, Joep: Nation, Volk und Vaterland zwischen Aufklärung und Romantik. In: Alexander von Bormann (Hg.): Volk - Nation - Europa. Zur Romantisierung und Entromantisierung politischer Begriffe. Würzburg: Königshausen \& Neumann 1998, S. 171-178.

Lehr, Walter: Die szenischen Bemerkungen in den Dramen des Altwiener Volkstheaters bis 1752. Wien 1965 [Diss.].

Leskovec, Andrea: Einführung in die interkulturelle Literaturwissenschaft. Darmstadt: Wissenschaftliche Buchgesellschaft 2011. (Einführung Germanistik) 
Lettner, Gerda/Pasetzky, Gilda: Revolutionärer Patriotismus und Friedensforderungen in der Musik des ausgehenden 18. Jahrhunderts. Haydn, Paul Wranitzky, Hebenstreit und Horix: Das historisch-musikalische Umfeld der ,Schöpfung' (1793-1800). In: Francia 30 (2003), H. 2, S. 45-71.

Lettner, Gerda: Das Spannungsfeld zwischen Aufklärung und Absolutismus. Die Ära Kaunitz (17491794). Göttingen: Vandenhoeck \& Ruprecht 2016. (Forschungen zur Kirchen- und Dogmengeschichte 105)

Leuchtenmüller-Bolognese, Birgit: Bevölkerungspolitik zwischen Humanität, Realismus und Härte. In: Herbert Matis (Hg.): Von der Glückseligkeit des Staates. Staat, Wirtschaft und Gesellschaft in Österreich im Zeitalter des aufgeklärten Absolutismus. Berlin: Duncker \& Humblot 1981, S. 177 208.

Linhardt, Marion: Kontrolle - Prestige - Vergnügen. Profile einer Sozialgeschichte des Wiener Theaters 1700-2010. Graz: LiTheS 2012. (LiTheS Sonderband 3)

Linke, Angelika: „Wer sprach warum wie zu einer bestimmten Zeit?“ Überlegungen zur Gretchenfrage der Historischen Soziolinguistik am Beispiel des Kommunikationsmusters ,Scherzen' im 18. Jahrhundert. In: Ulrich Ammon/Klaus Mattheier/Peter H. Nelde (Hg.): sociolinguistica. Internationales Jahrbuch für Europäische Soziolinguistik. Tübingen: Niemeyer 1999. (Historische Soziolinguistik 13) S. 179-208.

Löffler, Heinrich: Dialektologie. Eine Einführung. Tübingen: Narr 2003.

Lowack, Alfred: Die Mundarten im hochdeutschen Drama bis gegen Ende des achtzehnten Jahrhunderts: Ein Beitrag zur Geschichte des deutschen Dramas und der deutschen Dialektdichtung. Leipzig: Hesse 1905. (Breslauer Beiträge zur Literaturgeschichte VII)

Maas, Utz: Schrift - Schreiben - Rechtschreiben. In: Diskussion Deutsch 16 (1985), S. 4-25.

Mair, Karl: Die Öltrager des Zillertals. In: Tiroler Heimatblätter. Monatshefte für Geschichte, Naturund Volkskunde 11 (1933), H. 7/8, S. 263-265.

Mansky, Matthias: Der ,edle Wilde als lustige Figur? Funktionalisierung und Transformation bei Franz von Heufeld und Joseph Felix von Kurz-Bernardon. In: Franz M. Eybl (Hg.): Nebenschauplätze. Ränder und Übergänge in Geschichte und Kultur des Aufklärungsjahrhunderts. Bochum: Winkler 2014. (Das achtzehnte Jahrhundert in Österreich 28) S. 193-207.

Mansky, Matthias: Nachwort. In: Gottlieb Stephanie der Jüngere. Die abgedankten Officiers oder Standhaftigkeit und Verzweiflung. Ein Lustspiel von fünf Aufzügen. Hg. von Matthias Mansky. Hannover: Werhahn 2015, S. 131-159.

Marsch, Angelika: Die Salzburger Emigration in Bildern. Mit Beiträgen von Gerhard Florey und Hans Wagner und einem Verzeichnis der zeitgenössischen Kupferstiche. Weißenhorn: Konrad 1977.

Matschke, Klaus-Peter: Das Kreuz und der Halbmond: Die Geschichte der Türkenkriege. Darmstadt: Wiss. Buchgesellschaft 2004.

Mattheier, Klaus J.: „Mit der Seele Atem schöpfen“. Über die Funktion von Dialektalität in der deutschsprachigen Literatur. In: Klaus J. Mattheier [u. a.] (Hg.): Vielfalt des Deutschen. Festschrift für Werner Besch. Frankfurt a. M. [u. a.]: Lang 1993, S. 633-652.

Mauthner-Weber, Susanne: Venuswege. Erotischer Führer durch das alte Wien. Wien: Promedia 1996, S. 165-188.

Mautner, Konrad: Zwey schöne Lustige Lieder. Das Erste von dem Schrägel-Thomerl. Das Anderte von dem Jungen Rauff-Jodel. Gedruckt in disem Jahr. In: Bayerische Hefte für Volkskunde 7 (1920), S. 76-107.

McShane, David/Pernerstorfer, Matthias J. (Hg.): Der 30-jährige ABC-Schütz. Text, Musik und szenische Praxis im Wiener Volkstheater. 2. Band: Klavierauszug, Wien: Hollitzer 2011. (Don Juan Archiv Wien: Theatralia II)

Medick, Hans: Spinnstuben auf dem Dorf. In: Gerhard Huck (Hg.): Sozialgeschichte der Freizeit. Untersuchungen zum Wandel der Alltagskultur in Deutschland. 2. Aufl. Wuppertal: Hammer 1982, S. 1949.

Meid, Volker: Die deutsche Literatur im Zeitalter des Barock. Vom Späthumanismus zur Frühaufklärung 1570-1740. München: Beck 2009. 
Menninghaus, Winfried: Ekel. Theorie und Geschichte einer starken Empfindung. Frankfurt a. M.: Suhrkamp 1999.

Meschke, Kurt: Der Schwerttanz im germanischen Kulturkreis. Leipzig/Berlin: Teubner 1928.

Mitterauer, Michael: Familienformen und Illegitimität in ländlichen Gebieten Österreichs. In: Archiv für Sozialgeschichte 19 (1979), S. 123-188.

Moder, Richard (Hg.): Gregor Joseph Werner: Wienerischer Tandlmarkt. Partitur, Stimmen, Klavierauszug (vom Hg.). Wien, München: Doblinger 1961. (Diletto Musicale 81)

Moder, Richard (Hg.): Gregor Joseph Werner: Die Bauren-Richters-Wahl. Für 5 Singstimmen (3 Tenöre, 2 Bässe), 2 Violinen und Basso continuo. Erstdruck. Partitur, Streicherstimmen. Wien, München: Doblinger 1968. (Diletto Musicale 171)

Moser, Dietz-Rüdiger: Verkündigung durch Volksgesang. Studien zur Liedpropaganda und -katechese der Gegenreformation. Berlin: Schmidt 1981.

Moser, Hans: Schifferbrauch und Volksschauspiel im alten Laufen. In: Leopold Schmidt (Hg.): Kultur und Volk. Beiträge zur Volkskunde aus Österreich, Bayern und der Schweiz. Festschrift für Gustav Gugitz zum achtzigsten Geburtstag. Wien: Museum für Volkskunde 1954, S. 285-300.

Moser, Hans: Zwei Notburga-Spiele aus dem bayerischen Inntal. In: Beiträge zur Heimatkunde des nordöstlichen Tirol. Festschrift zum 70. Geburtstag Matthias Mayer's. Innsbruck: Wagner 1954. (Schlern-Schriften 138) S. 151-162.

Moser, Hans Joachim: Corydon, das ist: Geschichte des mehrstimmigen Liedes und des Quodlibets im Barock. 2 Bde. Braunschweig: Litolff 1933.

Moser, Oskar: Die ,Ehrliche Gemütserquickung'. Eine neuentdeckte Liedersammlung von 1691 aus der Offizin Kleinmayr in Klagenfurt. In: Die Kärntner Landsmannschaft 1963, Nr. 7 (Juli), S. 4-5.

Moser-Rath, Elfriede (Hg.): Predigtmärlein der Barockzeit. Exempel, Sage, Schwank und Fabel in geistlichen Quellen des oberdeutschen Raumes. Berlin: de Gruyter 1964.

Mozart, Wolfgang Amadeus: Neue Ausgabe sämtlicher Werke. Serie III: Lieder, mehrstimmige Gesänge, Kanons. Werkgruppe 9: Mehrstimmige Gesänge. Vorgelegt von C.-G. Stellan Mörner. Kassel [u. a.]: Bärenreiter 1971.

Mozart, Wolfgang Amadeus: Neue Ausgabe sämtlicher Werke. Serie III: Lieder, mehrstimmige Gesänge, Kanons. Werkgruppe 10: Kanons. Vorgelegt von Albert Dunning. Kassel [u. a.]: Bärenreiter 1974.

Mozart, Wolfgang Amadeus: Neue Ausgabe sämtlicher Werke. Serie III: Kammermusik. Werkgruppe 21: Duos und Trios für Streicher und Bläser. Vorgelegt von Dietrich Berke und Marius Flothuis. Kassel [u. a.]: Bärenreiter 1975.

Mozart, Wolfgang Amadeus: Kritische Berichte. Serie III: Lieder, Mehrstimmige Gesänge, Kanons. Werkgruppe 9: Mehrstimmige Gesänge (C.G. Stellan Mörner). Vorgelegt von Holger M. Stüwe. Kassel [u. a.]: Bärenreiter 2007.

Müller, Jan-Dirk: Der Körper des Buchs. Zum Medienwechsel zwischen Handschrift und Druck. In: Hans Ulrich Gumbrecht/K. Ludwig Pfeiffer (Hg.): Schrift. München: Fink 1993, S. 203-217.

Müller, Jan-Dirk: Medialität. Frühe Neuzeit und Medienwandel. In: Kathrin Stegbauer, Herfried Vögel, Michael Waltenberger (Hg.): Kulturwissenschaftliche Frühneuzeitforschung. Berlin: Schmidt 2004, S. 49-70.

Müller, Rolf-Dieter: Militärgeschichte. Köln/Weimar/Wien: Böhlau 2009.

Müller-Kampel, Beatrix: Hanswurst, Bernardon, Kasperl. Spaßtheater im 18. Jahrhundert. Paderborn [u. a.]: Schöningh 2003.

Müller-Kampel, Beatrix: Disziplinierter Körper, reglementierter Spaß. Zur politischen und zivilisatorischen Zurichtung des Hanswurst im 18. Jahrhundert. In: Oswald Panagl/Robert Kriechbaumer (Hg.): Stachel wider den Zeitgeist. Politisches Kabarett, Flüsterwitz und subversive Textsorten. Wien/Köln/Weimar: Böhlau 2004, S. 47-58.

Müller-Kampel, Beatrix: Hanswurst-Stranitzky. Zur Revision seiner Biographie. In: LiTheS. Literatur- und Theatersoziologie. Forschung, Dokumentation, Lehre. (2010). http://lithes.uni-graz.at/ forschung.html (letzter Zugriff am 11.05.2018).

Müller-Kampel, Beatrix: Die 30-jährigen ABC-Schützen. In: Kasperls komische Erben. Thaddädl, Staberl, Kratzerl \& Co. Wiener Volkskomödie im Wandel. Von der Typenkomik Anton Hasen- 
huts bis zur Charakterkomik Ferdinand Raimunds. Graz: LiTheS 2012. http://lithes.uni-graz.at/ kasperls_erben

Müller-Kampel, Beatrix: Komik und das Komische: Kriterien und Kategorien. In: LiTheS. Zeitschrift für Literatur- und Theatersoziologie Nr. 7 (2012), S. 5-39, http://lithes.uni-graz.at/lithes/12_07. html (letzter Zugriff am 14.05.2018).

Müller-Kampel, Beatrix: Komik in Vers und Reim. Am Beispiel von Gstanzln aus dem Salzkammergut. In: Christian Neuhuber/Elisabeth Zehetner (Hg.): Bairisch-österreichischer Dialekt in Literatur und Musik 1650-1900. Graz: Leykam/Universitätsverl. 2015, S. 161-174.

Münster, Robert: Zwei Singknaben-Liederbücher aus den letzten Jahren des Klosters Tegernsee. In: Sänger- und Musikantenzeitung 38 (1995), H. 3, S. 141-145.

Münster, Robert: Zwei Liederbücher der Tegernseer Singknaben Caspar Aiblinger und Marcus Seitz. In: Sixtus Lampl (Hg.): Tegernseer Jubiläumsreihe 746-1996. Bd. 1: Klingendes Tal. Zur Musikpflege von der Benediktinerabtei über den Kiem Pauli bis zur Gegenwart. Valley: Schloßverlag Valley 1996, S. 144-153.

Nagl, Johann Willibald/Zeidler, Jakob: Deutsch-Österreichische Literaturgeschichte. Ein Handbuch zur Geschichte der deutschen Literatur in Österreich-Ungarn. Hauptband: Von der Colonisation bis Kaiserin Maria Theresia. Wien: Fromme 1899.

Nemetz-Fiedler, Kurt: Die Lyrik Philipp Hafners. Wien 1927. [Diss.]

Nettl, Paul: Das Wiener Lied im Zeitalter des Barock. Wien: Passer 1934.

Neuhuber, Christian: Das Lustspiel macht Ernst. Das Ernste in der deutschen Komödie auf dem Weg in die Moderne: von Gottsched bis Lenz. Berlin: Erich Schmidt 2003.

Neuhuber, Christian: Ehrbar will man ergetzt werden ... Die hochdeutschen Lustspiele von P. Maurus Lindemayr. In: Christian Neuhuber (Hg.): Maurus Lindemayr: Die hochdeutschen Komödien. Kritische Ausgabe. Bd. 2: Kommentar. Wien: Praesens 2006, S. 13-150.

Neuhuber, Christian: und ein besonderer Liebhaber der Dichtkunst. Zum Leben und Werk Peter Gottlieb Lindemayrs. In: Peter Gottlieb Lindemayr: Lieder in oberösterreichischer Mundart. Kritische Ausgabe. Hg. und kommentiert von Christian Neuhuber. Wien: Praesens 2010, S. 93-141.

Neuhuber, Christian: Mein Gott, warum hast das Rabm Vieh erschafen ... Lindemayriana et al. in den Liederhandschriften HL 379a und HL 379b des Oberösterreichischen Volksliedwerks. In: Streifzüge 2. Beiträge zur oberösterreichischen Musikgeschichte. Hg. vom Oberösterreichischen Volksliedwerk/Volksliedarchiv durch Klaus Petermayr. Linz: Oö. Volksliedwerk 2011, S. 109-124.

Neuhuber, Christian/Pötsch, P. Altman OSB: Placidus Fixlmillners Dialektsingspiel Astrologus (1746). In: Klaus Petermayr und Andreas Lindner (Hg.): Streifzüge III. Beiträge zur oberösterreichischen Musikgeschichte. Linz: Ö̈. Volksliedwerk 2013, S. 67-86.

Neuhuber, Christian: Die vergessene Kunst. Prolegomena zu einer Ästhetik der österreichischen Dialektliteratur vor 1800. In: Franz M. Eybl (Hg.): Nebenschauplätze. Ränder und Übergänge in Geschichte und Kultur des Aufklärungsjahrhunderts. Bochum: Winkler 2014. (Das achtzehnte Jahrhundert und Österreich 28) S. 53-85.

Neuhuber, Christian: Ein Gottesgeschenk für die Bühne. Dramatisierungen der Dorothea-Legende im deutschen Sprachraum. In: Margita Havlíčková / Christian Neuhuber (Hg.): Johann Georg Gettner und das barocke Theater zwischen Nikolsburg und Krumau. Brno: Masarykova univerzita 2014, S. 131-182.

Neuhuber, Christian: Der Baron Wurstelsprung. Kontextualisierung, Analyse und Edition einer Krumauer Hanswurstburleske. Praha: Institut umění - Divadelní ústav v Praze 2015. (Beilage der Zeitschrift Divadelní revue 26/2)

Neuhuber, Christian: y glab es trambt mie. Dialektale Rede in Wiener Stücken des Wander-, Ordensund Hoftheaters 1665/66. In: Christian Neuhuber/Elisabeth Zehetner (Hg.): Bairisch-österreichischer Dialekt in Literatur und Musik 1650-1900. Tagungsband. Graz: Leykam/Universitätsverl. 2015, S. 61-116.

Neuhuber, Christian: will singer á Liedl. Das mundartliche Weihnachtslied in Österreich von den Anfängen bis zu den ,Sternsingern' P. Sigmund Fellöckers. In: Festschrift Anton Reidinger Saal Volksschule Krenglbach/Handschrift des Weihnachtsliedes Es wird schon glei dumper. Hg. vom Verein ,Initiative für Krenglbach'. Krenglbach: Plöchl 2016, S. 19-27. 
Neuhuber, Christian: Süßmayrs Der rauschige Hans von der Gruebn im Kontext der österreichischen Dialektkunst vor 1800. In: Klaus Petermayr/Andreas Lindner/Ernst Schlader (Hg.): Franz Xaver Süßmayr. Beiträge zum Jubiläumsjahr 2016. Linz: Oö. Volksliedwerk 2017, S. 43-52.

Neuhuber, Christian: $y$ bi a mä troy in grassen Nöthen. Zur kritischen Edition eines Paradestücks des Wandertheaters. In: editio 31 (2017), S. 59-78.

Neuhuber, Christian/Vodrážková, Lenka: Mundartenliteratur. In: Peter Becher [u. a.] (Hg.): Prager deutsche Literatur im regionalen Kontext. Ein Handbuch. Stuttgart: Metzler 2017, S. 398-403.

Neuhuber, Christian: Dann wan kein wurstl wäre so wäre die Commedie jezt aus - Zur Bedeutung der Wiener Hanswurst-Burlesken auf Schloss Krumau. In: Lisa Erlenbusch/Marko Ikonić/Christian Neuhuber (Hg.): Vom Wiener Kärntnertortheater nach Schloss Krumau. Die Hanswurst-Burlesken von Český Krumlov. Wien: Lehner 2018. [im Druck]

Neuhuber, Christian: Ein Wurstelsprung von Wien nach Český Krumlov. Zur kritischen Erstedition der Krumauer Hanswurst-Burlesken. In: Nestroyana 38 (2018), H. 1/2, S. $23-40$.

Neuhuber, Christian: I bin halt ä Mädl wie ä Rädl - Anmerkungen zur Figur der ,Sclavinn in Frieberts Das Serail. In: Matthias Pernerstorfer (Hg.): Das Serail (1778) by Joseph Friebert in historical, socio-political and cultural contexts. Wien: Hollitzer 2019. [im Druck]

Neuhuber, Christian: Werners Werke in Mundart. Weihnachtspastorellen - Der Wiennerische Tändlmarckt - Die Bauren-Richters-Wahl. In: Martin Czernin (Hg.): Gregor Joseph Werner. Eisenstadt 2019 [im Druck]

Neumann, Bernd: Geistliches Schauspiel im Zeugnis der Zeit. Zur Aufführung mittelalterlicher religiöser Dramen im deutschen Sprachgebiet. München: Artemis 1987.

Nicolai, Friedrich: Brief an Lessing vom 5. Juni 1777. In: Gotthold Ephraim Lessing: Werke und Briefe. Bd. 12: Briefe von und an Lessing 1776-1781. Hg. von Helmut Kiesel. Frankfurt a. M.: Dt. Klassiker Verl. 1994, S. 82.

Nicolai, Friedrich: Eine Untersuchung der Beschuldigungen, die Herr Prof. Garve wider diese Reisebeschreibung vorgebracht. [Anhang zu:] Friedrich Nicolai: Beschreibung einer Reise durch Deutschland und die Schweiz, im Jahre 1781. Nebst Bemerkungen über Gelehrsamkeit, Industrie, Religion und Sitten. 12 Bde. Bd. VII. Berlin und Stettin: Nicolai 1786.

Noa, Miriam: Volkstümlichkeit und Nationbuilding. Zum Einfluss der Musik auf den Einigungsprozess der deutschen Nation im 19. Jahrhundert. Münster [u. a.]: Waxmann 2013. (Populäre Kultur und Musik 8)

Nowak, Leopold: Ein Bauernkanon von Joseph Eybler. In: Jahrbuch des österreichischen Volksliedwerkes 8 (1959), S. 10-12.

Nowey, Waldemar: Der Bayrische Hiasl als heimatgeschichtliche, volkstümliche und literarische Gestalt. Ein Signal seiner Zeit - ein Signum unserer Heimat? 3. Aufl. Kissing: Selbstverlag Gemeinde Kissing 2003.

Nowosadtko, Jutta: Ordnungselement oder Störfaktor? Zur Rolle der stehenden Heere innerhalb der frühneuzeitlichen Gesellschaft. In: Ralf Pröve (Hg.): Klio in Uniform? Probleme und Perspektiven einer modernen Militärgeschichte der frühen Neuzeit. Köln/Weimar/Wien: Böhlau 1997, S. 534.

Obermayr, Anton: Catalogus musicalium et instrumentorum ad chorum Lambacensem pertinentium. The Lambach thematic catalogue (1768) Facsim. ed. / with annotations and commentary by Charles H. Sherman. Hillsdale, NY: Pendragon 2002.

Oesterreicher, Wulf: Verschriftung und Verschriftlichung im Kontext medialer und konzeptioneller Schriftlichkeit. In: Ursula Schaefer (Hg.): Schriftlichkeit im frühen Mittelalter. Tübingen: Narr 1993, S. 267-292.

Oesterreicher, Wulf: Sprachwandel, Varietätenwandel, Sprachgeschichte. In: Ursula Schaefer/Edda Spielmann (Hg.): Varieties and Consequences of Literacy and Orality. Franz H. Bäuml zum 75. Geburtstag. Tübingen: Narr 2001, S. 217-248.

Ong, Walter J.: Oralität und Literalität. Die Technologisierung des Wortes. Opladen: Westdeutscher Verlag 1987.

Özyurt, Şenol: Die Türkenlieder und das Türkenbild in der deutschen Volksüberlieferung vom 16. bis zum 20. Jh. München: Fink 1972. 
Paas, John Roger: The German Political Broadsheet 1600-1700. Vol.4. Wiesbaden: Harrassowitz 1994.

Pailler, Wilhelm: Weihnachtslieder und Krippenspiele aus Oberösterreich und Tirol. 2 Bde. Innsbruck: Wagner 1881/83.

Palla, Rudi: Verschwundene Arbeit. Ein Thesaurus der untergegangenen Berufe. Frankfurt a. M.: Eichborn 1995.

Paunel, Eugen von: Einleitung. In: Eugen von Paunel (Hg.): Die Eipeldauer Briefe 1785-1797. In Auswahl hg., eingeleitet und mit Anmerkungen versehen. Bd. 1. München: Müller 1918, S. XICXII.

Payer von Thurn, Rudolf: Wiener Haupt- und Staatsaktionen. 2 Bde. Wien: Verl. des Literarischen Vereins 1908/1910. (Schriften des Literarischen Vereins in Wien 10,13)

Perschy, Jakob M.: „Echter“ Heubauer und „falscher“ Krowod: Das letzte Projekt des Volksliedforschers Karl Magnus Klier. In: Archivar und Bibliothekar. Bausteine zur Landeskunde des burgenländisch-westungarischen Raumes. Festschrift für Johann Seedoch zum 60. Geburtstag. Eisenstadt: Amt d. Burgenländ. Landesregierung 1999. (Burgenländische Forschungen, Sonderband 22), S. 330-335.

Peter, Ilka: Gaßlbrauch und Gaßlspruch in Österreich. Salzburg: Müller 1953.

Petermayr, Klaus: Volksmusik in Oberösterreich. Lieder und Tänze um 1800 im Hausruckviertel aus der Sonnleithner-Sammlung der Gesellschaft der Musikfreunde in Wien. Hg. vom Oberösterreichischen Volksliedwerk. Wien/Köln/Weimar: Böhlau 2006. (Corpus Musicae Popularis Austriacae 18)

Petersen, Lars-Eric/Six, Bernd: Stereotype, Vorurteile und soziale Diskriminierung. Theorien, Befunde und Interventionen. Weinheim: Beltz 2008.

Pfotenhauer, Helmut: Literarische Anthropologie. Selbstbiographie und ihre Geschichte - am Leitfaden des Leibes. Stuttgart: Metzler 1987.

Pirker, Max (Hg.): Teutsche Arien Welche auf dem Kayserlich-privilegierten Wienerischen Theatro in unterschiedlich producierten Comoedien, deren Titul hier jedesmahl beygedrucket, gesungen worden. Mit Einleitung und Anmerkungen hg. 2 Bde. Wien/Prag/Leipzig: Ed. Strache 1927/28. (Museion. Erstausgaben und Neudrucke 2).

Pisk, Hans Viktor: Joseph Richter 1749-1813. Versuch einer Biographie und Bibliographie. Wien 1926. [Diss.].

Planert, Ute: Der Mythos vom Befreiungskrieg. Frankreichs Kriege und der deutsche Süden. Alltag - Wahrnehmung - Deutung 1792-1841. Paderborn: Schöningh 2007.

Podlech, Adalbert: Repräsentation. In: Otto Brunner/Werner Conze/Reinhart Koselleck (Hg.): Geschichtliche Grundbegriffe. Historisches Lexikon zur politisch-sozialen Sprache in Deutschland. Bd. 5. Stuttgart: Klett-Cotta 1984, S. 509-547.

Polenz, Peter von: Deutsche Sprachgeschichte vom Spätmittelalter bis zur Gegenwart. Bd. 2: 17. und 18. Jahrhundert. Berlin/New York: de Gruyter 1994.

Polheim, Karl Konrad: Studien zum Volksschauspiel und mittelalterlichen Drama. Mit einer Fotodokumentation. Paderborn [u. a.]: Schöningh 2002. (Volksschauspiele 5)

Popowitsch, Johann Siegmund Valentin: Vocabula Austriaca et Stiriaca. Nach der Abschrift von Anton Wasserthal hg. und eingeleitet von Richard Reutner. 2 Tle. Frankfurt a. M.: Lang [u. a.] 2004.

Pörnbacher, Hans: Literatur und Theater von 1550-1800. In: Max Spindler (Hg.): Handbuch der bayerischen Geschichte. Bd. 2: Das alte Bayern. Der Territorialstaat. Vom Ausgang des 12. Jahrhunderts bis zum Ausgang des 18. Jahrhunderts. München: Beck 1966, S. 848-883.

Pörnbacher, Hans/Hubensteiner, Benno (Hg.): Bayerische Bibliothek. Texte aus zwölf Jahrhunderten. Bd. 2: Die Literatur des Barock. Ausgewählt und eingeleitet von Hans Pörnbacher. München: Süddeutscher Verlag 1986.

Pörnbacher, Hans (Hg.): Bayerische Bibliothek. Texte aus zwölf Jahrhunderten. Bd. 3: Die Literatur des 18. Jahrhunderts. Das Zeitalter der Aufklärung. Vorarbeiten von Benno Hubensteiner. München: Süddeutscher Verlag 1990.

Probst, Christian: Lieber bayrisch sterben. Der bayrische Volksaufstand der Jahre 1705 und 1706. München: Süddeutscher Verl. 1978. 
Puchalski, Lucjan: Imaginärer Name Österreich. Der literarische Österreichbegriff an der Wende vom 18. zum 19. Jahrhundert. Wien: Böhlau 2000. (Schriftenreihe der Österreichischen Gesellschaft zur Erforschung des 18. Jahrhunderts 8)

Ragotzky, Hedda/Wenzel, Horst (Hg.): Höfische Repräsentation. Das Zeremoniell und das Zeichen. Tübingen: Niemeyer 1990.

Rainer, Werner: „Dö Pinzgara wolt’n kirfiart’n gehen“. In: Salzburg Archiv 29 (2004), S. 165-186.

Rapp, Christian: Wiener Typen. Zur Erfindung und Karriere eines Soziotops. In: Wolfgang Kos/ Christian Rapp (Hg.): Alt-Wien. Die Stadt, die niemals war. Katalog zur Ausstellung im Wien Museum, 25. November 2004-28. März 2005. Wien: Czernin 2004, S. 142-150.

Rattay, Kurt: Die Ostracher Liederhandschrift und ihre Stellung in der Geschichte des deutschen Liedes. Auf Grund der handschriftlichen Liedersammlungen des XVII. und XVIII. Jahrhunderts untersucht. Halle a.S.: Karras 1911.

Rattelmüller, Paul Ernst: Matthäus Klostermaier vulgo Der Bayrische Hiasl. München: Bruckmann 1971.

Reden, Alexander Sixtus von / Schweikhardt, Josef: Eros unterm Doppeladler. Eine Sittengeschichte Altösterreichs. Wien: Ueberreuther 1993.

Reichmann, Oskar: Dialektale Verschiedenheit: zu ihrer Auffassung und Bewertung im 17. und 18. Jahrhundert. In: Klaus J. Mattheier [u. a.] (Hg.): Vielfalt des Deutschen. Festschrift für Werner Besch. Frankfurt a. M. [u. a.]: Lang 1993, S. 289-314.

Reiffenstein, Ingo: Zur Sprachgestaltung im österreichischen Volkslied. In: Rudolf Pietsch (Hg.): Die Volksmusik im Lande Salzburg. II. Wien: Schendl 1990. (Schriften zur Volksmusik 13) S. 261268.

Reiffenstein, Ingo: Sprachvariation in den Briefen der Familie Mozart. In: Klaus Mattheier [u. a.] (Hg.): Vielfalt des Deutschen. Festschrift für Werner Besch. Frankfurt a. M. [u. a.]: Lang 1993, S. 361-381.

Reiffenstein, Ingo: ,Oberdeutsch' und ,Hochdeutsch' in Bayern im 18. Jahrhundert. In: Andreas Gardt/Klaus J. Mattheier/Oskar Reichmann (Hg.): Sprachgeschichte des Neuhochdeutschen. Gegenstände, Methoden, Theorien. Tübingen: Niemeyer 1995, S. 307-317.

Reiffenstein, Ingo: Aspekte einer bayerischen Sprachgeschichte seit der beginnenden Neuzeit. In: Werner Besch/Oskar Reichmann/Stefan Sonderegger (Hg.): Sprachgeschichte. 3. Tlbd. 2., vollst. neu bearb. u. erw. Aufl. Berlin/New York: de Gruyter 2003. (HSK 2.3) S. 2942-2971.

Reiffenstein, Ingo: Sprachvariation auf dem Salzburger Hoftheater. Die Dialektstücke von Ignaz Anton Weiser (1749/1750). In: Hubert Bergmann [u. a.] (Hg.): Fokus Dialekt. Analysieren - Dokumentieren - Kommunizieren. Festschrift für Ingeborg Geyer zum 60. Geburtstag. Hildesheim/ Zürich/New York: Olms 2010, 329-352.

Reiling, Jesko: Die Genese der idealen Gesellschaft. Studien zum literarischen Werk von Johann Jakob Bodmer (1698-1783). Berlin/New York: de Gruyter 2010.

Reinalter, Helmut (Hg.): Jakobiner in Mitteleuropa. Innsbruck: Inn 1977.

Reiterer, Karl: Lustige altsteirische Gsangeln, Vierzeiler und Lieder aus dem Ennstal und dem Ausseer Landl. Aussee: Grill 1906.

Richter, Heinrich M.: Österreichische Volksschriften und Volkslieder im siebenjährigen Kriege. Beiträge zur Geschichte der politischen Literatur im achtzehnten Jahrhundert. Wien: Gerold 1869.

Riedel, Wolfgang: Anthropologie und Literatur in der deutschen Spätaufklärung. Skizze einer Forschungslandschaft. In: IASL Sonderheft 6 (1994), S. 93-157.

Rindler, Peter P. J.: Die Weihnachtsspiele der Handschrift Ms.germ.qu. 1327 der Staatsbibliothek zu Berlin. Textedition, Analyse und Kontextualisierung. Graz 2015. [Dipl.]

Röcke, Werner/Schaefer, Ursula (Hg.): Mündlichkeit - Schriftlichkeit - Weltbildwandel. Tübingen: Narr 1996.

Röcke, Werner: Ostergelächter, Körpersprache und rituelle Komik in Inszenierungen des ,risus paschalis'. In: Otto Langer/Klaus Ridder (Hg.): Körperinszenierungen in mittelalterlicher Literatur. Berlin: Weidler 2002, S. 335-350.

Rohrer, Joseph: Uiber die Tiroler. Ein Beytrag zur Oesterreichischen Völkerkunde. Wien: Doll 1796. 
Rölleke, Heinz: Über Volks- und Geistliche Lieder bei Herder. In: Martin Keßler / Volker Leppin (Hg.): Johann Gottfried Herder: Aspekte seines Lebenswerkes. Berlin/New York: de Gruyter 2015, S. 115-128.

Rommel, Otto: Die großen Figuren der Alt-Wiener Volkskomödie. Hanswurst, Kasperl, Thaddädl und Staberl, Raimund und Nestroy. Wien: Bindenschild 1946.

Rommel, Otto: Die Alt-Wiener Volkskomödie. Ihre Geschichte vom barocken Welttheater bis zum Tode Nestroys. Wien: Schroll 1952.

Rösch, Gisela: Kiltlied und Tagelied. In: Rolf Wilhelm Brednich/Lutz Röhrich/Wolfgang Suppan (Hg.): Handbuch des Volksliedes. Bd. 1: Die Gattungen des Volksliedes. München: Finke 1973, S. 483-550.

Rösener, Werner: Die Bauern in der europäischen Geschichte. München: Beck 1993.

Rössler, Paul: Schreibvariation - Sprachregion - Konfession. Graphematik und Morphologie in österreichischen und bayerischen Drucken vom 16. bis ins 18. Jahrhundert. Frankfurt a. M. [u. a.]: Lang 2005. (Schriften zur deutschen Sprache in Österreich 35)

Rowley, Anthony: „Erste Paurn Clag“ und „ander Paurn Clag“: zwei mundartliche Bauernklagen aus der Mitte des 17. Jahrhunderts. In: Literatur in Bayern 27 (2012), H. 3, S. 20-29.

Rowley, Anthony R.: ,Was sy zLanzet zue hat tragn': „Der Bauernsohn in der Kirche“ und die „Baurnklagen“. Drei westmittelbairische Stücke aus der Mitte des 17. Jahrhunderts - Texte und Darstellung des Dialekts. In: Christian Ferstl / Anthony R. Rowley (Hg.): Was sich in Landshut zugetragen hat - und anderswo. Beiträge zur Schmellerforschung und darüber hinaus. Regensburg: edition vulpes 2013. (Jahrbuch der Johann-Andreas-Schmeller-Gesellschaft 2012) S. 11-89.

Rowley, Anthony: „Der Bauernsohn in der Kirche.“ - Was uns ein Dialektgedicht aus Niederbayern über das Mittelbairische erzählt. In: Elisabeth Frieben/Ulrich Kanz/Barbara Neuber/Ludwig Zehetner (Hg.): Dialekt und Religion. Beiträge zum 5. dialektologischen Symposium im Bayerischen Wald, Walderbach, Juni 2012. Regensburg: edition vulpes 2014, S. 37-47.

Rudin, Bärbel: Heinrich Rademin, Hanswursts Schattenmann. Jurist, Bühnenchef, Stückeschreiber Versuch über eine Gründerfigur des Wiener Theaters. In: Maske und Kothurn 48 (2002), H. 14: Theater am Hof und für das Volk. Beiträge zur vergleichenden Theater- und Kulturgeschichte. Festschrift für Otto G. Schindler zum 60. Geburtstag, S. 271-301.

Ruehs, Krista: Auch „böse“ Menschen haben ihre Lieder. Zur Rezeption von Wilderern in österreichischen Volksliedern des 18. bis 20. Jahrhunderts. In: Jahrbuch für Volksliedforschung 29 (1984), S. 32-57.

Ruoss, Emanuel: Von Sprachrichtern und Provinzialismen. Zu Johann Jakob Bodmers Position im Normierungsdiskurs. In: Sprachspiegel 71 (2015), H. 2, S. 34-40.

Salge, Christine: Studien zur Wiener Festkultur im Spätbarock. Feuerwerk und Illumination. In: Martin Engel [u. a.] (Hg.): Barock in Mitteleuropa. Werke - Phänomene - Analysen. Hellmut Lorenz zum 65. Geburtstag. Wien/Köln/Weimar: Böhlau 2006/2007. (Wiener Jahrbuch für Kunstgeschichte LV/LVI) S. 401-418.

Sartori, Franz: Neueste Reise durch Österreich ob und unter der Enns, Salzburg, Berchtesgaden, Kärnthen und Steyermark in statistischer, geographischer, naturhistorischer, ökonomischer, geschichtlicher und pittoresker Hinsicht unternommen. Wien: Doll 1811.

Schäffer, Jacob Christian: Versuche und Muster ohne alle Lumpen oder doch mit einem geringen Zusatze derselben Papier zu machen. Regensburg: [o.V.] 1765.

Schaller-Pressler, Gertraud: Volksmusik und Volkslied in Wien. In: Elisabeth Theresia Fritz/Helmut Kretschmer (Hg.): Wien, Musikgeschichte: Volksmusik und Wienerlied: Teil 1. Wien: LIT 2006, S. 3-147.

Schauer, Herbert: „Das pöbelhafteste Produkt der deutschen Litteratur“. In: Meinhard Knigge (Hg.): Zwischen Zettelkasten und Internet. Ein Feststrauß für Susanne Koppel zum 31. Oktober 2005. Unter Mitwirkung von Renate Lempart und Detlev Gerd Stechern. Eutin: Lumpeter und Lasel 2005, S. 3950.

Schenda, Rudolf: Volk ohne Buch. Studien zur Sozialgeschichte der populären Lesestoffe 1770-1910. Frankfurt a. M.: Klostermann 1970. 
Schenker, Walter: Dialekt und Literatur. In: Zeitschrift für deutsche Philologie 96 (1977), Sonderheft Sprache, S. 34-48.

Schennach, Martin P.: Revolte in der Region. Zur Tiroler Erhebung von 1809. Innsbruck: Wagner 2009. (Veröffentlichungen des Tiroler Landesarchivs 16)

Scheuringer, Hermann: Von der Sprache des Pöbels zur dialektalen Variabilität. Eine kommentierte Bibliographie zur oberösterreichischen Dialektforschung. In: Oberösterreichische Heimatblätter 40 (1986), S. 15-37.

Scheutz, Martin: Die lutherischen bauren machen es endlich so derb, daß es nicht ärger seyn kunte. Geheimprotestantismus und Transmigration im Schatten der Benediktiner von Lambach um die Mitte des 18. Jahrhunderts. In: Klaus Landa/Christoph Stöttinger/Jakob Wührer (Hg.): Stift Lambach in der Frühen Neuzeit. Frömmigkeit, Wissenschaft, Kunst und Verwaltung am Fluss. Tagungsband zum Symposion im November 2009. Linz: OÖLA 2012, S. 391-427.

Scheutz, Martin: 1683 - Zweite Türkenbelagerung Wiens. Internationale Konflikte, beginnende Zentralisierung der zusammengesetzten Habsburgermonarchie und Konfessionalisierung. In: Martin Scheutz/Arno Strohmeyer (Hg.): Von Lier nach Brüssel. Schlüsseljahre österreichischer Geschichte (1496-1995). Innsbruck/Wien/Bozen: StudienVerlag 2010, S. 111-134.

Schiewer, Gesine L.: Bodmers Sprachtheorie. Kontroversen um die Standardisierung und pragmatische Fundierung des Deutschen. In: Anett Lütteken/Barbara Mahlmann-Bauer (Hg.): Bodmer und Breitinger im Netzwerk der europäischen Aufklärung. Göttingen: Wallstein 2009, S. 638-661.

Schiffmann, Konrad: Drama und Theater in Österreich ob der Enns bis zum Jahre 1803. Linz: Verlag des Museums Francisco-Carolinum 1905.

Schindler, Otto G.: Über Schwert- und Reiftänze in Wiener Neustadt. Ein Beitrag zu niederösterreichischen Volkskunde. In: Jahrbuch des Österreichischen Volksliedwerkes 22 (1973), S. 36-39.

Schindler, Otto G.: ,Arlequin' a ,Don Quichotte' na Šumavě. Rakouské pramenÿ ke krumlovskému zámeckému divadlu knížat ze Schwarzenbergu. In: Jihočeský sborník historický 63 (1994), S. 6168.

Schindler, Otto G.: Die erlauchten Komödianten des Herzogs von Krumau. Der oberösterreichische Adel gastiert am Schloßtheater der Fürsten zu Schwarzenberg. In: Blickpunkte Oberösterreich 44 (1994), S. 3239.

Schindler, Otto G.: Stranitzky, Joseph Anton. In: Rudolf Flotzinger (Hg.): Österreichisches Musiklexikon. 5: Schwechat - Zyklus. Wien: Verl. der Österr. Akad. der Wissenschaften 2006, S. $2324 f$.

Schindler, Otto G.: Hanswurst in Preßburg/Bratislava. Deutsche Lustigmacher auf den ältesten Theaterzetteln Ungarns. In: Horst Fassel/Paul S. Ulrich/Otto G. Schindler (Hg.): Deutsches Theater im Ausland vom 17. zum 20. Jahrhundert. Interkulturelle Beziehungen in Geschichte und Gegenwart. Münster: LIT 2008, S. 95-122.

Schings, Hans Jürgen (Hg.): Der ganze Mensch. Anthropologie und Literatur im 18. Jahrhundert. DFG-Symposion. Stuttgart, Weimar: Metzler 1994.

Schissel von Fleschenberg, Othmar: Die erste handschriftliche Fassung von J. F. Primissers Kriegslied „N’ Stutzen hear bam Sokara“ 1796. In: Zeitschrift des Ferdinandeums für Tirol und Vorarlberg 3/49 (1905), S. 447-451.

Schlachta, Astrid: Die Emigration der Salzburger Kryptoprotestanten. In: Rudolf Leeb/Martin Scheutz/Dietmar Weikl (Hg.): Geheimprotestantismus und evangelische Kirchen in der Habsburgermonarchie und im Erzstift Salzburg. Wien/München: Böhlau/Oldenburg 2009, S. 63-92.

Schlossar, Anton: Deutsche Volkslieder aus Steiermark. Zugleich Beiträge zur Kenntniß der Mundart und der Volkspoesie auf bairisch-österreichischem Sprachgebiete mit Einleitung, Anmerkungen und ausgewählten Melodien herausgegeben. Innsbruck: Wagner 1881.

Schlossar, Anton: Deutsche Volksschauspiele. In Steiermark gesammelt. Mit Anmerkungen und Erläuterungen. Halle: Niemeyer 1891.

Schmeling, Manfred/Schmitz-Emans, Monika: Einleitung. In: Manfred Schmeling/Monika Schmitz-Emans (Hg.): Multilinguale Literatur im 20. Jahrhundert. Würzburg: Königshausen \& Neumann 2002.

Schmid-Cadalbert, Christian: Dialektliteratur. In: Klaus Weimar [u. a.] (Hg.): Reallexikon der deutschen Literaturwissenschaft. Bd. 1: A-G. Berlin [u. a.]: de Gruyter 1997, S. 347-350. 
Schmidt, Leopold: Formprobleme der deutschen Weihnachtsspiele. Emsdetten: Lechte 1937.

Schmidt, Leopold: Blumauer und das Volkslied. In: Germanisch-Romanische Monatsschrift XXVIII (1940), S. 87-100.

Schmidt, Leopold: Ein unbekanntes Mundartgedicht Blumauers. In: Germanisch-Romanische Monatsschrift 29 (1941), S. 147-150.

Schmidt, Leopold: Das deutsche Volksschauspiel. Ein Handbuch. Mit 6 Karten im Text und 18 Abbildungen auf Tafeln. Berlin: Erich Schmidt 1962.

Schmidt, Leopold: Eine Mondseer Liederhandschrift von 1827. In: Jahrbuch des österreichischen Volksliedwerkes 13 (1964), S. 12-44.

Schmidt, Leopold: Historische Volkslieder aus Österreich vom 15. bis zum 19. Jahrhundert. Ausgewählt und kommentiert von L.S. Wien: Österr. Bundesverlag 1971. (Wiener Neudrucke 1)

Schmidt, Leopold: Volksliedlandschaft Obersteiermark. Die Frühzeit ihrer Kenntnisnahme und Erforschung. Vom,Rauffjodel' bis zum,Gams-Urberl'. In: Österreichische Musikzeitschrift 28 (1973), H. 9, S. 371-389.

Schmidt-Dengler, Wendelin: Das Kontrastschema Stadt-Land in der Alt-Wiener Volkskomödie. In: Jürgen Hein (Hg.): Theater und Gesellschaft. Das Volksstück im 19. und 20. Jahrhundert. Düsseldorf: Bertelsmann 1973. (Literatur in der Gesellschaft 12) S. 57-68.

Schmidt-Dengler, Wendelin: Polarisierung als Gestaltungsprinzip auf dem Alt-Wiener Volkstheater. In: Jahrbuch der Grillparzer-Gesellschaft 10 (1973), S. 41-63.

Schmölzer, Annemarie: Die Handwerkersiedlung Hall. Vorläufer des heutigen Bad Hall. In: Oberösterreichische Heimatblätter 38 (1984), H. 3, S. 271-285.

Schneider, Johann Nikolaus: Ins Ohr geschrieben: Lyrik als akustische Kunst zwischen 1750 und 1800. Göttingen: Wallstein 2004, S. 32-45.

Schnell, Rüdiger: Literaturwissenschaft und Mediengeschichte. Kritische Überlegungen eines Mediävisten. In: IASL 34 (2009), S. 1-48.

Schnettger, Matthias: Der Spanische Erbfolgekrieg 1701-1713/14. München: Beck 2014.

Schnitzer, Claudia: Höfische Maskeraden. Funktion und Ausstattung von Verkleidungsdivertissements an deutschen Höfen der Frühen Neuzeit. Tübingen: Niemeyer 1999. (Frühe Neuzeit 53)

Scholz, Sabine: Die Entwicklung der österreichischen Pornographiegesetzgebung seit 1740. Frankfurt a. M. [u. a.]: Lang 1999.

Schön, Friedrich: Geschichte der deutschen Mundartdichtung. 3 Tlbde. Freiburg: Fehsenfeld 19201931.

Schopp, Josef: Das deutsche Arbeitslied. Heidelberg: Winter Universitätsverl. 1935.

Schort, Manfred: Politik und Propaganda. Der Siebenjährige Krieg in den zeitgenössischen Flugschriften. Frankfurt a. M. [u. a.]: Lang 2006.

Schröder, Martin: Ist eine strukturelle Theorie der Dialektliteratur möglich? In: Peter Wagener (Hg.): Sprachformen. Deutsch und Niederdeutsch in europäischen Bezügen. Festschrift für Dieter Stellmacher. Stuttgart: Steiner 1999, S. 281-288.

Schröder, Martin: Zwischen Aisthesis und Mimesis. Zur Funktion des Dialekts in der standardsprachlichen Literatur. In: Eckhard Eggers/Jürgen Erich Schmidt/Dieter Stellmacher (Hg.): Moderne Dialekte - Neue Dialektologie. Akten des 1. Kongresses der Internationalen Gesellschaft für Dialektologie des Deutschen (IGDD) am Forschungsinstitut für deutsche Sprache „Deutscher Sprachatlas" der Philipps-Universität Marburg vom 5.-8. März 2003. Stuttgart: Steiner 2005. (Zeitschrift für Dialektologie und Linguistik, Beihefte 130) S. 667-678.

Schrödl, Jenny: Vom Scheitern der Komik. In: Hilde Haider-Pregler [u. a.] (Hg.): Komik. Ästhetik, Theorien, Strategien. Wien/Köln/Weimar: Böhlau 2006. (Maske und Kothurn 51/4) S. 30-40.

Schryver, Reginald de (Hg.): Max II. Emanuel von Bayern und das spanische Erbe. Die europäischen Ambitionen des Hauses Wittelsbach 1665-1715. Mainz: von Zabern 1996. (Veröffentlichungen des Instituts für Europäische Geschichte 156)

Schuhladen, Hans: Der verlorene Sohn. Vom Schul- und Ordensdrama zum bayerisch-tirolischen Volksschauspiel. In: Helge Gerndt/Klaus Roth/Georg R. Schroubek (Hg.): Dona Ethnologica Monacensia. Leopold Kretzenbacher zum 70. Geburtstag. München: AJZ 1983, S. 227-250. 
Schulze, Ursula: Geistliche Spiele im Mittelalter und in der Frühen Neuzeit. Von der liturgischen Feier zum geistlichen Schauspiel. Eine Einführung. Berlin: Schmidt 2012.

Schulze, Winfried: Gerhard Oestreichs Begriff der ,Sozialdisziplinierung in der Frühen Neuzeit'. In: Zeitschrift für Historische Forschung 14 (1987), S. 287-317.

Seifert, Herbert: Die Oper am Wiener Kaiserhof im 17. Jahrhundert. Tutzing: Schneider 1985. (Wiener Veröffentlichungen zur Musikwissenschaft 25)

Senn, Walter: Mozartiana aus Tirol. In: Festschrift Wilhelm Fischer. Zum 70. Geburtstag überreicht im Mozartjahr 1956. Innsbruck: Im Selbstverlag des Sprachwissenschaftlichen Seminars der Universität Innsbruck 1956. (Innsbrucker Beiträge zur Kulturwissenschaft, Sonderheft 3) S. 49-59.

Siuts, Hinrich: Die Ansingelieder zu den Kalenderfesten. Ein Beitrag zur Geschichte, Biologie und Funktion des Volksliedes. Göttingen: Schwartz 1968.

Siuts, Hinrich: Brauchtumslied. In: Rolf Wilhelm Brednich/Lutz Röhrich/Wolfgang Suppan (Hg.): Handbuch des Volksliedes. Bd. 1: Die Gattungen des Volksliedes. München: Fink 1973, S. 343362.

Sommer-Mathis, Andrea: Tu felix Austria nube. Hochzeitsfeste der Habsburger im 18. Jahrhundert. Wien: Musikwissenschaftlicher Verlag 1994.

Sonderegger, Stefan: Aspekte einer Sprachgeschichte der deutschen Schweiz. In: Werner Besch / Anne Betten/Oskar Reichmann/Stefan Sonderegger (Hg.): Sprachgeschichte. Ein Handbuch zur Geschichte der deutschen Sprache und ihrer Erforschung. 3. Tlbd. Berlin/New York: De Gruyter 2003. (HSK 2.3) S. 2825-2888.

Sonnek, Anke: Emanuel Schikaneder. Theaterprinzipal, Schauspieler und Stückeschreiber. Kassel [u. a.]: Bärenreiter 1999. (Schriftenreihe der Internationalen Stiftung Mozarteum Salzburg 11)

Sonnenfels, Joseph von: Briefe über die Wienerische Schaubühne. Hg. von Hilde Haider-Pregler. Graz: Akademische Druck- und Verlagsanstalt 1988. (Wiener Neudrucke 9)

Sonnleitner, Johann: Hanswurst, Bernardon, Kasperl und Staberl. In: Johann Sonnleitner (Hg.): Hanswurstiaden. Ein Jahrhundert Wiener Komödie. Salzburg/Wien: Residenz 1996, S. 331-389.

Sonnleitner, Johann: Die Wiener Posse. Begriff und Wirkungsästhetik um 1770. In: Franz M. Eybl (Hg.): Nebenschauplätze. Ränder und Übergänge in Geschichte und Kultur des Aufklärungsjahrhunderts. Bochum: Winkler 2014. (Das achtzehnte Jahrhundert in Österreich 28) S. 137-150.

Stanzel, Franz K.: Europäer. Ein imagologischer Essay. 2., aktual. Aufl. Heidelberg: Winter 1998.

Stanzel, Franz K.: Zur literarischen Imagologie. Eine Einführung. In: Franz K. Stanzel (Hg.): Europäischer Völkerspiegel. Imagologisch-ethnographische Studien zu den Völkertafeln des frühen 18. Jahrhunderts. Unter Mitwirkung von Ingomar Weiler und Waldemar Zacharasiewicz. Heidelberg: Winter 1999, S. 9-39.

Stanzel, Franz K.: Telegonie - Fernzeugung. Macht und Magie der Imagination. Wien/Köln/Weimar: Böhlau 2008.

Stein, Roger: Das deutsche Dirnenlied. Literarisches Kabarett von Bruant bis Brecht. Köln/Weimar/ Wien: Böhlau 2007.

Steiner, Katharina: Edition und Kommentar: Heft 6a aus der Sammlung Bühnenstücke und Gedichte aus dem Kloster Beuerberg (1740-86, BStB Cgm 5719). Graz 2019. [Dipl.]

Stellner, František: Zu den Ergebnissen des Siebenjährigen Kriegs in Europa. In: Prague Papers on History of International Relations 4 (2000), S. 85-98.

Strobach, Hermann: Bauernklagen. Untersuchungen zum sozialkritischen deutschen Volkslied. Berlin: Akademie-Verlag 1964.

Strolz, Johann Nepomuk Georg: Bürgall, ein Zillerthaler Volkslied. In: Der Sammler für Geschichte und Statistik von Tirol (1807), Bd. 2, S. 57-69.

Sturm, Marcellinus: Lieder zum Theil in baierischer Mundart von P. Marcelin Sturm, ehemaligem Augustiner. In Musik gesetzt nach den eigenen Melodien des Verfassers von dem kön. Advokaten Giehrl in Neunburg vorm Walde. [O.O.: o.V.] 1819.

Suppan, Carl Victor: Die Donau und ihre Schiffahrt. Wien: Selbstverl. 1917.

Suppan, Wolfgang: Lieder einer steirischen Gewerkensgattin aus dem 18. Jahrhundert. Handschrift 1483 des Steiermärkischen Landesarchivs Graz. Graz: Selbstverlag des Historischen Vereins für Steiermark 1970. 
Süß, Vinzenz (Hg.): Salzburgische Volks-Lieder mit ihren Singweisen. Salzburg: Verlag der Mayrischen Buchhandlung 1865.

Tantner, Anton: Ordnung der Häuser, Beschreibung der Seelen. Hausnummerierung und Seelenkonskription in der Habsburgermonarchie. Innsbruck/Wien/Bozen: Studien-Verl. 2007.

Trost, Pavel: Das späte Prager Deutsch. In: Acta Universitatis Carolinae. Germanistica Pragensia II (1962), S. 31-39.

Trümpy, Hans: Schweizerdeutsche Sprache und Literatur im 17. und 18. Jahrhundert (auf Grund der gedruckten Quellen). Basel: Krebs 1955. (Schriften der Schweizerischen Gesellschaft für Volkskunde 36)

Tuschner, Wolfram: Ein Wildschützenlied aus dem Mollnertal aus der Zeit um 1740. In: Jahrbuch des Oberösterreichischen Musealvereines - Gesellschaft für Landeskunde 142 (1997), S. 255-268.

Vasold, Manfred: Die Eruptionen des Laki von 1783/84. Ein Beitrag zur deutschen Klimageschichte. In: Naturwissenschaftliche Rundschau 57 (2004), H. 11, S. 602-608.

Vogt, Jürgen: Starke Gefühle. Zu den prärationalen Grundlagen ästhetischer Erfahrung. Teil 1: Kants Ekel. In: Zeitschrift für Kritische Musikpädagogik (2007), S. 54-71, http://www.zfkm.org/07-vogt. pdf (letzter Zugriff am 20.05.2018).

Wagner, Hermann F.: Die Volksdichtung in Salzburg. Salzburg: Mayr 1882.

Wagner, Joseph Maria: Ein historisches Volkslied vom Jahre 1689. In: Die deutschen Mundarten 7 (1877), S. 243-252.

Wangermann, Ernst: Die Waffen der Publizität. Zum Funktionswandel der politischen Literatur unter Joseph II. Wien: Verlag für Geschichte und Politik. München: Oldenburg 2004. (Österreich Archiv)

Wangermann, Ernst: Emigrationen und Transmigrationen österreichischer Protestanten im 18. Jahrhundert. In: Sylvia Hahn/Andrea Komsloy/Ilse Reiter (Hg.): Ausweisung - Abschiebung - Vertreibung in Europa. 16.-20. Jahrhundert. Wien: Studienverlag 2006, S. 73-86.

Waniek, Gustav: Gottsched und die deutsche Litteratur seiner Zeit. Leipzig: Breitkopf und Härtel 1897.

Weber, Ernst: Spittelberg-Lieder. In: Rudolf Flotzinger (Hg.): Oesterreichisches Musiklexikon. Bd. 5: Schwechat - Zyklus. Wien: Österr. Akademie der Wissenschaften 2006, S. $2265 f$.

Weber, Gottfried: Ueber eine Originalhandschrift von Mozart. In: Cäcilia. Eine Zeitschrift für die musikalische Welt I (1824), S. 179-182.

Weber, Carl Julius: Sämmtliche Werke. Eilfter Band: Die Möncherei oder geschichtliche Darstellung der Klosterwelt und ihres Geistes. Stuttgart: Hallberger 1836.

Weber, Karl Julius: Deutschland, oder Briefe eines in Deutschland reisenden Deutschen. Zweiter Band. Stuttgart: Franckh 1827.

Wehrl, Karl: Der ,neue Geist'. Eine Untersuchung der Geistesrichtungen des Klerus in Wien von 1750-1790. In: Mitteilungen des Österreichischen Staatsarchivs 20 (1967), S. 36-114.

Weilen, Alexander von: Das Theater. 1529-1740. Separatabdruck aus Band VI der ,Geschichte der Stadt Wien'. Wien: Verl. des Alterthumsvereines zu Wien 1917.

Weiler, Ingomar: Ethnographische Typisierungen im antiken und mittelalterlichen Vorfeld der „Völkertafel“. In: Franz K. Stanzel (Hg.): Europäischer Völkerspiegel. Imagologisch-ethnographische Studien zu den Völkertafeln des frühen 18. Jahrhunderts. Unter Mitwirkung von Ingomar Weiler und Waldemar Zacharasiewicz. Heidelberg: Winter 1999, S. 97-118.

Weinberger, Elisabeth (Hg.): Kurprinz Joseph Ferdinand, Prinz von Asturien (1692-1699). Kinderleben im Konzert der Mächte. München: Staatliche Archive Bayerns 2012. (Veröffentlichungen der Staatlichen Archive Bayerns 37)

Weinhold, Karl: Weihnacht-Spiele und Lieder aus Süddeutschland und Schlesien. Mit Einleitungen und Erläuterungen. Mit einer Musikbeilage. Graz: Damian \& Sorge 1853.

Weinhold, Karl: Ueber das deutsche Volkslied in Steiermark. In: Mitteilungen des historischen Vereins der Steiermark 9 (1859), S. 61-84.

Weinhold, Karl: Steyermarckischer Raufjodel. In: Zeitschrift des Vereins für Volkskunde 4 (1894), S. 335-336. 
Wenzel, Horst: Repräsentation. In: Jan-Dirk Müller (Hg.): Reallexikon der deutschen Literaturwissenschaft. Neubearbeitung. Bd. III: P-Z. Berlin, New York: de Gruyter 2003, S. 268-271.

Wenzel, Horst: Höfische Repräsentation. Symbolische Kommunikation und Literatur im Mittelalter. Darmstadt: Wiss. Buchgesellschaft 2005.

Wenzel, Horst: Mediengeschichte vor und nach Gutenberg. Darmstadt: Wissenschaftliche Buchgesellschaft 2007.

Werner, Richard Maria (Hg.): Der Wiener Hanswurst. Stranitzkys und seiner Nachfolger ausgewählte Schriften. 1. Bd.: Lustige Reyss-Beschreibung aus Saltzburg in verschiedene Länder von J. A. Stranitzky. Wien: Konegen 1883. (Wiener Neudrucke 6)

Westenrieder, Lorenz (Hg.): Beyträge zur vaterländischen Historie, Geographie, Statistik, und Landwirthschaft, samt einer Uebersicht der schönen Litteratur. Vierter Bd. München: Joseph Lindauer 1792.

Wiegand, Hermann: Makkaronische Dichtung. In: Harald Fricke (Hg.): Reallexikon der deutschen Literaturwissenschaft. 3., neubearb. Aufl. Bd. 2: H-O. Berlin/New York: de Gruyter 2000, Sp. 527530.

Wiesinger, Peter: Die sprachlichen Verhältnisse und der Weg zur allgemeinen deutschen Schriftsprache in Österreich im 18. und frühen 19. Jahrhundert. In: Andreas Gardt/Klaus Mattheier/Oskar Reichmann (Hg.): Sprachgeschichte des Neuhochdeutschen. Gegenstände, Methoden, Theorien. Tübingen: Niemeyer 1995. (Reihe Germanistische Linguistik 156), S. 319-367.

Wiesinger, Peter: Dialektgeographie als Kulturgeschichte. An Beispielen aus dem bairischen Dialektraum. In: Andreas Gardt/Ulrike Haß-Zumkehr/Thorsten Roelcke (Hg.): Sprachgeschichte als Kulturgeschichte. Berlin/New York: de Gruyter 1999. (Studia Linguistica Germanica 54), S. $295-$ 349.

Wiesinger, Peter: Zur bairisch-oberdeutschen Schriftsprache des 16. und frühen 17. Jahrhunderts in Österreich unter dem Einfluss von Reformation und Gegenreformation. In: Walter Hoffmann [u. a.] (Hg.): Das Frühneuhochdeutsche als sprachgeschichtliche Epoche. Werner Besch zum 70. Geburtstag. Frankfurt a. M. [u. a.]: Lang 1999, S. 241-273.

Wiesinger, Peter: Die Stadt in der neueren deutschen Sprachgeschichte V: Wien. In: Werner Besch, Oskar Reichmann/Stefan Sonderegger (Hg.): Sprachgeschichte. Ein Handbuch zur Geschichte der deutschen Sprache und ihrer Erforschung. 3. Tlbd. 2. vollständ. neu bearb. u. erw. Aufl. Berlin/ New York: de Gruyter 2003. (HSK 2.3) S. 2354-2377.

Wiesinger, Peter: Dialekt im Urteil der Aufklärung. Über Wiener Dialektpredigten von 1782. In: Albrecht Greule [u. a.] (Hg.): Die bairische Sprache. Studien zu ihrer Geographie, Grammatik, Lexik und Pragmatik. Festschrift für Ludwig Zehetner. Regensburg: Ed. Vulpes 2004. (Regensburger Dialektforum 5), S. 143-161.

Wiesinger, Peter: Bairisch-österreichisch - Die Wiener Stadtkanzlei und die habsburgischen Kanzleien. In: Albrecht Greule [u. a.] (Hg.): Kanzleisprachenforschung. Ein internationales Handbuch. Berlin/Boston: de Gruyter 2012, S. 415-439.

Wiesinger, Peter: Die Entwicklung der deutschen Schriftsprache vom 16. bis 18. Jahrhundert unter dem Einfluss der Konfessionen. In: Peter Wiesinger: Das österreichische Deutsch in Gegenwart und Geschichte. 3., aktual. und neuerlich erweit. Aufl. Wien/Berlin: LIT 2014. (Austria: Forschungen und Wissenschaft. Literatur- und Sprachwissenschaft 2), S. 301-312.

Wiesinger, Peter: Das Verhältnis von Dialekt und Schriftsprache in Österreich und die literarische Verwendung von Dialekt vom 16. bis zum 18. Jahrhundert. In: Christian Neuhuber/Elisabeth Zehetner (Hg.): Bairisch-österreichischer Dialekt in Literatur und Musik 1650-1900. Tagungsband. Graz: Leykam/Universitätsverl. 2015, S. 9-39.

Wittmann, Reinhard: Nachwort. In: Anton von Bucher: Bairische Sinnenlust bestehend in welt- und geistlichen Comödien, Exempeln und Satiren. Mit einem Nachwort hg. von Reinhard Wittmann. München: Idion 1980, S. 1-26.

Wolfram, Richard: Volkstänze aus Deutsch-Mokra. In: Das deutsche Volkslied 41 (1939), S. 30-33.

Wolfram, Richard: Schwerttanz und Männerbund. Kassel: Bärenreiter 1936-1938.

Wolfram, Richard: Ein neugefundenes Schwerttanzmanuskript des 18. Jahrhunderts aus dem Salzkammergut. In: Jahrbuch des österreichischen Volksliedwerkes 32/33 (1984), S. 147-166. 
Wolkan, Rudolf: Wiener Volkslieder aus fünf Jahrhunderten. 1. Band: Einleitung/ 1500-1799. Wien: Wiener Bibliophilen-Gesellschaft 1924-26, Nr. XXXVII.

Wuermling, Henric L.: Die Sendlinger Mordweihnacht. 1705 - die erste europäische Revolution. München, Wien: Langen Müller 1985.

Wurm, Sylvia: Die Bauern im 18. Jahrhundert. In: Adel - Bürger - Bauern im 18. Jahrhundert. Ausstellung des Landes Niederösterreich. Schallaburg '80. 1. Mai bis 2. November 1980. Wien: [o.V.] 1980. (Kataloge des niederösterreichischen Landesmuseums. N.F. 96) S. 38-43.

Wurzbach, Constant von: Biographisches Lexikon des Kaiserthums Österreich. Bd. 12: Klácel - Korzistka. Wien: Verlag der k. k. Hof- und Staatsdruckerei 1864.

Zack, Viktor/Geramb, Viktor von: Die Lieder vom boarischen Hiasl in Deutschösterreich. In: Bayerische Hefte für Volkskunde 6 (1919), S. 1-34.

Zahn, Josef von: Historische Lieder des 16. und 18. Jahrh. In: Steiermärkische Geschichtsblätter 5 (1884), S. 245-255.

Zaupser, Andreas Dominikus: Versuch eines baierischen und oberpfälzischen Idiotikons. Nebst grammatikalischen Bemerkungen, über diese zwo Mundarten, und einer kleinen Sammlung von Sprüchwörtern und Volksliedern. München: Lentner 1789.

Zechmeister, Gustav: Die Wiener Theater nächst der Burg und nächst dem Kärntnerthor von 1747 bis 1776. Graz/Wien/Köln: Böhlau 1971.

Zehetner, Elisabeth: Kaufrufe und Dialekt in der Literatur - Zwischen Dokumentation, Literarisierung und Typenbildung. In: Christian Neuhuber/Elisabeth Zehetner (Hg.): Bairisch-österreichischer Dialekt in Literatur und Musik 1650-1900. Tagungsband. Graz: Leykam/Universitätsverl. 2015, S. 143-160.

Zehetner, Elisabeth: Dialekt und die literarische Darstellung von Fremden vor 1800. Untersuchungen zum Verhältnis zwischen Eigenem und Fremdem. Graz 2016. [Dipl.]

Zeidler, Jakob: Ueber Feste und Wirtschaften am Wiener Hofe während des 16., 17. und 18. Jahrhunderts. In: Jahrbuch der Oesterreichischen Gesellschaft vom weissen Kreuze 1890, S. I-XVIII.

Zeman, Herbert: Alt-Wiener Volkskomödie. In: Horst Albert Glaser (Hg.): Deutsche Literatur. Eine Sozialgeschichte. Bd. 4. Reinbek/Hamburg: Rowohlt 1992, S. 323-329.

Zingerle, Oswald: Lieder aus der Zeit der Türkenkriege. In: Anzeiger für Kunde der Deutschen Vorzeit. N.F. 27 (1880), Sp. 180-183.

Ziska, Franz/Schottky, Julius Max (Hg.): Oesterreichische Volkslieder mit ihren Singweisen. Pesth: Hartleben 1819.

Zumthor, Paul: Die orale Dichtung: Raum, Zeit, Periodisierungsproblem. In: Hans-Ulrich Gumbrecht, Ursula Link-Heer (Hg.): Epochenschwellen und Epochenstrukturen im Diskurs der Literatur- und Sprachhistorie. Frankfurt a. M.: Suhrkamp 1985. (stw 486) S. 359-375.

\section{Wörterbücher und Idiotika}

Adelung, Johann Christoph: Grammatisch-kritisches Wörterbuch der hochdeutschen Mundart, mit beständiger Vergleichung der übrigen Mundarten, besonders aber der Oberdeutschen. Mit D.W. Soltau's Beyträgen, revidirt und berichtiget von Franz Xaver Schönberger. 2. Aufl. 4 Bde. Wien: Bauer 1811.

Bayerisch-Österreichisches Wörterbuch. II. Bayern. Bayerisches Wörterbuch (BWB). Hg. von der Kommission für Mundartforschung. Bearbeitet von Josef Denz, Bernd Dieter Insam, Anthony R. Rowley und Hans Ulrich Schmid. München: Oldenburg 1995ff.

Castelli, Ignaz Franz: Wörterbuch der Mundart in Oesterreich unter der Enns. Wien: Tendler 1847.

De Luca, Ignaz: Beiträge zu einem Tyrolischen Wörterbuch. In: Johann Christoph Adelung: Magazin für die Deutsche Sprache. Bd. 2/1. Leipzig: Breitkopf 1783, S. 101-126.

Delling, Johann von: Beiträge zu einem baierischen Idiotikon. München: Lentner 1820. 
Deutsches Rechtswörterbuch (Wörterbuch der älteren deutschen Rechtssprache). Bd. 1-11. Weimar: Böhlau 1914-2005ff.

Deutsches Wörterbuch von Jacob Grimm und Wilhelm Grimm. 16 Bde. [in 32 Teilbänden]. Leipzig: S. Hirzel 1854-1960.

Fulda, Friedrich Carl: Versuch einer allgemeinen deutschen Idiotikensammlung. Sammlern und Liebhabern zur Ersparung vergeblicher Mühe bey bereits schon aufgefundenen Wörtern, und zu leichterer eigener Fortsetzung gegeben. Berlin, Stettin: Nicolai 1788.

Höfer, Matthias: Die Volkssprache in Oesterreich vorzüglich ob der Ens, nach ihrer innerlichen Verfassung und in Vergleichung mit andern Sprachen. Wien: Binz 1800.

Höfer, Matthias: Etymologisches Wörterbuch der in Oberdeutschland, vorzüglich aber in Oesterreich üblichen Mundart. 3 Tle. Linz: Kastner 1815.

Hornung, Maria: Wörterbuch der Wiener Mundart. Unter Mitarb. von Leopold Swossil. Wien: ÖBV 1998.

Hübner, Lorenz: Salzburgisches Idiotikon. In: Lorenz Hübner: Beschreibung des Erzstiftes und Reichsfürstenthums Salzburg in Hinsicht auf Topographie und Statistik. 3. Bd. Salzburg: Hübner 1796, S. 955-984.

Hügel, Franz Seraph: Der Wiener Dialekt. Lexikon der Wiener Volkssprache (Idioticon Viennense). Wien/Pest/Leipzig: Hartleben 1873.

Kainz, Walter/Walcher, Eduard: Weststeirisches Wörterbuch. Grammatik und Wortschatz nach Sachgruppen. Bearb., erg. u. hg. von Claus Jürgen Hutterer. Wien: Böhlau 1987.

Lexer, Matthias: Kärntisches Wörterbuch. Mit einem Anhange: Weihnacht-Spiele und Lieder aus Kärnten. Leipzig: S. Hirzel 1862.

Lethmüller, Ignaz (Hg.): Versuch einer Vereinigung der Mundarten von Teutschland als eine Einleitung zu einem vollständigen Teutschen Wörterbuche mit Bestimmungen der Wörter und beträchtlichen Beiträgen zur Naturgeschichte aus den hinterlassenen Schriften des berühmten Herrn Prof. Joh. Siegm. Val. Popowitsch. Wien: Kurzböck 1780.

Loritza, Carl: Neues Idioticon Viennense, das ist: Die Volkssprache der Wiener mit Berücksichtigung der anderen Landesdialekte. Wien/Leipzig: Stöckholzer 1847.

Mareta, Hugo: Proben eines Wörterbuchs der österreichischen Volkssprache. Zweiter Versuch. Wien: Carl Gerold's Sohn 1865. [Separat-Abdruck aus dem Jahresbericht des Obergymnasiums zu den Schotten in Wien am Schlusse des Schuljahres 1865.]

Misson, Josef: Ein altdeutscher Beinstock. Landwörterbuch der unterennsischen Mundart 1852. Erste Veröffentlichung aus dem Originalmanuskript. In: Da Naz, a niederösterreichischer Baurnbui, geht in d'Fremd. Gedruckt nach der Originalhandschrift. Mit dem erstmaligen Abdruck der ,Worterklärung des Dichters. Wien: Hollinek 1947, S. 79-176.

Nicolai, Friedrich: Beschreibung einer Reise durch Deutschland und die Schweiz, im Jahre 1781. Nebst Bemerkungen über Gelehrsamkeit, Industrie, Religion und Sitten. 12 Bde. Bd. VII. Berlin und Stettin: Nicolai 1786, S. 96-104.

Popowitsch, Johann Siegmund Valentin: Vocabula Austriaca et Stiriaca. Nach der Abschrift von Anton Wasserthal herausgegeben und eingeleitet von Richard Reutner. 2 Tle. Frankfurt a.M:. [u. a.]: Lang 2004. (Schriften zur deutschen Sprache in Österreich 32/33)

Queri, Georg: Kraftbayrisch. Ein Wörterbuch der erotischen und skatologischen Redensarten der Altbayern. Mit Belegen aus dem Volkslied, der bäuerlichen Erzählung und dem Volkswitz. Hg. und mit einem Nachwort von Michael Stephan. 2. Ausg. München: Allitera 2010.

Reutner, Richard (Hg.): Der Abschnitt ,Dialecti“ aus den vermischten Schriften des Johann Siegmund Valentin Popowitsch (1705-1774). Wien: Edition Praesens 2003. (Schriften zur diachronen Sprachwissenschaft 13)

Schatz, Josef: Wörterbuch der Tiroler Mundarten. 2 Bde. Innsbruck: Wagner 1955f.

Schmeller, Johann Andreas: Die Mundarten Bayerns grammatisch dargestellt. München: Thienemann 1821.

Schmeller, Johann Andreas: Bayerisches Wörterbuch. Mit der wissenschaftlichen Einleitung zur Ausgabe 1939 von Otto Maußer. Jubiläumsausgabe [Nachdruck] der von G. Karl Frommann bearbeiteten 2. Ausg. 2 Bde. München: Oldenbourg 2002. 
Schmieder, Pius: Idiotikon. In: Maurus Lindemayr's Sämmtliche Dichtungen in obderennsischer Volksmundart. Mit einer biographisch-literarischen Einleitung und einem kurzgefaßten Idiotikon hg. von Pius Schmieder. Linz: Korb 1875, S. 375-413.

Schöpf, J[ohann] B[aptist]: Tirolisches Idiotikon. Nach dessen Tode vollendet von Anton J. Hofer. Hg. auf Veranlassung und durch Unterstützung des Ferdiandeums. Innsbruck: Wagner 1866.

Sonnleitner, Joseph: Mundart der Österreicher oder Kern ächt österreichischer Phrasen und Redensarten. Von A bis Z. Wien: [o.V.] 1811.

Stelzhamer, Franz: Idioticon. In: Lieder in obderenns'scher Volksmundart. Wien: Rohrmann 1837, S. $173-183$.

Stelzhamer, Franz: Worterklärung. In: Neue Gesänge in obderenns'scher Volksmundart. Wien: Ueberreuter 1841, S. 321-352.

Stelzhamer, Franz: Idioticon. In: Gedichte in obderenns'scher Volksmundart. Regensburg: Manz 1846, S. 227-235.

Stöckl, Wolfgang: Die Mundart zwischen Hausruck und Mondsee. Grunddialekt und Berufssprachen. [Attersee]: Ed. Sommerfrische 2008.

Tscholl, Josef: Die Südtiroler Mundart in Wortschatz und Struktur. Brixen: Weger 1999.

Unger, Theodor: Steirischer Wortschatz als Ergänzung zu Schmellers Bayerischem Wörterbuch für den Druck bearb. u. hg. v. Ferdinand Khull. Graz: Leuschner und Lubensky 1903.

Wörterbuch der bairischen Mundarten in Österreich. Hg. im Auftrag der Österreichischen Akademie der Wissenschaften von Eberhard Kranzmayer unter Mitwirkung von Viktor Dollmayr [u. a.]. Wien: Kommissionsverl. der Österr. Akademie d. Wissenschaften $1970 \mathrm{ff}$.

Wörterbuch zur oberösterreichischen Volksmundart. Gesammelt von Otto Jungmair, für die Drucklegung bearbeitet von Albrecht Etz. Hg. vom Stelzhamerbund der Freunde oberösterreichischer Mundartdichtung. Linz: Selbstverl. d. Stelzhamerbundes 1978.

Zaupser, Andreas: Versuch eines baierischen und oberpfälzischen Idiotikons. Nebst grammatikalischen Bemerkungen über diese zwo Mundarten und einer kleinen Sammlung von Sprüchwörtern und Volksliedern. München: Lentner 1789.

Zehetner, Ludwig: Bairisches Deutsch. Lexikon der deutschen Sprache in Altbayern. Regensburg: edition vulpes 2005 .

Ziller, Leopold: Was nicht im Duden steht. Ein Salzburger Mundart-Wörterbuch. Hg. von der Gesellschaft für Salzburger Landeskunde. Salzburg: Selbstverl. 1979.

Ziska, Franz: Auszüge aus dem noch ungedruckten österreichischen Idiotikon. In: Anzeige-Blatt für Wissenschaft und Kunst 25 (1824), S. 1-27; 26 (1825), S. 1-20.

Ziska, Franz: Erklärung der mundartlichen Wörter. In: Österreichische Volkslieder mit ihren Singeweisen. Gesammelt und hg. von Franz Ziska u. Julius Max Schottky. [Faksimileausgabe] Wien: Wiener Bibliophilen-Ges. 1970, S. 262-283. 


\section{AUTORENVERZEICHNIS}

Christian Neuhuber ist Assoziierter Professor für Neuere deutsche Literatur an der Universität Graz. Seine Forschungsschwerpunkte liegen in der Literatur vom Barock bis zur Gegenwart mit Fokus auf Intermedialität, Editionsphilologie, Dialektkultur und Theatergeschichte.

Stefanie Edler ist als wissenschaftliche Mitarbeiterin am Grazer Institut für Germanistik im Fachbereich Deutsche Sprache tätig. Ihre Forschungsschwerpunkte liegen in der (historischen) Dialektliteratur sowie im Bereich der Variations- und Soziolinguistik des Gegenwartsdeutschen.

Elisabeth Zehetner studierte Germanistik und Soziologie. Als Projektmitarbeiterin forscht sie im Bereich von Dialektliteratur, digitalen Geisteswissenschaften sowie Wissenschaftsforschung. 


\section{REGISTER}

\section{Sachregister}

Aberglaube 329,379

Ablass 92

Adam und Eva-Spiel 39-41

Aderlasslied 442

Advent 22, 39, 45

Adventlied 22

Adventspiel 45

Alm, Almleben $\quad 234,245,246$

Almenlied 261

Anrufungslied 67

Ansingelied 404, 405, 411-414, 416, 417

Arbeitslied 301, 404-410, 468

Arbeitslied-Parodie 506

Arie $\quad 62,268,298,304,306,315,317,356,358,406$, 409, 410, 469, 539

Arlecchino, Arlequin 298, 464, 585

Aufklärung $\quad 37,66,198,200,208,214,218,224$, $225,230,318,328,329,333,335,398,474,569$

Authentizität $\quad 49,141,168,170,186,209,249,278$, 287, 306, 334, 360, 378, 403, 550, 566, 593, 594

fingierte Authentizität $96,113,131,198,351,574$ 580

simulierter/fehlerhafter Dialekt $\quad 41,51,121,287$, $471,529,549,605$

Bauer als König (rusticus imperans, Eintageskönig) 285, 289, 291, 294, 358, 438, 569

Bauer im Himmel $\quad 87,88,174$

Bauer in der Kirche $82,280-282,284$

Bauer in der Stadt $\quad 169,171,187,192,201,207,213$, 280, 337, 361

bäuerliche Sprecher $\quad 22,36,69,82,87,88,95,100$ $123,169,171,192,194,198,199,202,204,207,209$, $210,213,222,224,232,250,428,432,435,438,440$, 478, 502, 551, 560, 565

Bauerndialog, Bauerngespräch $95,102,109,112$, $113,127,132,143,160,170,171,181,207,262,280$, $347,444,526,551,560$

Bauernhochzeit 353

Bauernklage 231, 250, 251, 253-262

Bauernkriege 95, 123

Bauernlob 250, 262-266, 525

Bauernschelte 268,269,291

Bauernspott $13,36,88,148,171,178,250,253$, 258, 268, 278, 336

Bayerischer Erbfolgekrieg 142

Beichte $84,85,87,501$

Beichtparodie $\quad 84,85,87,502,507$

Bekehrungslied 69,70
Beleuchtung, Illumination $\quad 168,175,177-181,197$, 202, 387

Bernardon 295, 317, 375, 408, 585

Bernardoniade 585, 589

Beschimpfung, Schimpfwörter $100,104,114,133$, 557, 574

Besserungskomödie 357, 388, 590

betrunkener Bauer (Topos) 286, 448

Binnenexotik 234, 342, 353, 359

Bodenständigkeit, Aufrichtigkeit, Natürlichkeit 29 , 209, 218, 250, 297, 361, 571

brachiale Komik, Derbkomisches $37,51,63,90$, 273, 291, 319, 476, 486, 542

Brauch, Brauchtum 21, 403-405, 411-413,

416-421, 424, 433, 445, 457-459, 461-469, 568

Brief, Brieffiktion $\quad 141,186-192,214,217,326$,

333-338, 512, 556, 575, 597

Broschürenflut $42,326,581,595$

bukolische, arkadische Dichtung 261, 517

Burleske 295, 305, 317, 375, 393, 408, 474, 539, 585, 586

Stegreifburleske $\quad 585,586$

Commedia dell'arte $\quad 42,276,287,585$

Dreikönigslied 22

Dreißigjähriger Krieg 95, 130, 154, 320, 548

Drescherlied 410,505

Edler Wilder 333,378

Ekel 421, 482, 486, 488, 492-495, 498, 499, 504, 507

Ekellied 474, 493-495

Erbauungslied 69,70

erweiterte Preßfreiheit 37, 595

Essen, Festmahl, Gefräßigkeit $\quad 56,99,176,182,193$, 199, 319, 327, 470, 490, 493, 494, 507

Fäkalkomik $\quad 318,476,478,479,507,517,518$

Fasching, Fastnacht $39,45,49,51,55,65,76,316$, 396, 420, 474, 511

Faschingskomödie 46, 152, 467

Faschingslied 308

Fastnachtspiel $\quad 13,46,63,148,149,251,267,420$

Feindbilder 97, 112, 156

Französische Revolution $\quad 144,198,226,228,230$

Frauenschelte $\quad 379,393,504,538,539,541$

Fremdsprachiger Akzent/gebrochenes Sprechen $42,111,138,294,339,340,377,379,381,384,386$, 392, 395

Makkaronismus 377 
Freudenlied $189,424,425,437$

Funktionen von Dialekt in der Kunst 11, 17

Dialekt und Authentizität, Natürlichkeit 13, 29, 141, 168, 198, 209, 218, 249, 306, 329, 361, 515

Dialekt und Emotion $\quad 66,419,520,547,568,580$

Dialekt und Identitätsstiftung/Identifikation 22, 35, 96, 132, 198, 306, 339, 405, 566, 569

Dialekt und Intimität/Nähe $340,473,474,501$, 512

Dialekt und Komisierung $\quad 13,51,56,148,186$, 209, 249, 295-297, 299, 311, 361, 376, 474

Dialekt und Manipulation/Propaganda 96, 131, $136,168,547,548,560$

Dialekt und Mündlichkeit 96, 136, 381, 473

Dialekt und Provokation 454, 474, 547

Dialekt und regionale Verortung 29, 139, 340, 351, 352, 354

Dialekt und soziale Verortung/Kontrastierung $13,31,35,39,258,286,293,297,329,354,392$, 474, 532, 574

Dialekt und Sprachspiel, Spiel mit Lauten, Dechiffrierlust $\quad 311,339,381,395,453,480$

Dialekt und Stigmatisierung/Abwertung 209, $266,267,361,473,507,515,547,594,596,597$, 606

Dialekt und Unterhaltung/Scherz $\quad 91,295,435$, 447, 454, 481, 498, 586

Dialekt und Verortung/Kontrastierung 249

Dialektkunst als Gegenkunst $\quad 473,475,483$

Gassllied, Gasslreim 403, 457-459, 461, 524

Gebet 21, 66

fingiertes Gebet 227

Gebetslied 548

Geschlechterbilder, Weiblichkeit/Männlichkeit $132,206,233,306,323,324,504,508,515,521,538$, 539

Gstanzl 403, 457, 515-519, 521
Hirtenspiel 234, 465

Hochzeit, Hochzeitsbräuche $112,141,186,187$, $189,192,193,290,293,353,404,418-421,427$

Hochzeitslied $\quad 405,421,427,428$

Identitätsbildung, Gemeinschaftsbildung 100,111 , $115,118,168,206,224,267,302,306,339,398,404$, 405

Idylle, Idyllisierung $\quad 219,234,245,246,262,306$, 361

Jakobiner 226, 228, 230-233

Jakobinerprozesse $\quad 215,228$

josephinische Reformen 208, 210, 224, 264

Jüngstes Gericht, Jüngster Tag $\quad 174,319,321$

Kandidatenlied 75

Kanon 352, 353, 451, 453, 456, 478-480, 513

Kärntnertortheater $\quad 57,105,108,298,304,317,375$, $385,393,408,582,586,589$

Kasperl 296, 305, 325, 395, 594

Kasperliade 593

Kaufruf $\quad 226,250,309-314,316-318,379,383,385$, 392

Kindelwiegelied 22

Kindertheater 298

Klagelied, Trauerlied $\quad 114,116,204,548$

Scherzklage, komisches Klagelied 78, 499, 541, 602

Klostereintritt, Noviziat $\quad 75-79$

Klosteroperette $\quad 61,154,409,542$

Koalitionskriege 96, 144-146, 166, 203, 213, 217, 336, 338, 352, 364, 397

komisierendes Missverstehen/Umdeuten 29, 36, $83,89,171,174,181,280,282,333,440,551$

Komödie, Lustspiel $\quad 12,151,152,218,286$, 289-291, 297, 304, 317, 337, 354, 356, 357, 359, 388 $474,481,488,569,588,590$ ,regelmäßige' Komödie 588

Händler, Krämer $\quad 178,298,302,309-311,315-317$, Kontrastierung von Dialekt und Standard 29, 31, $353-356,358,359,374,378,379,381,383,384,386, \quad 53,61,258,286,287,293,297,361,474,481,507$, 388,392

Hanswurst $\quad 56,106,107,149,295,338,354,371$, $373-377,386,393,582,596$

Hanswurststück 57, 105, 353, 539, 583

Hanswurststreit 212,587-591, 593, 594

Haupt- und Staatsaktion $\quad 465,585$

Heiligenspiel $56-58,60,61,63$

Heischelied 22, 55, 411

Herbergsuche-Lied 22 $531,532,593$

Krankheit $\quad 238,482,483,486,488,490-492$

Krönung 195-199, 201, 203

Laien-, Dilettantenspiel 30, 39, 40, 56, 60, 154, 465, 586

Lazarusspiel $\quad 452$

Lazzo 61, 585

Legendenspiel $\quad 56,57$

Herrschaftsaffirmation $96,164,167,168,172,190$, Leopoldstädter Theater 216, 296, 453, 592 $195,209,227$

Liebesleidlied 408

Herrschaftskritik 164, 220,221, 228,231, 234, 236, Liebeslied 256, 474, 520-523, 532 237

Herrscherlob, Huldigung $98,106,109,169,170$, $178,182,186,189,190,192,198,200,202,209,218$, Männerschelte 535

363,395

Marienlied 67 
Märtyrerspiel 56

Messparodie 90

miles gloriosus 267, 343

Modeklage, Modespott $\quad 250,269,271,319-325$

Moralisierung, Bekehrung $\quad 68,70$

Mündlichkeit 96, 132, 136, 140, 186, 311, 378, 566, 567

fingierte Mündlichkeit $\quad 77,168,381,473,512$

mündlichkeitsnahe Sprachformen 95, 168, 216, 278

orale Sprachkultur $\quad 13,68,220,381,501$

überzeichnete Mündlichkeit 166

Mythisierung, Legendenbildung 240

Nachspiel $56,57,528$

Nachtwächterlied 35

Nation, Ethnie $\quad 146,364,391$

Nationalcharakter $\quad 366,368$

Völkertafel 341

Volksstereotype $\quad 340-366,368,373,374,377,390$, 392, 393

Neujahrslied $\quad 22,308,324,412-417$

Nikolausspiel 55

Offertoriumsgesang $\quad 21,35,57$

Ölberglied 46

Ordenstheater $13,40,49,65,151,183,291,294$

$297,452,466,488,542$

Ostermärlein 568,569

Ostern 46, 568

Österreichischer Erbfolgekrieg $\quad$ 130-136, 191

Pamphlet, Schmähschrift $\quad 37,121,507,548,564$, 573, 593, 598

Pantomime 298

Paradeisspiel 39

Paradieslied 517

Parodie 63, 420, 517, 550

Passionslied 46, 47

Passionsspiel 46

Pfälzischer Erbfolgekrieg/Neunjähriger Krieg 105, 112-115

Pickelhäring 288, 582

Polnischer Thronfolgekrieg $\quad 158,159$

Pornographisches 461, 474, 512, 513, 515-517

Posse $\quad 65,296,325,527,590,591,601$

Predigt, Kanzelrede 21, 566-571, 573

Predigtparodie, Predigtsatire $517,576,579$

Primizlied 430-433

Professlied 434

Promotionslied 441

Propaganda, Agitation $95,96,98,100,102,115$, $120,121,123,124,129,131,135,138,142,144,159$, $177,185,191,192,196,198,203,209,213,217,224$, 226, 227, 350, 362-365, 397, 507, 549, 554, 559

Protestanten

Exulantenlied 549
Kryptoprotestanten $\quad 123,553,557,562$

Protestantenvertreibung 548-551, 553, 554, 556, 557, 559-565

Emigrationspatent 559

Prozessionsgesang 63

Quodlibet 52, 275, 298, 316, 406, 407

Rätsellied 408

Räuberlied 240, 246

Rauflust, Prügeleien $\quad 197,253,278,327,342,343$, 347

Regiolekt, regionale/lokale Verortung $29,36,51$, $106,209,339,342,344,352,354,361,374,378,566$, $569,571,580,582$

Reiselied 348, 366, 371, 373

rührendes Lustspiel $\quad 212,220$

Satire $51,52,63,71,77,85,92,214,215,217,230$, 250, 299, 326-328, 333, 367, 369, 414, 415, 576, 589, 593, 597

Personalsatire 81

Scherzrede 420

Schnaderhüpfel $\quad 457,461,462,481,515,519$

Schriftsprache, Literalität, konzeptionelle Schriftlichkeit $16,18,66,249,311,328,339,369$

Schultheater $12,46,49,53,151,183,251,354,356$, $375,544,601$

Schwank 31, 88, 569

Schwerttanz 463

Sexualität, Erotik $\quad 134,234,246,261,313,314,317$, 461, 473, 474, 482, 500-502, 505, 507, 508, 512, 514, $515,517-519,526,536,580$

Siebenjähriger Krieg 137-141, 163, 285

Singspiel $40,51,58,152,154,201,216,218,234$, $238,258,268,275,291,293,296,298,314,337,384$, $406,407,437,438,465,467,472,491,521,523,527$, 542,545

Sintflut-Motiv 61

Sittenklage, Zeitklage $\quad 72,269,308,318,320,323$

Soldaten, Soldatenleben $\quad 111,128,139,146,147$, $149,156,157,160-166,268,383,393,526$

Desertion, Fahnenflucht $\quad 125,147,149$

Soldatenklage 381

Soldatenwerbung, Rekrutierung $\quad 147,157,159,161$, 163,165

Soldatenwerbelied $\quad 156,158-160,256,267$

Soldat-wider-Willen $148,151,383$

Zwangsrekrutierung $125,152,154,162,164,526$

Sonnleithner-Sammlung $35,221,261,403,505,514$ Sozialkritik $53,71,72,77,87,93,142,164,214$, 215, 231, 232, 234, 236, 246, 251, 253, 256, 328, 335

Soziolekt, soziale Verortung $\quad 31,209,293,295,306$, $354,392,532,574$

Spanischer Erbfolgekrieg $\quad 117-130,156,169$ 
Spott, Verhöhnung $\quad 63,71,78,79,81,90,96,99$, $114,127,129,130,133,134,136,234,236,268,269$, 299, 308, 366, 416, 541, 550, 551, 554, 574, 595 Spottlied $\quad 63,71,79,229,308,320,324,444,458$, $517,538,541,551,554,562,565$

Sprache der Nähe $15,66,77,96,168,419,454,512$, 580

sprachkritischer Diskurs $\quad 16,66,329,336,404,570$, 573, 574, 587, 596, 597, 601, 604, 606

Sprachreform, Sprachreinigung $\quad 267,329,369$

Sprachrealismus $132,219,249,316,329$

Sprachreform, Sprachreinigung 570

Standard, überregionale Leitvarietät $\quad 21,329,339$, 369, 596

Standeslied, Berufsstandslied 250, 256, 300, 301, 303-306, 469

Stegreiftheater, Improvisationstheater $\quad 355,585$, 588,589

Stereotypisierung $96,100,103,250,301,304,311$, 340-342, 347, 350, 358, 364, 366, 374, 377, 390, 392

Sünde, Sündhaftigkeit, Sündenfall 39-46, 318-320, 366

Systemkritik 97, 220, 227, 250

Tabubruch $53,133,290,421,474,478,482,483$, $486,494,495,501,502,507,515,518$

Tanzlied 261, 462, 496

Taufe $82,169,172,174,404$

Taufmahllied 424, 425

theaterästhetischer Diskurs $\quad 582,587,588,591,593$, 595

Tirolerlied 204, 361, 364, 521

Travestie 53, 408

Trinklied 447-449, 451

Trunksucht, Trinklust $\quad 151,253,285,291,319,327$, 357, 448, 490, 567

Trutzlied, Trutzgsangl $271,461,560$

Türkenkriege 97, 98, 102-112, 145, 163, 269

Türkenbelagerung 96,98-100, 102, 105-107

Typisierung, Stilisierung $106,120,209,267,295$, $301,303,304,306,307,311,315,316,327-330,340$, $341,353,362,395,521,584,585,594$

Überlieferungslage $\quad 38,406,411,548$

Archivierung 97, 220, 441

mündliche Verbreitung und Überlieferung 13 , $68,139,140,162,220,227,229,257,403,478$, $501,512,518$

unvollständige Überlieferungslage $\quad 34,39,195$

Universitätstheater $\quad 45,151,291,356,542$

Variation, Variabilität 14

Adaption, Überarbeitung, Erweiterung $\quad 48,81$, $156,158,273,281,286,291,295,307,316,344$ $394,396,482,502,523,527,529,541,549,578$
Improvisation, Variation von Formeln und Arrangements 411, 412, 585

Kombination, Kompilation $\quad 33,256,262,298$, 379, 521, 522

Kontrafaktur 46

mündliche Tradierung, Umsinge- und Zersingungsprozesse $24,34,348,386,486,521$, 522, 549

vaterländische Dichtung $106,168,209,212,218$, 364, 583

verdeckte Verfasserschaft

anonyme Autorschaft $123,314,338,581,595$

falsche Autorenangabe 92

pseudonyme Autorschaft, Autoren- und Herausgeberfiktion $53,54,92,103,121,127$, $326,333,335,511,573,576,579,581,598,604$

Verkündigungslied 22

Verlachen, Verlachkomik 97, 99, 258, 268, 289, 304, 308, 369, 588

Verschriftung, Literarisierung von Dialekt 14,15 , $49,95,135,148,165,168,186,212,262,278,287$, $318,334,380$

Vexierlied 480,517

Volksgesang $46,47,49,221,240,246,250,271$, $273,308,361,386,400,403,408,448,483,488,493$ 496, 502, 518, 536

Volkskunst, Volksliteratur $\quad 262,299,303,395,403$, 418, 457, 605

Volksschauspiel $\quad 40,51,55,60,63,354$

Volksstück 359

Vorspiel 39, 53, 408

Vulgär- und Fäkalsprachliches $99,133,318,319$, 474, 479, 480, 482, 483, 486, 495, 516

Wandertheater $\quad 45,58,286,289,291,582,585$

Weihnachten, Weihnachtskreis 21-24, 26-38, 174, 417

Anbetung des Kindes (Topos) 24, 174, 178, 206

Weihnachtslied, Hirtenlied $\quad 22,24,28-30,33-38$, 412, 517

Weihnachtsspiel $\quad 12,30,31,34,39,255$

Werbelied, Werbedialog 447, 474, 534

Wilderer 233, 234, 238-240, 253

Wildererlied $\quad 234-237,241-246,256,418$

Zeitschrift, Periodikum $\quad 217,328,334,335,571,572$

Zensur 51, 160, 168, 216, 221, 224, 227, 335, 461, 474-476, 507, 512, 513, 586, 588, 589

Zimbrische Dialektkultur 67

Zwergenkarikaturen $\quad 351,371,383,384,583$

Zwischenspiel, Intermedium $56,148,149,151,152$, $276,291,294,465,542,544$ 


\section{Ortsregister}

Aachen 289

Admont 49, 79, 355

Aichkirchen 562, 564

Aidenbach 129

Anspan 299, 300

Augsburg $\quad 22,241,311,317,351,385,583$

Bad Hall 222

Baumberg 375

Baumburg 432

Belgrad 109, 110

Benešov 542

Berlin 24, 31, 101, 103, 252, 278, 380, 600

Beuerberg 61, 63, 238, 491

Bogenhausen 576,578

Bonn 289

Braunau 129, 247, 248

Breslau 289

Brixen 128, 365, 372

Dachau 56, 57, 418

Deutsch-Mokra 461, 463

Döbling 148

Dresden 141

Ebensee 445,446

Ebermannstadt 81, 282

Ebersberg 247

Eferding 127

Eger 135

Erlau 31

Fiecht 438

Fließ 56

Frankenmarkt 124

Frankfurt 195, 198, 199

Freising 46

Garsten 46, 62, 432, 500

Geisenhausen 252

Göttweig 439

Graz 348, 370

Grinzing 148

Güns 429

Hall (i. Traunviertel) 223

Halle 600,601

Hallein 31, 442

Hessen 31

Hietzing 307

Hirschau 276

Hochstädt 127

Hüttau 552, 557

Ingolstadt 78
Innsbruck $22,63,65,87,128,204,372$

Ischl 434

Kagran 333

Kammer 445

Kelheim 129

Kiefersfeld 60

Klagenfurt 421

Köln 289

Konstantinopel 332

Krems 367

Kremsmünster $\quad 297,324,414,415,434,436,452$, $542,544,545,554$

Krumau 586

Laas 57

Laibach 289,338

Lambach $57,76,193,194,200,437,472,483,542$

Landsberg 51

Landshut 251

Laufen 248

Lauffen 247,248

Leipzig $\quad 600,601$

Leogang 221

Linz $\quad 72,95,127,136,201,220,476,505,555$

London 480

Luzern 51

Mainz 102

Mammendorf 417

Mariahilf 308

Mariapfarr 284

Marienberg 545

Meran 545

Molln 236

Moskau 374

München 327

Neukirchen 476

Nürnberg $\quad 352,541$

Oberammergau 46

Obernberg 247

Ofen 102

Ostrach 379

Ottakring 579

Paris 368

Passau 122

Peterwardein 109

Plattling 129

Prag 133, 135, 196, 336, 363, 578

Přelouč 336, 337

Pressburg 589 


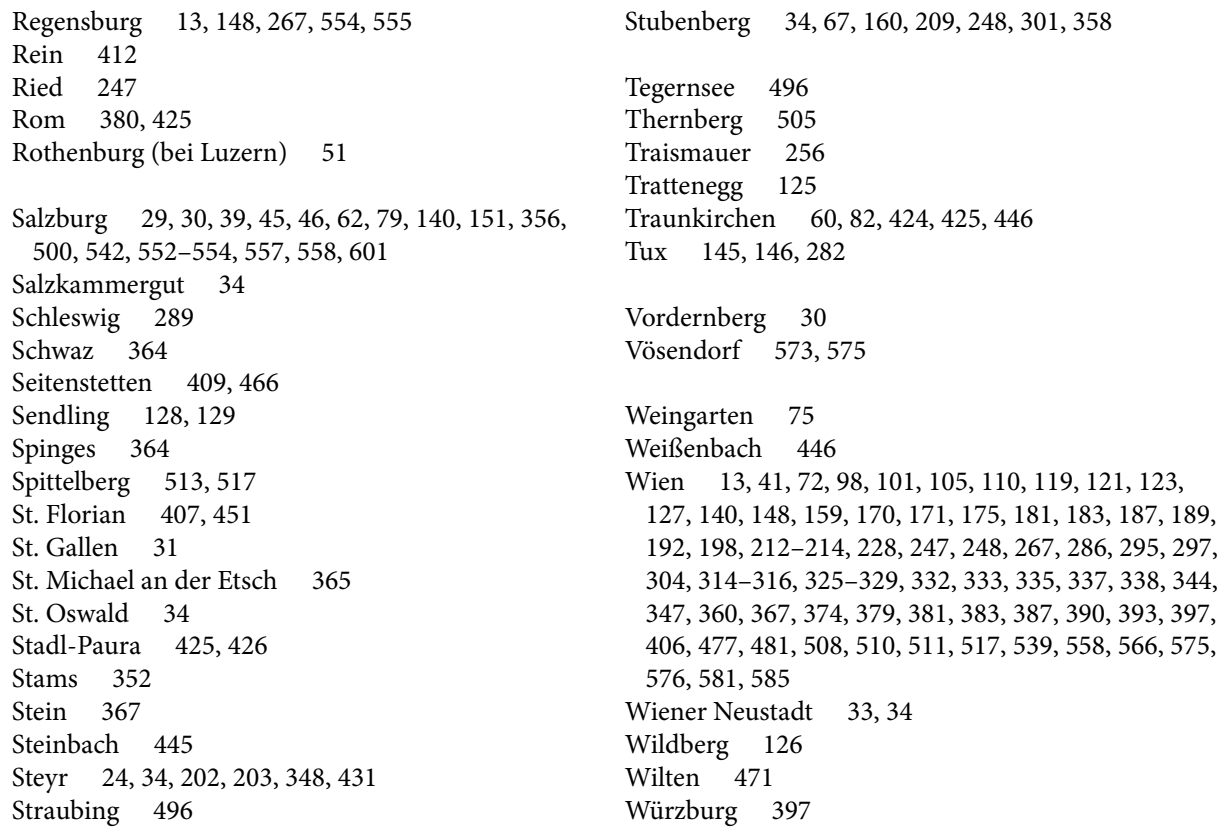

\section{Personenregister}

Abele, Matthias 95, 342, 461

Abraham a Sancta Clara (Ulrich Megerle) 568

Albrechtsberger, Johann Georg 461

Angerer, Edmund 438, 480

Antoine de Pas, Marquis de Feuquières 113

Arnim, Achim von 47, 523

Artner, Therese von (Theone) 428, 429

August II. von Polen 158

Aumann, Franz Joseph $\quad 35,90,407,451$

Ayrenhoff, Hermann von 337

Bachtin, Michail 295

Baeck, Elias 384

Bäuerle, Adolf 334

Beer, Johann 150

Berner, Felix 298

Bessel, Gottfried $\quad 439,440$

Biber, Heinrich Ignaz Franz 57

Bibiena, Giuseppe 187

Bidermann, Jakob 569

Binder, Johann Michael 35

Blima, Wenzel 201, 218, 266, 364

Blumauer, Aloys $47,49,87,228,230,281,502,503$, 517
Bocaccio, Giovanni 546

328, 566, Bodmer, Johann Jakob 597-601

Boemus, Joannes 349

Braunschweig, Heinrich Julius von 12

Breitinger, Johann Jakob 597, 598, 600,601

Brenner, Oskar 56

Brentano, Clemens $\quad 47,523$

Brixi, Franz Xaver 91

Bucher, Anton von $\quad 53,54,61,77,92,408,579$

Bürger, Gottfried August 517, 604

Burghausen, Clemens von (Clemens Harderer) 568

Callenbach, Franz 347

Chladek, Ägid 578

Churchill, John, Duke of Marlborough 127

Cochem, Martin von 92, 579

Defraine, Carl 453

Denis, Johann Nepomuk Cosmas Michael 164, 165

Denso, Johann Daniel 601

Desselbrunner, Maria Barbara (Maria Barbara Pösch) 424

Ditfurth, Franz Wilhelm 256

Dittersdorf, Karl Ditters von 592

Donberger, Georg 35 
Dornblüth, Augustin 369

Dreyer, Johann Matthias 598, 600

Dückern, Theophil von $434,452,544$

Eberl, Ferdinand 337

Eberlin, Johann Ernst $\quad$ 151, 291, 293, 435, 542

Eckartshausen, Karl von 266

Egl, Steffan 148

Elenson, Andreas $\quad 287,289,291,470,569$

Eleonore Maria Josefa von Österreich 467

Elisabeth Christine von Braunschweig-Wolfenbüttel 169, 471

Elizaveta Petrovna Romanova 137

Enzinger, Moriz 64

Eugen Franz, Prinz von Savoyen-Carignan 105, 108-110, 112, 127

Eybler, Joseph $\quad 448,449$

Ezéchiel du Mas, comte de Mélac 113

Fast, Patricius $\quad 574,576$

Federspiel, Johannes Ulrich 57

Fellner, Koloman 476

Firmian, Leopold Anton Freiherr von 549, 551, 553, 559

Fixlmillner, P. Placidus 542

Franz I. Stephan von Lothringen $131,180,186$, 197, 439, 471

Franz II. von Österreich $\quad 201,204,216,226,228$, 329, 335

Friebert, Johann Joseph 298

Friedrich August II. von Sachsen (August III.) 159

Friedrich II. von Preußen 137, 146

Gabriel, Johann (vulgo Koasahansl) 299

Gaelle, P. Meingosus 535

Gerning, Johann Isaak von 521, 522

Gewey, Franz Xaver 334

Ghelen, Johann Peter von 177, 178, 181, 187

Gilowsky, Kajetan 228

Goebel, Georg 12

Goethe, Johann Wolfgang von 54, 353, 480

Gottsched, Johann Christoph $\quad 105,329,369,570$, $587,588,591,596-598,600,601$

Gottsched, Louise Adelgunde Victorie 601

Graser, Rudolph 570

Gräter, Friedrich David 300

Grimm, Friedrich Melchior 600

Gruber, Franz Xaver $\quad 49,261$

Gryphius, Andreas 13, 290, 529, 531

Gulich, Johann 12

Güntherode, Karl von 87

Guolfinger, Karl Franz, Ritter von Steinsberg 337

Hafner, Philipp $\quad 359,390-392,481,527$

Haibel, Johann Jakob 359, 521

Harderer, Clemens (Clemens von Burghausen)

Hasenhut, Anton 296
Hasenhütl, Maria 70

Haydn, Joseph $\quad 35,91,371$

Haydn, Michael 91, 234, 448, 449, 545, 601

Hayneccius, Martin 12

Hebel, Johann Peter 429

Hebenstreit, Franz 228-230, 233

Henneberg, Johann Baptist $\quad$ 49, 478, 479, 523

Hensler, Friedrich 296

Herberstorff, Adam Graf von 123

Herder, Johann Gottfried 483, 493, 604, 606

Heufeld, Franz von 297

Hirschbichler, Thomas 221, 416

Hobbes, Thomas 167

Hochberger, Joseph 511

Höfer, Matthias 249

Hoffmann, Leopold Alois $\quad 66,571,572$

Hohenwart, Stanislaus Leopold Graf von 229

Hollonius, Ludwig 286

Honeder, Anton (Anton Haneder) 246, 248

Hörttenhueber, Maria Barbara 424

Hübner, Lorenz $\quad 245,403,404,417,458,459,514$

Hume, David 348, 350

Innozenz XI. 97

Isabella von Bourbon-Parma 192, 193

Itzlfeldner, Franz Kaspar 285

Jacquin, Franziska von 456

Jacquin, Gottfried von 454, 455

Johann Georg III. von Sachsen 114

Joly, Ferdinand 465

Joseph Clemens von Bayern 289

Joseph Ferdinand von Bayern 116

Joseph I. von Österreich 128,169

Joseph II. von Österreich $142,178,181,193,194$, 198, 200, 206, 208, 209, 214, 216, 221, 224, 329, 387, $581,589,592$

Kagerer, Johann Michael 284

Kaltenbrunner, Karl Adam 340

Kara Mustafa 99

Karl Albrecht von Bayern (Karl VII.) 130, 131, 134, 195, 196

Karl Alexander von Lothringen $\quad 186,439,440$

Karl II. von Spanien 116

Karl IV. von Österreich 169

Karl Joseph von Habsburg-Lothringen $\quad 178,181$, 183

Karl Philipp Theodor 185

Karl Theodor von Pfalz-Sulzbach 142

Karl V. Leopold von Lothringen 97, 102, 114

Karl VI. von Österreich $108,130,189,204,471$

Kiennast, Franz de Paula 56, 57

Klostermayr, Matthias (Matthäus) 240

Klotz, Leonhard 45

568 Komlosyj, Lajos (Ludwig Komlóssy) 396

König, Johann Ulrich von 598, 600 
Kortum, Carl Arnold 517

Kramel, Friedrich 152

Kraus, Karl 330, 331

Kremser, Leander $\quad 46,432,500$

Krenner, Rupert 440

Kuenburg, Max Gandolf von 549

Kurz, Johann Joseph Felix von $\quad 295,375,394,408$, 529, 585, 589

Kurz, Susanna Franziska Antonia 298

La Roche, Johann Joseph $\quad$ 296, 395, 453, 592, 593

Lachner, Kaspar 201

Lang, Johann Baptist 108

Langthaller, Joseph 154

Leibniz, Gottfried Wilhelm 112

Lenglachner, Philipp 34, 302

Leopold I. von Österreich 97, 100, 112, 115, 118, $149,169,276,286,467,469$

Leopold II. von Österreich $198,200,201,204,210$, 471

Leopold Johann von Habsburg 104, 169

Lercher, Christoph 347

Lessing, Gotthold Ephraim 483, 493, 605

Lindemayr, Joseph Gotthard 424

Lindemayr, Maria Barbara Thekla 424

Lindemayr, Maurus $76,82,88,138,141,153,154$, $156,193,194,201,223-225,236,258,259,261,271$, $294,303,309,323,371,384,424,427,433,434,437$, $443,471,472,476,483,486,488,542,562-565,570$

Lindemayr, Maximiliana Barbara 427

Lindemayr, Peter Gottlieb $\quad 82,200,325,399,424$, $425,437,476$

Lindemayr, Susanne 425

Linser, Johann 118

Lippert, Friedrich Karl 523

Liscow, Christian Ludwig 598

Ludwig XIV. von Frankreich $112,113,117$

Ludwig XV. von Frankreich 159

Ludwig XVI. von Frankreich 194, 228

Luther, Martin $550,559,576$

Macpherson, James 604

Maria Amalia von Habsburg 471

Maria Anna von Habsburg-Lothringen 186

Maria Antonia, Erzherzogin von Österreich (Marie

Antoinette) $115,194,325,437,441,471$

Maria Josepha von Bayern 193, 194

Maria Theresia von Österreich $35,130-132,169$, $180,181,186,189,190,193,196,204,206,208,209$ $221,257,439,501,526,532,562,588,589$

Mascagni, Donato 282

Masen, Jakob 291

Maximilian II. Emanuel von Bayern 195,350

Maximilian III. Joseph von Bayern $\quad$ 131, 142, 194

Mayer, François 289

Mayer, Sebastian 513
Mayr, Andreas 252, 280, 281

Mehmed IV. 99

Mendelssohn, Moses 493

Meusebach, Karl Hartwig Gregor von 24

Meyer, Erenbert 437

Migazzi, Christoph Anton von 572, 576

Milbiller, Joseph 579

Miller, Florian von $\quad 130$

Molière 488

Montesquieu 186, 333

Mozart, Constanze $\quad 454,455$

Mozart, Maria Anna Thekla 454

Mozart, Wolfgang Amadeus 91, 291, 352, 371, 435 , 453-456, 478-480

Müller, I.A. 385

Müller, Wenzel $\quad 216,296,527$

Nagnzaun, Alfred 318

Napoleon Bonaparte (Napoleon I.) 144, 213

Neiner, Johann Valentin 373

Nicolai, Christoph Friedrich $\quad 564,565,578,583$, 604-606

Obermayr, Anton 449

Offner, Matthäus $\quad 49,355$

Ordonez, Karl von 316

Öttl, Ulrich 435

Pacher, Alfons 439

Pambichler, Norbert $\quad 409,410,465,467$

Pasterwiz, Georg 435, 545

Pauersbach, Joseph von $\quad 212,213,266$

Pergen, Johann Anton Graf von 226, 231

Perinet, Joachim 213-216, 527, 575, 576

Peter III. von Russland 137

Peternader, P. Leo 545

Petrasch, Joseph Leopold 590

Peyerl, Johann Nepomuk 479

Pezzl, Johann 508

Philipp Joseph Graf Kinsky 196

Philipp V. von Anjou 117

Pius von Savoyen 470

Plachy, Wenzel 318

Plank, Beda 435

Plausch, Peter (Pseudonym) 335

Pochlin, Joseph 573-576

Pöckenstein, Johann Martin von 118

Pöllinger, Johann 231, 232

Popowitsch, Johann Siegmund Valentin 404

Prasch, Johann Ludwig 404

Pregg, Matthias 151, 152, 544

Prehauser, Gottfried $\quad 373,585,586,589$

Primisser, Johann Friedrich $144,145,352$

Pyra, Jakob Immanuel 598

Rademin, Heinrich 106

Raggl, Michael 56 
Rathgeber, Valentin $\quad 45,371,414$

Ratschky, Joseph Franz 228, 517

Rautenstrauch, Johann 572

Reichardt, Johann Friedrich 449, 605

Reichssiegel, Florian $\quad 234,601,603$

Ricci, Julian 437, 438

Richter, Joseph $\quad 217,227,328-331,333,334,337$, 338, 509, 576

Riedel, Andreas von 228-230

Rinn, Petrus 355

Rinswerger, Wolfgang $\quad 39,151,356-358,388$

Rist, Johann 13

Rohrer, Joseph 359

Rosegger, Peter 38

Rosner, Ferdinand $\quad 46,152$

Rost, Johann Christoph 598

Ruschitschka, Georg 229

Sailer, Sebastian $\quad 40$

Sartori, Franz 72

Schaitberger, Joseph 549,550

Schibl, Johann Baptist $\quad 427,428$

Schickmayr, Amand 437

Schikaneder, Emanuel $\quad 337,359,360,378,517,521$, 523

Schiller, Samuel $\quad 428$

Schmalnauer, Johann Michael 72

Schmeller, Johann Andreas 281

Schmeltzl, Wolfgang 406

Scholtzenberg, Johann Friedrich Scholtz von 149 , 465, 470

Schönwetter, Johann Baptist $\quad$ 176, 178, 181

Schosser, Anton 340

Schottelius, Justus Georg 13

Schranzhofer, P. Rogerius 352

Schrattenbach, Sigismund Graf von 284

Schuender, Johann Karl (alias Scheudner) 41

Schumacher, Alois 51,61, 63

Schwabe, Johann Joachim 601

Schwarzenberg, Joseph Adam von 586

Seitz, Markus 496

Selhamer, Christoph 569

Seyringer, Johann Carl 447

Seyringer, Joseph Ferdinand 441, 442

Shakespeare, William 285

Sichler, Johann 72

Sieberer, Joseph 65

Solari, Ignazio 282

Sonnenfels, Joseph von $329,588,589$

Sonnleithner, Joseph 403

Sparry, Franz $\quad 35,324,400,414,416,430,434,441$

Springenfels, Sigismund von 49

Stadler, Nonnos 434

Stadler, Sebastian 432

Stainer, Michael 431

Stanislaus I. Leszczyński 159

Stapel, Ernst 13
Starhemberg, Ernst Rüdiger von 98

Stauchner, Simon 231

Staudacher, Peter Paul 144, 145, 352

Steinsberg, Karl Guolfinger von 578

Stelzhamer, Franz 340

Sterzinger, Martin Andreas 118,120

Stiebinger, Mathias 82

Stifter, Adalbert 299

Stockhamer, Michael 261

Stranitzky, Joseph Anton $105,106,149,295,371$, $373,582,583,585$

Strobl, Andreas 569

Strommer, Johann 326,581

Stullebner, Rupert $\quad 551,553,556,557$

Sturm, Marcellinus $\quad 42,52,53,85,89,451,498,502$, 504, 517

Süßmayr, Franz Xaver $\quad$ 154, 435, 523

Thun, Johann Ernst Graf von 282, 283

Thürheim, Christoph Leopold von 467

Trautson, Johann Joseph von $569,570,572$

Trenck, Franz Freiherr von 134

Troll, Franz Xaver von 228

Tschink, Cajetan 66

Tuček, František Vincenc 337

Viganò, Maria 337

Viganò, Salvatore 337

Vogl, Georg 152

Weber, Karl Julius 314

Weigl, Joseph 318

Weiser, Ignaz Anton $\quad 291,293,294,542$

Weiskern, Wilhelm 589

Weissegger, Joseph Maria 572

Werner, Gregor Joseph $\quad 35,274,315,316,383$

Werth, Johann von 154

Wesenauer, Kajetan 34

Westenrieder, Lorenz von 417,418

Wetzinger, Gottlieb 220

Weylgoune, Johannes 434, 542

Widmann, Christian 409

Wieland, Kolumban 51

Wiesenpater aus Ismaning $\quad 576,578,579$

Wiesmayr, Katharina 427

Wild, M. 574

Winckelmann, Johann Joachim 483

Windisch, Karl Gottlieb von 590, 591

Wittola, Marc Anton 572

Wolff, Leo 568

Zaupser, Andreas Dominikus $\quad 404,412,448,449$, 458, 459, 461

Zechner, Johann Georg $\quad 35,275$

Zivilhofer, Wenzel 35

Zoller, Franz Karl 364 